\title{
Contacts et acculturations en Méditerranée occidentale
}

Hommages à Michel Bats

\section{Réjane Roure (dir.)}

DOI : 10.4000/books.pccj. 1768

Éditeur : Publications du Centre Camille Jullian

Lieu d'édition : Aix-en-Provence

Année d'édition : 2015

Date de mise en ligne : 6 avril 2020

Collection : Bibliothèque d'archéologie méditerranéenne et africaine

EAN électronique : 9782491788049

\section{Sobooks}

http://books.openedition.org

\section{Édition imprimée}

EAN (Édition imprimée) : 9782877725552

Nombre de pages : 562

\section{Référence électronique}

ROURE, Réjane (dir.). Contacts et acculturations en Méditerranée occidentale : Hommages à Michel Bats. Nouvelle édition [en ligne]. Aix-en-Provence : Publications du Centre Camille Jullian, 2015 (généré le 21 septembre 2021). Disponible sur Internet : <http://books.openedition.org/pccj/1768>. ISBN : 9782491788049. DOI : https://doi.org/10.4000/books.pccj.1768. 


\section{$\mathrm{B}$ ibliothèque d'Archéologie \\ Méditerranéenne et Africaine 15}


Dans la lignée des anciens Travaux du Centre Camille Jullian, la Bibliothèque d'Archéologie Méditerranéenne et Africaine (BiAMA) regroupe des travaux (monographies, actes de colloques, ouvrages collectifs) en relation avec les programmes scientifiques du Centre Camille Jullian, sur l'histoire et l'archéologie de la Gaule méridionale, de l'Afrique du Nord et du bassin méditerranéen. La BiAMA peut comprendre des sous-séries, comme la collection Études massaliètes (EtMassa).

\section{Responsable légal :}

Marie-Brigitte Carre, Directrice du CCJ

Directeur de la publication :

Sophie Bouffier et Henri Tréziny

Comité de pilotage :

Xavier Delestre, Marie-Brigitte Carre, Henri Tréziny

Conception graphique :

Véronique Gémonet

Mise en page :

Cédric Hamel, Véronique Gémonet

Direction scientifique de la série Etudes massaliètes :

M. Bats et H. Tréziny

Comité de lecture :

$\mathrm{Ph}$. Borgard (CCJ, CNRS), S. Bouffier (CCJ, AMU), J.-P. Brun (Collège de France), M.-Br. Carre (CCJ, CNRS), X. Delestre (CCJ, DRAC PACA), D. Garcia (CCJ, AMU), M. Griesheimer (CCJ, AMU), A. Hermary (CCJ, AMU), Ph. Jockey (CCJ, AMU), M. Lombardo (Professeur à l'Université de Lecce), S. T. Loseby (Professeur à l'Université de Sheffield), J.-M. Mignon (Service archéologique départemental du Vaucluse), P. Pomey (CCJ, CNRS), L. Rivet (CCJ, CNRS), J. Sanmarti (Professeur à l'Université de Barcelone), J.-Chr. Sourisseau (CCJ, AMU), H. Tréziny (CCJ, CNRS), C. Virlouvet (École française de Rome), E. Voutiras (Professeur à l'Université de Thessalonique).

(c) 2015 pour tous pays,

Éditions Errance, éditeur du groupe Actes Sud,

Place Nina-Berberova BP 90038

13633 Arles cedex

Tél. : 0490498691

Fax : 0490969525

Courriel : contact@editions-errance.fr

http://www.librairie-epona.fr

Centre Camille Jullian

Maison Méditerranéenne des Sciences de l'Homme

5 rue du Château de l'Horloge. BP 647, 13094 Aix-en-Provence Cedex 2

ISBN : 9782-87772-555-2

ISSN BiAMA : 2101-2849

Illustrations de couverture :

Thymiatêrion, du sanctuaire d'Aphrodite à Olbia de Provence (Hyères, Var) (Cl. Chr. Durand, CNRS-CCJ).

Abécédaire, du site de Lattara (Lattes, Hérault) (Cl. Musée Henri-Prades).

Illustration $4^{\text {èm }}$ de couverture :

Stèle du « Héros », du sanctuaire d'Aphrodite à Olbia de Provence (Hyères, Var) (Cl. Musée-Site archéologique d'Olbia, ville d'Hyères).

\section{Publications du Centre Camille Jullian}

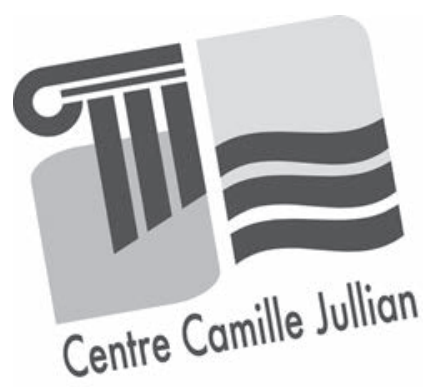

cet ouvrage a été publié avec le soutien du Labex ARCHIMEDE, programme «Investissement d'Avenir » ANR-11-LABX-0032-01 et de la Ville de Hyères-les-Palmiers

\section{archimede ARCHEOLOGIEETHISTOIRE DELA MEDITERRANEE ET DE
L'EG YPTE ANCIENNES}

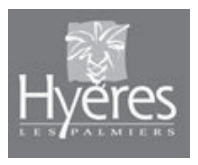

Envoyer les manuscrits à :

Bibliothèque d'Archéologie Méditerranéenne et Africaine Centre Camille Jullian

Maison Méditerranéenne des Sciences de l'Homme 5 rue du Château de l'Horloge. BP 647, 13094 Aix-en-Provence Cedex 2 


\title{
CONTACTS ET ACCULTURATIONS EN MÉDITERRANÉE OCCIDENTALE
}

\author{
Hommages À Michel Bats
}

\author{
Actes du colloque de Hyères, \\ 15-18 septembre 2011
}

Édités par Réjane Roure

Avec la collaboration de

Carmen Aranegui, Philippe Boissinot, Alain Bouet, Jean-Pierre Brun, Claire Joncheray, Dominique Garcia, Antoine Hermary, Rosa Plana, Michel Py, Pierre Rouillard, Clément Sarrazanas, Henri Tréziny, Florence Verdin

\section{études massaliètes 12}




\section{Sommaire}

Avant-propos - Réjane ROURE

\section{ÉTRUSQUES ET GRECS EN MÉDITERRANÉE NORD-OCCIDENTALE}

Les sources littéraires sur la topographie de Marseille grecque : César et Aviénus Henri TRÉZINY

Le site de Marseilleveyre entre Grecs et indigènes. État de la question, recherches récentes et nouvelles approches

Sophie BOUFFIER, Loup BERNARD, Delphine ISOARDI

Grecs et Étrusques à Lattes : nouvelles données à partir des fouilles de la Cougourlude

Isabelle DAVEAU, Michel PY

Un signe de la présence phocéenne en Languedoc occidental : un tétartémorion trouvé à Béziers

Richard PELLÉ, Laurent VIDAL, Hervé PETITOT

Commerces méditerranéens en Provence orientale au $1^{\text {er }} \hat{\text { âg }}$ du Fer : un état de la question

Laurence MERCURI

Genova al centro dei commerci massalioti lungo le rotte dell'alto Tirreno

Cristina NERVI

Vie quotidienne et transformations à Fratte (SA), un établissement étrusco-campanien situé

à l'embouchure du fleuve Irno.

Angela PONTRANDOLFO, Alfonso SANTORIELLO

Banquets rituels à Cumes au IVe siècle avant $J$.-C.

Jean-Pierre BRUN, Laetitia CAVASSA, Martine LEGUILLOUX, Priscilla MUNZI

Un dépôt de fondation en contexte domestique à Olbia de Provence (Hyères, Var)

Réjane ROURE, Claire JONCHERAY, David OLLIVIER, Pierre EXCOFFON, Carine DEAL,

Valérie SALLE, Maeva SERIEYS

Set cerimoniali e offerte nei luoghi di culto indigeni della Sicilia occidentale

Francesca SPATAFORA

Nuevos datos arqueológicos sobre la evolución urbana de Emporion

Pere CASTANYER, Marta SANTOS, Joaquim TREMOLEDA

Philistines and Phokaians : comparative hinterlands and Middle Grounds

Irad MALKIN

\section{QUESTIONS D'IDENTITÉS ET D'ACCULTURATIONS}

Le concept d'acculturation : son utilité et les limites dans son application à l'archéologie Philippe BOISSINOT

Rencontres culinaires : la culture matérielle incorporée

Michaël DIETLER

Forme di identità e interazione nel Tirreno settentrionale. Possibili indicatori, fra persistenza ed acculturazione. Alcune note

Eliana PICCARDI 
Interactions coloniales, cuisine et formes de consommation en Ibérie septentrionale

Joan SANMARTI

Identidades Ibéricas

Carmen ARANEGUI GASCÓ

Les Ibères à la rencontre des Grecs

Pierre ROUILLARD, Rosa PLANA-MALLARD, Pierre MORET

Características, evolución y particularidades del poblamiento indígena en el área de colonización griega

del Ampurdán. El caso del Mas Castellar de Pontós (Siglos VII-III aC.)

David ASENSIO, Enriqueta PONS

L'identité face au commerce : exemples languedociens

Daniela UGOLINI

Quel accompagnement pour quel mort? Les services funéraires du premier âge du Fer

en Languedoc occidental

Laura BOURDAJAUD, Thierry JANIN, Martine SCHWALLER

El guerrero de Corno Lauzo : revisión de los materiales

Raimon GRAELLS FABREGAT ....

La question des échanges et des assemblages funéraires à travers le mobilier métallique de la nécropole protohistorique du Causse à Labruguière (Tarn).

André RIVALAN, Laura BOURDAJAUD

Pratiques funéraires et identité culturelle: Marseille et les indigènes du Sud de la Gaule (IVe-II e s. av.J.-C.)

Bernard DEDET

Pratiques balnéaires et acculturation : quelques éléments de réflexion

Alain BOUET

Les figurines en terre cuite dans le Sud de la Gaule (VI ${ }^{-} I^{e r}$ s. av. J.-C.)

Antoine HERMARY

Du bon usage de la violence dans l'iconographie italiote et étrusque

Luca CERCHIAI, Natacha LUBTCHANSKY, Claude POUZADOUX

Mondo greco occidentale ed Etruria. Il tema di "Hercle alla fonte" nella glittica

Laura AMBROSINI.

Cavalli senza cavalieri. Il tripode di Cap d'Agde e i tripodi etruschi tardo-arcaici con protomi equine

Giacomo BARDELLI

\section{AUTOUR DE LA CÉRAMIQUE}

Le anfore greco-occidentali : riconsiderando la loro evoluzione e l'identificazione dei centri di produzioni Verena GASSNER

Muro Leccese (Puglia, Italia). Forme e funzioni delle ceramiche d'uso quotidiano in un centro messapico tra IV e III secolo a.C.

Liliana GIARDINO, Catia BIANCO, Francesco MEO

Herakleia di Lucania (Basilicata, Italia). Forme e funzioni delle ceramiche d'uso quotidiano in una città italiota tra III e II secolo a.C

Liliana GIARDINO, Teresa Oda CALVARUSO.

Les imitations de céramique coloniale des sites ibériques d'Ullastret (Catalogne)

Ferran CODINA, Aurora MARTIN, Gabriel De PRADO

La céramique fine ibérique du nord-est de la Catalogne. Les formes représentées dans l'oppidum ibérique de Sant Julià de Ramis

Josep BURCH, Jordi SAGRERA.

Caractérisation des ateliers céramiques de Rhodè (Roses, Catalogne)

Anna Maria PUIG GRIESSENBERGER

Vaisselle et alimentation à Pech Maho (Sigean, Aude) : l'îlot I à la fin du III' s. av. J. -C.

Anne-Marie CURÉ 
Le mobilier céramique du Cayla de Mailhac (Aude) aux $V^{e}$ et $I V^{e} s . a v . n$.è. : premières données Sébastien MUNOS

La céramique " commune massaliète »du site de Lattara (Lattes, Hérault) au Ve s. avant notre ère (-475 /-375). Première approche typologique et essai de classification.

Émilie COMPAN 437

À propos de quelques imitations de vaisselle campanienne de l'oppidum de l'Ermitage d'Agen

(Lot-et-Garonne)

Florence VERDIN 453

Amphores italiques des $I^{e}{ }_{-} I^{e r}$ S. av. J.-C. dans la région de Narbonne : provenance et chronologie

Corinne SANCHEZ.....

L'évolution du timbrage sur amphores vinaires italiques aux II et ${ }^{e r}$ av. J.-C.à partir du corpus toulousain Laurence BENQUET

La nécropole augustéenne de la villa de Sivier (Istres, Bouches-du-Rhône)

Frédéric MARTY et Bérengère PEREZ

\section{LA LOGIQUE DE L'ÉCRITURE}

L'écriture après l'économie? Peuples et réponses

Javier DE HOZ 501

Alphabet grec et langues indigènes de la Grande Grèce entre unité et variété

Paolo POCCETTI

Varietà scrittorie in ambito celtico

Aldo PROSDOCIMI.

Graffiti etruschi dalla Gallia e il piombo di Pech Maho : alcune questioni paleografiche e contenutistiche

Valentina BELFIORE

Contacts d'écritures : l'épigraphie paléohispanique du Midi gaulois

Coline RUIZ DARASSE

Noms de personnes et identités dans les inscriptions d'Olbia de Provence (IV $-I^{e r}$ s. av. J.-C.)

Clément SARRAZANAS

Liste des auteurs 


\section{Avant-propos}

La question des contacts entre les différents peuples qui bordent les rives de la Méditerranée nord-occidentale est l'une des thématiques majeures de la recherche archéologique de ces trente dernières années. Que l'on parle d'époque archaïque et classique, ou de Protohistoire et d'âge du Fer, les échanges et les processus d'acculturation de ces peuples (Grecs, Celtes, Phéniciens, Ibères, Ligures, Étrusques) qui rentrèrent alors en contact les uns avec les autres ont retenu l'attention des chercheurs travaillant sur l'expansion grecque dans ces régions, sur les trafics commerciaux et les échanges culturels. L'œuvre de Michel Bats traverse toutes ces thématiques : la présence des Phocéens et des Étrusques dans le bassin occidental de la Méditerranée, l'acculturation et les identités ethno-culturelles, les recherches sur la céramique et ses usages dans une perspective anthropologique, l'appropriation de l'écriture par les sociétés protohistoriques. Afin de rendre hommage à cet acteur majeur de la recherche archéologique protohistorique et méditerranéenne, un colloque international a été organisé à Hyères, du 15 au 18 septembre 2011, réunissant plus d'un centaine de participants. Nombre de ses collègues ont ainsi pu témoigner à Michel leur amitié et leur dette intellectuelle, dans une ambiance chaleureuse et conviviale, à l'image de celui qui a profondément marqué tous ceux qui l'ont rencontré et qui a fait naitre tant d'amitiés durables tout autour de la Méditerranée. La dimension internationale de la carrière de Michel Bats et l'impact de ses travaux se reflètent donc dans les 48 contributions réunies dans ce volume, qui forment les actes de cette rencontre.

Chercheurs italiens, français, espagnols, entre autres, présentent des articles qui permettent tout à la fois de dresser un bilan et de définir de nouvelles perspectives autour de la thématique des contacts et de l'acculturation. Ces actes offrent la possibilité de découvrir les recherches les plus récentes de l'archéologie dans l'aire géographique concernée - l'agglomération du Premier âge du Fer de La Cougourlude en France, le sanctuaire hellénistique de Cumes et les fouilles récentes de Fratte en Italie, les ateliers de potiers de Rosas et les dernières découvertes d'Emporion en Espagne -, tandis que d'autres auteurs se sont attachés à proposer des synthèses sur la présence grecque en Espagne, sur les pratiques funéraires, sur les identités culturelles et ethniques, sur les pratiques culinaires, sur l'origine de l'écriture, et même sur la notion d'acculturation.

Si un certain nombre de ces questions ont été débattues régulièrement lors des Congrès de Tarente pour l'Italie, et des Colloques de Calafell en Espagne, en France, le dernier grand colloque sur ces questions a été le congrès de l'Institut d'études étrusques qui s'est tenu à Marseille et Lattes en 2002 (publié en 2006) ; il faut ensuite remonter à 1997 pour le colloque de Carcassonne sur Mailhac et le Premier âge du Fer (publié en 2000), puis à 1990 pour le grand colloque sur Marseille grecque et la Gaule (publié en 1992). La tenue de ce colloque en 2011 (et la publication de ses actes) respecte donc une sorte de périodicité des manifestations sur ce sujet et offre à la communauté scientifique, comme au grand public, un ouvrage de synthèse et d'actualité sur la thématique des contacts et de l'acculturation en Méditerranée nord-occidentale.

À l'instar du colloque lui-même, les contributions ont été réparties entre quatre grandes thématiques, intitulées ici : Étrusques et Grecs en Méditerranée nord-occidentale, Questions d'identités et d'acculturations, Autour de la céramique, La logique de l'écriture. Les communications orales et les posters, enrichis par quelques contributions supplémentaires, ont été mêlés, en essayant toutefois de respecter une certaine cohérence géographique, chronologique ou thématique à l'intérieur de chacune des parties. Par ailleurs, soulignons que le volume compte de nombreux articles de jeunes chercheurs, à côté de ceux des archéologues qui ont côtoyé Michel tout au long de sa carrière, les complices des premiers temps comme ses anciens élèves devenus d'éminents chercheurs à leur tour.

Le colloque s'est déroulé sur trois journées, ponctuées d'événements en hommage au chercheur honoré. Il était inévitable d'inclure dans les festivités une visite du site d'Olbia de Provence sur lequel Michel Bats a débuté sa 
carrière d'archéologue, alors jeune étudiant venu travailler aux côtés de son professeur de Bordeaux Jacques Coupry ; où il a formé plusieurs générations à la fouille archéologique et à la céramologie dans les années 1980 et 2000 ; et où il dirige encore aujourd'hui un programme de recherche qui a permis d'étudier le tronçon septentrional de la fortification. Lors de la première soirée, Michel Bats a reçu la médaille de la Ville d'Hyères-les-Palmiers des mains de l'adjoint à la Culture Michel Pellegrino. Le lendemain soir, le Centre Archéologique du Var a offert un buffet qui s'est déroulé dans les merveilleux jardins de la Villa Noailles, dominant la ville jusqu'à la presqu'île de Giens et les îles d'Or. Enfin, après une dernière journée de fructueux et stimulants échanges scientifiques, le colloque s'est achevé par une nouvelle soirée à Olbia où un concert de rebétiko était organisé par le service de valorisation et de médiation du site d'Olbia, puis par la visite le dimanche matin d'une exposition consacrée au sanctuaire d'Aristée à L'Acapte, préparée par le Musée Archéologique de la ville d'Hyères.

Cette rencontre a été co-organisée par le laboratoire «Archéologie des Sociétés Méditerranéennes » (UMR 5140, Lattes-Montpellier) et le Centre Camille Jullian (UMR 7299, MMSH, Aix-en-Provence) avec le soutien de la Ville de Hyères-les-Palmiers, du Ministère de la Culture, de l'INSHS, de l'Université de Provence et du Centre Archéologique du Var. La publication des actes quant à elle a été rendue possible par la contribution du Labex ARCHIMEDE « Archéologie et Histoire de la Méditerranée et de l'Egypte anciennes » (Programme IA - ANR-11-LABX-0032-01), de la ville de Hyères-les-Palmiers, et également du Centre Camille Jullian qui a accepté de l'accueillir dans sa collection de la Bibliothèque d'Archéologie Méditerranéenne et Africaine (BIAMA), au sein de laquelle elle forme le numéro 12 des Études Massaliètes.

L'organisation de ce colloque s'est accompagnée de la préparation d'un ouvrage intitulé D'un monde à l'autre. Contacts et acculturation en Gaule méditerranéenne réunissant les principaux articles de Michel Bats, articulés en six chapitres introduits chacun par un ou deux chercheurs présentant la perspective historiographique de ces diverses publications : les usages de la vaisselle céramique, anthropologie de l'écriture, identités et acculturation, Marseille et la Gaule, Étrusques et Phocéens en Occident, Olbia de Provence. Ce volume a été publié par le Centre Jean Bérard de Naples (UMS 1797 CNRS/EFR), que Michel Bats a dirigé pendant dix ans. Le choix a été fait de placer au début de cet ouvrage une série de textes introductifs présentant la carrière et le parcours intellectuel de Michel Bats, qui avaient été présentés à l'ouverture du colloque de Hyères : il s'agit des contributions de Michel Gras (Pour un dialogue franco-italien), de Jean-Pierre Brun (Les années napolitaines (1991-2000)), d'Emanuele Greco (In Magna Grecia con Emanuele Greco) et d'Alain Schnapp et Bruno d'Agostino (L'anthropologie de l'antiquité et l'archéologie, réflexion sur un parcours). Enfin, ce volume - le n³8 de la Collection du Centre Jean Bérard - comprend la bibliographie complète de Michel Bats, ainsi que deux textes qu'il a lui-même rédigé pour présenter ses thématiques de recherche. Que toutes les personnes qui ont contribué, de près ou de loin, à cette série d'hommages, trouvent ici l'expression de notre gratitude. 


\section{MICHEL BATS}

\section{D'un MONDE À L'AUTRE}

Contacts et acculturation en Gaule méditerranéenne

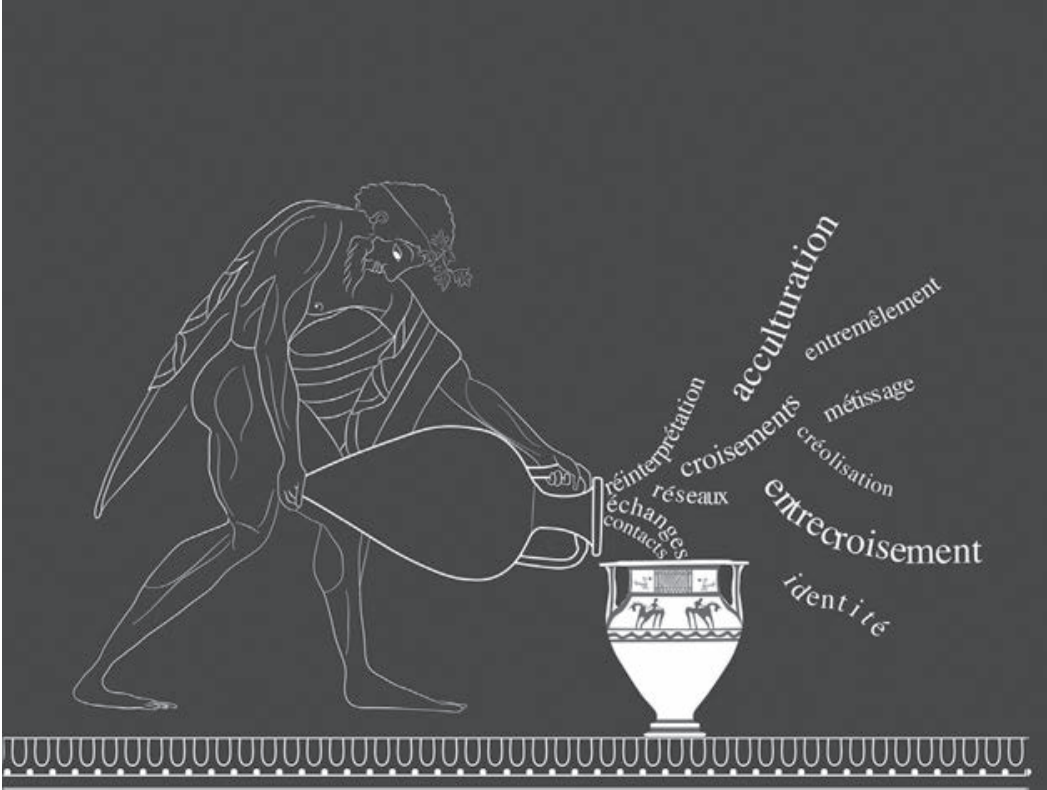

CNRS COLLLECTION DU CENTRE JEAN BÉRARD, 38 ÉFR

Comité scientifique du colloque

Bruno d'agostino (Université de Naples), Carmen Aranegui (Université de Valence, Espagne), Jean-Pierre Brun (Directeur du Centre Jean Bérard à Naples), Javier De Hoz (Université de Madrid), Michel Gras (Directeur de l'École française de Rome), Emanuele Greco (Directeur de l'École archéologique italienne à Athènes), Mario Lombardo (Université du Salento), Jean-Paul Morel (Professeur émérite Université de Provence), Michel Py (CNRS, Archéologie des Sociétés Méditerranéennes), Pierre Rouillard (Directeur de la Maison René-Ginouvès), Joan Sanmarti (Université de Barcelone), Henri Tréziny (CNRS, Centre Camille Jullian, MMSH, Aix-en-Provence).

Comité d'organisation du colloque

Philippe Boissinot (EHESS, TRACES, Toulouse), Alain Bouet (Université de Toulouse Le Mirail, TRACES, Toulouse), Dominique Garcia (Université de Provence, Centre Camille Jullian, MMSH, Aix-en-Provence), Thierry Janin (Université de Montpellier 3, Archéologie des Sociétés Méditerranéennes, Lattes), Rosa Plana (Université de Montpellier 3, Archéologie des Sociétés Méditerranéennes, Lattes), Réjane RouRE (Université de Montpellier 3, Archéologie des Sociétés Méditerranéennes, Lattes), Jean-Christophe SourissEAu (Université de Provence, Centre Camille Jullian, MMSH, Aix-en-Provence), Florence Verdin (CNRS, Ausonius, Bordeaux). 



\section{Étrusques et Grecs en Méditerranée nord-occidentale}





\title{
Les sources littéraires sur la topographie de Marseille grecque : César et Aviénus
}

\author{
Henri Tréziny \\ Directeur de recherche au CNRS \\ Aix Marseille Université, CNRS, Ministère de la Culture et de la Communication, \\ CCJ UMR 7299, 13094, Aix en Provence, France
}

\section{Résumé}

On étudie deux textes littéraires souvent utilisés pour l'étude de la topographie de Marseille. Dans les récits du siège de la ville par les Romains en 49 av. J.-C., on a eu tendance à expliquer les obscurités du texte de César dans le Bellum Ciuile en s'appuyant sur les passages correspondants de Lucain. Mais le poème épique de Lucain avait d'autres finalités et ne peut servir sans précautions à des interprétations topographiques. Il en va de même, mutatis mutandis, pour les vers d'Aviénus dans l'Ora maritima, qu'il faut d'abord étudier comme un poème de tradition hellénistique et que l'on ne peut utiliser tel quel pour restituer les paysages antiques.

Mots-clés : Marseille, textes antiques, topographie, César, Lucain, Aviénus

\footnotetext{
Abstract

This paper deals with the two literary texts often used to study the topography of Marseille. In the accounts about the siege of the city by the Romans in $49 \mathrm{BC}$, there was a tendency to explain the obscurities of the text of Caesar in Bellum Civile by pressing the corresponding passages of Lucan. But the epic poem of Lucan had other purposes and may not be used without precautions to topographical interpretations. The same thing exists, mutatis mutandis, for the verses of Avienus in Ora maritima, which must be study at first as a poem belonging to Hellenistic tradition and which cannot be used to understand the ancient landscapes.
}

Keywords: Marseille, ancient texts, topography, Cesar, Lucan, Avienus 
$\mathrm{D}$ ans son œuvre d'archéologue et d'historien, Michel Bats s'appuie en grande partie aussi sur les sources écrites, épigraphiques et littéraires, comme en témoigne notamment l'article de 1994 sur « Les silences d'Hérodote... ». Je ne reviendrai pas ici sur les origines de Marseille que les textes littéraires éclairent de façon ambiguë, mais plutôt sur l'utilisation que l'on fait des textes pour éclairer la topographie de Marseille grecque. Et je le ferai en commençant par la fin, en traitant d'abord du siège de la ville par César en 49 av. J.-C., puis du passage de l'Ora maritima où Aviénus décrit Marseille. Mon intention n'est pas ici de traiter de la topographie de la ville en tant que telle mais bien de la légitimité que nous pouvons accorder à des textes que l'on utilise fréquemment.

\section{Le siège de Marseille par César en 49 av. J.-C.}

Le siège de Marseille par les légions césariennes en 49 av. J.-C. nous est connu par deux sources essentielles, César, Bellum Ciuile, livre I et surtout livre II, et Lucain, Pharsale ${ }^{1}$. Jusqu'au début du $\mathrm{XX}^{\mathrm{e}}$ s. (découverte du «mur de Crinas » dans les terrains démolis autour de la place Jeanguin, derrière la Bourse), et même jusqu'aux années 1970/1980 (fouilles de la Bourse et de la butte des Carmes) ces textes (et quelques autres) étaient notre principale source d'information sur la topographie de Marseille. Ils ont donc été abondamment commentés. On retiendra surtout les contributions de Camille Jullian $(1899,1900)$, Michel Clerc (1898 puis 1929) et Gaston Vasseur (1914), et on suivra de près les importants apports de M. Euzennat et Fr. Salviat (1967, puis 1970 avec P. Veyne).

Les débuts du siège de Marseille et la première bataille navale sont décrits par César dans le livre I du Bellum Ciuile (I, 34-36, I, 56-58), mais les opérations proprement dites commencent au livre II (1-17).

César aborde franchement son sujet en décrivant d'abord les deux secteurs d'attaque choisis par Trébonius ${ }^{2}$ :

Duabus ex partibus aggerem, vineas turresque ad oppidum agere instituit. Una erat proxima portui navalibusque, altera ad portam ${ }^{3}$, qua est aditus ex

1 Le titre officiel de l'œuvre de Lucain est également Bellum Ciuile, mais l'appellation plus commune Pharsale permet d'éviter la confusion avec le texte de César.

$2 B C$, II, 1 : Texte et traduction P. Fabre, CUF, Paris 1936, avec quelques modifications (en italiques).

3 Les manuscrits donnent partem, « secteur », texte retenu par Jullian ; portam «porte » est une correction acceptée par Fabre. Le sens général n'en est pas modifié.
Gallia atque Hispania, ad id mare, quod adiacet ad ostium Rhodani. Massilia enim fere tribus ex oppidi partibus mari alluitur; reliqua quarta est, quae aditum habeat ab terra. Huius quoque spatii pars ea, quae ad arcem pertinet, loci natura et valle altissima munita longam et difficilem habet oppugnationem.

«(Trébonius) entreprend de pousser devant la place, sur deux points, une terrasse, des baraques d'approche et des tours. Une de ces positions d'attaque était à proximité immédiate du port et des chantiers maritimes, l'autre dans le voisinage de la porte par laquelle on pénètre dans la ville quand on vient de Gaule et d'Espagne, près de cette partie du rivage qui touche à l'embouchure du Rhône. Marseille est en effet baignée par la mer sur près des trois-quarts de son périmètre ; le dernier quart ${ }^{4}$ est le seul qui soit accessible par terre. Même de ce côté, la partie qui touche à la citadelle est défendue par la nature du terrain et un ravin extrêmement profond, ce qui en rend l'attaque longue et difficile. »

Le premier secteur est donc au Nord, vers la porte de Gaule et d'Espagne, du côté du golfe du Lion, c'est-à-dire sans doute dans la topographie médiévale et moderne, vers la Porte Galle ou la porte de la tour Sainte-Paule, par où passait le chemin d'Aix. Cette indication nous est confirmée par une scholie de Lucain, « vers un secteur se dressant à l'ouest, que l'on appelle urbisplicia », même si le sens de urbisplicia a fait l'objet de discussions. Quelle que soitl'origine de la scholie, elle suggère que l'existence d'une attaque par le Nord se trouvait également dans une source autre que le Bellum ciuile 5 .

La deuxième attaque se fait du côté du port et des navalia, ce que nous confirme aussi le scholiaste de Lucain « vers le port, vers cet endroit qu'on appelle la plaine du port ${ }^{6}$. Les arsenaux sont sans doute les neosoikoi (hangars à bateaux) dont l'extrémité occidentale a été découverte récemment dans les fouilles de la place VilleneuveBargemon près de la Mairie, et qui devaient se continuer jusqu'à la Bourse (Hesnard et al., 2001). L'emplacement de la deuxième attaque, sur la porte d'Italie dans le secteur de la Bourse, ne fait donc guère de doute.

\footnotetext{
4 Sur cette traduction, cf. Euzennat, Salviat, 1967.

5 Ad locum in occidentem adsurgentem urbisplicia dixerunt (M. Annaei Lucani Commenta Bernensia, III, 381, Teubner, Leipzig 1869, repr. Olms, Hildesheim 1967, éd. Usener). Sur cette discussion, cf. Euzennat, Salviat, Veyne 1970, p. 14 sqq. Le scholiaste se réfère explicitement à un certain Cornutus, que nous ne connaissons pas par ailleurs (mais qu'il ne faut pas confondre avec L. Annaeus Cornutus, l'un des maîtres de Lucain).

6 Ad portum, quem locum portus pedeon uocant. Un manuscrit porte la graphie portem : faut-il lire portam, une porte ? L'assaut porterait alors précisément sur la porte d'Italie.
} 
Après avoir exposé les choix du commandement romain, César en explique méthodiquement les raisons. C'est que Marseille est entourée d'eau sur « près des trois quarts de son périmètre. Il n'est donc possible de l'attaquer que sur le dernier quart du périmètre, dans la partie terrestre. Encore de ce côté-ci la partie centrale est-elle occupée par la citadelle ( $\operatorname{ar} x$ ) qui « est défendue par la nature du terrain et un ravin extrêmement profond, ce qui en rend l'attaque longue et difficile ${ }^{7}$. Au lieu de suivre l'ordre logique du syllogisme (on ne peut attaquer que du côté de la terre, mais le centre de ce côté est occupé par la citadelle, donc on attaque sur les côtés), César donne d'abord la conclusion (les deux axes d'attaque), avant les données topographiques qui la justifient.

Ici s'arrête la description du site de Marseille. César a démontré que le choix des deux axes d'attaque était imposé par la topographie et que la citadelle, arx, est précisément le secteur qu'il choisit de ne pas attaquer.

Chacune des directions d'attaque comprend une terrasse d'assaut (agger), des baraques d'approche (uineae), des tours (turres).

Pour qui douterait qu' il y avait bien un agger par zone d'attaque, lorsque, plus tard (BC, II, 14), les Marseillais tentent des sorties pour incendier les machines de guerre romaines, ils attaquent d'abord une des zones d'assaut (César ne dit pas laquelle) et détruisent la terrasse (agger), les mantelets (plutei), la tortue (testudo), la tour (turris), les pièces d'artillerie (tormenta). Puis ils font (sans succès cette fois) une autre attaque ad alteram turrim aggeremque, contre la seconde tour et le second agger, évidemment ceux du second secteur ${ }^{8}$.

Et pourtant, dans la discussion qui oppose Gaston Vasseur (1914, p. 213-226) à Michel Clerc (1898) sur l'emplacement de la butte des Carmes (à l'intérieur ou à l'extérieur de l'enceinte hellénistique) le principal argument porte sur l'emplacement et les dimensions de l'agger lancé contre la citadelle. Le point de départ de la discussion est à chercher chez Camille Jullian (1899, 1900), qui n'hésite pas à utiliser le texte de la Pharsale de Lucain pour rendre compte des obscurités du Bellum Ciuile.

Il est vrai que le texte de César n'est pas tout à fait aussi cohérent que je l'ai dit jusqu'à présent. Aussitôt après qu'il a mentionné l'arx, César commence à décrire les travaux de circonvallation et mentionne la construction d'un grand agger, précédé d'une galerie couverte

7 César décrit ainsi le site de Gergovie, qu'il renonce à attaquer directement : Caes., BG, VII, 36 : (Gergovia) posita in altissimo monte omnes aditus difficiles habebat, de expugnatione desperavit.

8 Caes., BC, II, 14 : Temptaverunt hoc idem Massilienses postero die. Eandem nacti tempestatem maiore cum fiducia ad alteram turrim aggeremque eruptione pugnaverunt multumque ignem intulerunt. $(\text { testudo })^{9}$. Puis, après le récit détaillé de la seconde bataille navale, il décrit avec force détails la construction d'une tour (II, 8-9), puis d'une autre galerie ou musculum (II, 10). On a l'impression à le lire que ces ouvrages sont uniques, mais César décrit probablement les ouvrages de l'une des lignes d'attaque, sans prendre la peine de dire qu'il y en a d'autres ailleurs. Il s'agit sans doute de textes rédigés à part, décrivant des opérations techniques, et insérés sans trop de soin dans le récit chronologique des opérations ${ }^{10}$. Il y a loin de ces textes à la description synthétique de l'assaut en II, 1 .

C'est le texte de Lucain dans La Pharsale qui privilégie un assaut unique contre l'arx, au moyen d'un agger de dimensions considérables. C'est lui qui justifie l'interprétation en ce sens des points faibles du récit de César. Mais c'est oublier que le propos de Lucain n'est pas celui de César. Là où le récit du Bellum ciuile, en dépit de son caractère parfois polémique et de nombreuses négligences dans la rédaction (Rambaud 1966), peut s'apparenter à un texte historique, en tout cas une chronique décrivant des faits réels, le texte de Lucain est d'abord un poème épique qui s'appuie sur des événements réels pour forger une grande fresque poétique. Il n'y a chez Lucain qu'une grande bataille navale (Pharsale, vers 509-762) ${ }^{11}$, alors que nous savons par le récit détaillé de César qu'il y en eut deux (BC, I, 56-58 et II, 3-7). La sortie faite par les Marseillais pour incendier les machines de guerre romaines s'est faite à l'heure la plus chaude de la journée, quand le vent soufflait le plus fort ${ }^{12}$ : chez Lucain, cela devient une sortie

9 BC, II, 1, fin : Ad ea perficienda opera $C$. Trebonius magnam iumentorum atque hominum multitudinem ex omni provincia vocat; vimina materiamque comportari iubet. Quibus comparatis rebus aggerem in altitudinem pedum LXXX exstruit, " Pour mener à bien ces travaux d'approche, $C$. Trébonius réquisitionne dans toute la province un grand nombre d'animaux et d'hommes ; il fait rassembler de l'osier et du bois. Lorsque tout cela est prêt, il élève une terrasse de quatre-vingt pieds de haut » (trad. Fabre).

10 On comparera les récits que Diodore de Sicile fait de la construction des remparts de Syracuse au livre XIV, ch. 18 de la Bibliothèque historique (année 401), puis au livre XV, ch. 13 (année 385) : le premier est une description détaillée des travaux sur un secteur de la muraille, le second un récit très synthétique des travaux de défense de Denys. Mais les deux textes, issus de sources différentes, font sans doute allusion au même programme de construction.

11 Le passage a été retraduit en français par A. Hesnard et A. Tchernia dans Hermary, Hesnard, Tréziny 1999, p. 149-151.

$12 B C$, II, 14 : Hostes ... nostris languentibus atque animo remissis, subito meridiano tempore, cum alius discessisset, alius ex diutino in ipsis operibus quieti se dedisset (...), portis se foras erumpunt, secundo magnoque uento ignem operibus inferunt. Hunc sic distulit uentus uti uno tempore agger, plutei (...) flammam conciperent ..., « L'ennemi (...), l'élan de nos troupes calmé et leur énergie se relâchant, soudain, vers midi, alors que les uns s'étaient éloignés et que les autres, fatigués par un long travail, s'étaient mis à faire la sieste dans les ouvrages mêmes (...), fait une sortie par les portes et, secondé par un vent violent, met le feu aux ouvrages. Le vent se propagea si rapidement qu'en un instant la terrasse, les mantelets (...) furent en flammes...». 


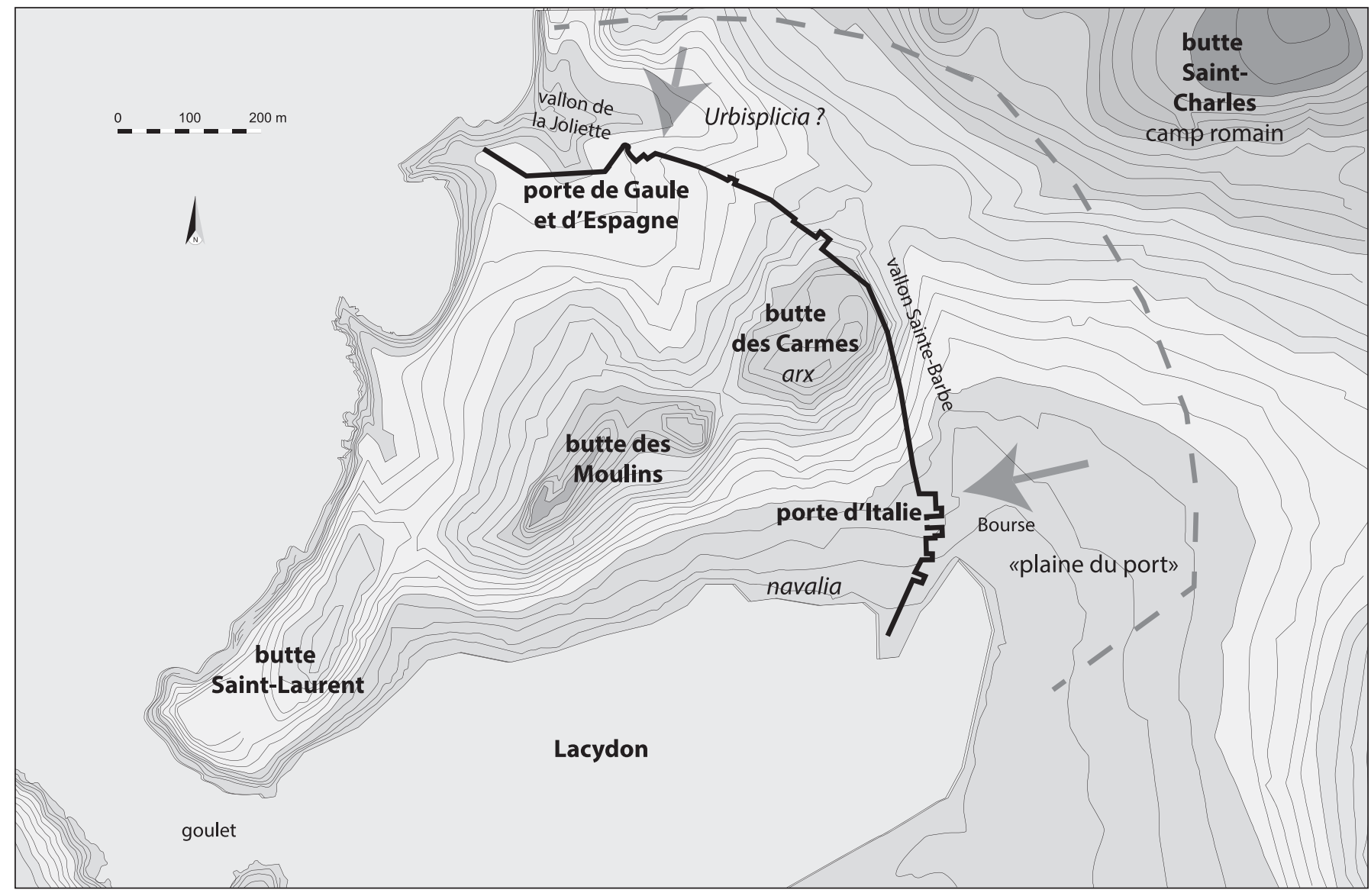

Fig. 1. Topographie de Marseille à l'époque du siège de César. La ligne pointillée indique le tracé possible de la circonvallation romaine, les flèches les deux principales directions d'attaque (Tréziny 2011).

nocturne, dans laquelle, même s'il ne l'écrit pas expressément, les flammes se reflètent sur les boucliers et les cuirasses, dans une esthétique baroque qui évoque les tragédies de Sénèque ou le grand incendie de Rome ${ }^{13}$.

\section{Pharsale, III, v. 498-506:}

Vltro acies inferre parant armisque coruscas nocturni texere faces, audaxque iuuentus erupit. Non hasta uris, non letifer arcus, telum flamma fuit, rapiensque incendia uentus per Romana tulit celeri munimina cursu. $\mathrm{Nec}$, quamuis uiridi luctetur robore, lentas Ignis agit uires, taeda sed raptus ab omni Consequitur nigri spatiosa uolumina fumi, Nec solum siluas, sed saxa ingentia soluit...

«(Les Grecs) se préparent à prendre l'offensive à la faveur de la nuit; ils cachèrent sous leurs boucliers les torches scintillantes et, guerriers audacieux, se précipitèrent au dehors. Les hommes n'ont point de lances, ni d'arc homicide, leur arme est la flamme, et le vent, propageant l'incendie, le porta d'un cours rapide à travers les retranchements romains. Et, bien qu'il lutte contre des troncs verts, le feu n'exerce pas ses ravages avec lenteur, mais, propagé par toutes les torches, il suit les volutes spacieuses de la noire fumée, et il ne consume pas seulement le bois, mais d'énormes roches,
Le but poursuivi par Lucain n'est pas le même que celui de César, et il n'y a rien d'étonnant à ce qu'il ait réuni les deux attaques de César sur les points faibles de la défense marseillaise en une seule attaque, monumentale, sur le point le plus fort.

Les textes de César et de Lucain appartiennent à des genres littéraires différents. C'est pour l'avoir oublié que l'on a voulu expliquer par Lucain les points obscurs du récit de César, alors même que le reste du récit césarien, parfaitement clair, contredit le texte de Lucain.

\section{La description de Marseille par Aviénus dans l'Ora maritima}

Le poète latin Festus Aviénus a vécu au IVe s. de notre ère. Il est l'auteur d'un poème en sénaires iambiques, l'Ora maritima, sans doute incomplet, qui décrit les côtes de la Méditerranée occidentale de Tartessos à Marseille. Le texte est souvent utilisé par les historiens et les archéologues de ces régions. On y a vu tantôt la transcription d'un périple maritime phocéen (thèse reprise récemment par Luca Antonelli 1998), tantôt un 
itinéraire terrestre (D. Ugolini à propos de Béziers). Les textes sur lesquels s'appuie Aviénus sont peut-être très anciens (comme il le dit lui-même au début du poème ${ }^{14}$ ), mais peut-être aussi d'époque hellénistique et romaine (Ugolini, Olive 1987), si bien que nous ignorons la date des paysages qu'il décrit.

On attribue avec beaucoup de vraisemblance à Aviénus deux autres poèmes, qui sont des traductions en hexamètres dactyliques d'œuvres hellénistiques également conservées, la Descriptio Orbis Terrae ${ }^{15}$, d'après la Périégèse de Denys d'Alexandrie ${ }^{16}$, et les Arati Phaenomena ${ }^{17}$, traduction des Phaenomena d'Aratos de Cnide ${ }^{18}$.

Il existe de l'Ora maritima plusieurs traductions et commentaires, soit de l'ensemble de l'œuvre ${ }^{19}$, soit de passages précis (pour Marseille Clerc 1928, Hesnard 2001).

Le texte qui nous occupe s'étend sur un peu plus de 8 vers. Il se compose de deux parties, une première descriptive se terminant par la phrase «la cité est une presqu'île », suivie d'une deuxième partie de portée plus générale. L'établissement du texte et sa ponctuation ont donné lieu à de nombreuses discussions. On donnera d'abord le texte et la traduction de l'édition Berthelot.

14 Dans le prologue du poème, Aviénus affirme ne se référer qu'à des auteurs anciens de la fin du VIe s. (Hécatée de Milet, Scylax de Caryanda) ou du Ve s. (Hellanicos de Lesbos, Philéas d'Athènes, Euctémon d'Athènes, Hérodote et Thucydide) et d'autres auteurs moins connus ; la seule exception serait Salluste, invoqué pour le Palus Maeotis (passage perdu).

15 Aviénus, Descriptio orbis terrae, texte établi par Paul Van de Woestijne, Bruges 1961 (avec apparat critique et index, sans traduction) ; L'« Orbis terrae » di Avieno, a cura di Amedeo Alessandro Raschieri. Acireale-Rome, 2010, texte latin, traduction italienne et commentaire ; voir aussi Raschieri 2010.

16 La description de la terre habitée de Denys d'Alexandrie ou La leçon de géographie, introduit et traduit par Christian Jacob ; traduction française d'extraits de la version grecque, revue et augmentée par Edward Wells, Paris 1990 ; Dioniso di Alessandria. Descrizione della terra abitata, traduit en italien par Eugenio Amato, Milan 2005 ; Guida delle terre abitate, Dionigi d'Alessandria, il Periegeta, a cura di Amedeo Alessandro Raschieri, Rome 2010.

17 Aviénus, Phaenomena Arati, texte établi et traduit par P. Soubiran, CUF, Paris 1981.

18 Aratos, Phaenomena, texte, traduction et commentaire par Jean Martin, CUF, Paris 1998 (2 vol.)

19 Principales éditions du texte : Rufi Festi Avieni Carmina, édités par Alfred Holder, Oettingen 1887 ; Aviénus, Ora Maritima, texte, traduction et commentaire par André Berthelot, Paris 1934; Avieno, Ora maritima : periplo massaliota del siglo VI a. de J.C. : junto con los demás testimonios anteriores al año 500 a. de J.C., éd. de A. Schulten, Barcelone 1922 ${ }^{2} 1955$; Avienus, Ora Maritima, texte, traduction et commentaire en anglais par John P. Murphy, Chicago 1977 ; Ruf Fest Aviè, Periple (Ora maritima), édité par Pere Villalba i Varneda, Barcelone, 1986 ; Luca Antonelli, Il periplo nascosto, texte, traduction et commentaire de l'Ora maritima en italien, Padoue 1998. Voir aussi Antonelli 2010.
Massilia et ipsa est; cuius urbis hic situs :

705 Pro fronte littus praeiacet; tenuis uia

Patet inter undas ; latera gurges adluit,

Stagnum lambit urbem, et unda lambit oppidum

Laremque fusa : ciuitas peninsula est :

Sic aequor omne caespiti infundit manus,

710 Labos et olim conditorum diligens

Formam locorum et arua naturalia

Euicit arte...

« ...et Marseille elle-même, dont voici la situation : le rivage s'étend en avant, un étroit chemin s'ouvre entre les eaux, la mer baigne les côtés, un étang entoure la ville et l'eau se répand dans la ville et les maisons, la cité est une presqu'île. Ainsi la main humaine a introduit la mer dans la terre, la forme des lieux et la nature du sol ont été modifiés par le labeur diligent des fondateurs... »

Le vers 706 (pro fronte litus praejacet) est énigmatique. La traduction Berthelot n'a guère de sens. Michel Clerc ${ }^{20}$, qui voit dans le texte d'Aviénus un récit maritime, traduit « À qui arrive du large, se présente le rivage ». Mais le texte de l'édition princeps (Venise 1488) porte fonte (leçon acceptée par Constans ${ }^{21}$ ), qui serait une source en arrière du rivage.

La suite dépend beaucoup des présupposés de chaque auteur. La tenuis via qui s'ouvre au milieu des flots est pour beaucoup une route maritime, qui donne accès au goulet d'entrée dans le port. Les mots qui suivent, latera gurges adluit, se rapportent alors à urbis : " les flots baignent les côtés de la ville » (Clerc, « La haute mer baigne le flanc de la ville»). Mais si on ne se place pas d'emblée dans une perspective maritime, la tenuis via devient un isthme dont les côtés sont baignés par les flots (Antonelli). On pourra objecter qu'Aviénus dit alors deux fois la même chose (la voie s'ouvre au milieu des eaux, les flots en baignent les côtés), mais c'est oublier que, comme l'écrit Jean Soubiran dans l'introduction aux Arati Phaenomena, cette « tendance à répéter la même idée sous des formes différentes » est une des caractéristiques du style d'Aviénus. Ainsi le vers 766 des Phaenomena d'Aratos de Cnide

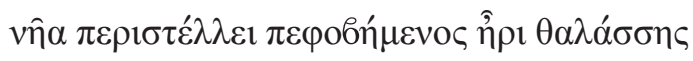

«(le marin) craignant la tempête ramène son navire » est-il transposé par Aviénus (Arati Phaenomena, v. 1393-1395) :

20 Clerc 1929, p. 167 et n. 5, p. 171 et n. 1. À la suite du livre de Clerc, le passage a été commenté par Constans (ci-dessous note 20), Busquet en 1932 et 1938, Roberty en 1932 et 1944, Duprat en 1935. 21 L. A. Constans, compte-rendu de Clerc, Massalia, dans JS, 1931, p. 31-39, deuxième partie (première partie dans $J S, 1930$, p. 460-467). 
doctus securam subducit ab aequore classem nauita et actaea retinet statione phaselum cum matutinae praesensit signa procellae.

« le marin avisé ramène sa flotte à l'abri loin de la haute mer et retient son esquif dans le port abrité lorsqu'il sent au matin les signes de la tempête »,

où le simple navire d'Aratos devient « la flotte de guerre et un frêle esquif », en somme " le bateau dans tous ses états », du plus grand au plus petit.

Cette caractéristique se retrouve, toujours dans les Phaenomena, dans la multiplication des mots de la sphère du « brillant », qui apparaissent proportionnellement au moins deux fois plus chez Aviénus que chez Aratos, souvent plusieurs fois dans le même vers ce qui est beaucoup plus rare dans le texte original (Lewis 2010). Plutôt que de « répétition », on parlera alors de « variations » autour d'un thème.

Les deux vers suivants sont ceux qui ont été le plus sollicités pour une description du paysage de Marseille.

\section{Stagnum ambit urbem et unda lambit oppidum laremque fusa ciuitas paene insula est.}

La traduction de Clerc est tout à fait caractéristique d'une tendance à interpréter le texte en fonction de l'idée que l'on se fait de la topographie: "l'eau stagnante longe la ville basse ; de sorte que l'eau, partout répandue, lèche la ville haute et la ville basse : la cité est une presqu'île ». Stagnum, " l'eau stagnante », doit être le Vieux-Port, ce qui oblige à traduire ambit (entoure) ${ }^{22}$ par « longe » (le Vieux-Port n'entoure pas la ville), et à comprendre urbem comme la «ville basse »; puis dans le couple oppidum laremque, larem est à nouveau la « ville basse ». Murphy (1976) sort de cette difficulté en coupant entre oppidum et larem: un lac entoure la cité et le flot lèche la ville ${ }^{23}$. Cela l'oblige à comprendre au vers suivant «Ayant répandu ses maisons, la ville est une presqu'île », ce qui n'est pas très satisfaisant.

Mais je ne crois pas que l'on doive couper entre oppidum et larem. Le couple oppidum/lar n'est qu'un développement de l'urbem qui précède, comme nous l'indiquent deux vers de la Descriptio (v. 367-368) :

22 Comme l'a bien vu Murphy 1976, reprenant une correction de Heinsius, le texte lambit des manuscrits, curieusement accepté par Villalba ou Antonelli, doit être corrigé en ambit, d'abord pour des raisons métriques (le vers ne peut se scander sous la forme donnée par les manuscrits), ensuite parce que si Aviénus aime répéter la même idée sous des formes différentes, il est moins adepte de l'anaphore.

23 Murphy: "A lagoon surrounds the city and the wave laps the town".
Hic urbs est Thebae, Thebae quae moenibus altis Praecinxit larem...

« Voici la ville de Thèbes, Thèbes qui entoure ses maisons de hautes murailles ».

Dans ce texte, qui s'inspire du vers 249 de la Périégèse, Aviénus remplace la description conventionnelle de Thèbes, et notamment l'épithète homérique hekatompylon (" aux cent portes ») tirée de l'Iliade, par une expression assez proche du passage de l'Ora maritima. Le couple moenia/lar, comme oppidum/ lar, ne sert pas à distinguer précisément deux parties de l'urbs mais plus généralement à désigner la ville par ses deux composantes, les maisons et le rempart, les parties pour le tout, le tout et ses parties.

Je suggère donc de lire le texte d'Aviénus de la façon suivante : "L'eau (sous la forme stagnum) entoure la ville, et l'onde (unda) répandue lèche le rempart et les maisons (oppidum laremque) ». De même que la classis et le phaselus des Phaenomena représentent le bateau sous toutes ses formes, stagnum et unda, comme gurges et peut-être fons, représentent toutes les formes de l'eau. Marseille est une presqu'île reliée à la terre par un isthme bordé par les flots, l'eau y est partout. Et je ne crois pas qu'il soit opératoire d'un point de vue topographique de faire des distinctions subtiles dans ce qui est avant tout un jeu littéraire.

La deuxième partie du texte n'est pas moins conflictuelle. La traduction la plus simple (Clerc, Murphy ${ }^{24}$ ) dit que l'eau tout entière (l'eau dans tous ses états ?) s'est déversée dans le pays, nouvelle variation autour de ce qui a été dit précédemment, et que le travail des fondateurs a vaincu la nature ; il faut sans doute comprendre des travaux de drainage et d'assèchement.

Berthelot, suivi par Antonelli, comprend autrement : c'est la main de l'homme (manus) qui a fait pénétrer l'eau dans les terres, l'action humaine (arte) s'opposant à l'état naturel (naturalia) ${ }^{25}$. Dans la première interprétation, Marseille est une presqu'île baignée par les eaux, et c'est l'action humaine qui la rend habitable. Dans la seconde, Marseille est une presqu'île, oui, mais pas seulement par un effet de la nature : l'homme y a aussi contribué.

24 Murphy : "So does the entire sea spread its force on the land. But the careful labor of its ancient founders skillfully conquered the shape of the place and the natural fields."

25 Mais, dans le même temps, Berthelot s'indigne : «Le tableau de Marseille brossé par Aviénus n'a pas grand rapport avec celui qu'elle offre à nos yeux ; nous ne trouvons nulle trace de l'étang ou marais qui aurait entouré la ville, pas davantage des bassins ou canaux creusés de main d'homme au milieu des maisons». 
Il se trouve que la documentation archéologique pourrait conforter l'une ou l'autre de ces interprétations. Nous pensons aujourd'hui que les marais de la Bourse sont en grande partie le résultat de l'ennoiement de carrières d'argile au début du $\mathrm{V}^{\mathrm{e}} \mathrm{s}$. Mais nous savons aussi que dès le $\mathrm{V}^{\mathrm{e}}$, et surtout à partir du $\mathrm{IV}^{\mathrm{e}} \mathrm{s}$., ces marais sont progressivement comblés ${ }^{26}$.

Mais ce qui est en jeu ici n'est pas la topographie de Marseille, et il serait en contradiction avec mon propos de vouloir utiliser ce que nous savons - ou croyons savoir de la topographie de Marseille pour traduire Aviénus.

Aviénus ne décrit pas précisément un paysage réel mais brode sur un canevas qui lui offre sans doute quelquefois des vues réelles, mais trop rarement pour que nous puissions l'utiliser avec efficacité. Pour lui, Marseille est une presqu'île et les huit vers qu'il y consacre ne sont que des variations autour de cette vision très vague. Comme les Tableaux de Philostrate ne sont pas la description d'un musée réel mais un texte de goût hellénistique ${ }^{27}$, la Descriptio est une suite de vignettes dont la précision et la fiabilité sont très variables. Même si la conclusion se révèle décevante pour l'historien, il faut admettre que style et composition obéissent avant tout à un projet littéraire plus que géographique ou historique ${ }^{28}$.

Cette note veut donc être d'abord un appel à la prudence quand on utilise des textes littéraires, cette prudence dont Michel Bats a toujours su user dans son travail d'historien.

\section{Bibliographie}

Antonelli 2010 : ANTONELLI (L.) - L'ora marittima di Avieno e la tradizione dei Geographi Graeci Minores. Hesperìa, 26, 2010, p. 189-217.

Bouiron, Mellinand 2013 : BOUIRON (M.), MELLINAND (Ph.), dir. Quand les archéologues redécouvrent Marseille, Paris 2013.

Bats 1994 : BATS (M.) - Les silences d'Hérodote ou Marseille, Alalia et les Phocéens en Occident jusqu'à la fondation de Vélia. AIONStAnt, NS 1, 1994, p. 133-148.

Braginskaja 1981 : BRAGINSKAJA (N. V.) - La composition des Tableaux de Philostrate l'Aîné. In : Ivanov V. S. et al, Structure du texte-81. Thèses du colloque, Moscou 1981, p. 129-133.

26 Pour une description générale de l'évolution du site de la Bourse, cf. Tréziny 2013, fig. 5 ; cette réinterprétation s'appuie sur les fouilles de carrières d'argile dans le chantier de l'Alcazar (Bouiron, Mellinand 2013, p. 54).

27 Prioux sous presse; Braginskaja 1981.

28 J.-L. Charrière me fait part courtoisement d'une autre hypothèse selon laquelle le passage d'Aviénus ne concernerait pas Marseille mais la zone des étangs vers Martigues, hypothèse que je ne retiens pas ici, mais qui montre la difficulté d'interprétation du poème d'Aviénus.
CAG Marseille : ROTHÉ (M.-P.) et TRÉZINY (H.) - Carte Archéologique de la Gaule, vol. 13/3, Marseille et ses environs, Paris, 2005.

Clerc 1898 : CLERC (M.) - Le développement topographique de Marseille depuis l'Antiquité jusqu'à nos jours. In : dans Études sur Marseille et la Provence, Congrès National des Sociétés Savantes de Géographie, XIX ${ }^{\mathrm{e}}$ session, 1898, p. 20-44.

Clerc 1929 : CLERC (M.) - Massalia. Histoire de Marseille dans l'Antiquité, des origines à la fin de l'Empire romain d'Occident (476 apr. J.-C.), t. 2, Marseille, 1929.

Euzennat, Salviat 1967 : EUZENNAT (M.), SALVIAT (Fr.) - Sur un passage de César (Guerre Civile, II, 1) et la topographie de Marseille pré-romaine. Etudes Classiques Aix, 2, 1967, p. 179-183.

Euzennat, Salviat, Veyne 1970 : EUZENNAT (M.), SALVIAT (Fr.), VEYNE (P.) - Les scholies bernoises de Lucain. César et Marseille antique, Études Classiques Aix, 3, 1968-1970, p. 13-24.

Hermary, Hesnard, Tréziny 1999 : HERMARY A., HESNARD A., TREZINY H. (dir.), Marseille grecque. La cité phocéenne (600-49 av. J.-C.), Paris, Errance, 1999. 184 p.

Hesnard et al. 2001 : HESNARD (A.), BERNARDI (Ph.), MAUREL (Chr.) - La topographie du port de Marseille de la fondation de la cité à la fin du Moyen Age, dans Bouiron M. et al. (éd.), Marseille : trames et paysages urbains de Gyptis au Roi René, colloque archéologique international, Marseille, 3-5 novembre 1999 (Études massaliètes 7), Aix-en-Provence 2001, p. $159-202$.

Jullian 1899 : JULLIAN (C.) - Notes gallo-romaines, 4. Lucain historien, Les préliminaires du siège de Marseille. REA 1, 1899, p. 310-316.

Jullian 1900 : JULLIAN (C.) - Notes gallo-romaines, 8. Lucain historien, 2. Le siège de Marseille : la terrasse d'approche. REA 2, 1900, p. 329-345.

Lewis 2010 : LEWIS (A.-M.) - The Frequency and Function of Words of Astronomical Brightness in the Latin Poetic Translations of Aratus' Phaenomena. RBPH, 88, 2010, p. 25-43.

Prioux sous presse : PRIOUX (E.) - Le vocabulaire de l'architecture chez Philostrate. In : Dire l'architecture dans l'Antiquité, colloque d'Aix-enProvence, octobre 2010, sous presse.

Rambaud 1966 : RAMBAUD (M.) - L'Art de la déformation historique dans les Commentaires de César, Annales de l'Université de Lyon, 1952. $2^{e}$ éd. augmentée en 1966.

Raschieri 2010 : Raschieri (A. A.) - L'image du monde entre l'écriture et la réécriture : le cas de Denys le Périégète et de son traducteur latin Aviénus. In : Isabelle Milliat-Pilot, éd., Texte du Monde, Monde du texte, colloque 2006, Grenoble 2010, p. 25-48.

Tréziny 2013 : TREZINY (H.) - L'espace périurbain de Marseille. In : M.C. Belarte et R. Plana Mallart, éd., Le paysage périurbain en Méditerranée occidentale pendant la Protohistoire et l'Antiquité. Actes du Colloque international, Institut Catalan d'Archéologie Classique, Tarragone, 6-8 mai 2009, Tarragone 2013.

Ugolini, Olive 1987 : UGOLINI (D.), OLIVE (Chr.) - Béziers et les côtes languedociennes dans l'Ora maritima d'Aviénus (vv. 586-594). RANarb 20 , 1987, p. 143-154.

Vasseur 1914 : VASSEUR (G.) - L'origine de Marseille. Annales Musée Hist Nat Marseille XIII, 1914 



\title{
Le site de Marseilleveyre entre Grecs et indigènes État de la question, recherches récentes et nouvelles approches
}

\author{
Sophie Bouffier \\ Professeur, Aix Marseille Université, CNRS, Ministère de la Culture et de la Communication, \\ CCJ UMR 7299, 13094, Aix en Provence, France \\ Loup Bernard \\ Maître de Conférences, Université de Strasbourg, UMR7044, MISHA \\ Delphine Isoardi \\ CR CNRS, Aix Marseille Université, CNRS, Ministère de la Culture et de la Communication, \\ CCJ UMR 7299, 13094, Aix en Provence, France
}

\section{Résumé}

L'article dresse le bilan d'une recherche collective sur le site de Marseilleveyre, localisé au sud du bassin territorial de Marseille grecque, dans un massif connu pour l'occupation antique d'un certain nombre de ses grottes. D'abord identifié comme un oppidum celto-ligure par les publications anciennes, il a fait l'objet de nouvelles recherches depuis 2008 dans le cadre d'un programme collectif de recherches sur l'ensemble du massif. Dans l'état actuel de la recherche, cet habitat au faciès celto-ligure a révélé une occupation en réalité limitée, à la fois par la chronologie, - entre la première moitié et le troisième quart du VI ${ }^{\mathrm{e}} \mathrm{s}$. av. J.-C. - et par l'extension topographique.

Mots-clés : Grecs, indigènes, Territoire, Marseille, grottes, céramique

\section{Abstract}

This paper presents the results of a collective research on Marseilleveyre site, located at south of territorial basin of Greek Marseille, in the homonymous hills, where some caves have been occupated during Antiquity. First identified as a Celtic-Ligurian oppidum by former publications, it has been the subject of new research since 2008 as part of a collective research program on the whole hills. In the present state of research, this Celtic-Ligurian settlement revealed a limited occupation, both for its chronology, between the first half and the third quarter of the sixth century a.C., and its topographic extension.

Keywords: native populations, territory, Marseille, caves, ceramics 
$\mathrm{S}$ itué dans le quartier de Sormiou, au sud du bassin marseillais, le site de Marseilleveyre occupe les replats de falaises calcaires, en aval des sommets de Marseilleveyre et de l'Homme Mort, entre le vallon des Trois Gancets à l'ouest, le col de la Sablière au nord, les sablières et le Vallon de la Jarre à l'est, le Vallon de l'Homme mort au sud. Il présente ainsi un vaste plateau orienté est-ouest, délimité au nord, à l'est et à l'ouest par une falaise, tandis que sa partie sud est surmontée par deux sommets. Installé à une cote qui oscille entre 190 et 220 m, il offre un panorama étendu à la fois sur la mer, Marseille et la plaine de l'Huveaune et domine les terres agricoles de Bonneveine et de la Pointe Rouge. Fermant la rade de Marseille au sud, le site de Marseilleveyre apparaît à la fois comme une limite et comme un point de carrefour entre la plaine de Marseille et l'intérieur des collines, apparemment fréquenté depuis le Néolithique. Trois sources pouvaient approvisionner le site en eau : la fontaine de Voire dans le Vallon de l'Homme mort au sud-est du site, le Puits du Lierre au sud, la source du vallon des Trois Gancets, à l'ouest.

\section{État de la question : historique des recherches sur le site et dans le secteur}

\section{Le site de Marseilleveyre ${ }^{1}$}

Il est évoqué pour la première fois par Isidore Gilles en 1876 qui mentionne trois groupes d'habitats dans le massif de Marseilleveyre dont celui qui nous intéresse aujourd'hui. Il le localise dans le vallon de la Font de Voire et y relève de très nombreux vestiges de murs, qu'il interprète comme des habitations et des fortifications, des restes de «poteries celtiques indigènes modelées », des fragments de meules en basalte de Beaulieu et un fragment en granit rouge. En revanche, il n'y voit pas de céramique grecque, " ce qui tendrait à prouver que la population a été immédiatement chassée ou absorbée par les Marseillais. »(Gilles 1876, p. 11-12). En 1929, Michel Clerc reconnaît logiquement des murs de terrasse dans les structures décrites par Isidore Gilles, tout en réaffirmant la présence de populations indigènes dans le massif (Clerc 1927-29, p. 38-39). Pour Georges Daumas, en 1934, ce mobilier marquait non pas l'oppidum, mais le lieu et le chemin de ravitaillement à l'eau de la source de Font-de-Voire, qui était la plus proche du site (Daumas 1934 ; 1936). Il est le premier à utiliser le terme d'oppidum pour cet habitat tout en précisant que « le terme est trop pompeux pour la station qui nous

1 Gantès, Rothé 2005. occupe » (Daumas 1934, p. 85). Il l'intègre toutefois dans un système d'oppida que les populations locales auraient constitué sur les collines du Rove, de la Nerthe, de l'Etoile et d'une partie du Garlaban, au nord et à l'est de Marseille. "L'oppidum de Marseilleveyre, au sud, complétait ainsi ce système stratégique qui encerclait tout le territoire phocéen » (Daumas 1934, p. 85). Ses recherches sur le site sont limitées. Il confirme la présence de céramique commune indigène, fragments de petits vases plutôt que de grands dolia, débris de meules et molettes à main en basalte, mais ne relève « aucune apparence de murailles en pierres sèches, nulle trace artificielle de retranchement $\gg$ (Daumas 1934, p. 90). Il en conclut que l'habitat devait être constitué de huttes ou de cabanes. Ses observations sont confirmées par Paul Agostini (1967). À partir de 1970, à la suite d'incendies de forêts qui ont mis à nu le plateau, un amateur passionné d'archéologie, Jean-Louis Garnier, sillonne le site pendant une trentaine d'années, et cherche à attirer l'attention des autorités archéologiques sur les détériorations variées qu'il subit. Lui aussi qualifie le site d'oppidum car il relève, outre la céramique, des fragments de meules et des galets assimilés à des balles de fronde, un alignement de blocs dans la partie sud-ouest du site, interprété comme un rempart, et dans la partie nord-est, une abondance de murets et tas de pierre qu'il assimile à des fonds de cabanes (Garnier 2000). Après des prospections en 1985 et 1991, Lucien-François Gantès parvient aux mêmes conclusions. Il décrit « de multiples constructions, isolées les unes des autres (tous les $75 \mathrm{~m}$ ) et implantées au point le plus haut du site (à $222 \mathrm{~m}$ d'altitude), dans un espace limité (long. $250 \mathrm{~m}$; larg. $200 \mathrm{~m}$ ) », soit environ trois maisons si l'on fait le calcul. Il ajoute : " au nord-est du site, entre la falaise nord et un mur de clôture, ont été observés les vestiges d'un bâtiment ( $8 \mathrm{~m}$ x $5 \mathrm{~m}$; haut. conservée : 0,40 m). Les murs, orientés nord-ouest/sud-est et nord-est/sud/ouest, sont formés de gros blocs $(0,63-0,40 \times 0,45-0,35$ x $0,40-$ $0,20 \mathrm{~m}$ ) posés de chant, en calcaire brut. Ils délimitent une surface relativement plane où le rocher affleure par endroits » (Gantès, Rothé 2005, p. 686).

En ce qui concerne le mobilier récolté lors de ces ramassages, d'après les données publiées prenant en compte une centaine de tessons, les importations sont très largement majoritaires, la CNT ne représentant que $10 \%$ des tessons et les céramiques de Marseille à peine $2 \%$ des fragments mentionnés par les auteurs. Les conditions taphonomiques expliquent en partie la surreprésentation du mobilier d'importation en général, et amphorique en particulier pour les assemblages de surface, la céramique non tournée se délitant plus facilement. Les formes et provenances reconnues mettent en lumière la grande majorité d'amphore étrusque, plus 
de $75 \%$, le reste du mobilier se répartissant en amphore phénico-punique (5\%), amphore corinthienne A (3\%), et des résidus variés (1\% d'amphore laconienne, $1 \%$ d'amphore de Milet, $1 \%$ d'amphore massaliète et quelques pâtes claires et tessons indéterminés). Le profil de ce mobilier a permis à L.-Fr. Gantès de dater l'occupation du site dans le courant du $\mathrm{VI}^{\mathrm{e}} \mathrm{s}$. av. J.-C. sans poser toutefois de terminus de fondation ou d'abandon.

À partir de 2007, dans le cadre d'un Projet Collectif de Recherches sur L'occupation du bassin de Marseille de la Préhistoire à l'époque moderne, mis en place au Centre Camille Jullian, avec la collaboration de l'Atelier du Patrimoine de Marseille, nous sommes intervenus sur le site d'abord par le biais de prospections. Notre intervention devait permettre de caler la chronologie du site et d'enrichir la réflexion sur l'occupation de ce secteur, ainsi que sur toute la ligne de crête qui domine la plaine marseillaise au sud. Les campagnes de prospections menées en 2007 et 2009 permirent de collecter un mobilier dont le faciès confirmait les ramassages antérieurs mais ont également constaté l'absence presque générale des structures mentionnées par nos prédécesseurs, à l'exception de la ligne rocheuse interprétée comme un probable mur de fortification, mais qui ne se prolongeait pas au-delà de la dite poterne (en dernier lieu, Collin Bouffier 2009).

\section{Les grottes}

Dans le massif de Marseilleveyre, la recherche a identifié depuis longtemps des grottes dont certaines ont été sondées à la fin du $\mathrm{XIX}^{\mathrm{e}}$ et au début du $\mathrm{XX}^{\mathrm{e}} \mathrm{s}$. Une réflexion sur l'occupation du massif et les relations des différentes communautés entre elles impose de chercher les liens qu'elles ont pu avoir avec l'établissement. Ces grottes ont fait l'objet d'un bilan complet, dressé par Anne-Lise Marsolat en 2005, dans le cadre d'un mémoire de DEA (Marsolat 2005). Dans la falaise orientale du site, en amont de la Sablière, la grotte dite funéraire a été pillée avant d'être fouillée par Bruno Bizot en 2010. La grotte Rolland ${ }^{2}$, à l'ouest du vallon des Trois Gancets, n'a livré aucun mobilier postérieur au Néolithique et ne peut donc être mise en relation avec le site. En revanche dans le cirque du Puits du Lierre, cinq grottes forment

2 Gérin-Ricard H., Préhistoire et protohistoire dans Masson P. (dir.), Les Bouches du Rhône. Encyclopédie départementale, $1^{\text {ere }}$ partie, Des origines à 1789, Paris-Marseille, Librairie H. Champion/ Archives Départementales des Bouches du Rhône, 1932, p.305 : "Boucher de Perthes y a trouvé des ossements humains en 1805 et MM. Fournier et Rivière y ont reconnu de la poterie robenhausienne et ossements indéterminables »; Fournier E., Feuille des Jeunes Naturalistes, $\mathrm{n}^{\circ} 271$. un ensemble assez cohérent : la grotte $\mathrm{n}^{\circ} 1$ du puits du Lierre, ou grotte de l'Argile, la grotte $\mathrm{n}^{\circ} 2$ du Puits du Lierre, la grotte du Pin, la grotte du Draiou et la grotte de l'Abreuvoir. Fouillées par Henri Bout de Charlemont entre 1910 et 1914, elles offrent un profil comparable avec un mobilier essentiellement en pâte claire de fabrication massaliète, vases de banquet (olpès, oinochoès, coupes et cratérisques), hydries et lampes, parfois miniaturisés (Bout de Charlemont, 1913, 1913(1912), 1912a, 1912b ; Vasseur 1914, p. 176). La grotte de l'Argile a en outre fourni deux figurines de terre cuite : une tête masculine barbue que l'on a pu rapprocher de celle d'un silène ou d'un Bes, une tête féminine à coiffure en couronne. Si l'occupation de certaines de ces grottes est attestée au Néolithique, elles ont surtout été fréquentées entre le $\mathrm{VI}^{\mathrm{e}}$ et le $\mathrm{III}^{\mathrm{e}} / \mathrm{II}^{\mathrm{e}}$ s. av. J.-C., avec un pic d'activité entre 525 et 450 . La céramique non tournée y est très peu représentée (Gantès 1990).

Dans le vallon de la Font de Voire, contigu à ce Cirque du Puits du Lierre, deux abris ont livré un mobilier constitué majoritairement de céramique non tournée de cuisine (bord de lopas ou de caccabé), coupes ou jattes, urnes : un mobilier qui ne semble donc pas être à destination votive. Après une première phase de fréquentation au Néolithique ou à l'âge du Bronze, une occupation est bien attestée à partir de la deuxième moitié du $\mathrm{VI}^{\mathrm{e}} \mathrm{s}$. av. J.-C. (coupe ionienne, lampe à réservoir ouverte type Agora 21A ou 22A en pâte claire massaliète, de la céramique grise ondée) et pendant le $\mathrm{V}^{\mathrm{e}} \mathrm{s}$. Les abris sont occupés également durant le second âge du Fer sans que l'on sache s'il y a eu rupture entre le Ve et le $\mathrm{III}^{\mathrm{e}} \mathrm{s}$. av. J-C. L'une des grottes est encore fréquentée à l'époque romaine (abri du fond, amphore gauloise, DSP grise et orangée). Il ne semble y avoir néanmoins aucun outil de transformation agricole, contrairement au site de Marseilleveyre, où abondaient les fragments de meules.

L'importante fréquentation de ce secteur du massif entre la seconde moitié du VI et la fin du $\mathrm{II}^{\mathrm{e}} \mathrm{s}$. av. J.-C est confortée par le mobilier conservé dans les musées marseillais, non localisé avec exactitude mais découvert dans le massif de Marseilleveyre.

On peut résumer le débat sur ces grottes à trois questions principales :

1. On s'est demandé depuis Bout de Charlemont quelle était la fonction de ces grottes : s'agissait-il d'habitats, éventuellement temporaires, de lieux de passage ou de lieux de culte ? Cette dernière hypothèse fait aujourd'hui consensus parmi les chercheurs depuis Paul Agostini (1967) et plus récemment Michel Bats $(1986,2001)$, L.-Fr. Gantès (1990), Patrice Arcelin et Jean-Louis Brunaux (2003), ceux-ci se fondant sur la destination presque exclusivement votive des objets découverts. 
Il faut probablement nuancer selon les grottes, qui ne semblent pas avoir eu toutes la même fonction. La fréquentation de certaines d'entre elles devaient répondre à des motivations religieuses, comme la grotte du Draiou, de l'Argile, mais d'autres semblent avoir servi soit de refuge, soit d'habitat, comme les deux grottes de la Fontde-Voire qui ont livré en outre des fragments de torchis ${ }^{3}$. Toutefois si l'habitat en grotte semble encore attesté en Provence au début du premier âge du Fer, trop peu de sites offrent des stratigraphies et des mobiliers réellement convaincants pour que l'on propose une occupation réelle comme habitat. Si certaines grottes peuvent être rattachées à des pratiques de déplacements pastoraux (le long de la Durance par exemple) (Kristiansen 1994), cette hypothèse reste ici une hypothèse de travail. En l'absence de sites bien conservés et documentés, il est difficile de trancher.

2. L'origine des occupants. La plupart des chercheurs se sont interrogés sur l'origine des visiteurs ou dédicants de ces grottes et ont pu d'ailleurs changer d'avis au cours du temps. Ils s'appuyaient pour cela sur la nature du mobilier, indigène ou grec, local ou importé, comme on l'a fait également pour d'autres sites, notamment celui de Saint-Marcel en partant du principe que la céramique indigène non tournée révélait l'identité non grecque des occupants de l'oppidum. Mais le débat reste ouvert, dans la mesure où, comme le soulignaient déjà Michel Bats (1988) ou Henri Tréziny (2010a), il faut se méfier de la méthode qui consisterait à identifier mécaniquement telle ou telle communauté ethnique en fonction de la céramique qu'elle utilise. Il faut tenir compte des mouvements commerciaux, et en contexte rural et agraire, la circulation des produits fabriqués ne se fait peut-être pas non plus comme dans le centre urbain. Le phénomène est probablement beaucoup plus complexe.

3 . En ce qui concerne les grottes cultuelles, la discussion réside aujourd'hui sur l'identification de la ou des divinité(s) : nymphes locales, divinités chtoniennes ou Dionysos pour sa fonction de dieu de la vigne ? Les publications antérieures à la première moitié du $\mathrm{XX}^{\mathrm{e}} \mathrm{s}$., fidèle à une historiographie religieuse qui défendait l'existence chez les Anciens d'un sentiment animiste de la nature, proposaient l'hypothèse d'un culte des nymphes, personnification des grottes ou de l'eau. On a proposé aujourd'hui qu'il s'agisse de cultes chtoniens : la nature du lieu, avec l'éventuelle présence d'eau, l'indifférenciation

3 Bout de Charlemont (H.), «Les fouilles de Marseilleveyre ». Bulletin Société Préhistorique Française, 11, 1914, p.109 : «un morceau de pisé, bien petit il est vrai, mais suffisant pour prouver l'emploi de ce genre de revêtement pour les parois des cabanes dont on peut reconnaître les fonds, tant dans ce cirque que dans celui du Puits du Lierre ». des offrandes et l'absence de dédicaces en seraient les preuves principales. L.-Fr. Gantès (1990), quant à lui, a proposé l'hypothèse d'un culte consacré à Dionysos pour les grottes de l'Argile et du Draïou : il s'appuie sur la présence d'objets liés au culte du dieu de la vigne: une coupe à yeux, et les vases à vin. Il met ce culte en relation avec la production viticole massaliète qui se développe dans la même période que la fréquentation des grottes, entre la deuxième moitié du VIe et le $\mathrm{II}^{\mathrm{e}} \mathrm{s}$. av. J.-C. avec un pic des dépôts d'offrandes entre 540 et 450 soit à l'akmè de la production massaliète. Hypothèse séduisante, mais on fera observer que les vases à vin, qui symbolisent les banquets ou offrandes en l'honneur de la divinité quelle qu'elle soit, sont des offrandes fréquentes dans tout culte grec.

Ces grottes et leur utilisation sont évidemment importantes pour l'extension de la chôra de Marseille grecque. Dans l'hypothèse de lieux de cultes fréquentés par les Massaliètes, il faut supposer que ces grottes faisaient partie intégrante de la chôra et que le culte s'est développé en lien avec la religion de la cité. Le bilan rapide dressé il y a quelques années par Michel Vidal et ses collègues pour le sud de la France, à partir des exemples aveyronnais, montre la spécificité de l'occupation des grottes marseillaises (Vidal et al., 2000), plus ancienne et de nature différente.

\section{Recherches récentes}

Entre 2008 et 2011, nous sommes intervenus sur le terrain par huit sondages restreints et une petite fouille dans les parties nord et est du site de Marseilleveyre, censées abriter des structures antiques. Il s'agissait de savoir si le site avait accueilli et selon quelle chronologie un habitat dense et organisé, dont les activités apparaissaient liées à l'exploitation de la terre, comme en témoignent les nombreux fragments de meules découverts. Devait-on envisager une occupation continue ou de simples hameaux installés sur certains plateaux ou vallons, comme semblait le suggérer la répartition des trouvailles ? Il fallait enfin vérifier l'existence de cette ligne de fortification que certains avaient notée sur le site. Si les habitants avaient jugé nécessaire de renforcer les défenses naturelles par un rempart, cela supposait qu'ils avaient l'intention d'en faire un établissement durable et pas un simple poste de défense destiné à servir de refuge en cas de danger.

Dans le secteur du dit « rempart », après nettoyage de la zone qui nous paraissait la plus intéressante, nous avons dégagé des blocs de taille importante qui ne formaient pas d'assises mais dépassaient largement les modules constatés habituellement sur les remparts protohistoriques - de l'ordre de $1 \times 2 \times 0,50 \mathrm{~m}$. pour les plus 


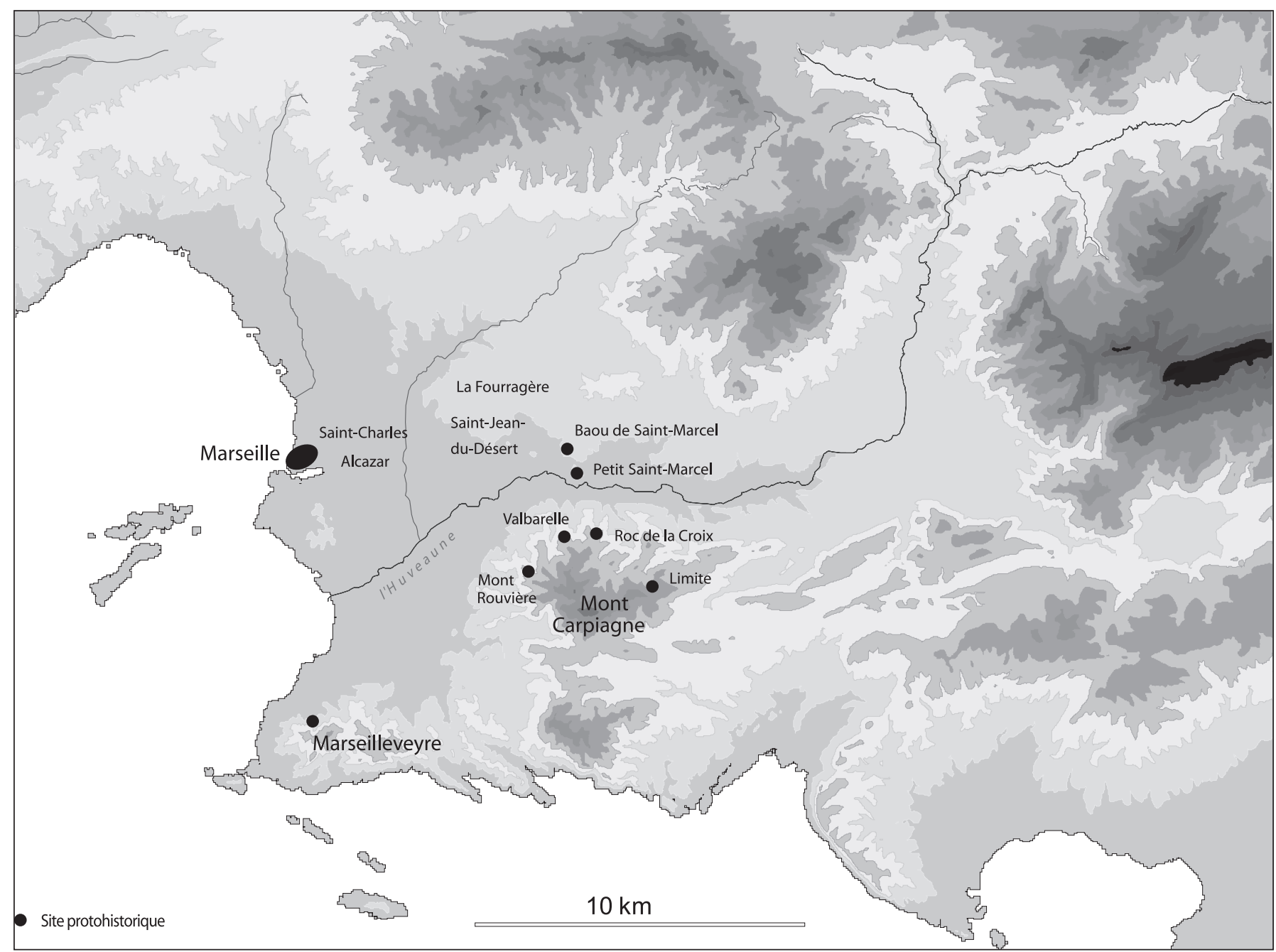

Fig. 1. Carte des sites protohistoriques, chantiers et massifs mentionnés dans le texte (V. Dumas CCJ pour le fond de carte, DAO L. Bernard).

importants. Le module des blocs, l'absence d'assises et le pendage des blocs les plus gros vers l'intérieur du rempart nous ont rapidement fait douter de l'existence d'une fortification à cet endroit. Le sondage réalisé perpendiculairement au rempart a révélé, sous le niveau de blocs, un niveau de cailloutis qui résultait en réalité du délitage des niveaux urgoniens du substrat - sur $40 \mathrm{~cm}$ environ. Un sondage de vérification, à l'arrière du dit « rempart », a confirmé la présence d'un niveau de cailloutis de délitage du substrat. En conclusion, l'absence de mobiliers ou de sols, le module comme le pendage des blocs d'urgonien excluent la présence d'un rempart protohistorique à cet endroit. C'est un résultat important sur la signification du site : en effet les superficies proposées dans la Carte Archéologique doivent être revues à la baisse (Gantès, Rothé 1995, p. 684-686) : en l'état de nos recherches, la superficie occupée est bien inférieure à ce qui était annoncé jusqu'à présent. Pour autant il semble que l'aménagement soit bien anthropique, il pourrait s'agir ici d'un cheminement implanté aux époques moderne ou contemporaine, comme on en observe tant dans les massifs marseillais.

Sur le plateau principal au nord-est du site, sept sondages furent implantés en 2008 et 2010 de part et d'autre du mur moderne et une fouille en 2011 sur l'un de ces sondages, à la cote $222^{4}$. C'est là qu'avaient été identifiés la majorité des vestiges en dur, et notamment le grand bâtiment en blocs réguliers qui malgré les prospections répétées n'a pu être retrouvé. Seule la partie au nord du mur moderne a donné des résultats positifs, tandis que l'espace central était dépourvu de structures et même de mobilier, situation qu'il faut peut-être attribuer à l'installation de la voie EDF qui traverse une partie du site. Aucune structure de pierre n'a été mise au jour ; en revanche, des fragments de torchis et d'argile rubéfiée ont été identifiés, analogues à ceux que nous avions mis

4 Bernard, Collin Bouffier et alii 2008 ; Bernard, Collin Bouffier et alii 2010 ; Bernard, Collin Bouffier et alii 2011. 
en évidence sur le site du Roc de la Croix ${ }^{5}$. Le négatif de ce qui semble avoir été un trou de poteau a également été découvert dans le sondage 2 de 2008. Par ailleurs, dans les quatre autres sondages positifs, le mobilier est abondant, voire très abondant et illustre une occupation humaine datée du VI ${ }^{\mathrm{e}} \mathrm{s}$. av. J.-C. En revanche, nous n'avons pas décelé de stratigraphie significative, les niveaux antiques apparaissant directement sous la terre végétale.

Les premiers comptages effectués varient en proportions selon qu'il s'agit de données de prospection, de sondages ou de la fouille, mais le lot de mobilier est cohérent bien qu'encore un peu limité pour proposer une interprétation chiffrée du faciès.

Sur la zone fouillée, les formes représentées sont globalement des conteneurs, amphores et urnes. On peut compter au moins 7 amphores étrusques, 1 amphore de Samos et au moins 3 urnes en CNT. Ce type de mobilier est destiné au stockage. Le diamètre des urnes en CNT est relativement important (entre 30 et $52 \mathrm{~cm}$ ) ce qui laisse présager de grandes capacités de contenance. La vaisselle fine est presque absente : elle est représentée par la coupe en céramique grise monochrome.

En ce qui concerne la chronologie du site, elle peut être affinée, mais reste encore assez ouverte faute d'éléments permettant une datation précise. Les formes de la céramique non tournée sont des formes qui apparaissent dès le $\mathrm{VII}^{\mathrm{e}} \mathrm{s}$. av. J.-C. et leur utilisation peut couvrir jusqu'au $\mathrm{V}^{\mathrm{e}} \mathrm{s}$. av. J.-C. Les urnes de type CNTPRO U3c et U3a sont utilisées entre 625/575 et 525 av. J.-C. Pour les amphores étrusques, les datations sont relativement similaires. On retiendra les deux fragments du type 1 / 2 de M. Py et J.-Ch. Sourisseau dont la diffusion couvre une période bien définie de 625 à 550 av. J.-C., comme terminus ante quem. La chronologie des types $3 \mathrm{~A}$ et $3 \mathrm{~B}$ est un peu plus flottante (entre 625 et 525 av. J.-C.). Néanmoins leur facture témoigne d'un certains archaïsme caractérisée par des anses très fines et un profil fortement globulaire. Le fond d'amphore grecque de Samos ne permet pas à lui seul de distinguer la forme archaïque (A-GRE Sam 2/3) de son évolution (A-GRE Sam 4). La coupe en céramique grise monochrome est attestée dès 575 av. J.-C. et existe durant tout le $\mathrm{VI}^{\mathrm{e}}$ et le $\mathrm{V}^{\mathrm{e}} \mathrm{s}$.

5 Bernard (L.), Collin Bouffier (S.), Copetti (A.), D’Ovidio (A.-M.) et Dumas (V.), Sondages sur le site du Roc de la Croix. Novembre 2006, rapport DRAC PACA, Aix-en-Provence, 2006 ; Bernard, Collin Bouffier et alii 2007 : Bernard (L.), Collin Bouffier (S.), Copetti (A.), Sondages sur le site du Roc de la Croix. Septembre 2007, rapport DRAC PACA, Aix-en-Provence, 2007.
Pour l'heure, nous posons l'éventualité d'une occupation entre la première moitié du VI $\mathrm{e}$ s. av. J.-C. et le $3 / 4$ de ce siècle, aucun des fragments ici observé ne pouvant permettre de conclusion définitive. Quant à identifier le type du gisement, il semble effectivement s'agir d'un habitat dont l'occupation semble continue mais de courte durée, d'après les vestiges céramiques.

Le faciès des campagnes de sondages comme de fouille renforce donc le faciès celto-ligure de l'établissement et conforte la datation connue pour le site, que l'on peut éventuellement faire remonter dans le $\mathrm{VII}^{\mathrm{e}} \mathrm{s}$. grâce aux spécificités du mobilier en CNT.

En effet, pour ce qui est de la céramique non tournée, ce sont essentiellement des vases de cuisine et de stockage que nous avons mis au jour. Les formes ouvertes sont des coupes tronconiques, écuelles et jattes connues dans d'autres contextes des $\mathrm{VII}^{e}$ et $\mathrm{VI}^{\mathrm{e}}$ s. av. J.-C. Ainsi sur les sites de Saint Blaise ou sur le site de l'Arquet à Martigues et en Vaucluse sur le site des Brassière- sud, sur les sites des Gandus, la Baume des Donzère, sur le site des Ribauds à Mondragon. Les formes fermées sont constituées de pots et de jarres. Pour certaines formes, on connaît des parallèles dans le type I des urnes provençales de P. Arcelin et sur le site de Bourbousson I daté du Ve s. av. J.-C. Pour d'autres, des profils similaires sont présents en Provence dans les formes Py U3a CNT PRO ou encore Arcelin 1971 Forme Ic, attribuables au $\mathrm{VI}^{\mathrm{e}} \mathrm{s}$. av. J.-C.

L'intérêt de cette céramique réside en particulier dans les décors observables sur certains fragments. Très stéréotypés, ils concernent essentiellement des panses. Ils se limitent aux techniques de l'impression et de l'incision. Deux registres décoratifs sont reconnus parmi ces fragments. En revanche, on a relevé l'absence du décor au peigne, caractéristique de la fin du premier âge du Fer en Provence et qui se développe pleinement durant le second âge du Fer.

\begin{tabular}{|c|r|}
\hline $\begin{array}{c}\text { Catégories de mobilier en contexte } \\
\text { 2010-2011 }\end{array}$ & Total structure \\
\hline Céramiques non tournée & 676 \\
\hline Amphore étrusque & 681 \\
\hline Amphore de Grèce orientale & 40 \\
\hline Amphore punique & 199 \\
\hline Importations idéterminées & 33 \\
\hline Grise monochrome & 4 \\
\hline Total & 1667 \\
\hline
\end{tabular}

Fig. 2. Comptage céramique des mobiliers trouvés en contexte lors des campagnes 2010-2011. 


\section{Bilan des recherches récentes sur le site}

En association avec les résultats des prospections et des différents sondages, il est aujourd'hui possible de réinterpréter le site. Il ne s'agit plus en l'état de nos connaissances d'un « oppidum » fortifié d'une dizaine d'hectares à phases multiples, mais plutôt d'un petit établissement indigène au moins contemporain de l'implantation de la colonie phocéenne autour de $600 \mathrm{av}$. J.-C. et occupé au moins pendant le $\mathrm{VI}^{\mathrm{e}} \mathrm{s}$. Toute l'occupation lisible se concentre aujourd'hui entre le mur de propriété et la rupture de pente, plus précisément vers l'Est. Suite aux campagnes de sondages, la première fouille en aire ouverte, menée en 2011, permet de proposer l'existence d'un établissement agricole, pérenne, et bénéficiant d'importations méditerranéennes. Ce site a été abandonné, au cours du VI ${ }^{\mathrm{e}}$ s. av. J.-C. Une reprise possible du site n'a pas pu être observée lors de la fouille ; seuls des céramiques trouvées hors contexte permettent de proposer une occupation du plateau de Marseilleveyre plus tardivement.

Quelles questions se dégagent de ce bilan?

\section{Les relations entre le site de Marseilleveyre et les grottes}

D'après l'ensemble des données, le site de Marseilleveyre et les grottes offrent une phase commune : le $\mathrm{VI}^{\mathrm{e}} \mathrm{s}$., mais peut-être seulement la seconde moitié du siècle. Alors que l'établissement du plateau de Marseilleveyre semble s'arrêter au $\mathrm{VI}^{\mathrm{e}}$, la fréquentation des grottes se prolonge jusqu'au $\mathrm{III}^{\mathrm{e}}$ ou $\mathrm{II}^{\mathrm{e}} \mathrm{s}$. av. J.-C. Pour chercher à comprendre les relations que les sites pouvaient avoir entre eux, il faut s'interroger sur les modes de circulation dans le massif et les cheminements possibles de l'établissement indigène aux grottes. Pour être brefs, depuis l'établissement de Marseilleveyre, on peut se rendre dans la plaine de Marseille par le vallon des Trois Gancets, donc vers la colonie phocéenne et vers la mer ; on peut s'enfoncer dans le massif, d'abord dans le cirque du Puits du Lierre où s'ouvrent les grottes cultuelles du Draiou, de l'Argile et du Puits du Lierre et où les occupants du plateau de Marseilleveyre pouvaient s'approvisionner en eau, puis dans le vallon de la Jarre, où se situent les deux abris de la Font de Voire. Ainsi parmi toutes les grottes inventoriées dans le massif, les seules grottes avec lesquelles l'établissement du plateau pouvait entretenir des rapports réguliers sont celles du cirque du Puits du Lierre, et du Vallon de la Jarre, qui sont les plus facilement accessibles. Ce secteur peut avoir été un point de rassemblement et de contact entre les indigènes du plateau et ceux du vallon de la Jarre autour des grottes. On peut supposer toutefois que l'établissement de Marseilleveyre, comme le suggère d'ailleurs sa position topographique, puisqu'il est installé sur la partie nord du plateau et regarde vers la plaine, était davantage tourné vers les réseaux d'activités du bassin ; le suggèrent également les nombreux fragments de meules découverts sur le site. Vu la nature pédologique du massif de Marseilleveyre, il est difficile d'y localiser une culture céréalière alors qu'il offre un environnement propice au pastoralisme, mais en l'état, des études de paléosols manquent pour ces périodes sur le site. L'établissement de Marseilleveyre apparaît ainsi comme le point de passage obligé, car le plus rapide et le plus facile, de l'intérieur du massif vers la plaine de Marseille.

À partir du Ves. av. J.-C., l'établissement de Marseilleveyre semble abandonné et les grottes du Cirque du Puits du Lierre ont leur existence propre. L'essor de toutes les grottes cultuelles du massif, au moment où disparaît l'établissement du site de Marseilleveyre, peut être lu de deux manières. Soit les Celto-Ligures ont pu prolonger, par des offrandes venues de la cité grecque, servant de témoins des relations commerciales qui s'étaient tissées entre les uns et les autres, un culte initié par leurs ancêtres de la fin de l'âge du bronze ou du début de l'âge du fer. Mais en l'état des publications et au vu de l'ancienneté des fouilles, il est difficile, voire impossible de proposer des cultes celtiques sur ces grottes. Les sites celtiques en relation avec des grottes sont mal étudiés dans nos régions méditerranéennes aux âges des métaux. Pour n'en citer qu'un, l'aven Plérimond (Var), celui-ci présente un faciès mobilier tout à fait spécifique et fort éloigné des dépôts de Marseilleveyre qui représentent des rites plus grecs que celtiques (Boyer et al. 2006). Seule exception, mais sans certitude aucune, l'existence d'un fragment d'épée en bronze du premier âge du Fer, avec une provenance possible de Marseilleveyre pourrait attester d'un culte ou d'une sépulture (Rothé, Tréziny, 1995, p. 691). Soit les Massaliètes ont développé dans ces grottes un culte extra-urbain et il s'agira d'en comprendre la signification. Depuis les travaux devenus classiques de Pierre Vidal-Naquet sur l'éphébie (1981), puis de François de Polignac (1995, ch. 2-3), on a mis l'accent sur l'importance des confins dans l'appropriation de l'espace de ravitaillement, la chôra, et les représentations symboliques du territoire. Aux époques archaïque et classique, l'avancée spatiale de la polis et de l'exploitation agraire du territoire est jalonnée par la mise en place de sanctuaires destinés à marquer la frontière et l'extrémité des eschatia, régions ultimes de l'espace civique, que la collectivité laisse généralement en friche, du fait des risques de conflits frontaliers. Dans les aires d'expansion grecque, notamment en Sicile ou en Grande Grèce, les Grecs installent des sanctuaires qui peuvent assurer le lien avec les populations locales ou au contraire officialiser la prise de possession de l'espace 
par la nouvelle cité. La défense du territoire et de ses limites est alors une priorité de la politique civique et militaire de la cité et est généralement confiée aux jeunes en cours de formation, les éphèbes, ou aux classes d'âge qui ne sont plus en état de servir à l'extérieur. Que ce soit la cryptie lacédémonienne ou l'éphébie attique, emblématiques de l'éducation du futur citoyen, mais que l'on retrouve dans d'autres cités grecques, la formation du futur hoplite passe par un séjour dans les zones sauvages de la chôra, où, par un processus d'inversion symétrique, le jeune mène une vie totalement contraire à celle qui caractérisera son existence de citoyen, à savoir des conditions de vie rude et austère marquées par l'isolement et le désordre. Parmi les dieux attestés dans ces rites d'initiation, outre Apollon ou Artémis, figure Dionysos. À Marseille, la destination cultuelle des grottes de Marseilleveyre pourrait donc être mise en rapport avec les rites d'initiation des jeunes citoyens massaliètes. Elles sont difficiles d'accès, soit parce qu'elles sont dissimulées au regard, soit parce qu'elles sont ouvertes dans des falaises, et nécessitent un fort entraînement physique et une endurance caractéristiques des formations athlétiques et militaires. Cette sacralisation des grottes pourrait aussi être mise en relation avec la progressive exploitation de la plaine et la culture de la vigne, - ce qui conforterait l'hypothèse de L.- Fr. Gantès sur la consécration d'au moins certaines d'entre elles à Dionysos. La viticulture est aujourd'hui mieux attestée, comme le montre le bilan de Philippe Boissinot sur les parcellaires de Marseille (Boissinot 2010). Dès la seconde moitié du $\mathrm{VI}^{\mathrm{e}}$ s. av. J.-C., les Massaliètes ont pris possession de l'ensemble de la plaine de l'Huveaune, qu'ils consacrent à la viticulture. Les frontières du territoire ont alors été repoussées aux collines bordant la plaine. On ne connaît pas pour l'instant de sanctuaires monumentaux dans le territoire massaliète, ni dans la plaine de l'Huveaune, ni à ses limites. Les grottes cultuelles du Draiou, de l'Argile et du Puits du Lierre peuvent avoir permis au centre politique d'embrasser l'ensemble du territoire en déléguant aux jeunes citoyens le contrôle de zones considérées comme sauvages ou dangereuses, d'autant que leur plus grande période de fréquentation correspond précisément à l'époque d'appropriation de la plaine et de mise en place de l'exploitation viticole, entre 540 et 450.

Les relations entre l'établissement de Marseilleveyre, les autres sites identifiés sur la région et la cité grecque de Massalia

Les résultats du PCR, complétés par les prospections inventaires d'Anne-Marie d'Ovidio sur les zones incendiées de Saint Cyr/ Carpiagne (D'Ovidio 2010), ont révélé l'occupation d'un certain nombre de replats des collines sud de Marseille depuis le col de la Limite jusqu'à Marseilleveyre. Plusieurs sites datés dès la première moitié $\mathrm{du} \mathrm{VI}^{\mathrm{e}}$, voire dès le $\mathrm{VII}{ }^{\mathrm{e}} \mathrm{s}$., ont été repérés. Le mieux connu pour l'instant est celui dit du Roc de la Croix au sud des deux buttes de Saint-Marcel sur la rive gauche de l'Huveaune : il a livré un mobilier, constitué à $80 \%$ environ de céramique non tournée, et à moins de $20 \%$ de céramique importée (en particulier amphore étrusque, phénico-punique, corinthienne, attique à la brosse). Des fragments de céramique indigène décorée sont comparables à celle que l'on connaît pour la fin du VII ${ }^{\mathrm{e}}$ - début $\mathrm{VI}^{\mathrm{e}}$ s. av. J.-C. sur le site de Tamaris (Duval 1998), ou du $1^{\text {er }}$ quart du $\mathrm{VI}^{\mathrm{e}}$ s. sur le site de Saint-Blaise. L'absence totale d'amphore massaliète et l'unique échantillon de céramique claire massaliète incitent à ne pas abaisser la chronologie du site après 550/540. En revanche, comme sur le site de Marseilleveyre, aucune structure en dur n'a été mise au jour : seuls des fragments de torchis en assez grande quantité sur la terrasse sommitale du Roc de la Croix attestent la présence d'un bâtiment en matériau périssable dont il ne reste aucune trace au sol. L'occupation pérenne du site est confirmée par la présence de fragments de meules en basalte qui témoignent d'activités locales de transformation des céréales.

D'autres sites ont été repérés sur cette même rive gauche de l'Huveaune. Au nord du mont Lantin, un éperon barré, situé au col de la Limite a livré en prospection du mobilier des $\mathrm{VI}^{\mathrm{e}} / \mathrm{V}^{\mathrm{e}} \mathrm{s}$. av. J.-C. dont de l'amphore étrusque. À la Valbarelle, petit plateau rocheux, situé en amont de l'Huveaune à l'entrée du bassin de Marseille, l'occupation décelée dans le cadre du PCR a été précisée par Anne-Marie d'Ovidio. Si l'on entre dans la plaine de Marseille, cette fois, sur la face occidentale du massif de Saint-Cyr et de la Gineste, qui borde au sud-ouest la plaine de Marseille, les prospections ont également localisé des fréquentations de l'Âge du fer ( $\mathrm{VI}^{\mathrm{e}}$, puis fin du second âge du fer) : un des versants du mont Rouvière offre la même physionomie que la Limite ou le Roc de la Croix, soit un éperon dominant les alentours. Les prospections de A.-M. d'Ovidio ont ajouté un nouveau site à celui du mont Rouvière identifié en 2007 : le site de Castel Roc, identifié sur le promontoire occidental du massif de Sainte Croix, d'une géomorphologie comparable au précédent.

En conclusion, si l'on cherche à comprendre ce qui se passe dans la partie méridionale du bassin de l'Huveaune, il semble qu'on puisse dégager les hypothèses suivantes. Si tous ces sites existent bien au moment de la fondation de Marseille, et s'ils abritent des habitats en matériaux périssables, comme à Marseilleveyre ou au Roc de la Croix, on peut suggérer que vers 600 , lorsque les Phocéens arrivent dans la calanque, les 
habitats indigènes, peut-être disséminés en quelques hameaux de rares maisons, constituent une sorte de ceinture au sud de Marseille. À l'entrée de l'Huveaune dans la plaine d'Aubagne, trois sites, la Limite, le Roc de la Croix, la Valbarelle, offrent une situation stratégique de première qualité. Ils balisent en quelque sorte l'accès aux vallons intérieurs du mont Saint Cyr et du mont Carpiagne, dans lesquels on pouvait pratiquer une agriculture favorisée par des aménagements de terrasses exploitant les pentes, ou plus vraisemblablement un élevage d'ovins, qui pourrait justifier une installation éventuellement intermittente des hauteurs. Ils offrent également des possibilités de refuge en cas de danger sur la moyenne vallée de l'Huveaune ou d'invasion depuis la plaine de Marseille et peuvent témoigner d'une fréquentation de la zone sans pour autant avoir accueilli d'habitat permanent. Sur la partie sud-ouest du bassin, les sites connus ouvrent également vers des zones de pâturage ou d'exploitation agraire, comme Marseilleveyre ou Castel Roc tandis que celui du mont Rouvière surplombe la voie d'accès aux monts de la Gineste et à la route de Cassis. Peuvent-ils suggérer la présence d'une ligne d'occupation des crêtes, en surplomb de l'Huveaune ? L'hypothèse que nous avions envisagée en 2010 (Bernard, Collin Bouffier et Tréziny 2010), à savoir de véritables habitats défendus éventuellement par des fortifications, sur le modèle de ce que semblait être l'établissement de Marseilleveyre, semble pour l'instant improbable. Les différents murs repérés lors des prospections sont en réalité modernes, murs de terrasse, murs de clôture de propriétés, murs de pacage du bétail, il ne s'agit pas de fortifications. On peut également faire l'hypothèse de simples postes de garde installés sur des sommets panoramiques : la problématique de l'intervisibilité prend ici tout son sens vu la situation topographique des sites identifiés jusqu'à présent. C'est suggérer néanmoins que les populations environnantes se sentaient menacées. Quels auraient été les périls ? Marseille ou les populations indigènes elles-mêmes, dont le texte de Justin (43.4) évoque l'organisation en chefferies réunies pour le mariage de la fille de Nannos ? En tout cas, la fortification de SaintMarcel dans le second quart du $\mathrm{VI}^{\mathrm{e}}$ s. av. J.-C., sur un site très probablement antérieur à la fondation de la cité phocéenne, - comme le suggère la présence d'une épingle vasiforme (Bernard 2003, p. 120 et 133, 243) doit probablement être mise en rapport avec le progressif abandon des sites repérés récemment. Si la durée de vie de ces établissements ne dépasse pas la seconde moitié $\mathrm{du} \mathrm{VI}^{\mathrm{e}} \mathrm{s}$. av. J.-C., voire la première moitié du Ve $\mathrm{s}$., on peut s'interroger sur les relations qu'ils ont entretenues avec les sites des Baou de Saint-Marcel. Le « verrou » de Saint-Marcel occupe en effet une situation privilégiée, contrôlant la vallée de l'Huveaune entre deux plaines cultivables, celles de l'embouchure de l'Huveaune à l'Ouest, celle d'Aubagne à l'Est. Le site est rapidement structuré par la construction d'un rempart et organisé selon un début de schéma urbain. Y a-t-il eu un phénomène de vases communicants, Saint-Marcel se peuplant des indigènes qui quittaient les campements des hauteurs ? Il semble bien qu'il se peuple progressivement et la disparition plus ou moins lente des établissements ou des campements celto-ligures antérieurs pourrait bien avoir favorisé son essor. En 2010, nous avions proposé plusieurs hypothèses, qui d'ailleurs ne s'excluaient pas. La première était que des populations qui vivaient plus à l'intérieur des terres se rapprochaient de la côte et des circuits commerciaux mis en place par la nouvelle colonie. C'est bien ce qui semble apparaître des recherches récentes sur les massifs sud de la plaine marseillaise. La seconde proposait que des populations, vivant dans les plaines et bas de pente, de façon relativement dispersée, se soient regroupées pour des raisons de sécurité sur les premières hauteurs. Mais jusqu'à présent, aucun témoignage archéologique ne nous a permis de la mettre en lumière. L'attestation d'un site à la Campagne Allemand n'a pas prouvé d'occupation antérieure au $\mathrm{V}^{\mathrm{e}} \mathrm{S}$. av. J.-C. (Boissinot 1998). C'est l'expansion territoriale de Marseille, et en particulier sa mainmise sur les terres fertiles de la basse vallée de l'Huveaune, qui inciterait les populations indigènes à modifier leur habitat. Le cas de l'oppidum de Saint-Marcel qui continue à diviser les chercheurs sur les circonstances et les auteurs de sa fondation est emblématique de ces rapports mouvants et difficiles à appréhender entre les Massaliètes et les indigènes du territoire. En ce qui concerne Marseilleveyre, les prochaines campagnes de fouille devraient permettre de confirmer ou d'infirmer nos premières conclusions.

\section{Bibliographie}

Agostini 1965 : AGOSTINI (P.) - Contribution à la connaissance du peuplement du massif de Marseilleveyre. Provincia, V, 268, mai 1965, p. 205-207. Agostini 1967 : AGOSTINI (P.) - Le massif de Marseilleveyre. Provence Historique, XVII, 70, p. 333-359.

Arcelin 1971 : ARCELIN (P.) - La céramique indigène modelée de Saint-Blaise (Saint-Mitre-les-Remparts, Bouches-du-Rhône), niveaux protohistoriques VII-VI. Paris, Ophrys, 1971, $182 \mathrm{p}$.

Arcelin, Brunaux 2003 : ARCELIN (P.), BRUNAUX (J.-L.) dir. - Cultes et sanctuaires en France à l'âge du Fer. Gallia, 60, 2003, p. 243-247.

Bats 1986 : BATS (M.) - Le territoire de Marseille grecque : réflexions et problèmes. In : Bats (M.), Tréziny (H.) dir. - Le territoire de Marseille grecque. Actes de la table ronde d'Aix en Provence (16 mars 1985). Aix, Publications de l'université de Provence, 1986, p. 17-42. (Etudes Massaliètes, 1).

Bats 1988 : BATS (M.) - Vaisselle et alimentation à Olbia de Provence (v.350-v.50 av. J.-C.). Modèles culturels et catégories céramiques, Paris, CNRS, 1988, 271 p. (Suppl. RAN, 18). 
Bats 2001 : BATS (M.) - La chôra de Massalia ? In: Problemi della chora coloniale dall'Occidente al Mar Nero. Atti del Quarantesimo Convegno di Studi sulla Magna Grecia, Taranto 2000. Tarente, Istituto per la storia e l'archeologia della Magna Grecia, 2001, p. 491-512.

Bernard 2003 : BERNARD (L.) - Confrontation de deux régions de l'Europe celtique à l'âge du fer : les cas de la Provence et du Baden-Württemberg, Thèse de doctorat sous la direction de D. Garcia, Université de Provence, AixMarseille 1, Aix-en-Provence 2003.

Bernard, Collin Bouffier et alii 2006 : Bernard (L.), Collin Bouffier (S.), Copetti (A.), D’Ovidio (A.-M.) et Dumas (V.) - Sondages sur le site du Roc de la Croix. Novembre 2006, rapport DRAC PACA, Aix-enProvence, 2006

Bernard, Collin Bouffier et alii 2007 : Bernard (L.), Collin Bouffier (S.), Copetti (A.) - Sondages sur le site du Roc de la Croix. Septembre 2007, rapport DRAC PACA, Aix-en-Provence, 2007.

Bernard, Collin Bouffier et alii 2008 : BERNARD (L.), COLLIN BOUFFIER (S.), COPETTI (A.), D'OVIDIO (A.-M.) - Sondages sur le site de Marseilleveyre. Aix-en-Provence, SRA PACA, 2008.

Bernard, Collin Bouffier, Isoardi 2010 : BERNARD (L.), COLLIN BOUFFIER (S.), ISOARDI (D.) - Sondages sur le site de Marseilleveyre, Aix-en-Provence, SRA PACA, 2010.

Bernard, Collin Bouffier, Tréziny 2010 : BERNARD (L.), COLLIN BOUFFIER (S.), TRÉZINY (H.) - Grecs et indigènes dans le territoire de Marseille. In. : TRÉZINY (H.) dir. - Grecs et indigènes de la Catalogne à la mer noire. Errance, Paris, 2010, p.131-145. (BIAMA, 3).

Bernard, Bouffier, Copetti 2011 : BERNARD (L.), BOUFFIER (S.), COPETTI (A.) et al., - Oppidum de Marseilleveyre. Campagne 2011, Aix-enProvence, SRA PACA, 2011.

Boissinot 1998 : BOISSINOT (Ph.) - Un lot de DSP dans le faubourg de Saint-Barnabé à Marseille. Les données stratigraphiques. In : Bonifay (M.), Carre (M.-B.), Rigoir (Y.) dir. - Fouilles à Marseille : les mobiliers (IIr - VII siècles ap. J.-C.). Lattes-Aix-en-Provence, ADAM-Errance, 1998, p.283-285 (Etudes Massaliètes, 5).

Boissinot 2010 : BOISSINOT (Ph.) - Des vignobles de Saint-Jean Du Désert aux cadastres antiques de Marseille. In : Tréziny (H.) dir. - Grecs et indigènes de la Catalogne à la mer noire. Errance, Paris, 2010, p. 147-154 (BIAMA, 3). Bout de Charlemont 1912a : BOUT DE CHARLEMONT (H.) - Au sujet des découvertes dans le massif de Marseilleveyre. Bulletin Société Préhistorique Française, 9, 1912, p. 161-162.

Bout de Charlemont 1912b : BOUT DE CHARLEMONT (H.) - Sommaire des fouilles et recherches faites à ce jour dans le massif de Marseilleveyre. Bulletin Société Préhistorique Française, 9, 1912, p. 535-536.

Bout de Charlemont 1913 : BOUT DE CHARLEMONT (H.) - Inventaire sommaire de mes fouilles et recherches à Marseilleveyre. Bulletin Société Archéologique de Provence, 19, 1913, p. 282-283.

Bout de Charlemont 1913(1912) : BOUT DE CHARLEMONT (H.) Découvertes dans le massif de Marseilleveyre. Bulletin Société Archéologique de Provence, 18, 1912 (1913), p.236-245.

Boyer et al. 2006 : BOYER (R.), DEDET (B.), MARCHAND (G.) - L'aven sépulcral de Plérimond à Aups, $\operatorname{Var}\left(\mathrm{VII}^{\mathrm{e}}\right.$ s. av. J.-C.). Gallia, 63, 2006, p. 171-209. Clerc 1927-1929 : CLERC (M.) - Massalia. Histoire de Marseille dans l'Antiquité, des origines à la fin de l'Empire romain d'Occident (476 apr. J.-C.). Marseille, Lafitte, 1927-1929.

Collin Bouffier 2002 : COLLIN BOUFFIER (S.) dir. - Rapport de prospection thématique. Zone 13 : occupation du sol dans le bassin de Marseille de la Préhistoire à l'époque moderne. Allauch, Château-Gombert, l'Estaque, Marseilleveyre. Aix-en-Provence, SRA PACA, 2002.
Collin Bouffier 2009 : COLLIN BOUFFIER (S.) dir. - L'occupation du sol dans le bassin de Marseille : de la Préhistoire à l'époque moderne. Document final de Synthèse 2007-2009. Aix-en-Provence, SRA PACA, 2009.

D'Ovidio 2010 : D'OVIDIO (A.-M.) - Marseille. Zones incendiées ouest Saint Cyr/Carpiagne, Bilan scientifique 2010, Aix-en-Provence, DRAC PACA.

Daumas 1934 : DAUMAS (G.) - L'oppidum de Marseilleveyre. Provincia, XIV, 1934, p. 84-92.

Daumas 1936 : DAUMAS (G.) - Inventaire des objets de la Collection de la Société en dépôt au Musée d'Archéologie de Marseille (Parc Borély). Provincia, 16, 1936, p. 301-310.

Duval 1998 : DUVAL (S.) - L'habitat côtier de Tamaris (13). Documents d'Archéologie Méridionale, 21, 1998, p. 133-180.

Gantès 1990 : GANTÈS (L.-Fr.) - Marseilleveyre. In : Voyage en Massalie. 100 ans d'archéologie en Gaule du Sud. Musées de Marseille. Marseille, Musées de Marseille/Edisud, 1990, p. 156-161.

Gantès, Rothé 2005 : GANTES (L.-Fr.), ROTHÉ (M.-P.) - Notice 232. In : Rothé (M-P.), Tréziny (H.) dir. - Carte archéologique de la Gaule. Marseille et ses alentours. 13/3. Paris, Académie des Inscriptions et Belles-Lettres, 2005, p.685-691.

Garnier 2000 : GARNIER (J.-L.) - Notice sur l'oppidum de Marseilleveyre, Aix-en-Provence, SRA PACA, octobre 2000.

Gilles 1876 : GILLES (I.) - Marseille depuis 3000 ans, celtique, grecque et chrétienne. Draguignan, 1876.

Guichard, Dedet 2002 : GUICHARD (V.), DEDET (B.) - Archéologie du TGV Méditerranée : fiches de synthèse. Tome 2, la Protohistoire. Lattes, Association pour la recherche archéologique en Languedoc oriental, 2002 (MAM, 9).

Kristiansen 1994 : KRISTIANSEN (K.), JENSEN (J.) éd. - Europe in the first millennium B.C. Sheffield, J. R. Collis publications, 1994 (Sheffield archaeological monographs 6).

Lattara Dicocer : LATTARA 06 - PY (M.) (dir.) - Dictionnaire des céramiques antiques (VII ${ }^{e}$ s. av. n.è. - VII ${ }^{e}$ s. de n.è.) en Méditerranée nordoccidentale (Provence, Languedoc, Ampurdan), 1993, réimp. 2007.

Marsolat 2005 : MARSOLAT (A.-L.) - Les grottes de Marseilleveyre. Inventaire et étude de matériel. Université de Provence, Aix-en-Provence, 2005. De Polignac 1995 : DE POLIGNAC (F.) - La naissance de la cité grecque : cultes, espace et sociétés, VIII ${ }^{e}-V_{I I}$ siècles, Paris, La Découverte, 1996, $230 \mathrm{p}$. Rothé, Tréziny 2005 : ROTHÉ (M-P.), TRÉZINY (H.) dir. - Carte archéologique de la Gaule. Marseille et ses alentours. 13/3. Paris, Académie des Inscriptions et Belles-Lettres, 2005, 925 p.

Tréziny 2010a : TRÉZINY (H.) - Note sur les céramiques indigènes présentes à Marseille. In : Tréziny (H.) dir. - Grecs et indigènes de la Catalogne à la mer Noire. Errance, Paris, 2010, 726 p. (BIAMA, 3).

Tréziny 2010b : TRÉZINY (H.) dir. - Grecs et indigènes de la Catalogne à la mer Noire. Errance, Paris, 2010, 726 p. (BIAMA, 3).

Vasseur 1914 : VASSEUR (G.) - L'origine de Marseille. Fondation des premiers comptoirs ioniens de Massalia vers le milieu du VIIe siècle. Résultats des fouilles archéologiques exécutées à Marseille dans le Fort Saint-Jean. Marseille, 1914. Vidal et al. 2000 : VIDAL (M.), VERNHET (A.) et PUJOL (J.) - Les grottes sanctuaires : à propos des exemples aveyronnais, première approche d'une étude comparative étendue au sud de la France et à la péninsule ibérique. In : DEDET (B.), GRUAT (Ph.), MARCHAND (G.), PY (M.), SCHWALLER (M.) - Aspects de l'Âge du Fer dans le Suc de Massif Central. Actes du XXI colloque international de l'Association française pour l'étude de l'Age du fer, Conques-Montrozier 8-11 mai 1997. Lattes : Association pour la recherche archéologique en Languedoc oriental, 2000, p. 65-80. (MAM, 6)

Vidal-Naquet 1991 : VIDAL-NAQUET (P.) - Le Chasseur noir : Formes de pensée et formes de société dans le monde, Paris, La Découverte 1991 [1981], $490 \mathrm{p}$. 


\title{
Grecs et Étrusques à Lattes : nouvelles données à partir des fouilles de la Cougourlude
}

\author{
Isabelle Daveau \\ Ingénieur chargé de recherche, Institut National des Recherches Archéologiques Préventives \\ Michel Py \\ Directeur de recherche au CNRS
}

\section{Résumé}

L'habitat du Ier âge du Fer au lieu-dit la Cougourlude, en bordure du ruisseau de la Lironde, à $1 \mathrm{~km}$ au nord-est du comptoir de Lattara (Lattes, Hérault) était connu depuis longtemps à travers divers sondages et découvertes avant de faire l'objet d'une importante opération de fouille préventive par l'INRAP en 2010 sur plus de $25000 \mathrm{~m}^{2}$. Le site a livré les vestiges d'un habitat occupé dès le début du Ir âge du Fer et se développant considérablement durant la deuxième moitié du $\mathrm{VI}^{\mathrm{e}} \mathrm{s}$. av. n. è. pour être abandonné quelques décennies plus tard, peu après la fondation de Lattara. Après la présentation des principales données de la fouille, l'accent est mis dans cet article sur le faciès céramique de la Cougourlude et la caractérisation des apports méditerranéens. Enfin sont interrogés les liens entre la Cougourlude et Lattara ainsi que le rôle respectifs des populations locales et des négociants grecs et étrusques.

Mots-clés : Premier âge du Fer, habitat, importations, Cougourlude, Lattara, Grecs, Étrusques

\begin{abstract}
The First Iron Age settlement located on La Cougourlude, near the river La Lironde, $1 \mathrm{~km}$ in the north-eastern side of the port of trade Lattara (Lattes, Hérault) was known for a long time through some digs and discoveries, before it has been excavated by the INRAP in 2010 on more than $25,000 \mathrm{~m}^{2}$. The site contained the rest of an important settlement dated from the beginning of the First Iron Age and strongly developped during the second half of the VIth c. BC, before it was given up a few decade later, shortly after the foudation of Lattara. After some lines about the main data from the excavation, this paper present in particular the ceramic facies of La Cougourlude and specifically the Mediterranean imports. Finally are questioned the links between La Cougourlude and Lattara and also the role of native population on one side and Greek and Etruscan traders on the other side.
\end{abstract}

Keywords: First Iron Age, settlement, imports, Cougourlude, Lattara, Greeks, Etruscans 
L 'existence d'un habitat du Ier âge du Fer au lieudit la Cougourlude, en bordure du ruisseau de la Lironde, à $1 \mathrm{~km}$ au nord-est du comptoir de Lattara (Lattes, Hérault) (fig. 1), était connue depuis longtemps à travers divers sondages et découvertes (Py 1988, 109). Depuis 2006, des fouilles préventives ont touché cette zone basse où la Communauté d'Agglomération de Montpellier a entrepris l'aménagement d'un vaste chenal devant servir d'exutoire au fleuve Lez en cas de crues. Une première opération, conduite par Oxford Archéologie dans le secteur du Mas de Causse, a notamment fourni, sous un complexe probablement cultuel d'époque hellénistique et romaine, un intéressant dépôt de 313 disques en bronze à rebord perlé de typologie étrusque (Feugère 2010). Les fouilles réalisées par l'Inrap de juin à septembre 2010 (Daveau 2010a) ont concerné deux secteurs, l'un prolongeant sur $5000 \mathrm{~m}^{2}$ la fouille du Mas de Causse en contrebas de l'ensemble cultuel; l'autre, à $140 \mathrm{~m}$ au nord, couvrant deux hectares sur une bande de $500 \mathrm{~m}$ de long sur la rive droite de la Lironde (fig. 2). Les deux secteurs ont livré les vestiges d'un habitat occupé dès le début du I ${ }^{\text {er }}$ âge du Fer mais se développant considérablement durant la deuxième moitié $d u \mathrm{VI}^{\mathrm{e}} \mathrm{s}$. av. n. è. pour être abandonné quelques décennies plus tard.

\section{Au carrefour des voies fluviale et terrestre}

Le site de La Cougourlude et du Mas de Causse s'étend sur les deux rives d'un ancien cours de La Lironde. Le paléochenal marquait bien plus le paysage que le ruisseau actuel : large de plusieurs dizaines de mètres, il était également beaucoup plus encaissé. Les niveaux de fonctionnement contemporains de l'habitat de l'âge du Fer n'ont pas été atteints dans les sondages opérés jusqu'à $4 \mathrm{~m}$ de profondeur. Il est donc difficile de préciser son régime hydrologique ; néanmoins, la tranche d'eau dans le chenal, supérieure à $2 \mathrm{~m}$, permet de supposer qu'il était navigable. Le rivage de l'étang, repoussé progressivement par les alluvions du Lez, se trouvait alors à moins de $200 \mathrm{~m}$ au sud du site, offrant un débouché rapide vers la mer.

Un gué existait selon toute vraisemblance entre les deux noyaux d'habitat, emprunté par un axe de circulation dont le tracé est fossilisé par l'actuelle route départementale reliant Lattes à Mauguio. L'ancienneté de cette voie a déjà été vérifiée : à l'ouest elle coïncide avec une importante artère de circulation de la cité de Lattara dont l'existence est attestée au moins depuis le $\mathrm{II}^{\mathrm{e}} \mathrm{s}$. av. n. è. (Py 1988, p. 115, fig. 28, V2 et V8); à l'est, elle structure la nécropole de la fin du VIe/début Ve s., contemporaine de la Cougourlude, fouillée au quartier de « La Pailletrice » à Pérols (Daveau 2010b). La suite de cet itinéraire devait longer le rivage des étangs littoraux, desservant les habitats implantés en bordure des lagunes.

C'est sans doute cette position particulière, au point de franchissement d'un cours d'eau par une voie de long parcours, au pied de la butte de Pérols et dans un secteur accessible à partir de l'étang littoral et de la mer, qui a motivé l'implantation en ce lieu d'un important habitat et d'un complexe cultuel.

\section{Les premiers temps de l'habitat}

Dans le secteur méridional du Mas de Causse, quelques fosses, un foyer et des trous de poteau signalant un ou plusieurs bâtiments sont attribués au Bronze final IIIb par un mobilier rare et peu typique, dont la datation est précisée par plusieurs datations $\mathrm{C}^{14}$ centrées sur les $\mathrm{X}^{\mathrm{e}}-\mathrm{IX}^{\mathrm{e}} \mathrm{s}$. av. n. è. Ces vestiges ténus témoignent d'un petit habitat, occupé sans doute sur une courte durée.

Ces aménagements sont recouverts par plusieurs dizaines de centimètres d'alluvions, déposées par le cours d'eau à l'occasion de ses débordements. Au sommet de cette séquence sont implantés les aménagements du Irr âge du Fer, écrêtés par les labours récents. La surface du sol coïncidait à peu de choses près avec l'actuelle, indiquant que les dépôts de crues épargnaient désormais le site.

Dans le courant du VII e s. av. n. è., de nouvelles installations prennent place à la Cougourlude, à $150 \mathrm{~m}$ au nord des vestiges précédents. Intervenant dans un paysage remodelé par les crues, en bordure d'un chenal dont le cours s'est infléchi en direction de l'ouest, cette occupation n'a semble-t-il pas de lien avec la phase précédente. Elle signe en revanche l'origine du village de la Cougourlude. À ses premières heures, l'habitat paraît modeste. Le semis d'aménagements, assez lâche, rassemble des bâtiments à mur de terre sur poteaux de bois, des fosses d'extraction de limon pour la construction, des foyers. Son emprise va progressivement s'étendre le long du cours d'eau, sans changer de morphologie. Durant le VII et la première moitié du $\mathrm{VI}^{\mathrm{e}} \mathrm{s}$., la Cougourlude ne se distingue guère, par sa forme et ses aménagements, des sites contemporains connus dans les plaines languedociennes, et notamment sur les rives nord de l'étang de Mauguio, à quelques kilomètres à l'est de Lattes (Py 1985). Pourtant dès la première moitié du VIe s., la proportion des céramiques importées par rapport aux productions locales est sensiblement plus importante que sur les sites voisins et traduit déjà une participation active au sein des réseaux d'échanges méditerranéens. La position géographique de la Cougourlude, à un point de rupture de charge entre transport maritime 


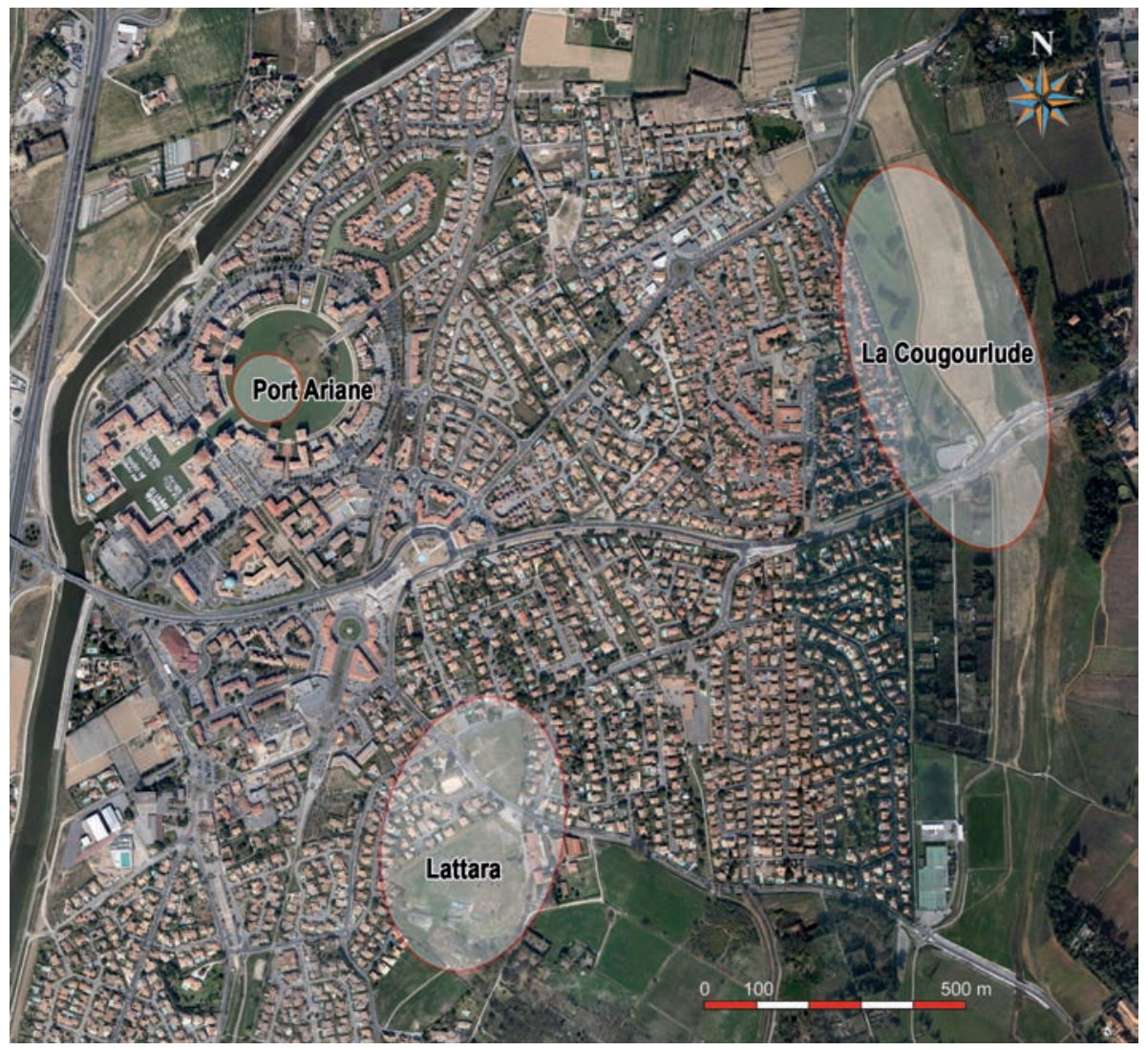

Fig. 1. Vue aérienne de Lattes et situation du village du ler âge du Fer de la Cougourlude par rapport au comptoir de Lattara et au gisement de Port Ariane (fond Google Earth ${ }^{\mathrm{TM}}$ ).

et terrestre, au croisement d'un axe de pénétration vers l'arrière-pays et l'oppidum de Sextantio (Castelnau-leLez) et d'une voie de grande circulation circum-littorale, a sans aucun doute favorisé son développement précoce.

\section{Un essor spectaculaire}

Durant la seconde moitié du VI ${ }^{\mathrm{e}}$ s., à partir des années 540-530 av. n. è., La Cougourlude connaît un développement rapide qui s'interrompra brutalement vers 475 . Tous les indicateurs témoignent de cet essor. Le village s'agrandit pour couvrir au tournant du siècle une superficie estimée à 17 ha. L'occupation se densifie, le nombre d'aménagements datés du dernier tiers du $\mathrm{VI}^{\mathrm{e}} \mathrm{s}$. est multiplié par deux et continue de croître au début du siècle suivant.

Durant cette période, deux imposants fossés traversent le site à $120 \mathrm{~m}$ de distance, se raccordant à l'est au paléochenal de la Lironde. Larges de 8 à $12 \mathrm{~m}$ et profonds de $3 \mathrm{~m}$ sous le niveau de décapage, leur ampleur évoque des ouvrages défensifs. Pourtant ils ne délimitent pas clairement l'habitat, qui s'étend de part et d'autre des deux creusements. Leur rôle pourrait aussi être lié à la gestion des eaux ou à la régulation des crues. Quoi qu'il en soit, le creusement de tels ouvrages laisse supposer une structure sociale complexe, capable de mobiliser une main-d'œuvre abondante sur des travaux collectifs.

Ces fossés et leurs répliques structurent localement l'habitat, dirigeant l'orientation des bâtiments ou des alignements de foyers situés dans leur voisinage. Aucune organisation à grande échelle qui témoignerait de l'ébauche d'un plan d'urbanisme n'est cependant perceptible. En cela, l'agglomération de la Cougourlude diffère profondément de la ville voisine de Lattara, fondée vers 500 av. n. è, ceinte d'une muraille et munie d'îlots d'habitations bâtis en briques sur soubassement de pierres (Janin 2008 ; Py 2009). Les structures identifiées à la Cougourlude correspondent par contre aux types d'aménagements rencontrés contemporainement sur les habitats ruraux et sur les sites de hauteur de la région (Py 1990). Les maisons sont des constructions en terre sur ossature de bois. Il n'en subsiste en général que les substructions - empreintes des poteaux plantés ou tranchées d'implantation des murs en terre. Deux de ces bâtiments, légèrement excavés, ont néanmoins conservé leur sol (fig. 3). Le plan des maisons, plusieurs fois rebâties au même emplacement, est difficilement 
restituable ; la plupart semblent avoir une, voire deux extrémités en abside. En complément des bâtiments, des silos enterrés (fig. 4) et des caves sont destinés au stockage. De nombreuses structures de combustion, de morphologie et d'usage variés, sont recensées : foyers lenticulaires, foyers construits, four excavé, four à sole perforée, foyers à pierres chauffantes... Enfin, d'innombrables fosses restent sans interprétation arrêtée.

Les matériaux rejetés dans les dépotoirs nous renseignent sur les activités pratiquées et les modes de consommation. Les premières études carpologiques réalisées par Isabel Figueiral (Inrap) et Laurent Bouby (CNRS) montrent sans surprise la prépondérance de l'orge vêtue, qui constitue la principale céréale cultivée au I ${ }^{\text {er }}$ âge du Fer, suivie du blé amidonnier. La présence de pépins de raisins correspondant au morphotype domestique pourrait signaler une culture locale de la vigne dès la fin du VIe s. av. n. è. Il s'agirait d'une des plus anciennes attestations en Gaule (Py 2001). L'élevage constituait une part importante de l'économie du site. Les bovins figurent au premier rang des espèces consommées, selon Isabelle Rodet-Belarbi (Inrap). Outre la viande, ils procuraient laitages, peaux et force de travail. Les basses terres hydromorphes de la vallée du Lez, peu propices à la céréaliculture antique, fournissaient en revanche de gras pâturages. La proximité des étangs laisse envisager la production de sel et l'exportation de viande sous forme de salaisons. En plus des activités domestiques et agricoles, l'artisanat était pratiqué. Des scories et culots de forge, découverts en divers points du site, témoignent du travail du fer. Coulures et chutes de plomb et de bronze signalent le traitement des alliages. Aucun aménagement n'est cependant clairement associé à la métallurgie. Dans le secteur du Mas de Causse, au sud, un four à alandier et sole suspendue évoque les fours de potiers contemporains rencontrés par exemple à Aspiran (Pezin 2004).

Les productions agricoles et artisanales ont pu être échangées avec profit. La forte proportion de mobilier méditerranéen au sein des dépotoirs et sur le sol des habitations (infra) traduit une participation active aux réseaux commerciaux. $\mathrm{Si}$, dans sa forme, l'habitat ne présente pas de caractère ostentatoire, les biens de consommations traduisent une certaine prospérité. Le nombre élevé d'amphores, par exemple, atteste une consommation importante de vin, boisson de prix en comparaison de la bière locale. La découverte de quelques objets de prestige (vaisselle métallique, récipient en verre moulé provenant de Chypre) témoigne également, si l'on se réfère aux nécropoles, du statut social élevé de leur propriétaire. Dès avant la fondation de Lattara, la Cougourlude a dû constituer une place d'échange, un premier site portuaire, accueillant les marchandises méditerranéennes et offrant un débouché aux productions indigènes.

\section{Le faciès céramique de la Cougourlude : caractérisation des apports méditerranéens}

Les fouilles de La Cougourlude et du Mas de Causse ont fourni un lot considérable de céramiques d'époque protohistorique (plus de 75000 tessons). Ces documents couvrant quelque quatre siècles se répartissent en sept phases, mais de manière très inégale, puisque la plupart se concentrent dans un demi-siècle environ (vers 530-475 av. n. è.) et plus de la moitié dans un seul tiers de siècle (vers 510-475).

Les deux premières phases livrent uniquement de la céramique non tournée de fabrication locale. Aux rares témoins du Bronze final dont on a parlé ci-dessus (phase 1) succède un lot de céramiques plus fourni attribuable au début de l'âge du Fer, provenant principalement de fosses (phase 2). Les points de découverte sont dès lors dispersés sur la totalité du gisement, aussi bien sur la rive droite de la Lironde (La Cougourlude) que sur la rive gauche (Mas de Causse), sans véritable concentration (fig. $\mathbf{6}, \mathrm{n}^{\circ} 2$ ). Les formes et les décors de vases (incisions simples et excisions) participent du faciès « suspendien » du Languedoc oriental. L'absence de tout vase tourné d'importation dans ce lot incite à le placer dans la phase ancienne de ce faciès, couvrant en gros le VII ${ }^{e}$ s. av. n. è. Un hiatus d'environ un siècle pourrait donc séparer cette phase de la précédente. Les comparaisons les plus proches se trouvent à Lattes même, sur le gisement de Port Ariane (Py 2007), et plus haut dans la vallée du Lez sur celui du Lycée Technique de Montpellier (Prades 1966).

On range dans une troisième phase les structures contenant les plus anciennes céramiques d'importation méditerranéenne, presque toutes d'origine étrusque : amphores de type 1, 3A et 3B, canthares en bucchero nero et rares tessons attribuables à des productions italo-corinthiennes. Les importations grecques sont encore ponctuelles ( 1 anse d'amphore magno-grecque, 1 fragment d'amphore de Clazomènes). Les fosses, silos et trous de poteaux de cette phase sont peu nombreux (une trentaine) et regroupés sur la rive droite de la Lironde, au sud du secteur de La Cougourlude (fig. 6, $\mathrm{n}^{\circ} 3$ ). Les proportions relatives des variantes d'amphores étrusques $(1 / 2,3 \mathrm{~A}, 3 \mathrm{~B})$, proches de celles de la phase I récent de l'oppidum de La Liquière, et la typologie des céramiques non tournées orientent la datation vers les premières décennies du $\mathrm{VI}^{\mathrm{e}} \mathrm{s}$. av. n. è.

La quatrième phase regroupe les structures attribuables au plein $\mathrm{VI}^{\mathrm{e}} \mathrm{s}$. (entre 570 et 540/530 environ). Celles-ci, deux fois plus nombreuses que précédemment (une soixantaine, mais sur un laps de temps certainement plus long) se distribuent sur l'ensemble du secteur de La Cougourlude, en rive droite de la Lironde (fig. 6, $\mathrm{n}^{\circ} 4$ ). 
Les céramiques non tournées locales gardent un faciès suspendien typique, notamment du fait de la présence de formes dans la tradition du VII e s. (par exemple les urnes à grand col ou les coupelles à fond ombiliqué), voire même du Bronze final (par exemple les couvercles à bord facetté). Le pourcentage d'urnes sans col, qui reste élevé, constitue également un lien fort avec les périodes précédentes. Ce qui distingue cette époque, c'est la nette croissance des importations méditerranéennes, que ce soit les amphores (26\% des tessons) ou la vaisselle tournée $(15 \%)$. Au sein de la vaisselle, les importations lointaines (vases attiques, coupes « ioniennes », canthares en bucchero étrusque) sont particulièrement rares $(0,5 \%$ de la vaisselle en usage); ce qui domine désormais, ce sont les céramiques grecques d'Occident : claire massaliète (4\%) et surtout grise monochrome (16\%). Les amphores sont plus diversifiées qu'à la phase précédente : les exemplaires étrusques dominent toujours (69\% des amphores) ; la forme $1 / 2$ est en net retrait, la plupart (96\%) se rattachant aux types 3A et 3B. Le développement des importations d'amphores grecques concerne principalement deux groupes d'origine magno-grecque : d'une part les amphores « de type corinthien B ancien » (A-MGR 1), produites sans doute à Sybaris (Sourisseau 2011, p.204) ; d'autre part les amphores naguère dénommées « ionio-massaliètes » (A-MGR 2), provenant de diverses zones de la Grande Grèce (Campanie, Calabre, Sicile) (ibid. p.206 sqq.). Ces catégories représentent $25 \%$ des tessons d'amphores de l'époque.

Les contextes de la cinquième phase (fig. 5) se caractérisent par la présence régulière d'amphores massaliètes non micacées et en regard par l'absence d'exemplaires micacés. Si l'on se réfère aux datations actuellement admises pour l'apparition de ces catégories d'amphores (Sourisseau 1997, p.28-29), on peut situer cet ensemble entre 540/530 et 510 av. n. è., chronologie que confirment des céramiques attiques à figures noires des années 540-510 (amphore à décor de rosettes incisées sur le bord dans le style d'Andokides, coupes « des petits maîtres », coupes de type A). Les restes de cette époque sont nettement plus abondants qu'auparavant (279 structures livrant 13316 tessons de vases) et occupent désormais toute la surface fouillée, sur les deux rives de la Lironde (fig. 6, ${ }^{\circ} 5$ ), mettant en évidence une première phase de densification de l'habitat. Le faciès culturel local tel qu'en témoigne la céramique non tournée se place clairement dans la continuité des phases précédentes, même si l'on note une disparition progressive des caractères les plus spécifiques du Suspendien et une tendance à une simplification des formes. Ce qui caractérise le plus cette phase, c'est la croissance du nombre de vases montés au tour dont la fréquence au sein de la vaisselle (36\% des tessons) est presque doublée.
Cette croissance est principalement due au développement de l'usage de vases gris monochromes, dont les formes (et probablement les origines) se diversifient. Bien qu'encore peu répandue, la céramique attique participe à ce développement, avec certes peu de belles pièces à figures noires, peut-être réservées à une frange réduite de la société, mais un nombre notable de coupes à vernis noir (principalement de type $\mathrm{C}$ ), qu'accompagne un lot équivalent de coupes « ioniennes » B2. Les importations amphoriques sont également en nette croissance, leurs restes atteignant $36 \%$ des tessons de la phase. Parmi elles, les amphores étrusques sont en net retrait, passant de 69 à $27 \%$ des tessons d'amphores, et leur typologie change avec une raréfaction des types archaïques $(1 / 2$, $3 \mathrm{~A}, 3 \mathrm{~B})$ au profit de types nouveaux (3C, 4 et 5). Ce sont les amphores massaliètes qui, dès leur apparition, prennent la première place sur le marché (56\% des tessons), suivies de loin par les autres amphores grecques - de Grande Grèce $(9,4 \%$ ), de Clazomènes ou de Lesbos $(4,4 \%)$-, tandis que les importations du monde ibérique $(2,6 \%)$ ou punique $(0,2 \%)$ restent ponctuelles.

La sixième phase, que l'on date entre 510 et 475 environ av. n. è., correspond à l'extension et à la densité maximales de l'habitat : elle est représentée par 294 structures réparties sur les deux rives de la Lironde (fig. 6, $n^{\circ} 6$ ) et par près de 50000 tessons représentant plusieurs milliers de vases (fig. 7). La céramique non tournée, qui constitue toujours les deux tiers de la vaisselle en usage, témoigne d'une réelle continuité avec la phase antérieure, les mêmes formes et les mêmes décors s'y retrouvant dans des proportions proches. Le goût pour les céramiques grises monochromes (26\% des tessons de vaisselle) se confirme, avec un panel de formes varié au sein duquel dominent les coupes carénées souvent ornées d'ondes incisées. Les céramiques à pâte claire massaliètes, bien qu'en progrès ( $9 \%$ des tessons de vaisselle contre $6 \%$ à la phase précédente) restent minoritaires : il s'agit principalement de coupes d'imitation B2, de cruches et de cratères à colonnettes. Les importations lointaines sont représentées par la céramique attique $(2,5 \%$ des tessons de vaisselle) et encore par quelques coupes « ioniennes » B2 de fabrication probablement magno-grecque. L'attique à figures noires compte une quarantaine de vases aux formes diverses : amphores, coupes des petits maîtres, coupe de Droop, coupe de Cassel, coupes plates souvent à bandes florales, coupes de type A, skyphos à pied bas, skyphoi mastoïdes. À leur côté, on compte une centaine de vases à vernis noirs parmi lesquels principalement des coupes de type $\mathrm{C}$ à lèvre incurvée ou continue. Sauf ponctuellement, la vaisselle étrusque est rare. Les importations d'amphore progressent encore, atteignant $51 \%$ des tessons recueillis. Parmi eux, on note $41 \%$ de fragments 


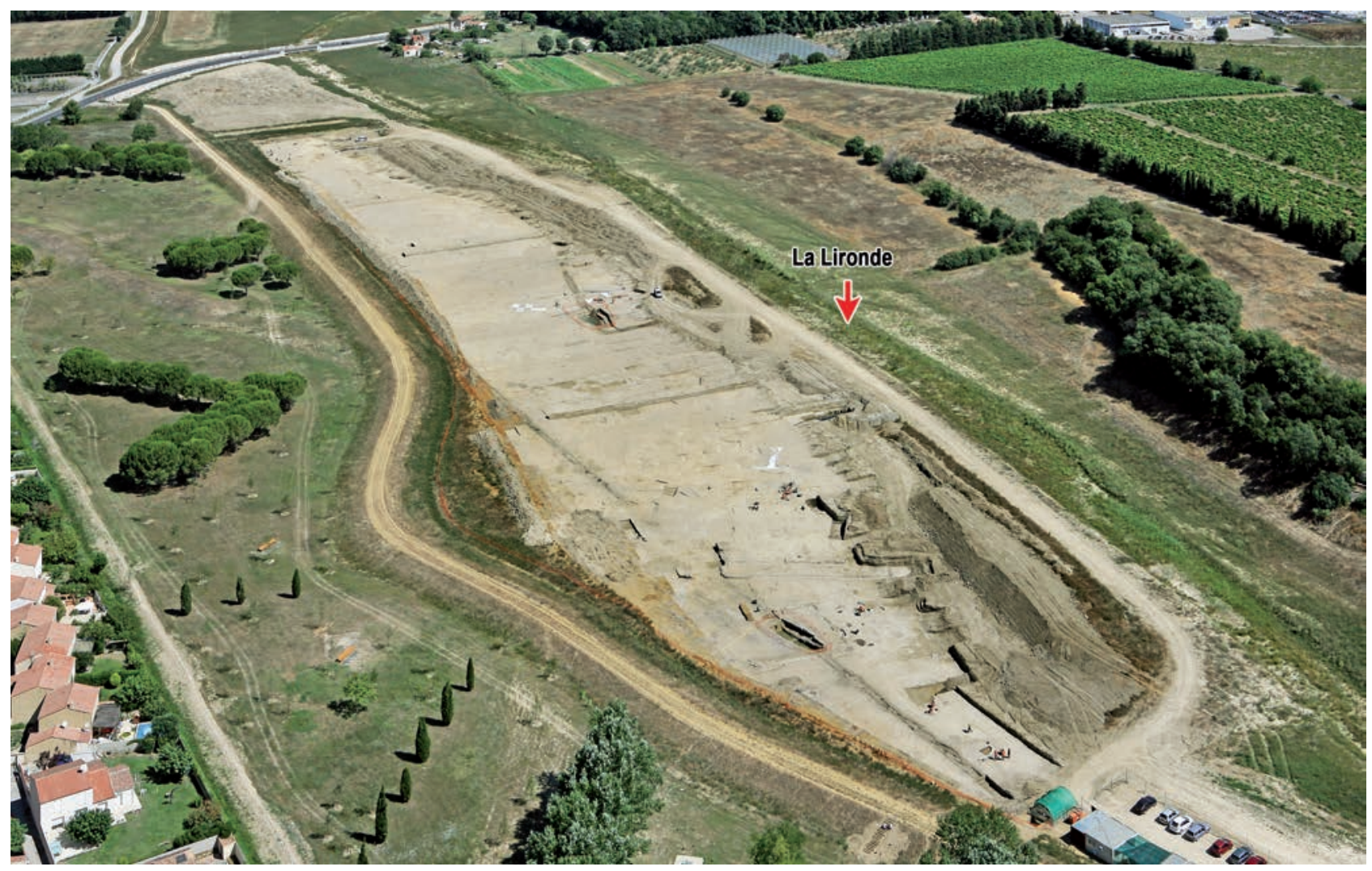

Fig. 2. Photographie aérienne des fouilles de La Cougourlude en rive droite de la Lironde (photo Cl. O’Sughrue).

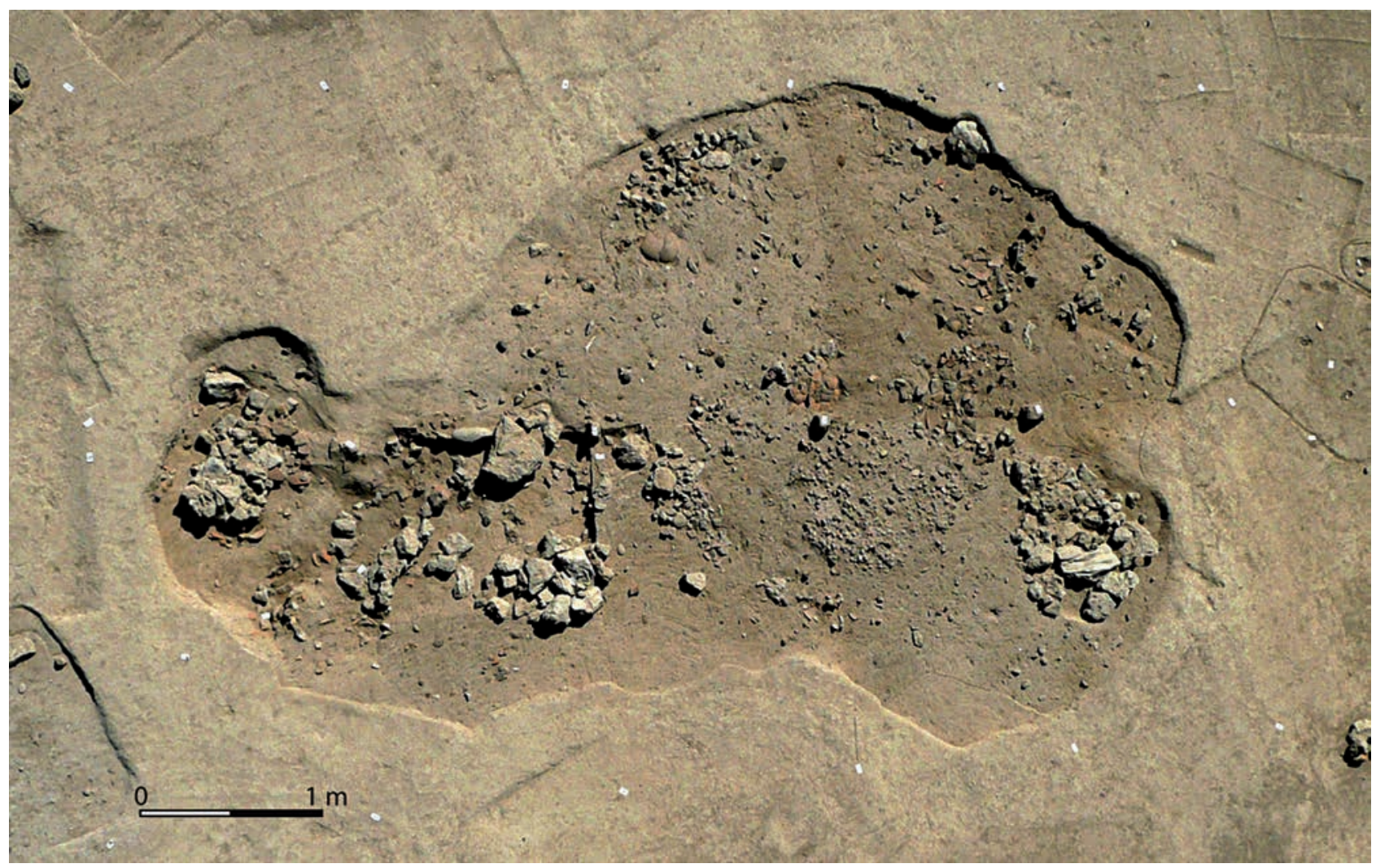

Fig. 3. Vue aérienne verticale d'une des cabanes excavées de la fin du $\mathrm{Vl}^{\mathrm{e}} \mathrm{s}$. av. $\mathrm{n}$. è. fouillée en bordure d'un des fossés traversant le village de La Cougourlude (photo N. Chardenon). 


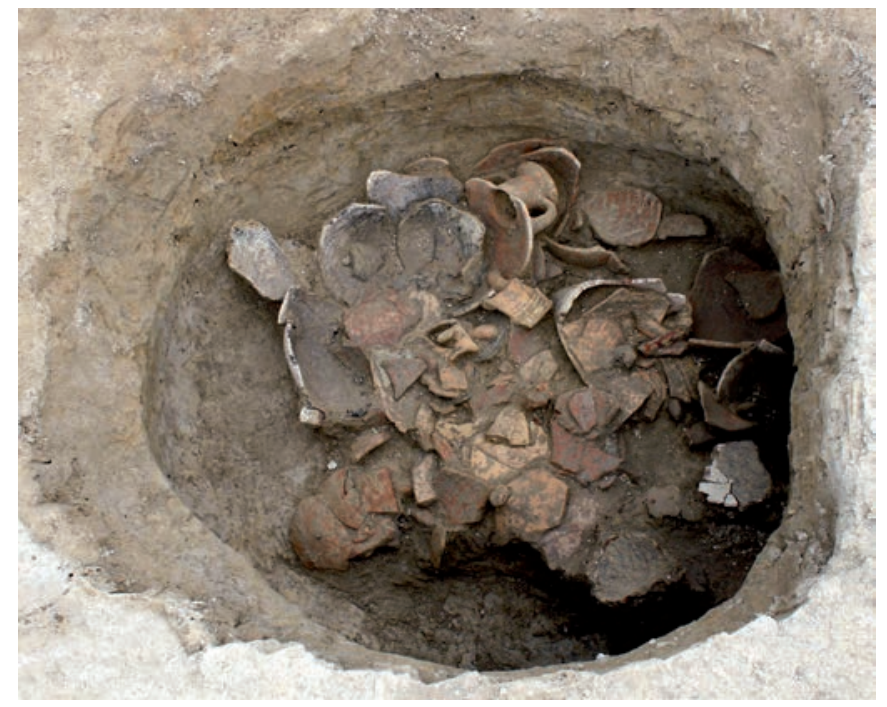

Fig. 4. Silo du début du Ve s. av. n. è. de La Cougourlude, rempli d'amphores massaliètes et étrusques (photo David Tosna).

d'origine étrusque, ce qui est nettement plus qu'à la phase précédente : il s'agit désormais presque exclusivement de formes récentes, de type 4, 3C et 5 dans l'ordre décroissant de fréquence. Cependant les amphores de Marseille restent majoritaires (51\% des tessons d'amphores), avec un tiers d'exemplaires non micacés et deux tiers de micacés, tous de forme 1 . Les amphores magno-grecques sont encore présentes $(5 \%)$, les autres amphores grecques sont rares $(0,5 \%)$ et principalement originaires de Clazomènes.

La septième phase, datable du deuxième quart du $\mathrm{V}^{\mathrm{e}} \mathrm{s}$. av. n. è., n'est attestée que par une vingtaine de structures, toutes situées en rive gauche de la Lironde dans le secteur du Mas de Causse (fig. 6, $\mathrm{n}^{\circ} 7$ ). Aucun document protohistorique postérieur à 475 n'apparaît plus en rive droite, ce qui montre que le vaste village qui s'était progressivement développé en ce lieu est totalement abandonné aux environs de cette date. Le faciès de cette phase se caractérise par une céramique non tournée toujours très présente $(69 \%$ des tessons de vaisselle), une nette progression des céramiques à pâte claire massaliètes $(23 \%)$ et par contre un fort retrait des vases gris monochromes (qui passent de 25 à $3 \%$ des tessons de vaisselle) et attiques (passant de 2,5 à $0,5 \%)$. Les apports amphoriques, qui restent conséquents (40\% du total des tessons), évoluent également : les importations magno-grecques ne sont quasiment plus attestées, les amphores étrusques tombent à un taux très bas ( $8 \%$ des tessons d'amphore). Ce sont les amphores massaliètes à pâte micacée qui constituent dès lors l'essentiel (89 \% des tessons d'amphore), selon une tendance qui s'affirmera ensuite durant plusieurs siècles dans le comptoir de Lattara.

\section{La Cougourlude et Lattara : questions ouvertes}

L'intérêt du gisement de La Cougourlude réside non seulement dans le fait qu'il s'agit de l'un des plus vastes habitats du ${ }^{\text {er }}$ âge du Fer fouillés dans le Midi de la France, mais également dans ses relations avec le comptoir voisin de Lattara dont il illustre en quelque sorte la préhistoire.

Du Bronze final au milieu du VI e s. av. n. è., cet habitat ne se distingue guère de ceux connus sur la rive nord de l'étang de Mauguio : il s'agit de villages de petite taille dont l'occupation n'est pas forcément continue, installés au débouché de cours d'eau dans un étang littoral alors plus vaste qu'aujourd'hui, vivant d'agriculture, d'élevage et de pêche sur un territoire relativement ouvert, et entretenant des liens étroits avec l'arrière-pays immédiat. L'insertion de ces villages dans un réseau d'échanges élargi à partir du début du $\mathrm{VI}^{\mathrm{e}}$ s., suite au développement du commerce maritime (ici essentiellement étrusque et grec) ne semble pas avoir changé radicalement le mode de vie de leurs habitants, foncièrement attachés à des pratiques traditionnelles.

Pour autant, l'examen des proportions d'achats extérieurs dans les deux premiers tiers du VI ${ }^{\mathrm{e}} \mathrm{s}$., de deux à quatre fois supérieures à la Cougourlude par rapport à ce que l'on observe sur les autres gisements régionaux, suggère que ce site joua dès cette époque un rôle de débarcadère privilégié pour le commerce méditerranéen, annonçant en quelque sorte celui de Lattara.

Cette forte attraction du delta du Lez, à laquelle la présence de l'oppidum de Sextantio à $7 \mathrm{~km}$ au nord ne fut certainement pas étrangère, se confirme à partir de 540/530 lorsque la surface et la densité d'occupation de l'agglomération s'accroissent brusquement. La rapidité de cette expansion ne peut pas s'expliquer par une croissance démographique naturelle. Le site a manifestement bénéficié à cette période d'un apport de population. Il est tentant de mettre en relation cet épisode avec l'abandon à cette époque des sites lagunaires précédemment établis sur les rivages de l'étang de Mauguio (Py 1985).

Ce regroupement n'est certainement pas sans rapport avec le dynamisme des échanges pratiqués sur le site, déjà sensible dans les années antérieures ; mais en même temps, cette expansion démographique offre les conditions d'une nouvelle croissance des importations dans lesquelles, à côté des Étrusques toujours actifs, Marseille prend à l'évidence une part de plus en plus importante. Sur ce point, le gisement de la Cougourlude offre des données et une chronologie tout à fait compatibles avec ce que l'on observe très généralement en Gaule méditerranéenne, où, d'Agde à Antibes, Marseille prend progressivement le contrôle des voies et des transactions maritimes.

Cette «normalité », en quelque sorte, des données fournies par les fouilles de la Cougourlude permet de 
réexaminer les circonstances de la fondation du comptoir de Lattara sur des bases nouvelles. L'absence jusqu'ici sur le territoire de Lattes de gisements de la deuxième moitié $\mathrm{du}^{\mathrm{VI}} \mathrm{I}^{\mathrm{s}} \mathrm{s}$. avait laissé place à l'hypothèse d'un continuum étrusque : d'un côté, il y avait les gisements lagunaires établis sur les rivages de l'étang de Mauguio qui, de la fin du VII ${ }^{\mathrm{e}}$ au milieu du $\mathrm{VI}^{\mathrm{e}}$ s., livraient une écrasante majorité d'importations étrusques ; de l'autre côté, il y avait Lattara, où s'affirmait à mesure des fouilles l'évidence d'une présence étrusque au début du Ve s. (Py 1995). D'où l'idée que cette installation aux origines de la ville pouvait résulter d'une activité tyrrhénienne ancienne et continue sur cette portion du littoral gaulois, sorte de zone commerciale sinon réservée, du moins préférentielle, s'insérant entre celles que Marseille consolidait contemporainement à l'ouest dans la vallée de l'Hérault et à l'est dans la basse vallée du Rhône.

L'analyse des céramiques recueillies à $\mathrm{La}$ Cougourlude permet de rejeter définitivement cette vision des choses en reflétant, ici comme ailleurs en Gaule méridionale, la montée en puissance de l'emporia massaliète au cours de la deuxième moitié du $\mathrm{VI}^{\mathrm{e}} \mathrm{s}$. À cette époque, les importations grecques produites ou relayées par Marseille, en forte croissance, s'ajoutent à une diffusion relativement constante de produits étrusques, qui, les échanges s'amplifiant, passent d'une position majoritaire à une position minoritaire sans changer radicalement de volume : c'est ce qu'indique clairement la calibration des apports amphoriques par rapport au volume de vaisselle consommée.

Une même prééminence des apports massaliètes sur les apports étrusques se confirme également au premier quart du $\mathrm{V}^{\mathrm{e}} \mathrm{s}$., à l'époque où des Étrusques sont installés dans Lattara, même si l'activité de ces derniers est perceptible dans l'évolution des importations amphoriques qui témoignent d'une recrudescence ponctuelle des taux d'amphores étrusques dans le premier quart du $\mathrm{V}^{\mathrm{e}} \mathrm{s}$. (supra). De cette constatation naissent plusieurs questions nouvelles : où débarquaient les produits massaliètes et leur accompagnement ? Qui les réceptionnaient, du moment que l'on sait que ce ne sont pas les Étrusques établis près du port de Lattara, dont les entrepôts ne contiennent (à une exception près) que des amphores étrusques ?

De toutes les hypothèses qui se présentent à l'esprit, la plus probable est certainement celle envisageant que Lattara ne fût pas à ses débuts un comptoir fondé et occupé par les seuls Étrusques à leur seul profit, mais un emporion indigène accueillant plusieurs communautés étrangères s'occupant de commerce, à l'instar de la plupart des emporia méditerranéens ; et que parmi ces communautés figuraient non seulement des Étrusques, mais aussi probablement des Massaliètes. Les fouilles de Lattara, qui n'ont concerné jusqu'à présent que $0,5 \%$ de la surface des niveaux de fondation du site intra muros, et bien moins encore si l'on compte les quartiers suburbains, laissent en fait une large place à une telle possibilité.

\section{Le rôle des Indigènes}

Ici comme ailleurs, l'augmentation très significative du volume des échanges au cours du $\mathrm{VI}^{\mathrm{e}} \mathrm{s}$. dut avoir un impact sur l'évolution de la société indigène. D'un point de vue général, les données disponibles à la Cougourlude ne témoignent pas d'une répartition telle qu'on puisse en déduire que ces importations étaient réservées à une frange privilégiée de la société locale : dès le milieu du $\mathrm{VI}^{\mathrm{e}} \mathrm{s}$. en effet, les amphores à vin sont partout en grand nombre, et la vaisselle tournée fort répandue, à tel point qu'on peut parler d'une consommation générale, voire même populaire. Si nous avons supposé ci-dessus que tel ou tel vase attique à figures noires de qualité pouvait avoir été réservé à une élite, de quelle nature qu'elle soit, cela ne reste qu'une supposition : car la répartition des fragments d'attique à figures noires sur le site est fort diffuse, de même que celle des fragments d'attique à vernis noir, les seules concentrations visibles correspondant aux plus grosses structures. Il n'y a pas en vérité dans les cartes de répartition de quoi repérer l'existence d'une aristocratie. Les rapports des dirigeants avec le commerce dont témoignent les céramiques devaient se situer à un autre niveau que l'accumulation de biens de prestige : notamment dans le contrôle des échanges, à travers les autorisations de commercer données aux étrangers, ou encore à travers les processus de redistribution des biens importés qui pouvaient servir à conforter leur pouvoir et à maintenir la cohésion sociale.

Il n'est d'ailleurs pas impossible que cette classe dirigeante, celle à laquelle profitaient «politiquement» les échanges à travers ces processus, ait résidé ailleurs : on pense évidemment dans cette perspective à l'oppidum de Sextantio, agglomération probablement plus importante que ne le laissent voir les recherches ponctuelles et désordonnées du siècle dernier (Vial 2003, 134-152), qui a livré - comme Nîmes et son voisinage - de la statuaire du Ier âge du Fer (Py 2011, 34-38) et qui put constituer la « place centrale » contrôlant le site d'interface de la Cougourlude. Il faut cependant garder à l'esprit que moins de $20 \%$ de la surface estimée du site a été explorée et que d'autres secteurs pouvaient comporter des aménagements plus ostentatoires.

Quoi qu'il en soit, ces élites jouèrent certainement un rôle direct dans la fondation de l'emporion de Lattara aux alentours de 500 av. n. è. Des relations suivies avec les négociants étrusques puis massaliètes durant plusieurs générations, une demande croissante de produits méditerranéens, une habitude de consommation créant une 


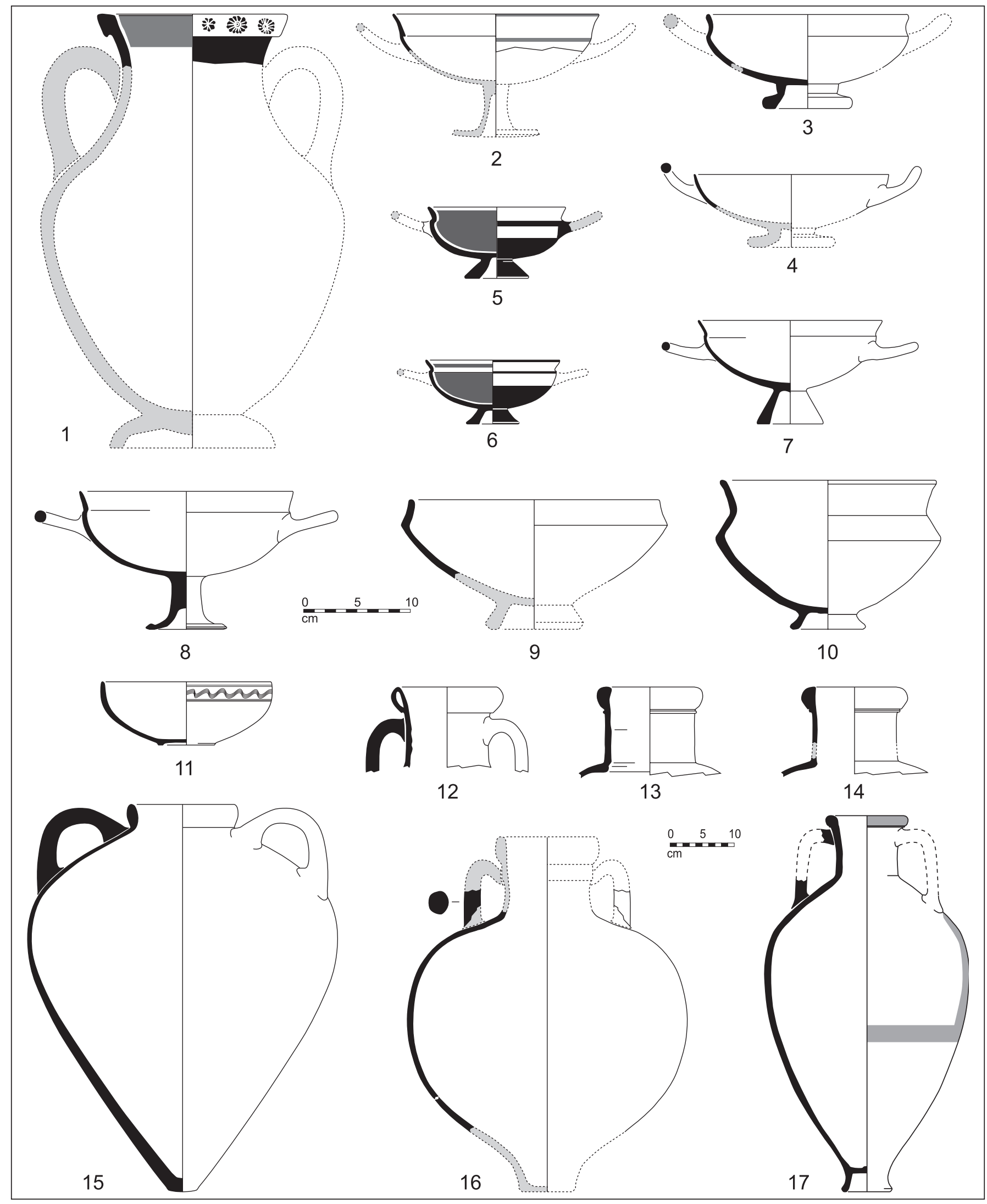

Fig. 5. Exemples de mobiliers d'importation de la phase 5 de La Cougourlude (vers 540/530-510 av. n. è.). 1-2 : attique à figures noires ; 3-4 : attique à vernis noir ; 5-6 : coupes "ioniennes" B2 ; 7 : céramique à pâte claire massaliète ; 8-11 : céramique grise monochrome ; 12-14: amphores massaliètes non micacées ; 15 : amphore étrusque $4 ; 16$ : amphore magno-grecque ; 17 : amphore de Clazomènes. 


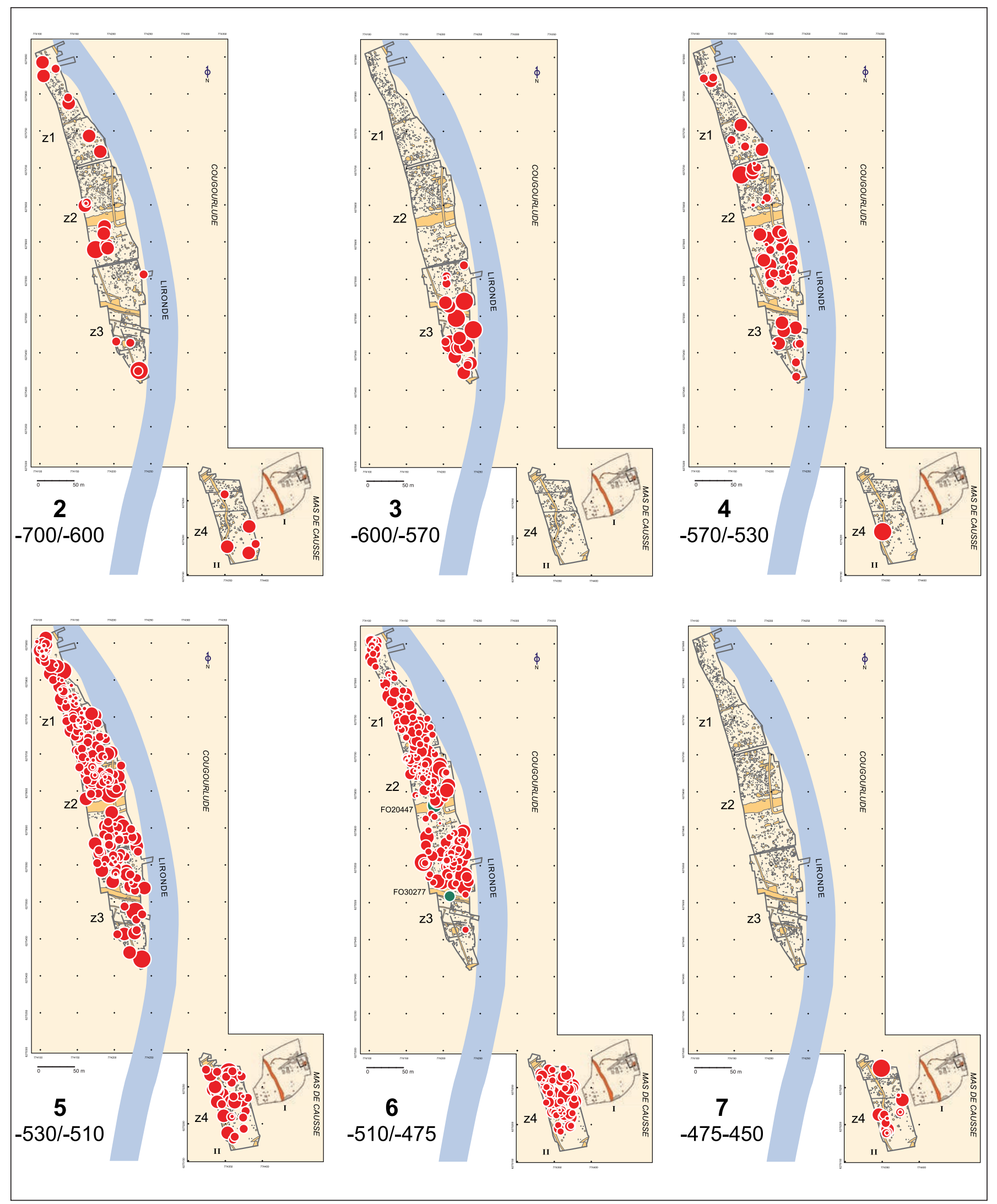

Fig. 6. Évolution de l'implantation l'habitat de La Cougourlude au cours des différentes phases de l'occupation du ler âge du Fer, d'après les structures datées par le mobilier. Les cercles sont proportionnels dans chaque phase au nombre d'artefacts livrés par les structures. 


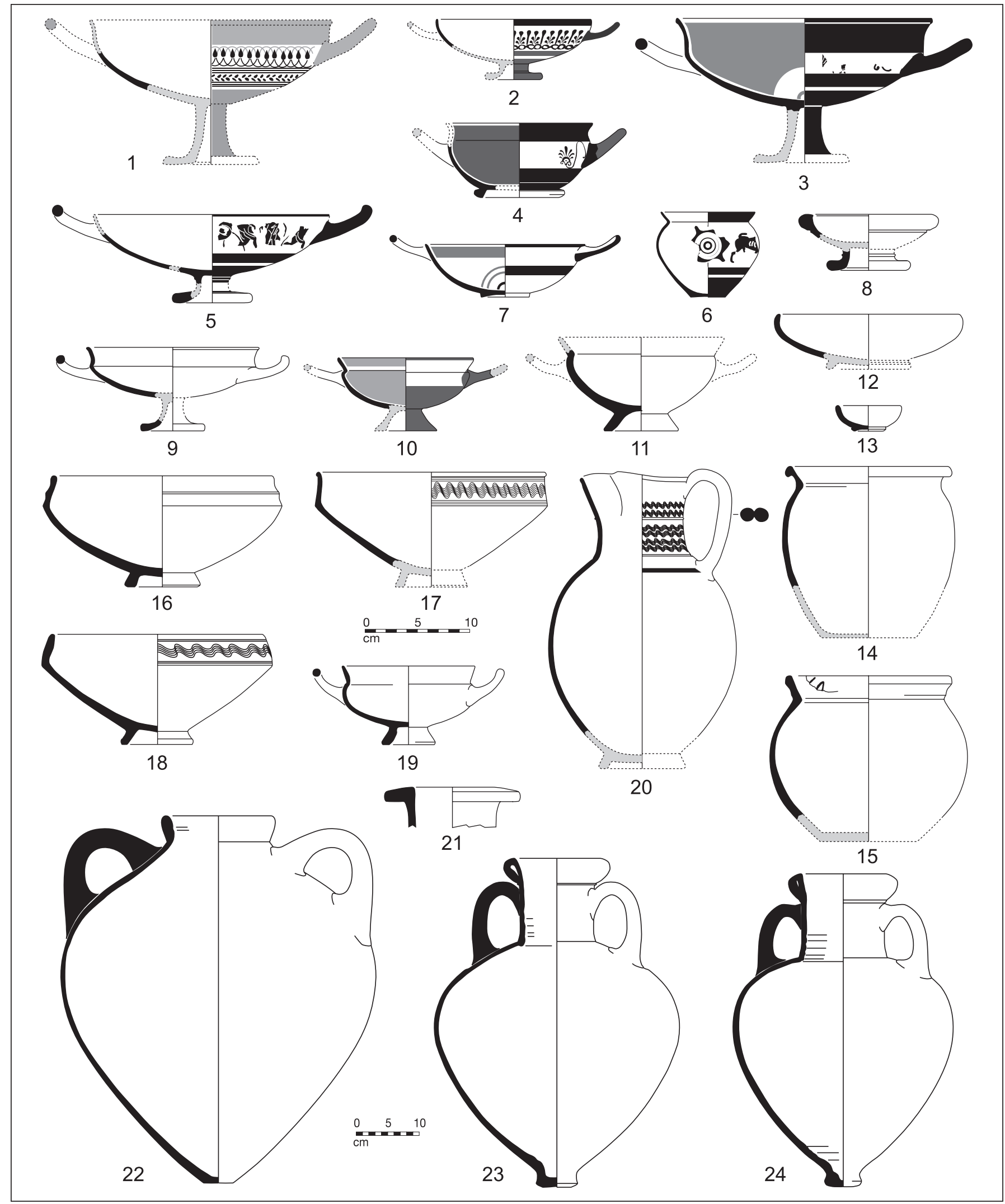

Fig. 7. Exemples de mobiliers d'importation de la phase 6 de La Cougourlude (vers 510-475 av. n. è.). 1-6 : attique à figures noires ;

7-9 : attique à vernis noir ; 10 : coupe "ionienne" B2 ; 11 : céramique à pâte claire massaliète ; 12-13 : bucchero nero étrusque ;

14-15 : céramique commune étrusque ; 16-20 : céramique grise monochrome ; 21 : amphore corinthienne A ; 22 : amphore étrusque 4 ; 23-24 : amphores massaliètes micacées de forme 1. 
forme de dépendance, ont pu faire naître à terme chez les dirigeants locaux (qui d'une manière ou d'une autre, nous l'avons dit, devaient gérer ces relations) le projet d'améliorer les conditions de ce négoce, de les renforcer structurellement, de les stabiliser dans le temps : et ce projet, on l'aura compris, c'est la création de l'emporion de Lattara. Que l'idée soit venue des Indigènes ou qu'elle ait été suggérée par leurs partenaires méditerranéens importe peu : de toute manière, une telle réalisation n'aurait pu se faire sans les occupants de ce territoire, sans l'accord de leurs dirigeants, et même, si l'on en juge par l'importance des travaux présidant à la création du nouveau comptoir et de sa fortification (Py 2009, 25-37), sans le concours actif de la population locale qui seule pouvait fournir les bras nécessaires. C'est à travers un tel processus, dont les fouilles du grand village de La Cougourlude permettent de comprendre l'initialisation, que peuvent s'expliquer les caractères particuliers de l'agglomération fortifiée qui lui succède, à la fois indigène par bien des aspects et révélant des influences méditerranéennes sur plusieurs points.

\section{Le processus d'abandon de La Cougourlude}

Le passage d'un site à l'autre et la désertion de l'agglomération de la Cougourlude méritent également une attention particulière. Bien que la mise en phase des données laisse l'impression d'un abandon soudain de la majeure partie du village vers 475 , il faut sans doute imaginer un processus progressif de transfert de population au cours du premier quart du $\mathrm{V}^{\mathrm{e}} \mathrm{s}$., non seulement vers Lattara intra muros, où des indigènes ont pu s'installer dès l'origine, mais également vers la zone suburbaine s'étendant le long du Lez au nord du rempart, où plusieurs sondages ont montré l'existence d'une occupation tout aussi ancienne sur une surface considérable (Py 2009, 79-81). La précocité de cette banlieue nord de Lattara, démontrée par le sondage 25 d'H. Prades (Py 1988, 91-93), et son extension sur plusieurs hectares, témoignent de l'attirance que le nouveau port put avoir pour les populations voisines dès sa création.

Le départ des Étrusques de Lattara aux alentours de 475, apparemment brutal puisque marqué par de très nettes traces d'incendie tant dans le sondage 3 d'Henri Prades que dans la zone 27 des fouilles programmées, voit l'achèvement de ce processus. Au-dessus des ruines des entrepôts dévastés, ce sont, pour un temps, des maisons de type traditionnel qui s'installent, soit en torchis sur poteaux porteurs (zone 27), soit en bauge sur solin de pierres (zone 1), tandis que le mobilier présente un faciès majoritairement indigène, avec des échanges désormais majoritairement massaliètes (Py 2009, 65-69). La chronologie et la nature de ces observations invitent évidemment à y voir un rapport avec la fin de l'occupation de l'agglomération précédemment établie au bord de la Lironde.

Quant à la prolongation de l'occupation du secteur du Mas de Causse sur la rive droite, on considérera qu'elle est liée d'une manière ou d'une autre à l'existence sur le versant du relief voisin, dès cette époque et peut-être antérieurement, d'un sanctuaire - ou du moins d'un espace rituel - qui perdurera jusqu'à l'époque romaine (Newman 2008).

\section{Bibliographie}

Daveau 2010a : DAVEAU (I.) - Lattes, La Cougourlude et Mas de Causse 2, Bilan Scientifique de la région Languedoc-Roussillon, Ministère de la Culture, 2010, p. 125-129.

Daveau 2010b : DAVEAU (I.), DEDET (B.) - Découverte d'enclos funéraires des environs de 500 avant J.-C. dans la plaine littorale languedocienne à Pérols (Hérault). In : Gestes funéraires en Gaule au Second Age du fer, Actes du XXXIII ${ }^{e}$ colloque international de l'AFEAF, 2010, p. 297-302.

Feugère 2010 : FEUGÈRE (M.), NEWMAN (Ch.) - Mobilier votif du Mas de Causse. In : Pernet (L.) et Py (M.) dir., Les objets racontent Lattara, Paris, Errance, 2010, p. 30-31.

Janin 2008 : JANIN (Th.), PY (M.) (Dir.) - Lattara, Lattes, Hérault, nouveaux acquis, nouvelles questions sur une ville portuaire protohistorique et romaine, Gallia, 65, 2008, p. 5-230.

Newman 2008 : NEWMAN (Ch.) - Lattes, Mas de Causse I, Bilan scientifique de la région Languedoc-Roussillon, Paris, Ministère de la Culture, 2008, p. 133-134. Pezin 2004 : PEZIN (A.) - Les fours de potier du Mas de Pascal a Aspiran (Hérault). In : Demoule (J.-P.) dir., La France archéologique, 20 ans d'aménagements et de découvertes, Paris, 2004, p. 115.

Prades 1966 : PRADES (H.), BELORGEOT (M.), CRASSOUS (J.) - Les découvertes hallstattiennes du Lycée Technique de Montpellier, Ogam, 18, 1966, p. 445-453. Py 1985 : PY (M.) - Les gisements lagunaires au premier âge du Fer. In : L'occupation des rivages de l'étang de Mauguio, Hérault, au Bronze final et au I ${ }^{e r}$ âge du Fer, III, synthèses et annexes, éd. ARALO, Cahier nº13, Caveirac, 1985, p. 47-84. Py 1988 : PY (M.) - Sondages dans l'habitat antique de Lattes : les fouilles d'Henri Prades et du Groupe Archéologique Painlevé (1963-1985), Lattara 1, Lattes, 1988, p. 65-146.

Py 1990 : PY (M.) - Culture, économie et société protohistoriques dans la région nimoise, Collection de l'École Française de Rome, 131, Rome-Paris, 1990, 2 vol, 958 p. Py 1995 : PY (M.) - Les Étrusques, les Grecs et la fondation de Lattes. In : Sur les pas des Grecs en Occident, Hommages à André Nickels, Études Massaliètes, 4, 1995, p. 261-276.

Py 2001 : PY (M.), BUXÓ (R.) - La viticulture en Gaule à l'âge du Fer, Gallia, 58, 2001, p. 29-43.

Py 2007 : PY (M.) - La céramique du I er âge du Fer de Port Ariane (VII ${ }^{\mathrm{e}} \mathrm{s}$. av. n. è.). In : Daveau (I.) dir., Port-Ariane, Lattes, Hérault, Construction deltaïque et utilisation d'une zone humide lors des six derniers millénaires, Lattara 20, Lattes, 2007, p. 405-420.

Py 2009 : PY (M.) - Lattara (Lattes, Hérault), comptoir gaulois méditerranéen entre Étrusques, Grecs et Romains, Éditions Errance, Paris, 2009, 348 p. Py 2011 : PY (M.) - La sculpture gauloise méridionale, éditions Errance, Paris, 2011, $200 \mathrm{p}$.

Sourisseau 1997 : SOURISSEAU (J. Chr.) - Recherches sur les amphores de Provence et de la basse vallée du Rhône aux époques archaïque et classique (fin $V I I^{e}$-début $I V^{k}$ s. av. J.-C.), Thèse de doctorat, Aix-Marseille I, 1997, 3 tomes.

Sourisseau 2011 : SOURISSEAU (J.-Chr.) - La diffusion des vins grecs d'Occident du VIII e au IVe s. av. J.-C. : sources écrites et documents archéologiques. In : La vigna di Dioniso, Istituto per la Storia e l'Archeologia della Magna Grecia, Tarente, 2011, p. 143-252.

Vial 2003 : VIAL (J.) - Carte archéologique de la Gaule, 34/3, le Montpelliérais, Paris, 2003, 479 p. 


\title{
Un signe de la présence phocéenne en Languedoc occidental : un tétartémorion trouvé à Béziers
}

\author{
Richard Pellé \\ Inrap, USR 3155 CNRS, IRAA \\ Société Française de Numismatique \\ Laurent Vidal \\ Inrap, UMR 7268 ADES \\ Hervé Petitot \\ Inrap
}

\section{Résumé}

Un tétartémorion phocéen a été découvert à Béziers au cours d'une fouille archéologique préventive menée par l'INRAP. Cette monnaie enrichit la carte de diffusion des monnaies archaïques en Languedoc-Roussillon. Le terrain, situé en périphérie de la ville antique, recèle aussi de nombreux tessons de poterie plus ou moins roulés. Correspondant de façon récurrente à des fragments d'amphore massaliète et étrusque mais aussi à des tessons de céramique modelée et des fragments de poterie à vernis noir. Des coquillages et des ossements de faune sont aussi présents mais plus rares. La couche s'étend des deux côtés d'une voie. L'ensemble des données atteste une mise en valeur agricole de ce secteur au plus tard à partir du début de la seconde moitié du $\mathrm{VI}^{\mathrm{e}} \mathrm{s}$. av. notre ère.

Mots-clés : monnaie, tétartémorion, Phocée, plantation, Béziers

\footnotetext{
Abstract

A Phocean Tetartemorion was discovered in Béziers during a preventive archaeological excavation conducted by INRAP. This coin enhances the map of archaic currencies in Languedoc-Roussillon. The land, located on the outskirts of the ancient city, also has many pottery more or less rolled. Corresponding to recurring fragments of massaliète and etruscan amphora but also shards of ceramic handmade and pottery fragments in black glaze. Shells and bones of animals are also present but rare. The layer extends on both sides of a road. The data confirms the agricultural development of this sector in later from the beginning of the second half of the sixth century. BC.
}

Keywords: coin, Tetartemorion, Phocée, plantation, Béziers 


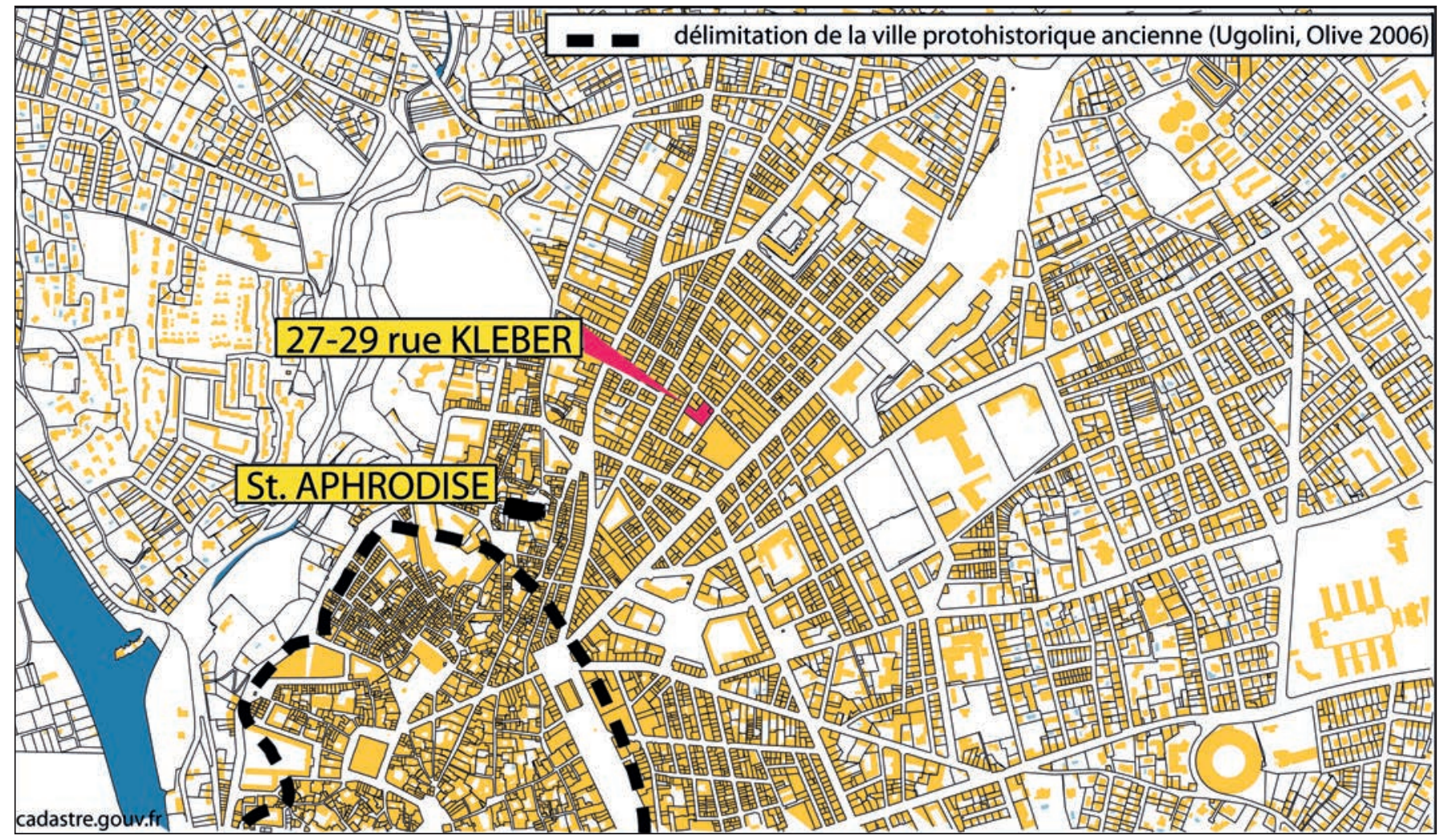

Fig. 1. Localisation de la fouille archéologique, en pointillé, emprise supposée de la cité protohistorique (DAO L. Vidal).

$\mathrm{L}$ a monnaie provient d'une fouille archéologique préventive menée par l'INRAP pour l'Office public de l'Habitat de Béziers au 27-29 de la rue Kléber (fig. 1). Elle a porté sur un ensemble funéraire romain, longeant une voie, découvert en diagnostic par le Service Archéologique Municipal de Béziers (resp. Elian Gomez). Le terrain, situé en périphérie de la ville antique, est le lieu d'une accumulation sédimentaire graduelle depuis la fin de l'époque romaine qui a exhaussé la surface topographique d'environ $1,40 \mathrm{~m}$.

\section{La monnaie : description et analyse}

Tetartemorion de Phocée ou quarante-huitième de statère (fig. 2)

Droit :

Anépigraphe

Tête de phoque à gauche

Revers :

Anépigraphe

Carré creux quadripartite

Frappé à Phocée vers 550-500 av. J.-C.

Argent, module $6,4 \mathrm{~mm}$, épaisseur 1,6 mm, poids $0,31 \mathrm{~g}$, axe du coin $5 \mathrm{~h}$

$\mathrm{Cf} \mathrm{BMC} \mathrm{n}^{\circ} 9$

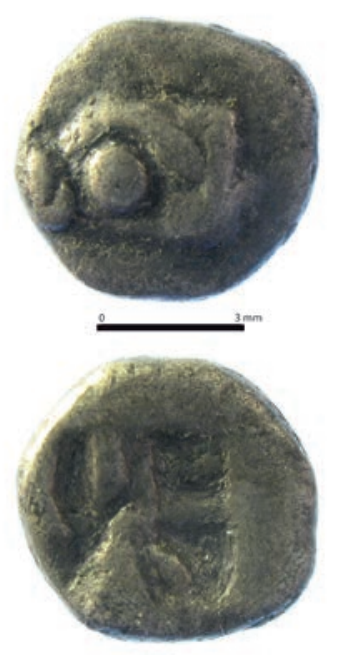

Fig. 2. Le tetartemorion (cliché Y. Manniez, DAO R. Pellé).

Le flan métallique est légèrement irrégulier. La frappe est assez bien centrée. L'état de surface est très bon. Le carré creux montre une usure importante du coin de revers, comportant vraisemblablement des fissures en formation. Le poids théorique du tetartemorion phocéen est de $0,22 \mathrm{~g}$. Cette monnaie fait partie de la gamme des poids 


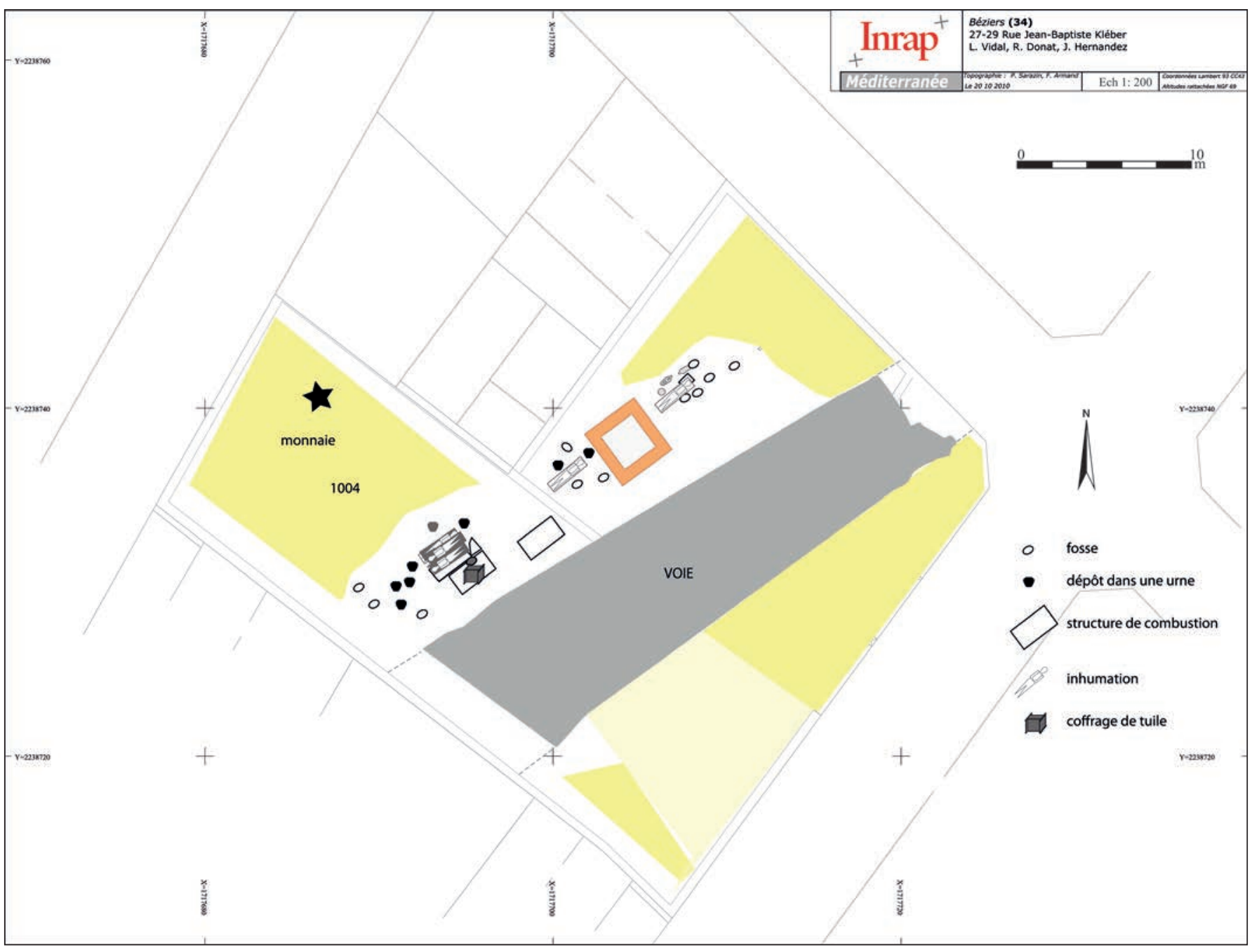

Fig. 3. Localisation des vestiges archéologiques et de la monnaie ; en jaune, l'Us 1004 (DAO L. Vidal).

lourds qui se rencontrent ponctuellement au sein des émissions des monnaies archaïques. La qualité de la gravure du droit le rattache sans hésitation à l'atelier phocéen.

\section{Le contexte archéologique}

Le terrain géologique (une molasse miocène jaunâtre limoneuse à gréseuse comprenant des bancs peu épais de calcaire coquillier) est recouvert par une couche d'environ 0,60 m d'épaisseur d'un sédiment limono-sableux brun moyen (Us 1004) (fig. 3). Cette dernière a livré la monnaie, mais recèle aussi de nombreux tessons de poterie plus ou moins roulés. On notera parmi eux la présence de fragments d'amphore massaliète et étrusque mais aussi de tessons de céramique modelée et de fragments de poterie à vernis noir. Des coquillages et des ossements de faune sont aussi présents mais plus rares. Il faut ajouter à ce mobilier archéologique une pointe de flèche de type grecque en bronze à trois ailerons (étude Y. Manniez Inrap) La couche s'étend sur l'ensemble de la surface de fouille des deux côtés de la voie, mais la densité des artefacts semble plus importante du côté nord. Le décapage mécanique réalisé à l'aide d'une mini-pelle dans l'angle nord de la fouille montre qu'ils sont parfois groupés avec des petits galets ou des cailloux.

Tout cela engage à voir dans ce niveau un horizon pédologique support de cultures à l'époque protohistorique, sans que l'on puisse déterminer si les artefacts ont été amenés dans le cadre d'une bonification régulière des terres par enfouissement de compost pour des plantations annuelles (céréaliculture, horticulture) ou bien dans le cadre d'une culture pérenne (viticulture) par dépôt dans des fosses de plantation. En tout cas, les conditions d'enfouissement de la monnaie ne se distinguent pas de celles des autres artefacts. L'ensemble atteste une mise en valeur agricole au plus tard à partir du milieu du $\mathrm{VI}^{\mathrm{e}} \mathrm{s}$. av. notre ère. 


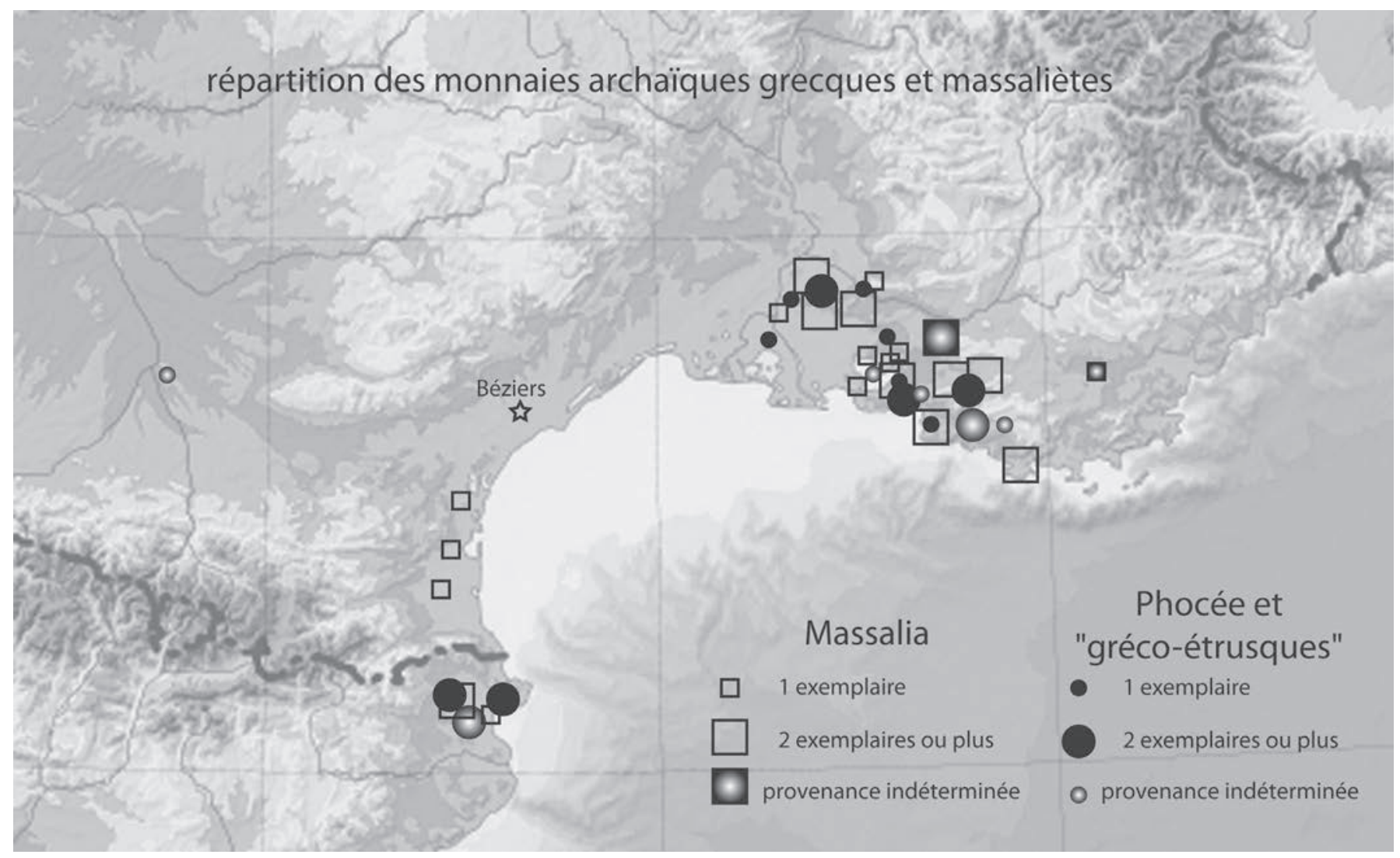

Fig. 4. Carte de répartition des monnaies archaïques ; d'après Py 2006 (DAO R. Pellé).

\section{L'apport de la découverte}

Cette monnaie, retrouvée dans un contexte archéologique contemporain de son émission et de son utilisation, comble un vide dans la diffusion des monnaies archaïques en Languedoc, voire en Roussillon. Au-delà de découvertes de trésors monétaires comme les cas d'Auriol dans les Bouches du Rhône, de Morella près de Valence ou de Rosas en Espagne, de Volterra ou de Vélia en Italie qui sont synonymes de thésaurisation et qui peuvent être interpréter comme un enfouissement d'une masse de métal précieux sans rapport implicite avec l'usage de l'objet en tant que monnaie, les pièces isolées apportent un aperçu plus clair sur la circulation monétaire.

$\mathrm{Au} \mathrm{VI}{ }^{\mathrm{e}} \mathrm{s}$. av. notre ère, les peuples celtes, celtibères ou italiques n'ont probablement pas encore acquis la notion d'échanges à travers un objet de petite dimension et de bien faible valeur portant la marque distinctive d'une cité-état bien éloignée de leurs territoires respectifs. Les monnaies isolées ne peuvent qu'indiquer la présence, même ponctuelle, ou le passage de personnes connaissant la monnaie et sachant l'utiliser, comme des commerçants ou des colons d'origine grecque ou encore d'indigènes vivant dans une cité grecque, indice dès lors d'une acculturation. Le tetartemorion phocéen qui atteste de cette situation à Béziers n'était certainement pas considéré comme un objet précieux conservé avec grand soin par un autochtone, au regard de sa petitesse. Il pourrait être lié à l'introduction de la viticulture dans le Biterrois par ces précédentes personnes si son enfouissement rentre dans le cadre de fosses de plantations (bien que la fouille n'ait pas pu clairement le déterminer), peut-être favorisée avec une présence grecque sur le site d'Agde dès le VIe s. av. notre ère.

La répartition des trouvailles de monnaies archaïques grecques dans le sud de la Gaule montre bien leur sphère de diffusion très limitée ; elles se rencontrent autour de Massalia et des proches voies d'accès maritimes ou fluviatiles (Rhône, étang de Berre) et autour de la colonie d'Ampurias (fig. 4). Il en est quasiment de même avec les monnaies archaïques émises par l'atelier massaliète, avec néanmoins une particularité pour le Roussillon où 3 exemplaires ont été retrouvés, toujours sur des sites proches de la mer ou des lagunes. Un grand vide existe sur la carte entre le Rhône et l'Orb, c'est-à-dire sur 
territoire des Volques Arécomiques, peuple qui n'émettra du numéraire que très tardivement (fin du $\mathrm{II}^{\mathrm{e}} \mathrm{s}$. av. J.-C. au plus tôt). Cette absence assez nette, qui, pour la période classique, se traduit aussi par une faible représentativité du numéraire par rapport à d'autres régions limitrophes, semble indiquer une certaine réticence de ce peuple à utiliser un moyen d'échange qui sans doute n'est pas immédiatement perçu comme une facilité ou une méthode comptable. En poussant la réflexion plus loin, il est possible aussi d'y voir des sphères d'influences commerciales, non grecques et n'utilisant pas la monnaie comme moyen d'échanges. Les quantités très importantes de céramiques étrusques retrouvées à Lattara ou dans les territoires de l'Hérault et du Gard pourraient témoigner dans ce sens pour le $\mathrm{I}^{\mathrm{er}}$ âge du Fer.

\section{Bilan}

Compte tenu de la datation proposée pour l'émission de la monnaie, cette dernière s'insère dans la série des très rares objets remarquables qui marque, pour le moins, le début du déploiement en Biterrois de l'entreprise commerciale grecque et peut-être plus spécifiquement phocéenne.

\section{Bibliographie}

BMC : British Museum Coins. Catalogue of Greek coins. Londres, 1873-1922. Py 2006 : PY (M.) - Les monnaies préaugustéennes de Lattes et la circulation monétaire protohistorique en Gaule méridionale, éd. ADAL, Lattes, 2006, 2 tomes [Lattara 19]. 



\title{
Commerces méditerranéens en Provence orientale au $1^{\text {er }}$ âge du Fer : un état de la question
}

\author{
Laurence Mercuri \\ Maitre de Conférences, Université Nice Sophia Antipolis, \\ CNRS, CEPAM, UMR 7264, 06300 Nice, France
}

\section{Résumé}

L'article effectue un bilan des importations méditerranéennes découvertes en Provence orientale, sur le littoral et à l'intérieur des terres. Celui-ci conduit à réexaminer la place de cette région au sein des échanges maritimes du $1^{\text {er âge }}$ du Fer et à reconsidérer la chronologie d'Antipolis et de Nikaia.

Mots-clés : Méditerranée nord-occidentale, Provence, Alpes-Maritimes, Antibes, Nice, âge du Fer, commerce maritime, Étrusques, Grecs

\section{Abstract}

This paper offered a synthesis about the Mediterranean imports discovered in oriental Provence, on the coast and the hinterland, which drives to revise the place of this area concerning the maritime exchanges during the First Iron Age and to reconsider the chronology of Antipolis and Nikaia.

Keywords: North Western Mediterranean Sea, Provence, Alpes-Maritimes, Antibes, Nice, Iron Age, maritime trade, Etruscans, Greeks 
$\mathrm{L}$ 'histoire de l'archéologie et les conditions de recherche en Provence orientale, en particulier dans les actuelles Alpes-Maritimes, ont conditionné l'image que nous avons aujourd'hui de cette région, ainsi que les hypothèses émises quant à sa place au sein des changements survenus durant le $1^{\text {er }}$ âge du Fer. En Méditerranée occidentale, ces changements ont été marqués avant tout par une grande mobilité et un accroissement des contacts et des échanges. Or, la Provence orientale y serait demeurée étrangère.

Le tableau historique que l'on admet aujourd'hui pour cette période résulte de la comparaison avec la région de Marseille et le Languedoc. Trois idées principales s'en dégagent :

- Le littoral de Provence orientale vit à l'écart des premiers échanges réalisés alors entre élites indigènes et élites gréco-étrusques sur les côtes occidentales ;

- les produits méditerranéens, s'ils y sont importés, se limitent à la frange littorale et ne pénètrent pas à l'intérieur des terres ;

- Nice est une fondation massaliète très tardive, pas antérieure au $\mathrm{III}^{\mathrm{e}} \mathrm{s}$. av. J.-C.

Chacune de ces hypothèses mérite aujourd'hui d'être réexaminée à la lumière d'un bilan des données archéologiques et textuelles.

\section{Un littoral à l'écart des premiers échanges?}

On sait que, dans l'analyse des premières pratiques commerciales du $1^{\text {er }}$ âge du Fer, s'est imposé le modèle de la praxis formalisé à partir de 1979 par A. Mele (Mele 1979 et 1986) et selon lequel les élites de cultures différentes pratiquent occasionnellement des échanges d'objets de prestige (métaux ou autre) dans le cadre d'une économie de don et de contre-don. Pour le sud de la Gaule, ce modèle s'appuie sur des objets étrusques ou grecs découverts isolés dans des contextes funéraires indigènes et dont les plus anciens, datés dans la $2^{\mathrm{e}}$ moitié du VII $\mathrm{s}$. et désormais bien connus, ont été découverts en Languedoc (fig. 1) : à Mailhac, une coupe profonde de type protocorinthien provenant de la nécropole du Grand-Bassin I (Gras 2000) ; à Agde, trois skyphoi et une oinochoè issus de la nécropole du Peyrou (Nickels et al. 1989 ; Gras 2004) et un skyphos de la nécropole du Bousquet (Mazières 2003 ; Janin, Py 2012).

En l'absence d'indices archéologiques, on s'accorde à reconnaître parfois la praxis dans des traditions littéraires comme celle de la fondation de Marseille pour la Gaule, telle qu'elle est rapportée par Aristote ( $a p$. Ath., XIII, 576), Trogue-Pompée et Justin (XLIII, 3-4) : Euxène (ou Prôtis) de Phocée reçoit femme et territoire de Nannos, roi des Ségobriges, au nom de la philia et de la xénia qui, à partir de ce moment-là, doivent unir d'une étroite alliance l'élite phocéenne et l'élite des Ségobriges.

On ne connaît pas de traditions comparables en Provence orientale. L'archéologie ne dit rien non plus d'éventuelles alliances entre commerçants méditerranéens et populations locales, si bien qu'on a toujours considéré que cette région se trouvait à l'écart des activités d'échanges élitaires, pourtant traditionnelles ailleurs en Méditerranée occidentale.

Il ne s'agit pas ici de faire dire aux textes ni à l'archéologie ce qu'ils ne disent pas. Pourtant, on oublie, quand on compare le Languedoc, la vallée du Rhône et l'extrême Sud-Est de la Gaule, que les marqueurs archéologiques témoignant d'une activité de praxis sur les côtes occidentales proviennent tous de contextes funéraires du $1^{\text {er }}$ âge du Fer et que, si on n'a pas retrouvé d'objets aussi anciens en Provence orientale, c'est peutêtre bien parce qu'on n'y a pas encore découvert à ce jour de nécropoles de cette période. Remarque simple mais pas sans importance. Car, tant que cette lacune archéologique ne sera pas comblée, l'argument $e$ silentio reste périlleux.

En revanche, si cette absence venait à être vérifiée, il faudrait alors comprendre le vide représenté par le littoral de la Provence orientale, et cela, jusqu'à Gênes, puisque la Ligurie italienne située à l'Est de Gênes présente un profil assez comparable à celui du Languedoc, les importations grecques y apparaissant dès le début du VII ${ }^{e}$ s. (Maggiani 2006, Gras 2005, Mercuri 2008), à Rapallo (Melli 1998), Massarosa, Pise et Chiavari (Gras 2000, De Marinis 2004) (fig. 1).

Cette disparité géographique semblant exister jusqu'au $\mathrm{V}^{\mathrm{e}} \mathrm{s} .{ }^{1}$, on s'accorde habituellement à mettre celle-ci au compte d'une configuration littorale du golfe de Ligurie hostile à la navigation, propice aux naufrages et mal adaptée à l'accostage des bateaux. On admet ainsi que ces mauvaises conditions maritimes auraient conduit à « court-circuiter » le fond du golfe pour privilégier l'itinéraire par la haute mer, depuis le nord de l’Étrurie jusqu'au golfe du Lion, en passant par la Corse.

Cette hypothèse a l'avantage d'être conforme aux sources textuelles. Selon Strabon $(4,6,2)$, « tout le littoral, depuis le port de Monoikos jusqu'à l'Étrurie, est droit ; on n'y trouve pas de ports mais seulement des lieux de mouillage et d'ancrage sans profondeur ». Le périple de Scylax $(4,6-7)$, écrit entre le $\mathrm{VI}^{\mathrm{e}} \mathrm{s}$. et le $\mathrm{IV}^{\mathrm{e}} \mathrm{s} .{ }^{2}$,

1 Cf., pour toute la période, une synthèse des importations méditerranéennes et, en particulier, étrusques, dans la vallée du Rhône et en Languedoc, dans Gras 2004.

2 Cf. Peretti (A.) - Il periplo di Scilace. Studio sul primo portolano del Mediterraneo, Pise 1979. 
dit peu de chose de cette portion de littoral, à moins de considérer (tout en surinterprétant) qu'il en souligne indirectement le vide signalé plus tard par Strabon en qualifiant la côte située à l'Ouest d'Antipolis jusqu'aux colonnes d'Héraclès de « terre tout entière pourvue de bons ports ».

Ainsi, sur la base de ces témoignages littéraires et en l'absence de données archéologiques substantielles, a-ton rangé le littoral de Provence orientale et le littoral ligure jusqu'à Gênes parmi les côtes restées à l'écart des circuits d'échanges maritimes.

\section{Absence d'impact des échanges dans l'arrière-pays ?}

Si on veut bien laisser de côté le déséquilibre quantitatif des découvertes archéologiques déjà signalé entre l'extrême Sud-Est de la Gaule et les régions plus occidentales, le tableau économique de la région alpine est comparable à celui de la basse vallée du Rhône à partir de l'âge du Fer moyen (v. 625-550/525). Certes, l'autoconsommation demeure première mais l'économie locale intègre aussi à partir de ce moment-là les échanges méditerranéens.

Pour la vallée du Rhône, on connaît bien aujourd'hui les lignes principales de l'économie régionale, en particulier grâce aux travaux de P. Arcelin (1986), M. Bats (1989, 1992, 1998) et L.-F. Gantès (1992), et l'archéologie sous-marine en a consolidé le tableau en apportant des données concordantes (notamment Pomey, Long 1992) : les importations étrusques et grecques prédominent dans la $1^{\text {ère }}$ moitié du $\mathrm{VI}^{\mathrm{e}} \mathrm{s}$. avant d'être rapidement concurrencées et distancées par les produits massaliètes, parmi lesquels, dès le $2^{\mathrm{e}}$ quart du siècle, la vaisselle fine à pâte claire et en grise monochrome, et, à partir de 550-540, les amphores vinaires. On enregistre les mêmes tendances en Provence orientale où les importations étrusques et grecques, peu nombreuses mais réelles, précèdent l'arrivée des productions massaliètes dans le courant du $\mathrm{VI}^{\mathrm{e}} \mathrm{s}$.

Certes, on est loin de pouvoir aujourd'hui avancer des statistiques comme dans la région de Marseille, à Saint-Blaise, au Baou de Saint-Marcel ou au Mont$\mathrm{Garou}^{3}$. Seules, les fouilles stratigraphiques menées sur le rocher d'Antibes laissent voir que, dans la chapelle du Saint-Esprit (1981-1984), les céramiques importées représentent $40 \%$ des fragments recueillis pour le dernier

3 Cf. Arcelin 1986 ; Bats 1989, p. 183-184 ; Arcelin (P.), Arcelin-Pradelle (Ch.), Gasco (Y.) - Le village protohistorique du Mont-Garou (Sanary, Var). Les premières manifestations de l'impérialisme marseillais sur la côte provençale. DAM, 5, 1982, p. 53-137. quart du $\mathrm{VI}^{\mathrm{e}} \mathrm{s}$., dont une majorité d'origine massaliète (amphores et vases à pâte claire) (Arcelin, Bats, Pollino 1984 ; Mercuri 2008) ${ }^{4}$, et, place Mariéjol et montée Dor de la Souchère (2009), 81\% (Bats 2011, p. 87-89).

À Nice, le réexamen du matériel d'importation des fouilles de F. Benoit et de D. Mouchot, effectué dans le cadre du projet collectif de recherche sur la colline du Château ${ }^{5}$, a permis de retrouver un tableau général similaire, malgré une documentation restreinte (Mercuri 2008, 2010, 2013). Les résultats principaux sont les suivants :

Les amphores étrusques y sont bien représentées avec 26 fragments pour un NMI de 11, les exemplaires datables se répartissant entre 575 et $400^{6}$ (fig. 2a) :

- 2 individus de forme PY 3A5, daté entre 575 et 450 : lèvre épaissie, col étroit oblique ; argile marron à noyau couleur rouille, mica ; engobe épais beige marron à l'extérieur et à l'intérieur du col ; diam. restitué $19 \mathrm{~cm}$;

- 2 de forme Py 4, v. 525-500 : argile rouge-marron à noyau gris-noir, fin mica blanc et doré, particules noires et rouges ; diam. restitué 17 et $14 \mathrm{~cm}$;

- 5 de forme PY 3C, datés entre 500 et $400: 1$ ) argile brique orangé avec nodules noirs et blancs et peu de mica, achrome, sans engobe ; 2) pâte brun-marron en surface, marron gris à l'intérieur ; engobe beige orangé assez épais ; 3) pâte brun-rouge avec nodules noirs, rougeâtre en surface ; 4) argile rouge avec noyau gris, mica blanc et nodules blancs, engobe crème ; diam. restitué $16 \mathrm{~cm}$; 5) lèvre arrondie, pendante et concave à l'extérieur ; pâte orangée, granuleuse, avec divers dégraissants dont mica blanc.

4 Publication en cours dans le cadre du projet collectif de recherche coordonné par É. Delaval sur les fouilles anciennes et récentes d'Antibes : Antipolis, des origines au royaume des Francs $\left(V I I^{e}-V I^{e}\right.$ s. av. J.-C./VI ${ }^{e}$ s. ap. J.-C.

5 La colline du Château à Nice, PCR coordonné par M. Bouiron depuis 2005.

6 Malgré la mention de bucchero nero dans une lettre de D. Mouchot à Ch. Lagrand (d'après Ch. Lagrand, dans Le bucchero nero étrusque et sa diffusion en Gaule méridionale. Actes de la table ronde d'Aix-en-Provence 1975, Aix-en-Provence 1976, p. 131), aucun témoignage n'a été repéré. Cette absence est d'autant plus remarquable que l'amphore étrusque est relativement bien représentée avec 11 individus et que le bucchero en est une vaisselle d'accompagnement fréquente. 


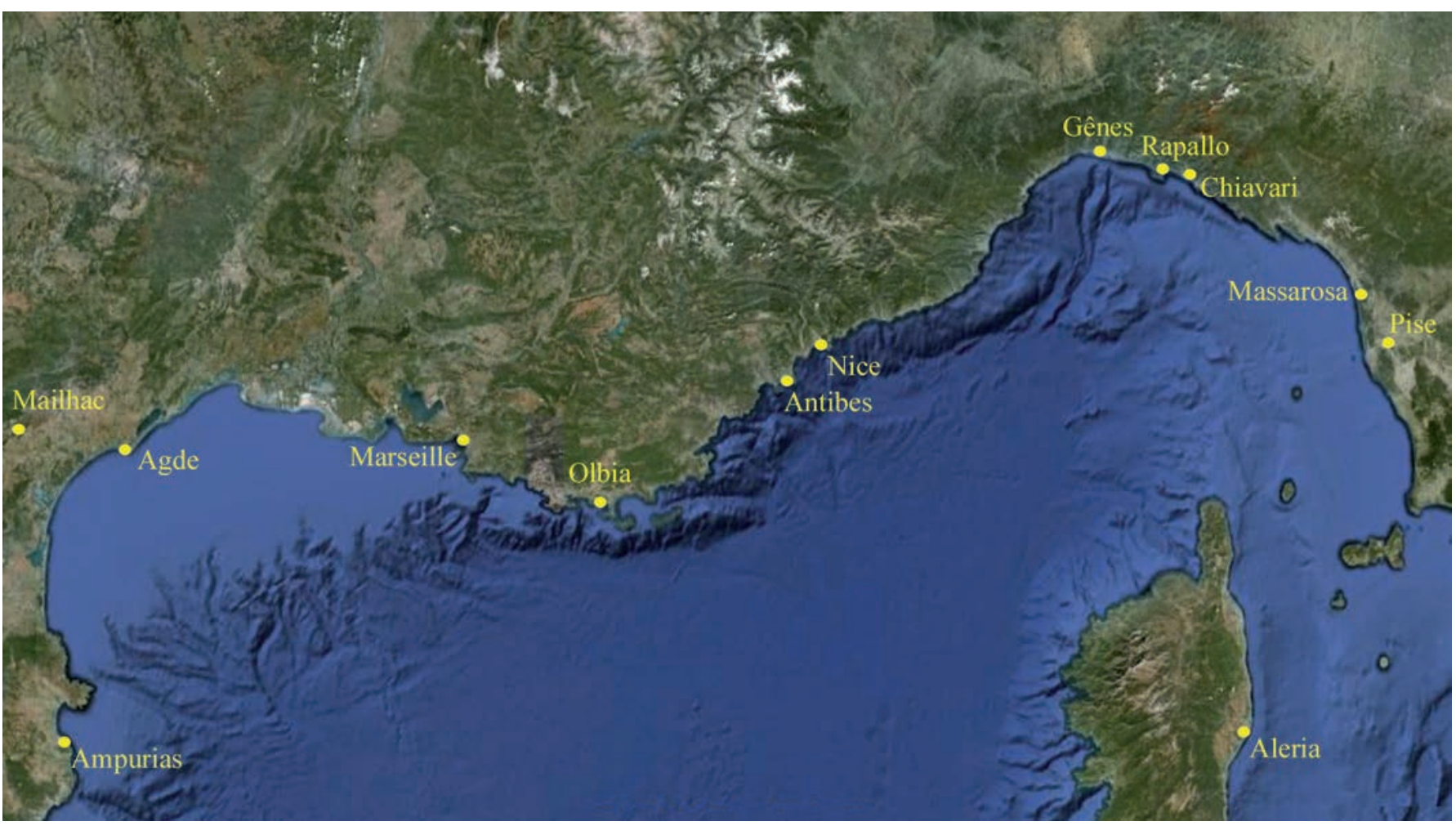

Fig. 1. Carte de situation.

Les amphores massaliètes, datables entre la fin du $\mathrm{VI}^{\mathrm{e}}$ et le début du $\mathrm{III}^{\mathrm{e}}$ s., s'élèvent à 177 fragments pour un NMI de $18^{7}$ (fig. 2b). Parmi les plus anciens, on compte : - 3 individus de première génération (type Bertucchi 1), en forme de toupie et en argile non micacée : pour l'argile, groupe 1 et 3 de Bertucchi ; respectivement, compacte, marron et rougeâtre par bandes, avec de petits dégraissants blancs, et beige à noyau gris, avec des nodules blancs ;

- un individu à bord replié et lèvre ovale sans moulure, datable dans le $1^{\text {er }}$ quart du Ve s. av. J.-C. : pâte marron rosé avec grosses paillettes de mica et nodules noirs. La céramique fine massaliète, quant à elle, débute dans le $2^{\mathrm{e}}$ quart du VI $\mathrm{e}$ s. av. J.-C. avec les pâtes claires, suivies de la grise monochrome, de la «pseudo-attique » et de la céramique grise peinte. Les autres céramiques fines proviennent principalement de la Grèce de l'Est pour le VIe $s$. - le plus ancien fragment importé appartenant à un bol de «Vroulia », du 2e quart du VI e s. - ; l'autre provenance principale est l'Attique pour les $\mathrm{V}^{\mathrm{e}}$ et $\mathrm{IV}^{\mathrm{e}} \mathrm{s} .^{8}$.

Ainsi, dans l'état actuel des connaissances, la colline du Château à Nice et le rocher d'Antibes semblent

7 Le NMI est probablement sous-évalué compte tenu de l'état fragmentaire des trouvailles et la difficulté d'identifier les individus à partir des seuls fragments de paroi.

8 Sur l'ensemble de ce matériel, cf. Mercuri 2013. bien s'insérer dès le début du $\mathrm{VI}^{\mathrm{e}} \mathrm{s}$. dans les circuits d'échanges méditerranéens, tout comme les sites littoraux de Provence occidentale. Ce qui nous échappe en revanche, c'est bien l'ampleur de ces échanges.

Par ailleurs, s'est imposée la thèse d'un commerce littoral sans diffusion dans l'arrière-pays (Gazenbeek 2004, p. 253), ce décalage entre la côte et l'intérieur des terres résultant de la nature même de la distribution des produits massaliètes qui serait prioritairement maritime (Bats 1992, p. 268). Les importations sont en effet rares dans les sites de l'intérieur comme celui du Baou des Noirs, à Vence, relativement bien documenté (Latour 1985), alors que l'impact des commerces méditerranéens est bien perceptible dans les sites littoraux à travers un matériel d'importation plus nombreux. C'est le cas du rocher d'Antibes et de la colline du Château à Nice, nous l'avons vu, mais aussi, ce qui est moins connu, des oppida de la butte de Saint-Cassien, à Cannes (céramique grise monochrome, pâte claire massaliète, amphores massaliètes de type Bertucchi 1, 3 et 4) (Gazenbeek 2003, p. 195-196, 201 ; CAG 06 2010, s.v.), du Pezou, à Vallauris (pâte claire du début V V s., céramique grise monochrome, amphores massaliètes et ioniennes à décor peint) (CAG 06, 2010, s.v.), et du domaine de Saint-Andrieu, à Villeneuve-Loubet (amphores étrusques et massaliètes, pâte claire massaliète, céramique grise monochrome, céramique attique) (Vindry 1978, p. 39-40 ; Bats 1990a, p. 210 ; CAG 06, 2010, s.v.) (fig. 3). 


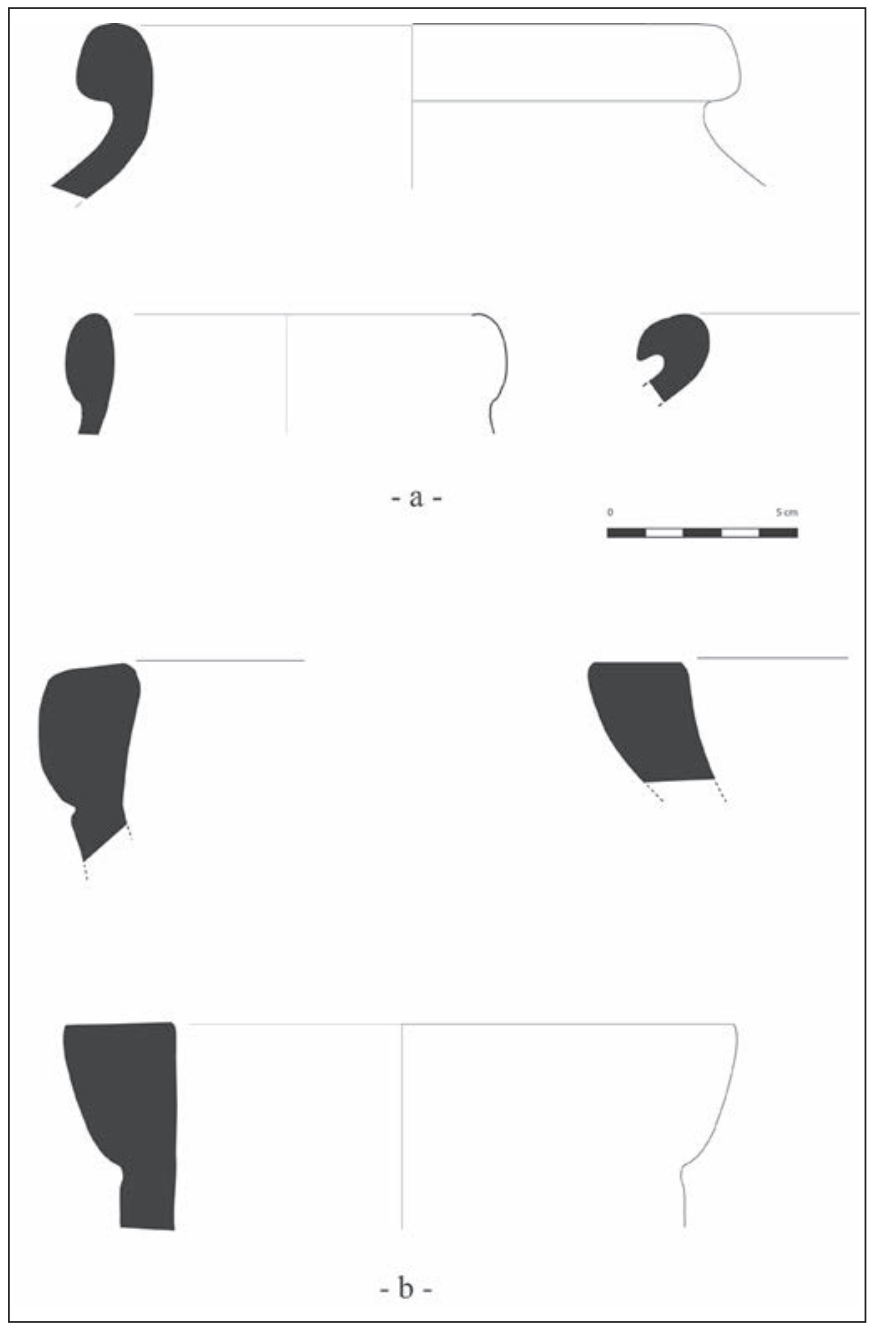

Fig. 2. Nice, colline du Château. a) Amphores étrusques.; b) amphores amssaliètes.

Cette déduction historique - un arrière-pays à l'écart des commerces méditerranéens - ne prend cependant pas suffisamment en compte la situation de l'archéologie dans les Alpes-Maritimes car la documentation ancienne à disposition provient pour l'essentiel de l'activité de l'érudition locale, alors que la recherche institutionnelle n'a lancé des programmes sur la protohistoire et l'Antiquité que dans les années 1980 : la fouille stratigraphique du Baou des Noirs à Vence (Latour 1985) et le projet collectif sur les enceintes de hauteur qui a permis un recensement et une classification des sites (Gazenbeek 2003) en font partie. Mais pour l'essentiel, ces travaux académiques reposent sur des prospections et rares ont été les fouilles de gisements. Le manque de données fiables est donc flagrant, il suffit de prendre pour exemple ne serait-ce que la difficulté de dater les enceintes protohistoriques dont $34 \%$ restent sans chronologie précise, selon un recensement récemment effectué entre Vence et Briançonnet (Lautier 2010).

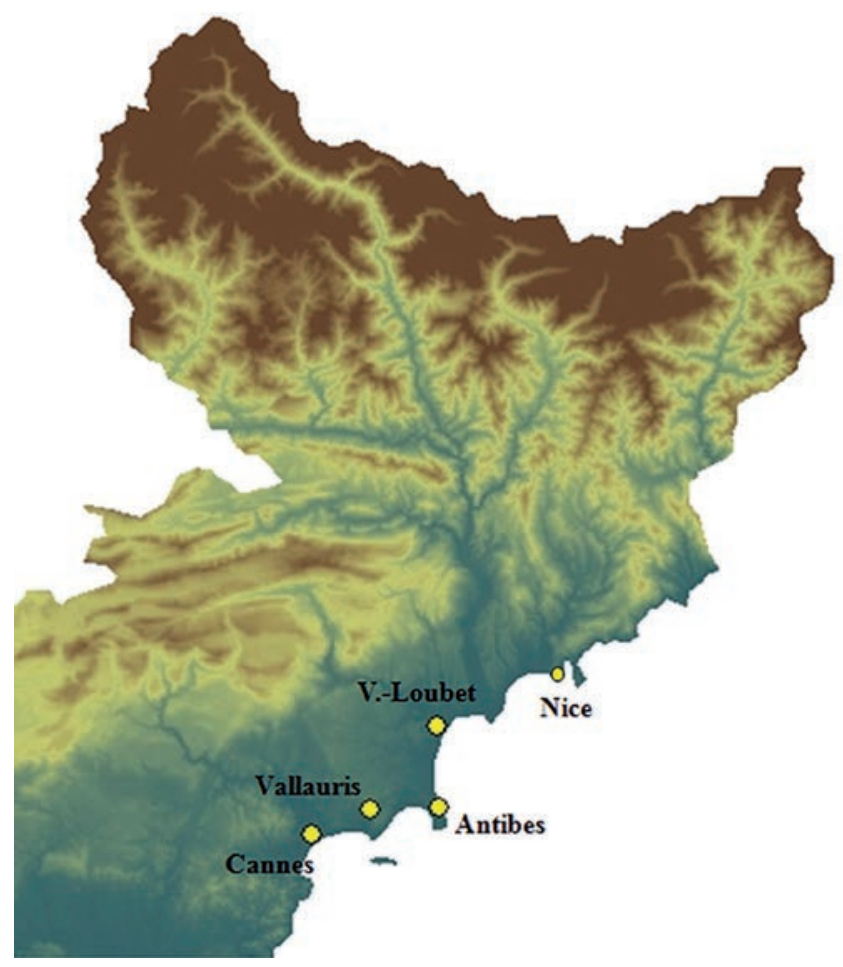

Fig. 3. Carte de répartition des importations méditerranéennes connues sur le littoral de la Provence orientale.

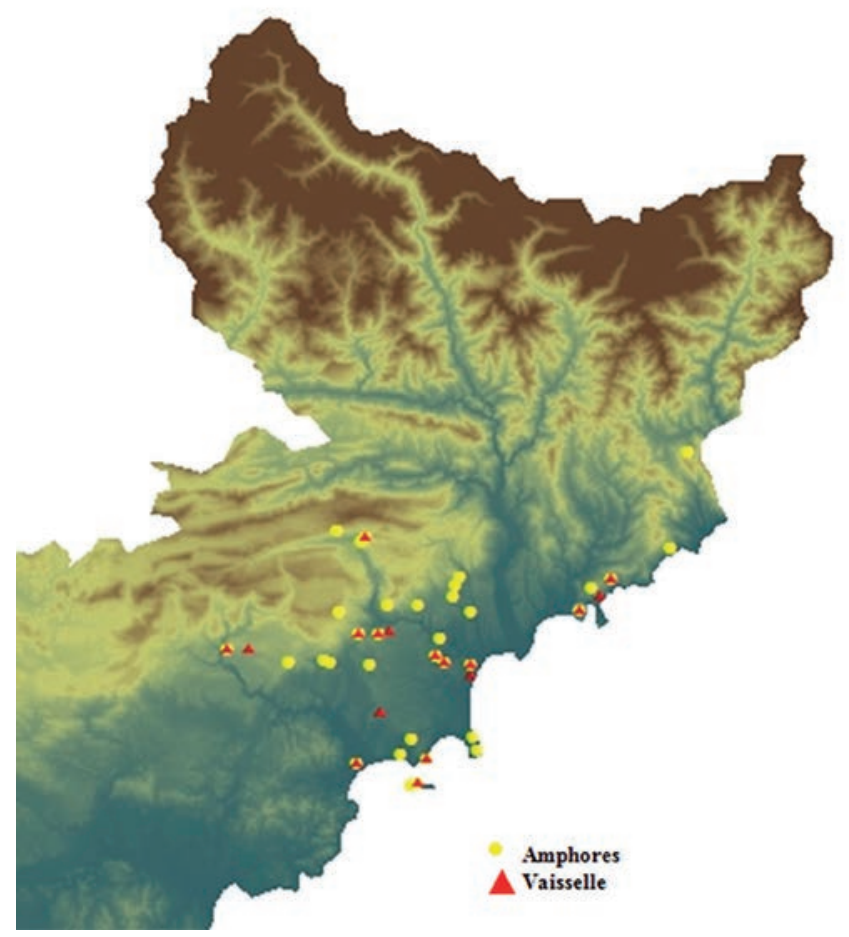

Fig. 4. Cartographie des importations étrusques et grecques dans l'arrière-pays et sur le littoral. 
Dans l'état actuel des connaissances, les sites archéologiques de la Provence orientale, en particulier ceux des Alpes-Maritimes, ne fournissent donc pas de données chiffrées pour une exploitation historique fiable et ne permettent pas de quantifier la pénétration du commerce maritime dans l'arrière-pays ni son éventuel impact sur les traditions artisanales locales durant le $1^{\text {er }}$ âge du Fer. Il semble néanmoins éclairant de proposer ici une cartographie provisoire des céramiques étrusques et grecques importées dans l'arrière-pays à partir des données collectées récemment par la carte archéologique des Alpes-Maritimes (2010) (fig. 4).

On en soulignera cependant d'emblée les défauts. La répartition des découvertes repose en effet exclusivement sur les grandes catégories de céramiques - amphores étrusques, amphores grecques, amphores massaliètes, bucchero nero etc - sans datation ni dénombrement précis compte tenu de l'accès difficile au matériel. On verra aussi que les données sont essentiellement concentrées dans la vallée du Loup, entre la Siagne et le Var, c'est-à-dire dans le secteur le mieux prospecté à ce jour. Enfin, cette cartographie se limite provisoirement à l'actuel département des Alpes-Maritimes alors qu'il faudra à l'avenir, pour pouvoir saisir les tendances et les variations, étendre l'investigation vers l'ouest jusqu'aux massifs montagneux de l'Estérel et des Maures, qui constituent une frontière naturelle. Ainsi, la cartographie actuelle reflète moins une situation historique que l'état de la recherche archéologique dans la région. Elle ne permet pas moins de tirer certains enseignements et d'offrir des perspectives.

Les cartes de répartition, en effet, mettent en évidence, contrairement à l'idée reçue, la circulation des importations maritimes à plus de $30 \mathrm{~km}$ à vol d'oiseau, à l'intérieur des terres, et indiquent clairement que les vallées de la Siagne et du Loup sont des voies de liaison habituelles entre le littoral et l'intérieur (fig. 4-6).

Au $1^{\text {er }}$ âge du Fer, certains habitats fortifiés de ces deux vallées apparaissent plus étroitement liés aux circuits d'échanges maritimes par la quantité et la variété des céramiques d'importation qu'ils ont restituées. C'est le cas de trois enceintes protohistoriques, deux découvertes à Roquefort-les-Pins et au Rouret, dans la vallée du Loup, et une à Saint-Cézaire, plus à l'Ouest, dans la vallée de la Siagne (fig. 7).

À Roquefort-les-Pins, l'enceinte de 0,6 ha, localisée à la cote 137 au-dessus du Loup, a fait l'objet de prospections en 2007 , qui ont permis de récolter des fragments d'amphores étrusques et massaliètes, et de la pâte claire (Lautier, Lepère 2007, p. 41-42 ; CAG 06, 2010, s.v.). Dans la commune du Rouret, au lieu-dit Campdu-Bois, une petite enceinte de 0,4 ha a restitué une quantité notable d'amphores étrusques et massaliètes, et de céramiques grises monochromes et à pâte claire (Vindry 1978, p. 29-30, 67, fig. 30 ; Bats 1990a, p. 210 ; Latour 2005, 2005a ; CAG 06, 2010, s.v.). Enfin, à Saint-Cézaire-sur-Siagne, l'enceinte du Camp-Long, de plus grande superficie (2,2 ha), a donné une quarantaine de fragments de céramique grise monochrome et à pâte claire, ainsi qu'un fragment d'amphore massaliète (Arcelin-Pradelle 1984, p. 110-115, 154 ; Bats 1990a, p. 210 ; Gazenbeek 2006, p. 29-38 ; CAG 062010 , s.v.).

Ces gisements sont prometteurs et l'archéologie doit à l'avenir s'employer à compléter ce tableau et étendre l'enquête aux vallées, plus ouvertes et plus pratiquables, du Var et du Paillon, qui ont pu contribuer, selon toute vraisemblance, à la circulation des produits méditerranéens et à leur acheminement vers l'intérieur des terres.

\section{Rouvrir le débat sur la chronologie d'Antipolis et de Nikaia}

On l'a donc vu, la Provence orientale s'insère dans les échanges méditerranéens dès le $1^{\text {er }}$ quart du $\mathrm{VI}^{\mathrm{e}} \mathrm{s}$. Cette nouvelle dynamisation a pu conduire à une restructuration du peuplement, manifestée par le regroupement des habitats sur la côte dont témoigneraient le rocher d'Antibes, la colline du Château à Nice et, également, le Castellar à Èze (Bats 1989). Dans ce contexte se pose donc la question du rôle des fondations massaliètes, Antipolis et Nikaia, et de la chronologie de leur occupation respective.

Pour la colonisation massaliète, le modèle le plus articulé à ce jour a été proposé par M. Bats (notamment 1989 et 1998). Celui-ci restitue une première phase de type emporique pour les $\mathrm{VI}^{\mathrm{e}}$ et $\mathrm{V}^{\mathrm{e}} \mathrm{s}$. av. J.-C., caractérisée par des échanges sur le littoral sans être accompagnée de l'implantation des Grecs. L'installation des fondations massaliètes n'aurait lieu qu'au IV $\mathrm{IV}^{\mathrm{e}} \mathrm{s}$., à un moment où Massalia, pour s'imposer aux populations locales, aurait transformé sa présence en une implantation véritable sous forme d'une série de forteresses, les epiteichismata mentionnés par Strabon (IV, 1, 5) qui auraient alors constitué des positions avancées pour protéger l'espace maritime de Massalia.

Ce modèle est construit non seulement à partir des textes mais aussi à partir du cas particulier d'Olbia de Provence, aujourd'hui la mieux connue des fondations massaliètes sur le plan archéologique (Bats 2004, p. 62). Antipolis lui serait donc contemporaine et Nikaia n'apparaîtrait qu'un peu plus tard, au III' ${ }^{\mathrm{e}}$ s. av. J.-C.

Pour Antipolis, depuis les fouilles préventives de la place Mariéjol (2009), la date du IV'e s. av. J.-C. est avancée moins sur la base de l'accroissement des importations 
massaliètes sur le rocher à cette époque (plus de $80 \%$ des céramiques depuis le $\mathrm{VI}^{\mathrm{e}} \mathrm{s}$. av. J.-C.) que sur celle d'un changement des pratiques alimentaires traduit par l'augmentation des récipients individuels en céramique tournée pour absorber les aliments (bols/écuelles et assiettes) (Bats 2011, p. 143).

Quant à la date de fondation de Nikaia, placée par l'historiographie vers le milieu du $\mathrm{III}^{\mathrm{e}} \mathrm{s}$., elle est déduite, par manque de données archéologiques, du témoignage de Polybe (XXXIII, 8-10), selon lequel Rome entreprit en 154 une expédition pour secourir les habitants d'Antipolis et de Nikaia assiégés par les Ligures Déciates et Oxybiens. C'est là sans aucun doute la première mention textuelle de Nikaia car, avant Polybe, Nikaia est absente des sources littéraires, en particulier des périples : elle n'apparaît ni dans la Périégèse du Pseudo-Scymnos (dont la source la plus ancienne remonte à Timée, mort v. 256), ni dans le Périple de Scylax, daté au plus tard au IVes.

Les modernes ont donc fixé la fondation de Nikaia, par déduction, au plus tôt dans le courant du $\mathrm{III}^{\mathrm{e}} \mathrm{s}$. av. J.-C. et en ont ainsi fait le rejeton ultime et tardif de Massalia ${ }^{9}$. On a voulu aussi voir une confirmation de cette date tardive dans les fouilles de la colline du Château par F. Benoit, selon qui le pourcentage de céramique non tournée fléchirait nettement entre le $\mathrm{III}^{\mathrm{e}}$ et le $\mathrm{II}^{\mathrm{e}}$ s. av. J.-C. Mais, seule, une véritable fouille stratigraphique pourra valider une telle thèse car, nous l'avons $\mathrm{vu}$, la documentation issue des fouilles des années 1970, ne peut faire l'objet de statistiques fiables ni conduire à des conclusions d'une telle portée.

Ajoutons que l'argument ex absentia fondé sur les sources littéraires est dangereux et qu'il convient d'admettre au contraire que, dans la chronologie de Nikaia, seul le terminus ad quem de 154 av. J.-C. peut être tenu pour certain et que, seule, l'archéologie sera susceptible à l'avenir de dater les phases antérieures de l'occupation de Nikaia.

La prudence est en effet de mise compte tenu de l'attestation d'une quantité significative d'importations méditerranéennes sur la colline du Château à Nice dès le $2^{\mathrm{e}}$ quart $\mathrm{du} \mathrm{VI}{ }^{\mathrm{e}} \mathrm{s}$, , même si, bien évidemment, une activité commerciale n'implique pas une fondation. En effet, dans l'état actuel des connaissances, la céramique non tournée domine dans le matériel archéologique du I ${ }^{\text {er }}$ âge du Fer et semble correspondre non pas à un établissement grec, mais bien plutôt à un habitat indigène de hauteur en relation avec le commerce maritime à partir du VI ${ }^{\mathrm{e}} \mathrm{s}$. av. J.-C. Dans ces conditions, l'hypothèse de M. Bats selon laquelle Nice présente, à l'âge du Fer, un

9 Sur ce débat, cf. Mercuri 2008. profil proche de celui du rocher d'Antibes est loin d'être infondée : comme à Antibes, on aurait affaire à Nice à un habitat indigène installé sur le promontoire, doublé (ou bien remplacé ?) dans un second temps par un établissement massaliète implanté quant à lui dans la plaine, près de l'embouchure du Paillon, selon une topographie plus conforme à celle des villes grecques (Bats 1990) ${ }^{\mathbf{1 0}}$.

La reconstruction historique qui fait de Nikaia une fondation massaliète du $\mathrm{III}^{\mathrm{e}} \mathrm{s}$. a connu de nombreux développements, appuyés notamment sur la théorie du binôme Antipolis / Nikaia. Depuis J. Ducat (1982), la recherche sur Antibes et sur Nice s'est en effet développée sur le thème de la dualité et, pour mieux dire, de la gémellité des deux fondations. Selon J. Ducat, l'approche comparée se justifie parce que les deux fondations «se présentent comme un couple presque inséparable », dans l'espace et le temps (Ducat 1982, p. 89), et que c'était là aussi la perception antique puisque les textes ne nomment jamais l'une sans l'autre : situées de part et d'autre du Var, elles sont toutes deux des forteresses massaliètes ; et toutes deux assiégées par les Ligures au même moment, elles doivent leur sauvegarde commune à l'intervention de Rome. La toponymie, bien entendu, n'est pas étrangère à cette vision duelle puisqu'Antipolis est étymologiquement la «ville d'en face »: de ce fait, Nikaia s'impose très naturellement comme l'autre terme du binôme géographique (Ducat 1982 ; Gras 2003), même si on a aussi supposé, dans une vision plus micro-géographique, qu'Antipolis pourrait avoir été nommée en référence à l'établissement protohistorique déjà implanté sur le rocher homonyme (Bats 1990). On a cependant souligné récemment les conséquences historiques de cette interprétation (Mercuri 2008) : si Antipolis tire son nom de sa position géographique par rapport à Nikaia, il faut en conclure en toute logique soit qu'Antipolis a été fondée après Nikaia, soit que les deux fondations massaliètes sont au moins aussi anciennes (IVe s., selon le modèle de M. Bats), et, dans ces conditions, que la chronologie basse de Nikaia n'est pas recevable. Nous l'avons vu, le corpus des céramiques importées issu des fouilles Benoit va dans ce sens : les données actuelles indiquent que la colline du Château, comme le rocher d'Antibes, commence à participer aux échanges maritimes dans le premier quart du $\mathrm{VI}^{\mathrm{e}} \mathrm{s}$. et que les liens économiques sont étroitement établis avec Marseille dès le début du Ve s. (Mercuri 2008).

10 Cependant, les tentatives d'identification d'un réseau urbain antique dans le centre historique de Nice relèvent encore de l'hypothèse de travail. Cf. St. Morabito, Localisation de l'établissement de Nikaia, Nice (Alpes-Maritimes). Histoire \& mesure, XVIII, 1/2, 2003, p. 39-71. 


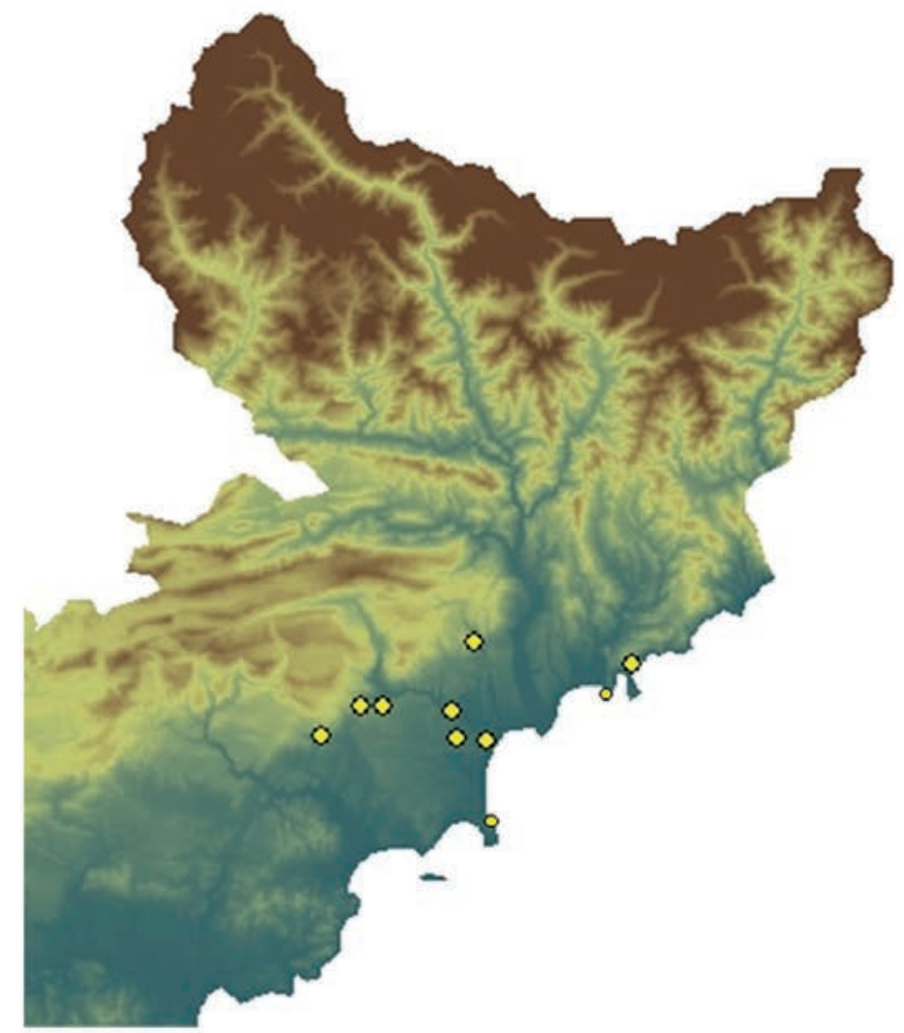

Amphores étrusques

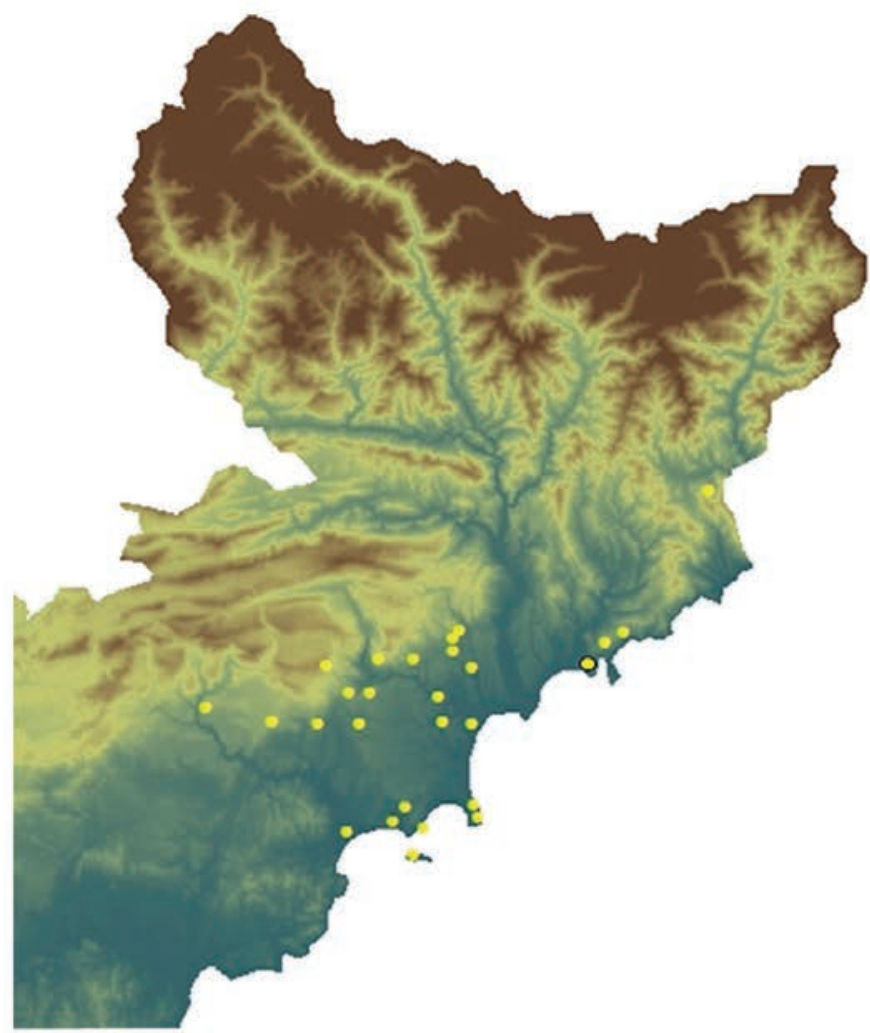

Amphores massaliètes

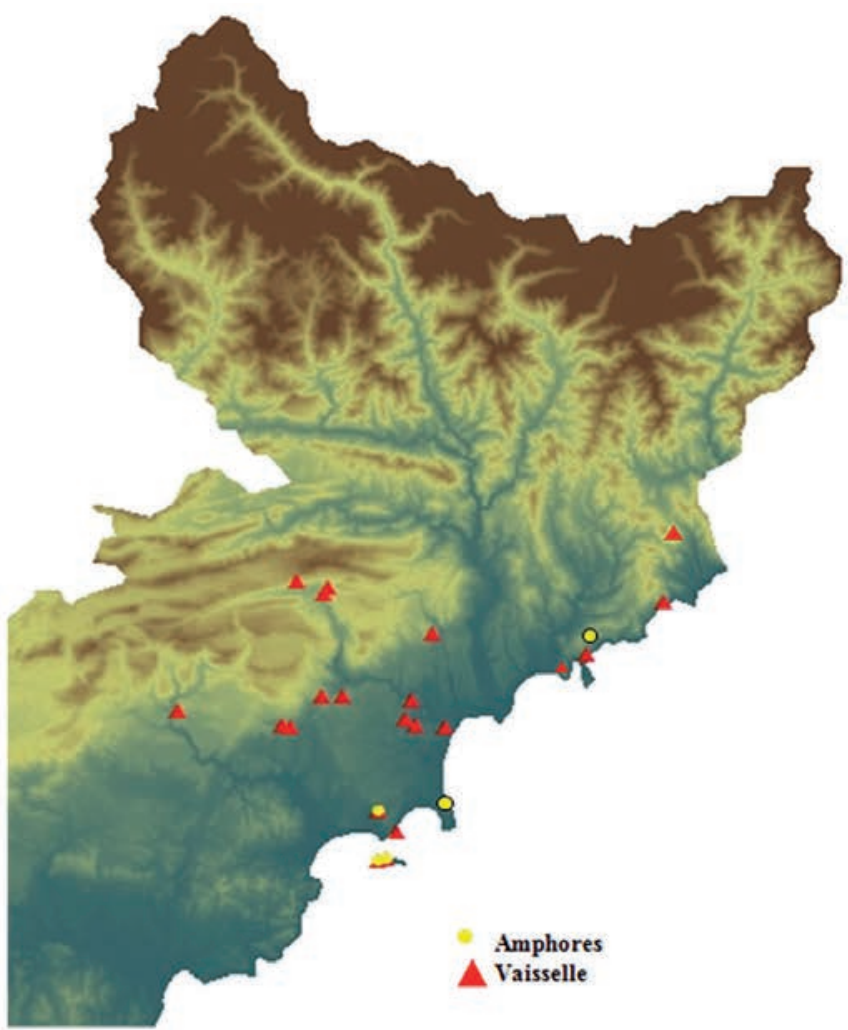

Importations céramiques grecques (sauf massaliètes)

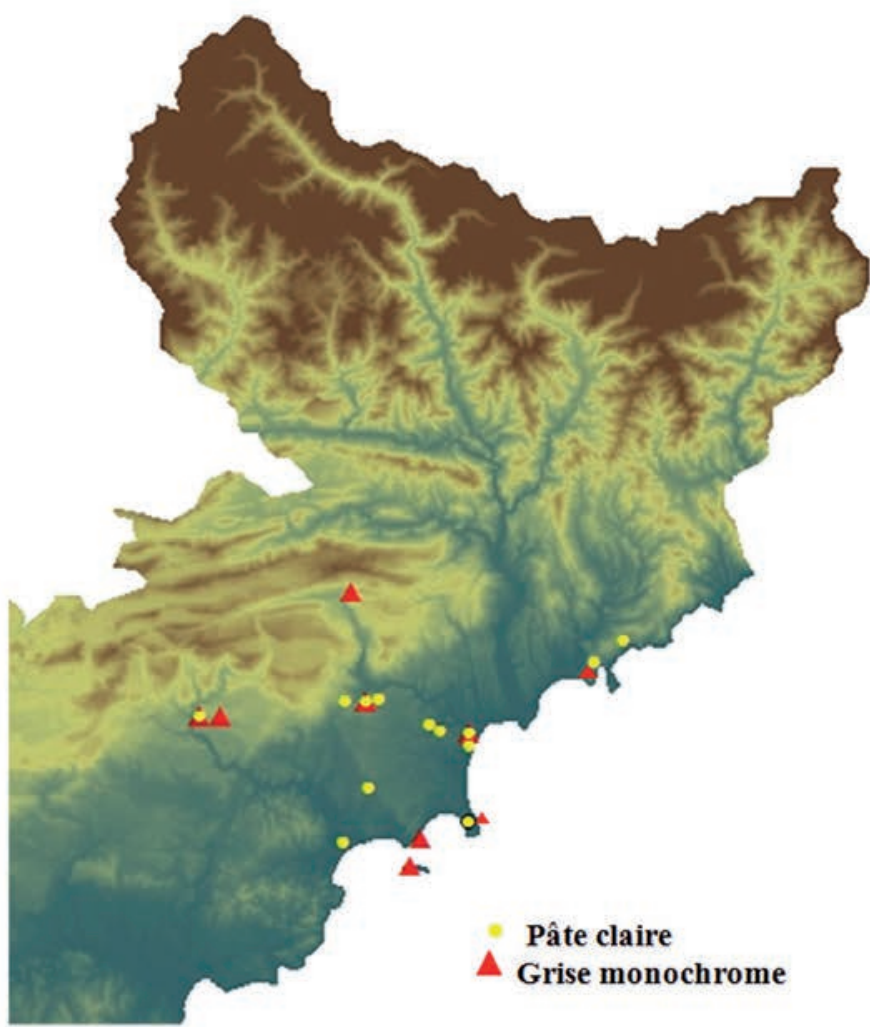

Céramique fine massaliète

Fig. 5. Cartographie des importations étrusques et grecques en Provence orientale par type de céramique. 


\begin{tabular}{|c|c|}
\hline Commune & Importations étrusques ou grecques \\
\hline Antibes & $\begin{array}{l}\text { Amphore étrusque ; amphore massaliète ; grise monochrome ; pâte } \\
\text { claire massaliète ; céramique ionienne ; céramique attique }\end{array}$ \\
\hline Bar-sur-Loup (plateau de la Sarrée) & Amphore étrusque ; amphore massaliète ; pâte claire massaliète \\
\hline Beaulieu-sur-mer & Bucchero nero \\
\hline Cannes (butte de Saint Cassien, île Sainte-Marguerite) & $\begin{array}{l}\text { Amphore massaliète ; grise monochrome ; pâte claire massaliète ; } \\
\text { céramique attique }\end{array}$ \\
\hline Châteauneuf de Grasse & Amphore massaliète \\
\hline Èze & Amphore massaliète ; pâte claire massaliète \\
\hline Gourdon & Amphore massaliète \\
\hline Grasse & Amphore étrusque ; amphore massaliète \\
\hline Gréolières & Grise monochrome \\
\hline Mougins & Pâte claire massaliète \\
\hline Nice (colline du Château) & $\begin{array}{l}\text { Amphore étrusque ; amphore corinthienne b ; amphore massaliète ; } \\
\text { grise monochrome ; pâte claire massaliète ; céramique ionienne ; } \\
\text { céramique attique }\end{array}$ \\
\hline Roquefort-les-Pins & Amphore étrusque ; amphore massaliète \\
\hline Le Rouret (Camp du Bois) & $\begin{array}{c}\text { Amphore étrusque ; amphore massaliète ; grise monochrome ; pâte } \\
\text { claire massaliète }\end{array}$ \\
\hline Saint-Cézaire-sur Siagne (Camp-Long) & Amphore massaliète ; grise monochrome ; pâte claire massaliète \\
\hline Sospel & amphore massaliète \\
\hline Spéracèdes & amphore massaliète \\
\hline Tourrettes-sur-Loup & amphore massaliète \\
\hline Vallauris (Le Pezou) & Amphore ionienne ; amphore massaliète ; grise monochrome \\
\hline Vence (Baou des Noirs) & Amphore étrusque ; amphore massaliète \\
\hline Villefranche-sur-Mer & Amphore massaliète \\
\hline Villeneuve-Loubet (Saint-Andrieu) & $\begin{array}{c}\text { Amphore étrusque ; amphore massaliète ; grise monochrome ; } \\
\text { pâte claire massaliète ; céramique attique }\end{array}$ \\
\hline
\end{tabular}

Fig. 6. Tableau des grandes catégories de céramiques étrusques et grecques découvertes sur les communes des Alpes-Maritimes (recensement 2012).

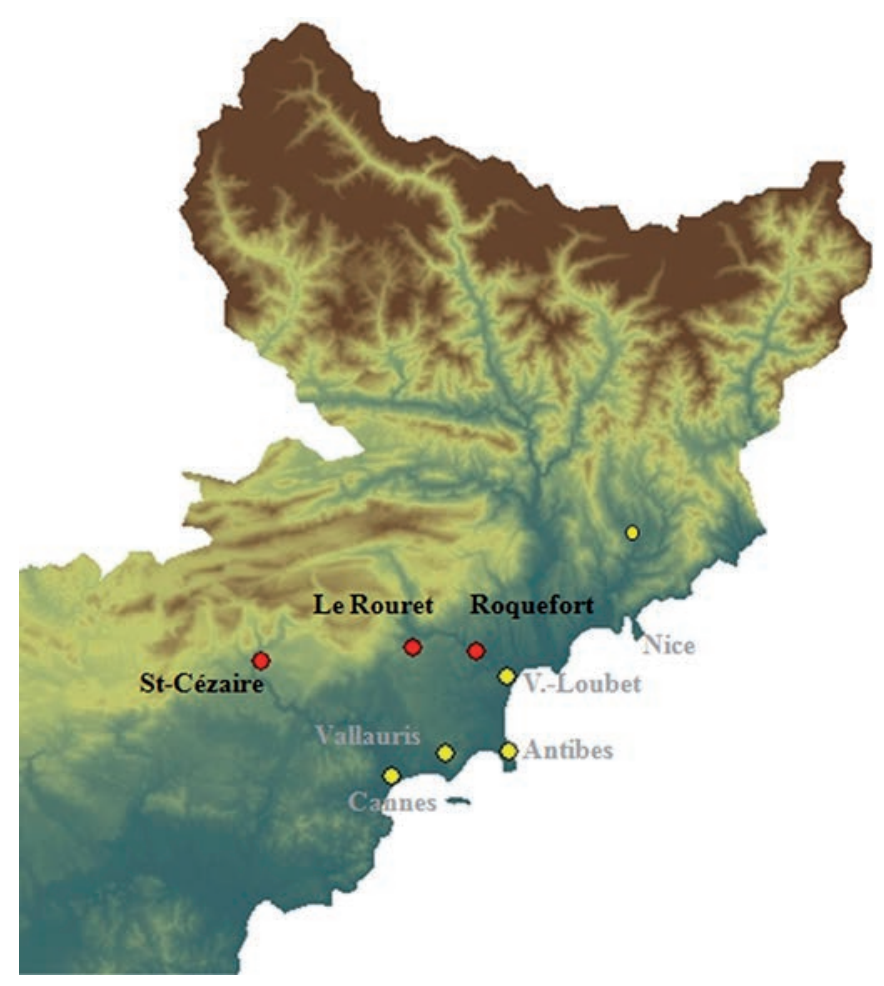

Fig. 7. Habitats fortifiés de Roquefort-les-Pins et du Rouret, dans la vallée du Loup, et de Saint-Cézaire dans la vallée de la Siagne, qui marquent les voies de liaison habituelles entre le littoral et l'intérieur. 
On le voit, la chronologie basse de Nikaia pose plus de questions qu'elle n'en résout. Elle a été également remise en question par M. Gras, qui a suggéré de mettre en relation le nom de Nikaia avec une possible réorganisation du secteur du Var après la bataille d'Alalia (Gras 2003). Dans cette hypothèse, si l'on suit le Pseudo-Skylax $(4,1)$ qui fait débuter la Tyrrhénie à Antion (Antipolis), le nom de Nikaia pourrait être la traduction grecque d'un nom étrusque équivalent visant à commémorer une victoire des Étrusques de Tyrrhénie sur les Grecs de Ligystique, tout comme Nikaia aurait été aussi, en Corse, le nom par lequel les Étrusques auraient rebaptisé le site grec d'Alalia après leur victoire sur les Phocéens, v. 540 av. J.-C. (d'après Diodore de Sicile V, 13 corrigé). Ce serait donc de cette époque que daterait le binôme Antipolis - Nikaia, les deux établissements se trouvant alors de part et d'autre de la frontière entre Grecs et Étrusques marquée par le Var (Gras 2005, p. 14). Mais rien pour l'instant, dans les données archéologiques de Nice, ne vient corroborer cette proposition. Et pourtant, seule, dans l'avenir, l'archéologie sera en mesure d'apporter des éléments nouveaux sur les fondations massaliètes et sur les rapports de la Provence orientale avec la Méditerranée.

\section{Bibliographie}

Arcelin 1986 : ARCELIN (P.) - Le territoire de Marseille grecque dans son contexte indigène. In : Bats (M.), Tréziny (H.) dir., Le territoire de Marseille. Actes de la table ronde d'Aix-en-Provence (1985), Aix-en-Provence, 1986 (Ét. Mass. 1), p. 43-104.

Arcelin, Bats, Pollino 1984 : ARCELIN (P.), BATS (M.), POLLINO (É.) Rapport des fouilles de la Chapelle du Saint-Esprit à Antibes. Campagnes 1981-1984 (inédit).

Arcelin-Pradelle 1984 : ARCELIN-PRADELLE (C.) - La céramique grise monochrome en Provence, RAN suppl. 10, Paris, CNRS, 1984.

Bats 1989 : BATS M. - La Provence protohistorique. In : Février (P.A.) éd., La Provence des origines à l'an Mil, Rennes, p. 169-256.

Bats 1990 : BATS M. - Antibes. In : Voyage en Massalie. 100 ans d'archéologie en Gaule du Sud, Marseille, 1990, p. 221-222.

Bats 1990a : BATS M. - La diffusion des amphores massaliètes en Provence orientale. In : BATS (M.) dir., Les amphores de Marseille grecque. Chronologie et diffusion. Actes de la table ronde de Lattes (11 mars 1989), Aix-en-Provence, 1990 (Ét. Mass. 2), p. 207-213.

Bats 1992 : BATS M. - Marseille, ses colonies et les relais indigènes du commerce massaliète en Gaule méridionale. In : Bats (M.), Bertucchi (G.), Congés (G.) et Tréziny (H.) dir., Marseille grecque et la Gaule, Actes des colloques de Marseille (1990), Aix-en-Provence, 1992, (Ét. Mass. 3), p. 263-278. Bats 1998 : BATS M. - Marseille archaïque. Étrusques et Phocéens en Méditerranée nord-occidentale. MEFRA 110-2, 1998, p. 609-633.

Bats 2004 : BATS (M.) - Les colonies massaliètes de Gaule méridionale : sources et modèles d'un urbanisme militaire aux IVe-III ${ }^{\mathrm{e}} \mathrm{s}$. av. J.-C. In : Agusta-Boularot (S.) dir., Lafon (X.) dir., Des Ibères aux Vénètes, Rome, Collection ÉFR 328, p. 51-64.

Bats 2011 : BATS (M.), Le matériel céramique protohistorique (fin VI ${ }^{\mathrm{e}} \mathrm{s} . /$ $\mathrm{I}^{\text {er }} \mathrm{s}$. av. n. è.) et Le faciès céramique des phases 1 à 4 . In : Thernot (R.) (dir.), Alpes-Maritimes, Antibes, Place Mariéjol et montée Dor de La Souchère. Du village protohistorique à la ville romaine, Inrap Méditerranée, Rapport de fouille, 2011, p. 85-100 et 143 (inédit).

CAG 06, 2010 : LAUTIER (L.), ROTHÉ (M.-P.) et al. - Carte archéologique de la Gaule. Les Alpes-Maritimes 06, Paris, 2010.

De Marinis 2004 : DE MARINIS (R. C.) - I Liguri tra $\mathrm{VIII}^{\circ} \mathrm{e} \mathrm{V}^{\circ}$ secolo a.C. In : I Liguri. Un antico popolo europeo tra Alpi e Mediterraneo, Gênes, Palazzo ducale, 2004, p. 197-211.

Ducat 1982 : DUCAT (J.) - Antipolis et Nikaïa : implantations et activités économiques. Ktema 7, 1982, p. 89-99.

Gantès 1992 : GANTÈS (L.-F.) - L'apport des fouilles récentes à l'étude quantitative de l'économie massaliète. In : Bats (M.), Bertucchi (G.), Congés (G.) et Tréziny (H.) dir., Marseille grecque et la Gaule, Actes des colloques de Marseille (1990), Aix-en-Provence, 1992, (Ét. Mass. 3), p. 171-178

Gazenbeek 2003 : GAZENBEECK (M.) COORD. - P.C.R. des enceintes de hauteur dans les Alpes-Maritimes, D.F.S. décembre 2003, Sophia-Antipolis, CEPAM, $344 \mathrm{p}$.

Gazenbeek 2004 : GAZENBEECK (M.) - Les oppida de la Ligurie occidentale : état de la question. In : Agusta-Boularot (S.), Lafon (X.) (éd.), Des Ibères aux Vénètes, Rome, 2004, p. 251-275.

Gazenbeek 2006 : GAZENBEECK (M.) - Le mobilier de l'enceinte de Camp Long à Saint-Cézaire-sur-Siagne (06). Mém. IPAAM 48, 2006, p. 29-38.

Gras 2000 : GRAS M. - Les Étrusques et la Gaule méditerranéenne. In : Mailhac et le premier âge du Fer en Europe occidentale. Hommages à O. et J. Taffanel (Carcassonne 1997), Lattes, 2000, p. 229-241.

Gras 2003 : GRAS M. - Antipolis et Nikaia. Les ambiguïtés de la frontière entre la Massalie et l'Italie. In: Peuples et territoires en Gaule méditerranéenne. Hommage à Guy Barruol, Montpellier, 2003 (RAN suppl. 35), p. 241-246.

Gras 2004 : GRAS M. - Les Étrusques vus de la Gaule. Échanges maritimes et implantations. DAM 27, 2004, p. 213-235.

Gras 2005 : GRAS M. - Parcours emporiques en Ligurie. In : Aei mnēstos : miscellanea di studi per Mauro Cristofani, Prospettiva (Florence), suppl. 2, 2006, p. 212-220.

Janin, Py 2012 : JANIN (TH.), PY (M.) - Grecs et Celtes en Languedoc. In : Hermary (A.), Tsetskhladze (G.R.), From the pillars of Hercules to the footsteps of the Argonauts, Louvain-Paris-Walpole (Ma), 2012, p. 141-162.

Latour 1985 : LATOUR (J.) - L'oppidum du Baou des Noirs à Vence (A.-M.). DAM 8, 1985, p. 9-24.

Latour 2005 : LATOUR (J.) - Le camp du Bois au Rouret (06) : étude du matériel de la collection Paul Goby en dépôt au musée de Grasse. Mém. IPAAM 47, 2005, p. p. 57-73.

Latour 2005a : LATOUR (J.) - Un lot d'objets en fer de la collection Paul Goby du musée de Grasse (06), p. 233-238.

Lautier 2010 : LAUTIER (L.) - Les systèmes de peuplement des Préalpes de Grasse de l'âge du Bronze à l'Antiquité tardive : apport de l'analyse factorielle à une étude de cas, Thèse de doctorat, Université de Nice SophiaAntipolis, 2010 (inédit).

Lautier, Lepère 2007 : LAUTIER (L.), LEPÈRE (C.) - Rapport de prospection-inventaire des vallées du Loup, de la Cagne et du Malvan. Commune de Roquefort-les-Pins, Valbonne, CEPAM UMR6130, 2010, 80 p. (inédit).

Maggiani 2006 : MAGGIANI (A.) - Rotte e tappe nel Tirreno settentrionale. In : Gli Etruschi da Genova ad Ampurias. Atti del XXIV convegno di studi etruschi e italici, Marseille-Lattes, 2002, Pise 2006, p. 435-453.

Mazière 2003 : MAZIÈRE (F.) - Le Bousquet (Agde). Une nécropole du premier âge du Fer. In : Archéologie en pays d'Agde. Bilan des recherches récentes. Catalogue de l'exposition. Agde, GRAA, 2001, p. 24-27.

Mele 1979 : MELE (A.) - Il commercio greco arcaico. Prexis ed emporie, Naples, 1979.

Mele 1986 : MELE (A.) - Pirateria, commercio e aristocratizia : replica a Benedetto Bravo. DHA, 12, 1986, p. 67-109

Melli 1998 : MELLI (P.) - Il recupero della tomba di Rapallo : nuovi dati sul popolamento del Tigullio tra la fine del VII e gli inizi del VI sec. a.C. Rivista di studi liguri, LXII, 1996, p. 95-114.

Mercuri 2008 : MERCURI (L.) - La Ligurie occidentale et la Méditerranée durant le premier âge du Fer. Bulletin du musée d'anthropologie préhistorique de Monaco, suppl. 1, 2008, p. 271-273. 
Mercuri 2010 : MERCURI (L.) - La colline du Château à Nice d'après les importations pré-italiques (fin VII ${ }^{\mathrm{e}} \mathrm{s}$. -fin IVe s. av. J.-C.). In : LAUTIER (L.), ROTHÉ (M.-P.) et al., Carte archéologique de la Gaule. Les Alpes-Maritimes 06, Paris, 2010, p. 539-541.

Mercuri 2013 : MERCURI (L.) - Les céramiques d'importation de l'âge du Fer (VI'-IVe s. av. J.-C.). In : Bouiron (M.) (dir.), Nice, La colline du Château. Histoire millénaire d'une place forte, Nice, 2013, p. 245-250, 290.

Nickels et al. 1989 : NICKELS (A.), MARCHAND (G.), SCHWALLER (M.), DUDAY (H.) COLlAB., COLUMEAU (P.) COLlAB. - Agde, la nécropole du premier âge du Fer. Paris, CNRS, 1989, 498 p. (Revue archéologique de Narbonnaise. Supplément 19)

Pomey, Long 1992 : LONG (L.), POMEY (P.) - Les premiers échanges maritimes du midi de la Gaule du $\mathrm{VI}^{\mathrm{e}}$ au $\mathrm{III}^{\mathrm{e}} \mathrm{s}$. à travers les épaves. - In : Bats (M.), Bertucchi (G.), Congés (G.), Tréziny (H.) dir., Marseille grecque et la Gaule, Actes des colloques de Marseille (1990), Aix-en-Provence, 1992, (Ét. Mass. 3), p. 189-198.

Vindry 1978 : VINDRY (G.) - Un siècle de recherches préhistoriques et protohistoriques en Provence orientale (1875-1975). DAM 1, 1978, p. 7-76. 



\section{Genova al centro dei commerci massalioti lungo le rotte dell'Alto Tirreno}

\section{Cristina Nervi}

\section{Résumé}

Situé le long des voies commerciales de la mer Tyrrhénienne, Gênes est un port d'intérêt majeur tant pour sa situation centrale au sein de la côte ligure, que pour son rôle de médiateur entre l'arrière-pays et les établissements côtiers.

Il s'agira ici d'analyser certains contextes céramiques qui présentent des éléments massaliotes. On s'attachera notamment à l'étude des productions amphoriques.

Au cœur d'un riche panorama commercial, la cité apparaît liée au commerce massaliote. Il sera ainsi particulièrement intéressant d'analyser le rôle du centre portuaire pris en tenaille entre Massalia et l'Étrurie, ainsi que les implications et les conséquences induites par ces deux pôles sur les échanges au sein de la cité, et plus largement, au sein des routes maritimes.

Mots-clés : Gênes, Mer Ligure, commerce, Massalia, Étrurie

\section{Abstract}

Genoa is one of the more important ports along the routes of the Tyrrhenian Sea, because of its central position on the Ligurian coast and because of its intermediary role between the hinterland and the coastal settlements.This paper deals with some pottery assemblage, that present Marseillaise attestations, considering particularly Marseillaise amphorae.

This paper will present a number of pottery assemblages where Marseille products, especially Marseille amphorae, are attested.

Genoa's trade links with Marseille are, however, part of a more complex commercial panorama. It is interesting to investigate just what was the role of this centre, located between Massalia and Etruria, and the extent to which these two poles had an effect on the development of Genoa within the wider context of North Western Mediterranean shipping routes.

Keywords: Genoa, Ligurian Sea, trades, Massalia, Etruria 


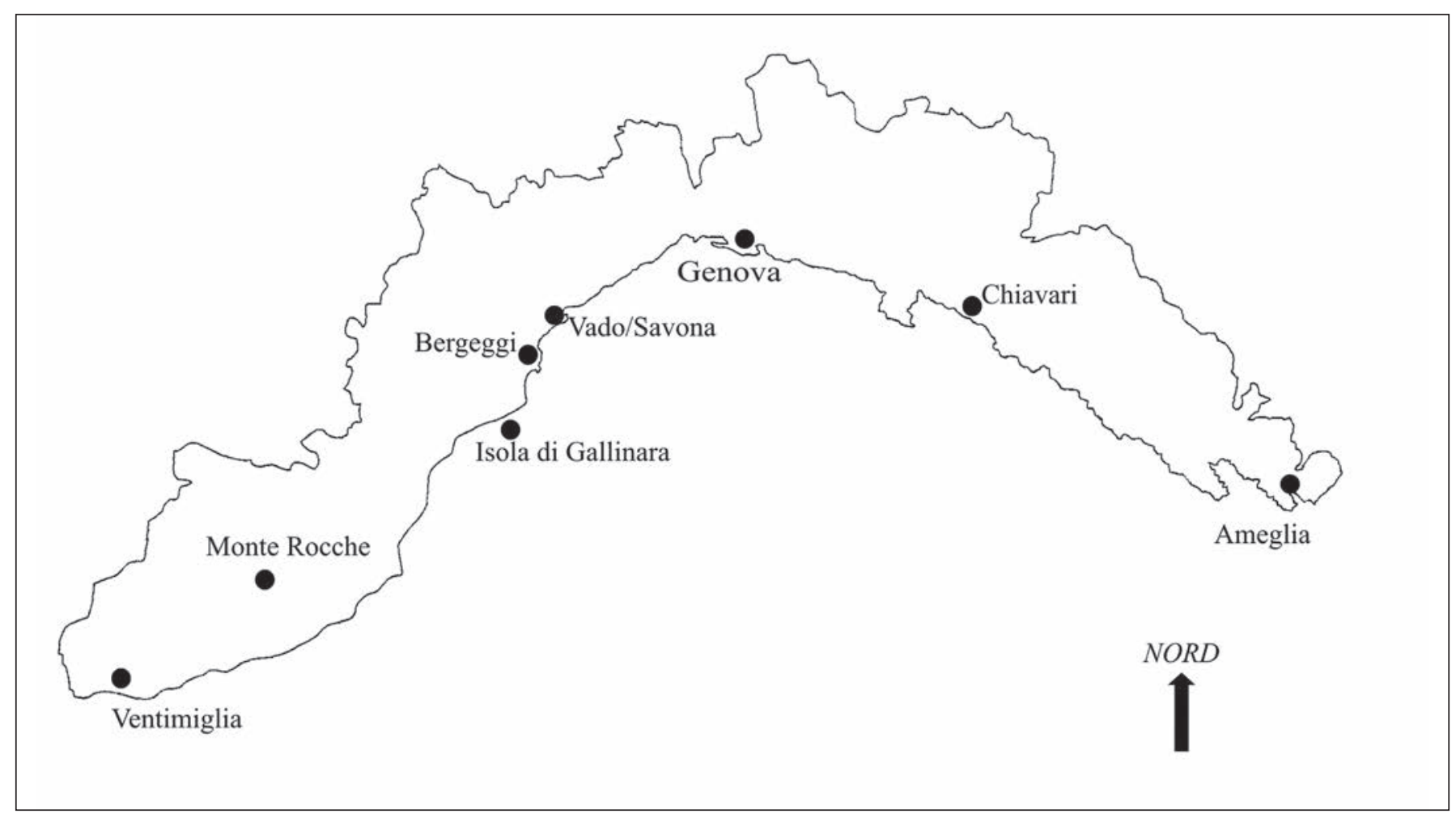

Fig. 1. Siti nominati in testo (elaborazione grafica dell'autore su carta tratta da Giannattasio 2007, fig. 47).

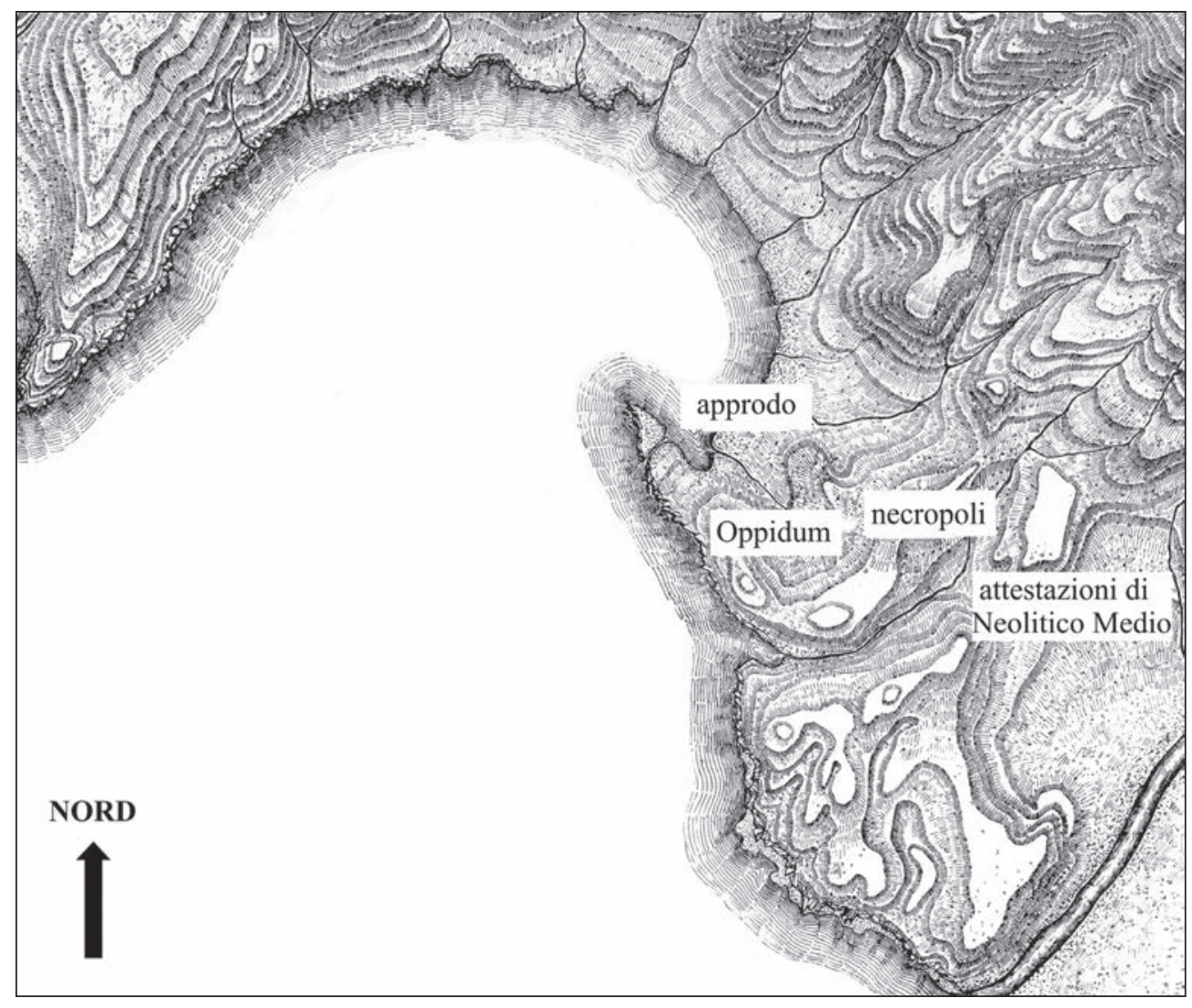

Fig. 2. Attestazioni archeologiche a Genova (elaborazione grafica dell'autore su carta tratta da Barbieri 1938, tav.1). 


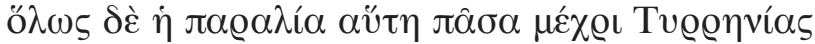

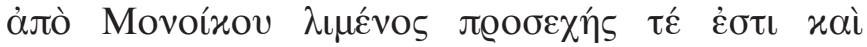

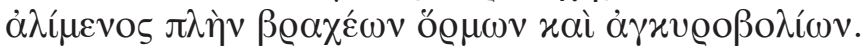

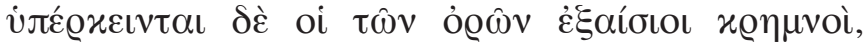

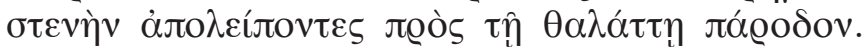

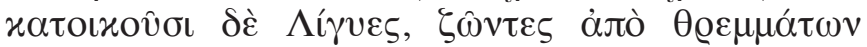

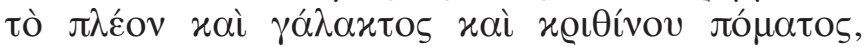

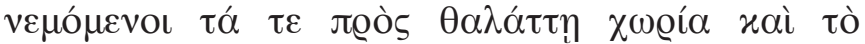

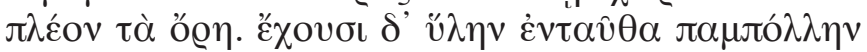

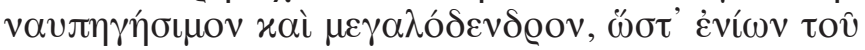

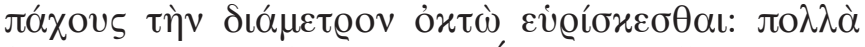

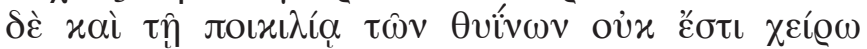

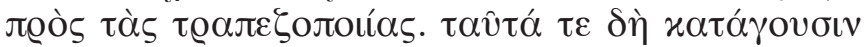

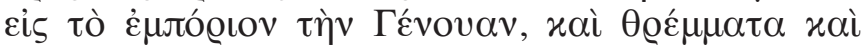

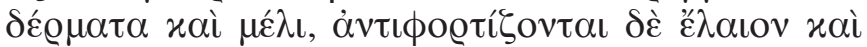

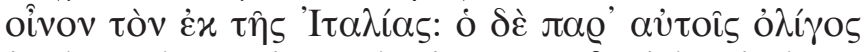

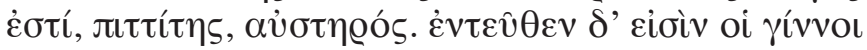

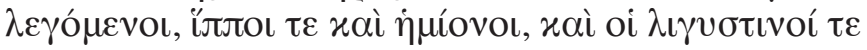

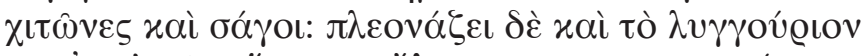

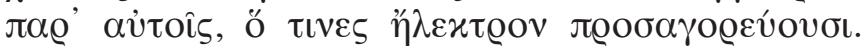

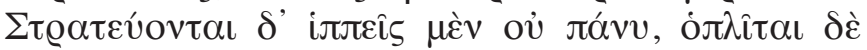

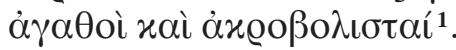

Strabone IV, 6, 2 (testo edito da F. Lasserre, PUF 1966).

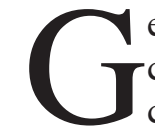
enova $^{2}$ per la sua posizione, affacciata sulla costa ai piedi dell'Appennino Ligure (fig. 1), costituisce il sito naturale per un emporio misto, legato a rotte commerciali verso la costa tirrenica, la Gallia e l'Iberia ed a collegamenti montani con la Pianura Padana, attraverso quella che sarà la Via Postumia (Melli 2004c, p. 167).

\footnotetext{
1 "In generale tutta questa costa da Monaco fino alla Tirrenia è esposta ai venti e senza porti, eccetto piccole rade e ancoraggi. La sovrastano, poi, gli enormi dirupi dei monti, lasciando uno stretto passaggio vicino al mare. Vi abitano i Liguri che vivono per lo più della carne dei greggi, di latte e di una bevanda di orzo ed occupano le terre vicino al mare e specialmente i monti. Hanno qui ricche foreste che forniscono legname per la costruzione delle navi e con alberi così grandi che il tronco di alcuni raggiunge il diametro di otto piedi; molti di questi, poi, anche per la varietà delle venature, non sono inferiori al legno di cedro per la fabbricazione delle tavole. Portano all'emporio di Genova questi legnami, animali, pelli, miele, ricevono in cambio olio d'oliva e vino italiano; il loro vino, infatti, è scarso, resinato e aspro. Di qui provengono i cosiddetti ginnoi - cavalli e muli - le tuniche liguri e i saghi. Presso di loro abbonda il lingurion, che alcuni chiamano ambra. Non sono affatto abili nelle campagne militari, come cavalieri, ma sono abili opliti e veliti" (traduzione tratta da Melli 2007, p. 24).

2 Questo contributo è dedicato al Professor Giovanni Leonardi (Università degli Studi di Padova) con cui ho avuto l'onore di condividere le prime esperienze di studio e la "passione" per la ceramica genuate.
}

Abitata dai Liguri, popolo definito audace, che produce legname, pelli, alleva resistenti animali da soma ${ }^{3}$, commercia corallo ed impara dagli Etruschi l'arte di lavorare i metalli.

La città venne coinvolta direttamente all'interno del fervore - legato alla migrazione di popoli, genti ed allo scambio di merci e materie prime - che accompagnò il Tirreno soprattutto a partire dall'età del Ferro.

La storia della città emerge da lacerti di indagini archeologiche (fig. 2), che sono stati sommersi dalla forte urbanizzazione del centro attuale, dal livellamento della morfologia naturale del territorio su cui sorge l'abitato, tramite l'asporto ed il riporto di massicce quantità di terreno. Tali azioni umane susseguitesi, in particolar modo nel corso del ' 900 , consentono una difficile lettura e comprensione dei rinvenimenti antichi, che a tratti emergono - spesso per mezzo di scavi urbani legati al progresso cittadino - e lasciano puntiformi testimonianze del passato arcaico. La ricostruzione diviene pertanto frutto di una meticolosa analisi dei dati archeologici che tenta di non tralasciare i minimi dettagli, data spesso la scarsa possibilità di indagini estese.

Tracce di frequentazione risalente al medio-neolitico (Del Lucchese 2010, p. 10-11) sono testimoniate nell'attuale sito della Stazione Ferroviaria di Genova Brignole, dove la vegetazione naturale veniva impiegata per l'alimentazione del bestiame allevato, come avvalorato dal rinvenimento di resti paleobotanici che attestano il taglio delle fronde per la nutrizione degli animali (Arobba, Caramiello 2010, p. 13-14). Nello stesso sito sono stati accertati resti di un muro afferibile all'età del Bronzo (Melli 2007, p. 26). Probabilmente l'insediamento genuate non era ancora costituito da un unico centro abitativo, ma da più nuclei sparsi in differenti aree della città, sulle pendici al di sopra di un approdo portuale.

Nell'ansa del Mandraccio, infatti, - ai piedi dell'attuale collina di Castello - sono emerse tracce di una possibile zona di approdo; gli strati individuati sono riconducibili ad un'area dal fondale basso, in cui le imbarcazioni trovavano probabilmente ricovero. I frammenti ceramici rinvenuti attestano reperti provenienti dall'area gallica, etrusca, punica ed egeo-anatolica (Melli 2007, p. 30). Si dimostra quindi che nel VII sec. a.C. Genova era già inserita lungo rotte che mettevano in collegamento l'Etruria con la Gallia e l'Iberia, già note e frequentate in epoca preistorica.

La città collocata in una naturale insenatura è sita al centro di approdi sia sulla costa di Levante (Chiavari), che su quella di Ponente (Vado).

3 Strabone IV 6, 2. 
Difficile tracciare le rotte seguite dalle imbarcazioni nell'Alto Tirreno: è possibile che le merci seguissero una navigazione per cabotaggio, seguendo nella fase più antica la costa e facendo scalo a Pisa, Ameglia (SP) - sito che cessa al sorgere dell'oppidum genuate -, Genova, Vado/Savona, Ventimiglia e viceversa.

La continuità delle rotte sino all'epoca romana ne testimonia l'imprescindibile caratteristica utilitaristica in un tipo di navigazione che non permetteva lo spingersi a lungo in mare aperto (Diodoro Siculo V, 39, 8).

Anche se una rotta - o quanto meno un collegamento - verso la Corsica e la Sardegna è confermata dalla presenza di reperti di anfore puniche, soprattutto del periodo tardo, definito ellenistico ${ }^{4}$.

Dato confermato anche dalle fonti (Liv. XXVIII, 46, 14), che in III sec. a.C. riportano del bottino depredato da una flotta punica in Etruria e della seguente cattura di Liguri Montani ${ }^{5}$ (Mastino 1985, p. 58).

I primi contatti con Massalia avvengono nel VI sec. a.C.: sono attestate precoci importazioni di anfore, come avvalorato dal rinvenimento presso 1'Isola Gallinara ${ }^{6}$ di una Bertucchi 2A (Giannattasio 2004, p. 11, n¹3; Spadea 2004, p. 392) e di ceramica a pasta grigia focese (Melli 2004a, p. 292).

La colonia focese rappresenta ${ }^{7}$ per i primi genuati un'area da cui probabilmente si importava soprattutto vino, anche se in percentuale minima ${ }^{8}$ rispetto a quello proveniente dall'Etruria.

Il legame con Massalia appare sorgere circa a metà del VI sec. a.C., ma permarrà debole a confronto di quello etrusco (Melli 2004a, p. 292), che si dimostra

4 La rotta verso la Sardegna è attestata dall'importazione di ossidiana già nel corso del Neolitico (Del Lucchese 2007, p. 66).

5 In un frammento dell' edictum de pretiis del 301 d.C. si riportano quattro rotte con partenza dalla Sardegna una delle cui destinazioni era forse proprio Genua - ERIM (K.T.), REYNOLDS (J.), The Copy 01 Diocletian's Edict on Maximum Prices lrom Aphrodisias in Caria. JRS, XL, 1970, p. 138 sg. fr. 4; GIACCHERO (M.), Edictum Diocletiani et collegarum de pretiis rerum venatium, integrum lere restitum e Latinis Graecisque Iragmentis, I. Genova, 1974, p. 224 cap. 35 , Il. 74-78.

6 L'Isola Gallinara è sita nel ponente ligure, di fronte all'attuale comune di Albenga (SV).

7 I contatti e gli scambi tra Genova e Massalia sono documentati sin dal periodo immediatamente successivo alla fondazione della colonia focese (Melli 2004d, p. 1).

8 L'introduzione della consunzione di vino all'interno di un gruppo sociale, in cui precedentemente tale abitudine non era prevista, potrebbe esser letta come un fenomeno di acculturazione e di assimilazione culturale (Dietler 2006, p. 229-249) nei confronti di società, o gruppi sociali, più complessi quali i Massalioti o gli Etruschi.

In generale i materiali archeologici rinvenuti risultano essere coerentemente contestualizzabili con quelli dell'area di Populonia, che appare -in questa fase- aver un legame preferenziale per le importazioni etrusche di Genova (Melli 2004d,p. 2). preponderante ${ }^{9}$, almeno sino al $\mathrm{V}$ sec. a.C. Per tali ragioni si ritiene che nei prodromi le merci massaliote fossero veicolate da vettori etruschi, che percorrevano l'Alto Tirreno, trovando in Genova un approdo sicuro nel percorso verso gli insediamenti gallici. Tale ipotesi potrebbe essere suffragata dalla presenza di centri quali Lattara. Non si affaccia l'ipotesi di legami diretti tra Genova e la colonia focese, almeno per questa fase più antica, ovvero le merci venivano trasportate da navi etrusche nella rotta di rientro da Occidente.

Anche le anfore greco-orientali e le ceramiche di importazione greca, potrebbero esser giunte a Genova per mezzo di vettori etruschi, che percorrevano l'Alto Tirreno, così come quelle dall'Etruria Meridionale e Settentrionale.

Genova sin dal suo primo ruolo di approdo diviene tappa obbligata per i naviganti che solcavano il Mar Ligure tra costa tirrenica e gallica e di conseguenza entra in contatto con merci e prodotti provenienti anche da aree molto distanti tra loro.

Proprio a fine VI sec. a.C., possono essere accertate le prime frequentazioni della collina di Castello (Melli 2004a, p. 287); forse in tale epoca vi sorgeva un'area sacra connessa a culti non indigeni di divinità protettrici degli stranieri, che frequentavano abitualmente l'approdo ai piedi della collina (Melli 2007, p. 63).

Il fenomeno troverebbe riscontro nella quantità di prodotti ceramici alloctoni individuati nelle fasi di frequentazione genuate di tale periodo ${ }^{\mathbf{1 0}}$.

Alla fine del VI sec. a.C., Genova è segnata dall'edificazione dell'oppidum pre-romano, che si estendeva per meno di un ettaro, in zona sopraelevata. In tale fase si assiste alla modellazione della sommità della collina di Castello ed alla creazione di un insediamento abitativo, costituito da abitazioni con zoccolo in muri di pietra ed alzato in legno (Mannoni 2010, p. 39-40).

Nasce l'oppidum pre-romano, che intraprende tra le proprie attività la lavorazione dei metalli (Melli 2004a, p. 287 e 293) ${ }^{11}$, provenienti dall' area di Populonia (Melli 2007 , p. 55) e da giacimenti di piombo della zona dell'alessandrino nel sud del Piemonte attuale. In tale attività

9 Le anfore etrusche costituiscono circa 1'80\% del totale delle importazioni. Nello scavo di Santa Maria in Passione si raggiunge l'86\% (Melli 2006, p. 617).

10 Tra i materiali rinvenuti sono attestati reperti ceramici di area Corinzia, coppe ioniche, anfore e ceramica comune di produzione etrusca (Melli 2004d, p. 1).

11 Sono stati rinvenuti scarti riferibili all'ultima fase di lavorazione prima della produzione dell'oggetto (Melli 2006, p. 619; Melli 2004b, p. 328). Anche nel castellaro di Bergeggi è attestata la lavorazione dei metalli a partire da metà V sec. a.C. (Melli 2004c, p. 168; Giannattasio, Odetti 2009, p. 42-44 ). 
potrebbe essere compresa la produzione di fibule (Melli 2004b, p. 342).

A metà circa del V sec. a.C. l'oppidum si dotò anche di una cinta muraria a doppia cortina (Melli 2007, p. 39), a difesa della zona abitativa (Melli 2004a, p. 288) ${ }^{\mathbf{1 2}}$.

$\mathrm{Nel}$ corso degli scavi succedutisi a più riprese nell'area dell'insediamento pre-romano e nelle sue immediate vicinanze ${ }^{13}$, sono emersi dati che permettono la ricostruzione dei possibili contatti commerciali degli abitanti insediatisi nell'area.

Nell'oppidum presumibilmente convivevano nuclei appartenenti ad etnie di differente origine - come si può dedurre dai corredi rinvenuti nella necropoli - ligure ed etrusca (Melli 2004b).

La nascita di questo centro costituisce una svolta nella storia della città, che diviene uno degli approdi lungo le rotte dell'Alto Tirreno. Le merci - provenienti anche dalla Magna Grecia ${ }^{14}$, dalla Grecia stessa, destinate ai mercati d'Occidente - giungono nel porto dell'emporio, lasciando tracce del loro utilizzo nelle abitazioni private, in cui sono state rinvenute inoltre anfore massaliote, che evidenziano i contatti con la colonia focese.

Nel V sec. a.C. le importazioni testimoniano ancora una spiccata preponderanza di produzioni etrusche, sia tirreniche che di area Padana (Melli 2004a, p. 218), da quest'ultima zona giungevano probabilmente anche elementi attribuibili a culture di tipo Veneto (Melli 2007, p. 19-20) o Golasecchiano (Melli 2004a, p. 295; Melli 2004b, p. 342), forse anche a mezzo di commistioni tra gruppi diversi, anche in maniera diretta, tramite possibili congiunzioni di abitanti dell'oppidum con donne provenienti da tale area, come documentato da alcuni elementi di corredo rinvenuti all'interno della necropoli pre-romana (Melli 2006, p. 620; Melli 2004c, p. 167).

La necropoli si estendeva ad est dell'oppidum lungo le pendici dei colli di Sant'Andrea e Santo Stefano ${ }^{15}$. Il contesto genuate si può definire di matrice etrusco-ligure, almeno per quanto si può dedurre dai corredi funerari, che accostano urne cinerarie di tipo ligure, a conteni-

12 Si è supposto che tale struttura difensiva sia da mettere in relazione con le incursioni dei Siracusani (453 a.C.) nell'Alto Tirreno (Melli 2004a, p. 288).

13 Melli 2006-2007; Melli 2007; Milanese 1987; Milanese, Mannoni 1984.

14 Il rinvenimento di un cratere falisco all'interno dei corredi della necropoli pre-romana conferma le importazioni dall'area magno-greca (Melli 2004b, p. 354), assieme a balsami e profumi, documentati dal rinvenimento di unguentari (Melli 2004a, p. 296).

15 La zona attualmente comprende una delle arterie principali del centro cittadino, Via XX Settembre, e la piazza alla sommità di essa -Piazza De Ferrari. Proprio per la creazione di tale nuovo assetto urbanistico è stato variato il pendio del colle di Sant'Andrea ed in tale occasione sono emerse le testimonianze più numerose della necropoli pre-romana. tori di importazione o produzione etrusca e dal fatto che le iscrizioni rinvenute attestano l'impiego dell'alfabeto etrusco; anche se l'onomastica talvolta riporta etnici di provenienza padana o celtica (Colonna 2004, p. 9-15). I Liguri non possedevano un proprio sistema di scrittura (Mannoni 2010, p. 49).

$\mathrm{Su}$ tale substrato culturale si innestano i rinvenimenti di reperti di importazione massaliota: per quanto concerne le anfore si può affermare con un certo margine di sicurezza ${ }^{16}$, che provengano da diverse aree, probabilmente legate alla chora massaliota, dedita alla produzione ed al commercio di vino ${ }^{17}$.

Le attestazioni prevedono un incremento delle importazioni nel corso del V sec. a.C., in concomitanza con una decrescita delle anfore di produzione etrusca ${ }^{18}$. Una relazione tra i due fenomeni è certamente da identificarsi con l'accrescersi dell'importanza delle esportazioni della colonia focese nel Mar Tirreno settentrionale, quale ne siano fattivamente le ragioni è dato da indagare, anche con possibili riscontri in altri siti liguri ed estendendo lo spettro nell'area di influenza corsa.

Un'ipotesi suffragata da fonti storiche potrebbe essere la battaglia del Mar Sardo (Melli 2007, p. 35) che portò ad una redistribuzione delle aree di competenza commerciale del Tirreno ${ }^{19}$.

I dati emersi dai contesti archeologici non consentono ad oggi di avanzare alcuna fondata ipotesi, se non la crescita esponenziale nell'importazione di vino dall' area massaliota.

Il rinvenimento in contesti abitativi di frammenti di anfore massaliote ${ }^{20}$ induce all'idea di un possibile reimpiego di tali contenitori in usi secondari, una volta svuotati del proprio contenuto originario (Milanese, Mannoni 1984, p. 139-140).

Quanto Massalia intervenisse direttamente negli scambi resta da definirsi, di certo è da evidenziare la maggiore portata di interessi commerciali legata all'esportazione di vino nel genuate e nella zona dell'attuale Liguria in generale ${ }^{21}$. A tale mole di affari faceva capo

16 Le analisi mineralogiche e petrografiche sono state effettuate su campioni di impasti provenienti dall'area dello scavo di San Silvestro, nella zona insediativa dell'oppidum (Milanese, Mannoni 1986, p. 136-137) e ne determinano la provenienza dal massiccio costiero dei Mauri.

17 Per un censimento completo ed aggiornato dei rinvenimenti anforei in Liguria si veda Melli 2004d, p. 16-17.

18 Nell'area di San Silvestro sono documentati i tipi Py 2 e 3 (Milanese 1987, p. 281).

19 Erodoto I, 166.

20 Gli anforacei rinvenuti sono contenuti in unità stratigrafiche immediatamente appoggiate alla roccia sterile e sono costituiti per la stragrande maggioranza da frammenti di pareti (Milanese, Mannoni 1984, p. 123).

$21 \mathrm{Si}$ veda a riguardo la carta distributiva di anfore massaliote ed etrusche in Liguria in Melli 2004d, fig. 2, p. 3. 
la colonia focese, che andava incrementando le proprie esportazioni, da determinare se ancora attraverso mediazione etrusca. Allo stato attuale delle ricerche non è dato fornire una risposta esplicitamente certa ${ }^{22}$.

Nella seconda metà del V sec. a.C. o nei primi decenni del IV sec. a.C., si ebbe un incremento demografico ${ }^{23}$ (Melli, 2004c, p. 168), che indusse alla modificazione dell'assetto dell'oppidum; venne soppressa una parte della cortina muraria per edificare nuove abitazioni e creare terrazzamenti per la coltivazione ${ }^{24}$.

Nonostante l'invasione celtica Genova non subisce una flessione negli scambi e non presenta tracce di decrescita o recessione nell'abitato (Melli 2007, p. 42), anche se dal IV sec. a.C. si assiste all'adozione di armi di tipo celtico (Melli 2007, p. 65).

Alla metà del IV sec. a.C. i legami con Massalia soppiantano quelli con l'Etruria; la percentuale di anfore massaliote diventa elevata e si assiste all'importazione di ceramica à pâte claire (Melli 2004d, p. 3), mostrando un legame sempre più stretto, che verrà reciso solo dal sopraggiungere degli eserciti romani, che lentamente ed inesorabilmente conquisteranno le terre dei Liguri.

Avviene un mutamento nei contatti commerciali del sito. Permane la connessione con l'area greco-orientale, mentre le importazioni di anfore corinzie cessano alla fine del V sec. a.C. per riprendere nel III sec. a.C.

Genova - emporio alle sue origini profondamente influenzato dal mondo etrusco - nel IV sec. a.C. diviene a totale pannaggio della colonia di Massalia, a seguito dello scemare dei commerci etruschi nel Tirreno settentrionale, ne consegue un forte incremento nelle importazioni di vino occidentale ed evidentemente un'inversione delle rotte commerciali. I Massalioti diventano protagonisti dei commerci dell'Alto Tirreno.

La Liguria attesta, inoltre, anfore massaliote anche in siti d'altura in provincia di Savona ${ }^{25}$ ed Imperia ${ }^{26}$. A Genova la percentuale di anforacei massalioti cresce sino a raggiungere circa a l' $80 \%$.

Il vino è la principale merce di scambio, ma sono documentate anche ceramiche fini, come la pâte claire,

22 In via ipotetica si è indicato un possibile commercio etrusco con appoggio massaliota (Rouillard 1992, p. 179-187; Melli, 2004c, p. 168).

23 La popolazione evidentemente si era arricchita di un maggior numero di autoctoni (Melli 2004a, p. 288), come testimoniato dall'uso più frequente di olle liguri all'interno dei corredi tombali (Melli 2006, p. 625).

24 Proprio nei terrazzamenti situati a sud dell'oppidum sono stati rinvenuti molti frammenti di anfore di produzione massaliota (Melli 2004a, p. 290).

25 Nel castellaro di Bergeggi (SV) si sono rinvenute anfore del tipo Bertucchi 3, 4 e 5 (Giannattasio, Odetti 2009, p. 259).

26 Nel sito di Monte Rocche (IM) sono state rinvenute anfore del tipo Bertucchi 4 e 5 (Piccardi 2004, p. 201). attestata in Santa Maria in Passione, alle pendici della collina di Castello; tali dati dimostrano un legame articolato con Marsiglia (Piccardi 2004, p. 200-204). Si impone la problematica di stabilire se anfore e ceramiche fini fossero veicolate attraverso vettori unici o differenti.

Tra i rinvenimenti anforei si segnala in particolare un bollo dall'area di San Silvestro ${ }^{27}$ databile al 372 a.C. circa o al terzo e ultimo quarto del IV sec. a.C. ${ }^{28}$

A metà IV sec. a.C. sono attestati prodotti provenienti dall'area iberica, probabilmente importati con la mediazione di Ampurias o delle Baleari (Melli 2004c, p. 172).

È probabile che Genova fosse già in contatto con Roma ${ }^{29}$. Il ruolo crescente di Roma deve aver - senza sorta di dubbio - segnato i commerci nell'Alto Tirreno, se non altro come nuova presenza, se si pensa che il primo trattato tra Roma e Cartagine risale al 509 a.C.

A partire dal III sec. a.C. si affacciano nuovi prodotti dall'area tirrenica - le anfore greco-italiche - ed anche contatti con il mondo punico. Quest'ultimo legame è da indagare, poiché potrebbe prevedere intermediari nei commerci - la Penisola Iberica, le Baleari, la Sardegna.

Sono documentati anche contatti con la costa catalana, da cui provengono alcuni tipi ceramici (Melli 2004a, p. 296).

I rapporti con Roma nel III sec. a.C. sono avvalorati sia dall'introduzione di un sistema commerciale di tipo monetale (Melli 2004a, p. 297) e dal fatto che Genova sia stata prescelta come base preferenziale per le guerre contro i Liguri e per l'accesso alla conquista della Pianura Padana (Melli 2004d, p. 4) ${ }^{30}$.

Le indagini archeologiche testimoniano tracce del declino e dell'abbandono dell'oppidum, per mezzo dell'individuazione di strati di crollo e di distruzione.

In III sec. a.C. e nella prima metà del II sec. a.C. si riscontrano importazioni puniche, egee ed iberiche, come la grigia ampuritana (Melli 2004c, p. 178).

Nella seconda metà del II sec. a.C. l'oppidum viene completamente abbandonato con il sopraggiungere dei Romani, che si insedieranno nella zona pianeggiante ad ovest della Collina di Castello.

A partire almeno dal V sec. a.C. Genova risulta fisicamente, e non solo, al centro dei commerci dell'Alto Tirreno; questa sua centralità è ribadita nel IV sec. a.C.,

27 Nell'area di San Silvestro sono attestati i tipi Py 5, 6, 7 e 8 (Milanese 1987, p. 281; Milanese 1990, p. 220).

28 Lattara 14, p. 215, p. 217-218, p. 227.

29 Tali contatti sono confortati dall'importazione di produzioni dell'Atelier des petites estampilles (Melli 2004d, p. 4; Melli 2007, p. 87), la cui produzione è documentata nelle zone del Lazio limitrofe a Roma.

30 Genova è porto di riferimento per Roma anche nel corso della Seconda Guerra Punica. 
quando diviene un approdo sicuro per le navi di Massalia dirette verso oriente. La Liguria è destinazione ed intermediario di merci e scambi, attraverso le sue valli scoscese che conducono al Piemonte, alla EmiliaRomagna, con valichi non certo agevoli, ma sicuramente diretti e veloci. Montagne che danno accesso dal Tirreno all'Italia del Nord ${ }^{31}$ ed in maniera minore a quella centrale per mezzo di una falce di terra abitata dai Liguri.

\section{Bibliographie}

Arobba, Caramiello 2010 : AROBBA (D.), CARAMIELLO (R.) - Evidenze di scalvatura in rami di frassino del neolitico medio. In : Del Lucchese (A.), Melli (P.), Archeologia metropolitana. Piazza Brignole e Acquasola, Genova, De Ferrari éd., 2010, p. 13-14.

Barbieri 1938 : BARBIERI (P.) - Forma Genuae, Genova, Edizione del Municipio di Genova éd., 1938.

Colonna 2004 : COLONNA (G.) - Dall'Oceano all'Adriatico: mito e storia preromana dei Liguri. In : De Marinis (R.C.), Spadea (G.) dir., I Liguri. Un antico popolo tra Alpi e Mediterraneo, Genova/Milano, Skira éd., 2004, p. 9-15.

Del Lucchese 2007 : DEL LUCCHESE (A.) - Genova prima di Genova. Un preludio. In : De Marinis (R.C.), Spadea (G.) dir., Ancora su I Liguri. Un antico popolo tra Alpi e Mediterraneo, Genova, De Ferrari éd., 2004, p. 65-66.

Del Lucchese 2010 : DEL LUCCHESE (A.) - La presenza umana nel neolitico. In : Del Lucchese (A.), Melli (P.), Archeologia metropolitana. Piazza Brignole e Acquasola, Genova, De Ferrari éd., 2010, p. 10-11.

Dietler 2006 : DIETLER (M.) - Alcohol: Anthropological/Archaeological Perspectives, Annual Review of Anthropology, 35, 2006, p. 229-249.

Giannattasio, Odetti 2009 : GIANNATTASIO (B.M.) - Monte S. Elena (Bergeggi-SV). Un sito ligure d'altura affacciato sul mare. Scavi 1999-2006, Genova, All'insegna del Giglio, 2009.

Giannattasio 2007 : GIANNATTASIO (B.M.) - I Liguri e la Liguria. Storia e archeologia di un territorio prima della conquista romana, Milano, Longanesi éd., 2007.

Giannattasio 2004: GIANNATTASIO (B.M.) - I Liguri, gli altri, il Mediterraneo. In: Giannattasio (B.M.), Canepa (C.), Grasso (L.),

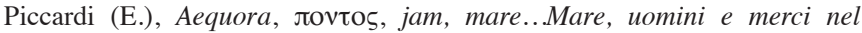
Mediterraneo antico, Atti del Convegno Internazionale di Genova (2004), Genova, All'Insegna del Giglio éd., 2004, p. 11-18.

Lattara 14 : M. Py (M.), Adroher Auroux (A.) Sanchez (C.) dir - Corpus des céramiques de l'âge du Fer de Lattes (fouilles 1963-1999), Lattara 14, 2001.
Mannoni 2010: MANNONI (T.) - Dati sull'ambiente antropizzato della Liguria appenninica prima della romanizzzazione. In: Angeli Bertinelli (M.G.), Donati (A.), Città e territorio. La Liguria e il mondo antico, Roma, Giorgio Bretschneider éd., 2010, p. 31-60.

Mastino 1985 : MASTINO (A.) - Le relazioni tra Africa e Sardegna, L'Africa Romana, 1985, vol. I, p. 24-91.

Melli 2007 : MELLI (P.) - Genova preromana. Una città portuale del Mediterraneo tra il VII e il III a.C., Genova, Frilli éd. 2007.

Melli 2006 : MELLI (P.) - L'emporio di Genova. Riflessioni e problemi aperti alla luce dei nuovi ritrovamenti. In: Gli Etruschi da Genova ad Ampurias, Atti del XXIV Convegno di Studi Etruschi ed Italici, Marseille/Lattes (2002), II, Roma, 2006, p. 609-637.

Melli 2006-2007 : MELLI (P.) - Santa Maria delle Grazie la Nuova (Genova), Archeologia in Liguria, Nuova Serie, II, p. 301-303.

Melli 2004a : MELLI (P.) - Genova. Dall'approdo del Portofranco all'emporio dei Liguri. In : De Marinis (R.C.), Spadea (G.) dir., I Liguri. Un antico popolo tra Alpi e Mediterraneo, Genova/Milano, Skira éd., 2004, p. 285-357. Melli 2004b : MELLI (P.) - Genova. La necropoli romana. In: De Marinis (R.C.), Spadea (G.) dir., I Liguri. Un antico popolo tra Alpi e Mediterraneo, Genova/Milano, Skira éd., 2004, p. 311-357.

Melli 2004c : MELLI (P.) - La Liguria interna nella seconda età del Ferro. In : Venturino Gambari (M.), Gandolfi (D.) dir., Ligures celeberrimi, Atti del Congresso Internazionale di Mondovì (Mondovì, 26-28 Aprile 2002), Bordighera, IISL éd., 2004, p. 165-190.

Melli 2004d : MELLI (P.) - The role of Genoa in the Mediterranean trade in Antiquity. In : Pasquinucci (M.), Weski (T), Close encounters: sea and riverborne trade, ports and hinterlands, ships construction and navigation in Antiquity, the Middle Ages and in Modern Time, Oxford, British Archaeological Reports, International Series 1283, 2004, p. 1-18.

Milanese 1990 : MILANESE (M.) - La diffusione delle anfore massaliote in Liguria, Etudes Massaliétes, 2, 1990, p. 217-222.

Lattara 14, M. Py, A. Adroher Auroux, et C. Sanchez - Corpus des céramiques de l'âge du Fer de Lattes (fouilles 1963-1999), Lattes, 2001.

Milanese 1987 : MILANESE (M.) - Scavi nell'oppidum pre-romano di Genova (Genova-San Silvestro), Roma, L’Erma di Bretschneider éd., 1987.

Milanese, Mannoni 1984 : MILANESE (M.), MANNONI (T.) - Gli Etruschi a Genova e il commercio mediterraneo, Studi Etruschi, LII, 1984, p. 117-146. Piccardi 2004 : PICCARDI (E.) - Il commercio massaliota nella Liguria costiera: un aggiornamento. In : Giannattasio (B.M.), Canepa (C.), Grasso (L.),

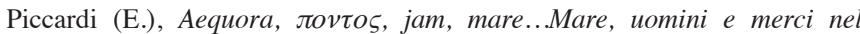
Mediterraneo antico, Atti del Convegno Internazionale di Genova (2004), Genova, All'Insegna del Giglio éd., 2004, p. 200-204.

Ruillard 1992 : RUILLARD (P.) - La place del Marseille dans le commerce des vases attigue à figures rouges en Méditerranée occidentale ( $\mathrm{V}^{\mathrm{e}}-\mathrm{IV} \mathrm{e}^{\mathrm{e}} \mathrm{s} . \mathrm{av}$. J.-C.), Marseille grecque et la Gaule, Collection Etudes Massaliétes, 3, p. 179-187. Spadea 2004 : SPADEA(G.) - Ingauni e Intemeli: la costa occidentale ligure tra IV e III secolo a.C. In : De Marinis (R.C.), Spadea (G.) dir., I Liguri. Un antico popolo tra Alpi e Mediterraneo, Genova/Milano, Skira éd., 2004, p. 391-393.

31 Tali percorsi sono da considerarsi unitamente alle vie fluviali padane dall'Adriatico. 



\title{
Vie quotidienne et transformations à Fratte (SA), un établissement étrusco-campanien situé à l'embouchure du fleuve Irno*
}

\author{
A. Pontrandolfo \\ A. Santoriello \\ Université de Salerne
}

\section{Résumé}

Le site de Fratte occupe une petite éminence à la périphérie nord de la ville actuelle de Salerne, au confluent du fleuve Irno avec les torrents Pastorano et Grancano. La zone fouillée, définie comme l'acropole, en raison non seulement de la qualité de ses structures, mais aussi de sa position topographique, a été aménagée en parc archéologique. L'importance de l'occupation peut être mise en relation avec l'expansion étrusque dans le sud de la Campanie durant les dernières décennies du VI ${ }^{\mathrm{e}} \mathrm{s}$. av. J.-C. Ensuite Fratte fut occupé par des groupes de Samnites entre la seconde moitié du $\mathrm{IV}^{\mathrm{e}} \mathrm{s}$. et le milieu du $\mathrm{III}^{\mathrm{e}} \mathrm{s}$. av. J.-C. et en raison de son importance ce site est entré dans la littérature archéologique, en étant identifié comme la Marcina mentionnée par les sources antiques, notamment par Strabon.

Mots-clés : Étrusques, Grecs, Samnites, urbanisme, tombes, échanges

\begin{abstract}
The old settlement in Fratte occupies a low flat topped hill situated in the northern neighbourhood of the present town of Salerno at the confluence of the river Irno with the streams Pastorano and Grancano. The investigated area, defined "acropolis", for the quality both of its structures and for its topographic position, was fenced and used as archaeological park. The importance of this settlement can be compared to the Etruscan expansion in southern Campania over the last decades of the 6th century B.C. It was later occupied by groups of Samnite origin in a period between the second half of the 4th century and the half of the 3rd century B.C. and for its importance it was included in the archaeological literature and was identified with the Marcina mentioned by literary sources, particularly by Strabo.
\end{abstract}

Keywords: Etruscans, Greeks, Samnites, urbanism, graves, exchanges

Traduction de l'italien au français de Maria Giovanna Canzanella. 
$\mathrm{L}$ 'ancien établissement de Fratte s'étend à la périphérie nord de la ville de Salerne, sur le plateau au sommet de la colline de Scigliato. Le site est une partie d'une implantation plus vaste, en position dominante au confluent du fleuve Irno avec les torrents Pastorano et Grancano. L'identification des premières traces de la présence d'un site archéologique dans la zone de Fratte remontent aux débuts du $\mathrm{XIX}^{\mathrm{e}}$ s., lorsque du matériel de surface et hors contexte apparaît pendant la construction de la manufacture des Cotoniere Meridionali. Plus d'un siècle plus tard, entre 1927 et 1929, A. Maiuri fouille dans la même zone une nécropole de 169 sépultures. Les recherches dans l'habitat commencent en 1947 avec P.C. Sestieri, dans l'actuel quartier de Fratte ; dans les années cinquante, V. Panebianco y conduit une fouille extensive qui révèle la présence d'un important noyau d'habitations, intégrées actuellement au parc archéologique (fig. 1). Dans les années soixante et soixante-dix, l'expansion urbaine du quartier de Fratte permet de découvrir 400 tombes, dans des espaces proches des zones fouillées durant les années vingt.

Une nouvelle étape de la recherche commence en 1985, dans le cadre d'un projet de valorisation du territoire du fleuve Irno. Depuis 1995 les activités de terrain se poursuivent sans interruption, dans le but d'identifier les éléments nécessaires à la compréhension et à la reconstruction des différentes phases de l'établissement ancien et de l'évolution du paysage naturel (Greco, Pontrandolfo 1990 ; Pontrandolfo 2009 ; Pontrandolfo, Santoriello 2011 ; Pontrandolfo, Santoriello, Tomay 2011). Les résultats de la recherche ont permis d'identifier la dynamique de l'habitat antique et, sur ces bases, un projet de réaménagement du parc archéologique a été conçu, vu comme lieu du palimpseste historique sous-jacent lié à une remise en valeur de l'actuel quartier urbain.

Les premières phases d'occupation du site de Fratte, de la fin du VII ${ }^{\mathrm{e}}$ s., sont documentées par les restes d'un grand édifice à abside (fig. 2), d'environ $15 \mathrm{~m}$ sur 6, encore en cours de fouille, dans la zone de la colline près du torrent Pastorano, au confluent de l'Irno. La richesse et la qualité du mobilier trouvé à l'intérieur - dont des céramiques d'impasto et des vases de bucchero, surtout des kantharoi - sont la preuve d'une importante présence des Étrusques, dans le cadre d'une circulation d'hommes et de biens complémentaire des petites escales sur la côte (par exemple à Vietri sul Mare, où on a trouvé des céramiques de la même époque, dont un vase protoattique attribué au Peintre de la Gorgone). Les objets provenant de ce grand bâtiment ressemblent au matériel des plus anciennes sépultures de Fratte, dont le mobilier consiste en vases de bucchero associés à des céramiques importées de Corinthe. Ces tombes, identifiées dans les années vingt sur la rive opposée du torrent Pastorano, sont une preuve évidente que, depuis les origines de l'habitat, l'espace des morts était nettement séparé de l'espace destiné à l'habitat. L'établissement situé aux bouches de l'Irno, contrôlant la partie nord du golfe de Salerne, surgit presque en même temps que la fondation de Poséidonia, au Sud du même golfe. La fonction originaire de cet emporion, liée aux petits ports étrusques de la Péninsule de Sorrente, se confirme au cours du VI ${ }^{\mathrm{e}}$ s., lorsque la communauté de Fratte joue un rôle fondamental de liaison entre les populations de Poséidonia et de Capoue. Ce statut plus important devient manifeste entre le dernier quart du $\mathrm{VI}^{\mathrm{e}}$ et la première moitié du $\mathrm{V}^{\mathrm{e}} \mathrm{s}$. av. J.-C. soit dans les riches mobiliers funéraires des tombes, soit dans l'habitat, qui s'agrandit, occupant de nouveaux espaces, suivant un programme d'urbanisme cohérent et organisé sur des axes réguliers. Ce phénomène s'intègre dans un processus bien documenté dans les communautés les plus avancées de l'Italie antique et représente un reflet évident d'importantes transformations structurelles, politiques et institutionnelles. Le plan d'urbanisme de Fratte est contemporain, en effet, des plans connus en Etrurie padane et tyrrhénienne, dans les centres de la Campanie étrusque, tels Capoue, l'habitat plus ancien de Pompéi, Pontecagnano, et surtout les poleis de la Grande Grèce, notamment Poséidonia, dont le plan d'urbanisme date de la fin du VIe s. av. J.-C. Cette phase de développement est la manifestation la plus concrète d'une période de croissance économique des communautés de la Péninsule italienne, régies par des aristocraties qui semblent avoir des comportements similaires, bien que non homogènes et non assimilables, dans les villes grecques, dans les villes étrusques et même dans les réalités indigènes plus proches de ces milieux qui ont atteint un niveau élevé et complexe de structuration politique. On est donc de plus en plus porté à partager l'hypothèse que l'établissement de la fin du $\mathrm{VI}^{\mathrm{e}} \mathrm{s}$. à l'embouchure de l'Irno puisse correspondre à Marcina, mentionnée par Strabon (V, 4, 13, C251) : au Irr S. av. J.-C., cet historien géographe reporte, d'après une source plus ancienne, peut-être Artémidore d'Ephèse : " Entre les Sirenussae et Poseidonia [se trouve] Marcina, fondation des Tyrrhènes, habitée par les Samnites. D'ici à Pompéi, par Nuceria, il y a un isthme qui ne fait pas plus de 120 stades ».

D'une manière de plus en plus évidente, la recherche archéologique semble confirmer une fondation tyrrhénienne du site de Fratte à l'époque tardo-archaïque, au moment de son plus grand épanouissement, et une occupation samnite dans le courant du IVe $\mathrm{s}$. En particulier, les inscriptions sur des vases faisant partie, avec d'autres objets, des mobiliers des tombes d'un secteur de la nécropole, laissent apercevoir une remarquable cohésion entre 


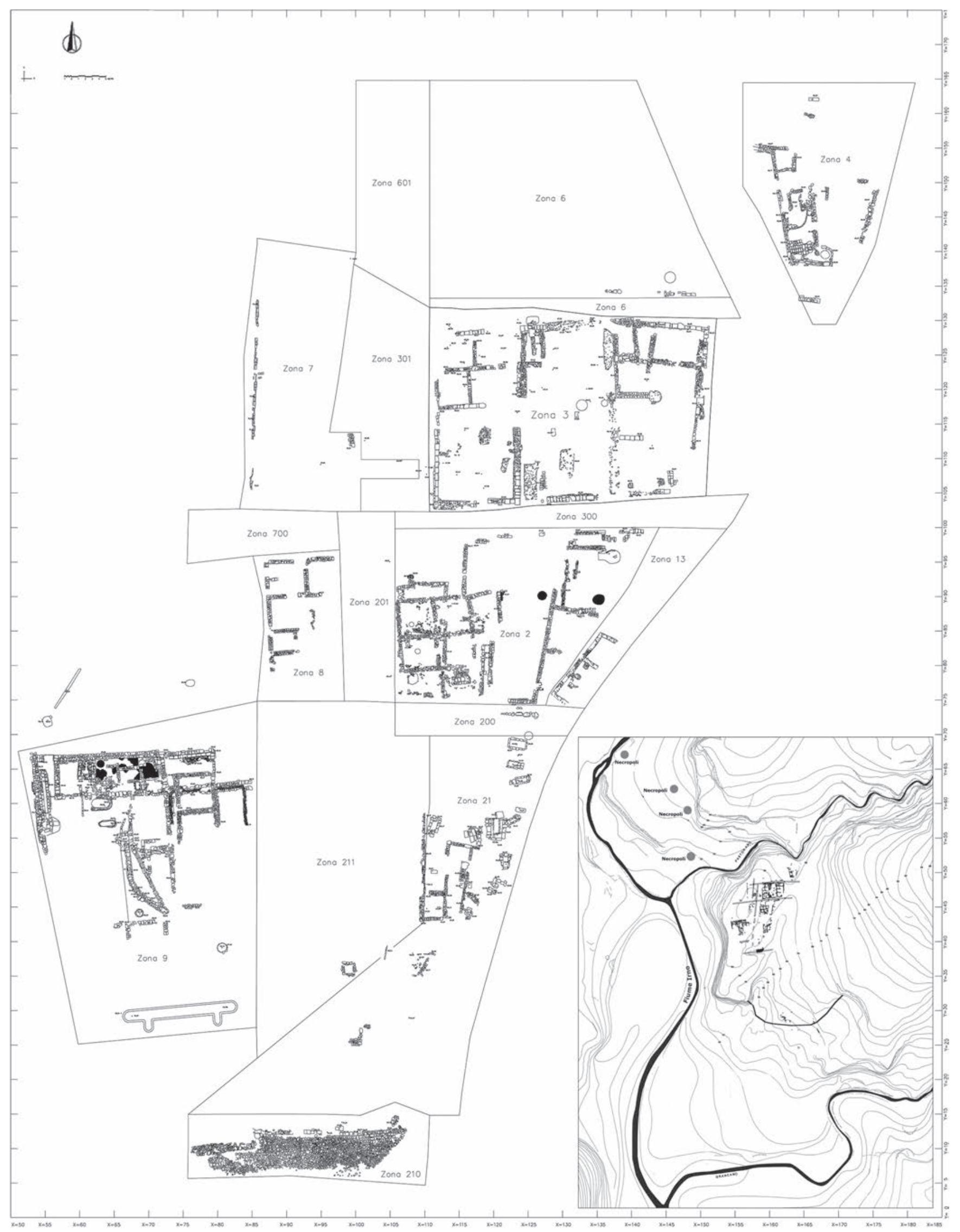

Fig. 1. Plan général de l'habitat de Fratte avec sa localisation dans la vallée du fleuve Irno. 


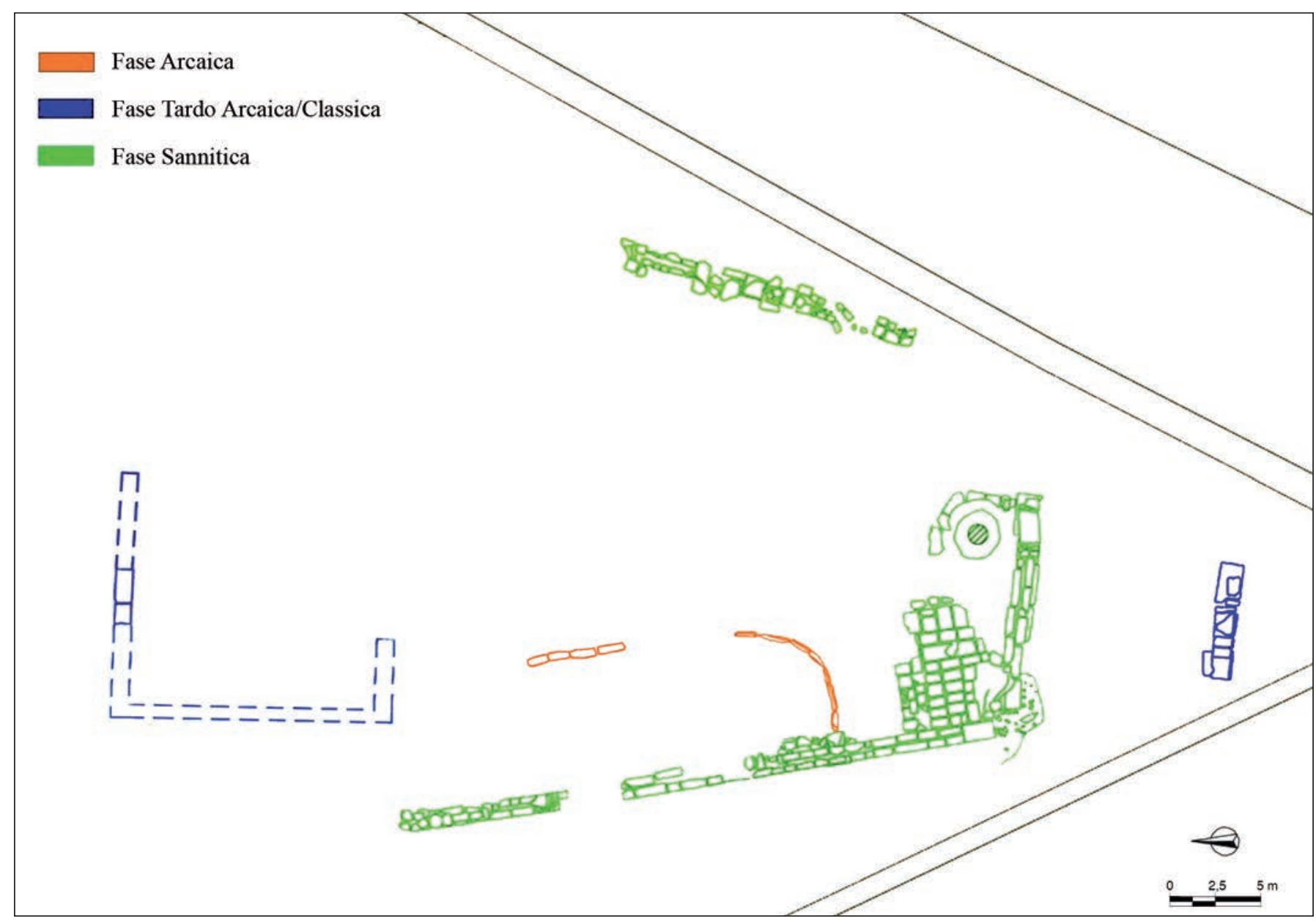

Fig. 2. Zone 4 : plan général avec l'édifice à abside (en orange). 


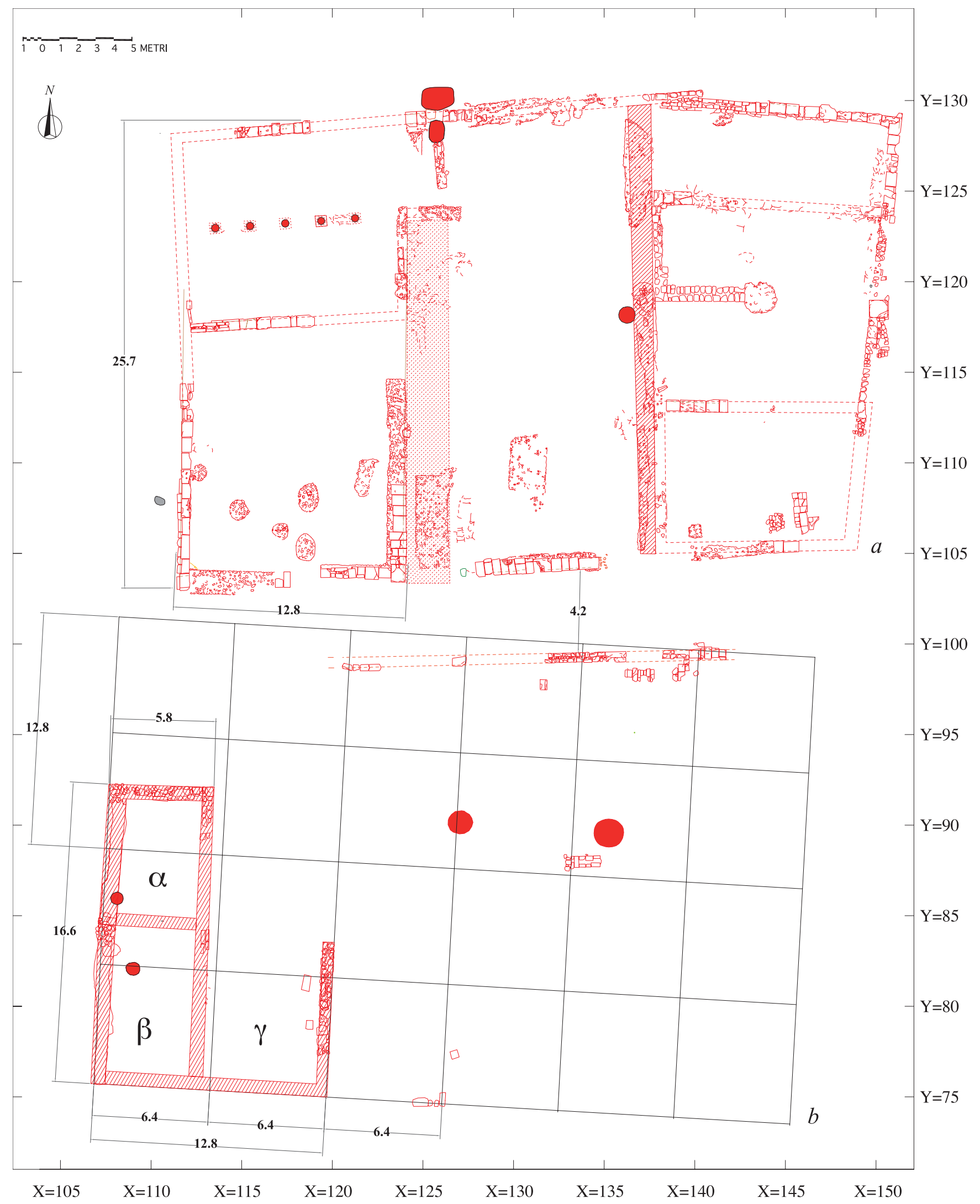

Fig. 3. Zones 2 et 3 : schéma du module théorique de l'organisation des espaces à l'époque archaïque. 
groupes de gens différents par l'appartenance ethnique et linguistique : nous avons donc là le signe d'une grande mobilité et d'une intégration sociales, un élément de distinction propre au site à l'embouchure de l'Irno, parmi les centres du pourtour du golfe de Salerne. Un exemple significatif en est l'inscription gravée avant cuisson sur une petite olpé fabriquée à Poséidonia, découverte dans une tombe fouillée en 1963-1964, célébrant, en vers, les jeux érotiques entre personnages étrusques, grecs et italiques, pratiqués dans cet espace privilégié d'intégration qu'est le symposion.

Sans forcer les données, nous croyons qu'il faut néanmoins approfondir la réflexion sur le phénomène qui voit, au moins dans les dernières décennies du VII ${ }^{\mathrm{e}} \mathrm{s}$, une projection sybarite sur la Mer Tyrrhénienne pour le contrôle de l'accès méridional au golfe de Salerne et, en même temps, une avancée étrusque pour le contrôle de l'accès nord du même golfe, n'est pas dû au hasard.

Il faut se demander si ces épisodes de mobilité gouvernée par des entités culturelles et politiques différentes sont les résultats d'oppositions ou plutôt de stratégies dictées par les intérêts convergents des aristocraties intéressées par le contrôle du secteur inférieur de la côte tyrrhénienne. Il faut aussi reconsidérer le rôle spécifique de Fratte par rapport à Pontecagnano, c'est-à-dire déterminer si la première est née en opposition avec la seconde, comme intermédiaire direct sur la voie entre Capoue et Poséidonia, ou si toutes les deux, sous des formes diverses, entrent dans un programme plus vaste de rapports qui, de toute façon, sont liés à des groupes aristocratiques.

Dans la zone archéologique au sommet de la colline de Fratte (environ $900 \mathrm{~m}^{2}$ ), lieu d'une « centralité » politique (une acropole ou un $a r x$ ), les recherches récentes ont conduit à l'identification de trois routes orientées dans le sens est-ouest, perpendiculaires à un axe NordSud. La mise en œuvre d'un plan d'urbanisme unitaire apparaît également dans l'adoption d'une unité de base de 12,80 m de long (fig. 3), utilisée pour définir, par multiples et sous-multiples, le plan des îlots, la distribution des espaces urbains et les dimensions des édifices. Les dimensions maximales des îlots dans le sens nord-sud, environ 25,60 m, sont un multiple de l'unité de base, ce qui restitue un module fondé sur un rapport longueur/largeur de $1: 2$.

Les deux îlots qui occupent la zone centre-nord de l'acropole dessinent des grands espaces bien distincts, à peu près rectangulaires, de 36 x $25 \mathrm{~m}$, aux côtés longs orientés dans le sens est-ouest. Un seul complexe résidentiel occupe en entier l'îlot septentrional qui, par ses dimensions, position et fonction des pièces, se caractérise comme une résidence aristocratique (fig. 3 et 4 ). Tout le côté occidental, ouvert sur une vaste esplanade centrale découverte et enrichie par une fontaine monumentale, est occupé par des espaces qui semblent destinés à des fonctions de représentation, peut-être à des cérémonies ; on pense, au contraire, à des fonctions de service pour deux petites structures du côté oriental, situées l'une face à l'autre et ouvertes sur un petit atrium qui permet également l'accès à la cour centrale à l'endroit où se situe un puits pour la captation de l'eau.

Les habitations de l'autre îlot, bien que construites elles aussi sur les côtés occidental et oriental, sont plus petites et apparemment bien distinctes et différenciées quant à leurs fonctions (fig. 3b). Le plan de la construction la mieux conservée, de 16,50 x 5,80 m, est celui d'une maison à pastas : un édifice rectangulaire, séparé en deux ou trois pièces de différentes dimensions, avec une petite cour. Le local au nord, à peu près quadrangulaire, devait être complètement couvert, tandis que l'autre, doté d'un puits pour l'approvisionnement en eau de la nappe phréatique, était vraisemblablement couvert par une toiture terminant à l'est par un porche donnant sur une aire ouverte et partiellement délimitée par un mur. Cette maison, comme l'autre similaire placée de l'autre côté de l'îlot, était probablement destinée à des activités complémentaires de celles des habitants de la casa-palazzo. Cette hypothèse serait renforcée par les larges surfaces laissées libres dans l'îlot, réservées peut-être à des potagers ou à des activités artisanales. Il faut également considérer la position de cet îlot, entre la casa-palazzo et l'aire sacrée au sommet du plateau.

De la zone sacrée, on connaît bien deux phases chronologiques (fig. 5). Dans la phase archaïque, l'édifice en blocs de tuf équarris présente un plan rectangulaire $(23 \times 6,50 \mathrm{~m})$, divisé en quatre espaces. La pièce centrale (de 6,50 x 7,50 m) est formée d'un espace interne précédé par une entrée étroite et allongée ; dans la pièce au milieu, de dimensions plus réduites $(2 \times 6 \mathrm{~m})$, il y a un puits d'évacuation, faisant partie d'un aménagement hydraulique assez complexe, réalisé sur toute la colline lors de la création du plan d'urbanisme à axes réguliers. Il s'agit d'un système constitué de canaux de surface, puits verticaux atteignant la nappe phréatique, puits de liaison et galeries souterraines. Ces dernières sont taillées dans le banc de tuf gris campanien, sont dépourvues de revêtement et montrent une structure à voûte, haute en moyenne $1,80 \mathrm{~m}$ sur $0,70 \mathrm{~m}$ de largeur. Revenant à l'édifice de culte, sur le côté nord de la pièce médiane, la fouille a mis au jour un petit canal qui avait à l'origine une entrée en maçonnerie située dans le coin nord-est de la structure. Au sommet de la canalisation on a trouvé les restes d'un récipient aux parois percées et un tuyau de terre cuite : éléments qui font penser à l'existence d'une fontaine monumentale. 


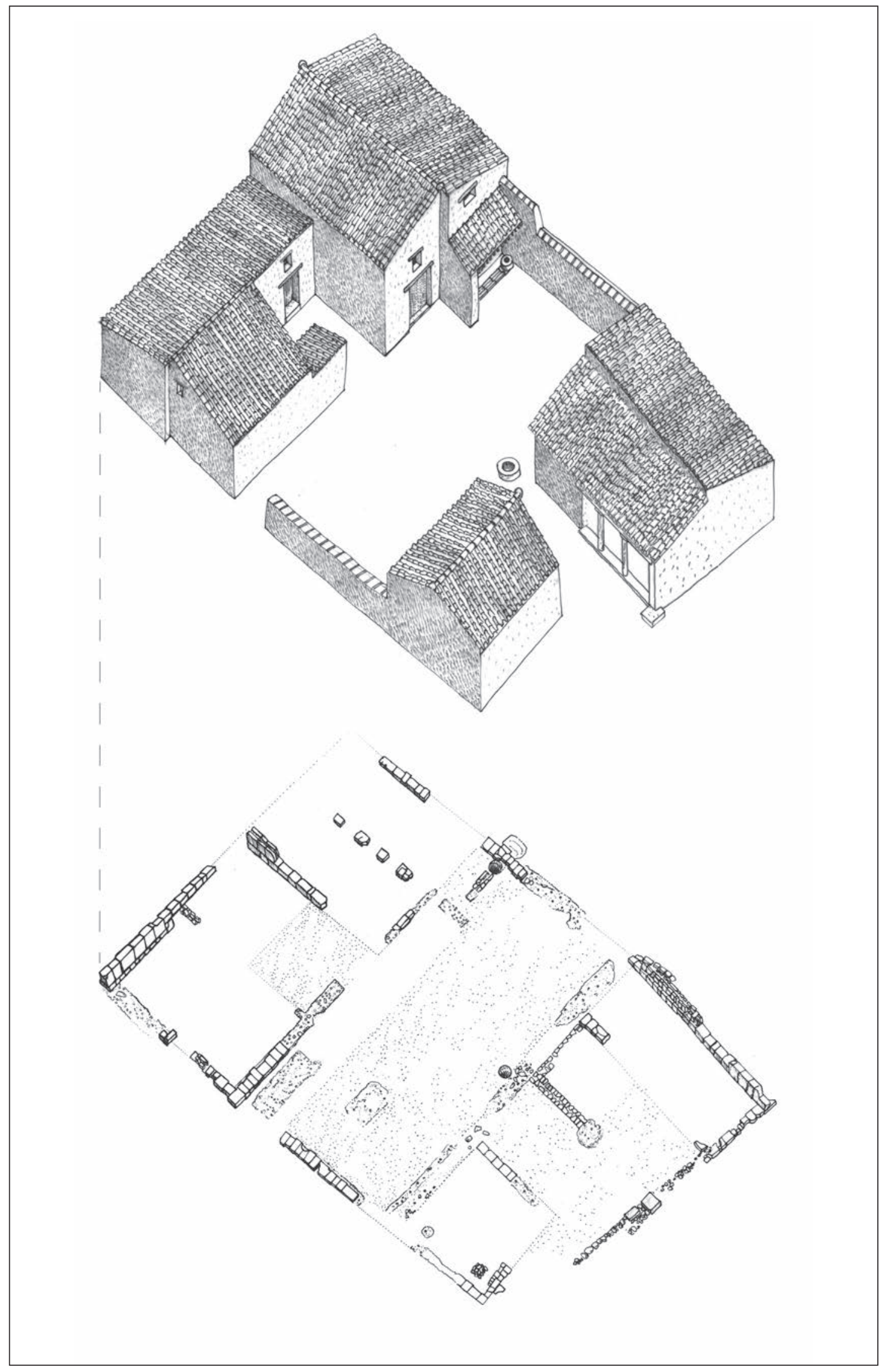

Fig. 4. Zone 3 : reconstruction axonométrique de l'îlot archaïque. 


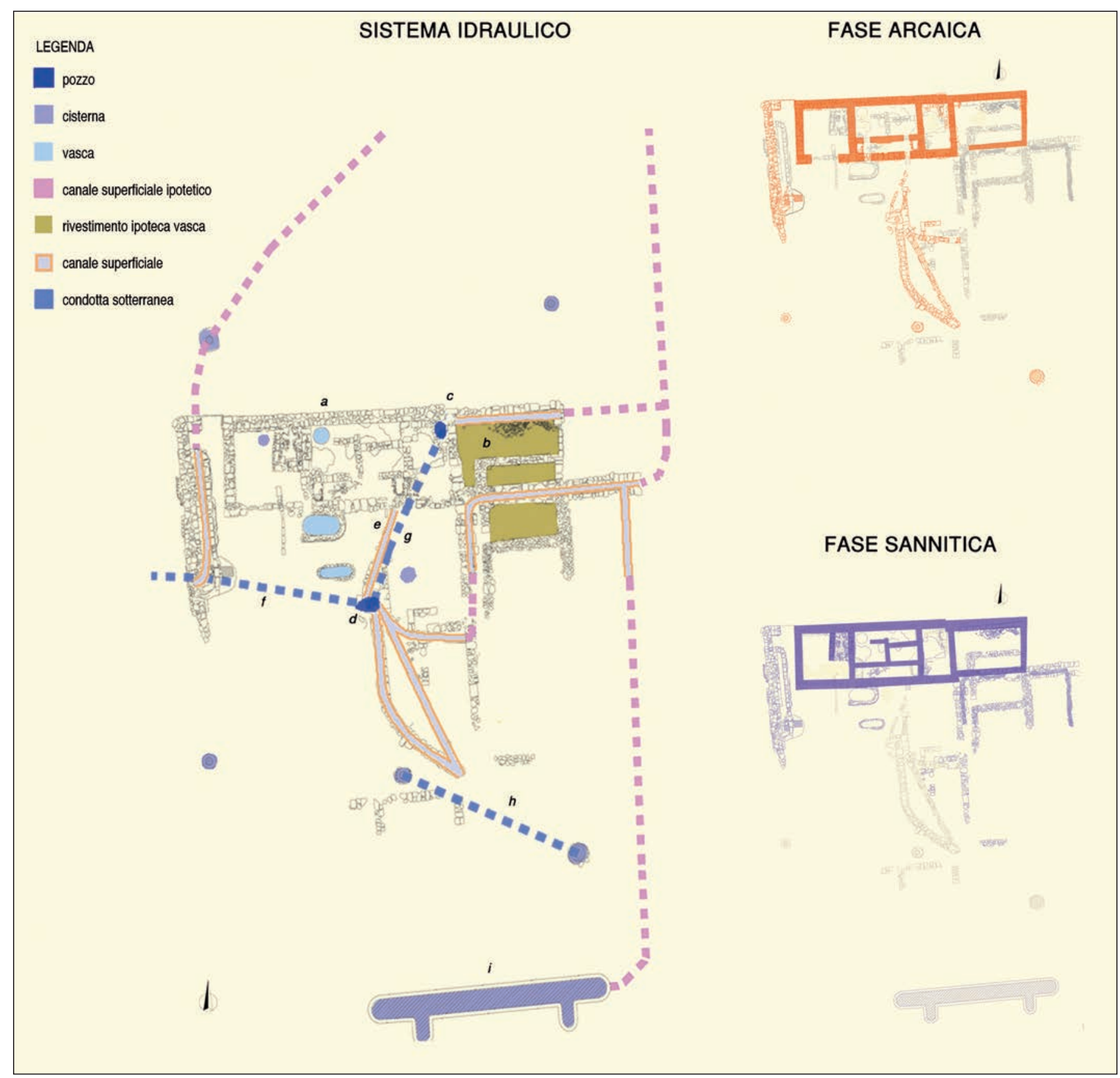

Fig. 5. Zone 9 : plan général de l'aire du sanctuaire (avec les phases archaïque et samnite) et du système hydraulique. 


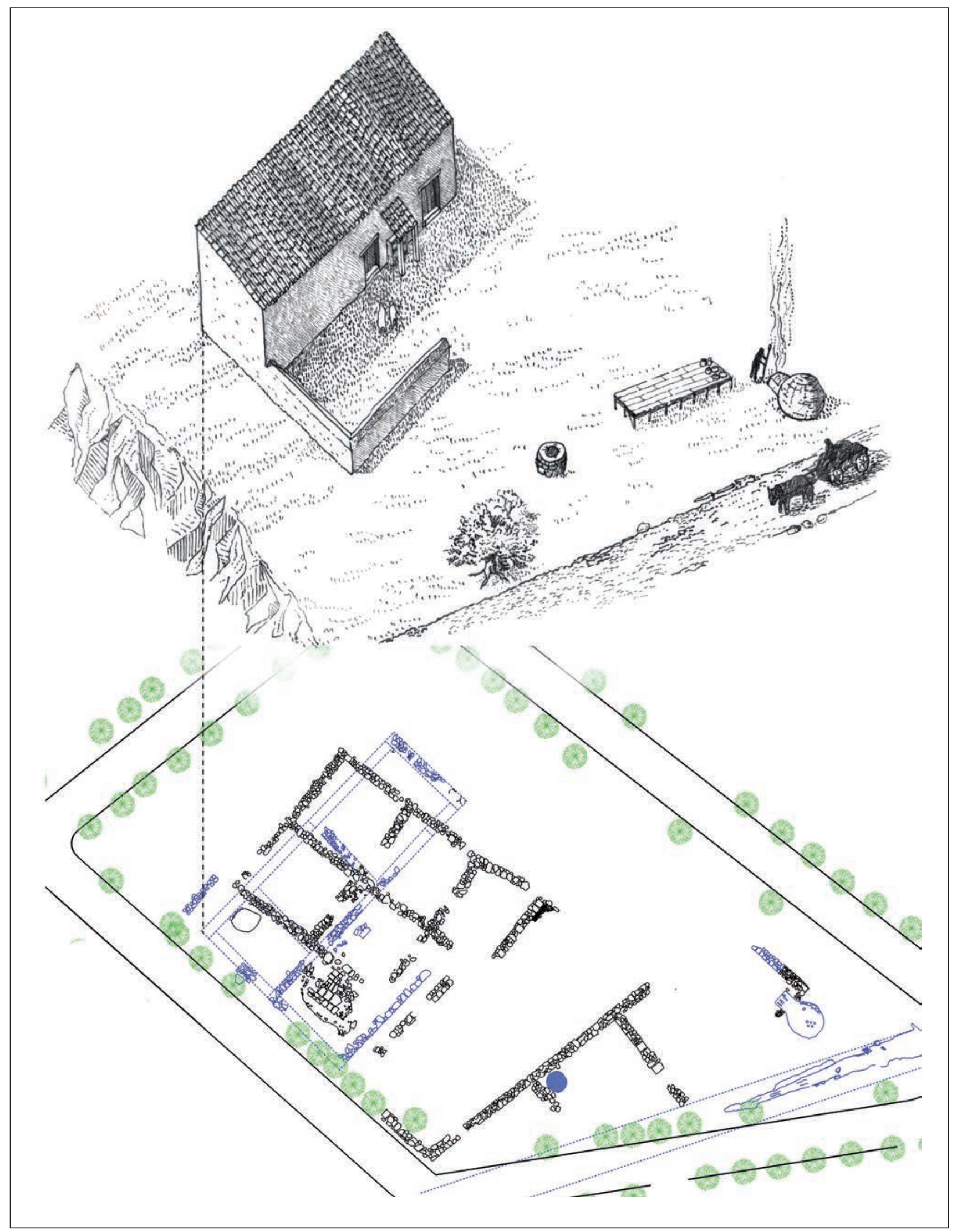

Fig. 6. Zone 2 : reconstruction axonométrique de l'aire à vocation artisanale à l'époque samnite. 
Dans un des puits situés dans l'aire libre devant l'édifice sacré, le mobilier découvert confirme la destination cultuelle de l'ensemble au sommet de la colline. Parmi les objets, on trouve une bague sertie d'une intaille en cornaline avec la représentation d'Heraclès en lutte contre le lion de Némée. Cette découverte témoigne de la fortune du culte du héros à l'époque archaïque et suggère de revenir aux nombreux vases attiques de très grande qualité, découverts dans la nécropole de Fratte et souvent décorés de scènes liées aux travaux d'Heraclès : la grande amphore du Peintre de Priam montrant Heraclès et le sanglier d'Erymanthe, l'hydrie du Peintre de Kléophrades montrant sur l'épaule du vase le héros enlevé par les Satyres, l'amphore à figures noires du Groupe de Léagros avec Heraclès étranglant le Triton, la kalpis à figures rouges représentant le héros frappant à mort Hippolyte, la reine des Amazones et, enfin, le cratère à figures noires avec l'image d'Heraclès en lutte avec le lion de Némée. Ces vases étaient déposés dans les sépultures des personnages éminents de la communauté, souvent associés à de la vaisselle en bronze de production étrusque, des chenets, des broches et d'un couteau en fer.

Après une période de stagnation, mais pas d'abandon, vers le milieu du IVe $\mathrm{s}$. le site de Fratte montre une nouvelle phase de développement, liée à l'arrivée des Samnites, phénomène qui s'observe dans la plupart des centres de la Campanie tyrrhénienne. Les fouilles ont permis de mettre au jour de nombreuses inscriptions en langue osque : c'est le cas de la tuile incisée, appartenant à une série plus étendue, portant l'anthroponyme de l'acheteur ou du destinataire, trouvée près du fourneau de la zone artisanale, qui témoigne de la samnitisation de l'établissement, où par ailleurs persistent, à la même époque, des inscriptions en grec et en étrusque, avec même des mots écrits dans des alphabets de différentes traditions.

Durant cette phase, les plans des édifices archaïques et les fonctions des îlots et de leurs espaces ne changent pas sensiblement.

La casa-palazzo voit des transformations dans l'architecture et dans la distribution des espaces qui ne modifient pas, cependant, l'essentiel des répartitions d'origine. Cette phase montre de manière plus évidente la destination artisanale de l'îlot voisin (fig. 6), où, dans la partie orientale, près d'un puits toujours en fonction, est installé un four. Derrière le four, un chemin en terre battue est aménagé vraisemblablement pour relier les différentes activités des secteurs du puits, du four et de la maison-ergasterion, cette dernière placée dans la zone orientale, où l'on voit bien la distinction des espaces pour la préparation de la nourriture, la conservation des denrées et les petites activités artisanales. Cependant, la découverte d'une grande quantité de céramique pour préparer et réchauffer la nourriture (marmites, clibani, récipients identifiables peut-être comme des cloches de cuisson) par rapport aux vases destinés à la consommation, et la présence de nombreux louteria, peut-être excessive pour une petite maison comme celle-ci, laissent ouverte l'hypothèse que tout cet ensemble de structures soit reliée à l'aire sacrée qui n'est pas loin, dans la partie méridionale de la colline, et puisse avoir eu des fonctions liées aux activités et aux pratiques de culte.

L'édifice archaïque de la zone du sanctuaire est agrandi et enrichi de décorations architectoniques, comme le clipeus avec Heraclès et le lion de Némée. Deux petits bassins de forme ovale, enduits de mortier hydraulique, sont aménagés dans l'espace d'en face, dont la limite occidentale voit la construction d'une petite chambre de combustion avec praefurnium et parois de tuiles. On assiste également à l'aménagement d'un système hydraulique souterrain, formé par une entrée avec un local quadrangulaire au fond, d'où partent deux longues galeries. Le matériel découvert à l'intérieur des couloirs souterrains, accumulé autour du milieu du III ${ }^{\mathrm{e}} \mathrm{s}$. av. J.-C., lors d'un brusque événement qui marque l'abandon du site, nous donne indirectement une «photo instantanée » des activités du sanctuaire. Les restes de faune renvoient à des sacrifices de suidés, d'ovi-capridés et d'une dizaine d'animaux apparentés au bos taurus. Les céramiques forment des services de table constitués de coupes, patères et coupelles à vernis noir, de cruches d'argile épurée de différentes tailles, associées à des vases à cuisson, surtout des marmites, ollae, lopades et caccabés. À côté de fragments de figurines féminines de terre cuite avec porcelet et d'antéfixes à tête d'Athéna, témoins d'un système de toiture à double pente soutenue par des poutres en bois et munie de gouttières, nous avons des inscriptions d'un très grand intérêt qui confirment la réalité mixte de cette communauté, avec des textes en grec et en osque, dont un fragment de dédicace à Heraclès. Cette inscription, notamment, est une preuve irréfutable de l'importance de la figure et du culte du héros grec auprès des populations italiques de la deuxième moitié du $\mathrm{IV}^{\mathrm{e}} \mathrm{s}$. et de l'expression d'identité politique que prend le culte auprès de ces communautés.

Durant cette phase, l'aire de l'acropole en contrebas du versant est de la colline et apparemment en rapport avec l'édifice sacré, est occupée par un petit groupe de tombes à chambre et à caisse, bâties avec des blocs de réemploi provenant des édifices archaïques, ornées de peintures et avec des mobiliers funéraires répondant, dans leur composition, à l'idéologie des populations samnites. Dans les sépultures masculines est toujours présent le ceinturon de bronze, souvent 


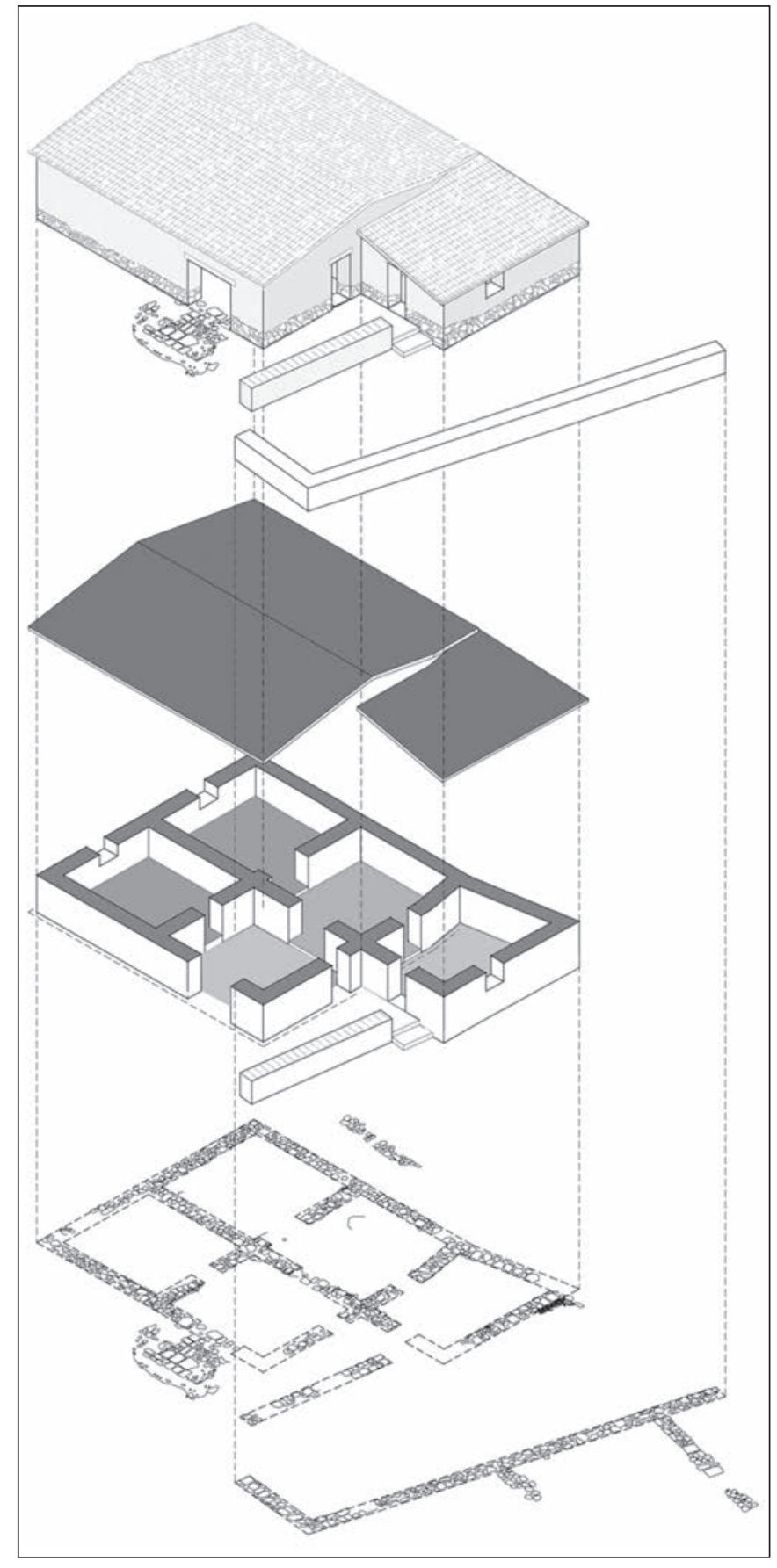

Fig. 7. Zone 2 : reconstitution axonométrique de l'implantation rurale républicaine.

répété, associé au couteau en fer placé dans un bassin en bronze ; dans les tombes féminines sont déposés des vases à parfums, des pyxides, des lébètes et un miroir en bronze. La position de ces sépultures dans un espace public, réaménagé avec des nouvelles fonctions, suggère d'une part une transformation à la verticale d'une société désormais samnite, d'autre part la formation d'une nouvelle structure politique : ces tombes sont l'expression de la classe dominante à Fratte entre la fin du IVe et la première moitié du III ${ }^{e}$ s. av. J.-C., terme chronologique de l'abandon du centre urbain, pour des raisons qu'en l'absence de textes, nous ne pouvons pas préciser.

La vision d'ensemble que nous donnent l'étude des nécropoles et les recherches systématiques menées dans le secteur monumental du site, montre la vie d'une implantation qui devait être bien plus vaste que ce qu'on perçoit aujourd'hui dans la zone archéologique : des indices de cette étendue nous viennent des résultats d'interventions localisées pour la protection du patrimoine, des prospections au sol et de l'étude des images de télédétection. Au sud-est de l'acropole, dans la zone de plaine proche des sources Vitologatti, ont été mis au jour des restes du tracé urbain à plan régulier : une série de voies et de structures relatives à des installations artisanales du IV e s. av. J.-C. Plus en amont, des restes de murs à double courtine et remplissage appartenant à un système de fortifications réalisé dès l'époque archaïque, ont été dégagés ; ces derniers définissent clairement des zones destinées à l'habitat. Ces murs s'étendent, avec une fonction stratégique de contrôle, jusqu'à la hauteur de Epipoli, où les prospections au sol ont révélé des structures et du matériel de l'époque samnite.

Près de la rive gauche de l'Irno, un tronçon de voie dallée témoigne, avec celle découverte par P.C. Sestieri dans le quartier des Case Popolari, de l'existence d'un réseau routier vers la côte, longeant le cours du fleuve. La rivière même, peut-être, était une voie de communication vers la mer : au pied du secteur méridional de la colline, il est possible d'imaginer la présence d'un lieu d'accostage naturel dont les indices seraient un ancien lit du fleuve clairement visible sur les anciennes photographies aériennes et quelques structures individualisées dans ce secteur.

La situation géographique particulière de ce site en fait un lieu naturel de passage et un point de confluence des axes routiers entre l'intérieur et la côte (fig. 8) : il s'agit en effet de l'un des parcours obligés, depuis la préhistoire, entre la plaine campanienne dominée par le Vésuve et la plaine du fleuve Sele. Sur ce tracé, à partir de l'époque historique, viennent s'insérer et se structurer des routes bien construites, comme c'est le cas de la voie A. Ce réseau, dès le IVe s. av. J.-C., occupe ce qui sera au II ${ }^{\mathrm{e}} \mathrm{s}$. av. J.-C. une partie de l'axe consulaire romain Regio-Capuan. Le tracé n'est pas encore tout à fait clair, mais Fratte a certainement exercé un rôle de charnière entre différents réseaux : la voie entre la basse vallée de l'Irno et la mer (voie A), documentée également par les récentes découvertes de Salerne, et la voie entre Fratte et la plaine du Sele, le long du parcours aux pieds des collines entre Ogliara et San Mango Piemonte (voie B), dans la vallée du Grancano-Fuorni. 


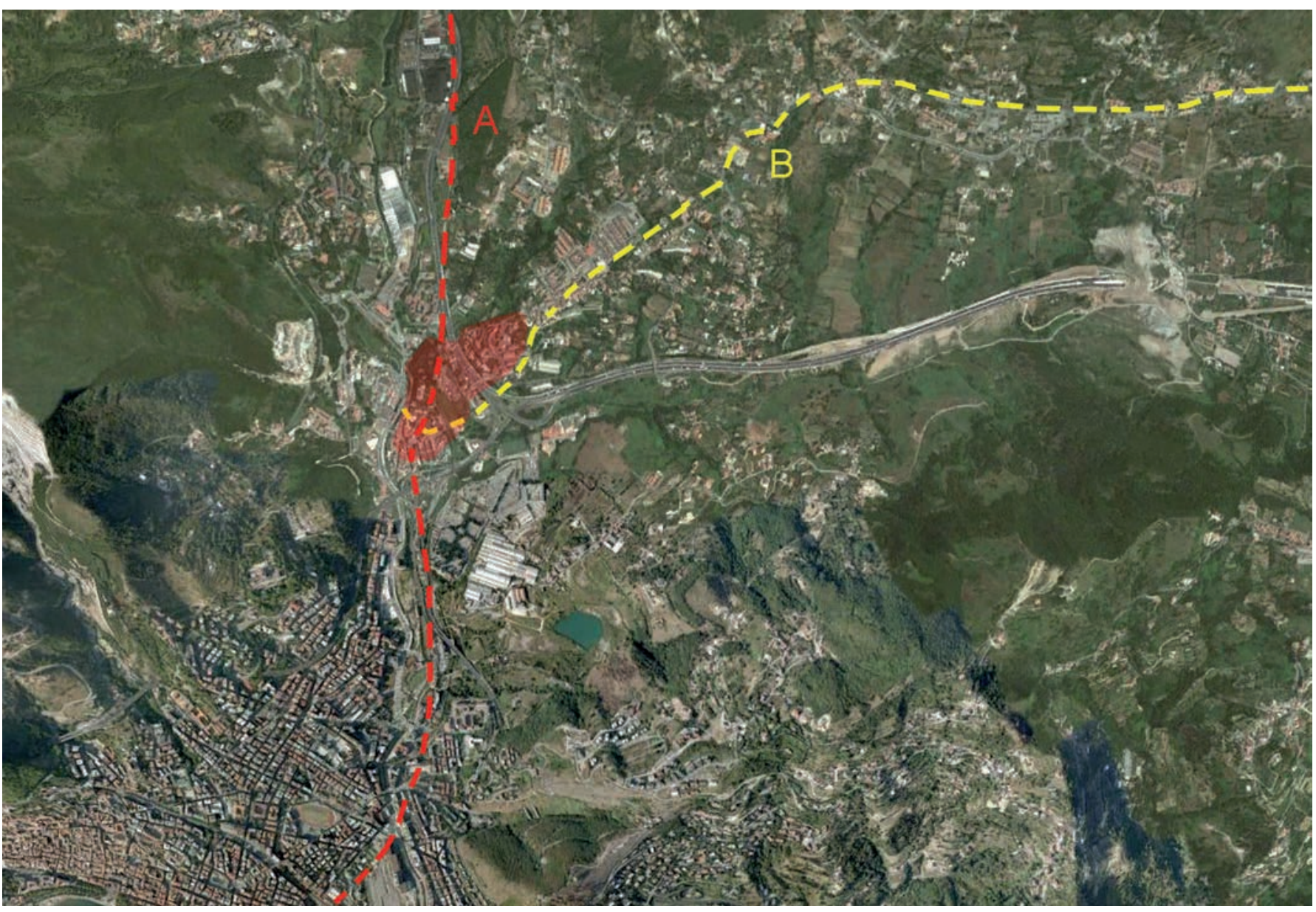

Fig. 8. Le réseau viaire dans la vallée du fleuve Irno.

Les établissements agricoles sont le signe le plus évident des transformations survenues auprès des populations italiques à la veille de la romanisation. Lorsque l'habitat de Fratte est abandonné, au milieu du III s. av. J.-C., sur les monuments de l'acropole, désormais privés de leur ancienne fonction, s'installe une grande structure rurale (fig. 7).

Cet ensemble, formé d'au moins 5 espaces quadrangulaires d'égales dimensions, recouvre en grande partie les structures de la zone artisanale de la phase samnite et représente sans doute le noyau de l'implantation rurale qui s'étend avec une série d'aménagements, même temporaires, également sur d'autres secteurs de la colline.

On peut comparer cette installation aux nombreuses implantations, de caractère plus ou moins marginal, situées le long des réseaux routiers primaire et secondaire; par ailleurs, elle est un des plus anciens témoignages de la présence des Romains dans une zone qui entre, en 194 av. J.-C., dans le territoire de la colonie de Salernum.

L'intervention romaine dans le golfe conduit à une transformation profonde du paysage, grâce à une organisation plus stable et durable de l'exploitation du territoire et du réseau viaire. La zone septentrionale de la vallée de l'Irno est parsemée, entre le I ${ }^{\text {er }} \mathrm{s}$. av. J.-C et le $\mathrm{I}^{\text {er }}$ s. apr. J.-C., de nombreuses installations agricoles qui semblent s'insérer dans une centuriation entrant dans le même contexte que celle de plus ample portée reconnue le long du littoral oriental de Salerne.

\section{Bibliographie}

Greco, Pontrandolfo 1990 : GRECO (G.), PONTRANDOLFO (A.) - Fratte. Un insediamento etrusco-campano. Modena, 1990.

Pontrandolfo 2009 : PONTRANDOLFO (A.) IN COLLABORAZIONE SANTORIELLO (A.) - Fratte. Il complesso monumentale arcaico. Salerno, 2009. Pontrandolfo, Santoriello 2011 : PONTRANDOLFO (A.), SANTORIELLO (A.) - Fratte. L'area a vocazione artigianalee produttiva. Paestum, 2011.

Pontrandolfo, Santoriello, Tomay 2011 : PONTRANDOLFO (A.), SANTORIELLO (A.), TOMAY (L.) - Il primo insediamento urbano. Fratte. In : Campanelli (A.), Dopo lo tsunami. Salerno antiqua. Napoli, 2011, p. 198-210.

Santoriello, Scelza 2008 : SANTORIELLO (A.), SCELZA (F.) L'applicazione di analisi quantitative a contesti stratigrafici critici. In : De Felice (G.), L'informatica e il metodo stratigrafico, Atti del Workshop (Foggia 6-7 giugno 2008). Bari, 2008, p. 91-106. 


\title{
Banquets rituels à Cumes au IVe siècle av. J.-C.
}

\author{
Jean-Pierre Brun \\ Laëtitia Cavassa \\ Martine Leguilloux \\ Priscilla Munzi
}

Centre Jean Bérard, USR 3133, CNRS - ÉfR, Naples, Italie

\section{Résumé}

Un programme de recherches archéologiques sur la colonie grecque de Cumes a été confié en 1993 à Michel Bats par la Surintendance archéologique de Naples. Dans le cadre d'un vaste projet associant quatre partenaires, la Surintendance, l'Université « Federico II », l'Université «L'Orientale » et le Centre Jean Bérard, les travaux ont porté sur le forum, les remparts et l'habitat, l'amphithéâtre ainsi que les abords de la ville. L'équipe du Centre a été chargée de ce dernier volet ayant comme objectif la recherche des ports. L'enquête sur les secteurs périphériques, au sud et au nord de l'acropole, en bordure de la mer et de la lagune de Licola, a permis de préciser la chronologie du site, sa topographie, sa sédimentologie et l'évolution de son environnement. À défaut de structures portuaires, les fouilles ont mis au jour des vestiges aussi divers que des tombes de l'âge du fer, un sanctuaire grec, une nécropole romaine ainsi que des bâtiments byzantins. Dans le sanctuaire grec, une série de pièces est interprétée comme des salles à banquets rituels.

Mots-clés : Cumes, Campanie, sanctuaire grec, repas rituels, salles à banquet

\footnotetext{
Abstract

In 1993, Michel Bats has been charged by the Soprintendenza archeologica of Naples to manage new researches at Cumae. This ambitious project involves four partners : the Soprintendenza itself, the

University "Federico II ", the University "L'Orientale" and the Centre Jean Bérard. The three Italian teams studied the forum, the remparts and the houses. The Centre Jean Bérard (CNRS-EFR) carried on excavations in the periphery of the Ancient city with the initial aim of discovering the harbour. Surveys and excavations outside the walls, to the South and the North of the Acropolis, along the seashore and the shores of the Laguna di Licola, established the chronology of the site, its topography, its sedimentology and the evolution of its landscape. Even if no remains of any harbour were discovered, the excavations revealed graves of the Iron Age, a Greek sanctuary, the Greek and Roman North cemetery of the city as well as Byzantine buildings. In the Greek sanctuary, a row of rooms can be interpreted as banquet halls for ritual meals.
}

Keywords: Cumae, Campania, Greek sanctuary, ritual meals, banquet hall 
$\mathrm{C}$ umes constitua un phare de la civilisation grecque en Occident. Quelle ait été ou non la plus ancienne colonie des Eubéens en Italie importe peu ici ${ }^{1}$. Quoi qu'il en soit, la colonie Eubéenne est un point de diffusion majeur de la civilisation grecque dès le haut archaïsme et elle exerce une forte influence sur les populations indigènes tant en matière de techniques que d'urbanisme, d'art, de religion et de consommation alimentaire.

La colonie grecque est située à une vingtaine de kilomètres à l'ouest de Naples, sur le rivage de la mer tyrrhénienne mais hors du golfe de Naples (fig. 1). La topographie de la ville est accidentée : l'acropole, une cheminée basaltique qui domine le rivage de $80 \mathrm{~m}$ en forme le point d'ancrage. À l'ouest, au sud et au nord, s'étend une plaine limitée vers l'est par la colline du Monte Grillo orientée nord-sud. Cette topographie a conditionné la forme de la cité : dès l'époque archaïque ancienne, les remparts s'appuient sur le Monte Grillo pour descendre vers le rivage à angle droit, englobant une superficie de 110 ha environ.

La cité a connu une histoire mouvementée commençant par une conquête militaire succédant à une phase de cohabitation entre les indigènes Opiques et les Grecs implantés à Pithécusses, sur l'île d'Ischia. Elle dut faire face à une attaque des Étrusques en 524 puis fut gouvernée par le tyran Aristodème vers la fin du VIe et au début du Ve $\mathrm{V}$. Les Cumains vainquirent les Étrusques en 474 grâce à l'appui du tyran de Syracuse mais la ville fut prise par les Samnites en 421. Par la suite, elle entra dans l'alliance de Rome, recevant la civitas sine suffragio en 338 et ne fit défection ni au moment de la guerre contre Pyrrhus, ni lors de la seconde guerre Punique. Hannibal fit en vain le siège de Cumes en 217. À partir de 194, le développement de la colonie romaine de Puteoli, dans un port naturel admirable, auparavant l'échelle de Cumes, a probablement affecté son potentiel commercial mais sans diminuer sa prospérité fondée sur un terroir d'une fertilité remarquable. La ville devint, à partir de la seconde moitié du $\mathrm{II}^{\mathrm{e}} \mathrm{s}$., un lieu de résidence de l'aristocratie romaine et se para de monuments luxueusement décorés : temples, forum, portiques, stade. L'embellissement de la ville connut une accélération notable au I $^{\text {er }}$ et II' ${ }^{\mathrm{e}}$ s. ap. J.-C., s'essouffla à partir de la fin du $\mathrm{II}^{\mathrm{e}} \mathrm{s}$. La ville continua toutefois d'être occupée intensément jusqu'au milieu du $\mathrm{VI}^{\mathrm{e}} \mathrm{s}$. La longue guerre entre les Goths et les troupes de Justinien scella son destin, la ville fut prise trois fois, en 536 par Bélisaire, en 542 par Totila, roi des Goths, et en 553 par le général byzantin Narsès à la suite d'un siège dévastateur. La ville basse

1 Sur cette question débattue : Greco 2009, contra Guzzo 2009. fut alors abandonnée et devint une immense carrière de matériaux, l'agglomération byzantine occupant l'acropole et l'étroite plaine côtière au sud de celle-ci.

Les recherches archéologiques récentes ont considérablement augmenté notre connaissance de la ville. À partir de 1994, sous l'impulsion et la conduite de Stefano De Caro, alors Surintendant archéologue de Naples, un vaste projet de recherche a associé quatre partenaires, la Surintendance, l'Université « Federico II », l’Université «L'Orientale » et le Centre Jean Bérard. Les fouilles ont porté sur le forum, les remparts et l'habitat, l'amphithéâtre ainsi que sur les abords de la ville. L'équipe du CNRS a été chargée de ce dernier volet ayant comme objectif initial la recherche des ports. L'enquête sur les secteurs périphériques, au sud et au nord de l'acropole, en bordure de la mer et de la lagune de Licola, a permis de préciser la chronologie du site, sa topographie, sa sédimentologie, l'évolution de son environnement, mais pas de trouver trace d'un éventuel port (Bats, Brun, Munzi 2009 ; Brun, Munzi 2011).

À défaut de structures portuaires, nos fouilles ont mis au jour des vestiges aussi divers que des tombes de l'âge du fer, un sanctuaire grec, une nécropole grecque et romaine ainsi que des bâtiments byzantins. Au nord des remparts de la ville, aux marges de la lagune de Licola, dans une zone non occupée par la nécropole grecque et samnite, un sanctuaire extra-urbain a été dégagé. Fondé dès l'époque archaïque, peut-être dès les lendemains de la fondation de la colonie, il a fonctionné jusqu'au début du I ${ }^{\text {er }}$ s. avant J.-C.

Les premières phases établies au-dessus de la nécropole pré-hellénique oblitérée par une épaisse couche de colluvions sont mal connues et nous ne pouvons pas prouver, même si nous en avons la conviction, que les niveaux du VII ${ }^{\mathrm{e}} \mathrm{s}$. sont identifiables comme ceux d'un sanctuaire. L'indication de la présence d'un lieu de culte bâti au début du $\mathrm{VI}^{\mathrm{e}} \mathrm{s}$. est donnée par la découverte dans une fosse du Ir ${ }^{\text {er }}$. avant J.-C. d'une antéfixe de terre-cuite de style Corinthien. Cette pièce attesterait donc une monumentalisation du sanctuaire à une époque où les remparts connaissent une phase de construction (D’Agostino, Fratta, Malpede 2005). Plusieurs puits sont alors creusés dans la zone que nous avons fouillée et sont associés à des constructions en pierre.

Vers le milieu du Ve s., les puits sont comblés et un nouveau bâtiment comprenant au moins trois pièces ouvrant sur une galerie est alors construit. Cet édifice est détruit à la fin du $\mathrm{IV}^{\mathrm{e}} \mathrm{s}$. et il est remplacé par une construction en opus africanum dont le plan nous échappe en grande part du fait de l'étroitesse de la zone fouillée. Ces nouvelles installations fonctionnent jusqu'au début du Ir s. av. J.-C. Dans les années 80 avant notre ère, en 


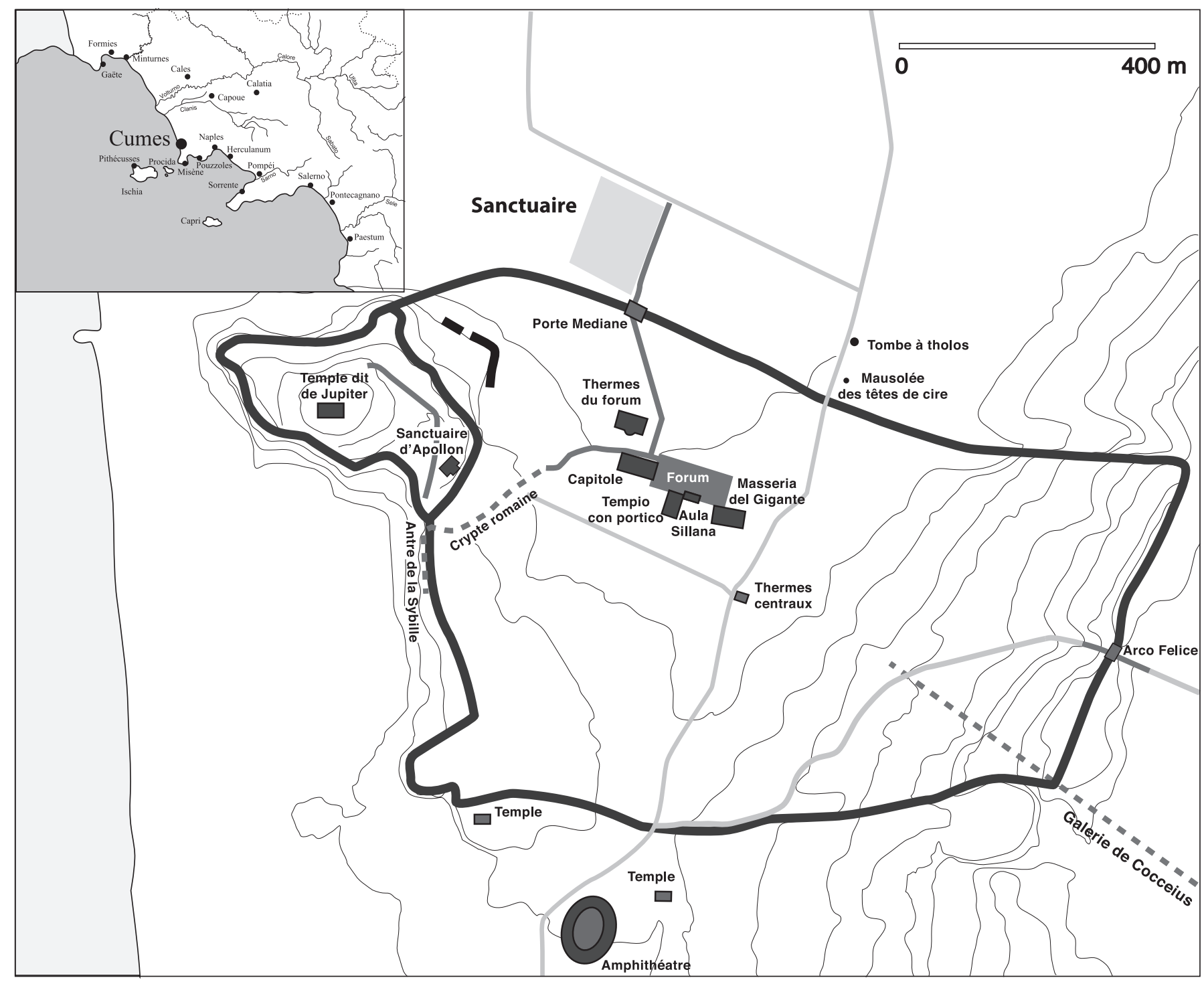

viabilité moderne

fortifications

viabilité antique

secteurs fouillés par le Centre Jean Bérard

Fig. 1. Plan de situation de Cumes (Dessin : M. Pierobon / CJB, CNRS- ÉfR). 


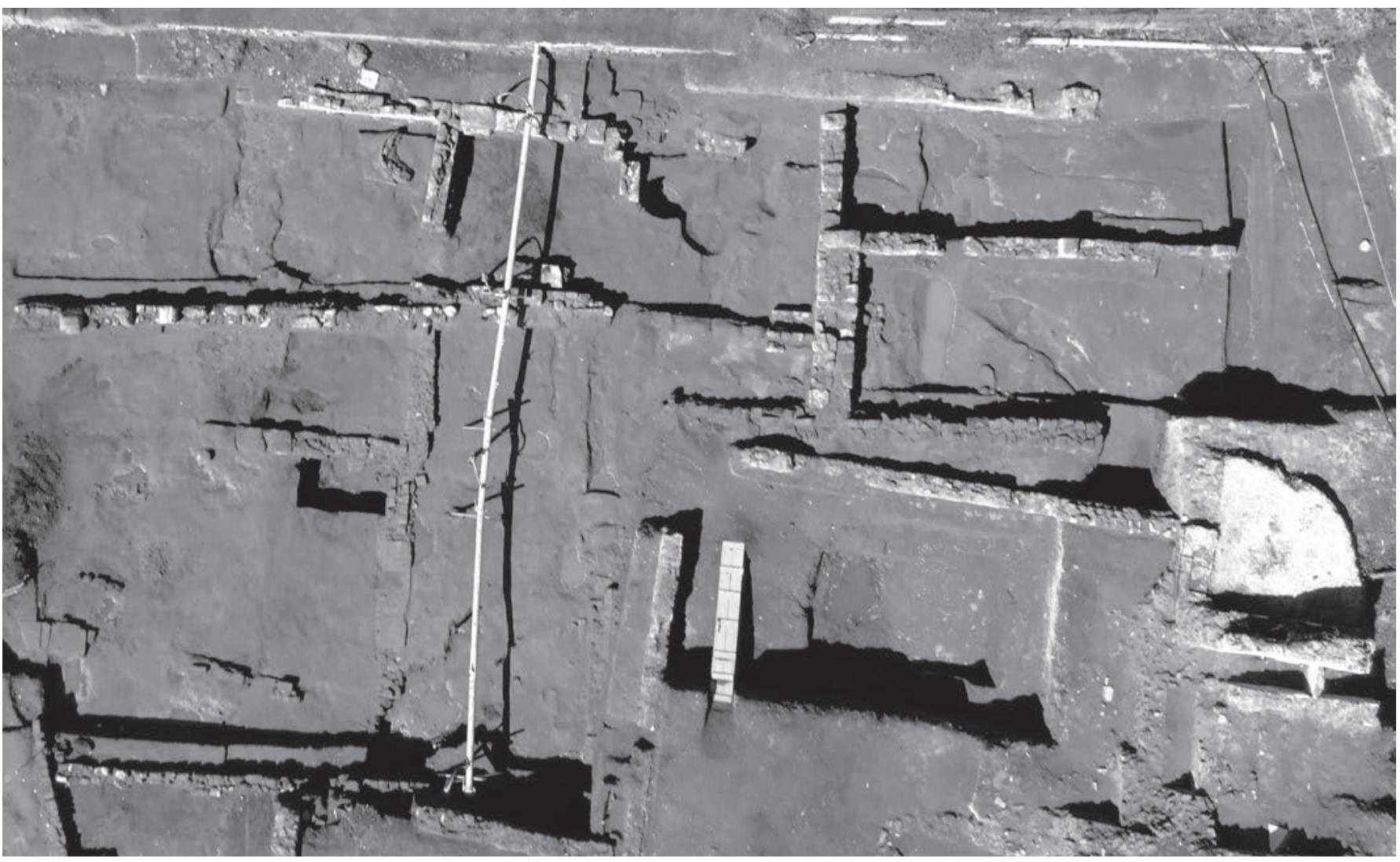

Fig. 2. Vue d'ensemble de la zone fouillée dans le sanctuaire (Cliché : J.-P. Brun / CJB, CNRS- ÉfR).

rapport avec des changements urbanistiques importants incluant le comblement du fossé en avant des remparts, le sanctuaire est désaffecté. Il est partiellement détruit par un large canal d'évacuation des eaux pluviales et usées, et recouvert d'une couche de gravats. C'est sur ce niveau que va s'étendre, à partir du milieu du ${ }^{\text {er }} \mathrm{s}$. av. J.-C., la nécropole romaine dont les monuments densément implantés empêchent d'explorer la partie sud du sanctuaire qui borde la via Domitiana.

\section{Le complexe cultuel des $\mathrm{V}^{\mathrm{e}}$-IV $\mathrm{S}^{\mathrm{e}}$. : structures et stratigraphie (fig. 2 et 5 )}

Le bâtiment construit dans le sanctuaire vers le milieu du $\mathrm{V}^{\mathrm{e}} \mathrm{s}$. comprend au moins trois pièces ouvrant sur une galerie bordant deux et probablement trois côtés d'une cour. Les murs sont édifiés en gros blocs de tuf de remploi à la base et l'élévation est faite de petites pierres de tuf. L'une de ces pièces, mesurant 3,50 par $4 \mathrm{~m}$, a conservé son sol (fig. 3). Au centre une structure carrée composée par plusieurs petits blocs de tuf servait de foyer. Sur le côté nord, se trouvait une amphore décapitée, enfoncée dans le sol. Le sol fait de tuf concassé couvre seulement la partie centrale de la pièce, donc l'espace de circulation autour du foyer. Contre les murs, ce sol est remplacé par la surface du remblai de préparation du sol, ce qui indique qu'une installation longeait les murs, probablement des banquettes de bois.

Les trois salles mises au jour ont été utilisées durant plus d'un siècle, étant entretenues avec soin. On ne trouve en effet pratiquement pas de détritus sur les sols.

Vers la fin du IV ${ }^{\mathrm{e}}$ s., ce bâtiment est désaffecté : les murs sont rasés et une épaisse couche de vases cassés répandue. La couche US 700137 et 700172 a livré 6072 vases identifiés à partir de 27502 fragments. Il s'agit principalement de céramique de cuisine mais aussi de vases à boire à vernis noir qui permettent de préciser la datation.

Ce dépôt semble attribuable à l'enfouissement de vaisselle et de vases de cuisine utilisés dans ces salles et probablement conservés dans une des pièces ou dans des armoires.

Cette action a été suivie d'une autre matérialisée par le creusement d'une fosse (FS700114) dans laquelle ont été déposés 28 vases entiers (fig. 4). Par sa composition et sa cohérence, le dépôt dans cette fosse ne semble pas de même nature que celui de l'épandage 700137-700172. 


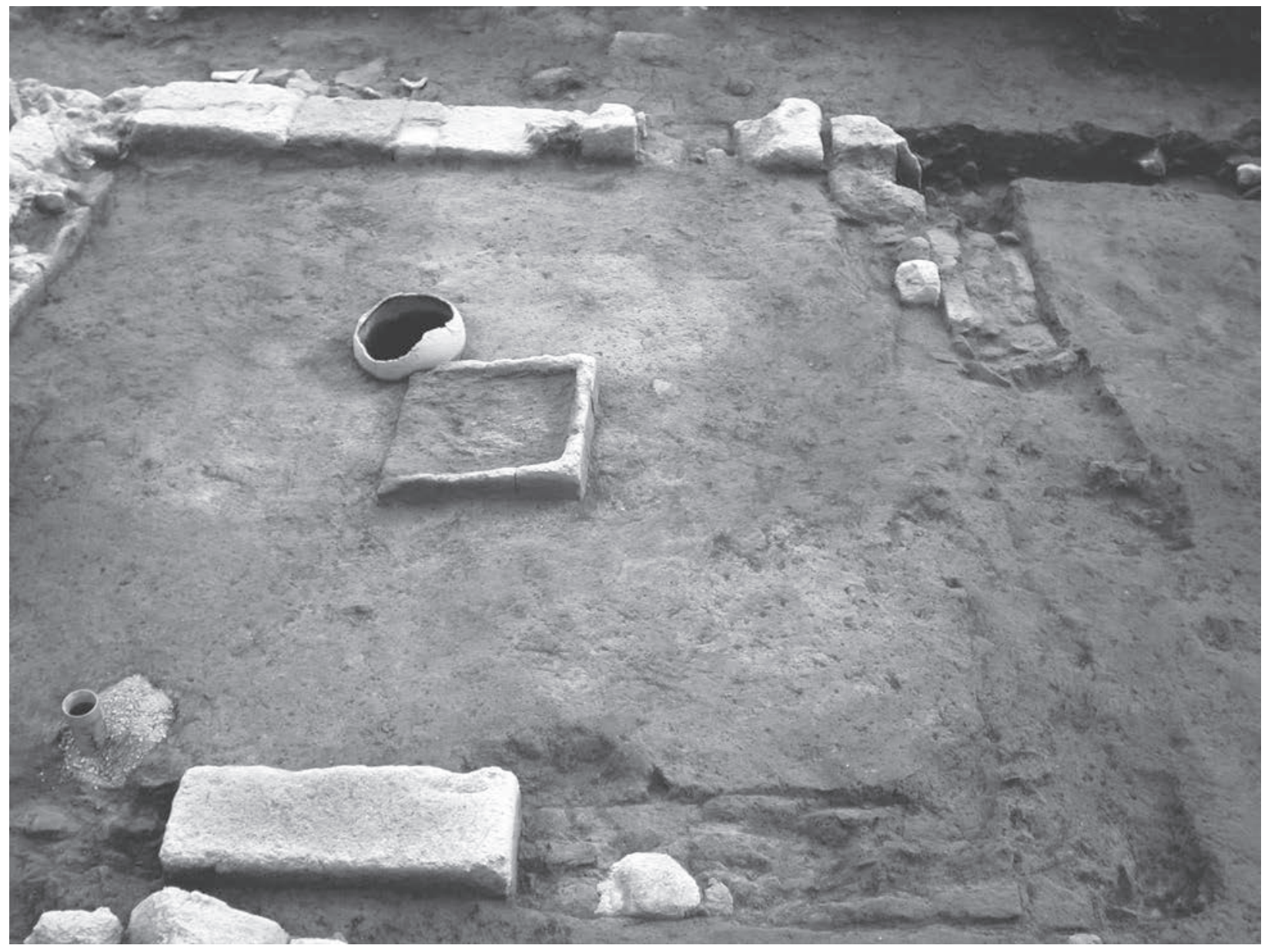

Fig. 3. Une des salles à banquet avec le foyer central et l'amphore décapitée (Cliché : J.-B. Brun / CJB, CNRS- ÉfR).

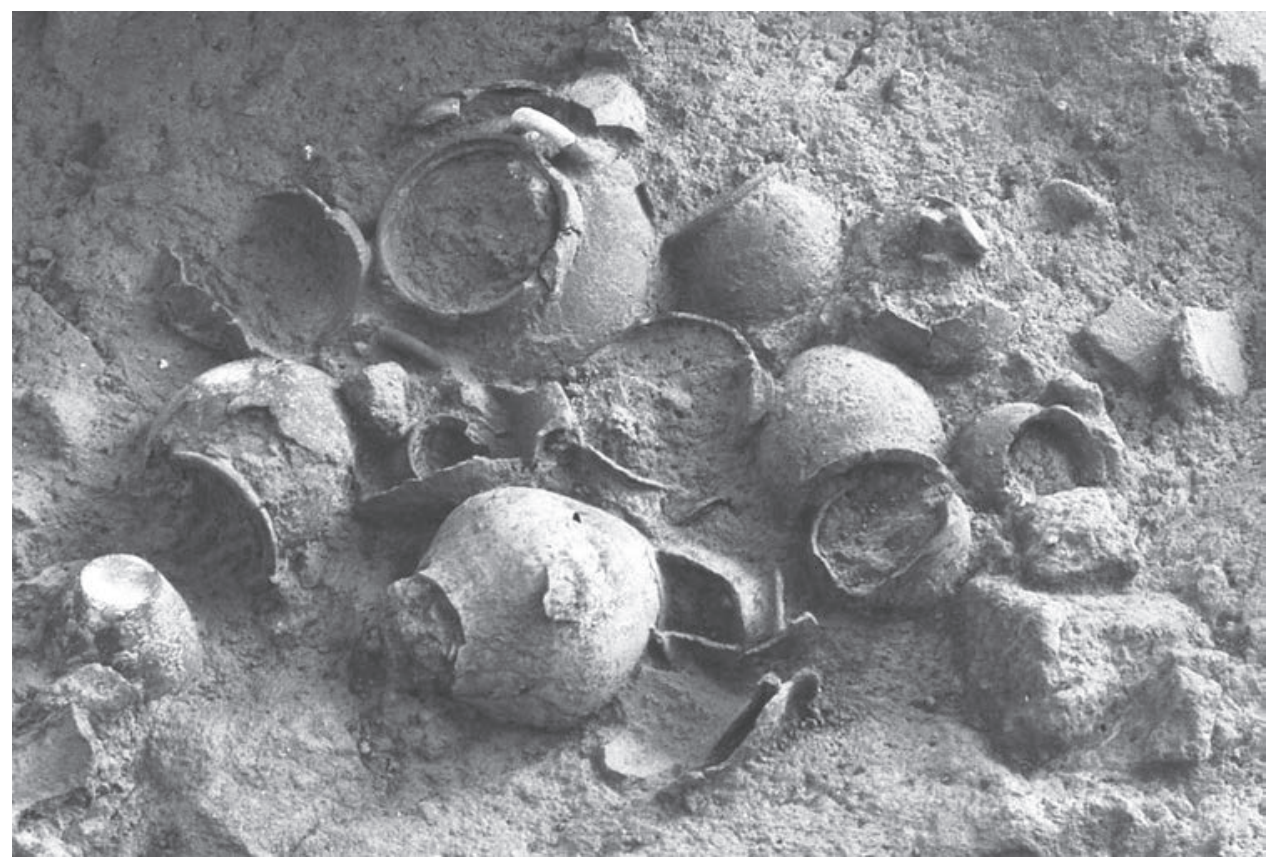

Fig. 4. Vases déposés dans la fosse FS700114 (Cliché : J.-P. Brun / CJB, CNRS- ÉfR). 


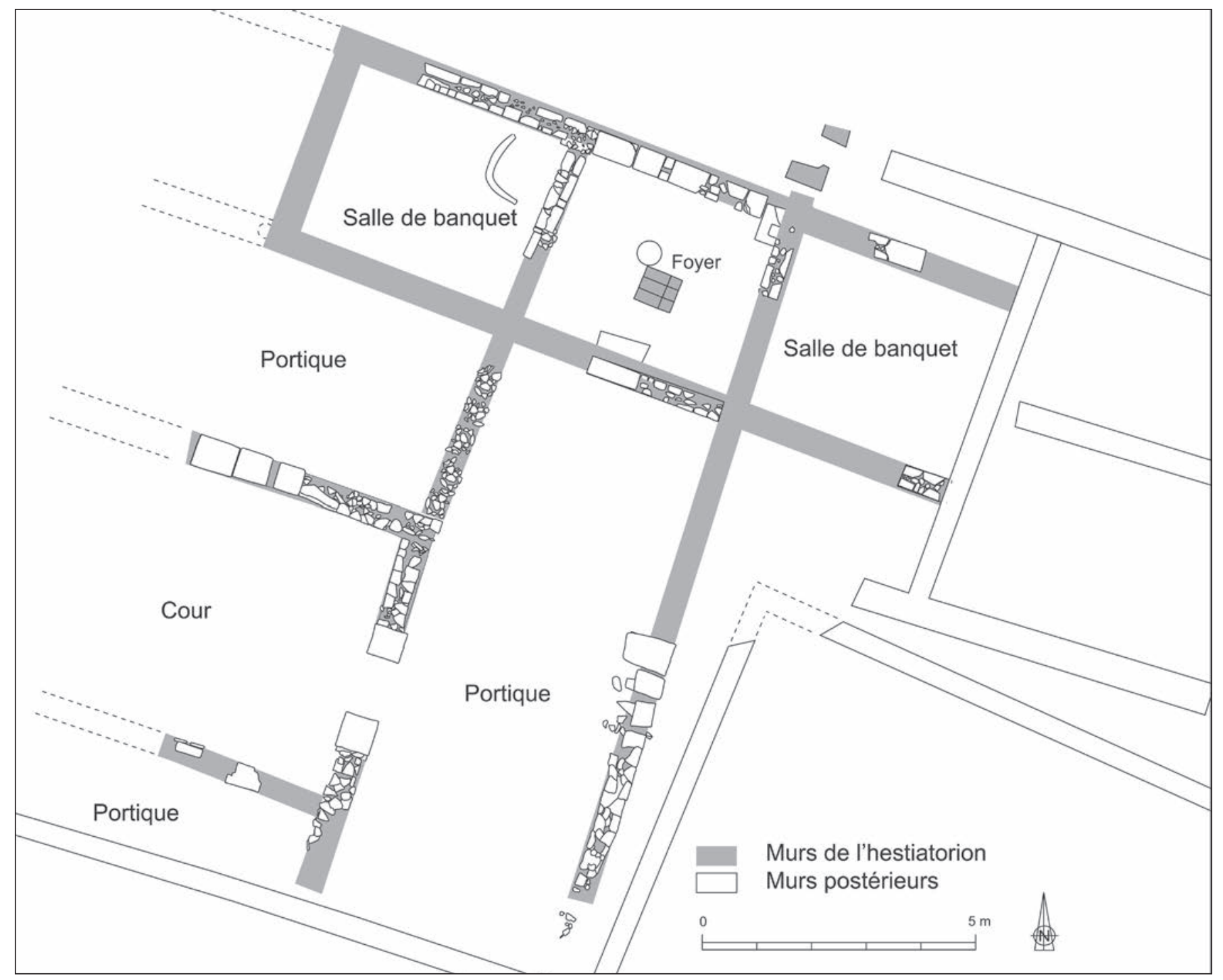

Fig. 5. Plan du bâtiment à l'époque classique (Relevé - dessin : J.-P. Brun / CJB, CNRS- ÉfR). 


\section{La vaisselle et les vases votifs}

En maintenant la distinction opérée à la fouille entre le vaste épandage 700137-700172 et la fosse FS700114, on s'aperçoit que les comptages, bien que portant sur des quantités incomparables car le mobilier de la fosse représente $0,5 \%$ du total, semblent témoigner de faciès différents.

Dans l'épandage, on trouve surtout de la vaisselle de table et de cuisine avec quelques vases miniatures (fig. 6). La vaisselle à vernis noir comprend 377 vases, essentiellement des skyphoi Morel 4373, des kylikes Morel 4240, des coupes à une anse Morel 6210 et 6230 , des coupes Morel 2586 et 2784, des coupelles à profil concave-convexe Morel 2424, 2433 e 2435-2437 et des coupelles Morel 2971 (fig. 7). À cela s'ajoutent des fragments de 22 vases à figures rouges.

Une petite partie de la céramique, $9 \%$, correspond à de la vaisselle de table et à quelques vases de réserve et de préparation, de type mortiers. La vaisselle de table comprend surtout des cruches et des amphores de table destinées à transporter et conserver les liquides, surtout du vin.

La plus grosse partie du mobilier, $81 \%$, est composée de récipients de cuisine, au total 5390 vases (fig. 8). Ce sont principalement des pots à cuire, des ollae à bord plat ou en bandeau, suivis de loin par des marmites et des faitouts et leurs couvercles, quelques rares poêles et des cloches de cuisson.

Enfin 174 vases miniatures se trouvaient associés au dépôt principal, il s'agit de calices destinés aux offrandes symboliques aux dieux, prémisses et parfums.

Dans la fosse FS700114, les proportions de vaisselle de cuisine sont du même ordre. Elle a restitué 28 vases complets dont 24 ollae et une caccabè en céramique culinaire, une petite olpé et deux amphores en céramique de table (fig. 9). La fouille de la fosse a restitué aussi un acrotère à disque et quatre antéfixes : une représentant un visage féminin, une à palmette inversée et deux à palmettes droites datées du milieu du VI ${ }^{\mathrm{e}} \mathrm{s}$. av. J.-C. (Dewailly, Munzi 2011). Les terres cuites, ainsi que certaines ollae, une des deux amphores et la petite cruche étaient situées dans la partie septentrionale de la fosse. Dans la vaisselle de cuisine, ce sont les urnes qui dominent à l'instar du dépôt principal ${ }^{2}$. Le contraste entre les éléments architectoniques et le matériel céramique est frappant, aussi bien pour la chronologie que pour leur signification manifestant une volonté précise. Le lot de

2 Notons que le remplissage de la fosse a livré un peu moins de 1300 fragments de céramique provenant d'environ 120 individus, mais il s'agit de tessons apportés avec la terre utilisée pour remblayer la fosse. terres cuites architectoniques conservées pendant près de deux siècles, revêt vraisemblablement malgré leur aspect fragmentaire, un grande valeur sacrée.

En ce qui concerne le matériel céramique la chronologie est homogène dans le dernier quart du $\mathrm{IV}^{\mathrm{e}} \mathrm{s}$.

\section{Les restes de repas}

Les salles étant régulièrement nettoyées et les sols propres, les ossements retrouvés proviennent uniquement de l'épandage 700137-700172 où ils sont bien moins nombreux que les vases : à peine 250 ossements, ce qui fragilise évidemment les conclusions qu'on peut en tirer. Toutefois leur répartition est suffisamment différente de la consommation habituelle, tant du point de vue des espèces consommées que des âges d'abattage pour qu'on s'interroge sur leur signification.

Les restes déterminés (253 fragments) qui proviennent presque exclusivement d'espèces domestiques et consommées sont dans un état de conservation satisfaisant, compte tenu de la nature du dépôt et des manipulations dont ils ont fait l'objet dans le cadre des préparations culinaires. Ces restes sont constitués de déchets de repas rituels et les résultats nous informent sur leur nature : la sélection des espèces, des âges d'abattage et des quartiers consommés. Quelques os de chiens témoignent seulement de leur présence dans les lieux, ce qui n'a rien d'étonnant lorsqu'on se rappelle la place des chiens dans l'iconographie des scènes de banquets.

\section{Sélection des animaux et des quartiers consommés}

La première caractéristique mise en relief par l'étude de la faune porte sur la sélection des animaux consommés (fig. 10). La distribution des restes par espèce montre une plus forte proportion de quartiers de porcs et de poules domestiques, loin devant ceux des bovidés et des petits ruminants (fig. 11).

Le choix des victimes s'effectuait également en fonction d'un deuxième critère, l'âge des animaux. Dans ce domaine, on observe quelques différences entre les espèces. Les porcs étaient jeunes : les quartiers proviennent d'animaux abattus entre 6 et 18 mois. Les quartiers de petits ruminants et de bovidés proviennent d'individus adultes, soit âgés de 6/7 ans (fig. 12).

La distribution des restes en fonction des segments anatomiques, pour les porcs et les oiseaux galliformes domestiques (espèces les plus fréquentes), indique une consommation privilégiée de certains quartiers. Pour les porcs, sont restés dans le sanctuaire les têtes, la partie supérieure des pattes antérieures, les épaules et la partie inférieure des pattes postérieures, les jarrets (fig. 13). 

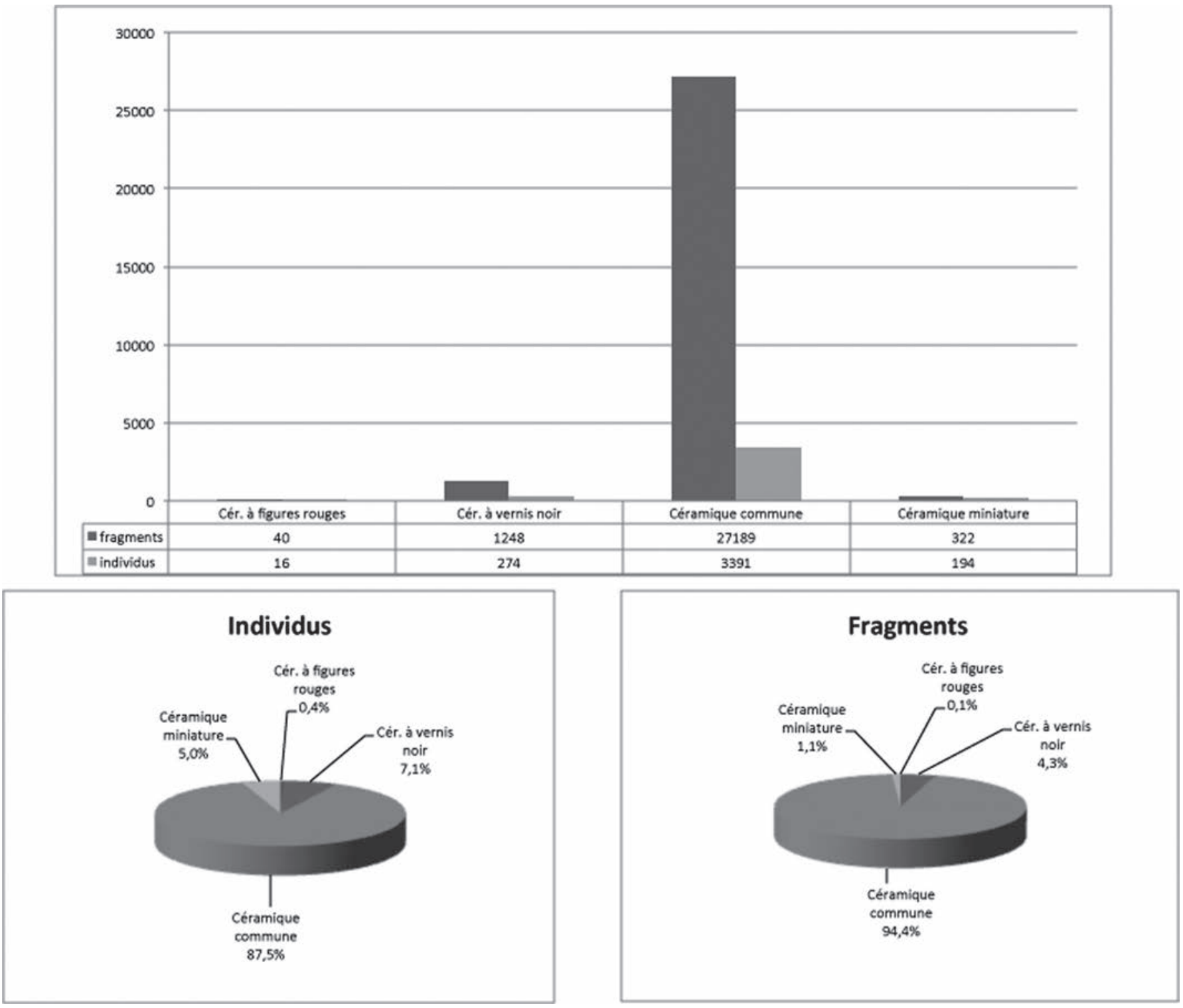

Fig. 6. Histogramme des catégories fonctionnelles de vaisselle des US 700137-700172 (Réal. : Pr. Munzi / CJB, CNRS- ÉfR). 


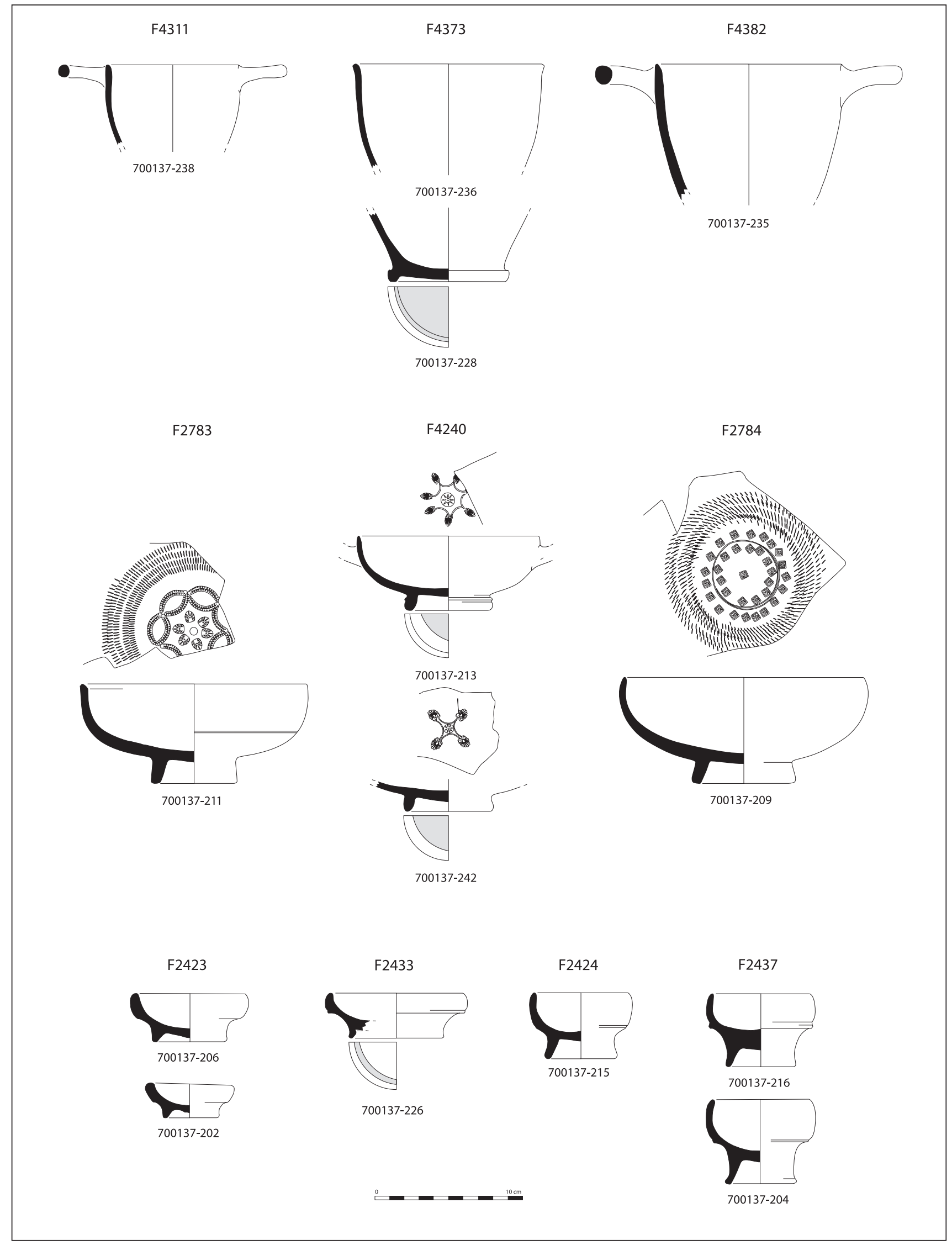

Fig. 7. Exemples des formes de vaisselle des US 700137-700172 (Dessin : G. Stelo / CJB, CNRS- ÉfR). 
JEAN-PIERRE BRUN, LAËTITIA CAVASSA, MARTINE LEGUILLOUX, PRISCILLA MUNZI

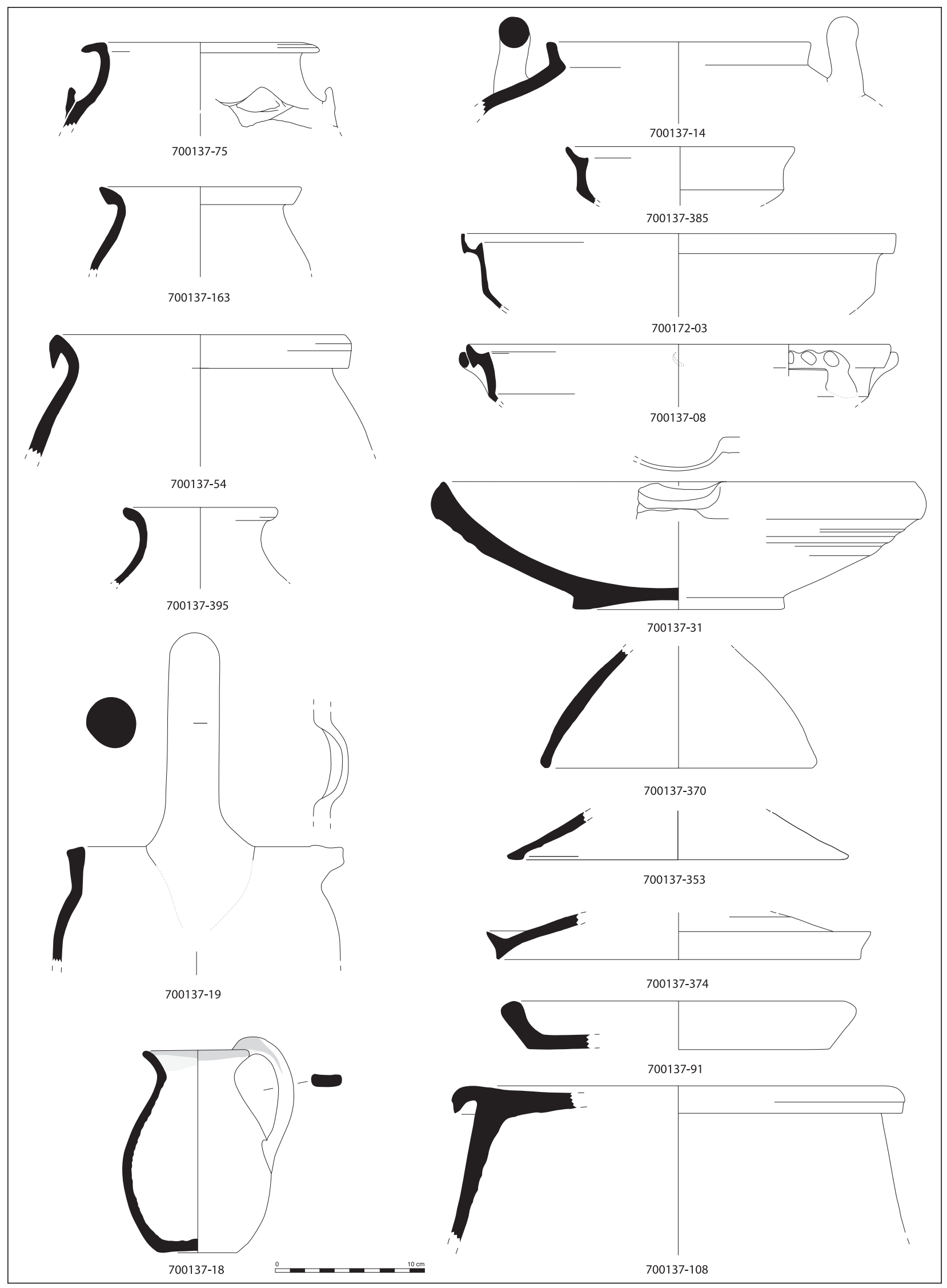

Fig. 8. Exemples des formes de vaisselle des US 700137-700172 (Dessin : G. Stelo / CJB, CNRS- ÉfR).

90 


$$
\begin{array}{ll}
2 & l \\
r & l \\
e & l
\end{array}
$$




\begin{tabular}{|c|c|c|c|c|c|}
\hline US $700137+700172$ & Bos t. & Ovis/Capra & Sus d. & Gallus sp. & Canis $\mathrm{f}$. \\
\hline Divers crânes & 2 & 3 & 12 & & 2 \\
\hline Mandibules & 1 & 2 & 17 & & 5 \\
\hline Dents isolées & 6 & 9 & 4 & & 1 \\
\hline Vertèbres cervicales & & 2 & 2 & & \\
\hline Vertèbres caudales & 1 & & & & \\
\hline Côtes & 10 & 2 & 8 & & \\
\hline Scapulas & 3 & 4 & 8 & 2 & \\
\hline Humérus & 1 & 9 & 13 & 7 & \\
\hline Radio-ulnas & & 2 & 5 & 12 & 3 \\
\hline Pelvis & & & & & 6 \\
\hline Fémurs & & 5 & & 12 & \\
\hline Tibias & 2 & 4 & 9 & 8 & 8 \\
\hline Carpes/Métacarpes & 4 & 1 & 8 & 1 & 1 \\
\hline Tarses/Métatarses & 2 & 5 & 1 & 2 & 1 \\
\hline Phalanges & 2 & & 3 & & 1 \\
\hline Autres & 1 & & & 8 & \\
\hline Total & 35 & 48 & 90 & 52 & 28 \\
\hline $\mathrm{PO}$ & 539 & 270 & 592 & 144 & \\
\hline
\end{tabular}

Fig. 10. Tableau des restes osseux des unités stratigraphiques 700137-700172 (Réal. : M. Leguilloux / CJB, CNRS- ÉfR).

Pour les oiseaux galliformes domestiques, on trouve les membres antérieurs et postérieurs (fig. 13). Dans ce dernier cas cependant le petit nombre de restes récoltés ne permet pas d'assurer une réelle sélection des quartiers.

\section{Interprétation et identification du rituel}

On manque de sites bien publiés pour comparer les restes de repas rituels dans les sanctuaires d'Italie méridionale. Trois exemples seulement ont fourni des données, les sanctuaires de Santa Venera et des Foce Sele à Poseidonia (Campanie) et celui de Syracuse (fig. 14). Dans le sanctuaire extra-urbain de Santa Venera, les restes d'ovinscaprins représentent une proportion écrasante contrairement au dépôt trouvé à Cumes, et les oiseaux (poules et pigeons) sont fréquents, avec 16,2\% des restes déterminés (Toco Sciarelli et coll. 1988).

Dans l'Héraion à l'embouchure du Sele, sanctuaire d'Héra argienne (Hera Argiva), les fouilles du début du siècle ont mis au jour un ensemble de petits édifices religieux et un grand nombre de statuettes de personnages féminins offrant une oie (Dewailly 1997). Les fouilles ont également mis au jour deux bothroi, comblés entre la fin du IVe $\mathrm{s}$. (date de creusement des puits) et la fin du $\mathrm{III}^{\mathrm{e}} \mathrm{s}$., Ils contenaient des ex-votos et des ossements d'animaux, mais le décompte de ces restes n'est pas donné ; les auteurs mentionnent des ossements de chèvres, de chiens, de chats et de tortues, ainsi que de nombreuses coquilles d'œufs associés à des os brûlés de volailles et de pigeons.

Le dépôt découvert à Syracuse provient d'un bothros situé près d'un autel qui serait la seule survivance des temples de Déméter et Coré, détruit par les Carthaginois au IV $\mathrm{s}$. Le sanctuaire aurait toutefois continué à fonctionner par la suite et le bothros contiendrait les restes de repas rituels qui se seraient déroulés au $\mathrm{II}^{\mathrm{e}} \mathrm{s}$. av. J.-C. (Villari 1989). L'examen des résultats montre qu'il s'agit d'un rite très différent puisque les restes de porcs sont majoritaires (fig. 14).

Le sanctuaire de la zone 700 à Cumes présente quelques similitudes avec les sanctuaires des $\mathrm{V}^{\mathrm{e}} / \mathrm{IV}^{\mathrm{e}} \mathrm{s}$. dédiés à Aphrodite et Héra de Poseidonia pour ses proportions élevées en restes d'oiseaux, mais pas pour les autres espèces. C'est surtout avec celui de Déméter et Coré à Syracuse qu'on trouve le parallèle le plus net, du fait de la part importante de quartiers de porcs consommés lors des repas rituels. La présence d'oiseaux est un indicateur pour permettre l'identification de la divinité à laquelle était dédiée le sanctuaire. Les ossements de ces espèces sont particulièrement présents dans les dépôts liés aux cultes (sacrifices, offrandes, banquets) de divinités féminines. Les cultes d'Aphrodite et Héra se caractérisant par la présence de volailles, auxquelles cependant sont généralement associées des offrandes de petits ruminants. La forte concentration de quartiers de 


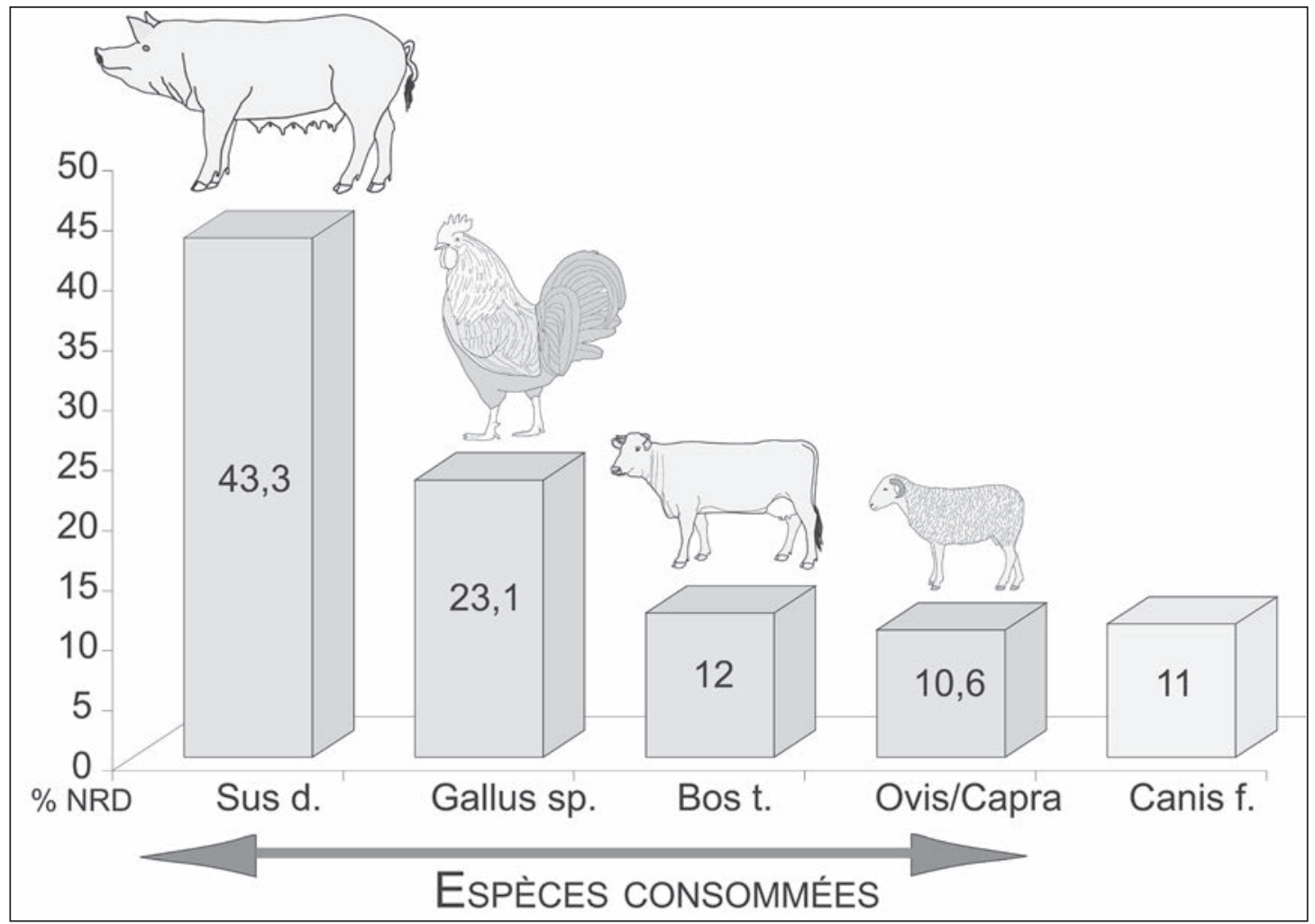

Fig. 11. Les principales espèces présentes dans les US 700137-700172 (\% NRD) (Réal. : M. Leguilloux / CJB, CNRS- ÉfR).

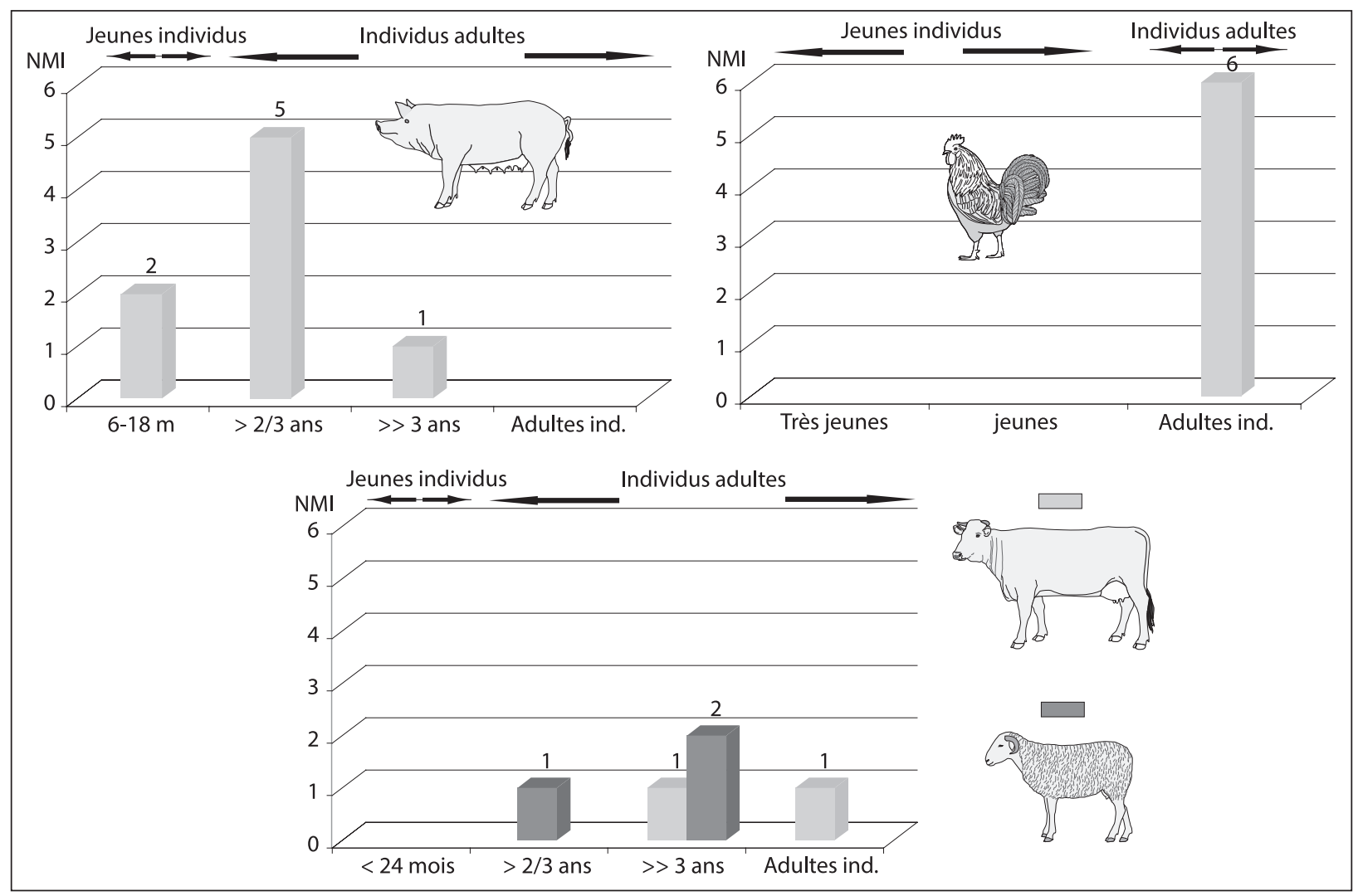

Fig. 12. Les âges d'abattage des animaux (Élab. : M. Leguilloux / CJB, CNRS- ÉfR). 


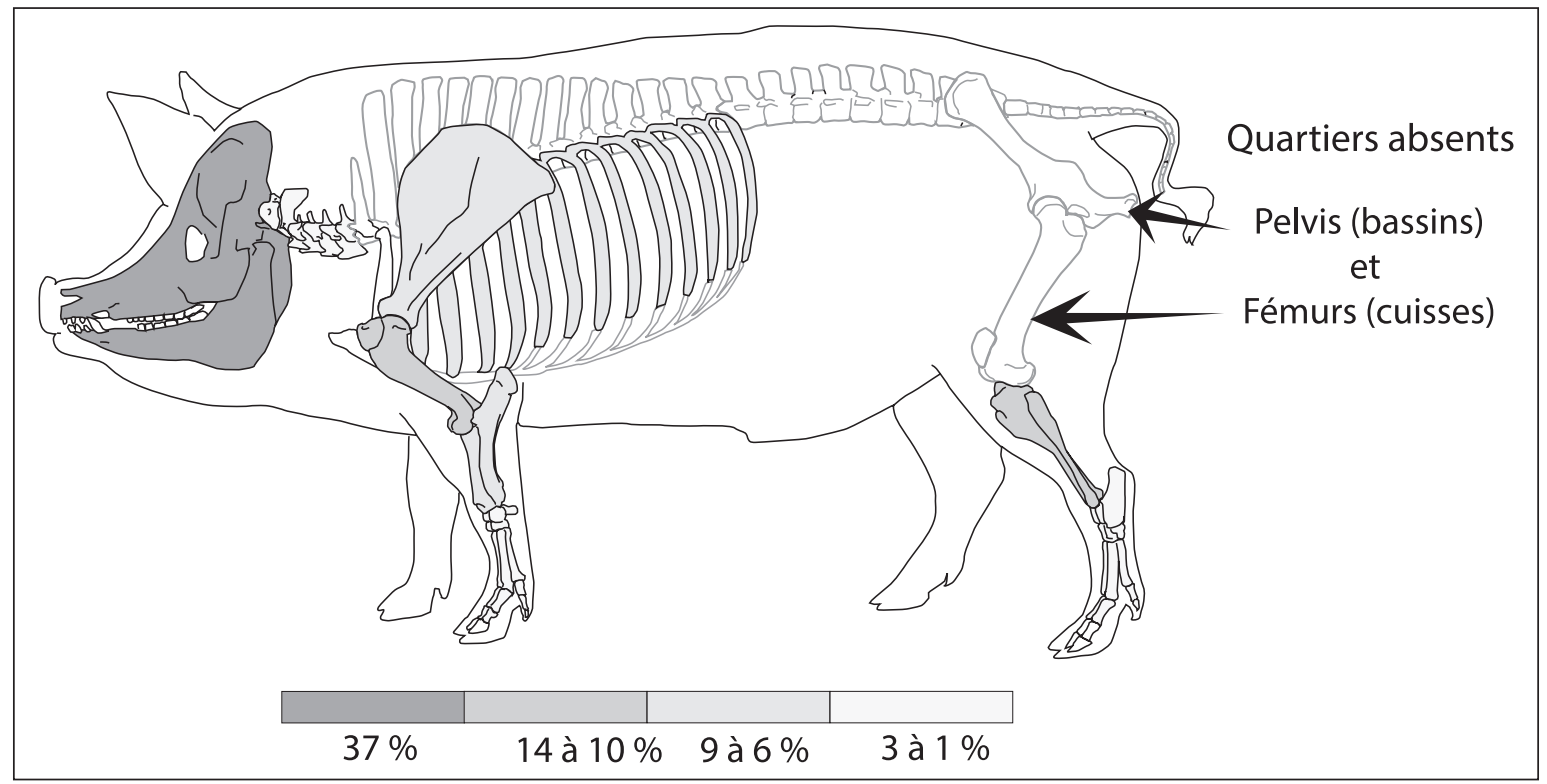

Fig. 13. Les quartiers de porcs et poules domestiques (\% NRD) (Réal. : M. Leguilloux / CJB, CNRS- ÉfR).

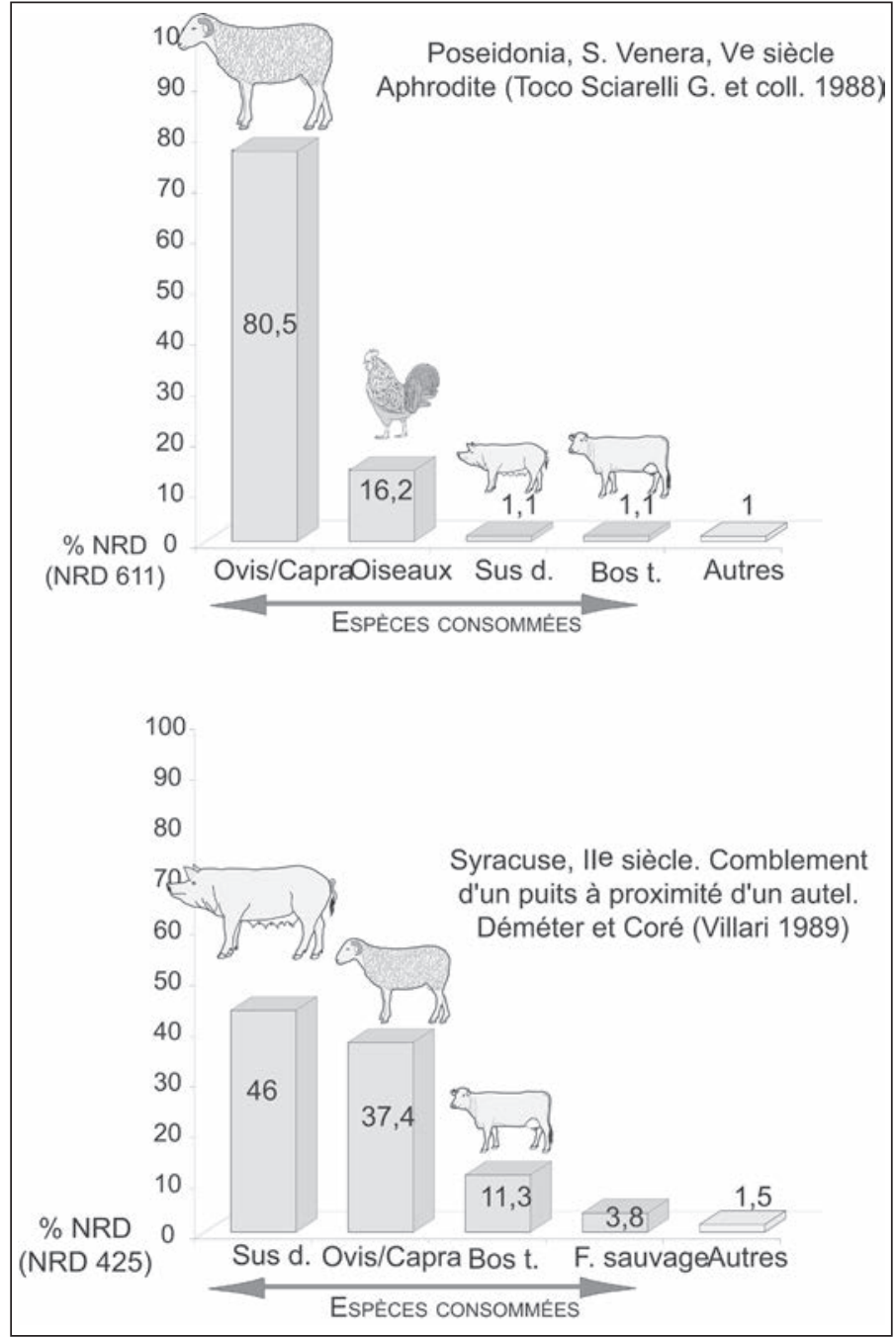

Fig. 14. La faune de repas rituels en Grande Grèce : les exemples de Paestum et Syracuse (Réal. : M. Leguilloux ; CJB, CNRS- ÉfR). 


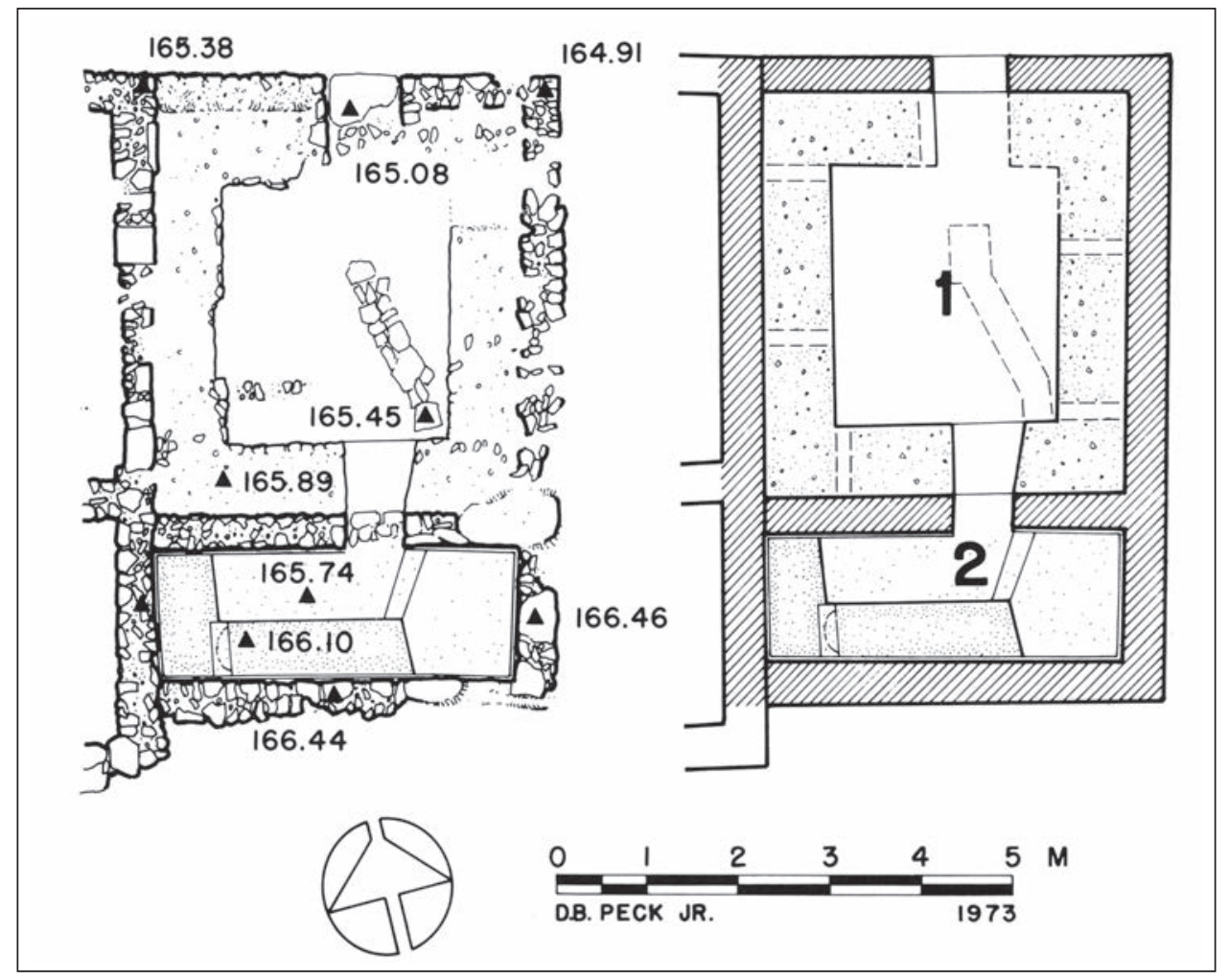

Fig. 15. Plan des hestiatoria du sanctuaire de Héra Lacinia à Crotone (d'après Seiler 1984, fig. 3).

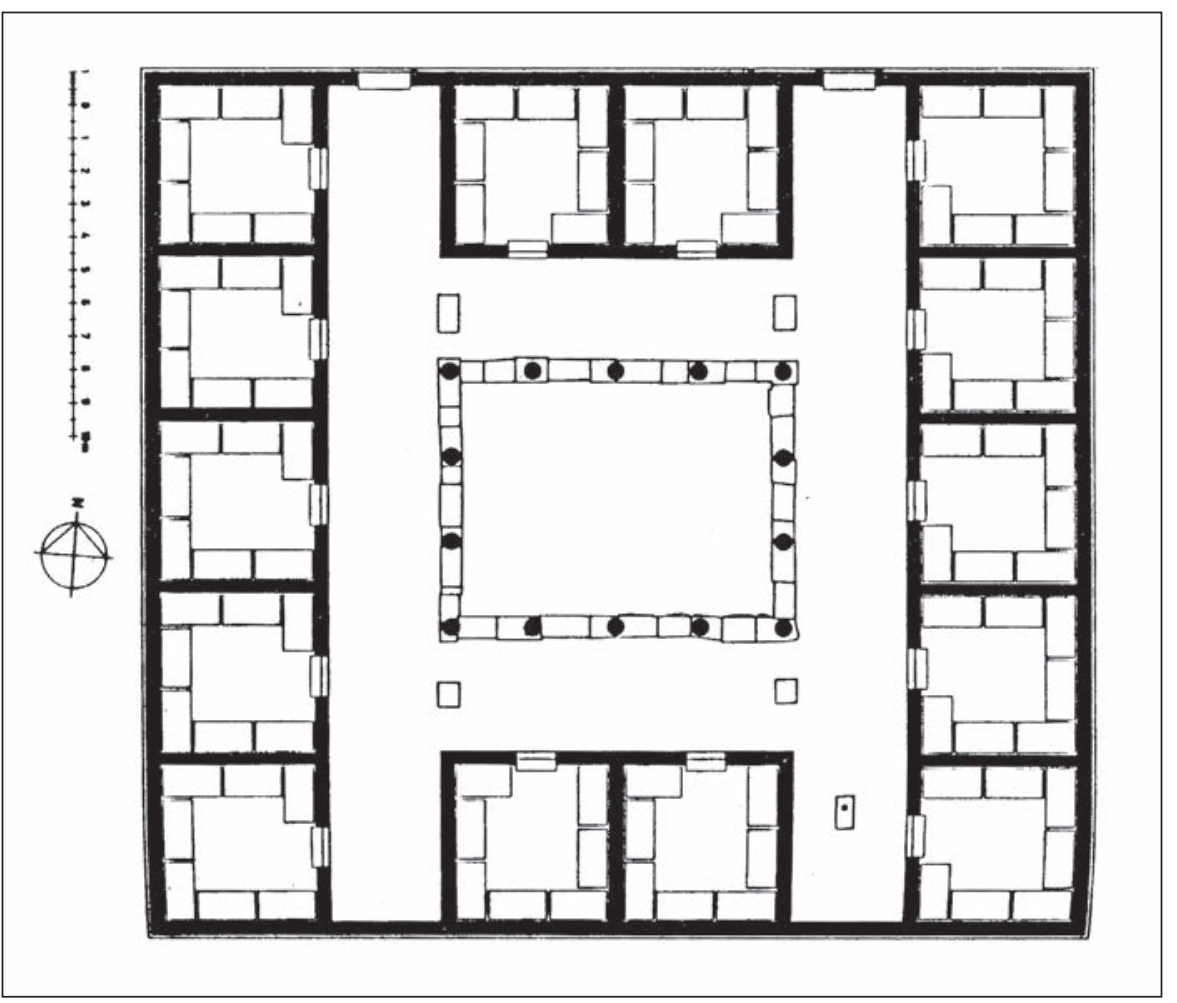

Fig. 16. Salle à banquet K-L du Ve $\mathrm{s}$. avant J.-C. dans le sanctuaire de Déméter et Corè à Corinthe (d'après Brookidis, Stroud 1997, fig. 15). 
porcs favorise l'hypothèse d'un sanctuaire consacré à Déméter et Corè, seules divinités associées avec régularité au porc et à sa consommation rituelle (Hermary, Leguilloux 2004, p. 59-134).

\section{Interprétation}

Notre hypothèse est que les salles alignées ouvrant sur la cour sont des salles de banquets rituels dans le sanctuaire. Le plan trouve des parallèles dans des ensembles de salles à banquets bien conservées dans des sanctuaires de Grèce propre, l'Héraion d'Argos, l'Asklépéion de Corinthe ou, en Grande Grèce, le sanctuaire d'Hera Lacinia à Crotone dont les salles ouvrent sur un portique analogue à celui que nous pouvons restituer ici (Will 1976 ; Bookidis, Stroud 1997 ; Seiler 1984) (fig. 15). Dans le détail, bien que deux des trois salles soient ruinées, les aménagements observés dans la salle centrale, avec le foyer central et l'existence supposée de banquettes de bois le long des murs trouve des parallèles en maçonnerie dans le sanctuaire de Déméter et Corè de Corinthe, où entre le VI ${ }^{\mathrm{e}}$ et le $I^{\mathrm{e}} \mathrm{s}$. un grand nombre de salles a été construit pour les banquets rituels (Hansen, Bookidis 1999) (fig. 16). La présence d'une amphore coupée à l'épaule, enfoncée dans le sol à côté du foyer, pourrait être interprétée comme un réceptacle à libations.

Comme les sols finaux des salles sont recouverts par l'épais dépôt de vases que nous venons de présenter, on est fondé à penser qu'ils étaient en usage dans ces mêmes lieux et qu'ils devaient être conservés dans un espace particulier, ou peut-être des armoires en bois qui ont dû être récupérés. La forte proportion de vaisselle culinaire, en particulier d'urnes, montre qu'on y faisait fréquemment la cuisine. Ces urnes sont les vases typiques de cuisson des populations italiques pour la préparation de la puls. Dans son ouvrage sur la vaisselle d'Olbia, Michel Bats a défini leur rôle (Bats 1988 p. 65-67) : l'olla sert à la cuisson des légumes bouillis et surtout de la bouillie de blé, de blé amidonnier et de millet. Dans le sanctuaire de Déméter et Corè de Corinthe, les fouilles publiées par N. Bookidis, de J. Hansen et L. Snyder ont pu retrouver des macrorestes de blé, lentilles, raisins et olives dans les salles de banquets ainsi que des ossements de porcelets et des arêtes de poissons. La publication ne fournit pas les comptages de la vaisselle, mais les auteurs disent que les vases les plus nombreux étaient les coupes à boire et que la vaisselle culinaire était peu représentée. À Cumes, le reste de la vaisselle, principalement des coupes à boire, certaines étant probablement utilisées pour manger la bouillie, renvoie à la pratique du banquet collectif.
Les ossements retrouvés montrent qu'on mangeait surtout de jeunes cochons et de la volaille. Lorsqu'on compare cette consommation avec les restes retrouvés dans des dépôts potentiellement interprétables comme des restes de repas rituels à Paestum et à Syracuse, on décèle quelques particularités. Dans le sanctuaire d'Aphrodite à Paestum, c'est la consommation de mouton qui domine largement devant la volaille, alors que le porc est quasiment inexistant. Dans un sanctuaire anonyme fouillé par Agnès Rouveret dans l'enclos d'Héra, les moutons dominent mais moins nettement et la consommation du cochon vient immédiatement après (inédit). À Syracuse, le comblement d'un puits associé à un autel dédié à Déméter montre une nette domination du porc devant le mouton. L'échantillon de Cumes est trop petit pour tirer des conclusions définitives, mais on peut observer que le parallèle le plus net correspond au culte de Déméter et Corè (Hermary, Leguilloux, 2004, p. 80-81).

Or l'analyse des textes et des inscriptions, notamment à partir de l'article de M. Détienne sur les femmes aux Thesmophories (Détienne 1979, p. 181-214) et de $\mathrm{Ph}$. Bruneau analysant les rituels à Délos (Bruneau 1970, p. 279-293), complété par les observations de J. Hansen et N. Bookidis (1999) à Corinthe montrent que les rituels prévoyaient non seulement l'enfouissement de porcelets dans les megara mais aussi le sacrifice de cochons, leur cuisson et leur consommation au cours des cérémonies. Les os des US 700137-700172 pourraient donc correspondre aux détritus de ces consommations rituelles. La cuisine du sacrifice tient en effet une place essentielle dans la culture grecque et italique : le sacrifice est au centre des pratiques alimentaires et religieuses et garant de la cohésion politique des citoyens.

La fosse FS700114 creusée en bordure du grand dépôt est stratigraphiquement et chronologiquement contemporaine de la destruction du bâtiment mais son interprétation ne paraît pas ressortir de la même logique. Plutôt que de l'enfouissement de vases mis hors d'usage lors de l'abandon des salles à banquet, il s'agirait plutôt des restes d'une cérémonie de clôture, comme on en connaît sur d'autres sanctuaires de la même époque en Campanie. À la fin du IVe s., Cumes est intégrée dans la culture samnite depuis un siècle et il n'est donc pas étonnant que l'on y pratique des cérémonies analogues à celles constatées à Pontecagnano et à Albanella notamment, où les officiants des cérémonies de désacralisation des lieux ont déposé les vases utilisés lors ces événements (Cerchiai 2008). À Cumes même, un autre complexe sacré, récemment fouillé au sud-est du Forum, a livré des traces d'une cérémonie analogue (Greco 2008 ; Tomeo 2008). 


\section{Bibliographie}

Bats 1988 : BATS (M.) - Vaisselle et alimentation à Olbia de Provence. Paris, CNRS, 1988.

Bats, Brun, Munzi 2009 : BATS (M.), BRUN (J.-P.), MUNZI (P.) - Ai margini della colonia greca di Cuma. In : Cuma, Atti del $48^{\circ}$ Convegno di Taranto 2008. Taranto, Istituto per la storia e l'archeologia della Magna Grecia, 2009, p. 525-552.

Bookidis, Stroud 1969 : BOOKIDIS (N.), STROUD (R.S.) - Sanctuary of Demeter and Kore on Acrocorinth, Preliminary report, 3, Hesperia 38, 1969, p. 297-310. Bookidis, Stroud 1997 : BOOKIDIS (N.), STROUD (R.S.) - Corinth XVIII, 3. The sanctuary of Demeter and Korè. Topography and architecture. Princeton, The American School of Classical Studies, 1997.

Brun, Munzi 2011 : BRUN (J.-P.), MUNZI (Pr.) - Les travaux du Centre Jean Bérard au nord de l'enceinte urbaine et au sud de l'acropole, Bulletin de la société française d'archéologie classique (xli, 2009-2010), Revue archéologique, 2011/1 - n 51, p. 150-172.

Bruneau 1970 : BRUNEAU (Ph.) - Recherches sur les cultes de Délos à l'époque hellénistique et à l'époque impériale. Paris, 1970.

Cerchiai 2008 : CERCHIAI (L.) - Cerimonie di chiusura nei santuari italici dell'Italia meridionale. In : Greco (G.) et Ferrara (B.) éd. - Doni agli dei. Il sistema dei doni votivi nei santuari, Pozzuoli, 2008, p. 23-27.

D’Agostino, Fratta, Malpede 2005 : D'AGOSTINO (B.), FRATTA (F.), MALPEDE (V.) - Cuma. Le fortificazioni, 1. Lo scavo 1994-2002, Napoli 2005. Détienne 1979 : DÉTIENNE (M.) - La cuisine du sacrifice en pays grec. Paris, 1979.

Dewailly 1997 : DEWAILLY (M.) - L'Héraion de Foce del Sele : quelques aspects du culte d'Héra à l'époque hellénistique d'après les terres cuites. In : Héra. Images, espaces, cultes. Actes du Colloque International de Lille (1993). Naples, Collection du Centre Jean Bérard 15, 1997, p. 201-210.

Dewailly, Munzi 2011 : DEWAILLY (M.), MUNZI (Pr.) - Cuma, un acroterio a disco con maschera di Gorgo. Dal ritrovamento all'ipotetica collocazione. In : Lulof (P.), Rescigno (C.), Deliciae fictiles IV, Architectural terracottas in Ancient Italy. Images of Gods, Monsters and Heroes. Oxford, 2011, p. 322-330.
Greco 2008 : GRECO (G.) - Strutture per un sacrificio. In : Greco (G.) et Ferrara (B.) éd., Doni agli dei. Il sistema dei doni votivi nei santuari, Pozzuoli, 2008, p. 29-48.

Greco 2008 : GRECO (G.) - Modalità di occupazione in età arcaica, nell'area del foro di Cuma. In: Greco (G.), Gasparri (C.), Cuma : indagini archeologiche e nuove scoperte : atti della giornata di studi. Napoli, 12 dicembre 2007, Pozzuoli, 2009, p. 11-42.

Guzzo 2009 : GUZZO (P.G.) - Kyme palaiotaton ktisma, Annuario della Scuola Archeologica Italiana di Atene, 2009-2010, Vol. LXXXVII [Serie III], p. 509-522.

Hansen, Bookidis et alii 1999 : BOOKIDIS (N.), HANSEN (J.), SNYDER (L.), GOLDBERG (P.) - Dining in the Sanctuary of Demeter and Kore at Corinth, Hesperia, 68, 1999, p. 1-54.

Hermary, Leguilloux 2004 : HERMARY (A.), LEGUILLOUX (M.) (AVEC LA COLL. DE V. CHANKOWSKI, A. PETROPOULOU) - Les sacrifices dans le monde grec. In: Thesaurus cultus et rituum antiquorum (ThesCRA) I, Processions, sacrifices, libations, fumigations, dédications. Los Angeles, The J. Paul Getty Museum, 2004, p. 59-134.

Pedley, Torelli 1993 : PEDLEY (J. G.), TORELLI (M.) - The Sanctuary of Santa Venera at Paestum. Il santuario di Santa Venera a Paestum. Rome, 1993.

Seiler 1984 : SEILER (F.) - Un complesso di edifici pubblici nel Lacinio a Capo Colonna. In : Crotone (Atti del XXIII convegno di studi sulla Magna Grecia, Taranto 1983), Taranto, 1984, p. 232-242.

Tocco Sciarelli et coll. 1988 : TOCCO SCIARELLI (G.) et coll. - I sanctuari. In : PoseidoniaPaestum, Atti del ventisettesimo convegno di studi sulla Magna Grecia, Taranto, 1988, p. 402-408.

Tomeo 2008 : TOMEO (A.) - Doni votivi e suppellettili nel complesso cultuale a S/E del Foro di Cuma. In : Greco (G.), Ferrara (B.) éd., Doni agli dei. Il sistema dei doni votivi nei santuari, Pozzuoli, 2008, p. 49-74.

Villari 1989 : VILLARI (P.) - Nature des offrandes animales du puits de Piazza della Victoria à Syracuse (milieu du $\mathrm{II}^{\mathrm{e}}$ siècle avant J.-C.), étude archéozoologique. Anthropozoologica, 11, 1989, p. 930.

Will 1976 : WILL (E.) - Banquets et salles de banquets dans les cultes de la Grèce et de l'Empire romain. In : Mélanges offerts à Paul Collart. Lausanne, 1976, p. 353-362. 



\title{
Un dépôt de fondation en contexte domestique à Olbia de Provence (Hyères, Var)*
}

\author{
Réjane Roure \\ ASM, Archéologie des Sociétés Méditerranéennes UMR5140, UPVM, CNRS, MCC, 34000, Montpellier, France \\ Claire Joncheray \\ Docteur Université Paris X Nanterre \\ David Ollivier \\ CNRS-LA3M \\ Pierre Excoffon \\ Ville de Fréjus \\ Carine Deal \\ Ville de Hyères-les-Palmiers \\ Valérie Salle \\ Ministère de la Culture \\ Maeva Serieys \\ Département du Vaucluse
}

\section{Résumé}

Plusieurs objets atypiques ont été découverts au sein de tranchées de fondation de mur à Olbia de Provence, lors des fouilles menées sous la direction de Michel Bats entre 2002 et 2008, certains formant un ensemble complexe de plusieurs éléments enfouis simultanément. La localisation de ces objets comme leur caractère particulier poussent à les interpréter comme des dépôts à caractère rituel en contexte domestique. Après une présentation détaillée des trois ensembles mis au jour au sein de l'îlot VI, ces dépôts seront mis en perspective avec des découvertes similaires dans le monde grec, dont une découverte faite à Agde dans les sondages de la rue Perben.

Mots-clés : Dépôt, fondation, pratiques rituelles, Olbia de Provence, Grecs, période hellénistique

\begin{abstract}
Many unusual objects were discovered in foundation wall's dig at Olbia in Provence, during the excavations driven by Michel Bats between 2002 and 2008; in one case, several elements were simultaneously buried. Thanks to the location of these objects as their special character, they have been interpreted as ritualistic deposits in domestic contexts. After a detailed presentation of the three sets discovered in the block VI, these deposits will be compared with similar findings in the Greek world, as a discovery made in Agde in Perben street.
\end{abstract}

Keywords: Deposit, foundation, ritual practices, Olbia de Provence, Greek, Hellenistic period

* Ce travail est inscrit dans l'axe thématique Identités du programme scientifique du Labex ARCHIMEDE, programme IA-ANR-11-LABX-0032-01 


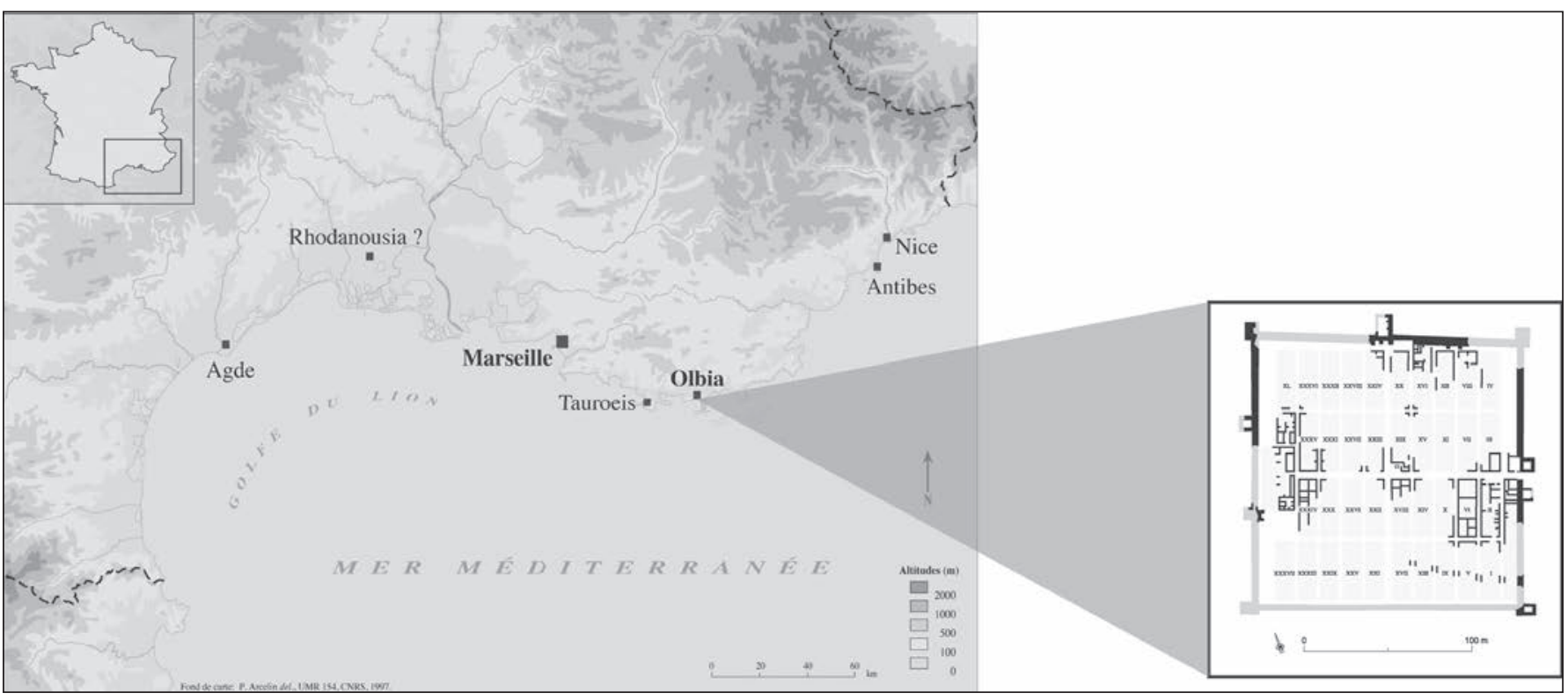

Fig. 1. Localisation d'Olbia de Provence et plan d'ensemble de la ville (DAO R. Roure et M. Bats).

A fin de surveiller la route maritime reliant Marseille à la Ligurie, les Phocéens installèrent un établissement fortifié, Olbia, dans le dernier quart du $\mathrm{IV}^{\mathrm{e}} \mathrm{s}$. av. J.-C., à proximité de la presqu'île de Giens. Le plan de cette création s'inscrit dans la tradition des fortins hellénistiques fondés sur le pourtour du bassin occidental de la Méditerranée (Bats 2004) : un rempart de forme quadrangulaire enserre des îlots d'habitation de module identique, qui se répartissent entre deux rues principales et des rues secondaires se croisant à angle droit (fig. 1).

L'îlot VI, fouillé entre 1982-1989 et 2002-2008 sous la direction de Michel Bats, a révélé une organisation initiale en trois maisons de dimensions strictement identiques et de plan interne à peu près équivalent : deux séries de pièces au nord et au sud sont séparées par un espace ouvert central correspondant à une pastas. Au sud de cette cour, se trouvent systématiquement une pièce oblongue à l'est et une pièce de dimensions plus modestes à l'ouest ; au nord, sont localisées deux pièces quadrangulaires de taille équivalente, dont le sol a parfois reçu dès l'origine un revêtement de béton de chaux (fig. 2).

Dans trois espaces de la maison centrale, des objets inhabituels ont été découverts au sein des comblements de tranchées de fondation de mur, en lien avec la phase la plus ancienne de l'occupation du site. La localisation de ces objets comme leur caractère atypique poussent à les interpréter comme des dépôts de fondation en contexte domestique. Nous commencerons par une présentation précise des trois ensembles mis au jour lors de la fouille de l'îlot en 2008, puis nous les mettrons en perspective avec des découvertes similaires dans le monde grec.

\section{Les dépôts de l'îlot VI d'Olbia de Provence}

Le plus important dépôt en nombre d'objets provient de la tranchée de fondation de l'un des premiers murs de refends de la maison centrale de l'îlot VI. Les deux autres sont constitués d'objets isolés - un biberon et un trépied en plomb - également enfouis sous les remblais d'installation de cette même maison (fig. 2).

\section{Le dépôt complexe de la pièce nord-ouest}

Ce premier ensemble correspond à huit objets de nature différente (fig. 3), réunis dans la tranchée de fondation du mur est de la pièce située dans la partie nord-ouest de la maison ${ }^{1}$. Les huit objets ont été placés dans la tranchée de fondation, au creux d'un petit élargissement volontaire de celle-ci, vraisemblablement juste après la construction du mur, puis ils ont été scellés comme le reste de la tranchée de fondation par un remblai de terre limono-sableuse de quelques centimètres d'épaisseur dont le sommet a

1 Les objets ont été retirés de la tranchée les uns après les autres au fur et à mesure de leur découverte avant qu'on prenne conscience du caractère très particulier de cet assemblage et l'ensemble n'a donc pas pu être photographié in situ. 


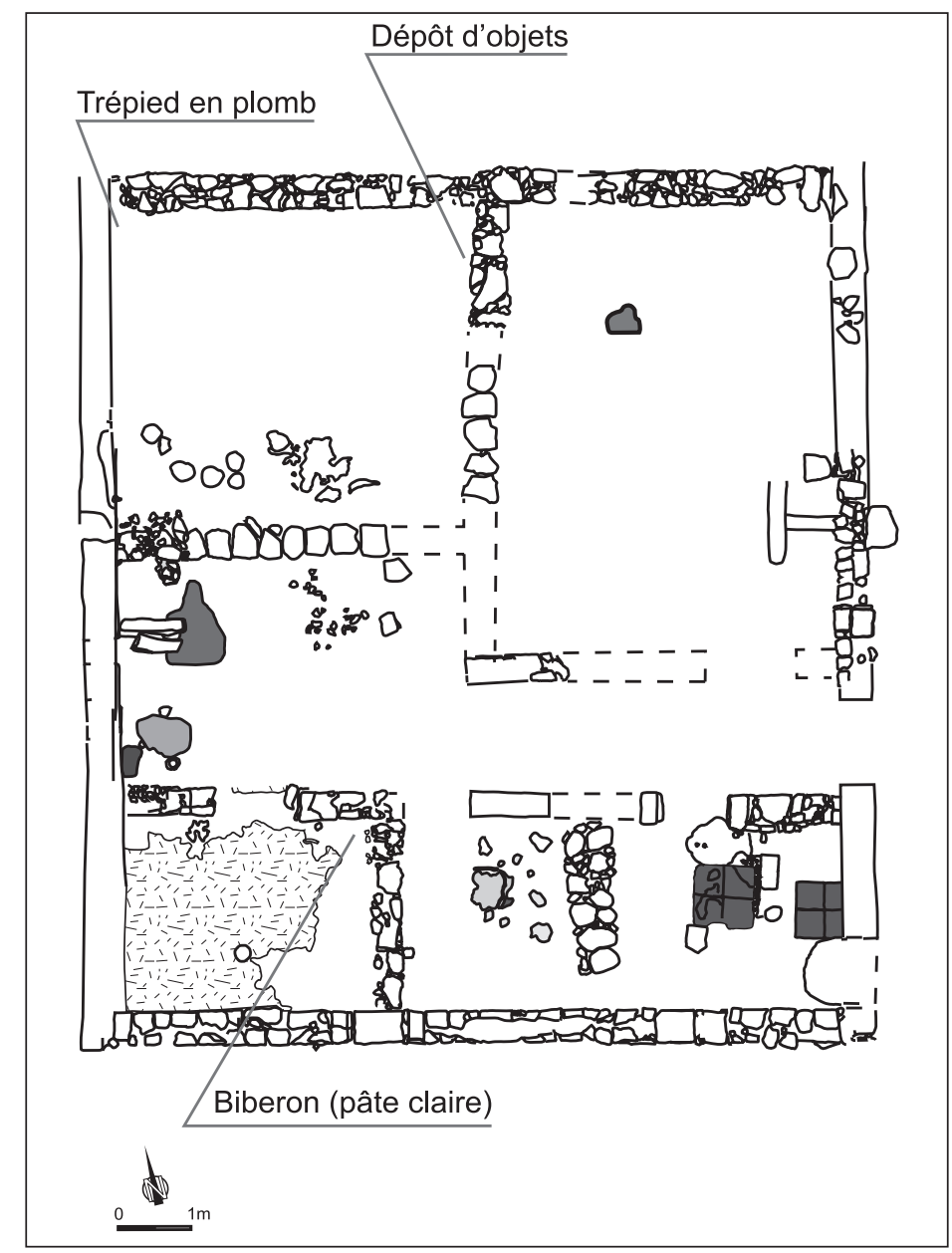

Fig. 2. La maison centrale de l'îlot VI avec la localisation des différents dépôts (DAO D. Ollivier et R. Roure).

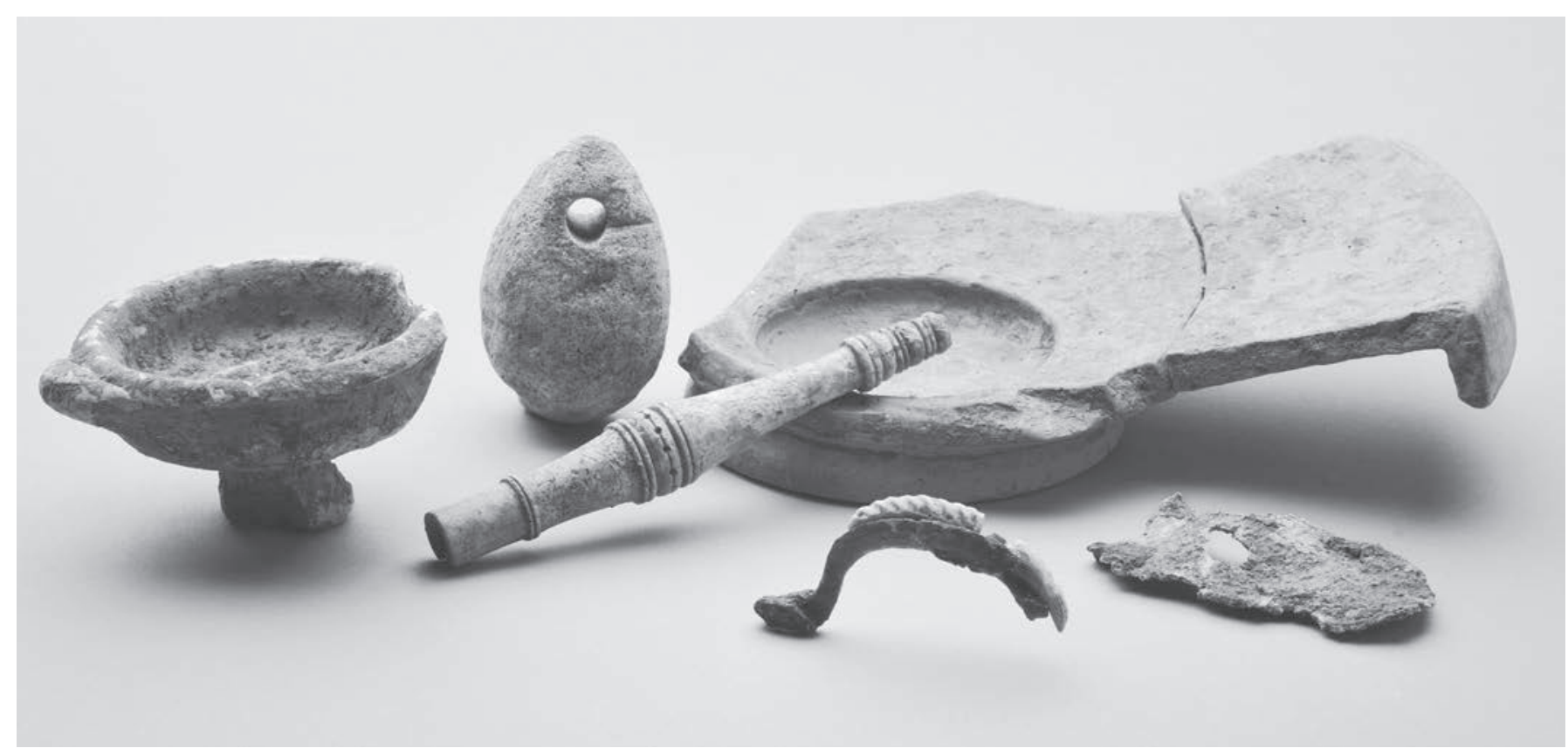

Fig. 3. Photo du lot d'objet déposé (cliché L. Damelet CCJ). 


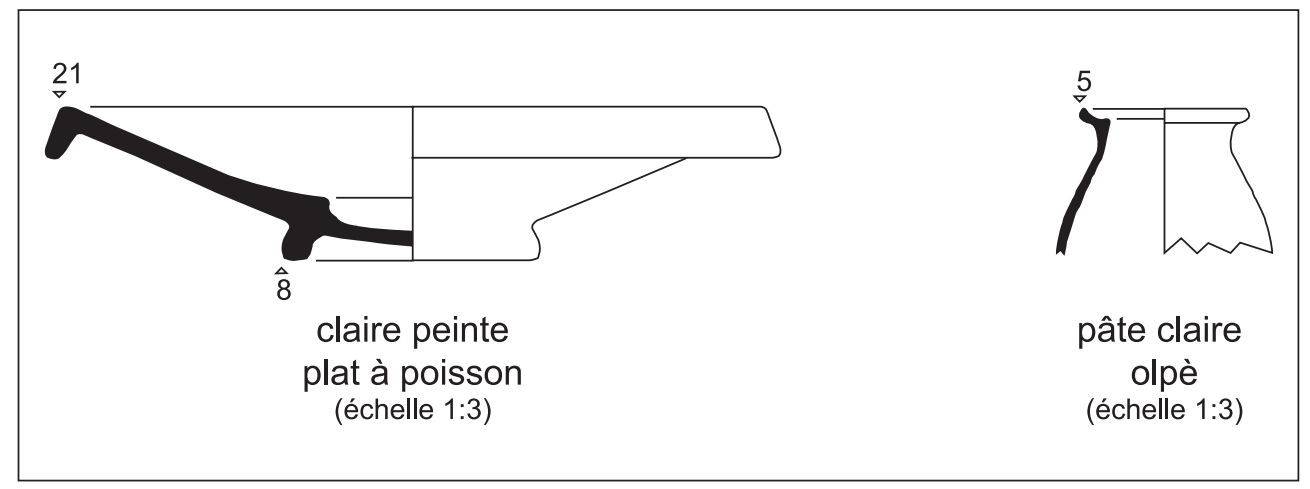

Fig. 4. Dessins du plat à poisson et de l'olpè .

servi directement de sol pour la première occupation de la pièce. La datation stratigraphique de cet ensemble est donc parfaitement claire : le dernier quart du $\mathrm{IV}^{\mathrm{e}} \mathrm{s}$. av. J.-C. ; datation confirmée par l'étude du mobilier.

Le dépôt regroupe plusieurs objets en céramique claire massaliète : un vase miniature, deux gros fragments jointifs d'un plat à poisson et un fragment d'olpè ; un peson en pierre ; un objet en os travaillé interprété comme un fuseau ; une fibule en bronze à décor de corail ; une monnaie perforée et un fragment de plaquette en plomb. Nous nous trouvons donc en présence de trois objets en céramique, un objet en os, un objet en pierre et trois objets en métal. Le nombre et la qualité de ces objets, que nous allons décrire l'un après l'autre ci-dessous, ont rapidement conduit à poser l'hypothèse d'un dépôt intentionnel lié à la fondation de la maison.

Le plat à poisson (type Cl-Mas 121) n'est pas complet mais la cupule centrale est intacte et la totalité de la forme est restituable (fig. 4a) : on peut estimer qu'un tiers du vase environ a été déposé dans cet ensemble ; des traces de peinture rouge et brune, typiques de ces productions massaliètes, sont nettement visibles, quoique mal conservées. Ce type de vase, qui est l'une des formes les plus emblématiques de la cuisine grecque, renvoie à la consommation de poissons, la cupule centrale étant destinée à recueillir la sauce liée à sa préparation.

L'olpè est également fragmentaire mais le bord et une partie de la panse sont présentes (fig. 4b). Ce type de vase de mesure, et/ou de libation, est très fréquent dans tous les contextes, domestiques comme rituels et funéraires.

Le troisième élément en céramique est un vase miniature, également en pâte claire massaliète : une coupe à deux anses (type kylix cl-mas 811) complète à l'exception d'une anse cassée net. La vasque est peu profonde mais bien marquée ; le pied est plein. Aucune trace de peinture n'a été observée, elles sont néanmoins extrêmement rares pour ce type de productions. Plusieurs vases miniatures ont été découverts à Olbia de Provence,

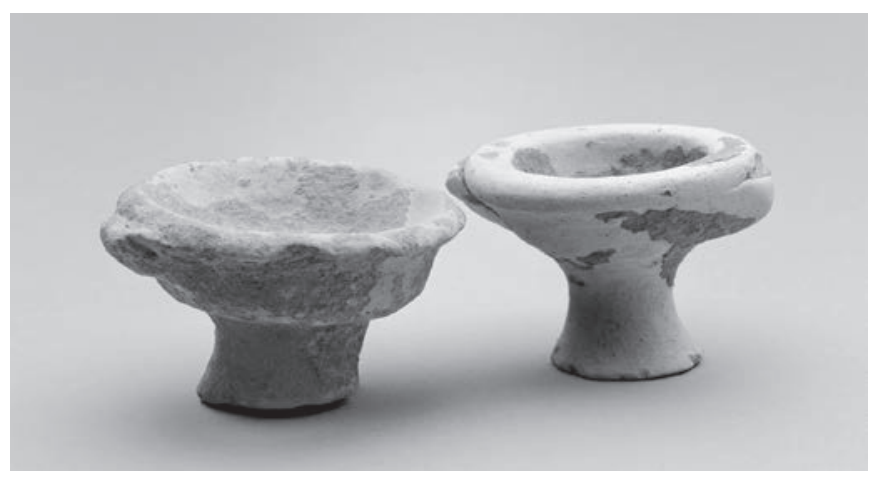

Fig. 5. Deux autres kylix découverts à Olbia (cliché L. Damelet CCJ).

jusqu'à présent au sein de remblais ou de dépotoirs, dans les fouilles anciennes comme dans les fouilles récentes ; la forme de la kylix est la plus fréquente (elle est quasiment systématique). Cependant l'exemplaire du dépôt ici présenté se distingue des autres découverts dans l'îlot, par un pied plus haut et plus marqué (fig. 5). Les vases miniatures - et plus largement les objets de taille réduite - sont récurrents dans les sanctuaires et autres espaces sacrés du monde grec : citons, entre autres, l'Achilléion de Sparte (Stibbe 2002), l'Antre Corycien (Jacquemin 1984, p. 65), le sanctuaire hellénistique de Cumes (Brun et al. dans ce volume). En ce qui concerne les exemplaires en céramique massaliète, il s'agit de formes rares découvertes exclusivement en contexte phocéen (Marseille, Olbia, Agde) pour les formes de kylix, ou dans des comptoirs littoraux marqués par leur proximité avec le monde grec (Lattes, Pech Maho, Peyriac-de-mer) pour d'autres formes miniatures (Py, Adroher, Sanchez 2001). Les fouilles de Marseille ont enrichi le corpus d'une dizaine d'exemplaires, découverts dans deux secteurs de la ville : le Parc des Phocéens et l'îlot des Pistoles, à chaque fois dans un contexte rituel. Dans l'îlot des Pistoles, il s'agit uniquement de formes de coupes sans anse (7 exemplaires) à pied relativement haut mais peu marqué et à 
vasque de faibles dimensions, découverts réunis dans une cupule modelée au sein d'une petite fosse sous le sol de béton d'une salle (Rothé, Tréziny 2005, p. 492). En ce qui concerne les découvertes du Parc des Phocéens, on note la présence de coupes sans anses à pied haut très proches des exemplaires de l'îlot des Pistoles, mais aussi de coupeskylix à deux anses similaires à l'exemplaire d'Olbia ; tous ces vases miniatures ont été découverts dans des fosses, parfois associés à d'autres objets (jeton en pâte de verre, monnaie, plaque de marbre, osselets, coquillage) (Rothé, Tréziny 2005, p. 502). Il faut enfin mentionner les exemplaires de céramique à pâte claire miniatures découverts dans les grottes de Marseilleveyre (Santos, Sourisseau 2011, p. 215), dont l'interprétation globale est délicate mais dont le caractère rituel semble indubitable, au moins pour certains éléments, les vases miniatures en particulier.

L'objet en pierre est de forme oblongue, globalement piriforme, sans angles vifs, légèrement élargi à la base et percé transversalement dans la partie supérieure (fig. 3) ; il mesure $5 \mathrm{~cm}$ de haut pour $3 \mathrm{~cm}$ de diamètre à la base et $1 \mathrm{~cm}$ au sommet. Il s'agit d'un galet aménagé et perforé, pour lequel on note également une trace d'usure sur le sommet de la pierre selon un axe opposé à celui de la perforation; et une autre trace d'usure qui part de cette perforation en s'amincissant ensuite, lié donc à la tension d'un fin cordage. Ce type d'objet peut être interprété soit comme un peson de métier à tisser, soit comme un lest de filet de pêche. Les traces d'usures pourraient être compatibles soit avec les tensions qui s'exercent dans un métier à tisser, même si les pesons liés à ce type d'activité sont plus majoritairement en terre cuite et non en pierre ; soit avec celles d'un filet de pêche, cet objet devant alors être considéré comme une évocation des activités halieutiques (il pourrait sembler alors tentant de lier cet élément nécessaire à la pêche au plat à poisson : de la pêche à la consommation du poisson en quelque sorte...).
L'objet en os travaillé, fragmentaire, constitue l'une des plus belles pièces du dépôt. Cet élément est cassé approximativement au milieu, 9,6 cm sont conservés (diamètre maximum $1,4 \mathrm{~cm}$ ), pour un poids de $15 \mathrm{~g}$. L'extrémité conservée est de forme arrondie, effilée et présente une série de huit moulures circulaires de différentes tailles, puis le corps est simplement poli jusqu'à un renflement au tiers inférieur qui présente à son tour des moulurations : deux tores circulaires fins encadrent une moulure ponctuée de fines perforations reliées entre elles par une incision sur tout le pourtour de l'objet. Le corps est ensuite à nouveau lisse sur $2 \mathrm{~cm}$ avant deux nouvelles moulurations assez fines qui marquent le départ de la partie terminale de l'objet (cassée) dont la partie conservée est à nouveau lisse et simplement polie (fig. 3). Cet objet est interprété comme un fuseau, même si son caractère fragmentaire ne permet pas d'être totalement affirmatif et peut inciter à proposer d'autres hypothèses comme celle d'un stylet ou bien du manche d'un petit instrument (notons qu'aucune trace liée à la présence d'une partie métallique n'a été observée au niveau de la cassure). On connaît toutefois de nombreuses occurrences de ce type de fuseau en os pour l'époque romaine et quelques-unes pour la période grecque : on utilisait sans doute plus couramment des fuseaux en bois, puisque qu'on retrouve beaucoup moins de fuseaux que de fusaïoles sur les sites archéologiques alors que ces deux éléments fonctionnaient ensemble. Le fuseau sert à créer le fil ; le matériau choisi, l'os tourné et poli, permet d'éviter toute friction entre le fil et l'instrument. En Gaule méditerranéenne on connaît des exemplaires à Ensérune, à Montlaurès et à Béziers (De Chazelles 2000) ainsi qu'à Marseille, au sein du mobilier d'une tombe à inhumation fouillée au XIX ${ }^{\mathrm{e}}$ s. (Rothé, Tréziny 2005, p. 678, fig. 997). Il est possible que l'objet ait cassé précisément au niveau de l'action de la fusaïole qui servait à donner du poids au fuseau (cf. reconstitution fig. 6). Si notre interprétation

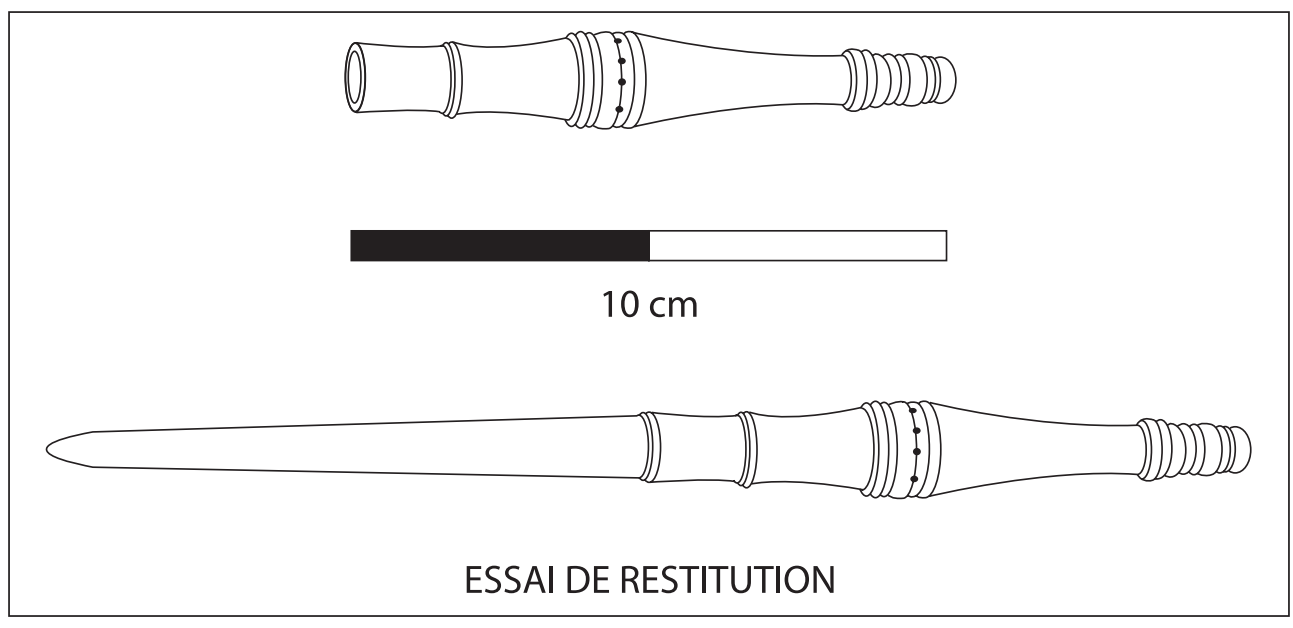

Fig. 6. Dessin et proposition de reconstitution du fuseau en os (dessin et DAO V. Salle). 


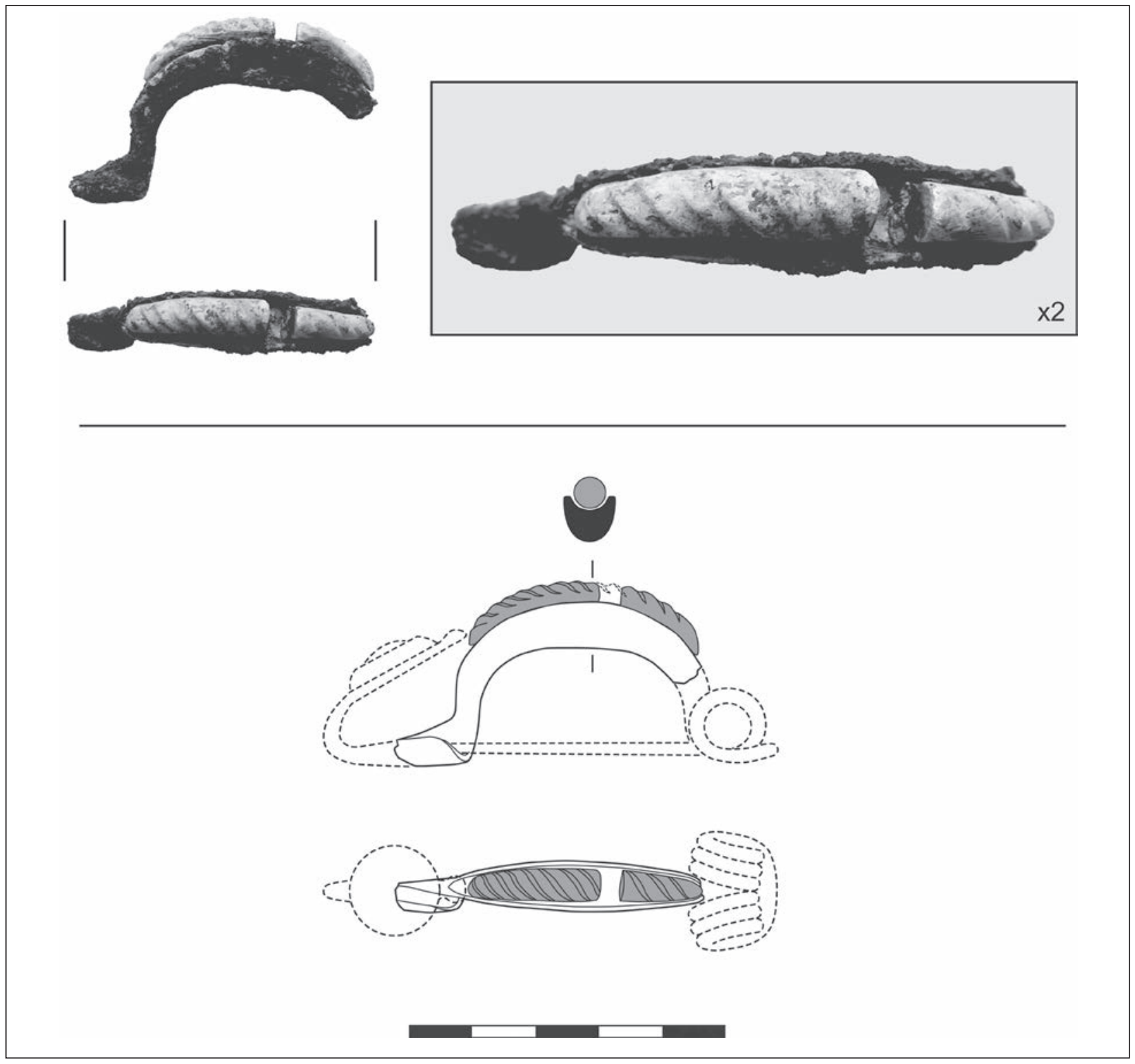

Fig. 7. Photographie et dessin de la fibule à décor de corail (cliché, dessin, DAO B. Girard).

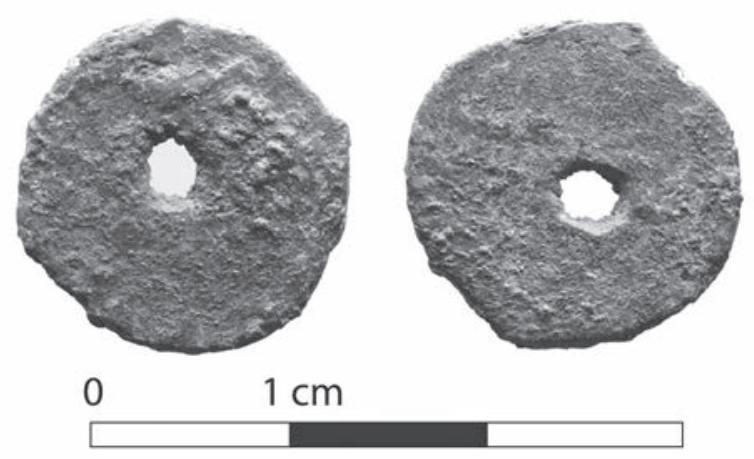

Fig. 8. Photographie de la monnaie perforée (cliché L. Damelet CCJ).

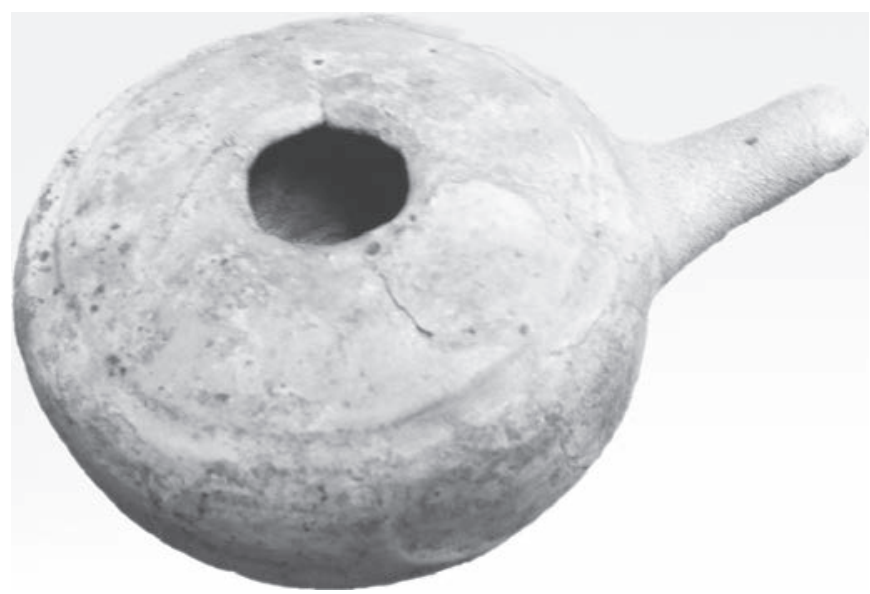

Fig. 9. Photo du biberon (cliché M. Bats). 


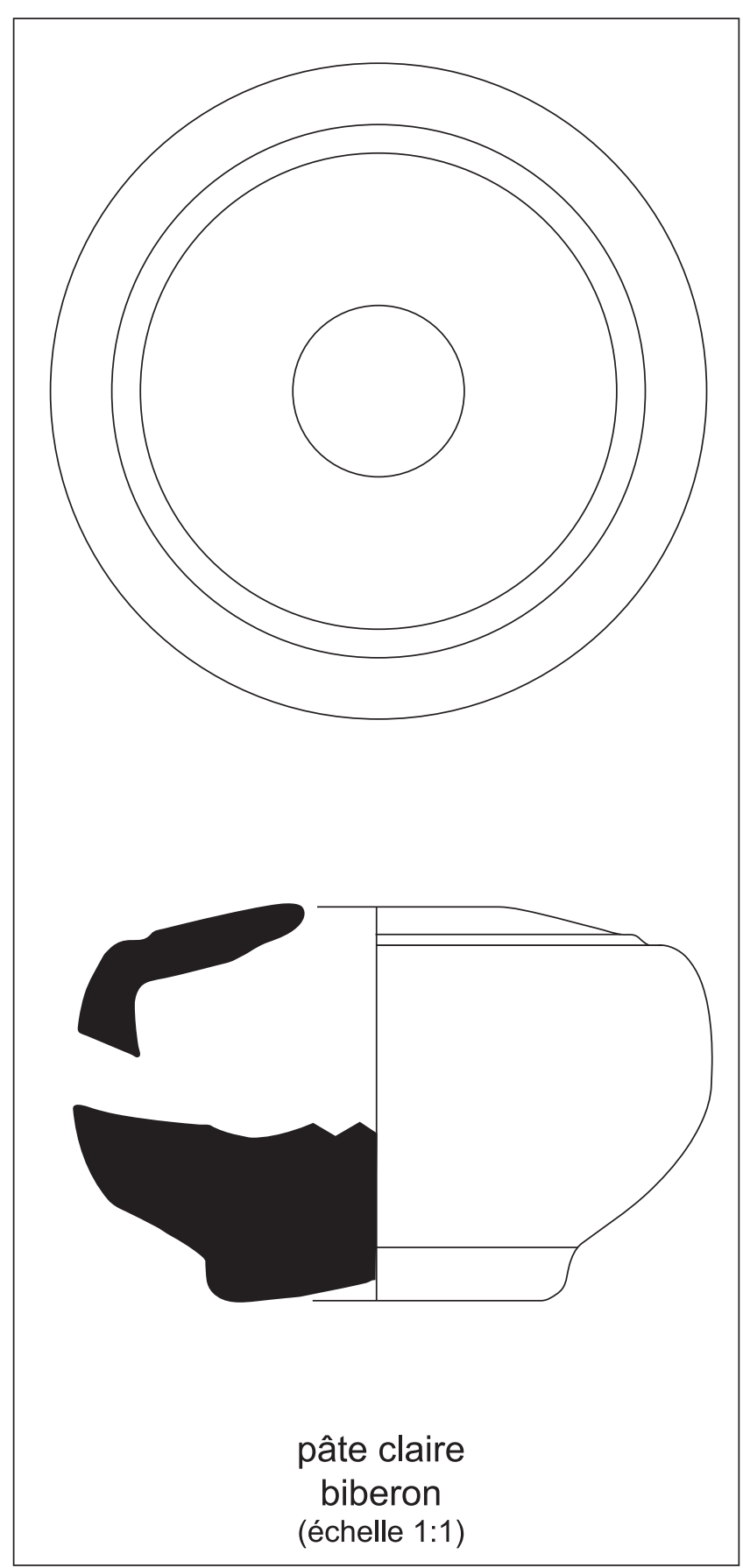

Fig. 10. Dessin du biberon.

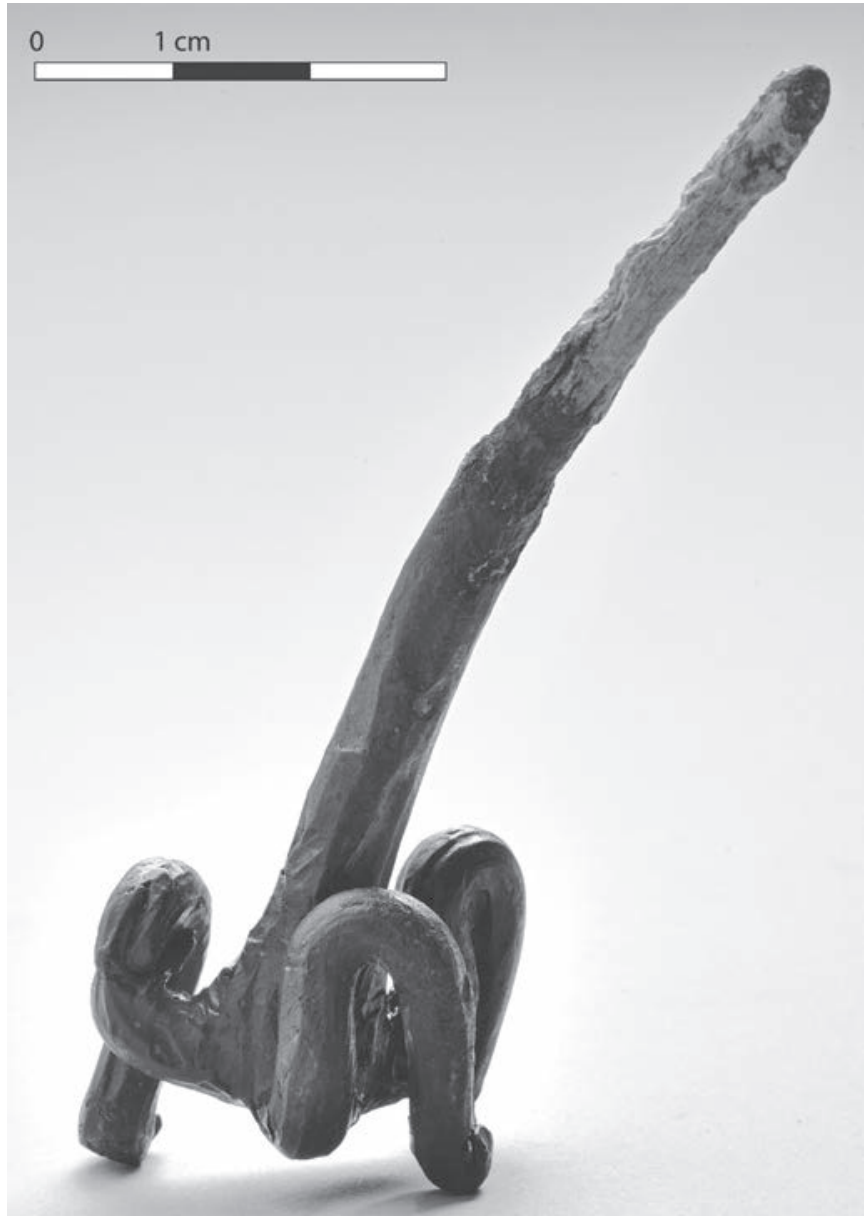

Fig. 11. Photo du trépied (cliché B. Girard).

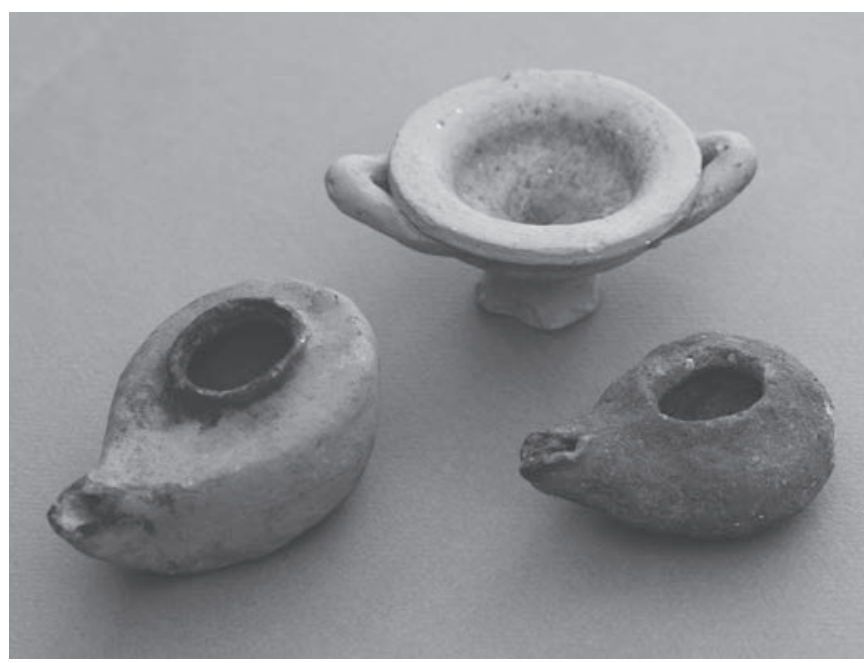

Fig. 12. Photo du vase miniature et des deux lampes à huile découverts à Agde, dans les sondages de la rue Perben (cliché R. Roure). 
comme un fuseau est correcte, cet objet renvoie donc au travail du textile et appartient à la sphère domestique.

Un second objet particulièrement exceptionnel au sein de cet ensemble est une fibule en bronze à décor de corail (Girard 2008). Encore une fois la pièce est incomplète puisque seul l'arc et un fragment du porte-ardillon sont conservés, ainsi que la perle en corail insérée dans la gouttière de l'arc ; cette dernière présente sur le dessus un décor de spires obliques en relief (fig. 7). Il est possible de rapprocher cet objet de deux séries bien connues : les fibules du type de Münsingen d'une part, dont la fourchette de datation couvre la seconde moitié du IVe et le début du III ${ }^{e}$ s. av. J.-C., les fibules de type « à double pied » qui correspondent à une production régionale diffusée localement, dont la datation est établie aux Ve et IVe s. av. J.-C. Dans le contexte régional, les fibules à décor de corail sont relativement rares et font de cet objet une pièce relativement atypique.

Le dépôt contenait également une monnaie en bronze dont le nettoyage a révélé qu'elle avait été perforée en son centre (fig. 8). La pièce est très usée : on ne distingue que la trace d'une tête à gauche au droit et l'arrière-train ou la queue tombante d'un animal à droite au revers. Il pourrait s'agir d'une monnaie punique, du type PUN-115 ${ }^{2}$ ou similaire, avec au droit un cheval debout à queue tombante. La présence de monnaie est typique d'un contexte rituel. Les offrandes monétaires sont en effet fréquentes dans le monde grec, comme chez beaucoup d'autres cultures. Le fait d'avoir perforé la monnaie peut être interprété comme une défonctionnalisation de celle-ci qui en rend tout usage fiduciaire impossible, peut-être précisément en vue de son dépôt rituel.

Le dernier objet appartenant au dépôt est une plaquette de plomb de $2 \mathrm{~cm}$ de large pour $6 \mathrm{~cm}$ de long et de quelques millimètres d'épaisseur (fig. 3). Elle présente elle aussi une perforation globalement circulaire ; il est possible que la plaque ait été plus large au départ, et que seule une partie de celle-ci ait été déposée. L'interprétation de cet élément est délicate : les plaques de plomb de ce type se retrouvent dans différents contextes ; on peut la rapprocher de la tablette d'envoûtement découverte dans le sanctuaire d'Artémis (Bats, Giffault 1997), également perforée, de datation plus récente ( $\mathrm{II}^{\mathrm{e}}-\mathrm{I}^{\mathrm{er}} \mathrm{s}$. av. J.-C.), mais son nettoyage n'a permis de retrouver aucune trace d'écriture. On pourrait sinon rapprocher cet élément des étiquettes de textiles en plomb, qui étaient attachées aux tissus (Radman-Livaja 2011), mais celles-ci ne sont pas attestées archéologiquement avant le Irr $\mathrm{s}$. av. J.-C. (Bats 2011). En dernière hypothèse, on pourrait évoquer l'idée que ce soit le

2 Un exemplaire déjà signalé à Hyères : Brun 1999, p. 478, notice 69-86. L'étude de cette monnaie a été réalisée par Michel Py. matériau lui-même - le plomb, qui ait fait l'objet d'un dépôt à caractère rituel.

L'association de ces huit objets est totalement inhabituelle et ne connaît pas de parallèle direct, associant autant d'éléments différents, même si on peut répertorier un certain nombre de cas de dépôts relativement similaires. Avant de présenter ces éléments de comparaison, évoquons d'autres objets atypiques retrouvés dans d'autres endroits de la même maison.

\section{Les objets isolés}

D'autres dépôts singuliers ont été enfouis sous les premiers niveaux d'occupation de la maison centrale (fig. 2).

Dans la pièce sud-ouest de la maison centrale, un biberon en céramique claire massaliète a été retrouvé (fig. 9 et 10), déposé avec soin dans l'angle nord-est de la pièce, recouvert d'une fine plaque d'argile jaune. Le biberon est complet à l'exception du bec qui est cassé : il s'agit probablement d'un objet qui a été utilisé avant son enfouissement, acte que l'on pourrait interpréter comme ayant une intention prophylactique visant à protéger les futurs enfants de la famille.

Dans la pièce nord-ouest, la même que celle du dépôt complexe, mais cette fois dans la tranchée de fondation de la portion ouest du mur de l'îlot, a été découvert un petit objet en plomb (fig. 11). Cet élément mesure $11,5 \mathrm{~cm}$ de long, de la base du pied à l'extrémité de la tige qui présente une extrémité amincie et arrondie, tandis que de l'autre côté se trouvent trois crochets ou trois pieds. La tige est courbée et les crochets sont tordus : l'objet a vraisemblablement été rendu volontairement inutilisable. Les parallèles de cet objet sont rares et sa fonction initiale est donc difficile à déterminer. Il pourrait s'agir d'un support de candélabre, mais en taille réduite.

\section{Une pratique connue dans le monde grec et phocéen}

Dans le monde grec, les dépôts liés aux fondations dans les maisons sont mal documentés notamment à cause d'un manque récurrent de recherches archéologiques consacrées spécifiquement aux espaces domestiques. Le dépôt rituel, tel que nous avons décidé de l'appeler, est toutefois une pratique de mieux en mieux connue grâce aux fouilles récentes. C'est la cohérence du matériel, sa qualité ou son caractère atypique, la localisation des objets et leur isolement qui donnent sens à ces dépôts.

Un premier parallèle très proche des dépôts d'Olbia se retrouve à Agde, également fondation phocéenne, où a été découvert, lors des sondages de la rue Perben, ce 
qu'André Nickels avait lui-même interprété comme un dépôt de fondation, dans un contexte daté lui aussi de la fin du IVe s. av. J.-C. (Nickels 1995, p. 82). Au fond d'une fosse verticale très étroite aménagée le long de la fondation d'un mur, étaient réunis un vase miniature de type kylix et deux lampes à huile (fig. 12), mêlés à un tubulus en terre cuite, à un fragment de lopas et à deux gros fragments d'amphore massaliète (provenant des couches anciennes selon le fouilleur). Le vase miniature imite les productions massaliètes, mais il s'agit d'un exemplaire modelé à la main, et pas tourné comme les vases miniatures découverts à Olbia ou à Marseille. Sa pâte ressemble à celle de la céramique à pâte claire massaliète mais elle ne possède pas les fins micas brillants caractéristiques de ces productions et pourrait donc être d'origine locale. Elle a forcément bénéficié d'une cuisson oxydante qui a permis d'obtenir la couleur beige clair typique des céramiques massaliètes et de traditions massaliètes. Les lampes à huile sont toutes les deux modelées et façonnées assez grossièrement, dans une pâte vraisemblablement locale contenant un dégraissant assez abondant, qui a cuit en atmosphère réductrice. Une des lampes mesure $8,2 \mathrm{~cm}$ de long pour $5,1 \mathrm{~cm}$ de large et $3,7 \mathrm{~cm}$ de hauteur; la seconde est plus petite et mesure $6,9 \mathrm{~cm}$ de long pour $4,7 \mathrm{~cm}$ de large et $2,6 \mathrm{~cm}$ de hauteur. Les deux lampes présentent des traces d'utilisation évidentes, bien conservées, marquées par des éléments charbonneux et une rubéfaction du bec, c'est-à-dire de la zone réservée à la combustion. Il est possible qu'elles aient été utilisées dans le cadre même du rite pratiqué lors de l'enfouissement de ces objets, vraisemblablement pour protéger la maison nouvellement fondée ${ }^{3}$. Les limites restreintes du sondage de la rue Perben ne permettent pas de savoir précisément à quelle partie de la maison appartenait le mur près duquel ces objets ont été déposés, ni même si on se trouve réellement en contexte domestique - toutefois il s'agit de la caractérisation proposée par le fouilleur.

Nous avons déjà évoqué des dépôts découverts dans la cité de Marseille en décrivant les objets d'Olbia, en particulier le vase miniature. Sont connus au moins trois dépôts en relation avec des fondations d'édifices : il s'agit des fosses du secteur de la Major, de celles qui s'alignent le long d'un mur au Parc des Phocéens et d'un ensemble localisé dans un îlot d'habitation de la rue des Pistoles (Rothé, Tréziny 2005, p. 420 ; p. 492 ; p. 502-503). Ces dépôts abritaient en général plusieurs objets associés, entiers pour la plupart, et étaient enfouis

3 Ces observations ont été faites par R. Roure directement sur les objets ; nous remercions Jean-Paul Cros, responsable du dépôt archéologique d'Agde (GRAA), de sa cordiale disponibilité. soit juste sous le sol, soit près d'un mur ; tous ces dépôts ont été mis en rapport avec des activités cultuelles.

En ce qui concerne d'autres cités de la Grèce, la pratique de l'enfouissement d'objet et le rapport au sacré dans le cadre domestique sont également connus même si les exemples sont relativement rares. Ces découvertes ont souvent servi à définir les fonctions des espaces, plus que les pratiques religieuses individuelles. En Attique, à Athènes, les fouilles (en 2005) d'un petit bâtiment (oikos), érigé au niveau de la Porte du Dipylon vers le Céramique lors de la première phase de construction, ont mis au jour un dépôt de fondation constitué d'ossements d'animaux, de céramiques et de lampes, daté du $\mathrm{V}^{\mathrm{e}} \mathrm{s}$. av. J.-C. ${ }^{4}$. Dans le Péloponnèse, à Loussoi, un dépôt de figurines en terre cuite, situé chronologiquement entre le milieu du Ve et le début du IVe s. av. J.-C. a été retrouvé dans la fondation ouest d'un bâtiment ${ }^{5}$. Dans ces deux cas, la présence du dépôt d'objets a été utilisée pour interpréter les ensembles fouillés comme des espaces sacrés.

À Olbia du Pont, plusieurs dépôts de fondation ont été identifiés ; notamment une monnaie en fondation des murs de la maison II-6 de la période hellénistique (Lejpunskaja, Guldager Bilde et al. 2010 ; Lejpunskaja, Samojlova 1993).

L'île de Chypre offre aussi une série de comparaison. À Vouni, huit bols ont été trouvés sous le sol d'une pièce proche des magasins, datant de 450-440 av. J.-C. ${ }^{6}$; à Kato Pathos, un grand dépôt d'amphores, de vaisselle de verre et de lampes a été localisé entre les piliers d'un bâtiment, en rapport avec des constructions antérieures à la période hellénistique ${ }^{7}$. Enfin à Amathonte, un dépôt de fondation composé d'une marmite renfermant une grande et une petite coupelles, antérieur à l'époque hellénistique, a été découvert dans une salle adossée à la muraille, en rapport selon les auteurs avec des cérémonies dites de « re-construction» (Petit 1989).

\section{Interprétations}

Il existe donc une documentation, quoiqu'encore disparate et rare, sur les dépôts rituels de fondation dans les espaces domestiques du monde grec : elle montre l'existence d'une pratique peu connue mais pourtant bien présente. Les actes d'enfouissement existent dans différents contextes rituels et religieux. Dans la littérature, plusieurs types de fosses peuvent accueillir des dépôts enterrés : le bothros et les mégara sont mentionnés le

BCH 128-129 [2004-2005] Chron., p. 1274-1276.

BCH 128-129 [2004-2005] Chron., p. 1366-1368.

W. Daszewski, dans le rapport d'activités du Département des antiquités de Chypre, 2007-2009.

7 SCE III, p. 280. 
plus souvent. Le bothros apparaît en particulier chez Homère (Iliade, livre 17, 1.58 et Odyssée, livre 6, $92-10.517-11.25 / 36 / 42 / 95)$. Mais ces termes liés aux enfouissements concernent les sacrifices sanglants et se situent dans un espace sacré. En ce qui concerne l'espace des maisons, des rites à caractère répétitif incluant des dépôts d'objets apparaissent dans la littérature grecque ; les mieux connus sont ceux liés aux Thesmophories, qui consistent à enfouir des vases et des animaux dans des fosses (Baumer 2010, 219). Cette pratique montre que des objets à caractère sacré peuvent être enfouis, dans les maisons athéniennes, dans le cadre d'un rite et pas seulement dans le but de conserver des offrandes.

En ce qui concerne les dépôts mis en évidence par l'archéologie, on peut remarquer qu'ils ont un caractère hétérogène mais ils permettent tous d'associer le moment de la fondation d'une maison, d'un espace, à un rite de protection. L'oikos, c'est-à-dire, la maison grecque, correspond à un espace habité, qui est un espace fermé comme dans le cas d'un sanctuaire. Le lien symbolique entre la maison et le temple existe dans le monde grec et il est représenté par une série de pratiques individuelles à caractère religieux. Ces gestes, qui ne correspondent pas forcément à un acte de parole religieuse, appartiennent à la sphère de la superstition et de la protection de la maison. Il s'agit d'une pratique individuelle, d'un geste qui ne relève pas du quotidien mais qui est en rapport avec la symbolique de la maison et sa fondation.

La fonction et la qualité des objets peuvent faire penser à une offrande, peut-être suite à une libation, en rapport avec des activités individuelles liées à la maison, c'est-à-dire le monde de l'habillement, de l'alimentation et de l'enfant. Ce geste d'enfouissement fait partie des pratiques rituelles de prise de possession d'un espace, pour protéger la maison et peut-être évoquer les actes marquants de la vie familiale. On peut remarquer que plusieurs objets découverts à Olbia appartiennent plutôt à la sphère féminine : les éléments liés à l'enfant - le vase miniature du dépôt complexe et le biberon de l'autre pièce -, ceux liés à l'alimentation - plat à poisson évoquant la préparation des aliments, olpè pour le service de la boisson - ceux enfin reliés aux activités autour du tissage - si l'on accepte les interprétations comme peson et comme fuseau. La sursignification du tissage, qui pourrait donc être évoqué par au moins deux objets, peut être replacée dans un contexte hellénique qui montre cette activité comme l'une des plus emblématiques des femmes, que l'on songe à Pénélope dans l'Odyssée ou aux nombreuses représentations des femmes en train de filer ou de tisser la laine sur les vases attiques (Scheid, Svenbro 2003). On pourrait également envisager un geste d'enfouissement en rapport avec un rite de passage ou bien un contexte particulier au moment de l'installation dans la maison, comme un mariage par exemple (Mossé 1991 ; Schmitt Pantel 2009), ce qui expliquerait l'unicité de cette pratique dans la maison centrale de l'îlot VI, puisque le mariage était marqué dans le monde grec par des échanges de bien, en particulier de tissu (Scheid, Svenbro 2003, 56 sq).

Un dernier élément peut être pris en considération dans le cadre de l'analyse de ces objets enfouis : le fait que l'existence de dépôts de fondation est très bien documentée dans le monde celte du midi de la Gaule. On recense en effet des dizaines d'exemples d'objets (vases, ossements d'animaux, coquillages...) enfouis dans des fosses dans les remblais d'installation des maisons ou à proximité des murs, en particulier près ou dans les seuils, à Lattes, Martigues, Montlaurès, Gailhan... (Belarte, de Chazelles 2011, 168 sq). Cette tradition des populations locales de la Gaule, attestée tout au long de l'âge du Fer, doit peutêtre être intégrée à notre réflexion sur ces dépôts et pourrait pousser à suggérer l'hypothèse de l'association entre des pratiques grecques et des pratiques celtes, association qui pourrait elle-même être liée à un mariage mixte entre deux membres de chacune de ces communautés, puisque ce type d'union est loin d'être rare dans les contextes de contacts et au-delà de cela de coexistence entre deux populations.

\section{Conclusion}

Les dépôts de fondation en contexte domestique correspondent donc à une pratique connue du monde grec mais peu documentée par l'archéologie, peut-être en grande partie parce que les recherches se sont principalement concentrées sur les contextes votifs et sacrés et ont souvent négligé les habitats domestiques, rarement fouillés intégralement, de sorte que peu de tranchées de fondation ont été entièrement vidées avec attention.

Sur le site d'Olbia de Provence, la fouille complète de l'îlot VI a permis d'exhumer un exemple de dépôt complexe dans la tranchée de fondation d'un mur de la maison centrale. Ces objets, brièvement présentés dans le catalogue de l'exposition Des rites et des hommes (Bats 2011b), forment un ensemble cohérent qui méritait une présentation un peu développée, puisqu'il est possible d'interpréter ces huit éléments très particuliers et deux objets isolés comme des dépôts de fondation dans un cadre domestique, sans rapport avec un rituel sanglant.

La confrontation entre les données, en contexte domestique, d'Olbia de Provence, celles du monde grec et celles du monde celte du Midi de la Gaule, permet d'argumenter en faveur de l'existence de ces pratiques individuelles liées aux croyances relatives à la protection de la maison et de l'espace domestique, ou relatives à des événements marquants de la vie de ses habitants. 


\section{Bibliographie}

Py, Adroher, Sanchez 2001 : PY (M.), ADROHER AUROUX (A.-M.), SANCHEZ (C.) - Dicocer, corpus des céramiques de l'Âge du Fer de Lattes (fouilles 1963-1999). coll. Lattara, 14, 2001, 2 t.

Bats 1990 : BATS (M.) - Colonies et comptoirs massaliètes, Olbia de Provence, L'Acapte. In : Lescure (B.) (éd.), Voyage en Massalie. Marseille, 1990, p. 173-175, 206-219

Bats 2004 : BATS (M.) - Les colonies massaliètes de Gaule méridionale : sources et modèles d'un urbanisme militaire hellénistique. In : AGUSTABOULAROT (S.), LAFON (X.) (éd.), Des Ibères aux Vénètes. Coll. EFR n³28, Rome, 2004, p. 51-64

Bats 2006 : BATS (M.) (dir.) - Olbia de Provence (Hyères, Var) à l'époque romaine ( $I^{e r}$ s. av. J.-C. - VII ${ }^{e}$ s. ap. J.-C.). Aix-en-Provence, 2006

Bats 2011a : BATS (M.) - Témoignages d'activités artisanales : les étiquettes en plomb inscrites des fouilles de l'espace Mangin à Fréjus. In : PASQUALINI (M.), Fréjus romaine. La ville et son territoire. Agglomérations de Narbonnaise, des Alpes-Maritimes et de Cisalpine à travers la recherche archéologique. Actes du 8e colloque historique de Fréjus, 8-10 octobre 2010, Fréjus, APDCA, 2011, p. 147-156

Bats 2011b : BATS (M.) - Olbia de Provence. In : Roure (R.), Pernet (L.), Des rites et des Hommes. Les pratiques symboliques des Celtes, des Ibères et des Grecs en Provence, en Languedoc et en Catalogne. Paris, Errance, 2011 (Archéologie de Montpellier Agglomération 2), p. 256-259

Bats, Giffault 1997 : BATS (M.), Giffault (M.) - Une tablette d'envoûtement en plomb à Olbia de Provence. Revue des Etudes Anciennes Mélanges J. Coupry., 99, 1997, p. 459-462

Baumer 2010 : BAUMER (F. E.) - Deux sanctuaires sur les flancs nord de l'acropole : les Thesmophoreia. In : Cité sous terre. Des archéologues suisses explorent la cité grecque d'Érétrie, Catalogue de l'exposition réalisée par l'École suisse d'archéologie en Grèce en collaboration avec l'Antikenmuseum Basel und Sammlung Ludwig. In folio éditions, 2010, p. 219-221

Belarte, de Chazelles 2011 : BELARTE (M. C.), DE CHAZELLES (C.-A.) Les manifestations de pratiques rituelles en contexte domestique en Ibérie et en Gaule méditerranéenne. In : Roure (R.), Pernet (L.), Des rites et des Hommes. Les pratiques symboliques des Celtes, des Ibères et des Grecs en Provence, en Languedoc et en Catalogne. Paris, Errance, 2011 (Archéologie de Montpellier Agglomération 2), p. 165-188

Brun 1999 : BRUN (J.-P.) - Carte archéologique de la Gaule, Le Var. Paris, 1999, 2 t.

Brun et al. dans ce volume : BRUN (J.-P.), CAVASSA (L.), LEGUILLOUX (M.), MUNZI (P.) - Banquets rituels à Cumes au IVe siècle avant J.-C. de Chazelles 2000 : DE CHAZELLES (C.-A.) - Eléments archéologiques liés au traitement des fibres textiles en Languedoc occidental et Roussillon au cours de la Protohistoire (VI'-Ier s. av. n. è.). In : Cardon D., Feugère M. (dir.), Archéologie des textiles, des origines au $V^{k}$ siècle, Actes du colloque international de Lattes, oct. 1999. Montagnac 2000, p. 115-130 (Monographie Instrumentum 14)

Girard 2008 : GIRARD (B.) - Une fibule en bronze à application de corail à Olbia. In : Bats (M.) (dir.), Olbia de Provence (Hyères, Var). L'Ilot VI. Rapport de fouille 2008. p. 62-69

Jacquemin 1984 : JACQUEMIN (A.) - Antre Corycien. BCH, Supplément, 1984, vol. 9

Lejpunskaja, Guldager Bilde et al. 2010 : LEJPUNSKAJA (N. A.), GULDAGER BILDE (P.) et al. éd. - The Lower City of Olbia (Sector NGS) in the 6th Century BC to the 4th Century $A D(2$ vols.). Black Sea Studies 13, Aarhus, Aarhus University Press, 2010

Lejpuns'ka, Samojlova 1993: LEJPUNS'KA (N.-O.), SAMOJLOVA (T.-L.) - Nova znachidka monety Eminaka v Ol'vii, in UkrainaGrecija : istoria ta sucasnict'. Kiev, 1993, p. 115-120

Mossé 1991 : MOSSÉ (C.) - La femme dans la Grèce antique. Bruxelles, 1991 ( $1^{\text {re }}$ éd Albin Michel 1983), $183 \mathrm{p}$.

Nickels 1995 : NICKELS (A.) - Les sondages de la rue Perben à Agde. In : Sur les Pas des Grecs en Occident. Etudes Massaliètes 4, 1995, p. 59-98

Petit 1989 : PETIT (T.) - Un dépôt de fondation au «palais » d'Amathonte. $B C H, 113,1989$, p. 135-148

Radman-Livaja 2011 : RADMAN-LIVAJA (I.) - Le rôle des étiquettes de plomb dans le travail du textile à Siscia. In : Alfaro (C.), Brun (J.-P.), Borgard (Ph.), Pierobon Benoit (R.) (éd.), Purpurae Vestes, III Symposium Internacional sobre Textiles y Tintes del Mediterráneo en el mundo antiguo. Valence, 2011, p. 181-196

Rothé, Tréziny 2005 : ROTHÉ (M.-P.), TRÉZINY (H.) - Marseille et ses alentours. Carte Archéologique de la Gaule 13/3. Paris, 2005, 925 p. Santos, Sourisseau 2011 : SANTOS RETOLAZA (M.), SOURISSEAU (J.C.) - Cultes et pratiques rituelles dans les communautés grecques de Gaule méditerranéenne et de Catalogne. In : Roure (R.), Pernet (L.), Des rites et des Hommes. Les pratiques symboliques des Celtes, des Ibères et des Grecs en Provence, en Languedoc et en Catalogne. Paris, Errance, 2011 (Archéologie de Montpellier Agglomération 2), p. 223-255

Scheid, Svenbro 2003 : SCHEID (J.), SVENBRO (J.) - Le métier de Zeus. Mythe du tissage et du tissu dans le monde gréco-romain. Paris, Errance, 2003, 160 p.

Schmitt Pantel 2009 : SCHMITT PANTEL (P.) - Aithra et Pandora. Femmes, Genre et Cité dans la Grèce antique. Paris, L'Harmattan, 2009, 224 p.

Stibbe 2002 : STIBBE (C. M.) - The Achilleion near Sparta. Some Unknown Finds. In : HÄGG (R.) (éd.), Peloponnesian Sanctuaries and Cults. Stockholm, 2002, p. 207-219 



\title{
Set cerimoniali e offerte nei luoghi di culto indigeni della Sicilia occidentale
}

\author{
Francesca Spatafora
}

Direttore Parco Archeologico di Himera

\section{Résumé}

La découverte d'un certain nombre d'ensembles à caractère sacré dans les villes indigènes de la Sicile occidentale a permis d'apporter quelques éclairages utiles sur le déroulement des cérémonies et sur l'idéologie religieuse des populations locales, en permettant également de mieux cerner les conséquences des importants contacts établis avec les populations grecques des zones côtières, surtout pendant le VI $\mathrm{e}$ s. av. J.-C.

Les ensembles considérés appartiennent à une longue période qui s'étend de la période archaïque jusqu'au début de la période hellénistique. En termes géo-topographiques, les sites concernés par la présence de zones de culte se situent pour la plupart dans des bassins ou de larges vallées fluviales. Des pratiques rituelles différentes ont pu être identifiées à travers l'analyse des offrandes et des instruments destinés à des fonctions sacrées.

Mots-clés : Sicile, Grecs, Phéniciens, culte, rituels, contacts, offrandes

\section{Abstract}

The discovery of many sacred places in indigenous towns of western Sicily allowed to bring some light on how ceremonies were made and on religious ideology of local populations, also allowing a better understanding of the important contacts with the Greek populations of coastal areas, especially during the sixth century BC.

Those sites belong to a long period from the Archaic time to the beginning of the Hellenistic time. Considering geo-topographical terms, the sites affected by the presence of sacred areas are mostly in ponds or large river valleys. Different ritual practices have been identified through the analysis of the offerings and instruments for sacred functions.

Keywords: Sicily, Greeks, Phoenicians, worship, rituals, contacts, offerings 
$\mathrm{L}$ a scoperta di alcuni contesti a carattere sacro all'interno di insediamenti indigeni della Sicilia occidentale, oltre a permettere qualche utile considerazione sul carattere delle cerimonie e sull'ideologia religiosa delle popolazioni locali, ha ugualmente contribuito a valutare con maggiore consapevolezza gli esiti degli intensi e continui contatti avviati, soprattutto nel corso del VI sec. a. C., con le popolazioni greche delle aree costiere.

I contesti considerati sono relativi a un periodo compreso tra l'età arcaica/tardo-arcaica e la prima età ellenistica. Sotto il profilo geotopografico, i siti interessati dalla presenza delle aree di culto prese in considerazione ricadono per la maggioranza entro il bacino del Fiume Belice (Monte Maranfusa, Entella) o a dominio dell'ampia vallata incisa da uno dei due rami dello stesso fiume (Iato), la più importante realtà idrografica della Sicilia occidentale che costituì, fin da età arcaica, la naturale via di penetrazione di Selinunte verso l'entroterra. Anche nel caso della Montagnola di Marineo, la collocazione nell'alta Valle del Fiume Eleuterio risulta di particolare interesse vista la vicinanza sia con la greca Himera, sorta poche decine di chilometri al nord-est della città sicana, di recente identificata con la Makella delle fonti letterarie (Spatafora 2001), che con le città fenicio-puniche della costa settentrionale dell'isola e, particolarmente, con Solunto, di cui la vallata dell'Eleuterio rappresentava il naturale entroterra (fig. 1).

Nel richiamare dunque l'attenzione su quei contesti, per buona parte già noti, è certamente utile tentare di ricostruire le diverse azioni rituali anche attraverso l'analisi, oltre che delle offerte, dello "strumentario" destinato alle funzioni più propriamente sacre, parametri che acquistano un'importanza fondamentale in assenza sia di documentazione epigrafica che di testi letterari utili a delineare gli aspetti religiosi delle comunità epicorie (Albanese Procelli 2006; Spatafora c.d.s.).

\section{Iaiatas/Monte Iato}

Come è noto, una delle più antiche aree sacre del centro indigeno posto sulla cima del Monte Iato (fig. 2), nell'alta valle del Fiume Iato e a dominio dell'alta valle del Belice Destro, è il cosiddetto Tempio di Afrodite (Studia Ietina II, p. 11-106).

L'oikos di tipo greco (fig. 3), privo di peristasi, con ingresso a porta sul lato breve orientale e tetto di tegole, richiama, sotto il profilo architettonico, analoghe realizzazioni di ambito siceliota e cronologicamente comprese dell'ambito del VI sec.a. C. (Romeo 1989).

Alle sue prime fasi di vita appartiene il deposito votivo rinvenuto all'interno dell'adyton, un'offerta dei

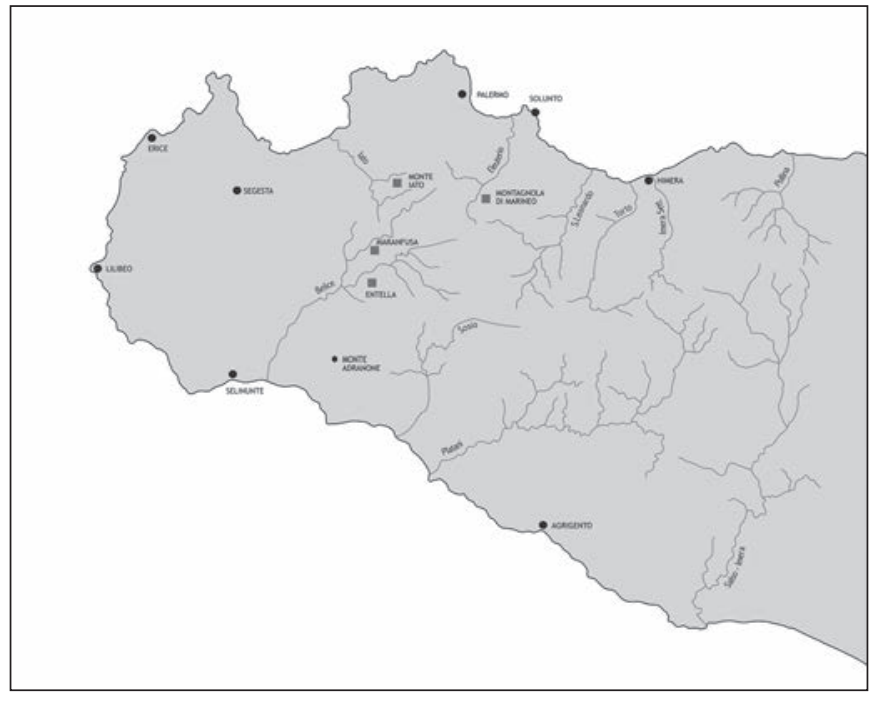

Fig. 1. Carta della Sicilia con indicazione degli insediamenti.

primi decenni del V secolo che, tuttavia, comprendeva anche materiali più antichi: in particolare facevano parte dell'offerta due Droop cups attiche dell'ultimo quarto del VI sec. a. C. e uno skyphos attico a vernice nera dei primi decenni del V sec. a. C. (fig. 4) (Studia Ietina II, p. 81-86, Abb. 8-10; Spatafora 2009b, p. 742743, fig. 7). Dei tredici vasi recuperati, tuttavia, solo i tre già ricordati provenivano dall'Attica mentre negli altri casi si trattava di produzioni coloniali o locali; a un'imitazione coloniale di una coppa ionica di tipo B1 (fig. 4) e ai quattro skyphoi a bande (fig. 5) erano associate, infatti, cinque scodelle a decorazione dipinta di fabbriche locali (fig. 6), un set utilizzato forse per il banchetto rituale e poi offerto alla divinità. La composizione stessa dell'offerta, oltre che la tipologia architettonica e il probabile culto praticato nell'area sacra, sembrano dunque suggerire l'esistenza di una comunità che fin da età arcaica si caratterizza per l'avvio di profondi processi di commistione che, come già supposto dagli scavatori (Isler 2002), già dagli inizi del VI sec. a. C. furono forse avviati a seguito dell'immissione pacifica di un piccolo gruppo di origine greca all'interno della compagine sociale locale. Tuttavia, secondo una visione meno legata a schemi tradizionali e indirizzata, invece, verso un'interpretazione sociologica del "fatto" religioso, la presenza di santuari così complessi e architettonicamente strutturati secondo modelli recepiti dal mondo greco coloniale, collocati in un'area ben demarcata anche topograficamente, potrebbe far pensare, in una visione quasi "emporica" del luogo sacro, a spazi di incontro e di culto interetnici, destinati allo scambio tra élites indigene e coloniali (Öhlinger c.d.s.), attribuendo quindi alla religione anche una valenza politica ed economica. 


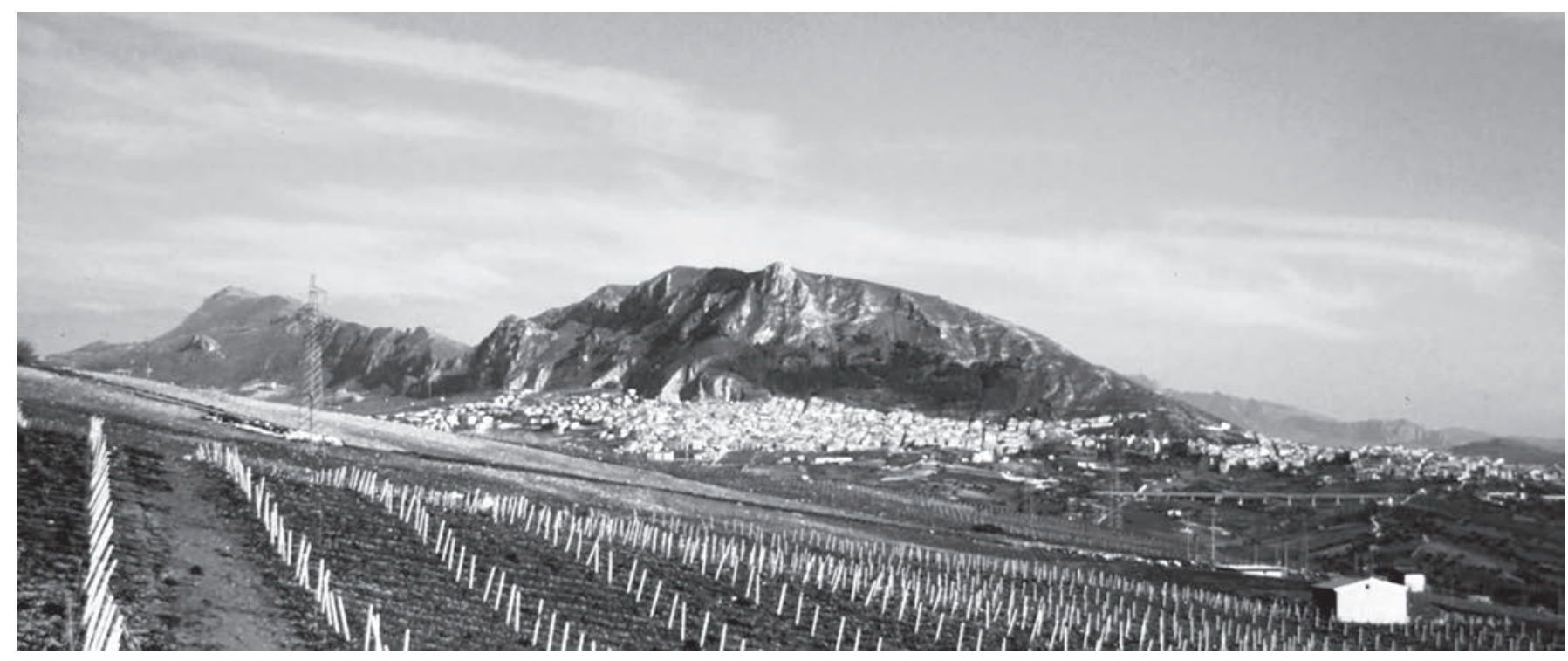

Fig. 2. Monte lato : veduta da sud.

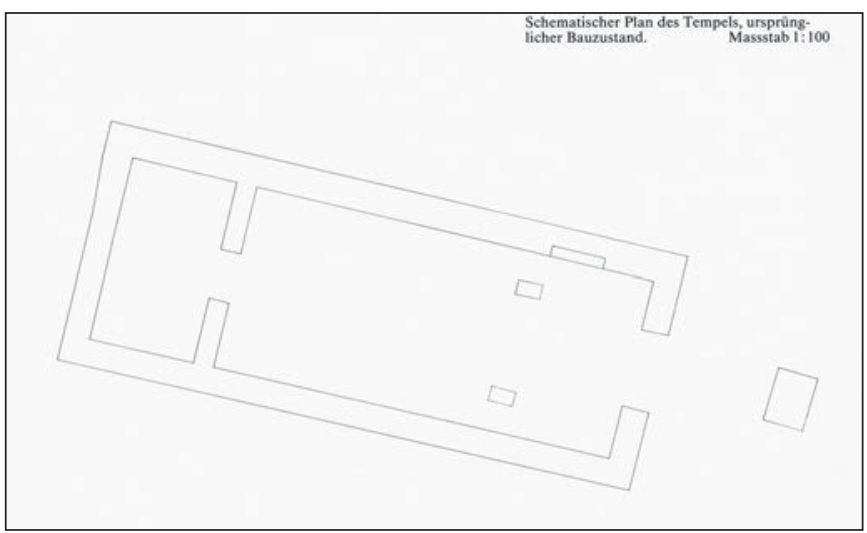

Fig. 3. Monte lato : planimetria del Tempio di Afrodite (da Studia letina II).

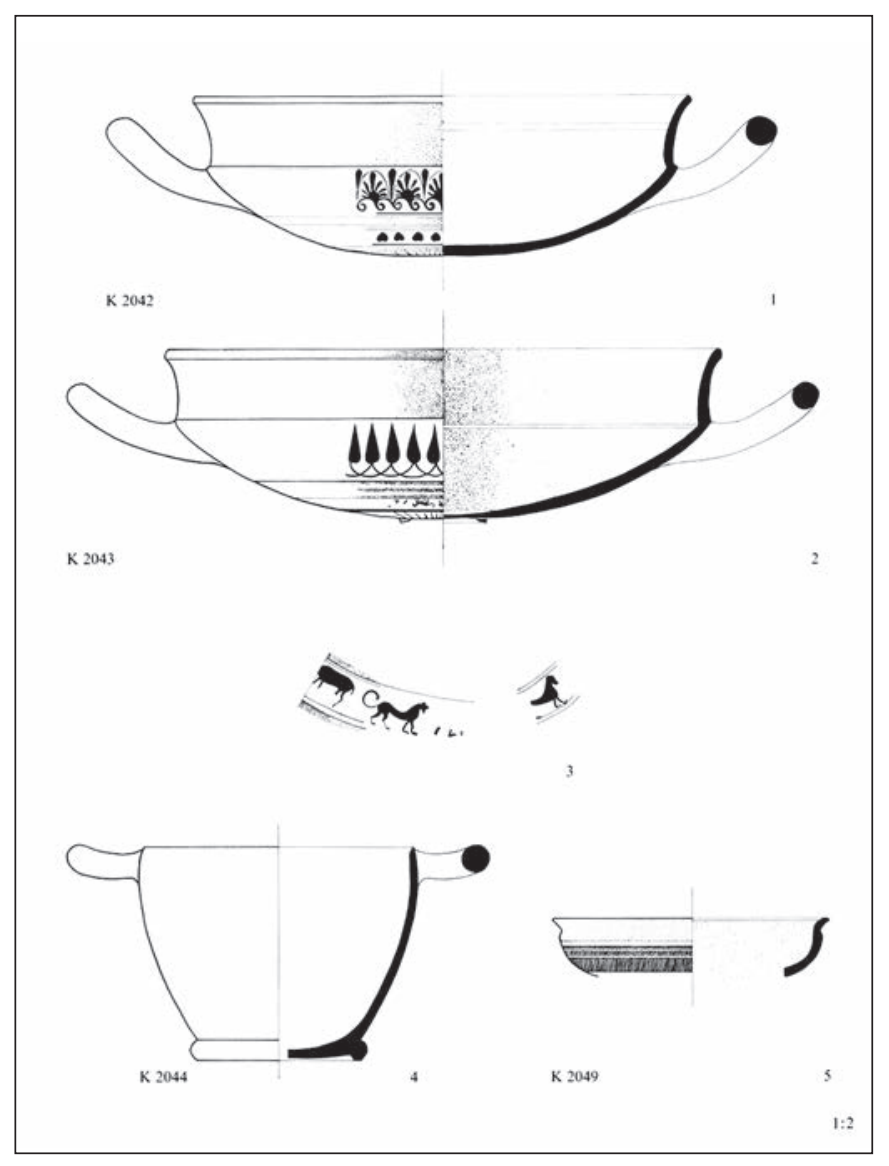

Fig. 4. Monte lato : Vasi facenti parte dell'offerta nel Tempio di Afrodite (da Studia letina II). 


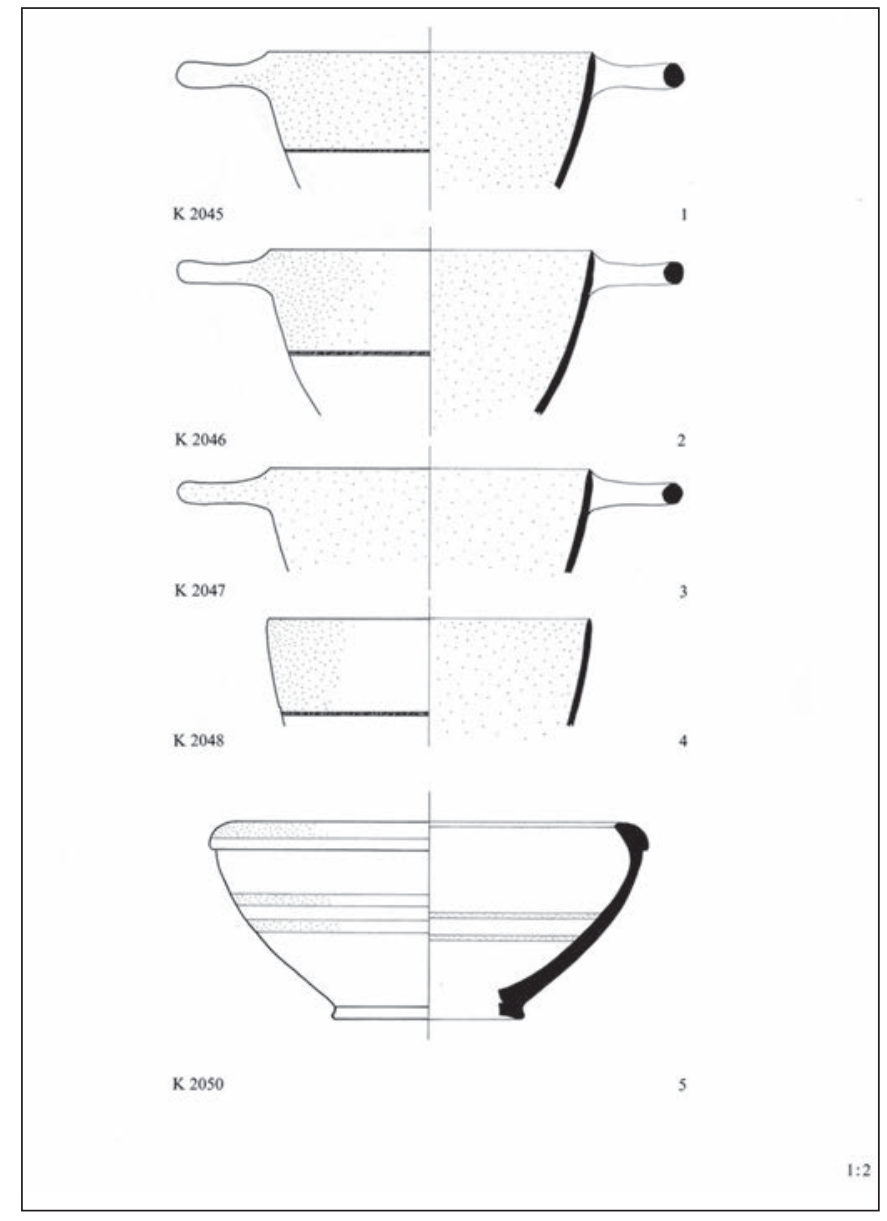

Fig. 5. Monte lato : Vasi facenti parte dell'offerta nel Tempio di Afrodite (da Studia letina II).

Il dato, tra l'altro, va letto e interpretato anche alla luce della documentazione archeologica di altri insediamenti dell'entroterra indigeno centro-occidentale dove, in alcuni casi, è attestata la presenza di spazi sacri in forma di capanne circolari - tipologia legata alla tradizione (Palermo 2006) e ripresa anche dai modellini di capanne/sacello diffusi in tutta l'area sicana (Gullì 2009) - in altri, da semplici edifici a pianta rettangolare a più o ad un solo ambiente (Spatafora in c.d.s.), non sempre facilmente distinguibili dai coevi edifici di uso esclusivamente domestico.

\section{Monte Maranfusa}

E' questo il caso, ad esempio, del complesso recentemente riportato alla luce a Monte Maranfusa, in un'area a mezza costa situata in posizione baricentrica rispetto al grande insediamento indigeno posto su una rocca calcarea che si eleva nella media Valle del Belice (fig.7), poche decine di chilometri a Sud di Monte Iato.

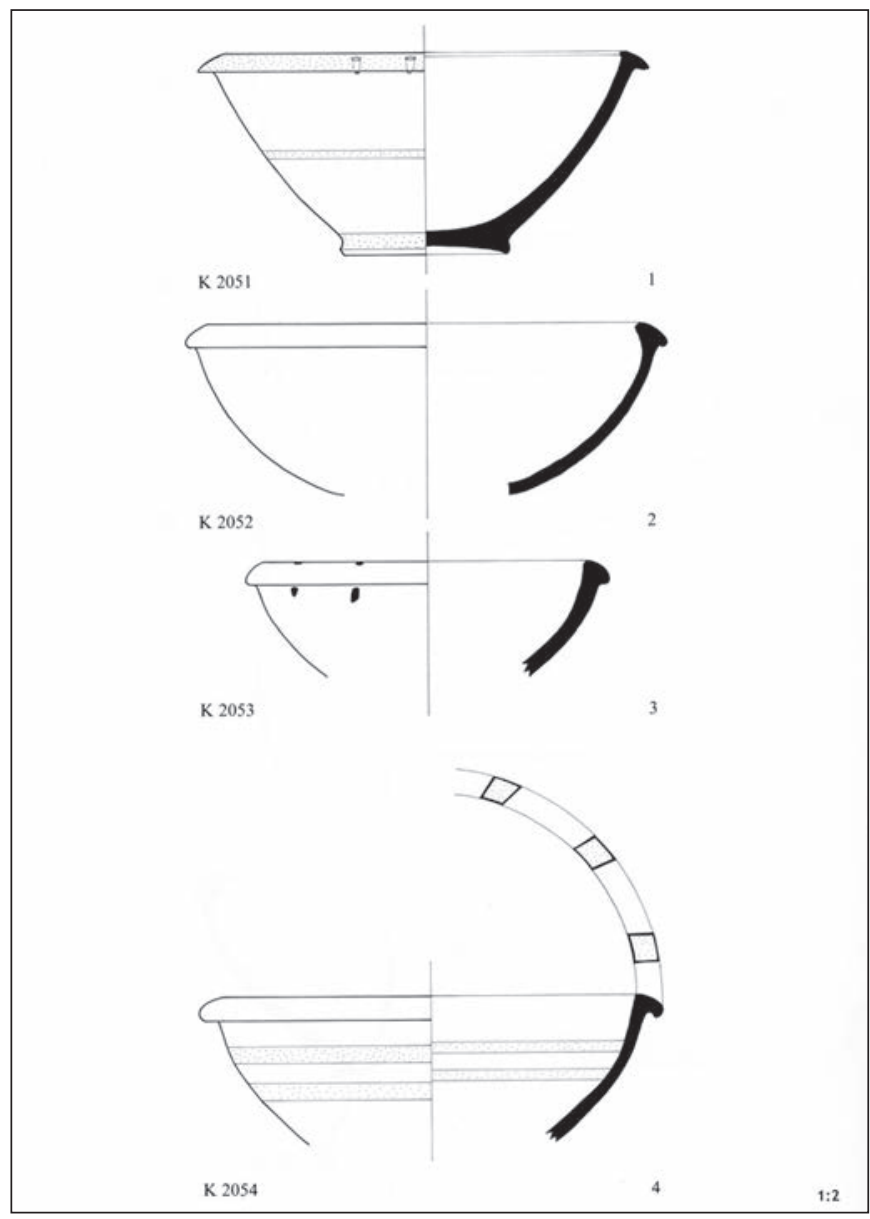

Fig. 6. Monte lato : Vasi facenti parte dell'offerta nel Tempio di Afrodite (da Studia letina II).

Gli edifici in questione sono tra l'altro inseriti in un contesto naturale che si contraddistingue per la presenza di un pendio orlato da una balza rocciosa da cui si domina il corso del ramo destro del fiume Belice.

Considerato il livello, non ancora definito, della ricerca, non è certa la destinazione sacrale dell'intero complesso, organizzato su tre terrazze artificialmente sostenute da muri (fig. 8). Pur tuttavia, ciò che sembra connotare gli edifici, adagiati in posizione digradante da SE verso NO è la deposizione di un'offerta, avvenuta almeno in due momenti, in uno degli ambienti dell'Edificio B (fig. 9) (Spatafora 2010, p. 34); la tipologia e le modalità di deposizione trovano confronto in altri più noti complessi di area sicana (Gullì 2005) e lasciano dunque ipotizzare l'esecuzione di azioni rituali dalla forte impronta identitaria, caratterizzando in senso sacro il complesso architettonico.

Del resto anche i caratteri architettonici dell'edificio - costituito da almeno tre ambienti, di cui quello destinato all'offerta risulta parzialmente seminterrato e senza sbocchi verso l'esterno, aprendosi 
esclusivamente sul secondo vano accuratamente lastricato che funge quasi da vestibolo - non rispondono ai criteri che improntano i coevi edifici a carattere domestico (Spatafora 2003, p. 65-86), anche se la distribuzione planimetrica dei vani non si discosta in maniera significativa da essi.

L'offerta, rinvenuta nell'angolo nord-orientale del vano seminterrato, comprendeva, ad esclusione di poche forme da cucina miniaturizzate, una serie di brocchette di produzione locale a decorazione geometrica dipinta con orlo trilobato o con beccuccio di versamento, alcune delle quali caratterizzate anche da raffigurazioni animali (fig. 10) e, in un caso, da una figura umana molto stilizzata (Spatafora 2010, fig. 20). Particolarmente interessante è anche la presenza di un modellino fittile di capanna/sacello anch'esso di dimensioni miniaturistiche (fig. 11); un secondo esemplare, sempre a pianta circolare e a decorazione incisa e impressa, ma maggiore per dimensione, si è invece rinvenuto nell'Edificio A (Spatafora 2010, fig. 21), in associazione a forme ceramiche che alludono alle pratiche del banchetto e del simposio, tra cui un grande cratere di produzione locale a decorazione geometrica dipinta, ispirato, per la forma, a modelli della ceramica greca (fig. 12).

Se dunque l'Edificio A fa parte del complesso a carattere cultuale - seppure destinato ugualmente ad attività domestiche e di riunione sociale, secondo una tipologia che affonda le sue radici almeno in età protostorica e che solitamente trova nella capanna circolare il modello architettonico meglio rispondente a quella pluralità d'uso - la celebrazione delle cerimonie a carattere religioso prevedevano evidentemente il consumo del cibo e l'azione del bere, mentre i vasi destinati all'offerta sembrano semplicemente evocare tali pratiche (vasi da cucina miniaturistici) ma, soprattutto, appaiono connessi pressoché esclusivamente ad attività di spargimento di liquidi nel terreno proprie dei culti ctoni.

\section{Makella/La Montagnola di Marineo (fig. 13)}

E' noto ormai da diversi anni il rinvenimento, proprio a ridosso del muro di fortificazione meridionale dell'antica Makella di una piccola area sacra connotata, soprattutto, dalla presenza di un offerta di armature, elmi e schinieri in bronzo di tipo greco (Spatafora 2002; Spatafora 2006, p. 218-220) (fig. 14).

La sovrapposizione di numerose strutture più tarde, non ha ancora permesso di definire la planimetria dell'edificio sacro, caratterizzato probabilmente da uno spazio chiuso e da un'area all'aperto.
Il numeroso materiale riportato alla luce sembra relativo alla celebrazione di cerimonie che prevedevano la cottura di alimenti, il sacrificio di animali e, quindi, il banchetto e le libagioni (Spatafora 2002). Il set cerimoniale comprendeva, infatti, tra i numerosi oggetti rinvenuti, una larga pignatta troncoconica, raccolta all'interno di una fossa/focolare, una piastra fittile utilizzata probabilmente per la cottura diretta dei piccoli ovicaprini i cui resti, evidentemente un sacrificio per la divinità, sono stati rinvenuti all'interno di una brocca appoggiata ad un piccolo altare di pietra, e numeroso vasellame da mensa o destinato alla conservazione di liquidi. La maggior parte del vasellame è di produzione locale, per lo più a decorazione geometrica dipinta: di ottima qualità le anfore e le idrie, evidentemente destinate a contenere liquidi per le libagioni (fig. 15).

Quasi del tutto assenti le ceramiche d'importazione anche se appare particolarmente significativo il rinvenimento di un frammento di coppa di Siana (fig. 16), un elemento di prestigio, piuttosto arcaico rispetto all'intero contesto che, come nel caso delle Droop cups o delle Kassel cups, è abbastanza diffuso nei contesti a carattere sacro - vedi, ad esempio, i materiali dal temenos di Athena a Himera - pur risultando egualmente attestato in diversi contesti indigeni di area occidentale (Spatafora 2009b, p. 744, fig. 10).

Avendone trattato già in diverse occasioni, non mi soffermerò né sulla tipologia dell'offerta né, più in generale, sulla definizione del piccolo santuario. Voglio solo sottolineare come, anche in questo caso, si tratti di un luogo sacro dal carattere fortemente ibrido, che denota quindi profondi processi di commistione già ben avviati dalla seconda metà del VI sec. a. C. in un'area dell'entroterra sicano rivelatasi assai permeabile sotto il profilo culturale.

\section{Entella}

Sul fianco meridionale della Rocca d'Entella (fig. 19), in vista del corso del Belice Sinistro e nei pressi di un'area di necropoli, è stato riportato alla luce un piccolo santuario ctonio, probabilmente un thesmophorion posto a mezzacosta di un ripido pendio terrazzato immediatamente al di fuori della porta nord-occidentale della città (Spatafora 2009a, con bibliografia precedente) .

Non sappiamo se fin dall'inizio il santuario sia stato dedicato a Demetra; certamente, però, il carattere ctonio del culto è accertato a partire dalle prime fasi di vita dell' area sacra, caratterizzata, prima della costruzione di un piccolo sacello a pianta quadrangolare di cui rimangono pochi brandelli di strutture murarie, da offerte votive deposte negli anfratti della roccia (fig. 18) che, emergendo in più punti, caratterizza il paesaggio in senso rupestre. 


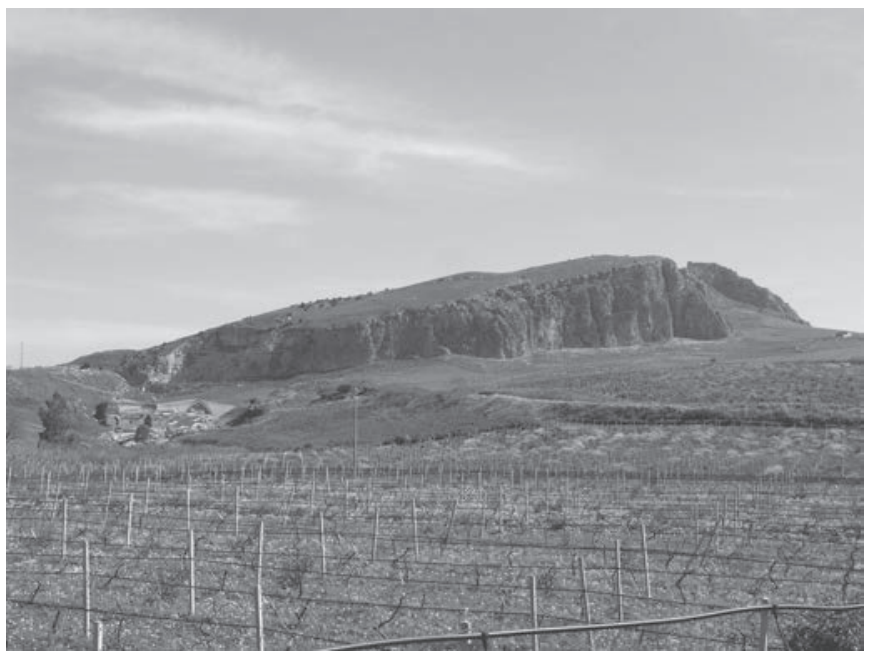

Fig. 7. Monte Maranfusa : veduta da sud.

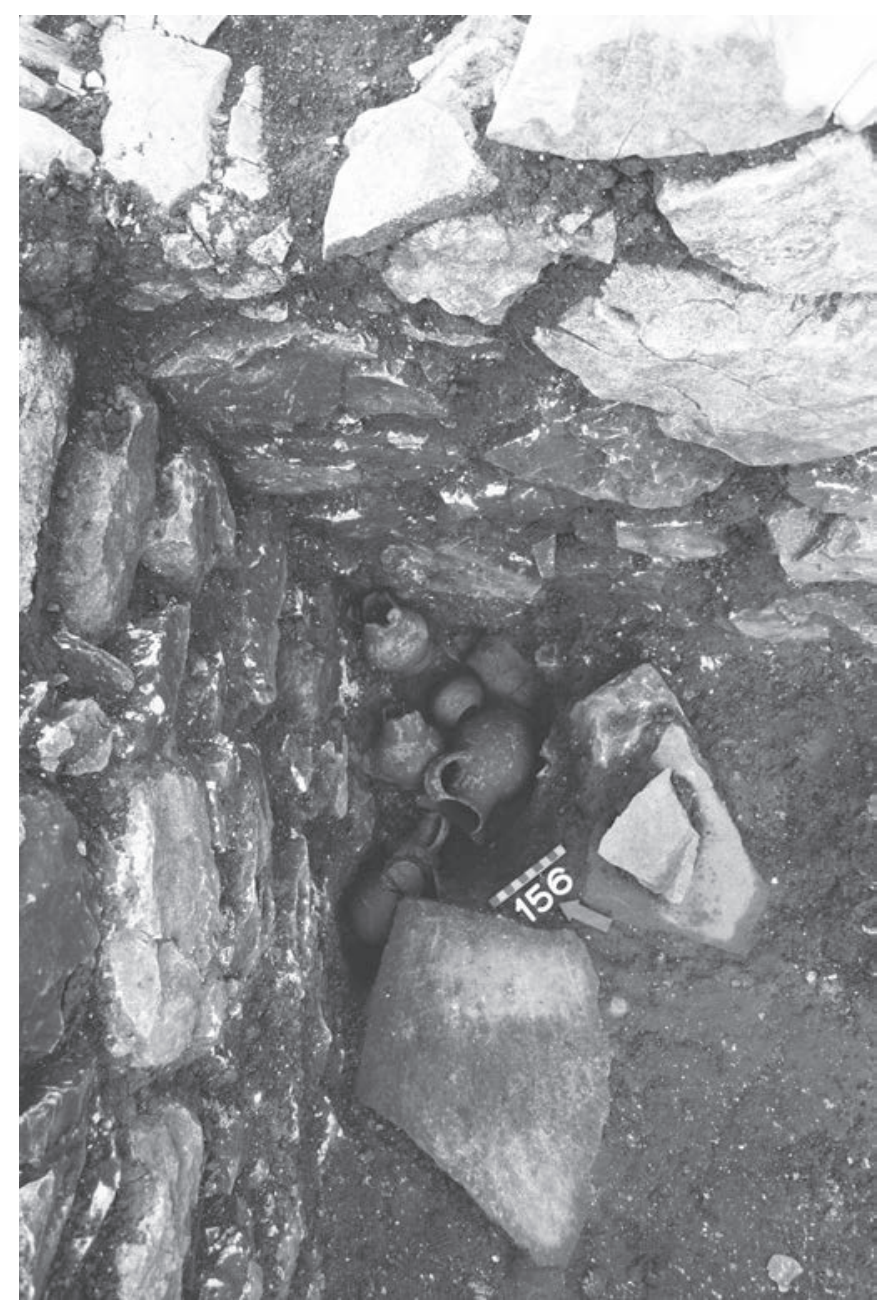

Fig. 9. Monte Maranfusa; edificio B: l'offerta.

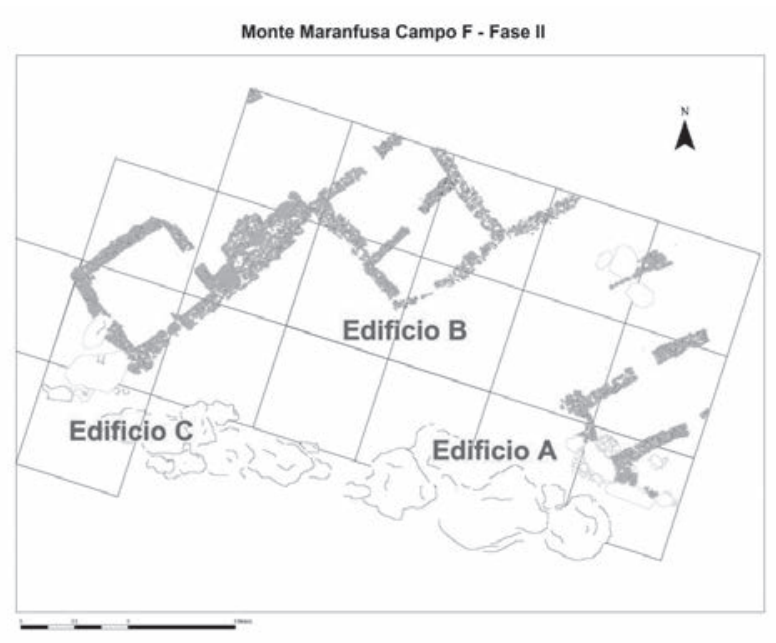

Fig. 8. Monte Maranfusa : il complesso di edifici del Campo F.

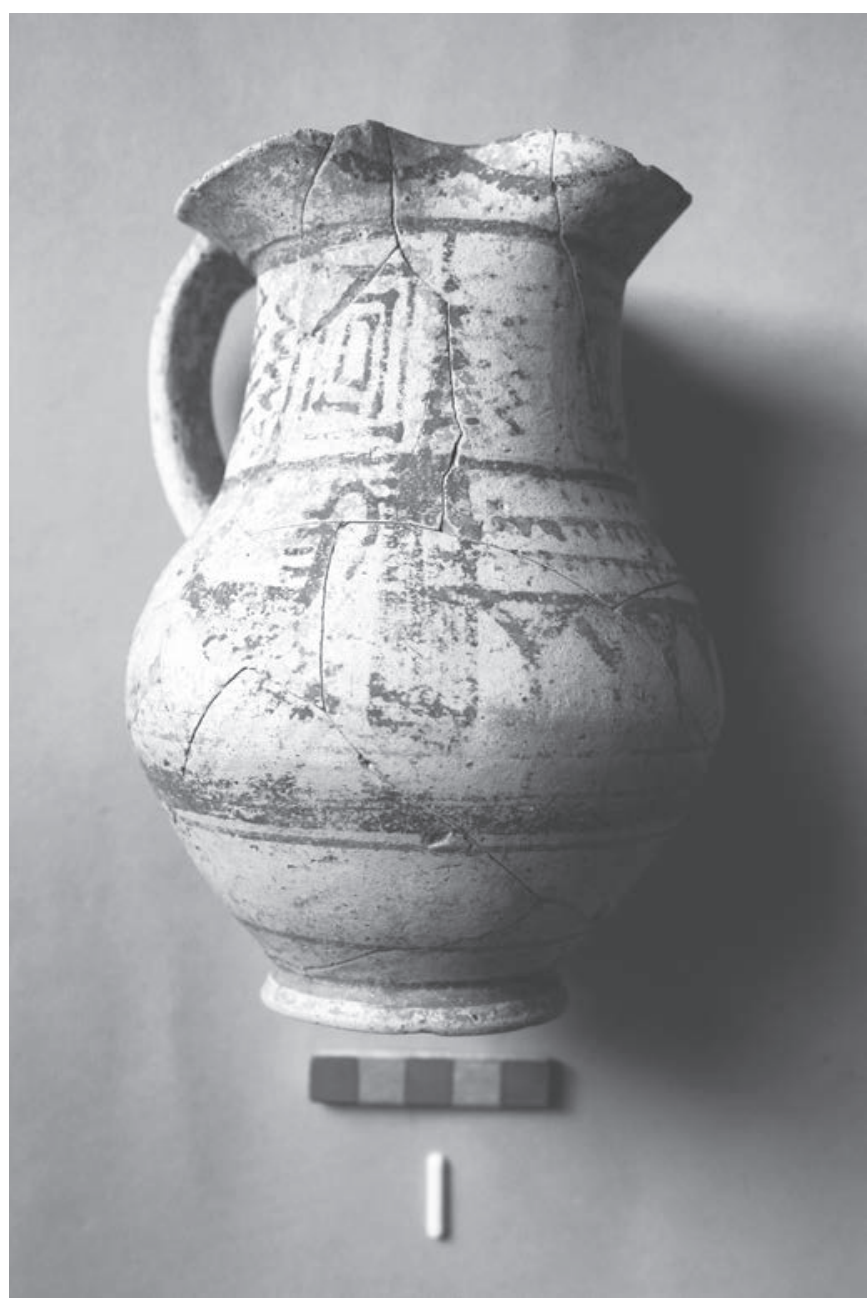

Fig. 10. Monte Maranfusa ; edificio B : oinochoe trilobata di produzione locale a decorazione dipinta. 


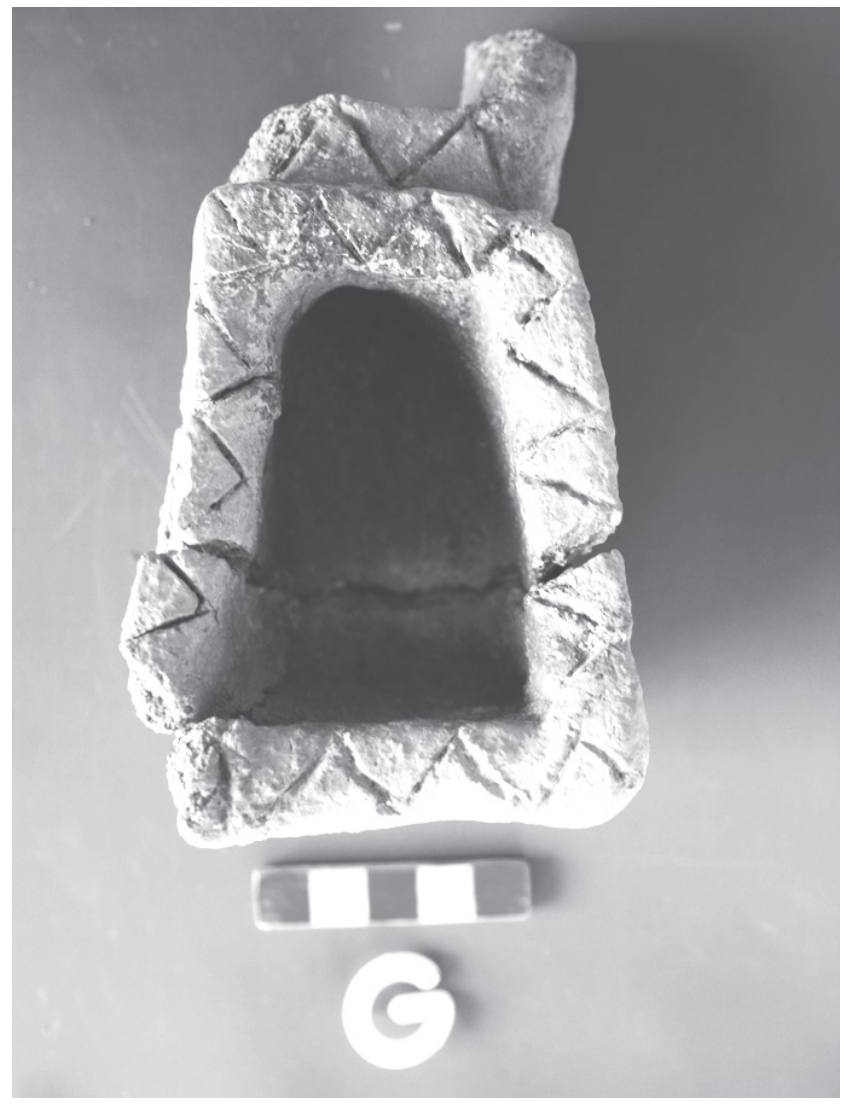

Fig. 11. Monte Maranfusa ; edificio B : il modellino di capanna/sacello miniaturizzato facente parte dell'offerta.

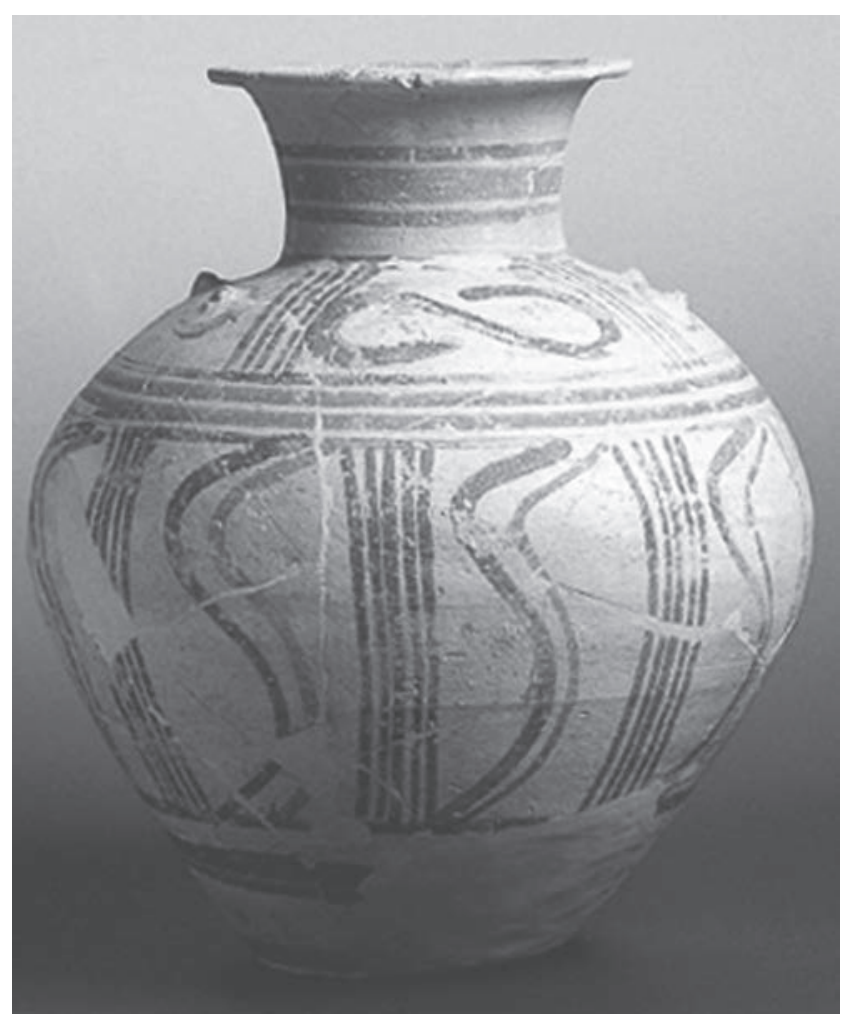

Fig. 15. La Montagnola di Marineo : vaso di produzione locale a decorazione dipinta dal santuario nei pressi della fortificazione.

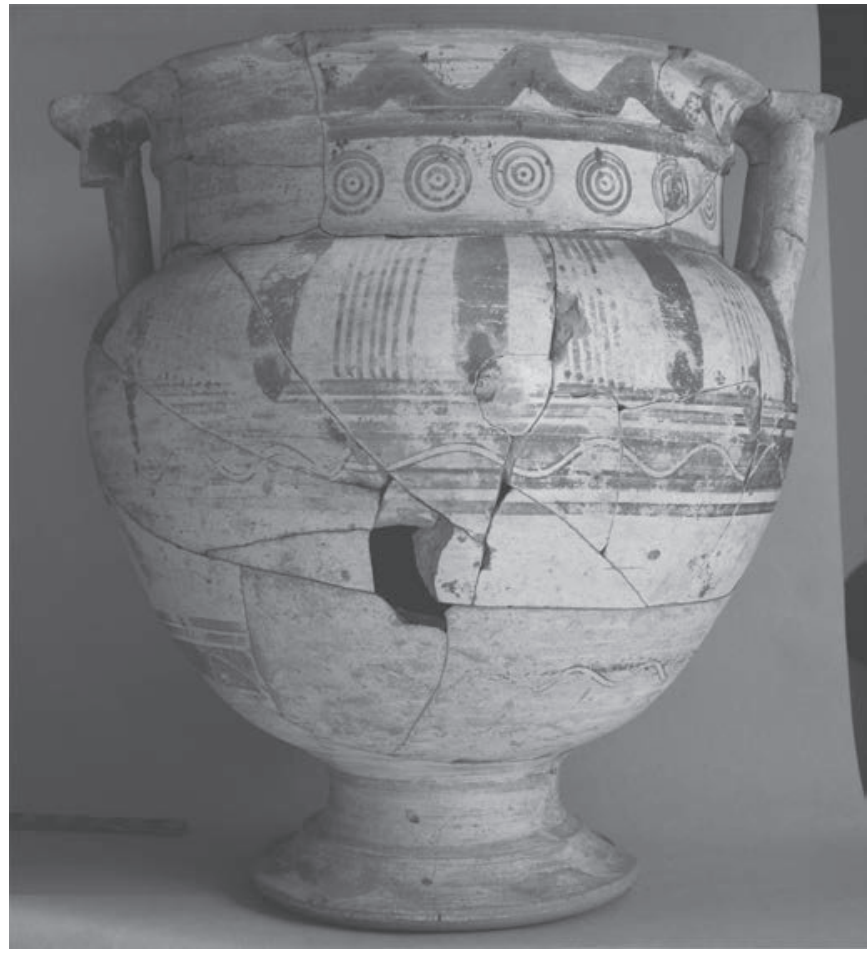

Fig. 12. Monte Maranfusa; edificio A : cratere di produzione locale a decorazione dipinta.

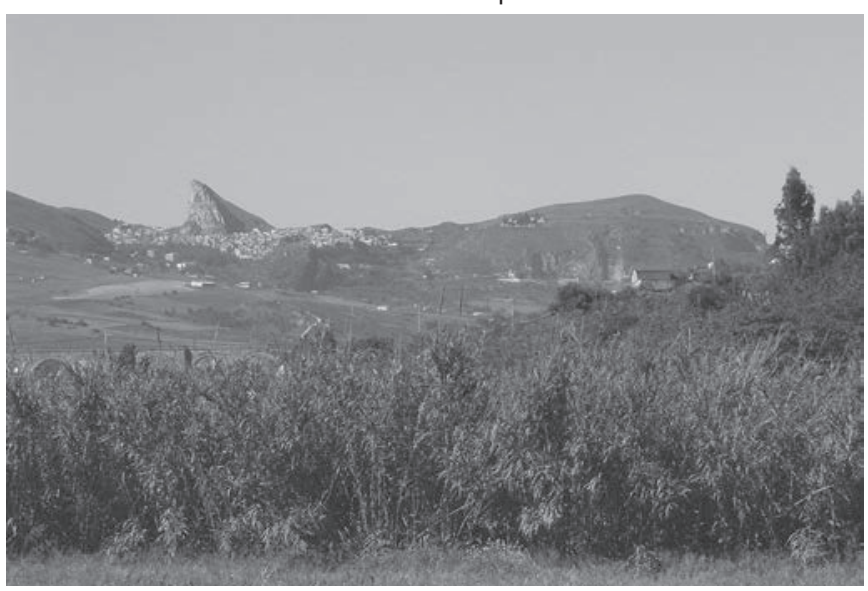

Fig. 13. La Montagnola di Marineo/Makella : veduta da nord.

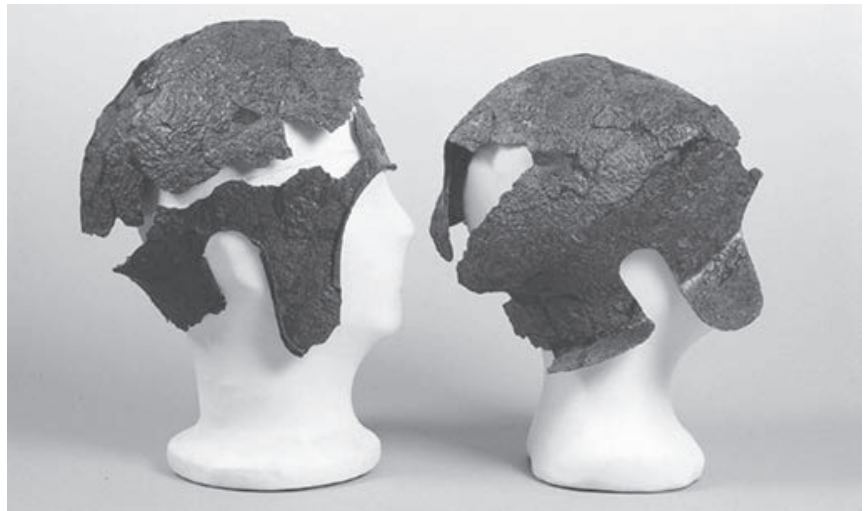

Fig. 14. La Montagnola di Marineo : elmi calcidesi dal santuario nei pressi della fortificazione. 
Le nove offerte rinvenute coprono un ampio arco cronologico compreso tra il VI e il III sec. a. C. (Spatafora 2009a, p. 519-520); nella maggioranza dei casi, e soprattutto nelle fasi più antiche, esse sono composte da forme chiuse miniaturistiche: anforette, olle, hydriai di fabbriche locali a decorazione geometrica dipinta (fig. 17), tranne nel caso dell' offerta $C$ costituita da una coppa ionica di tipo B1 e da un'altra coppetta acroma a vasca emisferica.

Nella parte sud-occidentale dell'area di scavo, invece, le offerte, sempre deposte nelle fenditure degli affioramenti gessosi, comprendevano anche materiali forse utilizzati per il banchetto rituale e successivamente dedicati alla divinità, come pentole a listello interno, scodelle, olpai e brocchette oltre a qualche lucerna.

Tra il V e il III sec. a. C., tuttavia, le offerte più numerose consistevano soprattutto in terrecotte votive raffiguranti divinità e offerenti di vario tipo e modulo: statuette femminili sedute in trono, busti e maschere con alto polos, figure femminili con porcellino e fiaccola $\mathrm{o}$, più raramente, con altri attributi (Spatafora 2009a, p. 520-522). Si tratta di tipi coroplastici legati al culto di Demetra e Persefone - ampiamente diffuso e documentato in ambiente siceliota e magno greco (Hinz 1998, p. 55-217) - che, nel caso di Entella, assumono una valenza documentaria particolarmente significativa sia per il luogo di rinvenimento che in relazione alla quantità delle attestazioni, oltre mille esemplari tra integri e frammentari.

Ricco e vario sembra essere stato lo strumentario utilizzato per la celebrazione delle cerimonie notturne: pignatte a listello interno rinvenute nei pressi di focolari, vasi per il consumo dei cibi, soprattutto ciotole e scodelle, lucerne. Attestate anche le forme miniaturizzate, soprattutto kotiliskoi e krateriskoi, che richiamano la pratica del banchetto e delle libagioni e le lucerne monolicni e polilicni su alto stelo svasato verso il piede che, così come denuncia la mancanza di tracce d'uso, sembrano aver perso la loro funzionalità a favore di una utilizzazione simbolica, evocatrice del complesso rituale notturno.

\section{Conclusioni}

In presenza di contesti dall'accentuata connotazione sacrale, a prescindere dall'analisi delle caratteristiche architettoniche dei luoghi chiaramente deputati a fatti e cerimonie di carattere religioso, è solitamente ovvio porsi alcuni interrogativi circa le divinità destinatarie dei culti, il significato e le funzioni delle offerte, il carattere e la natura delle cerimonie.

In una più ampia visione socio-antropologica, inoltre, la valutazione di questi elementi, seppure spesso parziale

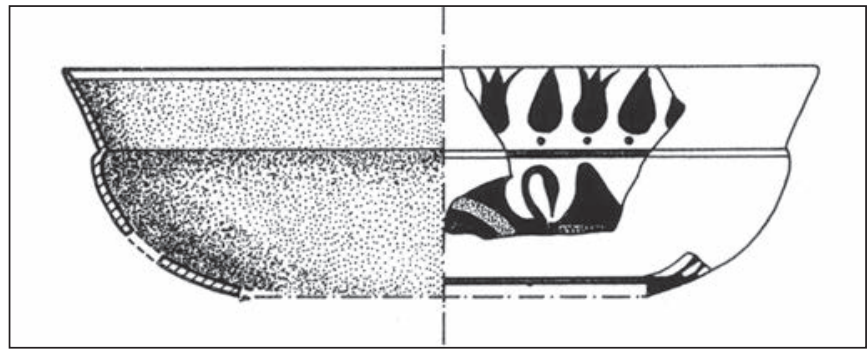

Fig. 16. La Montagnola di Marineo : frammento di coppa di Siana dal santuario nei pressi della fortificazione.

e incompleta, può tornare utile per meglio comprendere relazioni interculturali e funzione sociale dei singoli luoghi di culto, in special modo in presenza di insediamenti indigeni dell'entroterra più o meno esposti e permiabili a contatti esterni e a fenomeni di commistione.

I casi esaminati possono considerarsi, in tal senso, sufficientemente emblematici, anche perché accomunati da alcuni fattori determinanti per una valutazione complessiva dei diversi elementi: la posizione in un'area di confine particolarmente esposta, per condizioni geotopografiche, al contatto con i Greci della costa e con i Fenici insediati nella cuspide nord-occidentale dell'isola; la cronologia delle aree sacre prese in considerazione, risalenti almeno alla seconda metà del VI sec. a. C., un periodo che conosce una evidente accelerazione di quei processi di mediazione culturale tra mondo indigeno e coloniale che si definiranno in maniera più solo in età tardo-arcaica e classica.

Particolarmente interessante si rivelano gli aspetti connessi all'ideologia religiosa che traspare dalle diverse tipologie di aree sacre e dalle varietà di azioni rituali che si consumavano in quegli spazi.

Le evidenti e macroscopiche differenze che caratterizzano i quattro casi presi in considerazione sono il segno più evidente di come la società indigena si trasformi gradatamente e in forme e modi diversi attraverso il contatto con le realtà coloniali, privilegiando in alcuni casi un atteggiamento autoreferenziale utile a sottolineare una marcata coscienza identitaria, interagendo, in altri casi, con gli altri soggetti coprotagonisti della scena.

E se a Monte Maranfusa l'azione rituale e gli oggetti che compongono l'offerta richiamano in maniera significativa altri contesti di area sicana strettamente legati a pratiche e culti tradizionali poco codificati, seppur evidentemente connessi ai concetti di riproduzione e fertilità, l'offerta nel coevo tempio di Monte Iato, comprendente oltre ai vasi locali utilizzati per le cerimonie anche produzioni vascolari di pregio acquisite attraverso le colonie della costa o direttamente importate dalla Grecia, mostra l'esistenza di forti processi di commistione già ben avviati nel VI sec. a. C. e, sotto il profilo 


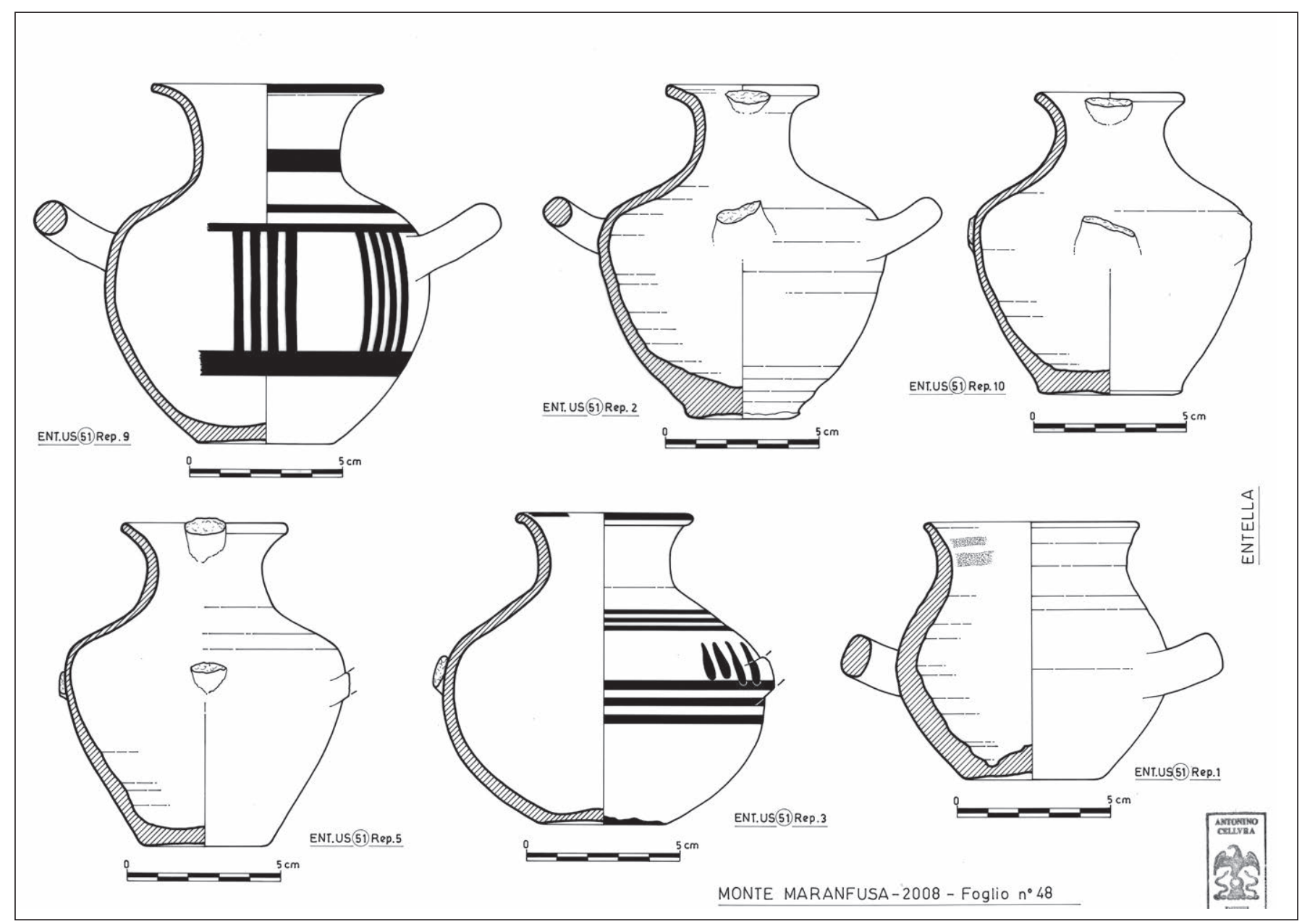

Fig. 17. Thesmophorion di Entella : vasi miniaturistici che componevano una delle offerte in anfratto roccioso.

dell'ideologia religiosa, l'introduzione nel centro indigeno di forme di culto mutuate dall'esterno.

Non è improbabile, del resto, che il tempio - con la sua articolata tipologia architettonica che comprendeva anche un altare esterno per la celebrazione di cerimonie comuni - possa avere funzionato da luogo di incontro per un'utenza più ampia di quanto non fosse quella che frequentava lo spazio sacralizzato di Monte Maranfusa che, anche nella tipologia architettonica sostanzialmente analoga alla coeva architettura domestica, appare strettamente legato a una frequentazione locale o addirittura familiare.

Anche il piccolo santuario della Montagnola di Marineo, con la sua straordinaria offerta di armature di tipo greco e con il suo ricco e composito set cerimoniale, sembra legato strettamente alla popolazione e alla storia del sito, se non addirittura a un fatto particolare di quella storia (Spatafora 2006, p. 220): la composizione dell'offerta, tuttavia, a prescindere dalla sua primaria accezione religiosa, potrebbe suggerire - per quel piccolo luogo sacro significativamente edificato immediatamente all'interno della fortificazione - una probabile connotazione politica, così come del resto anche recentemente proposto per quanto riguarda i più noti e importanti santuari di Grecia e Magna Grecia (La Torre 2011).

Analogamente a Monte Iato, invece, il santuario extramoenia di Entella - il cui carattere ctonio si manifesta con evidenza fin dalla prima frequentazione dello spazio sacro pur assumendo solo successivamente quella chiara connotazione tesmoforica testimoniata dai rinvenimenti (Spatafora 2002; Spatafora 2008; Spatafora 2009a) - sembra destinato a una frequentazione più ampia di quanto non sia quella locale, anche in considerazione del fatto che all'interno della città è documentata l'esistenza di spazi sacri ugualmente connessi ai culti ctoni (Parra 2011, con bibliografia precedente). La lunga durata di utilizzazione di quello spazio a scopi cultuali - frequentato, seppure in modo sporadico, fino ad età tardo-romana - nonché la straordinaria ricchezza in termini quantitativi delle 
offerte, lasciano infatti ipotizzare che il thesmophorion entellino, con il suo culto già ben codificato in età tardo-arcaica, possa avere costituito il punto di aggregazione religioso per quel vasto comprensorio territoriale belicino densamente abitato durante l'età del Ferro e, ancora, in periodo arcaico, classico ed ellenistico.

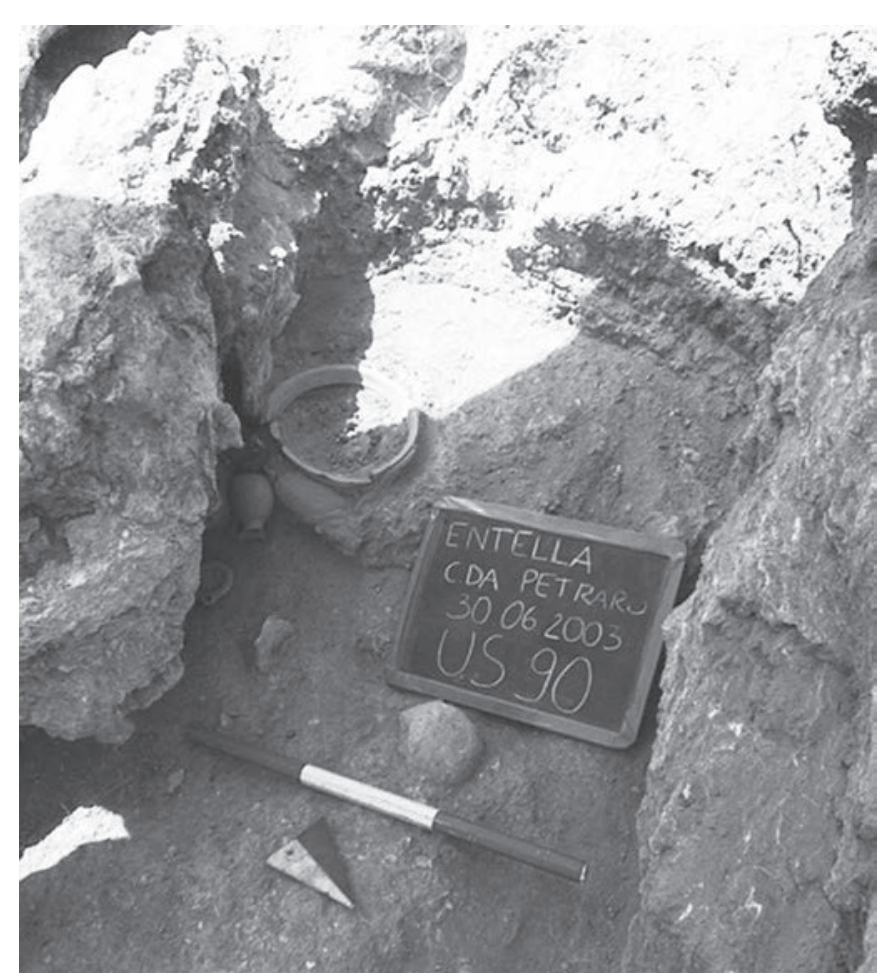

Fig. 18. Thesmophorion di Entella : offerta in anfratto roccioso.

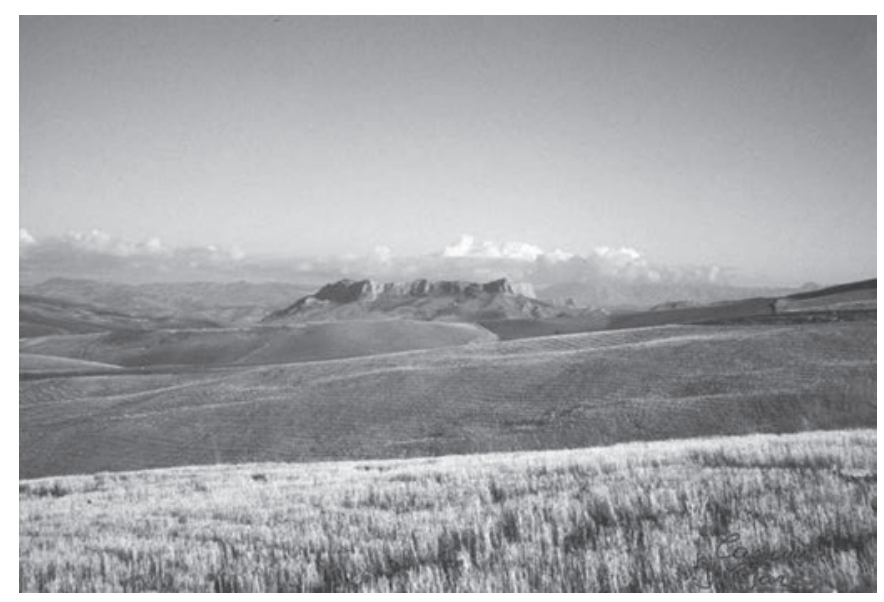

Fig. 19. La Rocca di Entella.

\section{Bibliografia}

Albanese Procelli 2006 : ALBANESE PROCELLI (R. M.) - Pratiche religiose in Sicilia tra protostoria e arcaismo. In : Anello (P.), Martorana (G.), SAMMARTANO (R.) ed., Ethne e religione nella Sicilia antica. Rome 2006, p. 43-70

Gullì 2005 : GULLÌ (D.) - Caratteri di un centro indigeno nella valle del Platani. Nuove ricerche. Sicilia Antiqua II, 2005, p. 9-62.

Gullì 2009 : GULLÌ (D.) - I modellini di capanna a pianta circolare di Casteltermini. In : La Sicilia in età arcaica. Dalla apoikiai al 480 a.C. Palerme 2009, p. 259-265

Hinz 1998 : HINZ (V.) - Der Kult von Demeter und Kore auf Sizilien und in der Magna Graecia. Palilia 4, Wiesbaden, Reichert, 1998.

Isler 2002 : ISLER (H.P) - Monte Iato. Indigeni e greci in età arcaica. In : Spatafora (F.), Vassallo (S.), Sicani Elimi e Greci. Storie di contatti e terre di frontiera, Catalogo della mostra. Palerme 2002, p. 76-80

La Torre 2011 : LA TORRE (F. G.) - Le lance di Temesa e le offerte di armi nei santuari di Magna Grecia e Sicilia in epoca arcaica. Quaderni di Archeologia, 1, 2011, p. 68-104

Öhlinger c.d.s. : ÖHLINGER (B) - Monte Iato : Archaic cult places of local and interregional scale-a view of the sociology of religion. In : Sanctuaries and the power of consumption. Networking and the formation of elites in the archaic western Mediterranean world (Innsbruck 20 / 23 Marzo 2012), Atti, in c.d.s. Palermo 2006 : PALERMO (D.) - I santuari dell'area sicana. In : Guzzone (C.) ed., Sikania. Tesori archeologici della Sicilia centro-meridionale (secoli XIII-VI a. C.), Catalogo della mostra (Wolfsburg-Hamburg Ottobre-Marzo 2006). Palerme 2006, p. 89-92

Parra 2011 : PARRA (M. C.) - Entella. Scavi nell'area centrale (SAS 3/30 2007-08) : risultati e prospettive di ricerca. ASNSP, serie 5, 2011, 3/2 supplemento, p. 45-48.

Romeo 1989 : ROMEO (I.) - Sacelli arcaici senza peristasi nella Sicilia greca. Xenia, XVII, 1989, p. 5-54

Spatafora 2001 : SPATAFORA (F.) - Un contributo per l'identificazione di una delle « città di Sicilia » dei decreti di Entella. In : Da un'antica città di Sicilia. I Decreti di Entella e Nakone, Catalogo Mostra (a cura della Scuola Normale Superiore di Pisa). Pise 2001

Spatafora 2002 : SPATAFORA (F.) - La Montagnola - Makella. In : Spatafora (F.), Vassallo (S.) (a cura di), Sicani, Elimi e Greci. Storie di contatti e terre di frontiera, Catalogo Mostra. Palerme 2002, p. 87-90

Spatafora 2003 : SPATAFORA (F.) - Monte Maranfusa. Un insediamento nella media Valle del Belice. L'abitato indigeno. Palerme 2003 (Beni Culturali- Palermo 7)

Spatafora 2006 : SPATAFORA (F.) - Vincitori e vinti: sulla deposizione di armi e armature nella Sicilia di età arcaica. In : Guerra e pace in Sicilia e nel Mediterraneo antico (VIII-III sec.a.C.). Arte, prassi e teoria della pace e della guerra,Atti V Giornate Internazionali (Erice 2003), I. Pise 2006, p. 218-221

Spatafora 2008 : SPATAFORA (F.) - Entella : il Thesmophorion di Contrada Petraro. In : Di Stefano (C. A.) ed., Demetra. La divinità, $i$ santuari, il culto, la leggenda,Atti del I Congresso Internazionale Enna, 1-4 luglio 2004. PiseRome 2008, p. 273-284

Spatafora 2009a : SPATAFORA (F.) - Entella : lo scavo di Contrada Petraro. Annali Scuola Normale Superiore di Pisa, IX, 2 (2004), Pisa 2009, p. 513-526 Spatafora 2009b : SPATAFORA (F.) - Culti e ceramiche greche nei santuari dei centri indigeni della Sicilia occidentale. In : Fortunelli (S.) - Masseria (C.) ed., Ceramica attica da Santuari della Grecia, della Ionia e dell'Italia, Atti del Convegno di Studi (Perugia 14-17 marzo 2007). Bari 2009, p. 121-131

Spatafora 2010 : SPATAFORA (F.) - Per un' « archeologia degli incontri »: Sicani ed Elimi nella Sicilia greca. In : Tréziny $(\mathrm{H})$ éd., Contacts et échanges technologiques entre Grecs et indigènes de la Catalogne à la Mer Noire. Aixen-Provence 2010, p. 25-40

Spatafora c.d.s. : SPATAFORA (F.) - Tra Elimi e Sicani: ideologia religiosa e luoghi sacri. In : La Sicilia in età Arcaica. Dalle apoikiai al 480 a.C. (Caltanissetta 27-29 marzo 2008), Atti, in c.d.s.

Studia Ietina II : ISLER (H.P.) A CURA - Studia Ietina II. Zürich, 1984. 


\title{
Nuevos datos arqueológicos sobre la evolución urbana de Emporion
}

\author{
Pere Castanyer \\ Marta Santos \\ Joaquim Tremoleda \\ Museu d'Arqueologia de Catalunya - Empúries
}

\section{Résumé}

Cet article présente les résultats des dernières recherches archéologiques réalisées dans le quartier portuaire et dans le secteur central de la Neapolis d'Emporion, qui ont permis de renouveler nos connaissances sur l'origine et le développement postérieur d'Emporion. De nouvelles données ont été acquises dans le secteur du port sur le lien entre le nouveau noyau urbain et la mer ; sur les remaniements de cette voie d'accès ; et des éléments de mobiliers appartenant à un sanctuaire proche ont également été découverts. Dans la ville, les travaux menés autour de l'agora et de la stoa ont permis d'obtenir des éléments plus précis sur l'urbanisme des phases initiales d'Emporion. Nous présentons aussi les résultats des nouvelles fouilles réalisées sur les nécropoles autour de la cité grecque.

Mots-clés : Emporion, port, sanctuaire, rempart, architecture, urbanisme, nécropole

\section{Abstract}

This paper shows the results of the latest archaeological research carried out in the port area and in the central area of Neapolis Emporion, which helped to renew our understanding of the origin and subsequent development of Emporion. New data were acquired in the harbor area on the link between the new urban core and the sea; the rearrangement of this path, and items of pottery belonging to a near sanctuary were also discovered. In the city, the researches around the agora and the stoa have yielded more specific elements about the urbanistic planning during the initial stages of Emporion. We also present the results of new excavations at the necropolis around the Greek city.

Keywords: Emporion, harbour, sanctuary, rampart, architecture, urbanism, necropolis 
$\mathrm{L}$ as investigaciones arqueológicas en torno a la evolución urbana del antiguo núcleo colonial foceo de Emporion cuentan hoy con más de un siglo de historia, a partir del inicio de las excavaciones promovidas desde la Junta de Museus de Barcelona en el año 1908. Desde muy pronto, el interés de los trabajos arqueológicos se centró sobre todo en el descubrimiento de los restos pertenecientes a su principal sector urbano, al sur del antiguo puerto natural, que hoy identificamos con el término de Neápolis. De esta manera, y como resultado de las sucesivas intervenciones efectuadas durante esta primera gran etapa de las excavaciones emporitanas, hasta 1936, fueron exhumadas una gran parte de las estructuras constructivas que definían el entramado más reciente del antiguo núcleo griego, a partir del siglo II a.C. y hasta los inicios de la época imperial romana. Estas evidencias incluían los restos del perímetro defensivo, los diversos edificios de uso cultual y otros espacios de uso público, especialmente los que formaban parte de complejo del ágora y la estoa, en la parte central del espacio urbano, juntamente con el resto de construcciones con funciones domésticas, artesanales o comerciales. Todos estos elementos hicieron posible el conocimiento del urbanismo de la ciudad durante esta última etapa así como de las características arquitectónicas de sus principales edificaciones (Puig i Cadafalch 1913 y 1920 ; Mar, Ruiz de Arbulo 1993, p. 155-186).

Sin embargo, el carácter parcial y la complejidad de la secuencia estructural correspondiente a otras evidencias constructivas anteriores, puestas también al descubierto por las excavaciones, dificultaba la interpretación de las fases precedentes del urbanismo del núcleo griego. Sólo pueden exceptuarse determinadas zonas más intensamente exploradas, como es el caso del sector meridional de Neápolis, nuevamente objeto de importantes trabajos arqueológicos entre 1985 y 1990 que permitieron reintepretar la secuencia evolutiva de los principales espacios religiosos y también de los lienzos de murallas que habían protegido este extremo de la ciudad (Sanmartí 1988; Sanmartí, Castanyer, Tremoleda 1988, 1990 y 1992; Sanmartí, Nolla 1986). Las limitaciones de la información disponible eran aún más evidentes con respecto a las etapas más antiguas de la ocupación del núcleo de la Neápolis, conocidas únicamente a través de los diversos sondeos estratigráficos realizados de manera puntual en determinados lugares de su topografía (Ruiz de Arbulo 1994).

Entre 1994 y 1997, la oportunidad de poder llevar a cabo nuevas actuaciones arqueológicas en el subsuelo de Sant Martí de Empúries hizo posible obtener datos de enorme interés para reconstruir los inicios del establecimiento foceo y la naturaleza del enclave originario de la Palaia Polis mencionado en el texto de Estrabón, así como de la ocupación indígena precedente (Aquilué et al. 1999; Aquilué et al. 2002 y 2010). En los últimos años, sin embargo, los más recientes trabajos de excavación emprendidos en relación con la antigua ciudad griega de Emporion han permitido contrastar estas informaciones con nuevas evidencias arqueológicas que, por primera vez, han mostrado en una extensión ya más significativa, algunas de las construcciones pertenecientes a las primeras etapas del nuevo núcleo urbano desarrollado a partir de la segunda mitad del siglo VI a.C. al sur de la ensenada portuaria. En esta comunicación presentada en el coloquio de Hyères en homenaje al amigo Michel Bats hemos querido resaltar algunos de los principales datos obtenidos en estos trabajos arqueológicos más recientes, que él mismo ha podido conocer de primera mano en sus visitas a Empúries realizadas en los últimos años. Finalmente, mencionaremos también las últimas excavaciones realizadas en el entorno suburbano, al sur de la Neápolis, en las que ha sido posible documentar una nueva área funeraria griega utilizada ya a partir del siglo V a.C.

\section{El barrio portuario de Emporion}

Entre las intervenciones arqueológicas realizadas durante los últimos años en Empúries, debemos destacar las desarrolladas en el ángulo noroeste de la Neápolis, en el marco de las obras de construcción de los nuevos almacenes arqueológicos del museo, que han puesto al descubierto restos de diversas edificaciones pertenecientes al barrio portuario de la antigua ciudad griega (Aquilué et al. 2008, p. 192-194; Aquilué et al. 2011, p. 123-131). Se trata de una zona hasta hace poco totalmente desconocida para la investigación emporitana, puesto que gran parte de las construcciones hoy visibles habían quedado afectadas por las obras realizadas en el siglo XVII durante la edificación del convento de Santa Maria de Gràcia, sobre cuyos restos, una vez iniciado el proceso de recuperación del conjunto arqueológico en el año 1908, fueron creadas las primeras infraestructuras museísticas. La fisonomía de este sector quedó aun más desfigurada en los años 60-70 del siglo XX con la creación de una gran terraza artificial para albergar diferentes cisternas, obras que comportaron una considerable sobreeelevación respecto al antiguo relieve de esta zona en época griega.

El proyecto de edificación de los nuevos almacenes arqueológicos, que hizo necesario desmontar las construcciones modernas y contemporáneas antes mencionadas, facilitó la realización de una importante actuación arqueológica en los años 2007 y 2008, gracias a la cual ha sido posible conocer el extremo noroeste de la Neápolis y, especialmente, su conexión con el límite 
de la bahía natural que se extendía más al norte y que constituía el puerto del antiguo emporio griego. Aunque la compleja estratigrafía documentada permite establecer diferentes fases de ocupación, que abarcan desde los inicios del núcleo urbano de la Neápolis en el siglo VI a.C. hasta la actualidad, nos centraremos aquí únicamente en la descripción de las estructuras correspondientes a las etapas más antiguas.

Especial atención merecen los datos relativos a la reconstrucción paleotopográfica de esta zona portuaria, hoy completamente alterada por múltiples procesos de carácter natural y antrópico, que nos permiten contrastar las hipótesis formuladas años atrás a partir de prospecciones geofísicas y geológicas o, de forma más indirecta, también por las excavaciones subacuáticas llevadas a cabo en la fachada marítima de Emporion (Blech, Marzoli 2005; Marzoli 2005; Rambaud 2005; Nieto, Raurich 1998; Nieto et al. 2005). El hallazgo de las diferentes estructuras que sirvieron para delimitar el extremo noroeste de la ciudad griega, así como también el rebaje de parte de la potente capa de arena que hoy cubre totalmente la antigua ensenada portuaria, dejaron al descubierto diferentes niveles de guijarros y arena correspondientes a una antigua playa que comenzaba a partir de este punto del litoral del antiguo puerto y que probablemente se prolongaba también en su límite occidental, facilitando así el varado de las embarcaciones. Las características de esta paleocosta permiten comprender por qué en este sector se emplazó, desde el inicio, el acceso principal que comunicaba el nuevo recinto griego de la Neápolis con la zona portuaria. Efectivamente, a partir de este punto y en dirección al este, el promontorio rocoso sobre el que se asienta la ciudad asciende bruscamente, formando un pequeño acantilado - de cubierto en parte durante las excavaciones llevadas a cabo por E. Gandia en 1921 (Mar, Ruiz de Arbulo 1993, p. 75-76) -, factor que hacía totalmente inviable la comunicación con el puerto.

El acceso al interior del espacio urbano se realizaba a través una rampa (fig. 1) parcialmente excavada en el substrato rocoso y delimitada a ambos lados por diversas construcciones, irregularmente conservadas a causa de las constantes reformas efectuadas posteriormente en esta zona. En la parte occidental, donde el perfil de la roca natural desciende hasta cotas más bajas, se pudo excavar una interesante secuencia estratigráfica que permite fechar con precisión las primeras obras de acondicionamiento de este extremo urbano. Por encima de una especie de escorrentía natural, que suponemos había servido originariamente para canalizar las aguas y los residuos hacia la playa y el mar, se construyó en un determinado momento una terraza artificial sobre la cual se dispuso un espacio al descubierto delimitado al oeste por un modesto porche sustentado con pilares de madera. Para la construcción de esta terraza fue preciso levantar dos muros orientados perpendicularmente, de casi un metro de anchura, capaces de contener la importante aportación de tierras necesaria para elevar el terreno. La excavación del potente estrato de relleno, formado por diferentes capas de tierra cenicienta con una gran concentración de materiales arqueológicos, permite proponer una cronología para la ejecución de esta obra en torno a los años finales del siglo VI o los inicios del siglo $\mathrm{V}$ a.C. En nuestra opinión, el hecho de que la construcción de esta terraza se realizara en una fecha más reciente, en algunos decenios, respecto a la creación del núcleo de la Neápolis, parece obedecer a que se trataba sencillamente de una ampliación o modificación del límite originario de este extremo de la ciudad. La composición orgánica de los estratos de relleno excavados, con un alto porcentaje de materiales procedentes de residuos domésticos, sería otro argumento en favor de esta hipótesis.

La estructura y la planta de este sector no debió cambiar substancialmente a lo largo del siglo V a.C., si bien cabe mencionar el refuerzo efectuado en el muro perimetral en L que delimitaba la terraza, manteniendo, a la vez, el acceso en rampa hacia la playa del puerto. Con respecto a la funcionalidad de este espacio concreto situado en el extremo noroeste del núcleo, llama extraordinariamente la atención el hallazgo de numerosas ofrendas votivas, así como de piezas de indudable carácter ritual. Destaca, así, la gran cantidad de fragmentos de kernoi, de formas y decoraciones diversas, y generalmente coronados con representaciones en miniatura de pequeñas hídrias, que fueron recuperados en diversos niveles estratigráficos, así como también el hallazgo de diversas ofrendas votivas formadas por depósitos de pequeñas olpai que aparecieron enterrados en esta zona (Aquilué et al. 2011, p. 129-131; Santos, Sourisseau 2011, p. 225-226). Cierran el apartado de piezas singulares algunas escasas terracotas que representan animales y también posibles divinidades, como es el caso de una cabecita femenina tocada con polos, que podría corresponder a Deméter. La inusual concentración de este tipo de objetos permite plantear la probable existencia de un santuario o espacio cultual en este sector adyacente al antiguo acceso a la playa portuaria. La construcción de la terraza sobreelevada habría posibilitado la creación de un espacio en gran parte al aire libre, habilitado para la realización de determinadas prácticas rituales, las cuales podemos imaginar relacionadas con la actividad marinera y comercial inherente al ámbito portuario de la ciudad, en el cual los navegantes y marineros podían ofrecer sus libaciones. Significativamente, otro de los restos que podemos relacionar con esta área sacra corresponde a una estructura de combustión de planta cuadrada, delimitada por un muro de obra, quizás con funciones de altar-hogar, que 


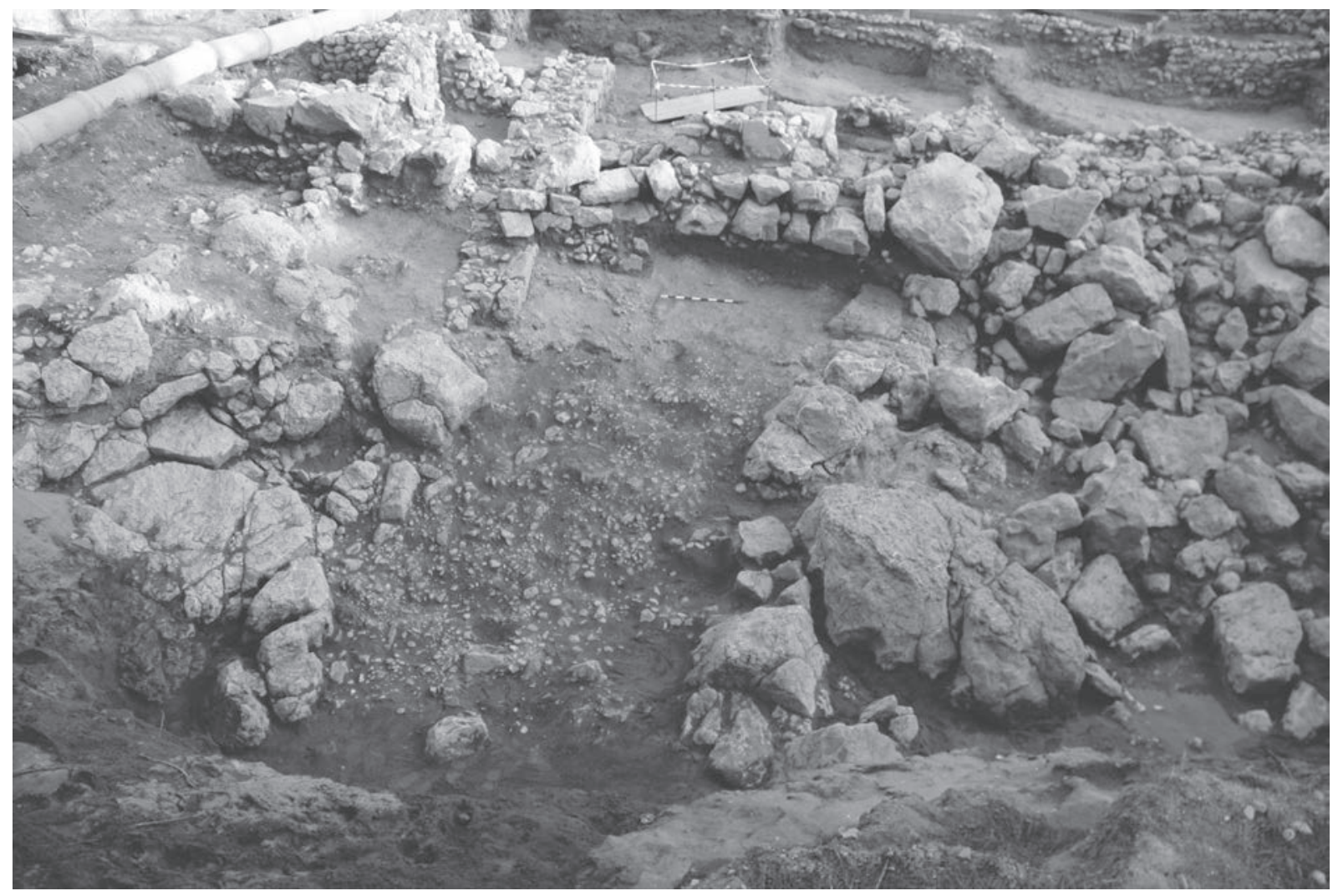

Fig. 1. Detalle de la rampa que originariamente facilitaba el acceso desde la antigua playa portuaria hacia el interior de la ciudad griega (Foto: MAC-Empúries).

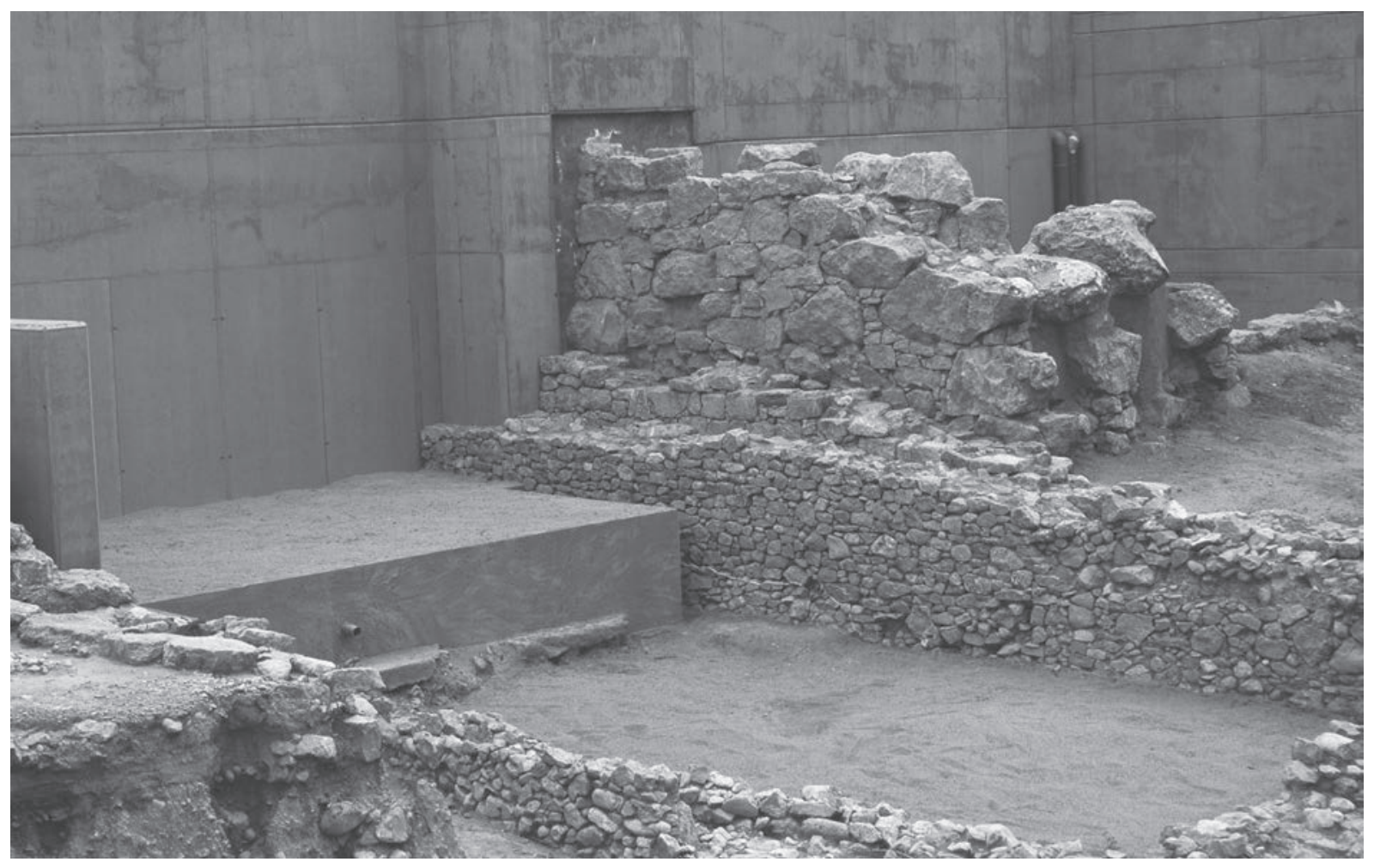

Fig. 2. Restos del lienzo de muralla puesto al descubierto en la excavación del sector noroccidental de la Neápolis, adosado a los diversos muros que previamente habían servido para delimitar la terraza sobreelevada construida en este extremo de la ciudad a finales del siglo VI a.C. (Foto: MAC-Empúries). 


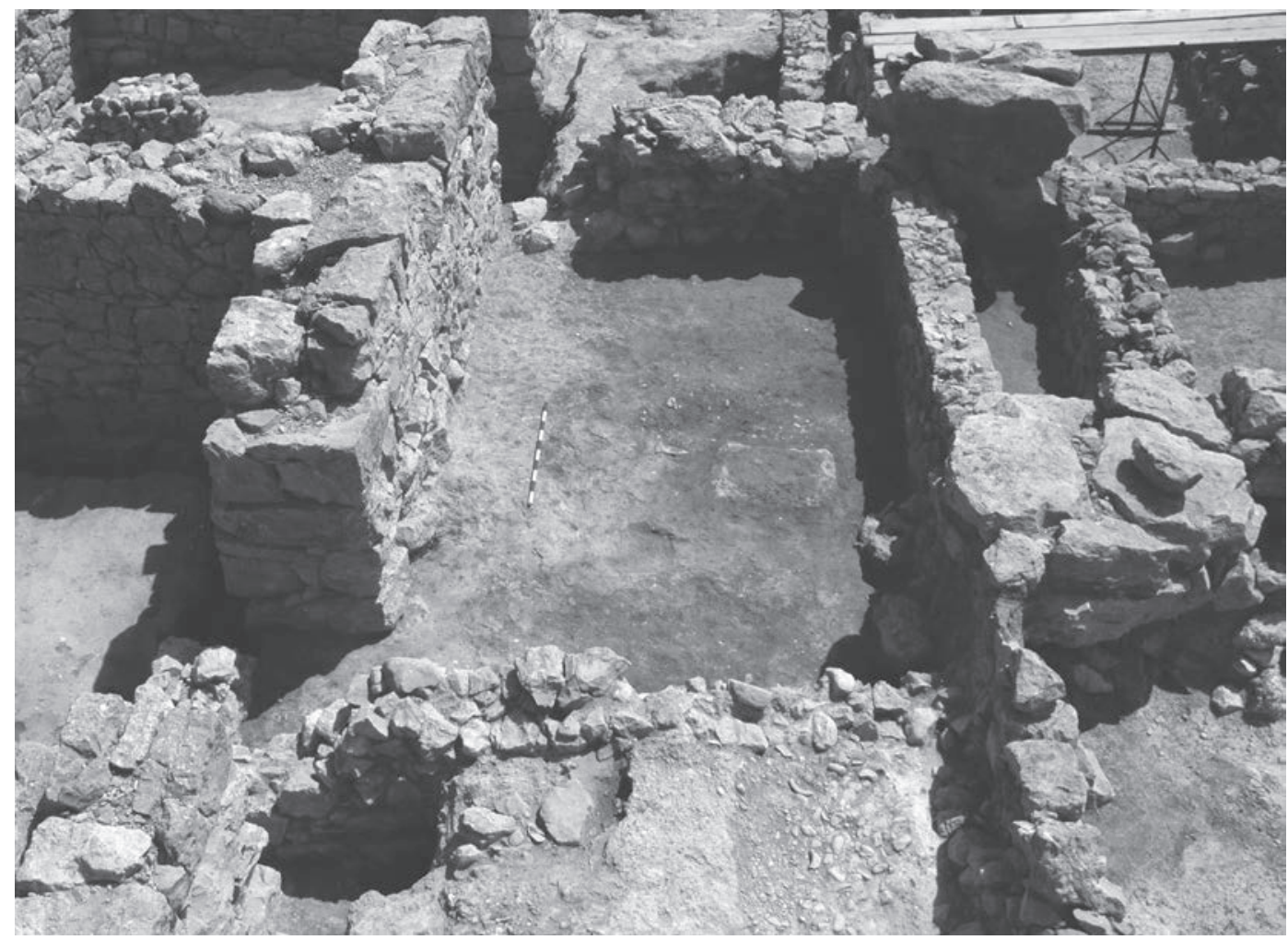

Fig. 3. Uno de los ámbitos domésticos documentados en la excavación de la estoa correspondiente a la ocupación de este sector de la ciudad griega en el siglo $\mathrm{V}$ a.C., por debajo de otros restos de construcciones más recientes y de algunas de las cimentaciones de las estructuras de la estoa (Foto: MAC-Empúries).

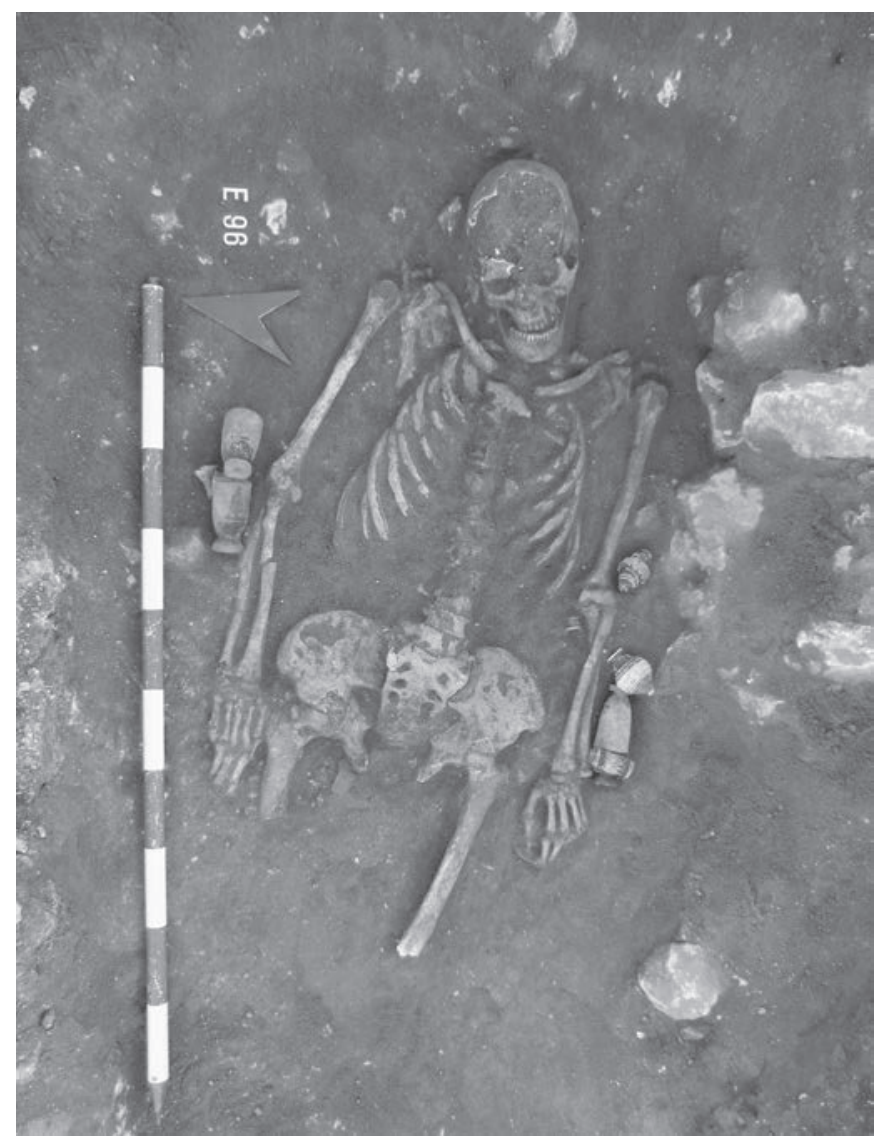

Fig. 4. Una de las tumbas de inhumación (E-96) que se han documentado en el nuevo espacio de necrópolis excavado al sur de la ciudad griega, datable en el siglo $\checkmark$ a.C., con un ajuar funerario formado por tres lécitos áticos y otros recipientes para aceites perfumados realizados en pasta vítrea. (Foto: MAC-Empúries). 
se mantuvo en uso a lo largo de todo el siglo $\mathrm{V}$ a.C. y que, por sus características, se diferencia claramente del tipo de hogares descubiertos hasta la actualidad en los ambientes domésticos de Emporion.

Aunque los rebajes producidos posteriormente en esta zona han hecho desaparecer los niveles estratigráficos correspondientes a los siglos IV y III a.C., podemos imaginar que el acceso al puerto continuaba todavía en pleno uso. Los cambios más notables que afectaron a este barrio portuario tuvieron lugar hacia mediados del siglo II a.C., con la construcción un nuevo lienzo defensivo que, apoyándose en los viejos límites de los siglos VI y V a.C., completó definitivamente la configuración del ángulo noroeste de la ciudad (fig. 2). La nueva muralla, de unos dos metros de anchura y de aparejo poligonal, contaba además con un imponente bastión de 8 x $10 \mathrm{~m}$. reforzando el ángulo del recinto. La coincidencia cronológica de esta construcción con las dataciones propuestas para la edificación de la muralla meridional de la Neápolis (Sanmartí, Nolla 1986), la reforma de sus principales santuarios urbanos (Sanmartí, Castanyer, Tremoleda 1990) o la remodelación del sector central con la configuración del conjunto ágoraestoa (Aquilué et al.2011,131-145), inducen a pensar que formaba parte también del importante proceso de transformación de los principales espacios públicos de la ciudad griega, llevado a cabo con posterioridad a los inicios de la presencia romana en este territorio y con anterioridad a la fundación de la nueva ciudad romana en la parte superior del promontorio emporitano. En aquel momento, el primitivo acceso en rampa al puerto fue substituido por una calle enlosada y dotada de diversos tramos escalonados, hecho que permite intuir un posible cambio funcional de esta vía que, no debemos olvidar, coincide también con la reestructuración y ampliación de las instalaciones portuarias situadas en la fachada oriental de la ciudad (Nieto, Raurich 1998; Nieto et al. 2005, p. 94-98). Estas obras, dentro de las cuales debemos incluir también la construcción en el litoral del enorme muro de protección conocido como el «malecón», facilitaron la adaptación de la ciudad a la nueva realidad impuesta por Roma y, una vez más, permitieron la adecuación de la infraestructura portuaria a las nuevas necesidades comerciales que el momento requería.

\section{Las recientes excavaciones en el sector de la estoa de la Neápolis}

Otro de los sectores del antiguo núcleo griego que ha sido objeto recientemente de nuevas intervenciones arqueológicas corresponde al espacio ocupado por los restos constructivos de la estoa helenística. De esta importante edificación pública de la ciudad, en el límite septentrional de la plaza del ágora, se conservan sobre todo sus potentes cimentaciones, puestas ya al descubierto durante las excavaciones efectuadas en la Neápolis durante los primeros decenios del siglo XX (Mar, Ruiz de Arbulo 1988 y 1993, p. 160-171). En su parte más oriental, los restos de la estoa aparecieron además reutilizados y en parte desfigurados por la construcción, siglos más tarde del abandono de las estructuras urbanas de la Neápolis, de algunas de las cámaras funerarias que rodeaban la cella memoriae paleocristiana situada algo más al norte, sobre los vestigios de un antiguo edificio termal. Estos primeros trabajos arqueológicos permitieron documentar también en esta zona la superposición de toda una serie de estructuras constructivas correspondiente a la evolución del antiguo núcleo griego con anterioridad a la construcción de la estoa en el siglo II a.C., conservadas de manera más o menos fragmentaria entre sus cimentaciones, y que cabía poner en relación con los restos igualmente exhumados bajo los rellenos aportados para crear, en aquel mismo periodo, la amplia plaza del ágora.

La complejidad estructural mencionada, y el hecho de que las antiguas excavaciones habían comportado un rebaje parcial y desigual de la estratigrafía, dificultaban enormemente la comprensión y la interpretación de esta zona concreta de la ciudad. Por este motivo, a partir del año 2005 el Museu d'Arqueologia de CatalunyaEmpúries decidió emprender un nuevo proyecto de intervenciones en este sector con el doble objetivo de documentar lo más exhaustivamente posible la secuencia arqueológica aún conservada y, a la vez, plantear una nueva adecuación y presentación museográfica de los restos de la estoa, sin duda uno de las edificaciones más significativas de la estructura urbana correspondiente a la época tardohelenística, en la cual se enmarcan buena parte de los restos hoy visitables en la Neápolis.

Las sucesivas campañas de excavación realizadas en el sector de la estoa (Aquilué et al. 2011, p. 137-145), desarrolladas sobre todo en el marco de los Cursos de Arqueología de Empúries entre los años 2005 y 2010, han hecho posible, en primer lugar, precisar el proceso constructivo de las estructuras que formaban parte de aquel edificio, documentando el trazado y la entidad de los grandes rebajes y zanjas efectuadas para cimentar la doble columnata existente en su parte frontal, así como los muros de los diferentes ámbitos alineados al norte o las dos grandes cisternas construidas también en aquel mismo momento. Los rellenos de estas trincheras constructivas han aportado un rico contexto de materiales arqueológicos que han permitido confirmar una datación hacia mediados del siglo II a.C. para la edificación de la estoa y, con ella, de la reestructuración arquitectónica de esta parte central del núcleo en torno a la nueva plaza 
del ágora, enmarcándose plenamente en el importante proceso de reformas urbanas que resultó en un cambio casi completo de la fisonomía de la ciudad. Tal como se ha recordado antes al hacer alusión a las construcciones de esta misma cronología documentadas en el extremo noroeste de la ciudad, este periodo de especial dinamismo e importante actividad edilicia en Emporion, posibilitados por la intensificación de la actividad comercial y portuaria en el nuevo contexto creado con la presencia romana en la zona, se detecta arqueológicamente de manera clara a través de la nueva definición del recinto defensivo, así como de los espacios cultuales y de uso público de la ciudad, comportando igualmente importantes transformaciones por lo que respecta al hábitat privado o a las infraestructuras portuarias.

A pesar de los grandes rebajes y recortes del terreno producidos con motivo de la construcción de la estoa, el resto de vestigios conservados en este sector han permitido conocer, en una superficie relativamente amplia, las fases anteriores de ocupación del núcleo griego de la Neápolis, mostrando una notable superposición de estructuras y niveles correspondientes a su ocupación continuada durante prácticamente cuatro siglos, cubriendo el largo periodo desde la primera instalación focea en este lugar hasta las grandes transformaciones urbanas del siglo II a.C. Se trata de restos de muros, rellenos, pavimentos y niveles de circulación, conservados generalmente de manera muy fragmentaria y parcial, pero que hacen posible restituir las trazas del entramado urbano anterior, formado en este sector por una serie de espacios de habitación separados por algunas callejuelas orientadas de norte a sur. Estas sencillas vías de circulación, de menos de $2 \mathrm{~m}$. de anchura, servían también para la evacuación de las aguas residuales, y desembocaban al sur en una calle transversal de mayor amplitud, orientada de oeste a este, que también aparece documentada en los viejos diarios de excavación de E. Gandia justo en el límite entre la estoa y el ágora. Las nuevas secuencias recientemente excavadas han mostrado, además, cómo esta estructura urbana anterior se adaptaba a la topografía natural del promontorio litoral, formando un declive relativamente marcado desde el oeste y en dirección a la costa, declive que aparece hoy enmascarado por los importantes trabajos de nivelación efectuados durante las reformas tardohelenísticas. De esta manera, las casas y las callejuelas antes mencionadas aparecen dispuestas en sucesivas terrazas, con una diferencia de cotas de casi $2 \mathrm{~m}$. entre los dos extremos de la zona excavada, entre el límite oeste y el tercio central de la estoa.

Por lo que respecta a las construcciones documentadas, las fases más recientes, pertenecientes a la ocupación de este sector del núcleo griego durante el siglos III y la primera mitad del siglo II a.C. las conocemos de manera más limitada, debido a los rebajes constructivos de la estoa, así como también a los trabajos de excavación precedentes. Las estructuras correspondientes a la ocupación anterior, a lo largo de los siglos V y IV a.C., permiten definir espacios sucesivos con una funcionalidad básicamente doméstica, delimitados por muros formados por sencillos zócalos levantados con piedras irregulares y alzados de tapia o adobe, con suelos o niveles de uso realizados con arcilla compactada que a veces aparecían asociados a soleras rubefactadas utilizadas como hogares, aunque, desgraciadamente, la parcialidad de los restos impide obtener una visión más completa de la articulación de estas casas (fig. 3).

Los niveles más profundos de la estratigrafía, relativamente menos alterados por las trincheras de cimentación de la estoa, corresponden a la ocupación tardoarcaica del núcleo y han sido documentados sobre todo durante los últimos trabajos de excavación realizados en este sector en el año 2012. Si tenemos en cuenta la secuencia de utilización de alguna de las callejuelas antes mencionadas, parece que el trazado de los ejes que definen la trama urbana de esta zona del núcleo griego arranca ya de los últimos decenios del siglo VI a.C. En estas fases más antiguas, cabe destacar que los ámbitos de habitación aparecen asociados con espacios destinados a actividades de transformación metalúrgica, tal como se desprende de la presencia de algunos pequeños hornos y estructuras de combustión en cubeta, así como del hallazgo de numerosas escorias y residuos de bronce y de hierro. Parece definirse, así, un probable barrio artesanal correspondiente a este primer periodo de la estructuración urbana del nuevo núcleo de la Neápolis. De los datos de la excavación parece desprenderse, además, que los más antiguos restos constructivos documentadas en el sector de la estoa responden de hecho a una etapa de crecimiento significativo del espacio habitado respecto a un primer núcleo originario situado algo más al norte, probablemente creado junto al límite del puerto natural poco tiempo más tarde de la primera instalación focea en el promontorio litoral de Sant Martí d'Empúries, la antigua Palaia Polis.

\section{Una nueva área funeraria al sur de la ciudad griega de Emporion}

Las intervenciones recientes que se han mencionado en los dos epígrafes anteriores han permitido recuperar informaciones de gran interés para la interpretación de las fases más antiguas del urbanismo de la Neápolis, ofreciendo una imagen más amplia y consistente sobre la evolución, la articulación y los usos de determinados sectores de este primer recinto urbano respecto a la que 
hasta hoy ofrecían los datos obtenidos en los diversos sondeos estratigráficos realizados en el yacimiento. En los últimos años, estas informaciones se han completado con otras nuevas evidencias arqueológicas referidas al enclave foceo de Emporion, en este caso relacionadas con la ocupación de la zona periurbana y, más específicamente, con las áreas de uso funerario situadas en el entorno más inmediato de la ciudad.

Así, las excavaciones realizadas a lo largo del año 2010 en un determinado espacio suburbano situado al sur de la ciudad griega, con motivo de una obra pública - la construcción del futuro centro de recepción de visitantes a la entrada del conjunto arqueológico -, permitieron documentar una nueva zona de necrópolis hasta entonces inexplorada. Se trata de una parcela de relieve poco escarpado, situada en la vertiente oriental del gran promontorio emporitano en parte ocupado por los restos de las ciudades griega y romana. Su posición la sitúa justamente entre otras áreas ya conocidas de necrópolis: por un lado, las tumbas documentada bajo la actual zona del Parking del recinto arqueológico -más próximas respecto al límite meridional de la ciudad griega- y, por otro lado, más hacia el sur, los cementerios Bonjoan y Granada (Almagro 1953 y 1955; Sanmartí, Nolla, Aquilué 1983-1984, p. 116-124; Aquilué et al. 1999, p. 37-39; Castanyer coord. 2003, p. 41-51).

Las denominaciones modernas de estos espacios situados en el entorno de la ciudad hacen referencia a los propietarios de las fincas donde se localizaron las tumbas y, en realidad, no definen necrópolis diferentes sino más bien una extensión progresiva del área de uso funerario. Desde el pequeño promontorio costero del Portitxol, donde sabemos de la existencia de las tumbas más antiguas, mal conocidas, algunas de la cuales datan del siglo VI a.C., los espacios cementeriales fueron con el tiempo ocupando gran parte de la vertiente oriental de la colina de Empúries hacia el norte, bordeando los antiguos caminos que conducían a la ciudad (Santos 2009, p. 33-38).

La nueva zona funeraria, excavada intensivamente, ha proporcionado hallazgos de cronología diferente, a lo largo de un prolongado periodo que se extiende entre los siglos V a.C. y II d.C., con dos etapas diferentes de enterramientos, correspondientes la primera de ellas al núcleo griego de Emporion, mientras que la segunda se relaciona con la ocupación posterior de la ciudad romana. Durante las dos actuaciones arqueológicas realizadas en el año 2010 se excavaron un total de 110 tumbas, 44 de las cuales se pueden fechar entre los siglos V y III a.C. (Tremoleda et al. 2012, p. 66-75). La distribución de las estructuras funerarias no seguía una disposición ni una ordenación aparente, si exceptuamos algunas agrupaciones de tumbas, detectadas especialmente en la fase más reciente de uso de este espacio cementerial en el siglo II d.C.
La necrópolis de época prerromana, la más antigua del conjunto, se localizaba en una posición más cercana respecto al perímetro de la ciudad griega. Por lo que respecta a este período, se confirma nuevamente el uso de los dos rituales funerarios documentados previamente en Empúries a lo largo de la antigüedad: la inhumación y la incineración (Tremoleda 2009, p. 19-23). A este último ritual responde la presencia de una estructura circular llena de cenizas y madera carbonizada en el interior, posiblemente un bustum destinado a incinerar los restos de un individuo adulto (E-234). Por otro lado, fue posible localizar también un ustrinum, con fragmentos de alabastrones de pasta vítrea deformados por el fuego, en el cual, una vez realizadas las cremaciones, se habían recogido los restos para ser posteriormente depositados en el lugar definitivo de la tumba, dentro de una urna o directamente en una fosa practicada en el subsuelo.

Sin embargo, en esta área de necrópolis relacionada con el núcleo colonial griego de Emporion, las inhumaciones son, de nuevo, ampliamente mayoritarias. El claro predominio de este ritual suele interpretarse como una consecuencia de la introducción de su práctica por parte de los pobladores foceos, a pesar de la persistencia del ritual incinerador que ya era practicado desde mucho tiempo antes por la población autóctona.

La conservación de las tumbas correspondientes a esta primera fase de necrópolis era bastante deficiente, ya que en muchos casos resultaron afectadas por fosas y rebajes producidos posteriormente en época romana tardorrepublicana, un periodo durante el cual este espacio suburbano fue ocupado para otros usos no específicamente funerarios, sino más bien relacionados con actividades de tipo industrial o artesanal.

El nivel sobre el cual se practicaron los enterramientos corresponde a unas arenas de color anaranjado muy características que se encuentran sobre la roca natural caliza del subsuelo. De ésta se aprovechaban las depresiones o las fisuras naturales, que ofrecían una sencilla protección para los cuerpos o también para las ánforas reutilizadas como cajas mortuorias. Si a estas últimas, que corresponden casi siempre a perinatales, unimos el resto de inhumaciones correspondientes a individuos infantiles, veremos que los muertos de corta edad están bien representados.

Cabe reseñar que para contener las tumbas de perinatales siempre aparecen utilizadas ánforas ibéricas. Al tratarse de recién nacidos, para introducir el cuerpo no era necesario, en la mayoría de los casos, romper las bocas de los envases; en cambio, sí que resultaba habitual la colocación de una piedra a modo de tapadera en la parte de la abertura. De este grupo destaca poderosamente la presencia de un ajuar de guerrero en uno de los enterramientos (E-229), formado por un soliferreum 
enrollado y depositado sobre el ánfora, mientras que por debajo se colocó una espada. El esqueleto del recién nacido se halló únicamente acompañado por un amuleto de hueso que llevaba como colgante.

El resto de las inhumaciones, por regla general, son de características muy simples, con la deposición del cuerpo del difunto en decúbito supino, frecuentemente orientado con la cabeza al este, aunque a veces esta orientación este-oeste resulta sólo aproximada. Por lo que respecta a la estructura de las tumbas, las correspondientes a adultos o a subadultos consistían mayoritariamente en una fosa simple, a veces imposibles de detectar en el nivel de arenas en que fueron excavadas, y a menudo sin ningún tipo de acompañamiento. En algunos casos, sin embargo, el perímetro de las fosas aparecía delimitado mediante diversas piedras pequeñas y medianas. Como elemento de señalización y protección, las tumbas solían cubrirse con un pequeño túmulo.

Destacaremos brevemente algunas de las inhumaciones que proporcionaron un ajuar funerario asociado. La tumba E-18 corresponde al enterramiento de un individuo infantil acompañada de un lécito ático de figuras negras, un anforisco de pasta vítrea, un vaso de cerámica de pasta clara y diversas cuentas de collar, tres de ámbar y una de pasta vítrea. La tumba E-44 tenía asociada una navaja de hierro y un ungüentario cerámico de forma globular. En la tumba E-60 el cuerpo del difunto había sido encajado en la roca natural, junto con un lécito ático de figuras rojas decorado con palmeta, un vasito de cerámica de pasta clara, una fíbula y un brazalete de bronce. La E-64 era una tumba delimitada con piedras de la que proceden un escifo de barniz negro y una jarra de pasta clara. La tumba E-76 contenía un lécito ático con decoración reticular y puntos blancos sobrepintados. La E-82 corresponde a una inhumación con una fíbula y una punta de hierro. De manera semejante, la tumba E-90 tenía como objetos personales una cuenta de pasta vítrea y un pendiente. Uno de los depósitos funerarios más destacables corresponde a la inhumación E-96, delimitada por una caja de piedras, y estaba formado por tres lécitos áticos de figuras negras decorados con palmetas, dos anforiscos y un alabastron de pasta vítrea, así como una fíbula que se halló sobre el hombro (fig. 4). Asociada con el enterramiento E-99, se recuperaron también los restos de una gran cílica ática de figuras rojas. Finalmente, la tumba E-100 corresponde a una inhumación infantil en caja de piedras, acompañada por una jarra decorada con bandas pintadas y dos piezas de terracota: una pequeña muñeca articulada y una figurita masculina representando a un panadero en actitud de proceder a hornear una serie de panes dispuestos sobre una pala, un tipo de representación que recuerda las figuras de género conocidas como terracotas beocias.
Con respecto a las restantes zonas de necrópolis relacionadas con el pasado griego de la ciudad, que a finales del siglo XIX e inicios del XX fueron objeto de una intensa actividad de saqueo y excavaciones clandestinas, y que sólo en parte pudieron ser exploradas en los trabajos dirigidos por M. Almagro (1953), los resultados del estudio de este nuevo sector cementerial aportará un cúmulo de informaciones que nos hablan en primera persona acerca de las creencias, los rituales y las prácticas funerarias, pero también de las condiciones de vida, las patologías, la riqueza material... constituyendo, en definitiva, un reflejo de como se vivía y como se moría en una sociedad dinámica como la que se desarrolló en la ciudad griega de Emporion.

\section{Bibliografía}

Almagro 1953 : ALMAGRO (M.) - Las necrópolis de Ampurias, I. Introducción y necrópolis griegas, Barcelona, 1953 (Monografías Ampuritanas III.1)

Almagro 1955 : ALMAGRO (M.) - Las necrópolis de Ampurias, II. Necrópolis romanas y necrópolis indígenas, Barcelona, 1955 (Monografías Ampuritanas III.2).

Aquilué et al. 1999 : AQUILUÉ (X.), CASTANYER (P.), SANTOS (M.), TREMOLEDA (J.) - Guies del Museu d'Arqueologia de Catalunya. Empúries, Tarragona, 1999.

Aquilué et al. 2002 : AQUILUÉ (X.), CASTANYER (P.), SANTOS (M.), TREMOLEDA (J.) - Nuevos datos acerca del hábitat arcaico de la Palaiapolis de Emporion. In : LUCE (J.M.) (coord.), Habitat et Urbanisme dans le monde grec de la fin des palais mycéniens à la prise de Milet (494 av. J.-C.), Pallas, 58, Toulouse, 2002, p. 301-327.

Aquilué et al. 2008 : AQUILUÉ (X.), CASTANYER (P.), SANTOS (M.), TREMOLEDA (J.) - Intervencions arqueològiques a Empúries (L'Escala, Alt Empordà) als anys 2006 i 2007. Novenes Jornades d'Arqueologia de les Comarques de Girona (L'Escala-Empúries 2008), p. 185-200.

Aquilué et al. 2010 : AQUILUÉ (X.), CASTANYER (P.), SANTOS (M.), TREMOLEDA (J.) - Grecs et indigènes aux origines de l'enclave phocéenne d'Emporion. In : Tréziny (H.) (éd.), Grecs et indigènes de la Catalogne à la mer Noire. Actes des rencontres du programme européen Ramses 2 (20062008), Aix-en-Provence -Paris, 2010, p. 65-78. (Centre Camille Jullian, Bibliothèque d'archéologie méditerranéenne et africaine 3)

Aquilué et al. 2011 : AQUILUÉ (X.), CASTANYER (P.), SANTOS (M.), TREMOLEDA (J.) - Resultats de les darreres intervencions arqueològiques a la Neàpolis de la ciutat grega d'Empòrion (Empúries, l'Escala, Alt Empordà). Tribuna d'Arqueologia 2009, Barcelona, 2011, p. 121-147.

Blech, Marzoli 2005 : BLECH (M.), MARZOLI (D.) - Cambios en el paisaje costero del Empordà. Las investigaciones interdisciplinares llevadas a cabo por el Instituto Arqueológico Alemán, Madrid. Empúries 54, 2005, p. 45-58.

Castanyer coord. 2003 : CASTANYER (P.) (COORD.) - 10 anys d'arqueologia a l'entorn d'Empúries (1993-2002), Girona, 2003.

Mar, Ruiz de Arbulo 1993 : MAR (R.), RUIZ DE ARBULO (J.) - Sobre el ágora de Emporion. Archivo Español de Arqueología 61, 1988, p. 39-60.

Mar, Ruiz de Arbulo 1993 : MAR (R.), RUIZ DE ARBULO (J.) - Ampurias romana. Historia, Arquitectura y Arqueología, Sabadell, 1993.

Marzoli 2005 : MARZOLI (D.), Die Besiedlungs- und Landschaftsgeschichte im Empordà von der Endbronzezeit bis zum Beginn des Romanisierung, Mainz-am-Rhein, 2005 (Iberia Archaeologica 5).

Nieto, Raurich 1998 : NIETO (X.), RAURICH (X.), La infraestructura portuaria ampuritana. III Jornadas de Arqueología Subacuática (Valencia 1997), Valencia, 1998, p. 57-76. 
Nieto et al. 2005 : NIETO (X.), REVIL (A.), MORHANGE (CH.), VIVAR (G.), RIZZO (E.), AGUELO (X.) - La fachada marítima de Ampurias: estudios geofísicos y datos arqueológicos. Empúries, 54, 2005, p. 71-100.

Puig i Cadafalch 1913 : PUIG I CADAFALCH (J.) - Els temples d'Empúries. Anuari de l'Institut d'Estudis Catalans IV (1911-1912), Barcelona, 1913, p. 303-322.

Puig i Cadafalch 1920 : PUIG I CADAFALCH (J.) - La colonia grega d'Empúries, Anuari de l'Institut d'Estudis Catalans VI/1915-1920, Barcelona, 1920, p. 694-712.

Rambaud 2005 : RAMBAUD, F. - Reconstrucción de la línea de costa en el territorio de Ampurias. Empúries 54, 2005, 54-70.

Ruiz de Arbulo 1994 : RUIZ DE ARBULO (J.) - Situación de sondeos estratigráficos en la Neàpolis de Ampurias (1908-1983). Iberos i griegos. Lecturas desde la diversidad (Ampurias 1991), Huelva Arqueológica 13.2, p. 59-72.

Sanmartí 1988 : SANMARTÍ-GREGO (E.) - Datación de la muralla griega meridional de Ampurias y caracterización de la facies cerámica de la ciudad en la primera mitad del siglo IV a. de J.-C. Revue des Études Anciennes, XC, 1-2, 1988, p. 99-137.

Sanmartí, Castanyer, Tremoleda 1988 : SANMARTÍ-GREGO (E.), CASTANYER (P.), TREMOLEDA (J.) - La secuencia histórico-topográfica de las murallas del sector meridional de Emporion. Madrider Mitteilungen, 29, 1988, p. 191-200.

Sanmartí, Castanyer, Tremoleda 1990 : SANMARTÍ-GREGO (E.), CASTANYER (P.), TREMOLEDA (J.) - Emporion: un ejemplo de monumentalización precoz en la Hispania republicana. Los santuarios helenísticos del sector meridional. In: Zanker (P.), Trillmich (W.) (dirs.), Stadbild und
Ideologie. Die Monumentalisierung hispanischer Städte zwischen Republik und Keiserzeit, München, 1990, p. 117-144.

Sanmartí, Castanyer, Tremoleda 1992 : SANMARTÍ-GREGO (E.), CASTANYER (P.), TREMOLEDA (J.) - Nuevos datos sobre la historia y la topografía de las murallas de Emporion. Madrider Mitteilungen 33, 1992, p. 102-112.

Sanmartí, Nolla 1986 : SANMARTí-GREGO (E.), NOLLA (J.M.) - La datation de la partie centrale du rempart méridional d'Emporion (L'Escala, Alt Empordà, Catalogne). Documents d'Archéologie Méridionale, 9, 1986, p. 81-110.

Sanmartí, Nolla, Aquilué 1983-1984 : SANMARTÍ-GREGO (E.), NOLLA (J.M.), AQUILUÉ (X.) - Les excavacions de l'àrea del Parking al sud de la Neàpolis d`Empúries. (Informe preliminar), Empúries 45-46, Barcelona, p. $110-153$

Santos 2009 : SANTOS (M.) - El paisatge funerari de l'Emporion grega entre els segles VI i III aC. El món funerari a l'antiga Empúries, Girona, 2009, p. 33-38.

Santos, Sourisseau 2011 : SANTOS (M.), SOURISSEAU (J.-Chr.) - Cultes et pratiques rituelles dans les communautés grecques de Gaule méditerranéenne et de Catalogne. In : Roure (R.), Pernet (L.) (dir.), Des rites et des Hommes, Errance, Paris, 2011, p. 223-255.

Tremoleda 2009 : TREMOLEDA (J.) - Rituals de la mort. El món funerari a l'antiga Empúries, Girona, 2009, p. 19-23.

Tremoleda et al. 2012 : TREMOLEDA (J.), SANTOS (M.), CASTANYER (P.), MONTURIOL (J.) - Nou espai de necrópolis excavat a Empúries, Camí de Ronda 3, l’Escala, p. 66-75. 


\title{
Philistines and Phokaians: comparative hinterlands and Middle Grounds
}

\author{
Irad Malkin \\ Cummings Chair of Mediterranean History and Culture, \\ Tel Aviv University, Department of History
}

\begin{abstract}
Greek colonization implies a ship-to-shore, or a coast-to-hinterland, perspective. Inevitably, due to lack of nonGreek literary evidence and the limits of interpretation of material evidence, we tend to follow this perspective when studying interactions with peoples of the hinterland. However, we do not always know what questions to ask. I suggest that by analyzing an analogous situation we may get a richer understanding of the spectrum of issues involved. In this article I study the cycle of Samson in the Book of Judges, since it provides us with a reverse situation: a hinterland perspective on "Aegean colonists" who established city-states on the coast (Gaza, Ascalon and Ashdod) and kept advancing to the hinterland (Ekron, Gath, Timna). Several points of comparison to the colonial situation in southern France are made. Finally, the case of the Philistines, who did not become Greek, indicates the contrast with other migrants: the Ionians, for example, similarly settling on narrow coastlands in Asia Minor, eventually became "Greek" through the pull of maritime networks from which the Philistines became separated.
\end{abstract}

Keywords: colonization, hinterland, migration, Phokaia, Phoenicians, Hebrews, Ionians, Philistines, intermariage

\section{Résumé}

La colonisation grecque implique une dynamique qui va de la côte vers l'arrière-pays. Inévitablement, en raison du manque de données littéraires non grecques et des limites de l'interprétation des indices matériels, nous avons tendance à suivre cette perspective lorsque l'on étudie les interactions avec les peuples de l'arrière-pays. Cependant, nous ne savons pas toujours quelles questions poser. Je suggère que par l'analyse d'une situation analogue, nous pouvons obtenir une meilleure compréhension de l'ensemble des problèmes en jeu. Dans cet article, j'étudie le cycle de Samson dans le Livre des Juges, car il nous offre une situation inverse : un point de vue de l'arrière-pays sur les « colons de la mer Égée » qui ont établi des cités-états sur la côte (la bande de Gaza, Ascalon et Ashdod) sans s'avancer dans l'arrière-pays (Hékron, Gath, Timna). Plusieurs points de comparaison avec la situation coloniale dans le sud de la France sont relevés. Enfin, le cas des Philistins, qui ne sont pas devenus grecs, offre un contraste avec d'autres migrants : les Ioniens, par exemple, installés sur la côte étroite de l'Asie Mineure, sont finalement devenus " grecs » par l'attraction des réseaux maritimes dont les Philistins se sont séparés.

Mots-clés : colonisation, arrière-pays, migrations, Phocéens, Phéniciens, Hébreux, Ioniens, Philistins, mariages mixtes 
$\mathrm{F}$ or those interested in ancient Mediterranean colonization the view from the sea is the natural one to adopt: together with the ancient Greeks and Phoenicians we observe the world from ship to shore. This is the correct perspective insofar as it follows the pattern of foundations on offshore islands and mainland promontories. Similarly, when we examine relations with non-Greek peoples we mostly do so from the coastal perspective of the colonies and their adjacent territorial hinterland, the chôra. Massalia, for example, founded cities and was influential in an enormous coastal chôra. This was typical of Greek maritime colonization: no huge territorial conquest (as Julius Caesar would effect in Gaul in the mid-first century BCE), but coastal hinterlands. The chorra remained narrow in size (some $5-15 \mathrm{Km}$ ) for some 600 years. ${ }^{1}$

What we miss, however, is the reverse, local perspective, the view from the hinterland. For Massalia we have a lovely tale about one of the founders, Protis, marrying Gyptis, a local princess, implying negotiated relations with "natives" among whom Protis and his men settled. ${ }^{2}$ It is suspiciously similar to another Phokaian story about Lampsake (eponym of Lampsakos, another Phokaian colony) who mediated between the colonists and the local population in a similar way. ${ }^{3}$ Both Lampsake and Gyptis are portrayed as local, non-Greek women, the union with whom enables integration by the Greek settlers, thus hinting at an initial Middle Ground situation. ${ }^{4}$

Certain local perspectives are suggested by the archaeological evidence from southern Gaul. Over time, it points to a series of "anti-poleis", i.e., either Greek or non-Greek settlements evolving or being founded in a parallel band and within a relatively short distance from each other (as the name Antipolis, for example suggests, although more often we observe non-Greek settlements founded in relation to the Greek ones). These also probably served as points of material and cultural exchange. Their existence gives the lie to a scholarly approach that sees the relations of "colonists and native populations" as a zero-sum game, where the success of the one is inevitably at the expense of the other. Moreover, it also gives the lie to the very term "native": the foundation of

1 I wish to thank the editors of this volume for their help and patience. Special thanks are due to Assaf Yasur-Landau of Haifa University and Seymour Gitin, Director of the F.W. Albright Institute for Archeological Research, Jerusalem, and to Tal Goldfajn and Israel Finkelstein of Tel Aviv University, for their comments and help in a field that is new to me. Responsibility for the text that follows remains of course mine. 2 Justin 43.3.8-11; Athenaeus 13.576a-b. Cf. Pralon 1992.

3 Plutarch, On the Virtues of Women, 18; Polyaenus, Strat.8.37cf. Steph. Byz. s.v. Lampsakos.

4 On the use of the term «Middle Ground» in colonial encounters see Malkin 2002 and below. these new, non-Greek settlements, points to movement and immigration towards the coastal areas, perhaps even at the expense of other "natives". Thus I prefer to call such populations "local" rather than "native." $5 \mathrm{We}$ would have liked to know what reaction, attitude and impact those newly arriving from the sea had on the hinterland, non-Greek peoples and, conversely, how these Greeks were seen. However, explicit expressions of local perspective are inaccessible to us: we simply have no specifically relevant, non-Greek sources from Gaul. ${ }^{6}$

How might it have seemed were we to have access to such perspectives? What might have been the attitudes, types of contact, and spatial relations that the people of the hinterland had with those inhabiting coastal strips? We may suppose, with some degree of probability, that the modalities of encounter would have included trade, technology (exchange and services, e.g., metalworking), intermarriage, and labor. Yet all we can do is guess at the spectrum of relations.

To picture what might have been we can look for an analogy. In my view we do have precisely such a hinterland perspective in some of the books of the Old Testament pertaining to both the Philistine and the Phoenician coastal cities vis-à-vis the Israelites who inhabited the hinterland. Here I wish to illustrate the thematic characteristics of such views from the hinterland through the cycle of Samson stories in the Book of Judges. ${ }^{7}$ My purpose is to suggest a spectrum of local attitudes and aspects of Middle Ground co-existence. I make no claim to the historicity of any of the Samson episodes, nor shall I commit myself to any specific date for its composition, although I am in general inclined to the view that the cycle does not reflect the realities of the twelfth and eleventh centuries BCE (supposedly the time of Philistine settlement and growth) but of the eighth and seventh centuries BCE. ${ }^{8}$ All we can say is that in a comparable structural circumstance (strong, technologically developed coastal cities of Aegean origins vs. weaker hinterland peoples) we may expect a similar range of attitudes and practices of space within the colonial Middle Grounds and at the major colonial sites themselves.

5 Hodos 2006 with Malkin 2011b. Admittedly, "local” also begs the question, since it assumes movements that are regional; it is quite possible, however, that non-Greeks could come closer to the coast from far-away.

6 See Mullen 2013.

7 On the structure of the Samson-cycle in the Book of Judges see Amit 1992, pp. 248-286. I am currently also studying the stories of the migration of the Danites, the new city foundation following the conquest of a town under feeble Sidonian protection, and the establishment of a new temple.

8 Finkelstein 2002 with references to the debate and below. 


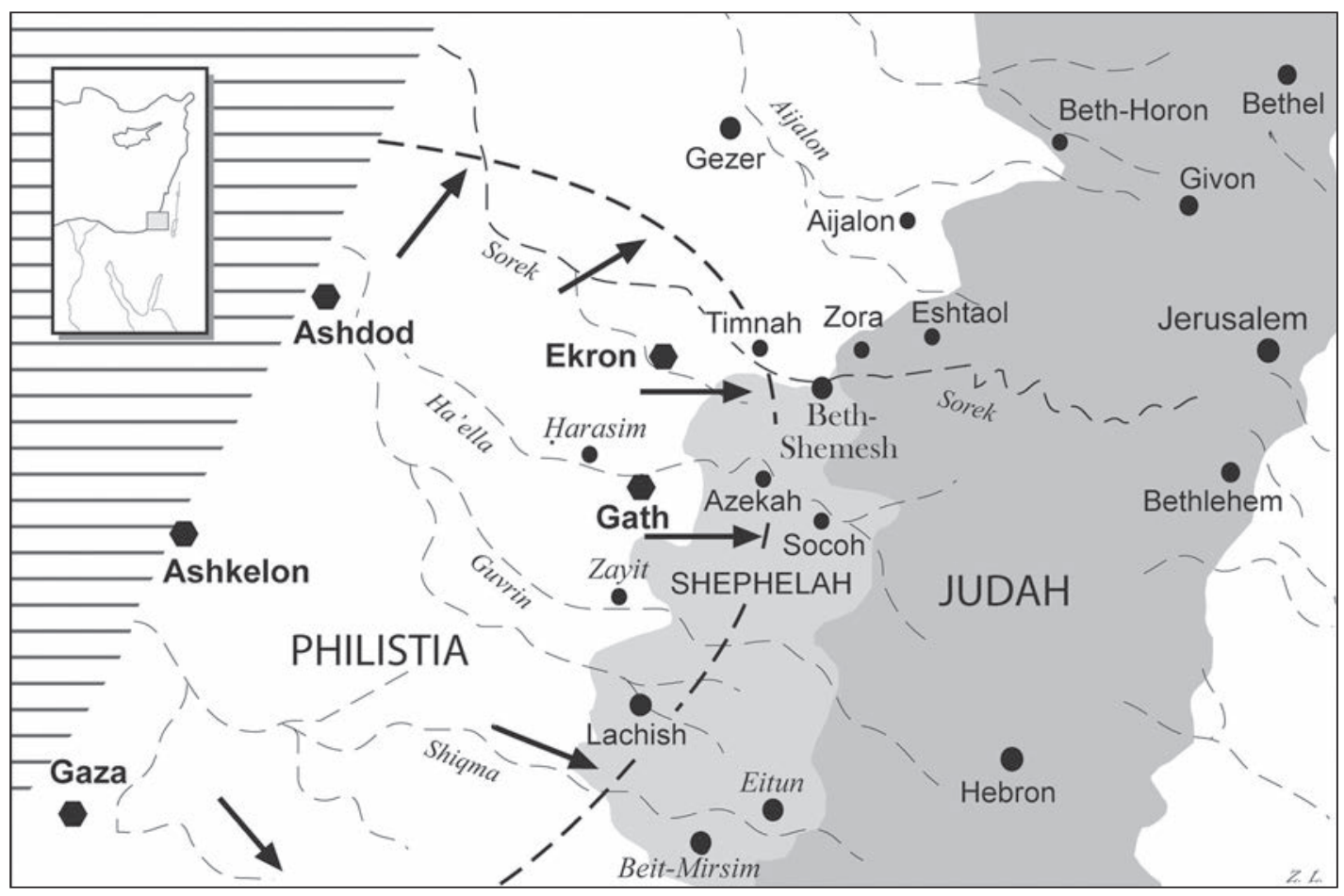

Fig. 1. Philistia during Iron Age I (after Bunimovitz and Lederman 2011).

It is important to stress again one of the main traits of a colonial Middle Ground: ${ }^{9}$ it is a negotiated "third space" where nobody has the force to completely dominate the other; where each "side" plays a double mirror game of mutual images for the sake of accommodation or the control of hostilities; where "creative misunderstandings" encourage new forms of encounters and cultural contacts; where the metaphoric Middle Ground may overlap with the actual middle ground, a physical space, where people meet. Samson, a frontier person who inhabited that middle ground, supposedly the quintessential anti-Philistine folk-hero, will be shown to be also the one most eager to assimilate among Philistines. I see common characteristics with the Scythian king Skyles, who tried to live in both worlds (in the Greek polis Olbia and among his Scythian people), and, like Samson, ended up dead as a result. ${ }^{10}$

The attitudes that will be revealed are not counterintuitive: a strong sense of being under the protection/ domination of a coastal city state; technological inferiority; a sense of envy and admiration mixed with hatred;

9 In detail: Malkin 1998; 2002; White 1991; 2006.

10 Hdt. 4.76-80. In Herodotus it is the Scythians themselves who kill their king, the narratological opposite of the Samson story. Yet the two stories also reflect the same (apparent) «impossibility» of crossing cultural boundaries. a wish to keep apart while stressing cultural and ethnic differences, such as "uncircumcised Philistines" and the worship of other gods, contrasted with a reality of frequent interaction, specifically marriage and paid sex.

Parallels between Greek ktiseis (foundation stories) and Hebrew migration-conquest-and foundation stories have been pointed out before, sometimes in order to determine the direct historiographical impact of Greek writing traditions on certain Biblical texts. ${ }^{11}$ For example, In his article "The Danite campaign northward (Judges XVII-XVIII) and the migration of the Phokaians to Massalia (Strabo IV 1.4)" Nadav Na'aman looks for similarities in procedure, notably the cult transfer of sacred objects, in order to point to close parallelism and to claim probable influence of Greek foundation stories on the particular story of the Danites conquest and colonization (and hence dating the story as post mid-sixth century).

I have no idea how reliable is this kind of Quellenforschung, and I can easily see the argument going the other direction as well (Hebrews influencing Greeks). But influence is not my interest here. In general, I would assume that such stories can arise independently within a situation that is structurally similar: settlers

11 Weinfeld 1988a; 1988b; 1993. Cf. Malkin n.d. 
arrive from the sea; their settlements develop into city states; these do not conquer huge territories but content themselves with control of an agricultural chôra. This would be true of Philistines, Phokaians and Phoenicians (both those already existing in the Levantine coast and the Phoenicians settlements in the Mediterranean).

Samson was born to a Danite family in Tsor'a at a time when "... the Israelites again did that which was bad in the eyes of Jehovah; and Jehovah delivered them into the hand of the Philistines for forty years." (Judges 13.1). Upon his birth it was prophesied that he "shall begin to save Israel out of the hand of the Philistines." (13.5). Most commentators take the point of view of the biblical author and his editors in terms of his theological purpose, the relations between Jehovah and the Israelites. My concern, however, will be more with the narrative details that sometimes work against that professed purpose, such as the types of interaction; directions, places and their spatial dimension; and incidental details of material culture and social habits.

The geography is significant: Samson moves within a territory between the hinterland strip (Tsor'a, Eshta'ol) ${ }^{12}$ of the anti-polis type (see below on Tsor'a and Timna) and the Philistines who inhabit cities within the coastal strip of Palestine, such as Ascalon, Ashdod, and Gaza. This is a movement within the frontier zone between Philistines and Israelites, as well as inside the Philistine chôra ("territory") itself. Their cities are walled and have heavy iron gates; iron and iron working is also their advantage and monopoly. In comparison, the Judeans inhabit the hinterland; they fear the Philistines but seem to have constant interactions with them. Samson's own encounters are mostly with Philistine women, two of whom he marries, but he also tries to befriend young Philistine men, who are called his "companions," מרעים, close friends), even though they betray him. ${ }^{13}$

Samson seems to have been frequenting the Philistines at Timna, which is identified with Tel Batash, apparently a Philistine sub-colony of Ekron (Tel Miqne). ${ }^{14}$ Note that Timna is a Philistine secondary foundation that pushed the Philistine area of settlement further inland. Henceforward, Samson's exploits will lead him in a geographical trajectory towards the coast: first the

12 Samson's family lived «between Tsor'a and Eshta'ol» Judges 13.25. Tsor'a is mentioned in Joshua 15.32 and is specified as the frontier of the Dan tribe 19.41. A frontier city facing the Philistines, it was fortified by Rehoboam, King of Judea against the Philistines (1 Chron. 11.5-12). For the expression and its Danite territorial significance see Zakovitch 1982, p. 74.

13 The meaning of «mere' $a$ is a "close friend"; Cf. Judges 14.11; $14.20 ; 15.2 ; 15.3$ and Genesis 26.26; Job 6.14 and more. It is sometimes akin to "brother" 2Samuel 3.8; Proverbs 19.7.

14 Kelm and Mazar 1995; Dothan 1995. frontier town Timna, where he meets his first Philistine wife, then a raid on Ascalon, and finally Gaza, further to the south on the coast, where he first visits a prostitute. Finally, his meeting with Delilah is in a middle ground that is both concrete and metaphoric: he met the woman (was she Philistine, Canaanite, or an Israelite? The text is silent on this) in the Sorek river valley, a true Middle Ground zone connecting Philistia and the hills of Jerusalem. Spatially, this is a movement from the hinterland, from Tsor'a to the more recent, neighboring Philistine settlement, then to the great city states, then to the Middle Ground, where identities are ambiguous, and finally back to Gaza, the southernmost coastal Philistine city, were Samson would bring down Dagon's temple, killing a crowd of Philistines and himself.

Samson, first alone, then accompanied by his parents, "comes down" to Timna. "Coming down" is also the expression is 1 Samuel (13.20) “ ... but all the Israelites

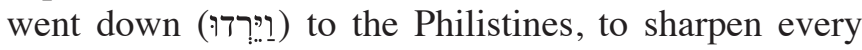
man his plowshare, and his coulter, and his axe, and his mattock." Here the image is explicit: all Israelites supposedly would descend and frequent the more technologically advanced, metal-working, Philistines center (regardless of the political reasons the biblical author imputes for this frequentation). ${ }^{15}$

Samson's goal, so it appears from the terms of the narrative, was to assimilate in Philistine society: at Timna he thought he had found new companions and a new wife ${ }^{16}$ who was expected to remain, so it seems, in Timna and not follow him to his home at Tsor'a. His anger and subsequent feats of revenge can be interpreted as a reaction to a failure at becoming "one of the (Philistine) lads": he was mocked, cheated by his companions, and lost his wife to one of them.

When Samson first announced his intention to marry the Timnite woman his parents were unhappy:

Then his father and his mother said unto him: 'Is there never a woman among the daughters of thy breth-

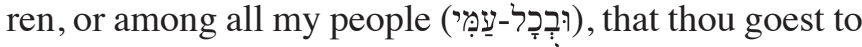

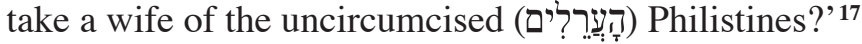

Note the contrast, on the one hand, between the ethnic ("my people") and the cultural markers of difference (uncircumcised) and, on the other, the actual contacts which seem more common than not. Eventually, both Samson and his parents go to Timna (so the hero's going

15 Cf. Amos 6.2: “... go down (וּר ) to Gath of the Philistines.” On the literary significance of «down» and «up» in the Samson's cycle Zakovitch 1982, pp. 89; 118; 120; 135.

16 The expression «From among the daughters» (of the

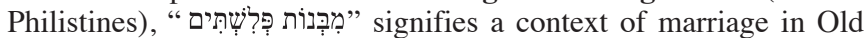
Testament Hebrew. Zakovitch 1982, p. 93.

17 Opposing marriage with foreign women: Crenshaw 1978, pp. $78-81$. 
is not exceptional) to seek the woman's hand. ${ }^{18}$ Nor does the father of the Philistine woman (her name is not given) appear to behave as if the marriage was exceptional. The marriage banquet is then soon arranged at the father-inlaw's home (not in Judea), together with Samson's new "companions" who seem to be all Philistines. Eventually, one of them will be given Samson's wife. ${ }^{19}$

The marriage is accompanied by a feast (literally a drinking-feast (מִשְׁת ), probably involving also song, music and dance; ${ }^{20}$ it is presented as habitual for young people and is not marked as something peculiar to the Philistines. That is simply the custom of the young men, says the biblical author: "For so used the young men to do" (14.10). riage across the divide was not only common, but the accompanying ritual too was familiar to all. We can see this later too, when the Philistines become furious when the father of the bride behaves against the common convention of the Middle Ground.

Yet the undercurrent of the biblical author's story is that one had better not trust Philistines. The woman from Timna is forced to betray her new husband, eliciting from him the answer to a riddle on which he had bet heavily with the Philistine companions. She did this under duress, as the thirty Philistine companions threatened to burn down both her and father's house (or just her father). There is no doubt as to their ethnicity: twice they are characterized as "belonging to her people" (14.17-18), again stressing the ethnic difference with Samson. What is noteworthy is that somehow the answer to the riddle transcends the companions: the woman reveals the secret "to her people"

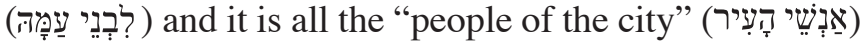
who come up with the answer.

Having lost the bet, Samson takes revenge: he goes "down" (it is not clear from where, probably from Timna

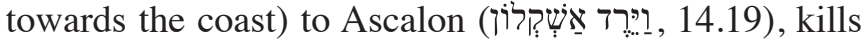
thirty Philistines, and robs them ${ }^{22}$ so he can pay his betting debt. Then he returns to the hinterland, to his parents.

18 For the contradictions in the text (at some point it seems the parents were absent) Zakovitch 1982, p. 86.

19 Curiously, the Septuagint renders the Hebrew in verse 11 "when they saw him, that they brought thirty companions to be with him" as when they "feared" him. The Hebrew word (wרְָאוֹתָם (when they saw) could be read, by adding one letter as ביראתם, when they feared, en tô phobeisthai autous. Cf. Josephus, Ant. Jud. 5.8.6.

20 Cf. Jeremiah 7.34; 16.9; 25.10; 33.11 Galpaz-Feller p. 93-116.

21 Cf. Jeremiah 6.11; Zechariah 9.17; Lamentations 5.13; Ecclesiastes. 11.9.

22 He seems to rob them of more than the bet's worth: he takes their חָלִיצוֹתָם something equivalent to suits of arms.
After a while Samson attempted visiting his estranged wife at her father's home but was told he was too late: her father tells him she had been given away "to one

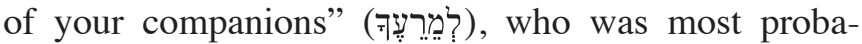
bly a Philistine who had attended the feast, which now explains Samson's ire against all Philistines: "This time shall I be quits with the Philistines, when I do them a mischief." (15.3)

The whole episode works within the framework of a common Middle Ground. Giving the bride "to a companion" is not an innocent, personal act. Ancient Near Eastern laws, since the law code of Hammurabi (no. 161), are in fact quite specific precisely against this particular offense, especially if the "companions" were also the groomsmen at the wedding feast. The Lipith Eshtar Law no. 21 specifies to the same effect that if, after the groom had come to the house of his father-inlaw and made his engagement, and then "they" forced him out and gave his wife to his companion, they will return to him the engagement gifts that he had brought, but his wife may not be a wife to his companion. Perhaps originally they were armed, protecting the feast. ${ }^{23} \mathrm{Ap}$ parently giving the bride not just to someone else, but specifically to a companion of the groom, puts particular shame on the groom's head.

Thus far Samson is to be justified in his anger; but what was he angry about? A law, common to both Philistines and Hebrews, had been broken. The Philistines too were angry: they killed the Philistine father-in-law and his daughter and the reason seems to relate to the breakdown of those common conventions (see below). But the question should be: why were they common in the first place? It appears that both Hebrews and Philistines integrated into a Near Eastern koinê that had been in place long before them. Marriage is of course a reciprocal arrangement and mixed marriages (and their related property issues) need a commonly accepted convention to follow. ${ }^{24}$ The same language of reciprocal conventions also appears in what follows.

Moreover, the father of the bride justifies himself, saying to Samson "I thought you hated her." This statement is not really about emotions, but refers to a commonly accepted divorce-terminology. The root w.נ. ("hate, hatred, to hate") applies to men and women alike. If a man "hated" his city and abandoned it and his wife, she may be given to another and he may not reclaim her. ${ }^{25}$ Thus, in the eyes of the father-in-Law, Samson had forfeited his wife (א.נ. ש appears twice in the same

23 Cf. Song of Songs 3.7-8. Galpaz-Feller p. 93-131.

24 Cf. Van Selms 1950.

25 Eshnuna no. 30; Hammurabi no. 136 with Galpaz-Feller p.124-132. 
sentence). "Hate" is also a reason for a man to leave his wife: "I gave my daughter to this man for a wife and he hated her." 26 "Hate money" and "hate judgment" can sometimes serve as technical terms for the divorce itself. ${ }^{27}$ Apparently women too could make themselves "hateful" to justify divorce. So what we have here is an entire terminology of inter-sexual, formal relations. If these are indeed the issues that reverberate behind the text it implies another Middle Ground dimension: both Philistines and Israelites, not only celebrate according to a commonly accepted framework, "as the boys do," but also adhere to laws and conventions that regulate matrimonial links. These conventions were common to both yet originated with neither. ${ }^{28}$

In anger, Samson ties burning torches to the tails of 300 foxes and sends them throughout the cultivated fields and olive plantations of the Philistines to burn. ${ }^{29}$ This is a nice illustration of the rich agricultural chôra of the Philistines, characteristic precisely of what Greeks would also have grown: cereals, olives, and vines. Timna has its vines (14.5) and Samson's foxes burn down wheat fields and olive plantations.

The Philistines then inquire as to who did this and why. Their reaction is to turn not against an ethnic other, but against another Philistine, one of their own: When told it was Samson's father-in-law who was to blame because he had given his daughter to someone else, another Philistine, they "go up" (15.6) to Timna (a frontier settlement up in the hinterland) and burn down the daughter and her father's house. Note that it was not the people of Timna who did this, implying a more official Philistine action (which it explicitly becomes later in the story with the seranim; see below). It appears they were unhappy with a breakdown of a common arrangement of intermarriage with the hinterland people. A Philistine uneasiness about Judean reaction is also implied. It is narrated as if intermarriage firmly belonged to a common mental horizon. Samson's parents, who, expressing the biblical author's anti-Philistine attitude, supposedly abhorred the idea, but theirs is the voice of the meta-narrative of the divine purpose. The story stresses the interruption of a modus vivendi to the extent that the breakdown of a contract with an Israelite merits the death of the blameworthy Philistines, father and daughter, at the hands of other Philistines. This is an

26 Deut. 24.3; 21.15 Galpaz-Feller p.125.

27 Galpaz-Feller p. 93-132.

28 See the discussion in Galpaz-Feller 2006 pp. 124-131. She thinks the law is even more specific: a woman may not be given to someone who was one of the actual groomsmen, but this seems to depend on Samson's story as we have it.

29 This could be compared to Ovid Fasti 6.679ff. important point to remember when discussing marriage conventions among coastal "colonies" and hinterland, such as that which Elymian Segesta had with both Greeks and Phoenicians in Sicily. ${ }^{30}$

We have just noted a mixture of aspects: cultural animosity and awareness of ethnic difference; a Hebrew sense of being "lorded over" by Philistines (although we do not see any evidence for direct rule); a reality of movement within the spaces of the hinterland and the colonies; contact, familiarity and marriage across ethnic divides. Samson not only marries a Philistine woman; had matters gone well he might have become part of a group of Philistine companions. In other words, such integration is presented as part of an acceptable spectrum of expectations.

By analogy, discussions concerning intermarriage in Greek colonies inevitably move in the dark, depending on interpreting quasi-historical tales (such as that of Protis), material objects, such as fibulae, foreign-sounding personal names (although xenia-relations may provide the reason for those rather than ethnic origins, e.g., Libys, a king of Cyrene), ${ }^{31}$ and evidence for marriage rights from the Classical period. ${ }^{32}$ Moreover, we lack the diachronic dimension: the Samson story relates to a period when the Philistines were well-established. ${ }^{33}$ The story of Protis relates to the time of Massalia's foundation, not to its subsequent life. In later traditions, Massaliots are supposed to be rather conservative and exclusionary in their relations with non-Greeks, but again, we have no idea about the history of such attitudes.

Samson, unhappy that his wife had been killed, resorts to further, yet measured, revenge: "and after that I'll cease," he says (15.7). Samson kills many and retires; only now do the Philistines react, sending "up" an army (15.11). Again we get a glimpse of the spatial perceptions involved: the Philistines literally "went up" (ויעלו) to make camp ${ }^{34}$ in Judea. The Judeans inquire why they had "come up" (לָמָה עָלְיתֶם), clearly indicating the spatial perspective of those living "up" from the shore.

30 Thuc. 6.6.2; cf. Hodos 1999.

31 Malkin 1990.

32 Coldstream 1993; Hodos 1999; Graham 2001; Sheperd 2005; Delamard and Mariaud (2007); Esposito and Zurbach (2010); Guzzo (2012).

33 According to the school that sees the Samson cycle as reflecting the eighth and seventh centuries Gath had been in ruins for quite some time. See note 37 .

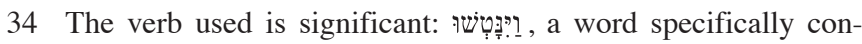
nected with Philistine armies, signifies something like taxis, the order of camp. 1Samuel 4.2; 30.16; 2Samuel 5.18; 5.22. 
The threat is sufficient for the Judeans to go and arrest Samson: "Then three thousand men of Judah went down to the cleft of the rock of Etam, and said to Samson: "do you not know that the Philistines rule over us? What is this that you have done to us? And he said unto them: 'as they did unto me, so have I done unto them.'”(15.11). The Judeans hand him over to the cheering Philistines. But Samson, the strong-man hero, having liberated himself from the ropes, finds a jawbone of an ass, and kills a thousand more Philistines. What is noteworthy is the Judean readiness to hand him over, following quite a reasonable Philistine demand. We are still in the accommodated space of the Middle ground, but now the excess is Samson's, not theirs (remember they have just executed the Philistine wrongdoer).

Samson becomes thirsty and cries to God lest he die at the hand of the arelim, the "uncircumcised"(15.18). The appellation arelim is significant, as it appeals again to circumcision as an ethnic marker. We know that circumcision was the butt of many an Egyptian joke about Greeks. ${ }^{35}$ One wonders about attitudes to such differences in the Greek colonial world; for example, how would the circumcised Kolchians have seen the Greeks of the Black sea? ${ }^{36}$ Arelim in the Hebrew of the Old Testament comes up in dire confrontational circumstances: Saul falls on his sword, rather than die at the hand of the arelim (1Samuel 31.4). On the other hand, the details of contact and interaction in the story of Samson stand in marked contrast to the expressed attitude that stresses difference. Samson will now move to his second Philistine woman, the whore from Gaza. In terms of textual criticism it would seem that the avowed purpose of the narrator's voice (Philistines as "absolute others") is contradicted by the details he transmits (familiarity and close contacts with philistines). This is not uncommon with ethnic stereotypes in historiography. Ammianus Marcellinus, for example, when writing an ethnography of the Gauls he portrays them as barbaric, nomadic, and roofless; however, when describing a march through Gauls in which he participated he tells of passing by well-built stone houses. He seems unaware of the start contradiction between the topos of the barbarian and the experience of life which seems no different from that of the "civilized" Romans.

Samson goes to Gaza of his own free will. It probably indicates a view of a common type of visit by Hebrews to Philistine cities: they might be going there for trade,

35 Bohak 2000; cf. Isaac 2004.

36 Hdt. 2.105 also notes that the Phoenicians and «the Syrians» (this may be a reference to hinterland peoples, such as the Jews, as he distinguishes them from other «Syrians» in the same passage) too are circumcised. metal-needs, or sex. Paid sex is not a common criterion discussed among scholars of Greek colonization as a factor of the Middle Ground. One wonders to what extent this was also a dimension in Greek-local relations in the world of Greek colonies. ${ }^{37}$ The Samson story suggests that it is something to look for in the evidence.

Luckily for Samson, he departs from Gaza in the middle of the night while the Philistine Gazans plot to capture him. "And Samson lay till midnight, and arose at midnight, and laid hold of the doors of the gate of the city, and the two posts, and plucked them up, bar and all, and put them upon his shoulders, and carried them up to the top of the mountain that is before Hebron."(16.3) This is a distance of some fifty $\mathrm{km}$ (too far for the Philistines to carry their gates back). Here too we note the "up-down" spatial dimensions: Samson climbs the mountain facing Hebron, looking back, down, to the Philistine coast. The fantastic story also emphasizes metal (the gates) as especially marking the Philistines, implying perhaps a gift of iron by Samson to the Judeans.

Unperturbed, Samson moves on to his third woman, the notorious Delilah, who lives in the area between Philistines and Israelites, the valley of the Sorek stream. The Sorek flows along some $70 \mathrm{~km}$, from the hills of Jerusalem via Beth Shemesh (the area of Tsor'a), and the Shephelah, the region of the Philistines. It thus links both areas: the Israelite hinterland and the Philistine country, forming a geographical middle ground between the two. This may explain why Delilah is not expressly called a Philistine; ${ }^{38}$ she might have been Canaanite or even a Hebrew. What is important is precisely the ambivalence: it indicates a Middle Ground of complex identities and complex contacts.

The "lords of the Philistines" bribe her to discover the secret of his strength. It is noteworthy that now we get the entire leadership of the Philistines, sarnei plishtim or so it seems, rather than the officials of a particular Philistine city. ${ }^{39}$ Delilah eventually succeeds, Samson is captured, blinded, and serves in the prison. The narrative now becomes flamboyant: thousands of Philistines gather in the temple, all wishing to abuse the blind slave; but his strength is renewed and Samson pulls down the temple which collapses and kills himself and thousands more.

The biblical author has his chance to describe the foreignness of the Philistines through their religion: (16.23)"And the lords of the Philistines gathered them together to offer a great sacrifice unto Dagon their god

37 Cf. Glazebrook and Henry 2011. Cf. Galpaz-Feller 2006, pp.133-148.

38 Cf. Zakovitch 1982, p. 168 n7.

39 Zakovitch 1982, p. 169. 


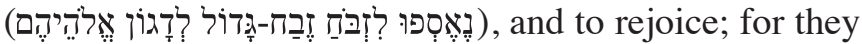
said: 'Our god hath delivered Samson our enemy into our hand.'(16.24) And when the people saw him, they

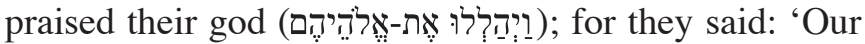
god (אֶלה מעינו) hath delivered into our hand our enemy, and the destroyer of our country, who hath slain many of us." The author's aim is implied: "their god (Dagon)" is inferior to Yahweh. ${ }^{40}$ But in terms of the details revealed, it indicates close familiarity with Philistine rites, temples, and the make-up of the participating public. This includes the seranim as well as men and women. "Now the house was full of men and women; and all the lords of the Philistines were there; and there were upon the roof about three thousand men and women (...)". (16.27)

The Philistine of the Samson stories appear distinctly foreign in terms of the narrative (uncircumcised, worshipping foreign gods); and yet, to the extent the stories reflect eighth- and seventh-century realities, we are no longer dealing with the Philistines of the Bronze Age. We now see them a few centuries since arrival, having pushed further inland and assimilated into the local Middle Grounds, with a mixture of both Aegean and Semitic elements in their language and religion. ${ }^{41}$ Their coastal cities never became anything like their northern neighbors the Phoenicians, who kept their religion and set out to sea. ${ }^{42}$ As for the Greeks, it was the sea and its networks that allowed the Phoenicians to keep and enhance their distinctiveness, instead of being absorbed in the neighboring hinterlands. By analogy, like the Phoenicians, Greeks in Asia Minor or southern France, living within the confines of relatively narrow chôrai, also kept (and constantly developed) their Greek distinctiveness since their main orientation was the Mediterranean networks, not the hinterlands. The Philistines, on the other hand, seem to have been looking inland, away from the sea.

Perhaps this is because none of the Philistine cities (Gaza, Ascalon, Ashdod; Ekron and Gath were further inland) had a port equivalent to the Phoenician ports further up north. As for their religion, Dagon, so prominent

40 Cf. 1 Samuel, chapters 1-6.

41 Cf. Stone 1995; Faust 2012,p. 135 «Iron I population in the south 'played' with material traits in their ethnic negotiations and boundary maintenance. The Israelites interacted with the dominant Philistines, and defined themselves in contrast to them. The Philistines, too, viewed the Israelites as their «other,» and prior to their rapid acculturation in the Iron II, continuously raised the boundaries between the Israelites and themselves.» For a detailed examination of the material evidence, indicating too the «moment» of transition to fuller assimilation on the part of the Philistines, see Faust and Lev-Tov, 2011. On diet (pigs, absent from neighboring non-Philistine sites) as a mark of ethnic distinctiveness see Hesse 1990. Hesse and Wapnish 1997.

42 A general overview: Albright 1975; Dothan 1982; Dothan 1986; Mazar 1986. in the story of Samson, is probably not an Aegean deity: he is first known to us from Mesopotamia, dating to the third millennium BCE. In Canaan, he became a god of the earth's fertility and its grain, and that is how he was worshipped by the Philistines. ${ }^{43}$ On the other hand, Aegean elements persisted in Philistine culture: the term seranim seems to be a Bronze-Age legacy ${ }^{44}$ A seventh-century Philistine inscription from Ekron (Tel Miqne), ${ }^{45}$ mentions five kings. One is called Ikasau, which Joseph Naveh understands as "the Achaean"; most probably it is the same as "Achish," 46 a name known from the story of David and Achish King of Gath, yet relating to an episode that supposedly had taken place three centuries earlier (Gath had been destroyed ca. 835). ${ }^{47} \mathrm{It}$ also mentions a major deity that could be identified as Pytho-Gaia, an Aegean deity, which seems likely to be related to the numerous "Ashdoda" figurines found in various Philistine sites. ${ }^{48}$ Yet the inscription is written in Semitic, and the names of the four other kings have Semitic names.

The eighth- and mostly seventh-century Philistine areas may be compared to the Middle Ground in southern Italy: there too, within some three centuries since colonization, the late fifth-century Greeks in southern Italy were "absorbed" (or at least no longer spoke Greek) among Lucanians and Oscans, yet kept some distinctive characteristics of the Hellenic identity. ${ }^{49}$

The situation of the people living in the Sorek river valley may be analogous to the situation around ancient Arles by the Rhône: lying by a river route, with good connectivity and with a mixed population. In southern France, the two communities, Massalia and Arles, indicate the difference between a Greek city (Massalia), a foundational colony, and the Middle Ground areas of mixed habitation..$^{\mathbf{5 0}}$

43 Dothan 1982: Brug 1985, pp. 20-21; 182-188; Ehrlich 1995, p. 71. For a different interpretation see Singer 1992.

44 Yasur-Landau 2001 p. 312-3, 343 contra Finkelstein 2002 pp. 136-7 On seren and its relation to tyrannos see Cuny 1922; Pintore 1983; Garbini 1992. For other points Gitin see 2010.

45 Dothan and Gitin 1993; Gitin et al. 1997; Sasson 1997; Naveh 1998.

46 Finkelstein 2002, pp. 133-136. Contrary to Finkelstein, I see no reason why Achish could not have been a name preserved in dynastic genealogies. He is correct to note that in Assyrian records all other names of Philistine rulers are Semitic.

472 Kings 12.17 tells of Haza'el king of Damascus, who campaigned in the Shephelah (c. $835 \mathrm{BCE}$ ) and conquered the city of Gath. See, however, 2 Chron. 26.6 (first half of the eighth century). Cf. Finkelstein 2002, p. 141.

48 Gitin and Dothan 1997; Naveh 2009, pp. 359-374; SchäferLichtenberger 2000; Yasur-Landau 2001; cf. Finkelberg 2005, p. 157 49 Asheri 1999.

50 Hodge 1998, p. 160, and Rouillard 1992,p. 183; Morel 2006, p. 392. 
When we observe the chorra of Massalia, or the coastal areas of southern France, we note clusters of habitations that functioned as Middle-Ground networks, involving Greeks and non-Greek populations. Storage facilities (silos, granaries) found in several native sites close to Phokaian settlements are seen as having served for an exchange of commodities. ${ }^{51}$ As Brian Shefton and Michel Bats have shown, ${ }^{\mathbf{5 2}}$ this is no simple "exchange." The chôra indicates how the edges of regional networks created new neighborhoods with a guarded outlook, at once marking a difference yet serving as a vehicle of cultural and material transmission. We have seen such a wide spectrum of exchange and convivenza explicitly in the Samson cycle.

Agathe (Agde) may be comparable to Timna (Tel Batash): its foundation seems to have come after long periods of Middle-Ground contacts. Timna seems to have been a secondary Philistine foundation, further inland. It is in fact quite near to Tsor'a, Samson's home, itself a frontier town. The context may be the seventh century since Timna may have changed hands after the Assyrian conquest (King Sennacherib's campaign in 701), since it appears predominantly Philistine mostly in the seventh century, but not in the eighth. Similarly, the archaeological data seems to indicate that having been reduced from its earlier Iron Age I size, Ekron became a major Philistine city again in the seventh century with a huge olive oil industry. ${ }^{53}$ Similarly perhaps, the first Greek material (four Greek vases) has been found in the non-Greek necropolis of Peyrou, dating to the third quarter of the seventh century. During the last third of the sixth century some Phokaians settled by the Bessan River, some fifteen $\mathrm{km}$. from the sea, at La Monédière. They were also frequenting the site of Agathe (five kilometers from the sea), where they finally settled around the end of the fifth century. ${ }^{54}$

Tsor'a and Timna may be also compared with Antipolis. Although the site of Greek Antipolis has not been discovered, it was probably founded during the last quarter of the sixth century. Its name is highly significant: it lays apparently "opposite" (anti-) a local village with prominent Greek influence in its material culture. ${ }^{55}$ As I have noted elsewhere, ${ }^{56}$ this "dance" of

51 By Emporion, Agathe, at Martiques near Marseille, and at MontGarou by Toulon. Morel 2006, p. 383.

52 Shefton 1994, pp. 65-66; Bats 1992.

53 Joshua 15.10. Kelm and Mazar 1995; cf. Ofer 1994. I am grateful to Sy Gitin for these observations.

54 Morel remarks that the site is somewhat similar to Emporion: a small, similar rectangular plan, with a wall whose position changed several times. Morel 2006, pp. 389-90.

55 Bats 1994, p.146.

56 Malkin 2011, Chapter 5.
Greek and native settlements, "talking" to each other at close distances, is a consistent pattern that is seen also in Massalia's later foundations. Yet this is a MiddleGround dance: The "Greek" is not entirely Greek, and the "native settlement" seems mixed. Both Samson and Delilah seem to fit this description: in spite of the express aim of the biblical author, to show how God wanted a pretext to punish the Philistines, and in spite of stressing their foreignness (cult, circumcision), the reality that comes out from the details is very similar to the kind of mixtures one might expect: Samson yearns for Philistine company, both masculine (his "companions") and feminine (his women). I wish we had this kind of color, folkloric as it may be, for the Middle Grounds of the Greek colonial world.

Most of the places settled by Israelites which are named in the books of Joshua and Judges are conquered, not founded ex nihilo; at least this is the image projected for us. One wonders about the history of Tsor'a and Eshta'ol, for example, which may further be compared to the site of Baou de Saint Marcel: about the time of Massalia's foundation we find evidence there for a native site that was settled and fortified ca. 575. It lies inland only seven kilometers from Massalia, and although it contains much Greek material, the place seems to have been non-Greek and newly established in relation to the Greek presence-all this with in the first generation of Greek settlement. ${ }^{57}$

The phenomenon of "antipolis" foundations (Greeks facing a native site or vice versa) is familiar in the history of colonization in various periods and areas. New settlements create new economic niches and attract people from the hinterland who work and produce for the newcomers, trade (and marry?) with them. ${ }^{58}$ Such observations should seriously modify some of the simplistic Orientalist notions current in postcolonial theory, seeing colonization as a zero-sum game where natives inevitably lose to the colonists. ${ }^{59}$

Michel Bats, a perceptive and wise student of this phenomenon in southern France, applies the term "gateway communities" to the string of native communities that were created parallel to the Phokaian-Massaliot ones, perhaps analogous to the term I prefer, "MiddleGround networks," forming local clusters that undergo

\footnotetext{
57 Shefton 1994, pp. 66-69.

58 As Robert Bartlett (1993) has shown with the medieval colonization of Europe, as well as Walter Hawthorne (2001) for the upper Guinea coast. Sometimes, as Kelly (2002) shows with regard to the history of seventeenth-century Dahomei in Africa, an entire "nation kingdom" can be set up on a European model to face those landing on the shore. The shore itself was a middle ground in the sense that neither Europeans nor Dahomeians had been there before. 59 Malkin 2004.
} 
fluctuating connections. The story in Judges provides us with an illustration of such a Middle Ground from the perspective of the hinterland: on the one hand, animosity, suspicion and derision; on the other, lively interaction on various levels.

There are also some general implications to be drawn from all this with regard to the question of formation of collective identity and the emergence of commonalities of civilization. Why were the Philistines "not Greek"? Or, conversely, why did other Aegean migrants become Greek and the Philistine did not? The question does not relate to the DNA of migrants (e.g., "were they actually Greek-speaking Mycenaeans?") but to the civilizational formation that took place during the Dark Ages which formed the basis of Greek civilization in the early Archaic period. Most would agree that Philistines have an Aegean origin, migrating and settling around the late $12^{\text {th }}$ or the $11^{\text {th }}$ centuries as part of the great kinesis, the upheaval that formed the context of the "Ionian" and of other migrations, such as to Cyprus. ${ }^{60}$ Some may have arrived by sea, others by coastal land routes. Yet both in terms of their material culture, and certain aspects of their religion, they seem "Aegean" in origins. As would happen with the Aegean migrations to Cyprus and Asia Minor the Philistines might have become Greek, except they did not. Settling on the coast, their settlements evolved into important city states. This is also what happened to the migrants who reached the shores of Asia Minor during the Dark Ages, except that the latter kept in touch with, and were invigorated by, the maritime networks that crystallized their commonalities as a civilization and defined their identity as Greeks. Instead of merging with their neighbors the "Ionians," for example, were "pulled" to the sea and became more Greek, whereas the Philistines lost their maritime orientation and gradually (over a few centuries), were acculturated into the region. For the Greeks the process was heightened in the seventh and sixth centuries with further colonization in the Central and western Mediterranean, and the Black Sea.

60 Cretan origins seem to be the consensus among biblical authors: Amos (9.7) and Jeremiah (47.4) speak of Kaphtor,identified with Crete; cf. Akkadian Kaptaru and the Egyptian Kefteu. However, Egyptian origins are spoken of in the Philistines came from Egypt Genesis 10.13-14; 1 Chron 1.11-12. See Vercoutter 1956; Kitchen 1973, p. 54. Cf. Finkelberg 2005 p. 156. The origin of the Philistines is much debated. De Vaux 1978, pp. 503-507; Singer 1988; Finkelstein 2002, p. 150-155 (discussion also Cyprus and Anatolia). See now the magisterial research by Yasur-Landau 2010. For Asia Minor and Cyprus: Iacovou 1999; Vanschoowinkel 2006.
For this the Philistines had arrived too early and too soon: they reached shores that were simply too distant to be integrated in what later became Hellenic maritime networks. With no great port cities, they expanded inland. Within three or four centuries the Philistines had lost their Aegean language, yet seem to have kept their distinctiveness. The Samson cycle not only confirms this discrete identity but also provides a perspective from the hinterland, which we never get in the Greek colonial world. It is a mixture of, on the one hand, a notional confrontational identity ("them and us") ${ }^{61}$ and, on the other, indicating (in great detail) that we are in fact dealing with active, reciprocal Middle Grounds that affected both the Philistines (e.g., the adoption of Semitic language and deities) and the Danites who frequented Philistine cities for their wine, women, and iron and could expect inter-marriage. The Philistine and Greek relation to their local environment and the formation of different sort of Middle Grounds (hinterland- and sea-oriented) therefore seem both pertinent and fertile in allowing us to form the right questions about colonial and cultural encounters.

\section{References}

Asheri 1999 : ASHERI (D.) - Processi di 'decolonizzazione' in Magna Grecia : il caso di Poseidonia Lucana. In : La colonization grecque en Méditerranée occidentale, Actes de la rencontre scientifique en hommage à Georges Vallet organisé par le Centre Jean Bérard, l'École française de Rome, l'Istituto universitario orientale, et l'Università degli studi di Napoli 'Frederico II' (Rome-Naples, 15-18 novembre 1995), Rome, 1992, p. 361370 (Coll. EFR 251).

Albright 1975 : ALBRIGHT (W. F.) - Syria, the Philistines, and Phoenicia, I. The Sea Peoples in Palestine, CAH II.2A, 1975, p. 507-516.

Amit 1992 : AMIT (Y.) - The Book of Judges: The art of editing [Hebrew], Jerusalem, Bialik Institute, 1992.

Bartlett 1993 : BARTLETT (R.) - The Making of Europe: Conquest, Colonization, and Cultural Change, 950-1350, Princeton, N.J, Princeton University Press, 1993.

Bats 1992 : BATS (M.) - Marseille, les colonies massaliètes et les relais indigènes dans le trafic le long du littoral méditerranéen gaulois $\left(\mathrm{VI}^{\mathrm{e}}-\mathrm{I}^{\mathrm{er}} \mathrm{s}\right.$. av. J.-C.). In : BATS et al. 1992, p. 263-278.

Bats 1994 : BATS (M.) - Les silences d'Hérodote ou Marseille, Alalia, et les Phocéens en Occident jusqu'à la fondation de Vélia. In : Ridgway (D.), d'AGOSTINO (B.) (eds.), Apoikia: Scritti in onore di Giorgio Buchner, AION ArchStAnt n.s. 1, 1994, p. 133-148.

Bats et al. 1992 : BATS (M3), BERTUCCHI (G3), CONGES (G3), TRÉZINY (H.) (Éds.) - Marseille grecque et la Gaule. Études massaliètes 3 , Aix-en-Provence : ADAM and Université de Provence.

Bohak 2000 : BOHAK (G.) - Ethnic stenotypes in the Greco-Roman World: Egyptians, Phoenicians and Jews. In : Proceedings of the Twelfth World Congress of Jewish studies Jerusalem, 2000, p. 7-15.

Brug 1985 : BRUG (J. F.) - A literary and archeological study of the Philistines. BAR International Series 265. Oxford, 1985.

61 Eriksen 1993. 
Bunimovitz, Lederman 2011 : BUNIMOVITZ (SH.), LEDERMAN (Z.) Canaanite resitance: The Philistines and Beth-Shemesh - A case-study from Iron Age I, BASOR, 364, 2011, p. 37-51.

Coldstream 1993 : COLDSTREAM (J. N.) - Mixed Marriages at the Frontiers of the Early Greek World, OJA 12, 1993, p. 89-107.

Crenshaw 1978 : CRENSHAW (J. L.) - Samson: A secret betrayal, a vow ignored, Atlanta, 1978.

Cuny 1922 : CUNY (A.) - Questions gréco-orientales. XIII. Gr. tyrannos, Philistin seran, Revue des Études Anciennes, 24, 1922, p. 89-92.

Delamard, Mariaud 2007 : DELAMARD (J.), MARIAUD (O.) - Le silence des tombes. Masculin et féminin en Grèce protogéométrique et archaïque d'après la documentation archéologique funéraire. In : Sébillote Cuchet (V.), Ernoult (N.) éd. : Problèmes du genre en Grèce ancienne, Paris, 2007, p. $65-82$.

Dothan 1982 : DOTHAN (T.) - The Philistines and their Material Culture, New Haven, Yale Press, 1982.

Dothan 1995 : DOTHAN (T.) - Tel Miqne-Ekron : the Aegean Affinities of the Sea People's (Philistines') settlement in Canaan in the Iron Age I. In : GITIN (S.) ed., Recent Excavations in Israel: A View to the West, Archaeological Institute of America Colloquia \& Conference Papers No. 1, (Dubuque: Kendal/Hunt), 1995, p. 41-60.

Dothan 1998 : DOTHAN (T.) - Initial Philistine Settlement : From Migration to Coexistence. In : Gitin (S.), Mazar (A.), Stern (E.) eds, Mediterranean Peoples in Transition: Thirteenth to Early $10^{\text {th }}$ Century BCE. Jerusalem, 1998, p. 148-161.

Dothan T. and M. 1992 : DOTHAN (T.), DOTHAN (M.) - People of the Sea: The Search for the Philistines, New York, Macmillan, 1992.

Dothan and Gitin 1993 : DOTHAN (T.), GITIN (S.) - Miqne, Tel (Ekron). In : STERN (E.) ed., The New Encyclopedia of Archaeological Excavations in the Holy Land, Jerusalem, Israel Exploration Society, III, 1993, p. 1051-1059. Ehrlich 1996 : EHRLICH (S. CHARLES) - The Philistines in Transition : A History from ca. 1000-730 BCE, Leiden, Brill, 1996.

Eriksen 1993 : ERIKSEN (TH. HYLLAND) - Ethnicity and Nationalism: Anthropological Perspectives, London, Pluto (Anthropology, Culture, and Society).

Esposito and Zurbach 2010 : ESPOSITO (A.), ZURBACH (J.) - Femmes indigènes et colons grecs : quelques observations. In : ROUILLARD (P.) éd. Portraits de migrants, portraits de colons, Paris, 2010, p. 51-70.

Fantalkin 2001 : FANTALKIN (A.) - Mezad Hashavyahu : Its Material Culture and Historical Background, Tel Aviv, 28, 2001, p. 3-165.

Faust 2012 : FAUST (A.) - Between Israel and Philistia Ethnic Negotiations In The South During Iron Age I. In: Galil et al. 2012, p. 121-135.

Faust and Lev-Tov 2011 : FAUST (A.) and LEV-TOV (J.) - The Constitution of Philistine Identity : Ethnic Dynamics in Twelfth to Tenth Century Philistia, Oxford Journal Of Archaeology, 2011, p. 13-31.

Finkelberg 2005 : FINKELBERG (M.) - Greeks and pre-Greeks : Aegean Prehistory and Greek Heroic Tradition, Cambridge, Cambridge University Press. Finkelstein 1995 : FINKELSTEIN (I.) - The Philistines in Canaan, Tel Aviv, 22, p. 213-39.

Finkelstein 1996 : FINKELSTEIN (I.) - The Philistine countryside, Israel Exploration Journal, 46, p. 225-242.

Finkelstein 2002 : FINKELSTEIN (I.) - The Philistines in the Bible. A late monarchic perspective,Journal of the Society of OrientalResearch, 27, p. 131-167. Finkelstein and Silberman 2001 : FINKELSTEIN (I.) AND SILBERMAN (N. A.) - The Bible Unearthed: Archaeology's New Vision of Ancient Israel and the Origin of Its Sacred Texts, New York, Free Press, 2001.

Garbini 1991 : GARBINI (G.) - On the Origin of the Hebrew-Philistine Word seren. In : A.S. Kaye (A. S.) ed. - Semitic Studies in Honor of Wolf Leslau, Wiesbaden, Otto Harrassowitz, 1991, p. 516-519.

Galil et al. 2012 : GALIL (G.), GILBOA (A.), MAEIR (A. M.), KAHN (D.) Eds. - The Ancient Near East in the 12th-10th Centuries BCE: Culture and History. Proceedings of the International Conference held at the University of Haifa (2-5 May 2010), Münster, Ugarit-Verlag, 2012, (Alter Orient und Altes Testament, Band 392).

Galpaz-Feller 2006 : GALPAZ-FELLER (P.) - The Story of Samson: (Judges 13-16), Bern, Peter Lang, 2006.
Gitin 1987 : GITIN (S.) - Tel Miqne-Ekron in the 7th C. BC : City Plan, Development and the Oil Industry. In : Heltzer (M.) and Eitam (D.) eds - Olive Oil in Antiquity, Haifa, University of Haifa, 1987, p. 81-97 [= Olive Oil in Antiquity, Israel and Neighboring Countries from the Neolithic to the Early Arab Period, Padova, Sargon srl, 1996 (History of the Ancient Near East/ Studies VII)]

Gitin 1995 : GITIN (S.) - Tel Miqne-Ekron in the 7th Century B.C.E. : The Impact of Economic Innovation and Foreign Cultural in Infuences on a Neo-Assyrian Vassal City- State. In : GITIN (S.) ed. - Recent Excavations in Israel: A View from the West. Archaeological Institute of America Colloquia \& Conference Papers No. 1, Dubuque, Kendall/Hunt, 1995, p. 61-79.

Gitin 1998 : GITIN (S.) - Philistia in Transition : The Tenth Century BCE and Beyond. In : Gitin (S.), Mazar (A.), Stern (E.) eds., Mediterranean Peoples in Transition: Thirteenth to Early $10^{\text {th }}$ Century BCE. Jerusalem, Israel Exploration Society, 1998, p. 162-183.

Gitin 2004 : GITIN (S.) - The Philistines : Neighbors of the Canaanites, Phoenicians and Israelites. In : Clark (D. R.), Matthews (V. H.) eds - 100 Years of American Archaeology in the Middle East, Proceedings of the American Schools of Oriental Research Centennial Celebration, Washington D.C. (April 2000), Boston, 2004, p. 57-85.

Gitin 2010 : GITIN (S.) - Philistines in the Books of Kings. In : Lemaire (A.), Halpern (B.) eds - The Books of Kings Sources, Composition, Historiography, and Reception, Leiden, Brill, 2010, p. 301-364.

Gitin et al. 1997 : GITIN (S.) DOTHAN (T.), NAVEH (J.) - A Royal Dedicatory Inscription from Ekron, IEJ, 47/1-2, p. 1-16.

Glazebrook, Henry 2011 : GLAZEBROOK (A.), HENRY (M.) eds - Greek Prostitutes in the Ancient Mediterranean, 800 BCE-200 CE, Madison, University of Wisconsin Press, 2011 (Wisconsin studies in Classics).

Graham 1984 : GRAHAM (A. J.) - Religion, Women and Greek Colonization. In : Religione e città nel mondo antico. Atti Centro ricerche e documentazione sull antichità classica, Milan, 1984, p. 293-314. [Reprinted in GRAHAM (A. J.) Collected Papers on Greek Colonization, Leiden: Brill, 2001, p. 327-348.]

Guzzo 2012 : GUZZO (P. G.) - Fibule e identità a Pithekoussai, Archeologia Classica, 63, 2012, p. 509-535.

Hawthorne 2001 : HAWTHORNE (W.) - Nourishing a Stateless Society during the Slave Trade : The Rise of Balanta Paddy-Rice Production in GuineaBissau. Journal of African History, 42, 2001, p. 1-24.

Hesse 1990 : HESSE (B.) - Pig lovers and pig haters: patterns of Palestinian pork production, Journal of Ethnobiology, 10, 1990, p. 195-225.

Hesse, Wapnish 1997 : HESSE (B.), WAPNISH (P.) - Can pig remains be used for ethnic diagnosis in the ancient Near East? In: Silberman (N.A.), Small (D.) eds., The Archaeology of Israel: Constructing the Past, Interpreting the Present, Sheffield, University Press, 1997, p. 238-70 (JSOT Suppl. Ser. 237). Hodge 1998 : HODGE (A. TREVOR) - Ancient Greek France, London, Duckworth, 1998.

Hodos 1999 : HODOS (T.) - Intermarriage in the western Greek colonies, Oxford Journal of Archaeology, 18.1, 1999, p. 61-78.

Hodos 2006 : HODOS (T.) - Local Responses to Colonization in the Iron Age Mediterranean, London, Routledge, 2006.

Iacovou 1999 : IACOVOU (M.) - The Greek Exodus to Cyprus: The Antiquity of Hellenism, Mediterranean Historical Review, vol. 14, no. 2 , 1999, p. 1-28.

Kelly 2002 : KELLY (K.) - Indigenous Responses to Colonial Encounters on the West African Coast : Hueda and Dahomei from the Seventeenth through the Nineteenth Century. In : Lyons and Papadopoulos 2002, p. 96-120.

Kelm, Mazar 1995 : KELM (G.), MAZAR (A.) - TIMNAH : A biblical city in the Sorek Valley, Winona Lake, IN, Eisenbrauns, 1995.

Kitchen 1973 : KITCHEN (K.A.) - The Philistines', in D.J. Wiseman (ed.), Peoples of Old Testament Times (Oxford: Clarendon Press): 53-78.

Lyons, Papadopoulos 2002 : LYONS (CL. L.), PAPADOPOULOS (J. K.) eds. - The Archaeology of Colonialism, Los Angeles, The Getty Research Institute, 2002.

Machinist 2000 : MACHINIST (P.) - Biblical Traditions : The Philistines and Israelite History. In : Oren (E. D.) ed. - The Sea Peoples and Their World: A Reassessment, Philadelphia, University Museum of the University of Pennsylvania, 2000, p. 53-83 
Malkin 1990 : MALKIN (I.) - Lysander and Libys, Classical Quarterly, 40, p. 541-545.

Malkin 1998 : MALKIN (I.) - The Returns of Odysseus : Colonization and Ethnicity, Berkeley, University of California Press, 1998.

Malkin 2002 : MALKIN (I.) - A colonial Middle Ground : Greek, Etruscan, and local elites in the Bay of Naples. In : Lyons, Papadopoulos 2002, p. 151-181.

Malkin 2004 : MALKIN (I.) - Postcolonial Concepts and Ancient Greek Colonization, Modern Language Quarterly (special issue on Postcolonialism and the Past, eds. Barbara Fuchs and David J. Baker), 65(3), p. 341-64.

Malkin 2011 : MALKIN (I.) - A Small Greek World: networks in the ancient Mediterranean. Oxford and new York: Oxford university Press

Malkin 2011b : MALKIN (I.) - Review of Hodos 2006, Journal of Hellenic Studies. 2011

Malkin n.d. : MALKIN (I.) - Foreign Founders : Greeks and Hebrews. In : Mac Sweeney (N.) ed. - Foundation Myths in Dialogue, Philadelphia, University of Pennsylvania Press (Forthcoming).

Margalith 1994 : MARGALITH (O.) - The Sea Peoples in the Bible, Wiesbaden, Otto Harrassowitz, 1994.

Mazar 1986 : MAZAR (B.) - The Philistines and rise of Israel and Tyre. In : MAZAR (B.) - The Early Biblical Period: Historical Essays, Jerusalem, 1986, p. 63-82.

Morel 2006 : MOREL (J.-P.) - Phocaean Colonisation. In : Tsetskhladze (G. R.) ed. - Greek Colonisation: An Account of Greek Colonies and Other Settlements Overseas, Leiden, Brill, 2006, p. 358-428.

Mullen 2013 : MULLEN (A.) - Southern Gaul and the Mediterranean : multilingualism and multiple identities in the Iron Age and Roman periods, Cambridge, CUP, 2013.

Na'aman 2005 : NA'AMAN (N.) ) - The Danite Campaign Northward (Judges XVII-XVIII) and the Migration of the Phocaeans to Massalia (Strabo IV, 1,4), Vetus Testamentum, Vol. 55, Fasc. 1 (Jan., 2005), p. 47-60.

Naveh 1998 : NAVEH (J.) - Achish-Ikausu in the Light of the Ekron Dedication, BASOR 310, p. 35-37.

Naveh 2009 : NAVEH (J.) - Studies in West-Semitic Epigraphy, Jerusalem, p. 359-374

Ofer 1994 : OFER (A.) - All the hill country of Judah: From a Settlement Fringe to a Prosperous Monarchy. In : Finkelstein (I.), And Na'aman (N.) eds - From Nomadism to Monarchy: Archaeological and Historical Aspects of Early Israel, Jerusalem, Israel Exploration Society, 1994, p. 92-121.

Pralon 1992 : PRALON (D.) - Les fondatrices. In : Knibiehler (Y.) et al. éd. - Marseillaises : les femmes et la ville, des origines à nos jours, Paris, Côté-Femmes, 1993, p. 53-60.

Pintore 1983 : PINTORE (F.) - Seren, Tarwanis, Tyrannos. In : Carruba (O.), Liverani (M.) And Zaccagnini (C.) eds - Studi orientalistici in ricordo di Franco Pintore, Pavia: Gjes edizioni, p. 285-322 (Studia Mediterranea, 4). Rouillard 1992 : ROUILLARD (P.) - La place de Marseille dans le commerce des vases attiques à figures rouges en Méditerranée occidentale ( $V^{e}-I V$ e siècles avant J.-C.). In : Bats et al. 1992, p. 179-87.

Sasson 1997 : SASSON (V.) - The Inscription of Achish, Governor of Ekron, and Philistine Dialect, Cult and Culture, UF, 29, p. 627-39.

Schäfer-Lichtenberger 2000 : SCHÄFER-LICHTENBERGER (C.) - The Goddess of Ekron and the Religious-Cultural Background of the Philistines, IEJ, 50, p. 82-91.

Shefton 1994 : SHEFTON (B. B.) - Massalia and Colonization in the NorthWestern Mediterranean. In : Tsetskhladze (G. R.) and De Angelis (F.) eds - The Archaeology of Greek Colonisation: Essays Dedicated to Sir John Boardman, Oxford, Oxford University School of Archaeology, 1994, p. 61-85.

Sheperd 1999 : SHEPERD (G.) - Intermarriage in the Western Greek Colonies : the Evidence from the Cemeteries. In : Tsetskhladze (G. R.) ed. Ancient Greeks West and East, Leiden-Boston-Cologne, Brill, 1999, p. 267-300.
Sheperd 2005 : SHEPERD (G.) - Dead Men tell no Tales: Ethnic Diversity in Sicilian Colonies and the Evidence of the Cemeteries, Oxford Journal of Archaeology, 24.2, p. 115-136.

Singer 1988 : SINGER (I.) - The Origin of the Sea Peoples and their Settlement on the Coast of Canaan. In : Heltzer (M.) and Lipinski (E.) eds - Society and Economy in the Eastern Mediterranean (c. 15001000 B.C.), Leuven, Peeters, 1988, p. 239-250 (Orientalia Lovaniensia Analecta 23).

Singer 1992 : SINGER (I.) - Towards the Image of Dagon the God of the Philistines, Syria 69, p. 431-450.

Singer 2012 : SINGER (I.) - The Philistines in the North And The Kingdom Of Taita. In : Galil et al. 2012, p. 451-472.

Stone 1995 : STONE (B.J.) - The Philistines and Acculturation: Culture Change and Ethnic Continuity in the Iron Age, BASOR, 298, 1995, p. 7-32.

Van Compernolle 1983 : VAN COMPERNOLLE (R.) - Femmes indigènes et colonisateurs. In : Modes de contacts et processus de transformation dans les sociétés anciennes. Actes du colloque de Cortone (1981), Pise-Rome, 1983, p. 1033-1049 (Coll. EFR 67).

Van Selms 1950 : VAN SELMS (A.) - The Best Man and the Bride from Sumer to St. John with a new interpretation on Judges Chapters 14 and 15, Journal of Near Eastern Studies, 9, 1950, p. 65-79.

Vanschoowinkel 2006 : VANSCHOOWINKEL (J.) - Greek Migrations to Aegean Anatolia in the Early Dark Age. In : Tsetskhladze (G. R.) ed. - Greek Colonisation: An Account of Greek Colonies and Other Settlements Overseas, Vol. 2, Leiden, Brill, 2006, p. 115-141.

Vaux 1971 : VAUX (R. de) - The Bible and the Ancient Near East, Garden City, NY, Doubleday, 1971.

Vaux 1978 : VAUX (R. de) - The Early History of Israel, London, Darton, Longman \& Todd, 1978.

Vercoutter 1956 : VERCOUTTER (J.) - L'Égypte et le monde égéen préhellénique, étude critique des sources égyptiennes du début de la XVIII ${ }^{e}$ dynastie à la fin de la XIX $X^{e}$ dynastie, Le Caire, IFAO, 1956.

Weinfeld 1988a : WEINFELD (M.) - The promise to the Patriarchs and its Realization: An Analysis of Foundation Stories. In : Heltzer (M.) and Lipinski (E.) eds - Society and Economy in the Eastern Mediterranean (c. 15001000 B.C.), Leuven, Peeters, 1988, p. 353-369 (Orientalia Lovaniensia Analecta 23).

Weinfeld 1988b : WEINFELD (M.) - The Pattern of the Israelite Settlement in Canaan. In : EMERTON (J. A) ed. - Congress volume : Jerusalem 1986, Leiden, Brill, 1988, p. 270-283 (Supplement to Vetus Testamentum 40).

Weinfeld 1993 : WEINFELD (M.) - The Promise of the Land: The Inheritance of the Land of Canaan by the Israelites, Berkeley, University of California Press, 1993.

White 1991 : WHITE (R.) - The Middle Ground: Indians, Empires, and Republics in the Great Lakes Region, 1650-1815. New York, Cambridge University Press, 1991 (Cambridge Studies in North American Indian History).

White 2006 : WHITE (R.) - Creative Misunderstandings and New Understandings, William and Mary Quarterly, 63(1), p. 9-14.

Yasur-Landau 2001 : YASUR-LANDAU (A.) - The Mother(s) of All Philistines? Aegean Enthroned Deities of the 12th-11th Century Philistia. In : Laffineur (R.) and Hägg (R.) eds - Potnia. Deities and Religion in the Aegean Bronze Age, Proceedings of the 8th International Aegean Conference Göteborg (12-15 April 2000), Liège, University of Liège Press, p. 329-343 (Aegaeum, 22).

Yasur-Landau 2010 : YASUR-LANDAU (A.) - The Philistines and Aegean migration at the end of the Bronze Age, Cambridge, CUP, 2010.

Zakovitch 1982 : ZAKOVITCH (Y.) - The life of Samson (Judges 13-16): A critical literary analysis [Hebrew]. Jerusalem, Magnes Press, 1982. 


\section{Questions d'identités et d'acculturations}





\title{
Le concept d'acculturation : son utilité et les limites dans son application à l'archéologie
}

\author{
Philippe Boissinot \\ EHESS, TRACES UMR 5608 du CNRS, Université de Toulouse II
}

\section{Résumé}

Le concept d'acculturation, souvent mal maîtrisé et chargé d'un certain nombre de défauts peut toutefois encore être opératoire pour traiter des changements culturels provoqués par la rencontre entre deux groupes humains, surtout lorsqu'il s'agit de penser des phénomènes de grande ampleur. Il sera toujours d'utilisation délicate pour la Protohistoire, car les déductions sont souvent risquées à partir des seuls vestiges matériels qui ne peuvent bénéficier de sources indépendantes venant éventuellement les valider, comme le feraient par exemple des textes suffisamment explicites. Ces difficultés se rencontrent chaque fois qu'il s'agit de penser identité et changement. Or pour parler d'acculturation, il faut parvenir à caractériser l'identité de chaque groupe. Mais le concept d'identité, qui a pris depuis les années 1970 une coloration identitaire, doit lui aussi être manié avec de grandes précautions, à la lumière des derniers travaux de l'ethnologie sur ce sujet. On se demandera donc, finalement, si les raffinements que l'anthropologie a apportés à la notion d'acculturation s'avèrent ici, dans son application à l'archéologie, plus utiles qu'un simple effet heuristique, ou qu'une mise en garde vis-à-vis de quelques débordements interprétatifs - ce qui est loin d'être négligeable, après tout.

Mots-clés : acculturation, identité, artefact, ethnologie, anthropologie

\begin{abstract}
The concept of acculturation, often badly mastered and loaded of a number of defects can still however be operating to handle cultural changes caused by the meeting between two human groups, especially when it is a question of thinking of large-scale phenomena. It will always be delicate to use in Protohistory, because the deductions are often risked from the only material vestiges which cannot benefit from independent sources coming possibly to validate them, as would make it for example enough explicit texts. These difficulties appear every time when it's matter with tinking identity and change. Yet to speak about acculturation, it is necessary to succeed in characterizing the identity of each group. But the concept of identity, which took since the 1970's a new color, must be very carefully handled too, in the light of the last works of the ethnology on this subject. We shall thus wonder, finally, if the refinements which the anthropology brought to the notion of acculturation turn out here, in its application in archaeology, more useful than a simple heuristic effect, or that a warning towards some interpretative overflowing - what is far from being unimportant, after all.
\end{abstract}

Keywords: acculturation, identity, artefact, ethnology, anthropology 
$\mathrm{N}$ ous avons été quelques-uns - parmi lesquels il faut compter Michel Bats (2006), à qui nous rendons un amical hommage ici - à nous intéresser au concept d'acculturation, qui fut un temps taxé d'ethnocentrisme, et de bien d'autres défauts encore, comme celui de se référer à la notion protéiforme et relativement indéterminée de culture, ou encore, à celle de trait culturel, pour lequel il serait possible de se livrer à une petite comptabilité (Baré 1991). Ces critiques sont justifiées en grande partie, nous y reviendrons. Mais, pour qui veut aborder la question du changement culturel quand deux groupes humains sont mis en présence, ce concept peut encore rendre quelques services, surtout lorsqu'il s'agit de penser des phénomènes de grande ampleur. Il devient d'une application délicate dès lors que lesdits groupes ne nous sont pas donnés d'avance, ce qui est par définition le cas en Préhistoire, et de certains domaines de la Protohistoire. Car, des seuls vestiges matériels aux groupes qui les ont produits, les déductions sont souvent risquées, et ne peuvent bénéficier dans ces cas de sources indépendantes venant éventuellement les valider, comme le feraient par exemple des textes suffisamment explicites. Ces difficultés se rencontrent chaque fois qu'il s'agit de penser identité et changement, ce qui peut se concevoir, soit de façon antagoniste, soit en admettant leur compatibilité. Ainsi, pour dire qu'un groupe est affecté par un changement culturel - ce que l'on admet de manière plus spécifique avec l'acculturation -, encore faut-il reconnaître qu'il s'agit du même groupe, en d'autres termes, que son identité est malgré tout conservée. Cette dialectique, tant déclinée par divers courants philosophiques, se trouve de nos jours fort embrouillée, depuis que le concept d'identité a pris depuis les années 1970 quelques colorations supplémentaires, que l'on qualifiera, à la suite de V. Descombes (2013), d'identitaires. On se demandera donc, finalement, si les raffinements que l'anthropologie a apportés à la notion d'acculturation s'avèrent ici, dans son application à l'archéologie, plus utiles qu'un simple effet heuristique, ou qu'une mise en garde vis-à-vis de quelques débordements interprétatifs - ce qui est loin d'être négligeable, après tout.

\section{Le concept anthropologique d'acculturation}

Sans remonter jusqu'à l'inventeur du terme, l'américain J. W. Powell (1834-1902), auteur d'une étude sur le langage amérindien en 1880, il peut être utile de commencer par la formulation proposée par un collectif d'anthropologues des années 1930, à l'issue du célèbre Memorandum on the study of acculturation : «L'acculturation comprend des phénomènes qui résultent de ce que des groupes d'individus ayant des cultures différentes se trouvent en permanence en contact direct, entraînant des changements importants dans les modèles culturels de l'un ou l'autre groupe ou les deux » (Redfield, Linton, Herskovits 1936).

On remarque tout de suite que le reproche d'asymétrie - c'est-à-dire d'ethnocentrisme - ne peut être formulé à la lecture de propos aussi explicites, et qu'il n'y a pas lieu d'opposer a priori une " culture source » à une « culture cible », même si, dans bien des cas, les échanges culturels peuvent se faire préférentiellement de l'une vers l'autre. Sans doute, dans l'exemple de Marseille grecque, devons-nous reconnaître que ceux-ci s'effectuaient majoritairement de cette ville vers son environnement, tout en remarquant, surtout au moment de la fondation, que la porosité fonctionnait également dans l'autre sens (Boissinot 2005). Nous le constatons à partir de quelques artefacts (céramiques, constructions), et nous le savons grâce à la littérature antique qui nous décrit cette métropole comme particulièrement « conservatrice ». Mais que se passe-t-il dans d'autres colonies massaliotes, a priori toutes aussi grecques ? Manifestement, des phénomènes assez différents, parfois d'une telle ampleur que l'on ne sait plus si la culture doit encore être qualifiée de grecque ou de gallogrecque. La diversité de ces situations suffit à condamner définitivement toute synthèse dans les termes d'une « hellénisation », comme cela avait été présenté autrefois.

Venons-en à l'un des problèmes les plus aigus de la définition, à savoir la reconnaissance « de groupes d'individus ayant des cultures différentes ». De quel point de vue parle-ton ici ? De celui des individus eux-mêmes qui se définissent (subjectivement) en s'opposant à des « autres », ou bien, en prenant de la distance par rapport aux deux groupes, en regardant « objectivement » ce qui constitue chacune des cultures quoi qu'elles en disent? En se posant une telle question, ne confondons-nous pas ethnie et culture, et, pour cette dernière, ne supposons-nous pas, comme le faisaient en partie les auteurs de la définition, qu'il faille la concevoir comme une juxtaposition de traits culturels ? La notion de « culture archéologique », et, dans une moindre mesure, celle de « faciès culturel » ne jouent-elles pas d'ailleurs sur cette ambiguïté, faisant agir les porteurs de ces cultures en leur attribuant un quasi ethnonyme ? Nous ne reprendrons pas ici les critiques que nous et d'autres avons déjà faites à ce propos, en dénonçant cette assimilation entre ethnie et « État-nation au rabais », pour reprendre la formule de l'africaniste J.-L. Amselle (Boissinot 1998, Demoule 1999, Olivier 2003). S'il est évident que l'emploi de ces termes est problématique en Ethnologie, à plus forte raison il le demeure en Archéologie, lorsque les porteurs sont absents et que leur «culture » ne consiste qu'en vestiges très incomplets. Au mieux nous est-il possible de restituer des ensembles abstraits - selon la théorie des 
ensembles (Boissinot 2011a) -, que l'on peut bien appeler « faciès » si l'on veut, et de mesurer leur « distance » (c'est-à-dire leur ressemblance) entre eux, à une date donnée ou au fil du temps. Les problèmes surgissent dès lors qu'on les assimile à des totalités concrètes, comme le sont des ethnies pas exemple. En outre, parmi les différences que nous ne manquerons pas de constater entre les faciès, quelles seront celles qui compteront pour la question de l'acculturation que nous voudrions révéler? Devront-elles appartenir à un secteur de la vie sociale particulier, plus à même de trahir des changements que l'on pourra dire « essentiels »?

Le troisième constat que l'on peut formuler à partir de la définition de 1936 concerne la contiguïté spatiale, ce qui interdit la possibilité pour ces " groupes d'individus » d'être des groupes sociaux finement entrelacés dans l'espace, et qui pourtant peuvent se distinguer par des cultures spécifiques. Le cas préférentiellement visé est précisément celui illustré par la rencontre culturelle faisant suite à fondation grecque de Marseille sur un littoral étranger, ligure/celte en l'occurrence. Les rivages ont ceci de particulier d'interrompre les relations de proche-en-proche qu'autorisent les terres et de mettre en contact, par la navigation dans des espaces culturellement « vides » (la mer), des populations qui n'avaient pas de liens réguliers. Le contraste est selon cette ligne maximal, comme il l'est en principe dans les îles lors d'un premier contact - ces constats relèvent du modèle, d'une simplification de la réalité historique, pour laquelle il faudrait envisager d'autres relations, tangentielles (cabotage) par exemple, et selon des fréquences variables. Nous avons donc, avec l'exemple massaliote, un cas d'application tout à fait convainquant du concept d'acculturation. Mais, très vite, aux portes de la ville, quelques problèmes se posent : ceux que nous définissons comme «non-grecs » présentent certes des traits culturels qui se différencient fortement de ceux reconnus comme grecs, mais également entre eux, et certainement dans une moindre mesure. Faut-il cependant tous les compter comme des individus d'une " même culture » et les opposer d'un bloc avec les Grecs, sachant que le concept d'acculturation concerne des rencontres effectives entre des individus, non pas celles abstraitement restituées entre cultures ? En outre, comme l'ont très bien montré les anthropologues à propos des contacts étudiés, il est nécessaire de prendre en compte un certain nombre de paramètres, comme la grandeur des groupes concernés, ceux-ci pouvant être entièrement sollicités ou en partie ; le contact peut être amical ou hostile, les intentions des uns, conquérantes ou non, et leur univers matériel plus ou moins complexe, etc. Il va sans dire que ces particularités ne s'apprécient pas facilement avec les seules ressources de l'archéologie.
Les auteurs du Memorandum, puis M. J. Herskovits (1952) seulement, à l'occasion d'autres approfondissements, évoquent une conception en termes de processus. Ce concept est d'une application plus complexe qu'il ne paraît, et son utilisation ne résout sans doute pas les problèmes qu'on lui soumet, les philosophes ayant travaillé sur les questions temporelles trouvant d'ailleurs la question fort disputée (Livet, Nef 2009). S'agit-il d'une suite d'événements présentant une certaine unité, que l'on pourrait éventuellement découper en étapes ? Mais, ne serait-ce pas alors un événement non instantané, de type duratif, dont la durée pourrait être découpée en périodes et en sous-événements, une page d'histoire en quelque sorte ? - comme l'est par exemple la Révolution française, pour reprendre un cas emblématique. Les anthropologues qui se sont risqués dans la présentation d'une séquence-type pour l'acculturation reconnaissent généralement trois ou quatre étapes, chacune avec des alternatives (opposition/juxtaposition, acceptation/refus, assimilation/résistance, etc.) et donc, des destinées relativement variées. Vu les combinatoires possibles, ce genre de synthèse procède plus d'un rapprochement de cas présentant entre eux un air de famille, que de la reconnaissance d'un véritable principe structurant à l'œuvre. Lorsque deux groupes se rencontrent, les choses se passent plutôt dans un certain ordre, certains événements ouvrant sur la possibilité d'autres, sans forcément qu'il y ait un lien de causalité entre eux. Ainsi, on n'imagine pas qu'une culture syncrétique puisse se former dès l'abord, reconnaissant qu'il faille du temps pour que cela se passe. Sans doute aussi, y a-t-il des secteurs de la culture qui sont plus rétifs aux changements que d'autres, le domaine symbolique s'avérant plus résistant que celui de la technologie par exemple - nous le constatons pour le Midi où la forme des habitations, d'abord à pièce unique, évolue très lentement, alors que des matériaux et des techniques de construction étrangères (murs porteurs) sont adoptés très tôt, dans les zones de contact préférentiellement. Mais cela ne veut pas dire qu'une dynamique est lancée, toujours agissante, la même tout au long de son déroulement. En constatant une assimilation en fin de parcours, on peut nourrir l'illusion rétrospective que « quelque chose »a été voulu dès le départ, qui a fini par aboutir malgré quelques vicissitudes. Si cela se passait véritablement ainsi, on pourrait effectivement parler de processus, comme on évoque le pourrissement d'un fruit ou l'érosion d'une pente. F. Nef et P. Livet définissent les processus comme des flux qui nous apparaissent par des transformations d'aspects qui, avant d'être actuelles ont été virtuelles, pour le redevenir ensuite, soit un double couplage entre le virtuel et l'actuel. On peut éclairer cette formulation en reprenant l'un de leurs exemples à propos d'un type 
de processus que l'on peut appeler «emprunt»-une activité sociale en fait - et qui comprend dans son unité les actions de prêt, emprunt, restitution : «Si j'emprunte sa hache à mon voisin, il est entendu que je la rende : l'emprunt est actuel, la restitution est virtuelle. Quand je rends la hache, l'emprunt devient virtuel et la restitution actuelle » (Livet, Nef 2009 : 229). On assiste ainsi à un déplacement du curseur de l'actuel au fil du temps, plus particulièrement sur des aspects relativement circonscrits de la vie sociale. On peut également dire qu'une puissance s'actualise dans le temps, sans véritable début et fin, si ce n'est ses bornes connaissables, à des moments d'interférence. L'événement est pour ces auteurs un complexe de processus, ces derniers constituant les entités les plus fondamentales, qui peuvent par exemple s'exprimer par un verbe impersonnel, comme lorsqu'on dit « il pleut »-comme si on saisissait ce qui passait par le milieu. Sans détailler plus avant ces conceptions, on voit bien, d'une part leur caractère en partie contre-intuitif, mais qui donne à penser je l'espère, et d'autre part, les difficultés qui se présentent dès lors que l'on tente de penser l'acculturation comme un processus.

Ces réticences mises à part, les distinctions proposées par les anthropologues peuvent fournir un cadre pour qui ne veut pas s'arrêter au simple constat du changement culturel, toujours en acte, mais selon des modalités variées ; un changement que l'on souhaiterait replacer dans des dynamiques sociales, même si celles-ci demeurent pour une large part hypothétiques. En distinguant une acculturation libre, d'une autre qui serait forcée - sans parler du type planifié proposé par Roger Bastide (1978), qui ne concerne que des époques contemporaines - nous sommes amenés à mieux comprendre la profondeur des changements culturels opérés dans certains domaines, qui s'accompagnent également d'inerties dans d'autres secteurs. À la première doivent être associées des tactiques, et aux secondes s'ajoutent des stratégies, qui ne se conçoivent pas sans un certain déploiement spatial, chaque fois spécifique (De Certeau 1980). Les premières implantations grecques sur le littoral du Midi ont donné lieu à des phénomènes d'acculturation libre avec les populations de l'arrièrepays, que l'on ne peut en aucun cas supposer avoir été dominées - même si l'on ne peut exclure un peu de manipulation -, par la simple considération de produits grecs (céramiques) diffusés dans cette région. Avec ce qu'il convient d'appeler romanisation, le contact entre les groupes ne s'effectue plus selon une simple ligne littorale, mais dans les mailles d'un réseau qui se déploie dans les deux dimensions de l'espace. Il se fait au bénéfice de certains groupes (les Romains et certaines élites gauloises) et correspond à ce que l'on appelle une acculturation forcée, même si certains aspects de la vie des dominés ne connaissent que très peu de changements. En introduisant cette simple distinction libre/forcé, nous comprenons mieux pourquoi le vieux concept d'hellénisation doit être manié avec les plus grandes précautions, et nous disposons de quelques éléments pertinents pour mieux appréhender le syncrétisme de la religion gallo-romaine.

Avec le «principe de coupure » introduit par R. Bastide (1955) - ou de "balkanisation des cerveaux ", pour reprendre, en la modifiant, l'expression de P. Veyne (1983) -, nous pouvons mieux comprendre la personnalité des individus en situation d'acculturation qui peuvent participer de deux cultures à la fois sans être dans la contradiction, ni se conduire de manière incohérente. Ainsi, par exemple, dans une Afrique presque révolue, plusieurs médecines, occidentales et traditionnelles, peuvent-elles coexister sans que la logique de l'une ne vienne balayer celle de l'autre, la plupart des malades s'accommodant des deux, mais suivant les situations. Pour les contextes protohistoriques, nous aurons peu de chances d'approfondir de telles nuances, cependant essentielles pour mieux saisir les périodes de transition et une grande partie de la dynamique culturelle. Nous pourrons éventuellement les entrevoir en étudiant le contenu de quelques tombes, ou encore l'iconographie de certaines sculptures, quand des mobiliers d'origines diverses peuvent se trouver rassemblés...

\section{Les identités}

Nous avons déjà traité cette question à de multiples reprises (Boissinot 1998 ; 2005 ; 2011a\&b ; 2013), ce qui nous dispensera d'une étude détaillée de ce problème maintenant renouvelé par de nombreuses études philosophiques et sociologiques (en dernier lieu : Descombes 2013). Pour ne pas trop se perdre avec ce concept complexe - sans parler de mot-valise, si l'on s'en tient à son utilisation la plus fréquente -, il est nécessaire de distinguer deux aspects.

Le premier relève de l'identique et appartient aux domaines de la logique et de l'ontologie, développant une perspective objective prise sur l'identité dont nous avons besoin dans nos activités les plus quotidiennes, comme dans nos enquêtes les plus sophistiquées, pour connaître et reconnaître les choses ou les individus par exemple. Dès lors que l'on admet qu'identité et changement sont compatibles ou que la ressemblance n'est ni une condition nécessaire, ni suffisante de l'identité (Ferret 1996), on sort de quelques apories ou paradoxes depuis longtemps dénoncés. Ainsi, pour être l'adulte que je suis aujourd'hui, ai-je dû d'abord être un enfant, auquel je ne ressemble plus, pour devenir un jour 
un cadavre qui n'obéira plus aux mêmes principes de développement interne, devenant entièrement soumis à des modifications externes - on parlera alors de rupture de l'identité pour l'organisme que j'ai été, tout en reconnaissant une dépendance ontologique entre lui et le cadavre. On voit très bien sur cet exemple comment notre façon de découper le monde peut être structurée par des interrogations sur l'identité, qui ne concerne pas seulement quelques philosophes pointilleux, mais surtout notre façon de concevoir notre environnement et d'interagir avec lui. Chaque fois que nous sommes amenés à penser à la " même entité », pour la retrouver ou lui donner des limites, savoir s'il y en a deux ou une seule, nous avons en effet besoin de cette conception de l'identique.

Le second aspect peut être appelé identitaire et appartient à la sphère psycho-sociale depuis que l'on s'est complu à traduire des questions d'amour propre selon les termes de l'identité. En passant des questions «qui est-ce ? » ou « qui sont-ils? » vers « qui suis-je ? » ou «qui sommes-nous? », nous évoluons d'un point de vue objectif vers une perspective subjective. Ces interrogations peuvent se constater en acte, mais nécessitent le plus souvent le passage par le médium linguistique pour pouvoir être appréhendées - on pourrait dire qu'elles sont performatives. Avec les seules ressources de l'archéologie, il sera donc bien difficile d'en être averti.

Dans les deux cas, l'identité n'est pas une étiquette posée sur une entité, comme notre état-civil pourrait nous le laisser croire. C'est une relation d'équivalence (réflexive, symétrique, transitive) qui permet de comparer les entités les unes aux autres. On possède des qualités ou des propriétés, mais pas une identité. On développe cependant des tactiques ou des stratégies pour donner un ordre à ces qualités ou propriétés, en les mettant en avant dans certaines situations. En faisant cela, nous signalons ou, plus fortement, nous affirmons notre identité. À cette occasion, nous disons et/ou agissons de manière à bien faire apparaître la sorte d'individu que nous sommes et que nous avons choisi d'être en priorité : «j'ai fait cela en tant qu'homme », " j'ai agi ainsi parce que je suis un urbain », « en tant qu'Européen, je pense que », etc., avec tout un aspect causal revendiqué. Nous nous comportons ainsi régulièrement, et nous pouvons y recourir de manière souple ou dure, pour reprendre l'utile distinction de J.-L. Amselle (Amselle, M'Bokolo 1985). La seconde manière se rencontre préférentiellement lorsque des individus ou des groupes humains se voient assigner une appartenance de l'extérieur, qui entre en conflit avec celle qu'ils aimeraient afficher, au sein de dispositifs étatiques par exemple; mais pas uniquement. La manière souple en revanche, sans être forcément de la duplicité, ménage plus de jeu entre ces diverses affiliations. Parce qu'elle est plus difficile à saisir, et parce qu'elle est étrangère à la pensée d'un agent représentatif de l'État - qui jauge, comme chacun, selon ses propres catégories -, cette façon a été largement ignorée des ethnologues dans un premier temps, lesquels ont eu tendance, comme nous l'avons déjà indiqué, à concevoir toute entité collective comme un corpus stable de pratiques, parmi lesquelles figuraient l'usage d'une langue spécifique et l'adhésion à un territoire aux frontières marquées. On le sait, les archéologues ont repris ces conceptions sans critique et l'appliquent encore de nos jours. Mais comment pourraient-ils s'y prendre pour reconstituer ces entités sans voir les actes et sans entendre les mots ? Comme M. Bats l'a montré à propos du gallo-grec (Bats 2004), avec les ressources supplémentaires de l'épigraphie, il devient possible d'aller plus loin, et de suspecter par exemple l'expression d'une revendication identitaire gauloise. En revanche, nous ne le suivrons pas lorsqu'il prétend " préciser [...] une identité culturelle » en étudiant « les pratiques culinaires et les manières de table » des sites qu'il a étudiés (Bats $2006: 33$ ) : d'abord, parce que l'identité n'est pas une étiquette, nous l'avons dit ; ensuite, parce que le constat d'une différence, notamment dans les répertoires céramiques, n'est en rien la garantie d'une volonté de se différencier, et donc d'affirmer autre chose ; enfin, parce nous ne pouvons qu'imaginer des «pratiques » et des «manières » qui sont à reconstruire à partir de vestiges archéologiques. Quant au domaine funéraire, avec ses ensembles clos que l'on aimerait décrypter comme des messages, il est loin d'être certain, sauf peut-être pour les funérailles de quelque être exceptionnel, que la volonté de dire qui le mort a été - quelque chose comme relevant de l'identitaire - l'emporte sur toute autre considération, comme par exemple la nécessité de se protéger des esprits malveillants, ou encore, de tenir compte des circonstances précises de la mort ou de l'état des survivants (Boissinot 2008).

La notion d'identité collective traduit le fait, par exemple, que l'on ne peut être grec à soi tout seul. On l'est à plusieurs et en interagissant, parfois en délégant cette appartenance à un sous-groupe, à certaines occasions, si bien que l'on pourra dire que les Grecs ont fait la guerre aux Perses sans que tous les Grecs y aient effectivement participé. Ce n'est pas une propriété que l'on porterait en soi, comme le fait d'être mortel pour un humain, laquelle est distributive et ne nécessite aucune décision de la part du porteur. Pour décrire le cours de l'histoire nous avons besoin de recourir à de telles identités collectives car, contrairement à ce que pensent les partisans de l'individualisme méthodologique, la connaissance exacte du comportement de chacun des individus n'ajouterait rien de plus, si ce n'est de la confusion, à la compréhension des choses qui se sont passées. Les sociétés et les 
cultures, même si elles ont une « traduction » matérielle, n'existent que parce que des hommes pensent qu'elles existent, et, en général, cela participe d'un certain amour propre, et surtout de représentations. En l'absence de telles expressions, il sera bien difficile de décrire le contact entre cultures requis par le concept anthropologique d'acculturation. Dans le cadre de la Protohistoire du Midi, nous pouvons dire dans certaines situations ce que « grec » a pu vouloir dire ; mais, pour le terme « non grec », qui n'est rien d'autre qu'une construction historiographique, coïncidant éventuellement avec le terme « celte » pour cette partie occidentale de l'Europe, le recours à une quelconque identité collective s'avère particulièrement périlleux.

En résumé, peut-on concevoir l'acculturation sans se référer à un moment ou à un autre à ces questions d'identité ? Sous l'aspect identique, nous avons besoin de savoir quels sont les critères qui nous permettent de dire que deux entités appartiennent à la même culture. On peut le faire abstraitement en recourant à la notion de faciès, à moins qu'on ne le sache par d'autres sources, textuelles par exemple. Il sera toutefois nécessaire de connaître ce qu'en pens(ai)ent les « porteurs » euxmêmes, ce qui nous mènera insensiblement sur le terrain de l'identitaire, pour lequel l'archéologie seule s'avère quelque peu démunie.

\section{Des objets réinterprétés}

L'archéologie en revanche livre des artefacts à foison, et peut-être pouvons-nous saisir les phénomènes d'acculturation à travers eux ? En outre, ces objets sont souvent mis au jour dans des assemblages, ce qui autorise des mises en relation fonctionnelles et des comptages, qui peuvent être également appréhendés dans ce cadre - la tentation fut grande, un temps, de mesurer l'acculturation à partir du pourcentage de produits exogènes ayant atterri sur un site ! Mais il faut commencer par s'entendre sur nos engagements ontologiques vis-à-vis des artefacts, avant de se demander ce qu'il est possible de connaître à partir d'eux.

À l'inverse des substances naturelles définies à partir de leur composition, et des organismes, grâce à leur microstructure $(\mathrm{ADN})$, il ne sert à rien de mettre un artefact en poudre ou en tranches, et de l'observer au microscope par exemple, pour déterminer ce qu'il est réellement, c'est-à-dire de répondre à la question « qu'est-ce que c'est? ». L'artefact est ce qu'il est par la médiation des hommes qui lui attribuent une fonction, et généralement un nom, voilà pourquoi on dit que sa nature est nominale. La fonction s'élucide lorsqu'on est capable de dire pourquoi cet objet-là a été fabriqué et utilisé à cette occasion précise, lui et pas un autre. La nature des artefacts est en effet déterminée par l'usage que nous en faisons, et doit s'envisager en couplant l'intentionnalité des fabricants et celle des utilisateurs. Ces objets doivent être crédités d'exister pour exister véritablement, sinon ils ne sont que des bouts de matières, généralement assemblés, que l'on peut traiter comme des substances naturelles (Lenclud 2007). Ils n'existent donc en tant qu'artefacts que relativement à des observateurs et des utilisateurs. Ces derniers venant à disparaître, comme cela est le cas en archéologie, il ne nous restera que la forme - qui comprend la constitution matérielle -, quelques indices concernant le fonctionnement - observable grâce à des stigmates et envisageable dans un champ des possibles -, mais très peu de certitudes concernant la fonction. Sans doute, pour en savoir plus long, sera-t-on tenté de tenir compte du contexte de la découverte, de la relation que cet artefact entretient avec d'autres, de voir si ce genre de lien se répète ailleurs, et surtout, de se livrer à des rapprochements avec des objets semblables, mais mieux connus. À partir de ces considérations, on pourra se livrer à quelques hypothèses sur la fonction de l'objet dans la culture en question, en considérant éventuellement celle-ci comme un « système » où chaque chose a sa place.

Grâce à des méthodes maintenant bien rodées, l'archéologie est désormais capable de retrouver les lieux de production de nombreux artefacts. À défaut, elle peut suspecter que l'objet qui a été trouvé ici ne peut y avoir été fabriqué, soit que sa matière s'y oppose, soit que sa forme n'y trouve pas de parallèles, alors que ceux-ci existent ailleurs, soit encore, que le lieu de sa découverte ne coïncide pas avec le centre de son aire de diffusion. Quelle que soit la raison de son acheminement, l'artefact qui n'a pas été conçu sur place, ni commandé, se voit utilisé différemment, avec un fonctionnement qui peut éventuellement être proche, mais, très certainement, avec une fonction autre. Cette altération de la fonction est un phénomène relativement fréquent et sans doute une des clés de l'innovation ; il n'y a donc pas lieu de s'en étonner. On peut cependant trouver que la rationalité se trouve ici quelque peu malmenée puisque l'objet qui avait été conçu pour un but précis et lié à la satisfaction de besoins dans un univers bien connu, avec un usage dont les conséquences avaient été tout aussi justement envisagées - selon une des définitions courantes de la rationalité -, se trouve désormais plongé dans un autre monde. On doit dès lors parler de réinterprétation, même si l'on ne peut a priori exclure une réception passive. Celle-ci ne l'est manifestement plus lorsque l'artefact, que l'on peut toutefois toujours reconnaître par sa structure globale, se voit transformé dans sa forme et son fonctionnement - en laissant de côté la fonction, 
toujours problématique avec l'archéologie. M. Bats cite l'exemple très éclairant de certaines productions du bas Rhône au Ve s. av. n.-è. - qui avaient été nommées « pseudo-ioniennes » à une époque où toutes les nuances du concept d'acculturation n'étaient pas encore maîtrisées -, qu'il présente comme des "créations métisses », dans la mesure où elles mêlent des éléments reconnus comme grecs, et d'autres trouvant des références localement, qualifiées d' "indigènes »- un point de vue qui est le nôtre (etic), mais qui n'était certainement pas celui des protohistoriques (emic), qui devaient concevoir ces choses-là d'un bloc, si l'on reprend ici les critiques d'H. Corbin à propos du syncrétisme. Un cratère à pâte claire provenant d'un site gardois, décoré à la peinture d'une ligne ondulée et de cavaliers stylisés (Bats 2007 : fig. 90, 1), illustre parfaitement ce moment de création et de réinterprétation, un exemplaire pour lequel il faudrait beaucoup de mauvaise foi et d' " ethnocentrisme » pour le considérer comme une pâle copie d'un modèle grec. Et, à celui-là, de nombreux vases peuvent être associés, pour démontrer que ce phénomène n'est pas exceptionnel, même s'il demeure pour l'instant cantonné à une toute petite partie de l'activité productive - qu'en est-il de l'habitat et des activités rituelles par exemple dans le même secteur? On peut suivre l'auteur lorsqu'il reconnaît là l'indice d'un phénomène d'acculturation, avec une rencontre effective, sans doute régulière, et l'adoption de certaines pratiques liées à la consommation du vin - le cratère sert au mélange de l'eau et du vin dans le cadre du banquet grec - dans la logique propre de ces sociétés ; mais, plus difficilement, lorsqu'il suppose " une création en forme de revendication d'identité » (Ibid. : 198). Ce n'est pas parce qu'elles sont en outre absentes à Marseille même - d'où les cratères grecs ont été (indirectement) diffusés -, qu'il faille voir là un antagonisme, ou encore une volonté de se démarquer. Exister, en produisant sans reproduire (servilement) le modèle, n'est pas forcément la marque d'une revendication, la plupart de nos activités s'inscrivant dans des routines et des bricolages. À l'inverse, la Chine qui, de nos jours, imite beaucoup dans le domaine de l'artefact, garde son quant-à-soi, et personne n'en doute.

En conclusion, nous sommes convaincus, tout autant que M. Bats - dont les travaux à ce sujet sont particulièrement explicites -, qu'une bonne connaissance des concepts anthropologiques est une exigence à laquelle aucun archéologue ne devrait se dérober, ce qui est loin d'être le cas général dans le cadre de nos formations universitaires continentales. Il nous paraît utile d'en maîtriser également toutes les nuances, et ne pas se contenter de définitions « brutes », pour mieux être avertis que leur application à l'archéologie... posera toujours des problèmes, si bien que l'on peut être certain que cette " discipline » n'apportera rien de plus aux conceptualisations passées. En d'autres termes, ne comptons pas sur l'archéologie (seule) pour mieux comprendre ce qu'est l'acculturation. Au mieux, essayons de ne pas poser de mauvaises questions avec des outils inadaptés, ce qui constituera un gain cognitif non négligeable, comme l'est, par exemple, le détachement avec lequel il faut désormais considérer le terme d'imitation généralement employé dans ce genre de débats. Ce qui ne veut pas dire que rien n'est à connaître dans ce registre culturel. Au contraire, en affirmant une position présentiste, plutôt que d'être la voix autorisée disant ce qui s'est passé, sommes-nous invités à un dialogue fructueux dans le cadre de débats actuels sur les rencontres culturelles, où tout un champ de possibles pourra être décliné et, en retour, à porter un regard nouveau sur les objets du passé. Avec M. Bats, nous sommes assurés de pouvoir encore en discuter avec profit...

\section{Bibliographie}

Amselle, M'Bokolo 1985 : AMSELLE (J.-L.) ET M'BOKOLO (E.) - Au cœur de l'ethnie. Ethnie, tribalisme et État en Afrique, Paris, La Découverte, 1985 .

Baré 1991 : BARÉ (J.-F.) - Acculturation. In : Bonte (P.) et Izard (M.) (dir.), Dictionnaire de l'Ethnologie et de l'Anthropologie, Paris, PUF, 1991, p. 1-3.

Bastide 1955 : BASTIDE (R.) - Le principe de coupure et le comportement afro-brésilien, $X X X L$ Congresso Internacional de Americanistas, Sao Paulo, Anhembi, 1955, 1, p. 493-503.

Bastide 1978 : BASTIDE (R.) - Acculturation, Encyclopaedia Universalis, 1, 1978, p. 103.

Bats 2004 : M. BATS, GREC ET GALLO-GREC : les graffites sur céramique aux sources de l'écriture en Gaule méridionale ( $\mathrm{II}^{\mathrm{e}} \mathrm{I}^{\mathrm{Ir}} \mathrm{s}$. av. J.-C.), Gallia, 2004, p. 7-20

Bats 2006 : BATS (M.) - L'acculturation et autres modèles de contacts en archéologie protohistorique européenne. In : Szabo (M.) (dir.), Celtes et Gaulois, l'Archéologie face à l'Histoire, 3 : les Civilisés et les Barbares (du $V^{e}$ au II siècle avant J.-C.), Glux-en-Glenne, Bibracte 12/3, 2006, p. 29-41.

Bats 2007 : BATS (M.) - Entre Grecs et Celtes en Gaule méridionale : de la culture matérielle à l'identité ethnique, Pallas, 73, 2007, p. 191-198.

Boissinot 1998 : BOISSINOT (P.) - Que faire de l'identité avec les seules méthodes de l'archéologie ? In : D'Anna (A.) \& Binder (D.) (éd.), Productions et identités culturelles, Antibes, APDCA, 1998, p. 17-25.

Boissinot 2005 : BOISSINOT (P.) - Sur la plage emmêlés : Celtes, Ligures, Grecs et Ibères dans la confrontation des textes et de 1'archéologie. In : Boissinot (P.) \& Rouillard (P.) (dir.), Lire les territoires des sociétés anciennes, Madrid, Mélanges de la Casa de Velazquez, Nouvelle série, 35, 2, 2005, p. 13-43.

Boissinot 2008 : BOISSINOT (P.) - Genres et identités au risque de l'archéologie. Le cas de la Protohistoire, Pallas, 76, 2008, p. 137-149.

Boissinot 2011a : BOISSINOT (P.) - L'ethnicité en mode régressif, de l'âge du Fer à l'âge du Bronze. Quelques problèmes épistémologiques. In : Garcia (D.) (dir.), L’âge du Bronze en Méditerranée. Recherches récentes, Paris, Errance, 2011, p. 171-192.

Boissinot 2011b : BOISSINOT (P.) - Comment sommes-nous déficients ? Une manière d'envisager la spécificité de l'archéologie. In : Boissinot (P.) (dir.), L'archéologie comme discipline ?, Le Seuil, 2011, p. 265-308. 
Boissinot 2013 : BOISSINOT (P.) - De quelle identité parlons-nous entre historiens et archéologues ? In : Plana (R.) et Ménard (H.) dir., Contacts de cultures, constructions identitaires et stéréotypes dans l'espace méditerranéen antique, Montpellier, PUM/MSH Montpellier, 2013, p. 15-21.

De Certeau 1980 : DE CERTEAU (M.) - L'Invention du quotidien, 1. : Arts de faire, Paris, UGE, 1980.

Demoule 1999 : DEMOULE (J.-P.) - Ethnicity, Culture, Identity : French Archaeologists and Historians, Antiquity, 73, 1999, p. 190-198.

Descombes 2013 : DESCOMBES (V.) - Les embarras de l'identité, Paris, Gallimard, 2013.

Ferret 1996 : FERRET (S.) - Le bateau de Thésée. Le problème de l'identité à travers le temps, Paris, Minuit, 1996.

Herskovits 1952 : HERSKOVITS (M. J.) - Les bases de l'Anthropologie culturelle, Paris, Payot, 1952.
Lenclud 2007 : LENCLUD (G.) - Être un artefact. In : Debary (O.), Turgeon (L.) (éds.), Objets \& Mémoires, Paris, Éditions de la Maison des Sciences de l'Homme/Presses de l'Université Laval, 2007, p. 59-90.

Livet, Nef 2009 : LIVET (P.), NEF (F.) - Les êtres sociaux : processus et virtualité, Paris, Hermann, 2009.

Olivier 2003 : OLIVIER (L.) - « Peuples », « cultures » et manifestations archéologiques de l'âge du Fer : G. Kossinna, G. Childe et nous. In : Ploin (S.) et Jud (P.) (éd.), Habitats, mobiliers et groupes régionaux de l'âge du Fer, 2003, p. 231-239 (supplément 20 à la RAE).

Redfield, Linton, Herskovits 1936 : REDFIELD (R.), LINTON (R.), HERSKOVITS (M. J.) - Memorandum on the study of acculturation, American Anthropologist, 38, 1936, p. 149-152.

Veyne 1983 : VEYNE (P.) - Les Grecs ont-ils cru à leurs mythes ?, Paris, Le Seuil, 1983. 


\title{
Rencontres culinaires : la culture matérielle incorporée
}

Michael Dietler

Université de Chicago

\section{Résumé}

Dans l'analyse du phénomène colonial, la nourriture est un domaine de la vie sociale qu'il est impératif de cibler car les rapports entre cuisine et colonialisme sont nombreux et dans ce domaine l'utilité d'une approche anthropologique sur les rencontres culinaires et coloniales est évidente. Ce rapport entre cuisine et colonialisme découle du fait que des liens intimes existent entre pratiques culinaires et incorporation de l'identité, et entre commensalité et politique. L'alimentation n'est jamais simplement un acte de ravitaillement et la nourriture, de sa préparation à sa consommation, a été investie par nombre de symbolismes et de significations sociétales. La complexité des pratiques culinaires permet l'expérimentation et l'assimilation d'un élément étranger dans un ensemble de pratiques routinières sans changer la perception de continuité. Une fois présentées les bases théoriques de ces liens entre cuisine et colonialisme à partir de l'ethnologie comparative, pour donner un cadre au problème et aux données, sont proposés quelques exemples de l'analyse de la rencontre coloniale en France Méditerranéenne entre Étrusques, Grecs, Romains et indigènes.

Mots-clés : colonialisme, cuisine, alimentation, contacts, acculturation

\begin{abstract}
In the analysis of colonialism, the food is a domain of the social life which must be pointed because there are several links between cooking and colonialism and on this subject the utility of an anthropological approach on the culinary and colonial meetings is obvious. These relations between cooking and colonialism ensue from the fact that intimate links exist between culinary practices and incorporation of the identity, and between commensality and politics. The food is never a simple act of provisioning and the food, its preparation as well as its consumption, was invested by number of symbolism and societal meanings. The complexity of the culinary practices allows the experiment and the assimilation of a foreign element in a set of usual practices without changing the perception of continuity. Once presented the theoretical bases of these links between cooking and colonialism from the comparative ethnology, to give a frame to the problem and to the data, are proposed some examples of the analysis of the colonial meeting in Mediterranean France between Etruscan, Greeks, Romans and natives.
\end{abstract}

Keywords: colonialism, cooking, food, contacts, acculturation 
A voir l'opportunité d'offrir un petit hommage à Michel Bats me donne beaucoup de plaisir, et $\mathrm{j}$ 'ai choisi le thème de la cuisine pour ma contribution parce qu'il s'agit du sujet qui a suscité ma première rencontre avec les travaux de Michel. Si l'on me permet un petit moment de nostalgie, c'était il y a presque trente ans, en 1983, si je me souviens bien, que le jeune Michel Bats a rencontré le jeune Michael Dietler dans la bibliothèque du Centre Camille Jullian. Michel m'a demandé de lire quelques chapitres d'un manuscrit qu'il était en train de rédiger et de donner un avis critique à la lumière de mes expériences ethnologiques au Kenya. Il s'agissait en fait de son célèbre ouvrage sur Vaisselle et alimentation à Olbia (Bats 1988), une œuvre qui, à mon avis, reste trente ans plus tard un des meilleurs exemples de l'analyse du rapport entre la céramique et la cuisine. Je ne sais pas si mes quelques petits conseils l'avaient aidé, mais il est sûr et certain que ses travaux dans ce domaine, et bien d'autres d'ailleurs, m'ont aidé dans mes propres recherches, et je lui en suis très reconnaissant.

Alors, ce que je voudrais faire dans ce petit article est d'aborder le sujet des rapports entre cuisine et colonialisme. Comme archéologue anthropologue, je me suis surtout appliqué ici à établir d'abord des fondations théoriques basées sur l'ethnologie comparative pour donner un cadre au problème et aux données, puis j'utiliserai quelques exemples de l'analyse de la rencontre coloniale en France Méditerranéenne entre Étrusques, Grecs, Romains et indigènes, afin de montrer l'utilité de cette approche.

Dans l'analyse du phénomène du colonialisme, il me semble que la nourriture est un domaine de la vie sociale qu'il est impératif de cibler. Après tout, les cuisines du monde actuel sont dans une large mesure le produit d'une longue histoire de rencontres coloniales. D'ailleurs, la nourriture a beaucoup servi comme moyen matériel pour la mise en œuvre et le déroulement du colonialisme. Autrement dit, la nourriture n'est pas simplement un indice commode des transformations culturelles dans les situations coloniales, mais elle est également un agent de transformation. Et les transformations produites ne sont pas limitées à la dimension sémiotique de la consommation : toute l'économie politique des sociétés en contact est impliquée, avec la création d'un réseau d'enchevêtrements profonds (Dietler 2007, 2010).

Le rapport entre cuisine et colonialisme découle du fait que les liens intimes entre pratiques culinaires et incorporation de l'identité, et entre commensalité et politique, ont fait de la nourriture une arène importante pour l'élaboration des luttes coloniales autour de l'identité et des stratégies de contrôle et de résistance.
Bref, cibler la nourriture est une stratégie très prometteuse pour les archéologues cherchant à comprendre les situations coloniales et leurs effets de transformation. Or, malgré ces promesses, le rapport entre cuisine et colonialisme est loin d'être simple. Aller au-delà des généralités banales vers des aperçus interprétatifs utiles demande à la fois une inventivité méthodologique et une attention rigoureuse à la place de la nourriture dans un cadre théorique plus large.

On peut commencer ce travail avec l'observation suivante : alors que la consommation de la nourriture est indispensable pour maintenir la vie humaine, cette consommation n'est jamais simplement un acte de ravitaillement. Les gens n'ingèrent pas des calories ou des protéines : ils mangent des aliments - une forme de la culture matérielle sujette à des possibilités presque illimitées par des variations en termes d'ingrédients, de techniques de préparation, de combinaisons d'associations et d'exclusions, de modes de service et de consommation, d'évaluations esthétiques, et ainsi de suite. En plus, la nourriture est la forme principale de la «culture matérielle incorporée», c'est-à-dire une forme de culture matérielle faite exprès pour la destruction par le processus transformateur de l'ingestion dans le corps (Dietler 2001, 2009). Donc, la nourriture a un rapport uniquement intime avec le soi, et avec l'inculcation et la symbolisation de l'identité. Le sociologue Pasi Falk (1994) a offert une observation intéressante sur la signification ontogénique de la nourriture qui mérite être prise en considération. Il a constaté que la première perception de la différence par un bébé - c'està-dire de la frontière entre sujet et objet qui délimite le soi - est apprise par le moyen de la bouche sur le sein de la mère bien avant que la vue ne soit formée. Donc, selon Falk, la bouche sert à la fois comme le modèle pour tous les autres perceptions sensorielles et comme la porte qui gère l'incorporation de matière étrangère dans le corps au moyen du sens du goût qui est codé par la culture. D'ailleurs, étant donné que manger est un acte social qu'il faut répéter quotidiennement pour la survie biologique, il prend une place saillante parmi les pratiques routinières qui, comme Pierre Bourdieu l'a largement exploré (Bourdieu 1979, 1980), servent à inculquer l'habitus - c'est-à-dire la série de dispositions incorporées qui structure l'action et l'expérience de l'identité et de la différence. Donc, tout cela sert à souligner pourquoi la nourriture est si étroitement liée à l'identité et pourquoi elle est un medium symbolique très souple et très chargé. Or, cela devrait servir aussi à souligner que la nourriture n'est pas simplement un système de signes, et que manger n'est pas simplement la consommation de signes. Manger est aussi construire le soi dans un sens au delà du métaphorique. Donc, toute analyse ne doit pas cibler uniquement la dimension symbolique de la consommation : 
il faut que la consommation soit insérée dans les chaînes ou réseaux de commodités qui connectent la production à la consommation - surtout dans les cas coloniaux où on cherche en priorité à comprendre les rapports du pouvoir.

À cette étape de la discussion, il faut introduire deux questions qui vont guider la suite. D'abord, étant donné les liens très proches entre aliments et identité, pourquoi est-ce que les gens changent quelques fois leurs habitudes de cuisine dans les situations coloniales ? Et surtout, pourquoi adoptent-ils des nourritures et des pratiques exotiques ? Ensuite, quand ils adoptent ces exotismes, quelles sont les implications pour l'analyse du colonialisme?

On dit souvent que la cuisine est un des éléments de la culture le plus conservateur et le plus constant. Comme tous les truismes, cela n'est pas tout à fait vrai - mais pas tout à fait faux non plus. Les exemples de l'adoption enthousiasmée des mets étrangers sont abondants, et la plupart des cuisines du monde incluent beaucoup d'ingrédients non indigènes. Souvent même ces éléments exotiques sont « indigénisés » jusqu'au point où ils deviennent des marqueurs de cuisine ethnique locale. La tomate dans la cuisine italienne, la polenta dans la cuisine de l'Italie du Nord, le thé en Angleterre, la pomme de terre en Irlande, la patate douce en Nouvelle Guinée, le thé à la menthe en Afrique du Nord, le riz en Indonésie, la banane en Amérique Centrale, les cacahuètes en Afrique de l'ouest, et le maïs et le manioc parmi les Luo de Kenya sont tous des exemples d'éléments exotiques complètement « indigénisés ». Et, qui plus est, ils sont presque tous le résultat de rencontres coloniales - et des exemples qui montrent que ces emprunts vont dans les deux sens en situation de contacts. Mais, si la cuisine est si stable et liée si étroitement à l'identité, comment est-ce que cela est possible?

En partie, cela peut peut-être s'expliquer par le fait que ce qu'on appelle les « cuisines ethniques » concerne beaucoup plus que les ingrédients. Certes, dans certains cas, un élément individuel en nourriture peut devenir un symbole d'identité de groupe : soit une préférence, soit une prohibition. On pense au haggis des Écossais ou à la paella des Valenciens - ou à l'interdiction de manger le porc chez les musulmans et les juifs, ou le cheval, le chien et les insectes chez les Américains. Mais un élément seul ne fait pas une cuisine ethnique. Les cuisines ethniques sont composées de permutations distinctives de mets primaires et secondaires, d'épices, de techniques de préparation, de croyances concernant les types d'aliments qui sont appropriés pour les repas quotidiens et festifs, de contextes et de temporalités de consommation, etc. C'est la structure de tout un cycle de combinaisons de menus et de rythmes qui compte - ou ce qu'on appelle les « formats de repas » (Douglas 1984).
C'est précisément cette complexité qui permet l'expérimentation et l'assimilation d'un élément étranger dans un ensemble de pratiques routinières sans changer la perception de continuité ou faisant menace à l'identité. En fait, cela ne doit pas être surprenant, sauf si l'on a une conception de la culture irréaliste et trop figée. Or il faut voir la culture non pas comme une série de traits hérités du passé mais plutôt comme un projet créatif d'improvisations structurées, guidé par la perception de catégories, de cadres de raisonnement analogique, de dispositions esthétiques, et de valeurs - qui donnent structure aux formes de raisonnement, permettent de résoudre les problèmes, et de répondre aux opportunités. Parmi ces problèmes et ces opportunités se trouve le défi omniprésent de faire face aux peuples et aux objets exogènes par un processus sélectif de domestication et de refus. Cette appropriation sélective opère selon une logique culturelle mais, en même temps, elle a des effets transformatifs sur la reproduction de la culture. Mais, ce qui est plus important, il faut le reconnaître, est que ce processus opère par l'intermédiaire d'actions souvent contradictoires d'individus et de petits groupes aux intérêts et moyens sociaux bien différents. Dans le domaine de la nourriture, la détermination d'éléments ou de pratiques, soit éventuellement acceptés et transformés en « tradition », soit rejetés, est le résultat de ces luttes sur le terrain du goût engagées par les groupes avec des intérêts sociaux différents.

Alors, cette discussion amène trois questions de base. D'abord, pourquoi et comment est-ce que quelques éléments de cuisine sont appropriés dans les contextes coloniaux, alors que d'autres suscitent peu d'intérêt ou deviennent des points de contestation ou des symboles de différence ? Ensuite, quelles sont les conséquences inattendues de ces emprunts ? Et enfin, comment est-ce que les archéologues peuvent se servir de ces faits pour comprendre le colonialisme dans les sociétés anciennes?

Commençons avec la question «pourquoi ? ». Il faut tout de suite souligner que ce ne sont jamais les cultures ou les sociétés qui agissent, mais plutôt les petits groupes d'individus avec des actions et des intérêts différents, et souvent contradictoires. En plus, l'identité n'est pas quelque chose qui réside essentiellement au niveau des ethnies ou des nations. Elle est plutôt située dans le croisement des réseaux de parenté, de catégories sociales, de classes, de statuts, et ainsi de suite. Donc l'appropriation d'éléments de cuisine a beaucoup plus à voir avec la politique relationnelle à ce niveau qu'avec les ethnies, alors que ces processus à petite échelle ont des effets éventuels dans la définition de cuisines ethniques. Par exemple, les luttes entre les générations ou les sexes autour de l'autorité dans les villages, ou entre les hommes d'influence dans leurs luttes de prestige ou 
de pouvoir, peuvent créer des motivations fortes pour les emprunts exotiques. Et les dynamiques de classes et la symbolisation de la distinction servent souvent comme logique de demande pour l'exotique et l'imitation ou l'opposition des pratiques de consommation. Ce n'est que plus tard que quelques-uns de ces emprunts qui ont réussi à être insérés dans la vie quotidienne peuvent éventuellement devenir des marqueurs ethniques plus larges. Pour les Grecs anciens, par exemple, la nourriture a été un marqueur de toute une série de distinctions sociales imbriquées : Grecs contre barbares, citadins contre paysans, riches contre pauvres, hommes contre femmes, et ainsi de suite. Et, comme l'a montré Peter Garnsey (1999, p. 6), les nouveaux riches grecs imitaient les pratiques des élites, ce qui a produit toute une série de diffusions de pratiques culinaires dans la société (voir également Dentzer 1982).

Passant du pourquoi au comment, il est important de faire la distinction entre les pratiques routinières de consommation quotidienne, qu'on appelle les « repas », et les rituels de consommation plus performatifs qu'on appelle les «festins » (voir Dietler 2001). Tous les deux existent imbriqués dans un rapport sémiotique complexe où l'un donne sens à l'autre. Les façons multiples de marquer la dimension rituelle des festins (par exemple, au moyen des excentricités temporelles, par l'encadrement spatial ou architectural, par l'utilisation de types ou quantités de nourriture inhabituelles, par l'utilisation de vaisselle spéciale, etc) dépendent du jeu de contraste avec les modes de repas quotidiens. Mais, ce qui est essentiel à savoir, est que, outre les fonctions politiques importantes des festins (voir Dietler 2001; Hayden 2001), ils servent aussi comme des arènes pour la construction des valeurs et la validation des nouveautés exotiques, y compris, surtout, les nouveaux types d'aliments. Les mets introduits de cette façon peuvent éventuellement se diffuser dans le domaine quotidien - où ils peuvent devenir les marqueurs attendus du statut rituel des festins. On pense, par exemple, à l'introduction des cochons dans la Nouvelle Guinée étudiée par Polly Wiessner (2001). Les nouveautés peuvent aussi être diffusées dans l'autre sens, par exemple, avec la pratique coloniale commune de l'intermariage et l'introduction des ingrédients ou des techniques dans les repas quotidiens. Le cas de la pomme de terre en Finlande est exemplaire de ces complexités. Elle a été introduite depuis la Suède au cours du XVIII ${ }^{e}$ s. par le gouvernement pour améliorer les problèmes d'alimentation des paysans. Mais elle est restée peu appréciée pendant bien longtemps - jusqu'au moment où on a commencé à la traiter comme des mets traditionnels (les navets et les rutabagas) et à la préparer dans les potages et les bouillies. Préparée de cette façon, elle est devenue une partie du système traditionnel des repas quotidiens. Mais la pomme de terre cuisinée avec d'autres techniques exotiques (rôtie ou en salade, par exemple) n'est jamais entrée dans le système quotidien : en revanche, elle a été incorporée dans la nourriture des festins (Talve 1981).

Enfin, il faut aussi demander : quand des éléments de cuisine sont intégrés par ces moyens, quelles sont les conséquences dans les situations coloniales ? On doit dire d'abord que beaucoup de formes de nourriture ont été intégrées et " indigénisées » ; mais ce qui est plus intéressant est le fait que les agents en contact des deux côtés ont essayé d'utiliser la nourriture pour contrôler l'autre : « faire des sujets par le moyen des objets » dans la formulation de Jean et John Comaroff (1997, p. 218). Cela comprend à la fois les essais pour stimuler les nouveaux goûts et désirs, et les essais pour imposer les façons d'utiliser les nouveaux aliments ou techniques, aussi bien que la croyance (presque toujours fausse) que l'utilisation de tels objets ou techniques va obliger l'adoption de certaines formes de comportement attendues. Mais, en fait, quand ces objets traversent des "régimes de valeurs » différents, ils deviennent, en effet, des objets différents : ils arrivent sans les significations et les pratiques associées dans leur contexte d'origine. Donc, non seulement la consommation des aliments exogènes n'est pas un bon indice d'un soi-disant processus d'acculturation, mais souvent ces formes de nourriture intégrées deviennent même les marqueurs des frontières d'identité entre la société des consommateurs et la société d'origine. Un bon exemple est l'adoption et la transformation par les Anglais de la pratique chinoise de boire le thé, qui est devenu la quintessence de la culture anglaise. L'adoption par les Viennois de la pratique turque de boire le café, après la bataille de Vienne, en est un autre.

Mais ces adoptions ont presque toujours des conséquences inattendues pour tout le monde parce qu'elles engagent les consommateurs dans des réseaux d'enchevêtrement économique et politique. Les cas du thé, du sucre, et du rhum sont des exemples classiques de la croissance d'un nouveau goût pour un produit exotique qui a transformé l'économie politique coloniale à travers plusieurs continents (voir Dietler 2006 ; Mintz 1985 ; Pan 1975 ; Sahlins 1994). Dans le cas du thé, une demande croissante pour le thé en Angleterre obligeait les marchandes britanniques à ouvrir un commerce avec les rois d'Hawaii afin d'obtenir le santal exigé par les Chinois en échange de leurs feuilles de thé. Ce commerce eut comme résultat final l'épuisement du santal et le début du commerce de l'opium quand les marchands cherchèrent désespérément un autre produit désiré par les Chinois et capable d'assurer l'approvisionnement en thé (Sahlins 1994). Les rapports coloniaux globaux peuvent aussi avoir des effets tertiaires dans l'adoption 
des aliments : par exemple, l'introduction de la pomme de terre en Irlande et le maïs en Afrique ont été tous les deux le résultat d'entreprises coloniales parallèles lancées par les Anglais dans le Nouveau Monde, en Europe, et en Afrique.

\section{Le cas de la Gaule Méditerranéenne}

Une fois formulé ce résumé trop bref d'un sujet très compliqué, qu'est-ce que cela peut apporter à l'analyse archéologique des situations coloniales du passé ? Je tente de faire une petite démonstration avec une discussion, là encore bien trop brève et sommaire, de la rencontre entre Gaulois et Grecs en France méditerranéenne (Dietler 1997, 1998).

Par contraste avec beaucoup de situations coloniales récentes, en Gaule du sud, le répertoire des aliments de base était déjà assez similaire entre colons grecs et indigènes gaulois avant la rencontre (avec quelques exceptions). Or, bien sûr, il y avait beaucoup de variations dans l'importance relative de certains aliments et dans les techniques de cuisine et de consommation - autrement dit, les composants potentiels de la cuisine ethnique. On ne doit donc pas être étonné d'entendre que, malgré des similarités, les Grecs ont très souvent vu la cuisine comme un indice de la distance qui les a séparés des barbares, y compris des Gaulois. L'inverse a été sans doute aussi le cas, même si on ne dispose pas de textes gaulois pour le démontrer.

Parmi les quelques éléments de base qui ont été vraiment différents entre Grecs et Gaulois au début, on peut citer surtout la forme préférée d'alcool et de matière grasse : c'est à dire, le vin contre la bière, et l'huile d'olive contre la graisse animale. C'est dans le goût pour le vin qu'on voit l'emprunt le plus significatif, jusqu'au point où le commerce de cette boisson est devenu le pivot de l'économie politique coloniale. Il n'y a pas besoin ici de répéter en détail ce que j'ai déjà publié sur ce sujet (voir Dietler 1990 a et b, 2005, 2010). Je résume donc simplement en insistant sur le fait que la demande pour cette boisson chez les Gaulois n'est pas liée à un goût pour la culture grecque, mais, tout au contraire, aux possibilités d'adapter le vin au système des festins indigènes et à son utilité dans ce domaine de la politique commensale. Cette demande a subi des fluctuations à travers les siècles, et le vin n'a jamais remplacé les boissons traditionnelles, mais il a eu l'effet de créer des co-dépendances entre consommateurs de vin et de céréales dans les deux sociétés reliées par les marchands et les réseaux de producteurs.

Alors que les données sont plus ambigües, il apparaît que l'huile d'olive n'a jamais eu le même succès avant la conquête romaine, et que les goûts en matières grasses étaient plus résistants des deux côtés.

Quand on regarde les données sur d'autres aspects de la culture culinaire, il y a des faits intéressants qui sautent aux yeux. Tout d'abord, à part les mortiers, la céramique de cuisine exotique n'avait aucune attraction pour les Gaulois du Midi : malgré quelques évolutions stylistiques à travers les siècles, la céramique de cuisine dans les maisons indigènes est restée sans changements radicaux entre la fin de l'Âge du Bronze et presqu'un siècle après la conquête romaine (Dietler 2010, p. 235-239 ; Py 1993 ; Py et al. 2001). On voit cela dans les pourcentages minuscules d'importations de céramique grecque à Lattes : parmi des milliers de tessons de céramique indigène de cuisine identifiés, il y a moins de 200 exemples grecs (en dehors des mortiers) éparpillés sur 400 ans (Dietler 2010, p. 239 ; Py et al. 2001, p. 381-383). En outre, il y avait très peu d'imitations ou de formes hybrides. Même dans un habitat comme La Cloche au premier siècle av. n. è., à seulement $12 \mathrm{~km}$ de Marseille et plus de cinq siècles après la fondation de la colonie, environ $99 \%$ de la céramique de cuisine consistait en de la céramique non tournée traditionnelle (Lintott 1993, p. 23). Les catégories de céramique de cuisine indigène sont également restées très stables, ce qui est aussi une indication d'une stabilité dans les pratiques culinaires. Comme les données de Lattes le montrent bien, pendant plusieurs siècles les urnes restent toujours la forme la mieux représentée - indices d'une cuisine basée sur les bouillies, les potages et les ragoûts. Seules les jattes montrent un déclin quantitatif relatif (voir Dietler 2010 ; Py 1993, 2009).

Or, la vaisselle de table montre un fort contraste. Dans ce domaine performatif de la consommation, il y a eu assez vite une appropriation de quelques objets exogènes : surtout les coupes à boire et les cruches pour le service des boissons qui ont été ajoutées au répertoire local. Evidemment, ces vases sont étroitement liés à l'appropriation de la boisson exotique qu'était le vin. Mais on peut parfaitement boire du vin dans les bols traditionnels. Cela implique donc une importance attachée à la vaisselle dans le symbolisme des festins et une valeur de ces vases exotiques comme signe de distinction du statut de ces évènements. Après quelques siècles, les services à boire d'origine étrangère ont même plus ou moins remplacé les bols traditionnels dans ce domaine. On voit, par exemple, dans le cas de Lattes, qu'une chute dans le pourcentage de bols au sein du répertoire traditionnel à partir du dernier quart du $\mathrm{III}^{\mathrm{e}} \mathrm{s}$. av. n. è. ne correspond pas, en fait, à un déclin dans l'utilisation des bols, mais plutôt à leur remplacement par les bols campaniens (Dietler 2010, p. 248). Ce phénomène est aussi lié aux premières adoptions d'autres formes avec de nouvelles 
fonctions, comme les assiettes, un peu plus tard. Le résultat a été tel que, au I ${ }^{\text {er }}$ siècle av. n. è., environ $85 \%$ de la céramique non tournée à Lattes était pour cuisiner, et que presque tout le service de table était importé.

Chez les Massaliètes la situation était à peu près l'inverse. A Marseille et à Olbia, les Grecs furent très résistants à la céramique de table indigène pendant des siècles. Mais il en était autrement dans la cuisine. Il faut dire que l'analyse de la céramique de cuisine à Marseille est bien plus négligée que celle de la céramique fine. Mais les données de Marseille qui sont publiées semblent indiquer que pendant au moins le premier siècle après la fondation de la colonie les repas ont été cuisinés surtout dans des vases non tournés de formes indigènes (Gantès 1992 ; Moliner 2000 ; Dietler 2010, p. 233). Les Massaliètes n'ont pas produit leur propre céramique de cuisine avant le IV siècle av. n. è., c'est-à-dire 200 ans après leurs premières productions de vaisselle de table. A ce moment-là, le répertoire des formes de céramique de cuisine est devenu typiquement grec : ce qui est montré en détail par le travail exemplaire de Michel Bats à Olbia (Bats et al.2005, p. 254). Tout se passe comme si les Massaliètes ont été très soucieux de manifester et de célébrer leur identité grecque dans le domaine public et performatif de la consommation, mais qu'au début ils n'étaient pas très intéressés par ce qui se passait dans la cuisine. Ce n'est qu'à partir du IV $\mathrm{IV}^{\mathrm{e}} \mathrm{s}$. av. n. è. que l'orthodoxie s'impose dans la cuisine. Parmi les hypothèses d'explication on peut imaginer que, si les colons grecs se sont mariés avec des femmes indigènes (ou ont utilisé des esclaves indigènes comme cuisiniers), ils se contentaient de gérer la performance du repas dans le domaine masculin de la consommation, mais qu'ils n'étaient pas très intéressés par la façon dont les aliments ont été préparés dans le domaine féminin de la cuisine. Mais il est possible qu'après les premières générations il $\mathrm{y}$ avait plus de femmes grecques ayant émigré à Massalia, surtout après la chute de Phocée. Cette période correspond également à l'imposition d'un ethos de plus en plus conservateur et rigide dans le domaine politique et social - avec la célèbre constitution décrite par Aristote et sa hiérarchie politico-sociale archaïque. Ce n'est pas par hasard qu'il s'agit aussi de l'époque de l'émergence progressive de la construction d'une identité hellénique partagée dans la diaspora grecque en général : on peut imaginer toutes ces manifestions culturelles comme faisant partie d'une vague d'angoisse dans certains secteurs de la société, au sujet de la possibilité d'une «barbarisation» (une peur de " going native » qu'on a vu naître dans plusieurs autres contextes coloniaux). Alors que les données sont encore insuffisantes pour résoudre ces problèmes d'interprétation, il me semble que ces questions sont très importantes à poser.
On peut certainement en tirer beaucoup d'autres observations fructueuses sur le rapport entre cuisine et colonialisme. Mais, dans l'espace qu'on m'a accordé ici, mon propos est limité à quelques exemples, évidemment présentés de façon bien trop sommaire. Je voulais surtout suggérer l'utilité d'une approche anthropologique sur les rencontres culinaires et coloniales, tout en rendant hommage aux travaux pionniers de Michel Bats dans l'ouverture de ces pistes de recherche.

\section{Bibliographie}

Bats 1988 : BATS (M.) - Vaisselle et alimentation à Olbia de Provence (v. 350 - v. 50 av. J.-C.): modèles culturels et catégories céramiques, Paris, Revue Archéologique de Narbonnaise, Supplément 18, 1988.

Bats et al. 2005 : BATS (M.), BONIFAY (M.) FOY (D.), GANTÈS (L.-F.), MUKAI (T.), PASQUALINI (M.), PELLETIER (J.-P.) ET RIGOIR (Y.) - Les productions artisanales de Marseille : les céramiques et le verre. In : Rothé (M.-P.) et Tréziny (H.) dir., Marseille et ses alentours, Carte Archéologique de la Gaule 13/3, Paris , C.I.D., 2005, p. 252-268.

Bourdieu 1979 : BOURDIEU (P.) - La distinction : critique sociale du jugement, Paris, Éditions de Minuit, 1979.

Bourdieu 1980 : BOURDIEU (P.) - Le Sens pratique, Paris, Éditions de Minuit, 1980.

Comaroff, Comaroff 1997 : COMAROFF (J. L.) ET COMAROFF (J.) - Of Revelation and Revolution, Vol.2: The Dialectics of Modernity on a South African Frontier. Chicago, University of Chicago Press, 1997.

Dentzer 1982 : DENTZER (J.-M.) - Le motif du banquet couché dans le Proche-Orient et dans le monde grec du VII au IVe siècle avant J.-C., (Bibliothèque des Ecoles Françaises d'Athènes et de Rome 246), Paris, Boccard, 1982.

Dietler 1990a : DIETLER (M.) - Driven by drink: the role of drinking in the political economy and the case of Early Iron Age France. Journal of Anthropological Archaeology, 9, 1990, p. 352-406.

Dietler 1990b : DIETLER (M.) - Exchange, Consumption, and Colonial Interaction in the Rhône Basin of France: A Study of Early Iron Age Political Economy, Berkeley, PhD dissertation, University of California, 1990.

Dietler 1997 : DIETLER (M.) - The Iron Age in Mediterranean France: colonial encounters, entanglements, and transformations. Journal of World Prehistory, 11, 1997, p. 269-358.

Dietler 1998 : DIETLER (M.) - Consumption, agency, and cultural entanglement: theoretical implications of a Mediterranean colonial encounter. In : Cusick (J.) dir., Studies in Culture Contact: Interaction, Culture Change, and Archaeology, (ed.), p. 288-315. University of Southern Illinois Press: Carbondale.

Dietler 2001 : DIETLER (M.) - Theorizing the feast: rituals of consumption, commensal politics, and power in African contexts. In : Dietler (M.) et Hayden (B.) dir., Feasts: Archaeological and Ethnographic Perspectives on Food, Politics, and Power, Washington DC, Smithsonian, 2001, p. 65-114.

Dietler 2005 : DIETLER (M.) - Consumption and Colonial Encounters in the Rhône Basin of France: A Study of Early Iron Age Political Economy, Lattes, Monographies d'Archéologie Meditéranéenne, 21, 2005.

Dietler 2006 : DIETLER (M.) - Alcohol: anthropological/archaeological perspectives. Annual Review of Anthropology, 35, 2006, p. 229-249.

Dietler 2007 : DIETLER (M.) - Culinary encounters: food, identity, and colonialism. In : Twiss (K. C.) dir., The Archaeology of Food and Identity. Carbondale, IL, Center for Archaeological Investigations, Southern Illinois University, 2007, p. 218-242.

Dietler 2009 : DIETLER (M.) - Consumption. In : Hicks (D.) et Beaudry (M.) dir., The Oxford Handbook of Material Culture Studies, Oxford, Oxford University Press, 2009, p. 207-226. 
Dietler 2010 : DIETLER (M.) - Archaeologies of Colonialism: Consumption, Entanglement, and Violence in Ancient Mediterranean France, Berkeley, University of California Press, 2010.

Douglas 1984 : DOUGLAS (M.) - Standard social uses of food: introduction. In : Douglas (M.) dir., Food in the Social Order. New York, Russell Sage, 1984, p. 1-39.

Falk 1994 : FALK (P.) - The Consuming Body, London, Sage, 1994.

Gantès 1992 : GANTÈS (L.-F.) - L'apport des fouilles récentes à l'étude quantitative de l'économie massaliète. In : Bats (M.), Bertucchi (G.), Congès (G.), et Tréziny (H.) dir., Marseille grecque et la Gaule, Études Massaliètes 3 , Lattes, A.D.A.M Éditions, 1992, p. 171-178.

Garnsey 1999 : GARNSEY (P.) - Food and Society in Classical Antiquity, Cambridge, Cambridge University Press, 1999.

Hayden 2001 : HAYDEN (B.) - Fabulous feasts: a prolegomenon to the importance of feasting. In : Dietler (M.) et Hayden (B.) dir., Feasts: Archaeological and Ethnographic Perspectives on Food, Politics, and Power, Washington DC, Smithsonian, 2001, p. 23-64.

Lintott 1993 : LINTOTT (A. W.) - Imperium Romanum: Politics and Administration, London, Routledge, 1993.

Mintz 1985 : MINTZ (S.) - Sweetness and Power: The Place of Sugar in Modern History, New York, Viking, 1985.

Moliner 2000 : MOLINER (M.) - Les niveaux archaïques de la place des Pistoles à Marseille : un espace cultuel? In : Hermary (A.), Tréziny (H.) dir.,
Les cultes des cités phocéennes, Aix-en-Provence, Édisud, Études Massaliètes 6, 2000, p. 101-117.

Pan 1975 : PAN (L.) - Alcohol in Colonial Africa, Helsinki, Finnish Foundation for Alcohol Studies, 22, 1975.

Py 1993 : PY (M.) - Les Gaulois du Midi: de la fin de l'Age du Bronze à la conquête romaine, Paris, Hachette, 1993.

Py 2009 : PY (M.) - Lattara : Comptoir gaulois méditerranéen entre Etrusques, Grecs et Romains - Lattes, Hérault, Paris, Errance, 2009.

Py et al. 2001 : PY (M.), ADROHER AROUX (A.), et SANCHEZ (C.) DIR. Corpus des céramiques de l'Âge du Fer de Lattes (fouilles 1963-1999), 2 vol., Lattara 14, Lattes, A.R.A.L.O., 2001.

Sahlins 1994 : SAHLINS (M.) - Cosmologies of Capitalism: the transPacific sector of "the World System". In : Dirks (N. B.), Eley (G.), et Ortner (S.B.) dir., Culture/Power/History: A Reader in Contemporary Social Theory, Princeton, Princeton University Press, 1994, p. 412-455.

Talve 1981 : TALVE (I.) - The potato in Finnish food economy. In : Fenton (A.) et Owen (T. M.) dir., Food in Perspective, Edinburgh, John Donald, 1981, p. 277-282.

Wiessner 2001 : WIESSNER (P.) - Of feasting and value: Enga feasts in historical perspective (Papua New Guinea). In : Dietler (M). et Hayden (B) dir., Feasts: Archaeological and Ethnographic Perspectives on Food, Politics, and Power, Washington DC, Smithsonian, 2001, p. 115-143. 



\title{
Forme di identità e interazione nel Tirreno settentrionale. Possibili indicatori, fra persistenza ed acculturazione. Alcune note*
}

\author{
Eliana Piccardi \\ PhD Doctorante - Université de Gênes, DAFIST - Université d'Aix-Marseille I, CJJ
}

\section{Résumé}

Même un ensemble de témoignages dispersés comme celui de l'ancienne côte ligurienne pendant le deuxième âge du Fer peut être mis sous la lumière de diverses clés de lecture: l'interaction culturelle, la persistance des identités et l'acculturation. Le paysage archéologique de l'ancienne Ligurie apparaît être généralement caractérisé par une présence faible de la culture matérielle locale face aux apports allogènes ; néanmoins, au delà du hasard des trouvailles, il y a certaines caractéristiques apparemment récurrentes qui peuvent également être mises en perspective dans le cadre de l'ensemble du bassin nord tyrrhénien.

Mots-clés : Ligurie ancienne, région Nord-Tyrrhénienne, deuxième âge du Fer, marqueurs d'identité, interactions et persistance culturelles, acculturation

\begin{abstract}
Even a frame of scattered evidence as the one of the ancient Ligurian coast during the Second Iron Age may be put under the light of some reading-keys: cultural interaction, identity persistence and acculturation. The emerging landscape of archaeological evidence appears in ancient Liguria to be generally affected by a sort of "weaker" mark of the local material culture before the allogenic intakes; nevertheless, beyond the fortuity of findings, some seemingly recurrent features may be pointed out especially in sight of a progressive framing within the whole Northern Tyrrhenian Sea area.
\end{abstract}

Keywords: Ancient Liguria, Northern-Tyrrhenian area, Second Iron Age, identity markers, cultural interactions and persistence, acculturation * Questo contributo è dedicato a Maria Buzzalino, leale giovane collega di anni ormai lontani, con la quale fu condiviso il vivo interesse per
l'età del Ferro nella Gallia meridionale, sfociato nelle rispettive tesi di laurea $(1997 ; 2002)$. 
"In generale, è probabile che sia soprattutto l'incongruenza fra le formazioni etniche, culturali e politiche a far scattare quella riflessività che comporta una perdita di ovvietà nonché il diventar cosciente del senso culturale legante e vincolante. (...). I problemi che risultano da tale incongruenza si possono riunire in due gruppi: problemi di integrazione e problemi di distinzione."

Jan Assmann, La memoria culturale (Einaudi, trad. ital., Torino, 1997, p. 113)

\section{Premessa}

Negli ultimi decenni il dibattito sulle tematiche dell'identità e dei fenomeni acculturativi ha conosciuto un'indubbia fortuna non disgiunta da un'evoluzione critica sia della riflessione teorica, in parte rimodulata ed affinata grazie ai contributi recenziori, sia degli strumenti d'analisi connessi ad entrambe le categorie, sempre più sottratti ad una meccanicistica applicazione. Di questo approccio alle civiltà antiche sono state evidenziate le notevoli potenzialità, ma si sono rimarcati pure nodi problematici e limiti nella gestione dei dati, specie in mancanza di una congrua documentazione di-sponibile (Bats 2005, p. 30-39; Boissinot 2005, p. 26-35). Emerge comunque sempre più la tendenza a riconoscere un'interazione articolata e multidirezionale, anche al di là di possibili esiti nel senso dell'assimilazione culturale e della persistenza od affermazione identitaria, aspetti al centro di un ormai pluriennale interesse (Bats 2007, p. 191-198; Boissinot 1998, p. 19-23; Boissinot 2011, p. 9-22; Van Dommelen, Knapp 2010) ${ }^{1}$.

In questa prospettiva, il Tirreno settentrionale appare, se non entità geo-storica dai contorni definiti, certo 'luogo antropologico' - secondo la definizione di Marc Augé -, in quanto, nella storia, scenario di identità e dinamiche molteplici tra elementi autoctoni ed allogeni, che come tale offre interessante materiale per esplorare queste interazioni od 'interferenze' distribuite lungo l'arco di tempo successivo alla battaglia di Alalia fino al pieno consolidarsi della romanizzazione ${ }^{2}$.

1 Lungi dal rendere conto della doviziosa bibliografia in merito, si richiamano solo alcuni momenti della discussione, segnalando anche, tra gli interventi in questo stesso volume, quelli di $\mathrm{Ph}$. Boissinot e di M. Dietler.

2 Tale arco cronologico, deliberatamente assunto, consentirà uno sguardo sui fenomeni di quest'area che in parte travalicano la demarcazione corrente tra prima e seconda età del Ferro. Le esemplificazioni, evocate mediante cenni bibliografici riassuntivi, verteranno qui essenzialmente sull'orizzonte dell'antica Liguria tirrenica; sono tratte da un'avviata tesi di Dottorato a cura della scrivente (« Dinamiche
$\mathrm{E}$, in particolare, sulla scorta di recenti sintesi e nuove acquisizioni per quanto riguarda la Liguria (Ligures 2004; Liguri 2004; Liguri 2007; Giannattasio 2007; Launaro 2009; Mannoni 2010, p. 31-60), si profila una messe - in aumento - di evidenze potenziali da vagliare secondo tali chiavi di lettura, focalizzando sulle varie componenti in gioco con un'ottica di partenza il più possibile interna.

\section{Identità ed interazione: indizi ed elementi per una ricerca $(\mathrm{im})$ possibile ?}

Per le finalità delineate, le non copiose e diseguali fonti letterarie risultano poco utili, al di là di alcuni dati evenemenziali o di racconti leggendari difficilmente storicizzabili specie circa possibili contatti tra il comprensorio ligure e l'isola di Corsica ${ }^{3}$.

Ottica regressiva e registrazione sincronica offrono le testimonianze epigrafiche di varia estensione appartenenti alla piena romanità che recano, di volta in volta, tracce toponomastiche, etnonimiche, onomastiche e pure devozionali di ascendenza pre-romana. Spicca, in tale panorama, il documento bronzeo denominato "Tavola della Valpolcevera" o Sententia Minuciorum

insediative, economiche e culturali nel Tirreno settentrionale dalla battaglia di Alalia alla romanizzazione », Università di Genova, prof. B. M. Giannattasio, in co-tutela con l'Université de Provence, prof. D. Garcia), incentrata sia sull'antico areale Ligure gravitante sul Tirreno sia sull'isola di Corsica. Il tema della ricerca si ricollega idealmente ad una proposta di programma post-dottoriale presentata presso il Centre Camille Jullian nella primavera del 2003 ( «Les anciens Liguriens du Rhône à l'Arno de l'âge du Fer à la romanisation : formes d'identité, contacts et transformations, entre processus d'acculturation et à la recherche des possibles indicateurs archéologiques »), e alla successiva sintesi di un poster ufficioso a margine del Convegno Ligures Celeberrimi di Mondovì (aprile 2004) : « Forme di identità, contatti, processi di acculturazione. Alla ricerca di possibili indicatori archeologici », imperniato sull'articolata realtà storico-archeologica della Francia meridionale. Più recentemente, queste tematiche sono state riprese in una tesi di Dottorato presso l'Università di Genova a cura di F. Chiocci dal titolo « Incontri, contatti e processi di acculturazione tra Greci e Non-Greci nel Tirreno nordoccidentale : il caso di Massalia »; per un breve resoconto di essa : CHIOCCI (F.) - Territorio ed identità etnica da Marsiglia al Rodano : prospettive metodologiche. In : Angeli Bertinelli (M. G.) e Donati (A.) dir., Città e territorio . La Liguria e il mondo antico, Atti del IV Incontro Internazionale di Storia Antica, Genova, 19-20 febbraio 2009. Rome, Giorgio Bretschneider, 2010, p. 249-255.

3 Ad esempio, viene narrato il passaggio in Corsica di un gruppo di Liguri al seguito della bovara ligure 'scopritrice' dell'isola (Sall., Hist., II; fr. 11 ; Isid. Etym. XIV 6, 41); in apparenza cronologicamente meglio definita, nella scansione relativa offerta da Seneca ( $\mathrm{Ad}$ Helv., 7), è l'indicazione circa un arrivo di Liguri sull'isola collocato dal filosofo tra i contatti focesi e l'afflusso di elementi iberici seguiti poi dai Romani : la notazione senecana, per quanto di solito non accreditata di particolare affidabilità storica, risulta comunque suggestiva, specie alla luce della circolazione di materiali e di individui fra le due aree, anche recentemente evidenziata (Lechenault $\grave{a}$ paraître; Piccardi, Pêche-Quilichini sous presse). 
(117 a. C.), che attesta, nella seconda metà del II sec. a. C., persistenti assetti di organizzazione e sfruttamento del territorio fra alcuni gruppi liguri stanziati attorno a Genua, a proposito dei quali si ha una mediazione di rappresentanti romani (CIL II 7749; Mennella 2004 in Liguri 2004, p. 477-479). Tra i menzionati nuclei liguri, alcuni sono connotati da una propria identità e sembrano realizzare un differenziato grado di interazione con il sopravvenuto elemento romano: ad esempio, i Viturii Langenses risultano ancora legati ad una struttura tribale e ad un'economia di tipo agro-pastorale rispetto ai Genuates, i quali appaiono invece per lo più inurbati e dialoganti con i Romani ma soprattutto capaci di rivestire un ruolo in qualche modo egemone sulle altre componenti liguri circonvicine; queste ultime, da parte loro, si dimostrano comunque in grado di produrre un surplus vinicolo da versare come tributo in natura ${ }^{4}$.

Le esigue testimonianze di scrittura si limitano, per lo più, a semplici sequenze o singoli gruppi letterali, graffiti su reperti mobili - specie fittili, ma non solo -, provenienti da contesti sia domestici sia funerari (da Genova : Colonna 2004 in Liguri 2004, p. 302-307; da Bergeggi, Savona : Giannattasio, Odetti 2009, p. 100, n. 55, tav. XXIV, 10; dalla necropoli di Ameglia/Cafaggio, La Spezia : Maggiani 2004 in Liguri 2004, p. 385-386 e in Ligures 2004, p. 200-201). Si tratta sovente di contrassegni di identità/proprietà personale riconducibili in gran parte ad elementi onomastici - più o meno etnicamente connotati-, oppure anche di segni commerciali o di altro genere (ad esempio, sigle attinenti alla sfera del sacro, teonimi, offerte). Redatti in prevalenza con alfabeto etrusco settentrionale e talora meridionale ${ }^{5}$, corroborati da ulteriori indizi o dati di cultura materiale, possono documentare, più o meno in filigrana, mobilità se non fenomeni di interazione tra singoli individui e gruppi. È il caso, per citare due soli esempi, del ciottolo di serpentino dall'oppidum di Genova, recante l'iscrizione $m i$ nemeties, databile alla prima metà del V sec. a. C., di recente collegato ad un ipotetico spazio votivo (Melli 2007, p. 70-71), e di un'iscrizione da una tomba di età ellenistica della menzionata necropoli di Ameglia.

All'intersezione di varie problematiche si colloca un ritrovamento numismatico del 1923, rilevante ma precariamente documentato, eseguito nell'immediato entroterra di Genova (località Niusci/Ciaè, Serra Ricco'), in corrispondenza di uno snodo di percorsi tra costa ed interno,

4 Anche Livio (XL 41, 5) riferisce di una produzione vinicola locale dei Ligures, attestata almeno nel II sec. a. C., che è del resto ricordata - più genericamente - sia da Strabone (IV 6,2) sia da Plinio (Nat. Hist., XV 17, 66).

5 Alcune stele lunigianesi rilavorate nella prima età del Ferro recano iscrizioni etrusche o nel cosiddetto 'leponzio-ligure' (Maggiani 2004 in Liguri 2004, p. 221-222). forse presso una sorgente; il bacino vallivo è il medesimo di quello definito dai riferimenti toponomastici della ricordata Tavola bronzea ${ }^{6}$. Comprendeva un cospicuo insieme di nominali e divisionali (convenzionalmente definiti dracme ed oboli) ${ }^{7}$, privi per lo più di tracce d'usura e distribuiti lungo un ampio arco cronologico (in gran parte dal III al II sec. a. C.). Essi si inseriscono nel vasto filone già in maniera estesa noto per l'area padana interna ${ }^{8}$ e per la Gallia meridionale almeno fino al I sec. a. C. (Bérato 2002, p. 170; Feugère, Py 2011, ad es. p. 161-220) - delle emissioni monetali ispirate ai tipi massalioti, realizzate da zecche di ambito celtico, in questo caso prevalentemente transpadano. Sulla scorta delle caratteristiche di alcune serie viene postulata anche l'esistenza di officine liguri: in parte forse dei Genuates, ma soprattutto di taluni nuclei ancora poco romanizzati quali i Viturii Langenses o altri minori tra quelli collocati proprio in questo territorio dalla Tavola bronzea; siffatte emissioni, di scarso valore e di ridotta circolazione, risulterebbero funzionali a primitive forme di economia monetale (tributi e dazi viari), oppure sarebbero state appositamente create per un rito epicorico di offerte in corrispondenza di un luogo sacro ${ }^{9}$, collegato forse all'acqua e alla viabilità (Barello 2004 in Liguri 2004, p. 518-521 e Arslan 2004 in Ligures 2004, p. 120-124).

I labili indizi che si ricavano dall'epigrafia e dalla numismatica circa elementi potenzialmente riconducibili alla sfera del sacro rispecchiano in maniera esemplare una generalizzata evanescenza di tali dati nel passaggio tra prima e seconda età del Ferro. Dopo le manifestazioni preistoriche del Bego e delle statue stele in Lunigiana, rimangono un fenomeno abbastanza circoscritto alcune forme di interesse seriore attorno a queste ultime : rilavorazioni e talora iscrizioni nella prima età del Ferro, mentre allo scorcio della seconda età del Ferro si registrano isolate azioni di reimpiego a carattere utilitaristico come materiale litico per tombe a cassetta, accanto ad occasionali defunzionalizzazioni rituali, databili fino al I sec. a. C.- I sec. d. C. (Maggiani 2004 in Liguri 2004, p. 219-223 e in Ligures 2004, p. 199; Mannoni 2010, p. 52-53). Nella maggior parte dei casi, la ricostruibilità del sacro per le popolazioni liguri rimane per lo più delegata a sporadiche evidenze di cultura materiale mobile, quali elementi bronzei o fittili - ma non solo - interpretati come suppellettili

\footnotetext{
6 Emersa, circa quattro secoli prima, proprio in quest'areale.

7 Non quantificabile, ma in origine superiore al migliaio di esemplari secondo alcune ricostruzioni.

8 Sulla monetazione celtica padana si veda anche il recente intervento di G. Gorini : GORINI (G.) - La monetazione dei Celti in Italia. In : Les Celtes et le Nord de l'Italie, Actes du XXXVI ${ }^{\mathrm{e}}$ colloque international de l'AFEAF, Vérone, 17-20 mai 2012, à paraître. 9 Analoghe offerte in contesti naturali affini sono state trovate, ad esempio, nel Var a Correns (Garcia 2004, p. 113-114).
} 
od offerte votive, come ad Uscio e a Zignago nel Levante, e soprattutto sull'oppidum di Genova, sito dove però prevale la componente allogena, in particolare etrusca : qui, tra fine del VI e V sec. a. C., sono state ipotizzate delle aree sacre, rispettivamente una - con probabile carattere domestico - segnalata dal ricordato ciottolo iscritto, e un'altra, forse a vocazione sacrale-emporica, individuata da un tratto di « recinto monumentale » (Melli 2004 in Liguri 2004, p. 286-288 e in Ligures 2004, p. 173). Le espressioni devozionali, dunque, rimangono spesso in larga misura archeologicamente evanescenti, almeno fino alle estrinsecazioni di piena facies romana che possono talvolta rispecchiare anche tradizioni preromane. Ne sono oggetto potenziale determinati luoghi naturali rivestiti di aura simbolico-sacrale, quali boschi, fonti, snodi viari, e soprattutto sommità montane plausibili sedi di « culti delle vette » (Mannoni 2010, p. 48-50; per le Alpes-Maritimes : Salicis 2007, p. 7-20) : lo attestano, ad esempio, alcuni bronzetti ritrovati presso alture significative ${ }^{\mathbf{1 0}}$, i materiali della stipe di Caprauna ${ }^{11}$, lungo un percorso tra Albenga e l'interno (Gandolfi, Gervasini 2007 in Liguri 2007, p. 206-211), oppure, in maniera più indiretta, alcuni elementi nei documenti epigrafici - recanti talora epiclesi anche etniche -, o nei relitti toponomastici (Lautier, Rothé 2010, p. 475; Pucci 1997, p. 28-30; p. 42-46; p. 85-90) ${ }^{12}$.

Se, dunque, scrittura e sacralità, fondamentali per Jan Assmann nella definizione identitaria, forniscono per l'orizzonte prescelto testimonianze modeste, anche estendendo il campo all'ambito insediativo si constatano, nel complesso, indicazioni ad oggi piuttosto generiche ed eterogenee, desumibili per lo più da evidenze arealmente circoscritte e poco stratificate dal punto di vista cronologico (Giannattasio 2007, p. 126-150) ${ }^{13}$. Al di là di opere di terrazzamento tese a modellare ed ampliare, all'occorrenza, lo spazio fruibile (ad Uscio, a Camogli, sull'oppidum di Genova), nel panorama ligure gravitante sul Tirreno, infatti, tutta una serie di resti murari più $o$ meno cospicui segnalati in superficie su potenziali siti d'altura - specie del Ponente ${ }^{14}$ ma pure a Levante, pone

10 Si tratta quasi sempre di ritrovamenti del passato, decontestualizzati e poco documentati.

11 La stipe di Caprauna, oggetto anche di puntuali indagini tra cui recenti analisi sui materiali, ha pure restituito alcuni frammenti di ceramica indigena della seconda età del Ferro, oltre a resti di corna di capro collegate a tradizioni di matrice celtica (Melli 2004 in Ligures 2004, p. 182).

12 Sono, comunque, realtà ben lontane dalle più consistenti testimonianze sincretiche dell'orizzonte gallico sud-orientale : ad esempio, Lautier, Rothé 2010, p. 692; p. 738-740.

13 E solo di rado integrate da scarni cenni nelle fonti: ad esempio, circa le mura di Albenga all'epoca dell'impatto con i Romani (Plut., Aem. Paul., 6 1).

14 Tra cui i siti di Monte Bignone e di Monte Colma, sul medesimo crinale a ridosso di Sanremo (Imperia), scavati nei decenni centrali del XX spesso problemi interpretativi, in primis cronologici, in mancanza di indagini stratigrafiche correlate (Gambaro, Montinari 2007 in Liguri 2007, p. 121-124 e Gambaro, Del Lucchese 2007, in Liguri 2007, p. 125-129). In rari casi, come a Genova (a partire circa dalla metà del V sec. a. C. e fino alla romanizzazione : Melli 2007,p. 39-42) e a Bergeggi (Giannattasio, Odetti 2009, p. 82-85), situazioni più articolate sono cronologicamente un po' meglio definite e, in potenza, interpretabili anche come risposte verso stimoli esterni ${ }^{15}$. Ad oggi, soltanto sull'oppidum genovese, sito dalla fisionomia proto-urbana e marcatamente allogena, si intravede inoltre uno scenario più variato, non solo a livello di una potenziale individuazione di spazio pubblico e sacro forse già tra fine VI-inizi V sec. a. C., ma anche quanto a tecniche costruttive : almeno nel V e IV sec. a. C., vi sono attestate una cortina muraria a doppio paramento, un tratto di acciottolato esterno, il probabile impiego pure di mattoni crudi accanto a fittili di più o meno sommaria cottura (Melli 2004 in Liguri 2004, p. 286-290, f. 3 e 4; Milanese 1987, p. 306). Le piante delle unità abitative individuate nei siti liguri, ad un primo sguardo non riconducibili a forme prevalenti, riflettono come struttura fondamentale per lo più quella di una tradizione familiare mononucleare, e in pochi casi sono state esplorabili anche articolazioni funzionali degli spazi pertinenti, come ad Uscio e a Bergeggi : qui, per una pianta ovaleggiante (datata tra fine IV e prima metà del III sec. a. C.) vengono evocate affinità con alcune capanne absidate dell'orizzonte gallico meridionale (Giannattasio 2007, p. 131-133; p. 139-144; Giannattasio, Odetti 2009, p. 50-54). Circa le tecniche costruttive si registra in genere una serie di apprestamenti assai comuni, per lo più con zoccolatura di elementi litici ed elevato di materiali vegetali ed argilla pressata concotta, pratica ampiamente e a lungo documentata anche nella Gallia meridionale ${ }^{16}$. Assumono in prevalenza le forme più semplici di aree battute sia i piani d'uso sia i focolari, interni ed esterni alle unità, questi ultimi con superfici concotte e talora delimitazioni di pietre (oltre alla bibliografia via via citata, adde per Monte Rocche di Riva Ligure - Imperia -: Del Lucchese, Gambaro 2010, p. 28-32). Nell'insieme, per

secolo, per i quali si attendono studi specifici (Gambaro, Del Lucchese 2007 in Liguri 2007, p. 126). Rimangono non agevoli da definire, soprattutto a causa della continuità di vita, la consistenza di alcuni oppida potenziali (Savona) o ad esempio l'ubicazione di uno, come quello di Albenga, documentato dalle fonti (Giannattasio 2007, p. 137-138, p. 144). 15 Meccanismo che sembra cogliersi con maggiore evidenza, invece, nei comprensori limitrofi, come in Etruria (Ciampoltrini et al. 2008, p. 37-62; Pulcinelli, Corretti 2012 in Cambi 2012, rispettivamente, p. 69-120 e p. 347-370) e in Gallia meridionale (Garcia 2004, p. 80-87).

16 Per limitarci a qualche esempio di attestazioni nella regione contigua al territorio ligure : Lautier, Rothé 2011, p. 227, p. 290, p. 534 e p. 358 . 
questi aspetti, quindi, la Liguria tirrenica, salvo poche e scarne eccezioni, stenta per ora a mostrare modelli comuni ma anche omogenee tendenze crono-spaziali, oppure marcate specificità attribuibili al comprensorio considerato, al di là di cogenti fattori geo-morfologici che ricorrono ${ }^{17} \mathrm{e}$ di scelte improntate ad empirico pragmatismo.

Circa il mondo funerario, nel periodo selezionato, sono rilevanti soprattutto la necropoli di Genova (specie per i secoli V-IV sec. a. C.), e, all'estremità orientale dell'arco ligure, nell retroterra della futura Luni (La Spezia), quella di Cafaggio/Ameglia, il cui nucleo più cospicuo si colloca tra fine del IV e III sec. a. C., oltre ad una serie di evidenze andate disperse (tra cui le più tarde sepolture di Genicciola), sporadiche, o comunque di entità minore (Melli 2004 in Ligures 2004, p. 175, 182; Gervasini 2007 in Liguri 2007, p. 161-166; Giannattasio 2007, p. 151160). L'incinerazione, invalsa dall'età del Bronzo, si diffonde con l'uso di vasi a mo' di cinerario, che sono poi collocati in tombe a cassetta litica secondo la caratteristica tipologia nota in ambito ligure fin dalla prima età del Ferro e nella quale si suole individuare un vero e proprio marcatore etnico ${ }^{18}$. Riguardo ai corredi, poi, risaltano la manomissione rituale di oggetti della panoplia $\mathrm{e}$, forse, una peculiare attenzione talora postulabile per alcuni reperti - soprattutto fittili ma non solo - come si vedrà. A Genova il corpus più rappresentato è quello delle tombe a pozzetto scavate nel sostrato roccioso i cui corredi individuano, specialmente nel V e in parte nel IV sec. a. C., un preponderante nucleo etrusco con élites dedite a costumi simposiali, accanto ad occasionali componenti alloctone provenienti da altre zone dell'Italia settentrionale e della penisola. Dal IV sec. a.C. risulta incrementata la presenza celtica (con armi e fibule soprattutto) entro un quadro che, a livello di pratiche funerarie e rituali - come viene asserito dagli studiosi -, non appare registrare rilevanti mutazioni documentabili. Una - ad oggi - isolata attestazione genovese di tomba a cassetta, individuata non lontano dal raggruppamento di quelle a pozzetto ma in apparenza in un settore distinto, potrebbe indiziare una suddivisione etnica degli spazi necropolari, per ora non ulteriormente suffragabile (Melli 2007, p. 65-66 e p. 74-83). La struttura a cassetta litica, talora con tracce di piccoli tumuli di copertura, risulta particolarmente documentata nell'area ligure orientale degli Apuani nel corso

17 Si privilegiano luoghi atti a garantire, di volta in volta, sfruttamento delle risorse naturali, collegamenti, controllo del territorio, sicurezza e difendibilità.

18 Necropoli di Chiavari (VIII-VI sec. a. C.), Rapallo (fine VIIinizio VI sec. a. C.), Albenga (VII sec. a. C.) : Giannattasio 2007, p. 64-79. All'estremo Ponente si ricorda la tomba di Pornassio (val d'Arroscia, Imperia), forse della seconda metà del V sec. a. C. (Gambaro, Del Lucchese 2007 in Liguri 2007, p. 128-129). della seconda età del Ferro tra fine del IV e III-II sec. a. C., marcando una persistente tradizione epicorica ${ }^{19}$ (almeno fino all'iniziale età imperiale, allorché si registra talvolta pure l'uso di materiali fittili) che affiora in via occasionale anche al di fuori dei confini territoriali tradizionalmente assegnati ai Liguri (Maggiani 2004 in Liguri 2004, p. 389 e in Ligures 2004, p. 200-202; Paribeni 2004 in Liguri 2004, p. 378-380; Giannattasio 2007, p. 151; da ultimo, Ciampoltrini, Notini 2011, specie p. 13-36). Quanto al rituale, i resti dell'incinerazione secondaria vengono raccolti in urne, generalmente di impasto e protette da elementi fittili : ad Ameglia sono per lo più coppette di importazione rovesciate e solo di rado frammenti di anfore; sempre in questa necropoli, poi, soprattutto le ricorrenti presenze della panoplia testimoniano quella che è stata definita un'accentuata - ed in apparenza non traumatica - celtizzazione ${ }^{20}$. Si segnala, inoltre, la peculiare considerazione di cui appaiono rivestiti alcuni oggetti dei corredi, generalmente fittili ma talora anche metallici, rimaneggiati in modo vario e collocati entro contesti seriori, il che è aspetto non sconosciuto già nella necropoli di Genova e forse altrove (Giannattasio 2007, p. 157-158; Maggiani 2004 in Ligures 2004, p. 196-199; Melli 2004 in Liguri 2004, p. 315; p. 342; p. 344; p. 349; Gervasini 2007 in Liguri 2007, p. 164). Grazie all'estensione esplorata, la necropoli di Cafaggio/Ameglia consente pure di osservare, a livello dell'organizzazione spaziale, l'aggregazione di più tombe - forse corrispondenti a ri-spettivi gruppi familiari - entro recinti, all'interno di un originario allineamento (Durante 2004 in Liguri 2004, p. 374-378 e p. 384; p. 407; Giannattasio 2007, p. 153). Sempre quest'area ligure orientale restituisce indizi della successiva acquisizione di costumi e gusti funerari esogeni mediati dai romani o ad essi riconducibili : non solo attraverso particolari oggetti del corredo inseriti nella tradizionale sepoltura a cassetta - la cui struttura è ora formata anche da porzioni fittili (Gervasini 2007 in Liguri 2007, p. 163, p. 166) -, ma anche con la messa in atto di pratiche differenziate ed alternative, come attesterebbero l'uso di anfore tagliate nel territorio di Massa e di Lucca (Paribeni 2004 in Ligures 2004, p. 216, e in Liguri 2004, p. 380) o le tracce di un letto funerario decorato di tipo orientale da Genicciola (Mannoni 2010, p. 36-37).

In tale cornice documentabile, anche la dimensione funeraria, al pari delle altre, converge quindi in gran parte sui reperti mobili della cultura materiale, i quali, pure per

19 In alcune di esse si è occasionalmente rilevato il reimpiego di statue stele come materiale. Cfr. anche supra, nota 5.

20 Fenomeno percepibile anche nella cultura materiale della necropoli di Genova (Melli 2004 in Ligures 2004, p. 171-172; Melli 2007, p. 65-66), e analizzato nella sua complessità in aree come l'Iberia e la Francia meridionale (Bats 2007, p. 35-39). 
quanto concerne l'identità ligure o più genericamente la circolazione di produzioni eseguite in loco, forniscono sempre più riscontri di un percepibile dinamismo all'interno di questo settore nord-tirrenico, almeno a partire dal IV sec. a. C. e in quelli successivi. È documentata, ad esempio, nella necropoli di Aleria (Haute-Corse) la presenza di armi liguri nella seconda metà del IV sec. a. C. (Lechenault à paraître), e, tra III e II sec. a. C., si constata la trasmissione di tratti tipicamente liguri nelle più ricettive necropoli del contiguo territorio etrusco settentrionale; in entrambi i casi si possono postulare esiti connessi al mercenariato ligure (Melli 2004 in Liguri 2004, p. 294-295; Maggiani 2004 in Liguri 2004, p. 388389). Inoltre, prodotti ceramici di tradizione indigena corsa, e loro imitazioni, circolano tra le sponde tirreniche settentrionali - toscane e liguri -, almeno tra IV-III sec. a. C. e la romanizzazione (Piccardi, Pêche-Quilichini, sous presse). Accanto a componenti delle panoplie acquisiti da vari ambiti (elmi di produzione celtica ad Ameglia ed etrusco o centro-italica altrove), lo statuto di identità, pure etnica, affidato a potenziali marcatori tra i reperti mobili della cultura materiale - metalli e manufatti fittili soprattutto -, non potrà prescindere dalla persistenza diacronica di elementi considerati peculiari della tradizione ligure (propri del vestiario e dell'ornamento personale, come i bottoni conici bronzei e alcuni tipi di fibule, tra cui quelle apuane), ma andrà anche ricalibrato - incrociando più dati possibili - in presenza di produzioni realizzate localmente oppure a fronte di vere e proprie evoluzioni od imitazioni di modelli allogeni che inizialmente potevano indiziare contatti e mobilità fra i diversi gruppi umani (Ciampoltrini, Notini 2011, p. 42-46; Durante 2004 in Liguri 2004, p. 408; Gervasini 2007 in Liguri 2007, p. 162-163; Giannattasio 2007, p. 129; p. 143; Maggiani 2004 in Ligures 2004, p. 193-194; Melli 2004 in Ligures 2004, p. 168-169, p. 175 e p. 182-183; Melli 2004 in Liguri 2004, p. 288 e p. 294, p. 330; Melli 2007, p. 50, p. 55-56; Paribeni 2004 in Liguri 2004, p. 383-384).

Le testimonianze fittili affluite sull'oppidum di Genova offrono alcuni casi emblematici delle possibili implicazioni - anche se non da trattare in maniera deterministica - tra identità etnica degli utilizzatori di materia prima e dei detentori di know-how, oltre che dei potenziali fruitori culturali ${ }^{21}$. L'individuazione di vari bacini petrografici di provenienza dei reperti, infatti, pure in mancanza di centri produttivi diagnosticati in situ per

21 «In una stessa area vi possono essere più fabbriche legate a gruppi etnici differenti, e uno stesso gruppo etnico può ovviamente produrre ceramica in aree mineralogicamente diverse » (Mannoni 1995 [1972], p. 105). Va ovviamente considerata pure la possibilità dell'uso di tali bacini petrografici da parte di manodopera allogena. Quanto alle implicazioni identitarie e culturali della fruizione si veda anche M. Dietler, in questo stesso volume. quest'epoca nell'areale ligure considerato ${ }^{22}$, lascerebbe intravvedere (soprattutto nei secoli IV-III a. C., ma per talune ceramiche comuni già antecedentemente) un'attività manifatturiera su scala regionale e sub-regionale (ad esempio, operanti nei territori riconducibili ai Viturii poco ad occidente di Genova, ai Tigulli nel Levante ligure) ${ }^{23}$, con una serie di produzioni, sia autoctone sia riecheggianti modelli esterni, realizzate ad un diversificato grado di evoluzione tecnologica. Tra queste ultime, nuclei di ceramica comune prodotti nella regione appaiono risentire di influssi - a quanto consta, non per livello tecnico ${ }^{24}$ - dapprima (già almeno dalla metà del V sec. a. C.) esercitati delle importazioni di ceramica comune etrusca complementare ai carichi anforici in arrivo dall'Etruria, mentre in seguito, dopo il sopravvento dei flussi commerciali da Massalia, alcuni lotti ceramici - sebbene relativamente modesti - mostrano influenze, essenzialmente sul piano morfologico ma talora anche tecnologico, rapportabili a modelli colti, di possibile matrice greco-massaliota od etrusca e poi italica. Tali dinamiche non possono, del resto, essere sempre riducibili ad un meccanismo evolutivo del tutto lineare, non solo sul piano qualitativo ma anche in senso crono-spaziale. Se, in generale, non sembrano in una prima fase ravvisabili apporti di acculturazione particolarmente incisivi, rimanendo spesso siffatte produzioni ancorati a bassi standards tecnologici, tuttavia, successivamente - almeno nella prima metà del III sec. a. C. - , alcune delle produzioni ispirate a modelli allogeni mostrano un'evoluzione anche nel processo produttivo, come accade, ad esempio, per un nucleo di manufatti realizzato con argille del basso corso del fiume Polcevera immediatamente ad ovest del sito genovese (Milanese 1987, p. 327-331; Piccardi 2007, p. 110-113) ${ }^{25}$. In quest'ultimo caso, a livello di ipotesi, non può essere a priori escluso il trapianto di più evolute maestranze manifatturiere dall'esterno (è stato proposto etrusche : Milanese

22 Giova rimarcare qui che il sito dell'oppidum genovese sembra, tra l'altro, attingere a prodotti ceramici esterni - in taluni casi anche da aree regionali adiacenti - almeno fino al III sec. a. C. (Melli 2004 in Liguri 2004, p. 294).

23 Nelle aree orientali abitate dagli Apuani vengono di solito considerate tipiche, dalla seconda età del Ferro fino a ridosso della romanizzazione, ceramiche a fasce dipinte o le più rozze ceramiche comuni ad impasto 'vacuolare' (Ciampoltrini 2004 in Liguri 2004, p. 387-389; Maggiani 2004 in Ligures 2004, p. 191-192).

24 Il che, ad un primo stadio di analisi, non autorizzerebbe a postulare un'azione in loco di manodopera specializzata esterna.

25 M. Milanese offre una prima sintesi dei dati ceramici integrata in un più ampio scenario produttivo e commerciale; inoltre, ipotizza che fra i potenziali produttori che attingevano a quest'area petrologica potesse esservi la tribù ligure dei Viturii (Milanese 1987, p. 299-301) circa due secoli dopo ricordati nella Tavola bronzea insieme ad altre tribù liguri dell'hinterland genovese. 
1987, p. 301), ma non apparirebbe del tutto inverosimile - specie a quest'epoca - l'attività di un nucleo ligure che attingesse a questo areale petrografico ed operasse avendo acquisito più evolute capacità operative.

\section{Alcune note 'provvisorie' di sintesi}

Su questa eterogeneità qualitativa e distributiva della documentazione nel comprensorio considerato, anche a confronto della limitrofa realtà francese, incidono senza dubbio fattori contingenti quali le disomogenee - a parte pochi contesti - testimonianze disponibili, in certi casi assai polarizzate, oltre a continuità di vita, impatto antropico, peculiare geomorfologia dei luoghi. Al netto di tali difficoltà, ci si potrà interrogare circa l'impressione derivante da gran parte di quest'area (che in ogni caso offre una certa resistenza a sintesi unitarie) : quella di una fenomenica 'debolezza' delle evidenze, sia intrinseca, sia come esito di una mancata o tenue reattività a fattori esterni. Andrà valutata, pertanto, col progredire delle ricerche, l'eventualità che ciò risulti, effettivamente, un po' la cifra anche culturale per molte delle popolazioni preromane qui insediate, pure entro una gamma di valenze testimoniali ${ }^{26}$.

Questo panorama sembrerebbe, a tutta prima, un po' scoraggiare qualsivoglia tentativo di sondare le varie entità in gioco mediante la lente delle categorie interpretative prescelte; tuttavia può essere enucleata qualche indicazione tendenziale per futuri sviluppi di tali scenari.

Sull'oppidum di Genova, tra prima e seconda età del Ferro, a fronte di una generalmente riconosciuta predominanza etrusca ${ }^{27}$, almeno in una prima fase, non sembra si possano rilevare - in forme archeologicamente apprezzabili nella cultura materiale - né spiccate attitudini acculturatrici né disponibilità all'osmosi culturale, ma pare assistere piuttosto ad una giustapposizione dei vari elementi ${ }^{28}$; ciò, almeno, fino al successivo scenario, più dinamico, a partire dal IV sec. a. C. (in seguito al venir meno dell'assetto etrusco-padano e agli spostamenti invasionistici di popolazioni celtiche), nel quale concorrono, in variegata misura, fattori allogeni anche di segno differente tra cui l'affermazione commerciale

26 La provvisorietà di tale bilancio viene del resto ribadita dai ritrovamenti che si susseguono (ad esempio, a Genova, ad Albenga), malgrado la pluristratificazione dei siti.

27 Si discosta in parte Giannattasio 2007, p. 103-105. Data la parzialità dell'insediamento meglio noto, si sono postulati quivi anche altri nuclei di popolamento, coevi e preesistenti (Melli 2004 in Liguri 2004, p. 287 e p. 288).

28 Ciò in linea con le prevalenti prerogative commerciali dell'insediamento, naturale e strategico tramite fra costa e retroterra, e tappa fondamentale nell' arco tirrenico. massaliota, verso un'azione catalizzatrice foriera di una serie di effetti a catena non ancora omogeneamente analizzati. Tra i possibili riflessi di ciò nei settori della cultura materiale, non solo si registra per quanto riguarda le produzioni fittili il moltiplicarsi delle manifatture locali e regionali, con differenziate capacità artigianali (documentate sull'oppidum di Genova), ma, su un piano più ampio che potrebbe anche non escludere risvolti per così dire ideologici in senso lato, si osserva, ai confini orientali della compagine ligure presso gli Apuani, dopo un iniziale e pervasivo contatto con l'elemento etrusco ${ }^{29}$, l'emergere tra il IV sec. a. C. e la romanizzazione di espressioni identitarie abbastanza percepibili ${ }^{30}$.

L'impatto con il sopraggiungente elemento romano nella compagine ligure tirrenica, parzialmente riferito dalle fonti storiche, innesca senza dubbio anche a livello archeologico talune dinamiche di azione e reazione a stimoli esterni, che tra III sec. a. C. e i successivi agiscono spesso su realtà anteriori per noi poco definite : ad oggi, soltanto occasionalmente ciò si constata nella realizzazione di opere murarie (ad esempio, a Genova, forse a Bergeggi); nei casi più frequenti la sussistenza e la consistenza insediative se non commerciali di gran parte dei siti - soprattutto quelli minori, sovente indagati mediante sole surveys o vecchi scavi - acquisiscono maggiore visibilità e parametri tangibili proprio grazie alla mera circolazione di reperti mobili, soprattutto con il dilagare delle importazioni tirreniche ed italiche in genere ${ }^{31}$, mentre le conoscenze circa le produzioni locali rimangono per quest'epoca ancora un po' disgregate $^{32}$ (Ciampoltrini 2004 in Liguri 2004, p. 386-387; Gambaro 2004 in Liguri 2004, p. 498-500; Gambaro 2007 in Liguri 2007, p. 171-173; Gervasini 2007 in Liguri 2007, p. 159-167; Melli 2004 in Liguri 2004, p. 296-297; Melli 2004 in Ligures 2004, p. 180-181; Paribeni 2004 in Ligures 2004, p. 205-217).

La sistematizzazione più vasta possibile dei dati noti, quindi - al di là di semplici quadri distributivi dei manufatti -, pur non potendo verosimilmente approdare a soluzioni definitive per una realtà complessa, potrà

29 Con precoci esiti acculturativi già nella prima età del Ferro analizzati da A. Maggiani (Maggiani 2004 in Liguri 2004, p. 219-223).

30 Diversamente da quanto accade, allo stato attuale delle conoscenze, per altri popoli liguri (Ingauni, Intemelii nel Ponente Ligure) che la storiografia seriore bene individua come avversari dei Romani. 31 Va rimarcato che, non di rado, molti di questi siti d'altura oggetto di surveys, specie nel Ponente ligure, restituiscono esclusivamente materiali della romanizzazione e della romanità piuttosto che prodotti liguri (Gambaro 2008, p. 1445-1470).

32 Tra i quali, ad esempio, la prosecuzione dell'attività manifatturiera fittile regionale documentata sull'oppidum di Genova, o nel sito di Monte Follia, e una produzione locale di vernice nera a Ventimiglia (Gandolfi 2004 in Liguri 2004, p. 492-496), ormai entro un orizzonte pienamente romanizzato. 
costituire, ad una, sia l'imprescindibile presupposto, sia il principale campo di prova dei mirati strumenti di lettura messi a punto per tale approccio. È, dunque, essenzialmente secondo un'analisi estesa a molteplici aspetti che l'areale ligure tirrenico, nel passaggio tra prima e seconda età del Ferro fino alla romanità, potrà essere vagliato, anche perseguendo una maggiore scansione cronologica dei dati e dei fenomeni, malgrado la difficoltà di fondo nella gestione delle informazioni disponibili. Si esploreranno, quindi, i margini di continuità o discontinuità, non solo presenti all'interno della compagine considerata (ad esempio, nel tentativo di illuminare meglio i gruppi liguri noti dalle fonti), ma pure quelli rilevabili - specialmente a livello di meccanismi generali - rispetto ad ambiti storico-geografici circonvicini, contigui fisicamente, o anche d'oltremare. Accanto ai territori interessati ad est dalla presenza umana di Liguri ed Etruschi sovente richiamati, si focalizzerà l'osservazione sulla Gallia sud-orientale, e segnatamente sulla regione compresa nell'antica Liguria quale luogo in potenza privilegiato ove investigare il trapasso culturale rispetto alla porzione di mondo indigeno più o meno caratterizzata dall'influsso greco-massaliota ${ }^{33}$; lo sguardo sulla Liguria interna, poi, consentirà di verificare eventuali specificità rispetto a questa compagine ligure, sia circa le condizioni di partenza sia circa differenti reazioni ai contatti cispadani di varia matrice, mentre, sul versante tirrenico, andranno approfondite le potenzialità della Corsica, oggi al centro di una rinnovata stagione di indagini e di un rinvigorito slancio conoscitivo.

\section{Bibliografia}

Assmann 1997 : ASSMANN (J.) - La memoria culturale. Scrittura, ricordo e identità politica nelle grandi civiltà antiche. Torino, 1997,310 p.

Augé 2009 : AUGE (M.) - Nonluoghi. Introduzione a una anthropologia della surmodernità. Milano, 2009, 120 p.

Bats 2005 : BATS (M.) - L'acculturation et autres modèles de contacts en archéologie protohistorique européenne. In : Szabó (M.) dir., Celtes et Gaulois, l'Archéologie face à l'Histoire, 3 : les Civilisés et les Barbares (du $V^{E}$ au II siècle avant J.-C.). Actes de la table ronde de Budapest, 17-18 juin 2005. Glux-en-Glenne : Bibracte, Centre archéologique européen, 2006 (Bibracte 12/3), p. 29-41.

Bats 2007 : BATS (M.) - Entre Grecs et Celtes en Gaule méridionale : de la culture matérielle à l'identité ethnique. In: Identités ethniques dans le monde Grec antique. Pallas, 73, 2007. Presses Universitaires du Mirail, Toulouse, p. 191-198. Bérato 2002 : BÉRATO (J.) - Territoire et faciès culturel à l'âge du Fer dans le Var : bilan de vingt ans de recherches. In : Garcia (D.) et Verdin (F.) dir., Territoires celtiques. Espaces ethniques et territoires des agglomérations protohistoriques d'Europe occidentale, Actes du XXIV e colloque international de l'AFEAF, Martigues, 1-4 juin 2000. Paris, Éditions Errance, 2002, p. 160-172.

33 Bérato 2002, p. 160-172; senza prescindere, naturalmente, dalla circolazione quivi dei prodotti di area massaliota : si veda, ad esempio, il censimento della diffusione di ceramica grigia ad 'onde' in questo volume a cura di L. Mercuri.
Boissinot 1998 : BOISSINOT (PH.) - Que faire de l'identité avec les seules méthodes de l'archéologie?. In : D'Anna (A.), Binder (D.) dir., Productions et identités culturelles, Rencontres méridionales de Préhistoire récente, Deuxième session. Arles (1996), Antibes, APDCA éd., 1998, p. 17-25.

Boissinot 2005 : BOISSINOT (PH.) - Sur la plage emmêlée : Celtes, Ligures, Grecs et Ibères dans la conformation des textes et de l'archéologie. Mélanges de la Casa de Velázquez, 35, 2, 2005, p. 13-44.

Boissinot 2011 : BOISSINOT (PH.) - Des pratiques, des objets et des agents. In : Boissinot (Ph.) dir., L'archéologie comme discipline? (Le genre humain), Paris, Éditions du Seuil, avril 2011, p. 9-22.

Cambi 2012 : CAMBI (F.) DIR. - Il ruolo degli oppida e la difesa del territorio in Etruria : casi di studio e prospettive di ricerca. Trento, Tangram, 2012, 370 p. (Aristonothos 5).

Ciampoltrini et alii 2008 : CIAMPOLTRINI (G.), SPATARO (C.), MANFREDINI (R.) - Il Cippo etrusco da Sant'Ippolito di Santa Maria a Monte : paesaggi e insediamenti nel medio Valdarno inferiore fra VI e II secolo a. C. Biantina, La Grafica Pisana, 2008, 62 p.

Ciampoltrini, Notini 2011 : CIAMPOLTRINI (G.), NOTINI (P.) - La fanciulla di Vagli. Il sepolcreto ligure-apuano della Murata a Vagli di Sopra. Lucques, I segni dell'Auser, 2011, 80 p.

Del Lucchese, Gambaro 2010 : DEL LUCCHESE (A.), GAMBARO (L.) Ricerche archeologiche nel sito d'altura di Monte Rocche (Castellaro - IM). Campagne 2003 e 2005. In : Bulgarelli (F.), Del Lucchese (A.), Gervasini (L.) dir., Archeologia in Liguria, nuova serie, volume II, 2006-2007. Gênes, De Ferrari, 2010, p. 27-52.

Feugère, Py 2011 : FEUGÈRE (M.), PY (M.) - Dictionnaire des monnaies découvertes en Gaule méditerranéenne (530-27 avant notre ère). MontagnacParis, M. Mergoil- Bibliothèque nationale de France éd., 2011, 720 p.

Gambaro 2008 : GAMBARO (L.) - Importazioni di merci africane nelle aree rurali dell'estremo Ponente ligure tra l'età tardo-repubblicana e la tarda antichità. In : González (J.), Ruggeri (P.), Vismara (C.), Zucca (R.) dir., L'Africa romana. Le ricchezze dell'Africa. Risorse, produzioni, scambi, Atti del XVII Convegno di studio, Sevilla, 14-17 dicembre 2006. Rome 2008, p. 1427-1470. Garcia 2004 : GARCIA (D.) - La Celtique méditerranéenne. Habitats et sociétés en Languedoc et en Provence du VIII e au II siècle av. J.-C. Paris, Errance, 2004 (Collection des Hespérides).

Giannattasio 2007 : GIANNATTASIO (B. M.) - I Liguri e la Liguria. Storia di un territorio prima della conquista romana. Milan, Longanesi, 2007, 208 p. (Biblioteca di Archeologia 35).

Giannattasio, Odetti 2009 : GIANNATTASIO (B. M.), ODETTI (G.) dir. Monte S. Elena (Bergeggi-SV). Un sito ligure d'altura affacciato sul mare. Scavi 1999-2006. Florence, All'insegna del Giglio, 2009, 358 p.

Launaro 2009 : LAUNARO (A.) - La Val Polcevera dalla seconda Età del Ferro alla fine dell'Evo Antico. Rivista di Studi Liguri, LXXII-LXXIII, 20062007 [2009], p. 5-34.

Lautier, Rothé 2010 : LAUTIER (L.), ROTHÉ (M.-P.) DIR. - Les Alpes Maritimes. Paris, Académie des Inscriptions et Belles-Lettres, 2010, 832 p. (Carte archéologique de la Gaule 06).

Ligures 2004 : VENTURINO GAMBARI (M.) E GANDOLFI (D.) DIR. Ligures celeberrimi. La Liguria interna nella seconda età del Ferro, Atti del Convegno Internazionale, Mondovì, 26-28 aprile, 2004. Bordighera, Istituto Internazionale di Studi Liguri, 2004, 440 p.

Lechenault à paraître : LECHENAULT (M.) - Des mercenaires ligures en Corse? Les tombes à épées droites de la seconde moitié du IVe s. av. J.-C. dans la nécropole d'Aléria (Haute-Corse). In : Les Celtes et le Nord de l'Italie, Actes du XXXVI e colloque international de l'AFEAF. Vérone, 17-20 mai 2012. À paraître.

Liguri 2004 : DE MARINIS (R. C.) e SPADEA (G.) dir. - I Liguri. Un antico popolo tra Alpi e Mediterraneo, Catalogo della Mostra, Genova, 23 ottobre 2004-23 gennaio 2005. Milan, Skira, 2004, 680 p.

Liguri 2007 : DE MARINIS (R.C.) e SPADEA(G.) dir.-Ancora su ILiguri.Un antico popolo europeo tra Alpi e Mediterraneo. Gênes, De Ferrari, 2007, 296 p. Mannoni 1995 : MANNONI (T.) - La ceramica dell'età del Ferro nel Genovesato. Saggio di studio mineralogico. In : MANNONI (T.), Archeometria Geoarcheologia dei manufatti. Gênes, Escum, 1995 (1972), p. 88-114. 
Mannoni 2010 : MANNONI (T.) - Dati sull'ambiente antropizzato della Liguria appenninica prima della romanizzzazione. In : Angeli Bertinelli (M.G.) e Donati (A.) dir., Città e territorio. La Liguria e il mondo antico, Atti del IV Incontro Internazionale di Storia Antica,. Genova, 19-20 febbraio 2009. Rome, Giorgio Bretschneider, 2010, p. 31-60.

Melli 2007 : MELLI (P.) - Genova preromana. Una città portuale del Mediterraneo tra il VII e il III a. C. Gênes, Fratelli Frilli éd., 2007.

Milanese 1987 : MILANESE (M.) - Scavi nell'oppidum preromano di Genova (Genova S. Silvestro 1). Rome, «L'Erma» di Bretschneider, 1987, $390 \mathrm{p}$.

Piccardi 2007 : PICCARDI (E.) - Il bere e il mangiare presso i Liguri: tradizioni, commerci e processi di acculturazione dalla Seconda Età del Ferro alla romanizzazione. Alba Pompeia, n.s., XXVIII, II, 2, 2007 [2009], p. 97-116.
Piccardi, Pêche-Quilichini sous presse : PICCARDI (E.), PÊCHEQUILICHINI (K.) - Production, trading and imitation of pottery in the northern Tyrrhenian Sea area in the 2nd Iron Age: potential evidence of identity. In : Identity \& Connectivity. XVI SOMA Conference, Florence, $1^{\text {st }}-3^{\text {rd }}$ of March 2012. sous presse.

Pucci 1997 : PUCCI (I.) - Culti naturalistici della Liguria antica. La Spezia, Luna Editore, 1997, 100 p.

Salicis 2007 : SALICIS (CL.) - Dévotion indigène et cultes préromains : hypothèse d'interprétation de certaines structures de sommet dans les Alpes-Maritimes. Mémoires de l'IPAAM, XLIX. Nice, 2007, p. 7-20. Van Dommelen, Knapp 2010 : VAN DOMMELEN (P.), KNAPP(A. B.) dir.Material connections in the ancient Mediterranean. Mobility, Materiality and Mediterranean Identities. Londres e New York, Routledge éd., 2010, 256 p. 



\title{
Interactions coloniales, cuisine et formes de consommation en Ibérie septentrionale
}

\author{
Joan Sanmartí \\ Professeur à l'Université de Barcelone \\ Membre de l'Institut d'Estudis Catalans (UAI)
}

\section{Résumé}

La recherche développée durant ces dernières décennies dans le nord-est de la péninsule Ibérique a montré que le développement socioculturel des communautés indigènes durant l'âge du Fer, qui les menées à la formation de structures étatiques, est dû essentiellement à des causes endogènes. Il est également possible de démontrer que le volume et la nature des importations céramiques d'origine grecque et phénico-punique, ainsi que leurs versions indigènes, peuvent être expliqués en grande partie par les intérêts des élites locales, qui s'en sont servies pour leurs stratégies de contrôle social, et qui ont aussi probablement développé, à partir du IV ${ }^{\mathrm{e}} \mathrm{s}$. av. n. è., une cuisine de classe inspirée de celle des cultures méditerranéennes. On en conclut que les sociétés indigènes ont eu un rôle actif dans les interactions coloniales, qui a peut-être même conditionné les structures économiques des communautés exogènes installées sur ou près de la côte ibérique.

Mots-clés : Ibères, interaction coloniale, mutation socioculturelle, stratification sociale, cuisine, banquets

\begin{abstract}
The research developed in recent decades in the northeast of the Iberian Peninsula indicates that socio-cultural development of the indigenous communities during the Iron Age -which led to the formation of state-like structures- was mainly due to endogenous causes. It is now also possible to prove that the volume and nature of Greek and Phoenicio-Punic imported pottery -as well as some of their indigenous versions- can be explained largely by the interests of local elites, who used this material to enhance their strategies of social control, and probably developed, starting in the fourth century $\mathrm{BC}$, a class cuisine inspired by that of the aforementioned Mediterranean cultures. It is concluded that indigenous societies had an active role in colonial interactions, and that they may have even influenced the economic structures of the exogenous communities installed on or near the Iberian coast.
\end{abstract}

Keywords: Iberians, colonial interaction, sociocultural change, social stratification, cuisine, feasting 


\section{Introduction}

Les recherches développées durant ces dernières décennies ont montré que l'urbanisation du territoire ibérique et la formation des premiers états s'expliquent essentiellement par des causes endogènes (Sanmartí, 2004, 2010) et non pas par l'action des Grecs, des Phéniciens et des Puniques, comme cela avait été proposé à plusieurs reprises (Maluquer de Motes 1966 et 1982). Suivant cette ligne de travail, l'objet de ma contribution à ce colloque est d'analyser dans quelle mesure la préparation des aliments et certains rituels selon lesquels ils ont été consommés ont eu un rôle dans la création, la consolidation et l'approfondissement de la différenciation sociale au sein des populations de l'Ibérie septentrionale (fig. 1). Elle est donc fondée sur deux hypothèses à propos de la société ibérique qui sont directement en rapport l'une avec l'autre. La première, qui a été largement vérifiée au cours des dernières décennies, est que durant l'âge du Fer un processus de différenciation sociale s'est produit en Ibérie, ce qui suppose l'apparition et la consolidation d'élites sociales nettement séparées du reste de la société. La deuxième, qui se trouve au centre de mon travail, est que ces élites se sont servies de leurs rapports privilégiés, voire exclusifs, avec les Puniques et les Grecs pour bâtir, consolider et approfondir la différenciation sociale ; pour ce faire, elles ont adopté à chaque moment dans ces rapports des stratégies différentes, en fonction des mutations que la société ibérique elle-même a subi et auxquelles les groupes privilégiés ont réagi. Autrement dit, je pense que la nature des importations puniques et grecques dans le monde indigène, leur origine précise, leur volume, le fait même qu'elles existent, est pour l'essentiel la conséquence des stratégies de cette élite.

Mon but, donc, est de retrouver la logique sociale illustrée par ces importations et par l'adoption de pratiques culturelles exotiques, ce qui revient, finalement, à reconstituer les pratiques de consommation et de préparation des aliments qui ont servi à cette finalité de différentiation et de discrimination. Plus précisément encore, je cherche à découvrir si une cuisine de classe, spécifique des élites et à caractère nettement diacritique, a été créée.

Je rouvre donc un dossier déjà entamé dans quelques travaux antérieurs (notamment Sanmartí 2009), avec toutefois des précisions que je crois importantes, et aussi des apports nouveaux, surtout par rapport à la création d'une cuisine de classe. Il faut également dire que des travaux encore récents (Oliver 2000 ; Pons, Garcia 2008) ont largement traité le sujet de l'alimentation dans le monde ibérique - ce qui montre l'intérêt qu'il a suscité dans la recherche hispanique - mais sans insister suffisamment, je crois, sur les aspects sociaux qui sont en revanche au cœur de l'approche que je propose. C'est pour cette raison que le sujet m'a paru particulièrement indiqué pour ce colloque en hommage à Michel Bats, et aussi parce que la lecture de Vaisselle et alimentation à Olbia de Provence (Bats 1988) et de «Consommation, production et distribution de la vaisselle céramique » (Bats 1989) - avec, pour tout dire, les recherches J.-P. Morel (1994) - m'a amené pour la première fois à me poser des questions différentes sur la céramique, autres que la chronologie, l' «identité culturelle » ou la signification par rapport au volume et à l'intensité des rapports commerciaux.

Pour ce qui est de mes sources théoriques, il va presque sans dire que le travail de J. Goody ${ }^{1}$ y occupe une place très importante, surtout pour ce qui est des conditions nécessaires pour l'apparition d'une cuisine de classe différenciée (Goody 1982, p. 98 et 104-105). De même, je dois beaucoup aux travaux de M. Dietler sur la nature des banquets et son rapport avec les formes d'organisation des sociétés (Dietler 1999), car son modèle permet de comprendre les mutations de nature et de volume des importations dans le cadre de la nature changeante des structures sociales indigènes.

Je suivrai une démarche diachronique, depuis le Bronze final jusqu'à la conquête romaine. Je distinguerai à l'intérieur de cette longue période trois étapes, correspondant respectivement à des sociétés de petite échelle (fin du $\mathrm{II}^{\mathrm{e}}$ millénaire $-\mathrm{VI}^{\mathrm{e}} \mathrm{s}$. av. n. è.), à la formation des premières unités politiques régionales, dirigées par des élites héréditaires nettement séparées du reste de la société, et, finalement, au développement de systèmes administratifs qui signalent la consolidation des aristocraties.

\section{Avant les Ibères : cuisine et festins entre le Bronze final et le premier âge du Fer}

Malgré les nombreuses fouilles récentes de sites de cette période, nous ne comptons que sur quelques ensembles de céramiques trouvés in situ à l'intérieur de maisons et que l'on peut supposer à peu près complets, ce qui entrave l'interprétation fonctionnelle des vases. La meilleure information disponible pour le Bronze final provient de Genó, un petit hameau du $\mathrm{XI}^{\mathrm{e}} \mathrm{s}$. av.n.è.dans la Catalogne intérieure (fig. 1), qui fut détruit par un incendie violent après une très courte période d'occupation. Bien que la fonction des vases ne peut pas toujours être précisée, on constate que chaque maison possédait un

1 Que j'ai aussi découvert à partir de la lecture de Vaisselle et alimentation à Olbia de Provence. 


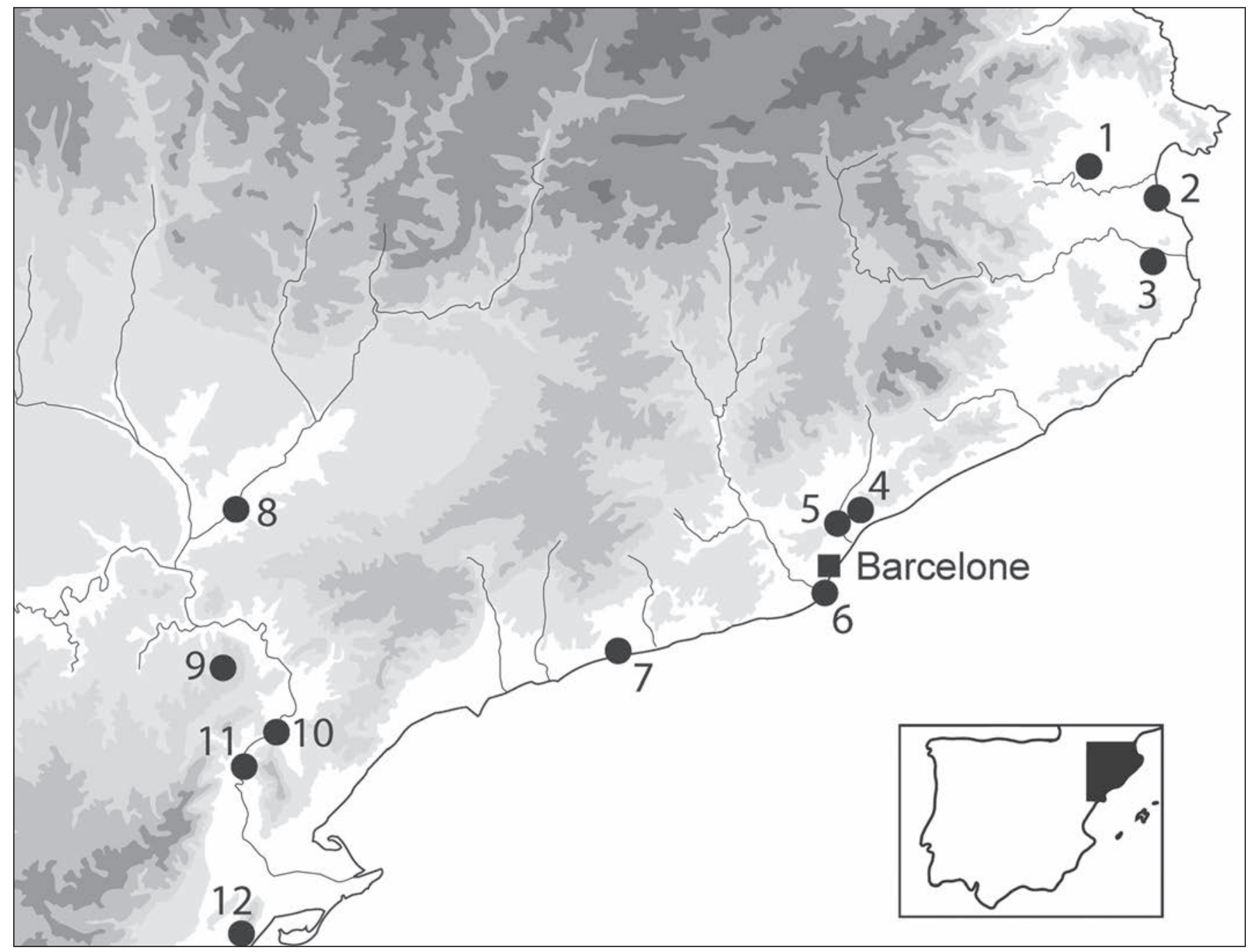

Fig. 1. Carte du nord-est de la péninsule Ibérique montrant la situation des sites mentionnés dans le texte. 1) Mas Castellar de Pontós ; 2) Emporion (Empúries-Ampurias) ; 3) Ullastret ; 4) Turó d'en Boscà ; 5) Puig Castellar de Santa Coloma de Gramenet ; 6) Montjuïc ; 7) Alorda Park ; 8) Genó ; 9) Turó del Calvari; 10) Barranc de Gàfols ; 11) Aldovesta ; 12) Sant Jaume-Mas d'en Serrà.

nombre important de récipients destinés au service et à la consommation des aliments (souvent à profil bitronconique), ainsi que quelques grands vases à stockage et encore autres de dimensions moyennes, profonds, à forme cylindrique, ovale, ou à profil en « $S$ » - c'est à dire, des pots -, dont la fonction culinaire paraît évidente et que l'on peut supposer destinés à la préparation de bouillies, soupes et potages (fig. 2). Ceci est cohérent avec la nature de la vaisselle, qui comprend, en plus de coupes à anses, des bols, forme appropriée à ce genre de préparations. On reconnaît en plus des jarres pour le service des boissons, dont la bière (Juan-Tresserras 1998).

Malheureusement, il n'y a pas d'autres sites ayant livré des documents aussi complets pour les $\mathrm{X}^{\mathrm{e}-V I I I}{ }^{\mathrm{e}}$ s. av. n. è., mais la documentation disponible pour le $\mathrm{VII}^{\mathrm{e}}$ - première moitié $d \mathrm{U} \mathrm{VI}^{\mathrm{e}} \mathrm{s}$. av. n. è.
- notamment à Aldovesta (Mascort et al. 1991), Barranc de Gàfols (Sanmartí et al. 2000) et Sant Jaume - Mas d'en Serrà (Garcia Rubert 2005) - montre que tous les vases à fonction probablement culinaire sont en fait des pots, tandis que les marmites sont absentes (fig. 3). On peut donc supposer qu'il y a eu peu ou pas de mutations dans les formes de préparation des aliments. Par conséquent, si l'on en juge par les vases employés pour la cuisson, on dirait que cette cuisine du Bronze final et du Premier âge du Fer est très similaire à la « civilisation alimentaire celte, voire germano-celte ou celte-ligure » dont parle M. Bats (Bats 1988, p. 214-219), à laquelle il faudrait ajouter par conséquent la notion d' « ibérique ». Il s'agirait donc d'une cuisine à base de bouillies, de soupes et de potages, mais d'autres préparations ne comportant pas l'usage de récipients ont dû exister : 


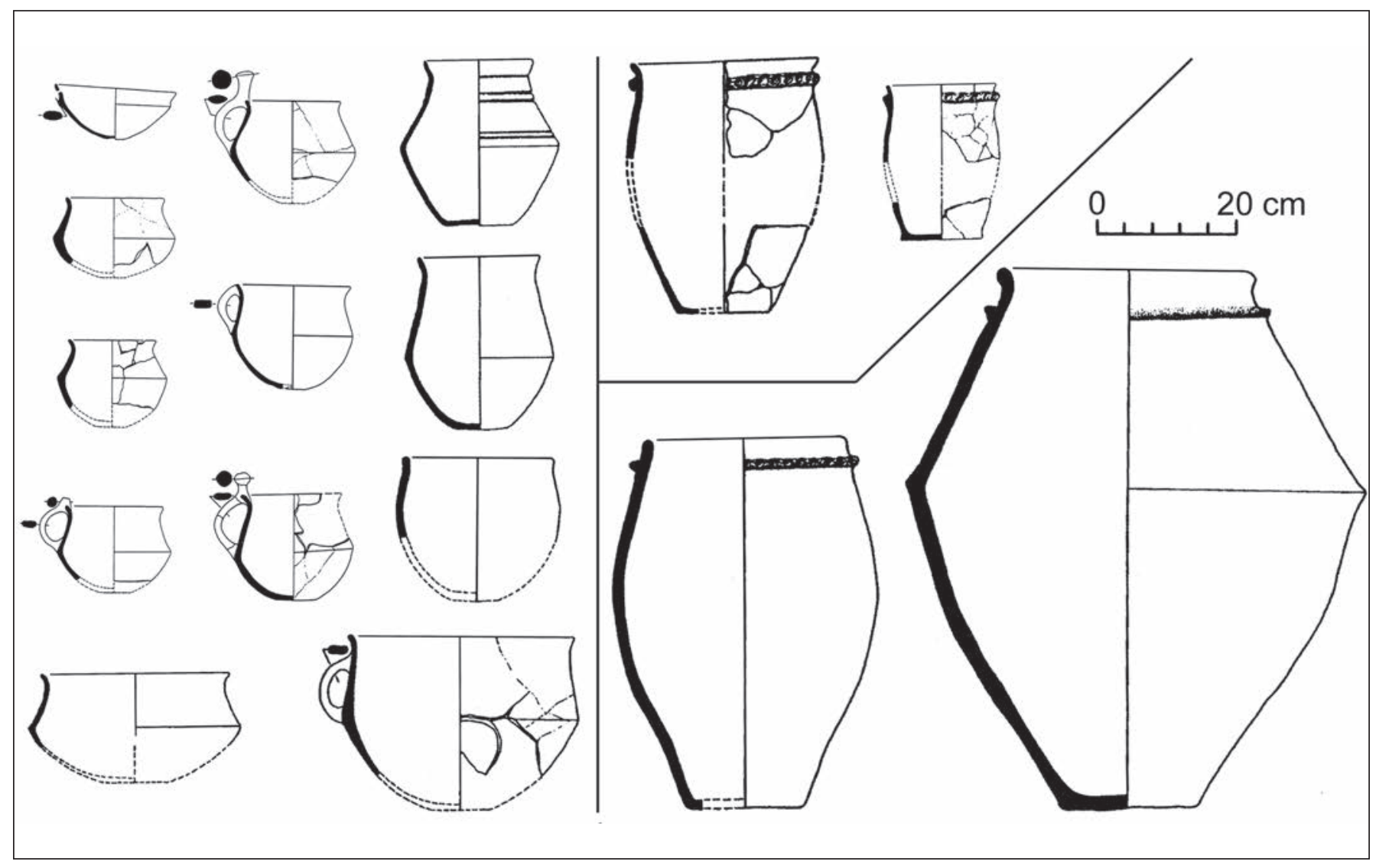

Fig. 2. Vases de la maison 11 du site de Genó (d'après Maya et al. 1998, modifié).

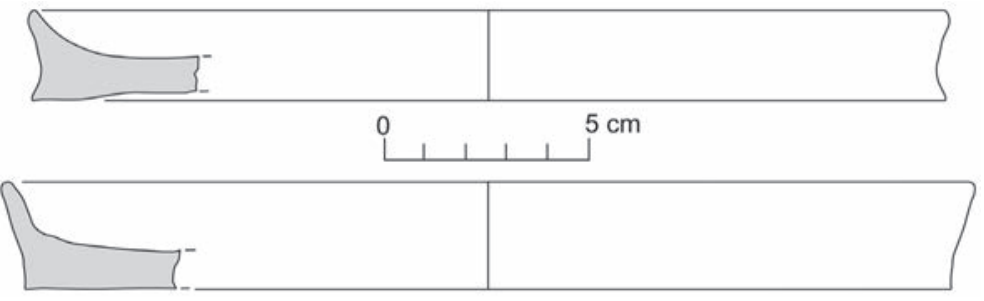

Fig. 3. Plats non tournés provenant d'Aldovesta. 


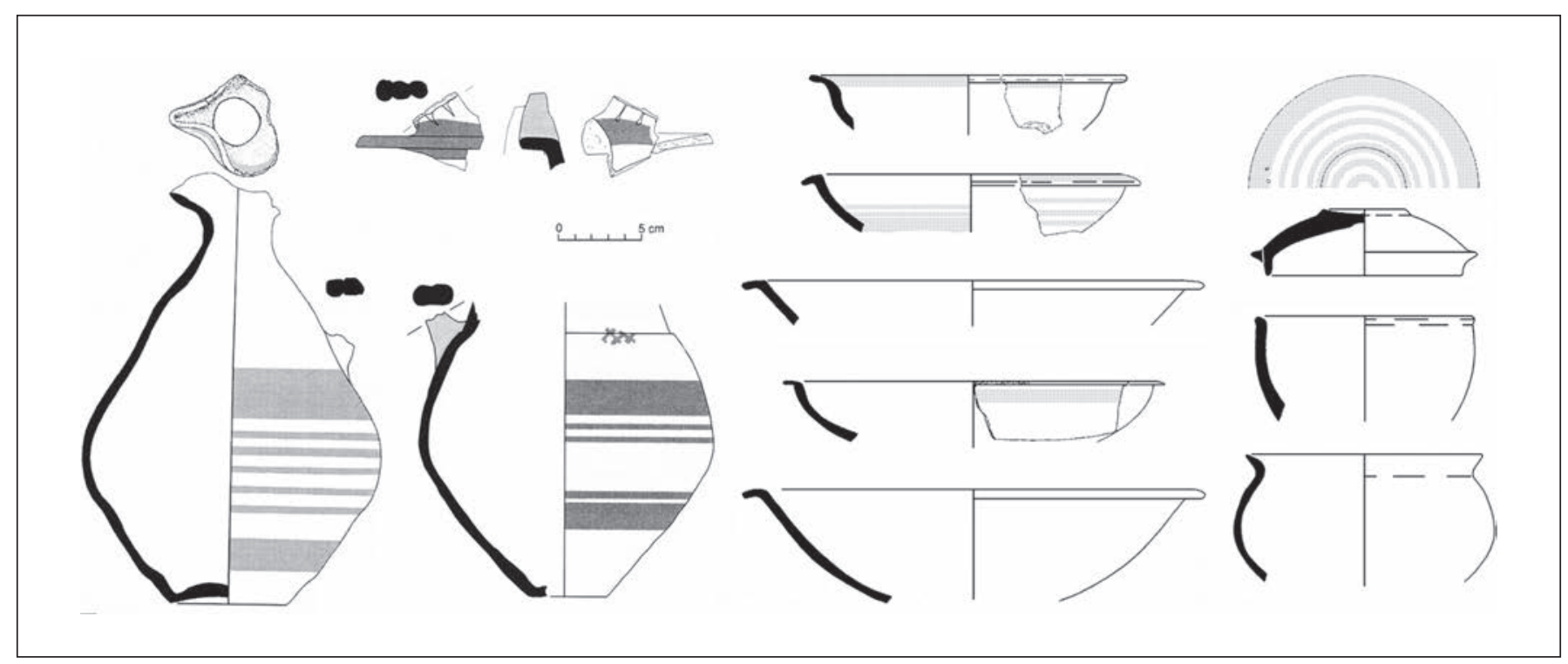

Fig. 4. Vaisselle tournée de Barranc de Gàfols.

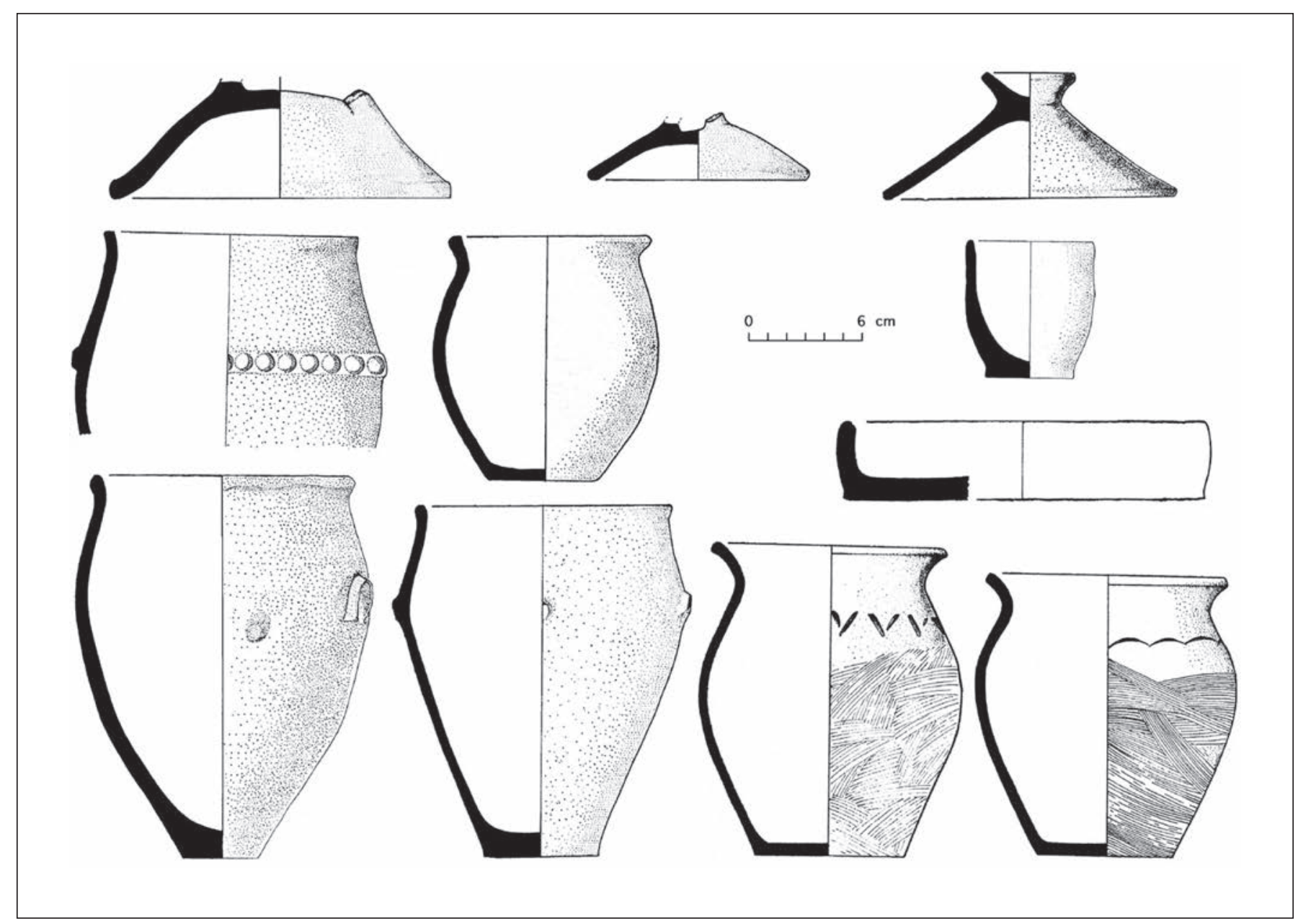

Fig. 5. Vases non tournées d'une maison de Turó de Mas Boscà datée vers 200 av. n. è. (d'après Junyent et Baldellou 1972, modifié). 
par rapprochement au feu ou aux braises de bouts de viande ou de poisson tenus avec des bâtons ou des pinces, ou l'usage d'ardoises comme surface de cuisson, peut-être aussi de grils en céramique et des broches en fer ; mais seules les broches sont attestées, dans certaines tombes tardives.

Nous sommes encore moins bien renseignés sur les banquets. En fait, nous manquons complètement de preuves directes de leur existence, qui peut toutefois être déduite, du moins à partir du $\mathrm{VII}^{\mathrm{e}} \mathrm{s}$. av. n. è., de deux sortes d'indices. D'une part, le fait que certaines tombes contiennent des objets qui sont probablement en rapport avec lui, comme les broches, déjà mentionnées, les simpula et les bols en bronze (Lucas 2003-2004; López Cachero 2007, p. 114-115). De l'autre, l'acquisition d'un grand nombre d'amphores phéniciennes provenant de la côte d'Andalousie durant le $\mathrm{VII}^{\mathrm{e}}$ et le début du VIe s.av.n. è. Ce fait est remarquable parce que le volume des importations est extrêmement élevé par rapport à toute autre période avant la conquête romaine (22\% du NMI ; $21 \%$ du nombre de fragments), ce qui doit s'expliquer parce qu'elles ont surtout servi à la redistribution, sous forme de banquets compétitifs, pour acquérir et conserver le pouvoir. Cette nécessité de redistribution indique une forme d'organisation sociale que, suivant M. Godelier, on peut désigner comme société « de potlatch » ou de «big men » (Godelier 1999), ce qui s'accorde parfaitement avec la documentation sur les formes d'occupation du territoire, non hiérarchisées et caractérisées par l'existence de grandes maisons isolées, contenant de nombreuses amphores phéniciennes (Aldovesta) ou des accumulations d'objets liés à la production de manufactures (des centaines de pesons pour métiers de tisserand à Sant Jaume - Mas d'en Serrà). On peut supposer que les deux sites étaient habités par des « big men» (Sanmartí 2010). Pour ce qui est des nécropoles, on remarque aussi, dans un contexte général apparemment égalitaire, l'existence de quelques tombes qui se distinguent par le nombre, l'origine ou la qualité des offrandes funéraires.

Remarquons aussi que les importations céramiques sont constituées presque exclusivement par des amphores, tandis que la vaisselle est quasiment absente, le reste du matériel étant constitué par d'autres grands conteneurs (pithoi, amphores à col) et des mortiers, qui ont peut-être servi à broyer des substances pour aromatiser le vin contenu dans les amphores. On peut en conclure que le vin semble simplement s'être ajouté à la bière, et l'avoir en partie remplacé, sans que pour autant les rituels de consommation aient subi des modifications importantes. Autrement dit, à cette époque, les éléments dirigeants de la société indigène ne semblent pas avoir été en mesure ou avoir jugé utile d'adopter de façon générale des rituels diacritiques, mais, par contre, ils ont été forcés d'importer de grandes quantités de vin pour la redistribution, sous des formes peut-être diverses, parmi lesquelles le banquet a dû être très important. L'ethos social égalitaire devait encore prévaloir.

Observons toutefois la présence dans certains contextes d'une forme nouvelle qui a probablement été introduite par les Phéniciens et qui permet de nuancer ce que nous venons de dire. Il s'agit de grands plats modelés, de faible hauteur, qui ne font pas partie du répertoire céramique indigène. On en a documenté deux exemplaires dans l'espace domestique de l'ensemble d'Aldovesta (Mascort et al. 1991, p. 31 et pl. 28, 1-2) (fig. 3). Des récipients semblables sont documentés à Sant Jaume - Mas d'en Serrà, sur la côte au sud de l'embouchure de l'Èbre, mais faits en argile non cuite, ils doivent avoir eu des fonctions différentes (Garcia Rubert 2005, vol. 3, planche 117). Or, il est important de noter que cette forme se retrouve aussi, mais toujours en petit nombre, dans des sites phéniciens Toscanos (Schubart, Maas-Lindemann 1984, p. 143, fig. 22, no-932), Chorreras (Aubet et al. 1979, p. 119 et p- 118, fig. 11, no 149), Morro de Mezquitilla (Schubart 1985, fig. 12), Lixus (Belén et al. 1996, p. 343, fig. 3 , $\mathrm{n}^{\mathrm{o}} 7$ et 9) - ou à forte influence phénicienne d'Occident (Ceuta) (Villada et al. 2010, p. 367, fig. 113, no 22), mais aussi à Carthage (Mansell 1999, p. 228-229, pl. 5, 46-48). En fait, c'est dans les contextes indigènes du Maghreb oriental qu'elle est particulièrement courante, par exemple à Althiburos, où les fouilles récentes en ont découvert des dizaines d'exemplaires, dont les plus anciens remontent au moins au $\mathrm{IX}^{\mathrm{e}} \mathrm{s}$. av. n. è. (Kallala, Sanmartí 2011). Il y a donc de bonnes raisons pour penser que c'est une forme que les Phéniciens ont adopté des indigènes du Maghreb oriental, qu'ils ont répandu vers l'extrême occident, et qui a finalement été adoptée ponctuellement dans la région de l'Èbre, sans doute par un personnage éminent.

Quant à la fonction précise de ces plats, ils peuvent être utilisés aussi bien pour la préparation de certains aliments - viande, légumes, pâte à pain et semoule, tel qu'on le fait actuellement avec des formes proches - que pour la consommation en commun, mais les exemplaires les plus profonds auraient servi - à en juger par leurs homologues contemporains - à griller les céréales ou à faire cuire la galette (Fayolle 1992, p. 177-181). La faible hauteur et la présence d'une quille à la base des deux exemplaires d'Aldovesta (qui les rapproche nettement de ceux d'Althiburos) indiquerait que, comme la majna moderne, ils étaient destinés à la consommation en commun et peut-être à la préparation d'aliments, 


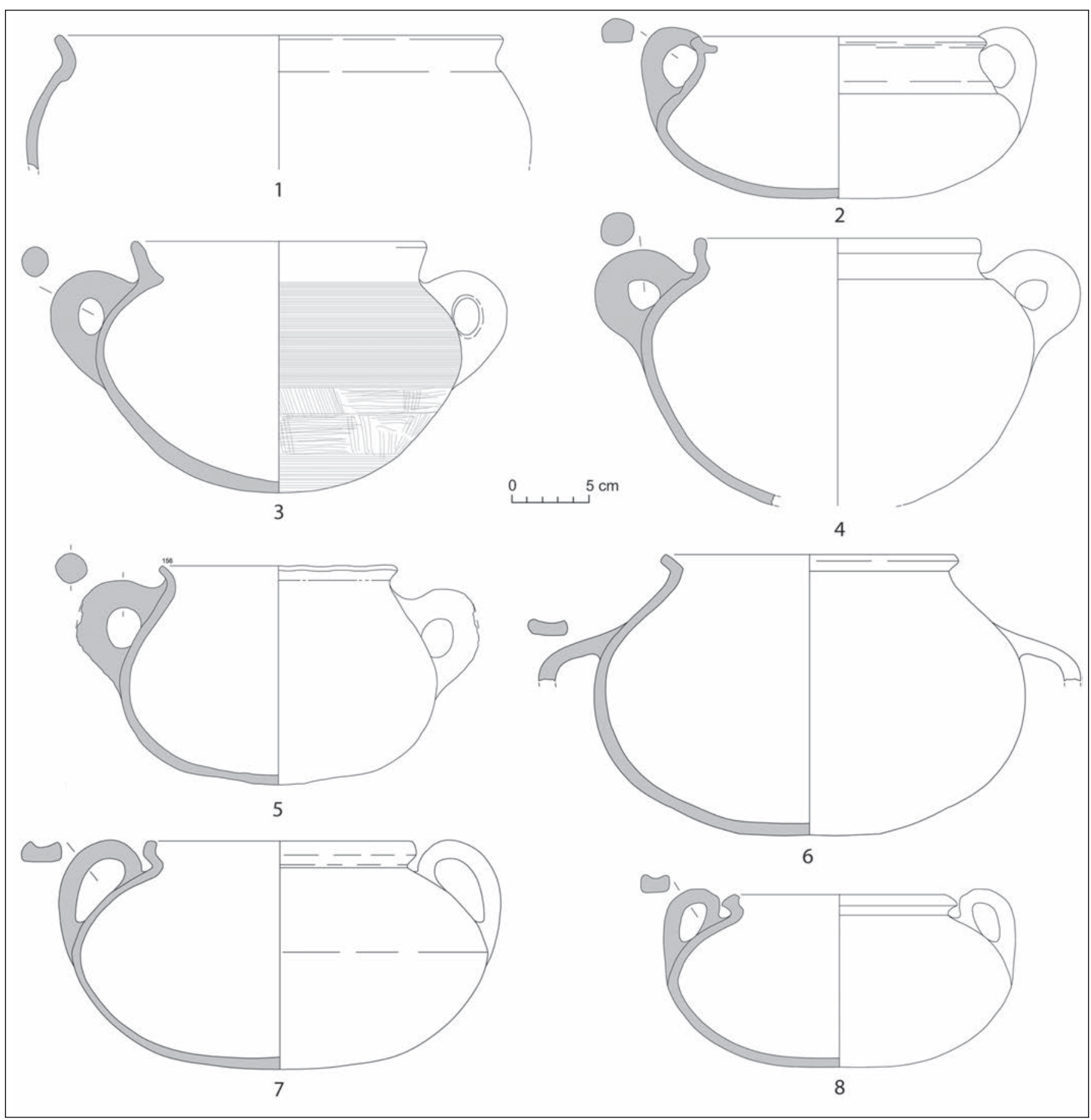

Fig. 6. Caccaboi tournés (1-4 et 7-8) et modelés (5-6) provenant d'Emporion (1), d'Ullastret (24-6 et 8) et d'Alorda Park (3 et 7). 


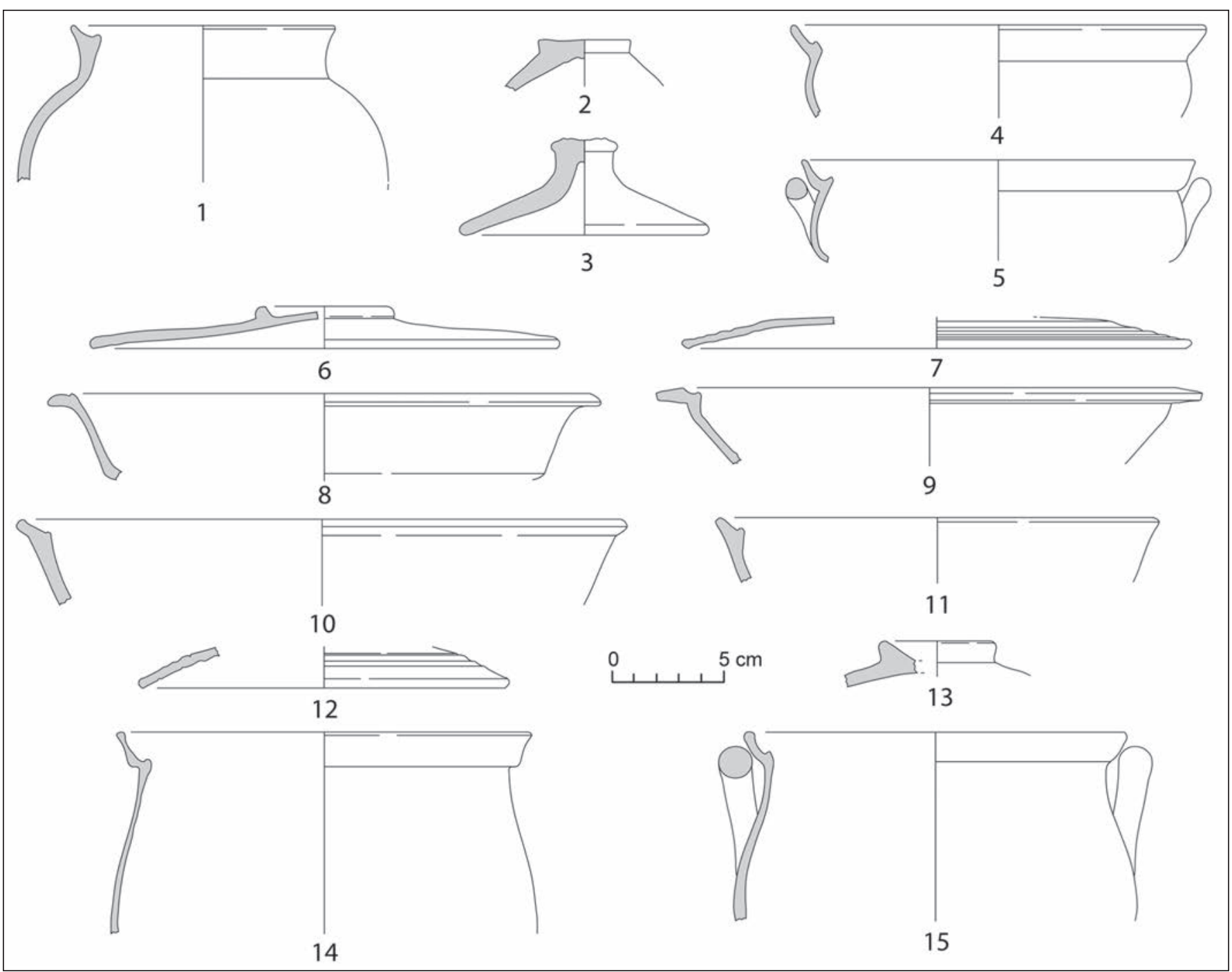

Fig. 7. Céramique culinaire carthaginoise provenant d'Alorda Park (1-4 et 6-13), Can Miralles-Can Modolell (5), Turó del Vent (14) et Can Bartomeu (15). 
plutôt qu'à la cuisson. Quoi qu'il en soit, il s'agit clairement d'un type de vase introduit par le contact avec les Phéniciens et qui, dans un contexte comme celui du site d'Aldovesta, ne peut être interprété que comme un signe de distinction par rapport aux usages culinaires ou de consommation propres aux communautés autochtones du Premier âge du Fer.

\section{Une subculture aristocratique de la consommation: (550-400 av. n. è.)}

Il faut probablement voir dans les plats d'Aldovesta un signe précurseur, car on remarque dès le début du deuxième quart du $\mathrm{VI}^{\mathrm{e}} \mathrm{s}$. av. n. è. une mutation importante dans la nature des importations, de sorte que la vaisselle devient de plus en plus importante par rapport aux grands conteneurs. Ceci est déjà évident au petit site de Barranc de Gàfols, sur le cours de l'Èbre, où l'on a documenté un nombre considérable de vases importés $(87 \%$ des fragments ; $86 \%$ du NMI pondéré par un), dont la plupart est de type phénicien et provient probablement du sud-est de la péninsule ibérique (et non plus de la côte andalouse) (Sanmartí et al. 2000). Dans cet ensemble, la vaisselle (bols et assiettes surtout, mais aussi des coupes, dont une imitant des formes corinthiennes, une lekané et deux cruches) (fig. 4) sont majoritaires (47\%), alors que les amphores de transport ne représentent que $14 \%$ de ce matériel et les autres conteneurs (pithoi, amphores à col et autres types apparentés) en constituent le $39 \%$ restant.

La documentation fournie par Barranc de Gàfols - à laquelle il faut ajouter celle qu'a livré plus récemment le site de Turó del Calvari, Vilalba dels Arcs (Sardà 2008) - est importante, entre autres raisons parce qu'elle montre que cette tendance dans la nature du matériel céramique importé n'est pas la conséquence de l' «arrivée des Grecs », qui dans le deuxième quart du $\mathrm{VI}^{\mathrm{e}}$ s. av. n. è. ont installé un emporion à Sant Martí d'Empúries et auraient imposé leurs produits. Étant donné que pas un seul des vases trouvés à Barranc de Gàfols ne peut être attribué à une production grecque, il faut plutôt en trouver les raisons dans le système social indigène, ou, plus précisément, dans les mutations qu'il a subi durant la première moitié du $\mathrm{VI}^{\mathrm{e}} \mathrm{s}$. av. n. è. Ces mutations ont abouti dès le milieu du siècle à la formation d'une société stratifiée et d'une idéologie légitimatrice de l'inégalité, tel qu'on peut l'inférer des indices perceptibles dans les formes d'occupation du territoire, dans le monde funéraire, dans les productions artisanales, dans la technologie de production et dans l'armement (Sanmartí 2004, 2010).
L'évolution que nous venons d'évoquer est nettement reflétée entre le milieu du $\mathrm{VI}^{\mathrm{e}}$ et la fin du $\mathrm{V}^{\mathrm{e}} \mathrm{s}$. av. n. è. par le volume et la nature des importations dans l'ensemble du territoire. Effectivement, on observe d'une part que le nombre des vases importés chute drastiquement par rapport à l'ensemble de vases (4\% du NMI ; $1 \%$ du nombre de fragments); de l'autre, on constate une augmentation encore plus poussée qu'à Barranc de Gàfols de l'importance relative de la vaisselle parmi le matériel importé (35\%), tandis que les amphores ne représentent maintenant que $10 \%$ des importations. Le premier phénomène est à mettre en rapport avec l'émergence d'une idéologie légitimatrice, dont il existe d'autres indices et qui naturalise et consacre le pouvoir de l'élite, ce qui rend inutile la redistribution à grande échelle de biens de prestige. Le deuxième indique que les vases importés étaient utilisés dans des festins diacritiques, dont le but était justement de réaffirmer et de rendre évidentes les différences entre les groupes sociaux par l'utilisation de récipients ou d'instruments particuliers et peut-être aussi suivant des rituels plus ou fidèlement inspirés de ceux du monde grec (Sanmartí 2009). Durant cette période, le plus grand nombre d'importations provient du monde grec (coupes « ioniennes », vaisselle attique, amphores « ioniennes » et massaliètes, parmi d'autres moins nombreux), mais nous ne croyons pas que ceci soit (ou soit seulement) la conséquence d'une concurrence " agressive » des Phocéens par rapport aux Phéniciens. On peut effectivement penser que les élites ibériques ont cherché à modifier l'origine des biens importés, justement pour en réaffirmer la condition de biens de prestige, et que si les Phocéens ont prévalu, c'est peut-être parce que, par la nature de leurs activités commerciales, ils étaient en mesure de fournir des marchandises bien adaptées aux besoins de la nouvelle aristocratie.

Par contre, pour ce qui est des pratiques culinaires on ne relève aucune modification par rapport à la période précédente. Certes, nous ne disposons pas d'ensembles de poteries provenant de contextes domestiques bien caractérisés, mais les formes que l'on peut supposer culinaires sont toujours des pots, pour l'essentiel du même type que ceux du Bronze Final et du Premier âge du Fer. En plus, il n'y a point de céramique culinaire importée, ni d'imitations locales des marmites plus ou moins profondes (caccaboi et lopades dans la terminologie grecque habituelle), qui sont les formes par excellence de la cuisine grecque et punique ; or, il serait logique d'en avoir trouvé, même si ce n'est qu'en très petite quantité, si des formes de préparation des aliments relevant de ces traditions culturelles avaient été adoptées par les Ibères. 
Il est vrai que, malgré leur longue tradition en Orient, ces formes sont fort rares ou simplement absentes, jusqu'à la fin du VI ${ }^{\mathrm{e}} \mathrm{s}$. av. n. è., dans les sites coloniaux installés sur ou près de la côte ibérique (Ramon 2007a ; Ramon 2010), ce qui mérite une réflexion approfondie ${ }^{2}$. Tout de même, la production de caccaboi et de lopades est bien attestée à Camposoto (San Fernando, près de Cadix) entre la fin du $\mathrm{VI}^{\mathrm{e}}$ et le milieu du $\mathrm{V}^{\mathrm{e}} \mathrm{s}$. av. n. è. (Ramon 2007b). Ils sont également présents à Ibiza durant le $\mathrm{V}^{\mathrm{e}}$ s. (Ramon 2010). Pour ce qui est des sites grecs, au moins un exemplaire a été documenté à Emporion dans un contexte de fin du $\mathrm{V}^{\mathrm{e}} \mathrm{s}$. av. n. è. (fig. 6, $\mathrm{n}^{\circ} 1$ ), sans oublier le lopas de Pointe Lequin, daté vers 510 av. n.è. (Long et al. 1992, fig. 38, no 18 et 19) ${ }^{3}$. Pourtant, il n'y en a pas la moindre trace dans des contextes indigènes, ni d'exemplaires importés ni de versions indigènes. On en conclura que, quelles qu'en soient les raisons, dans les communautés ibériques des $\mathrm{VI}^{\mathrm{e}}-\mathrm{V}^{\mathrm{e}} \mathrm{s}$. av. n. è. la différenciation sociale au niveau des subcultures alimentaires semble avoir porté essentiellement sur les formes de consommation - pas sur la préparation - des aliments. Mais, bien évidemment, cela s'est produit de façon très différente qu'au Premier âge du Fer : si les chefs du VII ${ }^{\mathrm{e}}$ - début du VI ${ }^{\mathrm{e}} \mathrm{s}$. av. n. è. avaient intérêt à redistribuer pour obtenir ou consolider leur pouvoir, les aristocrates du $\mathrm{VI}^{\mathrm{e}}-\mathrm{V}^{\mathrm{e}} \mathrm{s}$. av. n. è. manifestaient, en revanche, leur volonté de signaler et de marquer leurs différences par rapport au reste de la population. La partie idéologique, essentielle pour le pouvoir fondé sur l'inégalité (Godelier 1999, p. 28), était déjà gagnée.

2 D'après A. Delgado (2010, p. 37), ceci s'expliquerait dans la péninsule ibérique et à Ibiza par l'usage dans ces sites de récipients culinaires « indigènes » qui auraient eu les mêmes fonctions que les marmites phéniciennes (notamment, d'après elle, la cuisson de céréales par ébullition) et dont la présence dans ces contextes coloniaux s'expliquerait par la présence d'une population mélangée, formée en grande partie par des familles mixtes ou même purement indigènes. Cette conclusion, fort raisonnable, devrait peut-être s'appliquer aussi au cas de Carthage.

3 Dans les niveaux anciens de la Palaià Polis (Sant Martí d'Empúries) la céramique culinaire semble être exclusivement non tournée indigène (Castanyer et al. 1999, p. 231-240 ; Esteba, Pons, 1999, p. 240-242), ce qui conforterait en milieu grec les conclusions tirées des sites phéniciens archaïques par A. Delgado. Nous nous demandons toutefois si le fragment de bord de la phase IIIa (US 5248 ; fig. 263, 6, p. 311) n'appartiendrait pas à un caccabos, peutêtre tourné.

\section{L'adoption d'une cuisine de classe : (400-200 av.n. è.)}

Durant les IV et III $\mathrm{e}$ s. av. n. è., un système administratif a été développé, la complexité institutionnelle a sans doute augmenté et les différences sociales ont été approfondies. De nombreux indices conduisent à penser que les sociétés ibériques de cette époque se sont organisées sous des formes étatiques. Parmi les plus importants il faut mentionner la consolidation d'un système de peuplement fortement hiérarchisé, l'augmentation de la population, l'apparition de l'écriture et son usage pour une grande diversité de fonctions (y compris très probablement les documents administratifs) et le contrôle de l'élite sur la production vivrière (Sanmartí 2004 ; Sanmartí 2010).

Pour ce qui est des importations, leur volume par rapport aux céramiques indigènes est un peu plus important que durant l'Ibérique Ancien, mais il reste toujours nettement en dessous des pourcentages documentés aux VII ${ }^{\mathrm{e}}$ - début du VI ${ }^{\mathrm{e}}$ s. av. n. è. (4\% du NMI ; $1 \%$ du nombre de fragments). On en conclura logiquement que la consommation des produits importés reste encore nettement minoritaire, et qu'elle est donc une marque de classe sociale. Ceci est confirmé d'ailleurs par le fait que ce matériel est particulièrement fréquent dans les sites où d'autres aspects de la documentation permettent de supposer une présence importante des élites. Par exemple, à Ullastret - un grand site, sans doute la capitale des Indiketes ; à Alorda Park - un habitat de petite dimension, mais pourvu de fortifications importantes et de grandes maisons, ce qui permet de le considérer comme le centre d'une micro-région ; à Montjuïc - un port important ; ou à Mas Castellar de Pontós, où l'on a repéré d'autres éléments attestant une capacité d'achat importante, notamment un autel en marbre pentélique (Pons et al. 2002, p. 401). Par contre, le volume des importations est faible dans les simples villages comme Puig Castellar de Santa Coloma de Gramenet (3 \%) (Ferrer, Rigo 2003, p. 109, fig. 69), où les membres de l'élite sont absents, ou ne représentent qu'une très petite partie de la population, peut-être appartenant, en plus, à un niveau inférieur à l'intérieur de la classe aristocratique.

L'analyse de la nature des importations ne fait que confirmer cette interprétation, car les amphores -que l'on peut logiquement supposer être un élément d'un prix particulièrement élevé - deviennent plus rares, ce qui indiquerait aussi qu'elles constituaient l'apanage des élites. Tel qu'on pouvait l'attendre, elles sont particulièrement fréquentes là où le volume du matériel 
exotique et d'autres traits que nous avons déjà mentionnés permettent de proposer une présence importante de l'élite (Ullastret, Alorda Park, Montjuïc, Mas Castellar de Pontós).

On peut conclure que durant les $\mathrm{IV}^{\mathrm{e}}-\mathrm{III}^{\mathrm{e}} \mathrm{s}$. av. n. è. l'usage de la vaisselle et la consommation du vin (ou autres denrées alimentaires) importés sont toujours restés dans les mains de l'élite, qui, de même qu'à la période précédente, s'en servait comme élément de distinction. Il y a en plus des indices consistants qui permettent de penser que depuis le milieu du $\mathrm{IV}^{\mathrm{e}} \mathrm{s}$. av. n. è. la stratégie des élites a aussi incorporé une cuisine différenciée, probablement inspirée des pratiques culinaires grecques et puniques.

Effectivement, si la grande majorité des vases à cuisson sont toujours des pots qui se rattachent à l'ancienne tradition préibérique - même si parfois ils sont tournés - (fig. 5), on constate aussi durant cette période la présence de vases que l'on peut classer comme des caccaboi (fig. 6). Nous ne possédons pas de quantifications de ces types de récipients par rapport à l'ensemble des vases de cuisson, mais on peut affirmer qu'ils sont très peu nombreux, sauf à Ullastret, surtout durant le IVe $s$. av. n. è. ${ }^{4}$. En plus, ils sont surtout attestés dans des sites où la présence des élites peut être assurée pas des arguments indépendants que nous avons déjà signalé, tout particulièrement à Ullastret et à Alorda Park. Étant donné qu'il n'existe aucune raison pour avoir utilisé ces vases pour la cuisine locale, il faut supposer qu'ils attestent de la création depuis le IV ${ }^{\mathrm{e}} \mathrm{s}$. av. n. è. d'une cuisine de classe, possiblement inspirée en quelque mesure de la cuisine grecque et/ou punique.

Depuis le milieu du III ${ }^{e}$ s. av. n. è. on documente aussi la présence d'un certain nombre de vases culinaires carthaginois, surtout des lopades, mais aussi des chytrai et des caccaboi (fig. 7) (Sanmartí, Asensio 2005 ; Asensio 2004). Leur distribution semble aussi indiquer qu'ils étaient utilisés avant tout par les élites et que l'on peut donc considérer cela comme un indice supplémentaire de l'existence d'une cuisine de classe, ce qui est d'ailleurs logique, car on ne saurait pas expliquer l'importation de ces récipients pour préparer la cuisine traditionnelle.

4 Les centres de production sont méconnus. Il ne s'agit pas de productions puniques et, si on ne peut pas exclure que certains proviennent d'Emporion, où ce type d'objets est bien attesté, d'autres sont des productions indigènes, ce qui est assuré dans le cas des exemplaires non tournés, assez nombreux à Ullastret.

\section{Conclusion}

Au cours des siècles, le volume, la nature et la provenance des importations céramiques grecques et phénico-puniques - et de leurs versions indigènes - ont beaucoup changé. Ces mutations peuvent être expliquées à chaque moment par la nature changeante de l'organisation sociale indigène, telle qu'on peut la restituer à partir de l'analyse d'autres aspects de la documentation archéologique, notamment des formes d'occupation du territoire, de l'architecture domestique et des nécropoles. Il faut en conclure que les sociétés indigènes du nord-est de la péninsule Ibérique - ou plutôt leurs élites - ont joué un rôle actif et même déterminant dans le choix du matériel importé et dans l'adoption de pratiques culturelles exogènes, dont, à partir du IV e s. av. n. è., des formes culinaires de tradition grecque et/ou punique. Si les goûts et, surtout, les stratégies de contrôle social des élites ibériques ont eu le rôle essentiel que nous leur supposons dans les relations commerciales avec les sociétés que nous appelons - peut-être à tort - « coloniales », on peut penser que cela a eu des conséquences sur les structures économiques de ces dernières, ce qui pourrait peut-être expliquer, du moins en partie, des phénomènes comme la transformation de l'économie phénicienne du sud de la péninsule Ibérique à la fin de la période archaïque, ou l'essor de l'agriculture et la production amphorique d'Ebusus à partir du $\mathrm{V}^{\mathrm{e}} \mathrm{s}$. av. n. è. Il est donc nécessaire d'abandonner le cliché des sociétés indigènes de cette région comme des «peuples enfants», dont le développement socio-culturel était nécessairement tributaire des «grandes» civilisations de l'antiquité dont ils cherchaient à reproduire les formes culturelles (Maluquer de Motes, 1966, 1982, parmi d'autres), et de comprendre plutôt l'adoption de certains traits exogènes comme le résultat de choix sélectifs qui s'expliquent par les dynamiques strictement internes de ces sociétés.

\section{Bibliographie}

Asensio 2004 : ASENSIO (D.) - Cerámicas de cocinas cartaginesas en contextos ibéricos de la costa catalana. In MATILLA (G.), EGEA (A.), GONZÁLEZ (A.) ed., El mundo púnico: religion, antropología y cultura material, Actas del II Congreso Internacional del Mundo Púnico (Cartagena, 6-9 de abril de 2000), Murcia, Universidad de Murcia, p. 305-318 (Estudios Orientales 5-6). Aubet et al. 1979 : AUBET ( $\mathrm{M}^{\mathrm{a}}$.E), MAASS-LINDEMANN (G.), SCHUBART (H.) - Chorreras, un establecimiento fenicio al E. de la desembocadura del Algarrobo, Noticiario Arqueológico Hispánico, 6, 1979, p. 89-138. Bats 1988 : BATS (M.) - Vaisselle et alimentation à Olbia de Provence (v. $350-v .50$ av. JC). Modes culturels et catégories céramiques. Paris, Éditions du CNRS, 1988, 271 p., 71 pl. hors-texte (RAN supp. 18). 
Bats 1989 : BATS (M.) - Consommation, production et distribution de la vaisselle céramique. In ROUILLARD (P.), VILLANUEVA-PUIG (M-Chr.), Grecs et Ibères au IVe siècle avant Jésus-Christ: commerce et iconographie, Actes de la Table Ronde de Bordeaux. Bordeaux - Paris, 1989, p. 197-216 (Publications du Centre Pierre Paris 19, REA LXXXIX, 3-4).

Belén et al. 1996 : BELÉN (M.), ESCACENA (J. L.), LOPEZ ROA (C.), RODERO (A.) - Fenicios en el Atlántico. Excavaciones españolas en Lixus : conjuntos «C. Montalbán » y «cata basílica », Complutum Extra, 6 (1), 1996, p. 339-357.

Castanyer et al. 1999 : CASTANYER (P.), SANTOS (M.), TREMOLEDA (J.) - L'assentament d'època arcaica : fase III. In AQUILUÉ, X. dir., Intervencions arqueològiques a Sant Martí d'Empúries (1994-1996). De l'assentament precolonial a l'Empúries actual. Gérone, Museu d'Arqueologia de Catalunya - Empúries, 1999, p. 217-289.

Delgado 2010 : DELGADO (A.) - De las cocinas coloniales y otras historias silenciadas : domesticidad, subalternidad e hibridación en las colonias fenicias occidentales. In MATA (M.), PÉREZ JORDÀ (G.), VIVESFERRÁNDIZ (J.), De la cuina a la taula, IV Reunió d'Economia en el Primer Millenni aC, Valence, Universitat de València, 2010, p. 27-42 (Saguntum. Papeles del Laboratorio de Arqueologia de Valencia, Extra 9).

Dietler 1999 : DIETLER (M.) - Rituals of commensality and the politics of state formation in the «princely» socities of early Iron Age Europe. In RUBY (P.), Les princes de la Protohistoire et l'émergence de l'État, Actes de la table ronde internationale de Naples. Naples-Rome, Centre Jean Bérard, École Française de Rome, 1999, p. 135-152 (Coll. CJB 17/Coll EFR 252).

Esteba, Pons 1999 : ESTEBA (Q.), PONS (E.) - La ceràmica a mà. In AQUILUÉ, X. dir., Intervencions arqueològiques a Sant Martí d'Empúries (1994-1996). De l'assentament precolonial a l'Empúries actual, Gérone, Museu d'Arqueologia de Catalunya - Empúries, 1999, p. 240-242.

Fayolle 1992 : FAYOLLE (V.) - La poterie modelée du Maghreb oriental, de ses origines au XXe siècle. Technologie. morphologie, fonction. Paris, Éditions du CNRS, 1992, 298 p.

Ferrer, Rigo 2003 : FERRER (C.), RIGO (A.) - Puig Castellar. Els ibers a Santa Coloma de Gramenet. 5 anys d'intervenció arqueològica (1998-2002), Santa Coloma de Gramenet, Museu Torre Balldovina, 2003 (Monografies Locals 2).

Garcia Rubert 2005 : GARCIA RUBERT - El poblament del Primer Ferro a les terres del riu Sénia, Thèse doctorale inédite, Université de Barcelone, 2005,3 vols.

Godelier 1999 : GODELIER (M.) - Chefferies et États, une approche anthropologique. In : RUBY (P.), Les princes de la Protohistoire et l'émergence de l'État, Actes de la table ronde internationale de Naples, Naples-Rome, Centre Jean Bérard, École Française de Rome, 1999, p. 19-30 (Coll. CJB 17/Coll EFR 252).

Goody 1982 : GOODY (J.) - Cooking, cuisine and class : a study in comparative sociology, Cambridge, Cambridge University Press, 1982, $253 \mathrm{p}$. (Themes in the social sciences).

Juan-Tresserras 1998 : JUAN-TRESSERRAS (J.) - La cerveza prehistórica : investigaciones arqueobotánicas y experimentales. In : MAYA (J.L.), CUESTA (F.), LÓPEZ CACHERO (J.) ed., Genó : Un poblado del Bronce Final en el Bajo Segre (Lleida), Barcelone, Publicacions de la Universitat de Barcelona, 1998, p. 239-252.

Junyent, Baldellou, 1972 : JUNYENT (E.), BALDELLOU (V.) - Estudio de una casa ibérica en el poblado de 'Mas Boscà. Principe de Viana, 126-127, (année 33), 1972, p. 5-67.

Kallala, Sanmartí 2011 : KALlALA (K.), SANMARTÍ (J.) DIR. Althiburos I. La fouille dans l'aire du capitole et dans la nécropole méridionale, Tarragone, Institut Català d'Arqueologia Clàssica, 2011, 443 p. (Documenta 18).

Long et al. 1992 : LONG (L.), MIRÓ (J.), VOLPE (G.) - Les épaves archaïques de la Pointe Lequin (Porquerolles, Hyères, Var), des données nouvelles sur le commerce de Marseille à la fin du VIe et dans le première moitié du Ve s. In BATS (M.), BERTUCCHI, (G.), CONGÈS (G.), TRÉZINY (H.) dir., Marseille grecque et la Gaule, Actes des colloques de Marseille (1990) (Trav. du Centre C.-Jullian, 11), Lattes/Aix-en-Provence, A.D.A.M. éd./Univ. de Provence,1992, 502 p. (Et. Massa. 3), p. 199-234.
López Cachero 2007 : LÓPEZ CACHERO (J.) - Sociedad y economía durante el Bronce Final y la primera Edad del Hierro en el noreste peninsular: una aproximación a partir de las evidencias arqueológicas. Trabajos de Prehistoria, 64 (1), 2007, p. 99-120.

Lucas 2003-2004 : LUCAS (M.R.) - Simpulum y bebida, marcadores de prestigio y jefatura durante el Hierro I (siglos VII/VI a.C.) entre el Hérault y el Ebro. Kalathos, 22-23, 2003-2004, p. 95-134.

Maluquer de Motes 1966 : MALUQUER DE MOTES (J.) - El impacto colonial griego y el comienzo de la vida urbana en Cataluña, Barcelone, Consejo Superior de Investigaciones Científicas. Delegación de Barcelona, 1966, 23 p.

Maluquer de Motes 1982 : MALUQUER DE MOTES (J.) - Problemática histórica de la cultura ibérica", XVI Congreso Nacional de Arqueología: Murcia-Cartagena, 8-11 de enero 1982. Programas y Ponencias, Saragosse, Universidad de Zaragoza, 1982, p. 29-49.

Mansell 1999 : MANSELL (K.) - Handgemachte Keramik der Siedlungschiechten des 8. und 7. Jahrhunderts v. Chr. aus Karthago. Ein Vorbericht. In : RAKOB (F.) (ed.), Die Deutschen Ausgrabungen in Karthago, Karthago III, Mainz, Deutsches archaeologisches Institut, 1999, p. 220-238.

Mascort et al. 1991 : MASCORT (M.T.), SANMARTÍ (J.), SANTACANA (J.) - El jaciment protohistòric d'Aldovesta (Benifallet) $i$ el comerç fenici arcaic a la Catalunya meridional, Tarragone, Publicacions de la Diputació de Tarragona, 1991, 59 p., 45 pl. hors-texte.

Maya et al. 1998 : MAYA (J.L.), CUESTA (F.), LÓPEZ CACHERO (J.) ED. - GENÓ : Un poblado del Bronce Final en el Bajo Segre (Lleida), Barcelone, Publicacions de la Universitat de Barcelona, 1998, 263 p.

Morel 1994 : MOREL (J.-P.) - La céramique attique à vernis noir en Ibérie et à Carthage : une comparaison. In : CABRERA (P.), OLMOS (R.), SANMARTí (E.) ed., Iberos y griegos : lecturas desde la diversidad, Huelva, Diputación Provincial de Huelva, 1994, p. 323-344 (Huelva Arqueológica XIII, 2).

Oliver 2000 : OLIVER (A.) - La cultura de la alimentación en el mundo ibérico, Castelló, Diputació de Castelló, 2000, 193 p., 29 planches hors-texte (Collecció Universitària).

Pons et al. 2002 : PONS (E.), FERNÁNDEZ (M.J.), GONZÁLEZ (H.), LÓPEZ (A.), MARTÍN (A.), FUERTES (M.) - Els objectes ceràmics no recipients, els petits contenidors i els objectes no ceràmics. In : PONS (E.) dir. - Mas Castellar de Pontós (Alt Empordà), un complex arqueològic d'època ibèrica. Excavacions 1990-1998, Girona Museu d'Arqueologia de Catalunya - Girona, 2002, p. 369- 410

Pons, Garcia 2008 : PONS (E.), GARCIA (L.) - Prácticas alimentarias en el mundo ibérico. El ejemplo de la fosa FS362 de Mas Castellar de Pontós (Empordà-España), Oxford, 2008, 218 p. (BAR International Series 1753).

Ramon 2007a : RAMON (J.) - Excavaciones arqueológicas en el asentamiento fenicio de Sa Caleta (Ibiza), Barcelone, Universitat Pompeu Fabra, 2007, 358 p. (Cuadernos de Arqueología Mediterránea 16).

Ramon 2007b : RAMON (J.), RAMON (J.), SÁEZ (A.), SÁEZ (A.M.), MUÑOZ (A) - El taller alfarero tardoarcaico de Camposoto (San Fernando, Cádiz), Séville, Junta de Andalucía, 2007, 375 p.

Ramon 2010 : RAMON (J.) - La cerámica fenicia del Mediterráneo extremooccidental y del Atlántico (s. VIII - $1^{\text {er }} 1 / 3$ del VI aC). Problemas y perspectivas actuales. In : Motya and the Phoenician Ceramic Repertoire between the Levant and the West 9th - 6th Century BC, Proceedings of the International Conference held in Rome, 26th February 2010, Rome, Università degli Studi di Roma «La Sapienza », 2010, p. 211-253.

Sardà 2008 : SARDÀ (S.) - Servir el vino. Algunas observaciones sobre la dopción del oinochoe en el curso inferior del Ebro. Trabajos de Prehistoria, 65 (2), 2008, p. 95-115.

Sanmartí 2004 : SANMARTÍ (J.) - From local groups to early states : the development of complexity in protohistoric Catalonia, Pyrenae, 35-1, 2004, p. 7-42.

Sanmartí 2009 : SANMARTÍ (J.) - Colonial Relations and Social Change in Iberia (Seventh to Third Centuries BC). In : DIETLER (M.), LÓPEZRUIZ (C.) ed., Colonial Encounters in Ancient Iberia, Chicago/Londres, The University of Chicago Press, 2009, p. 49-88.

Sanmartí 2010 : SANMARTÍ (J.) - Demografía y cambio socio-cultural : el caso de la Iberia septentrional. In : BURILLO (F.) ed., Arqueología de la población, Actas del VI Coloquio Internacional de Arqueología Espacial, 
Teruel, Seminario de Arqueología y Etnología Turolense (Arqueologia Espacial 28), p. 91-108.

Sanmartí, Asensio 2005 : SANMARTÍ (J.), ASENSIO (D.) - Comercio púnico y estratificación social : la difusión de cerámicas comunes en la costa nororiental de la Península Ibérica. In SPANÒ (A.) ed., Atti del V Congresso Internazionale di Studi Fenici e Punici (Marsla-Palermo, 2-8 ottobre 2000), vol. III, Palerme, Università degli Studi di Palermo, 2005, p. 1299-1310. Sanmartí et al. 2000 : SANMARTÍ(J.), BELARTE(M.C.), SANTACANA(J.), ASENSIO (J.), NOGUERA (J.) - L'assentament del bronze final i primera edat del ferro del Barranc de Gàfols (Ginestar, Ribera d'Ebre), Barcelone, Universitat de Barcelona, 2000, 244 p. (Arqueo Mediterrània 5).
Schubart 1985 : SCHUBART (H.) - Morro de Mezquitilla. Informe preliminar sobre la campaña de excavaciones de 1982 realizada en el asentamiento fenicio cerca de la desembocadura del río Algarrobo, Noticiario Arqueológico Hispánico 23, p. 141-174.

Schubart, Maas-Lindemann 1984 : SCHUBART (H.), MAAS LINDEMANN (G.) - Toscanos. El asentamiento fenicio en la desembocadura del rio de Velez. Excavaciones de 1971, Noticiario Arqueológico Hispánico, 18, 1984, p. 39-205

Villada et al. 2010 : VILLADA (F.), RAMON (J.), SUÁREZ (J.) - El asentamiento protohistórico de Ceuta. Indígenas y fenicios en la orilla norteafrcana del estrecho de Gibraltar, Ceuta, Archivo General de Ceuta, 2010, 546 p. 



\section{Identidades ibéricas}

\section{Carmen Aranegui Gascó}

Université de Valence (Espagne)

\section{Resumen}

Todas las identidades son cambiantes pues dependen de los tiempos en que se formulan. La invención de los iberos como sujetos históricos tiene un recorrido de dos siglos de estudios. Desde la arqueología, las claves de su historia residen en la afirmación de un lugar fortificado (oppidum) sobre una red de asentamientos secundarios, en la aparición del arte en gran formato y en la escritura, principales exponentes de la culminación de la jerarquización social. La percepción de los pueblos de la vertiente mediterránea de la Península Ibérica muestra un cambio de escala cuando se convierten en hispanos. Es entonces cuando aparece un etnónimo común para todos ellos: los iberos.

Palabras clave: historiografía, Protohistoria, Cultura Ibérica, Identidad étnica

\section{Résumé}

Toutes les identités sont changeantes car elles dépendent des temps où elles ont été formulées. L'invention des Ibères en tant que sujets historiques n'a que deux siècles. D'un point de vue archéologique, les clefs de leur histoire se fondent sur l'affermissement d'un lieu fortifié (oppidum) dans un réseau de sites secondaires, sur l'apparition d'un art majeur et de l'écriture, ce qui constitue les principales preuves de l'aboutissement de la hiérarchisation sociale. La perception historique des peuples de la façade méditerranéenne de la péninsule Ibérique change d'échelle lorsqu'ils deviennent des Hispaniques. C'est alors qu'apparaît un ethnonyme commun à tous : les Ibères.

Mots-clés : historiographie, Protohistoire, Culture Ibérique, Identité ethnique 


\section{El debate sobre la identidad en síntesis}

Desde un presente en el que el sentimiento individual y colectivo de pertenencia se abre a perspectivas inéditas, tales como la multiculturalidad, la universalización de las redes de comunicación y la conciencia crítica frente a los nacionalismos (Wulff 2009, p. 7-50), resulta oportuno volver la mirada hacia la historiografía para analizar una cultura indígena como la ibérica (ss. VI-I a.C.) en lo que respecta a su papel identitario, a su percepción a lo largo del tiempo y a su estudio arqueológico.

¿Cómo se contemplaba la identidad en la antigüedad clásica? Sin ánimo de entrar a fondo en semejante tema, es sabido que la mención de un pueblo en los textos no significa el reconocimiento de su cultura específica (Cruz Andreotti 2010,p.17-52), ya que el ethnos era considerado entonces en el marco de las actitudes políticas reservadas a los ciudadanos, únicos capaces de identificarse públicamente como parte de un todo. El que una tribu extranjera sea nombrada en la literatura greco-latina no asegura que se le otorgue protagonismo histórico (Moret 2004, p. 31-62) y si algún término descriptivo de su gobierno u organización interna (mención de algún personaje como rey, jefe o magistrado...) pudiera hacer pensar lo contrario, sería preciso contextualizar el uso de dicho término, inferir su intencionalidad y ver, finalmente, si se trata de un préstamo del léxico clásico adecuado o inadecuado, en el marco de los modos de vida de gentes entre las que no pudo tener el mismo significado que en los centros del poder. Los autores clásicos, como los modernos, adaptaban sus relatos a su lenguaje, frente al que la intelectualidad de hoy debería ser crítica. Sin embargo, la tradición historiográfica convencional rara vez ha discutido la exactitud de la información escrita. El caso de Sagunto -su senado, su origen zacynthio... (Liv. XXI, 12-14; XXXI, 7, 1-5)es un ejemplo paradigmático de apropiación por parte de Roma de la identidad de un punto estratégico para convertirlo en casus belli (Aranegui 2004, p. 25-28); sin embargo el escenario saguntino derivado de las fuentes escritas ha merecido la mayor atención por parte de la academia.

En el Siglo de las Luces la helenización o romanización constituyeron el fundamento de la identidad cultural y política de los ilustrados europeos, no por la vía de la historia vivida (situación natural exclusiva de Italia y Grecia) sino por la de declararse depositarios de la razón, el saber y las artes del clasicismo. Con Francia a la cabeza, los escandinavos, rusos y centroeuropeos se remitieron al mundo greco-romano para construir una identidad colectiva universal característica de la modernidad (Habermas 1993 ; Hobsbawm, Ranger 1983). Fue una identidad discriminante porque de la misma manera que unos fueron incluidos, otros fueron excluidos del movimiento ilustrado y los argumentos

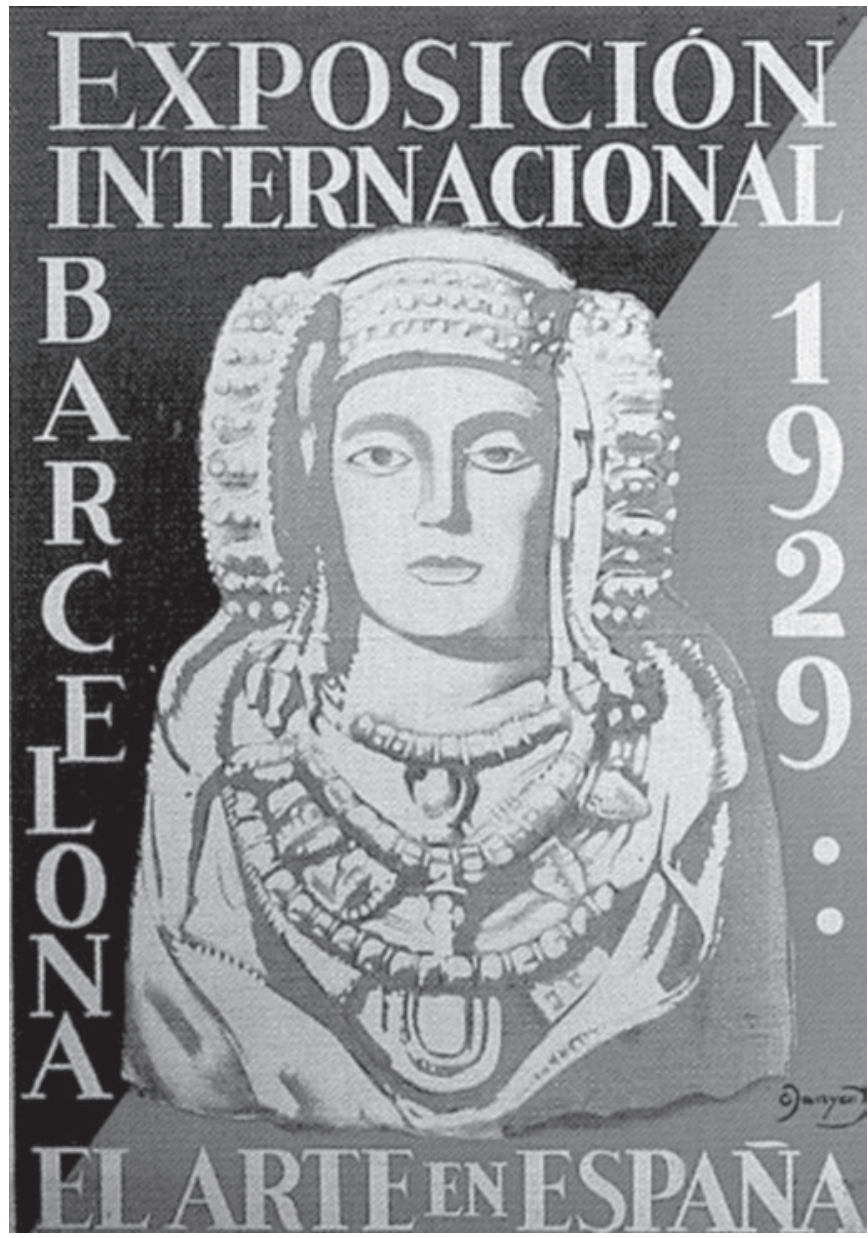

Fig. 1. Cartel de la Exposición Internacional de Barcelona de 1929 con la representación de la Dama de Elche, entonces en el Museo del Louvre.

que se adujeron para esto residieron en la naturaleza -física, social, confesional, histórica...- que hacía imposible su participación. Este fue el caso de España, de acuerdo con el análisis que hizo Voltaire (1756, p. 103105 ; p. 115) de su decadente devenir histórico el cual, algo después, se vio reflejado en el mapa del militar y geógrafo Bory de Saint-Vincent (1824) que establecía el límite suroccidental de Europa en los Pirineos, por razones geomorfológicas de porte científico, perfectamente acordes con el sentir de su época.

Sin embargo, en la Europa de los estados nación del s. XIX, las identidades se construyeron a partir de lo privativo, desde la reivindicación de una diversidad nacional que se quiso anclar en el pasado, poniendo en valor pueblos silenciados con anterioridad e incluso anónimos en las fuentes clásicas, en un marco distinto al ilustrado. Ello dio impulso a la arqueología protohistórica y popularidad a sus objetos fetiche, ya fuera la Dama de Elche, Vercingetorix o el caldero de Gundestrup, entre muchos otros, exponentes del carácter cambiante de los discursos 
identitarios, de acuerdo con su coyuntura, ideología y finalidad (Garcia 2008, p. 56-61).

Colin Renfrew afirma que la historia de la arqueología no es solo la de los métodos y técnicas sino también la historia de las identidades (Bahn 1996, vii) ya que la práctica arqueológica descubre aspectos del pasado susceptibles de ser reconocidos en el presente. Se puede sobreentender que lo más positivo y optimista de esta opinión radica en que lo arqueológicamente probado es menos manipulable que los documentos escritos, según este autor, pese a que es sabido que tampoco los vestigios materiales imponen una determinada identidad. Textos y piezas arqueológicas se eligen cada vez que se opera un cambio de paradigma identitario y la selección se hace en función de quién y qué se pretende probar (Schnapp 1997, p. 5-21).

Las excavaciones arqueológicas, la presentación de los yacimientos al público, las exposiciones de los museos... muestran el patrimonio que se quiere preservar y el modo en que cada país, o cada región, se aferra a su pasado historizándolo. La identidad se configura y representa en un proceso continuado de jerarquización de hechos en el tiempo y en el espacio, que apela al legado de la historia desde el campo de las construcciones ideológicas contemporáneas.

Por consiguiente, con ayuda de la antropología y de la etnografía, cobran importancia en nuestros días las representaciones simbólicas (ceremonias, rituales, artes...) inherentes a la afirmación de las identidades (hoy siempre en plural), a través de las cuales se perciben la manera de interactuar de diversos colectivos, la heterogeneidad de los grupos territoriales y la falacia de los nacionalismos, al mismo tiempo que la hermenéutica denota la complejidad de la comprensión de las sociedades humanas (Díaz-Andreu 1998, p. 199-218).

\section{Del Voyage pittoresque de Laborde y de L'Espagne primitive de Paris a La Etnología de Bosch Gimpera}

Alexandre de Laborde (París 1773- París 1842), de madre bearnesa e hijo de un comerciante natural de Jaca (Huesca) quien, después de haber hecho fortuna en Bayona, murió en la guillotina en la Plaza de la Concordia en 1794, Alexandre inició su educación superior en la corte de Viena, lejos de Francia, para pasar al servicio de Napoleón después de haber viajado por medio mundo. Era, dada su inclinación a la erudición, un hombre típico de la Ilustración, con una vida proyectada hacia el saber y el poder. En España gozó del favor de Carlos IV y de Godoy a partir del momento en que un equipo de selectos grabadores recorrió a sus órdenes distintas rutas para preparar la edición de su Itinéraire descriptif de l'Espagne (1809), guía que revela el refinado espíritu con que se dispuso a dar a conocer un país que no le era ajeno, lleno de peculiaridades pero digno de ser recuperado por Francia para la civilización.

Sin embargo la obra magna de Laborde fue el Voyage pittoresque et historique de l'Espagne (1806-1820), concebida en cuatro volúmenes, el primero de los cuales, que es doble, versa sobre Cataluña y sobre Valencia y las Islas Baleares, publicado en París con todo lujo de detalles y grabados de autores consagrados, a la vez que se editaba en España en la Imprenta Real y, en versión reducida, en alemán, con el fin de aproximar España a Europa. Pero, como se puede comprender, en 1808 dicho proyecto cambió radicalmente pues la derrota de las fuerzas napoleónicas suprimió el patrocinio inicial, de modo que Laborde asumió los gastos de edición y, con notable retraso, esta llegó a su fin. En estos volúmenes se describe aquello que España tenía que ofrecer a un viajero culto para divulgar el atractivo de lo hispano entre un público muy amplio, mientras los textos introductorios afirman ... les Indigetes, peuple féroce, adonné à la chasse et au pillage... (1806 I, p. 1) así como que los primeros pobladores de Valencia eran gentes pendencieras y divididas que no merecen atención y son ajenas a nuestro objetivo ([1975], p. 7).

Unos años después, en pleno romanticismo, Prosper Mérimée (1803-1870) confesaba en una de sus Lettres d'Espagne (1830 [1983, 103]) otro enfoque, al lamentarse de no haber visto nada en la misma ciudad -Sagunto- en la que Laborde había ilustrado un castillo, un circo y un teatro romanos...

Pero, volviendo al objetivo de esta comunicación, la segunda publicación de ineludible mención es el Essai sur l'art el l'industrie de l'Espagne primitive (19031904) de Pierre Paris (Rodez 1859 - Madrid 1931) cuyo perfil universitario es completamente diferente al del militar ilustrado anterior, además de pertenecer a una generación para la que el legado clásico estaba cambiando de orientación y de metodología de estudio, dando lugar a que aquellos viajeros del XVIII fueran sustituidos por arqueólogos de campo dispuestos a descubrir la antiguedad mediante la excavación. Con diferencia de un siglo respecto a Laborde, un investigador profesional conocedor del arte griego, formado en las más prestigiosas instituciones francesas, se ve obligado por circunstancias políticas a cambiar Atenas por la Universidad de Burdeos, desde donde va a tener la oportunidad de descubrir España. En 1887 acompaña al numismático Arthur Engel (1855-1920) a hacer un recorrido por la Península que es decisivo para su futuro profesional y personal puesto que, en adelante, resuelve dedicarse no solo a participar en las excavaciones 


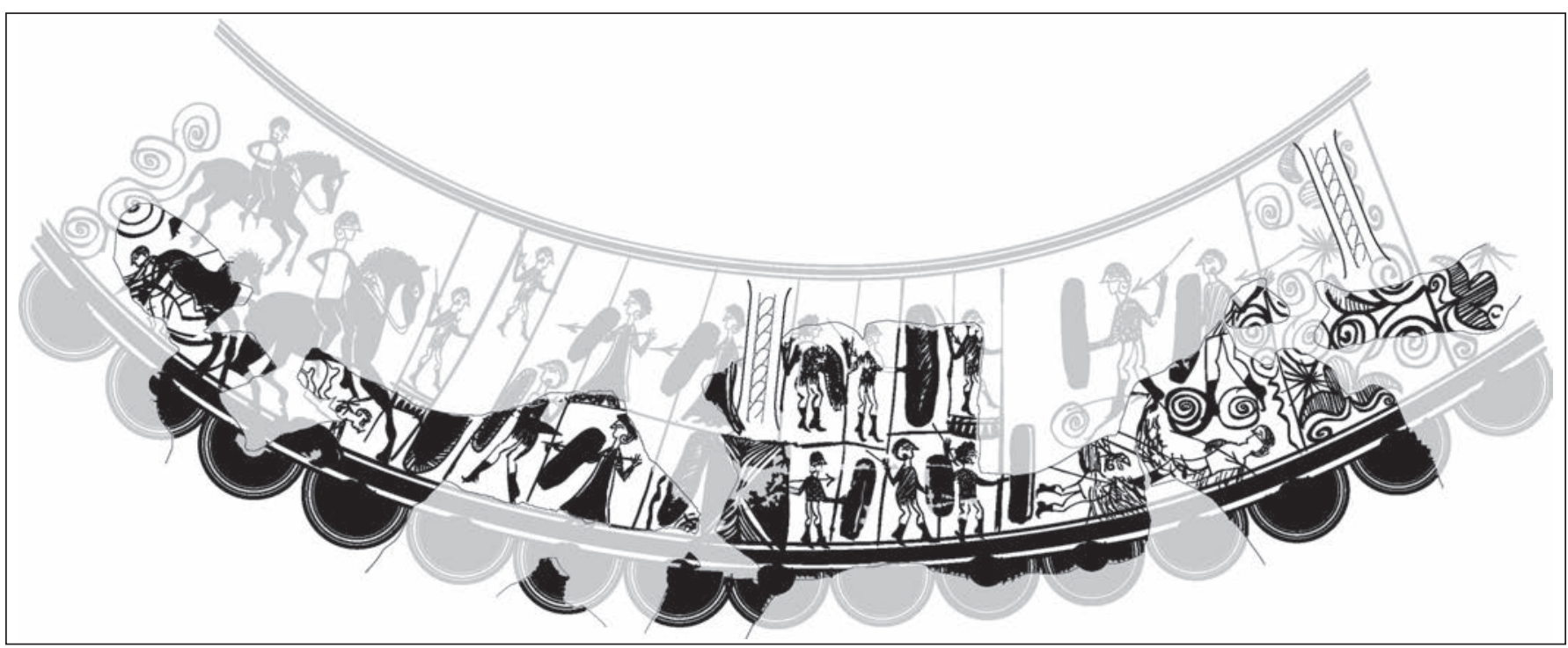

Fig. 2. Friso decorado de un vaso de la necrópolis del Castellar (Oliva), MAC (según C. Aranegui).

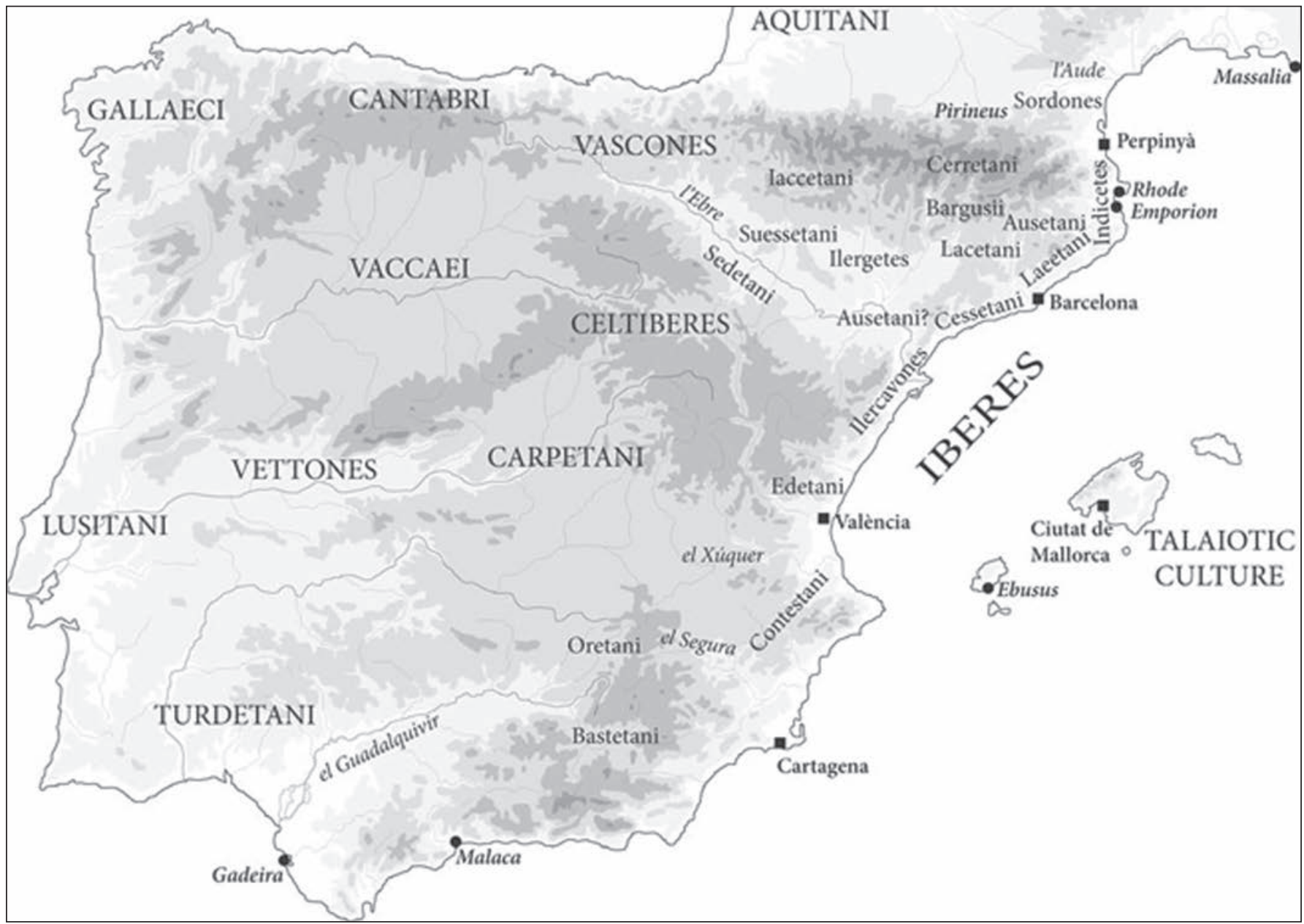

Fig. 3. Los pueblos iberos en la fachada mediterránea de la Península (según J. Sanmartí). 


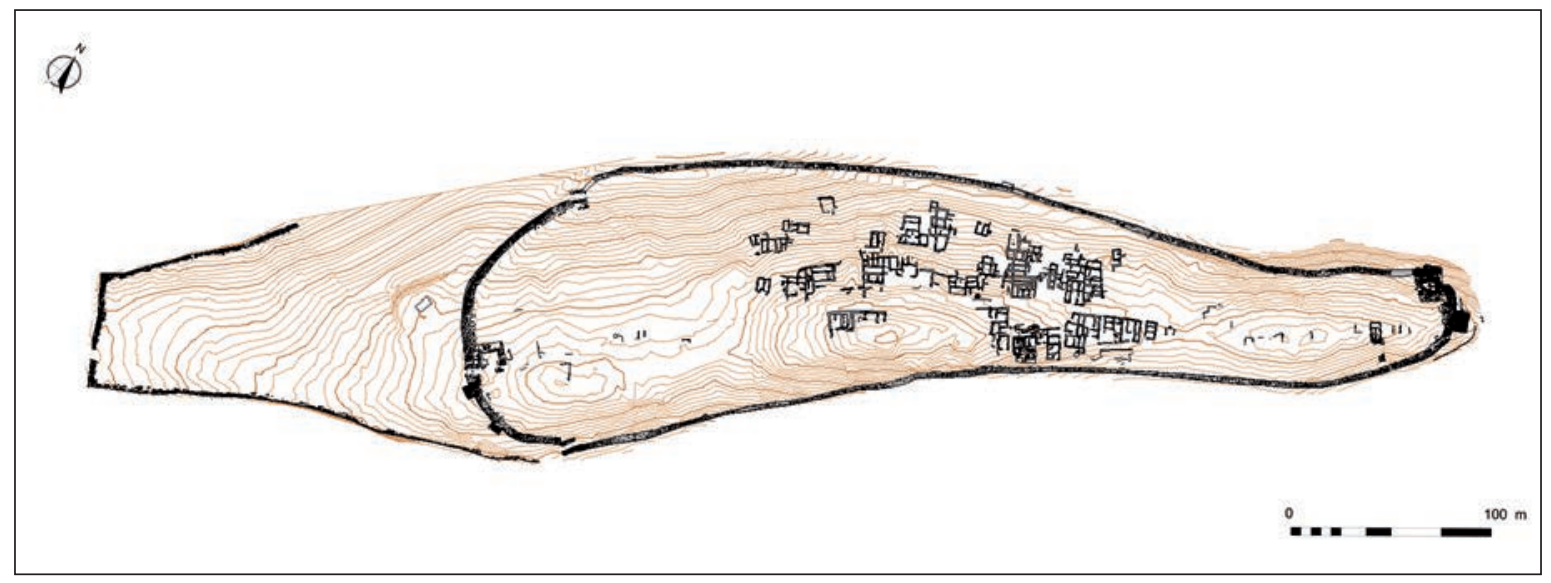

Fig. 4. Planta de la Bastida de les Alcusses (Mogente) (cortesía del Museo de Prehistoria de Valencia).

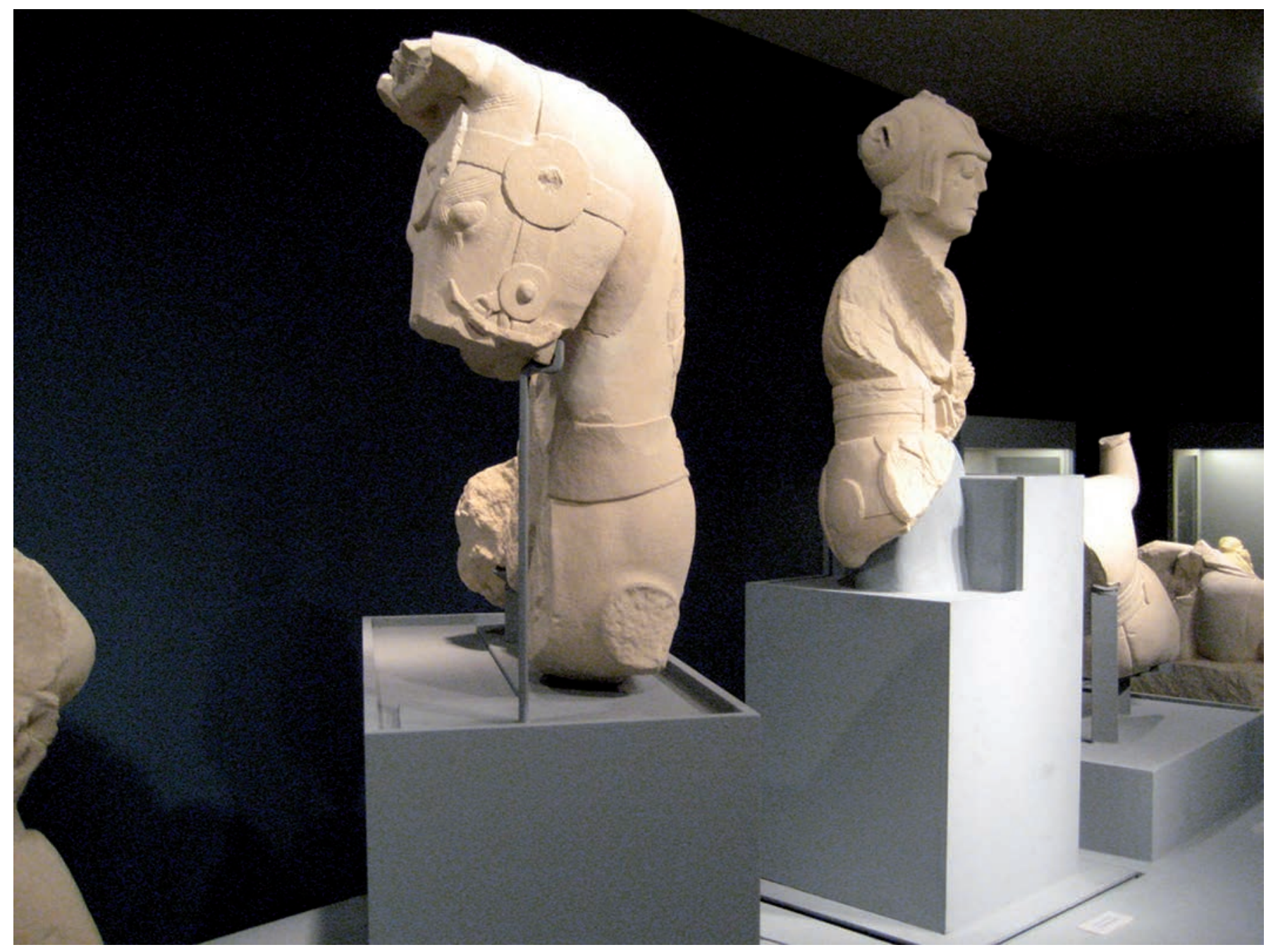

Fig. 5. Esculturas del Cerrillo Blanco de Porcuna (archivo exposición Los Iberos 1997-1998) 
arqueológicas programadas por Francia en España sino también a promover publicaciones periódicas, como el Bulletin Hispanique, creado en 1899, o a la fundación de la École de hautes études Hispaniques, en 1909, del Institut Français de Madrid, en 1913, y, finalmente, de la Casa de Velázquez, en 1928, de la que fue primer director, iniciativas todas que resultaron ser instrumentos de eficaz aproximación entre los dos países (Mora 2004).

Pero lo más interesante es el horizonte de Paris respecto al pasado civilizado peninsular que, con su obra, remonta el límite de la romanización. En efecto, aunque el título de su Essai utiliza el calificativo de primitive para referirse a la España prerromana, esa palabra tiene en él un significado equivalente a la España ibérica, que no se atrevió a emplear. Además, art et industrie denotan la valoración no solo de obras artísticas destacadas sino también de artefactos como fuente de conocimiento histórico, lo que, sin duda, constituye una innovación metodológica. Supera así aquella limitación a los orígenes y a las citas clásicas con que el desacreditado lingüista Édouard Philipon trataría en Les Ibères (Philipon, Arbois de Jubainville 1909) los entresijos de la cuestión del idioma ibérico.

Paris pudo utilizar en apoyo de sus tesis los resultados de las excavaciones francesas realizadas en el Cerro de los Santos (Montealegre del Castillo), Almedinilla (Córdoba), Osuna (Sevilla), Bolonia (Cádiz) y, muy particularmente, en la Alcudia de Elche (Alicante), donde fue testigo del descubrimiento casual de la Dama en 1897 y artífice de su traslado al Louvre, mediante gestiones que él mismo culminó satisfactoriamente, las cuales despejaron todo tipo de suspicacias respecto a la cultural de los iberos ante un foro internacional, e hicieron de tal Dama un símbolo privilegiado de lo español (Reinach 1898, p. 39-60 ; Jullian 1903, p. 101-111) (fig. 1). Pese a la relevancia de tantos logros, la bibliografía no ha tratado demasiado bien a este hispanista, buen conocedor de la arqueología ibérica de su tiempo (Rouillard 1995, p. 105-112), a quien se acusa de falta de objetividad y rigor (Moret 1997, p. 70-71). Se le ha imputado que su interés por la cultura ibérica fuera fruto, sobre todo, de sus anhelos personales, a pesar de que no estuvo aislado en su estudio, pues sus conclusiones se basan, como las de los demás hispanistas de su tiempo, en aceptar que el influjo colonial griego convirtió a los iberos en los primeros habitantes civilizados de toda la Península, según suscribía el paniberismo oficial de entonces -véase la Historia General de España (Cánovas del Castillo 1892)-. Desde ciertos sectores se le ha imputado igualmente su empeño en dar, por encima de todo, cauce institucional al hispanismo en el organigrama académico francés, famoso por el despliegue de centros culturales repartidos por el Mediterráneo, con excepción, hasta Paris, de España. Lo más llamativo de las reticencias sobre su labor es que su Essai ni fue traducido al castellano en su momento, ni lo ha sido hasta hoy. Tal vez, al cambiar el mensaje ilustrado de afrancesar España por el de hispanizar Francia, el autor se granjeó pocos partidarios entre las personas influyentes de ambos países. Tal vez, pese a sus recorridos en bicicleta por los caminos ibéricos, careciera de buenos amigos españoles, o bien, simplemente, vivió en un momento en que muchos españoles estaban saturados de los tópicos franceses sobre la Historia de España (Perez 2009).

Esto último podría, en cierto modo, explicar el mejor encaje de investigadores alemanes y españoles hacia finales del s. XIX y principios del XX. Ahí está el caso del epigrafista e historiador Emil Hübner (1834-1901), de orientación estrictamente positivista, ejemplar en su recopilación de inscripciones latinas, que entabló una buena relación con Juan de Dios de la Rada (1827-1901), con la Real Academia de la Historia y con el incipiente Museo Arqueológico Nacional. Aunque el más famoso, admirado y condecorado anticuario alemán de aquella época fue Adolf Schulten (Elberfeld 1870-Erlangen 1960). Discípulo de Theodor Mommsen (1817-1903) $\mathrm{y}$, principalmente, de su yerno Ulrich WilamowitzMöllendorf (1848-1931), Schulten realizó un incansable trabajo en España a partir de 1899, solo interrumpido por los paréntesis de los periodos bélicos. Para ello contó tanto con el apoyo del Kaiser Guillermo II, que financió sus excavaciones en Numancia (Soria), como con la colaboración de muchas instituciones españolas, incluidos el Institut d'Estudis Catalans y la Universidad de Barcelona, que le nombró doctor honoris causa en 1936, justo antes de la guerra civil. Hecha la salvedad de Antonio García y Bellido (1903-1972) (1960, p. 222-228), la interpretación tan docta como apasionada de los hitos heroicos de la genialidad hispana por quien fuera profesor en la Universidad de Erlangen, tuvo un gran éxito, tanto entre profesionales como entre el gran público. Con Schulten (Wulff 2004) el nacionalismo patrio se reconoció en Tarteso, Numancia, Sertorio y los textos clásicos, hitos que dieron lugar a publicaciones bien sistematizadas conforme al idealismo historicista de corte romántico, traducidas enseguida al castellano, que ensalzan la singularidad de la España eterna de la que, por cierto, no formaban parte los iberos, faltos (en los textos) de ese héroe o heroína, o de un paraje fuerte, entorno al que construir un relato emocionalmente potente.

La personalidad decisiva para salir del arbitraje extranjero sobre la arqueología peninsular fue Pedro Bosch Gimpera (Barcelona 1891- México 1974) (Gracia 2011) quien, a su llegada a la Universidad de Berlín en 1911, aceptó la sugerencia que le hizo WilamowitzMöllendorf y cambió la orientación helenista con la que 
había salido de Barcelona por el estudio de los pueblos prerromanos de la Península. Así es como regresó con una breve tesis presentada con éxito en Alemania que dio lugar a un fascículo en castellano (Bosch Gimpera 1915) del que merece la pena destacar el encabezamiento del título: Los problemas de la cerámica ibérica, para considerar seguidamente la significación tanto de problemas como de cerámica ibérica (fig. 2). Definir una problemática fue inseparable de cualquier investigación emprendida por Bosch, quien hizo frente a los temas que fueron de su interés desde una actitud crítica con respecto al estado de la cuestión precedente, imprescindible para hacer avanzar el conocimiento. La cerámica ibérica, soporte arqueológico de uno de sus primeros esquemas interpretativos de lo ibérico, era entonces reducida en número de vestigios, puesto que en aquellas fechas todavía no se habían iniciado grandes excavaciones, pero mostraba el problema de la pluralidad, fundamental para su autor, que también los etnónimos de los textos clásicos revelaban para una Península poblada por turdetanos, celtas, galaicos, cántabros, vascones... e iberos agrupados en tribus (layetanos, ilergetes, edetanos, oretanos, bastetanos...) en vísperas de la conquista romana (fig. 3 ).

Con el soporte de un centenar de vasos, Bosch consiguió ir más allá de las tesis en vigor acerca de los iberos, de su origen y de su cultura, tanto frente a investigadores extranjeros, como el mismo Paris, o nacionales, como Manuel Gómez Moreno (1870-1970). Además de su valor cronológico, que desmentía cualquier veleidad micénica (Vasseur 1905, p. 383), lo que le interesó al maestro de maestros fue que esa cerámica mostraba similitudes y diferencias tipológicas y decorativas en las distintas regiones, ya que ello autorizaba un modelo de círculos étnicos interrelacionados, que respondía a pueblos con ubicación, antecedentes e influencias externas diversificados, como el que propuso, siguiendo el esquema pueblo - material arqueológico - cultura, que había aprendido en Alemania. Fue así como se matizó el invasionismo y como se restringió el escenario de los iberos históricos a la vertiente oriental peninsular, entendidos estos, por primera vez, desde una perspectiva evolucionista plurilineal convencional (Cortadella 2003), que nada tenía que ver con la centralidad racial y étnica sostenida por Gustav Kossinna (1858-1931) y en España, por ejemplo, por Gómez Moreno. Con la pluralidad, la idea fuerza del nacionalismo racista quedaba fuera de juego.

Para la Exposición Internacional de Barcelona de 1929 Bosch no solo consiguió que el Palacio de Exposiciones de Montjuïc tuviera unas salas dedicadas a la prehistoria peninsular (en ellas se expuso la reproducción de la Dama de Elche, así como el plomo ibérico inscrito de la Bastida de les Alcusses de Mogente, exvotos ibéricos de terracota de la Serreta de Alcoy, etc.) sino también la convocatoria del IV Congreso Internacional de Arqueología, cita a la que acudieron los máximos representantes mundiales de la especialidad, junto a los del país, y que surtió un efecto sin precedentes de cara al reconocimiento de los progresos de la arqueología ibérica y de su calidad, de modo que se disipó la sospecha de falsificación con que se habían observado esculturas ibéricas en Viena (Exposición Universal de 1873) o, a través de vaciados de escayola, en París (Exposición Universal de 1878), superando el paniberismo y dando origen a la primera escuela de iberistas reconocidos internacionalmente.

En la Etnología (1932) explicó Bosch la cultura ibérica como un proceso de larga duración, diferenciado geográficamente y abierto a influencias diversas entre las que acababa prevaleciendo la griega. Hizo gala de su formación filológica al repasar tanto la Ora Maritima de Rufo Festo Avieno como las Geografías de Estrabón o Ptolomeo, a la vez que puso de manifiesto su conocimiento de yacimientos y materiales arqueológicos de los distintos paisajes de la Península, con lo que consiguió elaborar la primera visión sintética de su protohistoria, no superada durante muchos años. Pero su tesis generó discrepancias relativamente pronto, principalmente debidas a los avances de la investigación de campo, fecunda en hallazgos ibéricos después de la guerra civil (1936-1939), cuando Bosch estaba exiliado en Méjico y España asistía a la efervescencia nacionalista del primer franquismo, que pactó el regreso de la Dama de Elche a Madrid e hizo uso político de este icono (Ruiz, Sánchez, Bellón 2003, p. 161-188). Al mismo tiempo los arqueólogos se escindían entre celtistas e iberistas, muestra del antagonismo centro-periferia, solo superado en el curso de los años 1970, después de que se hubiera publicado la síntesis The Iberians (Arribas 1964), primer paso hacia la normalización de la explicación de esta cultura en el s. XX.

\section{La identidad del aristócrata, el oppidum y la tumba monumental}

Hoy, con menor presión política, parece haber llegado la hora tanto de liberar la cultura ibérica de esencialismos como de entender el contacto colonial como un fenómeno bi-direccional no determinante en sí mismo, al contrario de como lo planteaba el historicismo. Es evidente que ni hace falta inventar la diferencia, ni reclamar una identidad nacional anclada en el pasado, lo que amplía las vías para ordenar argumentos y datos, admitiendo, desde la arqueología, que los objetos no significan lo mismo en cualquier sitio (Dietler 1995, p. 89-111), que no hay un 

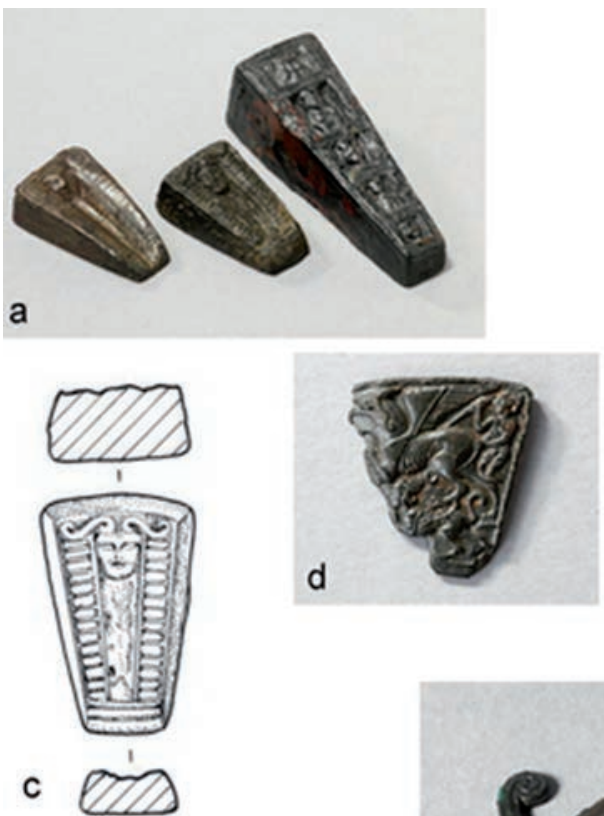

b
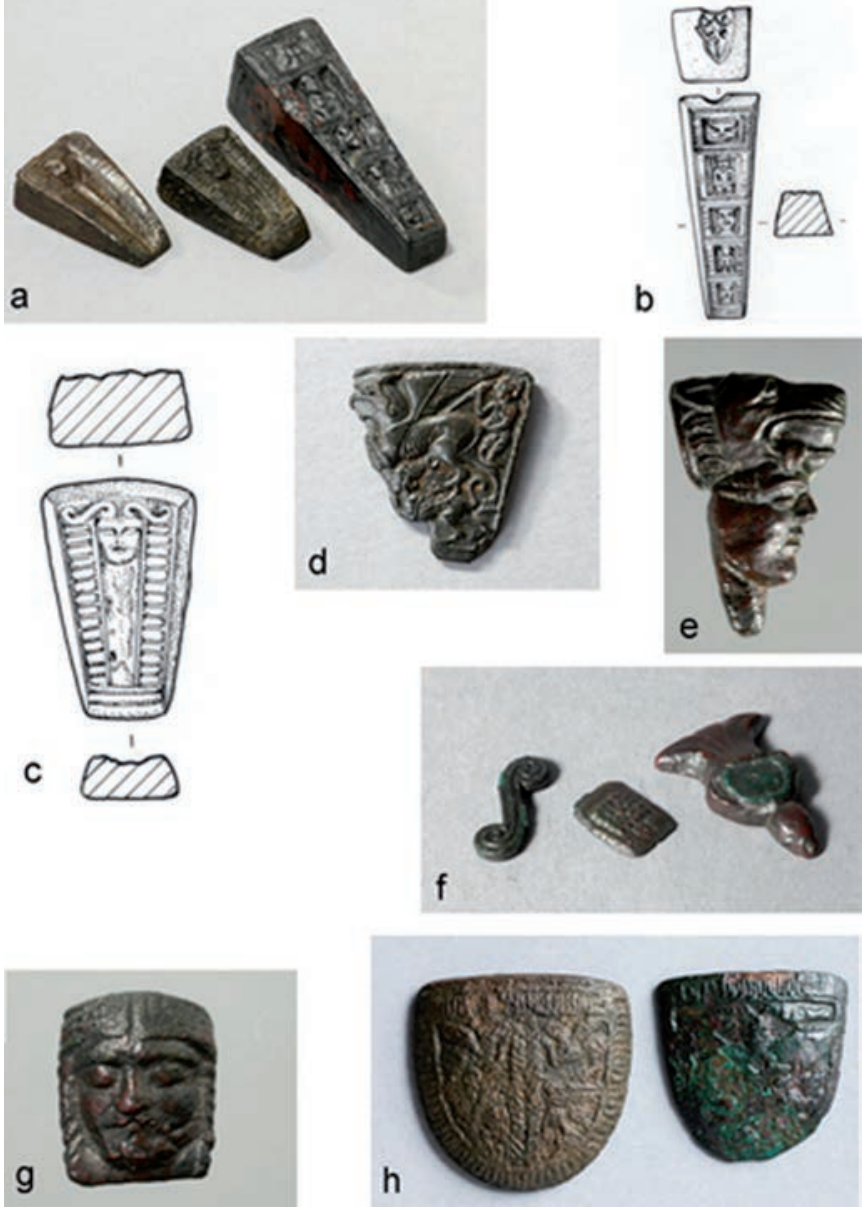

Fig. 6. La ostentación mediante la orfebrería. Matrices de orfebre de la tumba 100 de Cabezo Lucero (Guardamar del Segura) (cortesía de A. Perea).

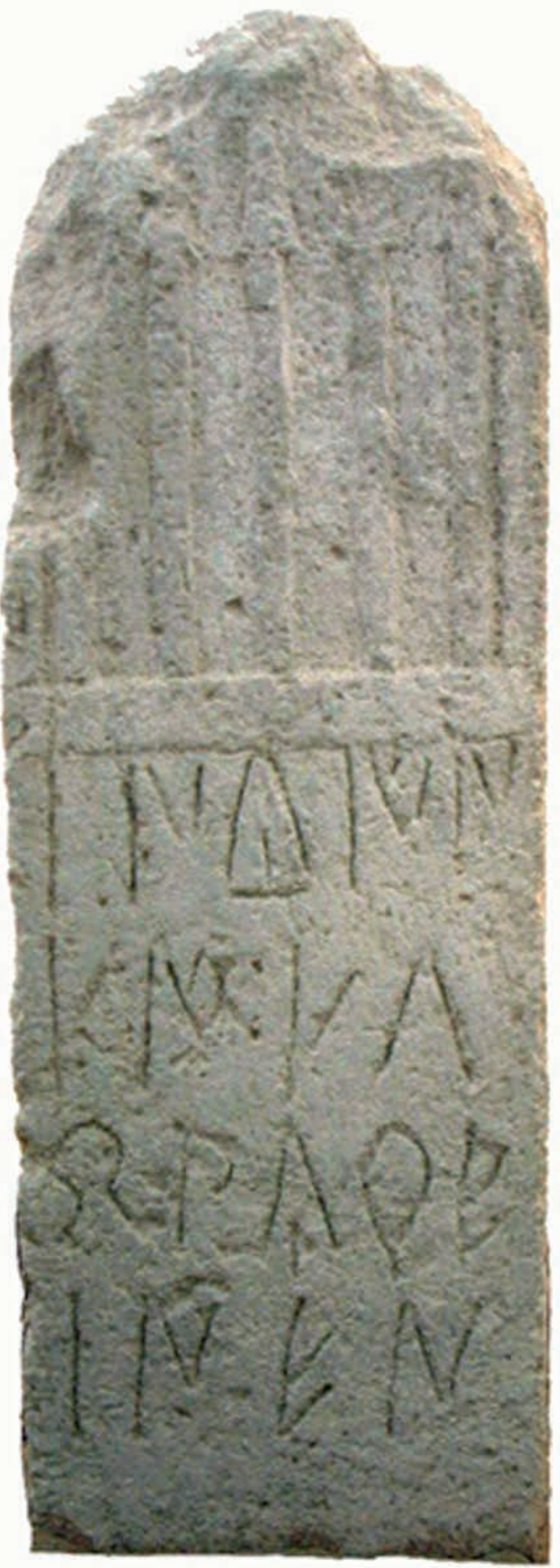

Fig. 7. La identidad en la tumba: estela ibero-romana de Badalona (cortesía J. Velaza). 


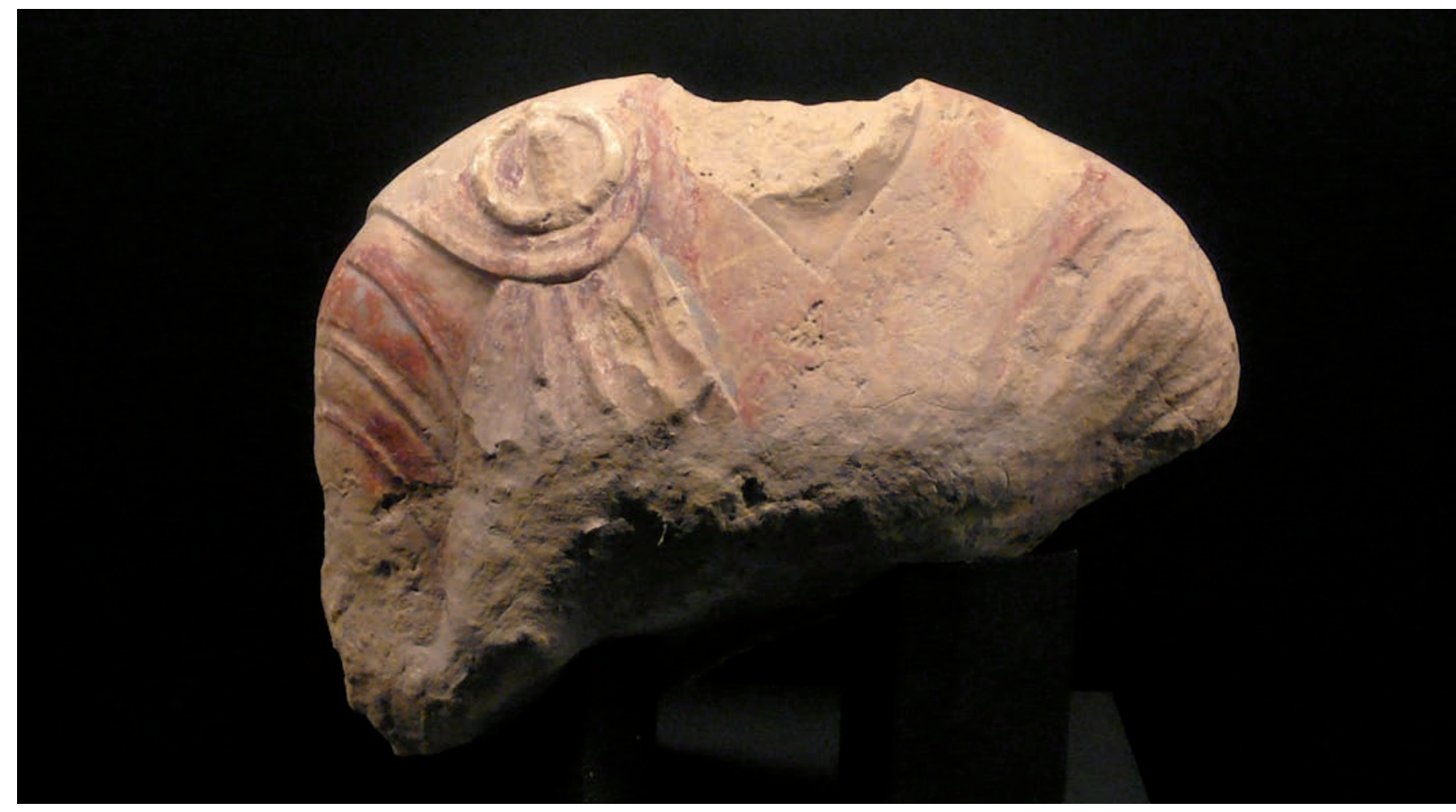

Fig. 8. La identidad en la indumentaria: personaje ibero-romano con manto sujeto con la fíbula anular ibérica (cortesía Centro de Interpretación de La Alcudia de Elche).

fósil director de la identidad y que los procesos de jerarquización de un territorio, propios de la aparición de las sociedades estructuradas, no son lineales (Ruby 1999) y, consecuentemente, la construcción de las identidades étnicas, tampoco.

Si se acepta que el modelo de las jefaturas (Brun 1987) es válido para la protohistoria porque observa las transformaciones endógenas de un grupo con más flexibilidad que el modelo centro-periferia, asumiendo que los hechos pueden ser almost the same, but not quite (Bhabha 1994, p. 122), se puede examinar la emergencia de las sociedades complejas en Iberia a partir una suma de marcadores y proponer la ampliación y transformación de la desigualdad en el curso del tiempo.

\section{El oppidum}

Conviniendo que la ocupación de un territorio está estrechamente ligada a la organización de la sociedad que lo vive, la cultura ibérica se inicia con un cambio de patrón demográfico hacia el 500 a.C., plenamente configurado a finales del s. V, tanto en áreas costeras como interiores, con ejemplos ya sea en el Alto Ampurdán (Llinàs et al. 1998), en las comarcas del Ebro (Noguera 2002) y Valencia (Bonet, Mata 2001, p. 175-186), en la Alta Andalucía (Ruiz 2009, p. 113-130) o en la meseta SE (Soria 2000), coincidente con una mejor explotación de los recursos y con una ampliación de la red de contactos de unas zonas con otras. Entonces aparecen las aglomeraciones que se denominan oppida, sedes de las jefaturas y referentes de unas identidades de alcance comarcal (fig. 4).

La ruptura, mayor o menor, de los patrones habitacionales del Bronce Final o del Hierro Antiguo se llevó a cabo manteniendo muchas tradiciones locales (Belarte 2009), si bien la complejidad urbanística se incrementó de manera muy notable en el s. VI a.C. Fue espectacular en la Alta Andalucía (Ruiz et al. 1991, p. 109-126), donde los habitantes de Castulo, Cazlona ; Basti, Cerro Cepero de Baza, o Ilturir-Iliberri, Albaicín, Granada... abandonaron definitivamente las cabañas para vivir en casas de plantas cuadradas agregadas, de distintos tamaños, con disposiciones longitudinales o reticulares, sobre superficies de más de $20 \mathrm{Ha}$, bien comunicadas con la costa SE hacia donde se amplió el litoral del Estrecho de Gibraltar. En el resto de la geografía ibérica no se aprecia el desplazamiento de un área neurálgica en la misma medida.

El oppidum ibérico no reproduce ningún modelo externo. No tiene plazas regulares con edificios públicos, ni apenas calles porticadas, ni infraestructura para suministro o evacuación de aguas, ni habitaciones para usos higiénicos... Sin embargo tiene casas lujosas, edificios rituales, almacenes y tiendas (Aranegui 2012), mejor urbanizados 
que los precedentes, total o parcialmente protegidos por una muralla compleja cuyas puertas marcan una circulación interior con calles de hasta $3 \mathrm{~m}$ de anchura.

Los cálculos medios a partir de las viviendas indican que los oppida de más de $10 \mathrm{Ha}$, como el Puig de Sant Andreu (Ullastret) en su conjunto, Burriac (Cabrera de Mar), Edeta (Liria), el Cerro de las Cabezas (Valdepeñas), Castulo (Cazlona) o Ategua (Córdoba)..., podían albergar entre 2500 y 3000 personas. Eran el lugar central al que acudían periódicamente los aldeanos para celebraciones comunitarias y del que recibían asistencia en caso de necesidad. La procedencia de todas estas gentes es, en buena medida, la misma que la de las etapas anteriores.

La identidad de alcance local se pone en evidencia cuando se ve que la obra pública más importante de un oppidum, su muralla (Moret 1998, p. 83-92), no está homologada más allá del ámbito comarcal. Las murallas no responden a una necesidad poliorcética: en el área ibérica no hubo ejércitos hasta la segunda guerra púnica (218-202 a.C.). No obstante, Emporion (L'Escala) se dotó de defensas complejas (Santos 2008, p. 49-79), por tradición y para garantizar su seguridad, y la inserción de los iberos en los tráficos mediterráneos tuvo repercusión en el valor estratégico del suelo y de las vías de comunicación, jalonadas de fortalezas y torres de vigilancia. La función simbólica de una muralla, no obstante, se tiene como causa principal de la misma (Goudineau 1980, p. 141-193), con el fin de crear el paisaje cultural de un pueblo, fenómeno que se hace visible hacia el 490 a.C. en Ullastret (Prado 2010, p. 567-581).

\section{La identidad en las necrópolis}

\section{El Ibérico Antiguo}

Uno de los signos más reveladores de la instauración de la desigualdad es la aparición de la tumba monumental en la Alta Andalucía, Murcia, Albacete, Alicante y S de Valencia a inicios del s. V a.C. A lo largo de más de un siglo se han ido descubriendo ya sea esculturas de gran formato asociadas a necrópolis, como los toros de Porcuna, del Molar (San Fulgencio) o de Las Agualejas (Monforte del Cid), o las esfinges de Agost, de Haches o del Salobral (Albacete), el caballo de Fuente la Higuera o la Dama de Baza, o bien los correspondientes mausoleos, construidos con fábricas mucho más elaboradas que las viviendas (Aranegui et al. 1997). De modo que el SE, donde se encuentran las cuencas minero-metalúrgicas de Linares, Granada y Cartagena y las vías de trashumancia de La Mancha, elaboró un paisaje funerario monumental, espectacular e identitario, desconocido en el resto del área ibérica.

La tipología arquitectónica funeraria es variada, con los máximos niveles de ostentación cuando incluye figuraciones en relieve, escenificaciones en bulto redondo o esculturas estáticas, siendo los programas ornamentales más suntuarios los que sufrieron destrucciones más violentas.

De atenerse a hallazgos del último tercio del s. XX o posteriores, la torre de Pozo Moro (Chinchilla) constituye una primera tipología, interpretada a partir de no más de un diez por cien de un edificio destruido poco después de su construcción (Almagro-Gorbea 1983 , p. 229-287). Edificada en una vía de trashumancia, cubre la incineración de un varón de más de cincuenta años. Con leones en cada una de las esquinas de su base, un cuerpo cuadrado en la cara visible de algunos de cuyos sillares aparecen bajorrelieves con escenas mitológicas, la torre remata con una gola egipcia, con numerosas referencias orientalizantes, e inaugura lo que sería una necrópolis que se utilizó largo tiempo, aunque no con total continuidad (Alcalá 2003). ¿Pertenece a un personaje con cultura oriental o a un jefe ibérico que se apropia de mitos orientales? ¿Es un monumento orientalizante, colonial o ibérico? Su cronología suscita discordancias, aunque el ajuar de la tumba, con una cílica atribuida al círculo ático del pintor de Pithos y una lecito de la clase Atenas 581, da una datación del 490 a.C. Podría entenderse, en definitiva, que es una construcción identitaria de un personaje que se reconoce en una tradición oriental ancestral, sin reproducir textualmente un sistema de imágenes oriental.

Otro descubrimiento tan importante como fue en 1897 el de la Dama de Elche se produjo en el Cerrillo Blanco de Porcuna, antigua Ipolca/Obulco, junto a una necrópolis más antigua abandonada. Entre 1975 y 1979 se recuperó allí un lote de 1486 fragmentos esculpidos que habían sido destruidos y enterrados en una fosa, cuyo estudio supuso una gran revelación (Negueruela 1990 ; León 1998, p. 81-97) (fig. 5). El complejo monumental había estado en pie apenas un par de generaciones (¿entre el 470 y el 420 a.C.?), tras las que fue eliminado (Zofío, Chapa 2005, p. 95-120). Muestra una temática heroica, con connotaciones de ritualidad asociadas a un cortejo de oferentes y a representaciones masculinas y femeninas ataviadas con túnicas, con alguna joya sencilla, y asociadas a algún animal, que articula un lenguaje simbólico distinto al de Pozo Moro.

Ambos ejemplos denotan la ostentación identitaria y la territorialidad vinculadas a la tumba de un príncipe o del fundador de un linaje, sin que se pueda demostrar cual de estas finalidades es primordial, o si son equiparables. En este entramado se pueden comprender las luchas entre iberos y la reiterada violencia contra los símbolos que marcaban el poder de una jefatura, deducible de la destrucción de las imágenes. 


\section{El Ibérico Pleno}

En el s. IV se asiste a una renegociación del imaginario colectivo. Aumenta el número de tumbas con ajuares destacados en una misma necrópolis, menos exclusivos que en el s. V. El primer grado de ostentación se transfiere ahora al armamento ofensivo (Quesada 2002, p. 35-64). Aparecen asimismo indicadores puntuales de alguna actividad productiva o artesanal, como balanzas (en Orley) (Lázaro et al. 1981), escalas de pesos (Cigarralejo), plomos inscritos en ibérico, instrumental para tejer (Rísquez, García Luque 2012, p. 257-276) o para hacer joyas (Cabezo Lucero) (Perea, Armbruster 2011, p. 158-171), vasos de perfumes..., objetos que sugieren una ampliación de las elites hacia sectores enriquecidos por la redistribución de bienes y llevan a plantear la identidad no de un príncipe sino de una oligarquía (fig. 6).

Su diversificación guarda una relación directa con la visibilidad de las mujeres. El imaginario las asocia al hilado y al tejido (Rafel 2007, p. 115-146), dedicándoles un espacio en el arte. Como sucede con las armas respecto a los hombres, los objetos para tejer no certifican que una tumba sea femenina, aunque en ambos casos se establece una transversalidad semántica entre lo femenino (el tejido lo es) y lo masculino (las armas lo son), propia de una sociedad más equilibrada que la principesca en sus referencias a ambos sexos, como fue la del Ibérico Pleno (ss. IV-III a.C.). En ella se prodiga la representación emblemática de la Dama (Olmos, Tortosa 1997), compartida por varias elites del SE en esta época (Chapa, Izquierdo 2010), que se perpetuará en la pintura cerámica característica del área valenciana (Aranegui, Mata, Pérez Ballester 1997).

El estatus, las armas y el género interactúan en la creación de los símbolos identitarios ibéricos.

\section{Renegociando identidades: los iberos en la Hispania Citerior (198 a.C.)}

El Ibérico Tardío discurre bajo el dominio de Roma cuyo éxito inicial residió en unificar a las elites de la vertiente mediterránea y de la Alta Andalucía bajo el etnónimo común de hispanos. Se trataba de las gentes que ya habían asimilado la escritura y la circulación monetaria, pero que se reconocían en el sistema del oppidum, que tuvo que dejar paso a la civitas. Ello exigió un severo reajuste territorial, con desplazamientos demográficos, abandonos y destrucciones en presencia de contingentes romanos. A la vez, la Vía Heraclea (Ps. Aristóteles, Mirabiles Auscultationes, 85) y la red portuaria fueron ampliadas; algunos santuarios tradicionales fueron dotados de templos (Ramallo, Noguera, Brotóns
1998, p. 11-69), con la colaboración de los iberos, que llegaron a integrarse en un Estado pluriétnico, como era el de la República Romana.

A la altura del s. II a.C. los pueblos iberos habían recorrido la más larga historia de contactos mediterráneos y continentales de los habitantes peninsulares y vivido procesos de interculturalidad que otros desconocían. Pero no habían experimentado la integración política. En esta época los rasgos privativos ibéricos eran el oppidum y la lengua y escritura propias, y su expresión simbólica debe deducirse, a falta de otros datos, del exvoto autorepresentativo (Nicolini 1973 ; Truszkowski 2006) y, en especial, de la pintura sobre cerámica. De todo ello, solo el oppidum tenía imperativamente que adecuarse a ese nuevo plus político que exigía ceñirse a la ciudadanía y pagar impuestos a Roma. Porque, en lo que respecta a las particularidades lingüísticas, simbólicas o religiosas, la metrópolis que venció a Aníbal no pretendía unificar a sus súbditos, sino dotarlos de un estatuto jurídico-fiscal claro. Los pequeños etnónimos comarcales o regionales fueron subsumidos en unas identidades hispánicas de más amplio alcance que las de antes de la conquista.

Sin embargo las elites ibéricas se mantuvieron, aunque cambiaran en parte su indumentaria o la señalización de sus tumbas (fig. 8). Es evidente que se recurrió al atractivo del símbolo para dar cohesión a los pueblos iberos, especialmente en el SE, pues convertirse en hispano-romano también pasaba, en la primera etapa de las Hispanias, por impulsar tradiciones autóctonas que, con frecuencia, se recompusieron y hasta se reinventaron para homologar a los autóctonos. La estrategia implícita en ese impulso, hizo indispensable la respuesta afirmativa de los notables y su consiguiente ostentación, con un llamativo renacimiento de las expresiones artísticas vernáculas por parte de los segmentos sociales pioneros en la romanización (fig. 7). Y, a la inversa, también Roma desplegó estrategias encaminadas a fijar la territorialidad con la creación de mitos y leyendas, como se hizo patente, sobre todo por parte de Sertorio, en la Citerior septentrional, entre el 80 y el 72 a.C. (García Mora 1991).

En conclusión, mientras Polibio, Estrabón o Livio nombraban una pluralidad de pueblos de Iberia, Roma desplegaba su política para convertirlos en el todo que llamamos iberos, inventado sobre la base de afinidades históricas preexistentes y discernibles de otras, consiguiendo la prevalencia del derecho sin erradicar los sentimientos de pertenencia. 


\section{Lista bibliográfica}

Alcalá 2003 : ALCALÁ-ZAMORA (L.) - La necrópolis ibérica de Pozo Moro, Madrid, 2003, 374 p. (RAH).

Almagro-Gorbea 1983 : ALMAGRO-GORBEA (M.) - Pozo Moro, el monumento orietalizante, su contexto socio-cultural y sus paralelos en la arquitectura funeraria ibérica. DAINST(M), 24, 1983, p. 229-287.

Aranegui 2004 : ARANEGUI (C.) - Sagunto. Oppidum, emporio y municipio romano, Barcelona, ed. Bellaterra, 2004, 264 p.

Aranegui 2012 : ARANEGUI (C.) - Los Iberos ayer y hoy. Arqueologías y culturas, Madrid, Marcial Pons, $380 \mathrm{p}$.

Aranegui, Mata, Pérez Ballester 1997 : ARANEGUI (C.), MATA (C.), PÉREZ BALLESTER (J.) - Dames et cavaliers dans la cité ibérique, París, L'Harmattan, 1997, $156 \mathrm{p}$.

Aranegui et al. 1997 : ARANEGUI (C.), MOHEN (P.), ROUILLARD (P.), ÉLUÈRE (CH.), COMS. - Les Ibères, Barcelona, Lunwerg ed., 1997, 375 p. (Min. de Cultura, Fund. 'la Caixa', AFAA).

Arribas 1964 : ARRIBAS (A.) - The Iberians (Ancient People and Places), Londres, Thames \& Hudson, 1964, 274 p.

Bahn 1996 : BAHN (P.) - Archaeology: Cambridge Illustrated History, Cambridge, CUP, 1996.

Belarte 2009 : BELARTE (M. C.) - L'espai domèstic i l'organització de la societat a la protohistòria de la Mediterrània occidental (Ier millenni $\mathrm{aC}$ ). Actes de la IV Reunió Internacional d'Arqueologia de Calafell (Calafell Tarragona, 6 al 9 de març de 2007), Barcelona/Tarragona, Universitat de Barcelona, Area d'arqueologia/Institut català d'arqueologia clàssica, 377 p.

Bhabha 1994 : BHABHA (H.K.) - The Location of Culture, Londres-Nueva York, Routledge, 1994, $408 \mathrm{p}$.

Bonet, Mata 2001 : BONET (H.), MATA (C.) - Organización del territorio y poblamiento en el País Valenciano entre los siglos VII al II a.C. In : Berrocal (L.), Gardes (Ph), coords., Entre celtas e iberos. Las poblaciones protohistóricas de las Galias e Hispania, Madrid, 2001, p. 175-186 (RAH y CV).

Bory de Saint-Vincent 1824 : BORY DE SAINT-VINCENT (J.-B.) - Notice sur la nouvelle carte d'Espagne, jointe a cet ouvrage. In : Bigland (J.), Histoire de l'Espagne, Paris, F. Didot, III, 1824, p. 1-19.

Bosch Gimpera 1915 : BOSCH GIMPERA (P.) - El problema de la cerámica ibérica, Memorias de la Comisión de Investigaciones Paleontológicas y Prehistóricas, Madrid, 1915, 70 p. (Museo Nacional de Ciencias Naturales).

Bosch Gimpera 1932 : BOSCH GIMPERA (P.) - Etnología de la Península Ibérica, Barcelona, 1932, $711 \mathrm{p}$.

Brun 1987 : BRUN (P.) - Princes et princesses de la Celtique, le premier âge du fer en Europe 850-450 av. J.-C., Paris, Errance, 1987.

Cánovas del Castillo 1892 : CÁNOVAS DEL CASTILLO (A.), dir. Historia general de España, Madrid, El Progreso ed., 1892, (RAH).

Chapa 2005 : CHAPA (T.) - Las primeras manifestaciones escultóricas ibéricas en el oriente peninsular. AEA 78, 2005, p. 23-47.

Chapa, Izquierdo 2010 : CHAPA (T.), IZQUIERDO, (I.), EDS. - La Dama de Baza. Un viaje femenino al más allá, Madrid, 2010, 299 p. (Ministerio de Cultura).

Cortadella 2003 : CORTADELLA (J.) ED. LIT - Etnología de la Península Ibérica de Bosch Gimpera, Pamplona, Urgoiti, 2003, 667 p.

Cruz Andreotti 2010 : CRUZ ANDREOTTI (G.) - Tarteso-Turdetania o la deconstrucción de un mito identitario. In : Bandera (Ma'L. de la), Ferrer (E.), eds., El Carambolo. 50 años de un tesoro, Sevilla, 2010, p. 17-52 (Universidad de Sevilla).

Díaz-Andreu 1998 : DÍAZ-ANDREU (M.) - Ethnicity and Iberians: The Archaeological Crossroads between Perception and Material Culture. European Journal of Archaeology 1998 (1.2), p. 199-218

Dietler 1995 : DIETLER (M.) - The Cup of Gyptis: Rethinking the Colonial Encounter in Early-Iron-Age Western Europe and the Relevante of Worldsystems Models. European Journal of Archaeology 1995 (3.2), p. 89-111.

Garcia 2008 : GARCIA (D.) - Nous et les autres. Débat avec Chr. Grataloup à propos des 'limites et territoires'. Archéopages 21, 2008, p. 56-61.
García Mora 1991 : GARCÍA MORA (F.) - Un episodio de la Hispania Republicana: la guerra de Sertorio, Granada, 1991.

García y Bellido 1960 : GARCÍA Y BELLIDO (A.) - Adolf Schulten. AEA 33,1960 , p. 222-228.

Goudineau 1980 : GOUDINEAU (C.) - La Gaule méridionale. In : G. Duby, dir., Histoire de la France urbaine, Paris, Seuil, 1980, p. 141-193.

Gracia 2011 : GRACIA (F.) - Pere Bosch Gimpera. Universidad, política, exilio, Madrid: Marcial Pons, 2011, 603 p.

Habermas 1993 : HABERMAS (J.) - El discurso filosófico de la Modernidad, Madrid, Taurus, 1993, $462 \mathrm{p}$.

Hobsbawm, Ranger 1983 : HOBSBAWM (E.J.), RANGER (T.) - La invención de la tradición, Barcelona, Crítica, 1983, 323 p.

Jullian 1903 : JULLIAN (C.) - La thalassocratie Phocéenne. À propos du buste d'Elche. $B H, 5,1903$, p. 101-111.

Laborde 1806 : LABORDE (A. DE) - Voyage pittoresque et historique de l'Espagne, I.1, Paris, P. Didot, 1806.

Laborde 1809 : LABORDE (A. DE) - Itinéraire descriptif de l'Espagne, 5 tomos y un atlas, Paris, P. Didot, 1809.

Laborde 1975 : LABORDE (A. DE) - Voyage pittoresque et historique de l'Espagne, E lPaís Valencià i les Illes Balears, I.2, reed. Barcelona, Publicacions de l'Abadia de Montserrat, 1975.

Lázaro et al. 1981 : LÁZARO (A.), ARANEGUI (A.), FLETCHER (D.), MESADO (N.) - Materiales de la necrópolis ibérica de Orley (Vall d'Uxó, Castellón), Valencia, 1981 (Serie de Trabajos Varios del SIP 70), 131 p.

León 1998 : LEÓN (P.) - La sculpture des Ibères, Paris, L'Harmattan, 1998, $187 \mathrm{p}$.

Llinàs et al. 1998 : LLINÀS (J.), MERINO (J.), MIRÓ (M.), MONTALBÁN (C.), PALAHÍ (LL.), SAGRERA (J.) - La Peralada ibèrica i medieval segons l'arqueologia. Les excavacions de 1989 a 1995, Figueres, 1998 (Monografies emporitanes 4).

Mérimée 1830 : MÉRIMÉE (P.) - Lettres d'Espagne, 1830, rééd. 1989, Tournai, éd. Complexe.

Mora 2004 : MORA (G.) - Pierre Paris. In : Tortosa (T.), coord., El yacimiento de La alcudia (Elche, Alicante): pasado y presente de un enclave histórico, Madrid, 2004, 27-42 (Anejos al AEA 30).

Moret 1997 : MORET (P.) - Pierre Paris (1859-131), précurseur de 1 archéologie ibérique. In : Les Ibères, Réunion des Musées Nationaux, Paris, 1997, p. $70-71$

Moret 1998 : MORET (P.) - Rostros de piedra. Sobre la racionalidad del proyecto arquitectónico de las fortificaciones urbanas ibéricas. In : Aranegui (C.), ed., Los iberos príncipes de Occidente. Las estructuras de poder en la sociedad ibérica, Barcelona, 1998, p. 83-92 (Saguntum-extra 1).

Moret 2004 : MORET (P.) - Ethnos ou ethnie? Avatars anciens et modernes des noms de peuples ibères : étapes et acteurs. In : Cruz Andreotti (G.), Mora (B.), coord., Identidades étnicas, identidades políticas en el mundo prerromano hispano, Málaga, 2004, p. 31-62.

Negueruela 1990 : NEGUERUELA (I.) - Los monumentos escultóricos ibéricos del Cerrillo Blanco de Porcuna (Jaén), Madrid, 1990 (Ministerio de Cultura).

Nicolini 1973 : NICOLINI (G.) - Les Ibères. Art et civilisation, Paris, Fayard, $1973,159 \mathrm{p}$.

Noguera 2002 : NOGUERA (J.) - Ibers al Ebre, Móra d'Ebre.

Olmos, Tortosa 1997 : OLMOS (R.), TORTOSA (T.), EDS. - La Dama de Elche. Lecturas desde la diversidad, Madrid, 1997, 321 p. (Colección Lynx). Paris 1903-1904 : PARIS (P.) - Essai sur l'art et l'industrie de l'Espagne primitive, Paris, E. Leroux éd., $412 \mathrm{p}$.

Perea, Armbruster 2011 : PEREA (A.), ARMBRUSTER (B.) - Tomb 100 at Cabezo Lucero: New Light on Goldworking in Fourth-cCntury BC Iberia. Antiquity, 85, 2011, p. 158-171.

Pérez 2009 : PEREZ (J.) - La légende noire de l'Espagne, Paris, Fayard, $252 \mathrm{p}$.

Philipon, Arbois de Jubainville 1909 : PHILIPON (É.), ARBOIS DE JUBAINVILLE (CH.-J. D') - Les Ibères : étude d'histoire, d'archéologie et de linguistique, Paris, H. Champion.

Prado 2010 : PRADO (D. de) - La fortificación ibérica del Puig de Sant Andreu (Ullastret, Cataluña): aspectos técnicos, formales y funcionales. In 
Tréziny (H.), éd., Grecs et indigènes de la Catalogne à la Mer Noire, París Aix-en-Provence, 2010, p. 567-581 (Actes des rencontres du programme européen Ramsès 2006-2008).

Quesada 2002 : QUESADA (F.) - La evolución de la panoplia. Modos de combate y tácticas de los iberos. In : Moret (P.), Quesada (F.), eds., La guerra en el mundo ibérico y celtibérico (ss. VI-II a.C.), Madrid, , 2002, p. 35-64 (CCV 78).

Rafel 2007 : RAFEL (N.) - El textil como indicador de género en el registro funerario ibérico. Treballs d'Arqueologia 13, 2007, p. 113-144.

Ramallo, Noguera, Brotóns 1998 : RAMALLO (S.), NOGUERA (J.M.), BROTÓNS (F.) - El Cerro de los Santos y la monumentalización de los santuarios ibéricos tardíos. Revista de Estudios Ibéricos 3, 1998, p. 11-69.

Reinach 1898 : REINACH (TH.) - La tête d'Elche au Musée du Louvre. REG 11, p. 39-60.

Rísquez, García Luque 2012 : RÍSQUEZ (C.), GARDÍA LUQUE (A.) Identidad de género y practicas sociales en el registro funerario ibérico. La necrópolis del Cigarralejo. In : Prados (L.), ed., La Arqueología funeraria desde una perspectiva de género, Madrid, , 2012, p. 257-276 (II Jornadas de Arqueología y Género en la UAM).

Rouillard 1995 : ROUILLARD (P.) - Le Pays Valencien et les archéologues français du XIX ${ }^{\text {e }}$ siècle. Saguntum 29, 1995, p. 105-112 (Homenaje a Milagro Gil-Mascarell).

Ruby 1999 : RUBY (P.), ED. - Les princes de la protohistorie et l'émergence de l'état, Nápoles-Roma, 1999 (CJB-ÉFR), 206 p.

Ruiz 2009 : RUIZ (A.) - Identidad social y príncipes. El caso del Alto Guadalquivir. In : Identidades, Arqueología espacial 27, Teruel, 2009, p. 113130 (Homenaje a M ${ }^{\mathrm{a}}$ Dolores Fernández Posse).

Ruiz et al. 1991 : RUIZ RODRIGUEZ (A.), MOLINOS MOLINOS (M.), CHOCLAN SABINA (C.) - Fortificaciones ibericas en la alta Andalucia. In : Fortifications : la problematica de liberic ple : segles IV-III A.C.: Simposi internacional d arqueologia iberica (1990, Mansera), 1991, p. $109-126$
Ruiz, Sánchez, Bellón 2003 : RUIZ (A.), SÁNCHEZ (A.), BELLÓN (J.P.) Aventuras y desventuras de los iberos durante el franquismo. In: Wulff (F.), Alvarez (M.), eds., Antigüedad y franquismo (1936-1975), Málaga, 2003, p. 161-188 (CEDMA).

Santos 2008 : SANTOS (M.) - L'arqueologia grega a Empúries. Un discurs en construcció. In : Dossier 100 anys d'excavacions arqueològiques a Empúries. Hipòtesis i certeses, Girona, 2008, p. 49-79 (Annals de l'Institut d'Estudis Empordanesos 39).

Schnapp 1997 : SCHNAPP (A.) - L'archéologie française entre identité nationale et identité culturelle. In : Schnapp (A.), ed., Une archéologie du passé recent? Paris, 1997, p. 5-21 (Fondation Maison des Sciences de l'Homme).

Soria 2000 : SORIA (L.) - La Cultura Ibérica en la provincia de Albacete: génesis y evolución a partir del estudio del doblamiento, Cuenca, 2000, 610 p. (Universidad de Castilla-La Mancha).

Truszkowski 2006 : TRUSZKOWSKI (E.) - Étude stylistique de la sculpture du sanctuaire ibérique du Cerro de los Santos (Albacete, Espagne). Monographies Instrumentum, 33, Montagnac, 2006.

Vasseur 1905 : VASSEUR (G.) - Découverte de poteries peintes à décoration mycénienne (céramiques ibéro-mycéniennes) dans les environs de Marseille. Comptes-rendus à l'Académie des Inscriptions et Belles Lettres, 1905, p. 383. Voltaire 1756 : VOLTAIRE (F.-M. AROUET) - Essai sur les moeurs et l'esprit des nations, Paris: Werdet et Lequien fils, 1756 [1829].

Wulff 2004 : WULFF (F.) - Adolf Schulten. Historia antigua, arqueología $\mathrm{y}$ racismo en medio siglo de historia europea. In : Schulten (A.), Historia de Numancia, Pamplona, Urgoiti, 2004, p. VII-CCLVI.

Wulff 2009 : WULFF (F.) - ¿Por qué las identidades hoy? Historia antigua y arqueología ante un cambio de paradigma. In : Wulff (F.), Álvarez MartíAguilar (M.), eds., Identidades, culturas y territorios en la Andalucía prerromana, Málaga, 2009, p. 7-50.

Zofío, Chapa 2005 : ZOFÍO (S.), CHAPA (T.) - Enterrar el pasado: la destrucción del conjunto escultórico del Cerrillo Blanco de Porcuna (Jaén). Verdolay, 9, 2005, p. 95-120. 



\title{
Les Ibères à la rencontre des Grecs
}

\author{
Pierre Rouillard \\ UMR 7041 ArScAn, Maison Archéologie et Ethnologie René Ginouvès, \\ Nanterre, Labex Les passés dans le présent
}

\section{Rosa Plana-Mallart}

ASM, Archéologie des Sociétés Méditerranéennes, UMR5140, UPVM, CNRS, MCC, 34000, Montpellier, France, Labex ARCHIMEDE (programme ANR-11-LABX-0032-01)

\section{Pierre Moret}

UMR 5608 TRACES, Université de Toulouse - Le Mirail

\section{Résumé}

La péninsule Ibérique offre ce trait spécifique d'avoir eu comme partenaires méditerranéens tout à la fois les Phéniciens, les Grecs et les Puniques. À un moment où il ne saurait être question de réécrire une « Hispania Graeca », il convient de saisir les modalités d'installation des Grecs, l'emporion, et les formes des échanges entre les communautés. L'archéologie nous enseigne comment les populations du nord-est de la Péninsule, avec les cas de Ullastret et de Pontos (Prov.de Gérone), se sont appropriées des traits helléniques ou comment, dans le cas du bas-Segura, notamment à Santa Pola (Prov. d'Alicante), se mêlent traits indigènes et traits grecs, surtout dans l'urbanisme. Le vase grec, avec ses usages, et le travail de la pierre offrent d'autres exemples d'intégration et d'échanges de modèles.

Mots-clés : colonisation grecque, emporion, urbanisme ibérique, vase grec, sculpture ibérique, Ampurdan, Bas-Segura, Ullastret (Gérone), La Picola (Santa Pola, Alicante)

\section{Resumen}

La península Ibérica presenta un carácter específico por el hecho de haber tenido como partenaires mediterráneos a la vez a fenicios, griegos y púnicos. En una época en la que no tendría sentido reescribir una "Hispania Graeca", es necesario analizar las modalidades de instalación de los griegos, mediante el emporion, y las formas de intercambio entre las comunidades. La arqueología muestra como las poblaciones del nordeste de la península, con los ejemplos de Ullastret y de Pontós (provincia de Girona), se apropian de elementos helénicos, o como, en el caso del Bajo Segura y en particular de Santa Pola (provincia de Alicante), se mezclan rasgos indígenas y griegos, principalmente en el urbanismo. El vaso griego, y sus usos, así como el trabajo de la piedra ofrecen otros ejemplos de integración y de intercambio de modelos.

Palabras clave: Colonización griega, emporion, urbanismo ibérico, vaso griego, escultura ibérica, Ampurdán, Bajo-Segura, Ullastret (Girona), La Picola (Santa Pola, Alicante) 
$\mathrm{M}$ ême dans une rencontre marquée du sceau de l'hellénisme, on ne saurait parler des Ibères à la rencontre d'un seul partenaire, les Grecs ; les Phéniciens et les Puniques sont aussi partenaires des Ibères, les uns ne pouvant, souvent, pas être isolés des autres dans nos analyses. Il faut présenter ce cadre général, et en fonction des autres interventions, notamment sur Ampurias et Rosas, nous nous focaliserons sur ce que l'on peut saisir archéologiquement, notamment de la " consommation », de " l'usage », de "l'intégration » de schémas grecs, de traits grecs, d'objets grecs, de « modèles » grecs, et cela plus précisément dans deux régions, l'Ampurdan et le sud du Pays Valencien.

\section{Entre Phéniciens et Grecs, les traits spécifiques de l'implantation grecque en péninsule Ibérique}

La péninsule Ibérique est la seule région méditerranéenne qui ait accueilli dans une grande proximité géographique, marchands grecs et marchands phéniciens. Plus encore, il y a symétrie dans les modalités d'installation, notamment avec une très grande proximité avec les indigènes, et la formule " d'indigènes immédiatement présents » rend compte des situations observées. Une autre symétrie s'observe quant aux effectifs établis : les communautés qui s'établissent sont de faible ampleur. L'étude des productions artisanales et artistiques de la péninsule témoigne d'une grande

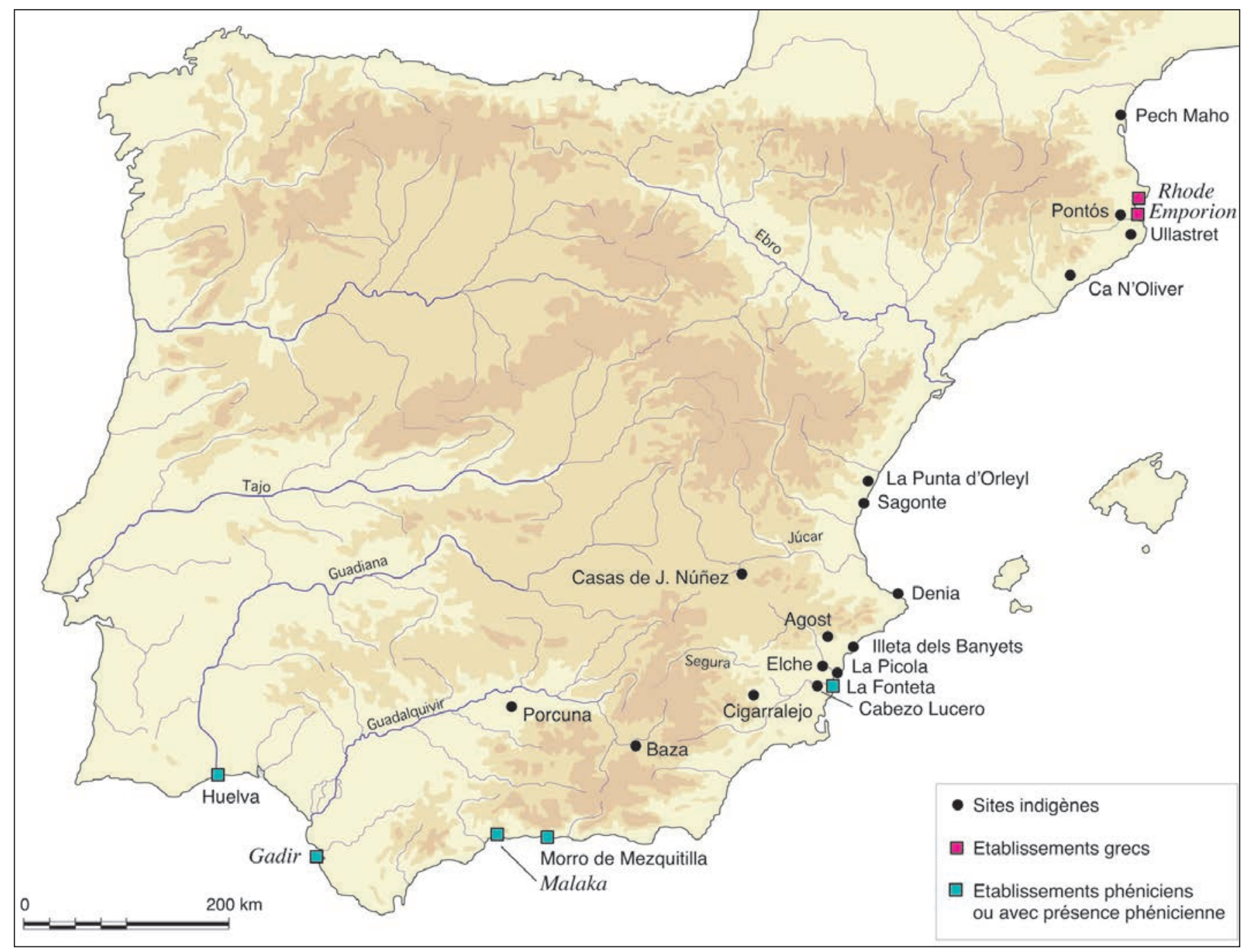

Fig. 1. Principaux sites phéniciens, grecs et ibériques de la péninsule Ibérique. 
porosité que ce soit pour les thèmes, les schémas, les techniques, un phénomène qui se caractérise aussi par sa durée puisque l'on retrouve Phéniciens et Puniques ; avec là une difficulté dans l'appréciation chronologique de bien des séries «puniques».

La chronologie est différente pour les premières installations de communautés phéniciennes ou grecques : fin $\mathrm{VIII}{ }^{\mathrm{e}}-\mathrm{VII}{ }^{\mathrm{e}}$ pour les premières, $\mathrm{VI}^{\mathrm{e}}$ pour la seconde, en fait celle de la seule Ampurias. Sur le début des installations phéniciennes, il y a débat. Morro de Mezquitilla (Malaga) était et est encore souvent présenté comme la plus ancienne, vers le milieu du VIII ${ }^{\text {s. (Maas- }}$ Lindemann 2000 ; Schubart 2006). La pêcherie de la rue Cánovas del Castillo à Cadix (Córdoba Alonso, Ruiz Mata 2005) serait de la même époque, mais les premiers acquis de la fouille conduite au « Teatro Comico » de Cadix montrent d'abord une fréquentation phénicienne auprès d'un habitat indigène, puis une installation phénicienne stable datable entre, selon les méthodes de datation utilisées, la fin du $\mathrm{IX}^{\mathrm{e}} \mathrm{s}$. et le second quart du VIII ${ }^{\mathrm{e}}$ s. (Zamora et al. 2010).

Au regard des dates de Morro de Mezquitilla fixées à partir de la typologie céramique, une controverse est née à la suite des datations $\mathrm{C} 14$ qui conduisent à relever cette chronologie au IX ${ }^{\mathrm{e}}$ s. (Nijboer 2005 ; Mederos 2005 ; Brandherm 2006). Et les dernières découvertes de Cadix ne manqueront pas d'alimenter le débat, d'autant plus qu'un point de repère important nous est fourni par le matériel exhumé ces dernières années à Huelva, un site qui a clairement accueilli des marchands de Méditerranée orientale. Longtemps le témoignage le plus ancien a été un fragment de pyxis attique du Géométrique Moyen II du milieu du VIII s. Aujourd'hui, nous disposons d'un matériel plus abondant et plus varié (González de Canales et al. 2006) : grec, sarde, villanovien, chypriote, phénicien (de la phase IV de Tyr, dans la sériation de Patricia Bikai). Le matériel grec est constitué de 9 pièces attiques du Géométrique Moyen II et de 21 plats à demicercles pendants datables du second quart du VIII ${ }^{\mathrm{e}}$ s., c'est à dire la phase IIA de Pontecagnano qui est sur ce site la première à recevoir des importations méditerranéennes (Bailo Modesti, Gastaldi 1999 ; D’Agostino 1999 ; Kourou 2005). Huelva, et désormais aussi Cadix et Malaga, s'ajoutent alors à une courte liste des sites de Méditerranée centrale et occidentale qui ont reçu dans un même temps les premières importations grecques. Dès lors, la « question eubéenne » peut être, au moins, posée aussi pour la péninsule Ibérique.

Deux données sont à souligner, la première est la grande antériorité de l'établissement de communautés phéniciennes au regard de celui de la seule communauté de Grecs à Ampurias au début du $\mathrm{VI}^{\mathrm{e}}$ s., la seconde est la présence de « signes » du commerce phénicien sur tout le littoral oriental de la péninsule (et aussi sur une bonne partie du littoral atlantique). Tel est le cas avec la Palaiapolis d'Ampurias qui a livré de nombreuses amphores de types phéniciens, une présence d'amphores phéniciennes - à l'exclusion de presque toute autre céramique phénicienne - qui est la règle au nord de l'embouchure du Segura, région qui abrite, à la Fonteta (Guardamar del Segura, Alicante) la communauté phénicienne la plus septentrionale du littoral méditerranéen de la péninsule (Rouillard et al. 2007).

Les rivages méridionaux de la péninsule comptent, à partir du milieu du VIII ${ }^{\mathrm{e}} \mathrm{s}$. et tout au long du VII ${ }^{\mathrm{e}} \mathrm{s}$, une longue série d'établissements phéniciens, notamment à Cadix et aux alentours, de Gibraltar à Alméria, mais aussi à l'embouchure du Segura et sur le littoral atlantique (fig. 1) ; dès lors les schémas orientaux sont largement présents dans la moitié méridionale de la péninsule, avec des zones de forte concentration : le Sud-Est autour de la basse vallée du Segura, la haute Andalousie, la vallée du Guadalquivir et Cadix. En nous limitant à la région sud-orientale, ces schémas orientaux sont bien perceptibles notamment dans la sculpture, dès la fin du $\mathrm{VI}^{\mathrm{e}} \mathrm{s}$. ou au début du $\mathrm{V}^{\mathrm{e}} \mathrm{s}$., avec des êtres hybrides ou une place dominante des animaux, comme on le voit à Elche, à La Alcudia de Elche, à Redoban ou Agost. Ce phénomène s'inscrit dans la durée, ce dont témoigne l'ensemble d'outils, de matrices et de moules d'orfèvres, riches de tout le bestiaire oriental, trouvés à Cabezo Lucero (Guardamar del Segura, Alicante) datés dans un contexte funéraire de la première moitié du IV s. av. J.-C. (Uroz Rodríguez 2006).

Une évocation de nos sources littéraires et/ou un rapide retour en arrière dans l'historiographie sont nécessaires à ce point : ces témoignages puisés dans la sculpture ou l'orfèvrerie ont été trouvés dans la région censée être la plus " hellénisée »- avec beaucoup de guillemets - de toute l'Ibérie, la seule en tout cas où, comme on le verra plus loin, sont réunis tout à la fois des témoignages toponymiques grecs, beaucoup de vases grecs, de la métrologie grecque dans l'architecture, et même une écriture gréco-ibère. Autre paradoxe : parmi les sites côtiers du Sud-Est, c'est à l'Illeta (Campello, Alicante) que l'on trouve le plus d'inscriptions en grécoibère. Il y a là de nombreuses importations de céramique grecque (fin $V^{e}$ et surtout $I^{e} \mathrm{~s}$.), mais aujourd'hui certains auteurs suggèrent des liens forts avec le monde punique (notamment Ebusus) (Sala Sellés 2010) . Et, toujours pour souligner que les débats sont complexes, 
dans une région réputée "phénicienne », à Huelva, on compte de nombreuses inscriptions grecques archaïques (González de Canales et al. 2006 ; Llompart et al. 2010).

Les Ibères se retrouvaient avec les Phéniciens et les Grecs dans des « lieux d'échange », une formule qui est la définition minimale que l'on puisse proposer du mot emporion ${ }^{1}$. Le partenariat entretenu par les Ibères avec les Grecs est explicité par les plombs commerciaux de Pech Maho et d'Ampurias (Lejeune et al. 1988 ; Decourt 2000); dans ces deux cas les Ibères interviennent dans les échanges.

Lieu d'échange, l'emporion est un « acteur » majeur sur le littoral péninsulaire, car il est le lieu de contact entre zones de cultures différentes et lieu de concentration et rencontre humaine. Une telle acception du terme permet d'envisager une multitude de sites et un « foisonnement emporique » pour reprendre la formule de Michel Gras (1993, p. 110) où se côtoient des emporia associés à une cité (tel est le cas, traité plus bas, de La Picola avec Elche) ou pas associés à une cité, au moins à ce que nous en savons (tel est alors le cas de Ampurias). Nous devons en convenir, notre perception de l'emporion est fortement soucieuse des réalités de terrain. La Péninsule Ibérique offre un exemple où le mot et la chose existaient avant le $\mathrm{V}^{\mathrm{e}} \mathrm{s}$. Bien des aspects juridiques nous échappent, mais comme à Vetren, en Thrace, les résidents se désignent comme emporitai, comme le disent les inscriptions de Pech Maho et de Ampurias. Plus tard vient à Ampurias la volonté de disposer d'institutions politiquement autonomes, comme la frappe de monnaies « EMP » ou les briques munies du timbre public « DÊM » l'attestent (De Hoz 2010).

La péninsule Ibérique ne compte pas d'apoikia, mais des installations de petite taille (Cadix étant probablement à part) où se côtoient Phéniciens et Ibères, Grecs et Ibères, et où l'indigène est présent. Il serait bien téméraire de vouloir proposer une définition unique pour le mot emporion, car les cas de figure sont variés : ainsi voit-on cohabiter Phéniciens et Ibères à La Fonteta (Guardamar del Segura, Alicante), Grecs et Ibères à Ampurias, mais à La Picola (Santa Pola, Alicante) les Ibères semblent être bien les seuls à vivre dans un environnement architectural riche d'ingrédients grecs. S'il y a bien un modèle hispanique d'emporion, avec ces deux traits majeurs que sont une faible taille et une présence immédiate de

1 Sans oublier la multitude de travaux récents qui approfondissent, non sans désordre, ce concept : Bresson, Rouillard 1993 ; Casevitz 1993 ; Gras 1993 ; Will 1993 ; Hansen 1997 ; Bresson 2000 ; Domínguez Monedero 2000 ; Lombardo 2002.
l'Ibère, il témoigne à lui seul de " la richesse foisonnante de l'emporion » pour reprendre la belle formule de Pierre Lévêque (1993).

\section{Deux régions et des sites}

Nous avons fait le choix de traiter principalement de deux régions où nous pouvons envisager des perspectives d'analyse différentes, et où nous sommes en présence de comportements différents.

\section{Le Nord-Est : l'Empordà}

Les deux seuls établissements grecs connus à ce jour se localisent dans l'extrême nord-est de la Péninsule Ibérique, placés à faible distance l'un de l'autre : Emporion fondé vers 580 et Rhodè vers la fin du Ve ou le début du IV s. av. J.-C. (fig. 1). Cette présence grecque est à rattacher à l'emprise phocéo-massaliète en Méditerranée nord-occidentale, qui serait à l'origine de l'installation d'un petit noyau grec sur la presqu'île de Sant Martí d'Empúries, où il y avait un village indigène du Premier âge du Fer (Aquilué et al. 1999). Ce site, désormais mixte, semble pouvoir être identifié au marché actif existant près des Pyrénées et fréquenté par les Massaliètes, cité par Aviénus (Antonelli 1998, p. 186). La fonction de l'enclave, un simple emporion, finit par désigner l'établissement grec, qui se développe notamment à partir du milieu du $\mathrm{VI}^{\mathrm{e}} \mathrm{s}$. avec la création, à peu de distance au sud du noyau primitif, d'une nouvelle agglomération sur la terre ferme (Aquilué et al. 2010). Cette double implantation, qui correspond à la Palaia Polis / Néapolis de Strabon (III, 4, 6), exprime également le passage d'emporion à Emporion, dont la frappe de monnaies à légende EMP dès le $\mathrm{V}^{\mathrm{e}} \mathrm{s}$. atteste l'identité et l'autonomie de cette communauté (PlanaMallart 2001, 2012).

Le peuplement indigène de cette partie septentrionale de la côte catalane, au Premier âge du Fer, est composé de petits villages ouverts et peu structurés, souvent formés de plusieurs noyaux voisins répartis dans un même secteur. C'est le cas des sites d'Empúries, d'Ullastret et de Mas Gusó, situés sur ou près du littoral (Martín, Plana 2012). Ces établissements ont reçu, vers la fin du VII et le début du VI e s., des importations, d'abord phéniciennes, plus tard étrusques et grecques, ce qui atteste leur insertion dans les courants d'échanges méditerranéens. Les pourcentages de mobilier importé augmentent après l'implantation des Grecs à Sant Martí d'Empúries, rendant compte des contacts noués entre ces communautés. 
Depuis l'origine, l'implantation grecque (Palaia Polis) utilise une architecture en dur, un plan quadrangulaire pour les habitations et des murs mitoyens qui permettent d'agglutiner l'habitat et de définir des îlots ouverts sur des rues (Aquilué et al. 2002). Quelques décennies plus tard, vers le milieu / seconde moitié du VI e s., la création de la Néapolis matérialise l'affermissement des Grecs dans cette partie du littoral et l'adoption d'une structure urbaine plus ou moins développée. En effet, les éléments archaïques mis au jour dans le cadre des fouilles récentes conduites dans le secteur de la stoa hellénistique signalent la mise en place d'une trame urbaine régulière, qui perdure dans ses grandes lignes jusqu'à la conquête romaine. Au Ve s., on connaît l'existence déjà d'une fortification et de sanctuaires, probablement aussi d'une place publique (Aquilué et al. 2010 ; Santos, Sourisseau 2011).

Si l'activité emporique est tournée vers les échanges, on constate néanmoins un développement parallèle de l'agriculture. C'est également le cas à Pithécusses, avec la mise en évidence d'une production de vin qui sera commercialisé auprès des sociétés indigènes du sud de l'Italie (Esposito 2012), ou à Marseille, où la fabrication d'amphores atteste aussi une production locale de vin dès le milieu du $\mathrm{VI}^{\mathrm{e}} \mathrm{s}$. (Boissinot 2010). Les études carpologiques et la découverte d'un grand nombre de batteries de silos signalent que l'arrière-pays d'Emporion était voué à la céréaliculture (Asensio et al. 2002 ; Plana-Mallart 2004). La fouille récente de sites placés dans un rayon d'une dizaine de km autour de l'établissement grec a montré l'existence d'un habitat rural dispersé dès les VI ${ }^{\mathrm{e}}$ et $\mathrm{V}^{\mathrm{e}} \mathrm{s}$. (Casas, Soler 2004 ; Casas 2010 ; Casas et al. 2010). Ces sites, dotés de silos, sont indigènes, mais le pourcentage élevé de céramique grecque découverte souligne des contacts étroits avec Emporion (Plana-Mallart 2012). Cette occupation rurale se densifie progressivement, marquée par la généralisation des « sites à silos » au cours des IV et III ${ }^{\mathrm{e}} \mathrm{s}$. L'accroissement de la production céréalière serait vraisemblablement en rapport avec l'activité commerciale d'Emporion, plus tard aussi avec celle de Rhodè.

La présence d'un arrière-pays fertile voué à l'exploitation céréalière est donc l'un des facteurs qui expliquent le développement des implantations grecques du littoral nord-est. Le contact avec le milieu indigène a été essentiel, évident dans la cohabitation à toutes les époques de Grecs et d'Ibères à Emporion. Ces rapports, qui expriment l'une des spécificités de la présence grecque en Ibérie, expliquent l'ampleur des influences helléniques qui pénètrent en milieu indigène. Deux sites de caractère très différent du proche environnement d'Emporion illustrent en particulier ce phénomène : Ullastret, situé au sud et à une quinzaine de $\mathrm{km}$ de distance ; Pontós, placé à une vingtaine de km à l'ouest.

Le site d'Ullastret se caractérise d'abord par sa physionomie, car il est constitué de deux agglomérations voisines distantes de $400 \mathrm{~m}$ et placées en bordure d'un ancien étang, l'une (Puig de Sant Andreu) implantée sur une colline de $50 \mathrm{~m}$ d'altitude, l'autre (Illa d'en Reixac) sur une presqu'île qui s'avance dans l'étang (fig. 2). Il se caractérise aussi par son développement précoce. Ainsi, l'adoption d'une architecture en dur et d'un plan quadrangulaire pour les habitations date ici du milieu du $\mathrm{VI}^{\mathrm{e}}$ s. (Martín et al. 2010). Un peu plus tard, à la fin du siècle, l'établissement de hauteur se dote d'une fortification qui renferme trois hectares de superficie, ce qui en fait la première grande agglomération fortifiée de la côte catalane. Les études métrologiques réalisées signalent l'utilisation de modules grecs dans la conception de la fortification (Moret 1998).

Une nouvelle phase de développement est perceptible dans la seconde moitié du Ve s., lié à la prospérité économique de l'oppidum. Le nombre de silos augmente, de même que le volume de céramiques d'importation, notamment de céramique attique, ce qui rend compte à la fois de l'importance de la production céréalière et de l'ampleur des échanges avec les Grecs. La découverte en réemploi dans des constructions du IVe $\mathrm{s}$. d'éléments de colonne et de blocs décorés atteste l'existence d'une architecture monumentale dans une période antérieure, soit le Ve s. (Martín, Plana 2012). L'influence grecque est évidente, comme le montrent, par exemple, une base de colonne découverte dans un bâtiment interprété comme un possible temple précoce (fig. 3) et deux grands blocs rectangulaires avec un décor d'oves et de motifs végétaux en relief mis au jour dans le cadre des fouilles récentes et qui devaient appartenir à la corniche d'un bâtiment certainement monumental. Cette influence grecque est également perceptible dans les productions céramiques, comme c'est le cas de la céramique à pâte claire peinte produite localement entre 450 et $380^{2}$. Enfin, la nécropole de Puig de Serra, utilisée du milieu du Ve à la fin du IV $\mathrm{e}$ s., permet aussi de percevoir l'intensité des contacts avec les Grecs. 87 sépultures d'incinération ont été fouillées et l'étude réalisée par Aurora Martín a montré que, dans $37 \%$ environ des cas, le vase funéraire était une céramique attique. Le mobilier d'accompagnement montre aussi la présence très fréquente de vases attiques

2 Voir la contribution de F. Codina, A. Martín et G. de Prado dans ce même volume. 
(Plana, Martín 2012, p. 130-132). Il faut noter que cette nécropole est une des rares connues dans cette région et qu'elle offre bien des traits voisins de ceux observés dans le sud-est.

Des sanctuaires ont été bâtis très tôt dans l'établissement grec d'Emporion, depuis au moins le Ve s. av. J.-C. dans la partie méridionale de la Néapolis (Santos, Sourisseau 2011). Ce modèle d'espace sacré n'a pas été adopté tout de suite par les sociétés indigènes, car c'est seulement à une époque plus tardive que l'on constate l'érection de temples à Ullastret (Casas et al. 2005). Néanmoins, un bâtiment de grandes dimensions situé sur la partie haute du versant nord-occidental de l'agglomération perchée, a été interprété comme un possible temple de la fin du $\mathrm{V}^{\mathrm{e}} \mathrm{s}$. Au plan, composé de salle et d'avant-salle, s'ajoute la découverte de la base de colonne citée précédemment. Quoi qu'il en soit, ce sont les temples du sommet de la colline qui sont les mieux connus. Les fouilles anciennes ont mis au jour deux temples, l'un plus grand que l'autre, datés du $\mathrm{III}^{\mathrm{e}} \mathrm{s}$. av. J.-C. (fig. 4a). Le plan est similaire, composé d'un porche in antis et d'une salle principale, et l'architecture est soignée, utilisant des blocs de taille. Parmi les particularités de ces bâtiments, il faut signaler la présence de contreforts dans le temple le plus petit et l'existence d'un revêtement du type opus signinum sur les faces interne et externe du temple le plus grand. Autour des temples, des fragments de stuc et des blocs moulurés ont été découverts (Oliva 1955, 404). On peut citer un bloc taillé sous forme de colonne à faible relief avec un chapiteau à volutes éolique recouvert d'une couche de stuc (fig. 4b), des fragments de corniche (fig. 4c) et un bloc avec un décor végétal en relief (fig. 4d). Ce dernier a été mis en rapport par Miquel Oliva (1955, p. 378), premier fouilleur du site, avec un autre bloc découvert près de l'entrée principale de l'oppidum (fig. 4e). Ce dernier, avec un décor de volutes en relief, présente un système qui permet de l'encastrer sur un autre élément architectonique. Il avait été utilisé, avec d'autres blocs bien équarris, comme assise inférieure du mur qui barre l'entrée lors de la dernière phase d'occupation du site. Ce contexte signale un déplacement des blocs, en provenance probablement des temples de la partie sommitale de la colline. M. Oliva rapproche ce bloc à décor de volutes d'un autre similaire découvert à Emporion.

Les temples d'Ullastret sont indubitablement de type méditerranéen et les éléments connus soulignent le poids des influences grecques. Si des approfondissements sont nécessaires, force est de constater que des rapprochements sont possibles avec certains décors utilisés dans les temples ioniques. En tout cas, il faut noter

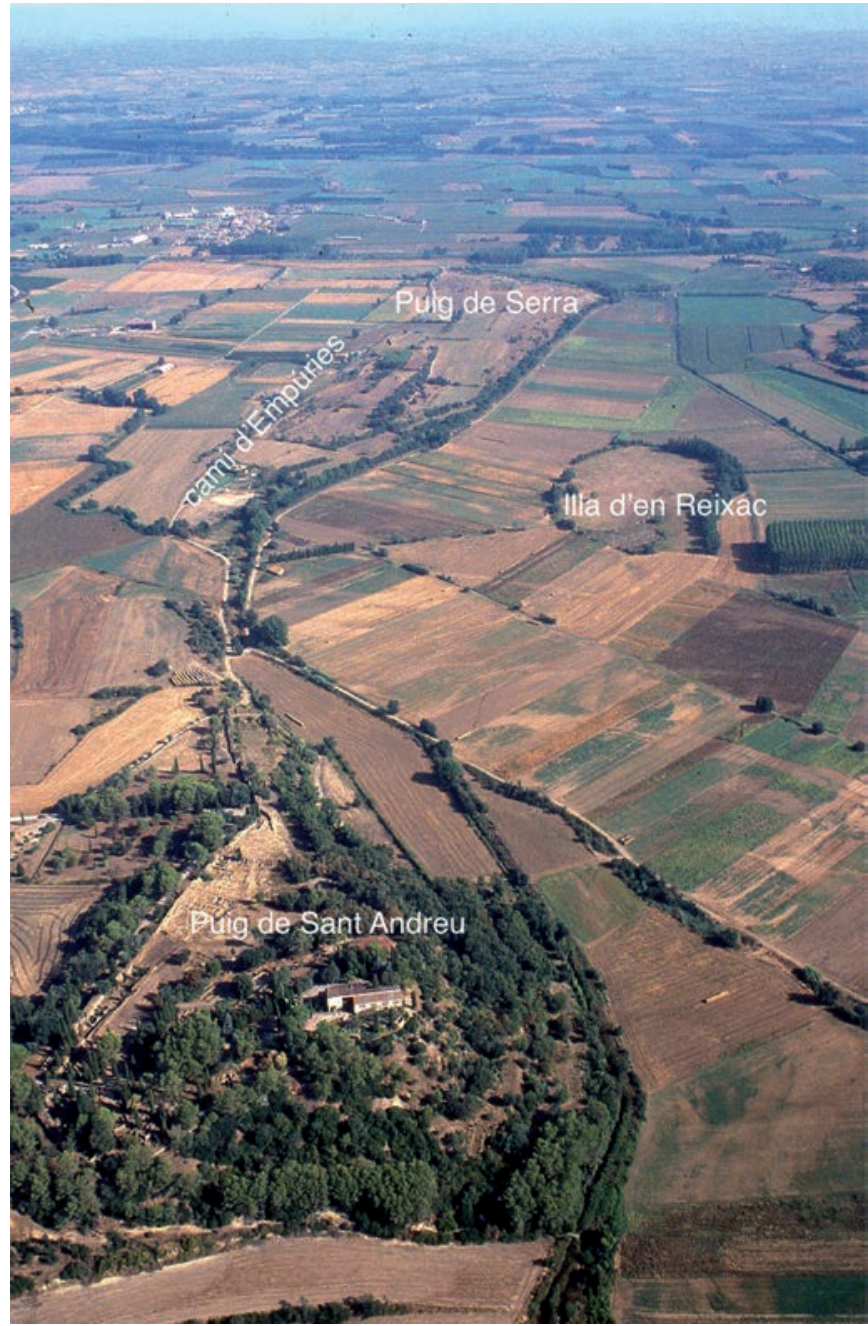

Fig. 2. Les agglomérations fortifiées d'Ullastret (Puig de Sant Andreu et Illa d'en Reixac) et la nécropole de Puig de Serra (cliché : François Didierjean).

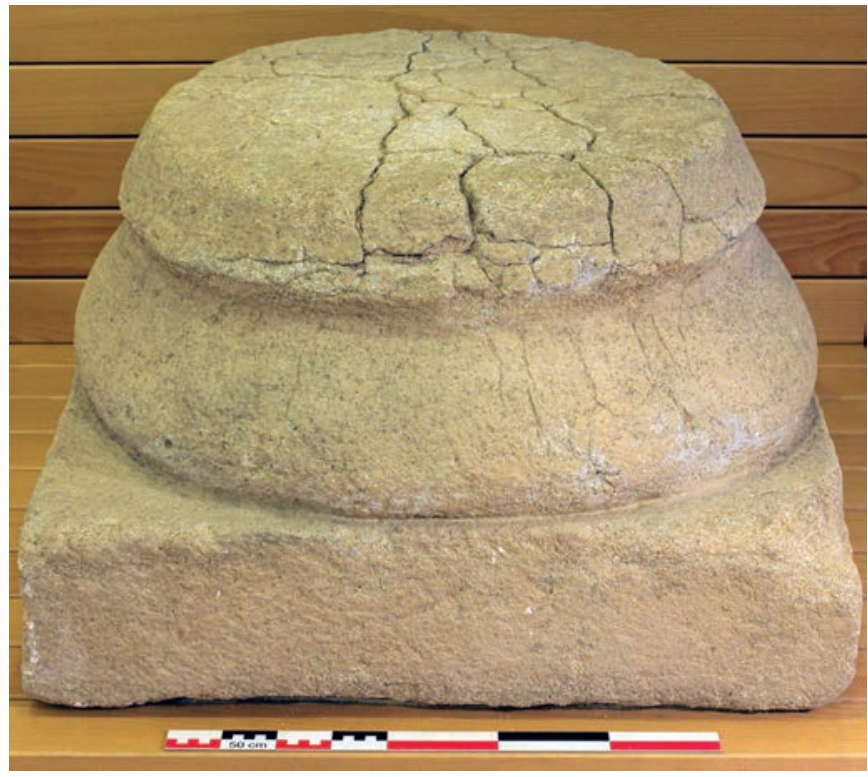

Fig. 3. Base de colonne de tradition classique (cliché : Museu d'Arqueologia de Catalunya-Ullastret). 


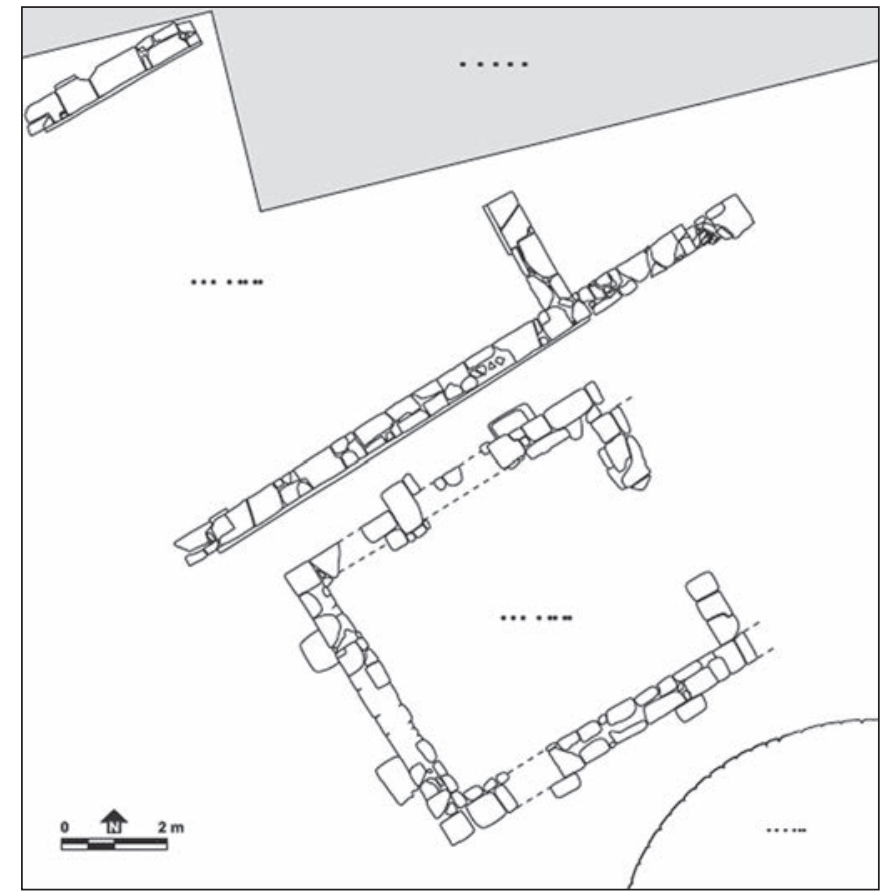

a

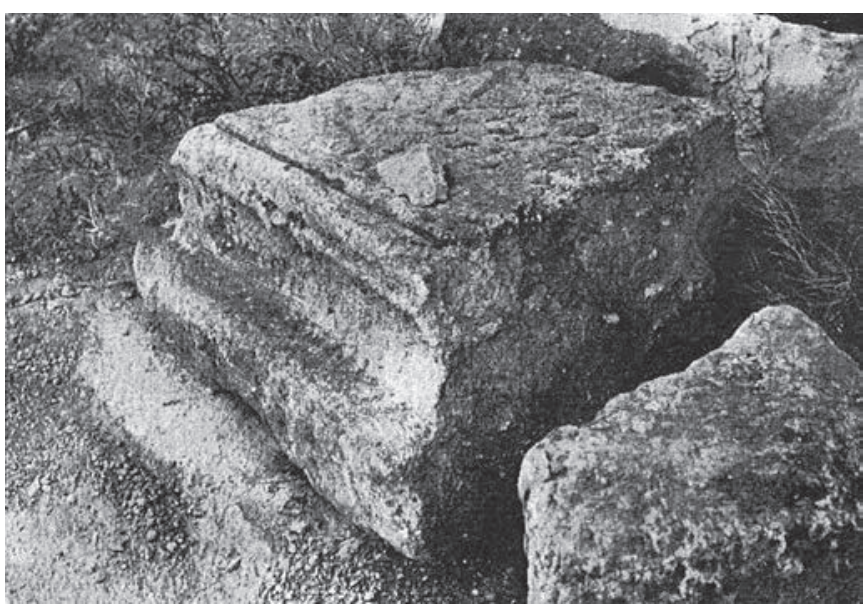

c

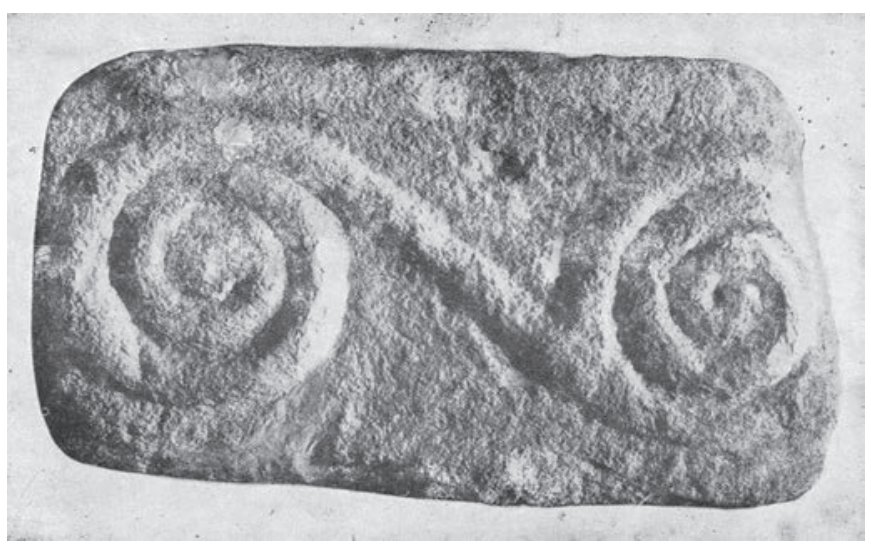

$\mathrm{e}$

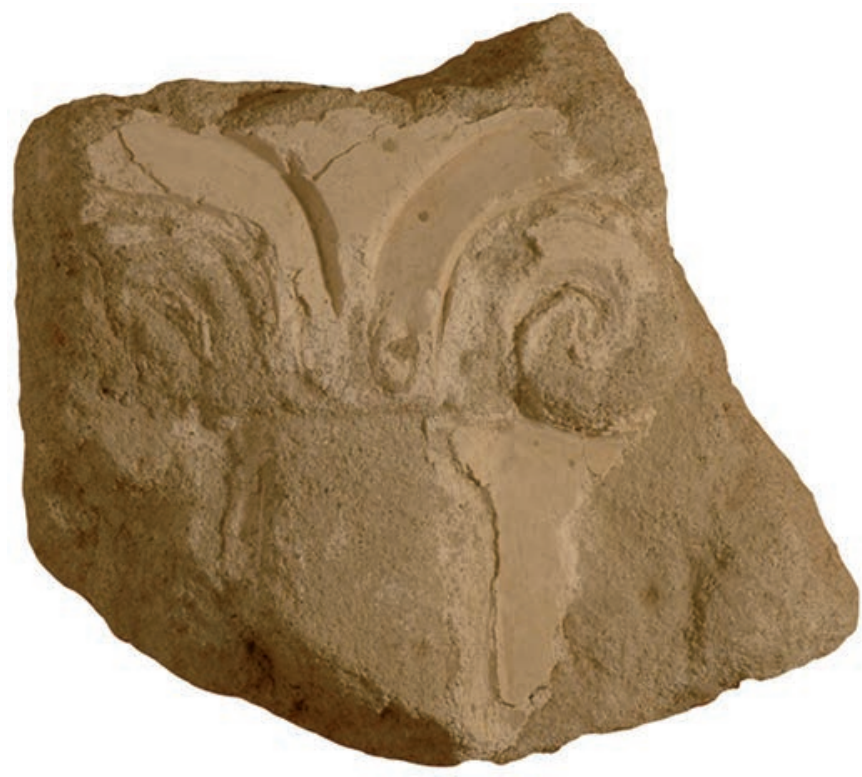

b

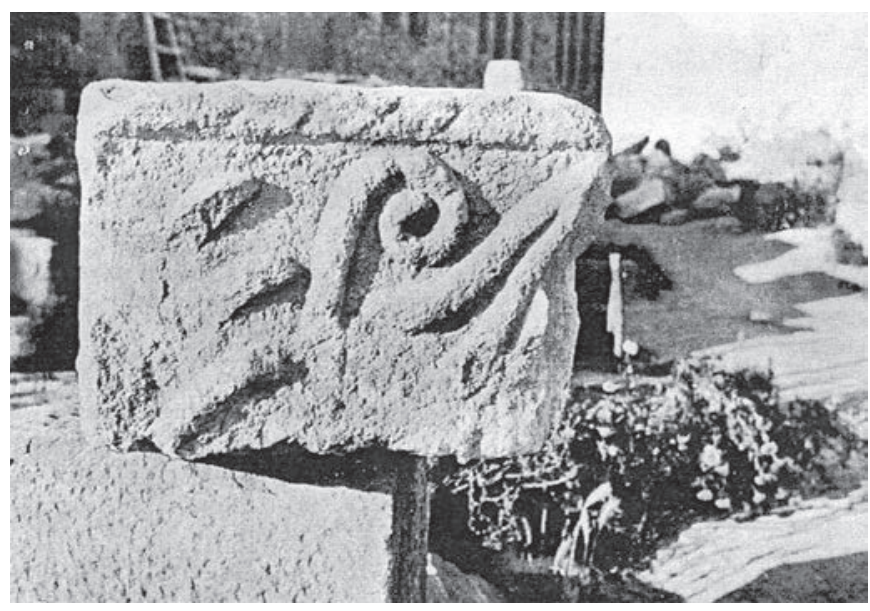

d

Fig. 4. Les temples de l'agglomération de Puig de Sant Andreu d'Ullastret (plan et clichés : Museu d'Arqueologia de Catalunya-Ullastret) :

- 4a: Plan des temples

- $4 \mathrm{~b}$ : Bloc représentant une colonne avec chapiteau à volutes éolique

- 4c: Fragment de corniche

- $4 \mathrm{~d}$ : Bloc à décor végétal en relief

- $4 \mathrm{e}$ : Bloc à décor de volutes 


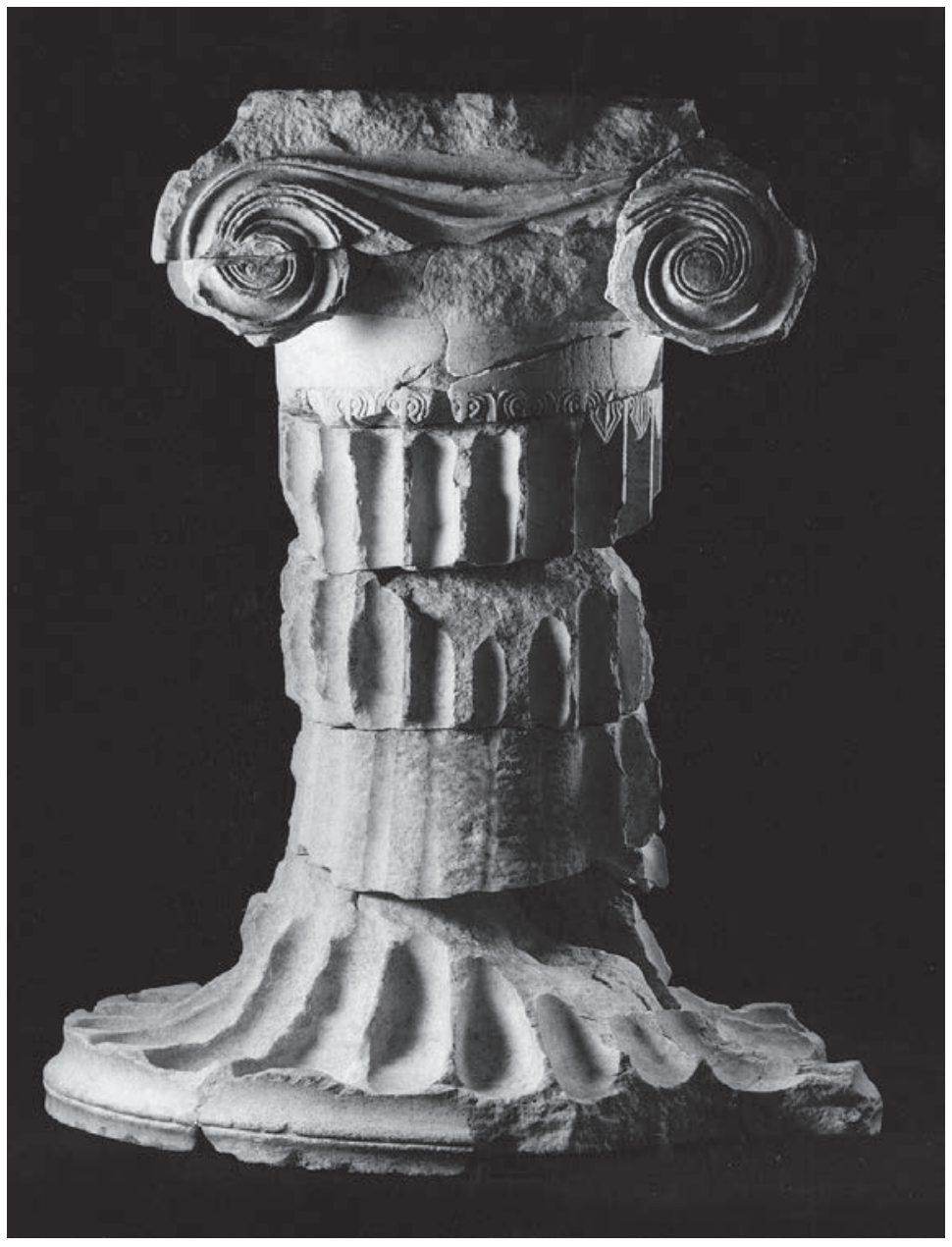

a

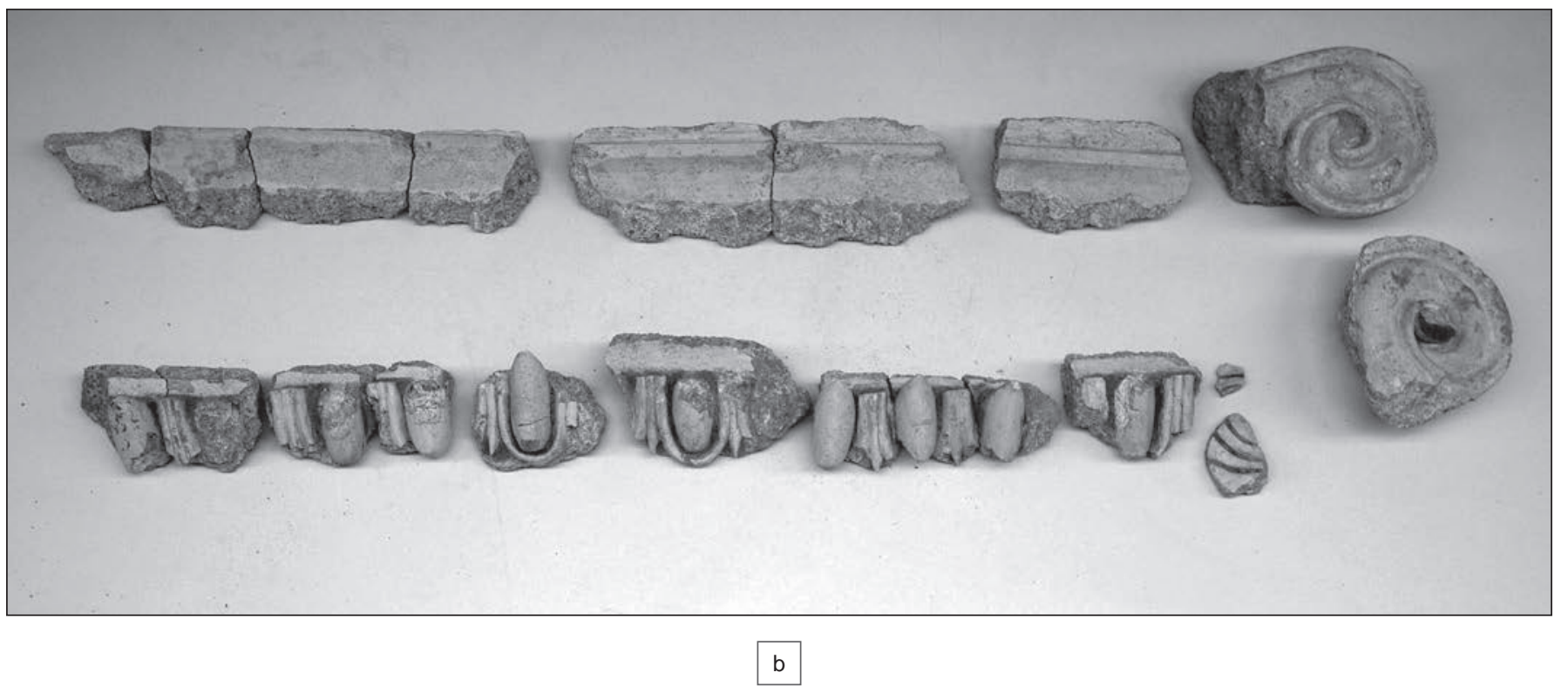

Fig. 5. Objets découverts dans le site de Mas Castellar de Pontós (clichés : E. Pons) $5 a$ : Autel en forme de colonne ionique ; $5 b$ : Fragments de corniche en stuc. 
que la pierre utilisée est toujours locale, ce qui suggère la présence d'artisans étrangers. L'utilisation d'un revêtement d'opus signinum dans le temple de grande dimension suggère également une influence punique. Devant ce grand temple, une citerne était intégrée dans le dispositif cultuel, mais il n'y a pas de traces d'autel. On ignore quelles sont la ou les divinités qui y étaient honorées, mais on peut citer la découverte d'un lot de masques en terre cuite, certains interprétés comme des représentations de Gorgone, Acheloos et d'un satyre, qui renvoient à des cultes mal connus.

Quant au site de Pontós, à l'ouest d'Emporion, l'occupation commence vers la fin du VII ${ }^{\mathrm{e}}$ s., mais l'établissement fortifié, d'un hectare environ de superficie, date du début du $\mathrm{V}^{\mathrm{e}} \mathrm{s}$. Le mur d'enceinte a été démonté vers 400 av. J.-C. et l'habitat associé a cessé de fonctionner peu de temps après, phénomène qui s'accompagne d'un changement dans la fonction de l'établissement, car le stockage de céréales dans des silos devient l'activité principale du site (Pons et al. $2010)^{3}$. Cette évolution particulière, notamment la destruction de la muraille et la transformation en centre spécialisé dans la conservation et la gestion de céréales, se rencontre uniquement sur un autre site du territoire, l'établissement de Peralada, au voisinage de la colonie de Rhodè. La position de ces deux sites, au contact de vallées fluviales et dans le proche arrière-pays des établissements grecs, suggère que cette transformation pouvait être liée à l'action des colonies dans le territoire environnant. Quoi qu'il en soit, la spécialisation économique du site de Pontós se poursuit au $\mathrm{III}^{\mathrm{e}} \mathrm{s}$. av. J.-C. À cette époque, le site comprend des maisons de grandes dimensions, organisées autour d'une cour centrale, qui sont interprétées comme des demeures aristocratiques.

Le mobilier d'importation découvert à Pontós atteste les liens étroits que ce site entretenait avec les Grecs du littoral. À preuve, l'autel en marbre du Pentélique mis au jour à l'intérieur de la maison 1 (fig. 5a), dans une salle vouée à des pratiques rituelles, et les fragments d'une corniche décorée d'une frise d'oves en stuc découverts à l'intérieur d'un silo placé au voisinage de la maison 2 (fig. 5b). Ce décor d'oves, qui comprend aussi quelques volutes, est, comme à Ullastret, de tradition ionique. Le comblement du silo a également livré des fragments d'enduit bleu et blanc et des briques crues. Si ces vestiges proviennent d'un même édifice, il s'agit sans doute d'un bâtiment exceptionnel. Le site de Pontós a également livré un fragment de sculpture, taillé dans une

3 Voir aussi la contribution de E. Pons et D. Asensio dans ce même volume. pierre locale et identifié à la partie avant d'un corps de lion. Ce fragment a été découvert, avec six autres blocs taillés sans décor, dans le niveau de destruction d'une pièce d'habitation accolée à la muraille et située à peu de distance de l'entrée, ce qui suggère une exposition près de la porte. Le contexte archéologique permet de proposer une datation au $\mathrm{V}^{\mathrm{e}} \mathrm{s}$.

Aussi bien à Ullastret qu'à Pontós, aux éléments architecturaux découverts relevant d'une influence grecque s'ajoutent d'autres objets que l'on rencontre aussi dans les centres grecs, souvent dans un contexte rituel : thymiatéria, askoi avec décor plastique, unguentaria et figurines en terre cuite. Il faut noter aussi l'existence, dans les deux établissements, de maisons à cour à plan complexe depuis au moins le milieu du IVe $\mathrm{s}$.

Si les contacts et les influences grecques sont perceptibles dans d'autres sites du littoral catalan, c'est dans les sites d'Ullastret et de Pontós qu'ils sont les plus manifestes. Ces sites, situés au voisinage d'Emporion, sont de nature très différente, car Ullastret correspond au grand oppidum de la partie septentrionale de la côte catalane et Pontós à un établissement de taille petite /moyenne voué à la gestion de la production céréalière. Il n'en demeure pas moins que, dans les deux sites, les contacts avec les Grecs ont été intenses. On peut même dire que, grâce à ces contacts et aux influences qui ont pénétré en milieu indigène, ces deux sites sont tout à fait exceptionnels dans le cadre du peuplement ibérique catalan. Pour autant, ces centres n'ont pas perdu leur identité indigène, bien affichée dans le cadre de la culture matérielle et de la physionomie de l'habitat. Ce mélange, dû aux contacts de cultures, en fait précisément deux sites majeurs pour analyser les processus déclenchés suite à l'arrivée et à l'installation de marchands en provenance de la Méditerranée Orientale.

\section{Le Sud-Est et le Bas Segura}

Dans cette région, souvent tenue pour la plus « hellénisée » de l'Ibérie - mais un tel terme est, on le verra, par trop simplificateur -, les indices d'une présence ou pour le moins d'une fréquentation grecque sont de plusieurs ordres. Il y a bien sûr la sculpture, avec l'ensemble d'Elche, et l'architecture, avec La Picola : nous en parlerons plus loin. Il y a aussi l'abondance des vases grecs, dans les nécropoles notamment, mais d'autres régions d'Espagne en ont livré presque autant. Non moins importante est l'existence d'une forme d'écriture gréco-ibère, inventée localement au Ve ou au IV $\mathrm{I}^{\mathrm{e}} \mathrm{s}$., et qui n'est connue que dans cette région (De Hoz 2010). 


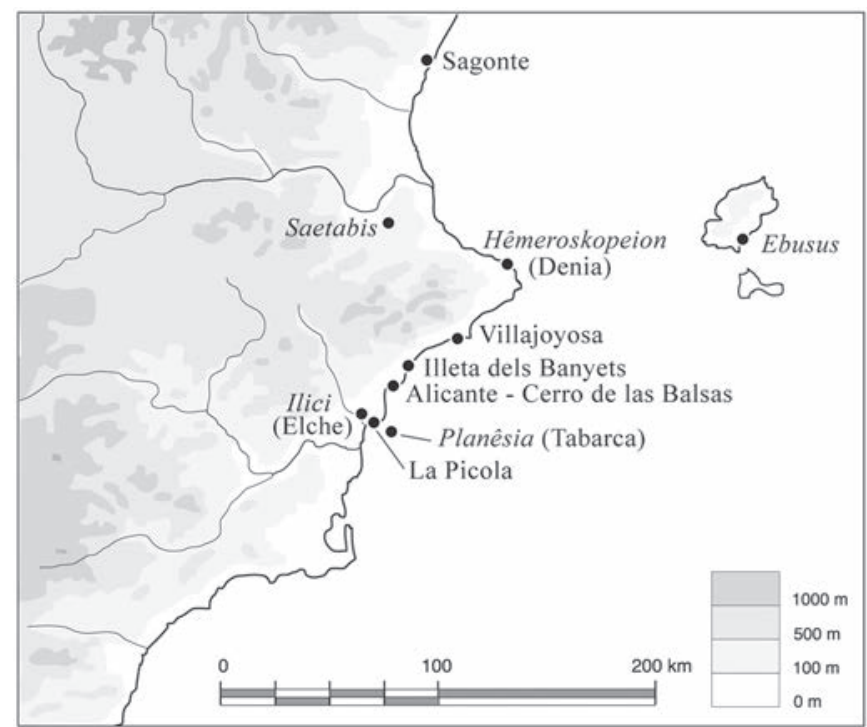

Fig. 6. Distribution des sites dans le sud-est de la Péninsule Ibérique.

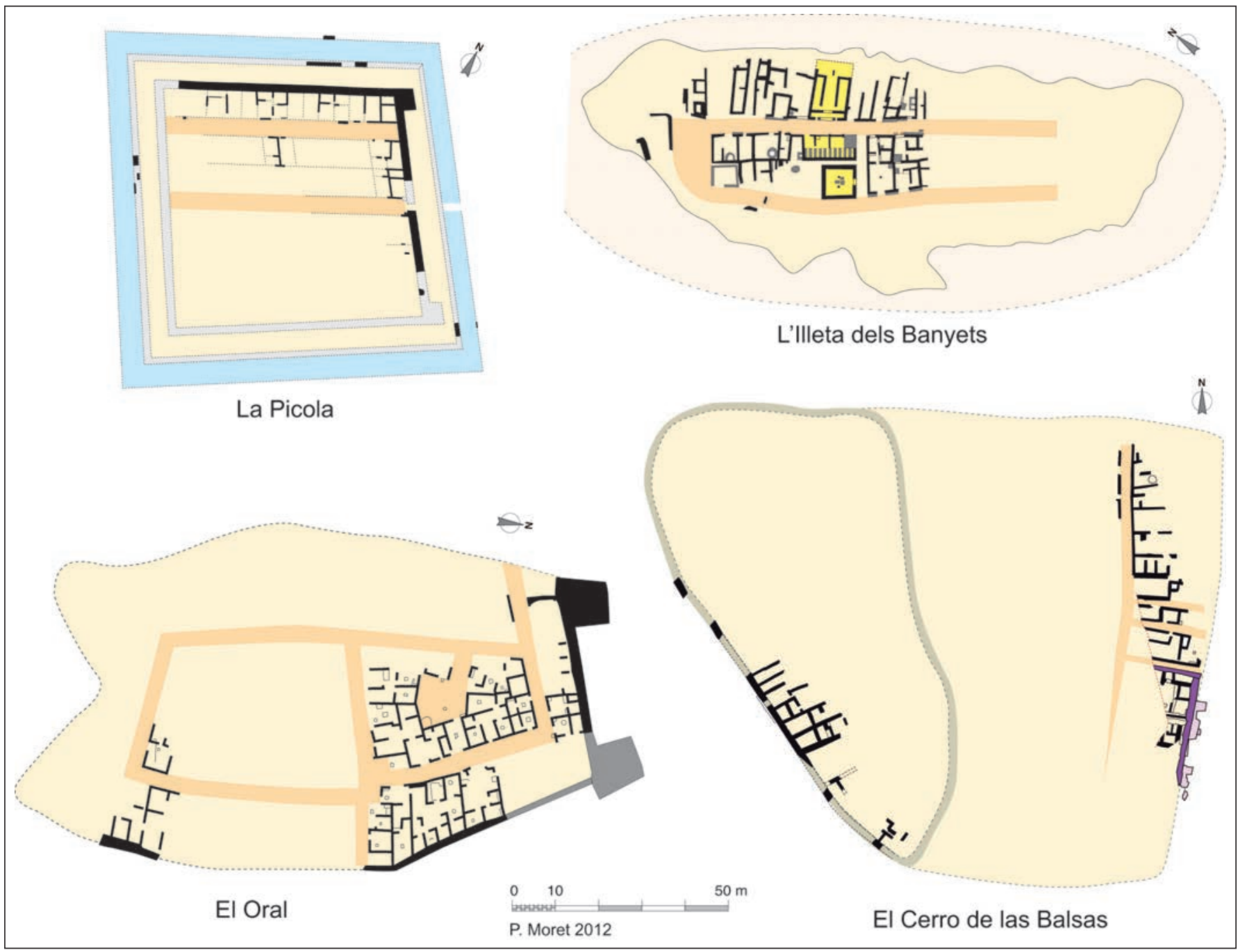

Fig. 7. Plans des établissements littoraux de La Picola à Santa Pola (d'après Badie et al. 2000), El Oral à San Fulgencio (d'après Abad et al. 2001), El Cerro de las Balsas à Alicante (d'après Rosser et al. 2003) et L'Illeta dels Banyets à Campello (d'après Martínez Carmona et al. 2007) (élaboration : P. Moret) 

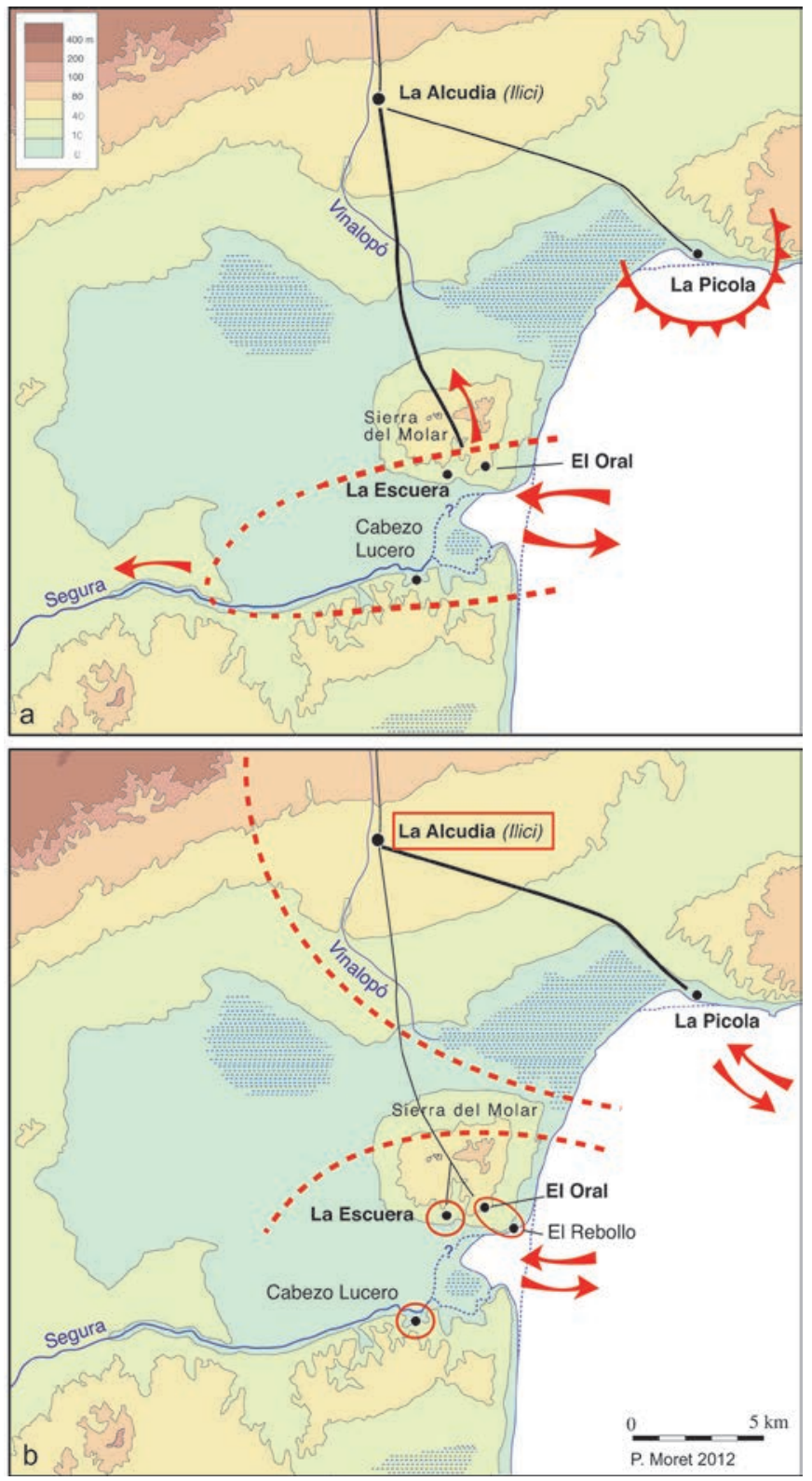

Fig. 8. Deux hypothèses d'organisation des territoires dans la deuxième moitié du Ve s. av. J.-C. entre Elche (Ilici - La Alcudia) et l'embouchure du Segura (élaboration : P. Moret).

Enfin, il faut aussi tenir compte des informations fournies par les sources littéraires et la toponymie, malgré leur ambiguiité et leur imprécision. La mention dans Strabon de «trois petites ville des Marseillais » sur la côte orientale de l'Espagne, entre le Júcar et Carthagène $(\mathrm{III} 4,6)$, jointe à celle de Mainakè près du détroit (III 4,2 ), a longtemps été une pièce à conviction cruciale dans les débats sur la présence grecque en Ibérie (fig. 6). Mais alors que certains projets de fouille des années 1960 avaient précisément pour objet de mettre au jour ces dernières « colonies » inconnues de l'Extrême Occident, le développement des recherches archéologiques a eu pour effet de rejeter ce dossier au second plan, car malgré l'intensité jamais démentie des recherches, aucune trace d'un établissement grec n'a pu être trouvée ni à Denia, site très probable d'Héméroskopeion - la seule des « trois petites villes » dont Strabon donne le nom -, ni dans la région de Málaga où Mainakè semblait devoir être située.

Les analyses de María José Pena (1993) et de Francisco Javier Fernández Nieto (2002) ont cependant montré, dans le cas d'Héméroskopeion, que l'approche des sources littéraires pouvait être renouvelée à condition qu'on les restitue dans leur contexte et qu'on sache faire un usage judicieux du comparatisme. La proposition de Fernández Nieto se fonde sur un rapprochement étymologique avec des termes techniques se rapportant à la pêche au thon, attestés par l'épigraphie dans des ports grecs de l'Hellespont - à Cos, Cyzique et Parion, c'est-à-dire non loin de la colonie phocéenne de Lampsaque -, pour faire d'Héméroskopeion un poste saisonnier où des guetteurs installés sur des observatoires fixes étaient chargés de repérer à distance l'arrivée des bancs de thons. Surprenante au premier abord, et sans doute indémontrable, cette hypothèse a cependant le mérite d'ouvrir le spectre des types d'établissements grecs jusqu'à des formes qui ne laissent pratiquement pas de traces archéologiques.

On pourrait évoquer aussi le cas de Planasia, nom grec de l'îlot de Tabarca, en face du site de La Picola dont nous allons parler. Ce nom désigne étymologiquement « l'île errante » (Moret 1997 et 2013) ; outre son riche arrière-fond mythique et cosmologique, il offre l'intérêt d'être pour ainsi dire superposable à la géographie des établissements phocéens en Occident, puisque on connaît deux îles homonymes aux abords d'Antipolis (l'île Saint Honorat) et d'Alalia (Pianosa).

Mais c'est surtout la fouille du site côtier de La Picola (Santa Pola, Alicante) qui a alimenté, ces dernières années, le débat sur la nature de la présence grecque dans le sud-est de l'Ibérie. Douze ans après la publication de la monographie consacrée à ce site (Badie et al.2000), le recul est suffisant pour qu'on puisse aujourd'hui tenter de faire un bilan des réactions et des débats que cette fouille a suscités. Rappelons d'abord à quelles conclusions nous étions parvenus au terme de cette étude.

La Picola est un petit établissement portuaire de plan presque carré, doté de fortifications développées : muraille, tours et fossé (fig. 7). Son tracé régulateur révèle l'utilisation systématique d'un module de six pieds de 29,6 cm dont l'origine est vraisemblablement grecque. Le plan d'ensemble fait penser aux epiteichismata du type Olbia, mais l'analogie n'est que formelle. 
En effet, la vaisselle de table et de cuisine, tout comme certains usages (en particulier l'inhumation d'infantes sous le sol des maisons), prouvent que les habitants étaient essentiellement des ibères. $10 \%$ de la vaisselle est grecque : c'est trop peu pour un établissement grec, mais c'est beaucoup pour un site ibère. La Picola apparaît donc comme un site hybride, mêlant des traits indigènes et grecs. Ces particularités prennent sens dès lors que l'on replace le site dans son contexte géographique. La Picola est le débouché maritime naturel d'Elche, à seulement $12 \mathrm{~km}$ de cette importante cité indigène, l'antique Ilici. Si près d'un voisin si puissant, on ne peut prêter à La Picola une existence autonome : ce ne pouvait être que le port d'Ilici. D'où notre hypothèse d'il $\mathrm{y}$ a douze ans : La Picola est fondée par des Ibères d'Ilici, avec apport de compétences grecques, et fonctionne, sous contrôle ibère, comme relais commercial ; elle peut donc être considérée comme l'emporion d'Elche.

Ce scénario fut ensuite précisé et, à notre sens, confirmé par les fouilles de la palaia polis d'Emporion qui ont révélé, pour la phase III c qui débute vers 540 av. J.-C., l'existence d'une rue rectiligne bordée par des habitations rectangulaires mitoyennes dont le plan fait inévitablement penser à La Picola, d'autant que le tracé régulateur de cet ensemble obéit au même rapport modulaire entre la largeur de la rue et celle des pièces d'habitation (Moret 2001, 2010). Ce parallèle ne laisse guère de doute quant à l'origine grecque, et plus précisément phocéenne, du schéma mis en œuvre à La Picola.

En contrepoint, il est aujourd'hui possible de comparer le plan de La Picola avec celui de trois autres sites littoraux de la province d'Alicante, contemporains ou un peu plus récents (fig. 7) : El Oral à San Fulgencio (Abad et al. 2001, Sala Sellés 2005), El Cerro de las Balsas à Alicante (Rosser et al. 2003) et L'Illeta dels Banyets à El Campello (Martínez Carmona et al. 2007). Ces quatre établissements sont de taille étonnamment petite : le Sud-Est ibérique apparaît comme le pays des emporia miniatures. Mais même dans ce contexte, La Picola se distingue par sa petite taille. Deuxième constatation : si l'on observe à El Oral comme à l'Illeta dels Banyets une organisation assez régulière de l'habitat et de la voirie, elle n'est pas orthonormée et standardisée comme à La Picola qui, de ce point de vue, reste un cas isolé - si l'on excepte le parallèle grec de la palaia polis d'Emporion, évoqué plus haut.

Dans ce contexte régional de mieux en mieux connu, nos propositions ont été discutées à plusieurs reprises au cours de la décennie écoulée. Certains auteurs ont admis l'essentiel de nos conclusions (entre autres : Bresson 2002 ; Domínguez Monedero 2007 ; Ruiz de Arbulo
2002-2003). Les enseignements que l'on peut tirer de l'étude des fortifications ont été réexaminés avec acribie par Fernando Quesada (2007, p. 77-80). Cet auteur constate d'abord que la part relative des fortifications dans l'établissement de La Picola, en volume et en surface, est exceptionnelle et fait penser « à un fortin plus qu'à toute autre chose », et reconnaît que les seuls parallèles possibles, pour la disposition des défenses, sont grecs. Mais il insiste avec raison sur le fait que la très petite taille de l'enceinte diminue beaucoup la portée des comparaisons avec des fortifications urbaines morphologiquement comparables, mais à une toute autre échelle. En effet, compte tenu de sa petite taille, l'enceinte de La Picola ne pouvait en aucune manière résister à l'attaque d'une armée ou à un siège en règle ; les menaces auxquelles elle répondait ne pouvaient être que de faible intensité. F. Quesada aborde là un point crucial, celui du rôle de cette fortification, qui est au cœur des interprétations alternatives proposées par plusieurs chercheurs des universités de Valence et d'Alicante. Pour synthétiser à grands traits l'état de la question, on peut distinguer deux scénarios concurrents. Tous les deux partagent un constat : le plan et l'architecture de Picola placent ce site nettement à part ; mais ce qui fait débat, c'est sa fonction.

Pour Carmen Aranegui, La Picola serait une fondation massaliète, un fortin «typologiquement comparable à Olbia de Provence », bâti sur cette côte pour s'opposer aux menées carthaginoises (Aranegui 2010, p. 694). Cette hypothèse soulève deux graves objections : en premier lieu, un faciès mobilier et culturel qui n'est pas grec, ou qui ne l'est que très minoritairement ; en second lieu, un contexte local qui est incompatible avec la notion grecque d'epiteichisma. En effet, tel que l'a défini Michel Bats (2004, p. 53 sq), l'epiteichisma est une place forte avancée, isolée en territoire ennemi ou potentiellement hostile, et qui en tant que telle est forcément liée à un dispositif territorial dont elle est en quelque sorte l'excroissance. Dans le cas de La Picola, la distance par rapport à Marseille - ou même par rapport à Emporion - est beaucoup trop grande pour que l'on puisse envisager une relation de ce type.

L'autre scénario, proposé par Jesús Moratalla, Ignacio Grau et Feliciana Sala (Grau, Moratalla 2001, p. 203 ; Grau, Moratalla 2004, p. 114 sq ; Moratalla 2005, p. 103 sq; Sala Sellés 2006, p. 138) s'appuie sur trois arguments : 1/ la fortification de La Picola est trop importante pour un établissement commercial, ce ne peut donc être autre chose qu'un fortin ; 2/ le lieu des échanges et de la réception des biens importés reste, du $\mathrm{VI}^{\mathrm{e}}$ au $\mathrm{III}^{\mathrm{e}} \mathrm{s}$., l'embouchure du Segura, alors que la baie de Santa Pola n'est occupée - par La Picola- que de façon ponctuelle 
et finalement éphémère, pendant moins d'un siècle, pour défendre Elche contre des pirates censés utiliser l'île de Tabarca (l'antique Planesia) comme base d'incursions ; 3/ les importations attiques sont bien présentes à Picola, mais très faibles à La Alcudia : vouloir identifier un point d'arrivage du commerce grec, directement lié à cette ville ibérique, ne serait donc pas un raisonnement pertinent. En somme, La Picola serait bien une fondation des Ibères d'Elche, mais à fonction strictement défensive, motivée par la menace des pirates qui sont supposés avoir occupé l'îlot de Tabarca tout proche (fig. 8-a).

Dans cette hypothèse, comme du reste dans celle de C. Aranegui, la prévalence de la fonction militaire est surestimée. S'il est vrai que la part occupée par les défenses est très importante, cette proportion très notable s'explique mécaniquement par la petite taille de l'établissement, comme on l'a vu plus haut (Quesada 2007), et elle n'implique pas une capacité militaire hors du commun. D'autre part, il est stérile d'opposer frontalement deux catégories exclusives : celle de l'emporion ouvert et celle de l'enclave coloniale fortifiée. De ce point de vue, J. Ruiz de Arbulo (2002-2003, p. 172-174) introduit une nuance intéressante en notant qu'un emporion de la fin du Ve s., tel que pouvait être La Picola, devait être bien différent des communautés mixtes de l'époque archaïque : on est à une époque d' affrontements militaires entre Grecs et Carthaginois en Méditerranée centrale, ce qui eut sans doute pour conséquence la généralisation du modèle du port fortifié, lieu où pouvaient se dérouler et s'enregistrer (grâce à la généralisation de la pratique scripturaire, dont témoigne le plomb de Pech Maho) des transactions commerciales plus étroitement contrôlées.

La mise en cause du rôle commercial de La Picola n'a pas non plus lieu d'être : la proportion d'importations, par rapport au total de la céramique mise au jour, y est plus importante que sur les deux autres sites littoraux de la région occupés au $\mathrm{V}^{\mathrm{e}} \mathrm{s}$. pour lesquels on dispose de données quantitatives : El Oral (Abad et Sala 1993, Abad et al. 2001) et El Cerro de las Balsas (Rosser et al. 2003). Si l'on prend en compte le total de la céramique (amphores et vaisselle), la proportion de vaisselle fine importée s'élève à 9,5\% à La Picola, contre 6 au Cerro de las Balsas et 1,2 à El Oral ; quant aux amphores grecques et puniques, elles représentent 10,6\% du même total à $\mathrm{La}$ Picola, contre 2 au Cerro de las Balsas et 4,5 à El Oral.

D'autre part, le choix du site, dans une baie abritée de la houle créée par les vents dominants du nord-est, et au plus près du canal de Tabarca par où passait nécessairement la navigation de cabotage, n'a rien d'anodin (Ferrer 2005). Face à cette réalité géographique, le fait que le site ne fût pas occupé avant 450 n'est pas un argument suffisant pour invalider l'idée que la fondation de La Picola ait pu répondre à un projet cohérent de développement commercial (dans le même sens, Molina Vidal 2005, p. 97 sq).

Même très mal connue pour cette période, La Alcudia de Elche était sans l'ombre d'un doute un important centre de pouvoir, et son port ne pouvait se trouver ailleurs qu'à Santa Pola. Mercedes Tendero (2005) a apporté des éléments du plus grand intérêt sur l'évolution du faciès mobilier de La Alcudia, même si la base statistique de son étude reste numériquement faible. On note d'abord que les formes rares de céramique ibérique qui sont les plus caractéristiques du site, comme les urnes amphoroïdes et les plats à anses, sont aussi présentes à La Picola. Ce répertoire commun confirme s'il était besoin le lien étroit qui existait entre les deux sites. Elle montre aussi que le site prend de l'importance à partir du milieu $\mathrm{du} \mathrm{V}^{\mathrm{e}} \mathrm{s}$., après une quasi absence d'importation au $\mathrm{VI}^{\mathrm{e}}$ et au début du $\mathrm{V}^{\mathrm{e}} \mathrm{s}$., et que cette montée en puissance, cette " éclosion» pour reprendre son terme, coïncide avec l'abandon d'El Oral, un peu plus au sud dans le Bas Segura (Tendero 2005, p. 314 sq). Cette constatation est importante. Au milieu du Ve s., La Alcudia n'est plus un poblado ibérique parmi d'autres ; c'est devenu un centre politique, bientôt une ville, qui structure son territoire et qui, pour mieux se développer, se dote d'un port, dans la baie abritée la plus proche, celle de Santa Pola ; et comme toute modification des équilibres territoriaux et commerciaux est nécessairement source de conflits, il est normal que ce nouveau port, concurrent de celui ou de ceux de l'embouchure du Segura, soit muni de solides défenses : tel est le sens et le contexte de la fondation de La Picola.

Plus généralement, il convient de s'inscrire en faux contre l'idée d'une distinction tranchée, radicale, entre la catégorie du fortin côtier et celle du port de commerce : elle est artificielle. Car qu'est-ce qu'un port au $V^{e} s$. ? Guère plus qu'un débarcadère, une plage où l'on tire les bateaux sur une plage ; et à proximité immédiate, des bâtiments d'habitation et d'autres liés aux activités maritimes, munis ou non d'une fortification selon le contexte. Si le but des Ibères d'Ilici avait été de surveiller l'îlot de Tabarca (probablement désert à l'époque), une simple tour de guet aurait largement suffi !

Enfin, l'existence de centres de redistribution actifs dans le Bas Segura n'exclut en aucun cas l'association La Picola - Elche, dans la mesure où les cités ibériques $\mathrm{du} \mathrm{Ve}$ s. ne contrôlaient sans doute pas matériellement des territoires très vastes et que rien ne permet d'affirmer que l'emprise territoriale de La Alcudia s'étendait jusqu'au Bas Segura inclus, comme l'a rappelé J. Molina Vidal 
(2005, p. 97-98). Les gros villages fortifiés de Cabezo Lucero (1,5 ha : Moret 1996, p. 484) et de La Escuera (entre 1 et 3 ha : Moret 1996, p. 486 et Moratalla 2005, p. 105), relativement importants pour la région, dépendaient-il directement d'Ilici (entre 3 et 6 ha au Ve s. : Moratalla 2005, p. 105) ? On peut en douter. Par conséquent, l'existence de trafics commerciaux très actifs dans le Bas Segura pendant toute la période considérée, entre le probable port d'El Rebollo, sur la rive nord de l'embouchure du Segura (Gutiérrez et al. 1998-1999, p. 33) et les villages échelonnés sur le cours inférieur du fleuve, rive nord (La Escuera) comme rive sud (Cabezo Lucero), n'exclut en aucune manière l'émergence possible, un peu plus au nord, d'un autre couple site littoral / site du proche hinterland. C'est ce scénario (fig. 8-b) qui nous paraît s'accorder le mieux avec l'ensemble des données archéologiques actuellement disponibles.

\section{Où et comment mesurer la place des Grecs?}

Il ne saurait aujourd'hui être question de réécrire une nouvelle Hispania Graeca, mais quelques exemples permettent de saisir comment dans des contextes péninsulaires variés - pris notamment dans deux régions le nord-est de la Péninsule et la basse vallée du Segura - des objets et des schémas grecs sont intégrés, détournés de leur fonction ou rejetés. Les usages du vase grec et l'iconographie de la sculpture offriront quelques exemples, sachant que Javier de Hoz approfondit dans ce même volume cette réflexion en soulignant, entre autres analyses, que l'usage du plomb comme support de textes chez les Ibères est un héritage grec, les Ibères reprenant la technique de la lamelle de plomb mais en attribuant aussi, avec les textes qu'ils gravent, les fonctions commerciales des plombs grecs.

\section{Le cas du vase grec}

Rappelons que le vase grec est présent dans la péninsule Ibérique dès la seconde moitié du VIII ${ }^{\mathrm{e}} \mathrm{s}$. av. J.-C., mais qu'il est vraiment abondant entre le milieu du $\mathrm{V}^{\mathrm{e}} \mathrm{s}$. et la première moitié du $\mathrm{IV}^{\mathrm{e}} \mathrm{s} \mathrm{s}^{4}$. Il s'agit d'abord de vaisselle de table, attique, que l'on retrouve dans des proportions voisines dans les habitats et dans les nécropoles. Le cratère peut servir d'ossuaire, le plat de couvercle pour une urne ibérique et le vase pour manger ou boire se retrouver dans une maison ou dans les restes d'une cérémonie collective, sur le lieu même de la crémation, de consommation de boissons - une forme de libation -

4 Sont repris ici des points traités dans Rouillard, 1991 et 2009a et 2009b.

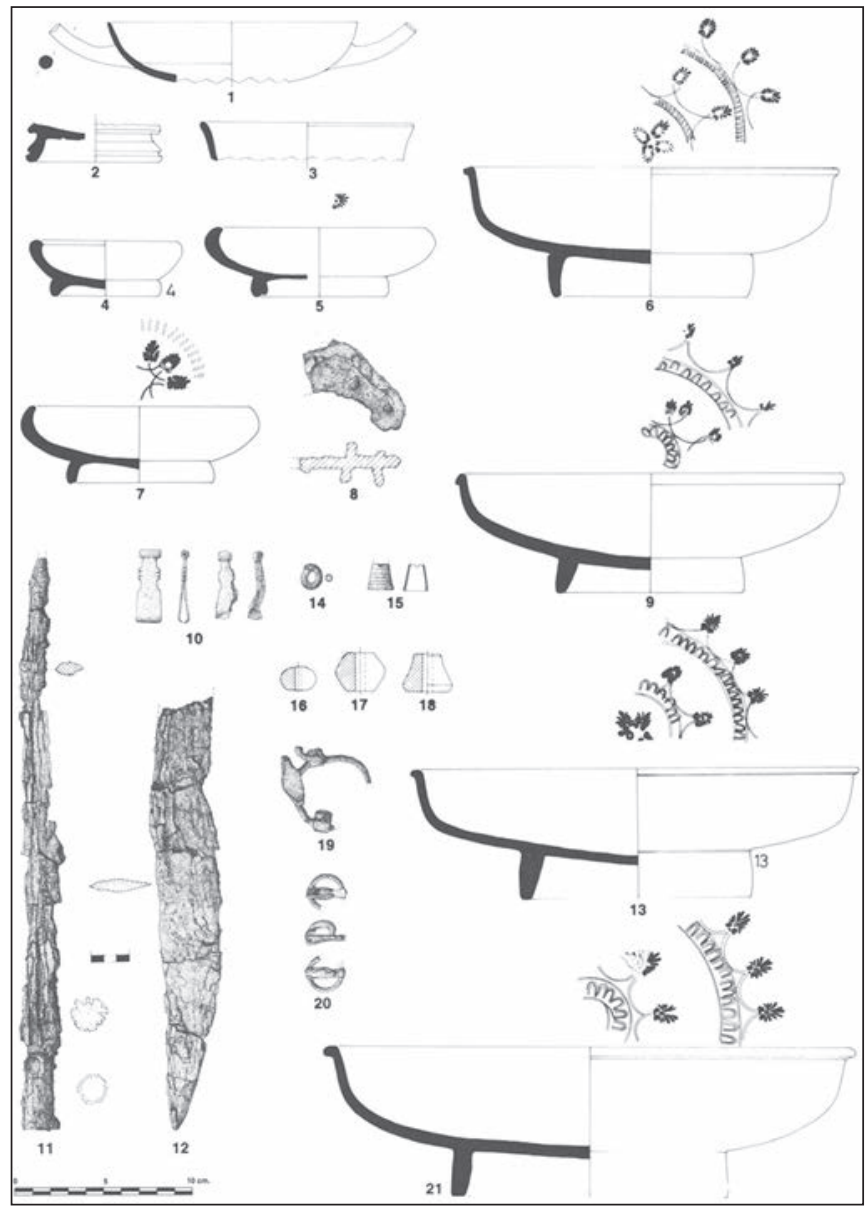

Fig. 9. Tombe 80 de Cabezo Lucero (Guardamar del Segura, Alicante) (d'après Aranegui et al. 1993, p. 252).

comme cela est observé par exemple à Cabezo Lucero (Guardamar el Segura, Alicante) (Aranegui et al. 1993, p. 87-94) (fig. 9) ou à Los Villares (Albacete) (Blánquez 1992 , p. 256 et fig. 3a). Parfois des vases grecs sont déposés comme objets personnels auprès du mort. Ceci vaut pour les nécropoles du Sud-Est de la Péninsule. Et à Ampurias les tombes indigènes ont livré des vases à boire grecs, quand les tombes grecques ont livré un panorama typiquement grec - avec des lécythes - qui n'ont pas suscité d'appropriation par les voisins ibères (Gailledrat 1995).

L'Ibère est acteur du choix, un choix sans doute conditionné pour partie par les contraintes du transport et pour partie par une connaissance - du fait du négociant des goûts et choix d'un usager lointain. La maîtrise des usages ibères devait être bien fine, car région sud-orientale et région méridionale ont recours à des répertoires sensiblement différents.

Le choix de l'Ibère se manifeste aussi dans l'usage prolongé d'un vase grec, au long d'une ou deux générations, ou encore dans les imitations que tel ou tel vase 


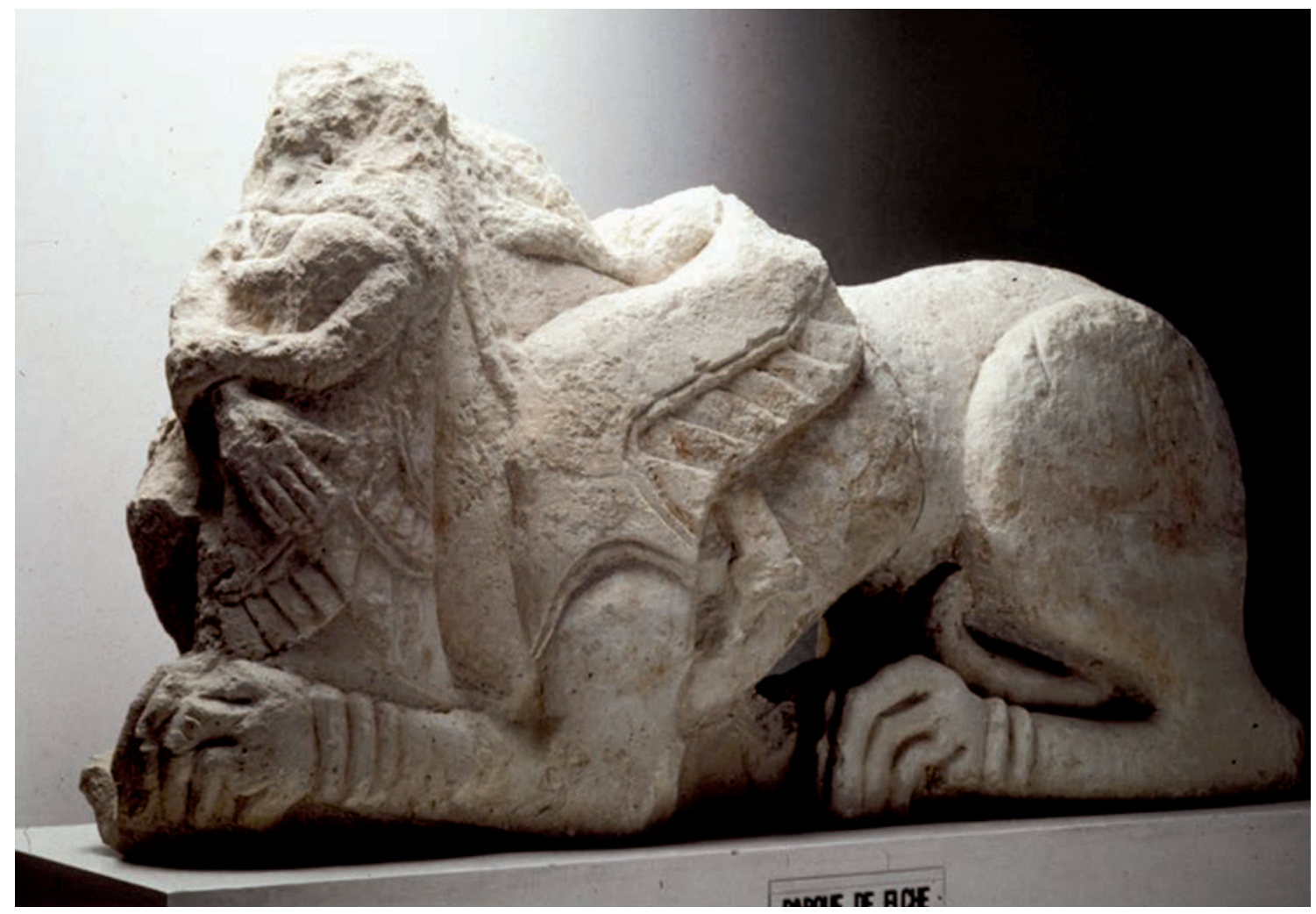

Fig. 10. Le sphinx du Parque de Elche. MAHE (cliché : P. Rouillard).

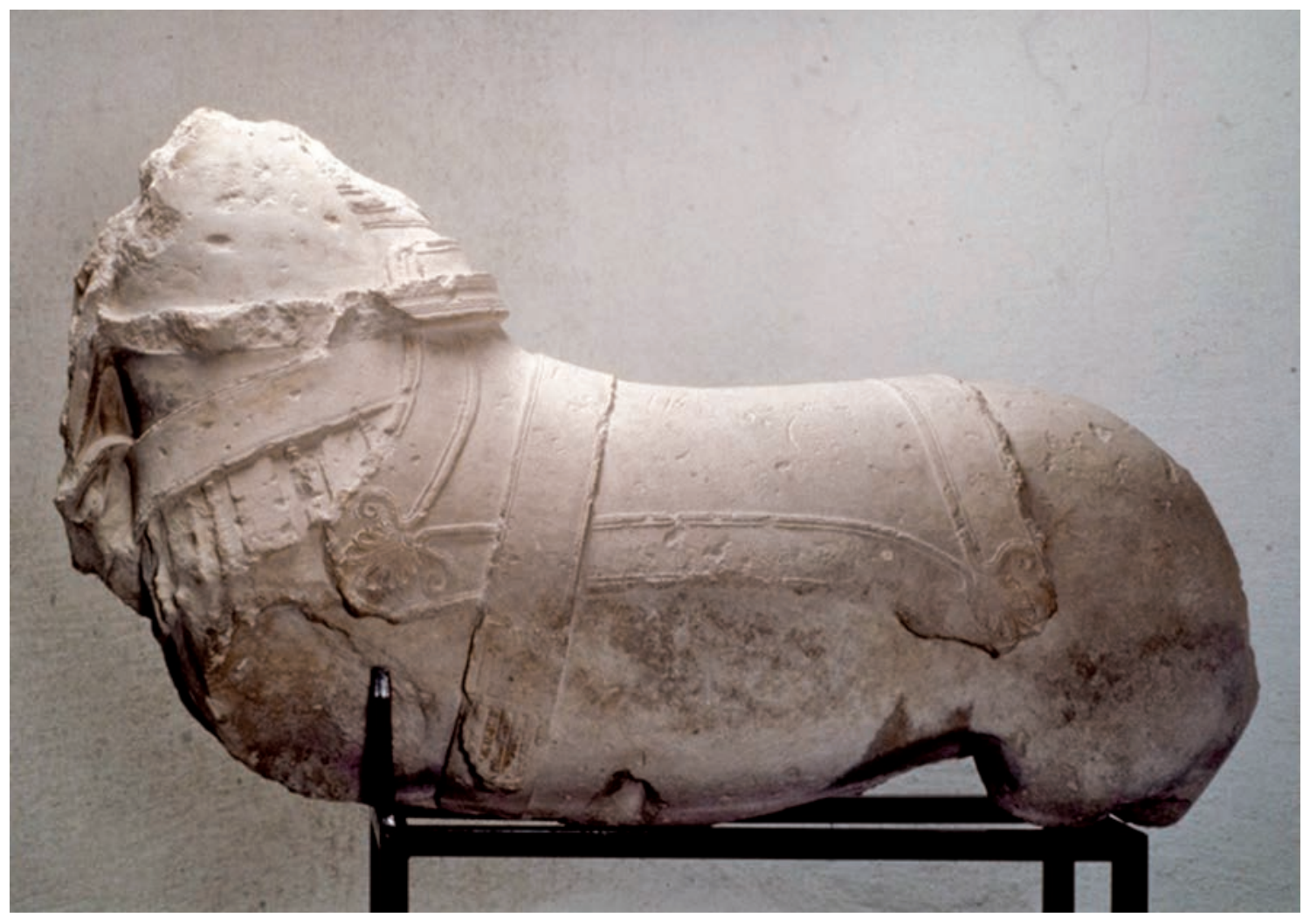

Fig. 11. Le cheval de Casas de Juan Nuñez (Albacete). Musée d'Albacete (cliché : P. Rouillard). 
grec suscite (Page del Pozo 1984). Relevons par exemple que le cratère grec qui inspire le plus le potier ibère est le cratère à colonnettes, une forme propre au $\mathrm{V}^{\mathrm{e}} \mathrm{s}$., très peu représentée dans la Péninsule. A quoi peut tenir la recréation de cette forme au $\mathrm{IV}^{\mathrm{e}} \mathrm{s}$. : à sa rareté, à un souci de rappeler une importation ancienne, à une fonction particulière qui nous échappe ? Le vase grec peut être « oublié »; ainsi est-il à peu près absent parmi les offrandes formulées dans les sanctuaires ibériques. Le même vase peut être détourné de sa fonction, que ce soit dans le cas du cratère utilisé comme urne, passant d'un usage collectif à l'usage le plus privé qui soit, ou lorsque un lécythe est jeté dans le feu d'un bûcher tel un vase à boire.

Bien des usages suscitent des interrogations : ainsi sur la présence de choes dans un silicernium à Los Villares (Albacete), ou sur le choix de telles ou telles iconographies réunies dans la tombe 43 de Baza (Grenade) (Sánchez 2000, p. 189-191) : là, trois vases présentent une scène d'héroïsation, mais on ne saura jamais quel sens a pour un bastétan la scène dionysiaque, l'animal psychopompe, ou l'arrivée d'Apollon à Delphes. La notion de commande me (P.R.) semble étrangère au monde ibérique et les vases grecs importés aux $\mathrm{V}^{\mathrm{e}}$ et $\mathrm{IV}^{\mathrm{e}} \mathrm{s}$. s'intègrent toujours dans des séries, souvent longues, produites industriellement à Athènes. En aucun cas nous n'avons reconnu une forme qui eût pu avoir été suscitée par le marché ibère comme cela s'est produit en Étrurie avec les amphores nikosthéniennes, ou en Italie du sud avec les nestorides.

Ce dossier est à affiner régulièrement, sachant qu'il est acquis que pour l'usage des vases grecs, certes dans un répertoire contraint par les modalités de transport, l'Ibère est acteur, comme les exemples rapidement présentés le soulignent, ou quand il fait le choix de l'ostentation en accumulant des vases, ou encore - comme on le verra - en faisant sculpter des pièces monumentales, en choisissant une immense cratère comme à Orleyl (Valence) (Lazaro et al. 1981), en choisissant une ou plusieurs pièces avant de lui attribuer une nouvelle fonction une ou deux générations plus tard.

\section{Le cas de la sculpture}

Avec la sculpture, on remarque combien les schémas et le poids, au fil du temps, des schémas orientaux sont plus présents, semble t-il, que les éléments grecs.

$\mathrm{Au}$ moment où les relations avec le monde oriental, phénicien ou grec, de l'époque archaïque à l'époque classique sont les plus actives (ce que l'on peut suivre très simplement en lisant les cartes de diffusion des céramiques grecques), les œuvres sculptées sont les plus nombreuses. Des œuvres pour les quelles on relève des structures, notamment un volume compacte, souvent cubique (sans doute elles-mêmes importées à l'origine) qui restent intactes au point d'exprimer une identité culturelle ibérique et dans lesquelles s'intègrent, des thèmes, des schémas phéniciens, grecs, puniques, italiques ${ }^{5}$.

La part de l'Orient est particulièrement sensible dans l'iconographie avec ces monstres et hybrides, présents à Pozo Moro (Albacete), Redoban, Elche ou Agost (Alicante). Les statues assises du Llano de la Consolacion (Albacete), du Cigarralejo (Mula, Murcie) ou d'Elche sont une réappropriation de la statue-cube égyptienne.

Le thériomorphisme, de tradition orientale, donne à la plastique ibérique un de ses traits les plus originaux (fig. 10); le thème de l'animal étant par ailleurs le premier à être traité dans les ateliers. Une différence essentielle avec le monde grec est l'absence de caractérisation individuelle des protagonistes. Ceci vaut pour toutes les formes d'expression artistique. Qui est reconnu comme dieu, déesse, héros, prince, prêtre ? On ne sait, et il suffit pour s'en convaincre de se mémoriser la liste des hypothèses formulées pour la Dame d'Elche.

L'intégration d'éléments grecs est une donnée acquise. Tel est le cas de la Dame d'Elche, avec, par exemple les plis de son manteau, de filiation grecque (Truszkowski, 2003, 324-329). Le cas du cheval de Casas de Juan Nuñez (La Losa, Albacete) (fig. 11) est discuté entre ceux qui estiment probable l'installation d'artisans samiens porteurs du décor de palmettes qui ornent les coins du tissu qui couvre l'animal (Faustoferri 2003) et ceux qui estiment bien mince cet argument (León 2003,28). Retenons encore cette pièce discutée qu'est la tête dite « $\mathrm{n}^{\circ} 1 »$ de Porcuna (Jaén), une tête disproportionnée par rapport à l'ensemble du corps, dont le trait majeur, propre au monde ibérique, est sa forme cubique ; dans ce cas sont intégrés des yeux obliques, des cils hauts, des paupières fines que l'on présente souvent, mais improprement, comme spécifiques du monde grec (Rolley 1994, p. 407 ; Croissant 1998 ; Léon 2003, p. 34).

On pourrait multiplier les exemples de lectures, d'intégrations, d'échanges de modèles ou de schémas, mais avec une interrogation supplémentaire : l'explication par le « fait colonial » n'est pas suffisante et surtout pas opportune, car on ne connaît pas d'atelier de sculpture à Ampurias, et la région sud-orientale de la péninsule ne connaît pas d'implantation grecque stable. Alors, qui se risquera à recomposer une nouvelle « Hispania Graeca » ?

$5 \quad$ Voir en général sur ce point Rouillard 2007. 


\section{Bibliographie}

Abad, Sala 1993 : ABAD (L.), SALA (F.) - El poblado ibérico de El Oral (San Fulgencio, Alicante). Trabajos varios del SIP, 90, Valencia, 1993. Abad et al. 2001 : ABAD (L.), SALA (F.), GRAU (I.), MORATALLA (J.), PASTOR (A.), TENDERO (M.) - Poblamiento ibérico en el Bajo Segura : El Oral (II) y La Escuera. Bibliotheca Archaeologica Hispana, 12, Real Academia de la Historia, Madrid, 2001.

Almagro-Gorbea 1983 : ALMAGRO-GORBEA (M.) - Pozo Moro. El monumento orientalizante, su contexto socio-cultural y sus paralelos en la arquitectura funeraria ibérica. Madrider Mitteilungen, 24, Madrid, 1983, p. 177-293.

Álvarez 2011 : ÁLVAREZ (M.) - Fenicios en Tartessos : nuevas perspectivas. BAR International Series, 2245, Oxford, 2011.

Antonelli 1997: ANTONELLI(L.) - I Grecioltre Gibilterra, Rappresentazioni mitiche dell'estremo occidente e navigazioni commerciali nello spazio atlantico fra VIII e IV secolo a. C. Hesperia, 8, Rome, 1997.

Antonelli 1998 : ANTONELLI (L.) - Il periplo nascosto. Lettura stratigrafica e commento storico-arqueologico dell'Ora Maritima di Avieno. Padoue, 1998.

Aquilué et al. 1999 : AQUILUE (X.), SANTOS (M.), BUXÓ R., TREMOLEDA (J.) - Intervencions arqueològiques a Sant Martí d'Empúries (1994-1996). De l'assentament colonial a l'Empúries actual. Monografíes Emporitanes, 9, Barcelona 1999

Aquilué et al. 2002 : AQUILUE (X.), CASTANYER (P.), SANTOS (M.), TREMOLEDA (J.) - Nuevos datos acerca del hábitat arcaico de la Palaia Polis d'Emporion. Pallas, 58, Toulouse, 2002, p. 301-327.

Aquilué et al. 2010 : AQUILUE (X.), CASTANYER (P.), SANTOS (M.), TREMOLEDA (J.) - Grecs et indigènes aux origines de l'enclave phocéenne d'Emporion. In : Tréziny (H.) éd., Grecs et indigènes de la Catalogne à la mer Noire, Actes des rencontres du programme européen Ramses (2006-2008), Bibliothèque d'Archéologie Méditerranéenne et Africaine, 3, Aix-enProvence, 2010, p. 65-78.

Aranegui 2010 : ARANEGUI GASCO (C.) - Ocupación económica, ritual y estratégica del litoral valenciano. Mainake, 32 / 2, 2010, p. 689-704.

Aranegui et al. 1993 : ARANEGUI (C.), JODIN (A.), LLOBREGAT (E.), ROUILLARD (P.) ET UROZ (J.) - La nécropole ibérique de Cabezo Lucero (Guardamar del Segura, Alicante). Collection de la Casa de Velázquez, 41, Madrid-Alicante.

Asensio et al. 2002 : ASENSIO (D.), FRANCÉS (J.), PONS (E.) - Les implicacions econòmiques i socials de la concentració de reserves de cereals a la Catalunya costanera en època ibèrica. Cypsela, 14, Girona, 2002, p. 125-140.

Aubet 2001 : AUBET (M. E.) - The Phoenicians in the west, Politics, Colonies and Trade. $2^{\mathrm{d}} \mathrm{ed}$., Cambridge University Press, 2001.

Badie et al. 2000 : BADIE (A.), GAILLEDRAT (E.), MORET (P.), ROUILLARD (P.), SANCHEZ (M. J.), SILLIERES (P.) - Le site antique de La Picola à Santa Pola (Alicante, Espagne). Paris-Madrid, 2000.

Bailo Modesti, Gastaldi 1999 : BAILO MODESTI (G.), GASTALDI (P.) DIR., Prima di Pithecusa, I più antichi materiali greci del Golfo di Salerno. Pontecagnano, 1999.

Bats 2004 : BATS (M.) - Les colonies massaliètes de Gaule méridionale. Sources et modèles d'un urbanisme militaire aux $\mathrm{IV}^{\mathrm{e}}-\mathrm{III}^{\mathrm{e}} \mathrm{s}$. av. J.-C. . In : Agusta-Boularot (S.), Lafon X. éd., Des Ibères aux Vénètes, Collection de l'École Française de Rome, 328, Rome, 2004, p. 51-64.

Bats 2008 : BATS (M.) - Massalia et les formes d'organisation inter-poleis et supra-poleis en extrême-Occident. In : Lombardo (M.) dir., Forme sovrapoleiche e interpoleiche di organizzazione nel mondo greco antico, Lecce, 2008, p. 492-504.

Blánquez 1990 : BLÁNQUEZ (J .) - La formación del mundo ibérico el el sureste de la Meseta (Estudio arqueológico de las necrópolis ibéricas de la provincia de Albacete). Albacete, 1990.

Blánquez 1992 : BLÁNQUEZ (J .) - Las necrópolis ibéricas en el sureste de la Meseta. In : Congreso de Arqueología Ibérica : Las Necrópolis, Madrid, 1992, p. $235-278$.
Blech, Ruano 1992 : BLECH (M.), RUANO RUIZ (E.) - Zwei iberische Skulpturen aus Úbeda la Vieja (Jaén). Madrider Mitteilungen, 33, Madrid, 1992, p. 70-101.

Boissinot 2010 : BOISSINOT (PH.) - Des vignobles de Saint-Jean du Désert aux cadastres antiques de Marseille. In : Tréziny (H.) éd., Grecs et indigènes de la Catalogne à la mer Noire, Actes des rencontres du programme européen Ramses (2006-2008), Bibliothèque d'Archéologie Méditerranéenne et Africaine, 3, Aix-en-Provence, 2010, p. 147-154.

Botto 2005 : BOTTO (M.) - Per una riconsiderazione della cronologia degli inizi della colonizzazione fenicia nel mediterraneo centro-occidentale. In : Bartoloni (G.), Delpino (F.) dir., Oriente e Occidente : metodi e discipline a confronto. Mediterranea, 1, Pise-Rome, 2005, p. 579-628.

Brandherm 2006 : BRANDHERM (D.) - Zur Datierung der ältesten griechischen und phönizischen Imprtkeramik auf der iberischen Halbinsel. Bemerkungen zum Beginn der Eisenzeit in Südwesteuropa. Madrider Mitteilungen, 47, Madrid, 2006, p. 1-23.

Bresson 2000 : BRESSON (A.) - La cité marchande. Scripta Antiqua, 2, Ausonius, Bordeaux, 2000.

Bresson 2002 : BRESSON (A.) - Quatre emporia antiques : Abul, La Picola, Elizavetovskoie, Naucratis. Revue des Études Anciennes, 104 (3-4), Bordeaux, 2002, p. 475-505.

Bresson, Rouillard 1993 : BRESSON (A.), ROUILLARD (P.) (dir.) L'emporion. Publications du Centre Pierre Paris, 26, Paris, 1993.

Cabrera, Sánchez 2000 : CABRERA (P.), SANCHEZ (C.) (ÉDS.) - Los Griegos en España. Madrid, 2000.

Casas 2010 : CASAS (J.) - Prensas para la elaboración de aceite en el establecimiento rural ibérico de Saus (Gerona). Notas sobre la explotación del campo en el territorio de Emporion. AEspA, 83, Madrid, 2010, p. 67-84.

Casas, Soler 2004 : CASAS (J.), SOLER (V.) - Intervenciones arqueológicas en Mas Gusó (Gerona). Del asentamiento precolonial a la villa romana. BAR International Series, 1215, Oxford, 2004.

Casas $\boldsymbol{e}$ t al. 2005 : CASAS (S.), CODINA (F.), MARGALL (J.), MARTIN (A.), DE PRADO (G.), PATINO (C.) - Els temples de l'oppidum d'Ullastret. Aportacions al seu coneixement. In : Món ibèric als Països Catalans. Homentage a Josep Barberà, Actes XIII Col.loqui Internacional d'Arqueologia de Puigcerdà, vol. II, Puigcerdà, 2005, p. 989-1001.

Casas et al. 2010 : CASAS (J.), NOLLA (J.M.), SOLER (V.) - Les sitges ibèriques del Camp de l'Ylla (Viladamat, Alt Empordà). Cypsela, 18, Girona, 2010, p. 223-242.

Casevitz 1993 : CASEVITZ (M.) - Emporion : emplois classiques et histoire du mot. In : Bresson (A.), Rouillard (P.) dir., L'emporion, Publications du Centre Pierre Paris, 26, Paris, 1993, p. 9-22.

Chapa Brunet 2005 : CHAPA BRUNET (T.) - Las primeras manifestaciones escultóricas ibéricas en el Oriente peninsular. AEspA, 78, Madrid, 2005, p. 23-47.

Cordoba Alonso, Ruiz Mata 2005 : CORDOBA ALONSO (I.), RUIZ MATA (D) - El asentamiento fenicio arcaico de la calle Cánovas del Castillo (Cádiz). Un análisis preliminar. In : Celestino Perez (S.), Jimenez Avila (J.) dir., El Periodo orientalizante. Anejos de AEspA, XXXV, Madrid, 2005, p. 1269-1322. Croissant, Rouillard 1996 : CROISSANT (F.), ROUILLARD (P.) - Le problème de l'art "gréco-ibère »: état de la question. In : Formes archaïques et arts ibériques. Collection de la Casa de Velázquez, 59, Madrid, 1996. p. 55-66.

Croissant 1998 : CROISSANT (F.) - Note sur le style des sculptures de Porcuna. In : Los Iberos, Principes de Occidente, Valencia, 1998, p. 283-286. D’Agostino 1999 : D'AGOSTINO (B.) - La ceramica greca e di tipo greco dalle necropoli della I Età del Ferro di Pontecagnano. In : Bailo Modesti (G.), Gastaldi (P.) dir., Prima di Pithecusa. I più antichi materiali greci del golfo di Salerno, Naples, 1999, p. 11-24.

Decourt 2000 : DECOURT (J.-Cl.) - Le plomb de Pech Maho, état de la recherche 1999. Archéologie en Languedoc, 24, 2000, p. 111-124.

De Hoz 2010 : DE HOZ (J.) - L'écriture gréco-ibérique et l'influence hellène sur les usages de l'écriture en Hispanie et dans le sud de la France. In : Tréziny (H.) éd., Grecs et indigènes de la Catalogne à la mer Noire, Actes des rencontres du programme européen Ramses (2006-2008), Bibliothèque d'Archéologie Méditerranéenne et Africaine, 3, Aix-en-Provence, 2010, p. 637-657. 
Dietler, López-Ruiz 2009 : DIETLER (M.), LÓPEZ-RUIZ (C.) dir. Colonial Encounters in Ancient Iberia, Phoenician, greek and indigenous relations. Chicago, 2009.

Domínguez Monedero 1996 : DOMÍNGUEZ MONEDERO (A. J.) - Los griegos en la Península Ibérica, Madrid, 1996.

Domínguez Monedero 2000 : DOMÍNGUEZ MONEDERO (A. J.) Algunos instrumentos y procedimientos de intercambio en la Grecia Arcaica. In : Fernandez Uriel (P.), González Wagner (C.), López Pardo (F.) éd., Intercambio y comercio preclásico en el Mediterráneo, Actas del I coloquio del CEFYP (1998), Madrid, 2000, p. 241-258.

Domínguez Monedero 2007 : DOMINGUEZ MONEDERO (A. J.) - Los griegos en Iberia. In : Sanchez Moreno (E.) dir., Protohistoria y antigüedad de la Península Ibérica, I: las fuentes y la Iberia colonial, Madrid, 2007, p. 319-402.

Dupré 2005 : DUPRÉ (X.) - Terracotas arquitectónicas prerromanas en Emporion. Empúries, 54, Barcelona, 2005, p. 103-123.

Esposito 2012 : ESPOSITO (A.) - La question des implantations grecques et des contacts précoloniaux en Italie du Sud : entre emporia et apoikiai. In : Martinez-Sève (L.) éd., Les diasporas grecques du VIII è la fin du III ${ }^{e}$ s. av. J.-C., Actes du colloque de la Sophau, Pallas, 89, Toulouse, 2012, p. 97-121. Faustoferri 2003 : FAUSTOFERRI (A.) - Artisti Ionici itineranti. In : Die Ägäis und das westliche Mittelmeer, 2003 p. 315-324.

Fernández Nieto 2002 : FERNANDEZ NIETO (F. J.) - Hemeroskopeion = Thynnoskopeion. El final de un problema histórico mal enfocado. Mainake, 24, 2002, p. 231-255.

Ferrer 2005 : FERRER GARCIA (C.) - Asentamientos portuarios históricos del litoral meridional valenciano. Méditerranée. Revue géographique des pays méditerranéens, 104, 2005, p. 119-128.

Gailledrat 1995 : GAILLEDRAT (E.) - Grecs et Ibères dans la nécropole d'Ampurias ( $\mathrm{VI}^{\mathrm{e}}-\mathrm{II}^{\mathrm{e}}$ siècle av. J.-C.). Mélanges de la Casa de Velázquez, 31 (1), Madrid, 1995, p. 31-54.

García y Bellido 1948 : GARCÍA Y BELLIDO (A.) - Hispania Graeca. Barcelona, 1948.

González de Canales et al. 2004 : GONZÁLEZ DE CANALES (F.) - El emporio fenicio precolonial de Huelva (ca.900-770 a.C.). Madrid, 2004.

González de Canales et al. 2006 : GONZALEZ DE CANALES (F.), SERRANO (L.) ET LLOMPART (J.) - The Pre-colonial Phoenician Emporium of Huelva, ca 900-770 BC. Babesch - Annual papers on Mediterranean Archaeology, 81, 2006, p. 13-29.

Gorgues 2010 : GORGUES (A.) - Économie et société dans le nord-est du domaine ibérique (III - I Ir s. av. J.-C.). Anejos de AEspA, 52, Madrid, 2010. Gras 1993 : GRAS (M.) - Pour une Méditerranée des emporia ». In : Bresson (A.), Rouillard (P.) dir., L'emporion, Paris, 1993, p. 103-112.

Gras et al. 1995 : GRAS (M.), ROUILLARD (P.), TEIXIDOR (J.), L'UNIVERS PHÉNICIEN. PARIS (2 ${ }^{\mathrm{E}}$ ÉD.), 1995.

Grau, Moratalla 2001 : GRAU (I.), MORATALLA (J.) - Interpretación socioeconómica del enclave. In : Abad (L.), Sala (F.) éd., Poblamiento ibérico en el Bajo Segura. El Oral (II) y la Escuera, Real Academia de la Historia, Madrid, 2001, p. 173-203.

Grau, Moratalla 2004 : GRAU (I.), MORATALLA (J.) - El paisaje antiguo. In : Iberia, Hispania, Spania. Una mirada desde Ilici, Alicante, 2004, p. 111-118.

Gutiérrez et al. 1998-1999 : GUTIÉRREZ (S.), MORET (P.), ROUILLARD (P.), SILLIÈRES (P.) - Le peuplement du Bas Segura de la protohistoire au Moyen Age (prospections 1989-1990). Lucentum, 17-18, Alicante, 19981999, p. 25-74.

Hansen 1997 : HANSEN (M. H.) - Emporion. A Study of the Use and Meaning of the Term in Archaic and Classical Periods. In : Nielsen (Th. H.) dir., Yet more Studies in the Ancient Greek Polis, Historia Einzelschriften, 117, Stuttgart, 1997, p. 83-105.

Kourou 1999 : KOUROU (N.) - Rassegene di : BAILO MODESTI (G.), GASTALDI (P.) dir., Prima di Pithecusa. I più antichi materiali greci del golfo di Salerno. Annali di Archeologie e Storia Antica, NS, 6, 1999, p. 219-223.

Kourou 2005 : KOUROU (N.) - Early Iron Age Greeks Imports in Italy. In: Bartoloni (G.), Delpino (F.) dir., Oriente e Occidente : metodi e discipline a confronto. Mediterranea, 1, Pise-Rome, 2005, p. 497-515
Lazaro et al. 1981 : LAZARO (A.), MESADO (N.), ARANEGUI (C.), FLETCHER (D.) - Materiales de la necrópolis ibérica de Orleyl (Vall d'Uxó, Castellón). Trabajos Varios del SIP, 70, Valencia, 1981.

Lejeune et al. 1988 : LEJEUNE (M.), POUILLOUX (J.), SOLIER (Y.) - Étrusque et ionien sur un plomb de Pech Maho. RAN, 21, Montpellier, 1988, p. 19-59.

Les Ibères : Catalogue de l'exposition. Paris-Barcelone-Bonn, Barcelona, 1997. León 1998 : LEÓN (P.) - La sculpture des Ibères. Paris, 1998.

León 2003 : LEON (P.) - Jonia e Iberia. Romula, 2, 2003, p. 13-42.

Lévêque 1993 : LÉVÊQUE (P.) - La richesse foisonnante de l'emporion. In : BRESSON (A.), ROUILLARD (P.) dir., L'emporion, Publications du Centre Pierre Paris, 26, Paris, 1993, p. 227-231.

Llompart et al. 2010 : LLOMPART (J.), ORTA (E. MA .), GARRIDO (J. P.), GONZALEZ DE CANALES (F.), SERRANO (L.) - Discusión en torno a la lectura y soporte de una inscripción griega con dedicatoria a la diosa $\mathrm{Hi} /$ Hestia en Huelva. Huelva en su historia, 13, Huelva, 2010, p. 3-14.

Lombardo 2002 : LOMBARDO (M.) - ÉMPOROI, EMPORION, EMPORITAI : forme e dinamiche della presenza greca nella penisola iberica. In : Sordi (M.) dir. - Hispania terris omnibus felicior, Premesse ed esiti di uin processo di integrazione, Pise, 2002, p. 73-86.

Maas-Lindemann 2000 : MAAS-LINDEMANN (G.) - Cerámica del Morro de Mezquitilla (Málaga). In : Bartoloni (P.), Campanilla (L.) dir., La ceramica fenicia di Sardegna. Dati, problematiche, confronti, Coll. di Studi Fenici, 40 , Rome, 2000, p. 225-233.

Martín et al. 2010 : MARTIN (A.), CODINA (F.), PLANA-MALLART (R.), DE PRADO (G.) - Le site ibérique d'Ullastret (Baix Empordà, Catalogne) et son rapport avec le monde colonial méditerranéen. In : Tréziny (H.) éd., Grecs et indigènes de la Catalogne à la mer Noire, Actes des rencontres du programme européen Ramses (2006-2008), Bibliothèque d'Archéologie Méditerranéenne et Africaine, 3, Aix-en-Provence, 2010, p. 89-104.

Martín, Plana 2012 : MARTIN (A.), PLANA-MALLART (R.) - Émergence et premier développement du pôle de peuplement ibérique d'Ullastret dans l'extrême nord-est de la Péninsule Ibérique : l'habitat aggloméré et son emprise précoce sur l'espace périphérique. In : Ropiot (V.), Puig (C.), Mazière (Fl.), Les plaines littorales en Méditerranée nord-occidentale. Regards croisés d'histoire, d'archéologie et de géographie de la Protohistoire au Moyen-Âge. Archéologie du paysage, 1, Montagnac, 2012, p. 63-75.

Martínez Carmona et al. 2007 : MARTINEZ CARMONA (A.), OLCINA (M.), SALA (F.) - Un posible sistema defensivo de época ibérica en la Illeta dels Banyets (el Campello, Alicante). Anales de Arqueología Cordobesa 18, Córdoba, 2007, p. 47-66.

Mederos 2005 : MEDEROS (A.) - La cronología fenicia. Entre el Mediterráneo oriental y el occidental. In : Celestino Perez (S.), Jimenez Avila (J.) dir., $E l$ Periodo orientalizante. Anejos de AEspA, XXXV, Madrid, 2005, p. 305-346.

Molina Vidal 2005 : MOLINA VIDAL (J.) - La cetaria de Picola y la evolución del Portus Ilicitanus (Santa Pola, Alicante). In : Molina Vidal (J.), Sánchez Fernández (M. J.), éd., El Mediterráneo: la cultura del mar y la sal, III Congreso Internacional de Estudios Históricos, Elche, 2005, p. 95-112.

Moratalla 2005 : MORATALLA (J.) - El territorio meridional de la Contestania. In : Abad (L.), Sala (F.), Grau (I.) éd., La Contestania ibérica, treinta años después, Alicante, 2005, p. 91-117.

Moret 1995 : MORET (P.) - Tite-Live et la topographie d'Emporion. Mélanges de la Casa de Velázquez, 31 (1), Madrid, 1995, p. 55-75.

Moret 1996 : MORET (P.) - Les fortifications ibériques, de la fin de l'âge du bronze à la conquête romaine. Collection de la Casa de Velázquez, 56, Madrid, 1996.

Moret 1997 : MORET (P.) - Planesiai, îles erratiques de l'Occident grec. Revue des Études Grecques, 110 (1), Bordeaux, 1997, p. 25-56.

Moret 1998 : MORET (P.) - « Rostros de piedra ». Sobre la racionalidad del proyecto arquitectónico de las fortificaciones urbanas ibéricas. In : Los Iberos, Principes de Occidente, Valencia, 1998, p. 83-92.

Moret 2001 : MORET (P.) - Emporion et les mutations de l'architecture ibérique au premier âge du fer. Zephyrus, 53-54, Salamanca, 2001, p. 379-391.

Moret 2006 : MORET (P.) - La formation d'une toponymie et d'une ethnonymie grecques de l'Ibérie : étapes et acteurs. In : Cruz Andreotti (G.), Le Roux (P.), Moret (P.) dir. - La invención de una geografía de la Península Ibérica, I. La época republicana, Malaga-Madrid, 2006, p. 39-76. 
Moret 2010 : MORET (P.) - La diffusion du village clos dans le nord-est de la péninsule Ibérique et le problème architectural de la palaia polis d'Emporion. In : Tréziny (H.) éd., Grecs et indigènes de la Catalogne à la mer Noire. Actes des rencontres du programme européen Ramses (2006-2008), Bibliothèque d'Archéologie Méditerranéenne et Africaine, 3, Aix-en-Provence, 2010, p. 329-332.

Moret 2013 : MORET (P.) - Honorato de Lérins, Heracles y las islas errantes. Cuadernos de Prehistoria y Arqueología de la Universidad Autónoma de Madrid, 37-38, Madrid, 2011-2012 (2013), p. 455-464.

Negueruela 1990 : NEGUERUELA (I.) - Los monumentos escultóricos ibéricos del Cerrillo Blanco de Porcuna (Jaén). Madrid, 1990.

Nijboer 2005 : NIJBOER (A. J.) - La cronologia assoluta dell'età del Ferro nel Mediterraneo, dibattito sui metodi e sui risultati. In : Bartoloni (G.), Delpino (F.) dir., Oriente e Occidente : metodi e discipline a confronto. Mediterranea, 1, Pise-Rome, 2005, p. 527-556

Oliva 1955 : OLIVA PRAT (M.) - Actividades de la delegación provincial del Servicio Nacional de excavaciones arqueológicas de Gerona en 1955. Anales del Instituto de Estudios Gerundenses, X, Girona, 1955, p. 317-411.

Olmos 1999 : OLMOS (R.) - Usos y transformaciones de la cerámica entre los iberos : los siglos V y IV a. de C. In : Villanueva Puig (M.-C.) et al. dir., Céramique et peinture grecques, modes d'emploi, 1999, p. 425-438.

Olmos, Rouillard dir. 1996 : OLMOS (R.), ROUILLARD (P.) DIR. Formes archaïques et arts ibériques. Collection de la Casa de Velázquez, 59, Madrid, 1996.

Page del Pozo 1984 : PAGE DEL POZO (V.) - Imitaciones de influjo griego en la cerámica ibérica de Valencia, Alicante y Murcia. Iberia Graeca, 1, Madrid, 1984.

Pena 1993 : PENA (M. J.) - Avieno y las costas de Cataluña y Levante (II). Hemeroskopeion-Dianium. Faventia, 15 (1), Barcelona, 1993, p. 61-77.

Plana-Mallart 2001 : PLANA-MALLART (R.) - D'emporion à Emporion : la colonie et son territoire. In : Problemi della « chora » coloniale dall'Occidente al mar Nero, Atti del XL convegno di Studi sulla Magna Grecia, Taranto, 2001, p. 545-566.

Plana-Mallart 2004 : PLANA-MALLART (R.) - Grecs et peuples indigènes dans l'extrême nord-est de la Péninsule Ibérique : communautés agraires et économie rurale. In : Chandezon (Chr.), Hamdoune (Chr.) éd., Les hommes et la terre dans la Méditerranée gréco-romaine. Pallas, 64, Toulouse, 2004, p. 243-265.

Plana-Mallart 2012 : PLANA-MALLART (R.) - La présence grecque et ses effets dans le Nord-Est de la péninsule Ibérique (VII ${ }^{\mathrm{e}}$ - début du IVe siècle av. n. è.). In : Martinez-Sève (L.) éd., Les diasporas grecques du VIII à la fin du III ${ }^{e}$ siècle av.J.-C., Actes du colloque de la Sophau, Pallas, 89, Toulouse, 2012, p. 157-178.

Plana, Martín 2012 : PLANA-MALLART (R.), MARTIN (A.) - El paisatge periurbà de l'oppidum d'Ullastret : una nova imatge de la morfologia i del funcionament d'una ciutat ibèrica. In : Belarte (M.C.), Plana-Mallart (R.) éd., El paisatge periurbà a la Mediterrània occidental durant la protohistòria i l'antiguitat / Le paysage périurbain en Méditerranée occidentale pendant la Protohistoire et l'Antiquité, Documenta, 26, Tarragona 2012, p. 123-148.

Pons et al. 2010 : PONS (E.), ASENSIO (D.), FUERTES (M.), BOUSO (M.) - El yacimiento del Mas Castellar de Pontós (Alt Empordà, Girona) : un núcleo indígena en la órbita de la colonia focea de Emporion. In : Tréziny (H.) éd., Grecs et indigènes de la Catalogne à la mer Noire, Actes des rencontres du programme européen Ramses (2006-2008), Bibliothèque d'Archéologie Méditerranéenne et Africaine, 3, Aix-en-Provence, 2010, p. 105-118.

Puig, Martín 2006 : PUIG (A. M.), MARTÍN (A.) - La colònia grega de Rhode (Roses, Alt Empordà). Sèrie monogràfica, 24, Museu d'Arqueologia de Catalunya - Girona, Girona, 2006.

Quesada 2007 : QUESADA SANZ (F.) - Asedio, sitio, asalto... Aspectos prácticos de la poliorcética en la Iberia prerromana. In : Berrocal (L.), Moret (P.) éd., Paisajes fortificados de la Edad del Hierro. Las fortificaciones protohistóricas de la Meseta y la vertiente atlántica en su contexto europeo, Real Academia de la Historia - Casa de Velázquez (Bibliotheca Archaeologica Hispana, 28), Madrid, 2007, p. 75-98.

Ramos Molina 2000 : RAMOS MOLINA (A.) - La escultura ibérica en el Bajo Vinalopó y el Bajo Segura. Elche, 2000.
Rolley 1994 : ROLLEY (C.) - La sculpture grecque. Vol. I, Paris, 1994. Rosser et al. 2003 : ROSSER (P.), ELAYI (J.), PEREZ (J. M.) - El Cerro de las Balsas y El Chinchorro : una aproximación a la arqueología del poblamiento prehistórico e ibérico de la Albufereta de Alicante. LQNT Monográfico 2, Alicante, 2003.

Rouillard 1991 : ROUILLARD (P.) - Les Grecs et la Péninsule Ibérique du VIII ${ }^{e}$ au IV siècle av. J.-C. Publications du Centre Pierre Paris, 21, Paris, 1991. Rouillard 2004 : ROUILLARD (P.) - Vases grecs entre habitats et sanctuaires en Gaule et en Espagne. Introduction à une enquête. Beihefte zum Corpus Vasorum Antiquorum Deutschland, II, 2004, p. 115-120.

Rouillard 2007 : ROUILLARD (P.) - Sur les rives de la Méditerranée, l'art ibérique. In : Abad (L.) dir., Arte ibérico en la España Mediterránea, Alicante, 2007, p. 317-328.

Rouillard 2009a : ROUILLARD (P.) - Le vase grec entre statut et fonction : le cas de la Péninsule Ibérique. In : Shapes and Uses of Greek Vases (VII ${ }^{\text {th }}$ II $V^{\text {th }}$ centuries B.C.), ULB, Bruxelles, 2009, p. 365-376.

Rouillard 2009b : ROUILLARD (P.) - Greeks and the Iberian Peninsula : forms of exchange and settlements. In : Dietler (M.), López-Ruiz (C.) dir., Colonial Encounters in Ancient Iberia, Phoenician, greek and indigenous relations, Chicago, 2009, p. 131-151.

Rouillard et al. 2007 : ROUILLARD (P.), GAILLEDRAT (E.), SALA (F.) Fouilles de La Rábita de Guardamar II, L'établissement protohistorique de La Fonteta (fin VIIIe-fin VIe s. av. J.-C.). Collection de la Casa de Velázquez, 96, Madrid 2007.

Rouillard, Sourisseau 2010 : ROUILLARD (P.), SOURISSEAU (J.-CH.) Entre chronologies et chronologie : le VII siècle. In : Étienne (R.) dir., La Méditerranée au VII e siècle av. J.-C. (essais d'analyses archéologiques), Travaux de la Maison René-Ginouvès, 7, Paris, 2010, p. 27-38.

Ruiz de Arbulo 2002-2003 : RUIZ DE ARBULO (J.) - Santuarios y fortalezas. Cuestiones de indigenismo, helenización y romanización en torno a Emporion y Rhode (s. VI - I a.C.). CuPAUAM, 28-29, 2002-2003, p. 161-202. Sala Selles 2005 : SALA SELLES (F.) - Consideraciones en torno a la arquitectura y el urbanismo de la Contestania Ibérica. In : Abad (L.), Sala (F.), Grau (I.) éd., La Contestania ibérica, treinta años después, Alicante, 2005, p. 119-146.

Sala Selles 2006 : SALA SELLES (F.) - Les fortificacions a la Contestània: entre la representació social i la defensa del territori. In : Oliver Foix (A.) éd., Arquitectura defensiva. La protección de la población y del territorio en época ibérica (Benicarló, 3-4 de febrero 2005), Sociedad Castellonense de Cultura, Castellón, 2006, p. 123-165.

Sala Selles 2010 : SALA SELLES (F.) - Nuevas perspectivas sobre la relaciones púnicas con la costa ibérica del sureste. Mainake, 32, 2010, p. 933-950. Sánchez 2000 : SÁNCHEZ (C.), VASOS GRIEGOS PARA LOS PRINCIPES IBÉRICOS. In : Cabrera (P.), Sanchez (C.) dir., Los Griegos en España, Madrid, 2000, 179-193.

Sanmartí-Grego, Santiago 1998 : SANMARTÍ-GREGO (E.), SANTIAGO (R.) - La lettre grecque d'Emporion et son contexte archéologique. RAN, 21, Montpellier, 1998, p. 3-17.

Santos, Sourisseau 2011 : SANTOS (M.), SOURISSEAU (J.-C.) - Cultes et pratiques rituelles dans les communautés grecques de Gaule méditerranéenne et de Catalogne. In : ROURE (R.), PERNET (L.) dir., Des rites et des hommes, Paris, p. 223-255 (Collection Archéologie de Montpellier Agglomération, 2). Schubart 2006 : SCHUBART (H.) - Morro de Mezquitilla. El asentamiento fenicio-púnico en la desembocadura del Río Algarrobo. Anejos de la Revista Mainake, 1, Malaga, 2006.

Tendero 2005 : TENDERO PORRAS (M.) - La cerámica del período ibérico antiguo en La Alcudia (Elche, Alicante). In : Abad (L.) et al. (éd.), La Contestania ibérica, treinta años después, Alicante, 2005, p. 305-316.

Tréziny dir. 2010 : TREZINY (H.) - Grecs et indigènes de la Catalogne à la mer Noire. Actes des rencontres du programme européen Ramses (2006-2008), Bibliothèque d'Archéologie Méditerranéenne et Africaine, 3, Aix-en-Provence, 2010.

Truszkowski 2003 : TRUSZKOWSKI (E.) - Réflexions sur la sculpture funéraire et votive du Sud-Est de la Péninsule Ibérique. $\operatorname{MDAI}(M), 44,2003$, p. 311-332. Truszkowski 2006 : TRUSZKOWSKI (E.) - Étude stylistique de la sculpture du sanctuaire ibérique du Cerro de los Santos (Albacete, Espagne). Monographies Instrumentum, 33, Montagnac, 2006. 
Uroz Rodríguez 2006 : UROZ RODRIGUEZ (H.) - El programa iconográfico religioso de la «Tumba del orfebre » de Cabezo Lucero (Guardamar del Segura, Alicante). Murcia, 2006.

Zamora et al. 2010 : ZAMORA LOPEZ (J. A.), GENER BASALLOTE (J. M.), NAVARRO GARCIA (M. A.), PAJUELO SAEZ (J. M.),
TORRES ORTIZ (M.) - Epígrafes fenicios arcaicos en la excavación del Teatro Cómico de Cádiz (2006-2010). Rivista di Studi Fenici, 38 (2), 2010 , p. 203-236.

Will 1993 : WILL (E.) - Compte Rendu de BRESSON, ROUILLARD (éd.), L'emporion. Revue de Philologie, LXVII, 2, p. 345-350. 


\title{
Características, evolución y particularidades del poblamiento indígena en el área de colonización griega del Ampurdán
}

\author{
El caso del Mas Castellar de Pontós (Siglos VII-III aC.)
}

\author{
David Asensio i Vilaró \\ Universitat de Barcelona; Universitat Autònoma de Barcelona; MónIberRocs SL \\ Enriqueta Pons i Brun \\ Museu d'Arqueologia de Catalunya - Girona
}

\section{Résumé}

Au cours de la première moitié du $\mathrm{VI}^{\mathrm{e}} \mathrm{s}$. av. J.-C., une enclave coloniale grecque s'établit à l'extrême ouest, l'Emporion focea, présence renforcée, au milieu du $\mathrm{V}^{\mathrm{e}} \mathrm{s}$. av. J.-C., par la fondation de la cité de Rhodé à proximité. Dans l'environnement immédiat de ces villes coloniales, on reconnaît aisément une population indigène très dense et dynamique, répartie en un éventail d'implantations de typologie très variée. Nous y trouvons de grandes villes de premier niveau (Puig de Sant Andreu et Illa d'en Reixac), comme des centres spécialisés (Mas Castellar de Pontós et même Peralada) et de petites implantations rurales (Mas Gusó, Camp de l'Ylla). Il est certain que ces communautés ont eu un niveau privilégié de contacts et de relations avec les agents coloniaux nouveaux venus. On peut penser que ce lien étroit et intense a pu engendrer certaines particularités dans plusieurs domaines importants pour ces communautés, comme, par exemple, les formes architecturales ou la culture matérielle.

Mots-clés : enclave coloniale, colonisation grecque, grandes villes, centres spécialisés, implantations rurales, culture matérielle, Protohistoire, Catalogne, Emporion, Ampurdan

\footnotetext{
Abstract

In the first half of the sixth century BC, a Greek colonial outpost was established in the far west, the Phocaean Emporion; its presence was reinforced with the founding of the nearby site of Rhode, in the mid-fifth century BC. In the immediate surroundings of these colonial towns we have considerable knowledge of a very dense and dynamic indigenous population formed by a range of settlements of very diverse types. We find cities of the highest level (Puig de Sant Andreu and Illa d'en Reixac), specialized centres (Mas Castellar de Pontós and, perhaps, Peralada) and small rural settlements (Mas Gusó, Camp de l'Ylla). It is most likely that these communities had some level of contact and privileged inter-relations with the newly arrived colonial agents. It is most likely that this connection, closer and more intense than normal, could lead to the development of certain particularities in some important areas in these communities, such as their architectural forms or their tangible culture.
}

Keywords: colonial enclave, Greek colonisation, cities, specialized centres, rural settlements, material culture Protohistory, Catalonia, Emporion, Empordà 


\section{Introducción}

La implantación de todo asentamiento colonial supone el inicio de cambios trascendentes en el lugar donde acontece. Para empezar, el fenómeno colonial conlleva una ineludible apropiación de territorio, ya sea circunscrita al solar donde se construirá el nuevo núcleo urbano, ya sea afectando terrenos circundantes, de menor o mayor extensión. En el caso de la colonización focea desarrollada en el extremo nordeste de la Península Ibérica se ha constatado como el núcleo fundacional griego de Emporion se asienta, hacia el 575 a.C., en un islote próximo a la costa donde ya existía un asentamiento indígena bien estructurado (Aquilué et al. 1999). A partir de esta primera afectación en el poblamiento indígena no cabe duda que la consolidación del centro colonial en los siglos sucesivos debió ampliar la incidencia en el territorio circundante. Hay un acuerdo unánime respecto al hecho de que la integración de población local en la Emporion griega es uno de sus rasgos más característicos (Sanmartí Grego 1993). Por contra, es mucho más incierta la naturaleza, e incluso la existencia misma, de una chora emporitana.

En el nombre mismo de "Emporion" se fundamenta su tradicional interpretación como enclave con una razón de ser eminentemente comercial. Se trata de una visión apoyada por evidencias arqueológicas de peso, como el excepcional plomo inscrito en dialecto jonio en el que se describen los detalles de una transacción entre un probable comerciante emporitano y agentes indígenas radicados en "Saiganthe" (Sanmartí Grego, Santiago 1988; Gracia 1995). Otro soporte clave de esta interpretación radica en las reducidas dimensiones del enclave que se mantiene, a pesar de diversas reformas urbanísticas importantes, dentro de un máximo de unas modestas 5 ha. de superficie hasta el siglo II a.C., cuando la ciudad entra dentro del dominio romano. En esta disyuntiva, la articulación de una chora de una cierta entidad, lo que comporta dinámicas de ocupación, explotación y defensa de una cantidad significativa de territorio, se considera o innecesaria o inviable a causa del escaso potencial demográfico de la colonia focea (Sanmartí Grego 1993, p. 92-94).

Con todo, R. Plana ha señalado la existencia de una parcelación regular de la llanura alrededor de Emporion que podría corresponder a la fosilización de un cadastro antiguo (Plana 1994). El probable uso de una unidad de medida jonia podría retraer hasta época protohistórica esta división regular de unos terrenos fértiles ubicados al oeste y sur de la colonia, que se reconoce en una extensa área de unos $150 \mathrm{~km}^{2}$. Cierto es que una estructuración del espacio agrícola circundante de esta naturaleza no es exclusiva de las grandes colonias de poblamiento, como en el caso de la mayoría de ciudades de la Magna Grecia. Así, también hay indicios de su existencia en pequeños enclaves periféricos, como por ejemplo la subcolonia massaliota de Olbia de Provenza (Benoit 1985) o en el modesto enclave jonio de Pharos, establecido en el siglo IV a.C. en la isla de Hvar, cerca de las actuales costas de Croacia (Kirigin 2006).

Por otro lado se constata que los centros indígenas fortificados se ubican a una distancia prudencial respecto de los enclaves coloniales de Emporion y Rhode, nunca inferior a los 20 o $25 \mathrm{~km}$ en línea recta (Martín, Plana 2001 ; Martín 2005). De hecho se observa como se dibuja una especie de corona de oppida ibéricos alrededor de la zona de colonización focea (fig. 2, F), que algunos autores consideran como marcadores de los límites hipotéticos de la chora o territorio bajo control de los enclaves coloniales griegos (Plana 2001). En el caso de Emporion se delimita una área de alrededor de $360 \mathrm{~km}^{2}$, superficie totalmente equiparable a la de la chora estimada para núcleos de entidad muy superior como, por ejemplo, la misma Massalia focea. Ante planteamientos tan dispares, ambos apoyados con argumentos de peso, creemos que una de las vías para afrontar esta problemática puede ser la que desarrollamos en este trabajo : el análisis de la estructura, naturaleza y evolución de los diferentes tipos de asentamientos indígenas conocidos en las inmediaciones del área de colonización. En este campo se están obteniendo avances destacados en los últimos años, con nuevos datos significativos que resumimos a continuación, con especial énfasis en la documentación procedente de las últimas campañas de excavación realizadas en el yacimiento del Mas Castellar de Pontós (Alt Empordà, Girona).

\section{Núcleos indígenas fortificados}

\section{El oppidum del Puig de Sant Andreu (Ullastret, Baix Empordà)}

En el curso del siglo VI a.C., en este lugar, se produce una transformación profunda del hábitat indígena. Un asentamiento extenso de fondos de cabañas es substituido por un recinto fortificado complejo, con un potente lienzo de muralla y torres de planta circular dispuestas a intervalos regulares que delimitan un área 
de 3 ha de superficie. Hacia finales del siglo V a.C. se documenta una segunda reforma trascendente, cuando las dimensiones del hábitat fortificado alcanzan cerca de las 9 ha y, en paralelo, aumenta la complejidad de las estructuras defensivas (se edifica un nuevo paramento de muralla sobre la base del antiguo, aparecen torres cuadrangulares de diversas variantes formales, se sofistican los dispositivos de defensa de las puertas, etc.) (Martín 2000). También de este momento arranca la construcción de casas de grandes dimensiones y enorme complejidad arquitectónica, entre las que destaca la llamada "Zona 14", una indudable residencia de $1100 \mathrm{~m}^{2}$ de superficie (Martín et al. 2004). Tanto la fortificación como el conjunto de residencias nobles perduran hasta finales del siglo III a.C., cuando es seguro que coexisten con edificios públicos como los dos templos exentos ubicados en el punto más elevado y preeminente de la ciudad ibérica. Otros aspectos destacados son el de la presencia de importantes agrupaciones de silos, tanto dentro como al exterior del perímetro amurallado, así como la existencia de un intenso uso y explotación del entorno periurbano (Plana, Martín 2005). Todo ello confirma su carácter de núcleo urbano de primer orden, con un papel sin duda preeminente en la vertebración política y económica del territorio indiketa.

\section{El núcleo de Sant Julià de Ramis (Girona)}

Se trata de un yacimiento con una importante ocupación de época romano republicana en el que recientemente se ha constatado que la bien conservada fortificación del siglo II a.C. se superpone a estructuras defensivas que arrancan del período ibérico antiguo. En concreto, se ha documentado una primera muralla, que se podría datar dentro del siglo VI a.C., que es totalmente transformada en el siglo $\mathrm{V}$ a.C. con la edificación de un nuevo recinto defensivo mucho más complejo que el anterior, en el que destaca un bastión macizo rectangular de $5,5 \mathrm{~m}$ de grosor. Todos estos elementos se concentran en el extremo meridional de la cima de una colina de unas 2,5 ha de superficie por la que se extienden los restos del hábitat antiguo (Burch, Nolla, Sagrera 2010). Se trata de una elevación situada en un lugar estratégico, un evidente nudo de comunicaciones entre costa y interior, en cuya base se ha localizado más de una agrupación de silos en uso durante los siglos III y II a.C. (Burch, Sagrera 2009). De esta documentación se desprende que ya desde el ibérico antiguo pudo constituir un núcleo urbano importante, quizás de segundo orden (en comparación a las dimensiones y entidad del del Puig de Sant Andreu) pero relevante en la estructuración del poblamiento de un territorio circundante.

\section{El poblamiento disperso: asentamientos rurales}

Recientemente se han dado a conocer la documentación de restos de diversos asentamientos agrícolas de llano, ubicados a muy corta distancia del núcleo urbano de la Emporion griega. Se trata de los yacimientos de Saus II (Camallera), a $12 \mathrm{~km}$ al oeste (Casas 2010), el de Mas Gusó (Bellcaire), a escasos $5 \mathrm{~km}$ al sur (Casas, Soler 2004) y los de Camp de l'Ylla (Casas, Nolla, Soler 2010) y Olivet d'en Pujol (Viladamat) (Casas 1989), también entre 4 y $5 \mathrm{~km}$ en lìnea recta hacia el oeste. Todos ellos se identifican a partir de la localización de un número variable de silos, desde los dos o tres de los yacimientos de Viladamat a los 38 excavados en el de Saus. Aunque en ningún caso se conservan otras estructuras in situ, la existencia de edificios asociados está confirmada por los restos de materiales constructivos diversos (adobes quemados, soleras de hogares, revoques de paredes, etc.) arrojados en su interior. La cronología de amortización de estas estructuras abraza desde el siglo VI a.C. (Mas Gusó, Saus) hasta finales del siglo IV a.C. (Olivet d'en Pujol).

Entre los materiales recuperados en los niveles de amortización de los silos cabe destacar cuatro bases de prensa de la segunda mitad del siglo V a.C., procedentes del yacimiento de Saus. Se trata de las piezas de este tipo más antiguas conocidas en todo el Mediterráneo occidental. A ello hay que añadir el hecho excepcional de la localización de más de una de estas muelas juntas en un mismo asentamiento. Igualmente poco habitual es el hallazgo, dentro de uno de los silos de Mas Gusó, amortizado en el siglo VI a.C., de una serie de fragmentos de revoques de pared, decorados con motivos impresos, conjunto de una notable complejidad técnica y estilística (Casas, Soler 2011, p. 41, fig. 10).

Finalmente, hay que señalar que la gran mayoría de materiales cerámicos corresponden a cerámicas de producción local, lo cual, junto a la naturaleza misma del asentamiento, que responde a una tipología ampliamente documentada en todo el mundo ibérico septentrional (Asensio et al. 1998, p. 377), confirma el carácter indígena de todos estos núcleos. Con todo también hay que reseñar que en ellos aparece sistemáticamente un repertorio de materiales de importación cuya cantidad y calidad superan de mucho los índices habituales en asentamientos de esta clase. 


\section{Los dos asentamientos sucesivos del Mas Castellar de Pontós (Alt Empordà)}

\section{Mas Castellar I : fase del poblado fortificado ${ }^{1}$}

Yacimiento ubicado en lo alto de una suave elevación situada a $25 \mathrm{~km}$ de la costa, en un punto equidistante de las colonias de Emporion y Rhode (Pons et al. 2002). La ocupación antigua se inicia en el siglo VII a.C., momento del que se han documentado únicamente algunos silos dispersos. En el período ibérico antiguo, en un extremo de la colina, se edifica un pequeño asentamiento fortificado, precisamente en el punto más elevado que coincide con la zona de más fácil acceso al rellano superior. A pesar de las modestas dimensiones del núcleo, en ningún caso superiores a unos $6000 \mathrm{~m}^{2}$ de superficie, las estructuras defensivas destacan por su buena factura, potencia y complejidad arquitectónica (Pons, Gonzalo, López 2005) (fig. 1, D). Los elementos conocidos hasta el momento son dos lienzos de muralla de 2,6 m de anchura, un muro avanzado paralelo al frontal meridional de la muralla y una monumental torre maciza situada en un ángulo de la fortificación, de planta rectangular y dimensiones más que notables : 11,5 $\mathrm{m}$ de lado largo y $7 \mathrm{~m}$ en los laterales (fig. 1,A). Este aparato defensivo se inutiliza de manera contundente a principios del siglo IV a.C., cuando el frontal meridional de la muralla se desmantela hasta su base y el espacio existente entre este lienzo y la muralla avanzada se usa como escombrera (Asensio, Pons 2009).

En la limitada porción de espacio intramuros excavado hasta el momento se ha localizado un gran patio abierto, desde el cual se accede a la torre del ángulo, y, a partir de aquí arranca una batería de ámbitos de planta rectangular alargada, adosados a la muralla. Se trata de unidades domésticas de estructura más bien simple, con dimensiones de entre 35 y $45 \mathrm{~m}^{2}$ de superficie interna. Con todo diversos elementos de cultura material parecen indicar que en esta especie de ciudadela fortificada pudieron residir sectores de la clase dirigente local, entre los que destacamos un fragmento de escultura de piedra arenisca en la que se identifica la parte delantera de un felino (Pons, Ruiz de Arbulo, Vivó 1998) (fig. 1, C), así como un depósito de cerámicas áticas con piezas de calidad o, cuando menos, poco habituales (Asensio 2011) (fig. 1, B).

1 La denominacion de las fases 0,1 y 2 de Mas Castellar corresponden a tres momentos conocidos con estructuras consolidadas en el yacimiento. En relación a la duración temporal o de la periodización del asentamiento, estas fases de construcción corresponderían a los períodes II-III (anterior al 425 a.C.), al periodo III (425-375 a.C.) y al período $\mathrm{V}$ (250-175 a.C.) respectivamente.

\section{Mas Castellar 0 : una primera fortificación?}

Las excavaciones de los años 2009 a 2011 han puesto al descubierto que el poblado fortificado, desmantelado a principios del siglo IV a.C., se había construido únicamente entre 25 y 50 años antes de su amortización y que éste se levanta sobre unas construcciones preexistentes. Podemos avanzar que las estructuras más antiguas corresponden a una edificación de planta, factura y dimensiones similares a las de la torre que se le superpone, pero en este caso no maciza y con subdivisiones internas (fig. 1, F y H). Tampoco está clara la existencia de paramentos de muralla asociados, por lo que es posible que se trate de un edificio exento, de naturaleza aún incierta (aunque también parece corresponder a una estructura de funciones defensivas) (fig. 1, E). Un rasgo singular de esta construcción es el hecho de que todas las paredes internas conservan restos de revoque con decoración pintada de color rojo, acabado que también se ha documentado, de manera mucho más parcial, en algún sector del paramento externo del edificio (en concreto, en el frontal o cara meridional). También destaca la existencia de un pavimento de adobes, de coloración diversa según las unidades, en el más reducido de los tres ambientes internos ${ }^{2}$. Sea lo que fuere, esta primera construcción se destruye dentro de la segunda mitad del siglo V a.C. de manera traumática y brutal. Entre ésta y el recinto fortificado que se le superpone (descrito en el apartado anterior) se ha documentado un potente estrato de derrumbe con indicios de un incendio muy intenso (vigas quemadas, acumulaciones de piedras caídas del edificio con la cara externa rubefactada). También hay que destacar la localización dentro de este nivel de destrucción (aún muy parcialmente excavado) de algunos materiales poco comunes, como el soporte de un lebes ático, conservado roto pero completo (Pons et al. 2012) (fig. 1, G).

\section{Mas Castellar II : fase del asentamiento abierto}

Tras el abandono definitivo del sector del núcleo (o núcleos) fortificado, a lo largo del siglo IV a.C. se alza un nuevo hábitat en una zona más al este del rellano superior (fig. 2, E). Se trata ahora de un enclave no fortificado en que la mayor parte de la superficie excavada está ocupada por dos grandes edificios de arquitectura compleja (438 $\mathrm{m}^{2}$ la Casa 1 y $484 \mathrm{~m}^{2}$ la Casa 2), separados por una amplia calle central (Pons et al. 2000). La estructura de ambos edificios se articula alrededor de

2 El mayor de los recintos aún no ha sido objeto de excavación. 
uno o dos patios abiertos en los que destaca la presencia de pórticos sostenidos por columnas con bases de piedra de muy buena factura (fig. 2, D). La interpretación de estos edificios como residencias de familias de alto rango es compatible con las evidencias del desarrollo en su interior tanto de actividades productivas y de transformación como de prácticas cultuales o de representación política. De hecho, asociado a este nuevo sector de hábitat, destaca un conjunto de materiales ciertamente excepcionales que se pueden interpretar en este sentido. Entre ellos cabe destacar la célebre ara de mármol del Pentélico, en forma de columna (fig. 2, A), la documentación de Ostrakon cerámicos (con paralelos directos en la misma Emporion), un fragmento de terracota de barniz negro que representa un Eros funerario (Pons, Ruiz de Arbulo, Vivó 1998) (fig. 2, B) o el más reciente hallazgo de restos de un plafón de decoración arquitectónica de yeso formado por fragmentos de cornisas, ovas, guirnaldas y volutas que conservan indicios de pintura azul y roja (Asensio, Pons, Fuertes 2007) (fig. 2, C).

También desde principios del siglo IV a.C. se habilita el resto del rellano superior y parte del rellano inferior como sendos enormes campos de silos (fig. 2, E). Cientos de estructuras de este tipo rodean el nuevo núcleo no fortificado, certificando una función económica trascendente como lugar especializado en la tarea de centralizar y gestionar una cantidad ingente de excedente cerealístico (Pons et al. 2001).

\section{Consideraciones finales}

La tendencia observada entre los núcleos fortificados de mayor entidad es la de un crecimiento constante de la complejidad estructural y arquitectónica de la trama urbana y, muy especialmente, de sus sistemas defensivos. De hecho se trata de una dinámica generalizada entre los asentamientos fortificados en toda el área del nordeste peninsular, alcanzando su máximo nivel de desarrollo dentro del siglo III a.C. (Sanmartí, Santacana 2005).

En este contexto, la evolución que muestra el Mas Castellar de Pontós es totalmente atípica, con una inutilización temprana (hacia el 400 a.C.) de un potente complejo defensivo construido poco antes ; estructuras que, a su vez, se alzan sobre los restos de una probable edificación defensiva anterior, derruida de manera traumática. El nuevo asentamiento que nace a partir del siglo IV a.C. responde a un patrón completamente diferente, como pequeño hábitat abierto especializado en la acumulación de excedentes agrícolas. Hay indicios que una transformación similar podría haberse dado en algún otro yacimiento de la zona, como es el caso del de Peralada, algo más al norte (Llinàs et al. 1998). Sea como sea, no se trata de un fenómeno exclusivo del territorio ampurdanés, ya que grandes campos de silos asociados a un modesto sector urbanizado compuesto por uno o unos pocos edificios complejos empiezan a documentarse lejos de la zona indiketa, con casos como el Turó de la Font de la Canya, en el Penedés, o Sant Esteve d'Olius, en la Catalunya central (Asensio, Francès, Pons 2002). Así, la filiación indígena de este modelo de asentamiento parece fuera de duda. Con todo, no deja de sorprender las muchas peculiaridades que presenta la fase moderna del Mas Castellar de Pontós, tanto a nivel estructural como, sobre todo, a nivel de cultura material, con diversos elementos absolutamente excepcionales, sin parangón en la gran mayoría de centros indígenas, incluyendo aquellos de mayor entidad, como el mismo de Ullastret.

Una observación análoga podría hacerse respecto de los asentamientos rurales más cercanos a Emporion. Su estructura y composición evidencia su carácter plenamente indígena, siendo perfectamente equiparable a decenas de pequeños asentamientos agrícolas del mundo ibérico. A pesar de ello, otra vez algunos de los materiales que proporcionan les confiere un cierto rasgo distintivo, bien evidente incluso en comparación con asentamientos del mismo tipo próximos, como, por ejemplo, los recientemente estudiados en las inmediaciones del oppidum de Ullastret (Gou-Batlle) (Martín et al. 2008).

En base a las consideraciones del apartado anterior, proponemos la hipótesis de una articulación territorial y socio-política del hinterland emporitano en los siguientes términos :

1 - El territorio que se extiende a partir de una corona de 20 a $25 \mathrm{~km}$ alrededor del área de colonización focea ampurdanesa es el que se encuentra plenamente inmerso en un dominio y estructura indígena, muy probablemente bajo un sistema organizativo complejo de tipo estatal, tal como se ha desarrollado en toda la zona de la costa catalana (Sanmartí 2001 ; Sanmartí 2004). Se trata de una vertebración característica donde se imbrican un lugar central o capital (Ullastret), diversos núcleos de segundo orden (Sant Julià de Ramis, Porqueres, Creueta) y múltiples asentamientos menores, todo ello con un alto nivel de interdependencia (fig. 2, F).

2 - El área intermedia, la que va desde yacimientos como el Mas Castellar de Pontós o Peralada hasta los 


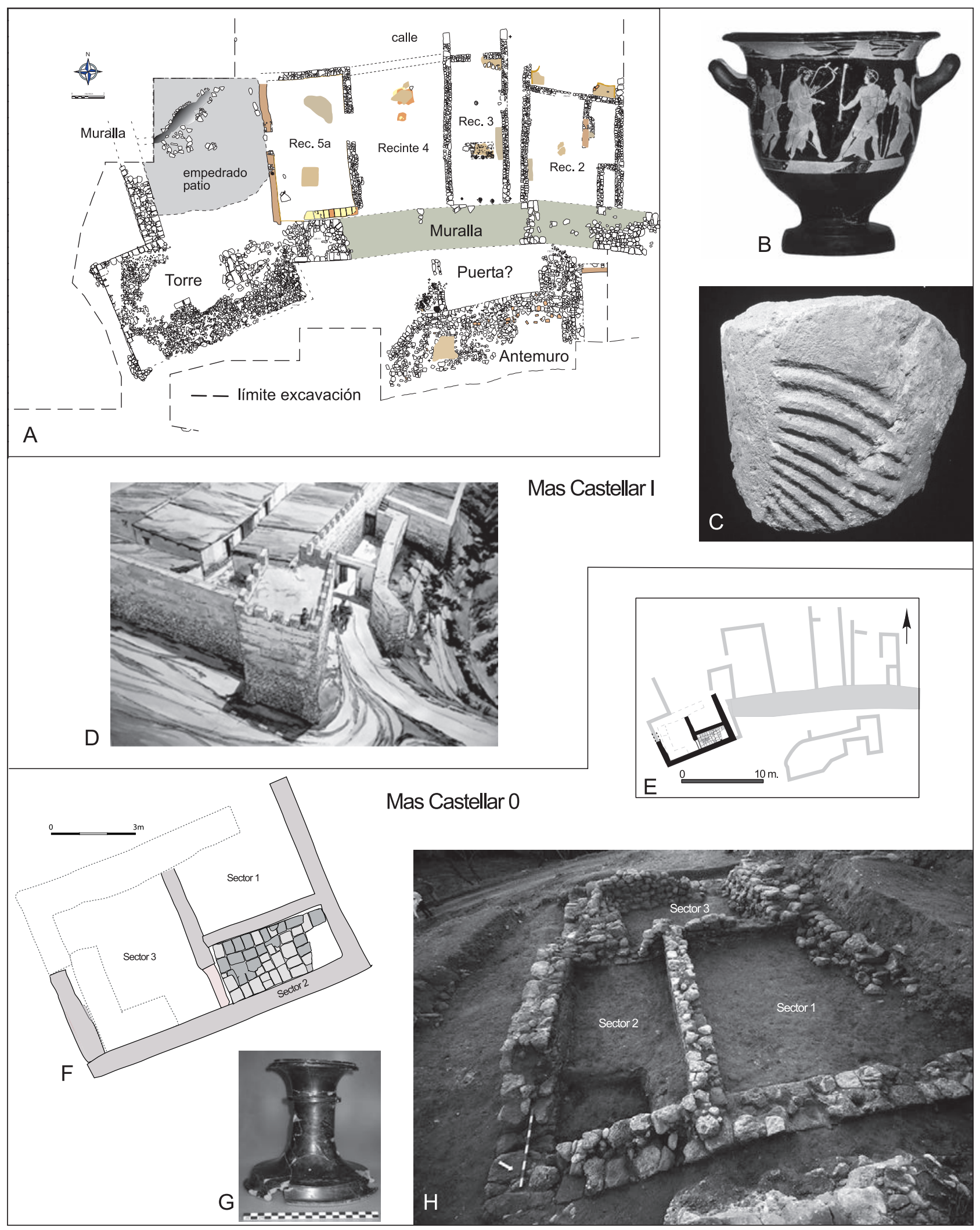

Fig. 1. A) Planta general del núcleo fortificado de la fase Mas Castellar I (425-375 a.C.); B) Cratera ática de la fase Mas Castellar I; C) Fragmento escultórico de la fase Mas Castellar I; D) Restitución hipotética del sistema defensivo de núcleo fortificado en la fase Mas Castellar I; E i F) Planta general y de detalle del edificio de la fase Mas Castellar 0 (antes del 425 a.C.);

G) Soporte de lebes ático del nivel de destrucción de la fase Mas Castellar 0; H) Vista general del edificio de la fase Mas Castellar 0. 


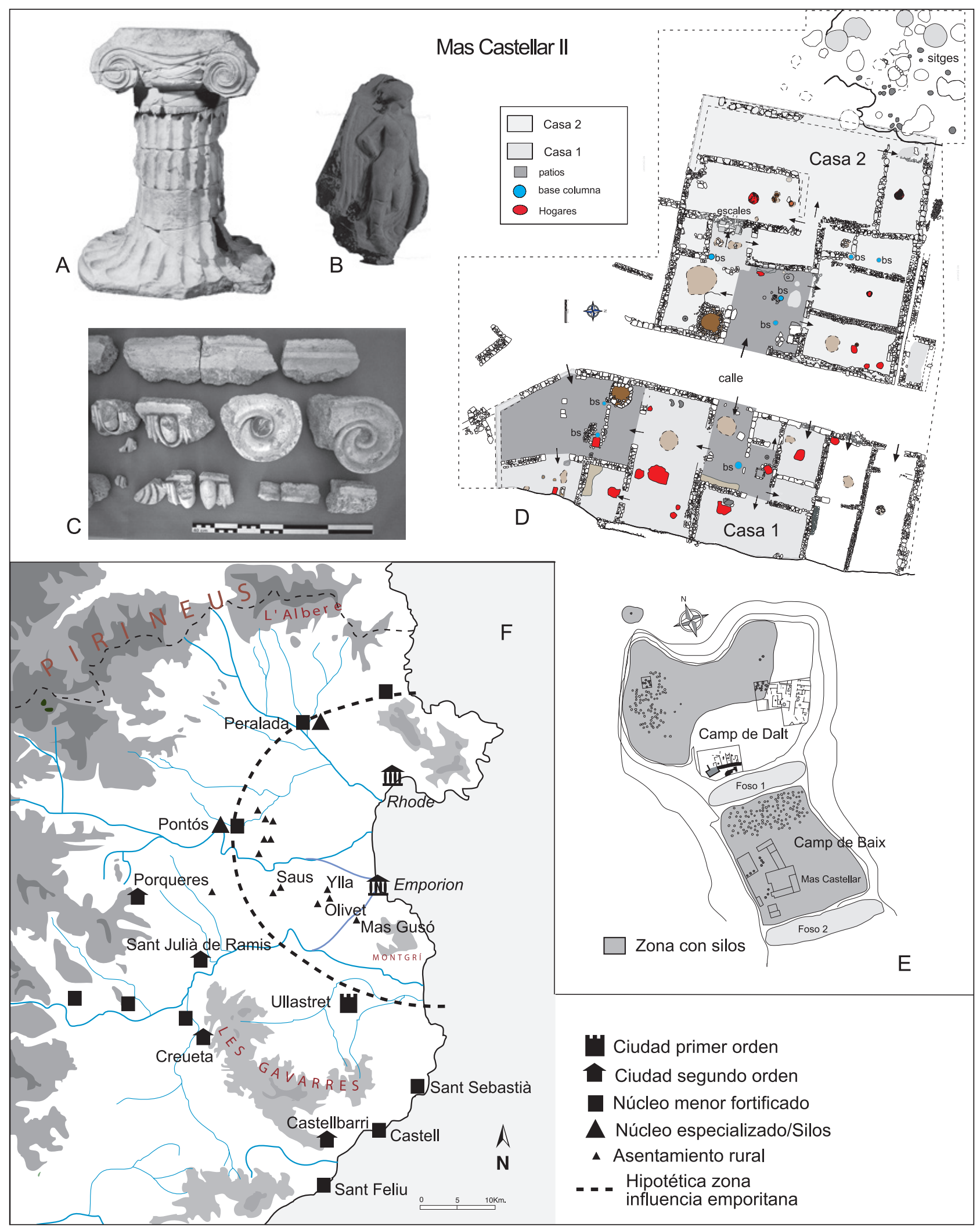

Fig. 2. A) Ara de mármol localizada en la Casa 1 de la fase Mas Castellar II (hacia 200 a.C.); B) Terracota de barniz negro de la fase Mas Castellar II; C) Fragmentos de estucos de decoración arquetectónica de la fase Mas Castellar II; D) Planta general del asentamiento abierto de la fase Mas Castellar II; E) Planta general del yacimiento del Mas Castellar, con indicación de las zonas destinadas a campo de silos; F) Mapa de las comarcas del Empordà, con indicación de los principales yacimientos mencionados en el texto. 
núcleos agrícolas de Viladamat o Bellcaire, a escasos $5 \mathrm{~km}$ del centro colonial, parece ocupada por población eminentemente indígena. Nuestra propuesta seria plantear que los habitantes de estos núcleos tengan unos lazos de dependencia social y económica que no provengan de los grandes oppida indiketas de la zona anterior sinó que radiquen en los propios centros de Emporion y Rhode (recordemos la contrastada relevancia de la presencia ibérica dentro del primero de los enclaves foceos). En el siglo $\mathrm{V}$ a.C. se da por generalizada la estructura clientelar en el seno de la sociedad ibérica y también se han expuesto argumentos que permiten vislumbrar que tanto el sistema de dependencias como su plasmación territorial no son inmutables, incluso pueden presentar una cierta inestabilidad (Ruiz Rodríguez 1998, p. 298). En este contexto creemos plausible pensar que el desarrollo de las relaciones coloniales en esta zona pudo originar cambios en las relaciones de poder en el seno de las elites locales, parte de las cuales pudieron integrarse y radicarse en los mismos núcleos foceos. Esto podría derivar en episodios de violencia entre segmentos de la sociedad ibérica, lo que podrían reflejar las destrucciones de las primeras fases constructivas del Mas Castellar de Pontós. Este cambio de orientación también podría explicar de manera satisfactoria las particularidades estructurales, materiales y/o evolutivas, de la mayoría de los yacimientos de este sector intermedio (Pons et al. 2010). Cabe señalar que la existencia de sectores de la población local reaccionando de manera diferente, incluso enfrontada, en situaciones de encuentro colonial ya ha sido descrita, por ejemplo, en el caso del hinterland de Massalia. En este sentido se ha interpretado la evidencia del oppidum de Mayans, también del siglo V a.C., con ciertos paralelismos evidentes en relación a lo que acontece en el Mas Castellar de Pontós (Bernard, Collin-Bouffier, Tréziny 2010 ; 138-139). Finalmente, atendiendo a la reciente reivindicación del interés de una perspectiva comparativa amplia (Stein 2005), hay que señalar que se trata de circunstancias bien conocidas en situaciones coloniales de épocas más recientes.

3 - No entramos a debatir si este hipotético territorio indígena de "nueva obediencia" radicada en los centros coloniales (fig. 2, F) puede tener o no la consideración de una auténtica chora emporitana. Ciertamente, esta chora estricta o "estándar" pudo estar circunscrita a aquel territorio necesario para el abastecimiento de las necesidades básicas, para lo cual, como demostró E. Sanmartí, bastaría una modesta área de unos $3 \mathrm{~km}^{2}$ adyacentes, los actualmente ocupados mayoritariamente por la zona urbanizada de la localidad de L'Escala (Sanmartí Grego 1993).

\section{Bibliographie}

Aquilué et al. 1999: AQUILUÉ (X.), SANTOS (M.), BUXÓ (R.), TREMOLEDA (J.) dir. - Intervencions arqueològiques a Sant Martí d'Empúries (1994-1996): de l'assentament precolonial a l'Empúries actual, Girona, 1999, 684 p. (Monografies Emporitanes, 9).

Asensio et al. 1998 : ASENSIO (D.), BELARTE (M.C.), SANMARTÍ (J.), SANTACANA (J.) - Paisatges ibèrics : tipus d'assentaments i formes d'ocupació del territori a la costa central de Catalunya durant el període ibèric ple. In : Actas del Congreso Internacional Los Iberos : Príncipes de Occidente, Barcelona, 1998, p. 373-385.

Asensio, Francès, Pons 2002 : ASENSIO (D.), FRANCÉS (J.), PONS (E.) Les implicacions econòmiques i socials de la concentració de reserves de cereals a la Catalunya costanera en època ibèrica. Cypsela, 14, Girona, 2002, p. $125-140$

Asensio, Pons, Fuertes 2007 : ASENSIO (D.), PONS (E.), FUERTES (M.) - La darrera fase d'ocupació del Mas Castellar de Pontós (Alt Empordà, Girona). In : Palahí (LL.), Nolla (J.M.), Vivó (D.) ed., De Kerunta a Gerunda. Els orígens de la ciutat, Col-lecció Història de Girona, 41, Ajuntament de Girona, 2007, p. 97-129.

Asensio, Pons 2009 : ASENSIO (D.), PONS (E.) - L'entrada meridional del nucli ibèric fortificat del Mas Castellar (Pontós, Alt Empordà) : una porta complexa del segle V a.C. Revista d'Arqueologia de Ponent, 19, 2009, p. 271-286.

Asensio 2011 : ASENSIO (D.) - La presència de ceràmiques púniques ebusitanes al nordest peninsular (segles V-III a.C.) : impacte econòmic i social de les relacions comercials entre l'Eivissa púnica i els ibers del nord. In: XXV Jornadas de Arqueología Fenicio-Púnica, Yoserim, la producción alfarera fenicio-púnica en Occidente, Treballs del Museu Arqueològic d'Eivissa i Formentera, 66, 2011, p. 223-254.

Bernard, Collin-Bouffier, Tréziny 2010: BERNARD (L.), COLLINBOUFFIER (S.), TRÉZINY (H.) - Grecs et Indigènes dans le territoire de Marseille. In : Tréziny (H.) éd., Grecs et Indigènes de la Catalogne à la Mer Noire, Aix-en-Provence, 2010, p. 131-145 (Bibliothèque d'Archéologie Méditerranéenne et Africaine, 3).

Burch, Sagrera 2009 : BURCH (J.), SAGRERA (J.) - Els sitjars. Excavacions arqueològiques a la muntanya de Sant Julià de Ramis, 3, Girona, 2009, 280 p. Burch, Nolla, Sagrera 2010 : BURCH (J.), NOLLA (J.M.), SAGRERA (J.) - L'oppidum ibérique de Sant Julià de Ramis. In : Tréziny (H.) éd., Grecs et Indigènes de la Catalogne à la Mer Noire, Aix-en-Provence, 2010, p. 119-128 (Bibliothèque d'Archéologie Méditerranéenne et Africaine, 3).

Benoit 1985 : BENOIT (J.) - L'étude des cadastres antiques: à propos d'Olbia de Provence. Documents d'Archéologie Méridionale, 8, 1985, p. $25-48$.

Casas 1989 : CASAS (J.) - L'Olivet d'en Pujol i els Tolegassos. Dos establiments agrícoles d'època romana a Viladamat. Sèrie Monogràfica del Centre d'Investigacions Arqueològiques de Girona, 10, Girona, 1989.

Casas, Soler 2004 : CASAS (J.), SOLER (V.) - Intervenciones arqueológicas en Mas Gusó (Gerona). Del asentamiento precolonial a la villa romana. Oxford, BAR International Series, 1215, 2004.

Casas 2010 : CASAS (J.) - Prensas para la elaboración de aceite en el establecimiento rural ibérico de Saus (Gerona). Notas sobre la explotación del campo en el territorio de Emporion. Archivo Español de Arqueología, 83, 2010, p. 67-84.

Casas, Nolla, Soler 2010 : CASAS (J.), NOLLA (J.M.), SOLER (V.) - Les sitges ibèriques del Camp de 1'Ylla (Viladamat, Alt Empordà). Cypsela, 18, 2010, p. 223-242.

Casas, Soler 2011 : CASAS (J.), SOLER (V.) - Mas Gusó (Bellcaire d'Empordà). Una primera valoració dels resultats de la campanya d'excavacions de 2010. Annals de l'Institut d'Estudis Gironins, LII, Girona, 2011, p. 27-50.

Gracia 1995 : GRACIA (F.) - Comercio del vino y estructuras de intercambio en el NE. de la Península Ibérica y Languedoc-Rosellón entre los siglos VII-V a.C. In : Celestino (S.) éd., Arqueología del vino. Los orígenes del vino en Occidente, Jerez de la Frontera, 1995, p. 297-331. 
Kirigin 2006 : KIRIGIN (B.) - Pharos, the parian settlement in Dalmatia: a study of a greek colony in the Adriatic. Oxford, BAR International Series, $1561,2006$.

Llinàs et al. 1998 : LLINAS (J.), MERINO (J.), MIRÓ (M.), MONTALBAN (M.C.), PALAHÍ (LL.), SAGRERA (J.) - La Peralada ibèrica i medieval segons l'arqueologia. Les excavacions de 1989 a 1995. Monograpies Emporitanes, 4, Figueres, 1998.

Martín 2000 : MARTíN (A.) - L'oppidum del Puig de Sant Andreu d'Ullastret. Aportació de les intervencions arqueològiques recents al coneixement dels sistemes defensius i de l'urbanisme. In: Buxó (R.), Pons (E.), eds. L'hàbitat protohistòric a Catalunya, Rosselló i Llenguadoc occidental, Actes del XIII Col.loqui internacional per a l'Estudi de l'Edat del Ferro, Girona, 2000, p. 107-122 (Sèrie Monogràfica del Museu d'Arqueologia de CatalunyaGirona, 19).

Martín, Plana 2001 : MARTÍN (A.), PLANA (R.) - El nord-est català en època ibèrica i l'entitat territorial de l'oppidum d'Ullastret. In: Martín (A.), Plana (R.) eds: Territori polític i territori rural durant l'edat del ferro a la Mediterrània occidental, Girona, 2001, p. 39-52 (Monografies d'Ullastret, 2). Martín et al. 2004: MARTÍN (A.), CASAS (S.), CODINA (F.), MARGALL (J.), DE PRADO (G.) - La zona 14 de l'oppidum del Puig de Sant Andreu d'Ullastret. Un conjunt arquitectònic dels segles IV i III a.C. Cypsela, 15, 2004, p. 265-284.

Martín 2005 : MARTÍN (A.) - Territori i hàbitat al nord-est català en època ibèrica. In : Món ibèric als pä̈sos catalans. I : Homenatge a Josep Barberà, XIII Col.loqui Internacional d'Arqueologia de Puigcerdà, 2005, p. 361-377. Martín et al. 2008 : MARTÍN (A.), PLANA (R.), CODINA (F.), GAY (C.) El jaciment Camp d'en Gou/Gorg d'en Batlle, un barri periurbà de l'oppidum d'Ullastret (Baix Empordà). Cypsela, 17, 2008, p. 161-183.

Plana 1994 : PLANA (R.) - La Chora d'Emporion. Paysage et structures agraires dans le nord-est catalan à la période pré-romaine. Paris, 1994, 228 p. (Annales Littéraires de l'Université de Besançon, 544).

Plana 2001 : PLANA (R.) - D'emporion a Emporion: la colonie et son territoire. In : Problemi della Chora coloniale dell'occidente al Mar Nero, Atti del XL Convegno di Studi sulla Magna Grecia, Taranto, 2000. Napoli, 2001, p. 545-566.

Plana, Martín 2005 : PLANA (R.), MARTÍN (A.) - L'estudi del territori de l'oppidum d'Ullastret (1997-2003). Ocupació extra-muros i paisatge rural. In: Món ibèric als països catalans. I : Homenatge a Josep Barberà, XIII Col. loqui Internacional d'Arqueologia de Puigcerdà, 2005, p. 347-359.

Pons, Ruiz de Arbulo, Vivó 1998 : PONS (E.), RUIZ DE ARBULO (J.), VIVÓ (D.) - El yacimiento ibérico de Mas Castellar de Pontós (Girona). Análisis de algunas piezas significativas. In : Actas del Congreso Internacional Los Iberos : Príncipes de Occidente, Barcelona, 1998, p. 55-64.

Pons et al. 2000 : PONS (E.), FERNANDEZ (M.J.), GONZALEZ (H.), GAGO (N.), BOUSO (M.) - El establecimiento agrario de Mas Castellar de Pontós (s.III-II aC). In : Buxó (R.), Pons (E.), ed. L'hàbitat protohistòric a
Catalunya, Rosselló i Llenguadoc occidental, Actes del XIII Col.loqui internacional per a l'Estudi de l'Edat del Ferro, Girona, 2000, p. 147-156 (Sèrie Monogràfica del Museu d'Arqueologia de Catalunya-Girona, 19).

Pons et al. 2001 : PONS (E.), FUERTES (M.), GAGO (N.), BOUSO (M.) Les sitges de l'assentament de Mas Castellar i les del territori. In: Martín(A.), Plana (R.) eds : Territori polític i territori rural durant l'edat del ferro a la Mediterrània occidental, Girona, 2001, p. 145- 156 (Monografies d'Ullastret, 2).

Pons et al. 2002 : PONS (E.) (dir.) - Mas Castellar de Pontós (Alt Empordà). Un complex arqueològic d'època ibèrica (Excavacions 1990-1998). MAC Girona, 2002, 635 p. (Sèrie Monogràfica, 21).

Pons, Gonzalo, López 2005 : PONS (E.), GONZALO (C.), LOPEZ (A.) - El sistema defensiu del poblat ibèric de Mas Castellar de Pontós (Alt Empordà, Girona). In : Món ibèric als països catalans. I : Homenatge a Josep Barberà, XIII Col.loqui Internacional d'Arqueologia de Puigcerdà, 2005, p. 379-392.

Pons et al. 2010 : PONS (E.), ASENSIO (D.), FUERTES (M.), BOUSO (M.) - El yacimiento del Mas Castellar de Pontós (Alt Empordà, Girona) : un núcleo indígena en la órbita de la colonia focea de Emporion. In : Tréziny (H.) éd., Grecs et Indigènes de la Catalogne à la Mer Noire, Aix-en-Provence, 2010, p. 105-118 (Bibliothèque d'Archéologie Méditerranéenne et Africaine, 3).

Pons et al. 2012 : PONS (E.), ASENSIO (D.), MORER (J.), JORNET (R.) - El complex arqueològic del jaciment ibèric de Mas Castellar de Pontós (Alt Empordà). La campanya 2010-2011), XI Jornades d'Arqueologia de les Comarques de Girona, Girona, 2012, 15 i 16 de juny.

Ruiz Rodríguez 1998 : RUIZ RODRÍGUEZ (A.) - Los príncipes iberos: procesos económicos y sociales. In : Los Iberos : Príncipes de Occidente. Actas del Congreso Internacional, Barcelona, 1998, p. 285-300.

Sanmartí 2001 : SANMARTÍ (J.) - Territoris i escales d'integració política a la costa de Catalunya durant el període ibèric ple (segles IV-III a.C.). In : Martín (A.), Plana (R.) eds : Territori polític i territori rural durant l'edat del ferro a la Mediterrània occidental, Girona, 2001, 326 p. (Monografies d'Ullastret, 2), p. 23-38.

Sanmartí 2004 : SANMARTÍ (J.) - From local communities to early states. Pyrenae, 35-1, Universitat de Barcelona, 2004, p. 7-41.

Sanmartí, Santacana 2005 : SANMARTÍ (J.), SANTACANA (J.) - Els Ibers del Nord. Rafael Dalmau Eds., Barcelona, 2005, 232 p.

Sanmartí Grego, Santiago 1988: SANMARTÍ GREGO (E.), SANTIAGO (R.A.) - La lettre grecque d'Emporion et son contexte archéologique. Revue Archéologique de Narbonnaise, 21, 1988, p. 3-17.

Sanmartí Grego 1993 : SANMARTÍ GREGO (E.) - Els ibers a Emporion (Segles VI-III a.C.). Laietània, 8 (Actes del Seminari El Poblament Ibèric a Catalunya, Mataró), 1993, p. 85-102.

Stein 2005 : STEIN (G.J.) - Introduction: the comparative archaeology of colonial encounters. In: (Stein, (G.J.) ed., The archqeology of colonial encounters, comparative perspectives. Santa Fe, School of American Research, 2005, p. 3-32. 



\section{L'identité face au commerce : exemples languedociens}

\section{Daniela Ugolini}

CR CNRS, Aix Marseille Université, CNRS, Ministère de la Culture et de la Communication, CCJ UMR 7299, 13094, Aix en Provence, France

\section{Résumé}

Les contacts, puis les échanges réguliers, entre les peuples du littoral et le monde méditerranéen ont eu des conséquences à différents niveaux. Du point de vue du mobilier céramique, l'arrivée des vases tournés a représenté un tournant dans la vie quotidienne. La baisse des vases non tournés et l'appauvrissement des formes marquent le recul d'une tradition, mais la vaisselle importée a introduit de nouvelles habitudes et suscité une certaine émulation. L'analyse comparée de quelques cas de la région Languedoc-Roussillon (France) fait ressortir des choix qui ont abouti à la formation, sur la côte, de quatre groupes humains distincts par leur mobilier.

Mots-clés : âge du Fer, amphores, Midi de la France, Grecs, grise monochrome, peuples indigènes, Phéniciens, vaisselle

\section{Abstract}

Contacts and, then, regular exchanges between the coastal peoples and the Mediterranean world had an impact at different levels. From the viewpoint of the pottery, turned vases arrival was a turning point in everyday life. The decrease of local not turned vases and the impoverishment of shapes marks the decline of a tradition, but imported ware introduces new practices and creates some emulation. A comparative analysis of a few cases of the LanguedocRoussillon (France) shows choices, which led to the formation, on the coast, of four human groups, different through their dishes.

Keywords: Iron Age, amphora, South of France, Greeks, gray ware, Native-born people, Phoenicians; crockery 


\section{Introduction}

La définition des ethnies indigènes est difficile sans l'appui des textes anciens, mais on sait que les communautés du Midi ne sont pas un conglomérat uniforme et que l'ouverture sur la Méditerranée a eu un impact décisif sur leur évolution (Bats 2007).

Une phrase de Michel Bats (Bats 2010,p. 12) résume parfaitement cette problématique : "Ces frontières sont poreuses et instables, parce que l'identité qu'elles définissent est une construction continue où la "tradition" est sans cesse renouvelée par absorption, antagonisme, innovation et manipulation".

Les contacts avec le monde méditerranéen ayant été particulièrement précoces dans la région LanguedocRoussillon (fig. 1), les mobiliers peuvent apporter une contribution à ces questions puisque y sont progressivement intégrés de nouveaux éléments importés et que la fabrication des vases tournés procure une grande quantité de vaisselle à vendre. A travers quelques exemples, on tentera de montrer la transformation radicale de la vaisselle quotidienne survenue en un court laps de temps et, concernant ces productions, les réponses face aux influences extérieures selon les espaces géographiques.

\section{Vers 650-625 av. J.-C. : les premiers contacts}

Après un Bronze final dont le mobilier laisse supposer l'existence d'un peuplement à peu près homogène dans le Midi, au début du premier âge du Fer apparaissent des faciès régionaux.

En Languedoc occidental, les critères autorisant ces distinctions sont déduits essentiellement des nécropoles et, pour le début, de celle du Grand Bassin I de Mailhac (Louis, Taffanel 1958). Puis, la nécropole du Peyrou a permis de mettre en évidence que c'est par Agde, offrant de remarquables possibilités portuaires naturelles, qu'arrivent les premières importations grecques du Midi (Nickels 1989). Dans l'aire orientale, plusieurs sites dont la Grotte Suspendue de Collias ont conduit à la définition du faciès "Suspendien" (Coste et al. 1976).

Les nécropoles occidentales sont nombreuses et les différences micro-régionales minimes (les vases de la nécropole de Négabous à Perpignan ${ }^{1}$ sont comparables à ceux du Peyrou à Agde, à plus de $100 \mathrm{~km}$ de distance). On peut donc retenir qu'au VII s. av. J.-C. ces populations ont une culture matérielle à peu près homogène.

1 Sur le site web de l'Inrap : http://www.inrap.fr/userdata/c_bloc_ file/9/9424/9424_fichier_CG66-Expo-Vases-flyer-15x21-BD.pdf.
Les premières importations grecques (650-625/600 av. J.-C.), antérieures à la fondation de Marseille, proviennent de quelques tombes de l'aire occidentale, entre les basses rives gauches de l'Hérault et de l'Aude. Certains de ces vases sont protocorinthiens (une coupe au Peyrou à Agde et une à La Courondelle à Béziers), d'autres sont ioniens (une oenochoé au Peyrou à Agde et un bol aux oiseaux à La Cartoule à Servian), pour d'autres encore on a proposé soit une origine grecque d'Italie méridionale (Nickels 1989), soit étrusque (Gras 2000) (trois coupes ou skyphoi du Peyrou (Agde) et du Grand Bassin I à Mailhac, auxquel(le)s il faut ajouter maintenant la pièce du Bousquet à Agde). Des vases non tournés copiant des modèles phéniciens (et aussi un vase tourné phénicien) sont attestés dans ces mêmes nécropoles. Dans tous les cas, cela ne dit pas "qui" les a amenés.

On a ainsi à cette période des vases grecs et des vases non tournés locaux d'influence phénicienne dont l'imitation va jusqu'à l'application d'une couverte rouge rappelant soit le «barniz rojo », soit simplement la couleur de la céramique tournée. Presque chacun de ces vases est un unicum, mais tous trahissent bien leur inspiration. Ces copies ne sont pas fidèles : entre autres, elles sont souvent plus petites que les originaux, et leur présence dans les mobiliers funéraires pourrait avoir un caractère allusif, symbolique en quelque sorte.

Il vaut la peine de rappeler que, par exemple pour les \pm 200 tombes de la nécropole du Peyrou à Agde (qui est l'une des plus grandes), quatre pièces sont grecques et quatorze «pseudo-phéniciennes ». Autrement dit, ces dernières sont au moins trois fois plus nombreuses.

Dans deux tombes du Peyrou (Agde) comportant une coupe grecque, il y avait aussi un de ces vases (Nickels 1989, T. 83 et T. 115). La troisième coupe provient d'une sépulture partiellement détruite, au loculus incertain et dont le mobilier - mal conservé - est peut-être incomplet (Ibidem, T. 22). Quant à l'oenochoé grecque, elle n'était pas associée à un vase pseudo-phénicien (Ibidem, T. 185).

La tombe 6 de la petite nécropole du Bousquet à Agde (Mazière 2003) est particulière car parmi le mobilier funéraire se trouvaient une coupe grecque (ou skyphos), un vase non tourné pseudo-phénicien et un autre, unique pour l'heure, qui me semble plutôt pseudo-grec (fig. 2) par son rapprochement convaincant avec les amphores archaïques de Méditerranée orientale (comparer, par exemple, avec celles de Lesbos : Clinkenbeard 1982, pl. 69). Cette association originale montre que des amphores grecques du $\mathrm{VII}^{\mathrm{e}} \mathrm{s}$. av. J.-C. ont fait partie des mêmes cargaisons et que les indigènes les ont également copiées.

On retrouve le binôme vase grec/vase pseudo-phénicien à La Cartoule à Servian (Espérou et al. 1980). 
La coupe grecque du Grand Bassin I à Mailhac a été trouvée hors contexte, mais les vases pseudo-phéniciens sont largement représentés dans cette nécropole (Louis, Taffanel 1958).

Dans l'une des deux tombes fouillées de la nécropole de La Courondelle à Béziers, il y avait une coupe protocorithienne, mais pas de vase pseudo-phénicien (Buffat et al. 2008).

Vase grec et vase pseudo-phénicien ne sont donc pas nécessairement associés, mais, sur huit vases grecs, cela se produit 4 fois sur 6 , deux cas restant incertains.

Les pièces pseudo-phéniciennes se rencontrent surtout de l'Hérault à l'Aude, mais une urne phénicienne tournée à anses bifides (restée inédite ?) a été trouvée dans une tombe - probablement de la première moitié du VII ${ }^{\mathrm{e}}$ s. av. J.-C. - de L'Agrédo à Roquefort-Corbières (Aude : Nickels 1989, p. 430) et une "puisette" à une anse non tournée engobée de rouge est issue d'une tombe de la nécropole de Bellevue à Canet, près des Pyrénées (Claustres 1956). Ces deux objets font ainsi le lien avec le Nord-Est ibérique et ses fréquentations phéniciennes bien attestées. Enfin, des originaux phéniciens sont attestés dans l'Aude (Mailhac/Le Traversant : Taffanel, Rancoule 1992; grotte de Buffens/Caunes-Minervois : Guilaine, Rancoule 1996).

L'hypothèse d'une action phénicienne (Py 1984), longtemps rejetée, est encore confortée - outre que par des objets métalliques importés et peut-être copiés au moins par l'élaboration locale du plat à large marli (Guilaine, Rancoule 1996, 133) (fig. 3). Il offre de nombreuses variantes, comme les originaux phéniciens, avec parfois un pied mi-haut ou haut qui est une originalité languedocienne, et n'a pas d'antécédent direct dans le répertoire du Bronze final, où existent pourtant d'autres plats. On peut ajouter que les plats à large marli sont utilisés comme couvercles dans les tombes phéniciennes, comme les plats non tournés de nos nécropoles. La forme semble absente du Gard, est rare dans l'Hérault oriental (p. ex., tumulus G3 de Cazevieille : Dedet 1979) et est très courante de l'Hérault occidental aux Pyrénées.

Ce plat est donc typiquement occidental : il semble bien dériver de prototypes phéniciens et contribue à donner corps à ces contacts. Contrairement aux pièces pseudo-phéniciennes dont il était question ci-dessus, il ne porte jamais d'engobe rouge, sans doute parce que le plat existait dans le répertoire indigène et que la nouvelle forme, correspondant à un usage connu et courant, a été rapidement adoptée. Le cas des vases pseudo-phéniciens et de l'amphore pseudo-grecque est, en effet, différent : les originaux arrivaient pleins d'un étonnant breuvage, ou d'une drôle de mixture salée, ou encore d'autres produits exotiques. Autrement dit, ils contenaient des produits étrangers à la consommation locale. La vaisselle indigène ne les a donc pas intégrés, semble-t-il, et il se peut que les copies n'aient eu qu'une fonction funéraire symbolique.

En définitive, les traces cumulées de l'influence sémitique sont anciennes, profondes et étendues. Surtout, au $\mathrm{VII}^{\mathrm{e}} \mathrm{s}$. elles sont les seules d'origine méditerranéenne que l'on puisse justifier aussi bien par les échanges que par un impact culturel direct. L'idée que les marchands phéniciens aient amené en Languedoc occidental, entre autres, les premiers vases grecs paraît donc recevable. Le mouvement émane d'Ibérie, a eu des effets sur l'évolution des peuples de part et d'autre des Pyrénées et n'est pas à confondre avec le commerce « ibérique » (celui des indigènes d'Ibérie) (Ugolini 1993 ; Ugolini, Olive 2006).

Il reste que pendant longtemps encore les vases méditerranéens de toutes origines restent ponctuels, comme devaient l'être ces premiers contacts, et la céramique non tournée domine.

\section{Entre 550 et 475 av. J.-C. : des contacts réguliers}

La documentation est beaucoup plus étoffée un siècle plus tard, lorsque les Grecs se sont installés dans le Midi et les trafics ont atteint un niveau qui a compté dans l'implantation et l'organisation des sites (Ugolini, Olive 2009).

Entre le troisième quart du $\mathrm{VI}^{\mathrm{e}} \mathrm{s}$. et le début du $\mathrm{V}^{\mathrm{e}} \mathrm{s}$. av. J.-C., les amphores témoignent de cet essor commercial (fig. 4A). Les taux les plus bas sont ceux de Ruscino, ceux de Pech Maho sont les plus élevés de l'Aude et ceux de La Monédière les plus forts de la région car, ici, les amphores arrivent avec une facilité qu'il faut mettre sur le compte de la navigabilité de l'Hérault, du port d'Agde, de la présence de Béziers et du nombre de sites à approvisionner. Autrement dit, la zone d'Agde conserve cette spécificité dans les trafics, qu'elle a eue dès le VII ${ }^{\mathrm{e}} \mathrm{s}$.

Par origines, les amphores n'ont pas la même distribution (fig. 4B). Deux exemples : à Pech Maho, elles se partagent d'abord équitablement par tiers (étrusques, grecques et ibériques), alors qu'à La Monédière grecques et étrusques occupent presque toute la place. Puis, à La Monédière, elles se répartissent par tiers, comme auparavant à Pech Maho, où les ibériques représentent près de la moitié. C'est manifestement l'augmentation des amphores ibériques qui provoque ces changements. Il reste à identifier «qui » les commercialise : négociants indigènes d'Ibérie? marchands grecs d'Emporion? Puniques? (Ugolini, Olive 2004). 


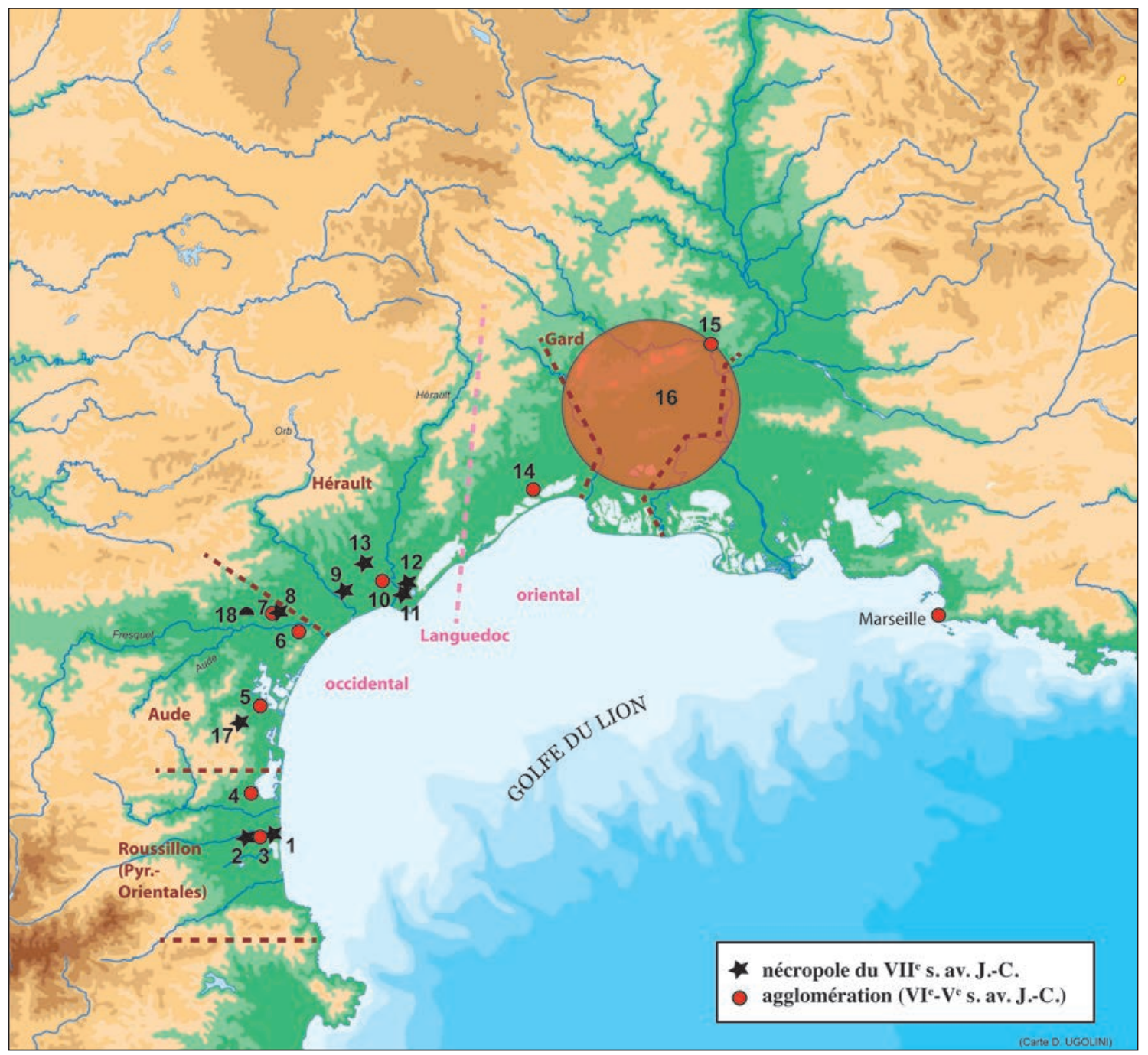

1 : Nécropole de Bellevue (Canet, Pyrénées-Orientales) ; 2 : Nécropole de Négabous (Perpignan, Pyrénées-Orientales) ; 3 : Ruscino (Château-Roussilon, Pyrénées-Orientales) ; 4 : Le Port 2 (Salses-le-Château, Pyrénées-Orientales) ; 5 : Pech Maho (Sigean, Aude) ; 6 : Montlaurès (Narbonne, Aude) ; 7 : Cayla II (Mailhac, Aude) ; 8 : Nécropole du Grand Bassin I (Mailhac, Aude) ; 9 : Nécropole de La Courondelle (Béziers, Hérault) ; 10 : La Monédière (Bessan, Hérault) ; 11 : Nécropole du Peyrou (Agde, Hérault) ; 12 : Nécropole du Bousquet (Agde, Hérault) ; 13 : Nécropole de La Cartoule (Servian, Hérault) ; 14 : Lattes (Hérault) ; 15 : Grotte Suspendue (Collias, Sainte-Anastasie, Gard) ; 16 : Région nîmoise (Gard) ; 17 : Nécropole de L’Agrédo (Roquefort-Corbières, Aude) ; 18 : Grotte de Buffens (Caunes-Minervois, Aude).

Fig. 1. Carte du Languedoc-Roussillon côtier avec les sites mentionnés dans le texte, les limites départementales approximatives (en marron) et la séparation entre Languedoc oriental et occidental (en rose). (Carte D. Ugolini).

La vaisselle tournée entraîne la baisse des céramiques non tournées (fig. 5A), phénomène qui est moins accentué dans le Nîmois. Les non tournées sont de plus en plus simples, peu décorées: urnes et coupes/bols de toutes les tailles pour tous les usages. La pauvreté des formes et leur polyvalence contrastent fortement avec la variété morphologique et fonctionnelle des céramiques tournées.

Le graphique de la fig. 6 regroupe les vases tournés par grands ensembles. Au premier quart du $\mathrm{V}^{\mathrm{e}} \mathrm{s}$., on a partout les mêmes groupes, mais pas dans les mêmes proportions : peu de vases étrusques et grecs (surtout attiques, auxquels s'ajoutent - à Pech Maho - des vases attribués à la Grèce de l'Est justifiant la colonne plus haute). Le mobilier se partage principalement entre grises monochromes, ibériques et apparentées, claires massaliètes et apparentées, vases à feu.

Le groupe massaliète est à son maximum dans l'Hérault occidental ; l'ibérique dans l'Aude, alors qu'il est peu consistant en Roussillon, où la proximité géographique justifierait pourtant des quantités significatives ; les céramiques à feu ont les meilleurs taux sur les marges de l'aire occidentale (La Monédière et Ruscino). 


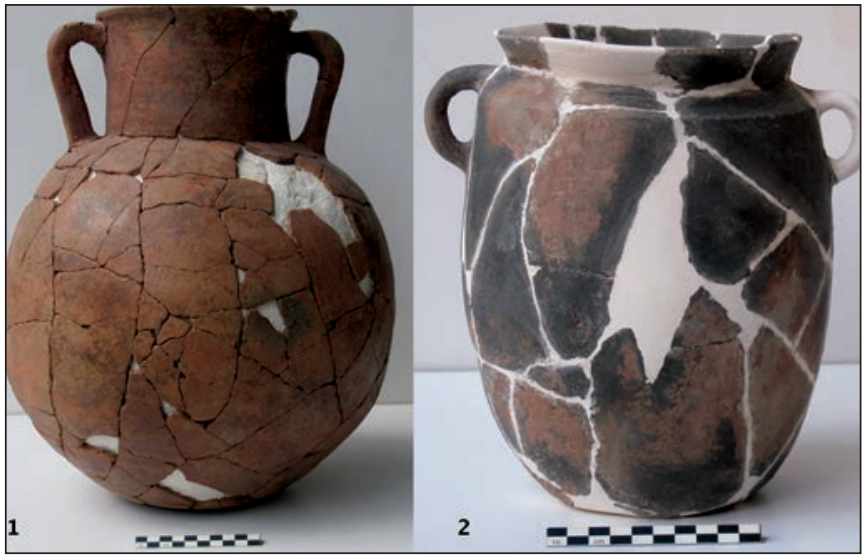

Fig. 2. Agde, Le Bousquet, Tombe 6. Imitations en céramique non tournée d'amphore grecque (1) et de vases phénicien (2). (Clichés J.-P. Cros).
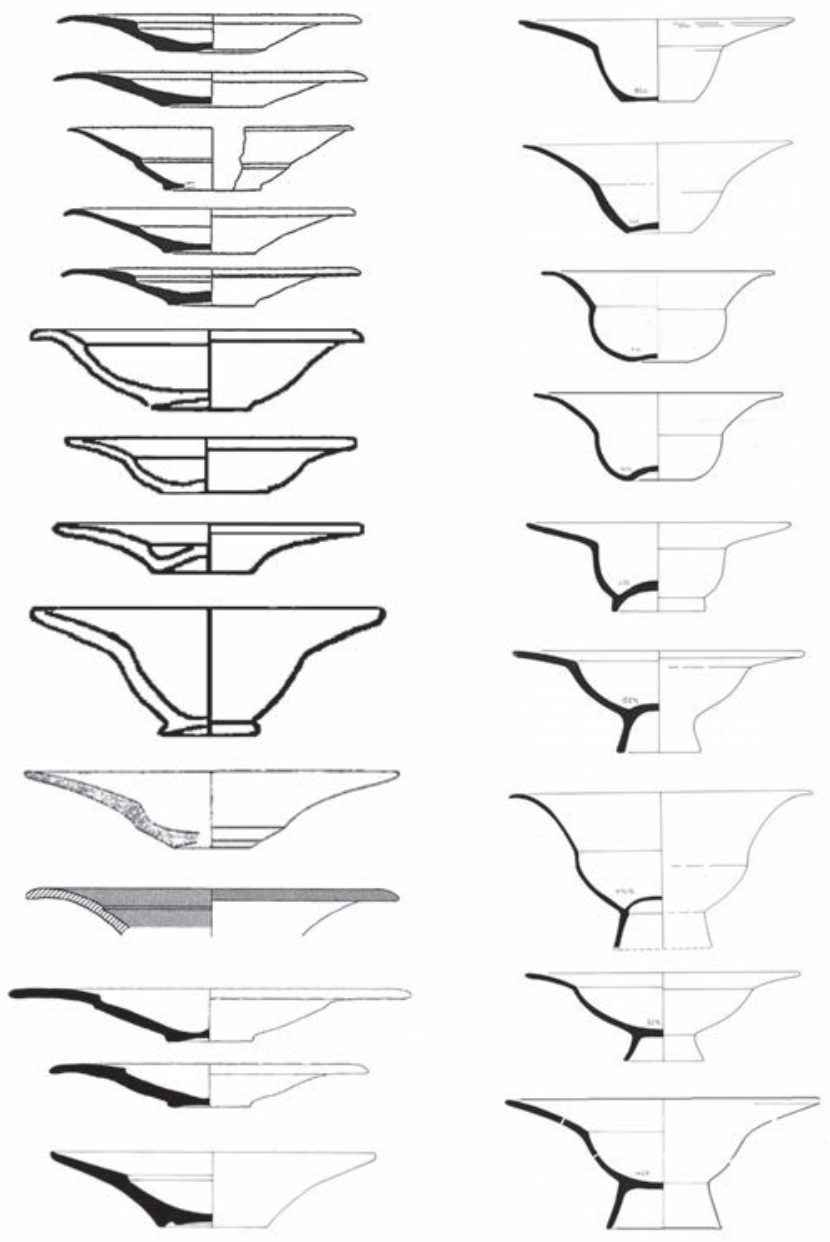

Fig. 3. Plats à marli phéniciens (sites divers), à gauche ; plats à marli non tournés languedociens (sites divers), à droite. Hors échelle.
Le groupe dont la fréquence est plus ou moins importante partout entre les $\mathrm{VI}^{\mathrm{e}}$ et $\mathrm{V}^{\mathrm{e}} \mathrm{s}$. est celui des grises monochromes. C'est donc sur ces productions que l'on propose quelques observations sur l'aire géographique considérée, mais ce qui vaut pour les grises monochromes se produit aussi pour d'autres groupes.

Longtemps appelées "phocéennes", puis libérées de leur carcan ethnique (Arcelin-Pradelle 1984) ${ }^{2}$, de nombreuses officines grecques et indigènes ont été en activité dans le Midi.

Peu abondantes en Languedoc oriental interne, où elles forment néanmoins le groupe dominant (3-5\%), elles le sont nettement plus sur la côte (La Cougourlude, près de Lattes : voir M. Py dans cet ouvrage). Les sites occidentaux fournissent des taux de 15-20\% (Aude, Hérault occidental) à 40-50\% (Roussillon). La fréquence de ces vases est donc plus ou moins affirmée selon les zones géographiques.

Les formes ne sont pas les mêmes partout. Dans la fig. 7 sont regroupées les principales, à titre indicatif et sans prétention à l'exhaustivité. Dans la région nîmoise, comme en Provence, la forme principale est la coupe ou bol caréné(e), à bord convergent ou divergent (ArcelinPradelle, Dedet, Py 1982) et cette grise est couramment décorée de motifs ondés ou de sillons horizontaux. Dans le répertoire occidental, la forme principale est le plat à marli. C'est d'ailleurs sur celui-ci qu'ont été définies les trois principales aires de production (Nickels 1978) et son succès tient peut-être à la préexistence du plat à large marli du VII es. Les plats à marli de l'Hérault occidental et de l'Aude sont comparables à ceux de Grèce de l'Est. La grise de ces zones est parfois décorée d'ondes ou de cannelures. En Roussillon, la grise n'est généralement pas décorée. Les plats à marli ont de nombreux détails morphologiques les écartant des standards grecs (Ugolini 2006), y compris une variante originale à cannelures internes (Nickels 1980).

$\mathrm{Si}$ on ajoute aux formes les plus répandues les autres vases, on constate globalement que les répertoires audois et roussillonnais ont des choses en commun, l'héraultais occidental a des points de convergence avec celui de l'Aude, mais peu avec ceux du Roussillon et du Languedoc oriental. Certaines formes sont grecques, d'autres indigènes et d'autres encore ibériques. Ce qui importe ici est que la grise monochrome laisse apparaître des différences régionales sensibles à tous les niveaux. Elles sont évidemment techniques, mais la sectorisation des formes est sans doute significative.

2 Problème récurrent, les qualificatifs d'ordre ethnique des classes céramiques masquent les lieux de production identifiés ou clairement localisés et sont à proscrire. La question a été plusieurs fois soulevée : voir en particulier Ugolini et al. 1991 ; Olive, Ugolini 1997 ; plus en général : Boissinot 2005. 


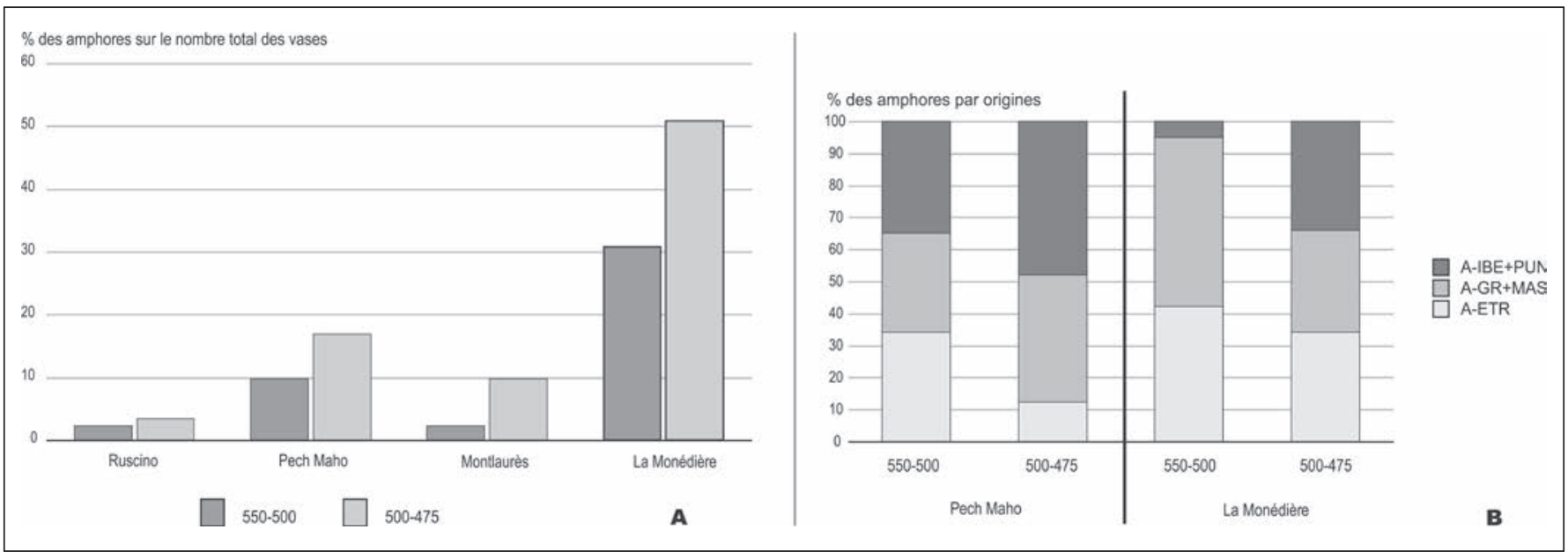

Fig. 4. A : Evolution de la fréquence des amphores par rapport au total des vases de 550-500 à 500-475 av. J.-C. B : Répartition des amphores selon les principales origines de 550-500 à 500-475 av. J.-C.

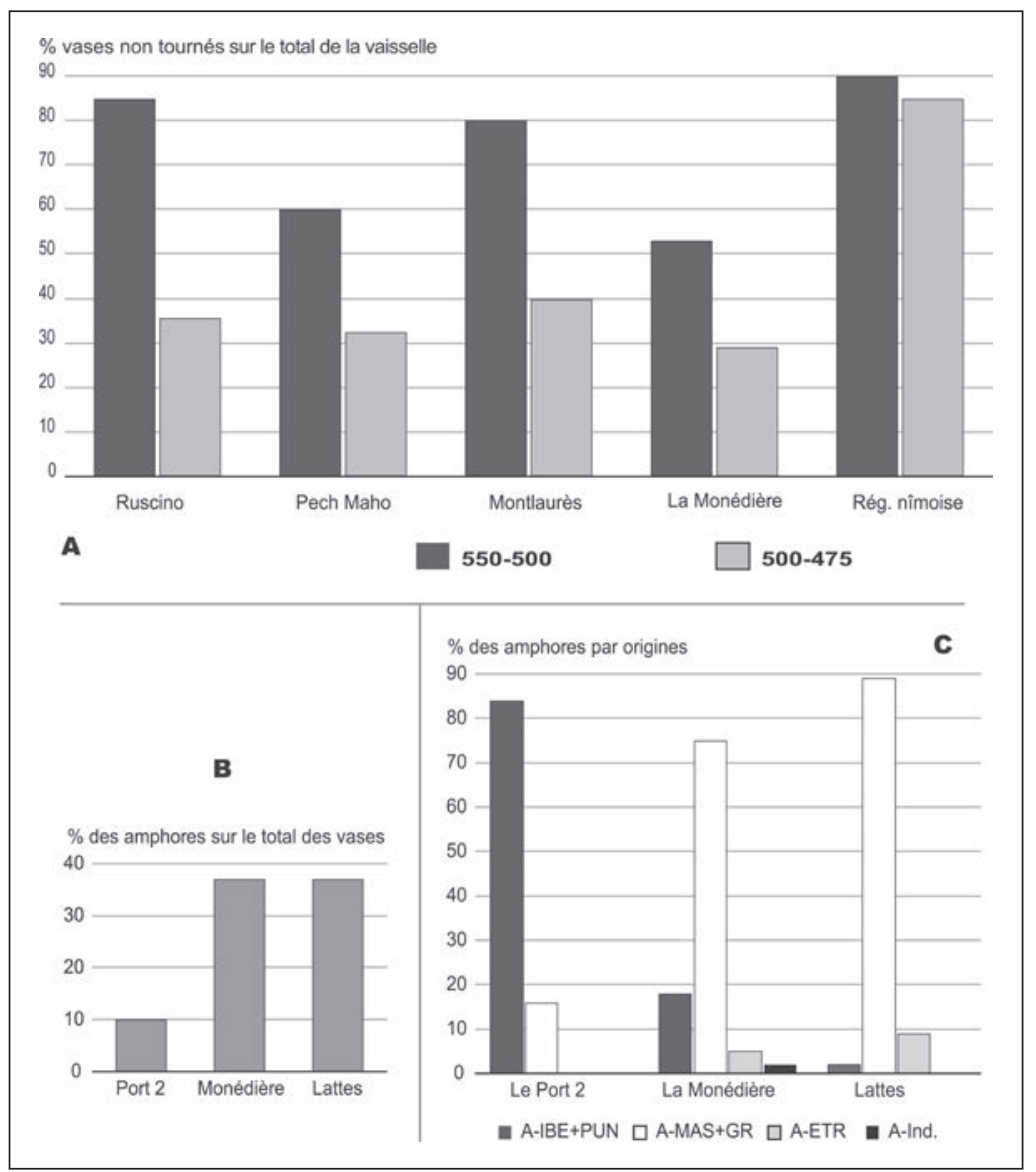

Fig. 5. A : Evolution de la fréquence de la céramique non tournée par rapport au reste de la vaisselle de 550-500 à 500-475 av. J.-C.

B : Les amphores par rapport au total des vases au Ve $\mathrm{S}$. av. J.-C. C : Répartition des amphores par origines au Ve s. av. J.-C. 


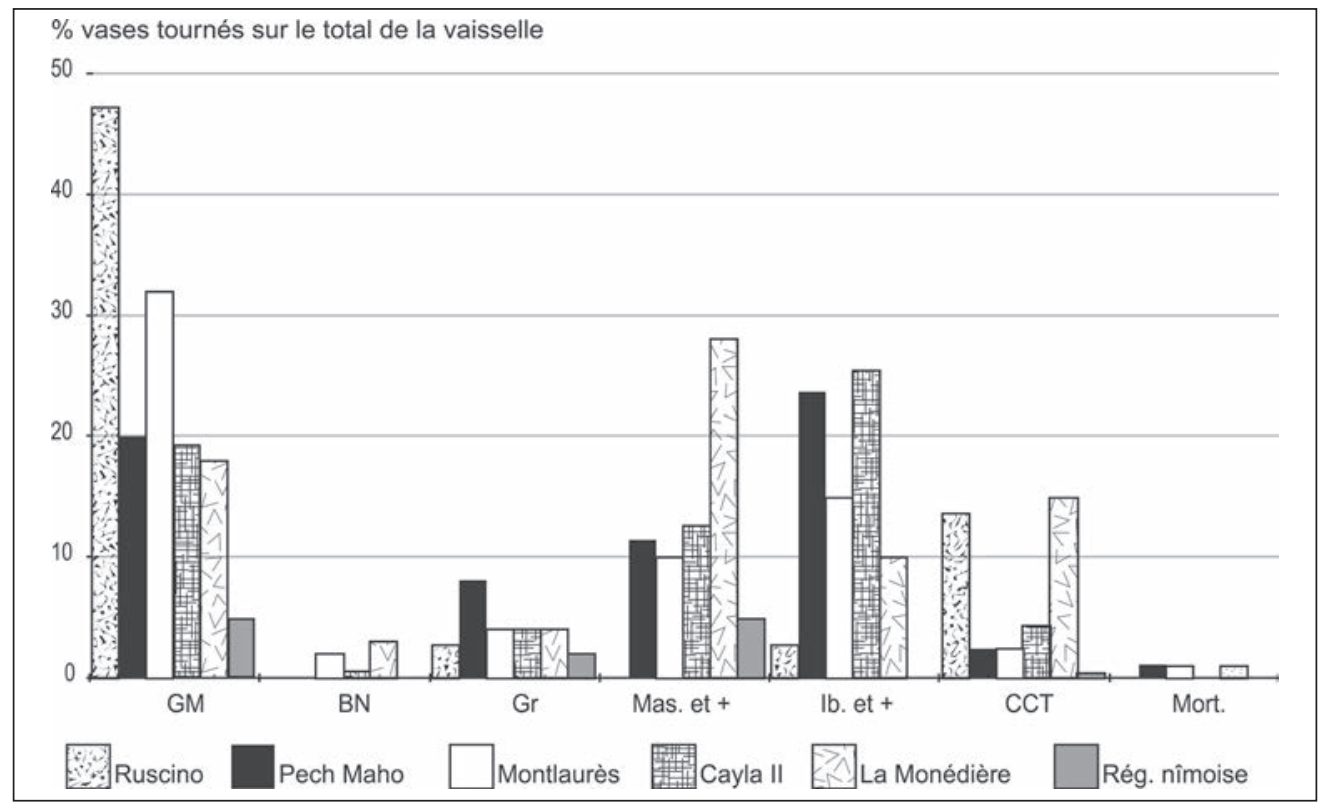

Fig. 6. Les vases tournés par rapport au total de la vaisselle pour la période 500-475 av. J.-C.

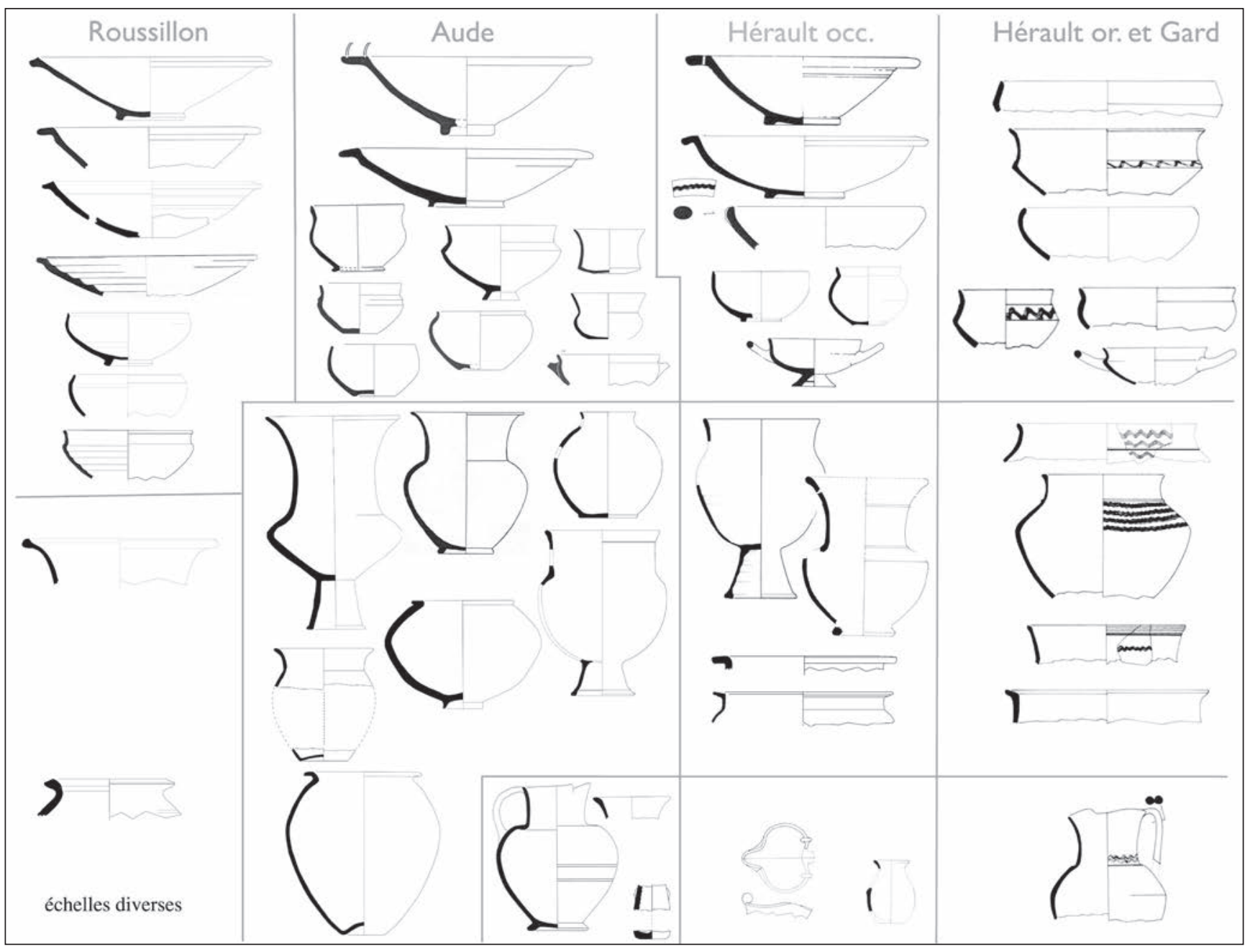

Fig. 7. Les formes de la céramique grise monochrome selon les aires géographiques ( $\mathrm{Vl}^{\mathrm{e}-\mathrm{V}} \mathrm{e} \mathrm{s}$. av. J.-C.). Dans le bandeau supérieur, les plus courantes. Hors échelle. 


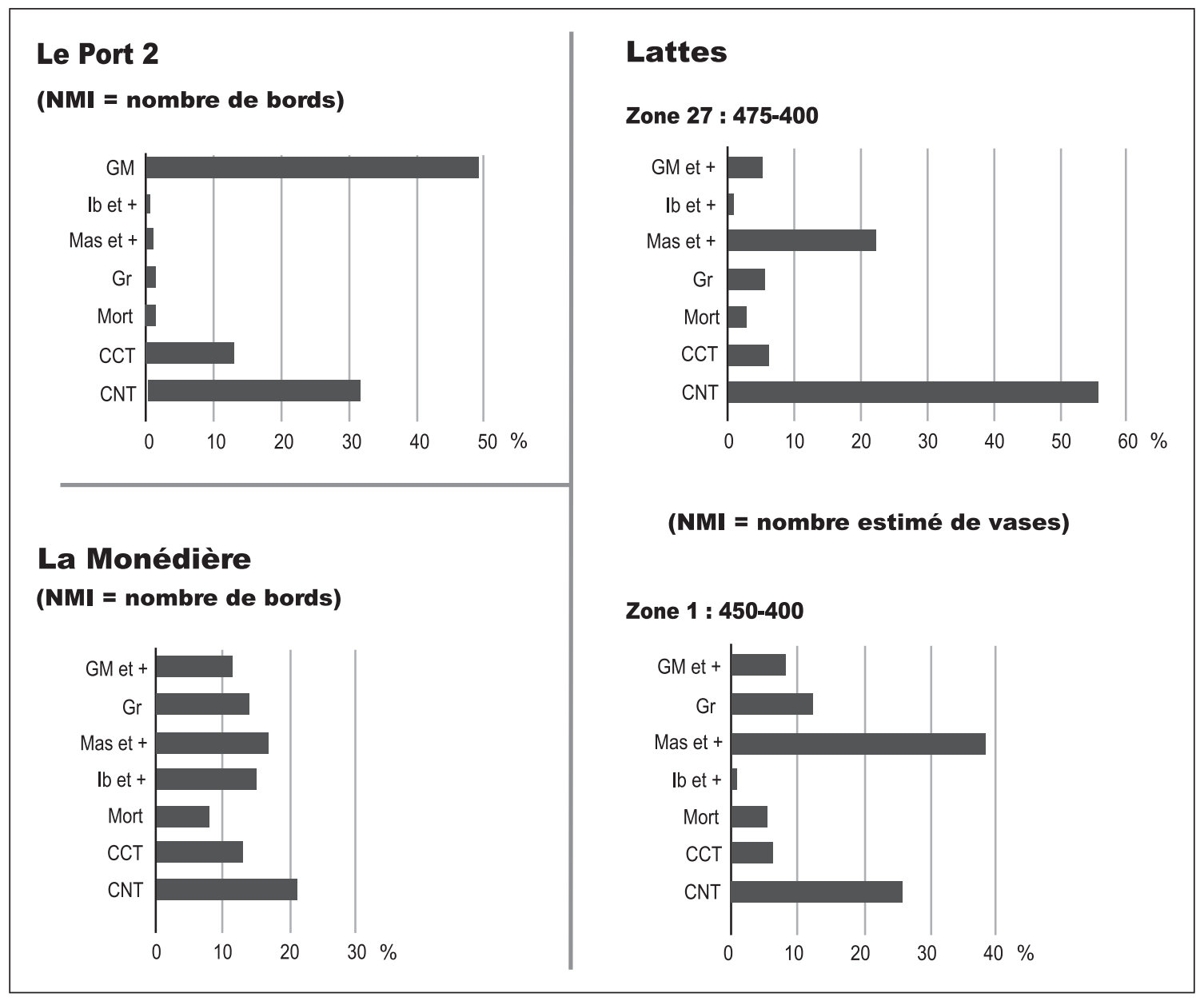

Fig. 8. Tendances du mobilier de la période $475-400$ av. J.-C. des sites du Port 2, de La Monédière et de Lattes.

\section{Au cours du $V^{\mathrm{e}}$ siècle : l'assimilation ?}

On a longtemps cru que les grises monochromes disparaissaient dans le deuxième quart du $\mathrm{V}^{\mathrm{e}} \mathrm{s}$. Bien que ce siècle soit mal documenté, on sait maintenant que ce n'est pas le cas partout (Nickels 1989a ; Ugolini et al. 1991 ; Olive, Ugolini 1997 ; Ugolini 2006). Quelques sites permettent de suivre une évolution qu'il est instructif de suivre parallèlement à celle des tendances commerciales.

Les flux amphoriques (fig. 5B-C) augmentent en Roussillon mais restent faibles en comparaison de La Monédière ou de Lattes. Les amphores ibériques dominent en Roussillon et les massaliètes dans l'Hérault, les deux courants s'équilibrant plus ou moins dans l'Aude (Ugolini, Olive 2004).

Le mobilier domestique du Port 2 (Salses-le-Château, Pyrénées-Orientales) est dominé par la grise, qui exclut quasiment les céramiques claires et autres vases importés, alors que la non tournée est stabilisée sur les valeurs antérieures ( $\pm 30 \%$ des vases). A La Monédière, la vaisselle garde sa diversité, mais l'attique a augmenté, alors que les grises monochromes $( \pm 12 \%)$ et les non tournées ont baissé $( \pm 20 \%)$. A Lattes, deux zones montrent que la vaisselle ne se répartit pas de la même manière. Cette consommation différentielle concerne principalement la non tournée (plus de $50 \%$ dans la Zone 27 ; autour de $25 \%$ dans la Zone 1 ) et la céramique à pâte claire (Zone 1 : près de $40 \%$ ), mais aussi la grise monochrome (fig. 8).

Les grises monochromes sont donc moins nombreuses à l'Est. Dans l'Hérault occidental, elles sont plus courantes et ont un répertoire standardisé plutôt de type grec. Dans l'Aude, elles sont aussi très bien représentées et ont le répertoire le plus large : les influences y sont croisées et intimement mêlées, les Grecs n'étant pas loin et les trafics ibériques soutenus. Il en ressort l'image d'une communauté ouverte et perméable. Enfin, la grise du Roussillon est standardisée, vraiment très abondante et réduite à quelques formes. Elle correspond à une communauté bien individualisée mais fermée, dans la mesure où la grise occupe, parmi les céramiques fines, quasiment toute la place. 


\section{Conclusion}

Par leurs mobiliers, les peuples du LanguedocRoussillon se singularisent dès le $\mathrm{VII}^{\mathrm{e}} \mathrm{s}$., lorsque apparaissent les deux premiers groupes (occidental et oriental). $\mathrm{Au} \mathrm{VI}^{\mathrm{e}} \mathrm{s}$., le groupe oriental se maintient, tandis que l'occidental se subdivise. La céramique seule ne peut définir des espaces ethniques ou politiques, mais, en tant qu'indicateur s'inscrivant dans l'histoire d'une région, elle contribue à délimiter des « espaces culturels ».

On ne saurait dire comment cela était perçu sur place et par les communautés voisines, ni s'il s'agit de choix délibérés ou d'un processus inéluctable dès lors que les indigènes ne sont plus seuls dans leur pays et que le commerce ne les touche pas de la même manière. On constate qu'en s'éloignant du rivage, les vases importés et la vaisselle tournée se font de plus en plus rares. La majorité des biens visibles distribués par les marchands méditerranéens reste donc sur le pourtour méditerranéen. Par contrecoup, les phénomènes d'acculturation (terme galvaudé mais bien pratique) perceptibles à travers le mobilier ne s'observent que là où la circulation est intense : sur la côte.

Par le mobilier, on délimite des espaces commerciaux, on mesure la capacité d'obtenir certains biens, le niveau de consommation, on en saisit l'énorme et rapide impact sur la vie quotidienne et on voit aussi que la céramique non tournée ne disparaît pas. Bien au contraire, elle reste à cette époque l'élément permanent et typique de la vaisselle indigène, et pas seulement pour la cuisson et la réserve. En ce sens, le groupe du Languedoc oriental reste homogène et solidement ancré dans sa culture, ce que d'autres indices montrent également (Ugolini 2010). A l'ouest, l'émergence de trois entités distinctes par leurs mobiliers traduirait un phénomène lié à l'action plus ou moins prononcée des partenaires extérieurs : l'une (Hérault occidental), au contact immédiat des Grecs, se dilue très vite ; la deuxième (Aude), sollicitée par deux principaux partenaires commerciaux, est mélangée ; la troisième (Roussillon), un peu à l'écart des trafics, emprunte assez tôt un chemin original.

Pour conclure en renouant avec la phrase de M. Bats citée au début, ces quatre espaces côtiers n'étaient vraisemblablement pas séparés par des « frontières », mais ils correspondent à des unités d'appartenance formées par leurs différentes relations avec les résidents grecs, d'une part, et, avec tous les négociants dont les activités ont parcellisé la côte, d'autre part. On ne saurait dire si de tels développements ont suscité des réflexes identitaires. Les rares sources contemporaines ne citent que des Lygiens/Ligures, éventuellement mêlés aux Ibères jusqu'au Rhône $\left(\mathrm{au} \mathrm{IV}^{\mathrm{e}} \mathrm{s} \text {. }\right)^{3}$, ce qui ne donne aucun renseignement utile de ce point de vue.

\section{Note pour la consultation des graphiques}

Les graphiques sont basés, autant que possible, sur le «nombre de bords » (= nombre de vases). Ceux de Lattes (fig. 8) s'appuient sur le "nombre estimé de vases », le « nombre de bords » n'étant pas fourni pour la céramique non tournée. Cette méthode laisse une plus grande visibilité aux classes peu représentées. Par exemple, le «nombre estimé » de vases gris monochromes de la Zone 1 est de 336 et le «nombre de bords » de 222 : soit un 1/3 de moins. Pour la région nîmoise il s'agit du « nombre de fragments » et on sait que le «nombre de bords » est bien inférieur. Ces modalités de décompte ont un impact substantiel. On l'aura à l'esprit lors de la consultation.

Abréviations utilisées dans les graphiques fig. 4-5-6 et $8: \mathrm{A}-\mathrm{IBE}+\mathrm{PUN}=$ amphores ibériques et puniques ; A-GRE + MAS $=$ amphores grecques et massaliètes ; A-ETR $=$ amphores étrusques $;$ A-Ind $=$ amphores d'origine indéterminée; $\mathrm{GM}=$ grise monochrome $; \mathrm{GM}$ et $+=$ grise monochrome et autres grises $; \mathrm{BN}=$ bucchero nero $; \mathrm{Gr}=$ céramiques grecques diverses (attique, de Grèce de l'Est, vernis noirs divers); Mas et $+=$ céramiques à pâte claire massaliètes et apparentées; Ib et $+=$ céramiques ibériques et apparentées $;$ Mort $=$ mortiers ; $\mathrm{CCT}=$ toutes céramiques tournées à cuire ; CNT = céramique non tournée.

Les données sont extraites de: Marichal, Rébé 2003 pour Ruscino (Château-Roussillon, Perpignan, Pyrénées-Orientales); Ugolini, Olive 2004 et données personnelles pour Le Port 2 (Salses-le-Château, Pyrénées-Orientales), pour Montlaurès (Narbonne, Aude) et pour La Monédière (Bessan, Hérault); Gailledrat, Solier 2004 pour Pech Maho (Sigean, Aude); Gailledrat, Taffanel 2002 pour le Cayla II (Mailhac, Aude) ; Lattara 21 pour Lattes (Hérault) ; Py 1990 pour la région nîmoise (Gard).

3 Les Élisyques, «ethnos » des Lygiens pour Hécatée de Milet (d'après les Ethniques d'Etienne de Byzance, s. v. Elisykoi), cités par Hérodote (VII, 165) dans l'armée carthaginoise lors de la bataille d'Himère, sont localisés autour de Narbonne par l'Ora Maritima d'Aviénus (v. 589-590). Pour le Pseudo-Scylax (Périple, 2), des Lygiens et des Ibères sont mélangés jusqu'au Rhône. Sur les Lygiens/ Ligures, la dernière étude est celle de Bats 2003. 


\section{Bibliographie}

Arcelin-Pradelle 1984: ARCELIN-PRADELLE (C.) - La céramique grise monochrome en Provence. Suppl. 10 à la Revue archéologique de Narbonnaise, Paris 1984, 171 p.

Arcelin-Pradelle, Dedet, Py 1982 : ARCELIN-PRADELLE (C.), Dedet (B.), Py (M.) - La céramique grise monochrome en Languedoc oriental. Revue archéologique de Narbonnaise, 15, 1982, p. 19-65.

Bats 2003 : BATS (M.) - Ligyens et Salyens d'Hécatée à Strabon. In : Textes réunis par Bats (M.), Dedet (B.), Garmy (P.), Janin (T.), Raynaud (C.), Schwaller (M.), Peuples et territoires en Gaule méditerranéenne. Hommage à Guy Barruol. Montpellier 2003, p. 147-166 (Suppl. 35 à la Revue Archéol. de Narbonnaise).

Bats 2007 : BATS (M.) - Entre Grecs et Celtes en Gaule méridionale protohistorique : de la culture matérielle à l'identité ethnique. In : Les identités ethniques dans le monde grec. Actes du Colloque international de Toulouse (9-11 mars 2006). Pallas, 73, 2007, p. 235-242.

Bats 2010 : BATS (M.) - Introduction. Les objets archéologiques peuventils véhiculer une identité ethnique ? In : Tréziny (H.) éd., Grecs et indigènes de la Catalogne à la Mer Noire. Actes des rencontres du programme européen Ramses2 (2006-2008). Aix-en-Provence, Centre Camille Jullian-Paris, Errance, 2010, p.9-12. (Bibliothèque d'Archéologie Méditerranéenne et Africaine ; 3).

Boissinot 2005 : BOISSINOT (P.) - Sur la plage emmêlés : Celtes, Ligures, Grecs et Ibères dans la confrontation des textes et de l'archéologie. Mél. CasaVelazquez, 35-2, 2005.

Buffat et al. 2008 : BUFFAT (L.), BOUVARD (E.), ROPIOT (V.), BÉNÉZET (J.) - La Courondelle 2. Occupation protohistorique et galloromaine dans la périphérie de Béziers (34). DFS ACTER, 2008. 181 p.

Claustres 1956 : CLAUSTRES (G.) - L'Âge du Fer en Roussillon. Bull.Soc. Agr.Sc.Litt. des Pyrénées-Orientales, 71, 1956, p. 57-75.

Clinkenbeard 1982 : CLINKENBEARD (B.G.) - Lesbian Wine and Storage Amphoras a Progress Report on Identification Hesperia. Journal of the American School of Classical Studies at Athens, 51-3, 1982, p. 248-268.

Coste et al. 1976 : COSTE (A.), DEDET (B.), GUTHERZ (X.), PY (M.) L'occupation protohistorique de la Grotte Suspendue de Collias (Gard). Gallia, 34-1, 1976, p. 129-166.

Dedet 1979 : DEDET (B.) - Les tombes du Languedoc oriental au premier Âge du Fer dans leur contexte culturel : acquis et problèmes. Revue archéologique de Narbonnaise, 12, 1979, p. 9-42.

Espérou et al. 1980 : ESPÉROU (J.-L.), NICKELS (A.) et ROQUES (P.) - La nécropole du premier Âge du fer de la "Cartoule" à Servian, Hérault. Archéoléologie en Languedoc, 3, 1980, p. 93-102.

Gailledrat, Solier 2004 : GAILLEDRAT (É.), SOLIER (Y.) - L'établissement côtier de Pech Maho (Sigean, Aude) aux VIe-Ve s. av. J.-C. (Fouilles 19591979). Pech Maho I. Lattes, éd. ARALO, 2004. (Monographies d'Archéologie Méditerranénne, 19).

Gailledrat, Taffanel 2002 : GAILLEDRAT (É.), TAFFANEL (O.) et (J.) Le Cayla de Mailhac (Aude). Les niveaux du premier Âge du fer $\left(V^{e}-V^{e} s\right.$. av. J.-C.). Lattes, Publ. de l'UMR 154 du CNRS, 2002. (Monographies d'Archéologie Méditerranénne, 12).

Gras 2000 : GRAS (M.) - Les Étrusques et la Gaule Méditeranéenne. In : Janin (T.) éd., Mailhac et le premier Âge du fer en Europe occidentale. Hommages à O. et J. Taffanel. Actes du Coll. Intern. de Carcassonne (17-20 septembre 1997). Lattes 2000, p. 229-242. (Monographies d'Archéologie Méditerranéenne, 7).

Guilaine, Rancoule 1996: GUILAINE (J.), RANCOULE (G.) - Les relations méditerranéennes pré-coloniales et les débuts de l'Âge du fer languedocien. Les influences puniques en Languedoc occidental. Complutum, 7, 1996, p. 125-140.

Lattara 21 : JANIN (T.) dir. - Premières données sur le Ve s. av.n.è. dans la ville de Lattara. Lattes, ARALO, 2010, 2 vol. (Lattara 21).

Louis, Taffanel 1958 : LOUIS (M.), TAFFANEL (O.) et (J.) - Le premier Age du fer languedocien. II - Les nécropoles à incinération. BordigheraMontpellier, éd. Institut International d’Études Ligures, 1958.
Marichal, Rébé 2003 : MARICHAL (R.), RÉBÉ (I.) (dir.) - Les origines de Ruscino (Château-Roussillon, Perpignan, Pyrénées-Orientales). Lattes 2003. (Monographie d'Archéologie Méditerranéenne, 16).

Mazière 2003 : MAZIÈRE (F.) - Le Bousquet (Agde). Une nécropole du premier âge du Fer. In : Archéologie en pays d'Agde. Bilan des découvertes récentes. Catalogue de l'exposition d'Agde, mars-avril 2003. Agde, GRAA, 2003, p. 24-27. Nickels 1978 : NICKELS (A.) - Contribution à l'étude de la céramique grise archaïque en Languedoc-Roussillon. In : Les céramiques de la Grèce de l'Est et leur diffusion en Occident. Actes du Coll. Intern., Centre Jean Bérard, 6-9 juillet 1976, Paris-Naples, Centre Jean Bérard, 1978, p. 248-267.

Nickels 1980 : NICKELS (A.) - Les plats à marli en céramique grise monochrome de type roussillonnais. In : Ruscino I. Suppl. 7 à la Rev. Archéol. de Narbonnaise, Paris 1980, p. 155-162.

Nickels 1989 : NICKELS (A.), avec la collaboration de MARCHAND (G.) et SCHWALLER (M.) - Agde. La nécropole du premier Âge du fer. Paris, éd. du CNRS, 1989. (Suppl. 19 à la Revue Archéol. de Narbonnaise).

Nickels 1989a : NICKELS (A.) - La Monedière à Bessan (Hérault). Le bilan des recherches. DocAMérid., 12, 1989, p. 51-120.

Olive, Ugolini 1997 : OLIVE (C.) et UGOLINI (D.) - La Maison 1 de Béziers et son environnement ( $\mathrm{V}^{\mathrm{e}}-\mathrm{IV} \mathrm{V}^{\mathrm{e}} \mathrm{s}$. av. J.-C.). In : Ugolini (D.) dir., Languedoc occidental protohistorique. Fouilles et recherches récentes. $V I^{e}-I V^{e}$ s. av. J.-C., p. U. p., Aix-en-Provence, 1997, p. 87-129. (Travaux du Centre Camille Jullian, 19).

Py 1984 : Py (M.) - La Liquière (Calvisson, Gard), village du premier Âge du fer en Languedoc oriental. Paris, Ed. du CNRS, 1984. (Suppl. 11 à la Revue Archéologique de Narbonnaise).

Py 1990 : Py (M.) - Culture, économie et société protohistoriques dans la région nîmoise. Rome, éd. Éc. Franç., 1990, 2 vol. (Coll. Éc. Franç. Rome, 131). Taffanel, Rancoule 1992 : TAFFANEL (O.) et (J.), RANCOULE (G.) - Une amphore de type phénicien-occidental à Mailhac (Aude). Archéologie en Languedoc, 1992, p. 47-50

Ugolini 1993 : UGOLINI (D.) - Civilisation languedocienne et ibérisme : un bilan de la question (VII ${ }^{\mathrm{e}} \mathrm{IV}{ }^{\mathrm{e}} \mathrm{s}$ s. av. J.-C.). DocAMérid., 16, 1993, p. 26-40.

Ugolini 2006 : UGOLINI (D.) - La céramique grise monochrome du Roussillon : les séries du "Port 2" (475-400 av. J.-C.), (Salses-le-Château, Pyrénées-Orientales). Archéologie en Languedoc, 30, 2006, p. 55-69.

Ugolini 2010 : UGOLINI (D.) - De la vaisselle au matériau de construction : techniques et emplois de la terre cuite en tant que traceur culturel en LanguedocRoussillon. In : Tréziny (H.) éd., Grecs et indigènes de la Catalogne à la Mer Noire. Actes des rencontres du programme européen Ramses2 (2006-2008). Aix-en-Provence, Centre Camille Jullian-Paris, Errance, 2010, p. 433-454. (Bibliothèque d'Archéologie Méditerranéenne et Africaine ; 3).

Ugolini et al. 1991 : UGOLINI (D.), OLIVE (C.), MARCHAND (G.), COLUMEAU (P.) - Un ensemble représentatif du $\mathrm{V}^{\mathrm{e}} \mathrm{s}$. av. J.-C. à Béziers, Place de la Madeleine, et essai de caractérisation du site. DocArchéolMérid., 14, p. 141-203.

Ugolini, Olive 2004 : UGOLINI (D.), OLIVE (C.) - La circulation des amphores en Languedoc occidental : réseaux et influences. In : Sanmartì (J.), Ugolini (D.), Ramon (J.), Asensio (D.) éd. scient., La circulaciò d'àmfores al Mediterrani occidental durant la Protohistòria (segles VIII-III aC) : aspectes quantitatius $i$ anàlisi de contiguts. Actes de la II Reuniò International d'Arqueologia de Calafell, Calafell, 21-23 de març del 2002. Barcelona 2004, p. 59-104. (Arqueomediterrània 8).

Ugolini, Olive 2006 : UGOLINI (D.), OLIVE (C.) - De l'arrivée à la consommation : l'impact des trafics et des produits étrusques en Languedoc occidental. In : Gli Etruschi da Genova ad Ampurias. Atti XXIV Convegno di studi etruschi e italici : Marseille-Lattes, 26 settembre-1 ottobre 2002, Pisa, Istituti editoriali e poligrafici internazionali, 2006, p. 555-581.

Ugolini, Olive 2009: UGOLINI (D.), OLIVE (C.) - Sites grecs, sites indigènes. Essai sur le fonctionnement des habitats de l'Hérault occidental (VI'-IVe s. av. J.-C.). In : Bertrand (I.), Duval (A.), Gomez de Soto (J.), MAGUER (P.) dir., Habitats et paysages ruraux en Gaule et regards sur d'autres régions du monde celtique. Actes du XXXI ${ }^{\mathrm{e}}$ Colloque International de l'Association Française pour l'Étude de l'Âge du Fer, Chauvigny, 17-20 mai 2007, Chauvigny, Association des Publications Chauvinoises, Mémoire XXXV, 2009, tome II, p. 215-243. 


\title{
Quel accompagnement pour quel mort ? Les services funéraires du premier âge du Fer en Languedoc occidental
}

\author{
Laura Bourdajaud \\ ASM-Archéologie des Sociétés Méditerranéennes, UMR5140, Univ Montpellier 3, CNRS, MCC, \\ 34000, Montpellier, France (doctorante) - Labex ARCHIMEDE, programme IA ANR-11-LABX-0032-01 \\ Thierry Janin \\ ASM-Archéologie des Sociétés Méditerranéennes, UMR5140, Univ Montpellier 3, CNRS, MCC, \\ 34000, Montpellier, France (professeur) - Labex ARCHIMEDE, programme IA ANR-11-LABX-0032-01 \\ Martine Schwaller \\ ASM-Archéologie des Sociétés Méditerranéennes, UMR5140, Univ Montpellier 3, CNRS, MCC, \\ 34000, Montpellier, France (Conservateur en chef du Patrimoine) - Labex ARCHIMEDE, programme IA \\ ANR-11-LABX-0032-01
}

\section{Résumé}

Dès la fin de l'âge du Bronze et jusqu'au moins la fin du premier âge du Fer, la pratique quasi exclusive de l'incinération est adoptée par les populations du Languedoc occidental. On dispose ainsi de plusieurs centaines de sépultures, rassemblées en nécropoles, qui permettent entre autres une lecture des assemblages funéraires. Leur composition, quantitative et qualitative, associant les vases cinéraires, les récipients voués aux liquides et ceux destinés aux solides, paraît être fonction du sexe et de l'âge au décès des individus. Le mobilier métallique semble également étroitement lié à ces paramètres sociaux. Ainsi que des restes osseux animaux pouvant éventuellement témoigner de pratiques de consommation en relation avec les funérailles. En se fondant sur les nécropoles mailhacoises, on s'interrogera sur la notion de service funéraire et on tentera d'en analyser les variétés et les évolutions.

Mots-clés : pratiques funéraires, premier âge du Fer, Languedoc occidental, services funéraires, paléosociologie

\begin{abstract}
From the end of the Bronze Age to the end of the first Iron Age, the almost exclusive practice of cremation is adopted by the population of western Languedoc. We have indeed several hundred graves, gathered in necropolises, which allow among other things an analysis of the funeral assemblies. Their composition, quantitative and qualitative, associating ossuaries, vases dedicated to liquids and solids, appears to be based on the gender and age at death of individuals. The metal objects also seem closely related to these social settings and also some animal bone remains which could possibly testify to consumption practices in connection with the funeral. Based on the analysis of the Mailhac necropolises we shall not only examine the concept of the funeral sets but also try to analyze the varieties and developments.
\end{abstract}

Keywords: funeral practices, first Iron Age, western Languedoc, funeral sets, paleo-sociology 
$\mathbf{S}^{4}$ ur un territoire traditionnellement délimité par la vallée de l'Hérault à l'Est, le Narbonnais au Sud, et le Carcassès à l'Ouest, les débuts de la Protohistoire méridionale sont principalement représentés par des nécropoles de sépultures secondaires à incinération. Ces dernières témoignent entre autre d'une homogénéité des pratiques funéraires indigènes, notamment caractérisées par le dépôt en fosse d'un vase cinéraire, accompagné d'objets métalliques et divers, parfois d'aliments carnés représentés par des restes osseux animaux et, surtout, d'un plus ou moins grand nombre de vases qui forment finalement l'essentiel des dépôts.

Principaux supports à la définition des différents faciès du Languedoc occidental face à l'indigence des données sur l'habitat, du IX ${ }^{\mathrm{e}} \mathrm{s}$. jusqu'au VII ${ }^{\mathrm{e}} \mathrm{s}$. av. n. è. au moins, les assemblages funéraires et leurs évolutions sensibles ont aussi été précocement mis à contribution dans la compréhension de ces communautés protohistoriques, et particulièrement suivant une perspective paléo-sociologique. Dans ce domaine, l'étude menée par A. Nickels de la nécropole agathoise du Peyrou (Nickels et al. 1989) constitue une référence essentielle pour le monde funéraire du Languedoc occidental, et au-delà, en donnant l'exemple remarquable d'une appréhension raisonnée de certains aspects de l'organisation des vivants, à travers la configuration de leur nécropole.

C'est aussi dans cet esprit que l'on interrogera ici la notion de service funéraire, par le biais d'une approche anthropologique des dépôts, visant à confronter la composition et les assemblages des récipients déposés dans les tombes, avec l'identité des défunts qu'ils accompagnaient. Cette première approche se fondera essentiellement sur les nécropoles indigènes de Mailhac, choisies, d'une part, pour l'importance des séries, constituées de centaines de sépultures secondaires à incinération intactes, qui permettent une vraie réflexion comparée entre les services, et ce, sur différentes phases chronologiques ; et d'autre part, parce que l'on dispose, pour ces tombes, à la fois des données de l'anthropologie physique et des études typo-chronologiques du mobilier céramique, métallique et divers. Ces dernières sont toutes indispensables à une approche anthropologique : pour déterminer l'âge au décès, donné par les analyses sur les restes osseux humains brûlés, et le sexe des individus, estimé suivant les assemblages d'objets métalliques et divers, comme A. Nickels en avait le premier fait la démonstration pour le Languedoc occidental ; mais aussi pour aborder directement les grandes catégories fonctionnelles des récipients, et tenter de passer de la vaisselle à l'alimentation, suivant en quelque sorte l'esprit d'une autre approche ethno-archéologique bien connue (Bats 1988).
De fait, à travers le choix des gisements mailhacois, l'étude concerne surtout les débuts de la Protohistoire méridionale, partant des nombreuses tombes du Moulin (Taffanel, Janin 1998), majoritairement caractéristiques du Bronze final IIIb (900-775 av. n. è.) et d'une période de transition vers l'âge du Fer (775-725 av. n. è.) ; jusqu'aux sépultures fouillées récemment dans la nécropole du Grand-Bassin I (Janin 2000 ; Janin et al. 2001), éponyme du faciès languedocien-occidental pour le début du premier âge du Fer. Ces ensembles pourront alors être mis en parallèle avec les tombes du Peyrou, à peine plus récentes.

La fin du premier âge du Fer, représentée à Mailhac par la «petite » nécropole du Grand-Bassin II (Janin et al. 2002), n'est toutefois pas prise en compte, notamment en raison de la relative pénurie générale de la documentation étudiée et publiée sur le $\mathrm{VI}^{\mathrm{e}} \mathrm{s}$. av. n. è., qui ne permet pas réellement de comparer la composition et les assemblages des services, suivant la perspective anthropologique proposée ici. De plus, ainsi centrées sur les services funéraires indigènes, les problématiques liées à la présence et l'influence grecques - observées par exemple dans la nécropole du Peyrou à Agde - ne seront pas traitées, pas plus que celles attachées à la parure ou aux armes, qui ne font pas véritablement partie des services tels que nous les entendons. Seront également exclues de cette étude les tombes dites «à simple ossuaire », installées dans la dépendance topographique des tombes " à vases d'accompagnement », et qui ont été mises en évidence aussi bien au Peyrou (Nickels et al. 1989, p. 401-410), qu'au Grand-Bassin I de Mailhac (Janin 2000, p. 121-122) ; en effet ces tombes, où l'on trouve hommes, femmes et enfants, posent de délicates questions d'ordre paléo-sociologique et mériteraient à elles seules un long développement.

\section{Les dépôts du Bronze final IIIb et de la transition vers l'âge du Fer}

À partir du IX $\mathrm{X}^{\mathrm{e}} \mathrm{s}$. av. n. è., les premiers dépôts sépulcraux, qui caractérisent le Bronze final IIIb mailhacois, sont très majoritairement constitués d'un ossuaire et de deux ou trois récipients d'accompagnement.

L'ossuaire en céramique est le plus souvent une urne, mais environ $7 \%$ des vases cinéraires recensés sont des plats, sans que cette particularité puisse encore s'expliquer (Taffanel, Janin 1998, p. 336). Le choix préférentiel d'une forme fermée pour les vases cinéraires se confirme néanmoins dès le début du premier âge du Fer à Mailhac, à l'opposé d'ailleurs de ce que l'on observe au Peyrou, où tous les ossuaires des tombes à 


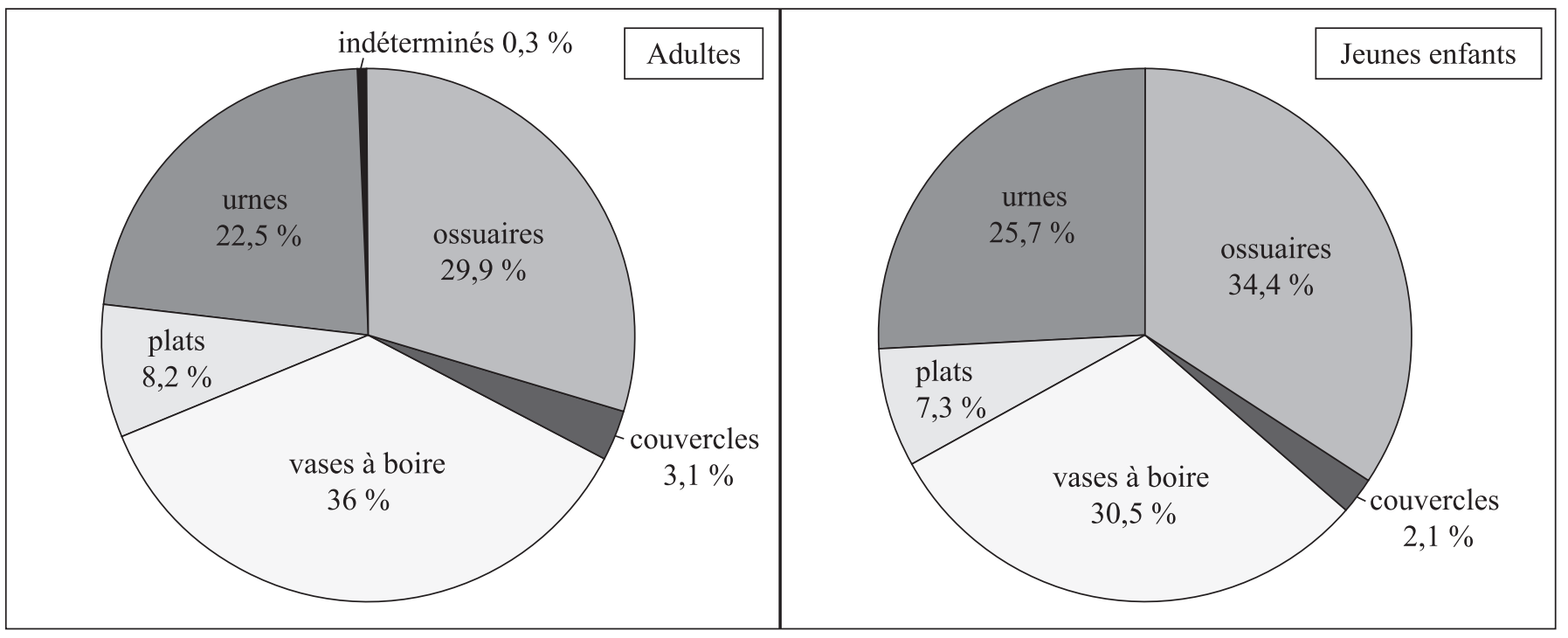

Fig. 1. Proportions moyennes des familles de récipients au sein des dépôts d'adultes et d'enfants (Bronze final Illb-Transition).

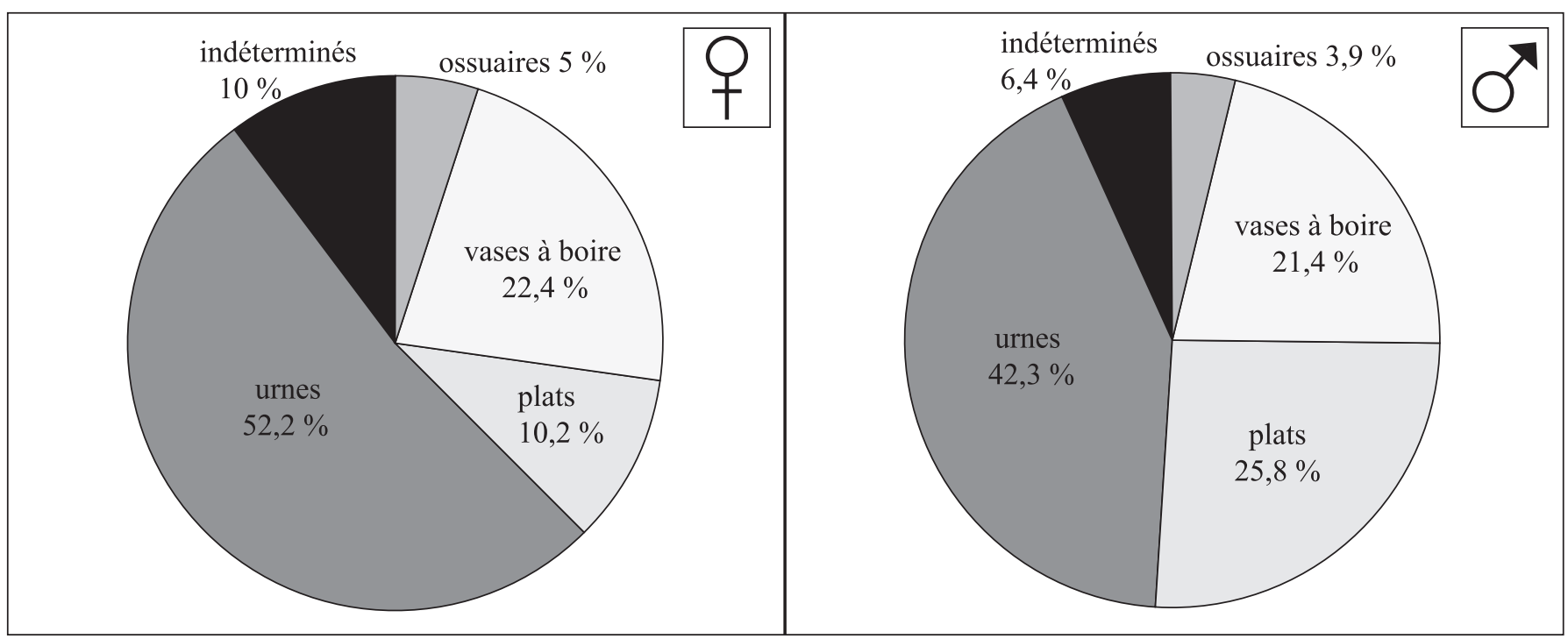

Fig. 2. Proportions moyennes des familles de récipients au sein des dépôts féminins et masculins (premier âge du Fer). 
vases d'accompagnement sont constitués par des coupes (Nickels et al. 1989, p. 361). Cela dit, comme à Agde, on retrouve très souvent parmi les dépôts mailhacois, la présence d'un vase à boire, généralement un gobelet, situé dans ou à proximité du vase cinéraire, et que l'on considère en ce sens comme le vase à boire du défunt (Nickels et al. 1989, p. 368 ; Taffanel, Janin 1998, p. 337).

En plus de cette association entre l'ossuaire et un petit récipient, les autres vases d'accompagnement sont le plus souvent constitués d'urnes, dont la morphologie évoque plutôt des fonctions liées au stockage ou à la petite réserve. Certaines d'entre elles renferment aussi un petit récipient qui, en plus d'un vase à boire s'ajoutant à celui placé au plus près des restes du défunt, peut aussi être assimilé à un vase « à puiser »; à l'instar de ce que l'on avait suggéré à travers la « paire » d'urnes avec coupelle, régulièrement observée dans les dépôts agathois, et manifestement caractéristique du faciès Grand-Bassin I (Nickels et al. 1989, p. 366-367 et 446-447).

Les plats sont finalement assez rares au Bronze final IIIb, et font même exception dans les services les plus anciens. Ils sont en fait une des caractéristiques de la mutation des dépôts funéraires durant la période de transition, marquée, outre une évolution typologique sensible (Taffanel, Janin 1998, p. 303-315), par une légère augmentation du nombre de récipients déposés dans les tombes (Taffanel, Janin 1998, p. 337), qui passe notamment par la multiplication des vases à boire et l'apparition de grands récipients ouverts, accompagnant de plus en plus régulièrement les urnes.

Excepté ces variations chronologiques, qui annoncent l'évolution sensible de la période suivante, les compositions funéraires présentent à ces époques une assez grande homogénéité. Pourtant, parallèlement à cette apparente uniformité, on perçoit tout de même une tendance générale à établir quelques différences entre les adultes et les plus jeunes individus. En effet, les jeunes enfants semblent recevoir un peu moins de vases en moyenne que les autres (Taffanel, Janin 1998, p. 358), et la composition proportionnelle générale des dépôts (fig. 1) tend à démontrer que la distinction se fait surtout à travers les vases à boire, dont la part est un peu plus importante dans les services destinés aux plus âgés. Il s'avère en plus que l'écart se creuse davantage du Bronze final IIIb à la période de transition, et concerne spécialement les jeunes individus de moins de sept ans.

Il est actuellement délicat d'aborder les éventuelles distinctions établies entre les hommes et les femmes, tant les premiers sont mal représentés à Mailhac, principalement en raison de la modestie quantitative des objets métalliques et divers présents dans les tombes masculines, par rapport aux sépultures féminines, et plus encore de la rareté des objets discriminants masculins parmi le mobilier qui leur est destiné à cette époque (Taffanel, Janin 1998, p. 350-353). Néanmoins, pour ce qui est observable, il apparaît quand même, là encore, une tendance générale pour les sujets adultes à déposer un peu plus de vases pour les sujets masculins (Taffanel, Janin 1998, p. 359), voire, précisément, un peu plus de vases à boire. Quelques dépôts anciens déjà composés de plus de deux vases à boire - exceptionnels pour le Bronze final IIIb - se révèlent, effectivement, être tous masculins (Taffanel, Janin 1998, p. 153-156, fig. 238), et l'évolution évoquée pour la période de transition est particulièrement perceptible dans les quelques tombes masculines (Taffanel, Janin 1998, p. 174-177, fig. 268 ; Janin et al. 2001, p. 25-27, fig. 17). Il ne s'agit cependant là que de tendances très générales, et les différences observées restent, somme toute, assez minimes.

Quoi qu'il en soit, il ressort d'abord de ces premiers services, parfois complétés par des dépôts de faune, l'idée initiale d'une consommation funéraire. Plus spécifiquement, les services céramiques, principalement composés d'urnes, associées à des petits récipients propices à une utilisation individuelle, pourraient bien témoigner de l'importance, si ce n'est d'une consommation de boissons, au moins du symbole de cette dernière. Il ne s'agit bien sûr pas d'avancer l'idée que les urnes, qui sont avant tout des conteneurs fermés largement polyfonctionnels, aient toutes contenu des liquides. En revanche, la part prépondérante des gobelets et petites coupelles dans les services, et le dépôt caractéristique d'un vase à boire personnel, portent bien à croire, eux, que la consommation de boissons est centrale dans l'idéologie funéraire. Les dépôts du premier âge du Fer tendent largement, du reste, à conforter cette perception.

\section{Le début du premier âge du Fer}

C'est à partir du dernier quart du VIII ${ }^{\mathrm{e}} \mathrm{s}$. av. n. è. que les services funéraires connaissent une évolution considérable avec, en premier lieu, une forte augmentation générale du nombre de récipients déposés dans les tombes. La moyenne passe globalement à une vingtaine de vases par défunt, mais le nombre total destiné à chacun présente cette fois de fortes inégalités, allant d'un seul à cinquante-huit récipients (cf. par exemple, les célèbres tombes dites de « cavaliers »: Taffanel 1962). Comme le laissaient augurer déjà les services les plus tardifs de la période de transition, les dépôts rendent très clairement compte de la multiplication sensible des vases à boire et des urnes. Les petites coupelles 


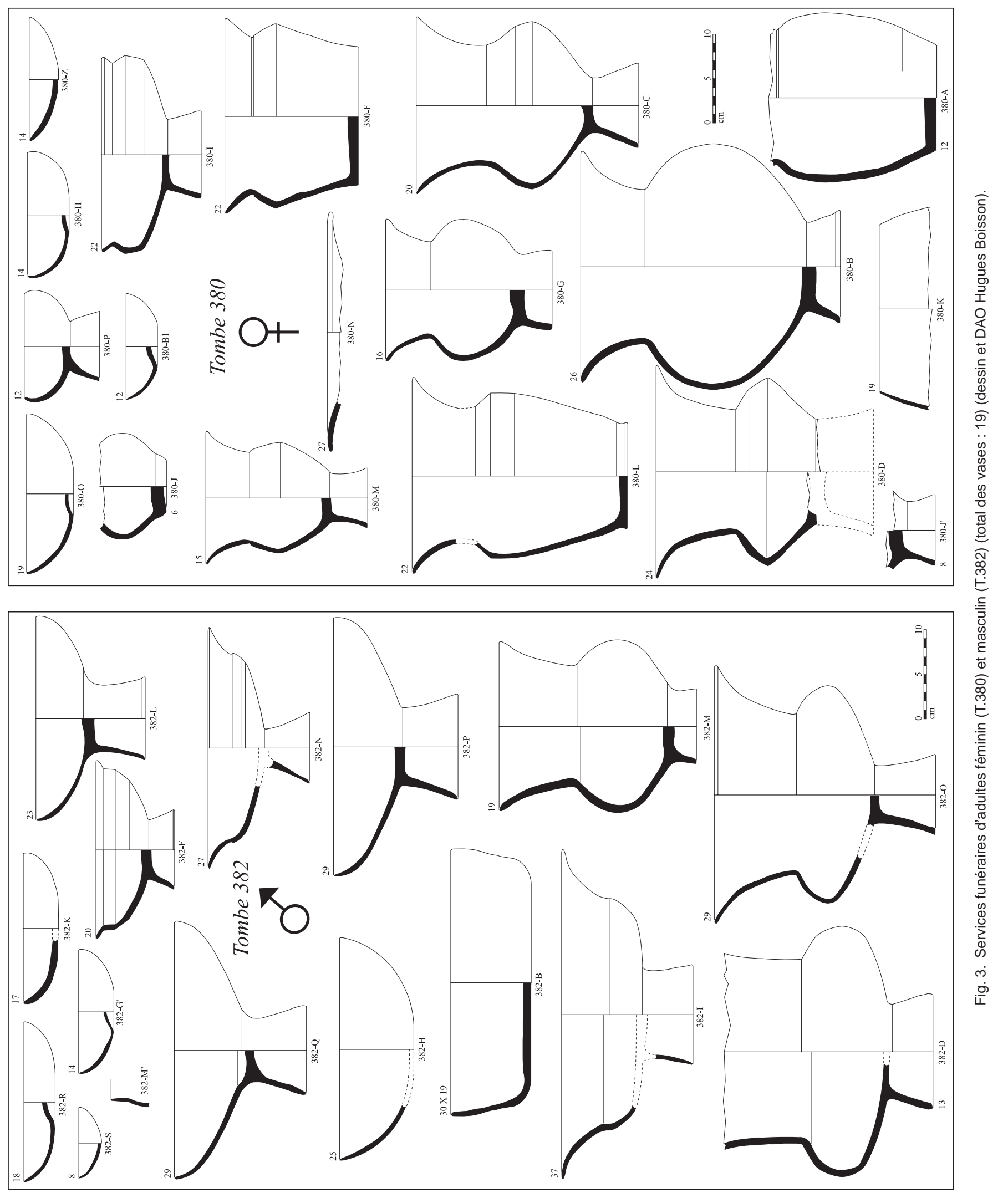


hémisphériques remplacent les gobelets, et la morphologie des urnes évolue notamment vers un agrandissement des cols et des pieds, typique du faciès Grand-Bassin I. De plus, s'ajoutent également à ces récipients un plus ou moins grand nombre de plats aux proportions variées, qui prennent désormais une part non négligeable dans les dépôts.

Cela dit, si l'on compare la composition proportionnelle des services estimés féminins et masculins - qui ne concernent ici que des sujets matures (plus de 14 ans) - une nette distinction se manifeste cette fois entre les hommes et les femmes (fig. 2). En effet, il apparaît que les dépôts féminins sont essentiellement composés d'urnes et de vases à boire, avec seulement un dixième de récipients représenté par des plats ; tandis que ces derniers sont nettement plus nombreux dans les services d'hommes, où ils forment plus d'un quart des dépôts, sans que cela soit particulièrement lié au nombre total de vases déposés dans les tombes. On observe par exemple, à nombre égal de récipients - de deux sépultures installées côte à côte dans la nécropole - que le service féminin présente six vases à boire, un unique plat et le reste d'urnes, alors que le service masculin est composé, outre les urnes, de cinq vases à boire et de huit plats (fig. 3).

De plus, en ce qui concerne la présence de ces plats dans les services d'hommes à Mailhac, on remarque également, à côté d'un plus ou moins grand nombre de coupes aux proportions moyennes, l'association quasi-systématique de deux grands plats de plus de 30 $\mathrm{cm}$ de diamètre à l'ouverture (fig. 4). Cette «paire » de récipients est en plus très régulièrement constituée soit d'une terrine, soit d'une coupe à large marli - deux types de vases assez rares dans les sépultures -, qui s'associent couramment à une grande coupe hémisphérique, dont les proportions sont manifestement absentes des services destinés aux femmes. En outre, dans la plupart des cas, ces grands plats sont aussi significativement déposés à proximité de l'ossuaire, renforçant certainement l'importance, ou la spécificité de ce type de dépôt. On soulignera en ce sens, avec intérêt, que cette paire de plats semble se dédoubler dans les sépultures contenant plusieurs hommes, ce qui tend à confirmer cette notion même de service funéraire (fig. 5).

Il apparaît donc que les distinctions liées au sexe se manifestent dans la composition des services dès le début du premier âge du Fer.

Les différences entre adultes et enfants ne sont toutefois pas en reste à cette époque, mais ont plutôt l'air de s'exprimer à travers la taille des récipients sépulcraux, généralement plus petits pour les enfants, comme on a pu par exemple l'observer dans la tombe d'un très jeune individu au Peyrou (Nickels et al. 1989, p. 70-72).

Ainsi, ce qui ressort d'une façon générale de la composition des services au début du premier âge du Fer est d'abord l'importance, non plus du symbole, mais cette fois d'une véritable consommation de boissons. On perd effectivement à cette époque la trace du vase à boire du défunt, au profit d'une multiplication générale des petits récipients, qui s'associent aux nombreuses urnes à cols et pieds hauts, dont on a déjà souligné la proximité typologique avec certaines formes de « cratères » méditerranéens (Janin 2000, p. 118) ; le tout formant alors de véritables services à boire dans les sépultures. De la sorte, l'importance de la boisson, qui perdure depuis le Bronze final IIIb, apparaît comme une caractéristique générale des pratiques funéraires mailhacoises, qui est apparemment commune aux funérailles masculines et féminines; à moins que les différences ne s'établissent dans la nature des liquides consommés, ce qui est évidemment très délicat à déterminer. On ajoutera en outre que la place de la boisson persiste jusqu'au moins la fin du premier âge du Fer à Mailhac : les vases d'accompagnement des tombes du Grand-Bassin II, malgré leur raréfaction progressive et leur état souvent fragmentaire et brûlé, attestent encore un dépôt de vases à boire (gobelets, canthares) et d'urnes ; et, plus significativement peut-être quant à la nature de la boisson, d'amphores et de quelques oenochoés (Janin, Taffanel et al.2002).

Toutefois, en ce qui concerne le début du premier âge du Fer, la multiplication des récipients et la configuration de ces services à boire évoquent également une dimension plus collective de la consommation face aux dépôts des autres périodes. D'ailleurs, au regard des services funéraires du Peyrou, ce symbole de partage des boissons pourrait aussi être une spécificité mailhacoise, ou encore être lié à un léger décalage chronologique. En effet, les services agathois, à peine plus récents que ceux du Grand-Bassin I abordés ici, révèlent, eux, un nombre globalement plus modeste de vases à boire par tombe, au profit du dépôt plus spécifique d'un petit récipient personnel au défunt.

Par ailleurs, cette dimension collective de la consommation se trouve aussi renforcée par la présence des plats, vraisemblablement liés à la présentation et au service des aliments. Ces vases, souvent peu profonds et largement ouverts, paraissent peu propices à contenir des liquides, mais semblent plutôt destinés à des préparations alimentaires solides, voire éventuellement semi-liquides ; ils suggèrent ainsi le développement d'une consommation de nourriture, dans un cadre plutôt collectif. Néanmoins, face à l'apparente homogénéité des services à boire, la 


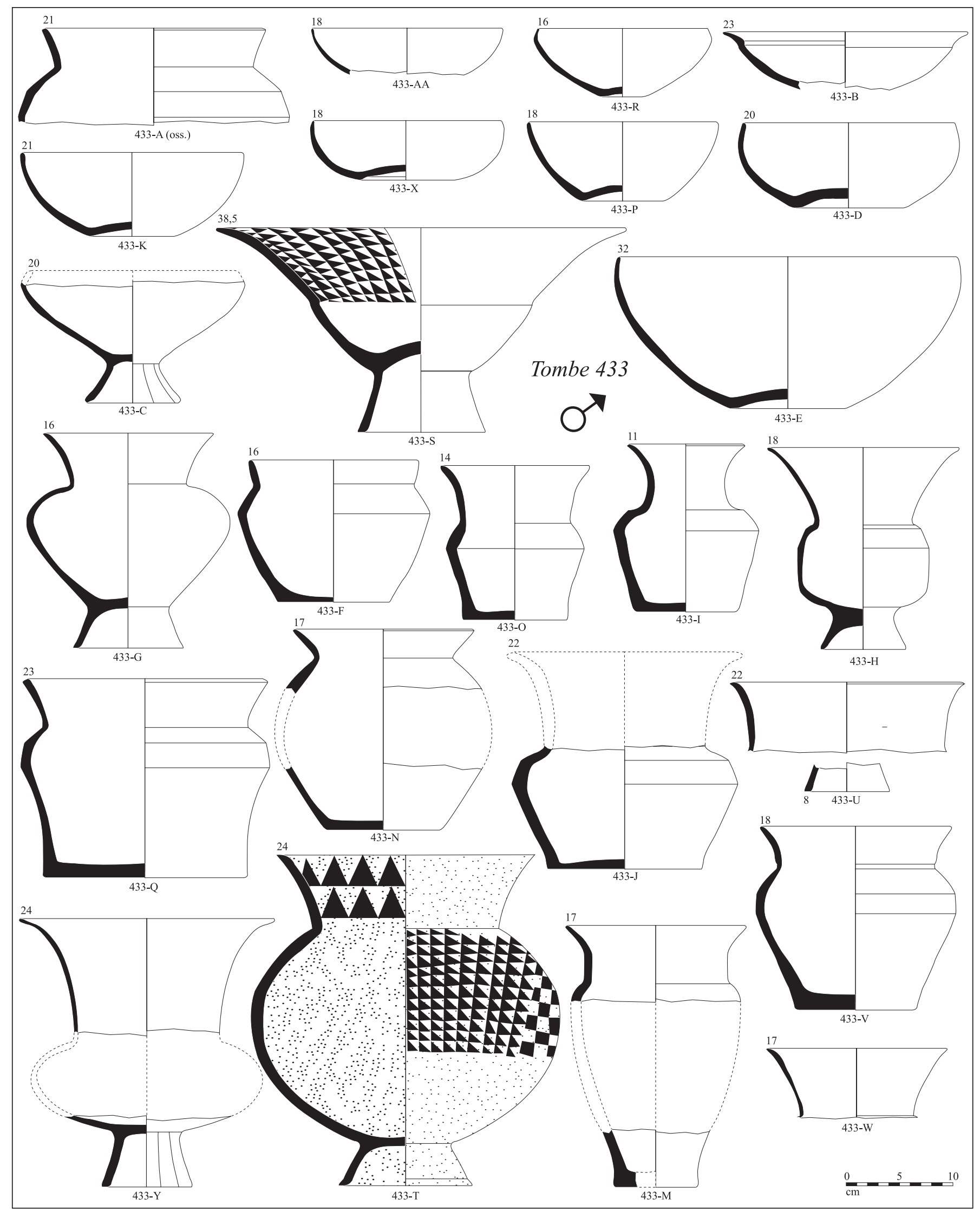

Fig. 4. Service funéraire de la tombe masculine 433 (total des vases : 28) (dessin et DAO Hugues Boisson). 


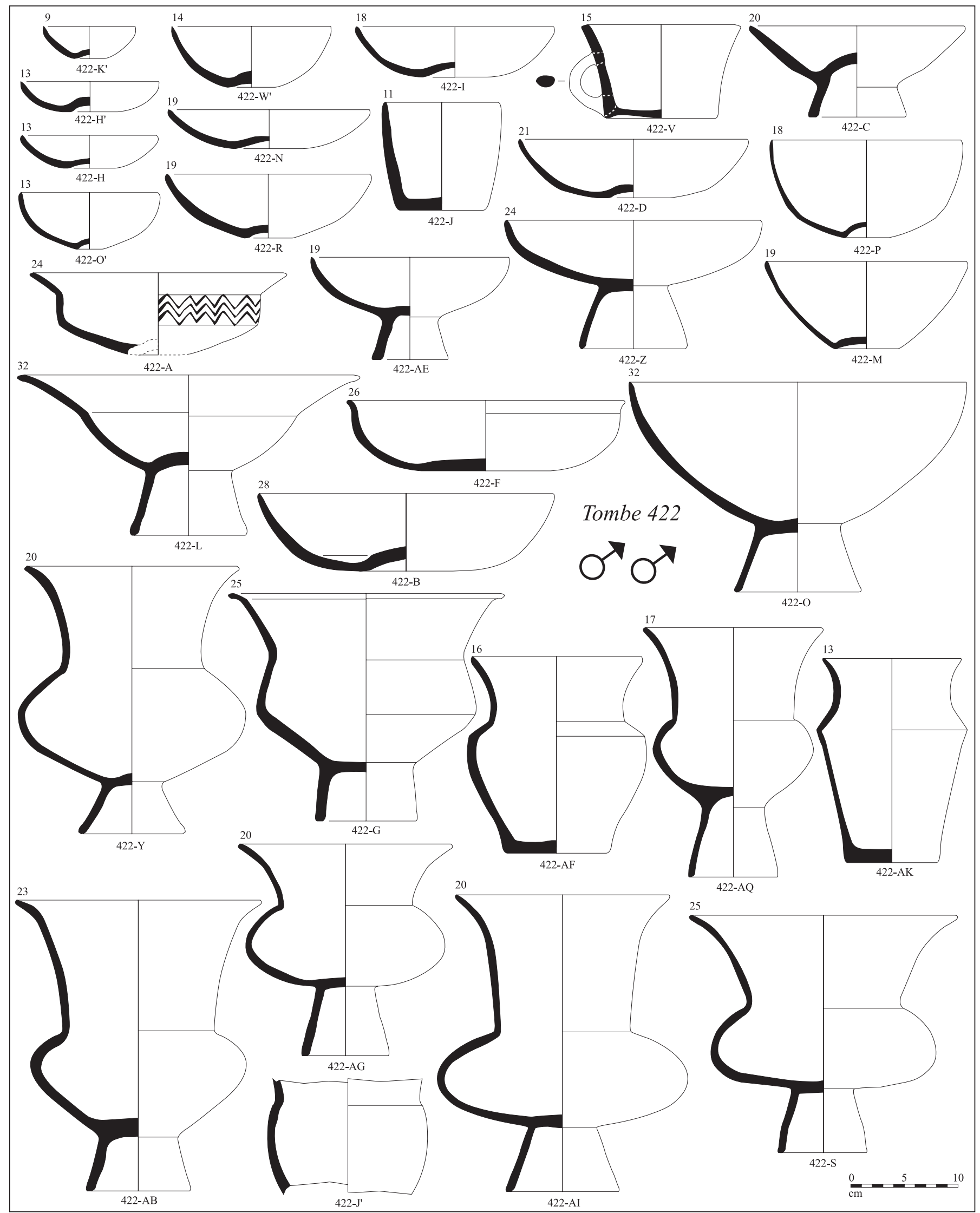

Fig. 5. Service funéraire de la tombe double d'hommes 422 (total des vases : 47) (dessin et DAO Hugues Boisson). 
multiplication des plats dans les dépôts masculins et la présence de deux grands exemplaires significativement absents des services féminins semblent induire que cette consommation collective de nourriture est plus particulièrement développée pour les hommes.

Du reste, cette association typique et apparemment caractéristique des tombes masculines, entre terrines ou coupes à large marli et grandes coupes hémisphériques, pourrait même témoigner d'une préparation alimentaire particulière durant les funérailles masculines, et ainsi d'une consommation différenciée selon le genre. À ce sujet, il faut peut-être souligner que les restes de faune, en plus de se raréfier davantage au regard des périodes antérieures, se concentrent également, dès le début du premier âge du Fer, quasi-exclusivement dans les sépultures masculines. De fait, ils s'associent aussi, avec les plats, à des petits couteaux en fer, objets masculins discriminants par excellence dès le dernier quart du VIII' s. av. n. è. Ainsi, l'association des petits couteaux tranchants, des grands plats de service des aliments et de quelques dépôts supplémentaires d'aliments carnés pourrait alors suggérer l'existence d'un lien particulier entre les funérailles masculines et la consommation de viande.

Au-delà des distinctions sexuelles qui se dessinent dans la composition des services funéraires, on évoquera pour finir la présence de certains éléments qui paraissent marquer un autre niveau de différentiation, particulièrement perceptible au sein des tombes individuelles masculines. Outre l'existence d'ornementations, et notamment des décors excisés caractéristiques qui renforcent la valeur intrinsèque de certains récipients, quelques services funéraires se distinguent davantage par la présence exceptionnelle de simpulums en bronze, ou encore de broches à rôtir en fer. Comme on l'a déjà souligné (Nickels et al. 1989, p. 447 ; Janin 2000, p. 126-127), la charge symbolique de ces objets dans la sphère méditerranéenne, tout autant que l'architecture, l'ampleur des dépôts sépulcraux et le positionnement topographique des tombes contenant ce mobilier, reflètent très certainement des défunts de haut rang, situés au sommet d'une hiérarchie sociale telle qu' on la perçoit dans le monde des morts. Au demeurant, ces ustensiles, comme parties intégrantes des services funéraires, induisent manifestement des distinctions dans les pratiques de consommation et de préparation des aliments. Les simpulums marquent ainsi, pour le moins, des pratiques de service et/ou de consommation "plus raffinées", en évitant un contact direct entre les liquides, ou les aliments, et les mains de leurs propriétaires, comme l'avait déjà bien formulé A. Nickels (Nickels et al. 1989, p. 447); et les broches - tout en constituant un indice supplémentaire du lien entre les funérailles masculines et la viande - attestent, elles, un mode de cuisson particulier, et probablement une consommation de viande rôtie, selon une pratique codifiée qui pourrait bien être réservée aux défunts les plus riches.

En somme, au terme de cette première approche, il apparaît que la composition des dépôts sépulcraux s'avère tout autant liée aux coutumes inhérentes aux funérailles qu'aux paramètres anthropologiques des sépultures. L'évolution et la régularité des assemblages languedociens témoignent ainsi d'une idéologie funéraire structurée, où l'alimentation et la consommation semblent tenir une place prépondérante ; et l'influence du genre et de l'âge au décès des individus, couplée à la présence de quelques objets de valeur, appuient, si besoin était, l'existence de « codes » de représentations sociales mis en place dans le monde des morts. Ces premiers résultats sur la composition et la signification des services funéraires ne sauraient bien sûr être définitifs, et il est encore nécessaire d'élargir l'étude à d'autres horizons géographiques de la Protohistoire. Ils manifestent néanmoins les possibilités de démêler en partie l'écheveau de ces nombreux vases déposés dans les tombes, et ouvrent un riche et passionnant champ des possibles quant à l'interprétation sociale des services funéraires protohistoriques.

\section{Bibliographie}

Bats 1988 : BATS (M.) - Vaisselle et alimentation à Olbia de Provence (v. 350-v. 50 av. J.-C.) : modèles culturels et catégories céramiques. Paris, CNRS, 1988 (RAN, Suppl. 18).

Janin 2000 : JANIN (T.) - Nécropoles et sociétés élisyques : les communautés du premier âge du Fer en Languedoc occidental. In : Janin (T.) éd., Mailhac et le premier âge du Fer en Europe occidentale : hommages à Odette et Jean Taffanel, Actes du Colloque international de Carcassonne (1997). Lattes, Association pour la recherche archéologique en Languedoc oriental, 2000, p. 117-131 (Monographies d'archéologie méditerranéenne 7).

Janin et al. 2001 : JANIN (T.), BOISSON (H.), CHARDENON (N.), LENORZER (S.), MARCHAND (G.), MONTECINOS (A.), POUPET (P.), VIAL (J.) - La nécropole protohistorique du Moulin à Mailhac. L'Entari (Aude). Rapport de fouille programmée 1998-2000. Service régional de l'archéologie Languedoc Roussillon, 2001.

Janin, Taffanel et al. 2002 : JANIN (T.), TAFFANEL (O.), TAFFANEL (J.), BOISSON (H.), CHARDENON (N.), GARDEISEN (A.), HERUBEL (F.), MARCHAND (G.), MONTECINOS (A.), ROUQUET (J.) - La nécropole protohistorique du Grand-Bassin II à Mailhac, Aude (VI ${ }^{e}-V^{e}$ s. av. n. è.). DAM, 25, 2002, p. 65-122.

Nickels et al. 1989 : NICKELS (A.), MARCHAND (G.), SCHWALLER (M.), AVEC LA COLL. DE DUDAY (H.), COLUMEAU (P.) - Agde, la nécropole du premier âge du Fer. Paris, CNRS, 1989 (RAN, Suppl. 19).

Taffanel 1962 : TAFFANEL (O. ET J.) - Deux tombes de cavalier du premier âge du Fer à Mailhac. Gallia, 20, vol. 1, 1962, p. 3-32.

Taffanel, Janin 1998 : TAFFANEL (O.), TAFFANEL (J.), JANIN (T.) - La nécropole du Moulin à Mailhac (Aude). Lattes, ARALO, 1998, 393 p., 478 fig., 3 annexes (Monographies d'Archéologie Méditerranéenne, 2). 



\section{El guerrero de Corno Lauzo : revisión de los materiales}

\section{Raimon Graells Fabregat}

Römisch-Germanisches Zentralmuseum, Ernst-Ludwig Plaz, 2. 55116, Mainz

\section{Resumen}

El nombre de Corno Lauzo se asocia, para los protohistoriadores, al conjunto funerario de la primera Edad del Hierro más conocido del sureste de Francia. Corresponde a un impresionante conjunto que entremezcla armas, vasos metálicos, ornamentos de vestuario y cerámicas de importación que corresponden a los más espectaculares elementos tanto de la tradición local como de los importados del momento. Pero el conjunto es atípico si se compara con el resto de tumbas del sur de Francia, del nordeste de la Península Ibérica y del Noroeste de Italia. Fue dado a conocer por O. y J. Taffanel, en 1960, como una tumba de guerrero y rápidamente se convirtió en un referente para analizar las aristocracias guerreras del Sur de Francia, el contacto con las grandes culturas del Mediterráneo, las ideas sobre acumulación y redistribución de riquezas y, finalmente, también la expresión de prácticas sociales alrededor del banquete o la asimilación del banquete "a la griega". A lo largo de los años, la investigación ha repetido el análisis de los hermanos Taffanel y no ha dado lugar a un (re)estudio detallado de aquél descubrimiento. A tal efecto creo pertinente discutir el conjunto en el marco del presente homenaje a M. Bats y así poner sobre la mesa los numerosos problemas sobre el ajuar de la llamada "tumba" de Corno Lauzo.

Palabras clave : primera Edad del Hierro, tumba de guerrero, armas, importados, aristocracias guerreras, banquete

\section{Résumé}

Le nom de Corno Lauzo est associé, pour les protohistoriens, au complexe funéraire du premier âge du Fer du sud-est de la France le plus connu. C'est celui d'un ensemble impressionnant, qui mêle armes, vases métalliques, ornements et céramiques d'importation, en même temps des éléments locaux et d des objets importés les plus spectaculaires. Mais l'ensemble est atypique par rapport à d'autres tombes du sud de la France, du nord-est de la péninsule ibérique et du nord-ouest de l'Italie. Il fut publié par O. et J. Taffanel en 1960 comme le tombeau d'un guerrier, et il est rapidement devenu une référence pour l'analyse des aristocraties guerrières du sud de la France, exemple du contact avec les grandes cultures de la Méditerranée occidentale, de l'accumulation et de la redistribution des richesses, et finalement aussi, de l'expression des pratiques sociales à travers du banquet « à la grecque » et de son interprétation locale. Au cours des années, la recherche a repris l'analyse des frères Taffanel et n'a pas donné lieu à une réexamen détaillé de cette découverte. C'est pourquoi, profitant de cet hommage à M. Bats, je voudrais mettre sur la table les nombreux problèmes que pose ce mobilier de la « tombe » de Corno Lauzo.

Mots-clés : premier âge du Fer, tombe de guerrier, armes, importations, aristocraties guerrières, banquet 


\section{Introducción}

En 1959 se recuperaron una serie de materiales metálicos y cerámicos rápidamente interpretados como evidencias de un contexto funerario en el límite entre los municipios de Mailhac y Pouzols-Minervois (Aude), durante la preparación de un viñedo (fig. 1, a). Por temas de propiedad del terreno y de calendario agrícola no pudo realizarse en ese momento la necesaria intervención arqueológica. A tal efecto se decidió documentar la situación de la tumba mediante triangulación de puntos (fig. 1,b) y sólo dos años más tarde se pudo practicar una intervención para excavar la que sería la "tumba de Corno Lauzo" (fig. 1, c). La tumba que entonces se excavó tiene unas dimensiones de $50 \mathrm{~cm}$ de diámetro por $55 \mathrm{~cm}$ de profundidad conservada. Los autores señalaron la ausencia de la cobertura, que habría sido destruida.

La tumba se publicó inmediatamente (Taffanel, Taffanel 1960) fijando en la retina de los protohistoriadores un conjunto fechado en la segunda mitad del s. VI aC excepcionalmente rico y atípicamente cargado de armas que, ante la falta de intervenciones arqueológicas en su entorno ${ }^{1}$, se ha ido interpretando como una tumba aislada (Graells 2010, p. 139-149) (fig. 1, d).

Esta excepcionalidad es la que mueve a realizar un estudio detallado de los materiales que integran el conjunto del Guerrero de Corno Lauzo. Aquí se presenta un avance que ofrece ya una nueva imagen del conjunto, proponiéndose que no se trate de un único conjunto funerario. Los argumentos para esta propuesta se basan en criterios de índole tipológica, cronológica y de lógica asociativa, tanto regional como particular dentro del grupo de tumbas de guerrero que caracterizan el momento central del s. VI aC en la región. El estudio que se presenta se centra en la discusión de los elementos de panoplia defensiva (el casco y la coraza) y los elementos de vajilla metálica (cista de cordones y, ahora, también una pátera) gracias a las novedades que surgen de la restauración, inédita, de los elementos metálicos de la tumba, en el Römisch-Germanisches-Zentralmuseum de Mainz que permite confirmar importantes consideraciones que ratifican observaciones de carácter tipológico ${ }^{2}$.

Como resultados más significativos, el llamado "casco" corresponde en realidad a un vaso metálico y la coraza, que permanece, cambia su morfología a favor de un cardiophylax discoidal decorado. De esta manera, la primera

\footnotetext{
1 Para una síntesis vid. Janin et al. 2002, p. 66-67.

2 Sobre la restauración realizada en el RGZM de la espada de la tumba de Corno Lauzo vid. Hundt 1969.
}

reconstrucción de los elementos de la tumba, basada en las tumbas de Sesto Calende y de Calaceite (Graells, Armada 2011), se abandona y la revisión aproxima el conjunto a los ajuares-tipo identificados en el área catalano-languedociense durante el s. VI aC (Graells 2013).

El conjunto de Corno Lauzo sigue presentando una gran tumba de guerrero, pero con un ajuar de primer rango militar distinto, dentro de los parámetros del sur de Francia y Catalunya, es decir, sin casco, y con un ajuar vascular más articulado (y más coherente) en relación a la cronología y contexto de la tumba, integrado por simpula y pátera de bronce. Pero la incoherencia cronológica del conjunto se explica ahora por la presencia de un segundo conjunto, quizás femenino, una generación más tardía que el del Guerrero.

\section{La cronología de la tumba y su ajuar cerámico}

El ajuar cerámico ha sido un problema para fechar la tumba y supone el grupo de materiales más incoherente, confundiendo a quienes han trabajado sobre la tumba y avivando un relativo debate acerca del valor real de las importaciones de vajilla ática como elemento seguro (se debatía la perduración antes de su amortización) y, por otro lado, la cronología de las ánforas masaliotas, de las que el ejemplar presente en la tumba de Corno Lauzo sería el exponente más antiguo (o de los más antiguos). Así el ajuar cerámico recogido se compone de una copa ática de figuras negras del grupo de pequeños maestros, una copa jonia y un ánfora masaliota.

La cronología propuesta para la copa ática, se sitúa entre el 550-540 aC y la cronología propuesta para la copa jonia B2 entre el 580-540 aC. Si empezamos por la copa ática es posible que la identificación como una producción del taller de "pequeños maestros" deba matizarse y considerarse una producción del grupo de las "floral Band-cups" de Beazley (1932), con una cronología de tercer cuarto avanzado de s. VI aC. La copa de bandas de la tumba de Corno Lauzo presenta paralelos en los ejemplares de 114, 119, 121, 122 y 127 de Corinto, fechados entre el 540-530 aC. Por otro lado la copa jonia B2 parece corresponder a un tipo avanzado, tipo IV del santuario de Gravisca (Boldrini 1994), con una cronología amplia de 580-520/500 aC a partir de la frecuencia de las producciones magno-griegas con fecha posterior al 540 aC. Finalmente la cronología que ofrece el ánfora masaliota tipo Bertucchi 1 presenta una cronología de 540-510 aC. Todo ello lleva a replantear la cronología de esta tumba y situarla en un momento ligeramente posterior, de 540-525 aC. 


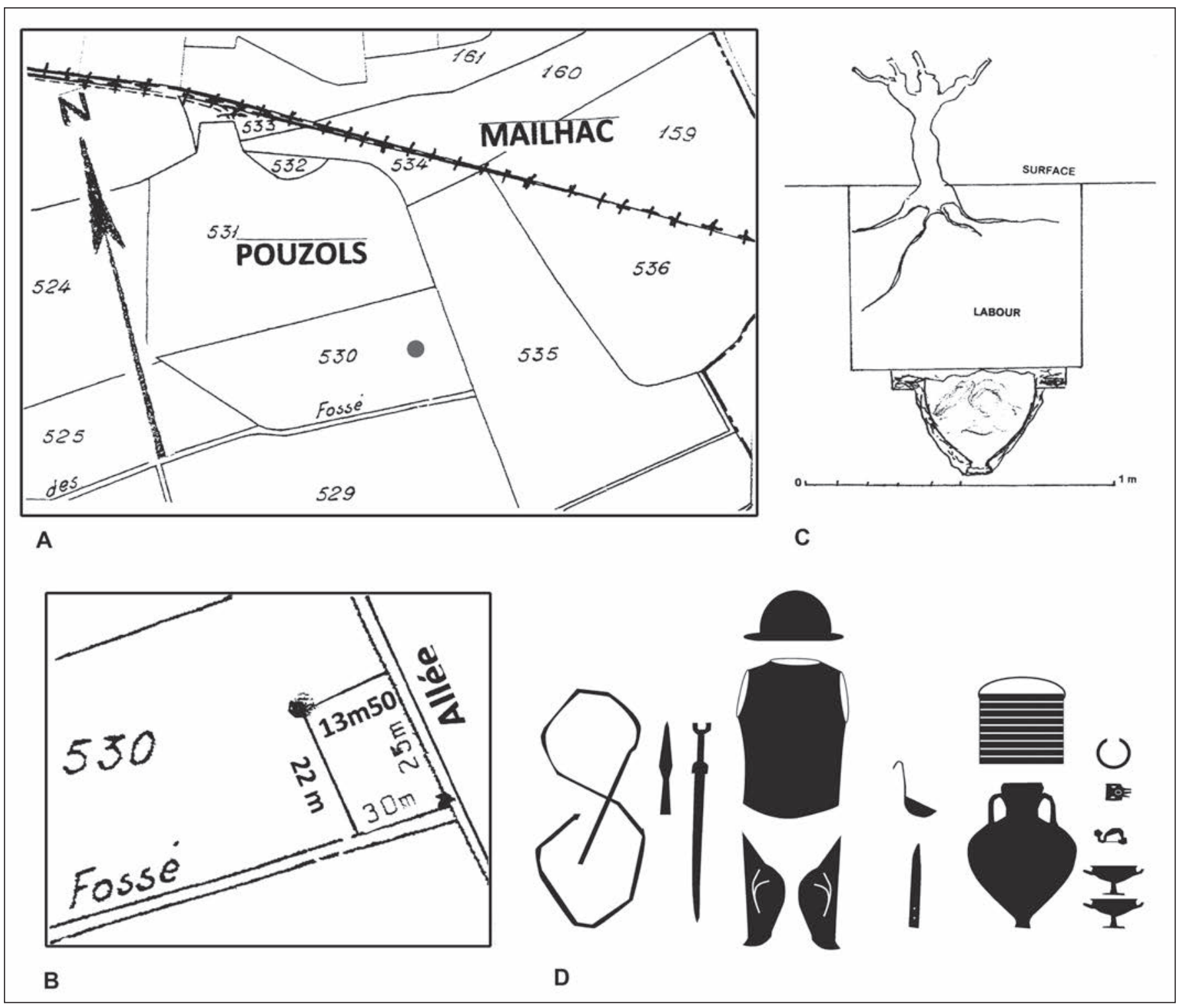

Fig. 1. La tumba de Corno Lauzo: A) Situación del hallazgo del conjunto de Corno Lauzo; B) Triangulación para situar el conjunto de Corno Lauzo; C) Sección de la excavación del punto donde se recuperó en superficie el conjunto de Corno Lauzo y donde se recuperaron restos de una tumba (Dibujos O. Taffanel); D) Esquema de composición del conjunto de Corno Lauzo a partir de la primera publicación (Dibujo R. Graells).

\section{El conjunto de vasos metálicos: un conjunto que aumenta}

El conjunto de vasos metálicos lo integran dos simpula de bronce de tipo catalano-languedociense (Lucas 2003-2004; Graells 2009 ; Graells 2013) (fig. 2, a, b), una cista de cordones, el borde plano de una pátera de bronce (hasta ahora interpretada como casco) y el pie cónico de un vaso de bronce indeterminado.

La cista de Corno Lauzo corresponde al tipo de cista con asas móviles torsionadas (Bouloumié 1976 ; DeMarinis 2000). La aproximación tipológica es posible a partir de la revisión de los fragmentos y sus características. Particularmente la pareja de asas torsionadas y los espacios sin decoración entre los cordones. De esta manera, la identificación tipológica permite concluir que corresponde a una importación centroeuropea. Para una interpretación sobre el mecanismo de llegada de esta pieza puede añadirse al catálogo otra cista de cordones recuperada en la necrópolis catalana de Can Canyís. De este modo, puede plantearse una importación directa pero quizás, más prudentemente a tenor del conocimiento que hasta el momento tenemos de este tipo de importaciones, como resultado de una mediación del norte de Italia a partir de finales del s. VII aC y s. VI aC (Graells 2013). Particularmente esta 

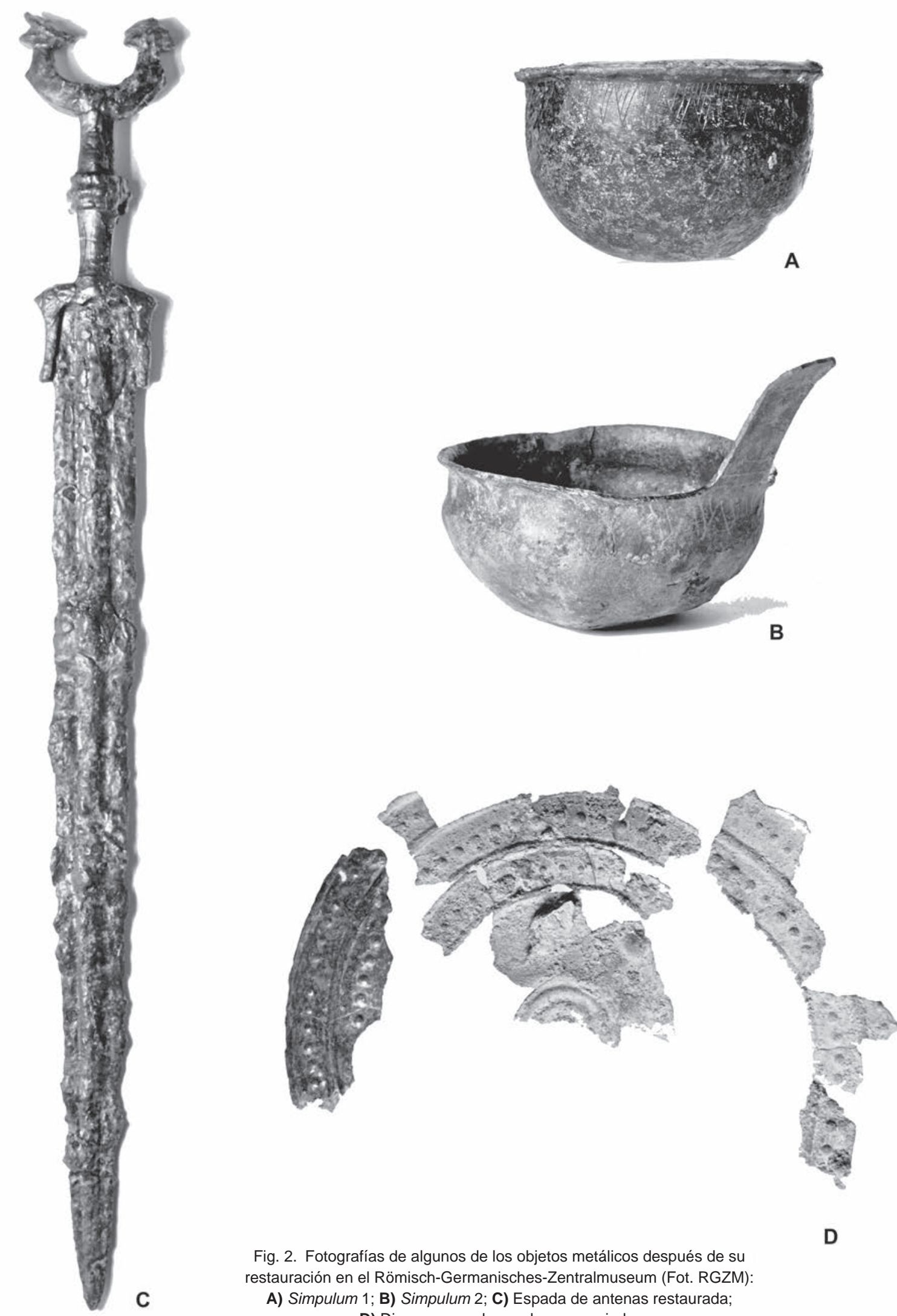

Fig. 2. Fotografías de algunos de los objetos metálicos después de su

D restauración en el Römisch-Germanisches-Zentralmuseum (Fot. RGZM): A) Simpulum 1; B) Simpulum 2; C) Espada de antenas restaurada; D) Disco-coraza decorado por repujado. 
mediación itálica toma fuerza si se observa el uso de este vaso en contexto funerario. Recordemos que en contexto galo el uso de la cista es habitualmente el de cinerario (Bouloumié 1976) (caso de las tumbas de Eigenbilzen, Sivry-les-Arnay, Revilly y Chaumoy), pero en contexto Golasecchiano y norte-itálico aparece en función de vaso de acompañamiento (De Marinis 2004), como en el caso de Corno Lauzo (y posiblemente también en el de Can Canyís). Este último detalle, combina dos elementos que coinciden y, por lo tanto, dan credibilidad a un intermediario del norte de Italia combinando, por un lado, el patrón de deposición y, por otro, los motivos técnicos. Así, en primer lugar, la deposición de la cista como elemento de ajuar pero no de urna cineraria, igual como sucede en las tumbas masculinas del área noritálica, donde sólo las tumbas femeninas presentan este vaso como urna se combina con la realidad de que la práctica totalidad de las cistas del área de Golasecca presentan (menos los casos de la tumba 7 de Mesocco y 1 de Pregassona) el borde enrollado hacia el exterior sobre un vástago de hierro (KM2) (De Marinis 2000 ; 2004), igual como la cista de Corno Lauzo.

La pátera, de borde liso, entra perfectamente en las series de páteras asociadas a tumbas con armas de segundo cuarto del s. VI aC, aunque el estado de conservación no permite mayores precisiones acerca de su tipología.

\section{El conjunto de panoplia militar : un conjunto que disminuye}

El conjunto de panoplia militar se divide entre el equipo ofensivo y el defensivo. El ofensivo, completamente realizado en hierro, se compone por una espada en hierro de antenas, que como ha sido señalado repetidamente no corresponde a los mismos tipos que se documentan en el nordeste de la Península Ibérica (Farnié, Quesada 2005) y que después de la restauración integra un fragmento que en un primer momento había sido interpretado como fragmento de una punta de lanza (fig. 2, c); un cuchillo de hierro ; un soliferrum permite proponer una cronología avanzada al conjunto de panoplia militar, pues la presencia de soliferra no se documenta hasta después mediados del s. VI aC.

La panoplia defensiva, en lámina de bronce, es quizás el repertorio que más ha cambiado después de la restauración y análisis. En un primer momento se identificaron unos supuestos fragmentos de casco, aunque los argumentos para identificarlo con un casco piceno con láminas remachadas no tenía correspondencia con la realidad de los fragmentos. La influencia para tal identificación era la presencia de un casco de ala ancha en la tumba B de Sesto Calende asociado también a una cista de cordones muy próxima a la de la tumba de Corno Lauzo (De Marinis 1975 ; 2009 ; Egg 1986). La restauración del "casco" ha invalidado dicha propuesta y ha demostrado su correspondencia a una pátera. En esa tumba lombarda había también un par de grebas de bronce, que sirvieron para interpretar las de la tumba de Corno Lauzo como fragmentos de cnémides de tipo anatómico, tipo que no tuvo difusión en Occidente (Farnié, Quesada 2005), mientras sí sabemos que encuentra paralelos en contextos golasecchianos, siendo la asociación más significativa la de la tumba de guerrero B de Sesto Calende (De Marinis 2004), y especialmente en contextos etruscos e itálicos de finales del s. VI y V aC. Así, los fragmentos de chapa leídos como fragmentos de cnémides de tipo anatómico, después de la restauración, se han demostrado de filiación catalano-languedocienses, acorde con la distribución tipológica de estos objetos en la región (Graells 2008, p. 109).

Otros fragmentos, en cambio, fueron identificados como una coraza, identificación que bebía de la publicación de la coraza de la tumba de les Ferreres de Calaceite con la que los fragmentos de chapa guardaban cierto parecido decorativo. Es de resaltar que la decoración de esa chapa metálica encuentra otros paralelos singulares como los fragmentos de coraza recuperados en la tumba 17 de la necrópolis de la Muralla Nord-Est de Empúries (Graells 2010), si bien esa tumba no presenta ningún fragmento de lo que podría identificarse con armamento. La restauración, otra vez, ha modificado esa interpretación demostrando la presencia de discos coraza decorados (fig. 2, d).

\section{Elementos de ornamentación del vestuario}

El ajuar se completa con una fíbula de pie levantado y un broche de cinturón de tres garfios con una aplicación de plata.

Este tipo de broches de cinturón encuentra pocos paralelos con tres garfios y alguno más cuando presenta un único garfio. Afortunadamente los ejemplares conocidos de broches de tres garfios han sido documentados con contexto y en el marco de excavaciones arqueológicas sistemáticas mientras que los casos de un único garfio y de dos corresponden a una pieza publicada en el catálogo Joyas de la Edad Oscura, otro broche de un garfio de la Peña Negra y un hallazgo en superficie, con dos garfios, de la necrópolis de Mas de Mussols, el cual presenta unas ligeras diferencias por lo que respecta a la forma de la placa de plata (Maluquer 1984, fig. 15.1). Los ejemplares de tres garfios con placas de plata se documentaron en la necrópolis de Serra de Daró y en la tumba 22 de la necrópolis de les Casetes (Garcia-Gandia 

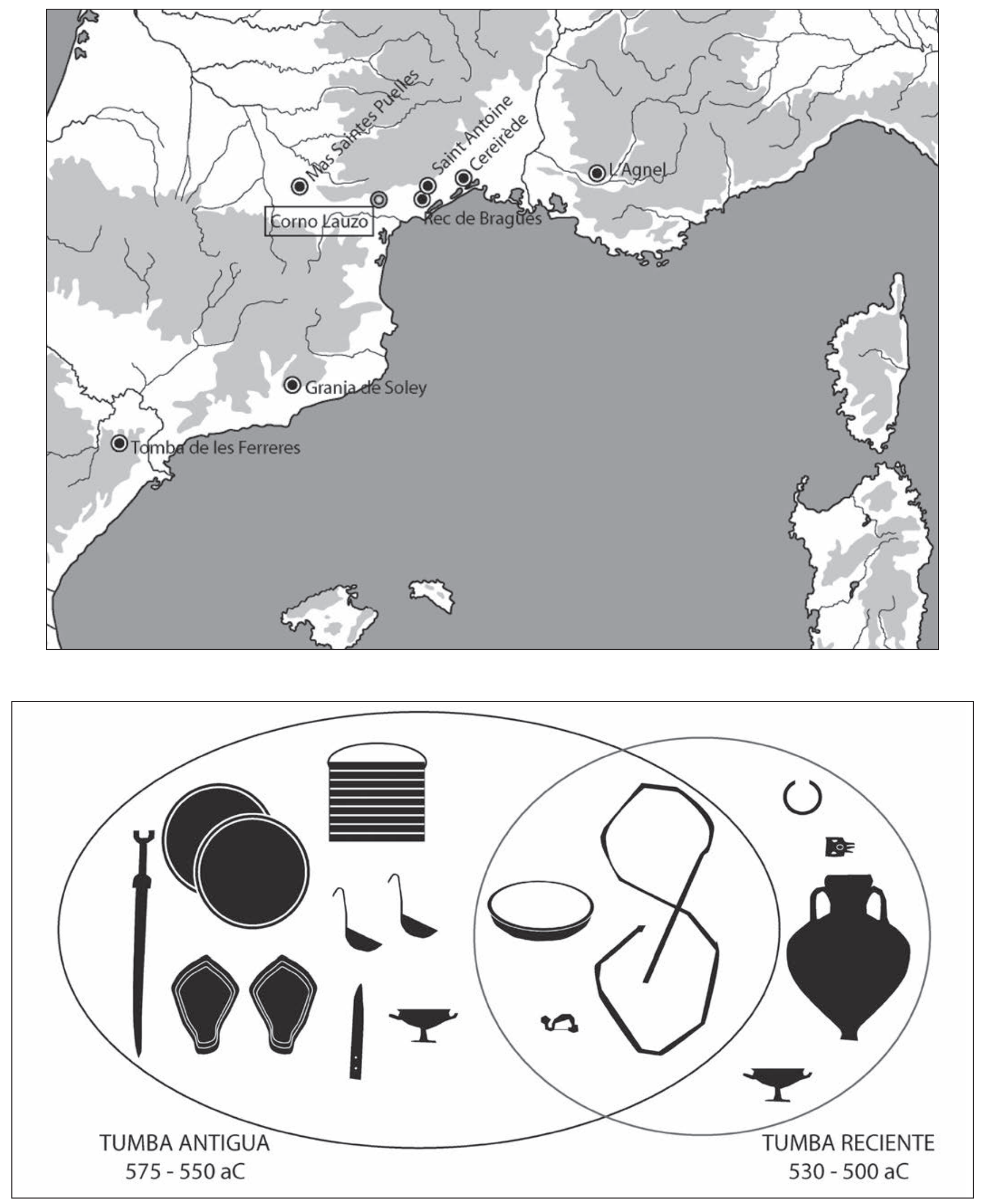

Fig. 3. Parte Superior: Distribución de las tumbas de guerrero aisladas en el Golfo de León occidental. Parte inferior: Propuesta de división de los materiales a partir de su cronología y su lógica asociativa (Dibujos R. Graells). 
2009, fig. 87). La tumba 20 de les Casetes presenta también un soliferrum, una larga punta de lanza, un botón, una cuenta de collar de plata y una fíbula anular hispánica (Garcia-Gandia 2009) (fig. 2).

La cronología de la fíbula, puede considerarse a partir de mediados del s. VI aC, mientras que el broche de cinturón se fecha en el último cuarto del s. VI aC, igual que el brazalete.

\section{Conclusiones}

El conjunto de Corno Lauzo sigue presentando restos de una gran tumba de guerrero, pero con un ajuar de primer rango militar distinto al que hasta ahora se consideraba.

La primera interpretación del ajuar por parte de los hermanos Taffanel tenía como influencias las publicaciones de las grandes tumbas de guerrero de Sesto Calende y Calaceite. Pero el ajuar había sido recuperado en dos momentos distintos con dos años de diferencia entre sí. De esta manera, la primera publicación presentó los dibujos y reconstrucciones ideales de los fragmentos sin una restauración correcta. Esta restauración se realizó en la década de los años 70 en el RömischGermanisches-Zentralmuseum de Mainz.

La restauración de los materiales permitió corregir esas primeras impresiones y reconocer elementos acordes con los parámetros del sur de Francia y Catalunya. Como resultados más significativos, el llamado "casco" corresponde en realidad a un vaso metálico y la coraza, que permanece, cambia su morfología a favor de un cardiophylax discoidal decorado. De esta manera, la primera reconstrucción de los elementos de la tumba, basada en las tumbas de Sesto Calende y de Calaceite, se abandona y la revisión aproxima el conjunto a los ajuares-tipo identificados en el área catalano-languedociense durante el s. VI aC: sin casco y con un ajuar vascular metálico más articulado (y más coherente) en relación a la cronología y contexto de la tumba integrado por dos simpula y una pátera de bronce.

Pero quedaba aún una ulterior corrección de carácter cronológico pues el ajuar presentaba materiales claramente datados en el segundo cuarto del s. VI aC y otros del último cuarto del s. VI aC. Hasta la fecha la interpretación obligaba a rebajar la cronología de los primeros y situar el segundo grupo en el inicio del último cuarto. El resultado era una asociación forzada en comparación con lo observado en el resto de tumbas de guerrero aisladas similares (fig. $\mathbf{3}$, a). Ahora, esa incoherencia cronológica del conjunto puede explicarse por la identificación de un segundo conjunto, quizás femenino, una generación más tardía que el conjunto del Guerrero.
Así, el famoso conjunto de Corno Lauzo debe leerse hoy como la asociación de una tumba de guerrero del segundo cuarto del s. VI aC y una segunda tumba fechada en el último cuarto del VI aC (fig. 3, b).

\section{Agradecimientos}

Este estudio se ha llevado a cabo bajo el financiamiento de la Alexander von Humbodt Stiftung. Quiero agradecer los importantes comentarios y sugerencias del Prof. Dr. M. Egg, del Dr. B. Dedet, del Prof. Dr. Th. Janin, del Sr. G. Marchand, de la Dra. E. Pons, de la Dra. R. Roure, pero especialmente a Mme. O. Taffanel, descubridora del conjunto de Corno Lauzo y que tuvo la amabilidad de facilitarme datos inéditos y mantener una viva discusión, así como autorizarme a utilizar dibujos y datos de la restauración acontecida en los laboratorios del Römisch-Germanisches Zentralmuseum (RGZM). Entre la celebración del coloquio en homenaje a M. Bats y su publicación, Mme. Taffanel murió (30 de mayo de 2012), queden estas páginas como testimonio de mi reconocimiento, admiración y gratitud.

\section{Bibliografía}

Beazley 1932 : BEAZLEY (J.D.) - Little-Master Cups. Journal of Hellenic Studies, 52, 1932, p. 167-204.

Boldrini 1994 : BOLDRINI (S.) - Le ceramiche ioniche. In: TORELLI (M.) dir., Gravisca, Scavi nel santuario Greco, 4, Bari, 1994, 324 p.

Bouloumié 1976 : BOULOUMIÉ (B.) - Les cistes à cordons trouvées en Gaule (Belgique, France, Suisse). Gallia, 34, 1, p. 1-30.

Egg 1986 : EGG (M.) - Italische Helme. Studien zu den ältereisenzeitlichen helmen italiens und der Alpen. Mainz, 1986, 261 p. (RGZM-Monographien 11). Farnié, Quesada 2005 : FARNIÉ (C.), QUESADA (F.) - Espadas de hierro, grebas de bronce. Símbolos de poder e instrumentos de guerra a comienzos de la edad del hierro en la península Ibérica. Comunidad Autónoma de la Región de Murcia, Murcia, 2005, 248 p. (Monografias del Museo de Arte Ibérico de El Cigarralejo 2).

García-Gandía 2009 : GARCÍA-GANDÍA (J.R.) - La necrópolis orientalizante de les Casetes (La Vila Joiosa, Alicante). Publicaciones de la Universidad de Alicante, Serie Arqueológica. Alicante, 2009, 247 p.

Graells 2008 : GRAELLS (R.) - La necrópolis protohistórica de Milmanda (Vimbodí, Conca de Barberà, Tarragona). Un exemple del món funerari català durant el trànsit entre els segles VII $i$ VI aC. Institut Català d'Arqueologia Clàssica, Tarragona, 2008, 167 p. (Hic et Nunc 5).

Graells 2009 : GRAELLS (R.) - Banquet funerari i elements de banquet en tombes del nord-est de la península ibèrica entre la primera edat del ferro $\mathrm{i}$ l'ibèric antic. Citerior, V, 2009, p. 189-218.

Graells 2010 : GRAELLS (R.) - Las tumbas con importaciones y la recepción del Mediterráneo en el nordeste de la Península Ibérica (ss.VII-VI aC). Revista d'Arqueologia de Ponent Serie Extra, 1, Lleida, 2010, 266 p.

Graells 2013 : GRAELLS (R.) - De Italia al Bajo Aragón: La dinámica de intercambios indígena entre el s. VII y VI aC. In : Colin (A.), Verdin (F.) dir., Mobilité des hommes, diffusion des idées, circulation des biens dans l'espace européen à l'àge du Fer, Actes du XXVe Colloque de l'AFEAF (Bordeaux, 2-5 juin 2011), supplément 30 d'Aquitania, Bordeaux, 2013, p. $727-736$ 
Graells, Armada 2011 : GRAELLS (R.), ARMADA (X.-L.) - La tumba de les Ferreres de Calaceite a partir de los materiales del Musée des Antiquités Nationales de Saint-Germain-en-Laye. Studi Etruschi, LXXIV, 2011, p. 17-37.

Hundt 1969: HUNDT (H.J.) - Der technische Aufbau des Dolchgriffes von Corno Lauzo. In: SCHÜLE (W.), Die Meseta-Kulturen der Ibersichen Halbinsel, Mediterrane und Eurasische Elemente in Früheisenzeitlichen kulturen Südwesteuropas, Berlin, 1969, p. 94-95.

Janin $\boldsymbol{e}$ t al. 2002 : JANIN (Th.), TAFFANEL (O.), TAFFANEL (J.), BOISSON (H.), CHARDENON (N.), GARDEISEN (A.), HÉRUBEL (F.), MARCHAND (G.), MONTÉCINOS (A.), ROUQUET (J.) - La nécropole protohistorique du Grand-Bassin II à Mailhac, Aude (VIe-Ve s. av. n. è.). $D A M$, 25, 2002, p. 65-122.

Lucas 2003-2004 : LUCAS (M.R.) - Simpulum y bebida, marcadores de prestigio y jefatura durante el Hierro I (siglos VII/VI aC): entre el Hérault y el Ebro, Kalathos, 22-23, p. 95-134.

Maluquer 1984 : MALUQUER (J.) - La necrópolis paleoibérica de "Mas de Mussols", Tortosa (Tarragona). Programa de Investigaciones Prehistóricas, VIII, Universitat de Barcelona, Barcelona, 1984, 34 p.
De Marinis 1975 : De MARINIS (R.C.) - Le tombe di guerriero di Sesto Calende e le spade e i pugnali hallstattiani nell'Italia nord-occidentale. In: Caffarello (N.) a cura di, Archaeologica. Scritti in onore di Aldo Neppi Modona, Arte e Archeologia - Studi e Documenti, 9, Firenze, 1975, p. 213-269.

De Marinis 2000 : De MARINIS (R.C.) - Il vasellame bronzeo nell'area alpina della cultura di Golasecca. In: De MARINIS (R.C.), BiaggioSimona (S.) a cura di, I Leponti, tra mito e realtà. Raccolta di saggi in occasione della mostra, Gruppo Archeologia del Ticino, 2000, p. 341-406.

De Marinis 2004 : De MARINIS (R.C.) - Principi e guerrieri nella civiltà di Golasecca. In : Marzatico (F.), Gleirscher (P.), a cura di, Guerrieri, principi ed eroi fra il Danubio e il Po, dalla preistoria all'alto medioevo, Trento, 2004, p. 293-303.

De Marinis 2009 : De MARINIS (R.C.), Sesto Calende, la seconda tomba di guerriero. In : De Marinis (R.C.), Massa (S.), Pizzo (M.) a cura di, Alle origini di Varese e del suo territorio. Le collezioni del sistema archeologico provinciale, Bibliotheca Archaeologica, 44, Roma, 2009, p. 162-203.

Taffanel, Taffanel 1960 : TAFFANEL (J.), TAFFANEL (O.) - Deux tombes de chefs à Mailhac. Gallia, XVIII, 1960, p. 3-32. 


\title{
La question des échanges et des assemblages funéraires à travers le mobilier métallique de la nécropole protohistorique du Causse à Labruguière (Tarn)
}

\author{
André Rivalan \\ Associé UMR5140 Archéologie des Sociétés Méditerranéennes \\ Laura Bourdajaud \\ Doctorante UMR5140 Archéologie des Sociétés Méditerranéennes
}

\section{Résumé}

Les fouilles préventives menées entre 1995 et 2010 dans la nécropole protohistorique du Causse ont entraîné la découverte d'un ensemble de 1030 tombes à incinération, dont certaines se distinguent nettement par la nature et la composition de leurs assemblages. À partir de l'analyse de ces quelques sépultures particulières, et surtout de leur évolution au cours du temps (925 - 450 av. n. è.), nous verrons tout d'abord en quoi leur mobilier d'accompagnement témoigne parfois d'échanges à longue distance, avant d'élargir notre propos aux divers apports que celui-ci est susceptible de fournir sur la question des assemblages funéraires. La présence d'un certain nombre d'associations spécifiques de mobilier au sein des sépultures, ou encore celle d'objets vraisemblablement importés constituent effectivement de précieux indicateurs sur les modalités encadrant les pratiques funéraires de l'époque, ainsi que sur les relations de nature commerciale, voir même culturelle, que cette communauté pouvait entretenir avec d'un côté les populations du Languedoc occidental et de l'autre, les communautés du quart sud-ouest de la France.

Mots-clés : Protohistoire, nécropole, incinération, premier âge du Fer, métal, échanges, France

\begin{abstract}
The preventive excavations conducted between 1995 and 2010 in the protohistoric necropolis of the Causse led to the discovery of a set of 1030 cremation graves, some of which are clearly distinguished by the nature and the composition of their artefacts. Thanks to the analysis of these particular graves, and especially their evolution over time (925 - $450 \mathrm{BC}$ ), we shall see first of all to what extent their funeral artefacts sometimes testifies of long distance exchanges, before widening our comments to the diverse contributions which this objects may provide to the question of the funerary assemblages. The presence of a certain number of specific combinations of artefacts within the graves, as well as imported objects, constitutes indeed, very valuable indicators on the modalities framing the funeral practices of that time, as well as on the commercial and cultural relations, that this community could maintain with the populations established in western Languedoc on one side and with the communities of the southwest quarter of France on the other.
\end{abstract}

Keywords: Protohistory, necropolis, crémation, First Iron Age, métal, exchanges, France 


\section{Présentation du site et des vestiges archéologiques}

La nécropole protohistorique du Causse (Labruguière, Tarn) constitue l'un des plus importants ensembles funéraires du Midi de la France en termes d'ensembles clos fouillés, du moins pour la période comprise entre 925 et 450 av. n. è. Les opérations préventives menées sur ce site entre 1995 et 2010 ont en effet permis l'exploration d'environ 1030 tombes à incinération ${ }^{1}$ et ont entraîné la découverte d'un mobilier céramique et métallique relativement abondant (Giraud, Pons, Janin et al. 2003 ; Buffat et al. 2012). Afin d'illustrer l'importance de cette série d'un point de vue quantitatif, et donc épistémologique, nous rappellerons notamment que ces fouilles ont livré pas moins de 1700 objets métalliques et près de 3120 vases en terre cuite ${ }^{2}$. On ajoutera, par ailleurs, que ces divers objets sont non seulement de nature et de fonction variées, mais aussi qu'ils sont très inégalement répartis au sein de ce vaste complexe funéraire et trouvent parfois leur origine géographique dans des contrées relativement lointaines. Cet abondant mobilier constitue par conséquent une source précieuse d'informations non seulement sur les pratiques funéraires de l'époque mais aussi et surtout sur les relations de nature «commerciale», voire même culturelle, que cette communauté pouvait entretenir avec les entités territoriales environnantes.

À la vue de ces quelques observations préliminaires, le lecteur comprendra dès lors tout l'intérêt que représente ce mobilier pour l'étude des pratiques funéraires de cette période, ainsi que pour toute une série de questions relatives à l'économie et à la structuration de cette communauté protohistorique. Nous verrons ainsi, à travers cet article, dans quelle mesure ce mobilier funéraire est susceptible de nous éclairer sur certains gestes réalisés dans le cadre des pratiques funéraires de l'époque, mais aussi sur leur évolution au cours du temps et leur probable signification sociale. La première étape de cette démarche nous conduira, en l'occurrence, à examiner l'évolution des assemblages de cette nécropole au cours du temps et surtout, au moyen de nouvelles matrices ordonnées, à rechercher ceux qui s'en distinguent. Elle

\footnotetext{
1 Ces nombreuses sépultures sont toutefois très loin de présenter le même état de conservation. Les observations effectuées sur le terrain montre en effet que près de 310 tombes sont plus ou moins arasées, et que 354 tombes sont fortement bouleversées ou totalement détruites. On notera enfin dans le même ordre d'idée que seules 559 sépultures sont correctement datables au sein de ce vaste ensemble funéraire (voir note 5).

2 Un volume de mobilier qui ne trouve par ailleurs guère de points de comparaisons à l'échelle régionale, sinon dans les nécropoles de Mailhac dans l'Aude (Taffanel, Janin 1998 et Janin et al. 2002).
}

nous conduira ensuite à analyser les groupes de sépultures ainsi définis au sein de ce vaste ensemble funéraire et, enfin, leur possible signification d'un point de vue économique et social.

Si cette démarche est ici pour le moins simple à formuler, sa mise en œuvre s'avère néanmoins très délicate étant donné l'état de conservation aléatoire des structures et des vestiges archéologiques. Outre la grande prudence que ce dernier paramètre implique d'un point de vue interprétatif, on notera également, dans le même ordre d'idée, que les résultats obtenus au terme de cette étude ne pourront être réellement «confortés » qu'après leur confrontation avec les autres grandes composantes de ces tombes (mobilier céramique, dépôt carné, architecture et répartition topographique), ainsi qu'avec les assemblages des principaux ensembles funéraires de la région, au premier rang desquels figurent bien évidemment les nécropoles de Mailhac dans l'Aude (Taffanel, Janin 1998 ; Janin et al. 2002) et certaines nécropoles tarnaises comme celles de Gourjade et du Martinet (Giraud, Pons, Janin et al. 2003).

\section{Nature et évolution des assemblages métalliques}

Les principales caractéristiques des assemblages funéraires de la nécropole du Causse ont déjà été analysées par les études précédentes (Giraud, Pons, Janin et al. 2003, p. 250-254) et ne feront par conséquent l'objet, dans les lignes qui vont suivre, que d'un bref rappel général et de certains ajustements. On notera ainsi à la suite de ces auteurs que les assemblages caractéristiques du Bronze final IIIb sont généralement constitués d'éléments vestimentaires et de parure corporelle (épingles, bracelets, torques, anneaux, boutons), ainsi que d'instruments dits de «toilette », tels que des pincettes et plusieurs types de rasoirs à double tranchant (fig. 1). À partir de la fin du VIII s. av. n. è., ce même mobilier métallique se distingue en revanche de celui de la période précédente par l'apparition des premiers couteaux en fer, de nouveaux types d'épingles ou de rasoirs en bronze, et enfin par une réelle introduction des fibules et des scalptoriums. Le mobilier de la phase récente (575-525 av. n. è.) se caractérise enfin par la disparition progressive des rasoirs et des épingles, au profit des couteaux à manche riveté et des fibules. On remarquera, pour finir, que l'une des autres nouveautés de cette période consiste en la réapparition des armes, épées à antennes et leurs fourreaux, au sein de cette nécropole, sans oublier l'introduction des agrafes de ceinture à un ou trois crochets, et celle des premiers mors de chevaux en fer (Giraud, Pons, Janin et al. 2003 ; Buffat et al. 2012). 
En marge de ces quelques caractéristiques générales, il conviendra également de rappeler la présence récurrente, durant ces trois grandes phases, d'un certain nombre d'objets métalliques importés ${ }^{3}$ dont la forme et l'origine sont, qui plus est, susceptibles de varier au cours du temps (fig. 2). Ces quelques pièces revêtent en effet ici une très grande importance puisqu'elles sont clairement les seules, au sein de ces diverses panoplies, qui permettent une approche pertinente des questions relatives à la nature des échanges à longue distance, et, ce faisant, d'esquisser l'évolution des possibles réseaux d'échanges sous-jacents. Ainsi, dès le Bronze final IIIb (925 - 775 av. n. è.), certains rares ensembles livrent un mobilier vraisemblablement importé soit du Languedoc occidental, soit de la sphère nord-alpine, à l'instar de certains types d'épingles (types à tête annulaire et sphérique, ou en rouelle; Kubach 1977 ; Audouze, Gaucher 1981) et de rasoirs à double tranchant (types «Pépieux », « Mailhac 2 » et probables variantes du type «Shledebrück» ou «Brentford»; Jockenhövel 1980). Hormis ces quelques types spécifiques d'objets métalliques, la nécropole du Causse a également livré certains rasoirs de type « Fréjeville », qui s'apparentent de toute évidence à un type nord-italique connu sous le nom de «Castellaro di Gottolengo » (Bianco Peroni 1979), ainsi que plusieurs fibules à double ressort et deux types d'armatures de flèche (pointe à pédoncule renflé et type «Le Bourget») qui, elles, proviennent vraisemblablement du Midi de la France, même si leur modèle est plutôt originaire du monde méditerranéen dans le cas des pointes de flèches (Guilaine 1972 ; Avila 1983), et de la sphère hispanique dans celui des fibules à double ressort (Schüle 1969; Karte 16).

Bien que l'origine des importations caractéristiques de la phase 725 - 575 av. n. è. n'apparaisse, en substance, guère différente de celle de la période précédente (fig. 2), ce mobilier exogène se distingue toutefois par une augmentation notable du nombre d'exemplaires correspondants, ainsi que par une apparition de nouvelles catégories de mobilier: couteaux en fer à manche riveté, épingles (types à tête en haltère, types à col enroulé et tête sphérique), rasoirs en croissant

3 Nous entendons ici par « importations » tous les objets rares de la nécropole dont le type se retrouve en abondance au sein d'une région périphérique donnée. Si la présence de copies locales est bien évidemment envisageable, celle-ci s'avère toutefois très difficile à démontrer et ne sera par conséquent retenue que pour quelques rares objets comme les rasoirs de type «Fréjeville » ou encore l'agrafe de ceinture en bronze mise au jour dans la tombe 1068 (fig. 2). Cette dernière se rapproche en effet du type «ibérique » à un ou plusieurs crochets, mais s'en distingue par la qualité médiocre de son décor et surtout le caractère fruste de son contour. (type « Magny-Lambert » et «Feldkirch / Poiseul»; Jockenhövel 1980), scalptoriums (Soutou 1959) et fibules serpentiformes languedociennes (Nickels et al. 1989 ; Giraud, Pons, Janin et al. 2003). S'il est bien évidemment difficile d'expliquer dans le détail ces quelques différences typologiques et quantitatives, on notera toutefois que la hausse très nette du nombre d'éléments concernés peut tout autant s'expliquer par une intensification des échanges entre la région tarnaise et le Languedoc occidental, que par l'apparition des premières relations de nature «commerciale » établies avec les communautés implantées à l'ouest de cette zone géographique.

Le mobilier exogène de la phase suivante (575 450 av. n. è.) se distingue en effet très nettement de celui des périodes précédentes par l'arrivée des premières pièces issues du quart sud-ouest de la France, et pour être plus précis, par la présence de quelques fibules en fer de type « Navarro - Aquitain », d'épées à antennes de type «Aquitain» et d'éléments de fourreaux en fer de même origine (fig. 1 et 2) (Mohen 1980). Malgré le développement rapide et durable de cet important axe d'échange, il importera néanmoins de souligner que les réseaux observés pour les périodes précédentes paraissent tout aussi actifs, et ce, en dépit de la disparition des pièces caractéristiques du nord de l'Italie. On citera notamment à titre d'exemple la découverte d'une fibule à pied en timbale et de mors à branches en «U » composites d'origine nord-alpine (Verger 1996 ; Feugère, Guillot 1986, p. 203, fig. 42), ou encore la présence de fibules de type «Golfe du Lion » et d'autres caractéristiques du faciès Grand-Bassin II languedocien (Janin et al. 2002), ainsi que celle de plusieurs épées à antennes en fer de type «Corno Lauzo » (fig. 1 et 2). Notons pour finir qu'hormis ces quelques importations plus ou moins directes de mobilier, les fouilles menées dans cette nécropole ont également permis de mettre au jour certaines pièces dont la provenance exacte est plus difficile à cerner en raison de leur caractère pour le moins ubiquiste. Le cas des agrafes de ceinture ibériques ou encore celui des pendeloques triangulaires constituent ici de bons exemples d'une telle situation, étant donné que ces objets sont connus à la fois dans le Midi et dans le quart sud-ouest de la France (Mohen 1980 ; Janin et al. 2002).

\section{Analyse des assemblages funéraires}

Après avoir vu les principales caractéristiques de ces assemblages au cours du temps, il convient maintenant d'approfondir leur analyse en nous intéressant à la question des panoplies individuelles, et surtout à celle de leur 


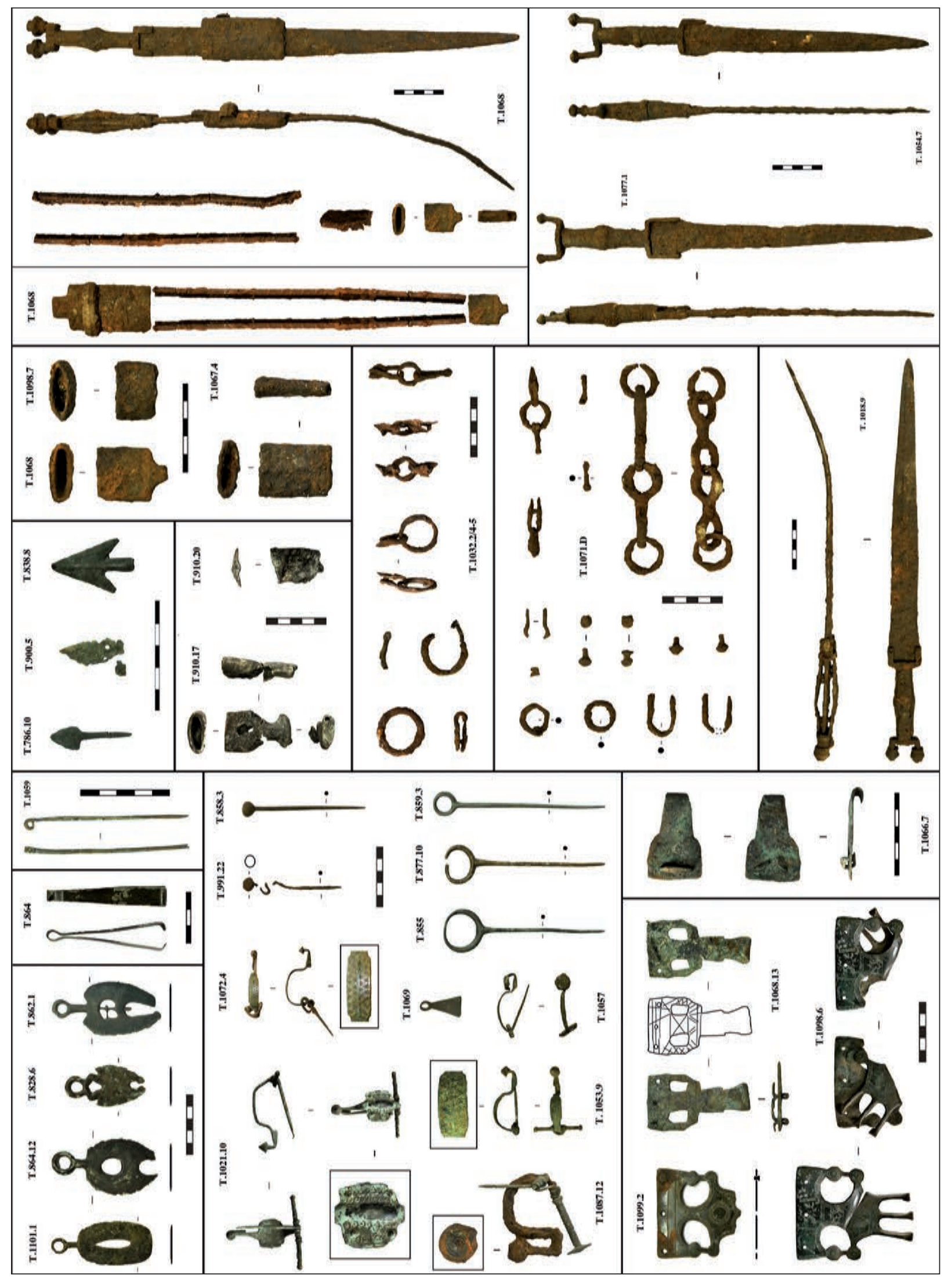

Fig. 1. Exemples d'objets métalliques découverts dans la nécropole du Causse. 

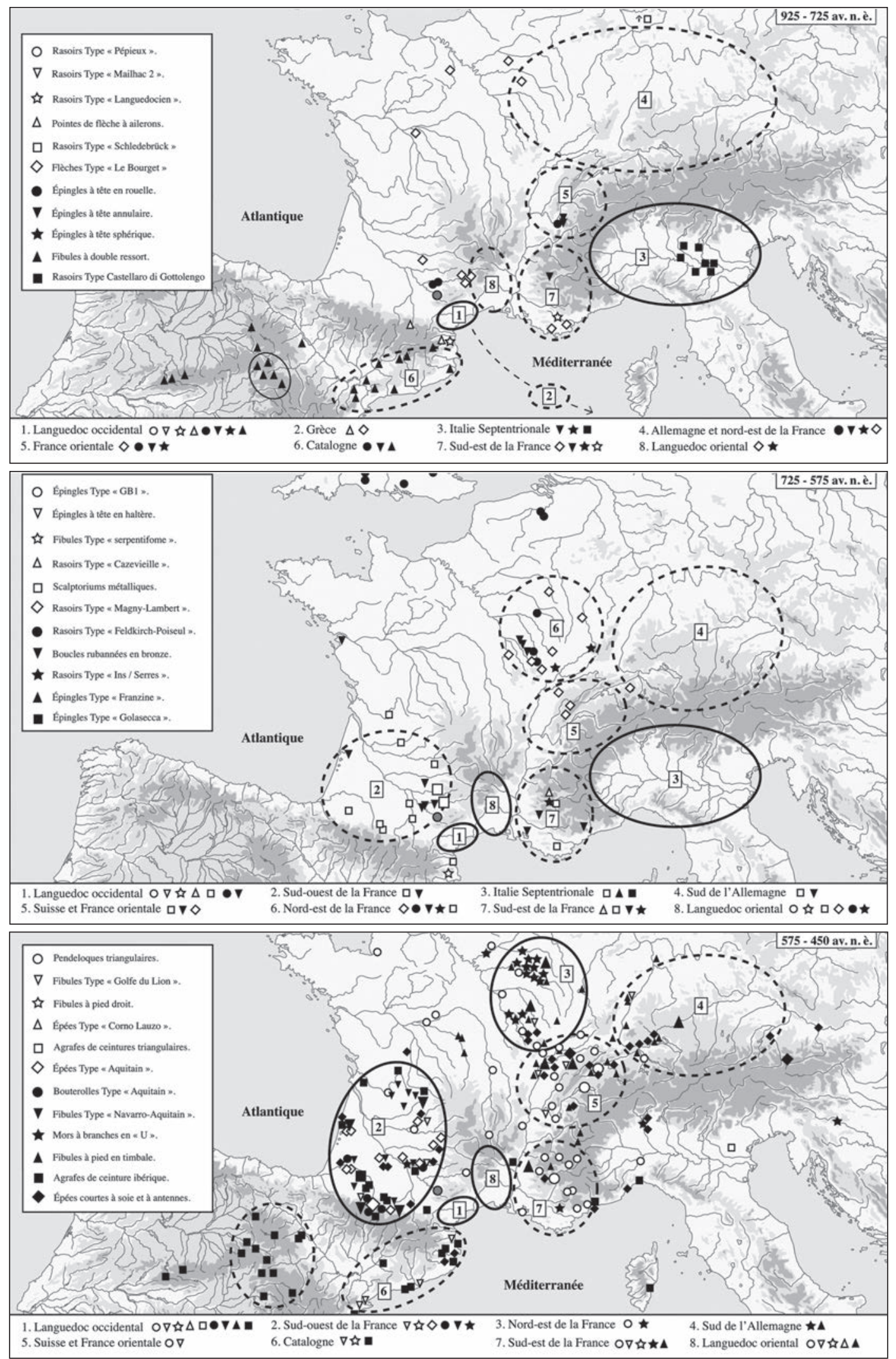

Fig. 2. Évolution et origine géographique du mobilier métallique d'importation (d'après Galan, Soutou 1959, Soutou 1959, Schüle 1969, Navarro 1970, Guilaine 1972, Roudil 1972, Carancini 1975, Peroni et al. 1975, Kubach 1977, Jockenhövel 1980, Mohen 1980, Audouze, Gaucher 1981, Sievers 1982, Avila 1983, Feugère, Guillot 1986, Nickels et al. 1989, Verger 1996, Cordier 2002). 


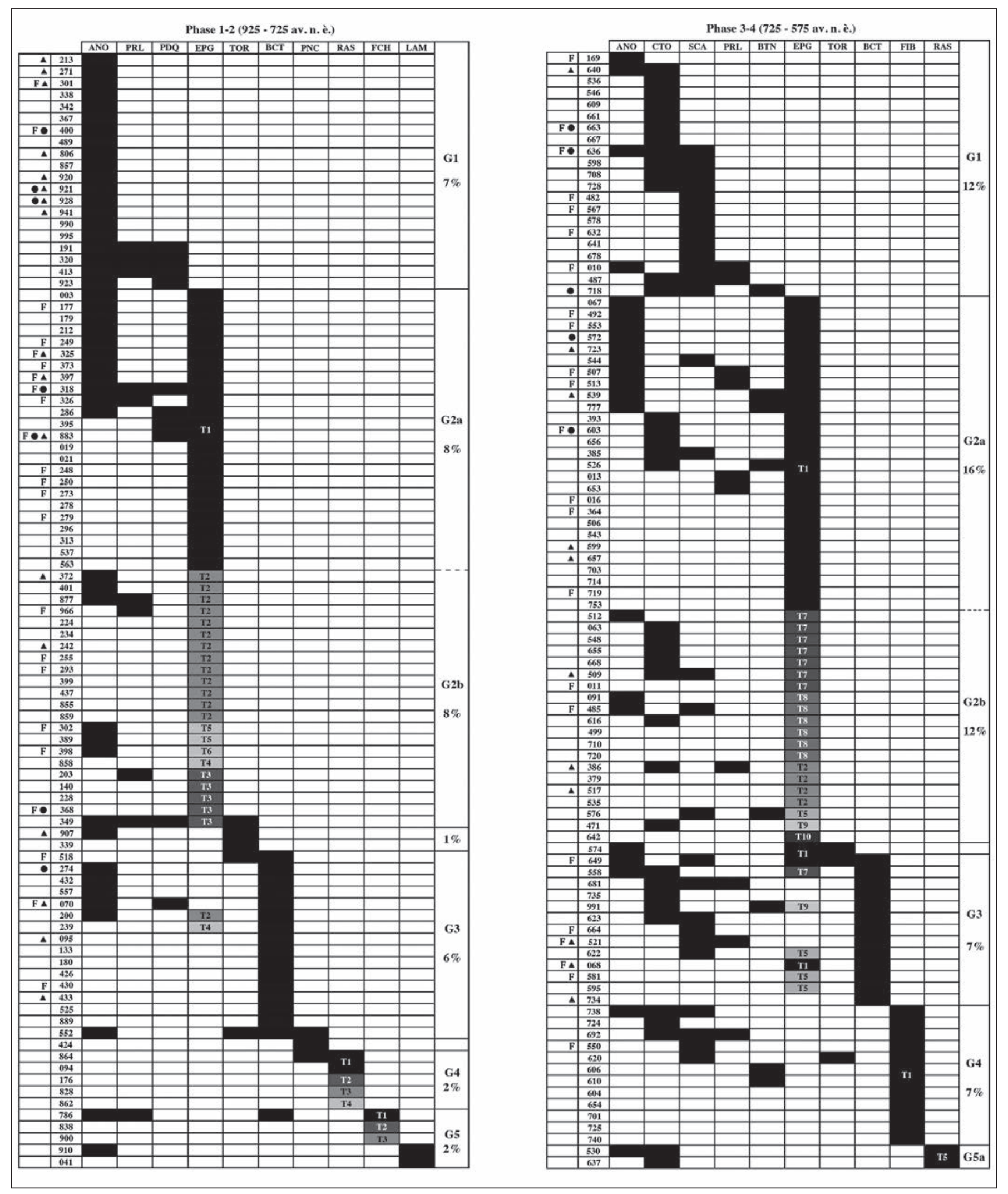




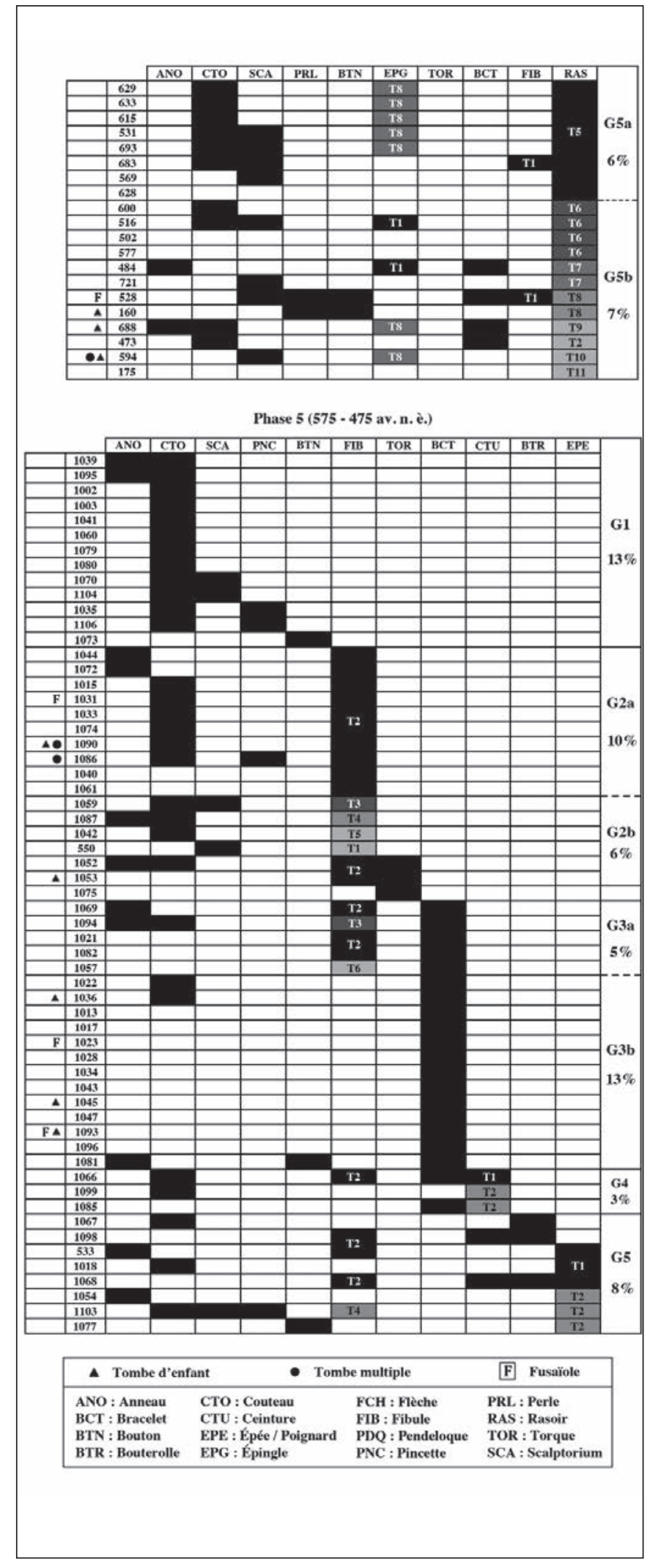

Fig. 3. Matrice des objets métalliques de la nécropole du Causse. évolution au cours du temps. Si cette démarche a bien évidemment fait l'objet d'une première approche dans le cadre des études chronologiques et paléo-sociologiques de la nécropole (Giraud, Pons, Janin et al. 2003, p. 162-210 et p. 234-237), on rappellera toutefois que les critères retenus ont logiquement été triés en fonction de leur rôle symbolique ou de leur valeur chronologique, et interdisent par conséquent une vision précise des associations de mobilier. C'est pour cette raison qu'il nous a semblé nécessaire non seulement de réaliser de nouvelles matrices de mobilier, mais aussi de les organiser en fonction de critères purement typologiques (fig. 3). Les nombreux objets apparaissent ainsi classés en fonction de leur catégorie (épingles, anneaux, couteaux, etc.) et de leur type ${ }^{4}$, tandis que l'ordre des critères dépend à la fois des grandes familles de mobilier correspondantes (parure, outils, armes), et de leur fiabilité d'un point de vue matriciel (Giraud, Pons, Janin et al. 2003, p. 234). Afin d'étayer ce dernier point méthodologique, on observera ainsi que les pièces trop récurrentes à l'échelle de la nécropole (couteaux, anneaux et scalptoriums), ou celles trop rares (perles, boutons et pendeloques) ont été classées à gauche du tableau, dans le but de morceler leurs attestations au sein des groupes matriciels, et ainsi privilégier les critères plus significatifs (fig. 3). Dans le même ordre d'idée, on notera enfin que les rares catégories de mobilier représentées par un unique objet au cours de l'une des cinq phases envisagées, ont logiquement été écartées de ces matrices afin d'éviter un morcellement inutile des groupes obtenus.

Avant d'examiner les différents éléments constitutifs de ces matrices, nous rappellerons tout d'abord qu'en dépit de leur nombre (1700 exemplaires) et de leur grande diversité typologique (supra), les objets métalliques de la nécropole du Causse se retrouvent néanmoins dans un nombre relativement limité de sépultures. Un examen des séries disponibles montre en effet que sur les

4 Les numéros attribués au divers types de mobilier correspondent aux formes suivantes : Épingles à tête enroulée (T1), à tête annulaire (T2), à tête en rouelle (T3), à tête sphérique (T4), de type du « Roc » (T5), à tête sub-conique (T6), à tête en crosse et col enroulé (T7), à tête en crosse (T8), de type «Grand Bassin 1 » (T9) et à tête en haltère (T10) / Rasoirs de type «Pépieux » (T1), « Mailhac 2 » (T2), «Schledebrück » (T3), « Fréjeville » (T4), «Quarante » (T5), « Magny / Lambert » (T6), « Castres » (T7), « Ins / Serres » (T8), «Languedocien » (T9), « Cazevieille» (T10), et « Feldkirch» (T11) / Fibules serpentiformes languedociennes (T1), de type « Golfe du Lion » (T2), à pied droit (T3), de type « Navarro-Aquitain » (T4), de type « Aquitain » (T5), et à pied en timbale (T6) / Flèches à pédoncule et pointe triangulaire (T1), de type «Égéen » (T2) et de type «Le Bourget » (T3) / Épées à antennes en fer de type « Aquitain» (T1) et de type « Corno Lauzo » (T2). 
559 tombes datables de la nécropole ${ }^{5}$, seuls $54 \%$ des ensembles ont livré ce type de mobilier spécifique. Si ce constat doit être nuancé en raison du fait que la part des objets métalliques s'accroît de manière significative entre la fin de l'âge du Bronze (40\% des sépultures) et le premier âge du Fer ( $70 \%$ des sépultures), celuici soulève néanmoins toute une série d'interrogations sur les possibles raisons sociales ou économiques d'un tel écart statistique (rareté et redistribution inégale du métal, signification culturelle du mobilier, système de type ploutocratique, etc.) ; et ce, d'autant plus que les inventaires de mobilier dont nous disposons montrent non seulement l'existence de plusieurs groupes matriciels distincts d'assemblages, mais aussi leur présence dans des proportions variables tout au long de la séquence chronologique envisagée (fig.3). Ainsi, un examen général de ces trois représentations graphiques fait tout d'abord clairement apparaître un premier groupe constitué uniquement de pièces «banales » (anneaux, couteaux, scalptoria, etc.) ou peu fiables d'un point de vue matriciel (Groupe 1), et un deuxième formé d'un élément de fixation vestimentaire ou capillaire (épingles et fibules), auquel vient parfois s'ajouter un ou plusieurs éléments du premier groupe. On remarquera par ailleurs que ce deuxième ensemble de sépultures (Groupe 2) est loin d'être homogène étant donné que certains de ces éléments de fixation se retrouvent dans des assemblages bien plus singuliers (voir infra), et qu'il semble exister une véritable bipartition au sein du groupe, entre d'un côté les sépultures pourvues d'un type extrêmement récurrent d'épingle ou de fibule (Groupe 2a) et de l'autre, celles pourvues de types importés plus ou moins rares à l'échelle de la nécropole (Groupe 2b). En marge de ces groupes, il convient ensuite de signaler la présence de quelques sépultures renfermant non seulement certaines des catégories précitées, mais aussi et surtout un ou deux bracelets de section variable (Groupe 3); et enfin, les tombes dont l'assemblage est constitué d'éléments plus rares et généralement importés, comme les rasoirs à simple ou double tranchant, les pièces d'armement (flèches, épées, poignards et bouterolles) et les agrafes de ceinture à un ou plusieurs crochets (Groupes 4 et 5).

Bien que les observations que nous venons de formuler paraissent clairement s'appliquer aux trois grandes phases d'occupation de la nécropole, il n'en demeure

5 Les sépultures prises en compte ici ont été datées dans le cadre des travaux originaux effectués sur cette nécropole (Giraud, Pons, Janin et al. 2003, p. 241-246 et Buffat et al. 2012, p. 79-84) et se caractérisent non seulement par leur bon état de conservation, mais aussi par la présence d'objets significatifs (céramiques ou métalliques) d'un point de vue chronologique. pas moins que ces divers assemblages semblent quelque peu varier au cours du temps et méritent par conséquent d'être précisés dans les lignes qui vont suivre. Un examen plus approfondi de ces matrices montre en effet que le nombre d'attestations par grande catégorie de mobilier est susceptible de fortement varier au cours du temps, à l'instar des rasoirs en bronze qui sont relativement rares au Bronze final IIIb ( $2 \%$ des sépultures) et quasi absents des tombes de la phase 5, alors qu'ils sont bien plus fréquents au début de l'âge du Fer (13\% des tombes), ou encore les fibules dont le nombre ne cesse de croître tout au long de cette période, au point de remplacer les épingles comme système de fermeture vestimentaire à partir du $\mathrm{VI}^{\mathrm{e}} \mathrm{s}$. av. n. è. On remarquera dans le même ordre d'idée que les diverses pièces d'armement (flèches, épées, poignards et bouterolles) sont presque absentes des contextes du début de l'âge du Fer, alors qu'elles se retrouvent en faible quantité à la fin de l'âge du Bronze ( $2 \%)$ et à la fin du premier âge du Fer $(8 \%)$. Notons pour finir que si certaines de ces spécificités, et d'autres comme la disparition progressive des scalptoria au cours de la Phase 5, paraissent refléter les trois temps classiques (apparition en faible quantité, apogée du nombre d'attestations et disparition progressive) qui caractérisent la « distribution quantitative d'un type d'objet au cours du temps » (Giligny 2002 , p. 144), celles liées à l'armement semblent en revanche résulter plutôt de pratiques culturelles spécifiques, et donc probablement du poids symbolique des objets en question. Un constat qui nous amène dès lors à nous interroger sur le sens à donner aux autres groupes de mobilier, et par la même occasion, aux sépultures correspondantes.

Ainsi, parmi les grandes questions soulevées par l'existence et l'évolution de ces cinq groupes de sépultures, celle de leur possible signification sociale ou culturelle au sein de cette nécropole constitue bien évidemment un élément majeur et tout à fait central pour la bonne compréhension des possibles mécanismes de représentation personnelle sous-jacents. S'il est bien évidemment tentant de considérer ce découpage matriciel comme le reflet d'un système purement hiérarchique et, ce faisant, de rapprocher les tombes des Groupes 4 et 5 d'un ensemble de personnages de haut rang social, la prise en compte des autres catégories de mobilier métallique, et en particulier la mise en évidence des autres groupes d'assemblages, nous montre néanmoins à quel point cette vision des choses est quelque peu simpliste, et surtout très insuffisante pour justifier l'existence d'une véritable hiérarchisation des sépultures. Afin d'étayer cette dernière remarque, il importe avant toute chose de rappeler que ce type de considérations nécessite à 
l'évidence une comparaison de ces divers groupes aux nombreux assemblages céramiques et fauniques de la nécropole, et ne pourront dès lors être validés qu'à l'issue de cette démarche spécifique. On notera d'ailleurs que les divers groupes que nous avons mis en évidence pourraient aussi refléter d'autres particularités culturelles, à l'instar du lignage du défunt, ou encore de son origine géographique. Les assemblages ainsi définis correspondraient dès lors à un découpage de type identitaire, et renverraient, pourquoi pas, à un système clanique et familial, ou encore à une nécropole de type communautaire. D'autres interprétations sont bien évidemment envisageables, comme celles imputables à l'âge ou au sexe du défunt ${ }^{6}$, mais l'on remarquera néanmoins que ces dernières demeurent fragiles, étant donné que la prise en compte de l'anthropologie nous montre que des sujets immatures se retrouvent dans de nombreux groupes d'assemblages distincts, tandis que l'intégration des fusaïoles dans le classement matriciel incite à voir la présence de sujets féminins dans la plupart des groupes mis en évidence (fig. 3).

Quoi qu'il en soit, et en dépit de toutes les questions que ces propos soulèvent, la présence de ces nombreux assemblages funéraires au sein de la nécropole ouvre toutefois de nouvelles et réelles perspectives dans la compréhension de ces ensembles protohistoriques et des pratiques funéraires sous-jacentes, tout en nous éclairant sur le probable rôle du mobilier métallique d'importation dans les mécanismes de représentations identitaires de l'époque.

\section{Bibliographie}

Audouze, Gaucher 1981 : AUDOUZE (F.), GAUCHER (G.) - Typologie des objets de l'âge du Bronze en France. Fascicule VI : épingles, Paris, Société Préhistorique Française, 1981, 114 p.

Avila 1983 : AVILA (R.) - Bronzene Lanzen - und Pfeilspitzen der griechischen Spätbronzezeit, Munich, 1983, 167 p., 64 pl. h. t. (Prähistorische Bronzefunde, V, 1).

Bianco Peroni 1979 : BIANCO PERONI (V.) - I rasoi nell'Italia continentale, Munich, 1979, 211 p., 118 pl. h. t. (Prähistorische Bronzefunde, VIII, 2). Buffat et al. 2012 : BUFFAT (L.), GALY (J.), BRUNET (V.), CADEILHANKÉRÉBEL (J.), MASBERNAT-BUFFAT (A.), RIVALAN (A.), SÉRÉE (F.) - La nécropole protohistorique du Causse (Partie Orientale) - Labruguière / Tarn, Rapport final d'opération 2012 (2 volumes), 1005 p.

Carancini 1975 : CARANCINI (G.-L.) - Die Nadeln in Italien. Gli spilloni nell'Italia continentale, Munich, 1975, 399 p., 113 pl. h. t. (Prähistorische Bronzefunde, XIII, 2).

6 Certains groupes d'assemblages semblent en effet dépendre du sexe du défunt (fig. 3), mais leur diversité au cours du temps et surtout leur multiplicité nous poussent toutefois à supposer l'existence de plusieurs autres paramètres.
Cordier 2002 : CORDIER (G.) - Le dépôt de l'âge du Bronze Final des Châtelliers à Amboise (Indre-et Loire), Revue Archéologique du Centre de la France, 41, 2002, p. 5-34.

Feugère, Guillot 1986 : FEUGÈRE (M.), GUILLOT (A.) - Fouilles de Bragny. 1 Les petits objets dans leur contexte du Hallstatt Final, Revue Archéologique de l'Est, 37, 1986, p. 159-221.

Galan, Soutou 1959 : GALAN (A.), SOUTOU (A.) - Les boucles d'oreilles rubanées du Midi de la France (début du Hallstatt II), Bulletin de la Société Préhistorique Française, 1959, p. 593-603.

Giligny 2002 : GILIGNY (F.) - De la fouille à l'interprétation : le traitement des données. In: Guide des méthodes de l'archéologie, La Découverte Guide Repères, Paris, 2002, p. 127 - 184.

Giraud, Pons, Janin et al. 2003 : GIRAUD (J.-P.), PONS (F.), JANIN (T.) - Nécropoles protohistoriques de la région de Castres (Tarn). Paris, Maisons des Sciences de 1'Homme, 2003, 3 vol. (1: 276 p. ; $2: 268$ p.; $3: 231$ p.) (Documents d'Archéologie Française, 94).

Guilaine 1972 : GUILAINE (J.) - L'âge du Bronze en Languedoc Occidental, Roussillon, Ariège. Paris, Klincksieck, 1972, 460 p., 134 fig., 11 pl. hors texte (Mémoires de la Société Préhistorique Française, 9).

Janin 1993 : JANIN (T.) - Âge au décès et "statut social" dans les sépultures à incinération du Premier âge du fer languedocien : première approche. Bulletins et Mémoires de la Société d'anthropologie de Paris, n.s., t. 5, 1993, p. 203-208.

Janin 2000 : JANIN (T.) - Nécropoles et sociétés élisyques : les communautés du premier âge du Fer en Languedoc occidental. In : Janin (T.) éd. - Mailhac et le premier âge du Fer en Europe occidentale. Hommages à Odette et Jean Taffanel. Lattes, ARALO, 2000, p. 117-132 (Monographies d'Archéologie Méditerranéenne, 7).

Janin et al. 2002 : JANIN (T.) - La nécropole protohistorique du Grand Bassin II à Mailhac, Aude ( $\mathrm{VI}^{\mathrm{e}}-\mathrm{V}^{\mathrm{e}} \mathrm{s}$. av. n. è.), Documents d'Archéologie Méridionale, 25, 2002, 65-122.

Jockenhövel 1980 : JOCKENHÖVEL (A.) - Die Rasiermesser in Westeuropa. Munich, 1980, 238 p., 104 pl. h. t. (Prähistorische Bronzefunde, VIII, 3).

Kubach 1977 : KUBACH (W.) - Die Nadeln in Hessen und Rheinhessen, Munich, 1977, 636 p., 131 pl. h. t. (Prähistorische Bronzefunde, XIII, 3).

Milcent 2004 : MILCENT (P.-Y.) - Le premier âge du Fer en France centrale. Mémoires de la Société Préhistorique Française, 34, 2004, 718 p., 125 fig., $132 \mathrm{pl}$.

Mohen 1980 : MOHEN (J.-P.) - L'âge du Fer en Aquitaine. Mémoires de la Société Préhistorique Française, 14, 1980, 339 p., 141 fig., 201 pl.

Navarro 1970 : NAVARRO (R.) - Las fíbulas en Cataluña, Instituto de Arqueología y Prehistoria, Universidad de Barcelona, 1970, 126 p., 24 fig.

Nickels et al. 1989 : NICKELS (A.), MARCHAND (G.), SCHWALLER (M.) - Agde, la nécropole du Premier Age du Fer. Paris, 1989, 498 p. (suppl. à la $R A N, 19)$.

Peroni et al. 1975: PERONI (R.), CARANCINI (G.L.), PONZI BONOMI (L.), CORETTI IRDI (P.), RALLO (A.), SARONIO MASOLO (P.), SERRA RIDGWAY (F.) - Studi sulla cronologia delle civilità di Este e Golasecca, Firenze, Sansoni Ed., 1975, 410 p., 24 pl., 117 fig.

Roudil 1972 : ROUDIL (J.-L.) - L'âge du Bronze en Languedoc oriental, Mémoire de la Société Préhistorique Française, 10, Éditions Klincksieck, Paris, 1972, 302 p., 27 pl., 109 fig.

Schüle 1969 : SCHÜLE (W.) - Die Meseta-Kulturen der iberischen halbinsel. Mediterrane und eurasische elemente in früheisenzeitlichen kulturen südwesteuropas. Berlin, Walter de Gruyter \& Co., 2 volumes, 1969, 318 p., 191 pl.

Soutou 1959 : SOUTOU (A.) - Les scalptoriums Hallstattiens du sud-ouest de la France, Bulletin de la Société Préhistorique Française, LVI, 1959, p. 121-128.

Sievers 1982 : SIEVERS (S.) - Die mitteleuropäischen Hallstattdolche, Munich, 1982, 160 p., 50 pl. h. t. (Prähistorische Bronzefunde, VI, 6).

Taffanel, Janin 1998 : TAFFANEL (O.), TAFFANEL (J.), JANIN (T.) La nécropole du Moulin à Mailhac (Aude). Lattes, ARALO, 1998, 393 p., 478 fig., 3 annexes (Monographies d'Archéologie Méditerranéenne, 2).

Verger 1996 : VERGER (S.) - Une tombe à char oubliée dans l'ancienne collection Poinchy de Richebourg. In : Mélanges de l'École française de Rome, Antiquité, T.108, n² 2, 1996, p. $641-691$. 



\title{
Pratiques funéraires et identité culturelle : Marseille et les indigènes du Sud de la Gaule (IVe-II' s. av. J.-C.)
}

\author{
Bernard Dedet \\ Directeur de recherche au CNRS \\ ASM, Archéologie des Sociétés Méditerranéennes, \\ UMR5140, UPVM, CNRS, MCC, 34000, Montpellier, France
}

\section{Résumé}

La comparaison entre les coutumes funéraires des populations indigènes du Sud de la Gaule au second âge du Fer et celles en usage dans la colonie grecque de Marseille met en évidence deux ensembles bien tranchés de pratiques. La réflexion prend en compte le « recrutement » des cimetières selon l'âge au décès, l'implantation des tombes, le traitement des corps, inhumés ou brûlés, et de leurs restes, ainsi que le mobilier placé auprès des défunts. Les mœurs indigènes en ce domaine sont ici traditionnelles. Elles ne sont ni transformées, ni seulement modifiées, au contact des colons grecs, quelle que soit la proximité ou l'éloignement géographique par rapport à Marseille et aux autres établissements coloniaux, malgré l'indubitable apport grec dans les changements économiques et sociaux du Midi méditerranéen. Pour leur part, les usages massaliètes reflètent bien plutôt les coutumes grecques de l'époque et aucune influence des mœurs indigènes ne semble transparaître non plus dans les tombes de la colonie. Cette étanchéité, qui reflète sans doute des conceptions très différentes de la mort et de l'au-delà, est une pièce à verser au dossier des rapports entre Grecs et Gaulois du Midi de la France.

Mots-clés : France du Sud, Indigènes, Marseille, influences, tombes, second âge du Fer

\begin{abstract}
The comparison between the funerary customs of the indigenous population of the south of Gaul during the second Iron age with the ones in use in the Greek colony of Marseilles shows two clearly separate groups of funerary practices. The study takes the analysis of the cemeteries populations into account, classing them by age at death, tomb spatial implantation, body treatments, buried or cremated, and of their remains, as well as the artefacts placed with the deceased. The indigenous customs are traditional in this case. They haven't been transformed or even modified under the influence of the contact with the Greek settlers however distant from Marseilles or other colonial etablishments, in spite of the indubitable Greek influence on the socio-economic changes of these Mediterranean regions of France. And on the other side, Massaliet practices tend to reflect Greek customs of their time, with no influence of indigenous ways perceptible in the tombs of the colony. This absence of mutual influence, that without doubt reflects very different conceptions of death and the beyond, is an element to add to the bigger picture of Greek and Gaul relationships in the south of France.
\end{abstract}

Keywords: South of France, Indigenous people, Marseilles, influences, tombs, second Iron age 


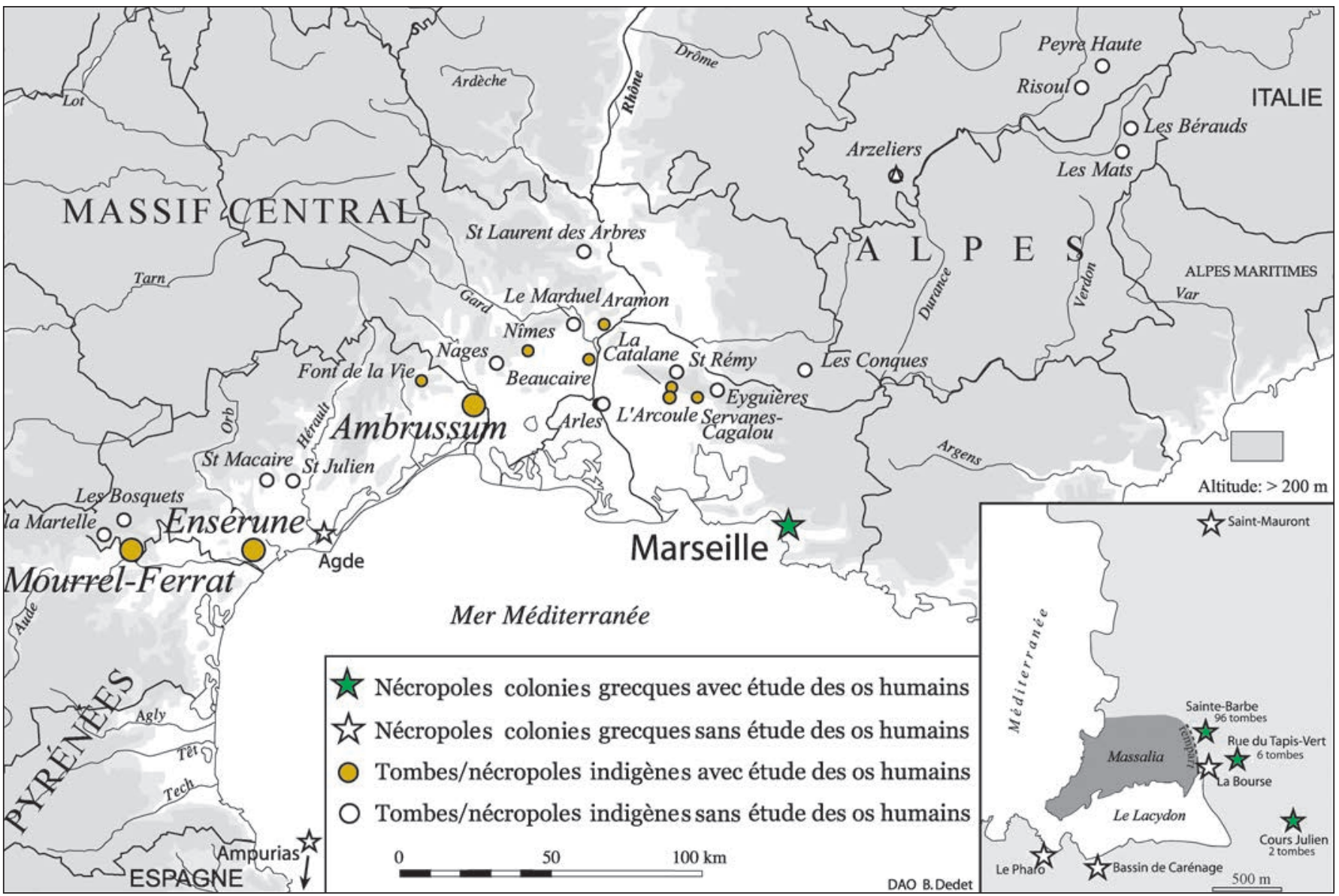

Fig. 1. Nécropoles ou tombes du second âge du Fer dans le Sud de la France (DAO B. Dedet, CNRS).

\section{Introduction}

La question des rapports entre colons grecs et populations indigènes de Gaule méridionale est habituellement abordée en terme d'échanges commerciaux et de leurs répercussions sur l'économie et le mode de vie des autochtones, y compris leur accès à l'écriture. Les usages funéraires, eux, qui reflètent aussi bien les dispositions sociales que les représentations collectives de la mort et de l'au-delà, sont rarement pris en compte. Pourtant ils constituent, à l'évidence, un indéniable marqueur d'identité culturelle. Cela rend d'autant plus précieux l'article de Michel Bats (2002) intitulé Du cratère sympotique au stamnos funéraire, qui aborde cette question pour une catégorie bien particulière de sépultures du Midi de la France. Pour ma part, c'est dans leur globalité que je m'attacherai ici à comparer ces pratiques funéraires des habitants de Marseille et des Indigènes du Sud de la Gaule, et cela permettra de s'interroger sur le degré de profondeur des relations entre les deux populations et sur les limites des processus d'assimilation (Dedet 2011a) ${ }^{1}$.

Cette comparaison n'est possible que depuis peu, depuis qu'on dispose d'une documentation satisfaisante des deux côtés, en quantité suffisante et incluant notamment l'analyse des restes osseux humains (fig. 1).

Pour Marseille, c'est la nécropole de Sainte-Barbe, avec une série de 96 tombes d'époque grecque, comprises entre les environs de 400 et 150 av. J.-C., qui donne une base solide pour connaître les usages funéraires de ses habitants, ou du moins d'un échantillon d'entre eux (Moliner et al. 2003). S'y ajoutent six tombes de la nécropole de la rue du Tapis-Vert (Chabaud, Féraud 1959, p. 84-86 ; Rothé, Tréziny dir., 2005, p. 599-600),

1 Je suis reconnaissant à Sylvie Dedet et à Georges Marchand, chercheur associé à l'UMR 5140, d'avoir pris le temps de relire le manuscrit et de m'avoir fait part de leurs remarques. 


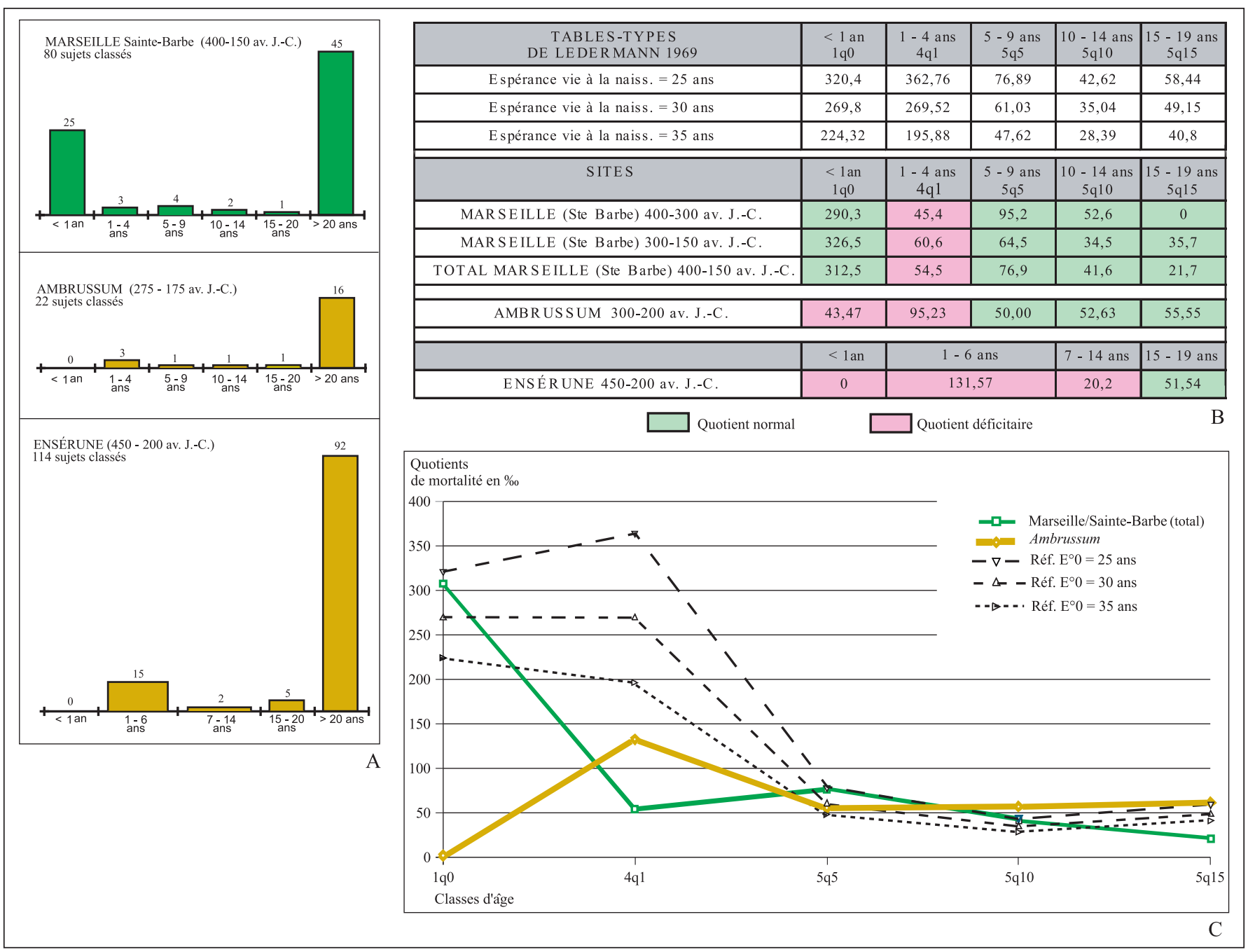

Fig. 2. A : Proportions des défunts entrant dans une classe d'âge déterminée pour les nécropoles de Marseille/Sainte-Barbe, d'Ambrussum et d'Ensérune. B : Comparaison des quotients de mortalité (en \%o) des défunts immatures pour la nécropole grecque de Marseille/Sainte-Barbe et les cimetières indigènes d'Ambrussum et d'Ensérune. Pour comparaison, tables-types de Ledermann (1969, p. 86-88) pour une espérance de vie à la naissance de 25 ans, 30 ans et 35 ans. En rose, les quotients inférieurs aux taux des tables-types. C : Comparaison de la courbe des quotients de mortalité (en \%) des défunts immatures de la nécropole grecque de Marseille/Sainte-Barbe avec celle du cimetière indigène d'Ambrussum et celles de trois populations de référence dont l'espérance de vie à la naissance $\left(E^{\circ} 0\right)$ est de 25 ans, 30 et 35 ans (d'après les tables-types de Ledermann 1969, p. 86-88) (DAO : B. Dedet, CNRS).

deux tombes du cours Julien (Rothé, Tréziny dir., 2005, p. 679) et des renseignements plus ou moins lacunaires sur le chantier de la Bourse (Bertucchi 1992, p. 132-134) ou les découvertes plus anciennes du bassin de Carénage, du Pharo et de Saint-Mauront (Bertucchi 1992, p. 128130 ; Rothé, Tréziny dir., 2005, p. 676-678) (fig. 1)².

2 La nécropole de la pointe de Vella à Port-de-Bouc, entre Marseille et l'embouchure du Rhône, considérée d'abord comme « hellénistique » et qui aurait attesté « l'installation de Grecs marseillais » (Marino $(\mathrm{H}$.$) , Rigeade (\mathrm{C}$.), Une nécropole hellénistique à la Pointe de Vella (Port-de-Bouc, Bouches-du-Rhône), DocAMérid, 28,2005 , p. 115-150.) se rapporte en fait à l'Antiquité tardive, selon les datations par le radiocarbone effectuées après la publication.
En regard, pour le monde indigène régional du second âge du Fer, on dispose principalement d'environ 120 tombes et d'un bûcher d'Ensérune (Hérault) s'échelonnant entre environ 500 et 200 av. J.-C., dont l'étude des os a été faite (Dedet, Schwaller 2010 passim; Schwaller et al. 1995 ; Bel et al. à paraître; Schwaller et al. à paraître), et de deux découvertes récentes, 13 tombes du dernier quart du $\mathrm{IV}^{\mathrm{e}} \mathrm{s}$. av. J.-C. de la nécropole de Mourrel-Ferrat à Olonzac en Languedoc occidental également (Janin et al. 2000), et un quartier de la nécropole d'Ambrussum, en Languedoc oriental, comprenant 25 tombes et un bûcher du III s. av. J.-C. (Dedet 2012). À cela s'ajoutent quelques tombes, soit du début de la période, comme celle de Font de la Vie à 
Saint-Bauzille-de-Montmel (Hérault) datée du milieu du $\mathrm{V}^{\mathrm{e}} \mathrm{s}$. (Dedet 1995), et celle de la Roussillonne à Nîmes, de la fin du IV ${ }^{\mathrm{e}}$ ou du début du III ${ }^{\mathrm{e}} \mathrm{s}$. av. J.-C. (Dedet, Gauthey 2008), soit des II et ${ }^{\mathrm{er}}$ S. av. J.-C., à Beaucaire (Dedet et al. 1974), Nîmes (Bel et al. 2008), Aramon dans le Gard (Genty, Feugère 1995) ou dans les Alpilles en Provence (Marcadal et al. 2003). Un secteur récemment fouillé, et en cours d'étude, de la nécropole du Sizen à Beaucaire, avec une centaine de tombes datées pour l'essentiel de la deuxième moitié du $\mathrm{IV}^{\mathrm{e}} \mathrm{s}$. et de la première moitié du siècle suivant, apportera sous peu une documentation particulièrement importante à ce sujet (Carme, Demangeot 2010) (fig. 1).

Cette analyse comparative sera organisée autour de quatre grands thèmes : la composition par âge de la population des défunts admis au cimetière ; le traitement des cadavres ; le matériel d'accompagnement ; les bûchers et la partie aérienne des tombeaux. Pour finir on s'interrogera sur les résultats de cette mise en regard des pratiques funéraires massaliètes et indigènes.

\section{La répartition des défunts dans les nécropoles selon l’âge au décès}

Une différence très importante entre les cimetières de Marseille et ceux du monde indigène se remarque dans la ventilation des défunts selon l'âge au décès (fig. 2). Elle concerne essentiellement les très jeunes enfants, mort-nés, nouveau-nés et nourrissons, soit la classe des moins d'un an.

Ces morts, à un âge qui connaît un très fort taux de mortalité dans une démographie de type ancien, sont complètement absents des nécropoles indigènes du Midi, à l'exception de ceux qui sont découverts dans la même sépulture qu'un adulte connoté féminin, et qui doivent marquer des décès de femmes enceintes ou en couches. Ce manque de cette classe d'âge est particulièrement significatif dans les trois nécropoles pour lesquelles les données sont abondantes, Ensérune, Mourrel-Ferrat et Ambrussum (fig. 2).

Au contraire, à Marseille/Sainte-Barbe, ces très jeunes morts sont bien attestés et leur présence est tout à fait conforme à la mortalité que l'on est en droit d'attendre d'une société pré-jennérienne : pour l'ensemble de la partie grecque de la nécropole, le quotient de mortalité de ces moins d'un an est de 312\%o correspondant parfaitement aux quotients de référence calculés par les démographes pour des espérances de vie à la naissance comprises entre 25 et 35 ans (fig. 2).
La classe suivante, celle des jeunes enfants de 1-4 ans, est bien marquée à Marseille mais elle apparaît aussi dans les nécropoles du monde indigène. Cependant, dans les deux cas, elle est plus ou moins sous représentée, avec des quotients de $45 \%$ à $61 \%$ à Marseille/Sainte-Barbe et 95\%o à Ambrussum (fig. 2).

En revanche, à partir des 5-9 ans, tant à Marseille que chez les Indigènes, la conformité avec la mortalité archaïque est atteinte.

De tout cela ressort une conclusion importante concernant l'âge d'admission au cimetière. À Marseille, la classe des 0-1 an accède normalement au cimetière. Une telle coutume est très courante dans le monde grec à partir de l'époque archaïque et durant les périodes classique et hellénistique. D'ailleurs, elle est bien attestée dans les deux autres colonies phocéennes de la région, à Agde et à Ampurias, même si, dans les deux cas, l'absence d'étude anthropologique ne permet pas de mesurer si la proportion de ces défunts correspond précisément à la mortalité attendue.

Il en va bien différemment dans les communautés indigènes du second âge du Fer où les tout-petits n'ont pas droit au cimetière communautaire, si l'on excepte cette présence de fotus de femmes mortes enceintes ou pendant l'accouchement. L'accession des enfants ne se fait que plus tard et progressivement, d'abord pour une part seulement des 1-4 ans, puis, semble-t-il, normalement à partir des 5-9 ans. C'est là un processus traditionnel puisqu'on le constate dans toutes les nécropoles de la région depuis au moins la fin de l'âge du Bronze (Dedet 2008a ; 2008b ; 2011b ; 2012).

Quel sort réserve-t-on à ces très jeunes défunts dans le monde indigène ? On retrouve beaucoup de périnatals ensevelis à l'intérieur des agglomérations des vivants, dans les maisons ou dans les cours domestiques. Actuellement, cent cinquante individus sont connus dans une trentaine d'habitats depuis le début du premier âge du Fer au moins et durant tout le second âge du Fer, en Roussillon (Ruscino, Port de Salses), en Languedoc (Pech-Maho, Cayla de Mailhac, Montlaurès, Ensérune, la Monédière, la Ramasse, les Gardies, Lattara, Gailhan, la Jouffe, Plan de Lavol, Vié-Cioutat, Castelvielh, la Liquière, Roque de Viou, Mauressip, Nages, le Marduel, Nîmes, Mas Saint-Jean, les Barbes-et-Fon-Danis et peutêtre Ambrussum), dans le sud du Massif central (Puech de Mus, Roc de l'Aigle) et en Provence (Baou de SaintMarcel, Saint-Blaise, Roquepertuse, Entremont) (fig. 3).

Cela est en total contraste avec Marseille : les fouilles d'habitations d'époque grecque effectuées à ce jour dans 
la cité massaliète, comme aussi à Olbia de Provence, n'ont livré aucune tombe ni aucun vestige de squelette de tout-petit ${ }^{3}$. Et il est important de souligner que l'usage marseillais tranche complètement avec celui d'oppida voisins : l'habitat du Baou de Saint-Marcel, qui a livré plusieurs tombes de nouveau-nés est à moins de huit kilomètres des murs de la colonie grecque.

\section{Le traitement des défunts à Marseille et dans le monde indigène}

\section{Les usages pour les moins d'un an}

Pour les fœtus et les sujets décédés en phase périnatale retrouvés dans les habitats du monde indigène, la norme est l'inhumation primaire individuelle, dans une petite fosse creusée juste aux dimensions du corps et cela, en total contraste avec les morts plus âgés qui ont accès au cimetière et qui sont tous incinérés à cette époque (fig. 4). D'après les observations faites sur la position des membres, ces enfants ne paraissent pas emmaillotés avant d'être mis en terre. Ils ne sont pourvus d'aucune pièce d'habillement ou de parure ou tout autre objet, sauf une ou deux exceptions à Pech-Maho, sur la marge du monde ibérique. En fait, du Bronze final à la première moitié du I ${ }^{\text {er }}$ s. av. J.-C., il existe dans le Sud de la France une habitude ou un modèle culturel bien défini d'ensevelissement en habitat réservé aux tout-petits (Dedet 2008a, p. 79-138; 2011b, p. 141-142). Et sa spécificité apparaît d'autant plus forte que les usages attestés pour cet âge dans la Marseille grecque sont fort différents.

En effet, tous les fœtus et périnatals déposés dans la nécropole Marseille/Sainte-Barbe sont inhumés mais en cela, et contrairement au monde indigène, ils ne se différencient pas des autres enfants plus âgés, mais de moins de dix ans, qui sont aussi tous inhumés, ni non plus des très nombreux adultes, en fait une majorité, également non brûlés. Les tombes de ces tout-petits se répartissent parmi celles des défunts plus âgés. Cependant le traitement de leur cadavre, qui échappe à l'incinération, paraît induire une localisation préférentielle dans le secteur occidental du cimetière où prédominent les adultes inhumés, tandis que dans la partie orientale prennent place surtout des adultes incinérés (fig. 5) (Moliner et al. 2003, p. 237-238). Dans les nécropoles du monde grec, à partir de l'époque classique, ces nouveau-nés, également inhumés, sont de la même manière mis à l'écart des adultes incinérés et, au contraire, associés aux adultes

3 Informations récentes de Manuel Moliner et Michel Bats. inhumés, sans que les raisons d'une telle disposition soient connues (Michalaki-Kollia 2010, p. 164).

Le mode de dépôt du corps, à Marseille/SainteBarbe, se fait de différentes manières. Il peut être déposé directement en pleine terre, mais cela ne concerne qu'une minorité de ces nouveau-nés (8 sur 23). Exceptionnellement, il peut reposer dans un cercueil en bois (1 cas). Mais en fait la grande majorité, 14 sur 23, sont placés dans un vase, l'enchytrismos des archéologues, une coutume bien connue en Grèce et que l'on retrouve dans les autres colonies de Méditerranée occidentale, Agde et Ampurias (fig. 6, A). Ici, ce réceptacle est le plus souvent une amphore massaliète, décolletée pour laisser passer le corps (fig. 6, B), et parfois une hydrie ou une œnochoé (fig. 6, C). Et c'est aussi dans une petite urne qu'est inhumé le « fotus » signalé dans l'un des enclos de la Bourse (Bertucchi 1992, p. 133). Dans ces enchystrismoi massaliètes, la position du corps est toute symbolique, la tête vers la sortie, conforme à la comparaison entre utérus et vase que l'on trouve déjà au $\mathrm{V}^{\mathrm{e}} \mathrm{s}$. av. J.-C. dans les traités du Corpus hippocratique (Gourévitch 2003,p. 24).

À Marseille/Sainte-Barbe, pour les plus âgés de cette classe d'âge, les rares nourrissons entre deux et douze mois d'existence, on ne se sert plus du vase-réceptacle. Les corps sont inhumés en pleine terre ou dans un coffrage. Dans le monde indigène, les très rares cas attestés d'ensevelissement de nourrissons au sein de la sphère domestique ne diffèrent en rien de la pratique concernant les périnatals; mais le traitement de la plupart de ces nourrissons nous échappe car trop peu nombreux sont ceux qui prennent place dans les habitats comme dans les nécropoles, en regard à la mortalité attendue ${ }^{4}$, ce qui en fait marque ici aussi un changement, une fois passé le premier mois de la vie (Dedet 2008a, p. 139-156).

Les Indigènes n'accompagnent d'aucun objet les corps des périnatals et il en va de même des quelques nourrissons déposés dans les habitats. Dans la nécropole massaliète, certes une bonne part de ces défunts est également dépourvue de tout matériel, mais ce n'est pas le cas pour tous. Un tiers de ces moins de 1 an est ici muni d'objets ou d'offrandes, le plus souvent valves de coquillages, surtout des coquilles Saint-Jacques, plus rarement olpé ou œnochoé ( 3 cas), guttus (qui a peut-être fait office de biberon) dans 1 cas, et, dans un autre cas, un corymbe, un élément floral en terre cuite provenant d'une couronne mortuaire à la mode grecque (fig. 6, D) .

4 Dans une société préjennérienne il meurt autant d'enfants à la naissance et dans le premier mois que dans les onze mois suivants. 


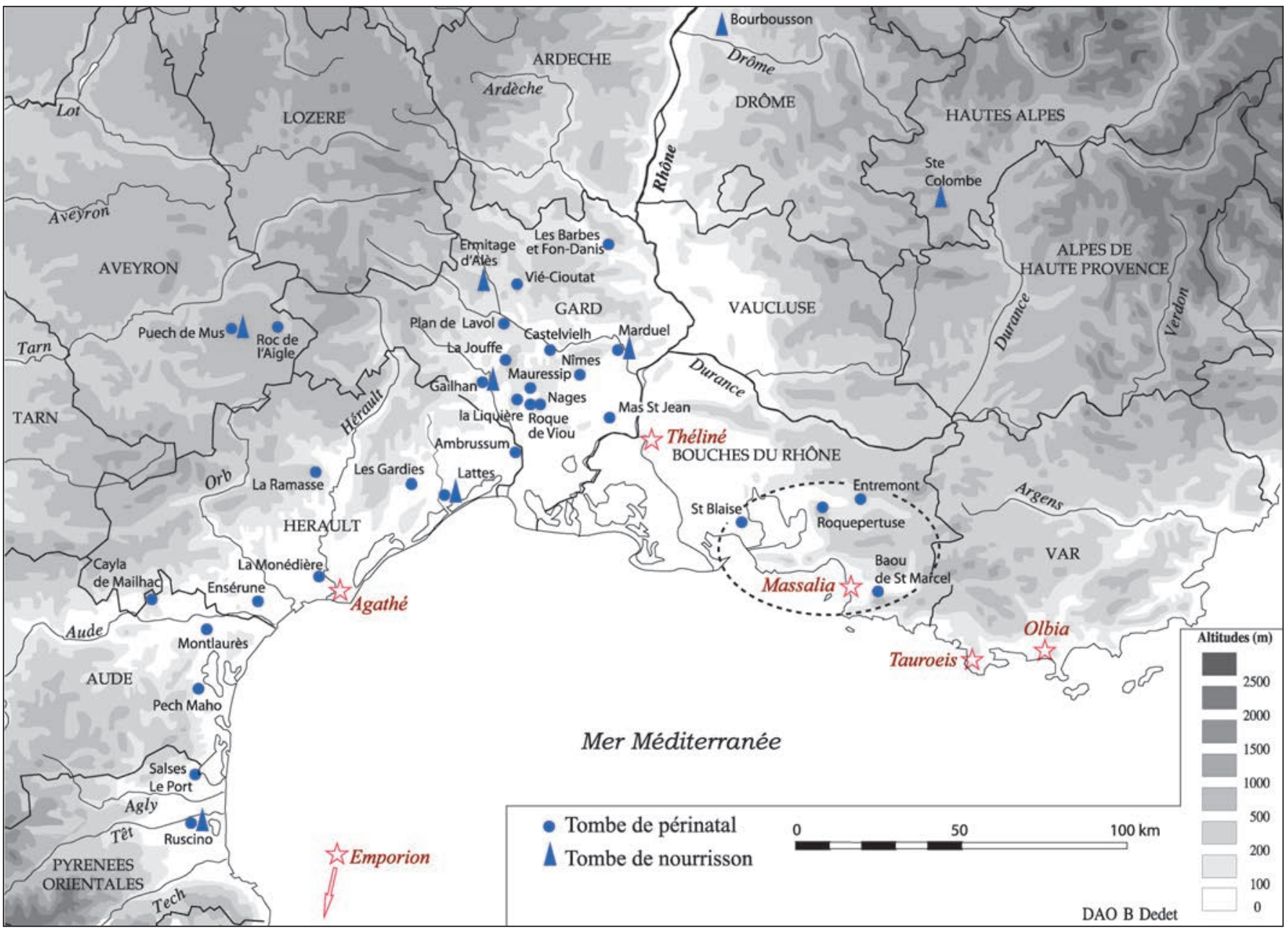

Fig. 3. Les habitats protohistoriques du Midi méditerranéen ayant livré des tombes ou des restes de périnatals et/ou de nourrissons. Le tireté signale particulièrement les oppida voisins de Massalia (DAO B. Dedet, CNRS).

\section{Le traitement du corps des défunts ayant dépassé le cap de la première année d'existence}

Dans le monde indigène méridional du second âge du Fer, tous les défunts admis dans les cimetières sont incinérés. La seule exception concerne les Alpes Méridionales où persiste l'usage de l'inhumation, au moins jusqu'au III' s. av. J.-C. C'est là l'aboutissement d'une progression très nette de l'incinération que l'on suit depuis le début du dernier millénaire avant notre ère (fig. 7). Au Bronze final III, l'incinération est la règle à l'ouest du fleuve Hérault et de la bordure occidentale du Massif central, tandis que l'inhumation est exclusive à l'est. Puis, au fil du temps, elle gagne du terrain vers l'est pour devenir exclusive partout à partir du milieu du $\mathrm{V}^{\mathrm{e}}$ S. av. J.-C., sauf dans les Alpes du Sud (Dedet 2004). Cela concerne du moins les morts «normaux » (fig. 8), en excluant les périnatals, nous l'avons vu, et les adultes et adolescents dont les restes, non brûlés, sont déposés dans des lieux cultuels, comme celui du Cailar dans le Gard au III' s. av. J-C. (Roure 2007). Autres exceptions notables à ce « tout incinération » dans le sud de la France du second âge du Fer, les colonies grecques pour lesquelles on connaît quelque peu les nécropoles, Marseille et Agde.

À Marseille, en effet, inhumés et incinérés se côtoient généralement. Plus précisément à Sainte-Barbe les deux pratiques en vigueur sont l'inhumation primaire et le dépôt secondaire d'incinération. Les portions de nécropole du Tapis-Vert et de Saint-Mauront montrent aussi cette dualité de traitement, tandis que la crémation est la règle à la Bourse aux $\mathrm{IV}^{\mathrm{e}}-\mathrm{III}{ }^{\mathrm{e}} \mathrm{s}$. av. J.-C. ${ }^{5}$ et que les deux sujets du Cours-Julien, un adulte et un jeune enfant, sont, eux, inhumés (fig. 9).

5 Exception faite du « fœtus » inhumé, signalé dans Bertucchi 1992, p. 133. 


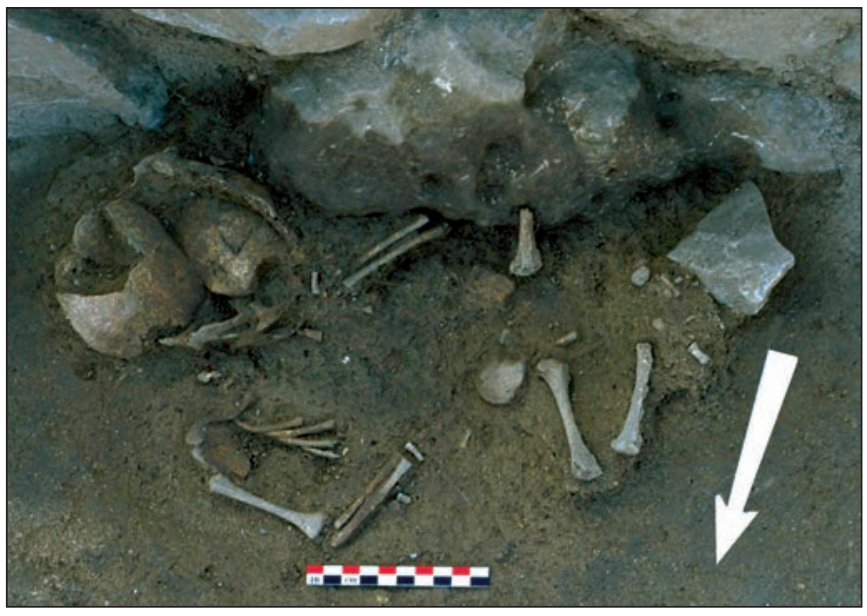

Fig. 4. Un exemple de sépulture de périnatal en habitat indigène : la tombe 24 de Lattes (Hérault) (DP 30080 de l'îlot 30), datée du premier quart du ler s. av. J.-C. (cliché UFRAL).

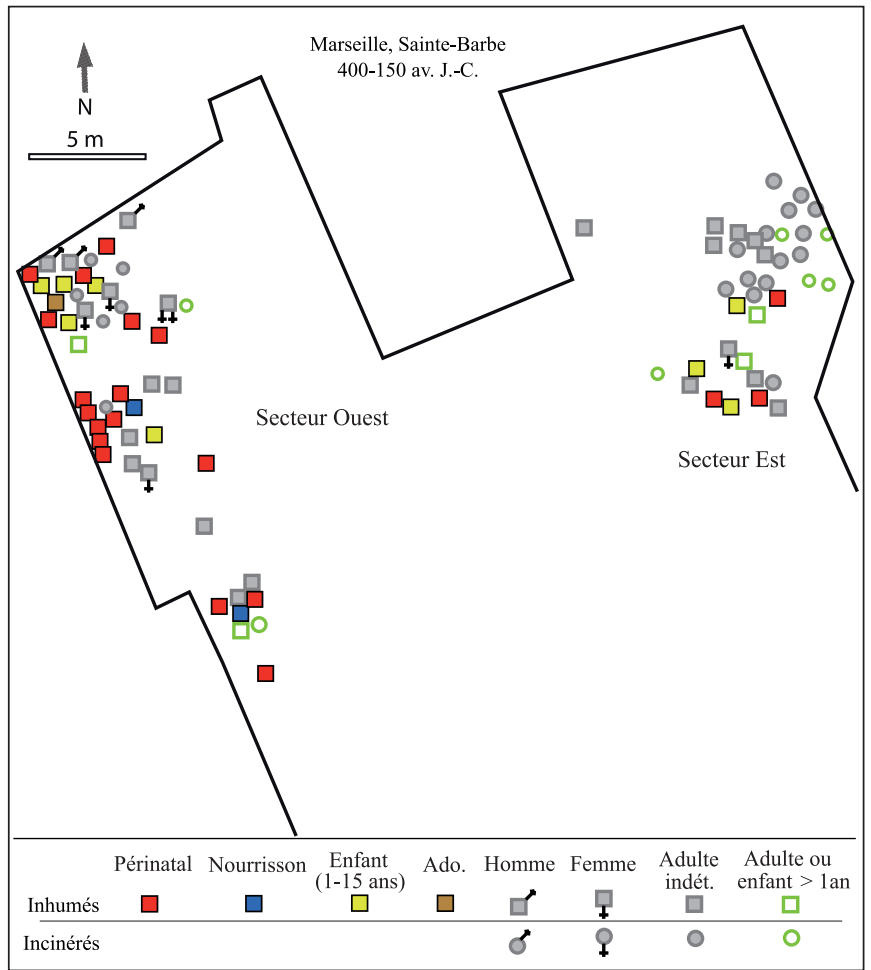

Fig. 5. Répartition spatiale des défunts de la nécropole grecque de Marseille/Sainte-Barbe en fonction de l'âge au décès (DAO B. Dedet, CNRS).

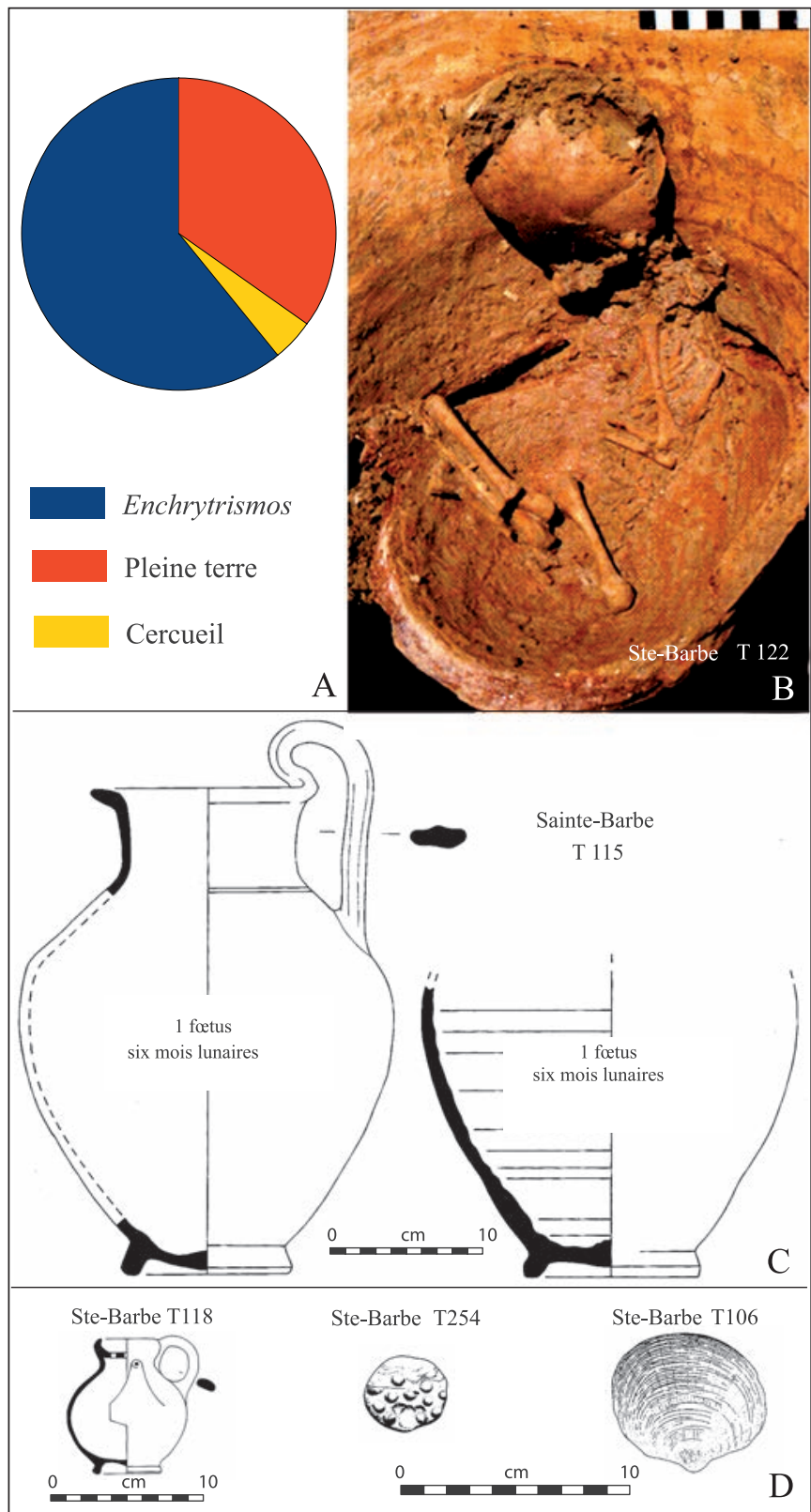

A : proportions des modes de dépôts des corps (DAO B. Dedet, CNRS).

B : un exemple d'enchytrismos en amphore massaliète, la tombe 122 (cliché S. Bien et F. Cognard, INRAP).

C : enchytrismos en cruches à pâte claire massaliète, pour deux fœtus dans la tombe 115 .

D : mobilier des tombes 118 (guttus à pâte claire massaliète), 254 (corymbe) et 106 (coquillage) (d'après Moliner et al. 2003).

Fig. 6. Traitement des périnatals dans la nécropole grecque de Marseille/Sainte-Barbe. 
La nécropole de Sainte-Barbe autorise plusieurs constatations intéressantes complémentaires sur cette variété de pratiques. D'une part, on remarque que l'incinération n'est pas pratiquée pour les enfants endessous de dix-douze ans. Les huit enfants de cette nécropole âgés entre un et dix-douze ans sont tous inhumés, et c'est aussi le traitement utilisé pour les deux jeunes enfants attestés à la rue du Tapis-Vert et au Cours Julien. D'autre part, les adultes et les adolescents de Sainte-Barbe se répartissent à peu près équitablement entre les deux procédés, vingt incinérés et vingt-sept inhumés (soit respectivement $43 \%$ et $57 \%$ ) (fig. 8). Et, par ailleurs, il ne semble pas qu'il y ait d'évolution dans la fréquence relative des deux types de traitement du corps, entre le début et la fin de l'utilisation du site, entre le $\mathrm{IV}^{\mathrm{e}} \mathrm{s}$. et le milieu du II ${ }^{\mathrm{e}} \mathrm{s}$. av. J.-C. (fig. 10).

Pour ces adultes, on ne constate pas à Sainte-Barbe de préférence pour l'un ou l'autre usage en fonction du sexe. Certes, le sexe biologique des incinérés n'est presque jamais déterminable, mais en revanche, on constate que parmi les vingt-sept inhumés figurent, d'après l'étude des os, quatre hommes et six femmes. L'inhumation n'apparaît donc pas réservée à l'un ou l'autre sexe.

L'âge, pour les adultes, ne semble pas jouer non plus un rôle dans ce choix. À Sainte-Barbe, parmi les quatre adultes jeunes comptabilisés se trouvent trois inhumés et un incinéré, et les six adultes âgés signalés sont tous brûlés. Au Tapis-Vert, les trois seuls adultes inhumés sont tous âgés, entre 40-45 ans et 55-60 ans.

Ce mélange de défunts incinérés et inhumés se retrouve dans une nécropole de la colonie grecque d'Agde, le Peyrou II, datée entre le milieu du $\mathrm{IV}^{\mathrm{e}} \mathrm{s}$. et le début du II ${ }^{\mathrm{e}} \mathrm{s}$. av. J.-C. Y prennent place vingt-quatre inhumations (parmi lesquelles un certain nombre de périnatals) ${ }^{6}$ et quatre incinérations (Dedet, Schwaller 2010, p. 273). Pareille situation prévaut dans les autres colonies phocéennes de Méditerranée occidentale, à Aleria (77 \% d'inhumations et $23 \%$ de crémations ; Jehasse, Jehasse 1973, p. 26) comme à Ampurias (Almagro Basch 1953, p. 29-213). Elle est bien connue en Grèce même, par exemple dans l'Athènes des $\mathrm{V}^{\mathrm{e}}-\mathrm{IV}^{\mathrm{e}} \mathrm{s}$. av. J.-C. (Étienne et al. 2006, p. 159), et si les nécropoles de la métropole de Marseille sont pour le moment inconnues, on soulignera que cette dualité inhumation/incinération est bien attestée à Clazomènes (Hürmüzlü 2004, p. 80-81), si proche de Phocée tant sur le plan géographique que, selon Hérodote (Histoires, I, 142), par la langue.

6 L'étude de cette nécropole n'a pas encore été faite.
Dans le monde grec cette juxtaposition n'est pas le reflet d'une réunion de populations ou d'ethnies différentes. Il en va certainement de même à Marseille car incinérés et inhumés ont un mobilier d'accompagnement tout à fait semblable et cet équipement diffère fortement de celui des autochtones du sud de la France.

\section{À propos du matériel accompagnant les défunts adultes et adolescents}

La comparaison entre Marseille et le monde indigène est également très instructive en ce qui concerne le matériel placé dans les tombes des adultes et des adolescents, et cela aux niveaux quantitatif et qualitatif.

À Marseille le défunt adulte n'est pas toujours accompagné d'objets. Si l'on en croit les fouilles de Sainte-Barbe, seules fiables sur ce sujet précis, une très forte proportion d'adultes, presque un sur deux (19 sur 44 soit $43 \%$ ), est dépourvue de tout accompagnement. Et ce sont surtout les inhumés qui sont concernés par cet usage, $75 \%$ d'entre eux, tandis que seulement $20 \%$ des incinérés sont concernés par cette absence. En revanche, dans le monde indigène, pratiquement toutes les tombes d'adultes et d'adolescents sont accompagnées de mobilier. Les cas où celui-ci est absent, comme Mourrel-Ferrat 18, sont très exceptionnels.

D'autre part à Marseille, lorsqu'ils sont présents, les objets sont peu nombreux dans chaque tombe. La grande majorité des dépôts ne compte qu'un ou deux éléments et le maximum constaté est de six. Ce sont les incinérés qui sont le plus souvent accompagnés d'objets et qui en sont aussi les mieux pourvus.

Dans le monde indigène, les quantités de matériel déposé auprès du mort sont très variables. Elles peuvent être faibles dans les tombes dites « à simple ossuaire »: seuls quelques objets personnels et des restes d'une offrande animale sont alors joints au défunt. Et ce dépôt peut être encore plus réduit comme dans la sépulture nîmoise de la Roussillonne, vers 300 av. J.-C., où une unique coupelle est déposée, introduite dans le vase ossuaire. Mais, très souvent, ce matériel est abondant, pouvant inclure 18 objets, comme par exemple dans la tombe 163 d'Ensérune.

Ces écarts dans la proportion d'adultes accompagnés ou non de mobilier et dans la quantité de ces pièces constituent une différence importante entre les deux domaines culturels. Mais il en est une autre, sans doute plus signifiante, qui concerne la nature même de ces objets. 
À Marseille, lorsque les morts ont un matériel d'accompagnement, le dépôt d'objets personnels est très rare : une fibule auprès de deux adultes (SainteBarbe T 99 et T 198), un anneau auprès d'un autre (Sainte-Barbe T 43), une bague auprès de trois autres (Sainte-Barbe T 96, T 245 et T 247) et un scalptorium dans la tombe de l'adulte du Cours Julien. La présence de restes de faune est également peu fréquente, concernant seulement cinq adultes de Sainte-Barbe (tombes 41, 49, 53, 102 et 198), os de cheval ou de bœuf, lorsque la détermination est possible, dont on ignore s'ils ont été brûlés avec le mort ou s'il s'agit de rejets de repas funéraires consommés par les survivants et ramassés avec les restes osseux humains. En fait, les objets les plus fréquents font référence à la toilette du cadavre ou à un hommage symbolique (fig. 11).

Relatifs à cette toilette mortuaire, les vases à parfum, lécythes, lécythes aryballisques, alabastres, unguentaria, olpés apparaissent dans beaucoup de tombes d'adultes pourvues de matériel, à Sainte-Barbe (T 47, 60, 96, 98, 102, 198 et 245), à la rue Tapis-Vert (T 2 et sarcophage 3), au cours Julien (t. d'adulte) ou encore à Saint-Mauront (T 5,8 et 14). Servant également à cette opération, des strigiles, se rencontrent dans plusieurs sépultures, à Sainte-Barbe (T 235, 242 et 247), à la rue Tapis-Vert (sarcophage 3) et au cours Julien (t. d'adulte) (fig. 11).

D'autres pièces évoquent des hommages symboliques. Des coupes et les coupelles pouvant servir à des libations sont présentes dans de nombreuses tombes de Sainte-Barbe (T 41, 43, 47, 96, 97, 98 et 257) et dans le sarcophage 3 de la rue Tapis-Vert. Il en va de même d'éléments de couronnes florales en céramique, fleurs, petits cônes, corymbes, percés d'un trou pour être enfilés, dans quatre sépultures de Sainte-Barbe (T 90, 192, 247 et 257) et une de la rue Tapis-Vert (urne en plomb 1), et parfois « dorés en-dessus » comme au Carénage (fig. 11).

Tout ce matériel affecte aussi bien des incinérés que des inhumés; ce sont exactement les mêmes objets ou types d'objets que l'on retrouve dans les deux cas (fig. 12 et fig. 13, C, D et E). D'autre part, ceux-ci n'indiquent jamais si c'est un homme ou une femme. L'examen comparatif des objets associés aux inhumés de Sainte-Barbe dont le sexe biologique est connu ne montre en effet aucun élément spécifique distinguant le sexe : sur les quatre hommes déterminés, deux n'ont pas d'accompagnement, un est pourvu d'un métacarpien de cerf et un autre d'une coupe et d'un lécythe attiques ainsi que d'une urne non tournée; et sur les six femmes attestées, trois ne possèdent pas de pièce d'accompagnement, une est munie d'un os d'animal, une d'une coupelle à pâte claire et d'un os de bœuf et une autre d'un objet en fer non déterminé.

En définitive, c'est donc essentiellement un matériel de culture hellénique qui prend place dans la tombe à Marseille, objets ayant servi à la toilette du mort, à l'honorer ou à faire des libations. Les sources écrites grecques en témoignent largement, de même que les nombreux lécythes attiques à fond blanc où ces pièces sont figurées sur le tombeau même (fig. 11). Et ce sont aussi les mêmes objets qui sont déposés à la même époque dans bien d'autres nécropoles grecques, comme par exemple celle de Kalfata à Apollonia du Pont (Hermary dir. 2010, p. 143-145). Bien différent est, en revanche, l'accompagnement des adultes du monde autochtone du Midi de la France.

Chez les Indigènes le dépôt se compose généralement de différents ensembles (fig. 13, A et B).

Ce sont surtout des objets personnels du mort, pièces d'habillement et de parure, objets d'activités de la vie quotidienne ou non, avec une connotation sexuelle souvent clairement annoncée. Auprès des femmes, on dépose fusaïole, chaîne ceinture à maillons doubles, pendants d'oreille, lot de deux bracelets ou plus, collier de perles en pâte de verre ou en corail. C'est le cas par exemple pour cinq des seize tombes d'adultes ou d'adolescents d'Ambrussum (T 2, T 6, T 11, T 19 et T 23) (Dedet 2012). Objets tranchants, comme couteaux et armes, signalent les hommes, et souvent c'est la panoplie complète, pointe et talon de lance, épée et sa suspension et bouclier, qui est attestée. À Ensérune, sur vingt-neuf tombes découvertes entre 1954 et 1965, neuf contiennent des objets présumés masculins, essentiellement des armes (tombes 146, 150/151, 157, 158, 163, $170,171,175$ et 178), et deux, des pièces présumées féminines, fusaïole ou boucles d'oreille (tombes 147 et 172) (Gallet de Santerre 1968, p. 73-83) ; et parmi les cinq sépultures fouillées en 1988 figurent deux dépôts avec armes et un avec fusaïole (Schwaller et al. 1995).

Les tombes à armes représentent environ un tiers des tombes d'adultes à Ensérune et à Ambrussum : comme, dans les deux cas, adultes présumés masculins et féminins s'équilibrent, une telle proportion pourrait signifier que tous les hommes en âge de combattre emportent des armes dans leur tombe, alors qu'à l'inverse, aucune tombe de Marseille d'époque grecque n'a livré d'arme.

Autre coutume très fréquente chez les Indigènes et peu courante à Marseille, celle de placer des restes animaux dans la sépulture. Toutes celles d'Ambrussum sont concernées, soit par un os isolé, ou, plus rarement, par 


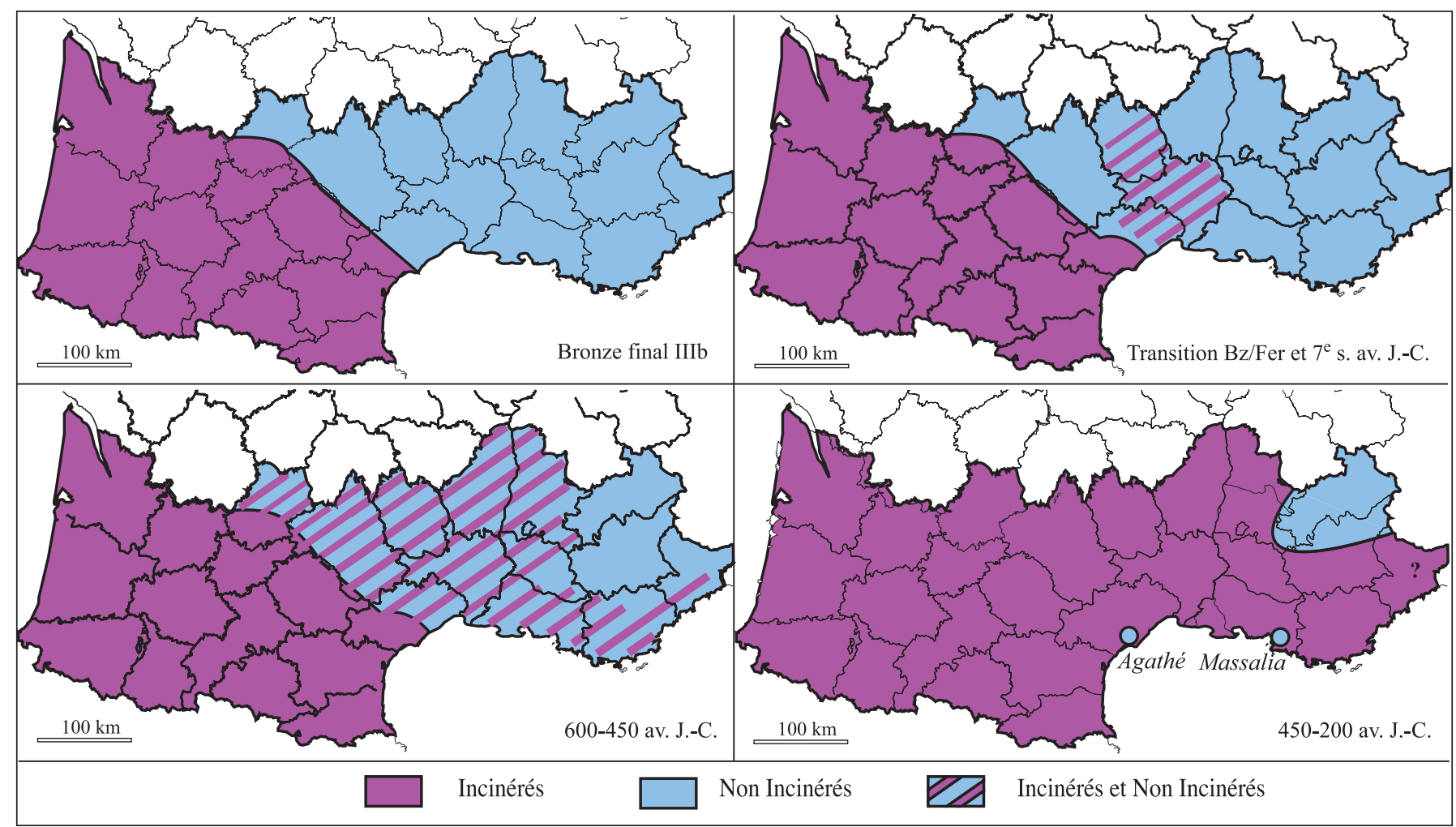

Fig. 7. Répartition schématique comparée des défunts incinérés et des défunts non brûlés des tombes de pleine nature dans le Sud de la France, du Bronze final III b à la fin du deuxième âge du Fer (DAO B. Dedet, CNRS).

une portion de squelette. Ces deux formules illustrent deux gestes différents, peut-être restes de repas partagés par les survivants auprès du bûcher ou de la tombe dans le premier cas, et, dans le second, sacrifice non consommé destiné à la personne décédée (Gardeisen in Dedet 2012). La plupart des tombes de Mourrel-Ferrat contiennent des os d'animaux isolés ${ }^{7}$ (Janin et al. 2000). Ceux-ci sont également bien présents dans les sépultures d'Ensérune au III' $\mathrm{s}$. av. J.-C., mais cette nécropole montre aussi une autre coutume constituée par le dépôt de volailles entières et de quartiers de caprinés et de porcs non brûlés. Ici de la viande préparée et non consommée a accompagné le défunt dans son tombeau (Schwaller et al. 1995, notamment p. 226-229).

D'autre part, on dépose dans quelques tombes, attribuables peut-être à une " élite », des vases qui renvoient à la consommation collective et socialisée du vin, avec l'usage de récipients empruntés à la culture grecque, mais pour en faire un autre usage que les Grecs : d'abord uniquement des vases à boire en céramique tournée,

7 Sur ce site, ces vestiges sont interprétés comme « des offrandes primaires (c'est-à-dire placées sur le bûcher) dont la présence dans la tombe ne relèverait finalement que du curage du bûcher » (Janin et al. 2000, p. 246).

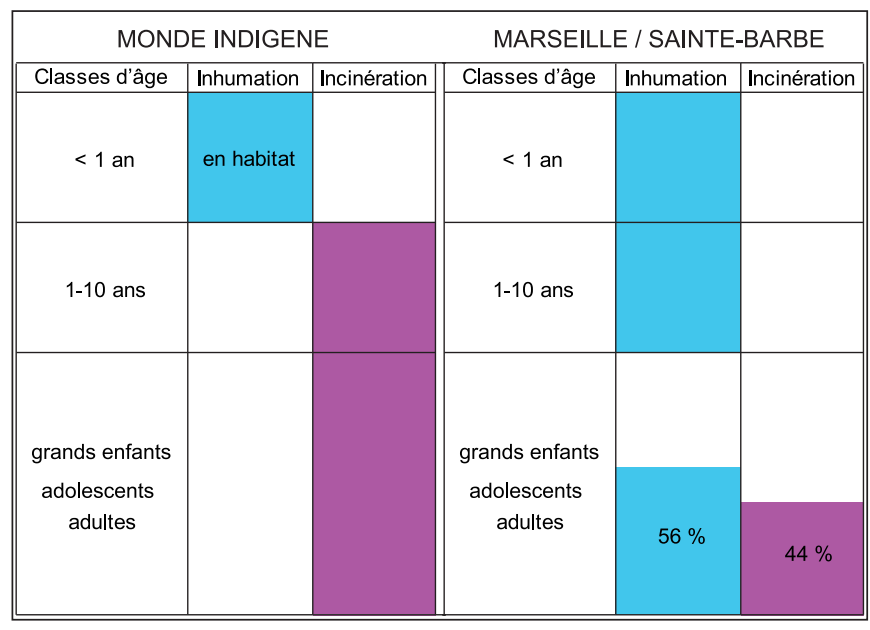

Fig. 8. Rapport inhumation-incinération en fonction de l'âge au décès dans le monde indigène et dans la nécropole grecque de Marseille/ Sainte-Barbe (DAO : B. Dedet, CNRS).

accompagnés, à partir des environs de 300 av. J.-C., du cratère d'importation qui sert aussi d'ossuaire, ainsi que d'offrandes animales symboliques (Bats 2002). Cette forme de banquet «à la grecque » dont les tombes indigènes témoignent, avec les accessoires étrangers pour le service du vin, ce sont autant d'emprunts à la culture grecque, mais non à leurs pratiques funéraires. 


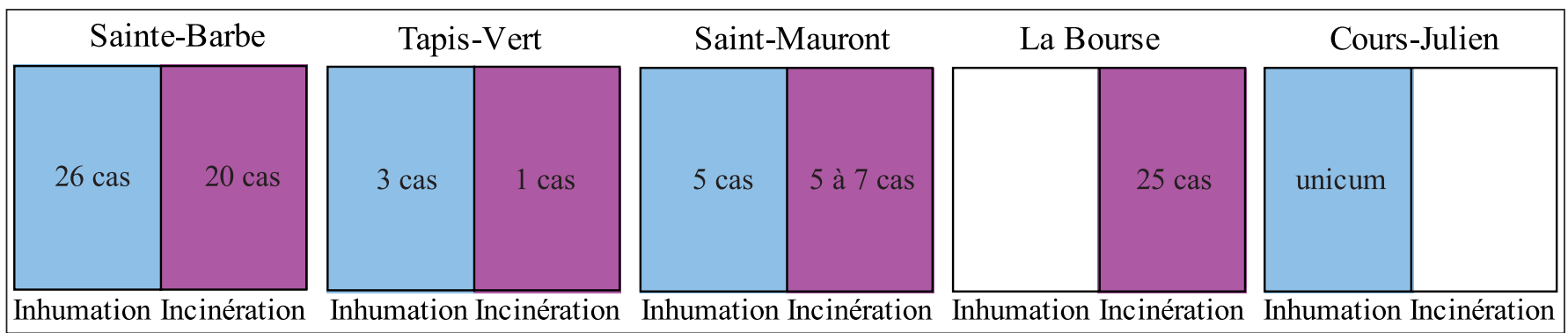

Fig. 9. Rapport inhumation-incinération dans les nécropoles grecques de Marseille (DAO : B. Dedet, CNRS).

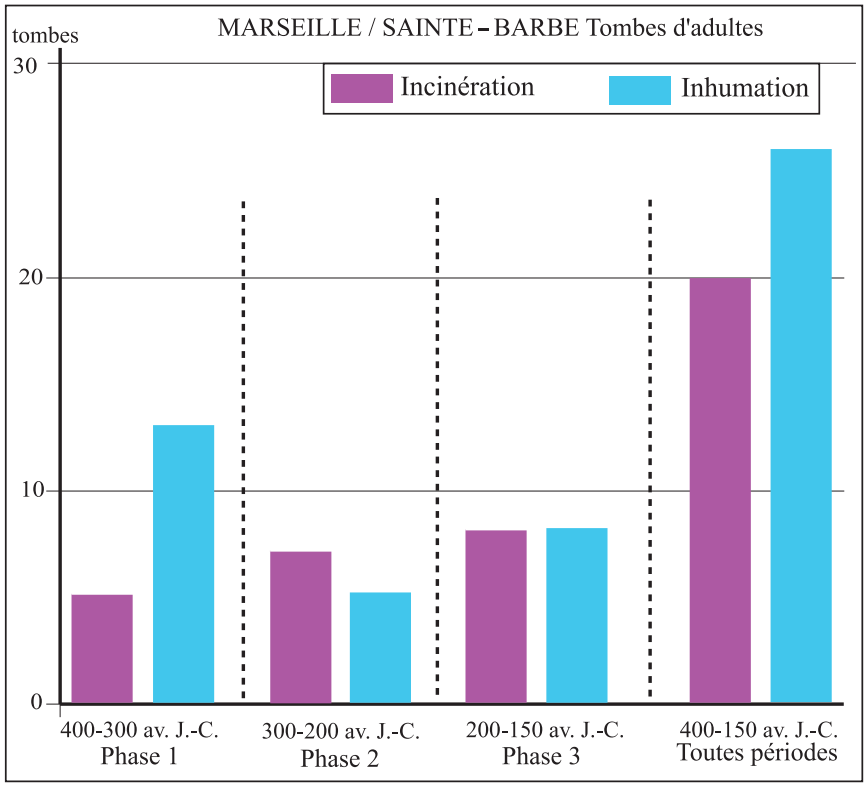

Fig. 10. Rapport inhumation-incinération dans la nécropole grecque de Marseille/Sainte-Barbe, par phase et pour l'ensemble (DAO : B. Dedet, CNRS).

Ainsi, dans ce monde indigène, à la différence de Marseille grecque, les dépôts dans les tombes, sont le reflet de la spécificité du défunt, son âge, son sexe, ses activités ou sa fonction et son importance sociale.

\section{Sur quelques autres aspects des pratiques funéraires}

La comparaison peut être étendue à d'autres dispositions des pratiques funéraires, qui ajoutent d'autres éléments au chapitre des différences.

\section{À propos des défunts incinérés}

Si à Marseille/Sainte-Barbe comme dans les trois nécropoles indigènes les mieux connues, Mourrel Ferrat, Ensérune et Ambrussum, il n'y a pas un secteur réservé à la crémation des défunts et un autre à l'ensevelissement de leurs restes, les tombes étant installées à proximité de ces bûchers, quelques différences paraissent exister sur ce sujet entre les deux domaines culturels, mais le faible nombre de cas connus incite à la prudence.

Chez les Indigènes ces bûchers sont généralement installés sur une plate-forme aménagée avec de la pierraille et de la terre rapportée. En particulier à Ambrussum, cette base est constituée avec des résidus provenant de l'habitat des vivants, et cela sans doute dans un but symbolique. Par contre à Marseille, les foyers sont placés à même le sol, laissant juste la trace d'une aire rubéfiée, sans aménagement de base.

Plus significatif est sans doute le caractère individuel ou partagé de ces lieux. Dans les nécropoles autochtones ils ont servi à plusieurs incinérations successives, comme l'indique la quantité d'os humains découverts. Par exemple, le bûcher B1 d'Ambrussum a fonctionné pour brûler cinq à sept défunts, vêtus et parés, accompagnés de leurs objets personnels adaptés à leur âge et/ou à leur appartenance sexuelle (Dedet 2012, p. 99-142). En revanche à Sainte-Barbe, seule nécropole de Marseille où ces structures ont été étudiées, elles n'ont livré chacune qu'une faible quantité d'os humains et cela pourrait indiquer qu'elles sont individuelles et non collectives, mais à condition qu'elles n'aient pas été nettoyées.

À Marseille, les restes osseux brûlés peuvent être déposés dans un ossuaire, c'est le cas le plus fréquent à Sainte-Barbe, ou bien directement dans la fosse, ou encore selon un procédé mixte associant les deux modalités précédentes, particulièrement présent dans les enclos de la Bourse où ces dépôts prennent place dans des caissons de pierres. Mis à part ces caissons, seulement représentés dans la région du bas-Rhône tardivement, au I ${ }^{\mathrm{er}}$ s. av. J.-C., ces trois formules, ossuaire, absence d'ossuaire et mixte, se retrouvent également chez les Gaulois du Midi, dans des proportions variables selon les nécropoles, mais dans ce monde indigène, il s'agit de trois pratiques tout à fait traditionnelles, d'usage bien antérieur à l'arrivée des Grecs, puisqu'elles sont reconnues dès le Bronze final IIIB. 


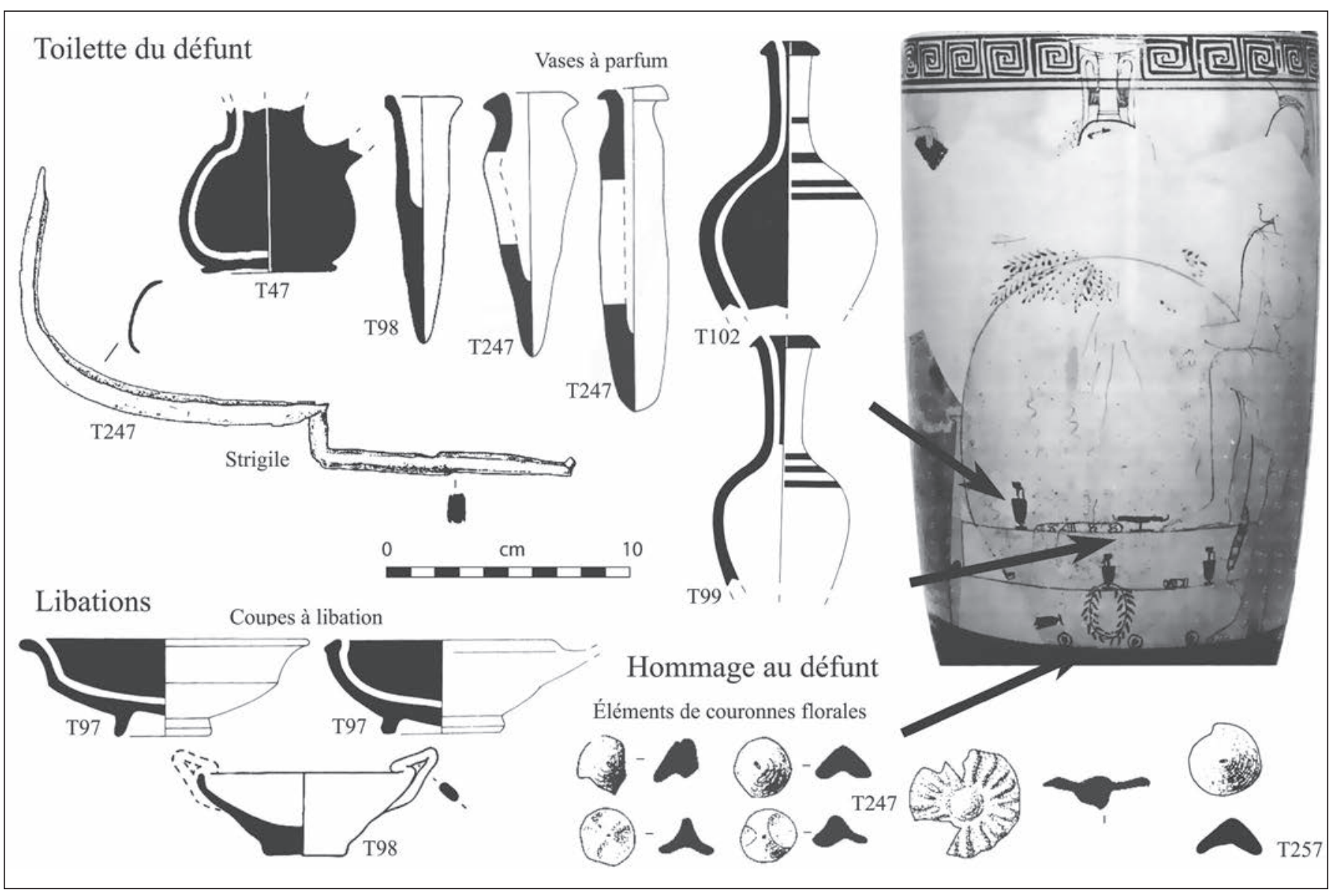

Fig. 11. Les objets déposés dans les tombes la nécropole grecque de Marseille/Sainte-Barbe, classés par fonction, toilette du défunt (vases à parfum, strigile), libations (coupes), hommage (corymbes, éléments de couronnes florales) (d'après Moliner et al. 2003, modifié). À droite, ces diverses catégories d'objets représentées sur un lécythe attique à fond blanc du peintre de Bosanquet, vers 440 av. J.-C. (d'après Oakley 2004, fig. 168).

À Marseille comme chez les Indigènes, l'ossuaire est très souvent un vase courant de la vie quotidienne, cependant l'emploi de récipients spécifiques, comme les urnes en plomb, y est attesté contrairement au monde autochtone. Par contre dans ce dernier, certains vases ou catégories de vases rares dans les habitats sont très nettement plutôt employés à cet usage funéraire. C'est le cas à Ensérune, avec les canthares à pouciers à vernis noir qui servent d'ossuaire pour deux tiers des tombes de la seconde moitié du $\mathrm{IV}^{\mathrm{e}}$ et le début du $\mathrm{III}^{\mathrm{e}} \mathrm{s}$., tandis que ces vases sont au contraire très rares dans les maisons de cet oppidum. C'est encore le cas à même époque des vases non tournés entièrement lissés, à cuisson fumigée, dans la nécropole de Beaucaire.

\section{La vision du tombeau}

Il existe à Marseille une catégorie de morts pour lesquels la vision du tombeau a une grande importance aux yeux des survivants. C'est manifestement le cas, au $\mathrm{IV}^{\mathrm{e}} \mathrm{s}$. av. J.-C., de ceux qui bénéficient des deux terrasses monumentales de la Bourse, près de la porte orientale du rempart de la cité phocéenne, soigneusement bâties à la mode grecque, en grand appareil et décorées de bossages ou de triglyphes sur les faces bordant la voie permettant l'accès à la ville. Mais pour tous les autres, la partie visible de la sépulture reste très modeste et ne marque le paysage que de manière discrète, et il en va de même dans le monde indigène.

À Ambrussum, la fosse ayant reçu le dépôt funéraire et ses abords immédiats où ont été posés des vases ou des portions de vases ne sont recouverts que d'un très léger monticule de terre incluant des éléments osseux et mobiliers provenant du bûcher, un dispositif somme toute peu remarquable. À Ensérune, en revanche, le loculus est recouvert d'une petite accumulation de pierres brutes et parfois signalée par une stèle brute. Pour le commun des mortels, à Marseille, un amoncellement de pierres, de tessons d'amphores et de matériaux de récupération, ou parfois des dallées couchées, ferment et recouvrent la fosse et beaucoup de ces tombes sont indiquées en surface par une pierre plantée, de taille fruste, souvent dégrossie en pyramide. Dans les deux domaines culturels, 
cette discrétion dans le marquage et le signalement du tombeau est tout à fait indépendante des caractères distinctifs du défunt et de ses funérailles, son âge et son sexe, le type de traitement de son corps et de ses restes, le matériel que l'on place dans la fosse sépulcrale. C'est bien là la preuve que l'important n'est pas tant le lieu où demeurent les restes du mort, que le devenir de sa part censée plus ou moins subsister ailleurs.

\section{Conclusions}

Au second âge du Fer, le Sud méditerranéen de la France offre donc deux ensembles de pratiques funéraires bien différents l'un de l'autre, celui des Indigènes et celui des Grecs de Marseille, sans influence réciproque notable (fig. 14). Certes, on pourra objecter que le corpus de sépultures utilisables peut paraitre relativement réduit, surtout pour Marseille où seulement 104 sépultures, réparties sur environ deux siècles, peuvent être prises en compte pour le moment. Mais, dans la colonie phocéenne, ces tombes appartiennent à plusieurs nécropoles où l'on retrouve, chaque fois, les mêmes pratiques, même si le Cours-Julien et la rue Tapis-Vert ne comptent que pour quelques unités, tandis que Sainte-Barbe est bien plus fournie en nombre. Et en plus, quoique non publiée en détail, la nécropole de la Bourse offre une architecture de type éminemment grec. Cet échantillonnage permet donc d'avancer un certain nombre de conclusions.

Les rites massaliètes reflètent bien plutôt les coutumes grecques de l'époque, accueillant les morts périnatals au cimetière de la cité, bien souvent à l'intérieur d'un vase, inhumant les enfants, inhumant certains adultes, incinérant d'autres adultes, ne plaçant dans la tombe que très peu de matériel, souvent même rien du tout, et généralement simplement les objets souillés ayant servi à la toilette du mort, aux actions liées à la cérémonie des adieux, à des libations et à des offrandes de couronnes de fleurs. Cette simplicité que manifestent les vestiges rejoint l'impression que donne Valère Maxime des obsèques marseillaises : "on amène les morts à leur sépulture en les transportant sur un chariot, sans lamentations ni plaintes. Le deuil ne dure que le jour des obsèques, avec un sacrifice groupant les gens de la maison, accompagné d'un banquet qui rassemble toutes les relations » (Faits et dits mémorables, II, 6-7).

Et aucune influence des mœurs indigènes en la matière ne semble transparaître dans les tombes de cette colonie grecque. Cela corrobore quelque peu l'image que les auteurs latins classiques ont donné de Marseille grecque, celle d'une communauté très fortement attachée à ses coutumes et à ses traditions d'origine, quoique isolée au bout du monde, environnée d'autochtones nombreux et décrits comme dangereux, baignée « des flots de la barbarie », pour reprendre l'expression de Cicéron dans le Pro Flacco (XXVI, 63). Rien non plus, dans les tombes que l'on connaît actuellement dans la colonie marseillaise, n'évoque la présence d'individus qui auraient été traités «à la manière indigène ».

De leur côté, les usages funéraires indigènes sont traditionnels, qu'il s'agisse des règles concernant l'âge d'acceptation au cimetière villageois, de l'accession progressive des enfants à ce lieu, du matériel soulignant la personnalité du défunt, insistant souvent sur son appartenance au monde masculin ou féminin, souvent aussi sur son importance sociale et/ou sur sa puissance, avec dépôt d'armes et de récipients attestant une forme de «banquet ». Et si les périnatals et les nourrissons n'ont pas d'accompagnement, c'est qu'ils ne sont pas encore considérés comme des êtres véritablement nés à la société. Ces pratiques indigènes sont dans la continuité de celles que l'on connaît dans la région depuis la fin de l'Âge du Bronze et durant le premier âge du Fer. Elles ne paraissent ni transformées ni seulement modifiées au contact des colons grecs, quelle que soit la proximité ou l'éloignement géographique par rapport aux établissements coloniaux, malgré la pénétration commerciale de ceux-ci et les transformations que cette dernière entraîne dans l'économie, dans certains modes de vie et dans la forme de l'habitat (fig. 14).

Cette étanchéité entre les deux sphères, en ce domaine, s'explique parce que l'on se situe au plus profond des préoccupations humaines, et qu'elle doit sans doute refléter deux conceptions de la mort fondamentalement différentes. D'ailleurs, les ethnologues ont maintes fois souligné pareil phénomène à propos de la colonisation européenne de l'époque moderne: "Les rites funéraires semblent être le bastion qui résiste le mieux à l'acculturation » écrit par exemple Louis-Vincent Thomas à propos de l'Afrique noire (1982, p. 251).

Pour les Indigènes du Midi de la France protohistorique, la mort n'est pas une fin de l'existence, mais un au-delà où le défunt peut entrer pour survivre sous différentes conditions et échapper en quelque sorte à elle. Elle lui ouvre la porte d'un ailleurs où le double du défunt va survivre avec le double des objets qui ont symbolisé son existence terrestre. Dans le texte sur plomb déposé dans une tombe de la nécropole de l'Hospitalet-du-Larzac en Aveyron, on trouve notamment mention en langue gauloise, du monde visible (vodercos), de la mort (nepos) et du monde invisible de l'outre-tombe (antumnos) (Lambert 1994, p. 160-172 ; Vernhet 1995). Certes, il s'agit d'un document daté du

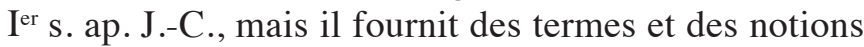




\begin{tabular}{|c|c|c|c|c|c|c|c|c|c|c|c|c|}
\hline \multicolumn{13}{|c|}{\begin{tabular}{|l|l} 
& Inhumation
\end{tabular}} \\
\hline \multicolumn{2}{|c|}{ TOMBES D 'ADULTES } & $\begin{array}{l}\text { Vase à } \\
\text { parfum }\end{array}$ & $\begin{array}{c}\text { Coupe } \\
\text { Coupelle }\end{array}$ & $\begin{array}{c}\text { Cruche } \\
\text { Urne }\end{array}$ & $\begin{array}{l}\text { Couronne } \\
\text { florale }\end{array}$ & Strigile & Bague & Fibule & Scalpt. & $\begin{array}{c}\text { Fuseau } \\
\text { peson/ép. }\end{array}$ & Coquillage & Faune \\
\hline \multirow{18}{*}{ Sainte-Barbe } & T47 & & & & & & & & & & & \\
\hline & T41 & & & & & & & & & & & \\
\hline & T 257 & & & & & & & & & & & \\
\hline & T 56 & & & & & & & & & & & \\
\hline & T98 & & & & & & & & & & & \\
\hline & T 96 & & & & & & & & & & & \\
\hline & T 60 & & & & & & & & & & & \\
\hline & T 102 & & & & & & & & & & & \\
\hline & T 235 & & & & & & & & & & & \\
\hline & T198 & & & & & & & & & & & \\
\hline & T245 & & & & & & & & & & & \\
\hline & T97 & & & & & & & & & & & \\
\hline & T 43 & & & & & & & & & & & \\
\hline & T 247 & & & & & & & & & & & \\
\hline & T90 & & & & & & & & & & & \\
\hline & T192 & & & & & & & & & & & \\
\hline & T 242 & & & & & & & & & & & \\
\hline & T53 & & & & & & & & & & & \\
\hline & & & & & & & & & & & & \\
\hline \multirow{3}{*}{ Rue Tapis-Vert } & Tombe 2 & & & & & & & & & & & \\
\hline & Sarco. 3 (2 sujets) & & & & & & & & & & & \\
\hline & Urne plomb 1 & & & & & & & & & & & \\
\hline Cours-Julien & Tombe adulte & & & & & & & & & & & \\
\hline & & & & & & & & & & & & \\
\hline \multirow{4}{*}{ Saint-Mauront } & Sépulture 5 & & & & & & & & & & & \\
\hline & Sépulture 8 & & & & & & & & & & & \\
\hline & Sépulture 14 & & & & & & & & & & & \\
\hline & Sépulture 7 & & & & & & & & & & & \\
\hline
\end{tabular}

Fig. 12. Tableau synoptique des associations de matériel dans les nécropoles grecques de Marseille, selon le type de traitement du cadavre (DAO : B. Dedet, CNRS).

religieuses indigènes, et issu d'un Larzac éloigné des centres urbains, il concerne un milieu autochtone, héritier direct du passé local. Non seulement les morts ont une autre vie dans cet au-delà, mais en plus les «nouveau-morts » peuvent transmettre des messages à des morts plus anciens et à des divinités, moyennant le passage sur le bûcher d'objets matériels. Et d'ailleurs Diodore de Sicile, décrivant les mœurs des Gaulois de Gaule du sud dans la première moitié du ${ }^{\text {er }}$ s. av. J.-C., ne laisse aucun doute à ce sujet : « au cours des funérailles, ils jettent dans le feu des lettres écrites à des parents déjà morts, comme si ces derniers pouvaient les lire » (Diodore de Sicile, Bibliothèque Historique, $\mathrm{V}, 28,6)$.

De leur côté, pour les massaliètes des $\mathrm{IV}^{\mathrm{e}}$, $\mathrm{III}^{\mathrm{e}}$ et $\mathrm{II}^{\mathrm{e}} \mathrm{s}$. av. J.-C., comme pour le commun des mortels de la Grèce d'alors, en dehors des cercles intellectuels ou philosophiques, la mort c'est d'abord l'arrêt des plaisirs de la vie et aussi un séjour vague au royaume des ombres, l'Hadès, sans repère ni espoir d'aucun accomplissement, une mort sans horizon (Rudhardt 1992 ; Lévy 1994 ; Mikalson 2009). D'ailleurs, quand Diodore de Sicile rapporte cette coutume indigène de charger les nouveaux morts de lettres adressées à des trépassés plus anciens l'expression qu'il emploie, "comme si ces derniers pouvaient les lire », pourrait bien indiquer que lui-même n'y croit pas.

$\mathrm{Au}$ demeurant, le constat d'une telle étanchéité entre les deux cultures du Midi méditerranéen de la France au second âge du Fer n'est pas le propre du seul domaine de la tombe. Il a déjà été formulé à propos d'autres aspects de la sphère religieuse et de certaines mœurs. Ainsi en est-il des espaces cultuels et des dépôts « rituels » indigènes, tant languedociens que provençaux qui ne contiennent aucun matériel emprunté au monde grec (Arcelin et al. 1992 ; Arcelin, Gruat dir. 2003 ; Golosetti 2009) à la différence, par exemple, de ceux des populations autochtones de Sicile et d'Italie méridionale en contact avec les colons grecs établis dans ces contrées (Vassallo 2006 ; Osanna 2010). Et très significative à cet égard est aussi la mise en évidence de la coutume gauloise de l'exposition de crânes humains, au Irr s. av. J.-C., à l'entrée de l'oppidum de la Cloche, aux Pennes-Mirabeau, à moins de quinze kilomètres de la Marseille grecque, comme l'ont souligné François Salviat et Louis Chabot (Salviat 1972, p. 520 ; Chabot 1983, p. 51). 


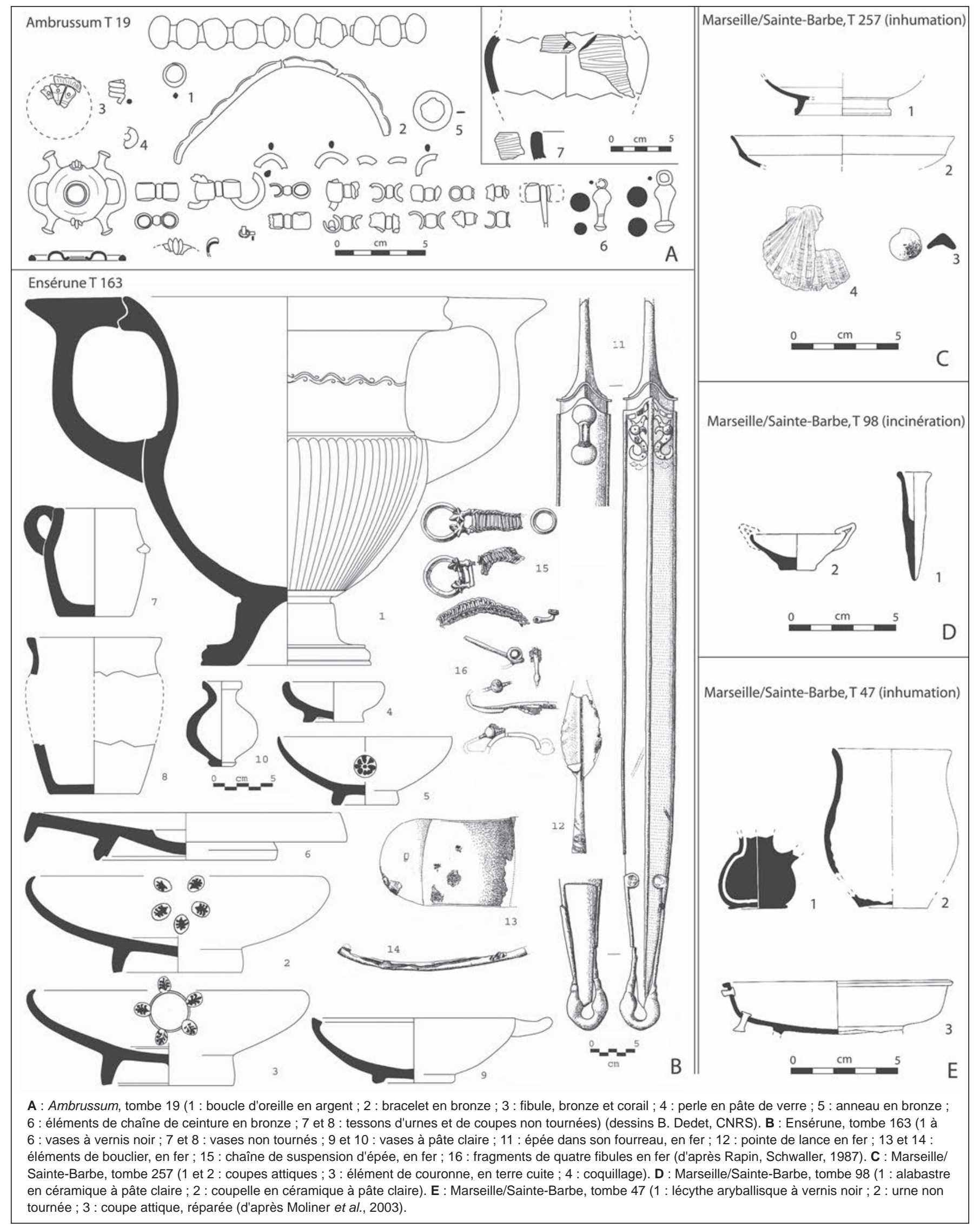

Fig. 13. Exemples de tombes du monde indigène et de Marseille grecque. 


\begin{tabular}{|c|c|c|c|}
\hline & INDIGĖNES, ler Âge du Fer & INDIGĖNES, II Âge du Fer & MARSEILLE, $\|^{e}$ Âge du Fer \\
\hline Périnatals & $\begin{array}{l}\text { Maison } \\
\text { Tous inhumés } \\
\text { Fosse } \\
\text { Pas d'objets }\end{array}$ & $\begin{array}{l}\text { Maison } \\
\text { Tous inhumés } \\
\text { Fosse } \\
\text { Pas d'objets }\end{array}$ & $\begin{array}{c}\text { Cimetière } \\
\text { Tous inhumés } \\
\text { Enchytrismos ou fosse } \\
\text { Objets pour } 1 / 3 \text { d'entre eux }\end{array}$ \\
\hline Enfants $<10$ ans & $\begin{array}{c}\text { Accès progressif au cimetière } \\
\text { Languedoc occidental : } \\
\text { Tous incinérés } \\
\text { Languedoc oriental / Provence } \\
\text { Tous inhumés avant Vle s., } \\
\text { Incinérés ou inhumés au Vle s. }\end{array}$ & $\begin{array}{l}\text { Accès progressif au cimetière } \\
\text { Languedoc / Provence : } \\
\text { Tous incinérés }\end{array}$ & Tous inhumés \\
\hline $\begin{array}{l}\text { Grands enfants } \\
\text { Adolescents } \\
\text { Adultes }\end{array}$ & $\begin{array}{c}\text { Tous incinérés } \\
\text { Mobilier } \\
\text { - plus ou moins abondant } \\
\text { - personnalité du défunt } \\
\text { (sexe, importance sociale) } \\
\text { - présence d'armes } \\
\text { (rares ou fréquentes) }\end{array}$ & $\begin{array}{l}\text { Tous incinérés } \\
\text { Mobilier } \\
\text { - plus ou moins abondant } \\
\text { - personnalité du défunt } \\
\text { (sexe, importance sociale) } \\
\text { - armes fréquentes }\end{array}$ & $\begin{array}{l}\text { Inhumés ou Incinérés } \\
\text { (avec même type de mobilier) } \\
\text { Pas de mobilier } \\
\text { dans } 40 \% \text { des tombes } \\
\text { Si mobilier, peu d'objets : } \\
\text { - toilette du mort } \\
\text { - libations } \\
\text { - hommage }\end{array}$ \\
\hline
\end{tabular}

Fig. 14. Tableau comparatif des usages funéraires du monde indigène et de la colonie grecque de Marseille. II montre, en ce domaine, d'une part la continuité entre le premier et le second Âge du Fer chez les Indigènes, malgré des évolutions dues à la dynamique interne de ce monde, et d'autre part l'étanchéité entre Indigènes et Marseille.

Les coutumes funéraires apparaissent donc comme un critère privilégié d'identification culturelle. Les deux grands groupes humains du Midi méditerranéen protohistorique, celui des Indigènes et celui des Grecs des colonies établies sur leur littoral n'y échappent pas. De ce manque d'échanges dans les pratiques mortuaires on peut peutêtre déduire et entrevoir certains comportements alors en vigueur dans un certain nombre de situations concrètes.

1) Le cas des mariages mixtes à Marseille. Quand meurt l'épouse indigène d'un colon grec, soit son corps serait renvoyé dans son village d'origine, soit, et sans doute plus vraisemblablement, celle-ci serait enterrée selon le mode grec, traduisant ainsi une forme d'assimilation par le mariage. Et, de toutes façons, pour les décès des descendants de ces mariages mixtes, on procèderait selon le mode grec.

2) À Marseille également, le cas des « Barbares » de la périphérie marseillaise venant travailler dans la colonie. À leur mort, les corps de ces indigènes seraient transférés dans leur village d'origine.

3) Enfin, le cas des Grecs qui pourraient vivre dans le monde indigène. D'après les exemples d'Ensérune, d'Ambrussum ou encore de Mourrel-Ferrat, s'il y a des Grecs dans ces oppida, ceux-ci n'y resteraient pas jusqu'à leur décès ou bien leur corps serait rapatrié dans la colonie dont ils sont issus. Mais l'absence de tombes «selon le rite grec » pourrait peut-être autoriser à douter que ces agglomérations gauloises eussent même accueilli des Grecs. Et dès lors, ne peut-on penser que l'indubitable apport grec dans les changements économiques et sociaux de l'âge du Fer du Midi méditerranéen soit surtout le fait d'intermédiaires indigènes?

\section{Bibliographie}

Almagro Basch 1953 : ALMAGRO BASCH (M.) - Las necrópolis de Ampurias. I. Introducción y necrópolis griegas. Barcelona, Diputación provincial de Barcelona-Consejo superior de investigaciones científicas 1953, 399 p. et XVIII pl. HT (coll. Monografías Ampuritanas III).

Arcelin et al. 1992 : ARCELIN (P.), DEDET (B.), SCHWALLER (M.) Espaces publics, espaces religieux protohistoriques en Gaule méridionale. Documents d'Archéologie Méridionale, 15, p. 181-242.

Arcelin, Gruat dir. 2003 : ARCELIN (P.), GRUAT (P.) dir. - La France du Sud-Est (Languedoc-Roussillon, Midi-Pyrénées, Provence-Alpes-Côtes d'Azur). In : Arcelin (P.), Brunaux (J.-L.) dir., Cultes et sanctuaires en France à l'Âge du Fer. Gallia, 60, 2003, p. 169-241.

Bats 2002 : BATS (M.) - Du cratère sympotique au stamnos funéraire, tombes à armes du Midi de la Gaule, IVe-Ier siècle av. J. -C. In : Müller (C.), Prost (F.) éd., Identités et cultures dans le monde méditerranéen antique. Paris, Publications de la Sorbonne, 2002, p. 277-301.

Bel et al. 2008: BEL (V.), BARBERAN (S.), CHARDENON (N.), FOREST (V.), RODET-BÉLARBI (I.), VIDAL (L.) - Tombes et espaces funéraires de la fin de l'Âge du Fer et du début de l'époque romaine à Nîmes (Gard). Lattes, Association pour le Développement de l'Archéologie en LanguedocRoussillon, 2008, 519 p. (Monographies d'Archéologie Méditerranéenne, 24). Bel et al., à paraître : BEL (V.), GARDEISEN (A.), MARCHAND (G.), SCHWALLER (M.) - Au tournant des $\mathrm{III}^{\mathrm{e}}$ et II ${ }^{\mathrm{e}}$ siècles av. J.-C. : une tombe singulière à Ensérune (Montady, Hérault), à paraître.

Bertucchi 1992 : BERTUCCHI (G.) - Nécropoles et terrasses funéraires à l'époque grecque. Bilan sommaire des recherches. In : Bats (M.), Bertucchi (G.), Congès (G.), Tréziny (H.), dir. Marseille grecque et la Gaule, actes du Colloque international d'Histoire et d'Archéologie et du V Congrès archéologique de Gaule méridionale, Marseille, 1990, Lattes/Aix-en-Provence, ADAM éditions/ Université de Provence, 1992, p. 123-137 (Études Massaliètes, 3).

Carme, Demangeot 2010 : CARME (R.), DEMANGEOT (C.) - Beaucaire, Collège Eugène Vigne. Bilan Scientifique de la Région Languedoc-Roussillon 2008. Paris, Ministère de la Culture, 2010, p. 68-71.

Chabot 1983 : CHABOT (L.) - L'oppidum de La Cloche aux PennesMirabeau (Bouches-du-Rhône) (synthèse des travaux effectués de 1967 à 1982). Revue Archéologique de Narbonnaise, XVI, 1983, p. 39-80.

Chabot, Féraud 1959 : CHABOT (L.), FÉRAUD (J.-B.) - La nécropole de la rue du Tapis-Vert à Marseille, Cahiers Ligures de Préhistoire et d'Archéologie, 8, p. 63-86.

Dedet 1995 : DEDET (B.) - Une illustration de l'évolution des pratiques funéraires en Languedoc oriental à l'Age du Fer: la tombe de Font de la Vie à Saint-Bauzille-de-Montmel, Hérault, Ve s. av. J.-C. Gallia, 52, 1995, p. 145-163. Dedet 2004 : DEDET (B.) - Variabilité des pratiques funéraires protohistoriques dans le sud de la France : défunts incinérés, défunts non brûlés. Gallia, 61, 2004, p. 193-222.

Dedet 2008a : DEDET (B.) - Les enfants dans la société protohistorique. L'exemple du Sud de la France. Rome, École française de Rome, 2008, 400 p. (coll. de l'École française de Rome, 396).

Dedet 2008b : DEDET (B.) - La mort du nouveau-né et du nourrisson dans le sud de la France protohistorique (IX ${ }^{\mathrm{e}}-\mathrm{I}^{\mathrm{er}} \mathrm{S}$. av. J.-C.). In : Gusi (F.), Muriel (S.), Olària (C.) coord., Nasciturus, Infans, Puerulus, vobis Mater Terra, la muerte en la infancia, Servei d'Investigacions Arqueologiques i Prehistoriques, Diputació de Castelló, Castelló, 2008, p. 143-182.

Dedet 2011a : DEDET (B.) - Les Gaulois du Midi et Marseille grecque : deux mondes funéraires. Gallia, 68-2, 2011, p. 1-45.

Dedet 2011b : DEDET (B.) - Changements de traitement funéraire des enfants selon l'âge au décès en France méridionale durant la Protohistoire. In : Castex (D.), Courtaud (P.), Duday (H.), Le Mort (F.) et Tillier (A.-M.) dir., Le regroupement des morts. Genèse et diversité archéologique, éd. Ausonius, Bordeaux, 2011, p. 135-159 (Thanat'Os 1).

Dedet 2012 : DEDET (B.) - Une nécropole du second Âge du Fer à Ambrussum, Hérault. Paris/Aix-en-Provence, éd. Errance/Centre Camille Jullian, 2012, 288 p. (coll. Bibliothèque d'Archéologie Méditerranéenne et Africaine, 11). 
Dedet, Gauthey 2008 : DEDET (B.), GAUTHEY (J.) - Tombe du second âge du Fer de La Roussillone à Nîmes, Gard. Documents d'Archéologie Méridionale, 31, 2008, p. 213-228.

Dedet et al. 1974 : DEDET (B.), MICHELOZZI (A.), PY (M.) - La nécropole des Colombes à Beaucaire (Gard), II $\mathrm{I}^{\mathrm{e}} \mathrm{I}^{\mathrm{er}} \mathrm{Z}$. av. J.-C. Revue Archéologique de Narbonnaise, VII, 1974, p. 59-118.

Dedet, Schwaller 2010 : DEDET (B.), SCHWALLER (M.) - Les pratiques funéraires en Languedoc et en Provence du Ve au milieu du II ${ }^{\mathrm{e}}$ s. av. J.-C. In : Barral (P.), Dedet (B.), Delrieu (F.), Giraud (P.), Le Goff (I.), Marion (S.), Villard-Le Tiec (A.) dir., Gestes funéraires en Gaule au Second Âge du Fer. Actes du 33e colloque de l'AFEAF, Caen 2009, thème spécialisé. Besançon, Presses universitaires de Franche-Comté, 2010, p. 269-290 (Annales littéraires, $n^{\circ} 883$; Série « Environnement, sociétés et archéologie», n 14$)$.

Étienne, Müller, Prost 2006 : ÉTIENNE (R.), MÜLLER (C.), PROST (F.) Archéologie historique de la Grèce antique. Paris, Ellipses, 2006 (2 édition), $399 \mathrm{p}$.

Gallet de Santerre 1968 : GALLET DE SANTERRE (H.) - Fouilles dans le quartier ouest d'Ensérune (Insula $\left.{ }^{\circ} \mathrm{X}\right)$. Revue Archéologique de Narbonnaise, I, 1968, p. 39-83.

Genty, Feugère 1995 : GENTY (P.-Y.), FEUGERE (M.) - Aramon (Gard). La nécropole du Ir $\mathrm{s}$. avant notre ère. Documents d'Archéologie Méridionale, 18, 1995, p. 143-195.

Golosetti 2009: GOLOSETTI (R.) - Dépôts rituels de la Protohistoire récente en Gaule méditerranéenne: définition et questions méthodologiques. In : Bonnardin (S.), Hamon (C.), Lauwers (M.), Quilliec (B.) dir., Du matériel au spirituel. Réalités archéologiques et historiques des "dépôts 》 de la Préhistoire à nos jours. Actes des XXIX ${ }^{\mathrm{e}}$ rencontres internationales d'Archéologie et d'Histoire d'Antibes. Antibes, Éditions APDCA, 2009, p. 293-302.

Gourevitch 2003 : GOURÉVITCH (D.) - Maternité et petite enfance dans la littérature médicale. In : Gourévitch (D.), Moirin (A.), Rouquet (N.) dir. : Maternité et petite enfance dans l'antiquité romaine. Catalogue d'exposition, Muséum d'Histoire naturelle. Bourges, éd. ville de Bourges, 2003, p. 24-26. Hermary dir. 2010 : HERMARY (H.) dir., Apollonia du Pont (Sozopol). La nécropole de Kalfata (Ve-III ${ }^{e}$ s. av. J.-C.). Fouilles franco-bulgares (20022004). Paris/Aix-en-Provence, Errance/Centre Camille Jullian, 2010, 200 p. et 129 pl. h.-t. (Bibliothèque d'Archéologie Méditerranéenne et Africaine, 5). Hürmüzlü 2004 : HÜRMÜZLÜ (B.) - Burial Grounds at Klazomenai : Geometric through Hellenistic Periods. In: Moustaka (A.), Skarlatidou (E.), Tzannes(M.-C.),Ersoy(Y.E.)éd.,Klazomenai,Téos and Abdera :Metropoleis and Colony. Proceedings of the International Symposium held at the Archaeological Museum of Abdera, 20-21 October 2001. Thessaloniki, 2004, p. 77-96. Janin et al. 2000 : JANIN (T.), DE BOUBY (J.), BOISSON (H.), CHARDENON (N.), GARDEISEN (A.), MARCHAND (G.), MONTECINOS (A.), SÉJALON (P.) - La nécropole du second âge du Fer de Mourrel-Ferrat à Olonzac (Hérault). Documents d'Archéologie Méridionale, 23, 2000, p. 219-248.

Jehasse, Jehasse 1973 : JEHASSE (J.), JEHASSE (L.) - La nécropole préromaine d'Aléria, 1960-1968. Paris, éd. du CNRS, 1973, 632 p., V et 184 pl. ht. (supplément à Gallia, XXV).

Lambert 1994 : LAMBERT (P.-Y.) - La langue gauloise. Paris, Errance, $1994,240 \mathrm{p}$.

Ledermann 1969 : LEDERMANN (S.) - Nouvelles tables-types de mortalité. Paris, INED, 1969, 260 p. (Travaux et documents, cahier n53).

Lévy 1994 : LÉVY (E.) - La mort en Grèce. In : Mélanges offerts à Claude Vatin, Aix-en-Provence, Publications de l'Université de Provence, 1994 , p. 119-127 (Travaux du Centre Camille Jullian, 17).

Marcadal et al. 2003 : MARCADAL (N.), MARCADAL (Y.), PAILLET (J.-L.) - La nécropole protohistorique et gallo-romaine de Servanes-Cagalou $\left(\mathrm{I}^{\text {er }} \mathrm{s}\right.$. av. J.-C. - -III' s. ap. J.-C.) à Mouriès (Bouches-du-Rhône) : sépultures et monuments funéraires. Documents d'Archéologie Méridionale, 26, 2003, p. 251-348.
Michalaki-Kollia 2010 : MICHALAKI-KOLLIA (M.) - Un ensemble exceptionnel d'enchytrismes de nouveau-nés, de fœtus et de nourrissons découvert dans l'île d'Astypalée, en Grèce : Cimetière de bébés ou sanctuaire? In : Guimier-Sorbets (A.-M.), Morizot (Y.) éd., L'enfant et la mort dans l'Antiquité I. Nouvelles recherches dans les nécropoles grecques. Le signalement des tombes d'enfants. Actes de la table-ronde d'Athènes, 2008. Paris, De Boccard, 2010, p. 161-205 (Travaux de la Maison René Ginouvès, 12).

Mikalson 2009: MIKALSON (J.D.) - La religion populaire à Athènes. Paris, Perrin, 2009, $261 \mathrm{p}$.

Moliner et al. 2003 : MOLINER (M.), MELLINAND (P.), NAGGIAR (L.), RICHIER (A.), VILLEMEUR (I.) - La nécropole de Sainte-Barbe à Marseille ( $I V^{e}$ s. av. J.-C. - II e s. ap. J.-C.). Aix-en-Provence, Édisud/Centre Camille Jullian, 2003, 491 p. (Études Massaliètes, 8).

Oakley 2004 : OAKLEY (J.H.) - Picturing death in classical Athens: the evidence of the white lekythoi. New York, Cambridge University press, 2004, 268 p. et VIII p. de pl. (Coll. Cambridge studies in classical art and iconography).

Osanna 2010 : OSANNA (M.) - Greci ed indigeni nei santuari della Magna Grecia: i casi di Timmari e Garaguso. In : Tréziny (H.) éd., Grecs et indigènes de la Catalogne à la mer Noire, actes des rencontres du programme européen Ramses2 (2006-2008). Paris/Aix-en-Provence, éd. Errance/Centre Camille Jullian), 2010, p. 131-145 (Bibliothèque d'Archéologie Méditerranéenne et Africaine, 3).

Rapin, Schwaller 1987 : RAPIN (A.), SCHWALLER (M.) - Contribution à l'étude de l'armement celtique : la tombe 163 d'Ensérune (Hérault). Revue Archéologique de Narbonnaise, 20, 1987, p. 155-183.

Rothé, Tréziny 2005 : ROTHÉ (M.-P.), TRÉZINY (H.) - Marseille et ses alentours. Paris, Maison des Sciences de l'Homme, 2005, 925 p. (coll. Carte Archéologique de la Gaule, 13/3).

Roure 2007 : ROURE (R.) - Armes et têtes coupées au Cailar (Gard) : premiers éléments de réflexion sur un dépôt rituel en Gaule méditerranéenne. In : Barral (P.), Daubigney (A.), Dunning (C.), Kaenel (G.), Roulière-Lambert (M.-J.) dir., L'âge du Fer dans l'arc jurassien et ses marges. Dépôts, lieux sacrés et territorialité à l'âge du Fer. Actes du XXIXe colloque international de l'AFEAF, Bienne, 2005. Besançon, Presses universitaires de FrancheComté, 2007, vol. 2, p. 653-658 (Annales littéraires; série "Environnement, sociétés et archéologie").

Rudhardt 1992 : RUDHARDT (J.) - Notions fondamentales de la pensée religieuse et actes constitutifs du culte dans la Grèce classique. Paris, Picard, $1992,344 \mathrm{p}$.

Salviat 1972 : SALVIAT (F.) - Circonscription de Provence. Gallia, XXX, 2, 1972, p. 511-541.

Schwaller et al. 1995 : SCHWALLER (M.), DUDAY (H.), JANIN (T.), MARCHAND (G.) - Cinq tombes à incinération du deuxième âge du Fer à Ensérune (Nissan-lez-Ensérune, Hérault). In : Arcelin (P.), Bats (M.), Garcia (D.), Marchand (G.), Schwaller (M.) éd. - Sur les pas des Grecs en Occident. Hommages à André Nickels. Paris/Lattes, Errance/ADAM éditions, 1995, p. 205-230 (Études massaliètes 4).

Schwaller et al. à paraître : SCHWALLER (M.,) MARCHAND (G.), GARDEISEN (A.), JANIN (T.), LEJARS (T.), ORLIAC (D.), RAPIN (A.), SANMARTI (E.), La nécropole du deuxième Âge du Fer d'Ensérune (Nissanlès-Ensérune, Hérault), à paraître.

Thomas 1982 : THOMAS (L.-V.) - La mort africaine. Idéologie funéraire en Afrique Noire. Paris, Payot, 1982, 272 p.

Vassallo 2006 : VASSALLO (S.) - Colle Madore, terre de frontière. In : Spatafora (F.), Vassallo (S.) dir., Des Grecs en Sicile. Grecs et indigènes en Sicile occidentale d'après les fouilles archéologiques. Catalogue d'exposition, Marseille 2006. Palerme, éd. Regione Sicilia 2006, p. 110-125.

Vernhet 1995: VERNHET (A.) - Une inscription magique en langue gauloise. Le plomb de La Vayssière, L'Hospitalet-du-Larzac. In : Dix ans d'archéologie en Aveyron. Montrozier, Musée du Rouergue, 1995, p. 267-269 (Guide d'Archéologie 3). 



\title{
PRATIQUES BALNÉAIRES ET ACCULTURATION : QUELQUES ÉLÉMENTS DE RÉFLEXION
}

\author{
Alain Bouet \\ Université de Toulouse 2-Le Mirail - TRACES.
}

\section{Résumé}

Les bains, par l'importance acquise durant l'Antiquité, sont un important signe d'acculturation. Il en est de même pour les strigiles qui sont indispensables à toute pratique. Quelques découvertes récentes mettent en évidence ce phénomène. Elles témoignent de l'attrait des élites indigènes pour cette nouvelle pratique ou de l'attachement de population à leur pratique antérieure à leur arrivée en Gaule.

Mots-clés : bains, strigile, acculturation, Gaule

\section{Abstract}

Bathing, because of the important role played in Antiquity, can be related to acculturation. The same thing can be made clear for the strigiles which are essential to any bathing practice. Some recent discoveries highlight the phenomenom. They provide further evidence of the way in which the native elites were attracted by this new social practice or, from the opposite point of view, of the people's attachment to their previous pratice before coming in Gaul.

Keywords: bathing, strigile, acculturation, Gaul 
L es bains, manifestation d'une préoccupation impérieuse pour l'être humain, à savoir l'hygiène, constituent un élément fondamental d'une société qui a atteint un certain niveau de développement. Tel est le cas dans le monde grec, puis romain. En Gaule, la création de thermes ou la découverte de matériel lié aux bains - et tout particulièrement les strigiles - sont donc des témoignages d'acculturation. Nous souhaiterions illustrer ce propos par quelques exemples.

Certaines découvertes archéologiques apparaissent essentielles à notre connaissance des sociétés passées. Tel est le cas de celle réalisée sur le site de la Ville à Cornebarrieu (Haute-Garonne) en 2006-2007 (Viers, Veyssière 2012). On ne connaît pour le premier état des vestiges que les bains, le reste de la villa, probablement à l'ouest, ayant été détruit lors de la construction d'un lotissement en 1986. Ce petit établissement s'inscrit dans un rectangle de 5,25 m sur 5,75 m, soit 30,18 $\mathrm{m}^{2}$ (fig. 1). Il est composé de trois pièces : un apodyterium de $7,90 \mathrm{~m}^{2}$ comprenant le long de ses parois sud et est une banquette maçonnée. Aménagé perpendiculairement à la première, se trouve le caldarium d'environ $13,50 \mathrm{~m}^{2}$ auquel on parvient par une porte large de $0,75 \mathrm{~m}$. Il comprend, en saillie sur sa paroi occidentale, une baignoire dont il ne reste plus que le praefurnium sous-jacent qui en assurait le chauffage. Contre la paroi sud, une trace circulaire correspond à l'emplacement d'un labrum méticuleusement récupéré au moment de l'abandon du bâtiment. La troisième pièce occupe l'angle sud-ouest de la construction. Elle est aménagée $0,60 \mathrm{~m}$ sous le niveau des autres salles et les parois qui la délimitaient vraisemblablement n'ont pu être mises en évidence du fait de l'état d'arasement.

Élément remarquable, cet édifice est construit en matériaux périssables. Les parois sont en effet montées en terre sur une ossature de bois. Le parement est recouvert d'un enduit blanc et la base des murs protégée par un solin de béton de tuileau. Seules des briques délimitent le praefurnium et les sols sont en opus signinum décoré de tesselles. Le tout était recouvert d'une toiture de tuiles, probablement à deux pans. Aucune alimentation en eau courante n'a été identifiée et aucun puits n'a été fouillé à proximité. L'eau devait être transportée depuis la source située à une trentaine de mètres de la construction.

De plus, ce bâtiment ne présente aucun hypocauste. Son plan est d'ailleurs antérieur à l'invention de ce mode de chauffage ${ }^{1}$ et il faut imaginer que la température était élevée grâce à un brasero. Le type de décor des sols sur

1 Ou au moins à sa diffusion si l'on en croit l'état 2 des bains de Fregellae édifiés dans la première moitié $\mathrm{du} \mathrm{II}^{\mathrm{e}} \mathrm{s}$. av. J.-C. qui comprend une petite étuve chauffée par un hypocauste à pilettes (Tsiolis 2013,p. 95). béton de tuileau² (opus punicum), l'organisation générale du monument, un caldarium avec bassin chauffé et labrum le rapproche de toute une série de constructions dont les plus connues sont les thermes de Musarna en Étrurie datés du dernier quart du $\mathrm{II}^{\mathrm{e}} \mathrm{s}$. av. J.-C. Il n'est en revanche pas évident de suivre la restitution de la baignoire telle que proposée par les fouilleurs. Ceux-ci s'inspirent des découvertes faites dans la villa Prato à Sperlonga (Italie) (Broise, Lafon 2001, p. 79-91) (fig. 2) et proposent, au-dessus du praefurnium, une baignoire individuelle possiblement accompagnée d'un pédiluve (Viers, Veyssières 2012, p. 117 n. 2). Or, sur le site italien, il n'existe aucun chauffage souterrain. Il nous semble qu'il est préférable d'envisager, comme à Musarna, une petite baignoire collective qui s'accorde bien aux dimensions proposées, soit une surface estimée à environ $3,20 \mathrm{~m}^{2}$. Elle n'était que partiellement chauffée par dessous, à savoir sur la seule surface correspondant au praefurnium, soit la moitié de son étendue. C'est d'ailleurs un aménagement semblable que l'on retrouve à Musarna : le bassin d'immersion est parcouru en sous-sol dans le sens de la longueur par un conduit de chauffe qui ne concerne donc qu'une partie de la surface totale.

Il est très vraisemblable que cette construction n'a pas été réalisée par une main-d'œuvre locale, mais probablement par une équipe spécialisée venue d'Italie. En ce qui concerne la datation, on sent les fouilleurs hésitants à proposer une datation trop haute. Selon eux, le bâtiment serait antérieur au milieu du $\mathrm{I}^{\text {er }}$ S. av. J.-C. Si le mobilier est rare, les niveaux situés sous le bâtiment, ainsi que les niveaux de circulation contemporains de sa construction contiennent du mobilier importé à partir de 125 av. J.-C. (Marty 2008). La construction a subi quelques modifications minimes. Ainsi, un évent constitué de trois cols d'amphore Dressel 1B emboîtés a été installé dans le praefurnium afin d'améliorer le tirage. Ces amphores n'apparaissent pas à Toulouse avant 70 av. J.-C. Enfin, un col de Pascual 1 a été utilisé lors de la mise en place d'une évacuation d'eau percée dans le mur oriental du caldarium. Celui-ci ne peut pas être antérieur à l'époque augustéenne. Le comblement du praefurnium qui scelle l'abandon du bâtiment a également fourni du mobilier augustéen. Les fouilleurs ne situent pas la construction à une date trop ancienne, car les briques du praefurnium sont d'un module proche de celles du fanum de l'emporion de Vieille-Toulouse.

2 Méandres de svastikas, carrés à point central, rectangle constitué de croisettes dans l'apodyterium, panneaux rectangulaires avec quadrillage losangé, fleuron central à six feuilles inscrit dans un méandre de svastikas et de carrés à point central dans le caldarium (Veyssières, Viers 2011, p. 235-239). 


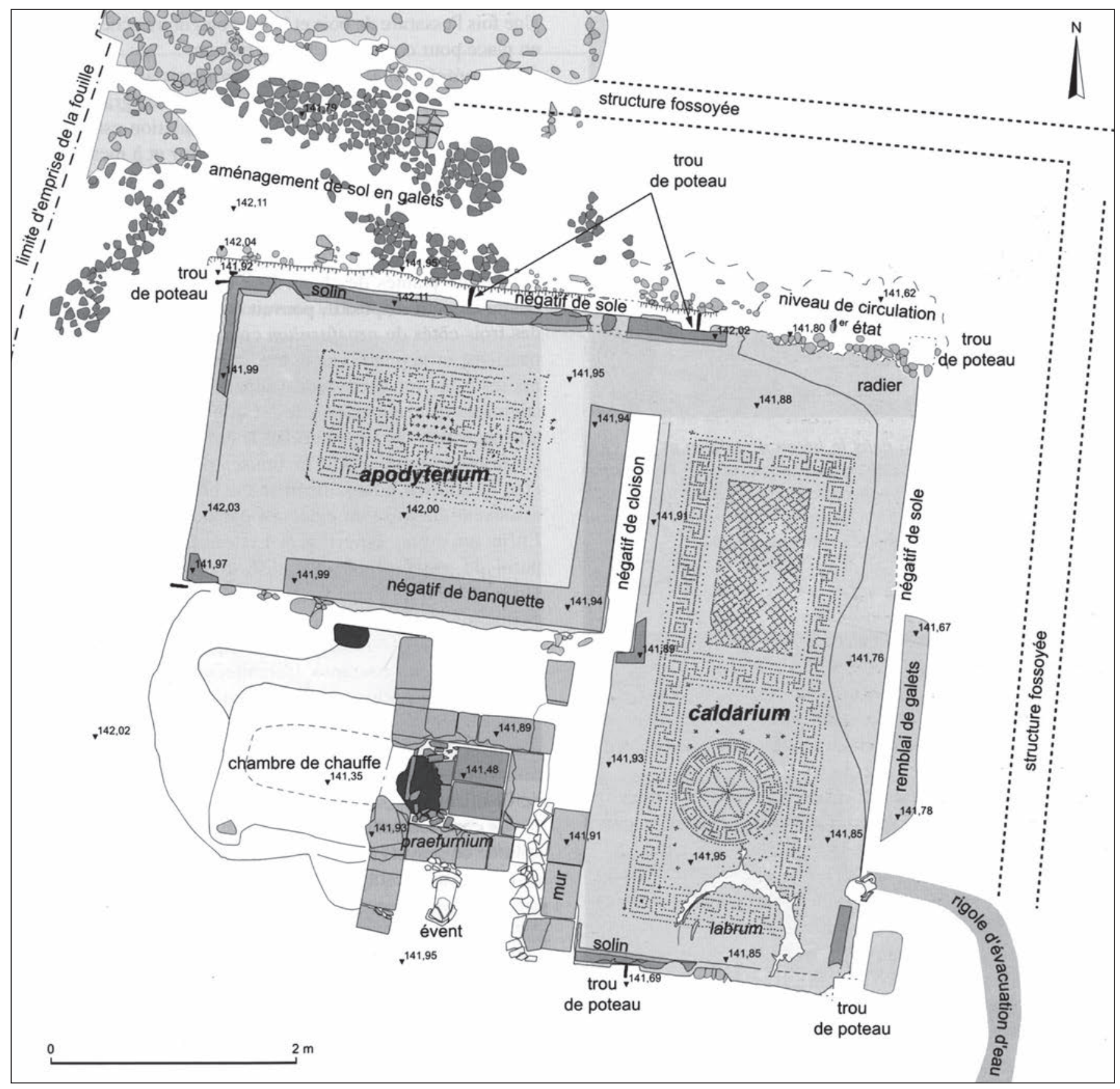

Fig. 1. Les bains de la villa de la Ville à Cornebarrieu (Viers, Veyssière 2012, p. 117).

Leur apparition à Tolosa est considérée comme n'étant pas antérieure au milieu du I ${ }^{\text {er }}$ s. av. J.-C. Ceci obligerait donc à faire évoluer cette date. Le plan de Cornebarrieu est tellement proche de celui de Musarna qu'envisager un écart de 50 ou 60 ans entre les deux constructions nous paraît inconcevable. Les réticences liées à une apparition précoce putative de la brique doivent selon nous être balayées. On ne construit plus au milieu du $\mathrm{I}^{\text {er }} \mathrm{s}$. des thermes de type étrusque. Nous plaçons donc leur construction à la fin du $\mathrm{II}^{\mathrm{e}} \mathrm{s}$. ou au

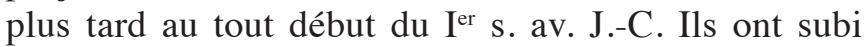

une première modification dans le deuxième quart du $\mathrm{I}^{\text {er }}$ s. av. J.-C., puis une autre à l'époque augustéenne avant d'être abandonnés après un siècle de fréquentation. Ils devaient alors apparaître comme totalement obsolètes et archaïques. Songeons qu'à cette époque les thermes du premier état de la Maison au Dauphin à Vaison-la-Romaine, au plan encore simple, mais incorporant le système d'hypocauste à pilettes, venaient d'être construits (Bouet 2003, II, p. 332-334). Et les Convènes faisaient de même dans le premier état des Thermes du Forum (Bouet dir. 2003, p. 569). 
Cette découverte permet de tirer plusieurs enseignements : il s'agit des thermes les plus anciens de Narbonnaise en dehors de ceux érigés en milieu grec ; le même type de plan, toute proportion gardée, est mis en place tant dans des thermes publics, qu'ici dans des thermes privés (fig. 3). On retrouve un plan avec un cheminement du baigneur strictement identique dans les bains de Musarna précédemment évoqués au dernier quart du $\mathrm{II}^{\mathrm{e}}$ s. av. J-C. (Broise, Jolivet 2004, p. 36-91), dans ceux du sanctuaire d'Héra Lacinia à Crotone (Italie) de la fin du $\mathrm{II}^{\mathrm{e}}$ ou début du $\mathrm{I}^{\mathrm{er}} \mathrm{s}$. av. J.-C. (Broise, Jolivet 2004, p. 91-95), dans ceux de Ca l'Arnau à Cabrera del Mar (Espagne) du milieu du II ${ }^{\mathrm{e}} \mathrm{s}$. av. J.-C. (Martín 2000 ; Broise, Jolivet 2004, p. 108-110) et probablement dans ceux de la rue Aubernon à Antibes (Alpes-Maritimes) (Bouet 2003, II, p. 33-34). On peut mentionner également une variante du plan qui fait alors accéder le baigneur au laconicum et au caldarium en repassant par l'apodyterium ${ }^{3}$. Tel est le cas de l'état 1 des bains de la maison du Cryptoportique à Vulci (Italie) au dernier quart du II ${ }^{\mathrm{e}}$ s. av. J.-C. (Broise, Jolivet 1991, p. 86-88; Broise, Jolivet 2004, p. 101-105) et vraisemblablement de ceux de Norba (Italie) (Broise, Jolivet 2004, p. 98-100) et de la via Sistina à Rome (Broise, Jolivet 2004, p. 100-101). En Espagne, ce plan a été reproduit dans les bains du Forum de Valence à la fin du $\mathrm{II}^{\mathrm{e}}$ ou au début du Irr s. av. J.-C. (Jordá, Lacomba 2000).

Les bains de Fregellae (Italie), qui viennent de faire l'objet d'une publication, sont des plus intéressants, mais, contrairement aux dires de son auteur, ne bouleversent pas la connaissance sur la pratique balnéaire telle qu'elle a pu être établie. Ils permettent d'en affiner la chronologie, ce qui est déjà beaucoup. L'état 1 , mis en place dans les trois dernières décennies du $\mathrm{III}^{\mathrm{e}} \mathrm{s}$. av. J.-C. (Tsiolis 2013, p. 95-104), comprend un vestibule d'entrée, un apodyterium, à moins que celui-ci ne se soit situé dans le vestibule, un laconicum dans lequel a été retrouvé un labrum en remploi et un caldarium avec un bassin chauffé par un conduit souterrain (fig. 4a). En somme, le schéma des bains de Musarna antérieurs de un siècle ! Détruits dans le premier quart du $\mathrm{II}^{\mathrm{e}} \mathrm{s}$., ils sont ensuite reconstruits en plus grand et comprennent désormais deux sections, l'une pour les hommes, l'autre, plus modeste, pour les femmes (fig. 4b). On y rencontre le même schéma de circulation : apodyterium, donnant accès au laconicum sur hypocauste ${ }^{4}$ ou au caldarium

3 Ce cheminement dans lequel l'étuve est dissociée du reste du circuit de bain continue à être mis en œuvre dans les thermes postérieurs, même après l'introduction du frigidarium. C'est d'ailleurs ce plan que décrit Vitruve $(\mathrm{V}, 10,5)$. Il s'agit du type $1 \mathrm{~b} 1$ de notre typologie (Bouet 2003, I, 172-173).

4 Voir note 1 .

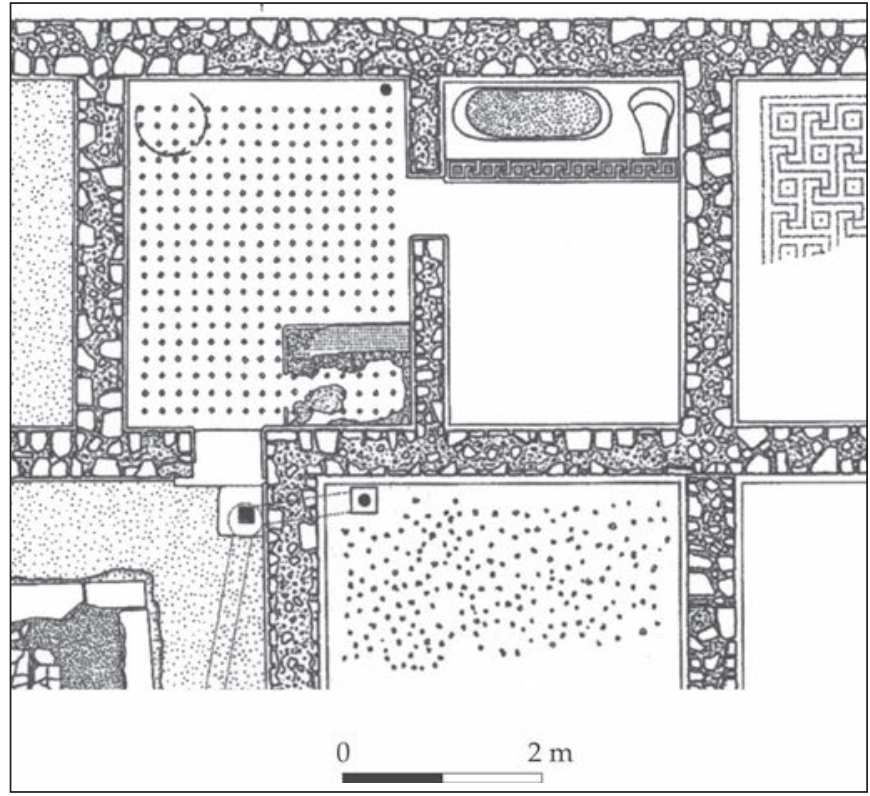

Fig. 2. Les bains de la villa Prato à Sperlonga (Broise, Lafon 2001, pl. I).

avec baignoire chauffé par un canal et labrum disposé en perpendiculaire pour les hommes, seulement apodyterium et caldarium de plan identique au premier pour les femmes. Ces deux sections correspondent aux deux variantes du cheminement telles qu'elles viennent d'être évoquées.

Retour à Cornebarrieu. On construit donc, bien loin de l'Italie, des édifices qui se calquent sur la pratique la plus récente de la péninsule, alors même que le bain n'est pas encore arrivé au terme de son évolution, achevée à l'époque augustéenne (Broise 1994 ; Bouet 2003, I, p. 8-9). Reste l'énigme de l'origine du commanditaire. Est-ce un membre de l'élite gauloise fortement imprégné de romanité dès les lendemains de la conquête ou un Italien installé dans les environs de Tolosa dont on connaît l'importance dès la conquête terminée ? Une partie de la réponse aurait pu se trouver dans le reste de la villa située vraisemblablement à l'ouest, à jamais disparu lors de la construction d'un lotissement en 1986.

Non loin de là, c'est un autre exemple précoce qui a été mis en évidence sur le site minier de Lascours à Ceilhes-et-Rocozels (Hérault) (Gourdiole, Landes 2002, p. 276-277 ; Bouet 2003, II, p. 74-75). Les bains y sont assez détruits et il n'est pas possible de restituer l'intégralité du plan (fig. 5). Toutefois, un des bassins comprend un décor de svastikas alternant avec des carrés à point central ; la pièce est en outre chauffée par un hypocauste constitué de massifs qui dessinent des canaux de chauffe. Ce système, antérieur à l'hypocauste à pilettes, n'est pas sans rappeler celui des Thermes républicains de Pompéi du début du $\mathrm{I}^{\mathrm{er}} \mathrm{s}$. av. J.-C. Le système est plus perfectionné que celui de 


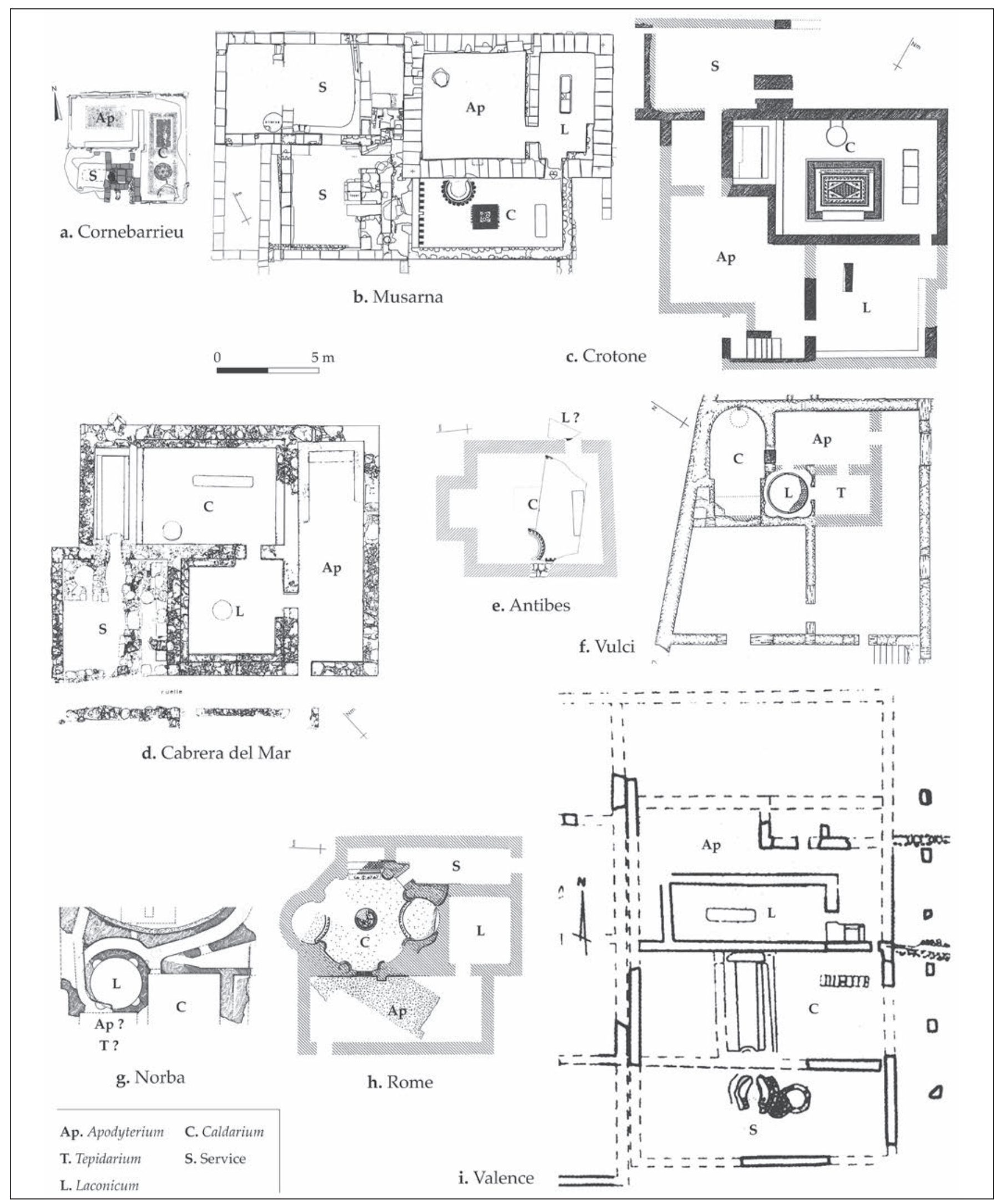

Fig. 3. Comparaisons des bains de la villa de la Ville à Cornebarrieu et des bains tardo-républicains (a. Viers, Veyssière 2012, p. 123 ;

b. Broise, Jolivet 1991, p. 90 ; c. Broise, Jolivet 2004, p. 92 ; d. Broise, Jolivet 2004, p. 109 ; e. Broise, Jolivet 2004, p. 107 ;

f. Broise, Jolivet 1991, p. 87 ; g. Broise, Jolivet 2004, p. 99 ; h. Broise, Jolivet 2004, p. 102 ; i. Jordá, Lacomba 2000, p. 152). 


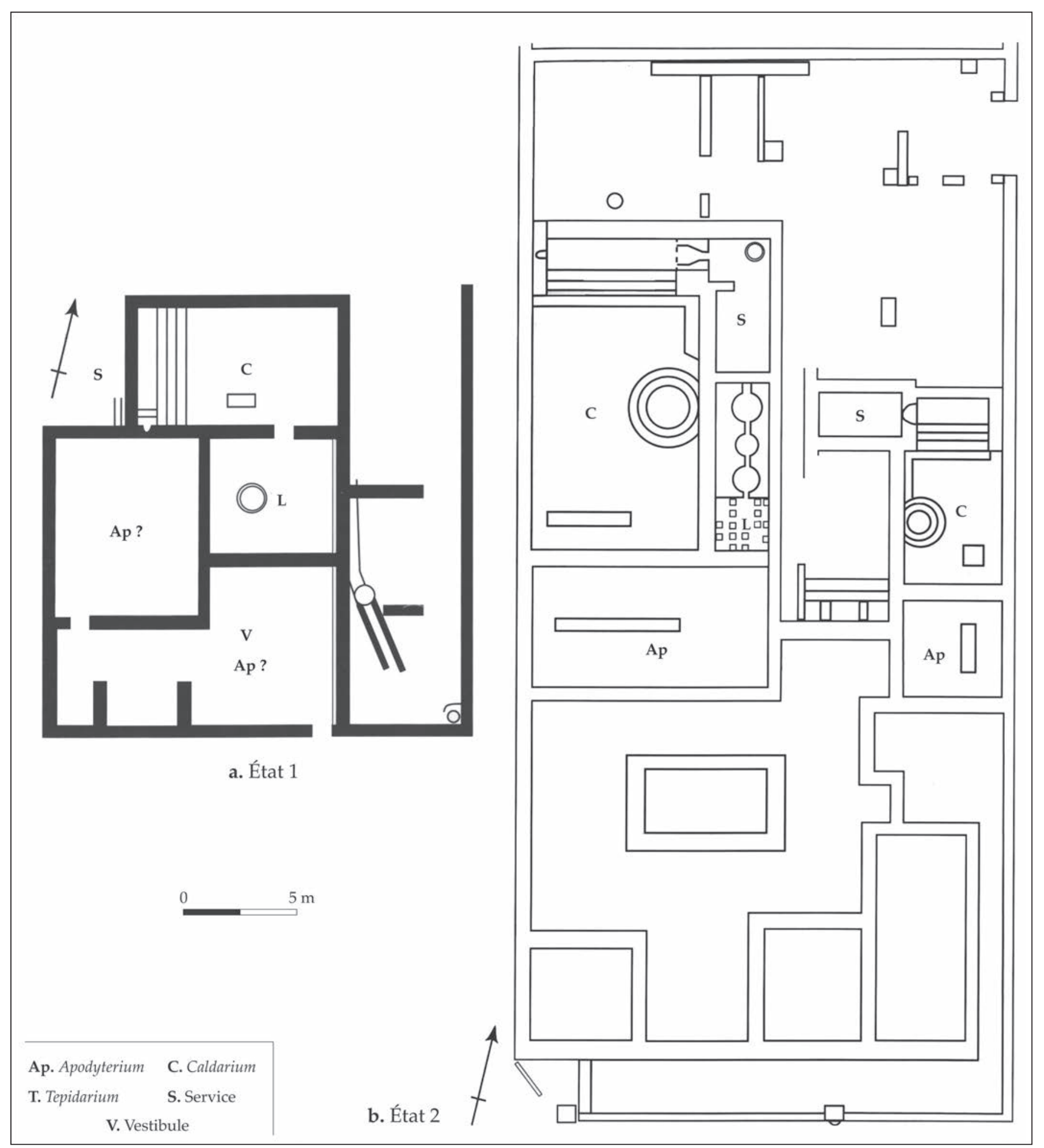

Fig. 4. Les deux états des bains de Fregellae (Tsiolis 2013, p. 96 et 91). 


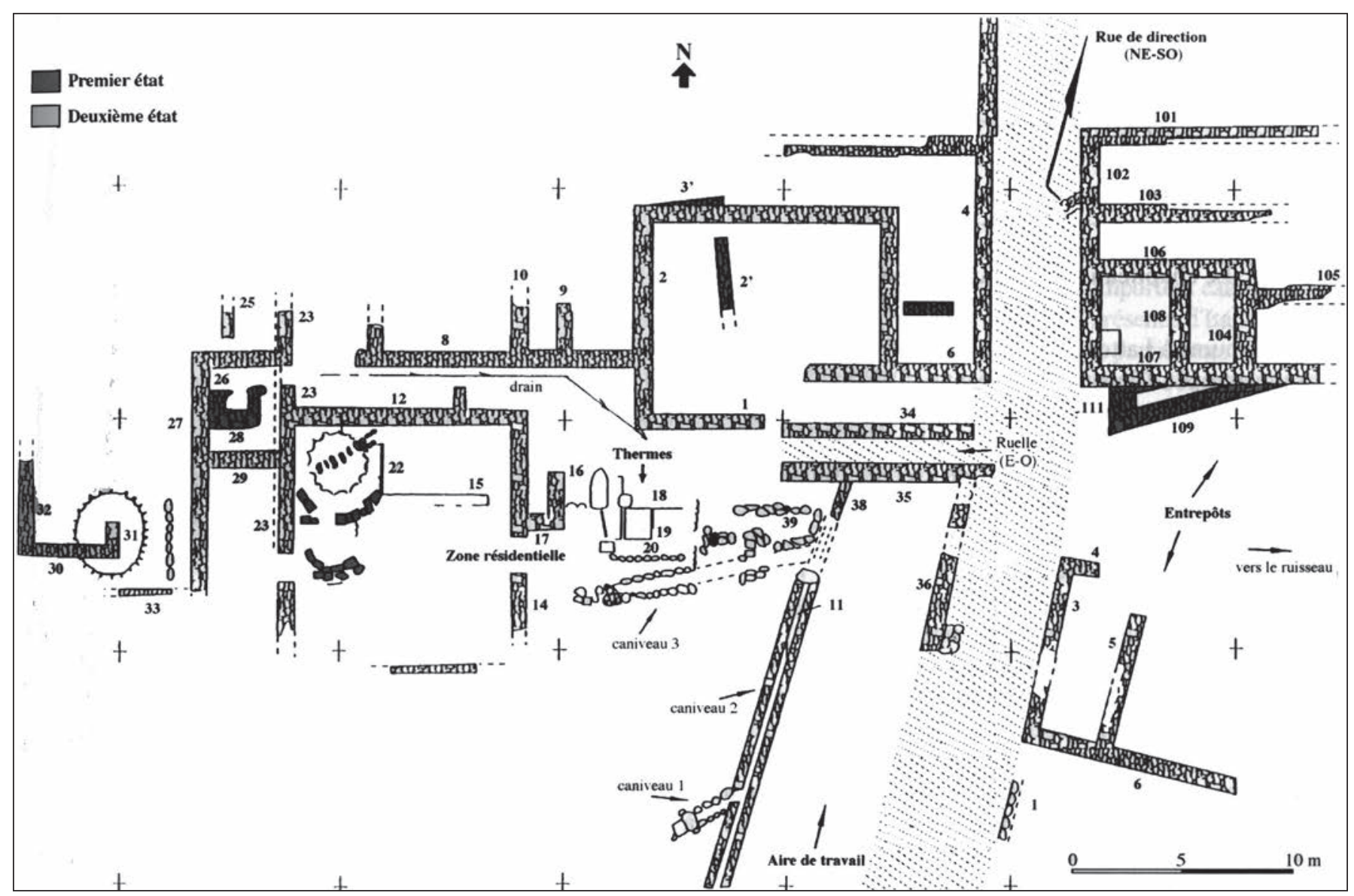

Fig. 5. Les bains au sein de l'agglomération de Lascours à Ceilhes-et-Rocozels (Gourdiole, Landes 2002, p. 275) .

Cornebarrieu que nous datons du début du I ${ }^{\text {er }}$ s. av. J.-C., ce qui n'allait pas à l'encontre de l'occupation du site qui se développe entre la fin du $\mathrm{II}^{\mathrm{e}} \mathrm{s}$. av. J.-C. et le premier tiers du $\mathrm{I}^{\mathrm{er}} \mathrm{s}$. ap. J.-C. Considérant sa petite taille, il est probable que la construction soit privée. Le site correspond à une concession accordée à quelques publicani travaillant en pays rutène comme en témoigne la forte proportion de céramiques importées, sans aucun doute liée à la présence d'une population originaire d'Italie (Bouet 2003, I, p. 321). Nous ne ferons enfin qu'évoquer le bâtiment, peu connu, de la rue Aubernon à Antibes (Alpes-Maritimes) (Bouet 2003, II, p. 33-34) (fig. 3e et 6). A été mise au jour dans une cave une partie d'un tapis mosaïqué représentant une enceinte crénelée à la périphérie d'une pièce large de $5,25 \mathrm{~m}$; un décor circulaire d'ondes devait se développer autour du pied d'un labrum. Un arrachement dans le sol témoigne de la présence d'une banquette. Là aussi, les motifs sont tout à fait identiques à ceux de Musarna à la différence que le sol y est intégralement mosaïqué, ce qui n'est pas le cas du site étrusque. Ce bâtiment pourrait être daté du I ${ }^{\text {er }}$ s. av. J.-C. Il n'est pas étonnant de retrouver ce genre d'aménagement à Antibes, une des fondations massaliètes sur le littoral gaulois, et donc forte d'une longue tradition méditerranéenne.

Il est un autre exemple d'édifice thermal qui, bien que de nature différente et plus récent, s'inscrit dans les mêmes problématiques. Il s'agit des thermes de Villeneuve à la périphérie de Fréjus (Var), à environ $1 \mathrm{~km}$ au sud du rempart de la ville (fig. 7). Ce complexe, malgré une élévation remarquable - plusieurs mètres de haut -, n'est pas intégralement connu. Suite aux dégagements menés entre 2006 et 2008 qui ont permis de mettre au jour un certain nombre de nouvelles structures $^{5}$, on peut supposer que le complexe couvrait au minimum une surface de $1800 \mathrm{~m}^{2}$. On remarque une pièce de service (zone 4) avec des niveaux de charbons et de cendres puis une pièce chauffée $3 \mathrm{~A}$ de $63 \mathrm{~m}^{2}$. Dans un massif carré, une salle circulaire de $25 \mathrm{~m}^{2}$, couverte d'une coupole, comprend en son centre une piscine de $3,90 \mathrm{~m}$ de diamètre et $0,72 \mathrm{~m}$ de profondeur. Dans trois

$5 \quad$ Voir l'état de la question, antérieur aux nouvelles fouilles dans Bouet 2003, II, p. 103-107. Pour les découvertes les plus récentes, voir Excoffon dir. 2011, p. 96-104. 
des quatre angles, est aménagé un bassin ${ }^{6}$. On parvient à cette pièce depuis l'espace 7 , mal connu. La salle a été interprétée comme un frigidarium. La vaste pièce 8 , qui comprend une exèdre axiale sur un de ses grands côtés, comporte en son centre une vaste piscine de $70 \mathrm{~m}^{2}$, profonde de 1,65 m, accessible à ses deux extrémités par trois marches. Deux autres bassins, profonds de 0,80 m, se trouvent contre les parois des petits côtés et un dernier enfin occuperait l'exèdre. On y parvient depuis l'espace 7 et la pièce 10C. Selon les fouilles anciennes, la pièce serait chauffée, vraisemblablement depuis la pièce de service 9 . La pièce 10A, accessible depuis le sud par une porte, est éclairée par une fenêtre percée dans sa paroi nord. Une arrivée d'eau témoigne pour sa part de la présence d'une fontaine ou d'un labrum.

Dans le cadre de cette étude, la pièce circulaire qui a connu deux états retient tout particulièrement notre intérêt (fig. 8). Elle comprenait à l'origine une série de niches basses, larges de 0,54 m, hautes de 1,20 m, profondes de $0,60 \mathrm{~m}$. Si seules onze sont actuellement visibles suite aux vicissitudes connues par cette salle, seize peuvent être restituées à l'origine. On parvient à cette salle, non pas depuis l'espace 7 , mais depuis la vaste pièce 8 . La pièce serait chauffée dans un premier temps, peut-être par un brasero. Les niches ont pu accueillir des baignoires individuelles, ce qui est un aménagement tout à fait original en Gaule Narbonnaise. Le fouilleur émet à son sujet une hypothèse qui passe malheureusement inaperçue dans le cadre d'une lecture rapide $^{7}$ de la publication, mais qui, des plus stimulantes, mérite d'être développée.

La datation de cet ensemble et de ses multiples remaniements est mal assurée en l'absence d'une étude exhaustive. Cependant, la mise en place pourrait intervenir autour du changement d'ère et ses ultimes transformations au milieu du $\mathrm{I}^{\text {er }}$ s. ap. J.-C. (Excoffon dir. 2011, 107).

Les pièces circulaires (tholoi) à baignoires individuelles - ou cuves plates - caractérisent en effet les bâtiments de type grec qui correspondent à la pratique du bain par affusion (fig. 9). Celle-ci est ensuite remplacée par le bain collectif de délassement, les cuves disparaissant au profit d'un labrum, comme en témoignent les thermes de Musarna précédemment évoqués. Cette

6 Contrairement à ce qui a été écrit (Excoffon dir. 2011,97), nous n'avons pas dit que ces bassins étaient des douches en nous appuyant sur la bouche circulaire qui se trouve en contre-haut. Nous y voyons des bassins (Bouet 2003, I, 38-39 ; II, 105). Quand à la bouche circulaire, avec un diamètre de $0,70 \mathrm{~m}$, elle ne peut évidemment pas être interprétée comme une arrivée d'eau, mais comme un oculus (Bouet 2003, I, 274).

7 Mentionnée seulement en note (Excoffon dir. 2011, 98 n. 27).

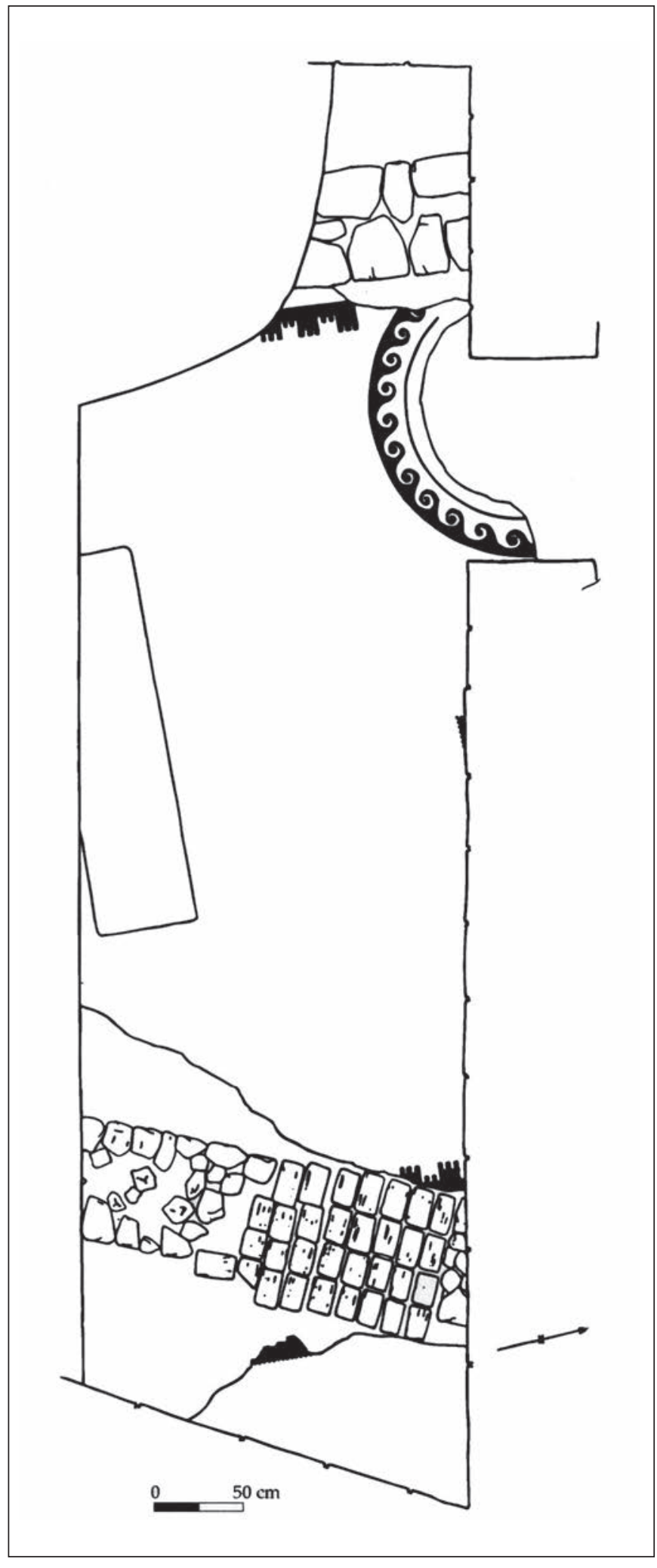

Fig. 6. Les vestiges des bains de la rue Aubernon à Antibes (Bouet 2003, II, p. 34). 


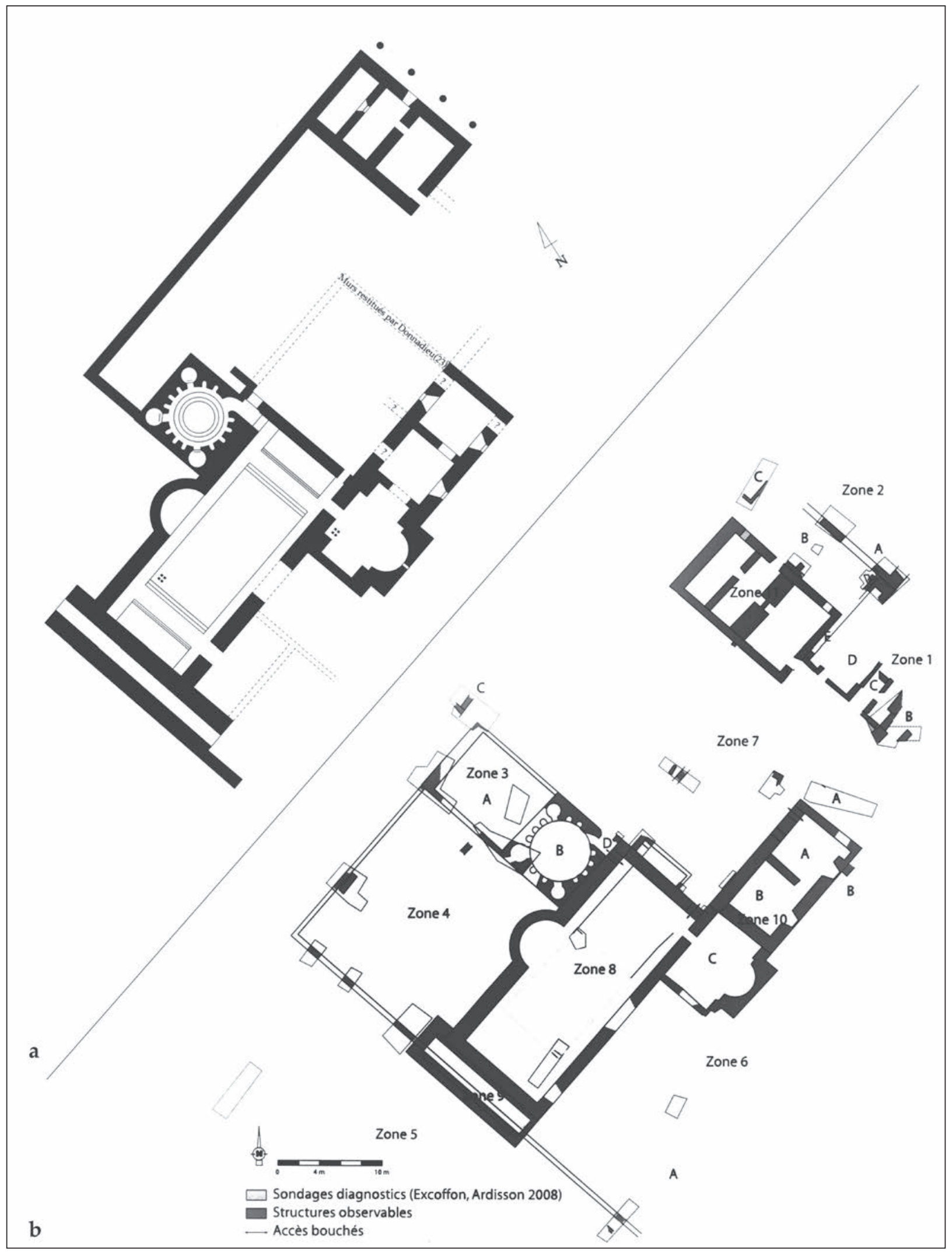

Fig. 7. Les thermes de Villeneuve à Fréjus d'après A. Donnadieu (1928) (a) et état actuel (b) (a. Bouet 2003, II, p. 104 ; b. Excoffon 2011, p. 98). 


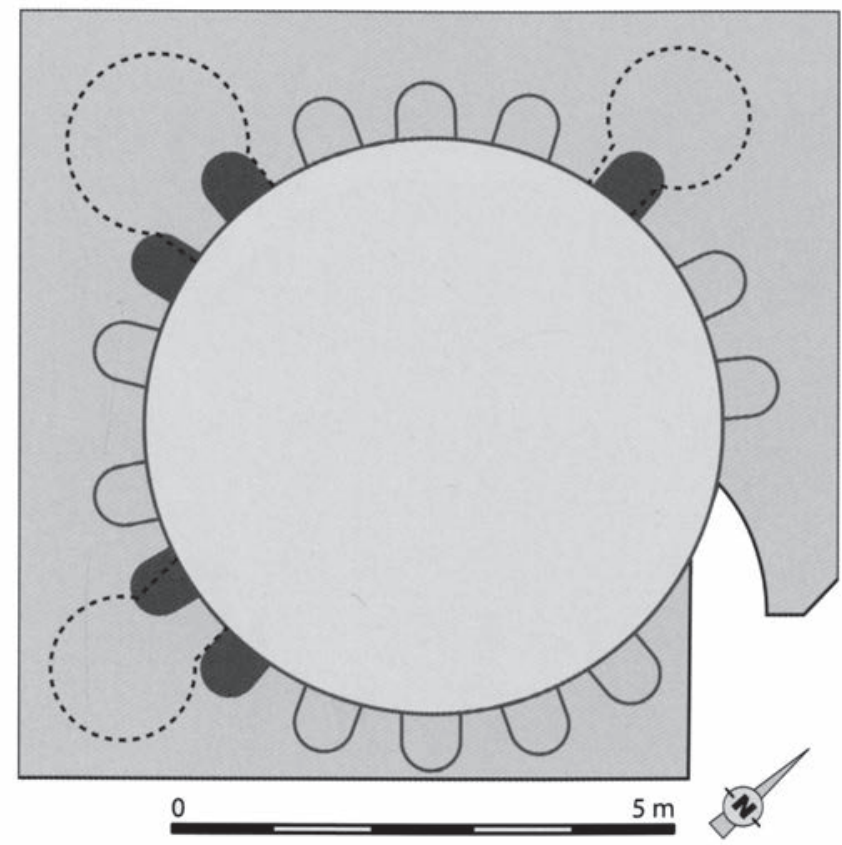

Fig. 8. Reconstitution du premier état de la pièce circulaire des thermes de Villeneuve à Fréjus (Excoffon 2011, p. 99).

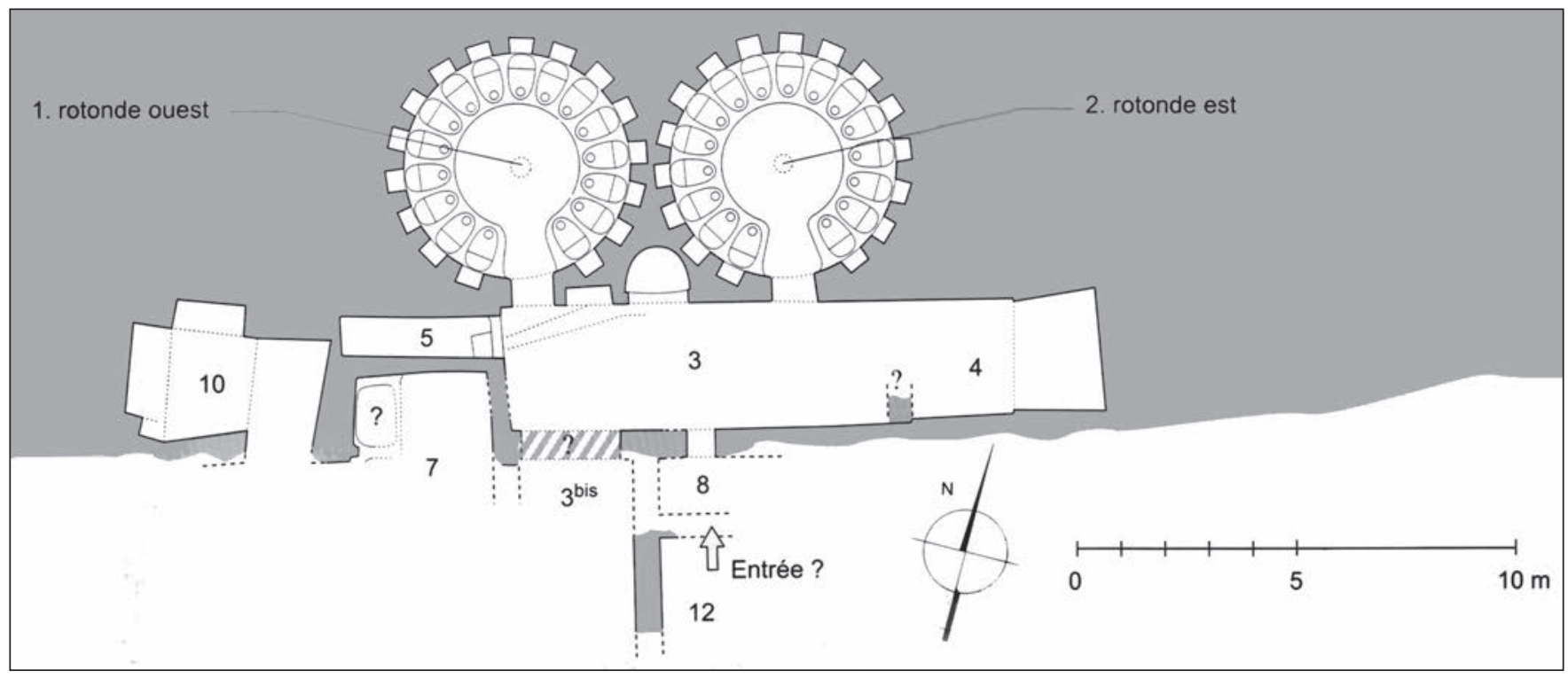

Fig. 9. Un exemple de pièces circulaires à cuves plates en Egypte : état 1 des bains de Taposiris Magna (III ${ }^{\mathrm{S}} \mathrm{s}$. av. J.-C. ?) (Fournet, Redon 2009, p. 137).

pratique se développe en Sicile dès le III ${ }^{\mathrm{e}} \mathrm{s}$. av. J.-C. et aboutit à l'époque augustéenne au modèle du bain romain qui n'évolue plus durant le haut-Empire. La Gaule du sud-est est d'ailleurs bien dotée en bain à cuves plates puisque ceux de la Rue Leca à Marseille du milieu du IVe s. av. J.-C. ont livré la plus grande rotonde (11 $\mathrm{m}$ de diamètre) qui pouvait accueillir une quarantaine de cuves (Conche 1999, p. 93-96). Et les exemples sont nombreux dans l'ensemble du bassin méditerranéen $^{8}$. La Gaule connaît ensuite une évolution identique à celle des autres régions occidentales de l'Empire, ce qu'atteste la découverte de Cornebarrieu. Il n'y a donc, a priori, pas de raison de retrouver une tholos avec cuves plates en Narbonnaise à l'époque augustéenne.

8 Voir le catalogue récemment publié (Fournet et al. 2013). 


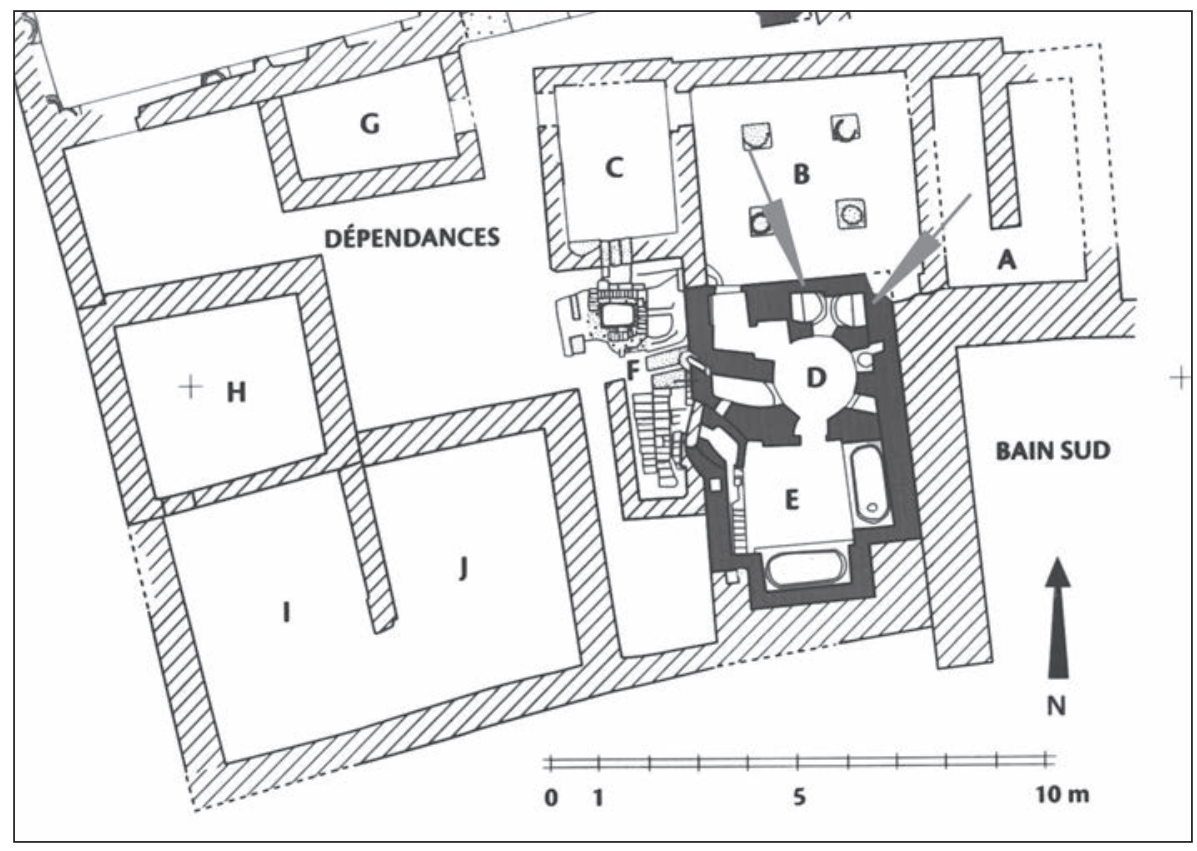

Fig. 10. Emplacement des cuves plates dans les bains sud de Tebtynis (Hadji-Minaglou 2009, p. 187).

Il est toutefois une région dans laquelle cette évolution n'a pas eu lieu : il s'agit de l'Egypte. Là, le bain grec, introduit après la conquête macédonienne, connaît une évolution propre. Les tholoi à cuves plates perdurent alors qu'elles sont abandonnées ailleurs et l'on en construit encore au début de notre ère (bains sud de Tebtynis, Fayoum ; Hadji-Minaglou 2009 ; fig. 10) et même jusqu'au $\mathrm{II}^{\mathrm{e}} \mathrm{s}$. (Broise 2009, 11). Or Fréjus a accueilli une partie de la flotte romaine, au même titre que Misène ou Ravenne. Cette flotte est constituée des navires à éperons saisis lors de la victoire d'Actium sur Antoine et envoyés là par Auguste ${ }^{9}$. Les effectifs des flottes étaient généralement constitués d'affranchis ou de pérégrins recrutés dans les provinces orientales où était établie une grande tradition maritime (Reddé 1986, p. 484-486). Un camp militaire est effectivement attesté de façon indubitable à Fréjus et, bien que ses limites - et donc son étendue - ne soient pas clairement connues, tous les chercheurs s'accordent à considérer que les thermes de Villeneuve en font partie intégrante ${ }^{10}$. Les données archéologiques actuelles attestent son existence à partir des années $15 / 5$ av. J.-C. et jusqu'aux années 40-50, époque à laquelle les lieux connaissent une désaffection partielle puis un abandon définitif autour de 70 (Goudineau, Brentchaloff dir. 2009, p. 580).

On peut donc se demander si le premier état des thermes de Villeneuve ne correspond pas à une tradition

9 Tacite, Ann., IV, 5.

10 Voir les différentes hypothèses concernant ses dimensions dans Goudineau, Brentchaloff dir. 2009, p. 37-40. orientale - égyptienne - de la pratique thermale qui se distingue alors pour une part de la pratique occidentale où elle apparaît « archaïsante » dans sa forme. Cette implantation serait due à la fréquentation de ces bains par des orientaux issus de la flotte de Fréjus. L'hypothèse, aussi fragile soit-elle, est des plus stimulantes car elle témoignerait de l'importation d'une pratique du bain différente de celle dominante et, par conséquence, de l'attachement d'une population à sa tradition hygiénique.

Si les bâtiments sont les témoins d'une activité balnéaire, il en est de même des ustensiles liés au bain, et en premier lieu des strigiles. La mise au jour de strigiles peut apparaître comme un vecteur d'acculturation. Il convient toutefois de distinguer les lieux de découverte et de ne pas interpréter toute exhumation dans ce sens. C'est pourtant ce qui a été récemment proposé (Mallet 2009). Certaines étrilles sont même considérées comme ne pouvant pas être compatibles avec la sphère thermale (Mallet 2009, p. 129). L'auteur, à partir de l'exemple d'un strigile à décor damasquiné daté de l'époque augustéenne, découvert dans un fossé entourant la villa des Champs-de-Choisy à Charny (Seine-et-Marne), considère qu'au regard de la date haute de cet objet, de sa morphologie générale, du fait que selon toute vraisemblance la villa dont il provient ne possédait pas de thermes, l'objet est plus symbolique - un signe d'acculturation -, que réellement utilitaire (Mallet 2009, p. 129). Pour la Provincia, le strigile, serait un important signe de romanisation et revêtirait des aspects symboliques bien différents selon qu'il ait appartenu à un vétéran, à un colon ou à un notable gaulois. Dans les Trois Gaules, le strigile constituerait « un symbole d'aptitude à exercer 


\begin{tabular}{|c|c|c|c|c|}
\hline Sites & $\begin{array}{l}\text { Type de } \\
\text { tombe }\end{array}$ & \begin{tabular}{|c|} 
Nombre \\
de strigiles
\end{tabular} & Datation & Bibliographie* \\
\hline Lattes (Hérault), La Céreirède & incinération & 1 & Vle s. av. J.-C. & \\
\hline Marseille (Bouches-du-Rhône), rue du Tapis Vert & inhumation & 1 & 430 av. J.-C. & \\
\hline $\begin{array}{c}\text { Marseille (Bouches-du-Rhône), îlot Sainte-Barbe, } \\
\text { tombe } 245\end{array}$ & incinération & 1 & première moitié IV $\mathrm{s}$. av. J.-C. & Moliner et al. 2003, p. 270 \\
\hline $\begin{array}{l}\text { Marseille (Bouches-du-Rhône), îlot Sainte-Barbe, } \\
\text { tombe } 247\end{array}$ & incinération & 1 & première moitié IV $\mathrm{s}$. av. J.-C. & Moliner et al. 2003, p. 271 \\
\hline $\begin{array}{l}\text { Marseille (Bouches-du-Rhône), îlot Sainte-Barbe, } \\
\text { tombe } 235\end{array}$ & incinération & 1 & seconde moitié IVe s. av. J.-C. & Moliner et al. 2003, p. 270 \\
\hline $\begin{array}{c}\text { Marseille (Bouches-du-Rhône), La Plaine } \\
\text { Saint-Michel }\end{array}$ & inhumation & 1 & IV $\mathrm{e} . / I I^{\mathrm{e}}$ s. av. J.-C. & \\
\hline $\begin{array}{c}\text { Marseille (Bouches-du-Rhône), îlot Sainte-Barbe, } \\
\text { tombe } 194\end{array}$ & incinération & 1 & première moitié $\|^{\mathrm{e}} \mathrm{s}$. av. J.-C. & Moliner et al. 2003, p. 267-268 \\
\hline Nîmes (Gard), Mail romain, tombe 68 & - & 2 & lers. av. J.-C. & \\
\hline $\begin{array}{c}\text { Beaucaire (Gard), nécropole des Marroniers, } \\
\text { tombe } 19\end{array}$ & incinération & 2 & 75 av. J.-C. & \\
\hline $\begin{array}{l}\text { Nîmes (Gard), rue d'Agobert et rue du Cirque- } \\
\text { Romain, tombe } 8\end{array}$ & incinération & 1 & deuxième quart ler $\mathrm{S}$. av. J.-C. & \\
\hline $\begin{array}{l}\text { Beaucaire (Gard), nécropole des Marroniers, } \\
\text { tombe } 13\end{array}$ & incinération & 2 & 50 av. J.-C. & \\
\hline $\begin{array}{l}\text { Beaucaire (Gard), nécropole des Marroniers, } \\
\text { tombe } 21\end{array}$ & incinération & 2 & $50 / 25$ av. J.-C. & \\
\hline Castelnau-le-Lez (Hérault), Navitau, tombe 5 & incinération & 1 & seconde moitié ler s. av. J.-C. & \\
\hline $\begin{array}{c}\text { Beaucaire (Gard), nécropole des Marroniers, } \\
\text { tombe } 5\end{array}$ & incinération & 4 & Époque augustéenne & \\
\hline $\begin{array}{c}\text { Beaucaire (Gard), nécropole des Marroniers, } \\
\text { tombe } 18\end{array}$ & incinération & 2 & Époque augustéenne & \\
\hline Boissières (Gard) & incinération & 4 & 30 av./10 ap. J.-C. & \\
\hline Le Cannet-des-Maures (Var), Blais 7 & ustrinum & 1 & milieu ler s. ap. J.-C./milieu Ile s. & \\
\hline Saint-Paul-Trois-Châteaux (Drôme), tombe 258 & incinération & 3 & $100 / 150$ & \\
\hline Saint-Paul-Trois-Châteaux (Drôme), tombe 158 & incinération & 4 & $140-150 / 200$ & \\
\hline Nîmes (Gard), avenue Jean-Jaurès, tombe 1113 & incinération & 2 & Haut-Empire & \\
\hline Nîmes (Gard), Saint-Baudille & - & 2 & Haut-Empire & \\
\hline Tresques (Gard), Courac I, tombe 6 & incinération & 1 & ler/lle s. & \\
\hline Bouillargues (Gard), Mas de Bourges, tombe 226 & incinération & 2 & & \\
\hline Courbessac (Gard), tombe 202 & incinération & 1 & & \\
\hline Nîmes (Gard), avenue Jean-Jaurès, tombe 99 & incinération & 2 & & \\
\hline Nîmes (Gard), avenue Jean-Jaurès, tombe 100 & incinération & 2 & & \\
\hline $\begin{array}{l}\text { Nîmes (Gard), chemin de la Lampèze et rue } \\
\text { Rouget-de-Lisle, tombe } 175\end{array}$ & incinération & 1 & & \\
\hline Nîmes (Gard), route d'Avignon, tombe 100 & incinération & 1 & & \\
\hline Nîmes (Gard), 94 route de Beaucaire, tombe 33 & incinération & plusieurs & & \\
\hline Nîmes (Gard), route de Beaucaire, tombe 42 & inhumation & 1 & & \\
\hline Nîmes (Gard), route de Beaucaire, tombe 44 & incinération & 1 & & \\
\hline Nîmes (Gard), Tour Magne & - & 1 & & \\
\hline Saint-Gervasy (Gard) & incinération & plusieurs & & \\
\hline Pignan (Hérault), la Garonne, tombe 1887 & - & 4 & & \\
\hline Apt (Vaucluse), quartier de la Madeleine & incinération & 1 & & \\
\hline
\end{tabular}

*La bibliographie, lorsqu'elle n'est pas mentionnée, pourra être trouvée dans Mallet 2009. 


\begin{tabular}{|c|c|c|c|}
\hline Sites & Type de tombe & Nombre de strigiles & Datation \\
\hline Boé (Lot-et-Garonne) & incinération ? & 2 & $\begin{array}{c}\text { dernier quart ler s. av. } \\
\text { J.-C. }\end{array}$ \\
\hline Antran (Vienne), La Croix-Verte & cénotaphe & 2 & fin ler s. av. J.-C. \\
\hline Chassenard (Allier) & incinération & 2 & 40 ap. J.-C. \\
\hline Aizier (Eure), hameau de Flacq & incinération & 2 & deuxième tiers Ile s. \\
\hline $\begin{array}{c}\text { Étretat (Seine-Maritime), pavillon } \\
\text { Lemaistre }\end{array}$ & incinération & 2 & Ile ou début IIle s. \\
\hline $\begin{array}{c}\text { Soissons (Aisne), Les Longues } \\
\text { Raies }\end{array}$ & - & 1 & fin ler s. ap. J.-C./IVe s. \\
\hline Eslettes (Seine-Maritime) & inhumation & 1 & Haut Moyen-Age \\
\hline Arpajon-sur-Cère (Cantal) & - & 1 & \\
\hline Villeseneux (Marne), l'Homme-Mort & - & 1 & \\
\hline $\begin{array}{c}\text { Lyon (Rhône), nécropole du Trion, } \\
\text { objets n770 et 771 }\end{array}$ & - & 1 & \\
\hline $\begin{array}{c}\text { Poitiers (Vienne), } \\
\text { Blossac-Saint-Hilaire }\end{array}$ & - & 2 & \\
\hline
\end{tabular}

Trois Gaules

un pouvoir particulier, indicateur du statut social de celui qui le possède » (Mallet 2009, p. 130). Ils n'auraient donc jamais servi en milieu thermal, les bains n'existant pas encore autour du changement d'ère.

Il convient de rester pour le moins prudent devant ces hypothèses qui ne reposent, selon nous, que sur un état de la recherche. S'il est vrai qu'aucun bâtiment thermal augustéen n'existe à Charny, il l'est également que seule une toute petite partie de la surface du site est connue et que rien n'empêche qu'il ait été placé dans la vaste zone non dégagée. On ne connaît pas à l'heure actuelle beaucoup de thermes augustéens dans les Trois Gaules. D'une part, les villes antiques dans nos régions ne sont connues que sur quelques pourcents tout au plus de leur surface générale. D'autre part, les niveaux les plus anciens -donc les plus difficilement accessibles-, sont souvent détruits par les constructions postérieures. Alors que l'on commence à percevoir la mise en place de l'infrastructure monumentale dès l'époque augustéenne - fora, sanctuaires - tant en Aquitaine que dans les provinces plus septentrionales, il serait étonnant que les bâtiments qui sont souvent en relation avec eux aient été négligés ${ }^{11}$. Sans compter que ces premiers édifices peuvent être en matériaux périssables. Avant sa découverte, qui aurait parié sur l'existence d'un édifice pleinement républicain à Cornebarrieu ?

Reprenons le problème en ne considérant que les strigiles découverts dans les tombes car ce sont autant d'objets quotidiens emportés par le défunt au-delà de la mort. Pour cela, nous nous reporterons à l'inventaire

11 Pour les régions septentrionales, voir Reddé et al. 2011. proposé par Fr. Mallet et F. Pilon ${ }^{12}$. Les autres découvertes, dans des habitats ou autres, ne sont que le fruit de leurs modalités d'abandon et de la plus ou moins grande méticulosité des récupérateurs.

Plusieurs constats s'imposent. Le premier est celui déjà réalisé que les découvertes sont beaucoup plus abondantes en Gaule du sud qu'ailleurs. Sur les 35 tombes, 22 ont fait l'objet d'une datation. Les plus anciennes trouvailles $(31,8 \%)$ sont à mettre en relation avec la pratique grecque du bain (Marseille) ou l'influence méditerranéenne (Lattes). Très nombreuses (41\%) sont ensuite celles qui s'étalent entre le I ${ }^{\text {er }} \mathrm{s}$. av. J.-C. et l'époque augustéenne. Les autres $(27,2 \%)$ correspondent aux découvertes du reste du Haut-Empire. Pour les Trois Gaules, moins nombreuses sont les tombes avec seulement 11 découvertes dont 6 seulement sont datées. $33 \%$ correspondent à la fin du Ir s. av. J.-C., $50 \%$ au Haut-Empire et on s'étonnera d'une découverte $(17 \%)$ dans une inhumation du Haut Moyen-Age. Cet échantillon est évidemment trop faible pour être représentatif, mais il montre toutefois que, comme en Gaule du sud, les strigiles font leur apparition dans les tombes au début de l'époque augustéenne. Et ceci est corroboré par les quelques découvertes d'étrilles dans des niveaux augustéens d'habitat comme à la place des Grands-Hommes à Bordeaux (20 av. -10 ap. J.-C.). C'est le moment où les premiers thermes se mettent en place, pour l'Aquitaine, à Périgueux ou à Saint-Bertrand-deComminges (Thermes du Forum).

12 Mallet 2009, p. 133-151. 
Le phénomène de dépôt de strigile dans les tombes est plus ancien en Gaule du sud-est ( ${ }^{\text {er }} \mathrm{s}$. av. J.-C.) parce que la conquête - et donc l'influence romaine - est antérieure à celle des Trois Gaules (fin du I ${ }^{\mathrm{er}} \mathrm{s}$. av. J.-C.). Mais dans les premiers temps, la réaction est partout identique. Les défunts se font enterrer avec leur strigile car le bain constitue bien une nouveauté, un nouvel usage social ${ }^{13}$. Ensuite, la généralisation - la banalisation pourrait-on dire - de la pratique thermale entraîne une diminution de ce type de dépôt $t^{14}$. Les strigiles sont bien un signe d'acculturation. Nous ne voyons là aucune fonction symbolique, mais un ustensile parfaitement utilitaire pour un des apports majeurs des bienfaits de la civilisation romaine.

Les thermes et les instruments de bain permettent donc aussi d'alimenter la réflexion sur l'acculturation. Les quelques exemples présentés ici ne concernent que les thermes hygiéniques, mais la même démarche pourrait être menée pour les thermes thérapeutiques, bien que leur organisation et leur modalité de fonctionnement soient beaucoup moins bien connues, tant en Gaule en particulier que dans l'Empire dans son ensemble. Les dernières fouilles dirigées à Olbia par Michel, apporteront, à n'en pas douter, des éléments essentiels pour les débuts du thermalisme en Gaule avec la découverte des thermes du bord de mer mis en place dans la seconde moitié du I ${ }^{\text {er }}$ s. av. J.-C. Belle contribution du chercheur sur le monde grec au début de la civilisation romaine !

\section{Bibliographie}

Bouet 2003 : BOUET (A.) - Les thermes privés et publics en Gaule Narbonnaise, Volume I. Synthèse. Volume II. Catalogue, Collection de l'EFR 320, Rome, 2003. Bouet dir. 2003 : BOUET (A.) dir. - Thermae gallicae, Les thermes de Barzan (Charente-Maritime) et les thermes des provinces gauloises, Suppl. à Aquitania-Ausonius, Bordeaux, 2003.

Broise 1994 : BROISE (H.) - La pratique du bain chaud par immersion en Italie et dans la péninsule Italique à l'époque hellénistique. Xenia Antiqua, 3, 1994, p. 17-32.

Broise 2009 : BROISE (H.) - Entre continuité et rupture, Introduction des pratiques balnéaires grecques et romaines en Egypte. In : Boussac (M.-Fr.), Fournet (Th.), Redon (B.) éd. - Le bain collectif en Égypte, Balaneia, Thermae, Hammam (Études urbaines 7), Le Caire, 2009, p. 9-15.

Broise, Jolivet 1991: BROISE (H.), JOLIVET (V.) - Le bain en Étrurie à l'époque hellénistisque. In : Les thermes romains, Actes de la table ronde organisée par l'École française de Rome (Rome, 11-12 novembre 1988), Collection de l'Ecole Française de Rome 142, Rome, 1991, p. 79-95.

Broise, Jolivet 2004 : BROISE (H.), JOLIVET (V.) - Musarna 2, Les bains hellénistiques, Collection de l'École Française de Rome 344, Rome, 2004.

13 Nous ne connaissons pas à l'heure actuelle de pratique balnéaire gauloise contrairement à la région nord-occidentale de la péninsule Ibérique (Bouet 2003, I, p. 320).

14 C'est ce que nous écrivions déjà il y a une dizaine d'années (Bouet 2003, I, p. 323-324 et 328-329).
Broise, Lafon 2001 : BROISE (H.), LAFON (X.) - La villa Prato de Sperlonga, Collection de l'École Française de Rome 285, Rome, 2001.

Conche 1999 : CONCHE (FR.) - Les fouilles de la rue Jean-François-Leca. In : Hesnard (A.), Moliner (M.), Conche (Fr.), Bouiron (M.) éd. - Parcours de villes. Marseille : 10 ans d'archéologie, 2600 ans d'histoire, Marseille, p. 90-101.

Excoffon dir. 2011 : EXCOFFON (P.) dir. - Ville et campagne de Fréjus romaine, La fouille préventive de "Villa Romana " (Bibliothèque d'Archéologie Méditerranéenne et Africaine 8), Aix-en-Provence, 2011. Fournet, Redon 2009 : FOURNET (TH.), REDON (B.) - Les bains souterrains de Taposiris Magna et le bain de tradition hellénique en Égypte. In : Boussac (M.-Fr.), Fournet (Th.), Redon (B.) éd. - Le bain collectif en Égypte, Balaneia, Thermae, Hammam (Études urbaines 7), Le Caire, 2009, p. 113-137. Fournet et al. 2013 : FOURNET (TH.), LUCORE (S. K.), REDON (B.), TRUMPER. (M.) - CATALOG. In : Lucore (S. K.), Trumper (M.) éd., Greek baths and bathing culture, new discoveries and approaches, Louvain-Paris Walpole, 2013, p. 269-333.

Goudineau, Brentchaloff dir. 2009 : GOUDINEAU (Chr.), BRENTCHALOFF (D.) dir. - Le camp de la flotte d'Agrippa à Fréjus, Les fouilles du quartier de Villeneuve (1979-1981), Paris, 2009.

Gourdiole, Landes 2002 : GOURDIOLE (R.), LANDES (CHR .) - Lascours, Ceilhes-et-Rocozels (Hérault). In : FICHES (J.-L.) dir. - Les agglomérations gallo-romaines en Languedoc-Roussillon, Projet collectif de recherche (1993-1999), I, Lattes, 2002, p. 271-281.

Hadji-Minaglou 2009 : HADJI-MINAGLOU (G.) - L'établissement thermal de Tebtynis (Fayoum). In : Boussac (M.-Fr.), Fournet (Th.), Redon (B.) éd. - Le bain collectif en Egypte, Balaneia, Thermae, Hammam (Études urbaines 7), Le Caire, 2009, p. 181-190.

Marín Jordá, Ribera i Lacomba 2000 : MARIN JORDA (C. M.), RIBERA I LACOMBA (A. R.) - Un caso precoz de edificio termal : los baños republicanos de Valentia. In : Fernandez Ochoa (C.), Garcia Entero (V.) éd., Termas romanas en el Occidente del Imperio, II Coloquio Internacional de Arqueología de Gijón, Serie Patrimonio 5, Gijón, p. 151-156.

Mallet 2009 : MALLET (FR.), avec la participation de PILON (F.) - Le strigile en Gaule, objet utilitaire et vecteur de romanité : l'exemple du strigile de la villa des Champs-de-Choisy à Charny (Seine-et-Marne), Gallia, 66-2, 2009, p. 113-151. Martín 2000 : MARTIN (A.) - Las termas republicanas de Cabrera del Mar (Maresme, Barcelona). In : Fernandez Ochoa (C.), Garcia Entero (V.) éd. Termas romanas en el Occidente del Imperio, II Coloquio Internacional de Arqueología de Gijón, Serie Patrimonio 5, Gijón, p. 157-162.

Marty 2008 : MARTY (P.) - Mobilier amphorique et sigillée italique du site de la Ville à Cornebarrieu (Haute-Garonne) : des témoins de la romanisation dans le Toulousain. In : Rivet (L.) dir. - Les productions céramiques en Hispanie Tarraconaise (II siècle avant J.-C. - IV siècle après J.-C.), Actes du congrès de l'Escala-Empùries, 1er-4 mai 2008, Marseille, 2008, p. 719-737.

Moliner et al. 2003 : MOLINER (M.), MELLINAND (PH.), NAGGIAR (L.), RICHIER (A.), VILLEMEUR (I.) avec la collaboration de FEUGERE (M.), GANTES (L.-FR.), MICHEL (D.), MONCHOT (H.), POURNOT (J.), WEYDERT (N.) - La nécropole de Sainte-barbe à Marseille (IVe $\mathrm{s}$. av. J.-C. $-I I^{e}$ s. ap. J.-C.), Études massaliètes 8, Aix-en-Provence.

Reddé 1986 : REDDE (M.) - Mare Nostrum, Les infrastructures, le dispositif et l'histoire de la marine militaire sous l'Empire romain, BEFAR 260, Rome, 1986. Reddé et al. 2011 : REDDE (M.), BARRAL (PH.), FAVORY (Fr.), GUILLAUMET (J.-P.), JOLY (M.), MARC (J.-Y.), NOUVEL (P.), NUNINGER (L.), PETIT (Chr.) dir - Aspects de la Romanisation dans l'Est de la Gaule, Bibracte 21, Glux-en-Glenne, 2011.

Tsiolis 2013 : TSIOLIS (V.) - The Baths at Fregellae and the Transition from Balaneion to Balneum. In : Lucore (S. K.), Trumper (M.) éd. - Greek baths and bathing culture, new discoveries and approaches, Louvain-Paris Walpole, 2013, p. 89-111.

Veyssière, Viers 2011 : VEYSSIÈRE (FR.), VIERS (C.) - L'opus punicum d'un balnéaire tardo-républicain dans le Toulousain. In : Balmelle (C.), Éristov (E.), Monier (F.) dir. - Décor et architecture en Gaule entre l'Antiquité et le haut Moyen Âge, Actes du colloque international, Université de Toulouse II-Le Mirail, 9-12 octobre 2008, Bordeaux (suppl. 20 à Aquitania), Bordeaux, p. 231-240.

Viers, Veyssière 2012 : VIERS (C.), VEYSSIÈRE (FR.) - Les bains tardorépublicains de Cornebarrieu (Haute-Garonne). Gallia, 69-2, 2012, p. 115-125. 


\title{
Les figurines en terre cuite dans le Sud de la Gaule (VIe-Ier S. av. J.-C.)
}

\author{
Antoine Hermary \\ Aix Marseille Université, CNRS, CCJ, UMR 7299, 13094, Aix-en-Provence, France
}

\section{Résumé}

Les sites archéologiques de Provence et du Languedoc sont probablement ceux qui, dans l'ensemble de la Méditerranée, ont livré le moins de figurines en terre cuite antérieures à l'époque romaine. Cet artisanat était visiblement peu développé à Marseille et il n'a pas intéressé les populations celtiques environnantes. Cependant, on note la présence de quelques objets caractéristiques du monde punique (ou ibéro-punique) : des brûle-parfums à tête féminine (Ensérune, Arles, Olbia) et une plaquette représentant peut-être le dieu Baal-Hammon (Ensérune). L'ensemble le plus original, d'époque hellénistique, provient de la ville massaliète d'Olbia.

Mots-clés : terres cuites, Provence, Languedoc, Olbia, Marseille, Arles, Ensérune

\begin{abstract}
In the archaeological sites of Provence and Languedoc, in South France, the terracotta figurines are less numerous than in the other areas of the Mediterranean world. The coroplastic art was obviously not very popular in Marseilles, nor in the neighbouring Celtic communities. However, some objects characteristic of the punic (or ibero-punic) world have to be mentioned: incense burners in form of feminine heads (from Ensérune, Arles and Olbia) and a relief which may represent the god Baal-Hammon (Ensérune). The most original group was found in the Massaliot colony of Olbia.
\end{abstract}

Keywords: Terracotta figurines, Provence, Languedoc, Olbia, Marseille, Arles, Ensérune 


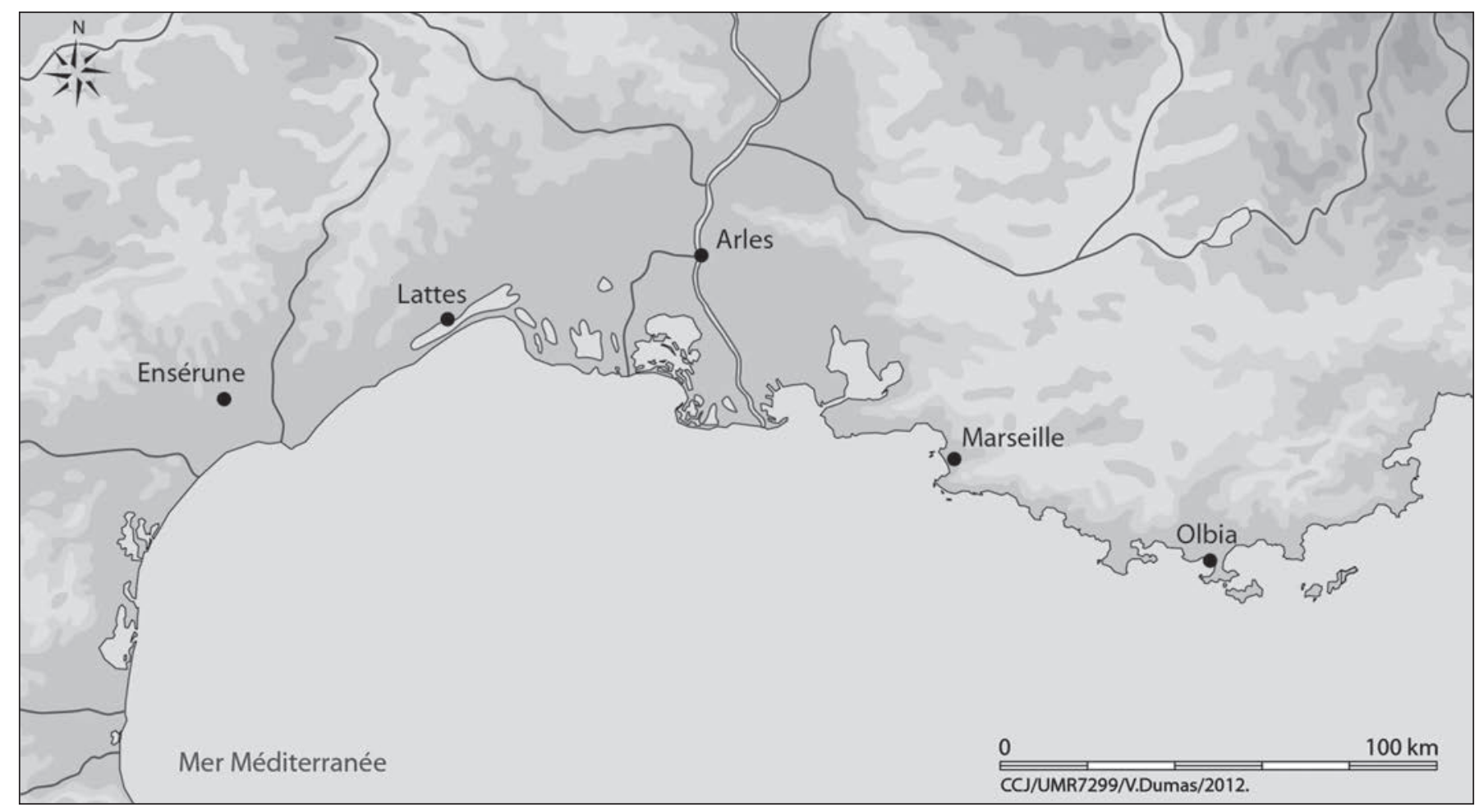

Fig. 1. Carte du Midi de la France avec les sites mentionnés dans le texte (Infographie V. Dumas).

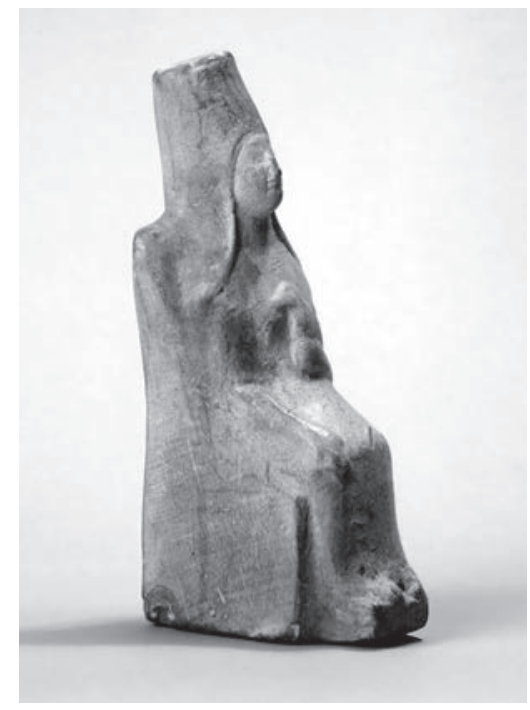

Fig. 2. Figurine trouvée place Vivaux. Marseille, Musée des Docks romains, inv. X II E 20-3960 (Photo CCJ, Ph. Foliot).
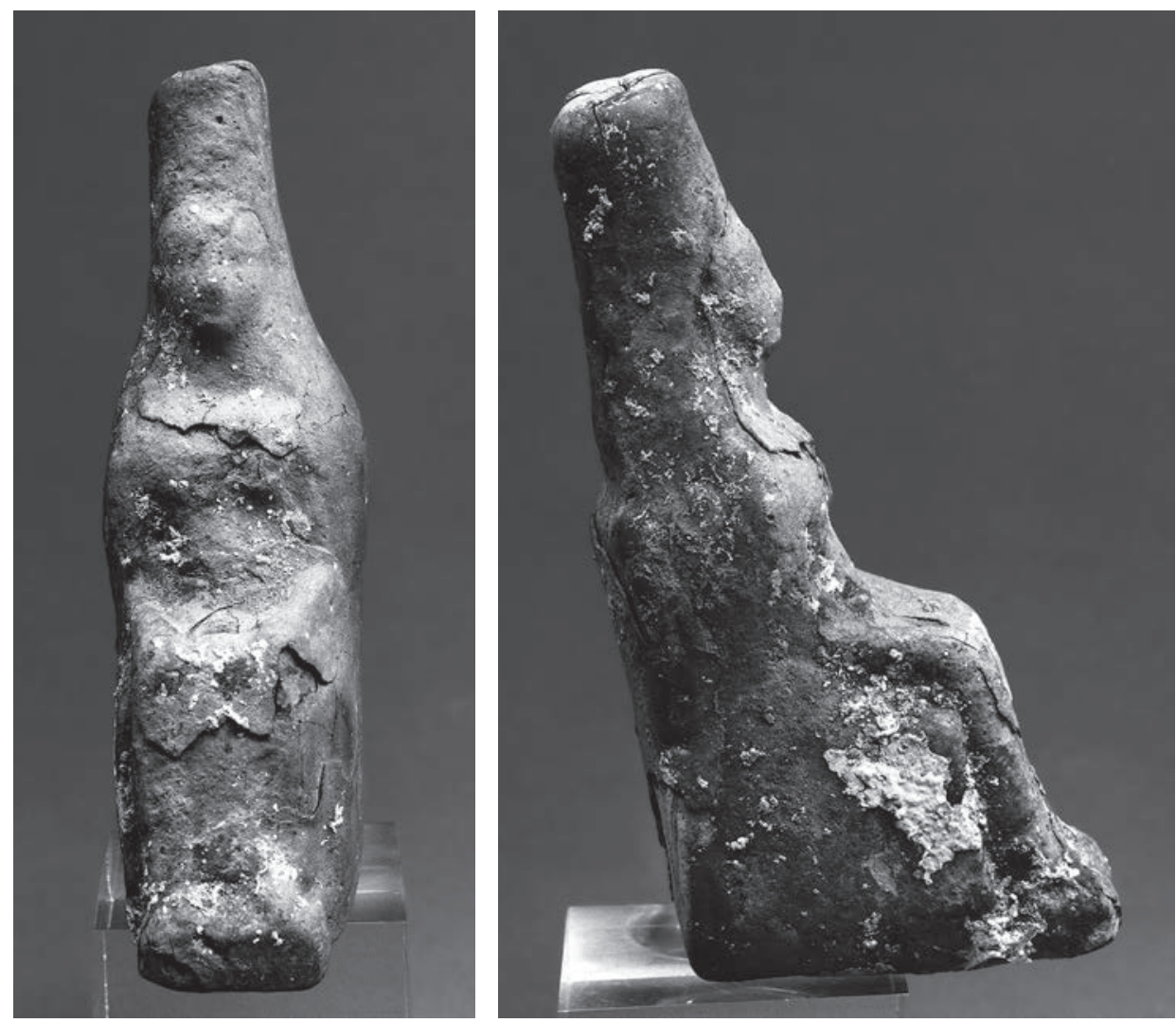

Fig. 3. a-b Figurine de l'épave de la Pointe Lequin A. Marseille, dépôt du DRASSM (Photos Centre Camille Jullian). 


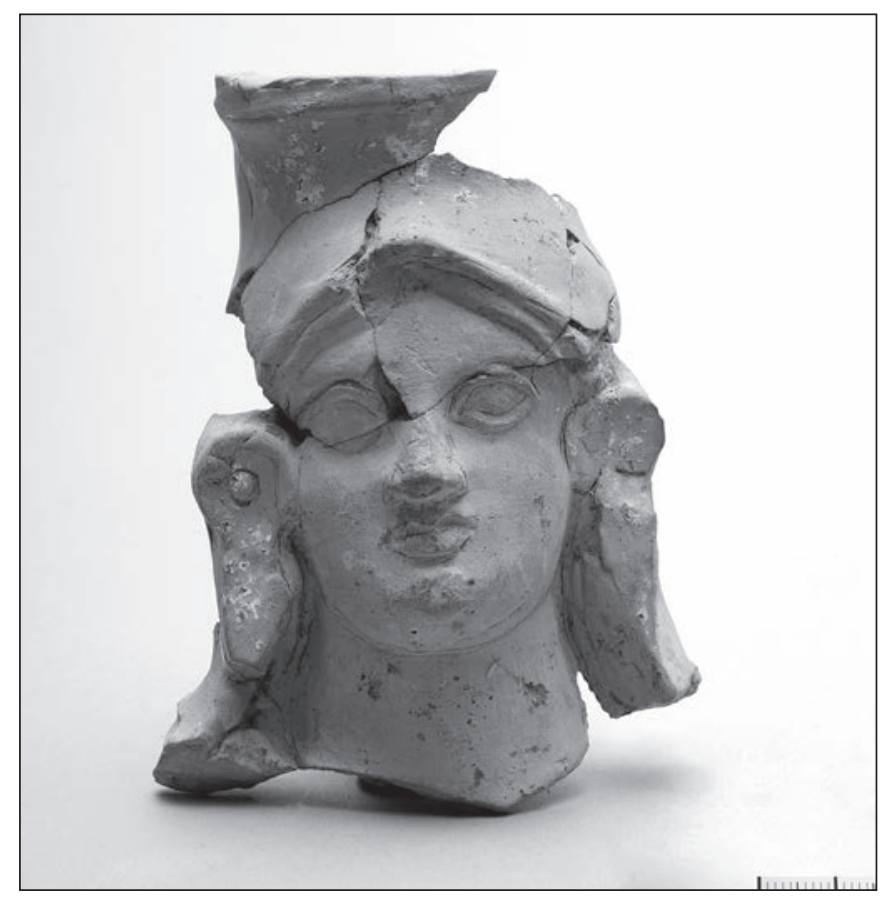

Fig. 4. Tête trouvée sur le site de la Bourse à Marseille. Musée d'Histoire de Marseille, inv. B 604 (TC 3) (Photo CCJ, Chr. Durand).

A lors que l'artisanat des figurines en terre cuite connaît un développement important dans d'autres régions de Méditerranée occidentale - villes grecques d'Italie du Sud et de Sicile, Carthage, péninsule Ibérique -, il est extrêmement discret sur la côte méditerranéenne française, de l'époque archaïque à la fin de l'époque hellénistique. La rareté de ce type de production à Marseille est frappante et explique probablement que cette catégorie d'offrande soit aussi limitée dans les sanctuaires et les nécropoles des établissements situés dans la zone d'influence directe de la ville phocéenne ${ }^{1}$. Pourtant, une étude de la documentation disponible fait état de cas intéressants, en particulier à Olbia, le site de prédilection de Michel Bats : c'est grâce à lui que j'ai pu mieux connaître ce petit ensemble qui fera l'objet d'une publication plus détaillée. Je présenterai, en attendant, un bilan général sur les terres cuites

1 Pour les nécropoles, la différence est sensible avec le site d'Emporion/Ampurias, où 26 figurines ont été mises au jour (cinq seulement dans les sanctuaires et une dans l'habitat): Horn 2011, p. 28 tableau 1 et annexe 1, passim; voir aussi Roure, Pernet 2011, p. 244 fig. 244-245. On note qu'aucune figurine en terre cuite n'est mentionnée dans Chausserie-Laprée (J.) dir. - Le temps des Gaulois en Provence. Catalogue d'exposition, Martigues, Musée Ziem, 2000.

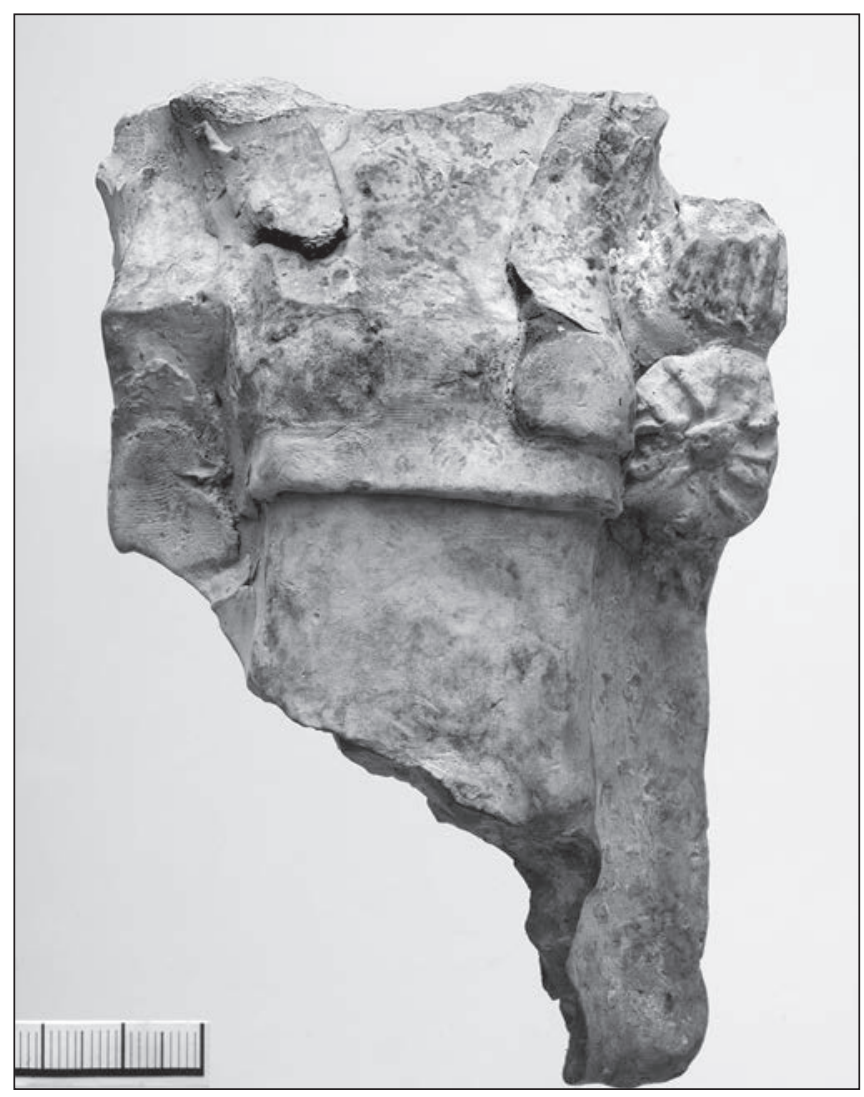

Fig. 5. Fragment de figurine de la Bourse. Musée d'Histoire de Marseille, inv. E 510 (Tc 16) (Photo CCJ, Chr. Durand).

mises au jour en Languedoc et en Provence, principalement à Ensérune, Lattes, Arles, Olbia et, bien sûr, Marseille (fig. 1), en incluant une catégorie d'objets intéressante, même s'il ne s'agit pas de figurines, celle des brûle-parfums (thymiatéria) à tête féminine ${ }^{2}$.

\section{Du VI ${ }^{\mathrm{e}} \mathrm{s}$. à la fin du $\mathrm{IV}^{\mathrm{e}}$ S. av. J.-C.}

Pour cette période d'un peu moins de trois siècles (de la fondation de Massalia à celle d'Olbia), la documentation est presque uniquement originaire de Marseille.

Parmi les quelques dizaines de figurines, presque toutes très fragmentaires, qui ont été mises au jour dans la ville phocéenne, peu remontent à l'époque archaïque, et aucune ne paraît antérieure à la seconde moitié du $\mathrm{VI}^{\mathrm{e}} \mathrm{s}$. av. J.-C. Le type de la femme assise est représenté par un exemplaire bien conservé, trouvé dans les fouilles

2 Je suis heureux de contribuer à cet amical hommage à Michel Bats, avec qui j'ai eu le plaisir de collaborer quand il dirigeait le Centre Jean Bérard de Naples et moi-même le Centre Camille Jullian à Aix, puis lorsque nous nous sommes occupés ensemble de la Revue Archéologique de Narbonnaise. 
de la place Vivaux, proche du port antique (fig. 2), et par trois autres fragments ${ }^{3}$. Il s'agit sans aucun doute d'importations originaires du monde grec égéen, où ces figurines de femmes portant une haute coiffe cylindrique («pôlos ») sont abondamment représentées ${ }^{4}$. La petite terre cuite des docks se distingue par l'oiseau tenu dans la main, mais cet « attribut » n'est pas suffisant pour proposer une identification du personnage, probablement une divinité ${ }^{5}$. Deux figurines fragmentaires découvertes dans l'épave de la Pointe Lequin A (une seule est bien conservée : fig. $3 \mathrm{a}$-b) donnent un exemple concret du mode de diffusion de ce type de production (Long, Miro, Volpe 1992, p. 220, fig. 41, 1) : on peut penser qu'il ne s'agit pas, dans ce cas, d'éléments d'une cargaison marchande, mais plutôt de statuettes protectrices des marins et du bateau, qui étaient éventuellement offertes dans les ports de destination ; une anecdote racontée par Athénée (XV, 675f-676c) rend compte d'une démarche de ce type ${ }^{6}$. Signalons que l'épave de la Pointe Lequin A contenait aussi un avant-train de sanglier en terre cuite (Long, Miro, Volpe, p. 220, fig. 41, 3) : cette figurine (ou vase plastique ?), d'un type rare, a un équivalent dans l'épave de Géla ${ }^{7}$ et rappelle les protomés de sanglier qui décorent la proue des navires de guerre figurés sur la céramique attique à cette même époque (fin du $\mathrm{VI}^{\mathrm{e}}$ s. av. J.-C.) et, à Marseille même, sur deux graffitis trouvés à l'Alcazar (Pomey, 2013); l'image du sanglier aurait donc joué un rôle dans la protection des navires ${ }^{8}$.

L'exploitation à grande échelle de carrières d'argile à proximité immédiate de Marseille (Bouiron, 2013) laisserait penser qu'au moins une petite partie de ce matériau était consacré à fabriquer des figurines ou des décors architecturaux. Ce n'est cependant pas le cas, autant qu'on

3 L'un provient également de la zone du port, les deux autres de la rue Négrel. Figurine de la place Vivaux : Hermary, Hesnard, Tréziny 1999, fig. p. 63 ; Roure, Pernet 2011, p. 232 fig. 216 ; Hermary 2012, p. $140 \mathrm{n}^{\circ} 14$.

4 Ainsi, dans l'Artémision de Thasos, le NMI de ces «dames assises à pôlos » est de 457, soit 17,2 \% des offrandes (HuysecomHaxhi 2009, p. 571).

5 Si l'on reprend l'exemple de l'Artémision de Thasos, les femmes assises tenant un oiseau ne sont qu'au nombre de 6 , alors qu'on connaît 167 korés debout tenant un oiseau : Huysecom-Haxhi 2009, tableau 2 p. 574.

6 Un certain Hérostratos de Naucratis avait sauvé le navire, qui faisait route de Paphos au delta du Nil, grâce à une statuette d'Aphrodite qu'il avait achetée à Paphos : à son arrivée il l'avait dédiée dans le sanctuaire de la déesse à Naucratis (l'événement est situé, de façon peu vraisemblable, au début du VII ${ }^{\mathrm{e}} \mathrm{s}$. av. J.-C.).

7 Panvini (R.) - La nave greca arcaica di Gela. Palerme, Salvatore Sciascia, 2001, p. 60-61.

8 Noter aussi que les seules figurines de sanglier trouvées en contexte funéraire dans le Nord-Ouest de la Méditerranée proviennent de tombes d'enfants d'Ampurias (Horn 2011, p. 106 ; Moliner 2012, p. 183 fig. 12, 14). le sache actuellement, malgré la découverte sur le site de la rue Négrel d'un bras appartenant probablement à une grande statuette 9 . Les potiers/coroplathes marseillais ont cependant fabriqué, vers la fin de l'époque archaïque, un type original de vase plastique, en forme d'être hybride associant un corps d'oiseau à une tête silénique cornue : plusieurs exemplaires proviennent de la zone du port, un autre de la rue Négrel (Collin-Bouffier 1999 ; Roure, Pernet 2011, p. 233 fig. 217-219). Les têtes siléniques sont attestées comme décor d'applique sur d'autres vases, vers la même époque, au Baou de Saint-Marcel (Hermary, Hesnard, Tréziny 1999, fig. p. 62 ; Roure, Pernet 2011, p. 239 fig. 238), on en trouve d'autres, plus tard, à Marseille. On peut aussi signaler un relief appartenant à un objet de type indéterminé - il ne peut pas s'agir d'une arula de type sicilien -, décoré d'un lion dévorant un taureau, provenant de la Bourse (Tréziny 2000, p. 89-90, fig. 7 ; Hermary 2012, p. $155 \mathrm{n}^{\circ} 32$ ), et un fragment d'applique représentant un arrière-train d'animal ou, plus probablement, de sphinx, mis au jour dans une tombe d'enfant de la nécropole du Tapis-vert (Moliner 2012, p. 183, fig. 15, 8).

C'est de l'époque classique que paraît dater le seul petit ensemble de figurines votives (toutes fragmentaires) trouvé dans la cité phocéenne. Ces fragments, qui proviennent des fouilles de la Bourse, faisaient partie de figurines-plaquettes (non modelées à l'arrière) représentant un personnage féminin trônant, coiffé d'un pôlos ; plusieurs modules sont attestés. Une tête (fig. 4) ${ }^{10}$ et un fragment de la partie médiane du corps, avec des éléments du trône (fig. 5) ${ }^{11}$, constituent les éléments les plus significatifs (Tréziny 2000, p. 89, fig. 5-6). Il n’y a guère de doute que ces personnages représentaient une divinité féminine dont le sanctuaire était situé près du rempart de la ville, probablement à l'extérieur, si l'on compare la situation de certains lieux de culte dans des cités grecques égéennes ou coloniales. En l'absence d'inscription l'identification du personnage est incertaine, mais, à l'époque classique, ce type iconographique convient mieux à Déméter ou à Héra qu'à une déesse juvénile comme Artémis. On pourrait avancer comme argument en faveur de Déméter la découverte dans la même zone de deux fragments de kernoi (?) et d'au

9 Mus. Hist. I.6.37 (3967). La longueur de l'avant-bras (11,3 cm) indiquerait, pour un personnage complet debout, une taille d'environ 60 cm. Villard 1960, pl. 42, 3 ; Benoit 1965, p. 187 pl. 3, 10.

10 H. 10,2 cm ; inv. B 604 (Tc 3). Argile rosée à grosses inclusions couleur brique.

11 H. 12,5 cm. Inv. E 510 (Tc 16) ; la conservation dans la vase a donné à l'argile une couleur très sombre. On distingue la main gauche du personnage, posée sur l'extrémité du bras du trône. 
moins une figurine de cochon ${ }^{12}$. On pourrait comparer une terre cuite fragmentaire de l'ancienne collection Calvet, conservée à Avignon, si elle a été réellement mise au jour à Marseille au début du $\mathrm{XIX}^{\mathrm{e}} \mathrm{s} .{ }^{13}$ : elle appartenait à un type de figure féminine debout, tenant une torche et un porcelet, certainement associé au culte éleusinien de Déméter et Koré. Le site de Morgantina, en Sicile, a livré des figurines tout à fait comparables qui dépendent de modèles syracusains (Bignasca 1992). Les terres cuites fragmentaires de la Bourse proviennent-elles d'un Thesmophorion situé près de l'entrée principale de la ville ? C'est l'hypothèse la plus vraisemblable, mais il faut rappeler qu'au moment où sont dédiées ces terres cuites de riches enclos funéraires sont établis à cet endroit, devant la principale entrée de la ville : or, le culte de la déesse infernale Hécate est bien attesté dans le monde ionien, en particulier à Milet : dans sa colonie d'Apollonia du Pont, le sanctuaire de la déesse se trouvait précisément devant l'entrée de la ville ${ }^{14}$. Soulignons en tout cas l'originalité des figurines de Marseille, dont le bas du corps étroit, couvert par un vêtement sans plis, a un caractère archaïsant qui suggère l'existence de modèles plus anciens.

Le seul autre fragment de figurine de cette période provient du site de Lattes. Il s'agit d'une tête féminine voilée (fig. 6), appartenant probablement à une femme assise, trouvée dans un contexte d'habitat daté du deuxième quart du $\mathrm{V}^{\mathrm{e}} \mathrm{s}$. av. J.-C. (Py 2009, fig. p. 326) : cette date est en accord avec le style du visage, à l'expression relativement sévère. Le type de la figurine et la présence d'un engobe blanc pourraient indiquer une origine attique (comparer Mollard-Besques 1954, $\mathrm{n}^{\circ} \mathrm{B} 7$, un peu plus ancienne). On peut supposer qu'il s'agit, comme pour

12 Tréziny 2000, p. 90 et 92, fig. 8-10 ; Rothé, Tréziny 2005, p. 544, fig. 697a-b ; Roure, Pernet 2011, p. 235 fig. 222-223. Les deux «kernoi » fragmentaires n'ont pas une structure tout à fait semblable à celle des objets traditionnellement définis comme des kernoi de type éleusinien : la partie supérieure est en effet occupée par de petites cupules et non par des vases miniatures.

13 Cavalier (O.) - La Grèce des Provençaux au XVIII ${ }^{e}$ siècle. Avignon, Fondation Calvet, 2007, p. 27 fig. 7 (dite à tort « peut-être d'origine chypriote »).

14 Pour le culte d'Hécate à Milet et dans ses colonies, voir Ehrhardt (N.) - Milet und seine Kolonien. Vergleichende Untersuchung der kultischen und politischen Einrichtungen. Francfort, Berne, New York, Paris, Peter Lang, 1988, p. 173-175. Pour le cas particulier d'Apollonia : Nedev (D.), Gyuzelev (M.) - Présentation de l'espace urbain et du territoire. In: Hermary (A.) dir., Apollonia du Pont (Sozopol). La nécropole de Kalfata ( $V^{e}-I I I^{e} s$. av. J.-C.), fouilles franco-bulgares (2002-2004). Paris, Éditions Errance, et Aix-enProvence, Centre Camille Jullian, 2010, p. 14-15 : « La situation du sanctuaire à la périphérie méridionale de la ville s'explique par les fonctions d'Hécate comme protectrice des voyageurs ou son rôle chthonien, étant donné la proximité de la nécropole hellénistique ». les figurines archaïques de l'épave de la Pointe Lequin et du port de Marseille, d'un objet déposé par un marin.

\section{L'époque hellénistique}

La documentation est numériquement très limitée et, cette fois, les exemplaires les plus intéressants proviennent d'autres sites que Marseille ${ }^{15}$. Il s'agit, en premier lieu, d'une petite série de brûle-parfums (thymiatéria) en forme de tête féminine coiffée d'une large couronne («kalathos ») qui supporte une coupelle, en général percée de trous, destinée à faire brûler de l'encens ou d'autres substances odorantes: mais dans bien des cas, aucune trace de combustion n'est visible et ces objets doivent alors être considérés comme des offrandes non fonctionnelles. Ces productions, qui paraissent s'échelonner entre la deuxième moitié du $\mathrm{IV}^{\mathrm{e}} \mathrm{s}$. et le $\mathrm{II}^{\mathrm{e}} \mathrm{s}$. av. J.-C., ont donné lieu à plusieurs études récentes (en particulier Marín Ceballos, Horn 2007 ; Horn 2011, p. 31-64). Un seul exemplaire (le plus ancien ?) provient de Méditerranée orientale ${ }^{16}$, les autres ont été mis au jour en Sicile occidentale, en Sardaigne (730 exemplaires proviennent du seul site de Paulilatino !), à Carthage, à Ibiza et sur la côte orientale de la péninsule Ibérique (Horn 2011, Annexe 1, p. 481$635 \mathrm{n}^{\text {os }}$ C685-C959). Cette aire géographique rattache clairement ces thymiatéria au monde punique ou ibéropunique, même si la tête du personnage et les motifs figurés sur le kalathos sont toujours de style grec.

Le fait que deux de ces brûle-parfums aient été trouvés à Ensérune - l'un près du rempart Nord, l'autre dans la nécropole (Ugolini 1983 ; Schwaller 1994, fig. p. 90) n'est pas surprenant, étant donné les liens attestés entre le Languedoc occidental et la péninsule Ibérique : c'est la raison pour laquelle ils sont présentés dans le livre de Frédérique Horn (2011, Annexe p. 483 n C687 et p. $501 \mathrm{n}^{\circ} \mathrm{C} 716$, tête de série d'un «type Ensérune »).

15 Je ne connais que par la publication de Fr. Horn (2011, Annexe 1 p. $23 \mathrm{n}^{\circ} \mathrm{C} 5$ ) une figurine féminine assise, tenant une phiale de la main gauche, qui provient de la zone d'habitat d'Ensérune : l'auteur la présente comme une importation de Grande Grèce et la date du IV ${ }^{\mathrm{e}} \mathrm{s}$. av. J.-C.

16 Il s'agit d'un brûle-parfum conservé au British Museum, trouvé dans une tombe d'Halicarnasse en 1856 : il est daté vers la fin du $\mathrm{V}^{\mathrm{e}} \mathrm{s}$. av. J.-C. par R. A. Higgins (Catalogue of Terracottas in the Department of Greek and Roman Antiquities, British Museum. Volume I. Greek: 730-330 B.C. Londres, British Museum, 1954, $\left.\mathrm{n}^{\circ} 444, \mathrm{pl} .62\right)$. Le caractère totalement isolé de cet exemplaire et sa découverte dans des fouilles anciennes interdisent de tirer des conclusions sur l'origine de ces brûle-parfums. Fr. Horn (2011, p. 56 n. 83) mentionne cependant un exemplaire inédit provenant du site « d'Arepta » (probablement Aptera) en Crète, conservé au musée de Chania (La Canée). 


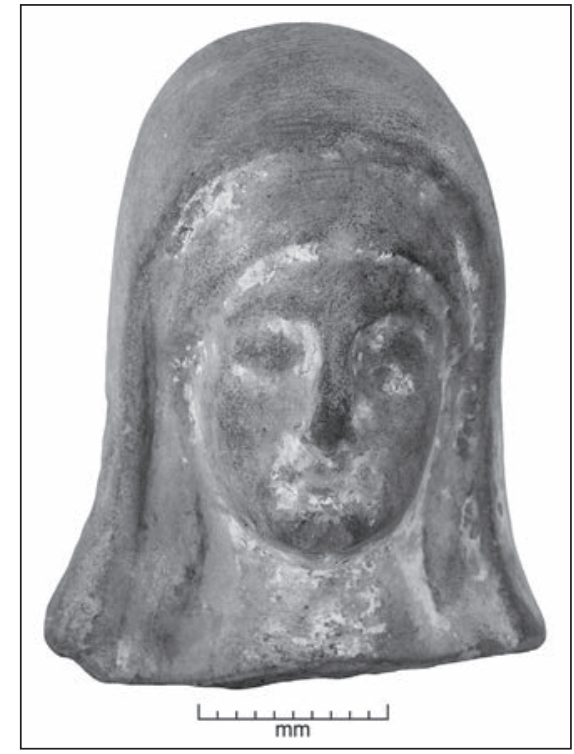

Fig. 6. Petite tête féminine trouvée à Lattes

(Photo Michel Py).

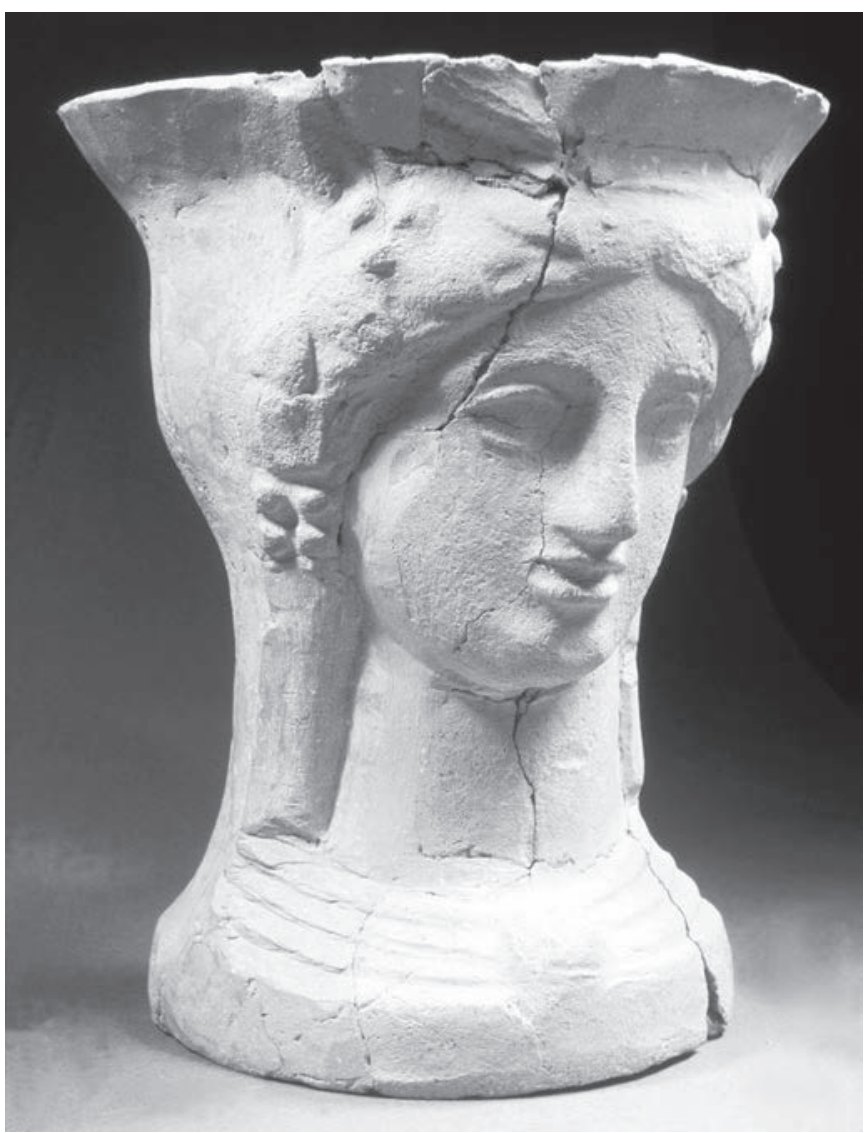

Fig. 8. Thymiatérion à tête féminine d'Arles. Arles, Musée Départemental Arles antique (Photo du musée).

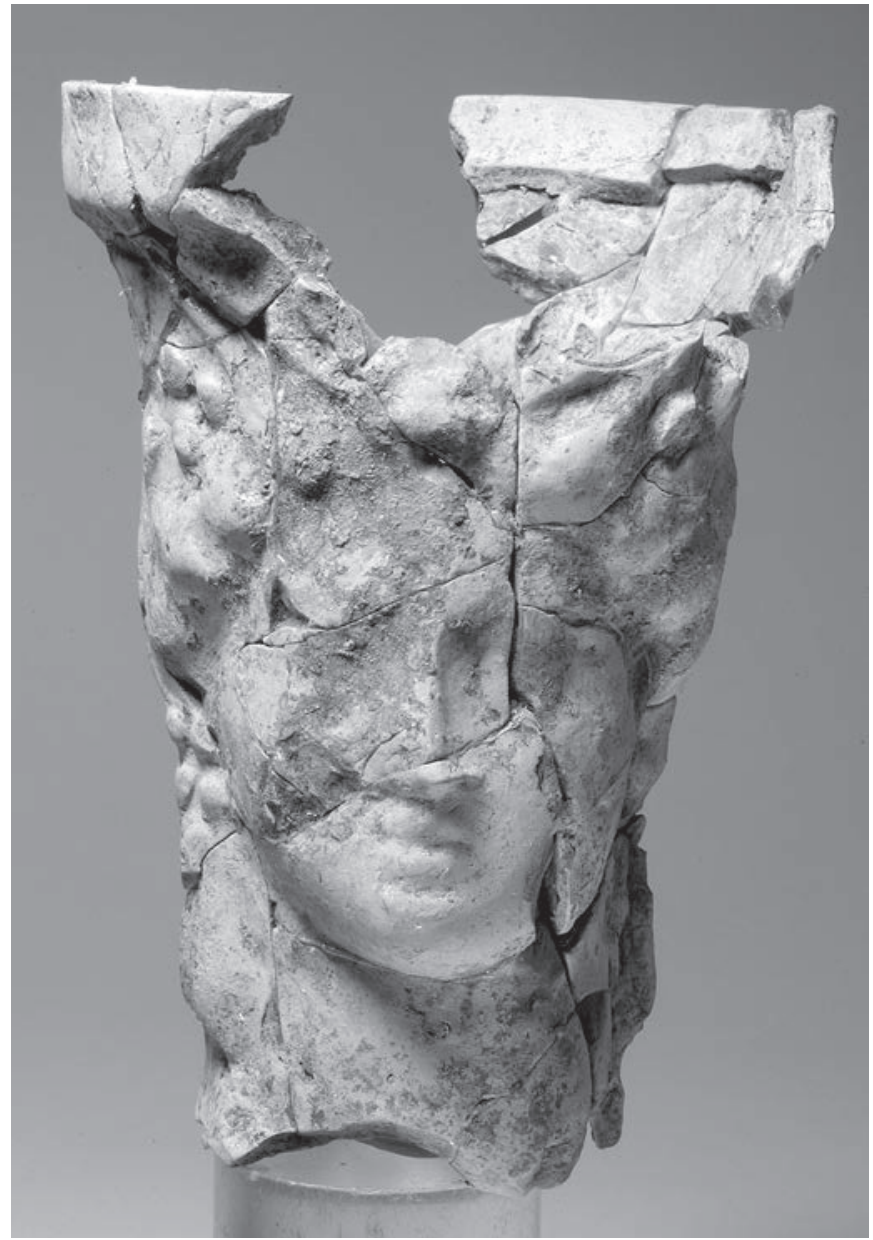

Fig. 7. Thymiatérion à tête féminine d'Olbia. Dépôt archéologique d'Olbia à Hyères (Photo $\mathrm{CCJ}$, Chr. Durand).

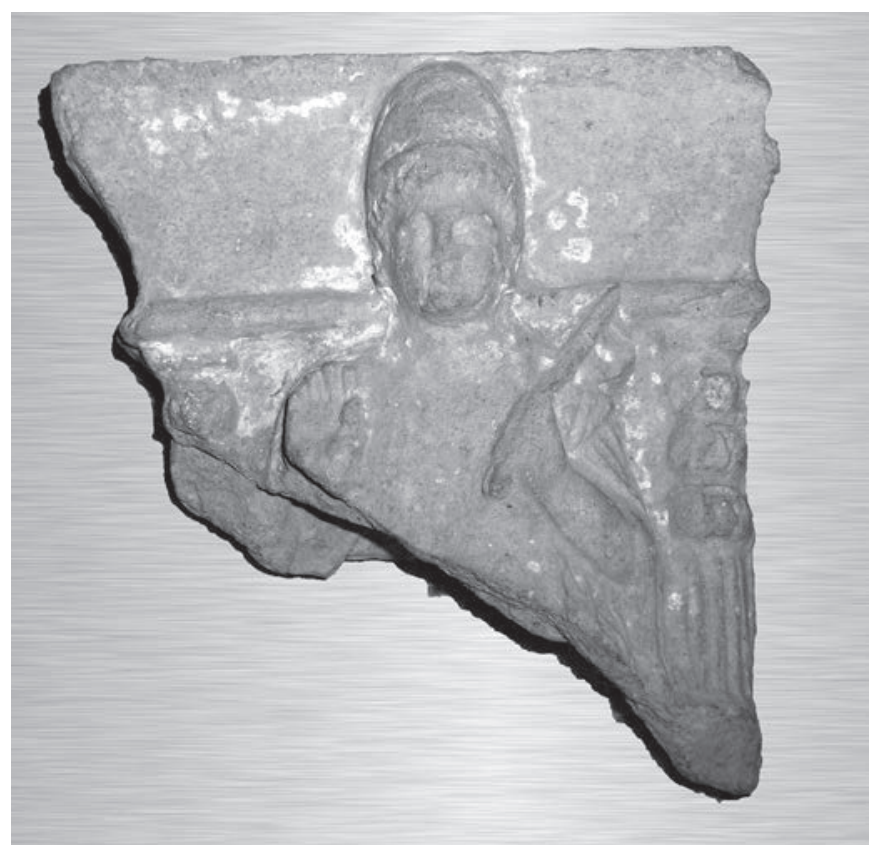

Fig. 9. Plaquette punique trouvée à Ensérune. Musée d'Ensérune M 775 (Photo Christian Olive). 


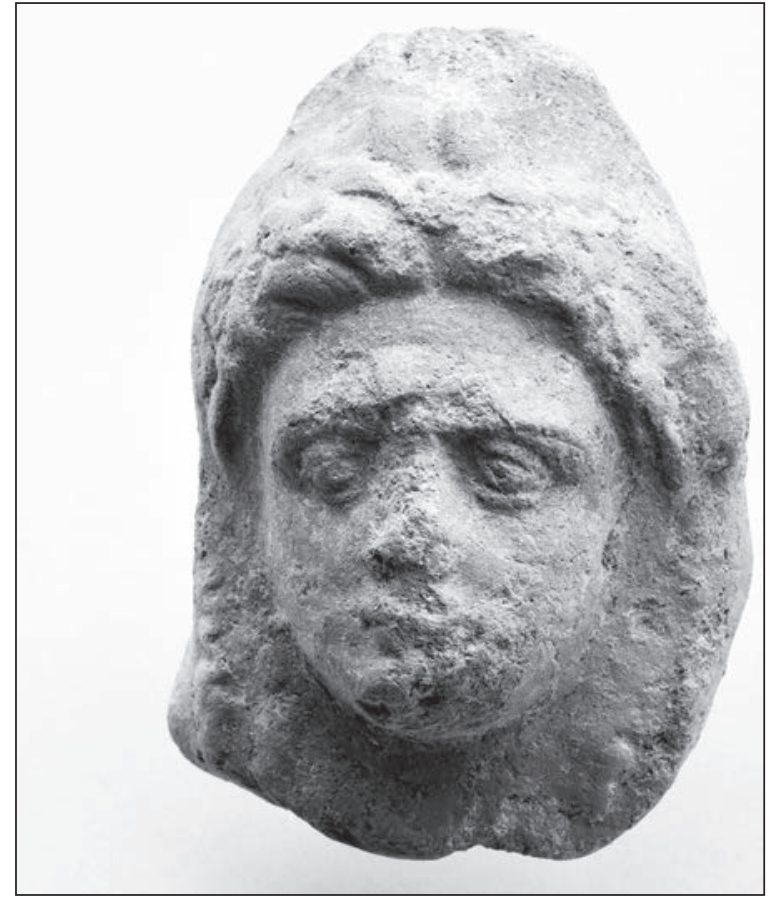

Fig. 10. Tête du dieu Pan, d'Olbia. Dépôt archéologique d'Olbia à Hyères (Photo $\mathrm{CCJ}$, L. Damelet).

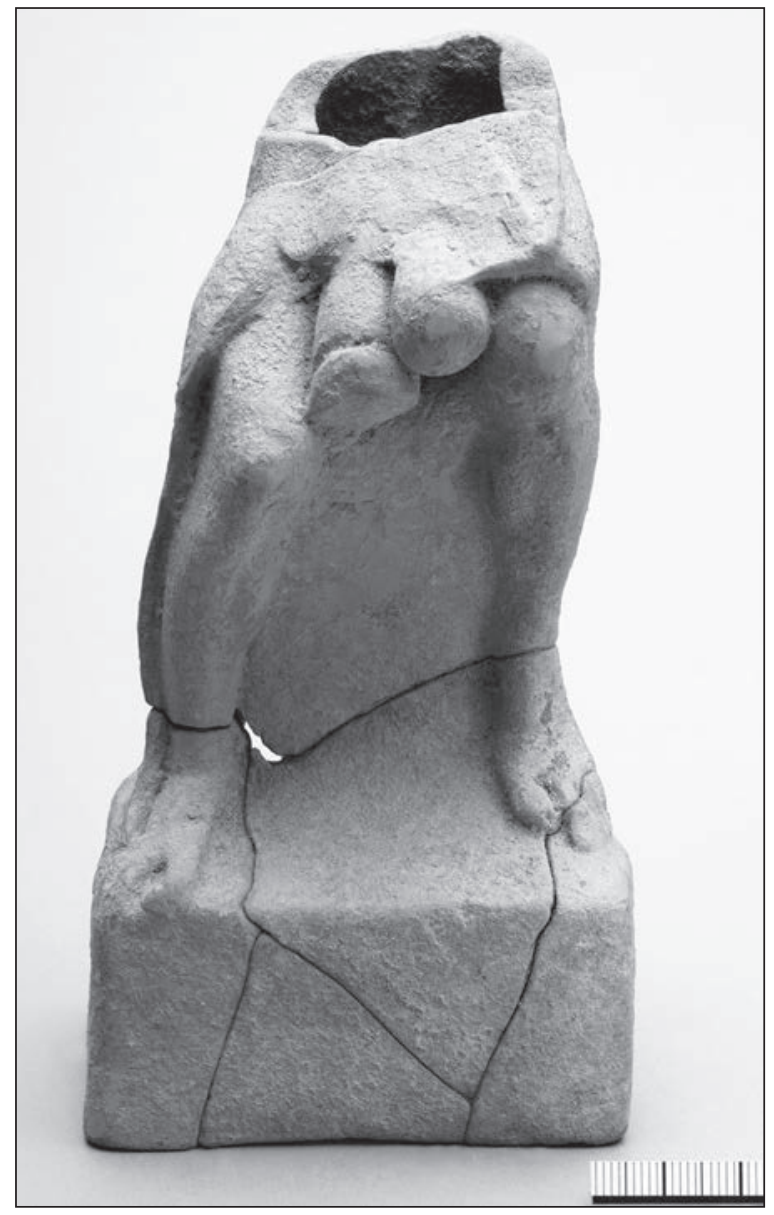

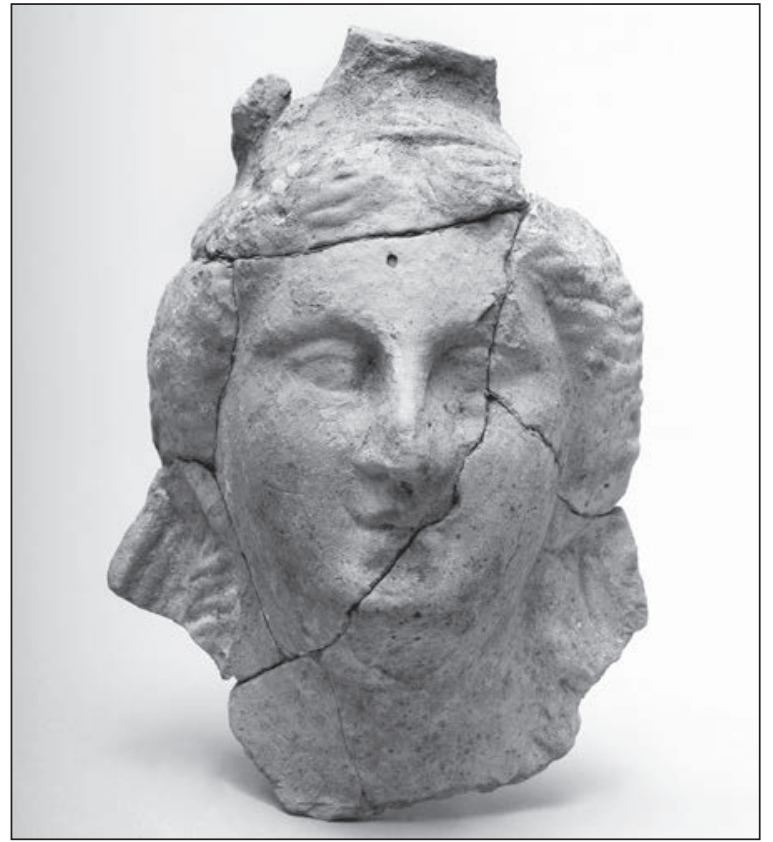

Fig. 11. Tête d'une grande figurine, du sanctuaire d'Artémis à Olbia. Dépôt archéologique d'Olbia à Hyères (Photo CCJ, Chr. Durand).

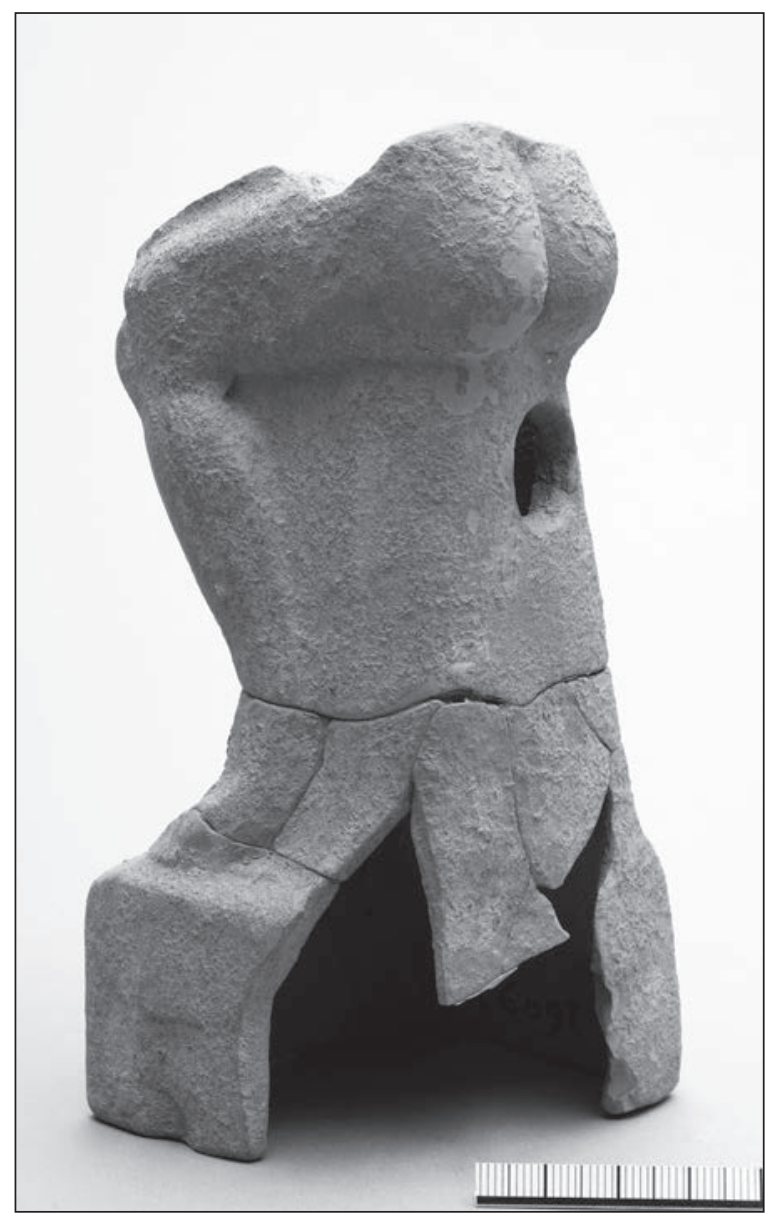

Fig. 12. a-b Personnage masculin fragmentaire, d'Olbia. Dépôt archéologique d'Olbia à Hyères (Photos CCJ, Chr. Durand). 
La présence d'un exemplaire à Olbia est plus inattendue (fig. 7), car la ville est à l'écart du réseau de diffusion mentionné précédemment (Pena 2007, p. 35 fig. 5 ; Bats 2011a, p. 257, fig. 264). On note que ce thymiatérion a été découvert dans le sanctuaire d'Aphrodite, lieu particulièrement approprié pour l'offrande d'un objet lié aux substances parfumées, même si, comme on l'a vu, cette fonction n'est pas toujours attestée (l'exemplaire d'Olbia est trop fragmentaire pour qu'on puisse le vérifier). Le quatrième brûle-parfum de ce type provient du quartier dit de l'Esplanade à Arles (fig. 8) ${ }^{17}$ : il s'agit d'une zone d'habitat qui paraît avoir été occupée entre le $\mathrm{V}^{\mathrm{e}}$ et le $\mathrm{II}^{\mathrm{e}}$ s. av. J.-C. (Rothé, Heijmans 2008, p. 475). Il paraîtrait naturel que, comme celui d'Olbia, ce thymiatérion soit parvenu sur le site via Marseille, mais la cité phocéenne n'a, pour le moment, livré aucun document de ce type ${ }^{18}$. L'origine de ces objets donne toujours lieu à des débats. J. Moratalla Jávega et E. Verdú Parra (2007, p. 365 fig. 11) se prononcent pour une diffusion à partir des villes puniques de Sicile occidentale, hypothèse que paraît étayer, en partie au moins, la découverte d'un nouvel exemplaire à Monte Iato, en Sicile centrale, probablement dans un sanctuaire domestique (Russenberger 2011). Pour d'autres, une origine carthaginoise est plus vraisemblable et, en dernier lieu, Frédérique Horn (2011, p. 62) considère que, « après l'élaboration des premiers prototypes dans une ou plusieurs cités puniques siciliennes, le relais a très vite été repris par les installations punico-sardes » (en particulier à Tharros). On constate, en tout cas, que les quatre brûle-parfums découverts dans le Sud de la Gaule appartiennent au même type iconographique, décoré, sur le kalathos, de deux oiseaux, probablement des cygnes, entourant des «pastilles » (fruits stylisés ?). Un exemplaire comparable, en très bon état de conservation, a été mis au jour à Ampurias : ce site a pu servir de relais dans la diffusion de ces thymiatéria vers le Languedoc et la Provence.

Quelle que soit l'identité de la tête féminine qui porte ces brûle-parfums ${ }^{19}$, on a affaire à un type de représentation qui entre aisément dans le cadre de la religion grecque. Ce n'est pas le cas pour une plaquette en terre cuite mise au jour à Ensérune, qui est caractéristique

17 Il n'est connu que par une mention et une illustration dans le catalogue Musée de l'Arles antique. Arles, Actes Sud, 1996, p. 37 fig. 20. Je remercie Alain Charron de m'avoir transmis la photographie reproduite ici.

18 On ne peut cependant pas exclure que l'un ou l'autre fragment de visage féminin ait appartenu à ce type d'objet.

19 On l'a en général rattachée au culte de Déméter et Koré, mais les cygnes (?) affrontés sur la série la mieux représentée conviendraient mieux à Aphrodite (voir ci-dessus). du monde phénico-punique (fig.9) ${ }^{20}$. Il reste la partie supérieure de l'objet (cassé en diagonale), fait en deux parties : la face antérieure, moulée, est raccordée à un arrière plat - sauf au niveau du fronton de l'édicule où il est légèrement bombé. Un personnage masculin de face, imberbe, se détache sur une façade architecturale composée de deux colonnettes cannelées - seule celle de droite est bien conservée - terminées par un triple chapiteau à feuilles retombantes, et d'un entablement constitué, au-dessus d'une épaisse moulure, d'un large fronton évasé en haut ${ }^{21}$. Le personnage lève la main droite, ouverte vers le spectateur, et tient dans sa main gauche, au-dessus de l'épaule, un objet qui, par comparaison avec d'autres exemplaires mieux conservés, est certainement une hache fenestrée. Un vêtement est posé sur l'épaule gauche (traces de peinture rose). La tête, en fort relief, est coiffée d'un haut bonnet conique ; de longues mèches frontales surmontent le visage qui est mal conservé ; on note qu'un bijou est fixé à l'oreille droite. Cette plaquette a été publiée par Gilbert Charles Picard dans un article qui porte le titre accrocheur « Hannibal à Ensérune » (Picard 1957). Le savant français avait bien noté qu'elle appartenait à une série attestée principalement à Carthage (voir Cherif 1997, p. 60-68, pl. XIX-XXII). Quelques exemplaires proviennent d'autres sites puniques de Tunisie, d'Ibiza et de Tharros en Sardaigne ${ }^{22}$. Dans tous les cas le personnage est assis en position frontale, la main droite levée, la hache dans l'autre ; quand il est représenté barbu, on l'a généralement interprété comme Baal-Hammon (Le Glay 1986) ${ }^{23}$. Certains auteurs ont parlé d'une version féminine de l'image (Uberti 1997, p. 192 ; Horn 2011, Annexe 1, p. 20, à propos de l'exemplaire d'Ensérune), mais cette interprétation n'est pas convaincante, même si le personnage est imberbe et porte, comme sur l'exemplaire d'Ensérune, des boucles d'oreilles : ce type de bijou est en effet bien attesté pour les hommes dans l'Afrique du Nord punique ${ }^{24}$. Il est légitime de se deman-

20 Je remercie Christian Olive pour la photographie reproduite ici. Inventaire au musée d'Ensérune M 775. H. conservée $8,1 \mathrm{~cm}$, larg. 7,9 cm, ép. $3,5 \mathrm{~cm}$. Le contexte de la découverte n'est pas clair : la nécropole d'après le cartel du musée, un dépotoir sur la pente Nord de la colline d'après Picard (1957, p. 58) ou encore «nécropole, contexte précis inconnu » d'après Horn 2011 (Annexe 1, p. $20 \mathrm{n}^{\circ} \mathrm{C} 1$ ).

21 Cette forme correspond à ce qu'on appelle la gorge égyptienne. 22 San Nicolás Pedraz (M.P.) - Coroplastica fenico-púnica. In : Producciones artesanales fenico-púnicas. VI jornadas de arqueología fenico-púnica (Ibiza 1991). Ibiza, Museu arqueològic d'Eivissa, 1992, p. 16-17.

23 En raison de la hache fenestrée, le nom de Melqart a été également avancé.

24 Voir Plaute, Pœnulus, 980 (pour des Carthaginois) et surtout Plutarque, Vie de Marius, XII, 4 : quand le prince numide Jugurtha est jeté en prison par les Romains, « les uns déchirèrent sa tunique, 
der comment un tel objet est arrivé dans le Languedoc occidental à une époque que l'on peut situer, d'après la date des exemplaires de Carthage, entre le III' $\mathrm{s}$. et la première moitié du $\mathrm{II}^{\mathrm{e}} \mathrm{s}$. av. J.-C. Gilbert-Charles Picard considérait - comme le suggère le titre de son article - que «Les sacra puniques ${ }^{25}$ d'Ensérune n'ont donc pu y être apportés que pendant la période (219-208) où la Gaule méridionale a été contrôlée militairement par Hannibal ; ils ont dû appartenir à un officier carthaginois, laissé pour assurer la liaison avec les autorités de la tribu celto-ibère » (Picard 1957, p. 58). Cette explication est reprise, avec un peu plus de prudence, dans la notice de l'article Baal-Hammon du LIMC: « ... sans doute vestige du passage d'Hannibal ou de l'occupation punique en 210-209 av. J.-C. » (Le Glay 1986, p. 57-59). Elle paraît difficile à défendre sous cette forme, mais il reste à expliquer la présence insolite de cet objet apparemment totalement étranger au contexte. Était-il perçu comme une curiosité «exotique»? Le personnage était-il reconnu comme une divinité protectrice, éventuellement assimilée à un dieu local ou grec ? Faut-il imaginer, sans faire nécessairement le rapprochement avec le passage d'Hannibal, qu'il témoigne de la présence d'une petite communauté punique à Ensérune ? Il est difficile de proposer une explication.

On revient avec la série des terres cuites hellénistiques d'Olbia à une iconographie grecque plus traditionnelle, malgré certains traits originaux (voir le thymiatérion illustré fig. 7). Sur les quelques dizaines de pièces, souvent très fragmentaires, mises au jour dans les fouilles de Jacques Coupry, puis de Michel Bats, beaucoup appartiennent à des figurines féminines couronnées fabriquées dans une argile claire, peut-être massaliète. D'autres sont faites d'une argile orangée dont l'origine n'est pas encore déterminée. Une tête moulée, que ses bords légèrement recourbés ne permettent sans doute pas d'identifier comme un décor d'applique, représente le dieu Pan, caractérisé par ses oreilles pointues et les petites cornes qui sortent discrètement au-dessus du front (fig. 10) ${ }^{26}$. La présence de l'image du dieu agreste dans l'habitat d'Olbia est intéressante, si on la compare au culte d'Aristée, lui aussi un dieu de la campagne, qui était célébré dans le sanctuaire extra-urbain de l'Acapte (Bats 2011b). Plusieurs figurines fragmentaires proviennent du sanctuaire d'Artémis. La plus remarquable

d'autres, dans la hâte de lui retirer de force ses boucles d'oreille en or, lui arrachèrent en même temps le lobe des oreilles » (trad. A.-M. Ozanam, éd. Gallimard).

25 Il désigne sous cette forme, outre la plaquette, les deux brûleparfums mentionnés plus haut et un petit masque en verre également trouvé à Ensérune.

26 Elle a été trouvée dans la rue Sud de l'îlot VI.Inv. M 6097, H. 8,2 cm, larg. 5,8 cm. Roure, Pernet 2011, p. $283 \mathrm{n}^{\circ} 117$ (« tête féminine »). est une tête féminine d'assez grandes dimensions, coiffée d'un haut diadème ou d'un pôlos (fig. 11) ${ }^{27}$ : elle appartenait probablement à une statuette de la déesse. L'argile orangée est du même type que celle d'un étonnant personnage masculin dont subsiste la partie inférieure (fig. 12 a-b) : assis sur un support rectangulaire, il est nu, en dehors d'une étoffe qui tombe le long de sa jambe droite et couvre en partie son pénis et un de ses testicules (?), de dimensions hypertrophiées ${ }^{28}$. On songe à une figurine de type prophylactique, mais je ne peux pas actuellement proposer de comparaison.

\section{Conclusion et perspectives}

L'artisanat des figurines, ou des reliefs, en terre cuite n'a apparemment pas connu le même développement à Marseille et dans les plus petites villes du Midi de la France que dans les cités de Grande Grèce, de Sicile, dans le monde punique, ou même à Ampurias. Le fait que, même si l'extension des fouilles a été beaucoup plus limitée, la cité phocéenne ait livré moins de figurines d'époque hellénistique que sa fondation d'Olbia est sans doute significatif et rejoint les observations que l'on peut faire sur la rareté des sculptures et des inscriptions votives dans l'ancienne Massalia. On note, d'autre part, que les sites celtiques de la région n'ont pas livré de figurines de type grec, ou d'imitations locales: la petite tête trouvée à Lattes est l'exception qui confirme la règle. Olbia constitue un cas particulier à la fois par la présence de figurines dans l'habitat et les sanctuaires urbains, mais aussi par leur absence dans le sanctuaire d'Aristée, à l'extérieur de la ville, où les fidèles offraient de petits vases portant souvent des dédicaces en grec, mais pas de figurines en terre cuite.

Même si le matériel est restreint, et souvent très fragmentaire, l'intérêt de ce domaine de recherche apparaît mieux encore si l'on prend en considération les quelques figurines et vases plastiques découverts dans l'épave de Camarat 2, datée à la fin de la période qui nous concerne, vers 50-40 av. J.-C. Ils appartiennent en effet à des séries jusqu'ici inconnues dans le Midi de la France et même, semble-t-il, en Méditerranée occidentale : personnage assis jouant de la cithare (Apollon ?), jeune garçon chevauchant un équidé ou jouant avec un chien, œnochoé

27 Inv. M 8936, H. 12,6 cm, larg. 9 cm. Roure, Pernet 2011, p. 283 $\mathrm{n}^{\circ} 115$ (les têtes féminines $\mathrm{n}^{\text {os }} 114$ et 116 proviennent aussi du sanctuaire d'Artémis).

28 Lieu de découverte inconnu. H. $15 \mathrm{~cm}$, larg. à la base 7,5 cm, ép. $6 \mathrm{~cm}$. 
en forme de tête de noir ${ }^{29}$. Leur fonction est difficile à définir : éléments complémentaires de la cargaison, ou mobilier appartenant à l'équipage ? Ils apportent en tout cas un témoignage supplémentaire sur le transport d'une catégorie d'objets qui, comme à Ensérune, Lattes, Arles et, au moins en partie, Olbia et Marseille, ont été diffusés sous la forme d'exemplaires isolés, au gré des échanges maritimes.

\section{Bibliographie}

Bats 2011a : BATS (M.) - Olbia de Provence, Hyères, Var. In : Roure (R.), Pernet (L.) dir. Des rites et des Hommes. Les pratiques symboliques des Celtes, des Ibères et des Grecs en Provence, en Languedoc et en Catalogne. Paris, Éditions Errance, 2011, p. 256-259.

Bats 2011b : BATS (M.) - L'Acapte, Giens. In : Roure (R.), Pernet (L.) dir. Des rites et des Hommes. Les pratiques symboliques des Celtes, des Ibères et des Grecs en Provence, en Languedoc et en Catalogne. Paris, Éditions Errance, 2011, p. 260-263.

Benoit 1965 : BENOIT (F.) - Recherches sur l'hellénisation du Midi de la Gaule. Aix-en-Provence, Faculté des Lettres, 1965.

Bignasca 1992 : BIGNASCA (A.) - Nuove terrecotte dell'offerente di porcellino e la prima metà del 4. Secolo a Morgantina. Antike Kunst, 35, 1992, p. 18-53, pl. 5-14. Bouiron 2013 : BOUIRON (M.) - «Ainsi la main humaine a introduit la mer dans la terre ». Réflexions sur les carrières d'argile de Marseille grecque archäque. In : Bouffier (S.), Hermary (A.) éd. Entre Marseille et Mégara Hyblaea. Archéologie des cités grecques d'Occident. Hommages à Henri Tréziny. BiAMA 13, Paris, Éditions Errance, et Aix-en-Provence, Centre Camille Jullian, 2013, p. 57-68.

Cherif 1997 : CHERIF (Z.) - Terres cuites puniques de Tunisie. Rome, Bonsignori, 1997.

Collin-Bouffier 1999 : COLLIN-BOUFFIER (S.) - Sources et fleuves dans les cultes phocéens. In : Hermary, Tréziny 2000, p. 69-80.

Hermary, 2012 : HERMARY (A.) - [Notices sur quelques objets de Marseille]. In: Garsson (M.) dir., Le Trésor des Marseillais. 500 av. J.-C., l'éclat de Marseille à Delphes, Catalogue d'exposition, Marseille, Vieille Charité, janvier-avril 2013. Paris, Somogy et Musées de Marseille, 2012.

Hermary, Tréziny 2000 : HERMARY (A.), TRÉZINY (H.) - Les Cultes des cités phocéennes. Actes du colloque international Aix-en-Provence I Marseille, 4-5 juin 1999. Aix-en-Provence, Édisud et Centre Camille Jullian, 2000 (Études massaliètes 6).

Hermary, Hesnard, Tréziny 1999 : HERMARY (A.), HESNARD (A.), TRÉZINY (H.) dir. - Marseille grecque, 600-49 av.J.-C. La cite phocéenne. Paris, Éditions Errance, 1999.

Horn 2011 : HORN (Fr.) - Ibères, Grecs et Puniques en Extême-Occident. Les terres cuites de l'espace ibérique du VIII ${ }^{e}$ au II ${ }^{e}$ siècle av. J.-C. Madrid, Casa de Velózquez, 2011.

Huysecom-Haxhi 2009 : HUYSECOM-HAXHI (St.) - Les figurines en terre cuite de l'Artémision de Thasos. Artisanat et piété populaire à l'époque de l'archaïsme mûr et récent. Athènes, École française d'Athènes, 2009 (Études thasiennes XXI).

Le Glay 1986 : LE GLAY (M.) - Baal-Hammon. In : Lexicon Iconographicum Mythologiae Classicae (LIMC), vol. III. Zurich et Munich, Artemis Verlag, 1986, p. 72-75, pl. 61-62.

29 Ce matériel est encore inédit, seules deux photographies (vase plastique et enfant jouant avec un chien) ont été publiées dans Gallia Informations, 1987-1988, vol. 1, p. 37, fig. 40. Je remercie MarieBrigitte Carre de m'avoir montré des photographies de l'ensemble des documents.
Long, Miro, Volpe 1992 : LONG (L.), MIRO (J.), VOLPE (G.) - Les épaves archaïques de la pointe Lequin (Porquerolles, Hyères, Var). Des données nouvelles sur le commerce de Marseille à la fin du $\mathrm{VI}^{\mathrm{e}}$ et dans la première moitié du $\mathrm{V}^{\mathrm{e}} \mathrm{s}$. av. J.-C. In : Bats (M.), Bertucchi (G.), Congès (G.), Tréziny (H.) éd., Marseille grecque et la Gaule. Actes du Colloque international d'Histoire et d'Archéologie et du Ve Congrès archéologique de Gaule méridionale (Marseille, 18-23 novembre 1990). Lattes, A.D.A.M. éditions, et Aix-en-Provence, Université de Provence, 1992, p. 199-234 (Études massaliètes 3).

Marín Ceballos, Horn 2007 : MARÍN CEBALLOS (M.C.), HORN (Fr.) éd. - Imagen y culto en la Iberia prerromana : los pebeteros en forma de cabeza femenina. Séville, Universidad de Sevilla, 2007.

Moliner 2012 : MOLINER (M.) - Le mobilier déposé dans les tombes d'enfants des colonies grecques de Marseille, Agde et Ampurias. In : Hermary (A.), Dubois (C.) éd., L'Enfant et la mort dans l'Antiquité III. Le mobilier associé aux tombes d'enfants. Paris, Éditions Errance et Centre Camille Jullian, 2012, p. 171-192 (BiAMA 12).

Mollard-Besques 1954 : MOLLARD-BESQUES (S.) - Musée National du Louvre. Catalogue raisonné des figurines et reliefs en terre-cuite grecs, étrusques et romains I. Époques préhellénique, géométrique, archaïque et classique. Paris, Éditions des Musées Nationaux, 1954.

Moratalla Jávega, Verdú Parra 2007 : MORATALLA JÁVEGA (J.), VERDÚ PARRA (E.) - Pebeteros con forma de cabeza femenina de la Contestania ibérica. In : Marín Ceballos, Horn 2007, p. 339-366.

Pena 2007 : PENA(M.J.) - Reflexiones sobre los peberos en forma de cabeza femenina. In : Marín Ceballos, Horn 2007, p. 17-40.

Picard 1957 : PICARD (G.Ch.) - Hannibal à Ensérune. In : Journées archéologiques d'Avignon 1956. Avignon, Palais du Roure, 1957, p. 57-59.

Pomey 2013 : POMEY (P.) - Les graffiti navals de l'Alcazar à Marseille : des pentécontores phocéennes? In : Bouffier (S.), Hermary (A.) éd. Entre Marseille et Mégara Hyblaea. Archéologie des cités grecques d'Occident. Hommages à Henri Tréziny. BiAMA 13, Paris, Éditions Errance, et Aix-enProvence, Centre Camille Jullian, 2013, p. 79-84.

Py 2009 : PY (M.) - Lattara, Lattes, Hérault. Comptoir gaulois méditerranéen entre Étrusques, Grecs et Romains. Paris, Éditions Errance, 2009.

Rothé, Tréziny 2005 : ROTHÉ (M.-P.), TRÉZINY (H.) - Carte archéologique de la Gaule. Marseille et ses alentours, 13/3. Paris, Académie des Inscriptions et Belles-Lettres, 2005.

Rothé, Heijmans 2008 : ROTHÉ (M.-P.), Heijmans (M.) - Carte archéologique de la Gaule. Arles, Crau, Camargues, 13/5. Paris, Académie des Inscriptions et Belles-Lettres, 2008.

Roure, Pernet 2011 : ROURE (R.), PERNET (L.) dir. - Des rites et des Hommes. Les pratiques symboliques des Celtes, des Ibères et des Grecs en Provence, en Languedoc et en Catalogne. Paris, Éditions Errance, 2011.

Russenberger 2011 : RUSSENBERGER (C.) - Peristylhaus 2, Ostbereich. In : Reusser (C.) et al., Forschungen auf dem Monte Iato 2010. Antike Kunst, 54, 2011, p. 82-95, pl. 18-19.

Schwaller 1994 : SCHWALLER (M.) - Ensérune. Guides archéologiques de la France, 1994.

Tréziny 2000 : TRÉZINY (H.) - Les lieux de culte dans Marseille grecque. In : Hermary, Tréziny 2000, p. 81-99.

Uberti 1997 : UBERTI (M.L.) - L'artigianato. In : Cherif 1997, p. 163-215. Ugolini 1983 : UGOLINI (D.) - Deux thymiateria à tête féminine du musée d'Ensérune. DAM, 6, 1983, p. 101-108.

Villard 1960: VILLARD (Fr.) - La céramique grecque de Marseille (VIe-IVe s.). Essai d'histoire économique. Paris, De Boccard, 1960. 


\title{
Du bon usage de la violence dans l'iconographie italiote et étrusque
}

\author{
Luca Cerchiai \\ Dipartimento di Scienze del Patrimonio Culturale - Università di Salerno \\ Natacha Lubtchansky \\ Université François-Rabelais de Tours - CeTHiS
}

Claude Pouzadoux

Centre Jean Bérard (USR 3133 CNRS/EFR)

\section{Résumé}

L'analyse des images n'est pas seulement destinée à compenser l'absence de sources écrites : elle offre également un observatoire privilégié des expressions symboliques des sociétés antiques et des processus de transmission et de perméabilité entre cultures. Les représentations étrusques et italiotes de la violence, question qui se pose inévitablement dans toute histoire de la colonisation, nous ont paru particulièrement emblématiques de la fabrication des stéréotypes en matière de perception et de définition d'une culture. C'est un des thèmes en effet, avec l'irrationnel et le fantastique, qui a contribué à fonder l'opposition entre la civilisation des Grecs et la sauvagerie des populations italiques. La représentation de la violence constitue un écran particulièrement exposé à la projection des préjugés culturels, comme le montre la perception différenciée qu'on en a eue dans chacun de ces deux blocs culturels - le monde grec et les populations de l'Italie.

Mots-clés : violence, vases, grecs, italiques, représentations, sacrifice, pouvoir, funérailles

\begin{abstract}
Analysing images is not only to compensate for the lack of written sources, it also provides an ideal vantage of symbolic expressions in ancient societies and processes of transmission and permeability between cultures. Etruscan and Italic representations of violence, an issue that inevitably arises in any history of colonization, have seemed especially emblematic manufacturing stereotypes on perception and definition of culture. This is one of the themes in fact, with the irrational and fantastic, which helped found the opposition between civilization of the Greeks and savagery of Italic populations. The portrayal of violence is particularly exposed to the projection of cultural prejudices screen, as shown in differentiated perception of it had in each of these two cultural blocks - the Greek world and the people of Italy.
\end{abstract}

Keywords: violence, vases, Greek, Italic, representations, sacrifice, power, funeral 
$\mathrm{P}$ our rendre hommage non seulement aux travaux de Michel sur le rôle des contacts et des interactions culturelles entre monde grec et non-grec dans la formation des identités sociales et ethniques, mais aussi pour répondre à ses réserves relatives au recours à la culture matérielle pour « saisir les représentations et les savoirs qui se cachent derrière les pratiques qui les mettent en acte et les transmettent » (Bats 1997, p. 409), nous avons choisi de manière paradoxale de recourir à une documentation et à un thème qui ne sont pas au centre de ses travaux, à savoir les représentations étrusques et italiotes de la violence (même si la question de la violence se pose inévitablement dans toute histoire de la colonisation). Le recours aux images n'est pas seulement destiné à compenser l'absence de sources écrites : il constitue aussi un observatoire privilégié des expressions symboliques des sociétés antiques et des processus de transmission et de perméabilité entre cultures. La familiarité qu'entretient Michel depuis de longues années avec les images nous permet de penser qu'il est d'ores et déjà convaincu de l'importance d'un tel médium pour réfléchir aux questions de cultures et d'acculturation dans la Méditerranée antique...

Le thème de la violence nous a paru, quant à lui, particulièrement emblématique de la fabrication des stéréotypes en matière de perception et de définition d'une culture. C'est un des thèmes en effet, avec l'irrationnel et le fantastique (Gruzinski, Rouveret 1976, p. 162), qui a contribué à fonder l'opposition entre la civilisation des Grecs et la sauvagerie des populations italiques. La représentation de la violence constitue un écran particulièrement exposé à la projection des préjugés culturels, comme le montre la perception différenciée qu'on en a eue dans chacun de ces deux blocs culturels - le monde grec et les populations de l'Italie ${ }^{1}$.

Qu'il s'agisse, pour le monde grec, d'exclure ou de reconnaître les traces de la violence dans les rites sacrificiels, sa présence dans la guerre et ses liens avec le pouvoir, la réflexion, menée dès l'Antiquité, puis par les historiens modernes, a depuis longtemps fourni le socle d'une approche dialectique de la question. Elle a d'abord été ignorée par les défenseurs d'une vision idéale de la civilisation grecque, qui s'appuyaient sur la condamnation de la violence par les poètes tragiques au $\mathrm{V}^{\mathrm{e}} \mathrm{s}$. dans

1 On trouvera une très pertinente mise au point historiographique sur la violence dans l'antiquité et en particulier dans le monde grec dans Beltrametti 2004. Le thème de la violence a été le sujet de plusieurs colloques récents dans les actes desquels sont présentés différents états de la question : Bertrand 2005 ; Fischer et Moraw 2005 ; Seidensticker et Vöhler 2006 ; Zimmermann 2009 ; Ando et Cusumano 2010 ; Masseria et Loscalzo 2011. Pour une mise au point historiographique et méthodologique sur les images grecques de la violence, voir Muth 2008. la cité classique, puis par les philosophes du IVe s, avant d'être reconnue grâce aux travaux des ritualistes anglais, des spécialistes de la tragédie et des historiens des religions, à commencer par E.-R. Dodds dans son ouvrage sur les Grecs et l'Irrationnel (1951) et W. Burkert dans Homo Necans (1972), pour n'en citer que quelquesuns $^{2}$. Cette dernière approche a permis de reconstruire le cadre complexe d'une société qui, loin d'ignorer la violence, l'a assumée et s'est dotée d'institutions pour identifier et canaliser les pratiques déviantes qui compromettent l'identité de la collectivité et la modernité de la cité. Ce faisant, les Grecs étaient bien conscients que le nomos, en tant qu'instaurateur de l'ordre, porte nécessairement la marque d'une violence, ce qu'on peut encore retrouver dans la morale laïque occidentale. Pour l'Italie préromaine, faute d'une documentation aussi abondante, l'approche est aussi moins approfondie et moins nuancée, comme si la présence sur les images étrusques et italiotes de pratiques non seulement condamnées par les poètes, les historiens et les philosophes athéniens à partir du Ve s. et surtout au IVe s. av. J.-C., mais aussi absentes du répertoire figuré grec, suffisait à fournir l'indice d'une spécificité culturelle qu'on pouvait construire contre la précédente et caractériser par un rapport univoque à la violence. L'opposition entre monde grec et populations de l'Italie antique, observée tant sur le plan artistique que plus largement anthropologique, s'est centrée sur cette question dès la fin du XVIII ${ }^{\mathrm{e}} \mathrm{s} .{ }^{3}$ : les Grecs, défenseurs de la mesure et de la modération, ne pouvaient que se distinguer des populations d'Italie, qui multipliaient dans les images les scènes de meurtres, de combats et de rituels sanglants.

Il convient donc de revoir, à la lumière des travaux récents sur le statut ambigu de la violence dans le monde grec, les scènes produites en Italie. Le dossier des représentations de sacrifices humains, avec leur cortège de corps mutilés et de têtes coupées, est un bon révélateur du rôle des images dans la construction des stéréotypes qui ont abouti à opposer ces deux cultures. Celles-ci ont même fini par faire accepter l'historicité, en Italie, d'une pratique jugée inconcevable dans le monde grec (Georgoudi 1999). Or, si les attestations archéologiques restent encore obscures, le sacrifice humain ne peut toutefois pas être exclu de la réalité historique grecque, qu'on le relègue au domaine du mythe, où il prolifère, et de l'épopée, ou qu'on n'y voie, avec P. Bonnechère, qu'une métaphore d'un rituel de passage entre classes d'âge (Bonnechère 1994) : le sacrifice humain était bien

\footnotetext{
2 Pour plus de détail nous renvoyons à la synthèse de Beltrametti 2004.

3 C'est le cas J.J. Winckelmann, dont la position sera reprise par de nombreux antiquaires et archéologues, dont Raoul-Rochette 1834.
} 


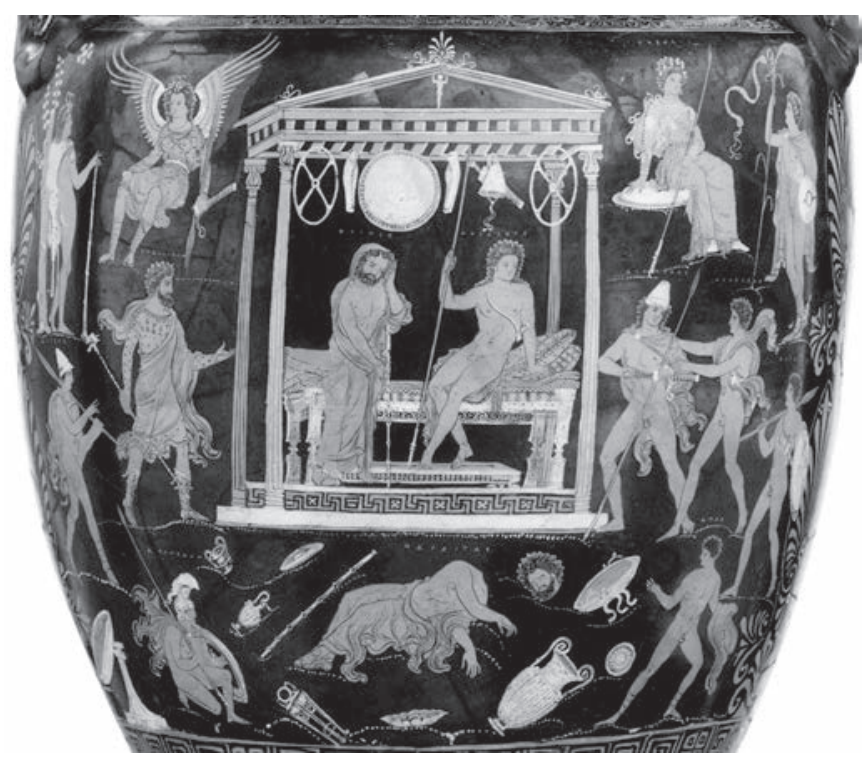

Fig. 1. Boston, Museum of Fine Arts, 03.80, Francis Barlett Donation of 1900, cratère à volutes apulien attribué au Peintre du Thersite de Boston, d'après Pouzadoux 2009, p. 32.

sûr tout à fait exceptionnel, mais non impossible, et parfois acceptable, en Italie comme en Grèce (Jost 1995).

Nous nous demanderons donc si et comment les représentations figurées des mythes grecs en Italie méridionale, centrale et en Étrurie, du VI ${ }^{\mathrm{e}}$ au $\mathrm{IV}^{\mathrm{e}} \mathrm{s}$., construisent une image de la violence, et dans quelle mesure celle-ci a pu servir à définir non seulement une altérité négative, mais aussi une identité religieuse et politique.

\section{Figurer la violence : pour une typologie des codes de représentation}

\section{Définir la violence}

Les nombreux travaux sur la violence, de l'antiquité à nos jours, s'accordent sur le fait qu'il est difficile, voire impossible, de la définir dans l'absolu. Déterminée culturellement, et non naturellement, elle ne peut être évaluée que relativement à un ensemble de règles qui régissent les rapports entre les hommes et les dieux et ceux des hommes entre eux. Une scène de guerre, par exemple, dans le monde grec ne constitue pas en soi une représentation de la violence. Il s'agit d'abord, comme l'a rappelé $\mathrm{S}$. Muth, de peindre les qualités des adversaires, celles du vainqueur et celles du vaincu, et de valoriser l'héroïsme, c'est-à-dire, un usage réglé de la force selon les codes de l'honneur et de la valeur. Ce n'est donc pas le recours à la force qui est perçu comme violent, mais le recours à une force illicite qui commence notamment là où finit la guerre, et, en particulier, quand les villes sont prises. La violence, pour les Grecs, est ce qui va au-delà des nécessités de la guerre. C'est aussi ce qui, au lieu de frapper les autres, l'ennemi, frappe les membres d'une même communauté qui se désagrège dans la stasis. Ces transgressions impliquent l'existence d'un point de vue apte à déterminer la frontière entre le licite et l'illicite. Nous tenterons de le saisir à travers une typologie des marques de la violence. Pour le construire, les peintres pouvaient tirer partie des rapports entre les personnages, de l'identité de l'agresseur et de celle de la victime, de la nature de l'acte et des interférences entre différentes sphères suscitées par le choix des lieux, des gestes et des instruments.

\section{Identifier la violence}

Les meurtres en famille constituent une des transgressions révélatrices du désordre susceptible de menaçer l'ordre social. Bien que les épisodes soient attestés aussi bien en Grèce qu'en Italie, le choix de représenter l'acte meurtrier varie selon les aires culturelles : la mort d'Itys, par exemple, tué par Procné dans la céramique attique (Chazalon, Wilgaux 2008-2009) est absente de la céramique italiote où l'on trouve en revanche, pour la première fois, le meurtre de ses fils par Médée, la plupart du temps à l'autel ${ }^{4}$. L'amplification régionale d'un thème a pu parfois sembler traduire l'attrait particulier pour cette violence intestine : ainsi le meurtre de ses enfants par Lycurgue est surreprésenté dans la céramique italiote par rapport à la céramique attique (Farnoux 1992) ; la même impression ressort des nombreuses scènes de meurtres en famille (meurtre de Clytemnestre, combat entre Etéocle et Polynice) représentées sur les urnes étrusques.

Le meurtre à l'autel, d'un enfant ou d'un vieillard, ou le viol d'une femme venue s'y réfugier font partie des formes d'expression récurrentes de la violence liée à la prise d'une ville, comme on en trouve dans les scènes d'Ilioupersis. Ainsi le caractère sacrilège du recours à la force est-il suggéré, sur deux vases attiques, l'hydrie Vivenzio $^{5}$ et la coupe d'Euphronios de la Villa Giulia ${ }^{6}$, par le viol d'une loi sacrée, le refuge à l'autel de Priam et de Cassandre. La combinaison de l'autel, du vieillard, du cadavre de l'enfant, des taches de sang et de la machaira finit par accentuer l'idée de la violence contrairement aux productions italiques où ces divers éléments sont disjoints du fait de la structuration de l'image en plusieurs registres. L'absence de l'autel près de Priam tombé au

\footnotetext{
4 Schmidt 1992, spéc. p. 391-392 et cat. nos $30,31,35,36,37$, avec ill.

5 Hydrie (Naples, Musée Archéologique National, inv. 81 699) : Beazley 1963,p. 189, no 74 ; Vasi antichi, p. 60-61, avec ill. coul.

6 Coupe d'Euphronios (Musée National de Villa Giulia, inv. 121 110) : Nostoi, p. 78-79, avec ill. coul.
} 


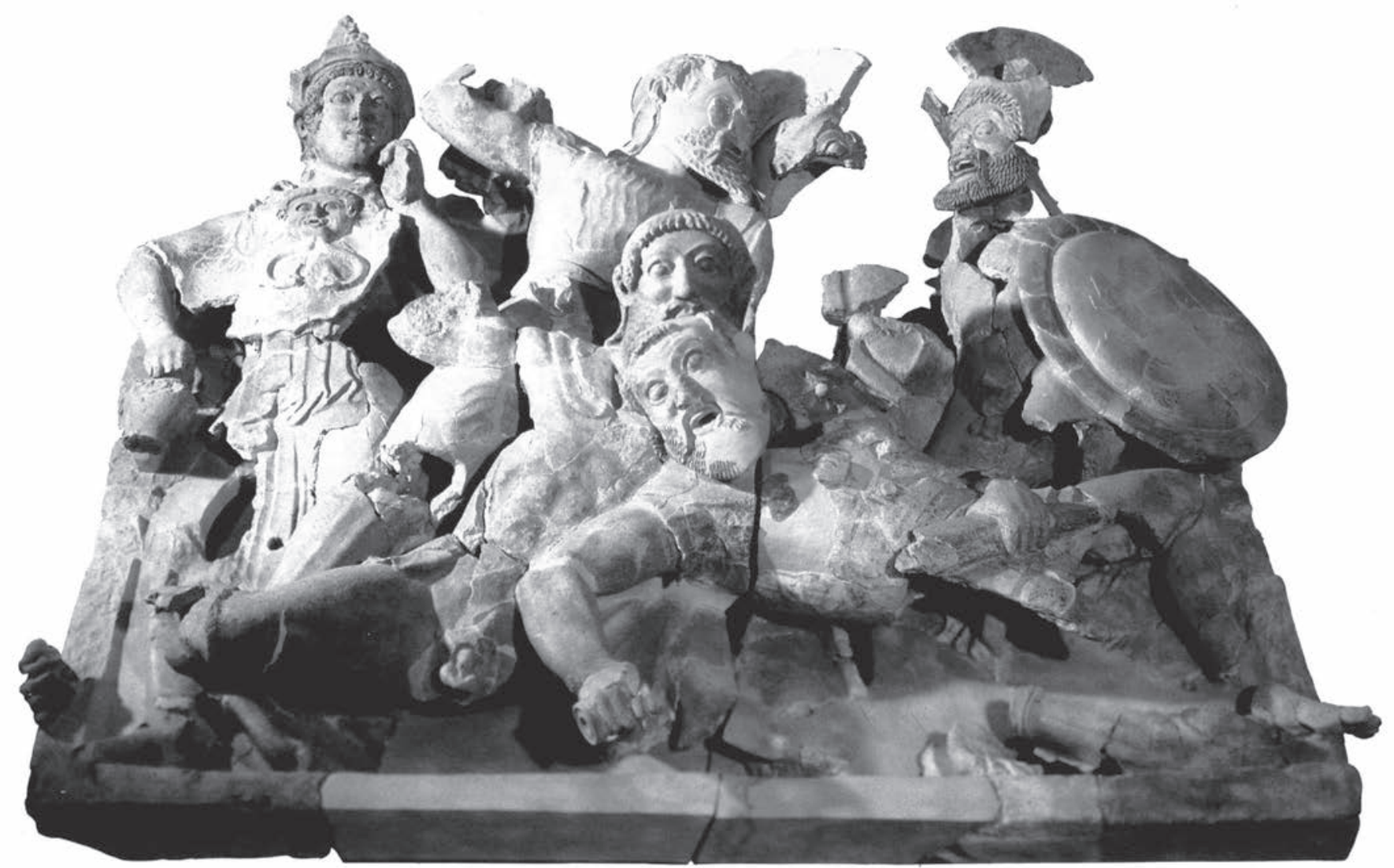

Fig. 2. Rome, Musée de la Villa Giulia, Fronton du temple A de Pyrgi, d'après Pugliese Carratelli 1986, fig. 571.

sol et tué par un guerrier sur le cratère étrusque à figures rouges de l'Ilioupersis ${ }^{7}$ évite en revanche la surenchère mise en scène dans le répertoire grec.

L'interférence entre les registres par le biais d'une transposition des gestes d'une sphère à l'autre offre une autre possibilité d'exprimer le caractère illicite d'une violence extrême. Tel est le cas, par exemple, de la saisie par les cheveux dans des scènes non guerrières comme celle du meurtre par Médée de ses enfants à $1^{\prime}$ autel ${ }^{8}$. La gesticulation des comparses permet elle aussi de caractériser la violence d'une action comme on peut le voir à travers l'agitation et la contorsion des personnages dans la scène de Busiris et Héraclès sur une hydrie de Caere ${ }^{9}$. Une telle violence est en revanche absente du même épisode représenté sur deux vases apuliens ${ }^{10}$, tandis que

7 Cratère de la Villa Giulia : Beazley 1947, pl. 23 p. 94 sq.

8 Cratère à volutes attribué au Peintre des Enfers provenant de Canosa (Munich, Antikensammlungen 3296 (J. 810) ) : Trendall, Cambitoglou 1982, 18/283, pl. 195 ; Pouzadoux 2007, p. 34, fig. 3.

9 Bonaudo 2004, p. 113-120, Cat. 34.

10 Dinos atribué au Peintre de Darius (New York, MMA 1984.11.7) : Laurens 1986, $\mathrm{n}^{\circ}$ 4, p. 148, avec ill. p. 126 ; amphore attribuée au Peintre de Baltimore (jadis marché de l'art Californie) : sur le vase attique c'est la prise par la gorge qui vient marquer le caractère anormal d'une mise à mort qui résulte d'un juste retournement d'une violence contre nature que la victime infligeait à ses hôtes. Cependant, dans le meurtre de Thersite par Achille (fig. 1) ${ }^{11}$ et la mort de Créüse, la gesticulation, qui traduit l'effroi des témoins, ne préjuge pas du caractère légitime ou non de la violence. Celui-ci ressort davantage de l'attitude perplexe ou affectée des témoins que sont les dieux, telle Athéna derrière Tydée sur le fronton de Pyrgi (fig. 2) (Paribeni 1969), et les vieillards, tel Phoenix debout à côté d'Achille sur le cratère apulien.

Plus encore que les éléments mentionnés ci-dessus, c'est le traitement des corps dans l'art étrusque et italiote qui a contribué à construire cette idée d'un goût pour la violence. Le motif le plus emblématique étant

Trendall, Cambitoglou 1983, p. 153, no 404, pl. 28, 2 ; Laurens 1986, $\mathrm{n}^{\circ} 3$, p. 148 , avec ill. p. 126.

11 Cratère à volutes apulien attribué au Peintre du Thersite de Boston (Boston, Museum of Fine Arts, 03.80, Francis Barlett Donation of 1900) : Trendall, Cambitoglou 1982, 17/75, avec bibliographie p. 472 ; Pouzadoux 2009, avec bibliographie antérieure. 
celui des têtes coupées que d'aucuns hésitaient cependant à restituer sur une urne étrusque figurant la légende d'Iphigénie en Tauride ${ }^{12}$. Particulièrement présent en Italie, jusque dans les représentations de la légende de Pélops et d'Hippodamie ${ }^{13}$, le motif n'est cependant pas absent de l'art grec comme on le voit sur plusieurs scènes de la mort de Troïlos ou d'Astyanax ${ }^{14}$. Elle est aussi la marque d'une violence explicite dans les représentations attiques de la mort de Penthée, alors que les peintres de vases italiotes ont préféré suggérer la violence de l'action en mettant l'accent sur la tension de l'agression plutôt que sur le résultat ${ }^{15}$. Si le versement du sang peut paraître parfois emblématique d'une vision italique de la violence, il faudrait voir aussi que celle-ci est caractérisée par la manière dont les héros saignent. L'égorgement de Polyxène sur une amphore «tyrrhénienne $\gg{ }^{16}$ rappelle en outre que les populations italiques n'ont pas l'apanage de la représentation des sacrifices humains comme nous le verrons plus bas.

Les objets peuvent aussi connoter la violence d'une action. La substitution de la machaira à l'épée dans les scènes attiques de la mort de Priam ou de Troïlos est un indicateur du caractère sacrilège de cette exécution. La portée tragique de cet instrument se vérifie dans les représentations italiotes du concours entre Marsyas et Apollon où sa seule présence annonce le supplice de l'écorchement (Denoyelle 1995). Les objets renversés traduisent, quant à eux, un bouleversement spatial indicateur d'un chaos. Tel est le cas des bassins renversés qui marquent un dysfonctionnement ou encore la dispersion et l'accumulation de la vaisselle ou de pièces de mobilier sur le cratère avec la mort de Thersite (fig. 1) ou celui avec la folie d'Héraklès ${ }^{17}$. La combinaison de ces codes permet aux peintres d'Etrurie et de GrandeGrèce de jouer sur le caractère implicite ou non de la violence, comme on peut l'observer dans la Tombe des Taureaux de Tarquinia.

12 Bonfante 1984, fig. IIb et IIIa.

13 Voir par exemple Pipili 1990, nos 12 et 14, p. 436, avec ill.

14 Pour la mort de Troïlos : Kossatz-Deissmann 1981, voir par exemple $\mathrm{n}^{\text {os }} 359 \mathrm{a}, 360,363,364$, p. 87-88, avec ill. Pour celle d'Astyanax : Touchefeu 1984, nos 7 à 24, p. 931-933, avec ill.

15 Comparer les exemplaires attiques avec le corps démembré et les exemplaires apuliens avec le corps en tension : Kossatz-Deissmann 1994, $\mathrm{n}^{\text {os }} 39-44$ (attiques) et $\mathrm{n}^{\text {os }} 3,6-16$, avec ill.

16 Amphore attique «tyrrhénienne » (Londres, B.M. 1897.7-27.2) : Touchefeu-Meynier 1994, n² 26, avec ill. p. 433.

17 Cratère en calice d'Asteas (Madrid, inv. 11 094) : Trendall 1987, 2/127, p. 84, pl. 46.

\section{Suggérer la violence}

Datée de l'époque archaïque, cette sépulture présente, au centre de la paroi du fond de la première chambre, une peinture figurant l'embuscade d'Achille à Troïlos (fig. 3) ${ }^{18}$. La violence d'Achille n'est ici qu'annoncée et suggérée, puisque que le moment même de la mise à mort du jeune troyen n'est pas dépeint. Toutefois cette violence contenue est présente à travers la combinaison de plusieurs des critères que nous avons énumérés.

Le lieu tout d'abord : l'embuscade a lieu, normalement, à la fontaine, Achille est caché derrière une structure construite, surmontée de deux statues de lion. Le lion de droite crache l'eau dans la vasque de la fontaine vers laquelle se dirige le cheval de Troïlos, pour s'abreuver. L'image, toutefois, selon un mode synoptique propre aux peintres des anciens temps - un mode symbolique et non naturaliste -, synthétise deux lieux, correspondant à deux étapes successives de la narration : la fontaine hors des murs de Troie, où a lieu l'embuscade, et l'autel du sanctuaire d'Apollon, où est perpétué le meurtre. Le second lieu est évoqué par la structure en assise de la "fontaine », le profil concave de la partie centrale, encadrée d'une base et d'un couronnement, les décors de volutes symétriques, autant de détails que l'on trouve sur les représentations étrusques d'autels sacrificiels contemporains ${ }^{19}$. Il s'agit donc d'une fontaine-autel, la seconde composante évoquant le sanctuaire d'Apollon où va avoir lieu le meurtre. Ce sanctuaire du dieu est aussi symbolisé, dans l'image, par le palmier, que Troïlos s'apprête à dépasser, ainsi que par tous les petits arbres qui entourent la fontaine-autel et en font comme l'a démontré A. Rouveret un espace consacré, un templum (Rouveret 1988).

Le traitement du corps dénudé de Troïlos, figuré en jeune homme imberbe aux cheveux encore longs, évoque son statut prochain de victime (Cerchiai 1980). En ce qui concerne les gestes et attitudes, la scène est empreinte d'un grand calme, s'opposant à l'agitation de la poursuite et de la mise à mort qui va suivre. L'emploi des objets est aussi notable dans cette scène de violence implicite : Achille, en armes et barbu, brandit une machä̈ra, le couteau sacrificiel, en remplacement de l'épée hoplitique, qu'on s'attend à voir à la main du héros armé de la cuirasse et du casque à cimier (Cerchiai 1980). Tout en étant contenue, la violence s'exprime à travers une série de critères à valeur iconique qui annoncent une action sacrilège : la mise à mort du jeune homme, malgré la protection demandée à Apollon, en se réfugiant dans son sanctuaire.

18 ICAR: http://icarhuma-num.fr/icardb/support.php?idsupport=TARQ73

19 Voir par exemple sur l'hydrie Ricci : Cerchiai 1995. 


\section{Afficher la violence}

Le second exemple, le meurtre de Thersite par Achille (fig. 1), qui réunit plusieurs de ces critères, met en scène une forme explicite de la violence, à travers le traitement du cadavre, l'emploi des objets, la gestuelle des comparses et la réaction des témoins. Gisant au sol, la tête séparée, le cadavre a perdu son humanité. La proximité entre les objets, les pièces en métal du banquet, renversés, et la tête de Thersite place cette dernière sur le même plan que la vaisselle. L'effroi suscité par l'action est exprimé par la fuite de certains personnages. L'intervention d'un héros, qui en retient un autre, introduit une tension et signale une anomalie, sans doute confirmée par l'expression de la douleur de Phoenix, le vieil homme debout à côté d'Achille. Les liens de parenté qui unissent le mort, Thersite, à son cousin, Diomède, permettent de comprendre que sa réaction est motivée par la vengeance. Son action répond à la logique de la loi du talion qui veut que l'on cherche à réparer la violence commise à l'encontre d'un membre du genos. Objet d'effroi et de réaction vive, cette violence sert une réflexion sur le pouvoir comme nous le verrons plus loin.

\section{Le sacrifice humain entre images et pratiques : Grèce/Italie}

L'établissement même d'une typologie de la violence iconique, à partir d'images s'échelonnant entre les $\mathrm{VI}^{\mathrm{e}}$ et le $\mathrm{IV}^{\mathrm{e}} \mathrm{s}$. avant J.-C. et produites par des cultures grecques, étrusques et italiotes, montre que le poncif d'un goût spécifique des populations de l'Italie antique pour les scènes sanglantes, qui les différencient des Athéniens par exemple, doit être nuancé. Qu'il s'agisse des vases attiques archaïques ou classiques, des peintures étrusques archaïques ou des reliefs hellénistiques, ou encore des vases italiotes, aucun n'a l'apanage des scènes de violence, qui se déplacent d'un pôle culturel à l'autre, en fonction des thèmes, sans préférence culturelle a priori. Quelques dossiers cependant, comme celui du sacrifice humain, et plus particulièrement celui des prisonniers troyens, nous invitent à revenir sur le rôle de la violence dans la construction de l'identité sociale, ethnique et culturelle.

La documentation iconographique, assez récente (jamais antérieure au $\mathrm{IV}^{\mathrm{e}} \mathrm{s}$. avant J.-C.), est propre à $1^{\prime}$ Italie ${ }^{20}$ : le sacrifice des prisonniers troyens pour les funé-

20 La bibliographie est très vaste et diffuse sur ces différents monuments. Pour une prise en compte de l'ensemble de la série, voir par exemple Maggiani 1985 et en dernier lieu Rouveret 2002, p. 349 sq. et Weber-Lehmann 2006.

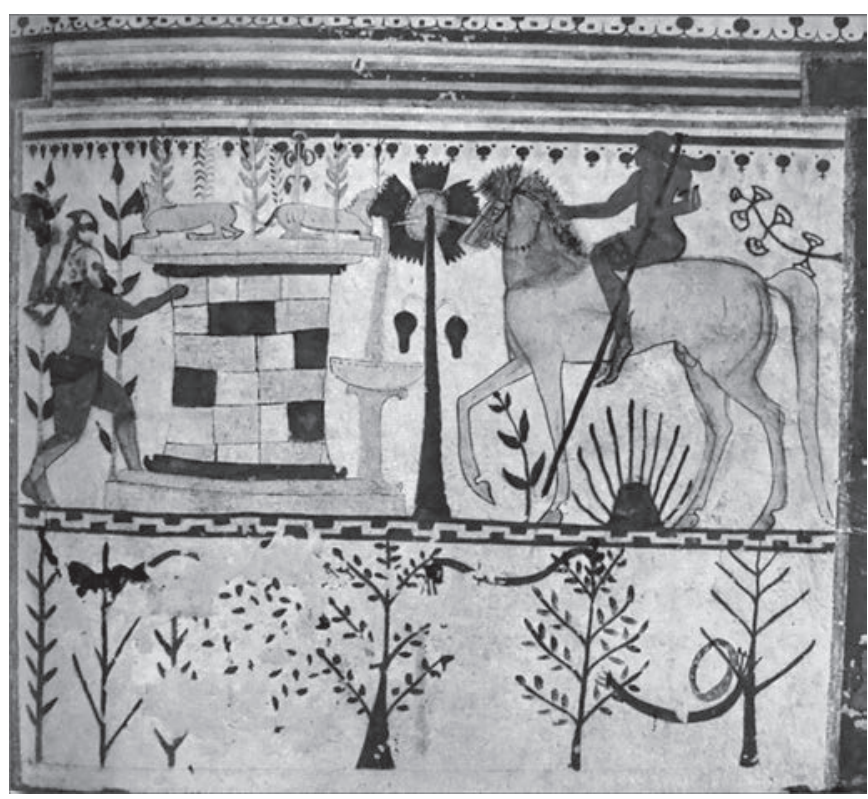

Fig. 3. Tarquinia, Tombe des Taureaux, d'après Pallottino 1952, p. 31.

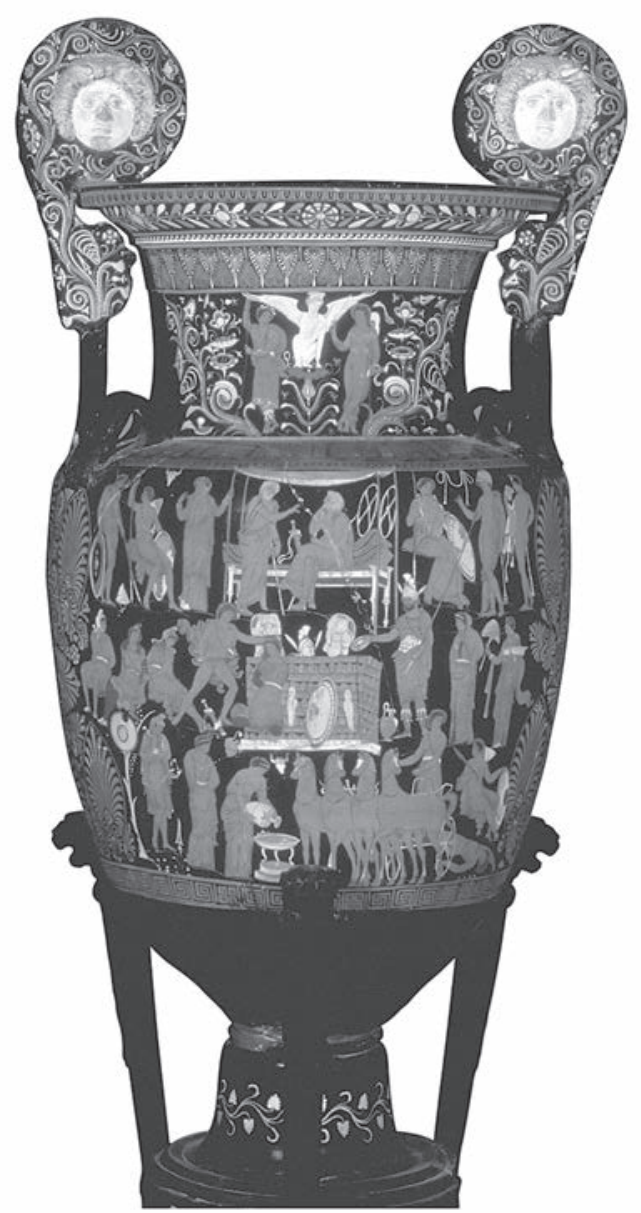

Fig. 4. Naples, Musée Archéologique National, cratère des Funérailles de Patrocle attribué au Peintre de Darius. Photo du musée. 
railles de Patrocle apparaît sur un vase italiote (fig. 4) ${ }^{\mathbf{2 1}}$, le premier de la série, sur cinq œuvres étrusques ${ }^{22}$ et deux latines ${ }^{23}$. Les analyses qui ont été menées de ces huit représentations iconographiques se sont attachées à caractériser l'action dépeinte selon un principe d'opposition entre populations grecques et non grecques. Dès la première moitié du $\mathrm{XIX}^{\mathrm{e}} \mathrm{s}$., on tend à opposer l'art de l'Italie préromaine porté vers ce type de représentations violentes, et celui de la Grèce qui ne l'a jamais mis en image $^{24}$. Des études récentes ont permis de nuancer une telle dichotomie. Rappelons, pour commencer, que c'est en milieu grec, Tarente, que cette scène est représentée la première fois avant d'être transmise à l'Italie centrale et à l'Étrurie. La prise en compte des contextes fait apparaître des différences dans la façon de verser le sang, distinguant les Italiotes (fig. 4) qui effacent la violence de l'acte, des Étrusques où la mise à mort du prisonnier troyen est montrée avec force effusion de sang ${ }^{25}$. Bien qu'elles soient présentes dans la céramique attique, les images grecques de sacrifice humain ${ }^{26}$ n'ont jamais fait l'objet des mêmes commentaires que leurs équivalentes en Italie. Quand on n'explique pas la présence de ces scènes violentes par la destination italienne de ces exportations, on montre qu'elles servent à construire une vision de l'altérité, disqualifiée par sa sauvagerie et sa transgression des lois sacrées. Le recours à la violence de la part des héros grecs est interprété comme une « contreréaction héroïque » comme c'est le cas d'Héraclès qui applique à Busiris le sort que ce roi barbare réservait à ses hôtes (Durand-Lissarrague 1999). On reconnaît que

21 Sur ce cratère du Peintre de Darius, voir en dernier lieu : Pouzadoux 2013.

22 Il s'agit de la Tombe François de Vulci, du Sarcophage peint du Prêtre de Tarquinia, d'une urne de Volterra, du sarcophage de Torre San Severo à Orvieto à reliefs, et du cratère à figures rouges du Cabinet des Médailles de la BNF. Voir Maggiani 1985, p. 210 sq. et en dernier lieu Weber-Lehmann 2006 et infra.

23 Pour le stamnos falisque de Berlin et la ciste prénestine Révil, voir : Maggiani 1985, p. 210 sq.

24 On opposera d'une part Raoul-Rochette 1834 et Michaelis 1871 qui dénoncent le goût prononcé de ces populations pour des épisodes sanglants et pour le pathos, à la différence des Grecs, et d'autre part la position de Beazley 1947 qui tente de réhabiliter le nom étrusque : « before finding fault with the Etruscan, it should be remembered, first, that after all it is taken from the Iliad ; secondly that there are Greek representations ; thirdly, that Virgil himself thought it necessary to imitate Homer and make Aeneas sacrifice eight prisoners to a shade », p. 8.

25 Rouveret 2002, p. 354 sq., pointe la libation de vin faite par Agamemnon, à droite de la mise à mort du Troyen, sur le cratère du Peintre de Darius, détail qui montre une atténuation de la violence par le peintre italiote, dans la mesure où le vin remplace le sang du sacrifice, l'acte de mise à mort en lui même n'étant pas montré. Elle l'oppose ainsi aux scènes étrusques où le poignard est figuré enfoncé dans la gorge du prisonnier.

26 Voir par exemple : Durand-Lissarrague 1999. les images de la violence existent, en Grèce, pour mettre à distance les comportements déviants, tandis qu'elles renvoient, en Italie, à des pratiques réelles.

Il faut pourtant bien admettre, avec S. Georgoudi, que le sacrifice humain " constitue une partie non négligeable de la culture grecque » (Georgoudi 1999, p. 79) ${ }^{27}$. L'analyse qu'A. Schnapp-Gourbeillon a menée du passage du chant XVIII de l'Iliade n'oriente pas non plus vers une condamnation univoque de l'épisode du sacrifice des prisonniers troyens (Schnapp-Gourbeillon 1982). Certes, le poète parle des kaka erga qu'Achille a commis. Mais c'est un comportement que le héros reproduit à d'autres moments de l'Iliade (désigné de la même façon : kaka erga) et qui caractérise la démesure du personnage : «ce n'est donc pas une pratique ponctuelle que condamne Homère, mais bien le personnage d'Achille porteur d'hybris » (Schnapp-Gourbeillon 1982, p. 82). Il ne faut donc pas faire du sacrifice humain, décrit dans l'Iliade, une interpolation mais bien le rattacher au contexte de l'épisode et à l'Iliade dans son ensemble : il marque un détournement et une perversion du rituel funéraire, répondant bien aux actes de cette figure héroïque et semi divine qu'est Achille. Le sacrifice des prisonniers troyens caractérise donc les funérailles de Patrocle, le double d'Achille, comme exceptionnelles (alors que les funérailles d'Hector sont décrites comme «bien humaines »).

On ne peut donc pas opposer deux cultures sur la base de la nature grecque ou non grecque de cet acte. Le clivage réside plutôt dans une vision du pouvoir qui caractérise l'époque archaïque et les communautés étrusques et italiques où l'arbitraire de la violence est non seulement reconnu et revendiqué comme l'apanage des puissants, mais aussi dans certains cas mis à distance.

\section{Violence, pouvoir et funérailles en Italie}

Nel mondo etrusco arcaico l'esercizio della violenza costituisce una delle manifestazioni della superbia dei principes : per questo la sua esibizione è iscritta nei codici culturali della comunità e si presta ad essere evocata dal paradigma eroico di Achille, sancita, in particolare, dal suo diritto 'trionfale' di procedere al sacrificio umano celebrato nei documenti iconografici. L'ostentazione di una pratica che Omero, a proposito di Achille, qualifica con la definizione ambigua di kakà erga, non dipende dalla propensione etnica o, tanto meno, da una ferocia 'barbara'; è piuttosto funzionale al sistema di legittimazione ideologica di una società gentilizia, governata

27 Voir aussi Jost 1995. 
da una oligarchia ristretta, in cui non giunge a compimento la distinzione tra il nomos collettivo della città e il diritto delle gentes, con un sistema 'privato' di relazioni, solidarietà e privilegi che non cessa di esercitare la sua funzione condizionante. Proprio la mancata realizzazione della città in quanto comunità politica può spiegare come la pratica del sacrificio dei prigionieri di guerra intesa come decima trionfale continui a marcare la storia etrusca aldilà dell'età arcaica, come dimostra la sua reiterazione nel Foro di Tarquinia in occasione della guerra contro Roma del 358-51 a.C. (Livio, VII, 15, 10). Ciò non significa che nella società etrusca non sia avvertita la contraddizione tra il privilegio aristocratico della violenza e il consolidamento del sistema di regole e garanzie collettive su cui si sostiene la città; al contrario, il problema informa il programma figurativo di uno dei monumenti più emblematici dell'Etruria tirrenica di età classica: il Tempio A di Pyrgi (fig. 2).

\section{La perplessità di Atena}

Come ha messo in evidenza G. Colonna (Colonna 2002), la costruzione del Tempio A, risalente al 470/60 a.C., si colloca nella temperie politica susseguente alla fine del 'regno' di Thefarie Velianas a Caere, configurandosi come la manifestazione di un nuovo ordine della città: non a caso, la sua collocazione all'interno del santuario di Pyrgi è concepita per ridimensionare e quasi nascondere il più antico Tempio $\mathrm{B}$, simbolo del potere tirannico di Thefarie Velianas esemplificato sul paradigma di Eracle. In questa clima si colloca la rappresentazione del mito dei Sette contro Tebe nel frontone posteriore del tempio, il cui fuoco espressivo non è costituito dal duello fratricida di Eteocle e Polinice riprodotto su uno dei mutuli laterali, ma dall'episodio di Tideo e Melanippo, avvinghiati in una lotta mortale, culminante nell'atto cannibalesco di Tideo che morde il cranio del suo avversario.

La messa in scena dell'episodio riveste il valore 'etico' di condannare l'esercizio arbitrario della violenza, gli effetti irrecuperabili e rovinosi della sua cieca ferocia: nei codici visuali e significativi della rappresentazione artistica tale prospettiva si traduce in una ricerca espressiva che punta all'enfatizzazione del pathos negli schemi compositivi e nella raffigurazione dei caratteri dei personaggi.

Il duello tra eroi ha perso ogni aristeia, regredendo ad una zuffa ferina senza vincitori, sintomo di uno smarrimento della condizione umana che nell'altorilievo frontonale accomuna anche gli altri contendenti fissati nel furore delle espressioni facciali, con le bocche dischiuse in preda alla ferocia e al terrore. Ma, forse, il senso di una tragica perdita di umanità poteva marcare anche l'episodio di Eteocle e Polinice identificabili grazie agli elmi - l'uno, con paragnatidi a corpo di cinghiale, l'altro, con protome di cavallo - che omologano gli eroi ad animali di cui è proverbiale la furia selvaggia. Il gesto di Tideo provoca il ritrarsi inorridito di Atena che porta la mano alla bocca e nasconde l'ampolla d'ambrosia, negandogli l'immortalità: questa prerogativa deriva ad Atena dalla sua natura di divinità astrale legata al fato, secondo una prospettiva cultuale che marca la sua personalità in ambito etrusco, connettendola alla mantica e alle sortes (Colonna 1984).

\section{Homonoia nella Tomba François}

Sulla Tomba François si è sviluppata una progressiva messa a fuoco che ha dato nuova luce e significato al ciclo pittorico ${ }^{28}$.

La tomba si colloca sulla collina di Ponte Rotto in allineamento ideale con il decumano della città, configurandosi simbolicamente come quella della gens fondatrice. Secondo una stessa prospettiva che valorizza le linee di discendenza, al suo interno, nella camera $\mathrm{V}$, sono traslati i resti di una più antica sepoltura a camera pertinente alla famiglia, scavata sopra l'ipogeo. L'immagine di un antenato, forse il padre di Vel Saties, era dipinta sulla chiusura della porta della camera, inquadrata, come in un'edicola, dalle figure di Vel Saties e di un altro membro della famiglia in atto di trarre gli auspici.

Sulla scia degli studi di F. Coarelli, che per primo ha valorizzato il sistema di corrispondenze significative istituite tra le scene dipinte, e di F. Roncalli, che ne ha inaugurato una lettura in chiave etico-politica, D. Musti ha proposto di rileggere il programma pittorico della tomba alla luce del motivo topico della concordial homonoia, valorizzandone la fortuna nella riflessione del mondo greco e romano dalla fine del $\mathrm{V}$ e nel corso del IV sec. a.C. ${ }^{29}$.

Ciò ha portato a ricercare il centro significativo del programma iconografico non nelle scene del cd. 'tablino', ma in quelle dell' 'atrio' e, in particolare, nelle coppie simmetriche e omologhe costituite da Vel Saties e dal suo consanguineo ai lati della camera $\mathrm{V}$ e, sul lato opposto, da Nestore e Fenice, gli anziani consiglieri dell'Iliade, essenziali nel ricomporre la crisi tra Achille e Agamennone che ha compromesso l'unità dei Greci. Essi si caratterizzano per la capacità di sapere interpretare i

28 Sulla tomba e il suo contesto: Buranelli 1987, Sgubini Moretti 2004; per lo studio del programma figurativo: Coarelli 1983, Roncalli 1987, Colonna 2003, D’Agostino 2003, Maggiani 2005, Musti 2005. 29 Musti 2005; secondo una non dissimile prospettiva Colonna 2003 e Maggiani 2005. 
segni, per una pronoia che riesce a indirizzare il futuro: per questo si contrappongono alle figure di Anfiarao e Cassandra, gli indovini inascoltati ugualmente rappresentati nell' atrio'. In questa chiave di lettura acquista una specifica pregnanza il gruppo di Eteocle e Polinice, già rifunzionalizzato nel Tempio A di Pyrgi per il suo valore di exemplum. Esso introduce una prospettiva fratricida nella saga della liberazione di Celio Vibenna da parte del fratello Aulo e del sodale Mastarna attraverso il rapporto di omologia istituibile con il gruppo di Marce Camitlnas e Cnaeve Tarchunias Rumach raffigurato in posizione speculare sul lato opposto dell' 'atrio'.

La scena storica si configura come l'episodio finale di un conflitto intestino alle città etrusche per il controllo di Roma e, in questa ottica, B. d'Agostino si riferisce ai fratelli Vibenna come ad "eroi della metis" e al loro gruppo come a una "banda di sodales": l'attacco vincente non è, infatti, rappresentato come un'azione eroica ma come un agguato notturno, rivolto contro avversari disarmati e inermi. Nella prospettiva storica di lungo periodo messa in campo nel programma iconografico la vittoria dei fratelli Vibenna non è risultata decisiva per volgere a favore degli Etruschi i rapporti con Roma e, dunque, si carica della marca negativa della violenza, esplicitata anche in questo caso a livello dei codici visuali del linguaggio pittorico attraverso la tensione esasperata dei corpi nello spasimo dell'agonia, le armi che affondano nelle carni e il sangue che sgorga copioso dalle ferite.

Il sacrificio dei prigionieri troiani è considerato dalla maggior parte degli studiosi come il contraltare giusto della lotta fratricida dei fratelli Vibenna, reduplicata sul piano mitico da quella di Eteocle e Polinice, perchè ripristina l'unità e l'homonoia dei Greci attraverso il giusto esercizio della vendetta per la morte di Patroclo. $\mathrm{Va}$, però, ricordato come $\mathrm{D}$. Musti, anche in questa prospettiva, abbia sottolineato l'esistenza di uno scarto tra una legittima poine e l'uso gratuito della violenza che si intravede nel gesto di tirare per i capelli il prigioniero troiano eseguito da Aiace Oileo, eroe che non a caso si macchia di hybris sacrilega nel rapimento e oltraggio di Cassandra. B. d'Agostino procede più oltre e suggerisce che l'intera scena mitica di sacrificio sia denotata dalla stessa prospettiva critica di quella storica ad essa speculare: secondo lo studioso la condanna riguarda proprio il comportamento trasgressivo di Achille che non si limita a uccidere i prigionieri ma giunge a sacrificarli. Da questo comportamento che oltrepassa la legittima misura scaturisce la condanna di Apollo, la cui presenza è evocata dalle piante di palma poste dietro Nestore e Fenice, consiglieri saggi tra i pochi ammessi nell' Iliade (XIX 311) alla veglia funebre per Patroclo.

Di fronte all'insufficienza della cieca violenza che marca il comportamento di un eroe antico come Achille, la soluzione viene piuttosto dalla capacità politica, dal lasciarsi ispirare dai segni giusti, come fa Vel Saties, lo sguardo assorto rivolto verso l'alto a interpretare l'auspicio ${ }^{30}$.

La capacité d'Achille à poser la question de l'arbitraire de la violence est également visible sur le cratère apulien de Boston avec la mort de Thersite (fig. 1). La disposition, de part et d'autre de l'édicule, de deux groupes qui représentent apparemment deux visions antinomiques de la justice, la loi du Talion d'une part (avec Pan et Poinè à gauche), et le jugement divin d'autre part (avec Athéna et Hermès à droite), livre une vision des contradictions du pouvoir fondé sur le recours autant inévitable que problématique à la violence pour rétablir l'ordre au sein du groupe.

\section{En conclusion : rites étrusques et consolations romaines}

Les usages allégoriques de la violence dans les rituels funéraires romains nous permettront de clore ce parcours qui nous a conduit de la Grèce à l'Étrurie en passant par la Grande-Grèce.

Pour expliquer la fréquence des scènes sanglantes sur les urnes et les sarcophages étrusques de l'époque hellénistique, plusieurs auteurs (Steuernagel 1998 ; De Angelis 1999) ont invoqué des nécessités rituelles dans lesquelles les sacrifices divinisants, rapportés par les textes, jouent un rôle lors les funérailles étrusques (Steuernagel 1998). Le sacrifice de Troïlos et celui d'Iphigénie sur les reliefs funéraires hellénistiques pourraient se référer à cette pratique sacrificielle, qui au quotidien n'utilisait que des animaux mais qui, dans certains cas exceptionnels, auxquels fait allusion la tradition littéraire, a pu concerner des prisonniers de guerre. Il est possible que la Tombe des Taureaux avec l'embuscade d'Achille à Troïlos (fig. 3) ait déjà voulu évoquer le sacrifice humain lié aux nécessités du rituel funéraire. Le répertoire mythologique des reliefs hellénistiques offrait plus largement, avec les duels fratricides (Etéocle et Polynice), les infanticides et les matricides (Iphigénie

30 Vale allora la pena di citare D’Agostino 2003, p. 108-09: "Vel Saties prende le distanze da quanto dicono i dipinti del tablinum, ponendo sullo stesso piano quanto è narrato nella scena storica. L'evocazione dei due saggi [Nestore e Fenice], portatori di pace, è rafforzata dalla presenza della palma : in essa è un richiamo alla saggezza delfica. L'allusione al comportamento trasgressivo di Achille e al triste destino riservato da Apollo implicano un incitamento al senso della misura, che deve essere guida nell'azione politica come nella guerra. Di queste virtù si fa paladino Vel Saties, in un momento in cui le vicende evocate dai dipinti dovevano essere ridiventate di tragica attualità a causa dello scontro con Roma". 
ou de Clytemnestre), une série de contre-exemples nécessaires à l'exaltation de la piété familiale et des liens d'amitié, mobilisés au moment de la mort d'un proche. À l'appui de cette explication donnée à l'usage de mythes grecs dans l'iconographie funéraire étrusque, F. De Angelis cite un passage des Fastes d'Ovide (II, 617-632), qui, de la même manière, quelques siècles plus tard, énumère le comportement condamnable de héros de la mythologie, précisément au moment des funérailles (De Angelis 1999):

«Bien sûr, quand on quitte les tombeaux et les proches qui ont disparu, on est heureux de reporter tout de suite ses regards sur les vivants, de voir, après tant de pertes, ce qui reste de notre sang et de compter les différentes générations. Pour venir il faut être pur : loin d'ici, oui, loin d'ici le frère impie, la mère cruelle envers sa progéniture, le fils qui trouve trop longue la vie de son père ou qui compte les années de sa mère, la belle-mère qui opprime injustement la bru qui lui est odieuse. Ici sont indésirables les deux frères, petits-fils de Tantale, l'épouse de Jason, celle qui remit aux paysans des semences grillées, Procné et sa sœur ainsi que Térée, leur bourreau à toutes deux, enfin quiconque recourt au crime pour augmenter sa fortune $»^{31}$.

\section{Bibliographie}

Ando et Cusumano 2010 : ANDO (V.), CUSUMANO N. (ÉD.) - Come bestie : forme e paradossi della violenza tra mondo antico e disagio contemporaneo, Caltanissetta, Roma, 2010 (Mathesis / Centro interdipartimentale Formedi produzione e trasmissione del sapere nelle società antiche e moderne dell’Università degli studi di Palermo ; 4).

Bats 1997 : BATS (M.) - Identité ethno-culturelles et espace en Gaule méditerranéenne (principalement aux $\mathrm{V}^{\mathrm{e}}$ et IVe siècles av. J.-C.). Confini e frontiera nella Grecità d'Occidente : atti del trentasettesimo convegno di studi sulla Magna Grecia, Taranto 3-6 ottobre 1997, Tarente, 1999, 409 p.

Beazley 1963 : BEAZLEY (J.D.) - Attic Red-figured Vase-Painters, $2^{e}$ éd., Oxford, 1963.

Beazley 1947 : BEAZLEY (J.D.) - Etruscan Vase Painting, Oxford, 1947 (Oxford monographs on classical archaeology, 1).

Beltrametti 2004 : BELTRAMETTI (A.) - Pensare, raccontare e rappresentare la violenza. Anche questo abbiamo imparato dai Greci ? Quaderni di Storia, 2004, 60, p. 5-45.

Bertrand 2005: BERTRAND (J.-M.) (ÉD.) - La violence dans les mondes grec et romain : actes du colloque international, Paris, 2-4 mai 2002, Paris, 2005. Bonaudo 2004 : BONAUDO (R.) - La culla di Hermes. Iconografia e immaginario nelle hydriai ceretane, Roma 2004.

Bonfante 1984 : BONFANTE (L.) - Un'urna chiusina con « têtes coupées » a New York. Studi di antichità in onore di Guglielmo Maetzke, Rome, 1984, p. 143-150.

Bonnechère 1999 : BONNECHERE (P.) - Le sacrifice humain en Grèce ancienne, Athènes-Liège, 1994.

31 Traduction R. Schilling, Ovide. Les Fastes, Tome I, Livres I-III, Paris, Les Belles Lettres, 1992, p. 52-53.
Buranelli 1987 : BURANELLI (F.) (ÉD.) - La Tomba François di Vulci, Rome, 1987.

Cerchiai 1980 : CERCHIAI (L.) - La màchaira di Achille : alcune osservazioni a proposito della « Tomba dei Tori ». AION(archeol), 2, 1980, p. 25-39, repris dans D'AGOSTINO (B.) et CERCHIAI (L.), Il mare, la morte, l'amore. Gli Etruschi, i Greci e l'immagine, Rome-Paestum, 1999, p. 91-106.

Cerchiai 1995 : CERCHIAI (L.) - Il programma figurativo dell'hydria Ricci. AK, 38, 1995, p. 81-91.

Chazalon, Wilgaux 2008-2009 : CHAZALON (L.), WILGAUX (J.) Violences et transgressions dans le mythe de Térée. AIONArchStAnt, Nuova Serie N. 15-16, p. 167-189.

Coarelli 1983: COARELLI (F.) - Le pitture della Tomba François a Vulci. Una proposta di lettura. DArch III S., 1, 1983, p. 43-69.

Colonna 1984: COLONNA (G.) - Athena/Menerva. LIMC II, 1984 p. $1050-1074$.

Colonna 2002: COLONNA (G.) - Il santuario di Pyrgi dalle origini mitistoriche agli altorilievi frontonali dei Sette e di Leucotea. ScAnt 10, 2000 (2002), p. 251-336

Colonna 2003: COLONNA (G.) - I rapporti tra Orvieto e Vulci dal Villanoviano ai fratelli Vibenna. DELLA FINA (G. M.) (ed.), Tra Orvieto e Vulci. Atti X Convegno Internazionale sulla storia e l'archeologia dell'Etruria, Orvieto 2002. AnnFaina, X, 2003, p. 511-24.

D'Agostino 2003 : D'AGOSTINO (B.) - Appunti in margine alla Tomba François di Vulci. Minetti A. (éd.), Pittura Etrusca. Problemi e prospettive, Sienne, 2003, p. 100-110.

De Angelis 1999 : DE ANGELIS (F.) - Tragedie familiari. Miti greci nell'arte sepolcrale etrusca. F. de Angelis et S. Muth (éd.), Im Spiegel des Mythos. Bilderwelt und Lebenswelt. Lo specchio del mito. Immaginario e realtà, Symposium, Rome, 19-20 février 1998, Wiesbaden, 1999 (Palilia, 6), p. 53-66. Denoyelle 1995 : DENOYELLE (M.) - Iconographie mythique et personnalité artistique dans la céramique protoitaliote, dans Modi e funzioni del raconto mitico nella ceramica greca italiota ed etrusca dal VI al IV secolo A.C. Atti del Convegno Internazionale (Raito di Vietri sul Mare, 29/31 maggio 1994), Salerne, 1995 (Centro Studi Salernitani « Raffaele Guariglia », Atti dei Convegni, 3), p. 83-101.

Durand-Lissarrague 1999 : DURAND (J.-L.), LISSARRAGUE (F.) Mourir à l'autel. Remarques sur l'imagerie du « sacrifice humain » dans la céramique attique. Archiv für Religionsgeschichte, 1, 1999, p. 83-106.

Farnoux 1992 : FARNOUX (A.) - s.v. Lykourgos I, LIMC VI, Munich, Zurich, 1992, p. 309-319.

Fischer et Moraw 2005 : FISCHER (G.), MORAW (S.) (éd.) - Die andere Seite der Klassik. Gewalt im 5. Und 4. Jahrhundert v. Chr., Kulturwissenschaftliches Kolloquium Bonn, Kunst- und Ausstellungshalle der Bundesrepublik Deutschland, 11.-13 Juli 2002, Stuttgart, 2005.

Georgoudi 1999 : GEORGOUDI (S.) - A propos du sacrifice humain en Grèce ancienne : remarques critiques. Archiv für Religionsgeschichte, 1, 1999, p. 61-82. Gruzinski, Rouveret 1976 : GRUZINSKI (S.), ROUVERET (A.) - Ellos son como niños. Histoire et acculturation dans le Mexique colonial et l'Italie méridionale avant la romanisation. MEFRA, 88-1,1976, p. 159-219.

Jost 1995 : JOST (M.) - Les sacrifices humains ont-ils existé ? L'histoire, 191, 1995, p. 12-14.

Kossatz-Deissmann 1981 : KOSSATZ-DEISSMANN (O.) - s.v. Achilleus, LIMC, I, Munich, Zurich, 1981, p. 37-200.

Kossatz-Deissmann 1994 : KOSSATZ-DEISSMANN (O.) - s.v. Pentheus, LIMC, VII, Munich, Zurich, 1994, p. 306-317.

Laurens 1984 : LAURENS (A.-F.) - L'enfant entre l'épée et le chaudron, DHA, 10, 1984, p. 203-25.

Laurens 1986 : LAURENS (A.-F.) - s.v. Bousiris, LIMC, III, Munich, Zurich, p. 147-152.

Maggiani 1985 : MAGGIANI (A.) (éd.), Artigianato artistico. L'Etruria settentrionale interna in età ellenistica, Milano, 1985.

Maggiani 2005: MAGGIANI (A.) - Eteocle nella Tomba François. ADEMBRI (B.) (ed.), AEIMNESTOS. Miscellanea di studi per Mauro Cristofani, Firenze 2005, p. 599-610.

Masseria et Loscalzo 2011 : MASSERIA (C.), LOSCALZO (D.) (éd.) - Miti di guerra, riti di pace. La guerra e la pace : un confronto interdisciplinare. Atti del Convegno (Torgiano 4 maggio 2009 e Perugia 5-6 maggio 2009), Bari, 2011. 
Michaelis 1871 : MICHAELIS (A.) - Il funerale di Patroclo. Anfora canusina del museo nazionale di Napoli. AnnInst, 43, 1871, p. 166-195.

Musti 2005 : MUSTI (D.) - Temi etici e politici nella decorazione pittorica della Tomba François. Dinamiche di sviluppo delle città nell'Etruria meridionale : Veio, Caere, Tarquinia, Vulci : atti del XXIII Convegno di studi etruschi ed italici, Roma, Veio, Creveteri, Pyrgi, Tarquinia, Tuscania, Vulci, Viterbo, 1-6 ottobre 2001, Pise, Rome, 2005, p. 485-508.

Muth 2008 : MUTH (S.) - Gewalt im Bild. Das Phänomen der medialen Gewalt im Athen des 6. und 5. Jahrhunderts v. Chr., Berlin, 2008.

Nostoi : NOSTOI. Capolavori ritrovati, mostra Roma, Palazzo del Quirinale, 21 dicembre 2007-2 marzo 2008, Rome, 2007.

Pallottino 1952 : PALLOTTINO (M.) - La peinture étrusque, Genève, 1952. Paribeni 1969: PARIBENI (E.) - La perplessità di Atena. Per una corretta lettura del frontone di Pyrgi. ArchClass, 21, 1969, p. 53-57.

Pipili 1990 : PIPILI (M.) - s.v. Hippodameia I, LIMC, V, Zurich, Munich, 1990, p. 434-440.

Pouzadoux 2007 : POUZADOUX (CL.) - Médée tragique dans la peinture apulienne. Bercoff (B.), Fix F. (éd.), Mythes en images : Médée, Orphée, Edipe, Éditions Universitaires de Dijon, Dijon, 2007, p. 25-40.

Pouzadoux 2009 : POUZADOUX (CL.) - Mythe et culture politique dans la peinture apulienne. M. Osanna (éd.), Verso la città. Forme insediative in Lucania e nel mondo italico fra IV e III sec.a.C.: atti delle giornate di studio, Venosa, 13-14 maggio 2006, Venosa, 2009, p. 23-39.

Pouzadoux 2013 : POUZADOUX (CL.) - Éloge d'un prince daunien. Mythe et image en Italie méridionale au IVe siècle av. n. è. Roma, EFR, 2013 (BEFAR, 352).

Pugliese Carratelli 1986 : PUGLIESE CARRATELLI (G.) (éd.) - Rasenna. Storia e Civiltà degli Etruschi, Milano 1986.

Raoul-Rochette 1834 : RAOUL-ROCHETTE (D.) - Lettre à M. le professeur Eduard Gerhard sur deux vases peints de style et de travail étrusques, publiés dans les Monuments inédits de l'Institut archéologique (t. II, pl. VIII et IX). Annales de l'Institut de correspondance archéologique, 1834, p. 264-294.

Roncalli 1987: RONCALLI (F.) - La decorazione pittorica. In : Buranelli (F.) (éd.), La Tomba François di Vulci. Rome, 1987, p. 79-110.

Rouveret 1988 : ROUVERET (A.) - Espace sacré/Espace pictural : une hypothèse sur quelques peintures archaïques de Tarquinia. AIONArchStAnt, 10, 1988, p. 203- 215.
Rouveret 2002 : ROUVERET (A.) - Figurer le corps ennemi : quelques remarques sur le thème du sacrifice des prisonniers troyens dans l'art funéraire étrusque et italique au $\mathrm{IV}^{\mathrm{e}}$ siècle av. J.-C. In Identités et cultures dans le monde méditerranéen antique. Études réunies par C. Muller et F. Prost en l'honneur de F. Croissant, Paris, 2002, p. 245-366.

Schmidt 1992 : SCHMIDT (M.) - s. v. Medeia, LIMC, VI, Munich, Zurich, 1992, p. 386-398.

Schnapp-Gourbeillon 1982 : SCHNAPP-GOURBEILLON (A.) - Les funérailles de Patrocle. In Gnoli (G.), Vernant (J.-P.) (éd.), La mort, les morts dans les sociétés anciennes, Paris, Cambridge, 1982, p. 77-88

Seidensticker et Vöhler 2006 : SEIDENSTCKER (B.), VÖHLER (M.) (éd.) - Gewalt und Asthetik. Zur Gewalt und ihrer Darstellung in der griechischen Klassik, Berlin, 2006.

Sgubini Moretti 2004: SGUBINI MORETTI (A. M.) (ed.) - Eroi Etruschi e Miti Greci. Gli affreschi della Tomba François ritornano a Vulci. Catalogo mostra, Vulci 2004, Roma 2004.

Steuernagel 1998 : STEUERNAGEL (D.) - Menschenopfer und Mord am Altar : griechische Mythen in etruskischen Gräbern, Roma, 1998 (Palila, 3).

Touchefeu 1984 : TOUCHEFEU (O.) - s.v. Astyanax I, LIMC, I, Munich, Zurich, 1984, p. 929-937.

Touchefeu-Meynier 1994 : TOUCHEFEU-MEYNIER (O.) - s.v. Polyxene, LIMC, VII, Munich, Zurich, 1994, p. 431-435.

Trendall 1987 : TRENDALL (A. D.) - The Red-Figured Vases of Paestum, Rome, 1987.

Trendall, Cambitoglou 1982 : TRENDALL (A. D.), CAMBITOGLOU (A.) The Red-figured Vases of Apulia, Volume II, Late Apulian, Oxford, 1982.

Trendall, Cambitoglou 1983 : TRENDALL (A. D.), CAMBITOGLOU (A.) - First Supplement to The Red-figured Vases of Apulia, Londres, 1983 (BICS, supplement 43).

Vasi antichi : Vasi antichi museo archeologico nazionale di Napoli, Napoli, 2009.

Weber-Lehmann 2006 : WEBER-LEHMANN (C.) - Das Trojaneropfer in Etrurien : ein griechischer Mythos und seine Inszenierung in der etruskischen Sepulkralkunst. In: Günther (L.-M.), Oberweis (M.) (éd.) - Inszenierungen des Todes : Hinrichtung - Martyrium - Schändung, Berlin ; London, 2006, p. 19-32.

Zimmermann 2009 : ZIMMERMANN (M.) (éd.) - Extreme Formen von Gewalt in Bild und Text des Altertums, Munich, 2009. 



\title{
Mondo greco occidentale ed Etruria. Il tema di "Hercle alla fonte" nella glittica
}

\author{
Dr. PhD Laura Ambrosini \\ Ricercatore \\ Istituto di Studi sul Mediterraneo Antico (ISMA) \\ Consiglio Nazionale delle Ricerche (CNR) - Roma - Italia
}

\section{Riassunto}

Tra le gemme considerate greco-occidentali è stato possibile identificare e ritrovare a Londra una gemma, uno scarabeo d'agata tagliato, con la raffigurazione di Hercle che raccoglie acqua da una fonte con un'anfora. La gemma reca l'iscrizione già identificata come greca e letta aióva (CIG 7317) (“sgorga!") interpretata come l'ingiunzione rivolta dall'eroe alla fonte. Nello studio si propone di identificare l'iscrizione come etrusca (come già fatto da H. Rix negli Etruskische Texte) e di leggerla aithna. Il termine aithna potrebbe essere identificato con quello di Aitne, ninfa di Sicilia, eponima della città di Aitna e del vulcano; in questo caso la ninfa sarebbe collegata alla Sicilia orientale, non contemplata nella cartina di distribuzione dei luoghi relativi alle "acque di Ercole", edite anche di recente. Il dato è rilevante perché lo scarabeo potrebbe essere stato realizzato da un artigiano greco (proveniente dalla Sicilia?) operante in Etruria proprio durante l'età di Ierone, fondatore di Aitna. Il confronto stilistico con il noto scarabeo di Parigi, rinvenuto in Etruria, con l'iscrizione eruchs (Erice) raffigurante un perfetto atleta, ci sembra documentare il lavoro in Etruria di artigiani greci, che inseriscono nella "nuova" realtà locale miti e tradizioni della loro terra d'origine, adattandoli alla cultura locale di età tardo arcaica.

Parole chiave: gemma, Hercle, fonte, anfora, ninfa, Sicilia, Aitna, Etruria, monete, specchio

\section{Résumé}

Parmi les gemmes considérées comme provenant de l'Occident grec, nous avons été en mesure d'en identifier une à Londres. Il s'agit d'un scarabée d'agate coupé, avec la représentation de Hercle qui recueille l'eau d'une source avec une amphore. La gemme possède une inscription déjà identifiée comme grecque, et lue aióva (CIG 7317) (« jaillit! »), interprétée comme un ordre donné par le héros à la source. Dans cette étude, on propose d'identifier l'inscription comme étrusque (comme cela a été fait par H. Rix dans Etruskische Texte) et de la lire aithna. Le terme aithna pourrait être identifié avec celui de Aitna, nymphe de la Sicile, éponyme de la ville de Aitna et du volcan. Dans ce cas, la nymphe serait reliée à la Sicile orientale, localisation non définie par la carte de diffusion des places liées aux « eaux d'Hercule », publiée récemment. La découverte est importante parce que le scarabée a peut-être été fait par un artisan grec (provenant de la Sicile ?) travaillant en Étrurie à l'époque de Hiéron, fondateur de Aitna. La comparaison stylistique avec la gemme de Paris, trouvée en Étrurie, avec l'inscription eruchs (Eryx), montrant un athlète parfait, nous semble documenter le travail des artisans grecs en Étrurie, qui inscrivent dans la «nouvelle situation des mythes et des traditions de leur patrie, s'adaptant euxmêmes à la culture locale de l'époque.

Mots-clés : gemme, Hercle, fontaine, amphore, nymphe, Sicile, Aitna, Étrurie, monnaie, miroir 


\section{La gemma del British Museum}

$\mathrm{Nel}$ mondo etrusco-italico Hercle è raffigurato in connessione con anfore e sorgenti su oggetti d'uso legati al simposio (candelabri ed oinochoai di bronzo di V-IV sec. a.C.) e all'ambito dell'ornamento personale o della toilette (gemme, specchi incisi ed intagli in osso; Gilotta 2003, p. 26-27).Tra le gemme con la raffigurazione di Hercle alla fonte ve n'è una particolarmente interessante, considerata, finora, greco-occidentale (lo scarabeo d'agata, è compreso nel LIMC per ben due volte, sia sotto la voce Herakles che sotto quella Hercle).

Già conservata nella Dattilioteca di Filippo Buonarroti a Firenze (Reinach 1895, p. 52, II, 14, 4), è stato possibile identificarla e rintracciarla nel British Museum di Londra $^{1}$ (fig. 1), al quale fu donata da Richard Woollett nel 1949. Di essa esiste anche una pasta vitrea moderna conservata Berlino (nr. 532) ${ }^{2}$.

La gemma è stata ricavata tagliando uno scarabeo di agata, alto 1,9 cm e largo $1,27 \mathrm{~cm}$ (fig. 2).

Di essa conosciamo delle belle riproduzioni grafiche edite dal A.F. Gori nel 1731-1733, ed in seguito da R.E. Raspe e J. Tassie nel 1791, da G. Micali nel 1832, e da A.L. Millin nel 1840 e da S. Reinach nel 1885 (Ambrosini 2011, p. 28, fig. 16c-d-e-f-g). Del calco realizzato da T. Cades possediamo una bella fotografia (fig. 3) conservata presso l'Istituto Archeologico Germanico di Roma, realizzata nel 1913 per l'Istituto dal fotografo Faraglia ${ }^{3}$.

Sulla gemma è raffigurato Hercle stante, con la clava, nell'atto di raccogliere acqua con un' anfora presso una fonte a protome leonina che sgorga da una roccia ${ }^{4}$.

La forma dell' anfora potrebbe richiamare quella delle anfore corinzie A (Koehler 1979), massaliote ${ }^{5}$, "ionico marsigliesi" (Slaska 1990, p. 228, fig. 4, 229-231) o di Lipari (Slaska 1990, p. 230, fig. 5) e di altre anfore diffuse sia in Etruria che in Sicilia nei primi decenni del V sec. a.C. o raffigurate nella ceramica e, in genere, nelle opere di stile severo. È quasi identica a quella raffigurata su un'altra gemma con la medesima scena e l'iscrizione hercle, conservata a Braunschweig (Ambrosini 2011, p. 25, n. 13). La forma dell'anfora, tuttavia, nello spazio limitato della gemma, è necessariamente stilizzata e

1 Inv. nr. 1949.7-12.2; cf. Ambrosini 2011, p. 27-28, n. 19.

2 Winckelmann 1760, p. 286-287, n. 1766; Roscher 1884, p. 2237. 3 Coll. Cades 24 IIIA 199 Ist. Neg. 5096.

4 Le protomi di leone, com'è noto, sono consuete nelle fontane pubbliche dell'antichità, a cominciare dalla fontana raffigurata sul vaso François e identificata dall'iscrizione krene (cf., ad esempio, Iozzo 2003, p. 17).

5 Tipo Bertucchi 2 - tipo Bertucchi 3 (Bertucchi 1990, p. 17, fig. 1). risulta pertanto impossibile attribuire il vaso ad un tipo e ad una produzione specifica ${ }^{6}$.

La gemma reca un'iscrizione la cui lettura ed interpretazione può aprire forse nuove prospettive nello studio del tema di Hercle alla fonte, ampiamente diffuso nel bacino del Mediterraneo.

Lo scarabeo di Londra mostra delle analogie stilistiche con quello conservato a Parigi - Cabinet des Médailles (fig. 4) proveniente dall'Etruria, con l'iscrizione eruchs (Erice) ${ }^{7}$. In esso, il re degli Elimi, eponimo del monte e del famoso santuario di Afrodite in Sicilia, che sfidava al pugilato e alla lotta i viandanti, ucciso da Herakles, è raffigurato come un perfetto atleta, con tutto il suo strumentario: halteres, disco, strigile ed aryballos. Questo scarabeo appare collegato alle gemme greche del Dry Style che recano la raffigurazione dell'atleta con il disco ${ }^{8}$. In effetti, per raffigurare l'eroe si utilizza una stock-figure di tipo atletico, alla quale viene aggiunta la didascalia con il nome. Ingrid Krauskopf si chiede se, con l'immagine di un mostro come Erice sullo scarabeo, certamente non un esempio di virtù, l'artigiano etrusco abbia voluto raffigurare l'eroe eponimo della sua terra d'origine (Krauskopf 1999, p. 415).

\section{L'iscrizione e la sua interpretazione}

La gemma di Londra reca un'iscrizione (fig. 5), comunemente identificata come greca e letta aióva, come tale, edita nel Corpus Inscriptionum Graecorum 7317, p. $91^{9}$.

Cerchiamo di ripercorrere brevemente le principali letture che ne sono state finora date dal ' 700 ad oggi. Il Gori, dopo aver descritto la gemma, all'epoca in possesso di Filippo Buonarroti, ricorda le fonti classiche (Pausania, Erodoto etc...) che mettono in connessione Herakles con le fonti d'acqua termale presso le quali l'eroe si ristora dopo le fatiche (Gori 1731-1733, p. 38-41, tav. XIV.IV). Legge l'iscrizione AIONA e la collega al

\footnotetext{
6 Ringrazio l'amico Jean-Christophe Sourisseau per avermi confermato questo dato.

7 Ambrosini 2011, p. 72, n. 120, con bibl. cit., fig. 110.

8 Cf., ad esempio, Boardman 1968, p. 82, n. 215, tav. XIV.215; Ambrosini 2011,p. 97.

9 "AIONA Aió $\nu \alpha$. In gemma, in qua Hercules clavae innixus, dextera amphorram tenens, qua aquam manantem de fonte excipit; edidit Gorius Mus. Florent. T. II. p. 38. Tab. XIV. N. 3. Winkelm. Gemm. Stosch. II. 1767. Tractavit Villisonus Mém. De l'Inst. Hist. Et litt. Ant. T. II. 1815 p. 148 sqq. Citarunt R. Rochettus Lettre à M. Schorn ed. alt. p. 117 Com. de Clarac Catal. des art.p. 39. Si vera lectio, videtur acclamatio esse: utere aspersione. Aiovầ est aspergere. Hercules usus est thermis, et dum aqua calida lavatur, ad spergit sese frigida. Villoisonus Aiovâ esplica ad fontem referens: "hic fons aspergit". AITNA restitutum ivit Rochettus, cui adstipulatur Gerhardus Auserlesene Vasenbilder II. p. 862. n. 7. Fortasse recte".
} 
verbo aıovó $\omega$, privo della lettera $\Omega$ finale, nel senso del lat. aspergo, perfundo. Il Gori spiega che Herakles, come se fosse un amuleto, si rivolge alla fonte prima di essere iniziato da Eumolpo al culto di Cerere. Propone poi una tesi alternativa, nel caso in cui l'iscrizione fosse letta da qualcuno $\mathrm{AI} \Omega \mathrm{NA} \Sigma$, saecula. In questo caso spiegherebbe la favola empia dell'eretico Valentino; seguono ulteriori collegamenti con Marcione e il trattato Abraxas, che mettono in evidenza aspetti relativi alla superstizione e alla funzione taumaturgica delle gemme, presto smentita da Simone Ballerini.

Il Ballerini nel 1743 sospetta della falsità dell'iscrizione: "vox AIONA fucum sapit" (Ballerini 1743, p. 12). Prova ne sarebbe l'iconografia della raffigurazione: alovów vuol dire superfundo cioè "versare sopra, cospergere", ma Herakles non è cosparso dall'acqua, ma prende l'acqua con l'hydria dalla fonte, recentemente rinvenuta. Rigetta le correzioni aıovó $\omega$ e AI $\Omega$ NA $\Sigma$ del Gori e, attraverso i testi di Tertulliano, S. Ireneo e S. Epifanio, dimostra che Herakles non ha nulla a che vedere con gli Aeones.

Winckelmann nel 1760 pubblica la pasta vitrea tratta da questa gemma, conservata nella collezione del Barone de Stosch. Per quanto riguarda l'iscrizione, riferisce solamente che Ballerini aveva sostenuto che l'iscrizione fosse un'aggiunta moderna ${ }^{\mathbf{1 0}}$, "mais s'il avoit vu ou la pierre, ou l'empreinte, il ne se seroit pas avancé jusqu'à ce point" (Winckelmann 1760, p. 287).

Francesco Eugenio Guasco nel 1775 cita la gemma di Buonarroti pubblicata dal Gori a proposito di Herakles connesso con le fonti (Guasco 1775, p. 51, con fig.).

Per Raspe e Tassie nel 1791, la gemma e l'iscrizione sono considerate entrambe "in the old style" e l'iscrizione, non interpretata, viene letta $\triangle$ NOIA (Raspe, Tassie 1791, I, p. 355, n. 5918, tav. XL.5918).

Wicar nel 1807 chiama in causa Mons. Huet secondo il quale i Greci erano a conoscenza del miracolo di Mosè $^{11}$ e lo avrebbero riprodotto su questa pietra in un tempo anteriore al quale avrebbero avuto contatti con gli Ebrei ${ }^{12}$. Sostiene poi che se l'iscrizione AIONA è coeva alla gemma, deriva dal verbo greco che significa "arroser"; se è posteriore, "on peut croire qu'il est relatif aux folies des Valentinies, hérétiques des premiers siècles du christianisme (Wicar 1807, p. 79, fig. a p. 82 a destra).

10 Winckelmann 1760, p. 286-287, n. 1766. In Ambrosini 2011, p. 88 , è scritto Buonarroti invece di Ballerini. Me ne scuso. L'errore è stato trascritto da Winckelmann 1760 , p. 286 , n. 5 , ripetuto in Visconti 1829, p. 224-225 e Reinach 1885, p. 52.

11 Si riferisce al miracolo di Mosè che colpisce laroccia del monte Oreb con il suo bastone per creare una sorgente nel deserto (Es. 17, 6 e Num. 20,8-11).

12 Il Wicar si riferisce al testo di Mons. Pierre-Daniel Huet (Wicar 1807, p. 82; Huet 1679, Propos. 4, n. 12).
Il Millin nel 1811 legge l'iscrizione AIONA che leggendo da destra verso sinistra, "signifie dèmence" e, da sinistra verso destra "veut dire arrose" (Millin 1811, p. 42, n. 477, tav. CXXI.477).

Ansse De Villoison nel 1815 la interpreta come àıovô, "arrose"; secondo lo studioso si tratterebbe dunque della fontana che serve a quelli che vogliono bagnarsi, "vogliono farsi delle docce". Il verbo che ricorre spesso in Ippocrate significa "aspergersi, gettarsi dell'acqua dall'alto sul corpo". Questa fontana, - prosegue De Villoison -, questa fonte termale, serve a dare delle docce. De Villoison va contro la tesi del Gori che ipotizzava la presenza di omega finale e di sigma. L'iscrizione aveva un senso più profondo e andava letta 'AI $\Omega N A \Sigma$, "i secoli" (Villoison (de) 1815).

E. Q. Visconti nel 1829 collega l'immagine raffigurata sulla gemma alla "sete d'Ercole in Libia, di cui Apollonio, $\mathrm{o}$ a quella che soffrì presso all'Aventino descrittaci da Properzio (Visconti 1829, p. 224-225, n. 227). I caratteri AN@IA (Anthiae) ci danno un nome in genitivo dorico, dubbio se dell'artefice o del possessore". Sembra inoltre non avanzare dubbi sull'autenticità dell'iscrizione.

Nel 1832 Micali legge l'iscrizione AMOIA ed interpreta la scena come "Ercole prende le acque vive al fonte dell'Oeta per la sua lustrazione". Informa inoltre il lettore che dell'iscrizione da parte del Gori, Winckelmann e Visconti sono state date differenti interpretazioni, ma che "Io m'attengo a più piana spiegazione del soggetto" (Micali 1832, p. 215-216, n. 4, tav. CXVI.4, n. 140).

Il Comte Charles de Clarac $^{13}$ nel 1844 inserisce la gemma tra le opere testimonianza di artisti dell' antichità. Documenterebbe infatti il nome di Anthias: "puisant de l'eau dans un vase, par Anthias".

Roul Rochette nel 1845 pone l'iscrizione sotto la voce ANTHIAS: legge l'iscrizione ANOIA oppure AIONA e per rispondere ad un dubbio espresso dal Visconti, cioè se si tratti del nome di un artista o di un proprietario della gemma, dice che non si tratta né dell'uno né dell'altro (Roul-Rochette 1845, p. 117-118). La parola AIONA va letta AITNA, perché è riconosciuto che nell'alfabeto etrusco la lettera $\Theta$ aveva il posto della lettera $\mathrm{T}$ greca. Sia la forma dei caratteri che il lavoro e lo stile della pietra indicano positivamente un'opera etrusca. Questa iscrizione, letta così, si accorda, d'altronde, perfettamente con il soggetto, che rappresenta Herakles che riceve in un grande vaso l'acqua che si versa da un grande ammasso di rocce.

Lo stesso soggetto è riprodotto su un altro scarabeo, di stile etrusco, dove Herakles, designato dal suo nome etrusco HERCLE, riceve l'acqua termale che sgorga da

13 Clarac (de) 1849 , p. 321, presente già nell'edizione del 1844 , p. 39 , che non ho potuto verificare perchè non disponibile. 


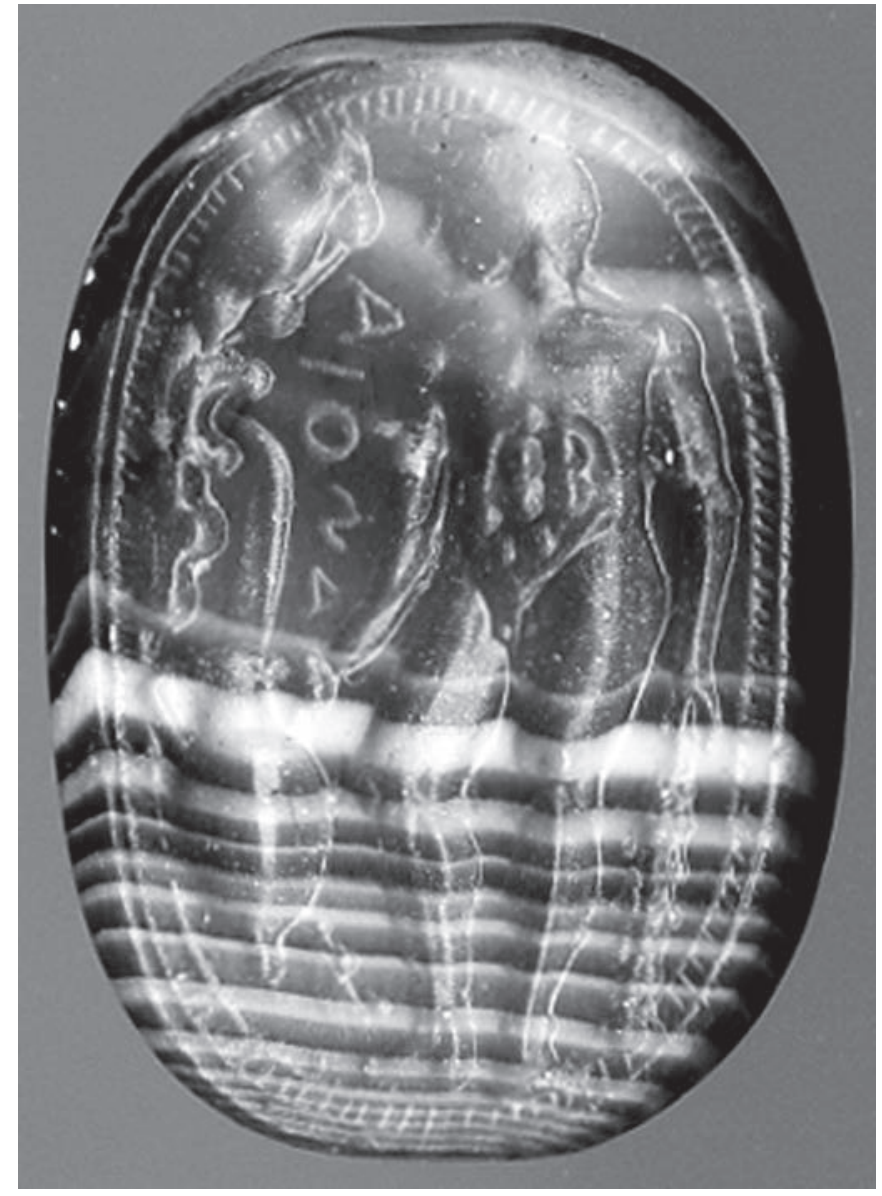

Fig. 1. Londra, British Museum, inv. n. 1949.7-12.2, scarabeo d'agata tagliato (Fotografia L. Ambrosini, Courtesy of (c) The British Museum-London).

una testa di leone, e si è spiegato questo soggetto con una circostanza del mito di Herakles, che si rimette dalle fatiche ai bagni caldi di Himera in Sicilia. Il nome AITNA inciso sul primo scarabeo, si richiama dunque a l'Aetna, dove si poteva con sufficiente verisimiglianza collocare la fonte delle acque termali della Sicilia; ed è in effetti da un enorme ammasso di rocce, e non da una maschera di leone che sgorga l'acqua raccolta da Herakles, su quello dei due scarabei che porta l'iscrizione AIONA, in modo che non fosse rimasto il minimo dubbio su questo soggetto.

La gemma viene citata come confronto da O. Jahn per la raffigurazione presente sulla cista Ficoroni nel 1852, ma nessun cenno è fatto all'iscrizione (Jahn 1852, p. 18, n. 1).

Köhler, sempre nello stesso anno (1852), afferma che la lettura $\triangle$ NOIA presente in Raspe, Tassie 1791 è completamente errata (Köhler 1852, p. 166-167, n. XIII). Propone di leggere l'iscrizione da sinistra verso destra, cioè ANOIA, anche se, a suo parere la lettura più corretta è da destra verso sinistra cioè AIONA "benetze", "bagna!". Lo scarabeo, continua Köhler, ha tutte le

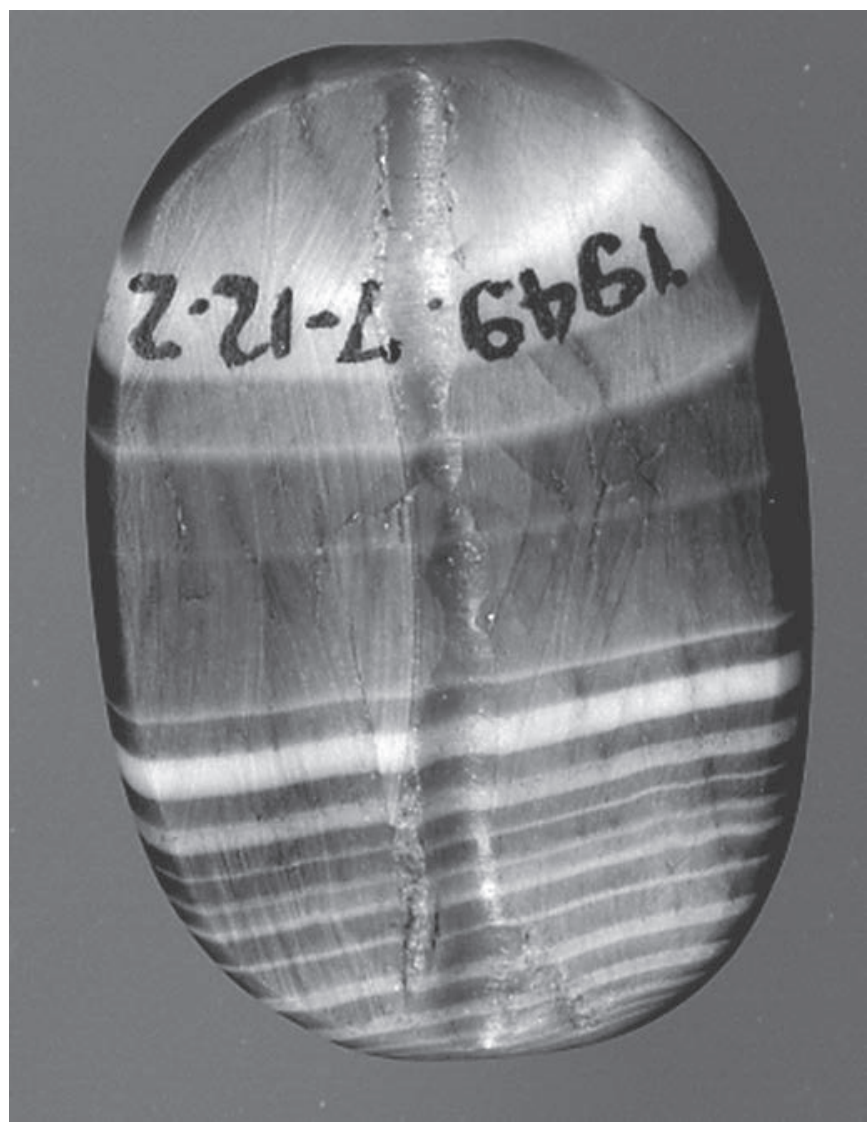

Fig. 2. Londra, British Museum, inv. n. 1949.7-12.2, scarabeo d'agata tagliato, rovescio (Fotografia L. Ambrosini, Courtesy of (c) The British Museum-London).

caratteristiche del secondo stile etrusco, ma l'iscrizione non è etrusca, è greca, quindi l'iscrizione o è posteriore oppure lo scarabeo è uno dei più tardi di questo periodo rinvenuto in un luogo dove c'erano molti abitanti greci.

Ariodante Fabretti nel 1867 nel Corpus Inscriptionum Italicarum 2551 bis trascrive l'iscrizione AIONA, intendendo la terza lettera come theta, leggendola cioè aithna.

Nel Lexikon a cura di Roscher si cita la gemma come un attento lavoro greco con la bella iscrizione accanto alla fonte aióva "sprudle" (Roscher 1884, I, p. 45 ss.). Il Reinach nel 1885, legge l'iscrizione aióva (?) (Reinach 1885 , p. 52, II, 14, 4, tav. 51.14). Furtwängler nel 1900 accetta la lettura $A M O I A$ che interpreta come $\alpha i o ́ v \alpha$ "sprudle", "gorgogliare sopra" (Furtwängler 1900, p. 39-40, n. 39, tav. VIII.39). Nel 1926, Jean Bayet data il nostro scarabeo, inciso da un artista greco, all'inizio del V sec. a.C. (Bayet 1926, p. 164). Guido Achille Mansuelli nel 1941 aveva precisato "l'ingiunzione rivolta dall'eroe alla fonte: aîova ("sgorga!") nello specchio di Riparbella si è tramutata in violenta minaccia (Mansuelli 1941, p. 105, n. I.1, tav. 11.1). 


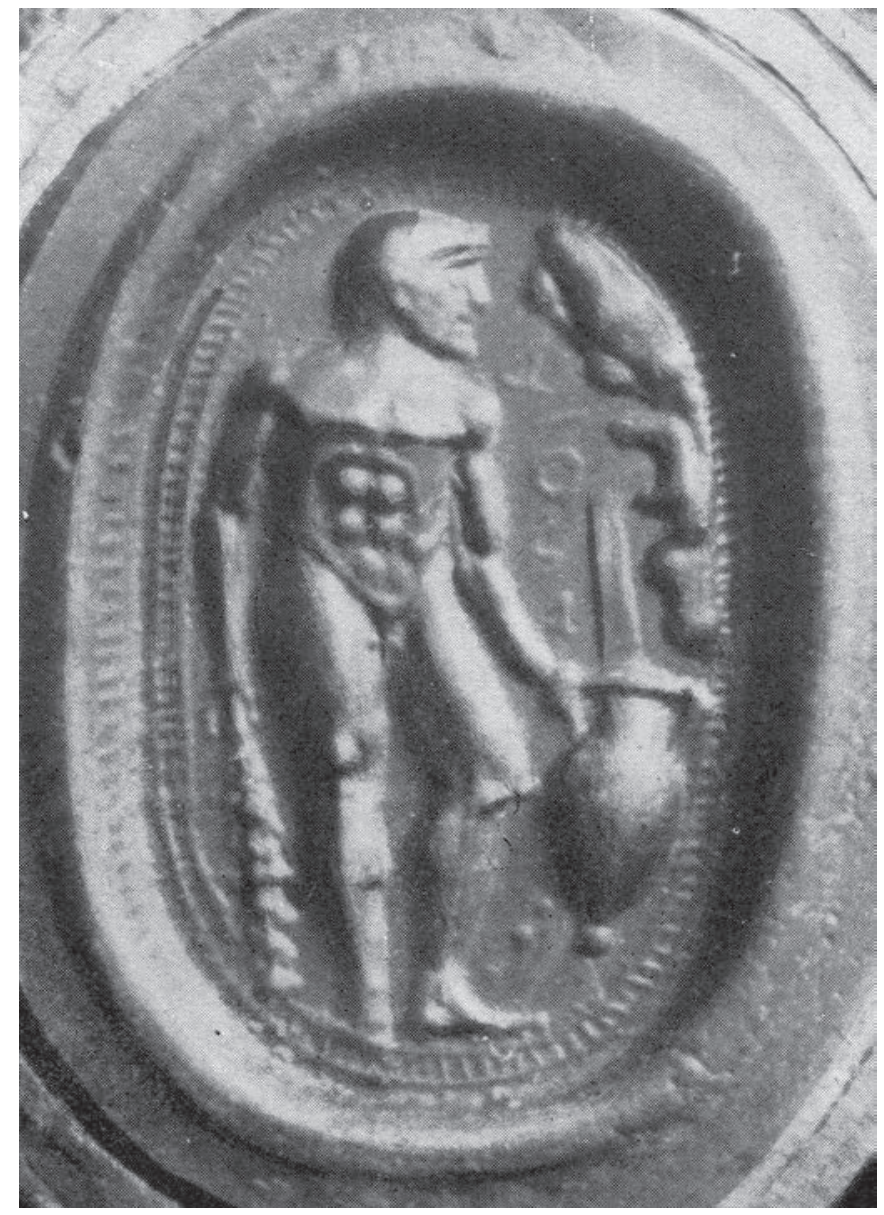

Fig. 3. Londra, British Museum, inv. n. 1949.7-12.2, scarabeo d'agata tagliato, calco (da Ambrosini 2011).

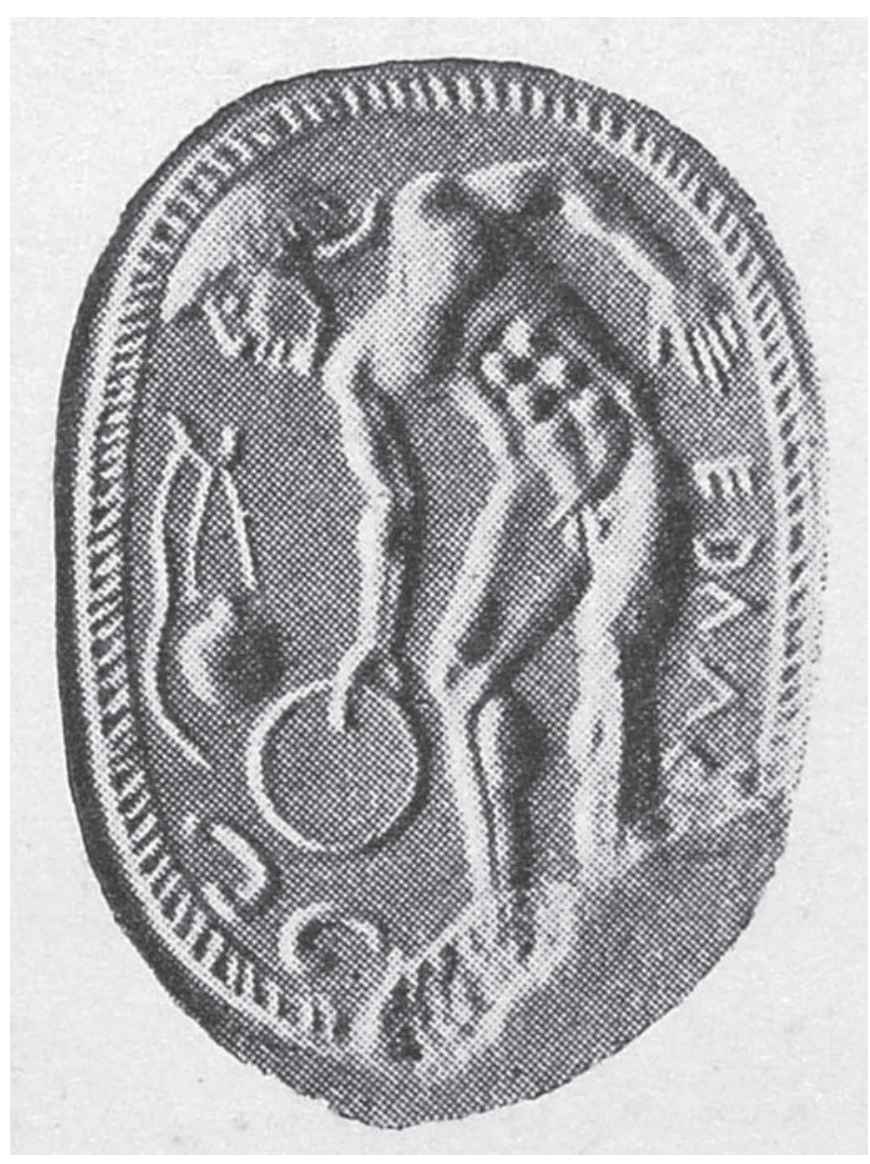

Fig. 4. Parigi, Cabinet des Médailles, inv. n. 87, scarabeo di corniola (da Ambrosini 2011).

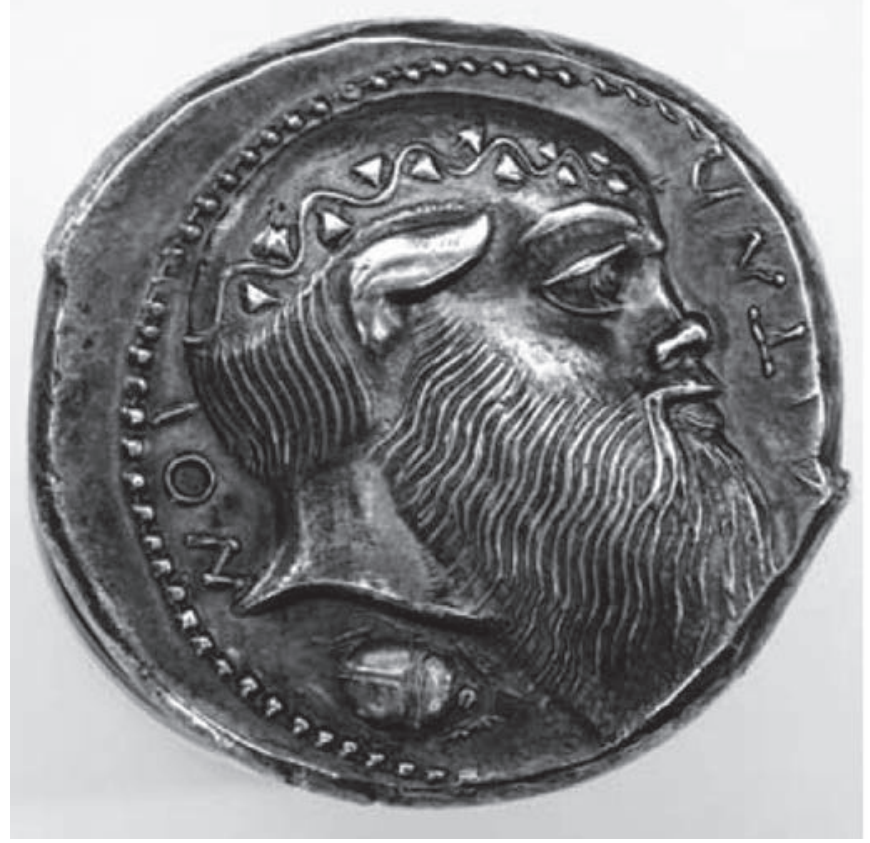

Fig. 6. Bruxelles, Bibliothèque royale de Belgique, tetradramma argento dell'Aitna Master, Collection Lucien de Hirsch (da Callataÿ (de) 2010). 
Lo scarabeo, di stile severo, è considerato greco (Mansuelli 1941, p. 105, n. I.1 e p. 106). Nel 1988 John Boardman afferma che l'intaglio assomiglia ad un'opera etrusca, ma l'iscrizione è greca, pertanto la gemma potrebbe essere di manifattura greco occidentale ${ }^{14}$. Lo studioso, riprendendo l'idea del Mansuelli, interpreta l'iscrizione come un'esortazione magica all'acqua a scorrere. Schwarz nel 1990, dal canto suo, nella voce Hercle del LIMC avanza timidamente l'ipotesi che l'iscrizione, giudicata greca dal Boardman, possa forse essere etrusca ${ }^{15}$. Nel 1991 con la lettura aithna l'iscrizione presente sulla gemma confluisce negli Etruskische Texte a cura di Helmut Rix ${ }^{\mathbf{1 6}}$. Nel 2000 Françoise-Hélène Massa Pairault, pur definendo lo scarabeo greco e l'iscrizione un imperativo "sgorghi!", nella didascalia della fotografia del calco definisce lo scarabeo ${ }^{17}$ : "Scarabeo con Eracle alla fonte Aiona", come se l'iscrizione fosse la denominazione della fonte (Massa Pairault 2000, p. 187, fig. 2b). Nel 2002 la nostra gemma è stata menzionata da McDonough poiché (?) messa in relazione dal Mansuelli con il noto specchio da Riparbella (Volterra), conservato a Berlino (McDonough 2002, p. 11).

\section{La nuova proposta interpretativa}

Nel 2011, nel contesto di un ampia ricerca sulle gemme etrusche con iscrizioni, rinviando per approfondimenti a questo studio, la sottoscritta ha proposto di leggere l'iscrizione AMOIA e di interpretarla come il termine etrusco aithna. Si tratta dunque, a nostro avviso, per il tema iconografico e per la presenza dell'iscrizione, di una gemma etrusca (realizzata da un artigiano di formazione greca) con l'iscrizione etrusca aithna ${ }^{18}$, resa in etrusco del nome Aitna, nome di una ninfa di Sicilia, ma anche della città fondata da Ierone. Lo scarabeo potrebbe essere stato realizzato da un artigiano greco (proveniente dalla Sicilia?) operante in Etruria nell'età di Ierone, fondatore di Aitna ${ }^{19}$. L'iconografia della scena raffigurata sulla gemma è prettamente etrusca (Marconi 1999). In ambito greco a questa quota cronologica Herakles con l'anfora è raffigurato, finora, soltanto su una pelike a

14 LIMC IV, 1988, Herakles 1326; cf. già Boardman, Vollenweider 1978, ad n. 230.

15 LIMC V, 1990, p. 207, Herakles/Herkle 84c.

16 ET OI G.72, p. 368

17 F.-H. Massa Pairault dovrebbe essere l'autrice anche della didascalia della figura $2 \mathrm{~b}$, a meno che essa non sia stata realizzata da chi ha curato la redazione del volume.

18 Tutta la bibliografia sulla gemma è disponibile in Ambrosini 2011, p. 27-28, n. 19, con bibl. cit., fig. 16 e 89-89.

19 Cf. la documentazione numismatica in Ambrosini 2011, p. 88-89.

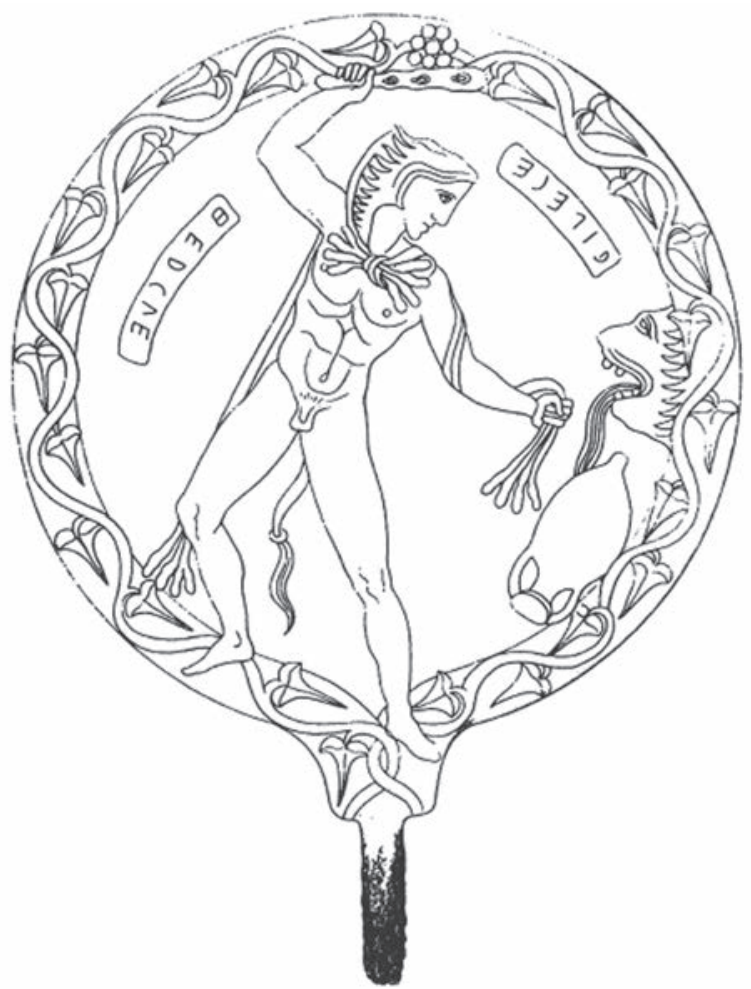

Fig. 7. Berlino, Staatliche Museen, inv. n. 3341, specchio etrusco in bronzo da Riparbella - Volterra (da McDonough 2002).

figure rosse attribuita al Pittore di Geras ${ }^{20} \mathrm{e}$ su un cratere a colonnette a figure rosse attribuita al Pittore di Pan ${ }^{21}$ nell'atto di trasportare due anfore. Anche l'iscrizione mostra caratteristiche etrusche: esse ci sembrano rilevabili nella forma e nell'andamento delle lettere alpha e $n y$, ma soprattutto nella presenza della lettera theta.

Il termine aithna richiama alla mente quello di Aitna, ninfa di Sicilia, figlia di Ouranos (oppure di Oceano) e $G e$, eponima della città di Etna. Aitna ebbe due gemelli da Adrano (o Hephaistos in Servius, Aen., IX, 581), dio dei Siculi, che abitavano intorno al vulcano, adorato in tutta la Sicilia e in modo particolare nella città che porta il suo nome, alle pendici dell'Etna. Per gelosia, Hera fece in modo che i gemelli di Aitna fossero inghiottiti dalla terra, ma questa li restituì, ed ecco perché i suoi figli ctoni sono detti "Palici", "i nati due volte" (vedi Ovidio e Virgilio). Aitna ricorre spesso nella mitologia dell'isola e che sia stata considerata una ninfa risulta dalla tradizione che la faceva figlia del fiume Simeto (Philipp. in Anthol. Pal., VI, 203; Ciaceri 1911, p. 249).

Secondo un'altra tradizione la madre dei Palici era Talia. Nella duplicità della tradizione sulla madre dei Palici, che vede accanto a Talia anche la ninfa Aitna ${ }^{22}$,

$20 \mathrm{ARV}^{2}$ 285,7; Boardman in LIMC IV p. 798, n. 1324.

$21 \mathrm{ARV}^{2}$ 551,5; Boardman in LIMC IV, p. 798, n. 1325.

22 Sui culti legati a Aitna: cf. Cook 1925, vol. III, p. II, p. 908-909. 
si celano forse, motivazioni ideologiche inerenti alla strategia politica di Ierone e ai rapporti etnici sviluppatisi con la rifondazione di Catania (Cusumano 2006, p. 128).

Nella monetazione di Catania, al tempo in cui si chiamò Aitna (476-461 a.C.), il nome della città è sempre scritto con il tau e mai con il theta. Lo stesso vale anche per le lingue dell'area sicula nelle quali non compaiono mai i segni per le occlusive aspirate come theta (come possiamo verificare, ad esempio, nella legenda AITNA, presenta nella litra emessa dalla città).

A nostro avviso, l'iscrizione presente sulla gemma londinese non può essere greca, perché il nome della ninfa Aitna in greco sarebbe stato scritto con il tau e non con il theta ${ }^{23}$.

Inoltre entrambe le lettere alpha hanno la traversa che va da sinistra in basso a destra in alto: questo ci fa capire che il senso dell'iscrizione è certamente destrorso AMOIA $\leftarrow$. Va tuttavia rilevato un dato importante: ovviamente per un Etrusco sarà stato più facile incidere sulla gemma le iscrizioni sinistrorse, piuttosto che le destrorse. La nostra iscrizione destrorsa, utilizzando la gemma come sigillo, diveniva sinistrorsa AlON A, secondo l'uso scrittorio corrente in Etruria. È stata dunque incisa, con direzione opposta all'uso scrittorio corrente in Etruria ${ }^{24}$. In fondo è lo stesso procedimento utilizzando nella preparazione dei coni monetali: anche la leggenda AITNAION, che sulla moneta è in positivo, è stata incisa in negativo (cioè con andamento inverso) sul conio.

Se nel caso della gemma di Londra si tratta, come pensiamo, della resa in etrusco del nome Aitna, il dato è rilevante, perché, a nostro avviso, lo scarabeo potrebbe essere stato realizzato da un artigiano greco (proveniente dalla Sicilia?) operante in Etruria. La cronologia della gemma, è compatibile con l'età di Ierone, fondatore di Aitna. In Etruria la presenza numinosa collegata alle acque sorgive rimaneva indeterminata, coerentemente con quanto avveniva anche nella concezione romana (Maggiani 2003, p. 39). La documentazione archeologica di ambito etrusco non fornisce molto aiuto: sembra tuttavia da studi recenti che la parola etrusca che indica in modo generico una nympha sia Lasa (Maggiani 2003, p. 41).

Agli occhi di un Greco una fonte è collegata intimamente all'immagine di una ninfa e va dunque collegata al suo nome. $\mathrm{Ci}$ appare pertanto sensato pensare che l'incisore abbia apposto l'iscrizione aithna (con theta, all'etrusca) per indicare il nome della ninfa Aitna.

23 Il dato mi è stato gentilmente confermato dal Prof. Alan Johnston, che ringrazio sentitamente.

24 Non c'è un grande divario tra il numero delle iscrizioni incise con direzione destrorsa (61 esemplari) e quelle con direzione sinistrorsa (51 esemplari): cf. (Ambrosini 2011, p. 105-106).

\section{Il tetradramma dell'Aitna Master}

Utile per un confronto con la nostra iscrizione è la legenda AITNAION presente sul celeberrimo tetradramma d'argento della città di Aitna, attribuita all'Aitna Master. La moneta, nota per essere definita "the coin of coins", attribuita all'Aitna Master, è stata rinvenuta vicino Catania (Callataÿ (de) 2010,p. 81). È stata studiata recentemente anche la paleografia della sua legenda. Le estremità delle lettere $n y$ sono dotate di punti, scarsamente attestati nel V sec. a.C., ma comuni, com'è noto, in età ellenistica; la moneta condivide questa caratteristica con i demarateia di Siracusa (Callataÿ (de) 2004, p. 51).

È interessante notare che sul celebre tetradramma, al di sotto della testa del Sileno, compare uno scarabeo ${ }^{25}$ (fig. 6). Gli scarabei dell'Etna erano famosi per le loro enormi dimensioni ${ }^{26}$, per questo l'animale compare come simbolo sul rovescio della moneta ${ }^{27}$. La moneta riveste un'importanza particolare poiché getta luce sulla breve vita della colonia di Aitna ${ }^{28}$.

La datazione del tetradramma dell'Aitna Master sembra essere compresa nella decade 476/5-466/5 a.C. durante la quale Ierone si stabilì a Catania, all'epoca chiamata Aitna (Callataÿ (de) 2010, p. 87). Gli esperti numismatici si interrogano ancora su quale sia stato l'evento, l'occasione speciale per la quale fu coniata la moneta: la fondazione di Aitna presso Catania ${ }^{29} \mathrm{o}$ la sua rifondazione a circa $15 \mathrm{~km}$ a Nord-Ovest di Catania, presso Inessa ${ }^{30}$.

Ierone, tiranno di Siracusa, che si proclama "Etneo" ${ }^{31}$, nel 476/5 a.C., s'impossessò di Katane. La città, distrutta da una colata lavica dell'Etna (Thuc., 3, 116), versava in difficili condizioni. Questo consentì la realizzazione del progetto politico del tiranno che ne deportò gli abitanti, di stirpe ionica, a Lentini, per creare un importante caposaldo di stirpe dorica. La ricostruì, con il nome di Aitna,

25 Sulla moneta resta fondamentale lo studio di Boehringer 1968; cf. da ultimi Callataÿ (de), Gitler 2004a; Callataÿ (de), Gitler 2004b; Callataÿ (de), Gitler 2004c; Callataÿ (de) 2005; Callataÿ (de) 2010.

26 Schol. Ar. Pac., 73 "e ieri tornò, recando seco un gigantesco scarafaggio etnèo" trad. di Ettore Romagnoli); cf. anche Plato Com., fr. II, 624 (ed. Meinecke). Così anche Callataÿ (de), Gitler 2004a, p. 58-59; Callataÿ (de) 2010, p. 84.

27 In Callataÿ (de), Gitler 2004b, p. 20, si avanza l'ipotesi che lo scarabeo sia stato utilizzato sulla moneta come local trademark. Uno scarabeo compare, accanto ad elementi di maggiori dimensioni, su monete di Abdera (Callataÿ (de), Gitler 2004b, p. 20, n. 6). Va anche ricordato che lo scarabeo nella mitologia greca rivestì particolare valore nella protezione dell'infanzia.

28 Tutti gli avvenimenti storici sono in Callataÿ (de), Gitler 2004b, p. 9-12. Per le fonti relative agli avvenimenti storici, cf. da ultimo Callataÿ (de) 2010, p. 86-87.

29 Com'è noto, la Pitica I, v. 110 ss. di Pindaro celebra la fondazione di Aitna.

30 Callataÿ (de), Gitler 2004b, p. 14; Callataÿ (de) 2010, p. 85-88.

31 Cf. ad esempio Pindaro, Pitica I. 
e la ripopolò con 10000 nuovi abitanti, fatti venire da Siracusa e dal Peloponneso ${ }^{32}$. La città è retta dal figlio Dinomene sotto la buona tutela di Cromio. Nella nuova città fu aperta una zecca che coniò tetradracme, dracme e litrae, in due distinte emissioni ${ }^{33}$. Poco dopo, nel 474 a.C., Ierone con i Cumani vince a Cuma gli Etruschi; vittoria paragonata da Pindaro (Pitica I, 136), insieme a quella sui Cartaginesi ad Himera del 480 a.C., alle famose battaglie dei Greci contro i Persiani a Platea e a Salamina.

\section{Herakles e i Dinomenidi $^{34}$}

Il mito di Herakles compare nella Prima Nemea, ode composta per Cromio, tutore e precettore di Dinomene, il figlio di Ierone, che regge la città di Aitna. I Dinomenidi utilizzano i motivi di propaganda eraclide e i riferimenti di ordine mitico-genealogico alla figura dell'eroe. Questi vengono funzionalizzati in modo socioculturale in relazione al rapporto col mondo indigeno: la politica di espansione ieroniana nel contesto etneo rivela un'ampia e coerente utilizzazione di motivi mitologici in rapporto al problema indigeno ${ }^{35}$.

\section{Il tema "Hercle alla fonte" tra Etruria e Sicilia}

L'antica saga di Herakles di ritorno dall'Iberia con i buoi di Gerione, com'è noto, può essere interpretata come espressione mitica dei primi contatti emporici intrapresi, fin dal II millennio a.C., tra i naviganti egei e le genti del luogo. Essa fa giungere Herakles con la sua mandria fino in Sicilia. Herakles decise di compiere il periplo dell'isola; lungo la costa fu accolto dalle Ninfe, che facevano scaturire per lui fonti di acqua calda (Himera e Segesta, con differenze tra Apollodoro e Diodoro che ha come fonte Timeo), affinché egli si rinfrancasse dalle fatiche del viaggio. Herakles si presenta in primo luogo come il benefattore, come colui che domina la natura e le sue forze, piegandole per il bene proprio e degli uomini e facendo sgorgare fonti sacre ${ }^{36}$.

32 Diodoro 11.49; Strabo 6.268; Pindaro Fr. 71 A Ierone di Siracusa. 33 Calciati 1987, p. 141, 1; 145,3. Per le fonti relative agli avvenimenti storici, cf. da ultimo Callataÿ (de) 2010, p. 86-87.

34 Cf. Giangiulio 1983, p. 830.

35 Pensiamo alle "Etnee" di Eschilo e al patrimonio mitico e genealogico della città siracusana e peloponnesiaca di Aitna.

36 Recentemente l'episodio di Herakles in Sicilia è stato connesso ad elementi di un paesaggio fortemente caratterizzato ed attraversato da numerose occasioni di confronto o di integrazione con la cultura greca (De Cesare 2003, p. 114, con bibl. cit.).

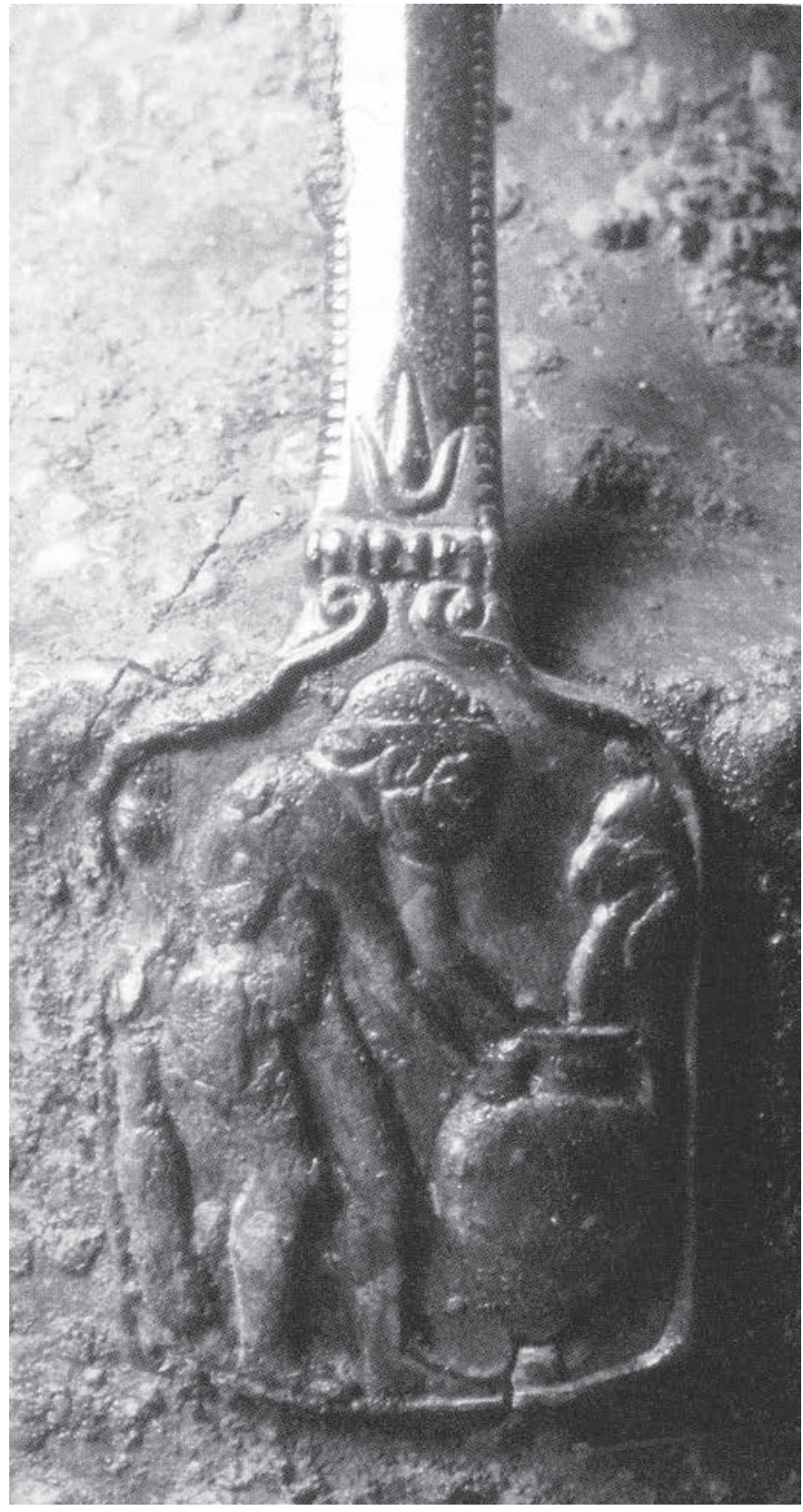

Fig. 8. Firenze, Museo Archeologico Nazionale, inv. n. 11930, oinochoe etrusca in bronzo di forma VI da Populonia - San Cerbone (da L'acqua degli dei 2003).

Sul tema esiste una considerevole bibliografia ${ }^{37}$.

La raffigurazione di Hercle che raccoglie acqua presso la fonte con l'anfora, può essere inserita nel contesto della tradizione "indigena" etrusca così come è stato fatto da C. Mc Donough per la scena incisa sullo specchio da

37 Ciaceri 1911, p. 242-243, 245, 249, 282; Sjöqvist 1962; Giangiulio 1983, p. 799; Sassatelli 1993, p. 127; Cusumano 1996, p. 195-196, 205, 211; De Vido 1997, p. 129, 136, 144-145, 157, 159, 162, 166, 167, 169; Marconi 1999; Vassallo 1999; De Cesare 2003; da ultimo Atti Messina 2011 (in stampa, pertanto non vidi). 


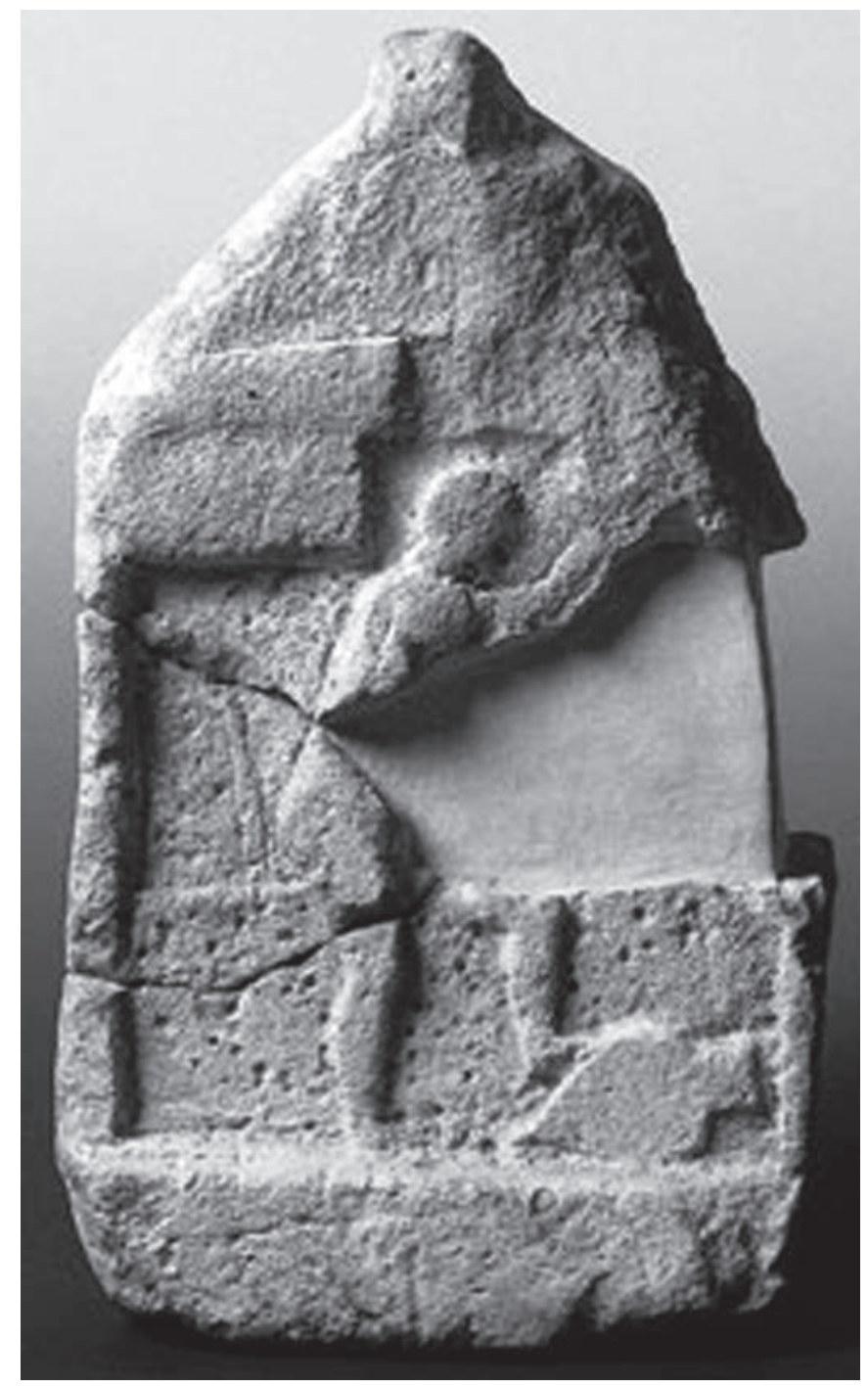

Fig. 9. Edicola da Colle Madore (da www.regione.sicilia.it).

Riparbella (Volterra) (fig. 7), interpretata, non come la lotta di Hercle con la fonte, ma come la sua creazione (McDonough 2002, p. 12): "Instead of attacking the fountain, perhaps Hercle has just brought it into being: this would be in keeping with the hero's role as the patron deity of hot springs". Nello specchio sarebbe dunque raffigurata "the heroic production of water by means of brute strength" (McDonough 2002, p. 17).

Nello specchio da Riparbella, Massa Pairault identifica la scena nella quale Hercle, raffigurato in assalto, obbliga con la minaccia la fonte a sgorgare e con la didascalia, che legge "vipece", un perfectum "si mise a sgorgare" (scil. l'acqua; Massa Pairault 2000, p. 187). Recentemente Vincenzo Bellelli ha proposto la lettura thipece, sulla scorta della identificazione, effettuata da Rix, del termine etrusco thi con "acqua" (Bellelli 2006 [2007], p. 206).
Colpisce l'assidua presenza della raffigurazione di Herakles che raccoglie l'acqua ad una fonte con un'anfora sulle gemme. La figura è dotata in almeno cinque gemme dell'iscrizione hercle (Ambrosini 2011, p. 25-27, n. 13-17).

Nelle raffigurazioni presenti sulle gemme e sulle oinochoai, secondo Mansuelli, Hercle sarebbe intento a prepararsi il bagno, mentre sugli specchi ci sarebbe il "diretto lavacro" e l'abluzione con l'ausilio di altri personaggi (Mansuelli 1941, p. 107).

Si tratterebbe dunque di due sequenze diverse, forse non necessariamente collegate, della medesima azione. Occorre riflettere sull'uso di questo tema iconografico sia sulle oinochoai, vasellame destinato ai simposi ed alle libagioni, che sulle gemme. Sull'oinochoe da PopuloniaSan Cerbone ${ }^{38}$ all'attacco inferiore dell' ansa compare la stessa raffigurazione: come ho già avuto modo di rilevare (Ambrosini 2009, p. 252), indizi di un uso sacrale del vaso possono essere tratti da alcune raffigurazioni, come quella presente sul celeberrimo specchio di Calcante ${ }^{39}, \mathrm{o}$ dai temi raffigurati proprio sulle placchette che costituiscono l'attacco inferiore dell'ansa. Questa forma sembra avere una particolare fortuna in ambito religioso per il rito della libagione e, forse, non è escluso che la raffigurazione di Hercle o di un giovane alla fonte sull'attacco inferiore di alcune anse di questo tipo di oinochoe possa avere qualche connessione con l'uso del vaso nel rituale. Le brocche bronzee di tardo V - inizio IV sec. a.C. a corpo angoloso sono stati recentemente considerati "vasi rituali" da Giovanni Colonna ${ }^{40}$.

Secondo Clemente Marconi il nesso con le sorgenti termali richiama la funzione salutifera di Herakles, trasparente nell'epiclesi di Alexikakos e il suo legame con l'atletismo, campi nei quali l'acqua calda, con funzione sia terapeutica sia di ristoro dallo stress atletico entra a pieno titolo (Marconi 1999, p. 205).

La proposta di identificare con Hercle alla fonte la scena presente sull'edicola da Colle Madore (fig.8), avanzata da Marconi, nonostante l'assenza di attributi (come Marconi stesso sottolinea) è stata confermata recentemente da Sclafani ${ }^{41}$. L'assenza degli attributi tradizionali dell'eroe, troverebbe la sua ragione nell'adattamento al contesto sociale locale. Va tuttavia sottolineato che anche in ambito etrusco esistono raffigurazioni di uomini, non caratterizzati come Hercle e privi di attributi, raffigurati

\footnotetext{
38 D. Zinelli in L'acqua degli dei 2003, p. 89-90.

39 Ambrosini 2006, p. 206, 230, fig. 15, con bibl. cit.

40 Ambrosini 2009, p. 252, con bibl. cit.

41 Sclafani 2011 (p. 24-25 fig. 1-2, 26, 29) è tentata dall'idea di applicare la lettura del tema iconografico fornita dalla Massa Pairault, "paideia maschile e riti di iniziazione giovanile della polis", all'ambito sicano.
} 
nell'atto di raccogliere acqua ad una fonte con l'anfora. Il tema, che merita di essere affrontato a più largo raggio, è stato interpretato, in alcuni casi, come la raffigurazione di un compagno o aiutante di Troilo che attinge acqua presso la fonte ${ }^{42}$.

La raffigurazione di Hercle che raccoglie l'acqua con l'anfora presso la fonte è stata collegata dalla Massa Pairault o ad episodi di accoglienza nei pressi di fonti restauratrici delle forze (in questo caso Hercle dimostra la sua iuventus e la sua virtus), o al mito argonautico (in questo caso Hercle inventa una fonte e viene onorato dagli iuvenes con una corsa atletica) (Massa Pairault 2000, p. 185-186).

Secondo Mario Torelli, connesso al raggiunto stadio puberale, al bagno che libera dalla fatica e all'attività della palestra svolta in ambito termale, il tema di Hercle alla fonte sarebbe in evidente rapporto con le acque calde (Ambrosini 2011, p. 88). Nelle gemme citate Hercle non è mai raffigurato nell'atto di brutalizzare la fonte per farla sgorgare così come ci riferiscono le fonti antiche ${ }^{43}$, pertanto, a mio avviso, sarà forse da preferire il collegamento con le fonti restauratrici delle forze, fatte sgorgare dalle Ninfe. Sembrerebbe confermare questa lettura l'esistenza di gemme etrusche nelle quali Hercle (con iscrizione) è raffigurato stanco, seduto su una roccia, presso la fonte (Ambrosini 2011, p. 24, n. 10-11).

Il dato emerso dalla gemma di Londra è rilevante perché, a nostro avviso, lo scarabeo potrebbe essere stato realizzato da un artigiano di formazione greca (proveniente dalla Sicilia?) operante in Etruria. Ci sembra infatti che la presa di coscienza fonologica del materiale consonantico della lingua indigena (theta al posto di tau) implichi una sorta di bilinguismo, fenomeno già messo in evidenza da Michel Lejeune in situazioni di contatto tra culture. Lo studioso ha posto in evidenza come i santuari extraurbani abbiano svolto il ruolo di luoghi privilegiati per i rapporti culturali e gli incontri tra comunità locali, mercanti ed artigiani (Lejeune 1983, p. 740).

Uno di essi potrebbe essere stato l'artefice della nostra gemma, un greco trasferitosi in Etruria che incide su uno scarabeo il nome della ninfa Aitna, secondo le norme grafiche del luogo.

La ninfa Aitna (denominata in etrusco aithna) sarebbe dunque collegata alla Sicilia orientale, non contemplata nella cartina di distribuzione dei luoghi relativi alle "acque di Ercole", edite anche di recente ${ }^{44}$. A Catania

42 Cf. ad esempio, D. Zinelli in L'acqua degli dei 2003, p. 91, con bibl. cit.

43 Apollonio Rodio IV, 1145-1149; Massa Pairault 2000, p. 186 e come forse si può desumere dalla scena presente sul noto specchio di Riparbella.

44 Bellelli 2006 [2007], p. 208, fig. 39, cf. Ambrosini 2011, p. 88. è noto finora soltanto un tempio ad Herakles dedicato da Ierone, mentre la figura di Herakles appare attestata in gran parte nella cuspide nord-occidentale dell'isola e lungo la costa settentrionale della Sicilia. Le Ninfe nella cultura greca, molto sensibile ai dati naturali, soprattutto se connessi ad elementi mitici o sacrali, sembrano emergere come traccia della religione locale, legata al territorio circostante.

Per quanto riguarda l'uso sulle gemme del tema iconografico di Hercle che raccoglie acqua alla fonte con l'anfora, può aver svolto una funzione di protezione, come tutte le divinità raffigurate sulle gemme (Ambrosini 2009, p. 89). Paradigma della lotta contro tutti i mali della terra, Hercle è visto come dio protettore e benefico che, per giunta, avendo raggiunto l'immortalità, in quanto uomo mortale, può essere l'emblema di una sorte felice nell'al di là. L'aspetto fortemente ctonio dell'eroe sarebbe testimoniato dal suo rapporto con le sorgenti calde (Jourdain-Annequin 1982, p. 252, 278; n. 230). Se coglie nel segno l'interpretazione fornita dalla Massa Pairault come tema di iuventus e paideia, la gemma si configurerebbe come un simbolo della transizione all'età adulta, avvenuta attraverso rituali di lustrazione e purificazione. Come ha giustamente sottolineato Barra Bagnasco si ha difficoltà a separare usi dell'acqua strettamente funzionali da quelli rituali. Questo si evidenzia ancora di più nel caso di Hercle, personalità a mezza strada tra il mondo umano e divino, assimilabile all'atleta o all'iniziato per le continue prove che deve superare (Barra Bagnasco 1999, p. 48). Lo scarabeo di Londra e quello di Parigi mostrano strette analogie non solo stilistiche, ma anche tematiche: sul primo è raffigurato Hercle presso la fonte (che noi proponiamo di interpretare come aithna in etrusco), nel secondo è raffigurato come un perfetto atleta, con tutto il suo strumentario eruchs (Sclafani 2011, p. 27, fig. 3), il re degli Elimi ucciso da Herakles, l'eroe eponimo del monte e del famoso santuario di Afrodite in Sicilia, che sfidava al pugilato e alla lotta i viandanti.

La Krauskopf ha messo in evidenza come, l'incisore, non avendo a disposizione modelli greci di lottatori e pugilatori, avrebbe fatto ricorso ad altri attributi atletici ${ }^{45}$. Entrambi gli scarabei ci sembrano documentare il lavoro in Etruria di artigiani greci ${ }^{46}$, che inseriscono nella "nuova" realtà locale miti e tradizioni della loro

45 Krauskopf si chiede se l'Etrusco abbia voluto per caso raffigurare l'eroe eponimo della sua terra d'origine (Krauskopf 1999 , p. 415; Ambrosini 2011, p. 97).

46 Secondo Boardman anche lo scarabeo con l'iscrizione eruchs è opera di un artigiano greco (Boardman 1968, p. 112; Ambrosini 2011, p. 97). 
terra d'origine ${ }^{47}$, adattandoli alla cultura locale di età tardo arcaica sia attraverso l'uso di schemi iconografici "importati", laddove non disponibili, sia attraverso l'uso della lingue etrusca per le didascalie, con le opportune modifiche fonetiche.

\section{Abbreviazioni bibliografiche}

Nel testo si sono utilizzate le abbreviazioni dell'Archäologische Bibliographie

\section{Abréviations}

ARV2: BEAZLEY (J.D.) - Attic Red-figure Vase Painters. Oxford, $1963^{2}, 3$ vol.

ET: RIX. (H.) dir. - Etruskische Texte. Editio minor, Tübingen, 1991, 2 vol.

LIMC: Lexicon Iconographicum Mythologiae Classicae

\section{Bibliografia}

Ambrosini 2006 : AMBROSINI (L.) - Le raffigurazioni degli operatori del culto sugli specchi etruschi. In : Rocchi (M), Xella (P.), Zamora (J.A.) dir., Gli operatori cultuali, Atti del II Incontro di studio organizzato dal "Gruppo di contatto per lo studio delle religioni mediterranee", Rome (2005), Vérone, Essedue Edizioni, 2006, 246 p. (Storia delle religioni - III), p. 197-233.

Ambrosini 2009 : AMBROSINI (L.) - La cisterna arcaica con l'incluso deposito di età ellenistica (Scavi Santangelo 1945-1946 e Università di Roma "La Sapienza» 1996 e 2006). Il santuario di Portonaccio a Veio. III, Rome, Monumenti Antichi dei Lincei, Giorgio Bretschneider Editore, 2009, 339 p. (Serie Miscellanea, Vol. XIII).

Ambrosini 2011 : AMBROSINI (L.) - Le gemme etrusche con iscrizioni. PiseRome, Fabrizio Serra editore, 2011, 144 p. (Mediterranea. «Supplemento» 6). Atti Messina 2011 : CALDERONE (A.) dir., «Qui fresca l'acqua mormora...» (Sapph. fr. 2,5). Un confronto interdisciplinare Atti del convegno Messina, 29-30 Marzo (2011). Rome, Giorgio Bretschneider Editore, in stampa.

Bayet 1926 : BAYET (J.) - Les origines de l'Hercule romain. Paris, De Boccard, 1926, 502 p. (BEFAR 132).

Ballerini 1743 : BALLERINI (S.) - Animadversiones in Museum Florentinum Antoni-Francisci Gori. Carpentras, apud Casparem Quenin, 1743, 15 p.

Bellelli 2006 [2007] : BELLELLI (V.) - Un bronzetto etrusco, Cerveteri e le "Acque di Ercole". Mediterranea, 3, 2006 [2007], p. 173-225.

Barra Bagnasco 1999 : BARRA BAGNASCO (M.) - Il culto delle acque in Magna Grecia dall'età arcaica alla romanizzazione. Documenti archeologici e fonti letterarie. In : AA. VV., Archeologia dell'acqua in Basilicata, Lavello (Pz), Consiglio Regionale di Basilicata, 1999, 192 p., p. 25-52.

47 Colonna 2000 (p. 306) definisce la gemma "un documento indiretto dei rapporti personali intrattenuti da un (mercante?) etruscomeridionale con la città, e forse col santuario" di Erice. In Sclafani 2011 (p. 27) poiché la raffigurazione compare su di un oggetto appartenente alla sfera privata, l'oggetto indica la scelta di un etrusco di identificarsi con il re sicano.
Bertucchi 1990 : BERTUCCHI (G.) - Les amphores massaliètes à Marseille : les différentes productions. In : Bats (M.) dir., Les amphores de Marseille grecque. Chronologie et diffusion (VI ${ }^{e} \mathrm{I}^{e r}$ s. av.J.-C.). Actes de la table-ronde de Lattes (11 mars 1989), Lattes-Aix en Provence, ADAM, 1990, 294 p. (Études Massaliètes 2), p. 15-20.

Boardman 1968 : BOARDMAN (J.) - Archaic Greek Gems. School and Artists in the Sixth and Early Fifth Centuries B.C. Londres, Thames \& Hudson, 1968, $236 \mathrm{p}$.

Boardman, Vollenweider 1978 : BOARDMAN (J.), VOLLENWEIDER (M.L.) - Ashmolean Museum. Catalogue of the Engraved Gems and Finger Rings, 1. Greek and Etruscan. Oxford, At the Clarendon Press, 1978, 122 p.

Boehringer 1968 : BOEHRINGER (C.) - Hieron's Aitna und das Hieroneion. $J N G, 18$, p. 67-98.

Calciati 1987 : CALCIATI (R.) - Corpus nummorum Siculorum. La monetazione di bronzo, 3. Mortara, Ed. I.P., 1987, 435 p.

Callataÿ (de) 2004 : DE CALLATAŸ (F.) - On the style of the Aitna Master. IsrMusStA, 3, 2004, p. 45-52.

Callataÿ (de) 2005 : DE CALLATAŸ (F.) - Tétradrachmes d'Aitna et de Naxos. In : Delsaerdt et al. dir., Cent trésor de la Bibliothèque Royale de Belgique, Bruxelles, Fonds Mercator, 2005, 240 p., p. 40-41.

Callataÿ (de) 2010 : DE CALLATAŸ (F.) - The Brussels tetradrachm of Aitna: possibly the most precious ancient coin of the world. In : Panagiotis (P.I.) dir., All that glitters... : the Belgian contribution to Greek numismatics: 29 September 2010-15 January 2011, Athènes, Belgian School at Athens, 2010, 106 p., p. 80-89.

Callatä̈ (de), Gitler 2004a : DECALLATAŸ (F.),GITLER (H.)-Le tétradrachme d'Aitna : une monnaie grecque unique. Archéologia, 412, juin 2004, p. 56-60. Callataÿ (de), Gitler 2004b : DE CALLATAŸ (F.), GITLER (H.) - The coin of coins : a world premiere. Catalogue exhibition, Israel Museum (2004), Jerusalem, 2004, n. 491, 50 p.

Ciaceri 1911 : CIACERI (E.) - Culti e miti nella storia dell'antica Sicilia. Catania, 1911, Forni, 342 p.

Clarac (de) 1849 : DE CLARAC (C.) - Manuel de histoire de l'art chez les anciens : description des musées de sculpture antique et moderne du Louvre: $3^{\text {ème }}$ partie: Catalogue des artistes de l'Antiquité jusqu'à la fin du VI siècle de notre ère. Paris, J. Renouard, 1849, $418 \mathrm{p}$.

Cook 1925 : COOK (A.B.) -Zeus. A Study in Ancient Religion. Cambridge, Cambridge University Press, 1925, 3 vol.

Cusumano 1996 : CUSUMANO (N.) - Eracle e l'elemento femminile in Sicilia. Per un modello interpretativo delle forme di contatto tra indigeni e colonizzatori nella Sicilia greca. In : Jourdain-Annequin (C.), Bonnet (C.) dir., II Rencontre héracléenne. Héraclès, les femmes et le féminin. Actes du colloque de Grenoble (22-23 octobre 1992), Rome, Institut historique belge de Rome, 291 p., p. 195-214.

Cusumano 2006 : CUSUMANO (N.) - I Siculi. In : Anello (P.), Martorana (G.), Sammartano (R.) dir., Ethne e religioni nella Sicilia antica. Atti del Convegno, Palermo (6-7 dicembre 2000). Rome, Kokalos suppl. 18, Giorgio Bretschneider Editore, 2006, 435 p., p. 121-145.

De Cesare 2003 : DE CESARE (M.) - Immagini greche nella Sicilia elima. In : Il greco, il barbaro e la ceramica attica. Immaginario del diverso, processi di scambio e autorappresentazione degli indigeni, 2 Atti del convegno internazionale di studi, Catania, Caltanissetta, Gela, Camarina, Vittoria, Siracusa (14-19 maggio 2001). Rome, L'Erma di Breschneider, 2003, 3 vol., p. 113-128.

De Vido 1997 : DE VIDO (S.) - Gli Elimi. Storie di contatti e di rappresentazioni. Pise, Scuola normale superiore di Pisa, 1997, 511 p.

Furtwängler 1900 : FURTWÄNGLER (A.) - Die antiken Gemmen. Geschichte der Steinschneidekunst. Berlin und Leipzig, Gesecke \& Devrient, $1900,237 \mathrm{p}$.

Giangiulio 1983 : GIANGIULIO (M.) - Greci e non-Greci in Sicilia alla luce dei culti e delle leggende di Eracle. In : Modes de contacts et processus de transformation dans les sociétés anciennes. Actes du Colloque de Cortone (24-30 mai 1981), Rome, Scuola normale superiore, 1983, 1164 p., p. 785-845.

Gilotta 2003 : GILOTTA (F.) - Nota sull'iconografia dell'acqua nel mondo etrusco-italico. In : L'acqua degli dei 2003, p. 25-32. 
Gori 1731-1733 : GORI (A.F.) - Museum Florentinum exhibens insigni ora vetustatis monumenta quae Florentiae sunt Ioanni Gastoni Etruriae Magno Duci dedicatum. Florence, Typographia Francisci Moücke, 1731-1733, 185 p., vol. II. Guasco 1775 : GUASCO (F.E.) - Musei Capitolini antiquae inscriptiones a Francisco Eugenio Guasco eiusdem musei curatore P. nunc primum conjunctim editae notisque illustrate. Rome, excudebat Johannes Generosus Salomonius, 1775, 234 p., vol. I.

Huet 1679 : HUET (P.-D.) - Demonstratio Evangelica: ad Serenissimum Delphinum. Paris, Janssonio - Waesbergios \& Boom, 1679, 725 p.

Iozzo 2003 : IOZZO (M.) - L'acqua e le donne ad Atene. In : L'acqua degli dei, 2003, p. 17-23.

Jahn 1852 : JAHN (O.) - Die Ficoronische Cista. Eine Archäologische Abhandlung. Leipzig, Verlag von Georg Wigand, 1852, $91 \mathrm{p}$.

Köhler 1852 : KÖHLER (H.K.E.) -Gesammelte Schriften V. Kleine Abhandlungen zur Gemmen-Kunde. St. Petersbourg, Leop. Voss., 1852, 204 p., vol. II.

Koehler 1979 : KOEHLER (C.G.) - Corinthian A and B Transport Amphoras $\mathrm{PhD}$ diss., Princeton, University Microfilms, 1979.

Krauskopf 1999 : KRAUSKOPF (I.) - Interesse privato nel mito. Il caso degli scarabei etruschi. In : Massa Pairault (F.-H.) dir., Le mythe grec dans l'Italie antique. Fonction et image. Actes du colloque international (Rome 1996). Rome, 1999, École française de Rome, 670 p., p. 405-421.

Jourdain-Annequin 1982 : JOURDAIN-ANNEQUIN (C.) - Héraclès en Occident. Mythe et histoire. DialHistAnc, 8, 1982, p. 31-48.

Lejeune 1983 : LEJEUNE (M.) - Rencontres de l'alphabet grec avec les langues barbares au cours du $1^{\text {er }}$ millénaire av. J.-C. In : Modes de contacts et processus de transformation dans les sociétés anciennes. Actes du Colloque de Cortone (24-30 mai 1981), Rome, Scuola normale superiore, 1983, 1164 p., p. 731-751.

L'acqua degli dei 2003 : L'acqua degli dei. Immagini di fontane, vasellame, culti salutari e in grotta, Catalogo della mostra (Chianciano Terme 2003). Montepulciano, Logo libri, 2003, 187 p.

Mansuelli 1941 : MANSUELLI (G.A.) - Uno specchio etrusco inedito del Museo Civico di Bologna e il mito di Ercole alla fonte. Studi Etruschi, 15, 1941, p. 99-108.

Marconi 1999 : MARCONI (C.) - Eracle in terra indigena? In : VASSALLO (S.), Colle Madore. Un caso di ellenizzazione in terra sicana, Palerme, Regione Siciliana, Assessorato dei Beni Culturali e Ambientali e della Pubblica Istruzione, 1999, p. 293-305. McDonough 2002 : MCDONOUGH (C.) - Hercle and the Ciminian Lake Legend: Source Study for an Etruscan Mirror. ClJ, 98, 1, Oct. - Nov., p. 9-19. Micali 1832 : MICALI (G.) - Storia degli antichi popoli italiani. Milan, Tipografia Ranieri Fanfani, 1832, 3 vol.

Millin 1811 : MILLIN (A.L.) - Galerie mythologique. Recueil de monuments pour servir à l'étude de la mythologie, de l'histoire de l'art, de l'antiquité figurée, et du langage allégorique des Anciens. Paris, P. Didot L'Ainé, 1811, 2 vol.
Raspe, Tassie 1791 : RASPE (R.E.), TASSIE (J.) - A Descriptive Catalogue of a Generale Collection of Ancient and Modern Engraved Gems, Cameos as well as Intaglios, taken from the most celebrated Cabinets in Europe. Londres, C. Buckton, 1791,2 vol.

Reinach 1895 : REINACH (S.) - Pierres gravées des collections Marlborough et d'Orléans des recueils d'Eckhel, Gori, Levesque de Gravelle, Mariette, Millin et, Philip de Stosch, Paris, Firmin-Didot et Cie, 1895, 195 p.

Roscher 1884 : ROSCHER (W.H.) DIR. - Ausführliches Lexikon der griechischen und römischen Mythologie. Leipzig, B. G. Teubner, 1884, 6 vol.

Roul-Rochette 1845 : ROUL-ROCHETTE (M.) - Lettre à M. Schorn; supplément au catalogue des artistes de l'Antiquité grecque et romaine. Paris, De Crapelet, 1845, $104 \mathrm{p}$.

Sassatelli 1993 : SASSATELLI (G.) - Spina nelle immagine etrusche. Eracle, Dedalo e il problema dell'acqua. In : Berti (F.), Guzzo (P.G.) dir., Spina. Storia di una città tra Greci ed Etruschi, Catalogo della mostra Ferrara (26 settembre 1993 - 15 maggio 1994), Ferrare, Ferrara arte, 1993 , p. 114-127.

Sclafani 2011 : SCLAFANI (M.) - Personalità divine minori del pantheon grecotra le comunità indigene della Sicilia occidentale. In : Dalla Riva (F.M.), Di Giuseppe (H.) dir., Meetings between Cultures in the Ancient Mediterranean, Proceedings of the $17^{\text {th }}$ International Congress of Classical Archaeology, Rome 22-26 sept. 2008, Bollettino di Archeologia on line I 2010/ Volume speciale [http://151.12.58.75/archeologia] edizione speciale, C.3.3., 2011, p. 22-30.

Sjöqvist 1962 : SJÖQVIST (E.) - Herakles in Sicily. OpRom, IV, 1962, p. 117-123.

Slaska 1990 : SLASKA (M.) - Le anfore massaliote in Etruria meridionale. In : BATS (M.) dir., Les amphores de Marseille grecque. Chronologie et diffusion ( $V I^{e}-I^{e r}$ s. av. J.-C.). Actes de la table-ronde de Lattes (11 mars 1989), Lattes-Aix en Provence, ADAM, 1990, 294 p. (Études Massaliètes 2), p. 223-233.

Villoison (de) 1815 : DE VILLOISON (A.A.) - Mémoires sur différents inscriptions grecques. Mémoires de l'Institut Royal de France, Classe d'Histoire et de Littérature Ancienne, II, 1815, p. 111-161.

Visconti 1829 : VISCONTI (E.Q.) - Esposizione dell'impronte di antiche gemme del principe Agostino Chigi raccolte per uso di sua eccellenza il sig. principe D. Agostino Chigi, in Opere varie italiane e francesi di Ennio Quirino Visconti raccolte e pubblicate per cura del Dott. Giovanni Labus. Milan, Antonio Fortunato Stella e figli, 1829, 516 p., vol. II.

Wicar 1807 : WICAR (J.-B. J.) - Tableaux, statues, bas-reliefs et camées, de la Galerie de Florence et du Palais Pitti, dessinés par M. Wicar... et gravés sous la direction de M. Lacombe... ; avec les explications, par M. Mongez l'aîné... ; imprimées sur papier-vélin superfin de Johannot d'Annonay. Paris, J. P. Aillaud - C. L. F. Panckoucke, 1807, 230 p., tome 4.

Winckelmann 1760 : WINCKELMANN (J.J.) - Description des pierres gravées du feu baron de Stosch. Florence, André Bonducci, 1760, 596 p. 


\title{
Cavalli senza cavalieri. Il tripode di Cap d'Agde e i tripodi etruschi tardo-arcaici con protomi equine
}

\author{
Giacomo Bardelli \\ Römisch-Germanisches Zentralmuseum Mainz - Universität Innsbruck
}

\section{Résumé}

En 1986, un trépied étrusque a été retrouvé au large du Cap d’Agde (Hérault), au lieu-dit « Tour du Castellas ». Ce trépied appartient à une série d'exemplaires étrusques en bronze traditionnellement associée à une production de Vulci, sur le littoral des Maremmes de l'actuel Latium. Ces objets sont normalement décorés avec de petites figures en bronze fondu, situées sur l'extrémité des petites tiges et sur les éléments en forme d'arc qui les unissent. Dans l'exemplaire du Cap d'Agde, on peut voir une femme ailée et un groupe de deux protomés chevalins placés dos à dos, chacun reproduit trois fois.

La présence de ces protomés chevalins permet d'associer ce trépied avec deux autres et quelques fragments de trépieds similaires, tous ornés du même groupe. Ce rapprochement fait émerger de nouveaux questionnements comme la signification des chevaux et les raisons de leur association avec un trépied. Nous rejetons l'interprétation d'un lien entre la figure ailée et les chevaux et proposons de donner à ces chevaux la fonction d'éléments symboliques, plutôt que de simples attributs décoratifs. Grâce à quelques comparaisons, on peut rappeler la tradition de l'association entre trépieds et chevaux dès l'époque géométrique en Grèce jusqu'à l'archaïsme étrusque. Cette étude permet ainsi de réaffirmer la valeur des trépieds et des chevaux comme objets de prestige de l'aristocratie.

Mots-clés : Cap d’Agde, trépied, bronze étrusque, Vulci, chevaux, iconographie, aristocratie

\begin{abstract}
In 1986 an Etruscan rod-tripod was found in the sea off the shore of Cap d'Agde (Dep. Herault), next the so-called "Tour du Castellas". It belongs to a group of Etruscan bronze tripods which are believed to have been fabricated in the ancient city of Vulci, on the Maremma coast of Lazio. These tripods are usually decorated by small cast figures placed on the top of the rods and on the arched fittings. On the Cap d'Agde tripod, a winged woman and a group made by two addorsed foreparts of horses are visible, both replicated for three times.

The presence of the horses' foreparts relates this tripod to other two and to some fragments of similar tripods that show as well the same cast group. This circumstance raises new questions about the meaning of the horses and their association with tripods. As an interpretation which includes the female figure and the horses is rejected, these last are eventually believed not to be just decorative patterns but rather symbolic elements. Thanks to some comparisons, a traditional association between tripods and horses from the geometric era is demonstrated, thus revealing to be valid throughout both Greek and Etruscan worlds. The strong relationship between tripods, horses and aristocracy is consequently reaffirmed.
\end{abstract}

Keywords: Cap d'Agde, tripod, Etruscan bronzes, Vulci, horses, iconography, aristocracy 


\section{Il tripode di Cap d'Agde}

Rinvenuto presso la località "Tour de Castellas", al largo della costa di Sète (dipartimento dell'Hérault) nell'agosto del 1986, il tripode in bronzo (fig. 1) conservato al Musée de l'Éphèbe di Cap d'Agde (inv. ${ }^{\circ}{ }^{1171}$ ) costituisce uno degli esempi più notevoli fra i materiali etruschi diffusi nell'Occidente mediterraneo e fu opportunamente reso noto fin dal momento del suo ritrovamento (Fonquerle 1986, p. 117). Il tripode, in buono stato di conservazione, è quasi completamente integro ${ }^{1}$ e appare impreziosito dalla presenza di decorazioni figurate in bronzo fuso che ne ornano la parte superiore (Mystère des bronzes antiques, p. 67).

Sulla base delle caratteristiche tipologiche e formali - piedi configurati a zampa felina, struttura portante ad aste e decorazioni in bronzo fuso - l'esemplare può essere facilmente annoverato tra i tripodi appartenenti alla serie vulcente della classe cosiddetta "a verghette", ormai definita nei suoi aspetti essenziali da lungo tempo (Riis 1939, p. 22-30; Neugebauer 1943, p.210-233; Riis 1998), ma tuttora priva di uno studio completo che affronti problemi ancora irrisolti di carattere stilistico, funzionale e cronologico ${ }^{2}$. Ciò spiega in parte perché il tripode di Cap d'Agde abbia finora ricevuto scarsa attenzione da parte degli etruscologi ${ }^{3}$, suscitando piuttosto l'interesse di quanti si sono occupati del commercio e della diffusione di materiali etruschi tra la Francia meridionale e la penisola iberica (Gran-Aymerich 2002, p. 208-209, p. 215; Gran-Aymerich 2006, p. 257).

Il contesto di rinvenimento, sfortunatamente, non aiuta a spiegare la presenza del tripode, né permette di ottenere indizi utili per la datazione, dal momento che le anfore rinvenute sul fondale marittimo in prossimità del tripode non sono ad esso associabili con assoluta certezza e indicano comunque una cronologia molto bassa ${ }^{4}$. Una collocazione cronologica approssimativa può essere suggerita dal confronto con altri tripodi dello stesso tipo e dall'analisi stilistica delle decorazioni figurate, chiaramente dipendenti dall'influsso ionico

1 Al momento del ritrovamento mancavano un piede, una delle figure femminili alate, quasi tutte le verghette orizzontali di raccordo tra i piedi e il probabile coronamento circolare fissato ai gruppi figurati.

2 I tripodi a verghette etruschi costituiscono il tema della mia ricerca di dottorato presso la Leopold-Franzens-Universität di Innsbruck, attualmente in corso sotto la guida del Prof. Alessandro Naso e finanziata dal RGZM di Mainz.

3 Eccetto Torelli 1986. Il tripode fece inoltre parte dei materiali esposti a Venezia nel 2000 in occasione della mostra sugli etruschi, per cui cf. BÉRARD-AZZOUZ (O.) - Tripode. In: Torelli (M.) dir., Gli etruschi, catalogo dell'esposizione (Venezia, Palazzo Grassi, 26 novembre 2000 - 1 luglio 2001), Milano, Bompiani, 2000, p. 557, n. 54.

4 Fonquerle 1986, p. 120; Garcia 2002, p. 79; Bergès 2003, p. 18; Berard-Azzouz 2003 tardo-arcaico e pertanto collocabili sullo scorcio del VI sec. a.C. (Torelli 1986, p. 120).

L'occasione di questo omaggio a Michel Bats permette di riconsiderare il tripode da un differente punto di vista, non tanto per discuterne il significato all'interno del contesto del Golfo del Leone, impresa peraltro non facile, quanto per approfondire il suo legame con una serie di esemplari a esso legati attraverso l'esegesi di un comune elemento iconografico. Il riesame del tripode consente infatti di guadagnare importanti elementi per la revisione di alcuni frammenti e offre lo spunto per ulteriori considerazioni circa la scelta e il significato delle decorazioni figurate poste a ornamento di alcuni esemplari affini.

\section{I tripodi etruschi decorati con protomi equine}

La caratteristica più interessante del tripode di Cap d'Agde è senza dubbio la sua decorazione figurata in bronzo fuso. Essa consiste in due soggetti principali, replicati per tre volte a fusione piena a partire dallo stesso modello e disposti in ordine alterno a coronamento della zona sommitale del tripode. Più precisamente, ciascuna delle verghette verticali isolate è ornata da una figura femminile con quattro ali (fig. 2), rappresentata nell'atto di incedere verso sinistra (una delle tre figure è purtroppo mancante, ma è verosimile pensare che si trattasse di una ripetizione delle altre due). Sugli archetti che collegano tra loro le altre verghette sono invece collocate le protomi di due cavalli, divergenti e con le zampe anteriori flesse (fig. 3).

Il tripode di Cap d'Agde non rappresenta un unicum: proprio la doppia protome equina si dimostra un dettaglio particolarmente interessante, poiché costituisce il trait d'union tra il tripode e altri esemplari della stessa serie. Fin dalle prime osservazioni ne fu giustamente sottolineata la "parentela" con un altro tripode, da Vulci, conservato al City Art Museum di Saint Louis (inv. $n^{\circ} 37.26$ ), anch'esso ornato da motivi vegetali e da protomi di cavallo, oltre che molto simile al precedente dal punto di vista stilistico (Riis 1998, p. 32, fig. 22). Il motivo delle protomi equine è condiviso anche da un terzo tripode, sempre rinvenuto a Vulci e oggi al British Museum di Londra (inv. $\mathrm{n}^{\circ} \mathrm{Br} .588$ ), che mostra però alcune differenze sotto il profilo stilistico e compositivo rispetto ai primi due (Haynes 1985, p. 264, n52). Grazie alla caratteristica comune della doppia protome equina è possibile ampliare questo ristretto gruppo di tripodi.

Vale allora la pena di riconsiderare tre frammenti figurati adespoti molto simili tra loro, per non dire identici, formati da un elemento ad arco con decorazione 
fitomorfa a esso sottesa, sopra il quale è collocata una doppia protome equina con orientamento divergente; i tre oggetti, poco noti benché pubblicati e qui presentati insieme, sono tuttora conservati, rispettivamente, presso l'Antikensammlung di Monaco (fig. 4), il Fitzwilliam Museum di Cambridge (fig. 5) e l'Ashmolean Museum di Oxford (fig. 6) ${ }^{5}$. Già a prima vista è evidente l'affinità rispetto agli archetti con cavalli dei tripodi citati in precedenza, pertanto non c'è alcun dubbio che ciascuno dei frammenti debba essere interpretato come l'elemento strutturale in cui si inserivano le verghette di un tripode. Lo stretto legame fra i tre oggetti fu giustamente notato da Poul Jørgen Riis, che tuttavia si limitò solamente a sottolineare la condivisione del tipo iconografico (Riis 1998, p. 33, fig. 23 e n. 76). Grazie a un'analisi autoptica dei tre frammenti è stato possibile non solo confermarne la già evidente somiglianza, ma anche certificare l'assoluta coincidenza tra le dimensioni e i dettagli tecnici di ognuno di essi ${ }^{6}$. Ciascun frammento è infatti il risultato di un'unica fusione e presenta due ribattini inseriti all'altezza della nuca dei cavalli, più due fori sul lato posteriore, probabilmente funzionali al fissaggio di un coronamento circolare, come nel caso del già citato tripode del British Museum ${ }^{7}$; in tutti i casi, inoltre, sembra che le verghette siano state inserite meccanicamente all'interno di fori appositamente predisposti. Alle strette similarità di carattere stilistico se ne aggiungono pertanto alcune di stampo puramente tecnico, a tal punto omogenee e regolari da far pensare con ragionevolezza che i tre elementi figurati fossero originariamente parte del medesimo tripode, forse rinvenuto già in condizioni frammentarie e andato disperso in molteplici collezioni ${ }^{8}$. Al pari di questo tripode, l'esistenza di un altro è dimostrabile a partire da due elementi molto simili rappresentanti la consueta doppia protome al di sopra di un elemento arcuato (Haynes 1985, p. 264,

5 Rispettivamente, inv. $n^{\circ} 3852, n^{\circ}$ GR.1.1952 e $n^{\circ} 1965.290$.

6 Di seguito le dimensioni degli oggetti: a) München, Antikensammlung, inv. $\mathrm{n}^{\circ} 3852$ - a. $14,1 \mathrm{~cm} ; 1.8,3 \mathrm{~cm}$; diam. fr. verghette $0,8 \mathrm{~cm}$; b) Cambridge, Fitzwilliam Museum, inv. ${ }^{\circ}$ GR.1.1952 - a. $14 \mathrm{~cm}$; 1. 8,1 cm; diam. fr. verghette $0,8 \mathrm{~cm}$; c) Oxford, Ashmolean Museum, inv. ${ }^{\circ} 1965.290$ - a. 13,7 cm; 1. 8,3 cm; diam. fr. verghette $0,8 \mathrm{~cm}$. Desidero ringraziare il Dr. Matthias Steinhart (Antikensammlung München), la Dr. Lucilla Burn (Fitzwilliam Museum, Cambridge) e il Dr. Michael J. Vickers (Ashmolean Museum, Oxford) per avermi accordato il permesso di visionare e misurare i materiali.

7 Questo tipo di ribattini non è visibile sugli altri esemplari con protomi equine appartenenti alla serie, contribuendo così ad accrescere le somiglianze tra i tre bronzetti.

8 Significativamente, prima di entrare a far parte delle attuali raccolte museali, tutti i frammenti appartennero a collezioni private, anche se non è possibile ricostruire ulteriormente le vicende di ciascuno di essi. $\mathrm{n}^{\circ} 52$ ) (fig. 7-8) ${ }^{9}$. Benché molto danneggiati (in entrambi i casi la decorazione fitomorfa non è conservata), i due frammenti sono chiaramente identificabili come parti di tripode e, al di là di alcune differenze di carattere stilistico, essi mostrano esattamente la stessa struttura degli elementi ad arco con cavalli già osservati in precedenza .

Se vale quanto osservato circa i frammenti appena citati, è allora possibile aggiungere altri due tripodi al ristretto gruppo degli esemplari con protomi equine. Queste acquisizioni hanno una certa importanza considerate in rapporto all'insieme della serie dei tripodi a verghette vulcenti, dove è possibile osservare una limitata, ma costante varietà di soggetti prescelti come ornamento degli archetti. Dopo il gruppo figurato con lotta tra due animali - presente su una decina di tripodi -, il motivo della doppia protome equina è infatti il più frequente. Senza dubbio va ricordato il favore incontrato dall'iconografia del cavallo negli oggetti etruschi in bronzo di età arcaica, ben evidenziato da Poul Jørgen Riis, che proprio nei cavalli riconobbe uno degli elementi principali di un motivo-guida (la cosiddetta "Horse-Lion-And-Acrobat Tradition") identificato all'interno del suo studio sulla bronzistica di Vulci arcaica (Riis 1998, p. 22). Per quanto riguarda $\mathrm{i}$ tripodi, se tale soggetto iconografico appare una costante condivisa da più esemplari oltre a quello di Cap d'Agde, la comprensione del significato della decorazione di quest'ultimo non potrà in nessun caso prescindere da una riflessione espressamente dedicata alla presenza delle protomi equine.

\section{Cavalli e tripodi: un'antica tradizione}

L'interpretazione delle figure del tripode di Cap d'Agde ha occupato finora un ruolo molto marginale all' interno degli interventi dedicati al tripode. Per quanto riguarda la donna, essa è vestita di un lungo chitone e indossa calzari leggermente appuntiti ai piedi, ma non presenta particolari attributi al di là della doppia coppia di ali. In passato è stata proposta da Mario Torelli un'identificazione con Eos/Thesan o con un'Artemide alata, sulla base di confronti con raffigurazioni incise su specchi etruschi di età tardo-arcaica (Torelli 1986, p. 120). La presenza dei cavalli, invece, non è mai stata adeguatamente valorizzata, non solo in relazione a un loro eventuale collegamento con la figura femminile, ma neppure come soggetto a sé stante. Per questi motivi, dopo aver sottolineato la relativa frequenza con cui

9 Entrambi i frammenti appartenevano un tempo alla collezione privata di S. Schweizer e compaiono in un catalogo d'asta di Sotheby's del 15 luglio 1980, p. 47, nº77-78. 
occorrono le protomi equine, appare legittimo domandarsi in che modo esse possano essere interpretate.

Una prima soluzione è naturalmente quella di cercare un collegamento tra la donna alata e i cavalli. Se si segue Mario Torelli, l'identificazione della figura femminile con Thesan si accorda molto bene con la presenza dei cavalli (Lampos e Phaeton, che secondo Omero trainavano il carro di Eos - Od., XXIII, 244-246), anche se questi non sono alati. L'idea di una Artemide nella sua accezione di Potnia theron (in questo caso Potnia hippon) sembra invece poco probabile. In generale, nessuna delle due iconografie associata ai cavalli sembra trovare diffusione in Etruria durante il periodo tardo-arcaico. Se per l'iconografia di Thesan con quattro ali esistono dei paralleli (es. un'hydria ceretana con rappresentazione dell'episodio di Thesan e Cefalo, per cui cf. CVA Paris, Louvre (9), III F a, pl. 10, n³-4), non altrettanto si può dire per Thesan con i cavalli, motivo che diventa decisamente più popolare in epoca tardo-classica ed ellenistica (per l'iconografia di Thesan cf. Bloch, Minot 1986). Un'identificazione con Thesan fu proposta da Otto Wilhelm von Vacano per il tipo dell'antefissa della dea con cavalli dal santuario $B$ di Pyrgi (dea che però non ha le ali; von Vacano 1979 [1981], p. 156), ma recentemente Erika Simon ha suggerito di interpretare la stessa figura come Selene/Artemide (Simon 2007, p.54). Quanto all'ipotesi di Artemide, la sua identificazione con la Potnia theron in Etruria durante l'epoca arcaica pone diversi problemi (Krauskopf 1984, p. 786-787). Ancora più isolato sarebbe il caso della Potnia hippon, che non trova però paralleli al di là della discussa dea con i cavalli di Pyrgi (in generale, sulla Potnia hippon cf. anche Scheffer 1994 e Gangutia 2002) ${ }^{\mathbf{1 0}}$.

A questo punto, tuttavia, diventa necessario avanzare un'obiezione di carattere metodologico, chiedendosi fino a che punto sia lecito interpretare congiuntamente i due soggetti figurati. La spiegazione più evidente, che porta a optare per una risposta negativa, risiede nella varietà dei soggetti associati di volta in volta alle protomi equine sugli altri tripodi. Nel tripode del British Museum i cavalli sono intervallati da tre personaggi che nulla hanno a che vedere con le figure femminili alate del tripode di Agde: vi si trovano infatti Eracle, una figura maschile alata che trasporta una fanciulla e un guerriero

10 Nonostante le difficoltà riscontrate, queste proposte restano valide anche qualora si volesse considerare la figura alata indipendentemente dalla semantica dei cavalli. Una riflessione più generale ed estesa anche ad altri casi di figure femminili alate non altrimenti identificabili sarebbe possibile a partire dall'idea di una Potnia hippon "destrutturata" per via di una perdita di fortuna del tema iconografico, ma ciò esula dal contenuto del presente contributo. Desidero ringraziare il Prof. Mario Torelli per l'utile discussione e i suggerimenti.

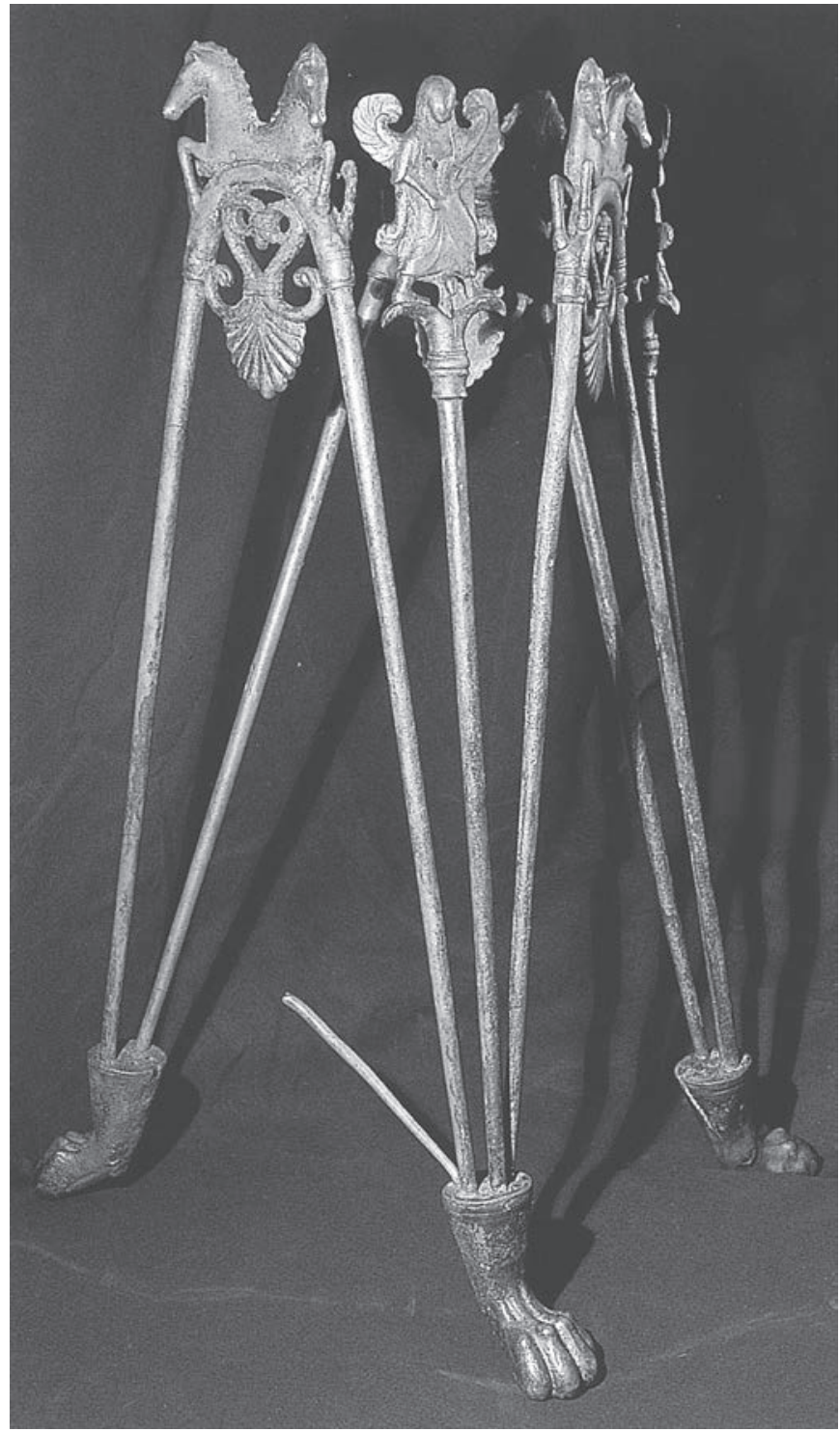

Fig. 1. Il tripode etrusco di Cap d'Agde (da: Mystère des bronzes antiques, p. 67).

armato (per l'interpretazione cf. Krauskopf 1987, p. 19). Lo stesso discorso è valido anche per il tripode di Saint Louis, dove ai cavalli si affiancano due figure femminili e una maschile, tutte secondo lo schema della corsa inginocchiata (su questo tripode cf. Torelli 1986, p. 120). Ora, se per il tripode di Cap d'Agde un collegamento tra la donna alata e le protomi equine non sarebbe da escludere a priori, negli altri due casi la presenza delle protomi non appare in alcun modo giustificabile all'interno di un contesto semantico che comprenda anche gli altri soggetti. Se si considera la regolarità con cui compaiono i cavalli, sempre in coppia e sempre collocati sugli archetti a intervallare le altre figure, si dovrà dedurre l'impossibilità di interpretare il motivo come parte integrante di ciascuna delle scene o degli episodi che ornavano il coronamento superiore di questi tripodi. 


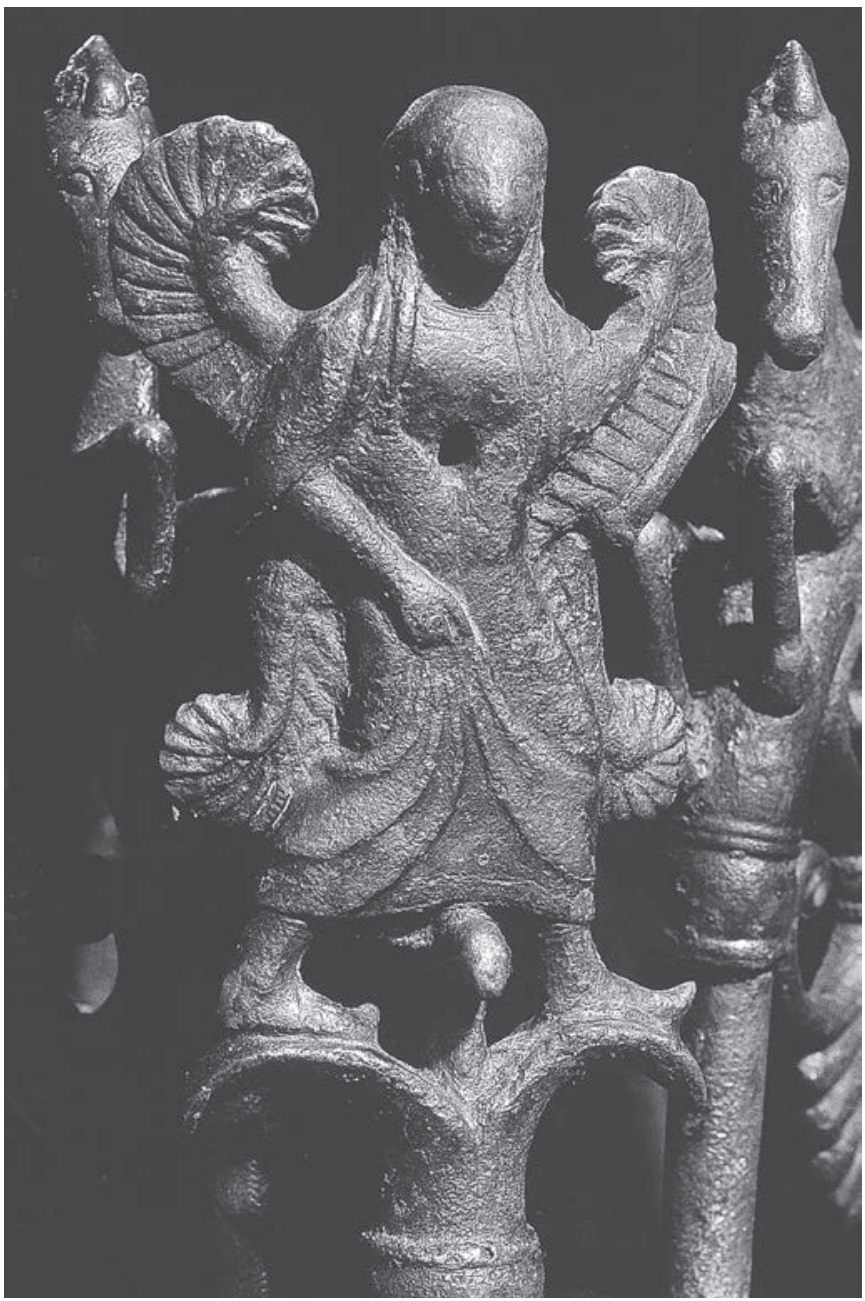

Fig. 2. Tripode di Cap d'Agde: dettaglio con la figura femminile alata (da: Mystère des bronzes antiques, p. 5).

I cavalli, pertanto, appaiono in veste di elemento isolato e a sé stante, nonché caratterizzato da una funzione marcatamente paratattica, piuttosto che narrativa.

Da un punto di vista strettamente iconografico appare abbastanza agevole rintracciare dei paralleli per il raddoppiamento della protome, già noto secondo il medesimo schema in Oriente e in Grecia (Herrmann 1968) e molto diffuso nel corso del VI sec. a.C. in altre classi di materiali tra Grecia, Italia meridionale ed Etruria, ad esempio su montanti di morso di cavallo (Lo Schiavo, Romualdi 2009, p. 75-78), anse orizzontali di hydriai (Rolley 1982, pl. 16, fig. 70), manici di bacino (Bellelli 2006, pl. 40) e su un curioso oggetto in bronzo dalla tomba 306 della necropoli di Spina in Valle Trebba, interpretato da Giuseppe Sassatelli come impugnatura di una lucerna ad olio (cf. l'intervento senza titolo in Spina e il delta padano, p. 165). Non sembra invece possibile stabilire se il doppio cavallo sia anche interpretabile in riferimento a un soggetto determinato

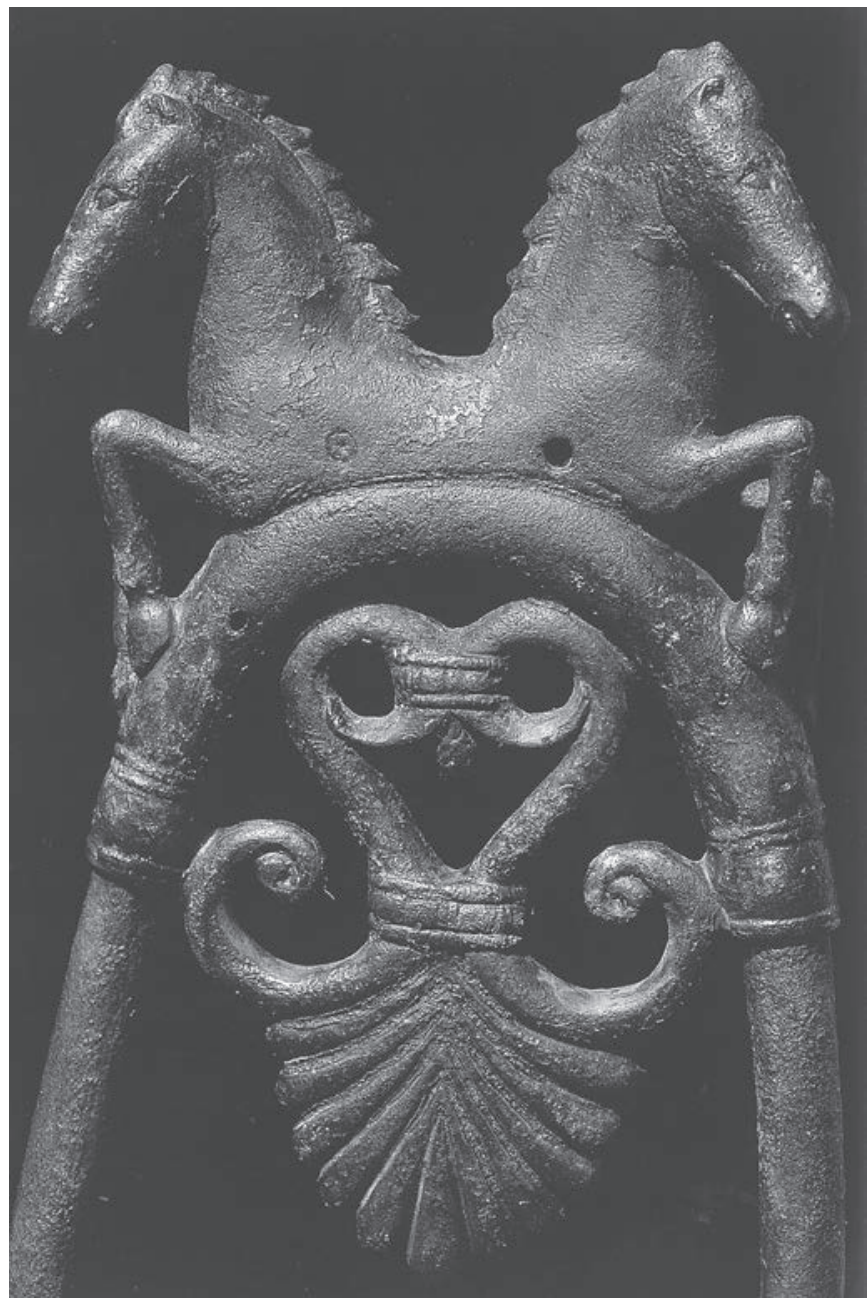

Fig. 3. Tripode di Cap d'Agde: dettaglio dell'arco con doppia protome equina (da: Mystère des bronzes antiques, p. 66).

(es. come reminescenza del motivo del Despotes hippon o come simbolo dei cavalli di una biga) ${ }^{11}$.

Un'alternativa possibile potrebbe essere quella di considerare le protomi come un riempitivo dalla semplice valenza decorativa. Riconoscere come le rappresentazioni di cavalli nel mondo antico fossero frequentissime sarebbe tuttavia fin troppo banale, né una riflessione generale sull'utilizzo e sui significati di questo soggetto potrebbe trovare spazio in questa sede e risultare adeguata al caso preso in esame. Pertanto, il fatto che il motivo venga riprodotto sui tripodi a verghette con una certa frequenza e secondo precise modalità, come testimoniato anche dai frammenti sopra ricordati, induce a scartare la tesi semplicistica di un suo valore meramente decorativo.

11 Le ipotesi, per quanto affascinanti, non presentano al momento alcun elemento per poter essere sostenute e dovranno essere considerate con prudenza. Ringrazio la Dott. Natacha Lubtchansky per la discussione su questo tema. 


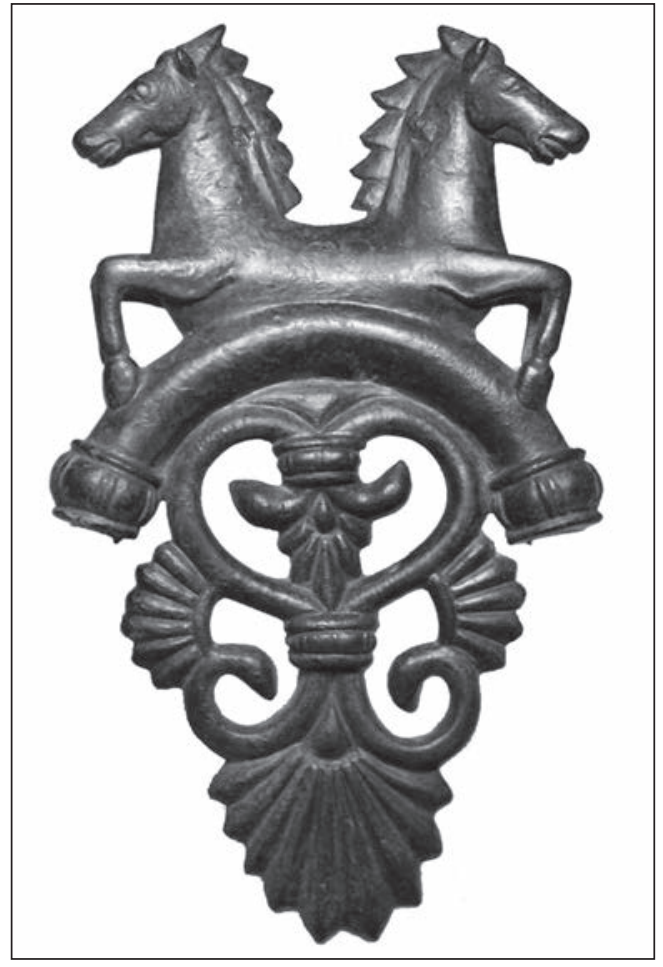

Fig. 4. Arco di tripode con doppia protome equina Antikensammlung, Münich (da: Riis 1998, p. 33, fig. 23).

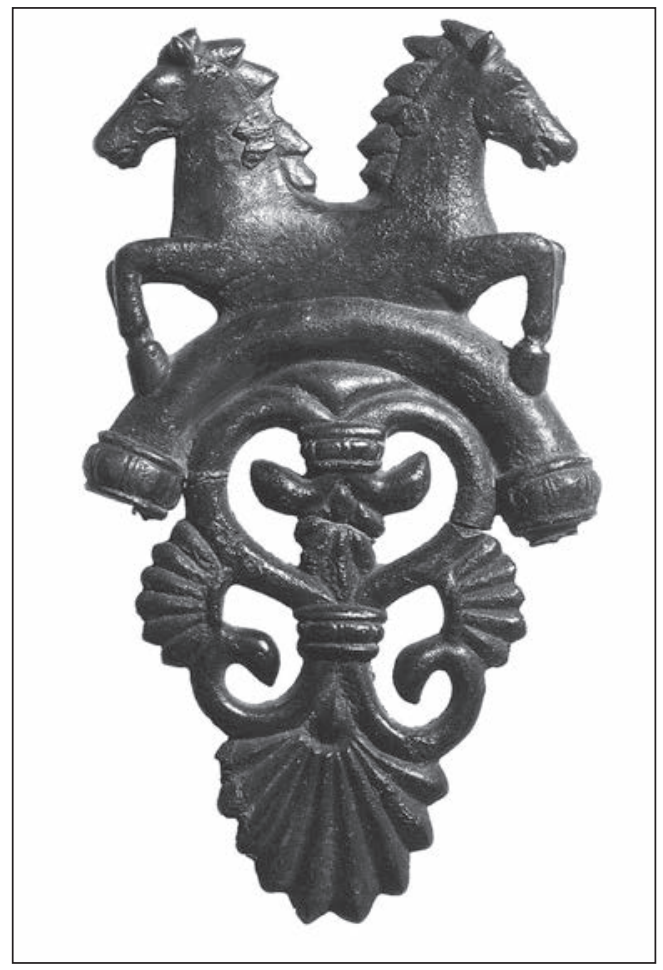

Fig. 5. Arco di tripode con doppia protome equina. Fitzwilliam Museum, Cambridge (da: Vassilika 1998, p. 39).

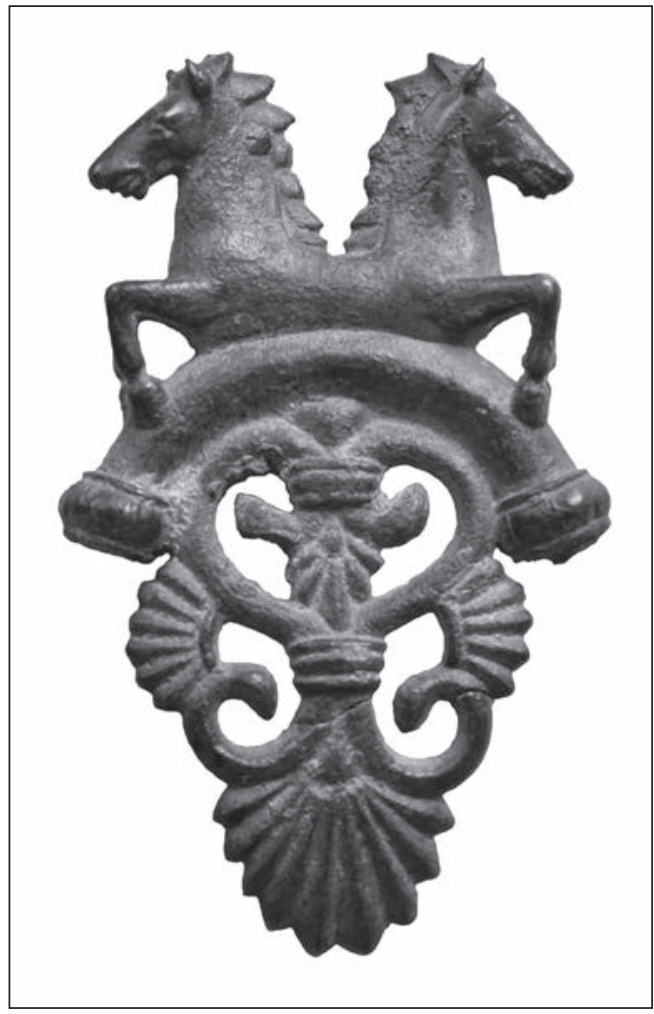

Fig. 6. Arco di tripode con doppia protome equina. Ashmolean Museum, University of Oxford (da: foto Bardelli). 


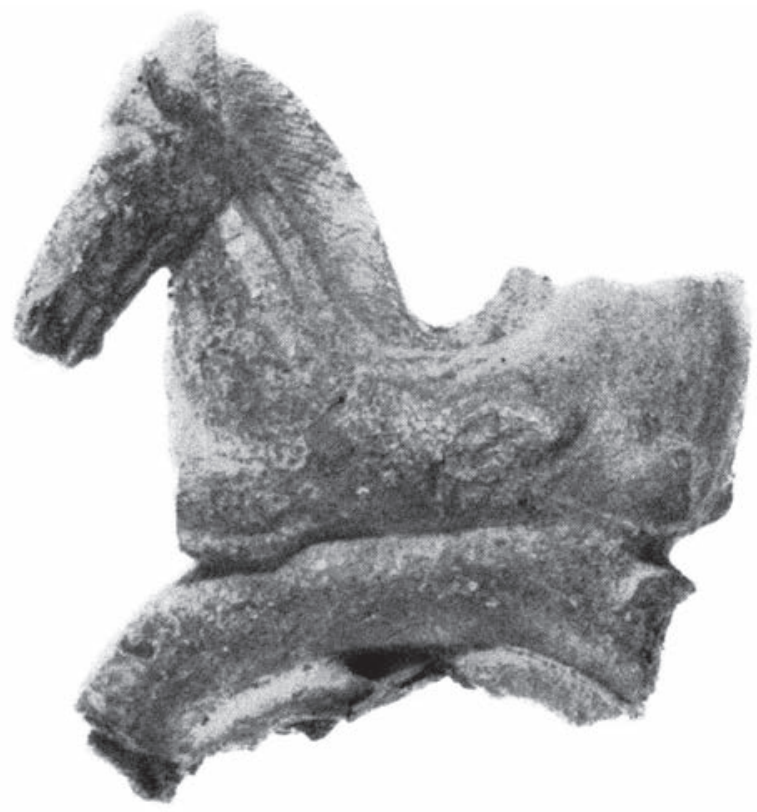

Fig. 7. Frammento di arco di tripode con doppia protome equina (da: Sotheby's auction catalogue, 15th July 1978, p. 47, n. 77).

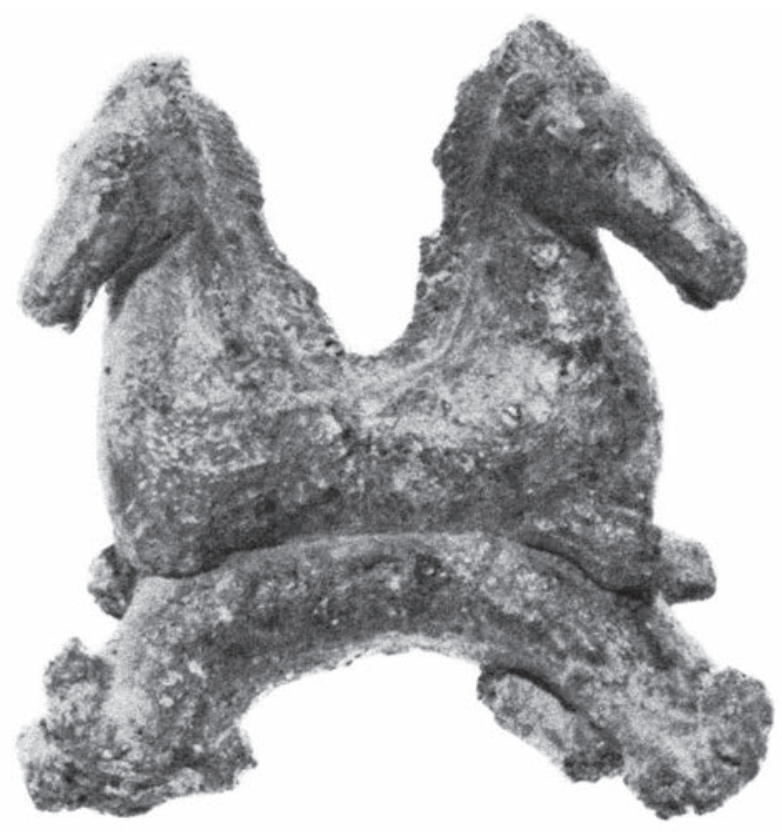

Fig. 8. Frammento di arco di tripode con doppia protome equina (da: Sotheby's auction catalogue, 15th July 1978, p. 47, n. 78).
In questo senso, una chiave di lettura più convincente si ottiene restringendo l'analisi ai casi in cui $\mathrm{i}$ cavalli, interi o raffigurati come pars pro toto, compaiono in associazione ai tripodi. Lo sguardo può essere rivolto in primis al mondo greco, dove troviamo le radici dell'associazione tra tripodi e cavalli a partire dall'epoca geometrica. Già sui tripodi greci di tipo geometrico, infatti, sono spesso presenti figurine di cavallo, normalmente collocate in corrispondenza dei grandi manici ad anello che ornavano il calderone (Maas 1978, p. 105110, pl. 35-43); i cavalli compaiono in forma di protome isolata anche sui tripodi a verghette dedicati nei grandi santuari di Olimpia e di Samo, disposti sull'anello di coronamento superiore ${ }^{12}$. Analogamente, il motivo è presente sugli splendidi esemplari a verghette rinvenuti al di fuori della Grecia, a Metaponto e a Trebenište ${ }^{13}$, nonché su un tripode affine di provenienza ignota conservato al Metropolitan Museum di New York ${ }^{14}$. È inoltre interessante notare come uno o due cavalli affiancati a un tripode siano il soggetto caratteristico di molte pitture vascolari, a partire dalla ceramica attica di epoca geometrica (Sakowski 1997, p. 33-43, n. 227-231) fino

12 Es. Herrmann 1979, p. 183, nS44; Gehrig 2004, p. 276-278, pl. 124-125; Bieg 2002, p. 52.

13 Bieg 2002, p. 57-58, fig. 44a-c, 45a-b; p. 152-153, nST41, ST42.

14 Picón (C.A.) - Tripod. BMM, 55, 2, 1997, p. 10. a diversi esemplari appartenenti a una classe di dinoi di epoca orientalizzante, rinvenuti in diversi centri del Metapontino: disposti quasi in maniera araldica, i cavalli sono raffigurati ai lati di un grande tripode, a ulteriore conferma dell'importanza e della diffusione di questo motivo iconografico (Orlandini 1991, p. 6-7).

Seguendo questo percorso, si noterà come anche in Etruria i cavalli fossero da tempo associati ai tripodi prima del caso degli esemplari vulcenti. Il motivo della doppia protome divergente compare su cinque piccoli finali di bronzo e ferro rinvenuti a Trestina e privi di confronti, per i quali è stata proposta, anche se con riserva, l'appartenenza a tripodi miniaturistici (Lo Schiavo, Romualdi 2009, p. 78-79, fig. 30). Singole protomi equine, invece, si alternano a teste di leone su un tripode arcaico da San Vincenzo, ora a Copenhagen (Riis 1998, p. 22-23). Leggermente diverso, ma non trascurabile, è il caso della cospicua serie di tripodi bronzei con cavallini prodotti a Vetulonia e a Veio, databili tra la fine dell'VIII sec. e l'ultimo quarto del VII sec. a.C. (Nachbaur 2011). Benché la loro funzione non sia del tutto chiara, è innegabile che questi oggetti ricordino molto da vicino la struttura dei tripodi geometrici, così come geometrica è l'ispirazione alla base delle figurine di cavallo che ne decorano le gambe ${ }^{15}$.

15 Su questo tipo di tripodi, tuttavia, i cavalli sono presenti sia isolati che in compagnia dei rispettivi cavalieri. 


\section{Cavalli senza cavalieri. Quale significato?}

Come si è potuto osservare, l'esistenza di una vera e propria tradizione decorativa che associa tripodi e cavalli appare pienamente dimostrabile e permette di escludere che la presenza delle protomi equine sui tripodi a verghette etruschi sia dovuta a un desiderio decorativo occasionale dei toreuti vulcenti. Il riconoscimento di tale tradizione pone a questo punto un ulteriore problema, ovvero l'interpretazione del significato dei cavalli.

In Grecia sia i cavalli che i tripodi erano compresi fra i premi per la vittoria negli agoni, come ricordava già Omero (Il. XXIII, 259-260); ciononostante, l'esistenza di un unico premio che consistesse in un tripode più uno o due cavalli non è attestata (Sakowski 1997, p. 38). In ogni caso, una simile usanza sembra ignota in Etruria e non pare al momento dimostrabile. Un'importante caratteristica condivisa da cavalli e tripodi risiede però nella loro connotazione di oggetti legati all'ideologia aristocratica ed è sicuramente valida tanto nel mondo greco quanto in quello etrusco.

Per quanto riguarda i cavalli, è fondamentale ricordarne l'importanza, a partire dal valore di status symbol all'interno di molti contesti delle società del Mediterraneo antico, fino al ruolo di fondamentale significato sociologico e ideologico soprattutto in area tirrenica, come dimostrato da Natacha Lubtchansky (Lubtchansky 2005, p. 257-265). Giova inoltre ricordare come proprio a Vulci, da un deposito votivo in località Banditella, siano venuti alla luce in anni recenti due cavallini in bronzo, datati da Alessando Naso alla fine dell'VIII - inizio VII sec. a.C. e interpretati come parte della decorazione applicata al coperchio di un grande recipiente che prevedeva forse anche la presenza di un Despotes hippon, a ulteriore testimonianza della diffusione in Etruria di un immaginario e di ideali legati a pratiche votive già proprie degli aristoi greci (Naso 2009 [2012]).

Analogamente, i tripodi costituivano uno dei doni votivi più cari alle élites, come testimoniano sia le fonti sia i numerosissimi frammenti rinvenuti all'interno dei principali santuari greci (Bieg 2002, p. 16); del tutto aristocratica, inoltre, era la pratica del banchetto, nella quale il tripode rientra di diritto in qualità di arredo fondamentale. L'usanza etrusca di deporre in tomba quei beni di prestigio che in Grecia finivano normalmente nei santuari veniva adottata anche per $\mathrm{i}$ tripodi. Anche se i contesti vulcenti dei tripodi a verghette sono quasi del tutto ignoti, il fatto che tali oggetti venissero deposti in tomba anche molte generazioni più tardi, come attestato da alcuni corredi al di fuori dell'Etruria propria ${ }^{\mathbf{1 6}}$, non può che confermarne il valore di preziosi keimelia tesaurizzati per anni e lascia supporre che giungessero in tali contesti secondo precise dinamiche di scambio tra pares (Guggisberg 2001 [2004]).

In conclusione, a prescindere da tipologia, funzione e destinazione finale dei tripodi, il loro valore altamente simbolico si spiega molto bene all'interno di comunità aristocratiche e ben si accorda con un'iconografia come quella del cavallo. I tripodi etruschi, al pari di quelli greci, dovevano innanzitutto possedere un forte valore evocativo, al di là della funzione pratica alla quale erano destinati. Per questo motivo, la scelta di rappresentare l'elemento equino nella porzione semanticamente più significativa dell'oggetto, ovvero il coronamento superiore, non poteva essere casuale. Non solo, infatti, tale associazione riproponeva una tradizione iconografica già canonica per i tripodi greci, ma si inseriva perfettamente all'interno di un'imagerie aristocratica di antichissime radici e ancora percepita come valida in Etruria sullo scorcio del VI sec. a.C. Slegate dal contesto simbolico o narrativo delle figure alle quali erano associate, le protomi equine dei tripodi vulcenti possono a buon diritto essere considerate come veri e propri attributi caratterizzanti.

Al termine di questa indagine, il tripode di Cap d'Agde riacquista un ruolo importante all'interno della serie dei tripodi a verghette vulcenti come esemplare di un gruppo fortemente connotato dalla presenza delle protomi equine. Comunque si voglia interpretare la figura alata, è chiaro che i cavalli si alternano ad essa con funzione simbolica, ma non entrano a far parte di un'eventuale interpretazione dei soggetti figurati secondo un'esegesi unitaria. Questa acquisizione pone ovviamente ulteriori interrogativi, soprattutto in relazione al gruppo dei tripodi dove, sugli archetti, è raffigurato il motivo della lotta tra animali. In ogni caso, appare ulteriormente ridimensionata la vecchia idea che i soggetti raffigurati su questi tripodi avessero un semplice valore ornamentale, scevro di qualunque contenuto semantico (Guarducci 1936, p. 46-47), come è già stato dimostrato in altre occasioni (Zancani Montuoro 1946-48; Jannot 1977). Molto più difficile, invece, è spiegare le ragioni della presenza di un tripode di questa classe nelle acque del Golfo del Leone. Per il momento ci si accontenterà di aver ridestato l'attenzione intorno a un monumento dell'artigianato etrusco altrimenti troppo poco indagato.

16 Ad esempio, i contesti di due tripodi rinvenuti, rispettivamente, nella necropoli di Spina e in una tomba celtica del Rheinland-Pfalz (presso Bad Dürkheim) testimoniano bene questa pratica. 


\section{Bibliografia}

Bellelli 2006 : BELLELLI (V.) - La tomba principesca dei Quattordici ponti nel contesto di Capua arcaica. Rome, L' «Erma» di Bretschneider, 2006 (Studia Archaeologica 142).

Bérard-Azzouz 2003 : BÉRARD-AZZOUZ (O.) - Trépied Étrusque. In : Mystère des bronzes antiques, p. 67.

Bergès 2003 : BERGÈS (C.) - L'archéologie sous les eaux en France, 50 ans d'Histoire. In : Mystère des bronzes antiques, p. 10-23.

Bieg 2002 : BIEG (G.) - Hochdorf V. Der Bronzekessel aus dem späthallstattzeitlichen Fürstengrab von Eberdingen-Hochdorf (Kr.Ludwigsburg). Griechische Stabdreifüße und Bronzekessel der archaischen Zeit mit figürlichem Schmuck. Mit Beiträgen von Peter Eichhorn und Werner Gauer. Stuttgart, Kommissionsverlag/Konrad Theiss Verlag, 2002 (Forschungen und Berichte zur Vor- und Frühgeschichte in Baden-Württenberg, Band 83).

Bloch, Minot 1986 : BLOCH (R.), MINOT (N.) - Thesan. LIMC, III, 1986, p. 789-797.

Fonquerle 1986 : FONQUERLE (D.) - Le trépied étrusque et le mobilier d'accompagnement dans le gisement sous-marin de « La Tour du Castellas » (côte languedocienne du département de l'Hérault). DHA, 12, 1986, p. 111-119.

Gangutia 2002 : GANGUTIA (E.) - La Potnia equina. Emerita, 70, 2002, p. $9-44$.

Garcia 2002 : GARCIA (D.) - Le trépied étrusque du gisement de La Tour du Castellas. In : Long (L.), Pomey (P.), Sourisseau (J.-C.) dir., Les Étrusques en mer. Épaves d'Antibes à Marseille, Exposition Musée d'Histoire de Marseille, Aix-en-Provence, Édisud, 2002, p. 78-79.

Gehrig 2004 : GEHRIG (U.) - Die Greifenprotomen aus dem Heraion von Samos. Bonn, Habelt, 2004 (Samos, 9).

Gli Etruschi e il Mediterraneo : DELLA FINA (G.M.) dir., Gli Etruschi e il Mediterraneo. Commercio e politica, Atti del XIII Convegno Internazionale di Studi sulla Storia e l'Archeologia dell'Etruria (Orvieto, 2005), Rome, Edizioni Quasar, 2006 (Annali della Fondazione per il Museo «Claudio Faina », 13).

Gran-Aymerich 2006 : GRAN-AYMERICH (J.) - Les Étrusques et l'extrême Occident $\left(\mathrm{VII}^{\mathrm{e}}-\mathrm{V}^{\mathrm{e}}\right.$ siècle av. J.-C.) : regards sur l'isthme gaulois et la Péninsule Ibérique. In: Gli Etruschi e il Mediterraneo, p. 253-283.

Gran-Aymerich, Gran-Aymerich 2002 : GRAN-AYMERICH (J.), GRANAYMERICH (É) - Les Étrusques en Gaule et en Ibérie: du Mythe à la réalité des dernières découvertes. EtrStud, 9, 2002, p. 207-226.

Guarducci 1936 : GUARDUCCI (M.) - I bronzi di Vulci. Studi Etruschi, 10, 1936, p. 15-53.

Guggisberg 2001 [2004] : GUGGISBERG (M.A.) - Keimelia: Altstücke in fürstlichen Gräbern diesseits und jenseits der Alpen. In : Guggisberg (M.A.) dir., Die Hydria von Grächwil. Zur Funktion und Rezeption mediterraner Importe in Mitteleuropa im 6. und 5. Jahrhundert v. Chr. Akten internationalen Kolloquiums (Bern, 12.-13- Oktober 2001), Bern, Verlag Bernisches historisches Museum, 2004, (Schriften des Bernischen Historischen Museums, 5), p. 55-63.

Haynes 1985: HAYNES (S.) - Etruscan Bronzes. Londres, Sotheby's Publications, 1985.

Herrmann 1979 : HERRMANN (H.-V.) - Die Kessel der Orientalisierenden Zeit, 2. Kesselprotomen und Stabdreifüße. Berlin, Verlag W. de Gruyter \& co., 1979 (Olympische Forschungen, Band 11).

Herrmann 1968 : HERRMANN (H.-V.) - Frühgriechischer Pferdeschmuck vom Luristantypus. JDAI, 83, 1968, p. 1-38.
Jannot 1977 : JANNOT (J.-R.) - Décor et signification: à propos d'un trépied de Vulci. $R A, 1977,1$, p. 3-22.

Krauskopf 1984 : KRAUSKOPF (I.) - Artemis/Artumes. LIMC, II, 1984, p. 774-792.

Krauskopf 1987 : KRAUSKOPF (I.) - Todesdämonen und Totengötter im vorhellenistischen Etrurien. Kontinuität und Wandel. Florence, Olschki, 1987. Lo Schiavo, Romualdi 2009 : Lo Schiavo (F), Romualdi (A.) dir., I complessi archeologici di Trestina e di Fabbrecce nel Museo archeologico di Firenze. Rome, G. Bretschneider editore, 2009 (Accademia Nazionale dei Lincei, Monumenti Antichi, Serie Miscellanea, volume 12).

Lubtchansky 2005: LUBTCHANSKY (N.) - Les cavalier tyrrhénien : représentations équestres dans l'Italie archaïque. Rome, Ecole française de Rome, 2005 (Bibliothèque des Écoles françaises d'Athènes et de Rome, 320). Maas 1978 : MAAS (M.) - Die geometrischen Dreifïße von Olympia. Berlin, Verlag W. de Gruyter \& co., 1978 (Olympische Forschungen, Band 10).

Mystère des bronzes antiques : BÉRARD-AZZOUZ (O.) - Mystère des bronzes antiques, Exposition 06 Juin/31 Décembre 2003. Cap d'Agde, Musée de l'Éphèbe, 2003.

Nachbaur 2011: NACHBAUR (E.) - Bronzene Pferdedreifüße aus Mittelitalien. AKB, 41, 2, 2011, p. 197-212.

Naso 2009 [2012] : NASO (A.) - Antichi bronzi vulcenti. In : Denoyelle (M.) et al. dir., Bronzes grecs et romaines, recherches récentes. Hommage à Claude Rolley (Paris, 16-17 juin 2009), INHA, 2012 [En ligne].

Neugebauer 1943 : NEUGEBAUER (K.A.) - Archaische Vulcenter Bronzen. JDAI, 58, 1943, p. 206-278.

Orlandini 1991 : ORLANDINI (P.) - Altri due vasi figurati di stile orientalizzante dagli scavi dell'Incoronata. $B A, 76,2,1991$, p. 1-8.

Riis 1939 : RIIS (P.J.) - Rod-tripods. AArch, 10, 1939, p. 1-30.

Riis 1998 : RIIS (P.J.) - Vulcientia vetustiora. A Study of Archaic Vulcian Bronzes. Copenhague, 1998 (Historik-filosofiske Skrifter 19).

Rolley 1982 : ROLLEY (C.) - Les vases de bronze de l'archaïsme récent en Grande Grèce. Naples, Publications du Centre Jean Bérard, 1982 (Bibliothèque de l'Institut français de Naples, II série, vol. 5).

Sakowski 1997 : SAKOWSKI (A.) - Darstellungen von Dreifußkesseln in der griechischen Kunst bis zum Beginn der Klassischen Zeit. Frankfurt am Main, Peter Lang Verlag, 1997 (Europäische Hochschulschriften, Reihe 38, Archäologie, Band 67)

Scheffer 1994 : SCHEFFER (C.) - Female Deities, Horses and Death in Archaic Greek Religion. In : Alroth (B.) dir., Opus Mixtum. Essays in ancient art and society, Stockholm, 1994 (Acta Instituti Romani Regni Sueciae, Series in $\left.8^{\circ}, \mathrm{XXI}\right)$, p. 111-133.

Simon 2007 : SIMON (E.) - Thesan-Aurora. Zur Deutung des Akroters von Chianciano Terme. Studi Etruschi, 71, 2007, p. 47-54.

Spina e il delta padano : REBECCHI (F.) dir., Spina e il delta padano: riflessioni sul catalogo e sulla mostra ferrarese. Atti del convegno internazionale di studi "Spina: due civiltà a confronto", (Ferrara, 21 gennaio 1994), Roma, L' "Erma di Bretschneider", 1998 (Studia archaeologica 90).

Torelli 1986 : TORELLI (M.) - Dialogue sur le trépied étrusque. DHA, 12, 1986, p. 120-121.

Vassilika 1998 : VASSILIKA (E.) - Greek and Roman Art. Cambridge, Cambridge University Press, 1998 (Fitzwilliam Museum Handbooks).

von Vacano 1979 [1981] : VON VACANO (O.W.) - Gibt es Beziehungen zwischen dem Bauschmuck des Tempels B und der Kultgöttin von Pyrgi ? In : Akten des Kolloquiums zum Thema „Die Göttin von Pyrgi“. Archäologische, linguistische und religionsgeschichtliche Aspekte, Tübingen, 16.-17. Januar 1979, Florence, Olschki, 1981, p. 153-160.

Zancani Montuoro 1946-48 : ZANCANI MONTUORO (P.) - Un mito italiota in Etruria. ASAA, 24-26, 1946-48, p. 85-98. 

Autour de la céramique 



\title{
Le anfore greco-occidentali: riconsiderando la loro evoluzione e l'identificazione dei centri di produzioni
}

\author{
Verena Gassner \\ Professeur Université de Vienne, Institut für Klassische Archäologie
}

\begin{abstract}
This contribution aims at describing the evolution of Western Greek amphorae from the 6th to the 4th c. BC. In the last years archaeological research as well as a series of interdisciplinary and archaeometric analyses made clear that the choice of a model for the Western Greek amphorae did not depend on the ethnic origin of producers or consumers, but from a variety of factors. Among these, the repertory of transport amphorae available in the region evidently played an important role. Thus on the Tyrrhenian coast of Italy until the 6th c. BC the prototype for transport amphorae was chosen from Phoenician-oriental models, while the productions of the Ionic-Adriatic region were influenced by Corinth. In this area we observe a plurality of types from the 6th c. onwards, which continues at least until the 4 th c. BC.
\end{abstract}

Keywords: Greek amphora, typology, archaeometry, Italy, productions

\section{Résumé}

Cette contribution s'attache à décrire l'évolution des amphores grecques en Occident du VI ${ }^{\mathrm{e}}$ au IV $\mathrm{e}$ s. av. J.-C. Ces dernière années, la recherche en archéologie ainsi qu'une série de travaux interdisciplinaires sur les analyses archéométriques ont montré que le choix des modèles des amphores grecques d'Occident ne dépendait pas de l'origine ethnique des producteurs ou des consommateurs, mais était davantage lié à une série de facteurs multiples. Parmi ceux-ci, le répertoire des amphores présentes dans la région joue apparemment un grand rôle. Ainsi, sur la côte tyrrhénienne de l'Italie, depuis le $\mathrm{VI}^{\mathrm{e}}$ s., le prototype des amphores de transport a été choisi dans les modèles de la Phénicie orientale, alors que les productions du côté de l'Adriatique et de l'Ionie sont influencées par le modèle de Corinthe. Dans cette région, on observe une grande variété de type depuis le VIe siècle, et ce, jusqu'au IVe s. av. J.C.

Mots-clés : amphores grecques, typologie, archéométrie, Italie, productions 
$\mathrm{N}$ egli studi di Michel Bats, caratterizzati da una ampia gamma di tematiche, le anfore greco-occidentali e le problematiche legate sia alla loro classificazione metodologica sia all'interpretazione antropologica e socio-culturale hanno sempre giocato un ruolo importante. In questo senso mi è particolarmente gradito offrire questo contributo, che mira a ripensare la loro evoluzione nell'ambiente coloniale del Mediterraneo occidentale nella complessa interazione fra tipologie morfologiche e caratteristiche dei siti di produzione $^{1}$.

\section{La problematica della nascita delle anfore greco-occidentali}

Per la ricostruzione dei rapporti economici e degli scambi fra le varie genti e città del Mediterrraneo le anfore da trasporto sono sempre state di particolare importanza perché rappresentano uno dei pochi indicatori archeologici per questi processi ${ }^{2}$. Perciò non meraviglia che da alcuni decenni lo studio delle anfore del Mediterraneo occidentale sia diventato un problema centrale nella ricerca archeologica in quest' area $^{3}$. I lavori si sono occupati soprattutto del repertorio morfologico sia delle forme intere sia di singoli elementi diagnostici, come per esempio gli orli. Allo stato attuale della ricerca disponiamo di varie tipologie per le anfore dal VI fino almeno al II sec. a.C. ${ }^{4}$. Essenziale per la comprensione dei rapporti commerciali e dunque per la ricostruzione di una parte importante dell'economia antica rimane però sempre l'identificazione dei centri di produzione, perché solo questa permette di seguire le dinamiche del commercio e dei reciproci contatti. In questo senso l'idea che l'anfora sia "l'immagine della città"(Gras 1987) è stata non solo centrale negli studi degli anni settanta, ma anche molto "conveniente" nella pratica archeologica, perché solo con quest'approccio dalla classificazione della forma si arriva anche all'identificazione del rispettivo centro di produzione.

Le ricerche degli ultimi decenni hanno portato nuovi risultati, ma hanno anche aperto nuovi filoni di

\footnotetext{
1 La correzione dell'italiano di questo testo è dovuto a Luigi Vecchio che ringrazio da cuore.

2 Per quanto riguarda l'aspetto economico sarebbe fondamentale conoscere cosa fosse contenuto in queste anfore, ma la domanda non trova quasi mai una risposta sufficiente, pertanto, in questa sede, tale problematica non viene presa in considerazione. Per una sintesi della problematica cf. da ultimo Brun 2011, p. 98-99; Sourisseau 2011, p. 155-156, ma anche Bechtold, Docter 2010, p. 101-103.

3 Vedi da ultimo la vasta bibliografia da Sourisseau 2011.

4 Vandermersch 1994; Gassner 2003, p. 173-219; Sourisseau 2011 .
}

discussione. Dopo la revisione del concetto etno-centrista nell'interpretazione della cultura materiale non crediamo più che la connotazione etnica di una polis sia decisiva per la sua scelta del tipo anforico e abbiamo anche compreso che da ciò ne consegue che non possiamo partire più dalla presupposta unità fra tipo di anfora e centro di produzione $^{5}$. Per questi studi l'approccio interdisciplinare, che ha coinvolto analisi archeometriche, ha giocato un ruolo importante ${ }^{6}$. Per quanto riguarda l'aspetto archeologico negli ultimi anni il contributo più importante per una comprensione migliore del problema della nascita delle anfore greco-occidentali è forse costituito dalla recente proposta di Jean-Christophe Sourisseau, di suddividere la forma più antica del VI sec. a.C. in due tipi $1 \alpha$ e $1 \beta$, il primo corrispondente al tipo delle cd. anfore Corinzie B, l'altro a quello delle Corinzie $\mathrm{A}^{7}$. Di conseguenza dobbiamo anche congedarci da un'altra idea molto seguita negli ultimi anni, cioè dall'ipotesi che tutte le città magno-greche e siceliote, fino alle colonie del lontano Occidente come Massalia, avranno condiviso un unico tipo per i loro contenitori di trasporto, quello delle anfore "ionico-massaliote" con orlo bombato e risega sottostante da cui si sono sviluppate in seguito le anfore MGS della tipologia di Christian Vandermersch ${ }^{8}$.

Dall'altro lato lo studio delle modalità di produzione, soprattutto del vino, ma anche dell'olio, insieme con nuove analisi nel campo dell'archeobotanica, ci ha fatto capire che la viticoltura in Italia ha una lunga tradizione che risale fino all'età di Bronzo e - a livello locale - ha giocato sicuramente un ruolo importante fin dalla nascita delle colonie in Occidente ${ }^{9}$. L'origine delle anfore greco-occidentali dunque non segnerebbe più l'inizio della viticoltura in Occidente, ma l'avvio di una produzione d'eccedenza e del commercio sovraregionale di questo surplus. Questo distacco dell'inizio della viticoltura dalla nascita delle anfore in Occidente con un intervallo di più di cento anni rende ancora più improbabile l'ipotesi che per la scelta del tipo di contenitore il mondo coloniale, avviando il commercio del vino, si sarebbe orientato verso la forma anforica della

5 Per questa discussione cf. Gassner 2003, p. 214-219 con la bibliografia precedente.

6 Da citare sono soprattutto le analisi francesi di Gilles Abbas, organizzate da Michel Bats e Jean-Christophe Sourisseau (Abbas 1999) e gli studi austriaci, pubblicati parzialmente in Gassner 2003 e nella bancadati www.facem.at. Per le produzioni della Calabria meridionale cf. anche Barra Bagnasco et al. 2001; Barone et al. 2002; Barone et al. 2004.

7 Sourisseau 2011, p. 184-189, fig. 7-14.

8 Cf. in questo senso da ultimo Savelli 2006, ma anche Gassner 2003, p. 216.

9 Brun 2011 
madrepatria da dove i coloni erano partiti due $\mathrm{o}$, più verosimilmente, tre generazioni prima.

Rispetto a questa nuova acquisizione anche le nostre domande possono essere diverse: ci si può chiedere, ad esempio, quale sia stato il criterio nella scelta dei contenitori escludendo il luogo di origine dei coloni; o anche quale sia il ruolo giocato dall'elemento indigeno in questa scelta, anche se esso probabilmente fungeva "soltanto" da manodopera ${ }^{10}$. Inoltre ci possiamo anche porre la domanda se le città magno-greche non avessero prodotto anfore già prima dell'inizio del VI sec. a.C., non ancora riconosciute tra i materiali a nostra disposizione, perché abbiamo sempre seguito il concetto della correlazione tra forma anforica e città, cercando così sempre soltanto il tipo "ionico-massaliota".

\section{Il quadro delle anfore sul versante tirrenico}

Finora le anfore occidentali più antiche sono note dal versante tirrenico. Le lunghe e accurate ricerche di Giorgio Buchner e David Ridgway a Pithecusa hanno messo in evidenza una produzione locale di anfore (tipo A e B) sin dal periodo tardo-geometrico ma che si ferma bruscamente nel VI sec. a.C. ${ }^{11}$. Tuttavia, in contraddizione con il concetto della dipendenza etnica dei tipi anforici, sia il più antico tipo $\mathrm{A}$ sia il tipo $\mathrm{B}$ del tardo VII e del VI sec. a.C. non richiamano la forma delle anfore della madrepatria calcidese di Pithecusa o di un'altra città greca, ma riflettono in modo abbastanza stretto il modello delle anfore fenicie o "orientali", utilizzato da vari centri fenici in Occidente e in seguito adottato anche dalle città dell'Etruria meridionale per i loro contenitori da trasporto. Questo aspetto, sorprendente e molto discusso, è stato in genere spiegato con l'esistenza di una forte presenza fenicia nella comunità di Pithecusa, dovuta al carattere emporico dell'insediamento ${ }^{12}$. Ma è questa davvero l'unica spiegazione possibile e dobbiamo dunque presumere che la produzione e il commercio del vino a Pithecusa era soltanto nelle mani di mercanti d'origine fenicia? $\mathrm{O}$ non sembra altrettanto $\mathrm{o}$ anche più verosimile l'ipotesi che tanto Pithecusa quanto i centri dell'area campana e centro-italica avrebbero prodotto anfore di derivazione fenicia perché queste erano i pro-

10 Cf. anche le considerazioni su questa problematica esposte da Sourisseau 2011, p. 212.

11 Di Sandro 1986, p. 106-118; Buchner, Ridgway 1993; Nizzo 2007 con un'analisi stratigrafica; cf. anche la sintesi recente di Sourisseau 2011, p. 149-173.

12 Sourisseau 2011, p. 158-159 con ampia bibliografia e una discussione della complessa problematica delle anfore centro-italiche; cf. anche Albore Livadie 1985 sulle ipotizzate produzioni etrusche nell'hinterland del golfo di Napoli. dotti più in circolazione in questo ambiente geografico e dunque fungevano anche da modello per le anfore pithecusane?

Questa produzione di anfore di tradizione fenicia/ etrusca a Pithecusa si interrompe improvvisamente in un momento non ancora chiaro del VI sec. a.C., cosa che è stata spiegata - ma la spiegazione appare molto probabile - con un'eruzione vulcanica sull'isola che avrebbe distrutto gran parte dei vigneti ${ }^{13}$. Finora, però, non è stato spiegato come si sarebbe sviluppata la viticoltura sull'isola dopo questo evento disastroso e quale possa essere la forma delle anfore in questo periodo. Un aspetto interessante, inoltre, è costituito dal fatto che, secondo le nostre analisi di alcune anfore greco-occidentali nel materiale anforico dello Scarico Gosetti non si trovano evidenze per una produzione locale o regionale ${ }^{14}$. Le anfore arcaiche della forma Sourisseau $1 \alpha$, ma anche le anfore più recenti della forma Sourisseau 2 , provengono invece tutte da centri della Calabria meridionale, mentre con l'arrivo di anfore del tipo MGS II si ha anche l'inizio delle importazioni da Poseidonia ${ }^{15}$. Anche se non possiamo valutare bene la rappresentatività della pubblicazione di Norma Di Sandro, stupisce la mancanza totale di anfore greco-occidentali locali o regionali dal golfo di Napoli.

Un punto interrogativo in questa discussione rimane la situazione a Cuma. Per questa città, ricca e dotata di un territorio vasto e molto adatto all'agricoltura, bisognerebbe presumere una cospicua produzione, anche in eccedenza, di vino e/o di olio e, dunque, la necessità di produrre anfore ${ }^{16}$. Allo stato attuale della ricerca, però, non abbiamo la minima idea di quale sia stato il tipo adottato per queste anfore. Per i centri etruschi nell'entroterra

13 De Caro, Gialanella 1998, p. 342-347 (con bibliografia precedente) propongono una datazione nella prima metà del VI sec. a.C., mentre Sourisseau 2011, p. 171-172 propende per una data nella seconda metà del VI sec. a.C.

14 Di Sandro 1986. Nell'anno 1995 grazie alla generosa disponibilità della Soprintendenza di Napoli abbiamo avuto la possibilità di riesaminare un numero di 37 anfore con analisi di sezione sottile (Roman Sauer)

15 Importazioni dalla Calabria - Forma Sourisseau $1 \alpha$ : Di Sandro 1986, sg 80 (M37/1), sg 82 (M37/2), sg 83 (M37/3), sg 84 (M37/4), tutte tav. 7. Forma Sourisseau 2/3: Di Sandro 1986, sg 88 (M37/5), sg 89 (M37/6); sg 90 (M37/7), sg 91 (M37/8), sg 92 (M37/9), tutte tav. 8; cf. anche Gassner 2003, p. 191-195 tab. 16. Produzione di Poseidonia Di Sandro 1986, p. 44-52, tav. 9 ("imitazioni di anfore marsigliesi"); ibid. p. 59-68, tav. 12 ("anfore c.d. Chiote"); cf. anche Gassner 2003, p. 197-201, tab. 18. Resta da chiarire se e in qual modo questa preponderanza di anfore dalla Calabria meridionale e/o dell'area dello Stretto riflette la dominanza politica di questo periodo.

16 Vandermersch 1996, p. 159, ma anche Albore Livadie 1985, p. 130 che presume una evoluzione decrescente per Cuma nel VI sec. a.C. Nuovi risultati potranno essere conseguiti dai recenti scavi a Cuma, condotti da varie équipes italiane e francesi, cf. per es. Gasparri, Greco 2007; Gasparri, Greco 2009. 


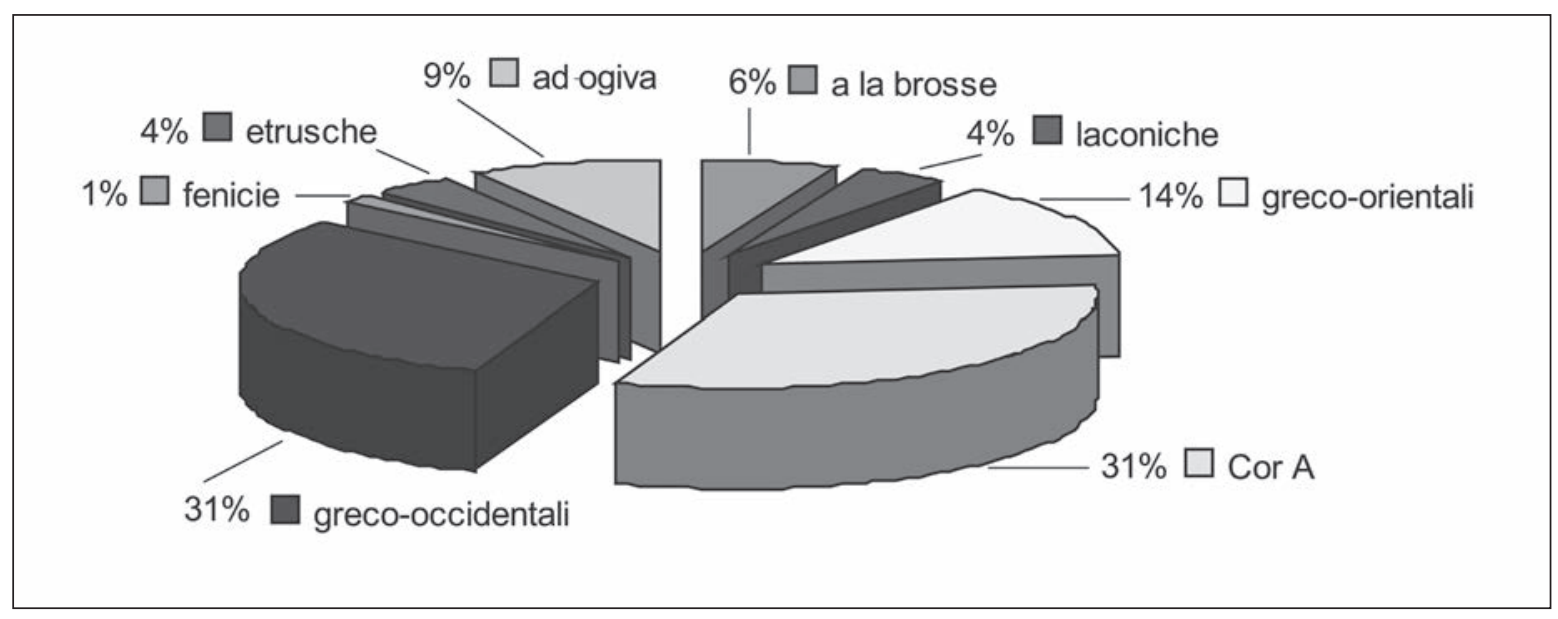

Fig. 1. Distribuzione delle anfore dal terrapieno delle mura tardo-arcaiche (diagramma basato su Savelli 2006, p. 105, fig. 34).

di Cuma e del golfo di Napoli è attestata una produzione di anfore di forma etrusca dalla fine del VII fino almeno al V sec. a.C. ${ }^{17}$, ma si ignora quali fossero i contenitori tipici di Cuma arcaica. Purtroppo finora disponiamo soltanto di pochi dati provenienti soprattutto dagli scavi delle mura di Cuma condotti dall'Università Orientale di Napoli (Savelli 2006). Il contesto più rilevante con un numero di anfore sufficiente per conclusioni affidabili è lo scavo del terrapieno delle mura tardo-arcaiche, la cui costruzione è stata connessa con buoni argomenti al dominio di Aristodemo. Il repertorio delle anfore comprende soprattutto anfore greco-occidentali (31\%) e anfore Corinzie del tipo A le quali - secondo Savelli presentano tutte l'impasto tipico della produzione di Corinto stessa. Il resto si divide fra importazioni greco-orientali (14\%), anfore etrusche (4\%) e anfore del tipo ad ogiva con fondo piano (9\%, fig. 1 $\left.{ }^{18}\right)$. Per le ultime, la Savelli prende in considerazione una possibile produzione a Pithecusa, senza che questa ipotesi possa risolvere il problema di una produzione locale cumana ${ }^{19}$. Secondo la Savelli, dunque, a Cuma tardo-arcaica non sarebbe esistita una produzione importante di anfore e questo fatto non lo possiamo spiegare con l'evento disastroso di una eruzione vulcanica come a Pithecusa stessa. In riguardo alle ricche risorse di Cuma l'ipotesi che la città non avesse prodotto un surplus di vino e/o olio non pare molto convincente. Quali possono essere allora le probabili soluzioni di questo problema?

17 Per la distribuzione delle anfore etrusche cf. anche Albore Livadie 1985, p. 129-133 e App. 3.

18 Il diagramma si basa sulle indicazione di Savelli 2006, p. 105, fig. 34, includendo soltanto i frammenti d'orlo per la individuazione dei MNI.

19 Savelli 2006, p. 126 con una prudente discussione della problematica dei fabrics.
Possiamo immaginare che anche Cuma utilizzasse il tipo di anfora ad ogiva con fondo piano (tipo B di Buchner) come Pithecusa e molti altri centri campani ? ${ }^{20} \mathrm{O}$ dobbiamo cercare gli indicatori per la produzione locale di Cuma - almeno dal tardo VI sec. a.C. in poi - nelle anfore greco-occidentali della forma Sourisseau $1 \alpha$ da una "produzione non identificata", il cui impasto viene descritto dalla Savelli come "gialla (Munsell 10YR-8/4), depurata (...) con inclusi di medie e grandi dimensioni di colore grigio e bianco" 21 ? Allo stato attuale della ricerca a Cuma non possiamo decidere.

Dando uno sguardo d'insieme alle anfore campane dal secolo VIII fino alla fine del VI vediamo, però, che per lungo tempo le anfore del tipo ad ogiva della tradizione fenicio-orientale costituiscono il modello di anfora par excellence in quest'area, mentre le differenti origini sia dei produttori sia dei consumatori evidentemente non avevano importanza per la scelta e l'accettazione del tipo. Ad un certo punto, in un momento ancora da definire meglio, ma presumibilmente allo scorcio del VI al V sec. a.C., questa situazione cambia almeno nei centri greci come nella nuova fondazione di Neapolis, dove troviamo anfore greco-occidentali delle forme Sourisseau 2/3 e MGS II di sicura provenienza locale fra i materiali della piazza N. Amore, ma anche come importazioni, sebbene rare, a Velia in contesti del V sec. a.C. (fig. 2) ${ }^{22}$.

20 Per un riassunto del problema delle anfore ad ogiva a Cuma da Savelli 2006, p. 125-126.

21 Savelli 2006, p. 119. Questa descrizione, anche se molto generica, potrebbe corrispondere ai fabrics cumani, come definiti dall'équipe della Federico II insieme con Maria Trapichler (Vienna) per questo periodo.

22 Napoli: M137/1, M137/4; MGS II: M137/2, M137/3, M137/5, Forma Sourisseau 2/3, materiali dagli scavi della Metropolitana, studiati da E. Scopetta nell'ambito della sua tesi di dottorato. Ringrazio la dott.ssa Daniela Giampaola ed E. Scopetta per la possibilità di 


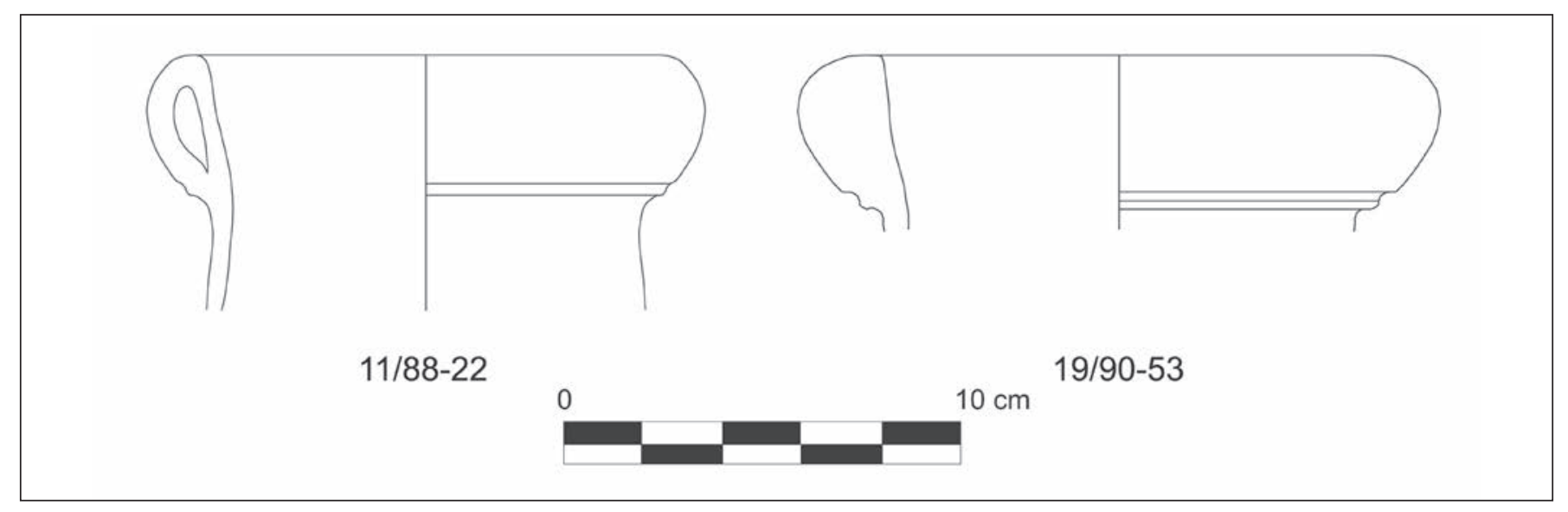

Fig. 2. Anfore dalla produzione di Napoli, da Velia: Inv. 11/88-22 (dalle case in mattoni crudi nell'area dell'Insula II); Inv. 19/90-53 (dall'area dell'incrocio stradale davanti all'Insula II, ultimo quarto del V sec. a.C.).

\section{La produzione di anfore nell'area ionico-adriatica}

Rispetto all'area tirrenica, la situazione sul versante ionico della Magna Grecia è ancora più complicata. Una serie di studi archeometrici su anfore da trasporto ed anche sulle probabili materie prime hanno confermato la produzione di anfore nella zona dell'odierna Calabria in generale, ma finora l'individuazione dei vari centri di produzione ci mette davanti ad una grande difficoltà. Il problema viene aggravato dal fatto che anche sull'altro lato del Mar Ionio, sulle coste della Grecia e dell'Albania, gli impasti presentano caratteristiche, per quanto note, che rassomigliano molto a quelle della penisola italiana. Una classificazione macroscopica spesso non è in grado di vedere le differenze fra queste produzioni e i centri magno-greci, e in molte occasioni anche l'analisi al binoculare non porta a risultati soddisfacenti. In questo senso anche la classificazione dei rispettivi impasti della Calabria e dell'area ionico-adriatica nella edizione di FACEM 2011 rappresenta soltanto un primo tentativo che nel futuro sicuramente sarà sottoposto a cambiamenti e correzioni ${ }^{23}$. Perciò le seguenti idee e proposte non possono essere più che ipotesi di lavoro, ancora da verificare con una serie di analisi mirate ${ }^{24}$.

visionare questi materiali. Velia, città bassa, forma Sourisseau 2/3: M6/7 (Inv. 11/88-22, case in mattoni crudi sotto l'Insula II, prima metà del V sec. a.C.) M6/120 (Inv. 19/90-53, incrocio stradale davanti all'Insula II, ultimo quarto del V sec. a.C.), cf. anche Gassner 2003, p. 203, fig. 103.

23 Gassner 2011a; Gassner 2011b.

24 Queste osservazioni si basano su anfore trovate a Velia, ma anche su anfore da Butrinto (Albania), studiate da Roald Docter ed analizzate in parte da Roman Sauer e da chi scrive, ma purtroppo non pubblicate finora. Sono grata all'amico Roald Docter di avermi
Allo stato attuale della ricerca possiamo partire dalla situazione seguente. Per prima cosa sappiamo che Corinto e le sue colonie hanno giocato un ruolo determinante nei contatti e nelle reti commerciali dell'area del Mar Ionio, fatto non sorprendete se si considera l'apertura del golfo di Corinto verso il Mar Ionio e il grande potere politico ed economico della città in età arcaica ${ }^{25}$. A Corinto stessa, è attestata una produzione di anfore con labbro orizzontale (il cd. tipo A), che comincia nell'VIII sec. a.C. e rimane attiva fino al II sec. a.C. ${ }^{26}$. La produzione del cd. tipo B, anche assegnata a Corinto da Koehler, oggi viene attribuita alla più importante colonia di Corinto, vale a dire Corcira, e questa ipotesi viene confermata dalla scoperta di una officina per anfore nel territorio dell'antica città ${ }^{27}$. Anche in questo caso lo sviluppo della forma come descritta dalla Koehler sembra ancora valido, ma dobbiamo rivedere la data per la nascita del tipo che, secondo gli studi del Sourisseau sulle anfore magno-greche, comincia già all'inizio del VI sec. a.C. (Sourisseau 2011, p. 214-215). In riguardo alle anfore della Magna Grecia le analisi archeometriche sia di Roman Sauer sia di Gilles Abbas e Barone favoriscono una produzione nella Calabria meridionale, in particolare sul versante ionico, con officine localizzabili da Sibari fino all'area dello Stretto (Gassner 2011).

permesso di utilizzare i dati suoi non ancora pubblicati per la presentazione in FACEM

25 Appare strano che in tutte le discussioni sull'influenza preponderante di Corinto la colonia siciliota più importante, Siracusa, finora abbia giocato soltanto un ruolo secondario (cf. Torelli 1994 [1997] p. 631-633) benché proprio per Siracusa abbiamo la testimonianza di una produzione precoce di vino, cf. Vandermersch 1996, p. 164-168. 26 Koehler 1979, p. 9-23, cf. anche Whitbread 1995, p. 255-346; Göransson 2007, p. 82-85.

27 Kourkoumelis Rodostamos 1988; Kourkoumelis 1990; PrekaAlexandri 1992; per i fabrics cf. Gassner 2011b. 


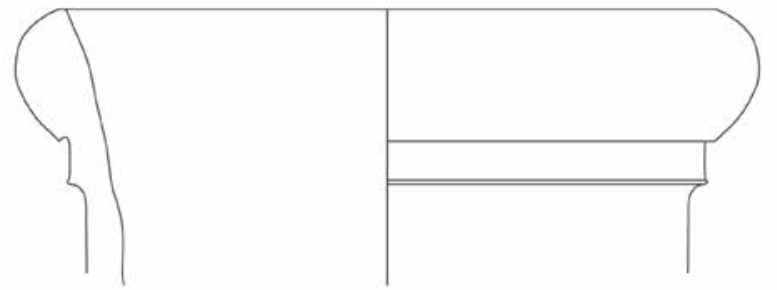

$\mathrm{M} 79 / 51$

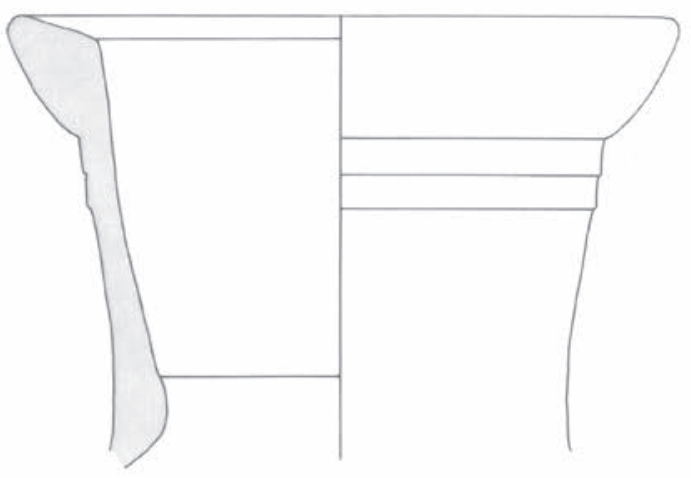

$\mathrm{M} 6 / 50$

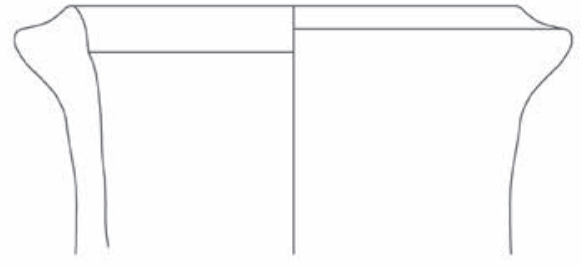

M79/68

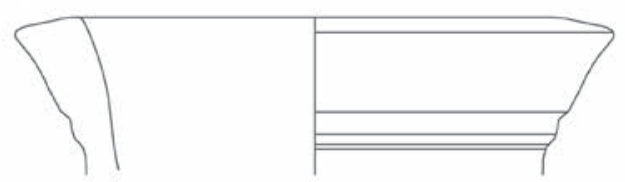

M79/65

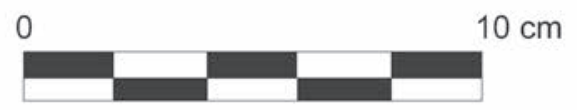

Fig. 3. Anfore dalla produzione corcirese, tipo "Corinzio B". Da Butrinto: M79/51= FACEM - http://facem.at/ion-adr-a-3 (Sourisseau 1a, VI sec. a. C.), M79/68, M79/65 = FACEM - http://facem.at/m-79-65 (tipo con orlo di forma di 8, IV sec. a.C.). Da Velia: M6/50 = Gassner 2003, Ilb. 81, tav. 38 (MGS I).

La netta correlazione del tipo di anfora con la provenienza da una città recentemente è stata messa in discussione dal Sourisseau, il quale ribadisce che un unico centro, probabilmente Sibari, avrebbe prodotto contemporaneamente anfore di due forme diverse, e che queste anfore non sono "imitazioni" casuali, d'importanza secondaria, ma un elemento indipendente nella tipologia delle anfore occidentali (Sourisseau 2011, p. 184-189). Le analisi delle anfore di Butrinto e di Velia hanno mostrato che questa pluralità delle forme non vale soltanto per certe produzioni magno-greche, come proposto da Sourisseau, ma anche per le officine dell'area epirota.

Per la produzione Corcirese le analisi archeometriche del Sauer hanno individuato vari impasti, caratterizzati da una cottura diversa e/o da una differente percentuale di sgrassanti ${ }^{28}$. Le forme di questa produzione (fig. 3)

28 Per i fabrics come per la loro descrizione dettagliata si vedano le schede in www.facem.at con immagini a colori, FACEM http://facem.at/ion-adr-a-1 a FACEM - http://facem.at/ion-adr-a-4. I campioni da Butrinto, presi in considerazione in questo contesto, corrispondono alla tipologia delle "Corinzie B" con le più antiche attestazioni assicurate nel materiale di Butrinto, corrispondenti alla forma Sourisseau $1 \alpha^{29}$. Per il V sec. a.C. sono attestate anfore del tipo Sourisseau 5/MGS I/ Gassner $5^{30}$, seguite da anfore del tipo con orlo di forma di 8 per il IV sec. ${ }^{31}$. Ma a Butrinto incontriamo anche un frammento di orlo di una anfora arcaica della forma Corinzia $\mathrm{A} /$ Sourisseau $1 \beta$, il quale è stato attribuito alla stessa produzione corcirese dalle analisi archeometriche e a cui possiamo aggiungere alcuni fondi di anfore dello

sono stati analizzati dal Sauer per la pubblicazione di Butrinto, cf. n. 25. Purtroppo i materiali di Butrinto spesso non sono contestualizzati cosicché la cronologia dipende soprattutto sulla classificazione dei tipi morfologici; cf. anche la sintesi da Gassner 2011b.

29 Butrinto: M79/15, M79/51 (fig. 3). Per le anfore della produzione corcirese non esiste una tipologia propria, cosicché in questa sede vengono utilizzate le tipologie sia quelle Corinzie sia quelle magno-greche del Sourisseau 2011 e del Vandermersch 1994.

30 Butrinto: M79/61, M79/62; Velia: M6/11, M6/12, M6/50 (fig. 3), M6/54.

31 Butrinto: M 79/30, M79/68 (fig. 3), M79/64, M79/65 (fig. 3). 


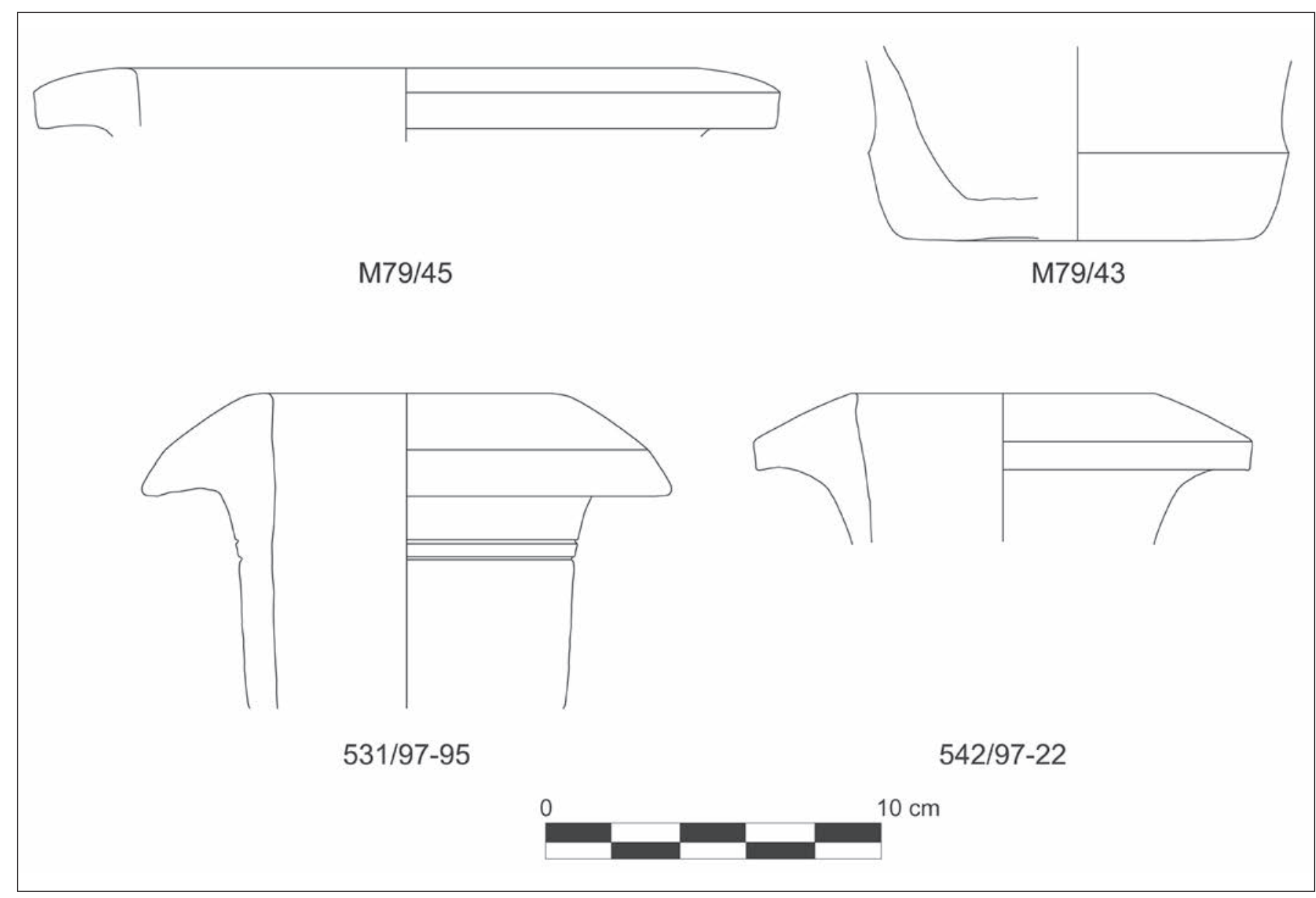

Fig. 4. Anfore dalla produzione corcirese, tipo "Corinzio A". Da Butrinto: M79/45 = FACEM - http://facem.at/m-79-45, M79/43 = FACEM - http://facem. at/m-79-43. Da Velia, scavi alle mura nella città bassa: Inv. 531/97-95 (primo terzo del IV sec. a.C.); Inv. 542/97-22 (inizio del III sec. a.C.).

stesso tipo (fig. 4) e almeno quattordici orli che Roald Docter ha attribuito a questa produzione con autopsia macroscopica ${ }^{32}$. Anche nel materiale di Velia abbiamo individuato due frammenti di orlo della forma tipica per le Corinzie A (fig. 4), il cui impasto sembra attribuibile alla produzione corcirese, ma questa attribuzione non è stata confermata dalle analisi archeometriche ${ }^{33}$.

Inoltre le analisi di altre anfore da Butrinto ci indicano che Corcira non è stato l'unico centro a produrre tutte e due queste forme di anfore perché anche in un'altra produzione, attribuita dal Sauer ad un centro non ancora localizzabile sulla costa epirota o albanese, incontriamo la stessa dualità con anfore della forma arcaica delle "Corinzie A" con labbro sporgente e anfore del IV sec. a. C con orlo alla forma di 8 , il quale

32 Orlo: M79/45 (fig. 4), fondi: M79/43 (fig. 4), M79/44, M79/49, tutti da Butrinto.

33 Velia, scavi alle mura della città bassa, 1997-1999: Inv. 531/9795, fase 2.1 (primo terzo del IV sec. a.C.); Inv. 542/97-22, fase. 2.4. (inizio del III sec. a.C.). normalmente viene classificato come tipico per le anfore "Corinzie B" (fig. 5) ${ }^{34}$. Anche se la base quantitativa è ancora troppo limitata per conclusioni definitive, sembra lecita l'ipotesi che Corcira ed altri siti della costa epirota o albanese abbiano prodotto anfore di tipologie ben distinte dal periodo arcaico fino almeno al III sec. a.C. In questo senso la situazione corrisponde molto bene a quella descritta dal Sourisseau per il materiale di Camarina.

Per la Magna Grecia allo stato attuale della ricerca non possiamo decidere se l'occorrenza di anfore greco-occidentali di due tipi diversi, ma contemporanei, costituisca un fenomeno singolare o se sia usuale nei diversi centri di produzione ${ }^{35}$. Né a Butrinto né a Velia abbiamo

34 Produzioni ION-ADR-A-5 e ION-ADR-A-6. Tipo Corinzia A: M79/48 (fig. 5); anfore con orlo alla forma di 8: M79/63 e M79/69 (fig. 5), cf. Gassner 2011b.

35 Per il repertorio anforico nella Siritide in età arcaica, cf. Berlingò 1995. 


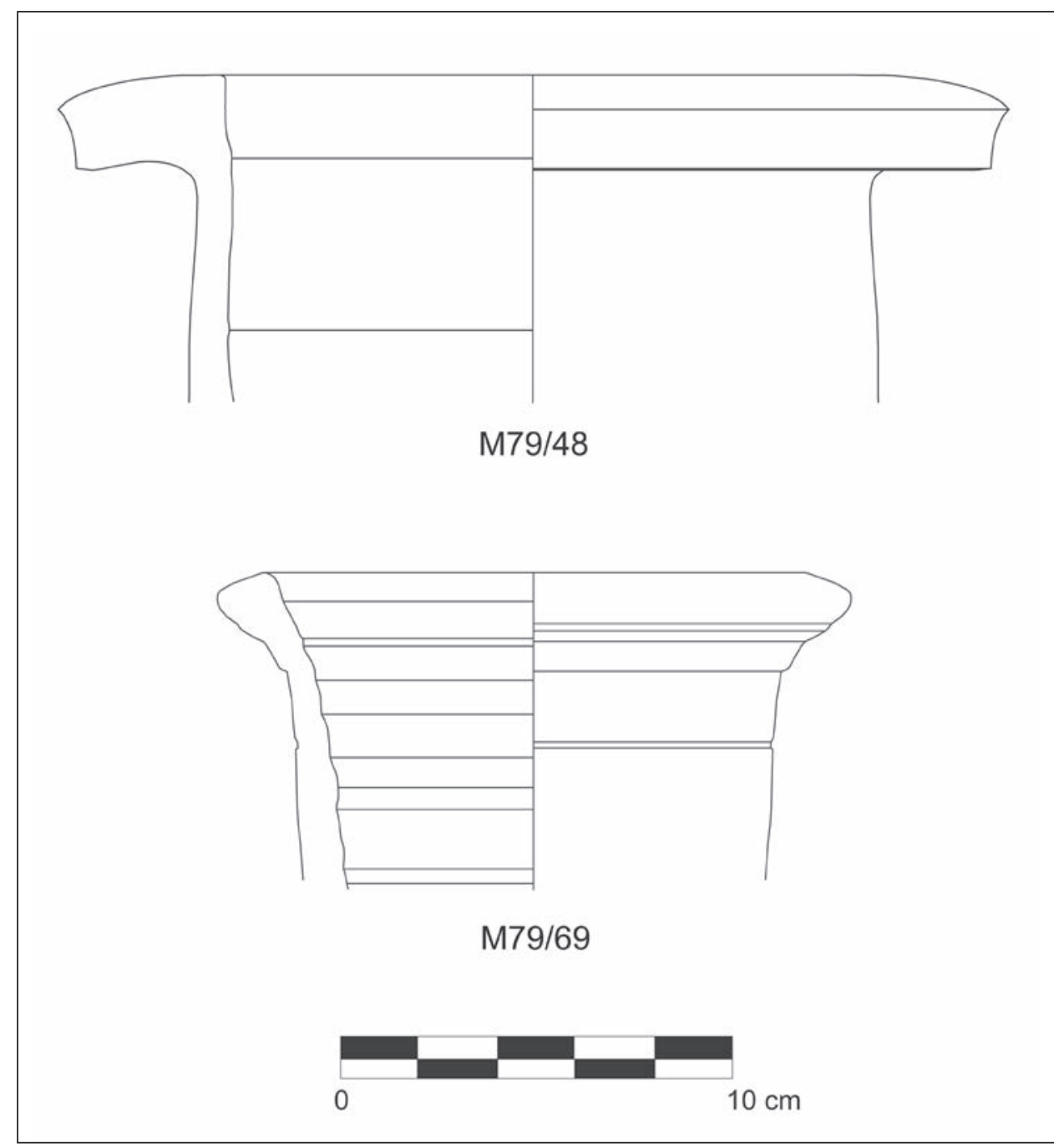

Fig. 5. Anfore da un centro non ancora localizzabile sulla costa epirota o albanese (ION-ADR-A-5 e ION-ADR-A-6). Da Butrinto: M79/48 = FACEM - http://facem.at/m-79-48 (tipo Corinzio A), M79/69 = FACEM - http://facem.at/ion-adr-a-5 (anfore con orlo alla forma di 8).

trovato attestazioni sicure per una produzione di anfore del tipo Corinzio A (=Sourisseau $1 \beta$ ) in Calabria o in Sicila, ma evidentemente in tutti e due i siti le importazioni dal versante ionico dell'Italia costituivano soltanto una percentuale molto ridotta cosicché le evidenze non sono indicative. Per l'età classica già Grace ha presupposto una produzione "locale" di anfore del tipo Corinzio A le quali facevano parte del carico della nave di La Madonnina nel golfo di Taranto (McCann 1972, p. 184). Questa ipotesi viene corroborata da due frammenti di anse con sezione circolare come le anse delle anfore Corinzie A, trovati a Velia in un contesto del inizio IV sec. a.C. ${ }^{36}$, per uno dei quali l'analisi archeometrica ha confermato la produzione in un centro della Calabria del

36 Velia, scavi alle mura della città bassa: Inv. 531/97-100a, Inv. 531/97-100b (M10/39). versante ionico ${ }^{37}$. La pluralità dei tipi nelle produzioni magno-greche dunque potrebbe essere un fenomeno di ampia diffusione fino almeno al IV sec. a.C.

Le indagini archeometriche permettono invece di disegnare in modo più chiaro il quadro delle produzioni della Calabria meridionale (fig. 6). Gli esemplari più antichi sono quelli della forma Sourisseau $1 \alpha$, come individuati per esempio fra le anfore dallo Scarico Gosetti ${ }^{38}$, mentre la fase di sviluppo della prima metà del V sec. a.C. viene documentata da anfore dalle case in mattoni crudi nella città bassa a Velia. Nel corso del V sec. a.C. l'orlo

37 In questo contesto rientra anche l'ipotesi di Göransson di una produzione/imitazione di anfore della forma Corinzia A a Euesperides, cf. Göransson 2007, p. 82-85.

38 M37/1-6, cf. Gassner 2003, p. 194 tab. 16. 

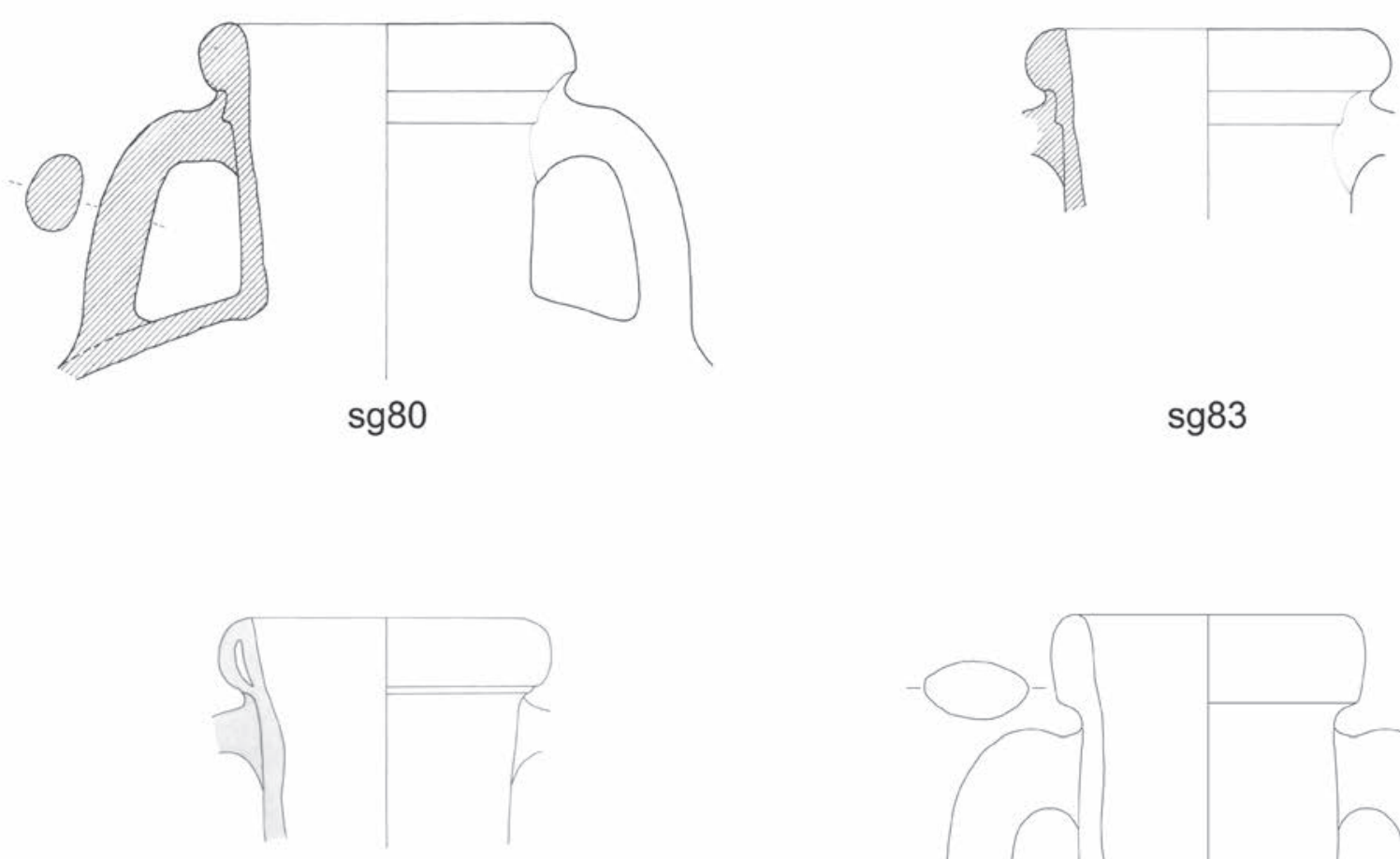

$\mathrm{M} 6 / 13$

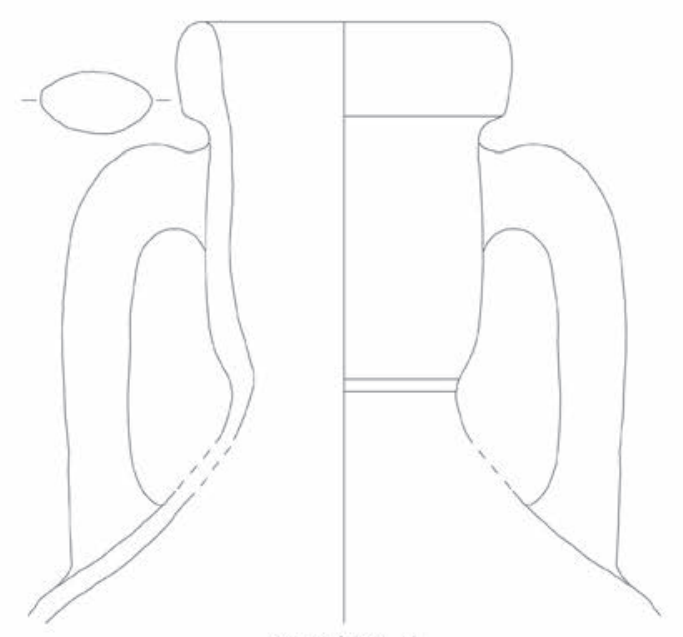

$674 / 92-1$

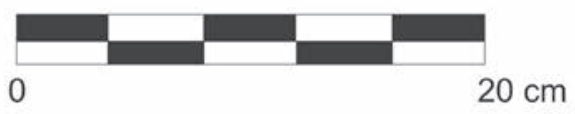

Fig. 6. Anfore dalle produzioni della Calabria meridionale. Da Ischia: Di Sandro 1986, sg 80, sg 83 (forma Sourisseau 1a). Da Velia: M6/13 (tipo Gassner 3, Gassner 2003, Ila.211, tav. 25), Inv. 674/92-1 (tipo Gassner 6, area dell'Insula II nella città bassa, fine del V sec. a.C.).

di queste anfore diventa più allungato (Gassner tipo 6) come dimostra la parte superiore di un'anfora, sempre dalla città bassa di Velia e da datare verso la fine del V sec. a.C. ${ }^{39}$. Nella discussione di questa problematica si vede bene che le tipologie esistenti del Vandermersch e del Sourisseau sono molto utili nel senso di una prima classificazione di forme, ma non risultano adeguate per indicare le peculiarità delle singole produzioni ${ }^{40}$.

39 Inv. 674/92-1, proveniente dall'area dell'Insula II.

40 Vandermersch 1994, p. 66 tipo MGS II; Sourisseau 2011, p. 176, fig. 6 , forma 5 .
La formazione dell'orlo dell'anfora 674/92-1 corrisponde al tipo Vandermersch MGS II o Sourisseau forma $4^{41}$, ma tutti e due gli autori comprendono con questa definizione anche la varietà dell'orlo Gassner 7, contemporanea all'orlo Gassner 6, ma caratteristica per le produzioni di Poseidonia e Velia ${ }^{42}$.

41 Vandermersch 1994, p. 66 fig. B = Sourisseau 2011, p. 176, fig. 6, forma 4 (campioni da Messina e Mylai).

42 Gassner 2003, p. 180-182 e Vandermersch 1994, p. 66 fig. A (anfora dalla nave di Porticello); Sourisseau 2011, p. 176 fig. 6, forma 4 (campioni da Paestum e dalla nave di Porticello). 
La forma Sourisseau $1 \alpha$ si trovava anche fra le anfore della nave di Cala Sant Vicenç, forse attribuibili alla produzione sibarita ${ }^{43}$. La composizione del carico di questa nave tardo-arcaica pone però non pochi problemi e ci fa riflettere di nuovo sulla pluralità delle forme nelle produzioni anforiche greco-occidentali (Santos 2008, p. $128-140$ e p. 147-149). La nave portava un carico misto, fra cui le anfore greco-occidentali giocavano un ruolo preponderante. Possiamo distinguere sei individui della forma Sourisseau $1 \alpha$ con un fabric che corrisponde bene alle materie prime del versante calabro a sud di Sibari ${ }^{44}$. Ma nello stesso carico, e perciò contemporanee, si trovano anche 15 anfore della forma Sourisseau 2 in un impasto molto simile a quello del primo gruppo. Se non vogliamo spiegare la differenza fra le forme con uno scarto cronologico fra i vari contenitori presenti nel carico, e data la similarità degli impasti, dobbiamo pensare che il tipo Sourisseau 2 non ha sostituito il tipo Sourisseau $1 \alpha$ in tutte le officine magno-greche nel corso della seconda metà del VI sec. a.C., ma che esisteva una coesistenza dei tipi Sourisseau $1 \alpha$ e $1 \beta$, ma anche di Sourisseau $2^{45}$. Con grande probabilità questo fenomeno continua fino in età classica perché in questo periodo troviamo accanto ad anfore con orlo allungato (forma Gassner 6, fig. 6) anche anfore del tipo MGS I, per cui una produzione magnogreca sembra possibile. Già il Vandermersch ha postulato una produzione di anfore MGS I nell'area fra Thurioi e Metaponto in base ad argomenti strettamente archeologici (Vandermersch 1994, p. 61-65) e questa ipotesi potrebbe essere corroborata da due orli del tipo MGS I a Velia ${ }^{46}$ con un impasto che assomiglia a quelli osservati da prodotti dal golfo di Taranto.

Dunque appare forse lecita l'ipotesi che la produzione anforica del golfo di Taranto (Taranto stessa, Siris/ Eraclea, Metaponto...) avesse utilizzato per le sue anfore (almeno in parte) il repertorio morfologico di Corinto o le sue colonie sia del tipo A sia del tipo B, anche se il materiale a nostra disposizione finora è ancora scarso. A favore di questa ipotesi depone anche l'occorrenza quasi esclusiva di anfore del tipo Corinzio A nella necropoli di Metaponto nel V sec. a.C. per le quali una produzione magno-greca non è stata esclusa dalle analisi archeometriche (Morter, Leonard 1998, p .731-747). Anche

43 Santos 2008; Sauer, Gassner 2008; Sourisseau 2011, p. 204-206. Quest'ultimo sostiene che il centro più importante sia da localizzare a Sibari, mentre all'equipe austriaca questa ipotesi sembra ancora da confermare.

44 CAL-A-6, vedi Gassner 2011a; per gli analisi cf. Sauer, Gassner 2008.

45 Cf. così, ma molto prudente Sourisseau 2011, p. 189-190.

46 Gassner 2003, p. 111-113, IIa.223 (M6/49); Inv. 158/99-4 (scavi alle mura della città bassa, non pubblicati, fase 1.1 [seconda metà del V sec. a.C.], attribuzione soltanto macroscopica). in età tardo-classica ed ellenistica nella regione sembra continuare la produzione di tipi somiglianti alle tipologie Corinzie, come di anfore MGS I e in seguito di anfore del tipo MGS III, fra cui alcune, come l'anfora da Cariati, sembrano svilupparsi dal tipo MGS I ${ }^{47}$.

\section{Conclusioni}

Anche se il nostro quadro delle tipologie e dei siti di produzione delle anfore da trasporto nel Mediterraneo occidentale è ancora molto lacunoso, le ricerche degli ultimi anni ci hanno permesso nuove visioni e spunti di discussione. È diventato evidente che nell'ambito coloniale le realtà antiche connesse alla produzione e al commercio di anfore sono molto più complesse di quanto supposto finora. La situazione dell'area campano-tirrenica divergente da quella ionico-adriatica dimostra con grande chiarezza che le decisioni per la scelta di un modello non erano tanto dettate dall'origine etnica dei produttori, ma più legate alle zone d'influenza e al repertorio di anfore presenti sui mercati regionali. In questo senso a Pithecusa e nel versante centro-tirrenico il modello viene preso dalle onnipresenti anfore fenicie/orientali, mentre nella zona del Mar Ionio, Corinto e i suoi prodotti diventano il fattore dominante. Mentre nel Tirreno le profonde trasformazioni politiche del periodo arcaico potrebbero essere la motivazione per un cambio brusco del tipo di anfora dal modello fenicio al quello greco, nell'area ionico-adriatica il momento più determinante per la diversificazione delle anfore grecooccidentali è stata forse la prima metà del VI sec. a.C., quando in alcune officine si modifica il tipo di orlo a labbro sporgente e orizzontale, caratteristico per i grandi contenitori di Corinto per la fase geometrica ed altoarcaica (tipo Corinzia A o Sourisseau $1 \beta$ ), sostituendolo con un orlo ingrossato con una caratteristica risega sottostante. Da dove viene l'ispirazione per questo nuovo elemento? Riconsiderando lo spettro di anfore dello scorcio fra VII e VI sec. possiamo prendere in considerazione sia le anfore milesie, sia le anfore cd. laconiche, poiché tutte e due avevano un orlo ingrossato con una risega rispettivamente una nervatura sottostante l'orlo ${ }^{48}$.

47 Anche in questo caso è da deplorare che Vandermersch confonde il tipo rappresentato dall'anfora da Cariati, con altri esemplari di forma generale molto diversa come un'anfora da Locri (Vandermersch MGS III, fig. B), vedi Vandermersch 1994, p. 70 fig. B. In favore di una produzione locale/regionale delle anfore "à pâte rouge" cf. anche Desy, de Paepe 1990, p. 193-217, per il fenomeno del cd. tipo Metapontino, cf. Desy, De Paepe 1990, p. 217-218 n. $150-155$, tav. 91

48 Per le anfore milesie Dupont 1998, p. 170-177; per le anfore laconiche Pelagatti 1989; Pelagatti 1992. 
La presenza delle anfore laconiche è ben attestata in Sicilia, al punto tale che proprio in questo ambito Pelgatti ha definito il tipo, mentre le strette relazioni tra Mileto e Sibari sono ben note dalle fonti. Tutti e due i gruppi di anfore potrebbero così aver avuto un certo influsso sulle produzioni magno-greche nella fase degli inizi o della prima metà del VI sec. a.C. Mentre per quanto sappiamo finora il quadro del versante tirrenico sembra abbastanza unitario dal periodo tardo-arcaico in poi, sul versante ionico-adriatico dal VI fino al IV sec. a.C. troviamo una coesistenza di vari tipi che allo stato attuale della ricerca non possiamo ancora differenziare bene secondo i loro siti di provenienza. Soltanto nel periodo ellenistico si comincia a sviluppare una koiné più uniforme in tutto il Mediterraneo, caratterizzato in Occidente dalle cd. anfore greco-italiche, nell'Egeo invece dalle contemporanee anfore del tipo mushroom rim $^{49}$.

\section{Bibliografia}

Abbas 1999 : ABBAS (G.) - Identification pétro-minéralogique des productions céramiques anciennes. Application aux amphores de Grande Grèce, Thèse de Doctorat, Université Montpellier II, Montpellier 1999 (2 vol. dactyl.) Albore Livadie 1985 : ALBORE LIVADIE (C.) - La situazione in Campania. In : Il commercio etrusco arcaico (Atti dell'Incontro di Studio, 5-7 dicembre 1983, C.N.R.), Rome,1985 (Quaderni del Centro di Studio per l'archeologia etrusco-italica 9), p. 127-154.

Barone et al. 2002 : BARONE (G.) et al. - Contributo delle analsis archeometriche allo studio delle ceramiche provenienti dagli scavi di Messina. Risultati preliminari. In : Bacci (G.M.), Tigano (G.) éd., Da Zancle a Messina. Un percorso archeologico attraverso gli scavi II (Regione siciliana. Assessorato dei beni culturali ed ambientali e della pubblica istruzione), Messine, 2002, p. $87-118$.

Barone et al. 2004 : BARONE (G.) et al. - Archaeometric Analyses on 'Corinthian B' Transport Amphorae found at Gela (Sicily, Italy). Archaeometry, 46, 4, 2004, p. 553-568.

Barra Bagnasco et al. 2001 : BARRA BAGNASCO (M.) - Mineralogical and Chemical Composition of Transport Amphorae Excavated at Locri Epizephiri (Southern Italy). Journal of Cultural Heritage, 2.3, 2001, p. 229-239.

Bechtold, Docter 2010 : BECHTOLD (B.), DOCTER (R.F.) - Transport Amphorae from Punic Carthage: an overview. In : Motya and the Phoenician Ceramic Repertoire Between the Levant and the West $9^{\text {th }}-6^{\text {th }}$ Century B.C., Rome, 2010, p. 85-116.

Berlingò 1994 [1995] : BERLINGÒ (I.) - Importazioni corinzie nella Sibaritide. In : Corinto e l'Occidente (Atti del XXXIV Convegno di Studi sulla Magna Grecia, Taranto 1994), Tarante, 1995, p. 417-442.

Brun 2011 : BRUN (J.-P.) - La produzione del vino in Magna Grecia e in Sicilia. In : La vigna di Dioniso. Vite, vino e culti in Magna Grecia (Atti del IL Convegno di Studi sulla Magna Grecia, Taranto 2009), Tarante, 2011, p. 97-142. Buchner, Ridgway 1993 : BUCHNER (G.), RIDGWAY (D.) - Pithekoussai I. Rome, Accademia Nazionale dei Lincei (Monumenti antichi IV), 1993. Cibecchini 2005/2006 [2007] : CIBECCHINI (F.) - The unsolved question of greco-italic amphorae. Some solution from shipwrecks. Skyllis, 7, 2005/2006 [2007], p. 50-58.

49 Per la discussione delle anfore greco-italiche, cf. Maggi 2004; Olcese 2004; Cibecchini 2005/06; Olcese 2010, p. 37-41; Panella 2010; per le anfore del tipo mushroom rim da ultimo Lawall 2004.
De Caro, Gialanella 1996 [1998] : DE CARO (S.), GIALANELLA (C.) Novità pithecusane. L'insediamento di Punta Chiarito a Forio d'Ischia. In : Bats (M.), D'agostino (B.) dir., Euboica. L'Eubea e la presenza in Calcidica $e$ in Occidente. Atti del Convegno Internazionale (Napoli, 13-16 novembre 1996), Naples, 1998, p. 337-353.

Desy, De Paepe 1990 : DESY (P.), DE PAEPE (P.) - Torre S. Giovanni (Ugento) : Les amphores commerciales hellénistiques et républicaines. Studi di Antichità, 6, 1990, p. 187-234.

Di Sandro 1986 : DI SANDRO (N.) - Le anfore arcaiche dallo scarico Gosetti, Pithecusa. Naples, 1986 (Cahiers Centre Jean Bérard 12).

Docter c. d. s. : DOCTER (R.F.) - The amphorae. In : HADZIS (K.), NANAJ (A.), NEEFT (C.W.) dir., Bouthrotos I. The Pottery (in c.d.s.)

Dupont 1998 : DUPONT (P.) - Archaic East Greek Trade Amphoras. In : COOK (R.M.), DUPONT (P.) dir., East Greek Pottery, Londres, Routledge, 1998, p. 142-222.

Gasparri, Greco 2007 : GASPARRI (C.), GRECO (G.) dir. - Cuma - il foro: scavi dell'Università di Napoli Federico II, 2000 - 2001 (Atti della giornata di studi, Napoli, 22 giugno 2002). Pozzuoli, 2007 (Quaderni del Centro studi Magna Grecia 5 / Studi cumani 1).

Gasparri, Greco 2009 : GASPARRI (C.), GRECO (G.) dir. - Cuma: indagini archeologiche e nuove scoperte (Atti della giornata di studi, Napoli, 12 dicembre 2007). Pozzuoli, 2009 (Quaderni del Centro studi Magna Grecia 7 / Studi cumani 2 ).

Gassner 2003 : GASSNER (V.) - Materielle Kultur und kulturelle Identität in Elea in spätarchaisch-frühklassischer Zeit. Untersuchungen zur Gefäßund Baukeramik aus der Unterstadt (Grabungen 1987-1994). Wien, 2003 (Archäologische Forschungen 8 / Velia-Studien 2).

Gassner 2011a : GASSNER (V.) - Amphorae Production in Calabria. In : FACEM (consulté le 06/06/2011) (http://www.facem.at/project-papers.php). Gassner 2011b : GASSNER (V.) - Amphorae Production of the Ionic-Adriatic Region. In : FACEM (consulté le 06/06/2011) (http://www.facem.at/projectpapers.php)

Göransson 2007 : GÖRANSSON (K.) - The transport amphorae from Euesperides. The maritime trade of a Cyrenaican city 400-250 B.C. Stockholm, 2007 (Acta Archaeologica Lundensia, series 4, n²5).

Gras 1987 : GRAS (M.) - Amphores commerciales et histoire archaïque. DialA, 5/2, 1987, p. 41-50.

Koehler 1979 : KOEHLER (C.G.) - Corinth A and B Transport Amphoras. Ph.D. diss., Princeton University, 1979.

Kourkoumelis 1990 : KOURKOUMELIS (D.) - Corcyrean Amphoras. ENALIA Annual 2, 1990, p. 42-47.

Kourkoumelis-Rodostamos 1988 : KOURKOUMELIS-RODOSTAMOS (D.) Recherches archéologiques à Corfou : topographie, questions historiques, amphores de transport et commerce antique. Université Provence Aix - Marseille 1, 1988.

Lawall 2004 : LAWALL (M.-L.) - Amphoras without stamps. Chronologies and Typologies from the Athenian Agora. In : $\Sigma T^{\prime} \varepsilon \pi \iota \sigma \tau \eta \mu о v \iota x \eta ~ \sigma v v \alpha \tau \eta \sigma \eta$

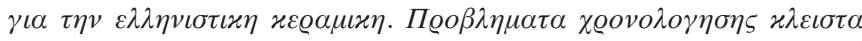

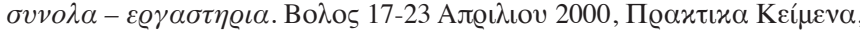
Athènes, 2004, p. 445-454.

Maggi 2004 : MAGGI (A.) - Problemi di classificazione e terminologia circa le anfore 'greco-italiche' e riflessioni sulla produzione velina. Orizzonti, 2004, p. 99-106.

McCann 1972 : MCCANN (A.M.) - A fourth century B.C. shipwreck near Taranto. Archaeology, 25, 1972, p. 180-187.

Morter, Leonard 1998 : MORTER (J.), LEONARD (J.R.) - Storage Amphorae, with an appendix by H. Iceland. In : CARTER (J.C.) dir., The Chora of Metaponto. The Necropoleis Vol. II, Austin, 1998, p. 731-47.

Nizzo 2007 : NIZZO (V.) - Ritorno ad Ischia. Dalla stratigrafia della necropoli di Pithekoussai alla tipologia dei materiali. Naples, 2007.

Olcese 2004 : OLCESE (G.) - Anfore greco-italiche antiche. Alcune osservazioni sull'origine e sulla circolazione alla luce di recenti ricerche archeologiche ed archeometriche. In : Metodi e approcci archeologici. L'industria e il commercio nell'Italia antica, Rome, 2004, p. 173-192.

Olcese 2010 : OLCESE (G.) - Le anfore greco-italiche antiche di Ischia: Archeologia e archeometria, Rome, 2010. 
Panella 2010 : PANELLA (C.) - Roma, il suburbio e l'Italia in età medio e tardo-repubblicana: cultura materiale, territori, economie. Facta. A journal of Roman material culture studies, 4, 2010, p. 11-124.

Pelagatti 1989 : PELAGATTI (P.) - Ceramica laconica in Sicilia e a Lipari. Materiali per una carta di distribuzione. BdA, 54, 1989, p. 1-62.

Pelagatti 1992 : PELAGATTI (P.) - Ceramica laconica in Sicilia e a Lipari. Materiali per una carta di distribuzione. BdA Suppl., 64,2, 1992.

Preka-Alexandri 1987 [1992] : PREKA-ALEXANDRI (K.) - A Ceramic Workshop in Figareto, Corfu. In : Blondé (F.), Perreault (J.Y.) dir., Les ateliers de potiers dans le monde grec aux époques géométrique, archaïque et classique. Actes de la Table Ronde organisée à l'École française d'Athènes (2 et 3 octobre 1987), BCH Suppl., 23, 1992, p. 41-52.

Santos 2008 : SANTOS RETOLAZA (M.) - Les amfores gregues. In : Nieto (X.), Santos (M.) dir., El vaixell grec de Cala Sant Vicenç (Pollença, Mallorca), Girona, 2008 (Monografies del CASC 7, Museu d'Arqueologia de Catalunya. Centre d'Arqueologia Subaquàtica de Catalunya), p. 125-152. Sauer, Gassner 2008 : GASSNER (V.), SAUER (R.) - The Shipwreck of Cala Sant Vicenç. Thin Section and Heavy Mineral Analyses ofAmphorae Samples. In : Nieto (X.), Santos (M.) dir., El vaixell grec de Cala Sant Vicenç (Pollença, Mallorca), Girona, 2008 (Monografies del CASC 7, Museu d'Arqueologia de Catalunya. Centre d'Arqueologia Subaquàtica de Catalunya), p. 355-371.
Savelli 2006 : SAVELLI (S.) - Le anfore da trasporto. In : Cuozzo (M.) et al., Cuma. Le fortificazioni 2. I materiali dai terrapieni arcaici, Naples, Istituto Universitario Orientale, 2006, p. 103-26.

Savelli 2009 : SAVELLI (S.) - Anfore greco-occidentali in Magna-Grecia: un aggiornatmento sul tipo 'corinzio B arcaico' e 'ionicomassaliota'. In: Camia (F.), Privitera (S.)dir., Obeloi, Contatti, scambi e valori nel Mediterraneo antico. Studi offerti a Nicola Parise, Paestum, (Tekmeria 11), 2009, p. 105-130.

Sourisseau 2009 [2011] : SOURRISEAU (J.-C.) - La diffusion des vins grecs d'Occident du VIII ${ }^{e}$ au IV ${ }^{e}$ s. av. J.-C., sources écrites et documents archéologiques. In : La vigna di Dioniso. Vite, vino e culti in Magna Grecia (Atti del IL Convegno di Studi sulla Magna Grecia, Taranto 2009), Tarante, 2011, p. 145-252. Torelli 1994 [1995] : TORELLI (M.) - Attorno a Demarato. In : Corinto e l'Occidente (Atti del XXXIV Convegno di Studi sulla Magna Grecia, Taranto 1994), Tarante, 1995, p. 625-654

Vandermersch 1994 : VANDERMERSCH (C.) - Vin et amphores de Grande Grèce et de Sicile. IV -III ${ }^{e}$ s. avant J.-C. Naples, Centre Jean Bérard, 1994. Vandermersch 1996 : VANDERMERSCH (C.) - Vigne, vin et économie dans l'Italie du sud grecque à l'époque archaïque. Ostraka, 5/1, 1996, p. 155-185.

Whitbread 1995 : WHITBREAD (I.) - Greek Transport Amphorae: A Petrological and Archaeological Study. Oxford, British School at Athens (Fitch Laboratory Occ. Paper, 4), 1995. 


\title{
Muro Leccese (Puglia, Italia). Forme e funzioni delle ceramiche d'uso quotidiano in un centro messapico tra IV e III secolo a.C.
}

\author{
Liliana Giardino \\ Catia Bianco \\ Francesco Meo \\ Dipartimento di Beni Culturali, Università del Salento
}

\section{Résumé}

La ville moderne de Muro Leccese, situé dans la péninsule du Salento, à une douzaine de kilomètres d'Otrante, recouvre un centre messapien actif entre la fin du VIII ${ }^{e}$ et le milieu du $\mathrm{III}^{\mathrm{e}}$ s. av. J.-C., bien connu pour les restes monumentaux de la muraille de la fin du IVe s. av. J.-C.

Dans la zone centrale de l'habitat messapien a été identifié un complexe résidentiel noble, dont le rôle est lié dès l'origine et par la suite à son emplacement sur une route qui correspond au tronçon urbain de la rue qui relie Otranto à la côte Adriatique. Un secteur du complexe est occupé par une série d'aménagements étroitement associés au stockage, à la cuisine et à la consommation de nourriture : une pièce utilisée comme cellier, une cuisine avec deux fours et une salle de banquet avec un autel au centre.

La persistance des usages, jusqu'à la fin de l'époque hellénistique, des catégories et des formes de céramiques de tradition protohistorique et la faible diffusion de celles qui sont rencontrées abondamment dans les niveaux de la ville italiote contemporaine sont quelques-unes des caractéristiques mises en évidence.

Mots-clés : Italie préromaine, Messapie, Muro Leccese, habitat, vie quotidienne, céramique

\section{Riassunto}

L'abitato moderno di Muro Leccese, situato nella penisola Salentina interna a una decina di chilometri da Otranto,si sovrappone a un centro messapico attivo tra la fine dell'VIII e i decenni centrali del III secolo a.C., ben noto per i resti monumentali della cinta muraria della fine del IV secolo a.C.

Nella zona centrale dell'abitato messapico è stato individuato un complesso residenziale gentilizio, icui ruolo emergente è ulteriormente evidenziato dalla sua ubicazione su una strada che rappresenta il tratto urbano della via di collegamento con Otranto e con la costa adriatica. Un settore del complesso è occupato da una serie di ambienti strettamente connessi con la conservazione, la cottura e il consumo del cibo: un locale utilizzato come dispensa, una cucina con due forni e una sala da banchetto con altare al centro.

La persistenza d'uso fino ad età ellenistica di classi e forme di tradizione protostorica e la scarsa diffusione di quelle ampiamente ricorrenti nei livelli coevi delle città italiote sono alcune delle peculiarità riscontrate.

Parole chiave: Messapia, abitato, età ellenistica, alimentazione, ceramica 
$\mathrm{L}$ 'abitato moderno di Muro Leccese si sovrappone a un centro messapico di cui si ignora il nome antico, posizionato su una strada istmica collegante la costa adriatica (Otranto) con quella ionica (Alezio) (fig. 1).

Villaggio di capanne tra la fine dell'VIII e la prima metà del VI sec. a.C., il centro riceve un'organizzazione di tipo urbano nella seconda metà del VI sec. a.C. (Giardino, Meo 2008, p. 14-15; Id. 2011, p. 20-25; Id. 2013, p. 310317; Id. c.s.). Alla fine del IV sec. a.C. la costruzione di una cinta muraria, i cui resti monumentali sono ben noti da tempo (Lamboley 1999; Bianco 2010), racchiude una superficie di oltre 100 ettari, collocando Muro Leccese tra gli abitati più grandi della Messapia di età ellenistica accanto a Oria, Rudiae e Ugento (D'Andria 1990 [1991]; Calvaruso 2001; Giardino 2008, p. 164-167; Giardino, Meo 2011, p. 26-39). Lo scontro con Roma alla metà del III sec. a.C.e gli eventi collegati con il bellum sallentinum provocano una distruzione violenta dell'abitato messapico e la sua destrutturazione definitiva, cui fa seguito, già a partire dall'età romana, una rioccupazione dell'area con piccoli nuclei insediativi a carattere sparso (Giardino 2003, p. 337-338; Id. 2008, p. 167).

Le indagini archeologiche condotte con continuità dalla cattedra di Urbanistica del mondo classico dell' Università del Salento in più di dieci anni (2000-2013) hanno interessato settori diversi della superficie interna alle mura (Giardino, Meo 2011, p. 40-43), concentrandosi maggiormente in un'area di proprietà comunale (località Cunella), ubicata nella parte centro-orientale dell'abitato antico (fig. 2).

L'area archeologica di località Cunella ha restituito una frequentazione umana che va, senza soluzioni di continuità, dalla fine dell'VIII sec. a.C. ai decenni centrali del III sec. a.C. Nella seconda metà del VI sec. a.C. si registra un esteso intervento di pianificazione dell' area che comporta lo spianamento delle capanne dell'età del ferro e la creazione di un tessuto urbano articolato secondo spazi funzionali: una strada est-ovest che rappresenta il tratto urbano della via istmica Otranto - Alezio; un grande complesso residenziale gentilizio e un'ampia terrazza, allineati a sud della strada; un'area riservata allo svolgimento di pratiche cerimoniali a nord della stessa (Giardino, Meo 2013; Id. c.s.) (fig. 3).

L'organizzazione di età arcaica persiste sostanzialmente inalterata fino alla distruzione violenta del III sec. a.C. Nella seconda metà del IV sec. a.C. il complesso residenziale gentilizio presenta al suo interno, in stretta contiguità topografica e funzionale, una sala da banchetto con altare centrale, un vano con funzione di dispensa e una cucina con 2 forni (Giardino 2008, p. 165-167; Giardino, Meo 2011) (fig. 3).
Il presente contributo offre una esemplificazione delle ceramiche in uso nell'abitato messapico di Muro Leccese tra la seconda metà del IV e il III sec. a.C., fornendo così un ulteriore campione alla panoramica delle forme e delle classi diffuse nel mondo messapico in questo stesso periodo (D'Andria 1990; Yntema 1990 [1991]; Id. 2001; Mastronuzzi, Melissano, Convertino 2013, p. 376; Mastronuzzi et alii 2013, p. 7-11). Per l'elaborazione delle singole forme si è applicata, secondo quanto proposto nel 1988 da Michel Bats, una loro articolazione su base funzionale, certamente più utile rispetto a quella tradizionale per classi ceramiche ai fini di una lettura in chiave antropologica della documentazione materiale (Bats 1988). Sul modello di quanto già proposto per le produzioni di III sec. a.C. della colonia tarantina di Herakleia (Calvaruso 2012), cui si rinvia per i criteri di assegnazione dei codici, anche per Muro Leccese è stata impostata una codificazione delle classi per funzione e delle forme per morfologia. I gruppi funzionali presentati sono collegati al cibo e ne ripropongono i singoli momenti d'uso: la conservazione, la preparazione, la cottura e il consumo.

In questa sede si tralasciano altre categorie relative ad ulteriori aspetti della vita quotidiana, quali le attività produttive, l'abbigliamento e gli strumenti per l'illuminazione.

\section{Conservazione del cibo}

I contenitori riportabili a questa funzione e in uso a Muro Leccese tra IV e III sec. a.C. sono le hydriai, le situle e le anfore da trasporto.

La conservazione dei liquidi sembra riservata prevalentemente alle hydriai (fig. 4, ML 24101.1), testimoniate da un numero consistente di individui, privi di variazioni morfologiche sensibili. Esse sono realizzate in ceramica comune o a fasce, con un'argilla nocciola ben depurata e compatta, rivestita da una sottile ingubbiatura beige. Le fasce, di colore dal rosso al bruno e di larghezza variabile, segnano l'orlo, la spalla, il corpo e le anse. Gli esemplari maggiormente conservati indicano una capienza di oltre 101 . Il tipo è documentato in contesti di fine IV - inizi III sec. a.C. della Messapia (D'Andria 1990, p. 166; Yntema 1990 [1991], p. 177; Mastronuzzi, Melissano, Covertino 2013, p. 376; Mastronuzzi et alii 2013, p. 7-11).

Per la conservazione dei cibi solidi sono utilizzate le situle, contenitori di tradizione protostorica, per forma e per caratteristiche tecniche (impasto) (fig. 4, ML 93101.1, 93102.1, 93103.1). Sono attestati due tipi, diversi per dimensioni e morfologia. Il primo (ML 93103.1) corrisponde a contenitori di capacità 
maggiore, con diametro dell'orlo superiore ai $40 \mathrm{~cm} \mathrm{e}$ cordone plastico con intacchi a stecca applicato sotto l'orlo (Yntema 2001, p. 322-323, Form N53). Il secondo tipo (ML 93101.1, 93102.1) è esemplificato da contenitori più piccoli (diametro dell'orlo fino a $30 \mathrm{~cm}$ ) ed è strettamente legato alle forme protostoriche per il profilo dell'orlo e delle pareti e per la presenza di un'ansa plastica arcuata, talvolta fiancheggiata da piccole bugne plastiche (Yntema 2001, p. 22, Form A01).

Le anfore da trasporto (fig. 4, ML 50101.1, 50102.1) rappresentano un contenitore di tipo particolare in quanto ad un uso primario (trasporto di vino e di olio di importazione) può essere affiancato un prolungato uso secondario per la conservazione di altri tipi di liquidi. Le forme più diffuse a Muro tra IV e III sec. a.C. sono le anfore greco-italiche e quelle di produzione corinzia B, con il tipico orlo a '8' (Koehler 1979, p. 201-208). La diffusione di entrambi i tipi in Messapia è ampia e ben documentata (D'Andria 1990, p. 165 e 167; Auriemma 2004, I, p. 309-311)

\section{Preparazione del cibo}

A questa funzione sono riportabili bacini e mortai.

I bacini sono prodotti in ceramica acroma e a fasce (fig. 5, ML 13301.1). I primi sono di grandi dimensioni, con vasca profonda e robuste anse a presa sull'orlo. Essi ripropongono una forma ampiamente diffusa nel mondo italiota (Metaponto: Vittoria 2011, p. 367, n49). I bacini a fasce (fig. 5, ML 13302.1) presentano dimensioni minori e soltanto alcuni sono dotati di anse. E' probabile che essi venissero usati anche per servire le pietanze in tavola.

I mortai sono attestati a Muro Leccese da pochi esemplari (fig. 5, ML 13401.1). Alcuni corrispondono al ben noto pelvis, altri sono tipicamente locali per forma e per caratteristiche tecniche (Yntema 2001, p. 263-264, Form M55).

\section{Cottura del cibo}

Pentole, casseruole, tegami, e teglie sono le forme attestate a Muro Leccese.

La forma di gran lunga più utilizzata è la pentola (fig. 6, ML 42105.1, 43103.1, 43104.1), documentata in più varianti morfologiche. Il primo tipo (ML 42105.1) ha un semplice orlo liscio, il collo a profilo concavo, corpo globulare, un'ansa verticale ed ha un lungo periodo d'uso a partire dall'età arcaica. Il secondo (ML 43103.1) è il più diffuso e presenta medie e grandi dimensioni, un ampio collo troncoconico, corpo quasi globulare e due false anse orizzontali impostate obliquamente. Il terzo tipo (ML 43104.1) è caratterizzato dalla presenza dell'alloggiamento per il coperchio.

Le casseruole (fig. 6, ML 33201.1) risultano in numero nettamente inferiore rispetto alle pentole. L'unico esemplare intero presenta un orlo con battente interno per il coperchio e anse a bastoncello sormontanti.

Anche il tegame (fig. 6, ML 33101.2) risulta poco diffuso a Muro Leccese. Le dimensioni dei frammenti rinvenuti non permettono di ricostruire per intero la forma originaria che tuttavia sembra richiamare quella ampiamente documentata nei contesti abitativi delle città italiote.

La teglia (fig. 6, ML 32101.2) è attestata da pochi esemplari, tutti di grande diametro, realizzati in un impasto di tradizione protostorica e con la parete interna rivestita da una spessa ingubbiatura (Manduria, Li Castelli: Burgers 1998, p. 156 e 158, n³30). Per questa forma è stato ipotizzato che servisse per fare per il pane (Yntema 2001, p. 320-321, Form N51).

\section{Consumo del cibo}

I vasi utilizzati in tavola sono il piatto, la scodella, la ciotola, lo skyphos, la tazza e la brocca.

I piatti (fig. 7, ML 11201.1) sono realizzati in ceramica a vernice nera, acroma o a fasce. I primi sono rari e di piccole e medie dimensioni, mentre in altri centri messapici sono generalmente documentati con un diametro più grande (Muro Tenente: Burgers 1998, p. 81 e 83, n48; Valesio: Yntema 2001, p. 150-151, Form K03c). Gli esemplari acromi o a fasce hanno la stessa forma di quelli a vernice nera ma sono più grandi.

Le scodelle (fig. 7, ML 13303.1, 13304.1) sono realizzate unicamente in ceramica a fasce e acroma. Alcuni esemplari presentano la stessa forma dei piatti ma hanno pareti più spesse e vasca più profonda e carenata. Il tipo più diffuso (ML 13304.1) appare di spiccata tradizione arcaica per l'orlo rientrante, la forma della vasca e la presenza di bande brune sulla faccia superiore dell'orlo e sulla parete (Manduria, Li Castelli: Burgers 1998, p. 148-149, n²70; Muro Tenente: Burgers 1998, p. 80-81, $\mathrm{n}^{\circ} 33,60-62, \mathrm{n}^{\circ} 84-85$; Valesio: Yntema 2001, p. 69-78, Form C21-22).

La ciotola (fig. 7, ML 11401.1, 11402.1, 12201.1) è ampiamente attestata. Gli esemplari a vernice nera (ML 11401.1, 11402.1) sono sempre di piccole dimensioni e appartengono a un numero limitato di forme. La ciotola più diffusa (ML 12201.1) è quella ad echino, monoansata o priva di ansa, in ceramica acroma o parzialmente verniciata per immersione (Vaste: D'Andria 1990, p. 135, n²09). 


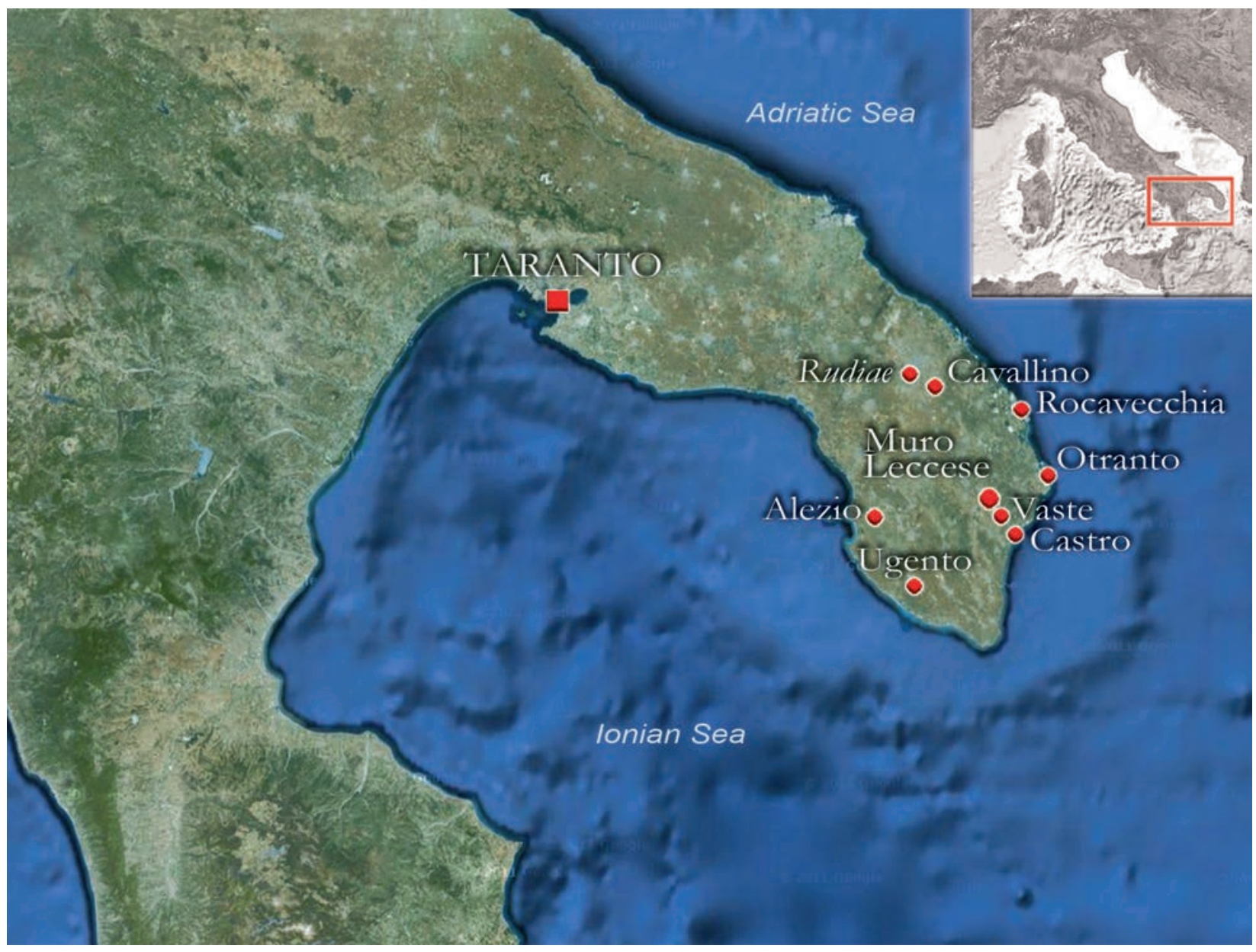

Fig. 1. Ubicazione di Muro Leccese in relazione ai principali siti della Messapia meridionalee alla vicina colonia greca di Taranto.

Nel consumo dei cibi liquidi prevale la tazza mononsata (fig. 7, ML 12301.1, 12302.1), acroma o a fasce, che rappresenta un contenitore tipico della produzione messapica (Valesio: Yntema 2001, p. 84-87, Form C35). Gli skyphoi a vernice nera (fig. 7, ML 13101.1) appaiono invece più rari. Le brocche sono prevalentemente acrome (fig. 7, ML 22201.1) e presentano un semplice orlo liscio estroflesso e un'ansa verticale sormontante. La loro capienza si aggira intorno ai 2 litri (Vaste: D’Andria 1990, p. 165, n²81).

\section{Osservazioni conclusive}

Il quadro complessivo delle ceramiche utilizzate nel centro messapico di Muro Leccese tra la fine del IV e il III sec. a.C. per conservare, preparare e cuocere il cibo conferma ed amplia quanto già noto da altri centri coevi della stessa area (D’Andria 1990; Yntema 1990 [1991]; Id. 2001 ; Mastronuzzi, Melissano, Convertino 2013, p. 376; Mastronuzzi et alii 2013, p. 7-11). Esso permette inoltre di elaborare delle riflessioni su alcuni aspetti culturali ed economici dell'area archeologica di Cunella nell'ultima fase di vita, immediatamente prima della sua violenta distruzione.

Una prima riflessione riguarda le abitudini alimentari. La prevalenza delle pentole per la cottura dei cibi suggerisce una dieta che privilegia zuppe e legumi (Bats 1988, p. 31-51). Alla preparazione del pane è riservata una forma specifica, attestata in Messapia (Yntema 2001 , p. 317 e 321) ma presente anche in area italiota. La diffusione di scodelle di grandi dimensioni e la rarità dei piatti induce a ipotizzare che il consumo del cibo a tavola avvenisse da un unico grande piatto centrale.

Altre peculiarità sono riconoscibili nella persistenza di classi (impasti) e di forme (situla, scodella ad orlo rientrante) di origine protostorica o arcaica (pentola, tazza), il cui uso appare persistere attraverso tutto il periodo arcaico fino all'età ellenistica; nella scarsa diffusione di classi (vernice nera) e di forme (piatti, skyphoi, anforette da dispensa, grandi pithoi) solitamente ricorrenti nei livelli coevi delle città italiote. Anche i crateri appaiono rari, sono solo di produzione locale e spesso presentano una decorazione dipinta a motivi vegetali 


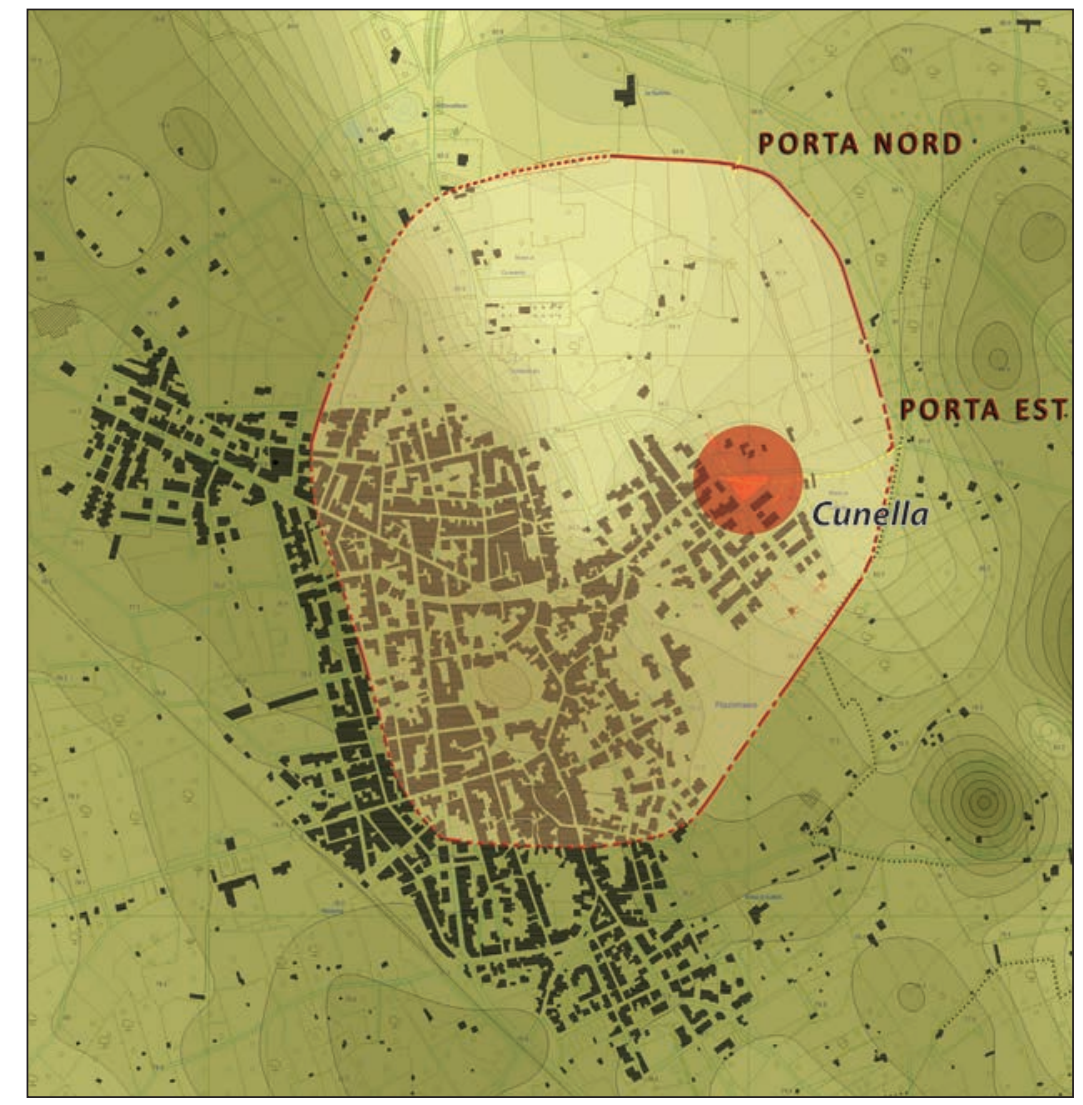

Fig. 2. Muro Leccese, ricostruzione del tracciato murario di IV sec. a.C. e ubicazione dell'area indagata.

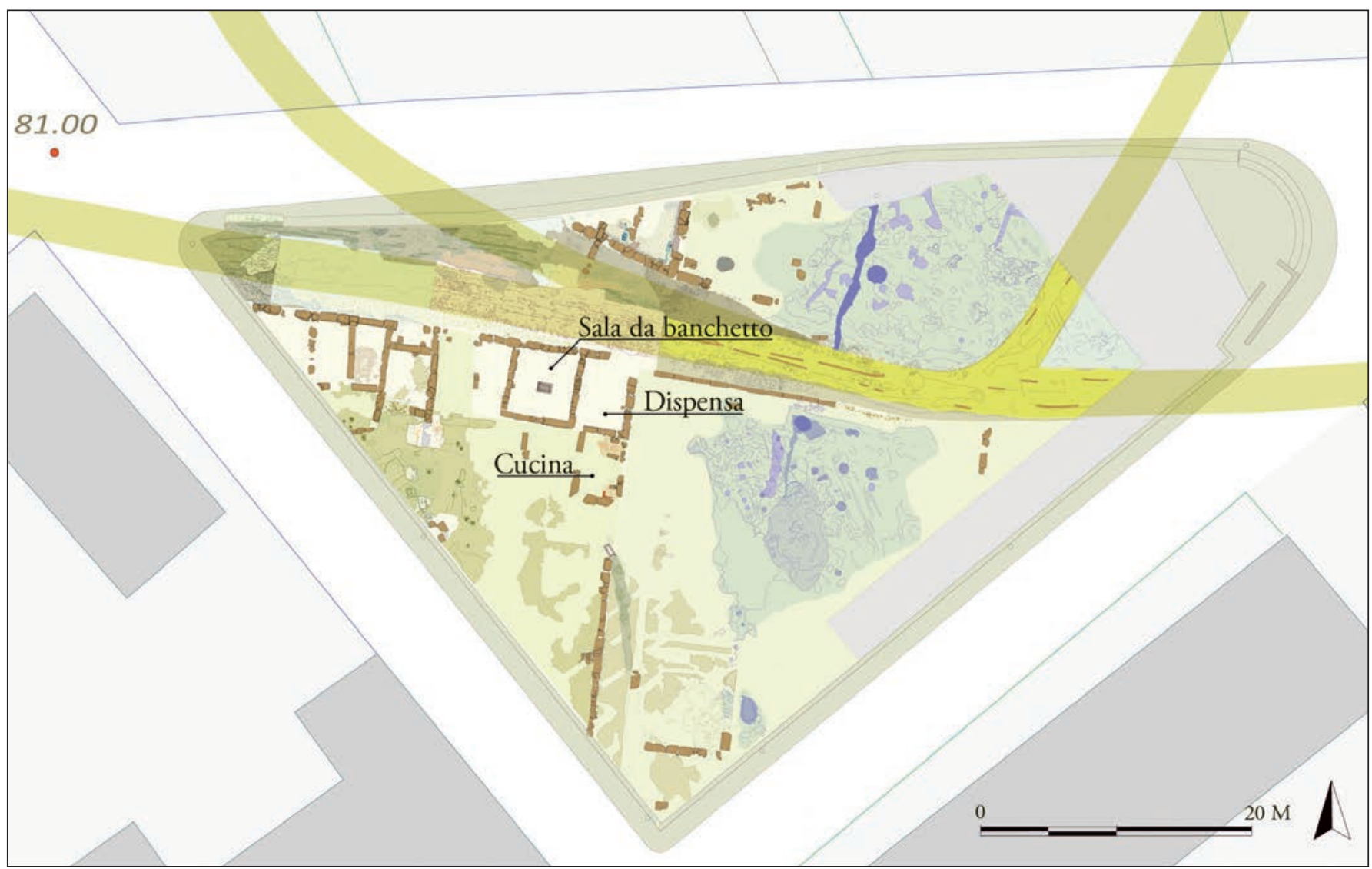

Fig. 3. Muro Leccese, abitato messapico. Planimetria dell'area archeologica in località Cunella. 


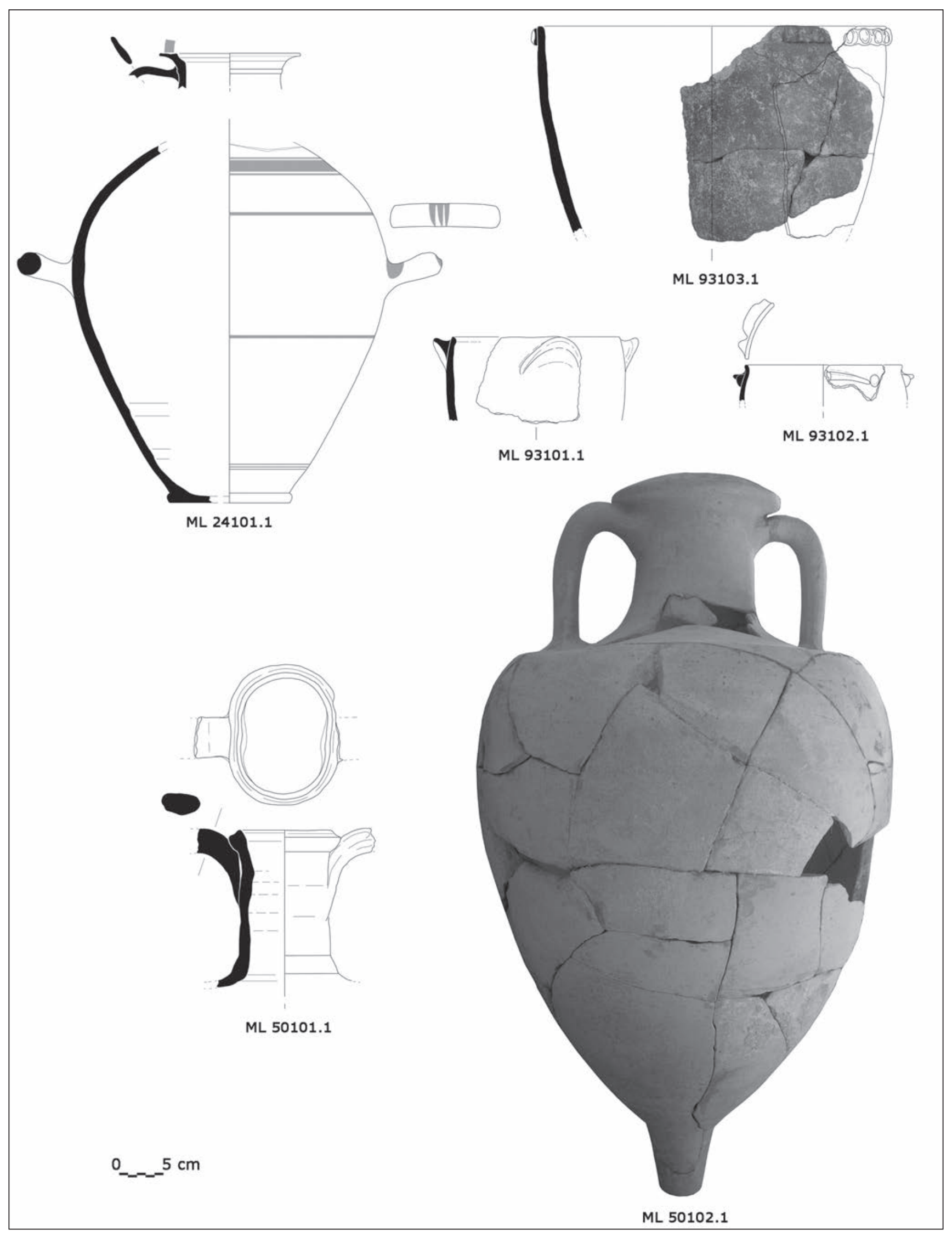

Fig. 4. Muro Leccese, località Cunella. Contenitori per la conservazione del cibo. 


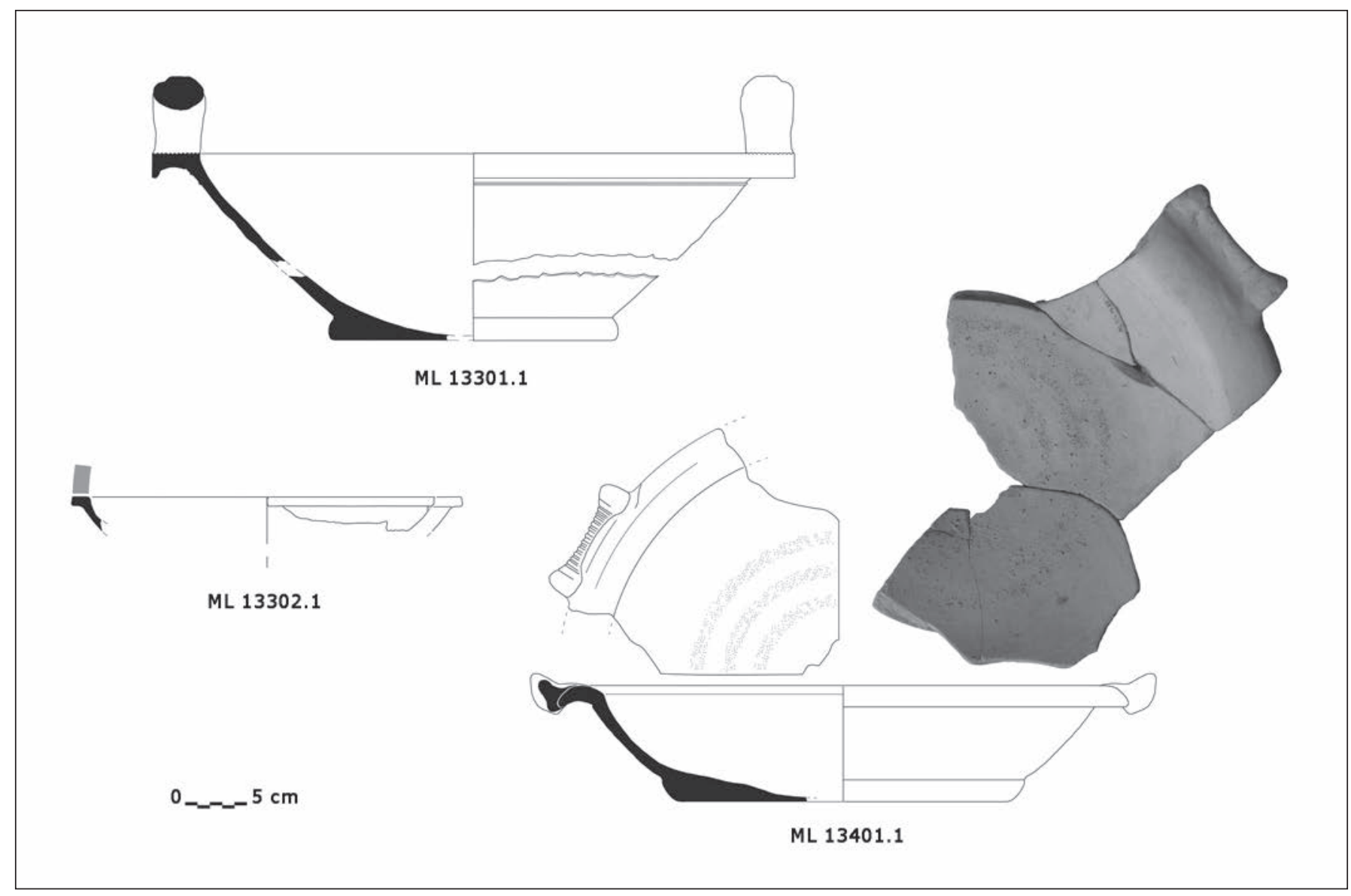

Fig. 5. Muro Leccese, località Cunella. Contenitori per la preparazione del cibo.

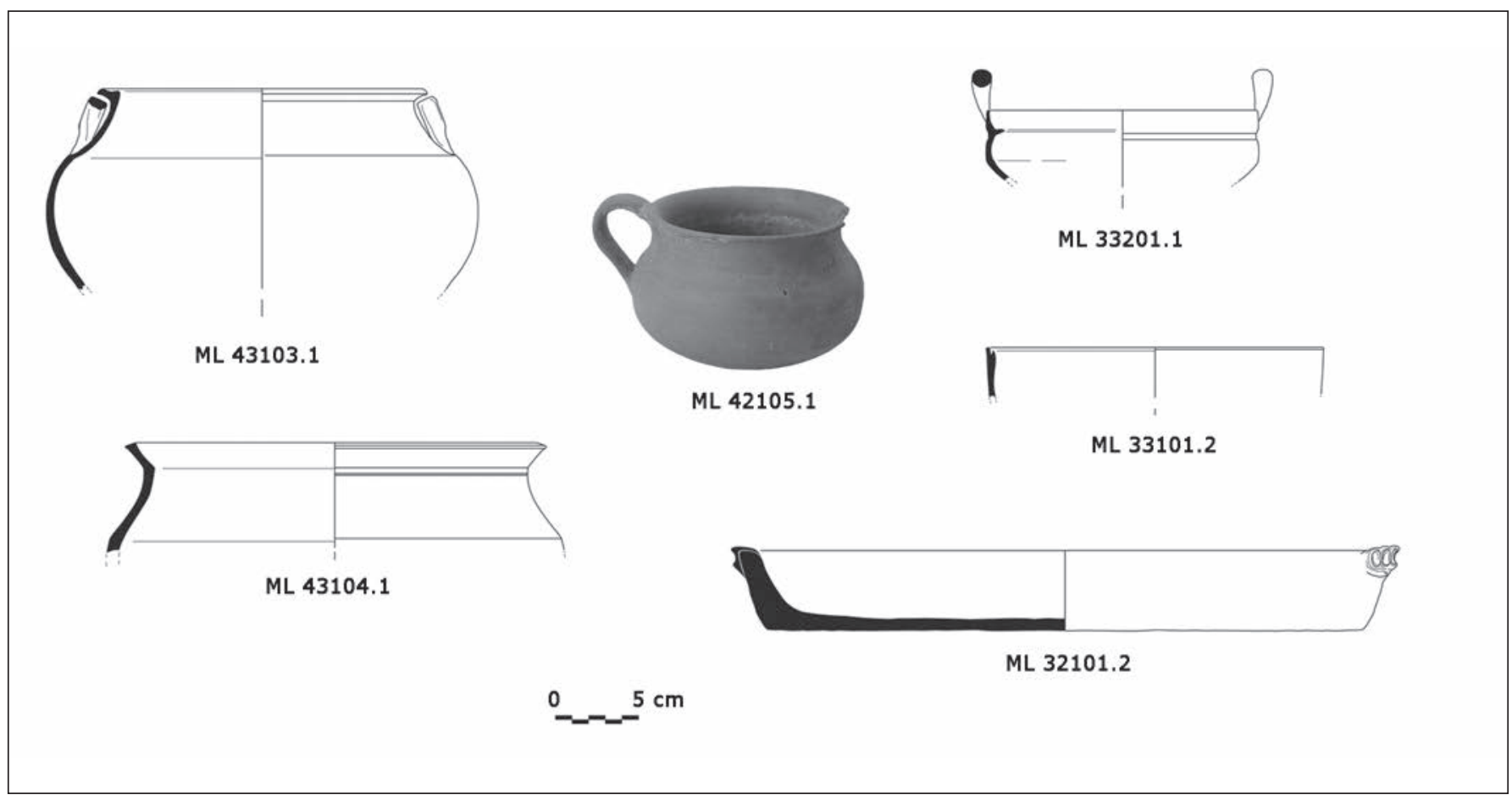

Fig. 6. Muro Leccese, località Cunella. Contenitori per la cottura del cibo. 


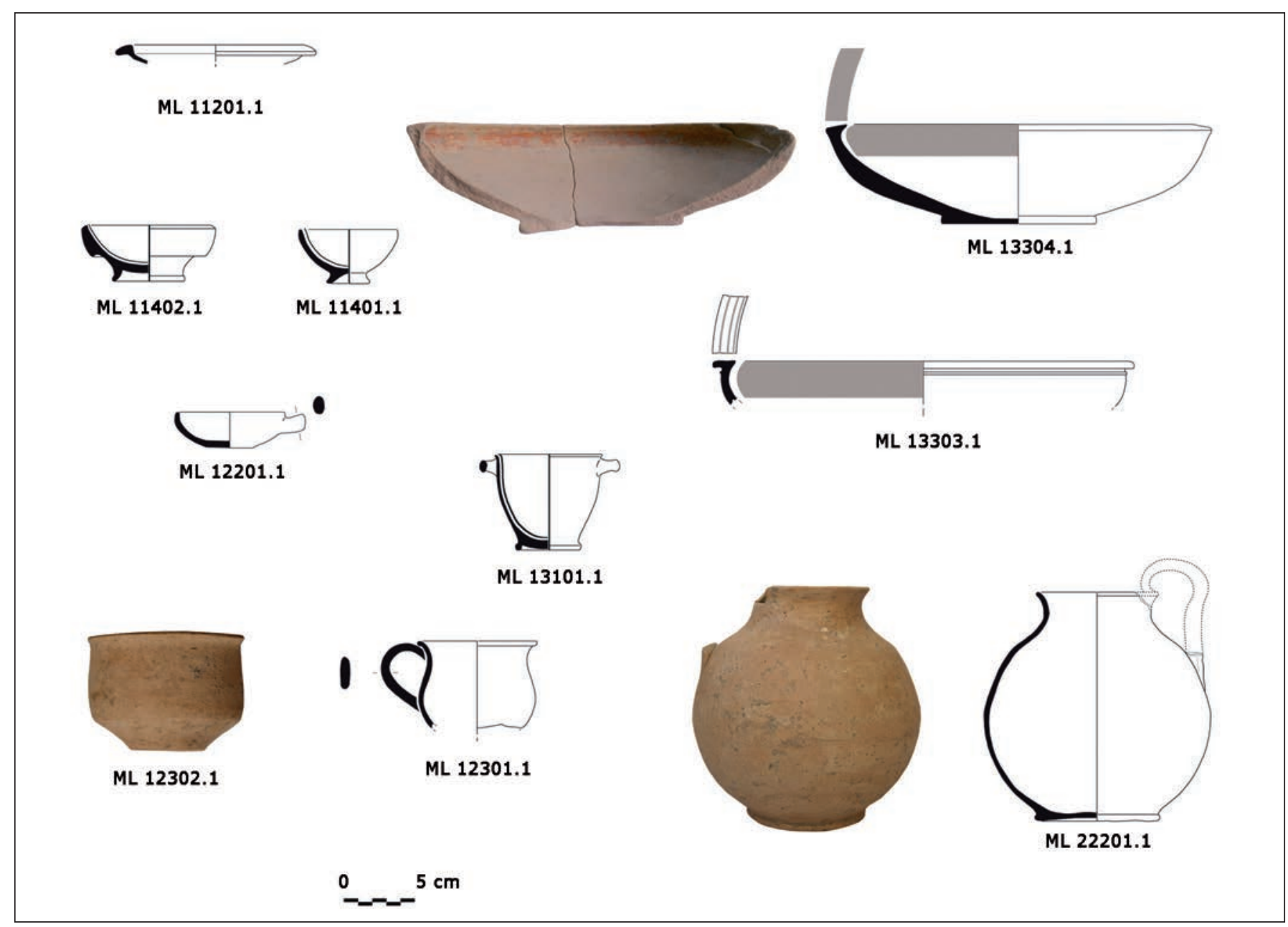

Fig. 7. Muro Leccese, località Cunella. Contenitori per il consumo del cibo.

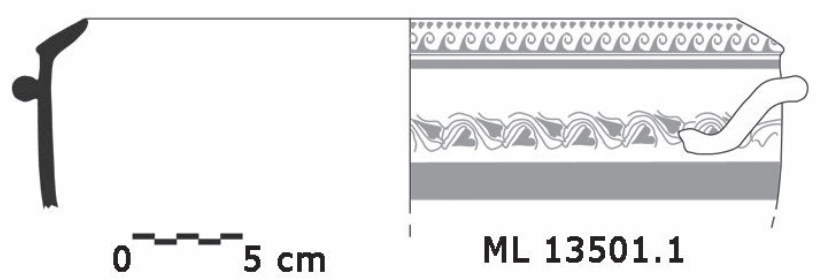

Fig. 8. Muro Leccese, località Cunella. Cratere con decorazione dipinta in rosso. 
(fig. 8, ML 13501.1) strettamente ispirata a quella ricorrente sulla ceramica di Gnathia. I contesti di provenienza sembrano suggerirne un uso prevalentemente rituale (Giardino, Meo c.s.).

Tutti i precedenti aspetti concorrono ad evidenziare per l'abitato messapico di Muro Leccese, tra IV e III sec. a.C., un marcato conservatorismo culturale che si esprime con una netta preferenza per la produzione locale di tradizione arcaica rispetto alle classi e alle forme maggiormente circolanti nel vicino mondo italiota.

\section{Bibliografia}

Auriemma 2004 : AURIEMMA (R.) - Salentum a salo. Porti, approdi, merci e scambi lungo la costa adriatica del Salento, I-II. Galatina, Congedo Editore, 2004.

Bats 1988 : BATS (M.) - Vaisselle et alimentation à Olbia de Provence (v. 350-v. 50 av. J.-C.). Modèles culturels et catégories céramiques. Paris, CNRS, 1988.

Bianco 2010 : BIANCO (C.) - Un sistema informativo come strumento per la documentazione, conoscenza e tutale di una cinta muraria antica. Il caso di Muro Leccese (Lecce, Puglia). Tesi di Dottorato in Topografia Antica, Università del Salento, 2010.

Burgers 1998: BURGERS (G.-J.L.M.) - Constructing Messapian Landscapes. Settlement dynamics, social organization and culture contact in the margins of Graeco-Roman Italy. Amsterdam, H.W. Pleket - F.J.A.M. Meijer Editors, 1998.

Calvaruso 2001 : CALVARUSO (T.O.) - Muro Leccese (Lecce), Sitrie. Taras, XXI, 1, 2001, p. 113-114.

Calvaruso 2012 : CALVARUSO (T.O.) - Herakleia di Lucania. Proposta di classificazione delle ceramiche di III secolo a.C. dalle fornaci della terrazza meridionale. In: Osanna (M.), Zuchtriegel (G.) dir., AMФI $\Sigma I P I O \Sigma$ POA $\Sigma$. Nuove ricerche su Eraclea e la Siritide. Venosa, Osanna edizioni, 2012, p. 241-257.

D'Andria 1990 : D'ANDRIA (F.) dir. - Archeologia dei Messapi. Catalogo della Mostra, Bari, Edipuglia, 1990.

D'Andria 1990 [1991] : D'ANDRIA (F.) - Insediamenti e territorio: 1'età storica. In: I Messapi, Atti XXX Convegno di Studi sulla Magna Grecia (1990), Taranto, 1991, p. 393-478.
Giardino 2003 : GIARDINO (L.) - Muro Leccese. Lecce. In: Guaitoli (M.) dir., Lo sguardo di Icaro. Le collezioni dell'Aerofototeca Nazionale per la conoscenza del territorio. Roma, Campisano Editore, 2001, p. 336-338.

Giardino 2008 : GIARDINO (L.) - L'attività archeologica a Muro Leccese. In: Pranzo (A.) dir., Salento, architetture antiche e siti archeologici. Lecce, Edizioni del Grifo, 2008, p. 164-167.

Giardino, Meo 2008 : GIARDINO (L.), MEO (F.) dir. - Muro Leccese. Recupero di un patrimonio. Catalogo della Mostra, Maglie, Gioffreda, 2008. Giardino, Meo 2011 : GIARDINO (L.), MEO (F.) dir. - Prima di Muro. Dal villaggio iapigio alla città messapica. Catalogo della Mostra, Lecce, Edizioni Grifo, 2011.

Giardino, Meo 2013 : GIARDINO (L.), MEO (F.) - Un decennio di indagini archeologiche a Muro Leccese. Il villaggio dell'età del ferro e l'abitato arcaico. In: Andreassi (G.), Cocchiaro (A.), Dell'Aglio (A.) dir., Vetustis novitatem dare. Temi di antichità e archeologia in ricordo di Grazia Angela Maruggi. Taranto, Scorpione editrice, 2013, p.299-319.

Giardino, Meo c.s.: GIARDINO (L.), MEO (F.) - Attestazioni di pratiche rituali di età arecaica nell'abitato messapico di Muro Leccese (Le). In: Giardino (L.), Tagliamonte (G.) dir. Archeologia dei luoghi e delle pratiche di culto, Atti del Convegno (Cavallino, 26-27 gennaio 2012). Bari, Edipuglia, c.s.

Koehler 1979 : KOEHLER (C.G.) - Corinthian A and B Transport Amphoras. Ann Arbor, Princeton University, 1979.

Lamboley 1999 : LAMBOLEY (J.-L.) - Muro Leccese, sondeges sur le fortification nord. Rome, École française de Rome, 1999.

Mastronuzzi, Melissano, Convertino 2013: MASTRONUZZI (G.), MELISSANO (V.), CONVERTINO (S.) - Contesti di età messapica nell' area di Fondo Giuliano a Vaste. In: Andreassi (G.), Cocchiaro (A.), Dell'Aglio (A.) dir., Vetustis novitatem dare. Temi di antichità e archeologia in ricordo di Grazia Angela Maruggi. Taranto, Scorpione editrice, 2013, p. 365-378.

Mastronuzzi et alii 2013 : MASTRONUZZI (G.), COLAIANNI (G.), FIORENTINO (G.), GIARDINO (C.), MELISSANO (V.) - Analisi stratigrafica e funzionale di un'area di combustione nel luogo di culto messapico di Piazza Dante (Vaste - Lecce). In: The Journal of Fasti Online, http://www. fastionline.org/docs/FOLDER-it-2013-292.pdf

Vittoria 2011 : VITTORIA (E.) - Plain and Banded Ware. In: Carter (J.C.), Prieto (A.) dir. The Chora of Metaponto 3. Archaeological Field Survey Bradano to Basento, I-III. Austin, University of Texas Press, 2011, p. 337-424. Yntema 1990 [1991] : YNTEMA (D.G.) - Le ceramiche e l'artigianato del Salento tra l'età del Ferro e la romanizzazione. In: I Messapi, Atti XXX Convegno di Studi sulla Magna Grecia (1990), Taranto, 1991, p. 139-184.

Yntema 2001 : YNTEMA (D.G.) - Pre-Roman Valesio: Excavations of the Amsterdam Free University at Valesio, Province of Brindisi, southern Italy. I. The Pottery. Amsterdam, Free University, Institute of Archaeology, 2001. 



\title{
HERAKLEIA di Lucania (Basilicata, Italia). Forme e funzioni delle ceramiche d'uso quotidiano in una città italiota tra III e II secolo a.C.
}

\author{
Liliana Giardino \\ Teresa Oda Calvaruso \\ Dipartimento di Beni Culturali, Università del Salento
}

\section{Résumé}

Cet article propose une présentation des céramiques produites dans la seconde moitié du III $\mathrm{s}$. av. J.-C. dans un atelier de la ville italiote d'Herakleia. Il s'agit exclusivement de céramiques destinées à un usage quotidien, en relation avec les différents stades de la conservation, de la préparation, de la cuisson et de la consommation de nourriture. Les céramiques ont été classées tout d'abord selon leur fonction originelle, et ensuite avec une numérotation ouverte.

Les productions des ateliers d'Herakleia offrent un précieux outil d'analyse pour les problèmes liés au $\mathrm{III}^{\mathrm{e}}$ s. av. J.-C. et même plus spécifiquement pour la seconde moitié de ce siècle, car elles fournissent un contexte « fermé » chronologiquement.

En ce qui concerne Herakleia, elles contribuent à témoigner de la vitalité économique de la ville à un moment généralement considéré comme une période de crise pour toutes les villes italiotes de la côte Ionienne (Metaponte, Tarente).

Mots-clés : Grande Grèce, Herakleia, époque hellénistique, four, céramique, vie quotidienne, alimentation

\section{Riassunto}

Il contributo presenta un quadro delle ceramiche prodotte nella seconda metà del III sec. a.C. in un'area artigianale della città italiota di Herakleia. Si tratta esclusivamente di vasellame di uso quotidiano, collegato con i diversi momenti della conservazione, della preparazione, della cottura e del consumo del cibo. Le ceramiche sono state articolate in base alla loro funzione originaria e secondo un criterio univoco di classificazione aperta.

Le produzioni delle officine eracleote, poiché costituiscono un contesto "chiuso" cronologicamente, offrono un prezioso strumento diagnostico per le problematiche relative al III sec. a.C. e ancor più specificatamente alla seconda metà. Per quanto riguarda Herakleia, esse contribuiscono ad attestare la vitalità economica dell'abitato in un periodo solitamente ritenuto di crisi per tutte le città italiote dell'arco ionico (Metaponto, Taranto).

Parole chiave: Magna Grecia, Herakleia, età ellenistica, fornaci, ceramica, vita quotidiana, alimentazione 


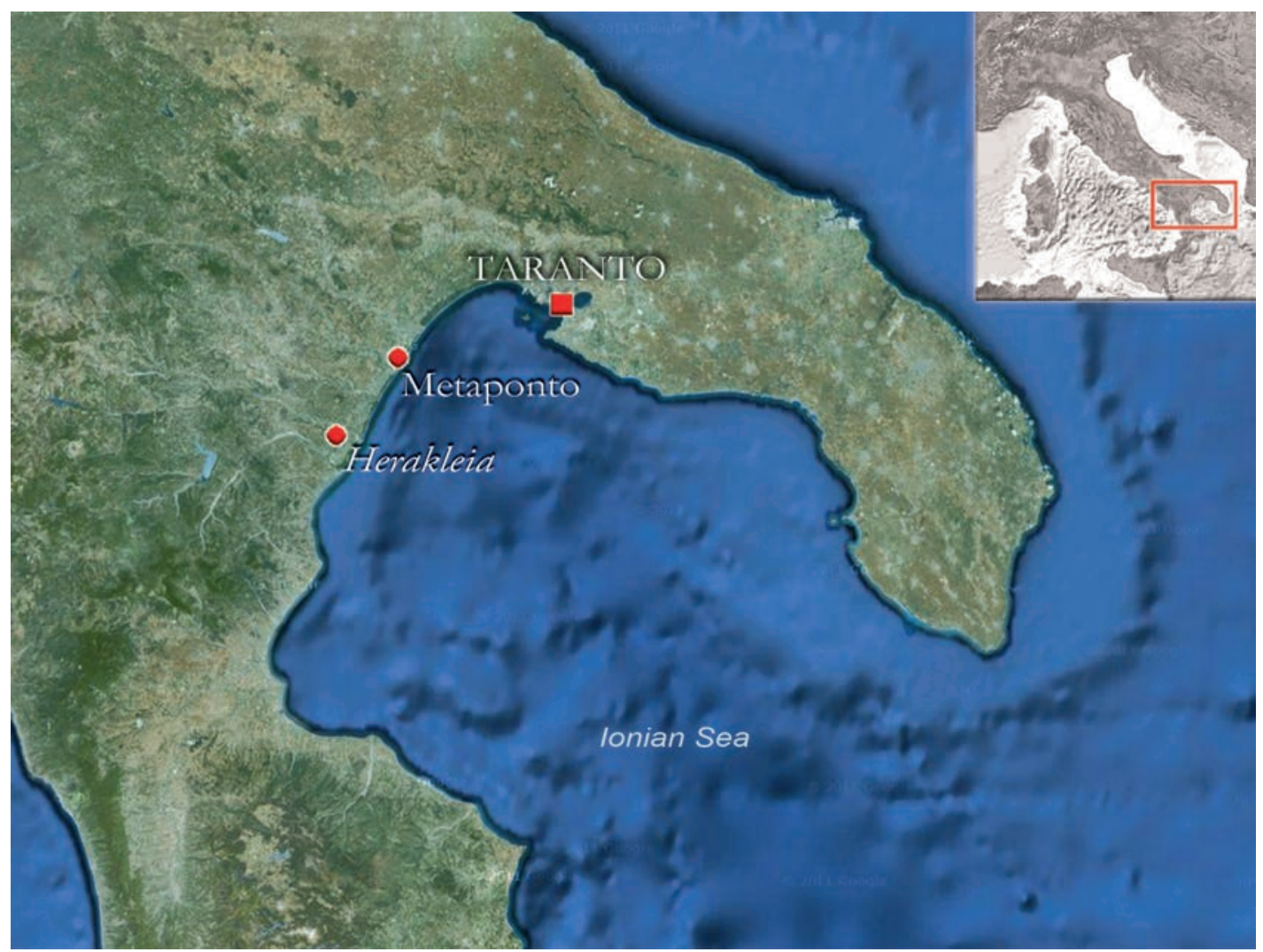

Fig. 1. Ubicazione di Herakleia (Archivio Soprintendenza per i Beni Archeologici della Basilicata).

$\mathrm{N}$ el corso del III sec. a.C., la colonia thurinotarantina di Herakleia non sembra interessata dalla crisi economica che investe le vicine città di Metaponto e di Taranto (fig. 1). La stipula del prope singulare foedus con Roma Pyrrhi temporibus (Ciceone, Pro Balbo, 22, 50) costituisce verosimilmente il presupposto principale di tale diversità.

La frequentazione delle aree santuariali e delle necropoli, una diffusa attività edilizia e un'intensa e articolata produzione artigianale persistono infatti con continuità per tutto il III e II sec. a.C., unitamente ad una occupazione del territorio con impianti agricoli ${ }^{1}$. Herakleia rappresenta pertanto uno dei pochi centri italioti la cui abbondante documentazione materiale permetta di riconoscere le trasformazioni che si sviluppano tra III e II sec. a.C.: il passaggio dalla "casa a cortile" di III sec. a.C. a quella "a cortile porticato" di II sec. a.C. ${ }^{2}$; la presenza di produzioni metallurgiche specializzate ('tomba dell'orafo') accanto a

1 Giardino 1999; De Siena, Giardino 2001, p. 144-151; Giardino 2004 [2005]; Lombardo 1996.

2 Giardino 1991 [1998], p. 177-183; 1992 [1996]; 2004 [2005], p. 412-415. quelle ceramiche ${ }^{3}$; lo sviluppo della produzione laniera (Giardino 2004 [2005], p. 420-422; Meo 2011; Id.2012).

Un intervento di tutela condotto nel 1973 dalla Soprintendenza per i Beni Archeologici della Basilicata nell' abitato moderno di Policoro, in via Napoli (fig. 2), ha portato all'individuazione di cinque fornaci, attive nella seconda metà del III sec. a.C. ${ }^{4}$. La loro ubicazione nel settore nordorientale della terrazza meridionale di Herakleia ha documentato per la prima volta la continuità di frequentazione di questo settore dell'abitato dopo il IV sec. a.C. Nell'area delle fornaci di via Napoli sono stati inoltre rinvenuti impastatoi togliere spazio per argilla, distanziatori di vasi, prodotti difettosi (fig. 3) e 6627 frammenti ceramici, riportabili a 1348 individui, 64 dei quali deformati o malcotti. Ricomponibilità e ripetitività delle forme, unitamente all'assenza di tracce di utilizzazione, inducono a identificare il complesso di vasi provenienti dall'area di fornaci di via Napoli come un "deposito di produzione" delle abbandonato in modo improvviso e definitivo tra la fine del III e gli inizi del II sec. a.C.

3 Giardino 1992, p. 151-169; Giardino 1992 [1996]; De Siena, Giardino 2001, p. 147-151.

4 De Siena, Giardino 2001, p. 147-149; Giardino 1996, p. 42; Giardino 2004 [2005], p. 404-405. 


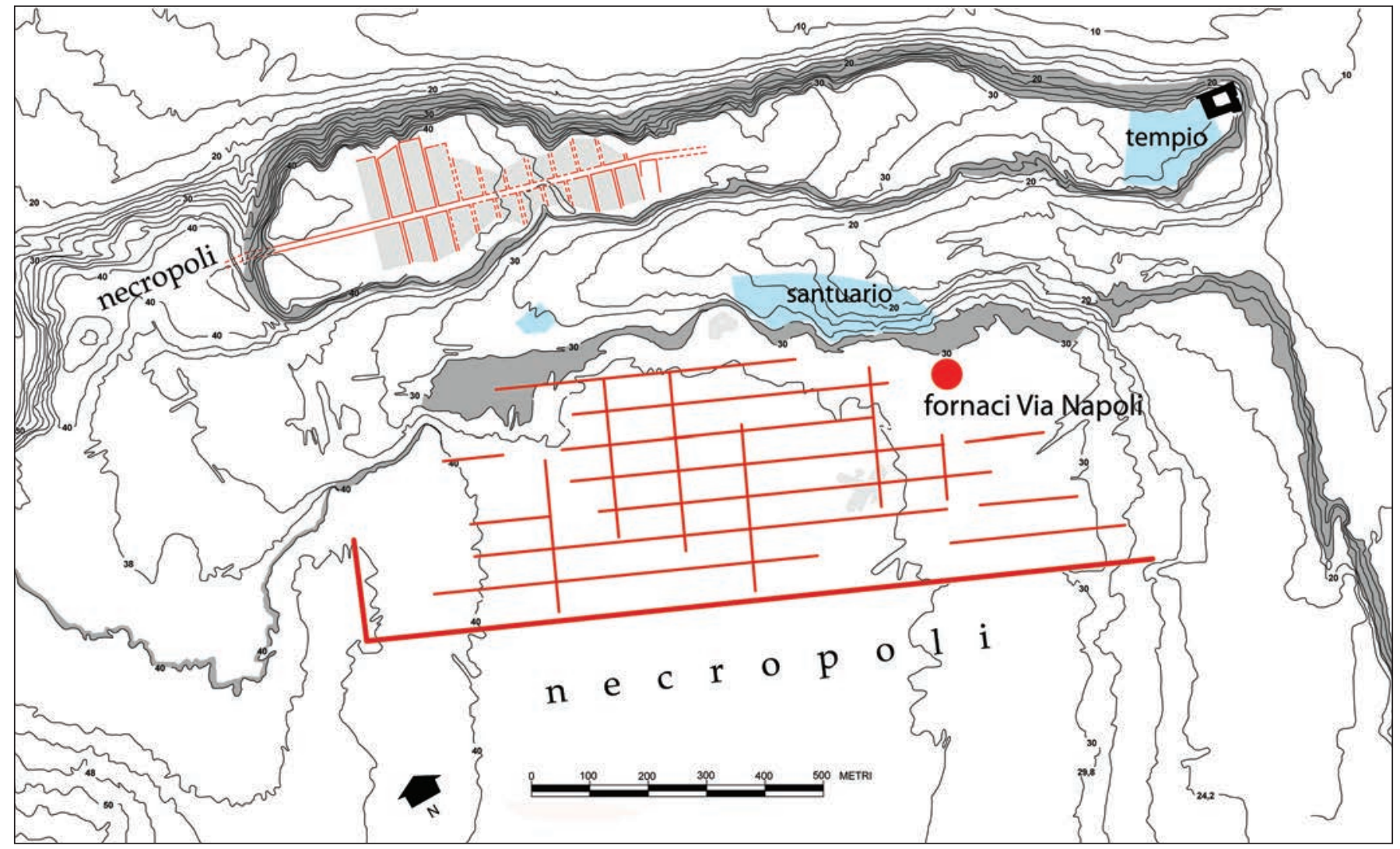

Fig. 2. Herakleia. Impianto urbano con ubicazione delle fornaci di via Napoli (Laboratorio di Urbanistica del mondo classico, Università del Salento).
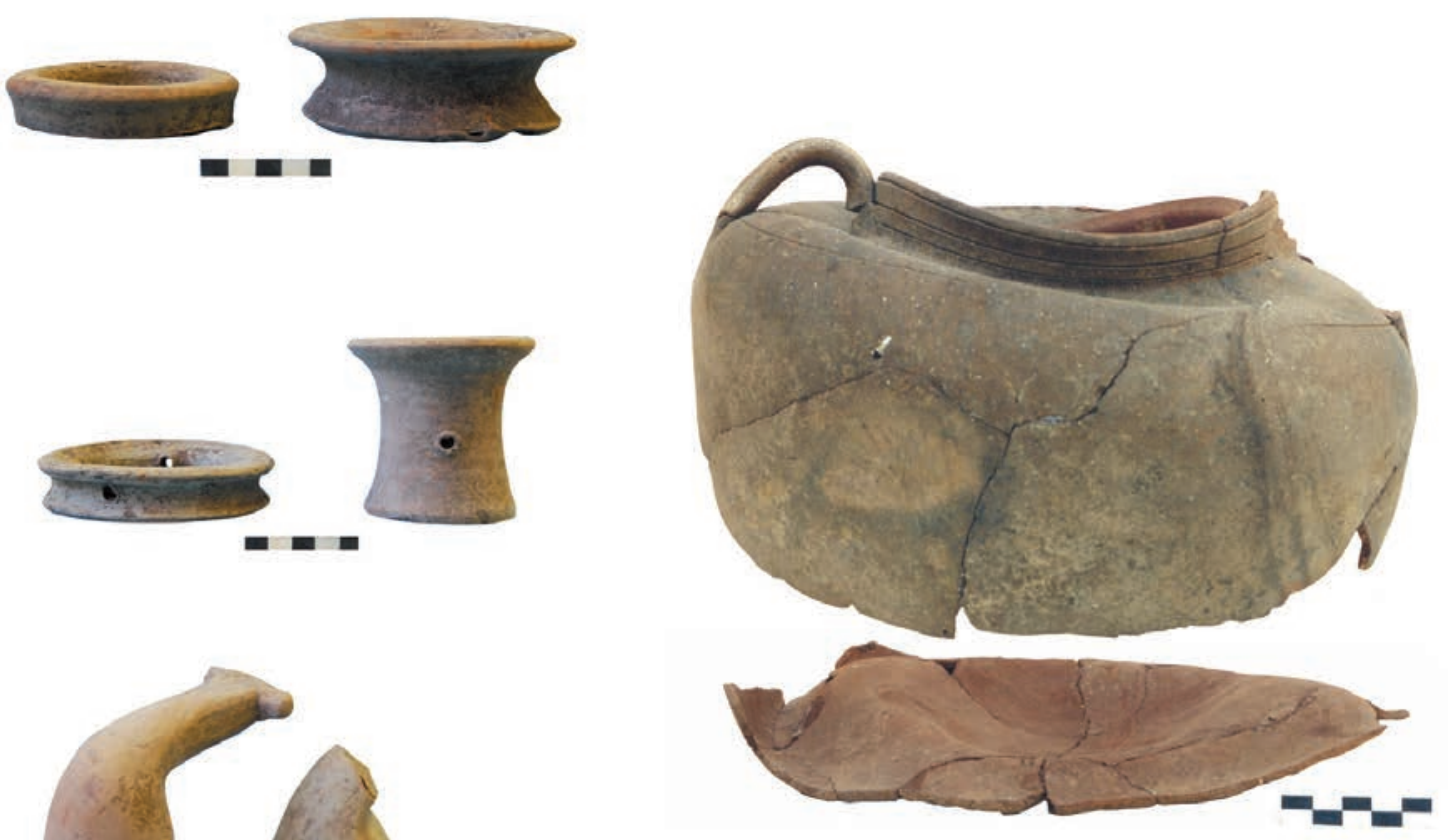

EC 43101.1

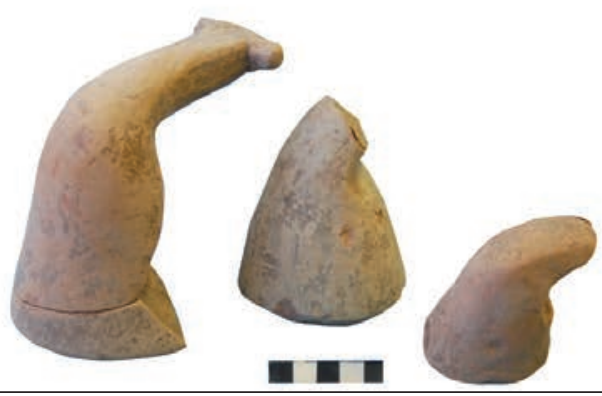

Fig. 3. Herakleia, fornaci di via Napoli. Indicatori di produzione (distanziatori, impastatoi, scarti di fornace). 


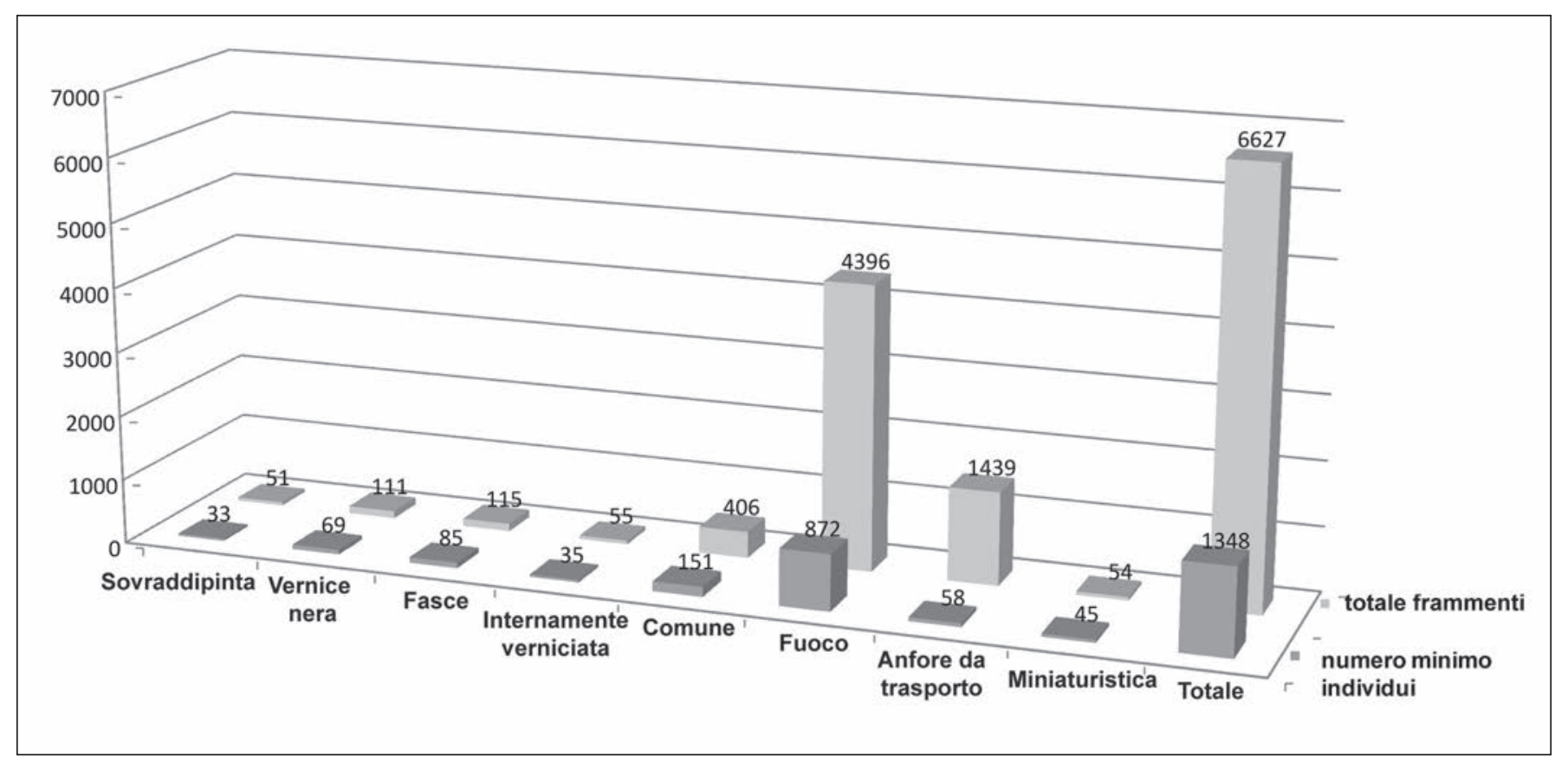

Fig. 4. Herakleia, fornaci di via Napoli. Grafico delle classi ceramiche prodotte (Archivio Soprintendenza per i Beni Archeologici della Basilicata).

In questa sede si presenta un quadro di tutte le ceramiche prodotte nelle officine della terrazza meridionale di Herakleia nella seconda metà del III sec. a.C. Le forme e le classi di materiali documentate indicano una produzione rivolta esclusivamente a vasi di uso quotidiano, pertinenti alla conservazione, alla preparazione e al consumo del cibo (fig. 4). Operando una ripartizione dei materiali in base alla loro funzione originaria, secondo quanto proposto da Michel Bats per il vasellame collegato all'alimentazione (Bats 1988), è stato inoltre elaborato un sistema di classificazione aperta delle forme (Calvaruso 2012), con l'auspicio che possa costituire una base di lavoro comune per quanti si occupano di Herakleia e delle ceramiche di III sec. a.C. (fig. 5-6).

\section{Conservazione del cibo}

I contenitori eracleoti riportabili a questa funzione sono costituiti dalle hydriai, dalle anfore da trasporto e dalle situle.

Le hydriai (fig. 7, EC 24101.1) sono attestate da un numero consistente di individui (47 circa), appartenenti ad un unico tipo morfologico, realizzato in ceramica comune. La capienza è di 10-15 1 circa. I frammenti di cinque esemplari sono malcotti e deformati. Anche le anfore da trasporto (fig. 7, EC 50101.1, EC 50101.2) ripropongono un'unica forma, tipica della produzione

\begin{tabular}{|l|l|}
\hline \multicolumn{2}{|c|}{$\begin{array}{c}\text { Herakleia. Terrazza meridionale. Fornaci } \\
\text { Definizione delle classi per funzioni e attribuzione dei codici }\end{array}$} \\
\hline CODICE & FUNzIONE \\
\hline 10000 & Ceramica da mensa e da dispensa forme aperte \\
\hline 20000 & Ceramica da mensa e da dispensa forme chiuse \\
\hline 30000 & Ceramica da fuoco forme aperte \\
\hline 40000 & Ceramica da fuoco forme chiuse \\
\hline 50000 & Anfore da trasporto \\
\hline 60000 & Ceramica per illuminazione \\
\hline 70000 & Ceramica per la cura personale \\
\hline 80000 & Ceramica miniaturistica \\
\hline
\end{tabular}

Fig. 5. Herakleia, fornaci di via Napoli. Codificazione delle classi in base alla funzione (Archivio Soprintendenza per i Beni Archeologici della Basilicata).

corinzia di tipo B, con orlo 'a otto' deformato per l'attacco delle anse e caratteristico del III sec. a.C. (Koehler 1979, p. 201-208). La loro produzione nelle fornaci di via Napoli è testimoniata dalle caratteristiche tipicamente eracleote dell' argilla e dalla presenza di frammenti malcotti o deformati. In totale sono documentati 59 individui, di cui 3 interi e 26 ricomponibili. Le situle (fig. 7, EC 12101.1), documentate soltanto da tre individui in ceramica comune e con ansa sormontante, ripropongono una forma ispirata ai recipienti metallici. Sono attestati esemplari con cottura difettosa. 


\begin{tabular}{|c|c|c|c|c|c|c|}
\hline \multicolumn{7}{|c|}{ HERAKLEIA. TERRAZZA MERIDIONALE. FORNACI. } \\
\hline FORME & \multicolumn{6}{|c|}{ CLASSI CERAMICHE } \\
\hline & Sovraddipinta & Vernice nera & A fasce & $\begin{array}{l}\text { Internamente } \\
\text { verniciata }\end{array}$ & Comune & Miniaturistica \\
\hline $\begin{array}{c}\text { Piattello } \\
11100\end{array}$ & & $\triangle \rightleftarrows$ & & 5 & & vit \\
\hline $\begin{array}{l}\text { Piatto } \\
11200\end{array}$ & & & & & & \\
\hline $\begin{array}{l}\text { Coppa } \\
11500\end{array}$ & & & & & & \\
\hline $\begin{array}{c}\text { Zuppiera } \\
11600\end{array}$ & & & & & & \\
\hline $\begin{array}{l}\text { Situla } \\
12100\end{array}$ & & & & & & \\
\hline $\begin{array}{c}\text { Skyphos } \\
13100\end{array}$ & 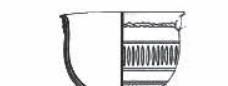 & & & & & \\
\hline $\begin{array}{l}\text { Tazza } \\
13200\end{array}$ & $190^{\circ}$ & & & & & \\
\hline $\begin{array}{c}\text { Mortaio } \\
13300\end{array}$ & & & & & & \\
\hline $\begin{array}{c}\text { Bacino } \\
13400\end{array}$ & & & & & & \\
\hline $\begin{array}{c}\text { Cratere } \\
13500\end{array}$ & & & & & & \\
\hline $\begin{array}{c}\text { Bicchiere } \\
81100\end{array}$ & & & & & & 1 \\
\hline $\begin{array}{c}\text { Craterisco } \\
83100\end{array}$ & & & & & & \\
\hline
\end{tabular}

Fig. 6. Herakleia, fornaci di via Napoli. Tabella delle forme pertinenti al consumo e alla preparazione del cibo e loro distribuzione nelle singole classi ceramiche (Archivio Soprintendenza per i Beni Archeologici della Basilicata). 
LILIANA GIARDINO, TERESA ODA CALVARUSO

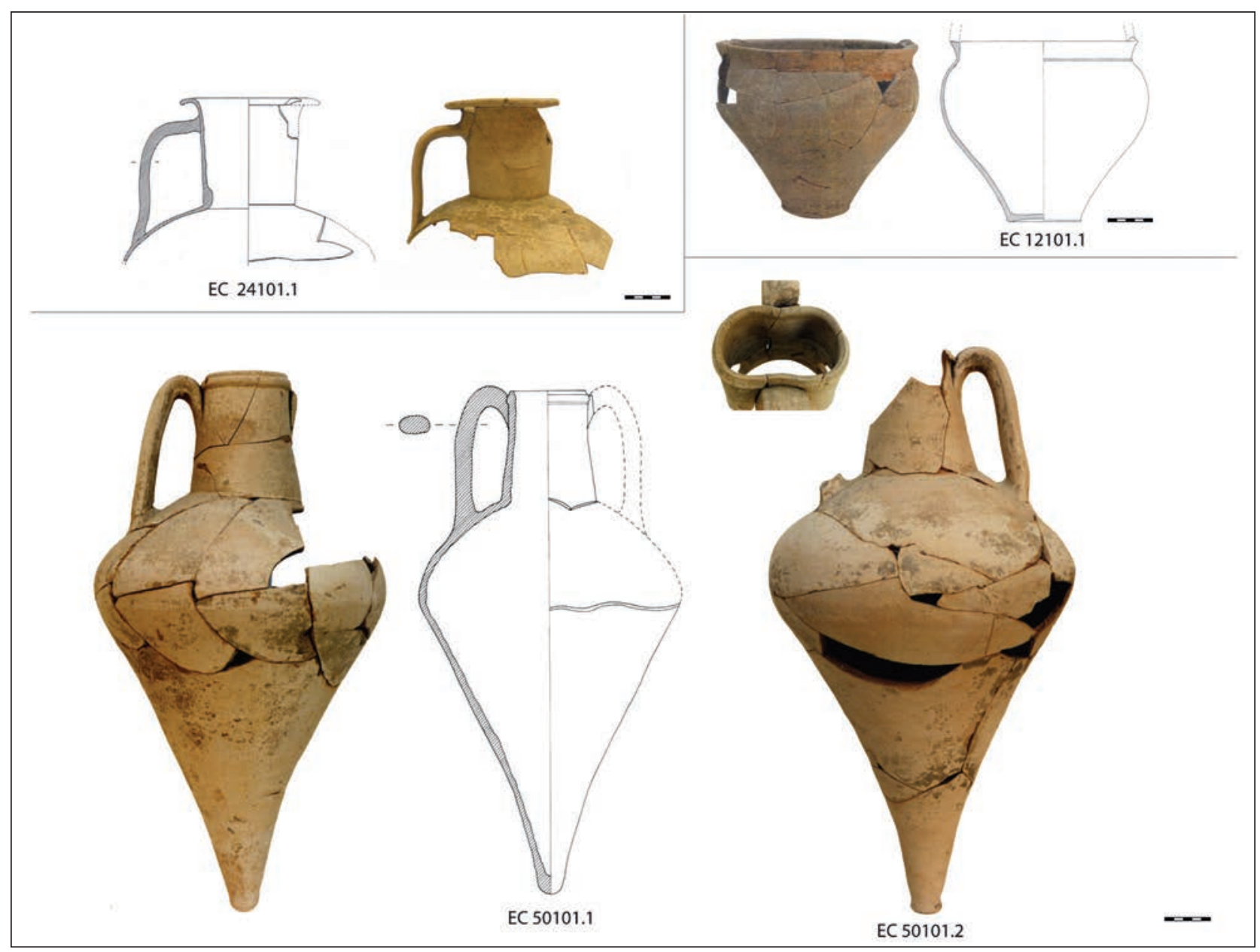

Fig. 7. Herakleia, fornaci di via Napoli. Contenitori per la conservazione del cibo (Archivio Soprintendenza per i Beni Archeologici della Basilicata).

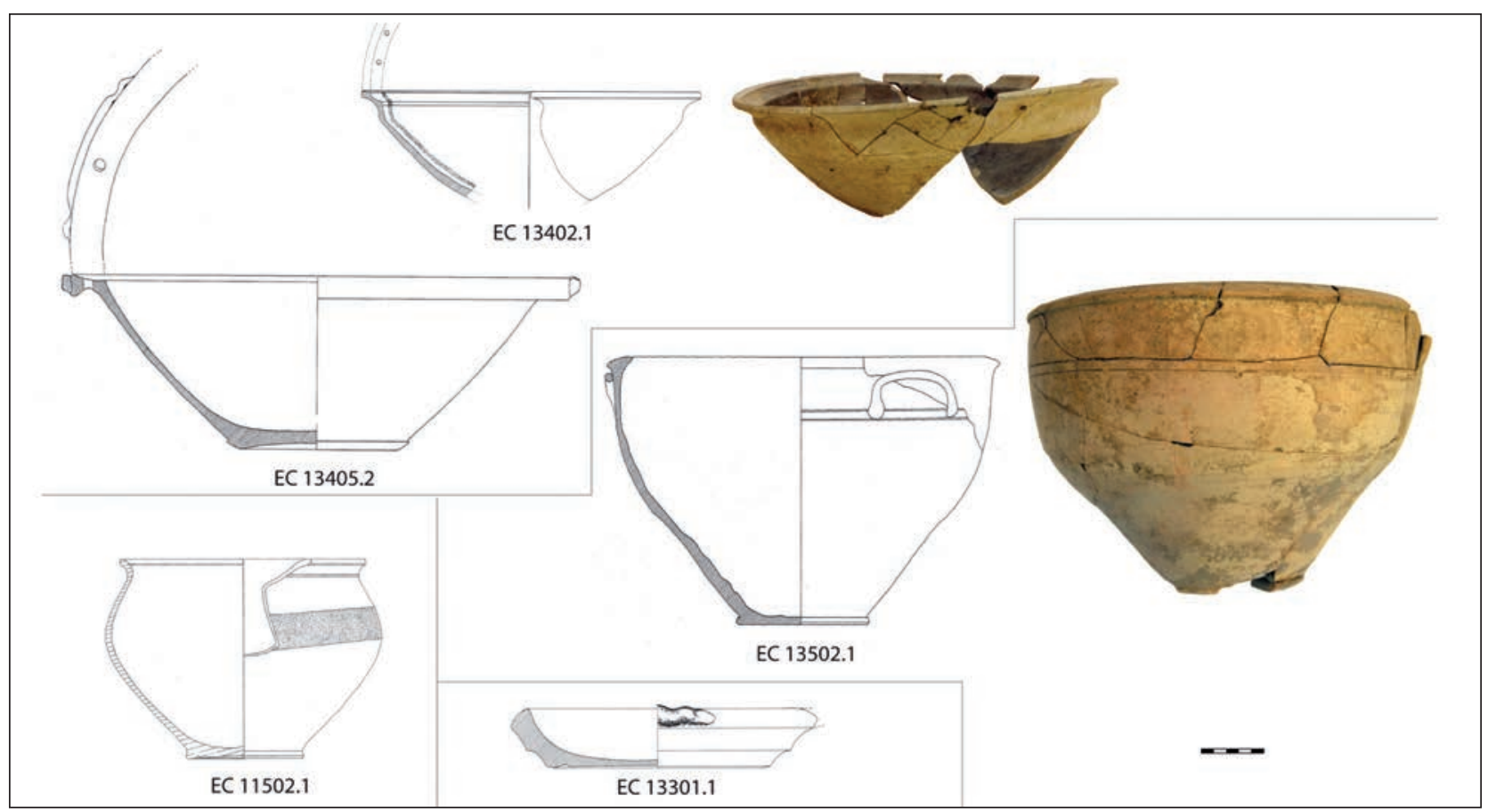

Fig. 8. Herakleia, fornaci di via Napoli. Contenitori per la preparazione del cibo (Archivio Soprintendenza per i Beni Archeologici della Basilicata).

372 


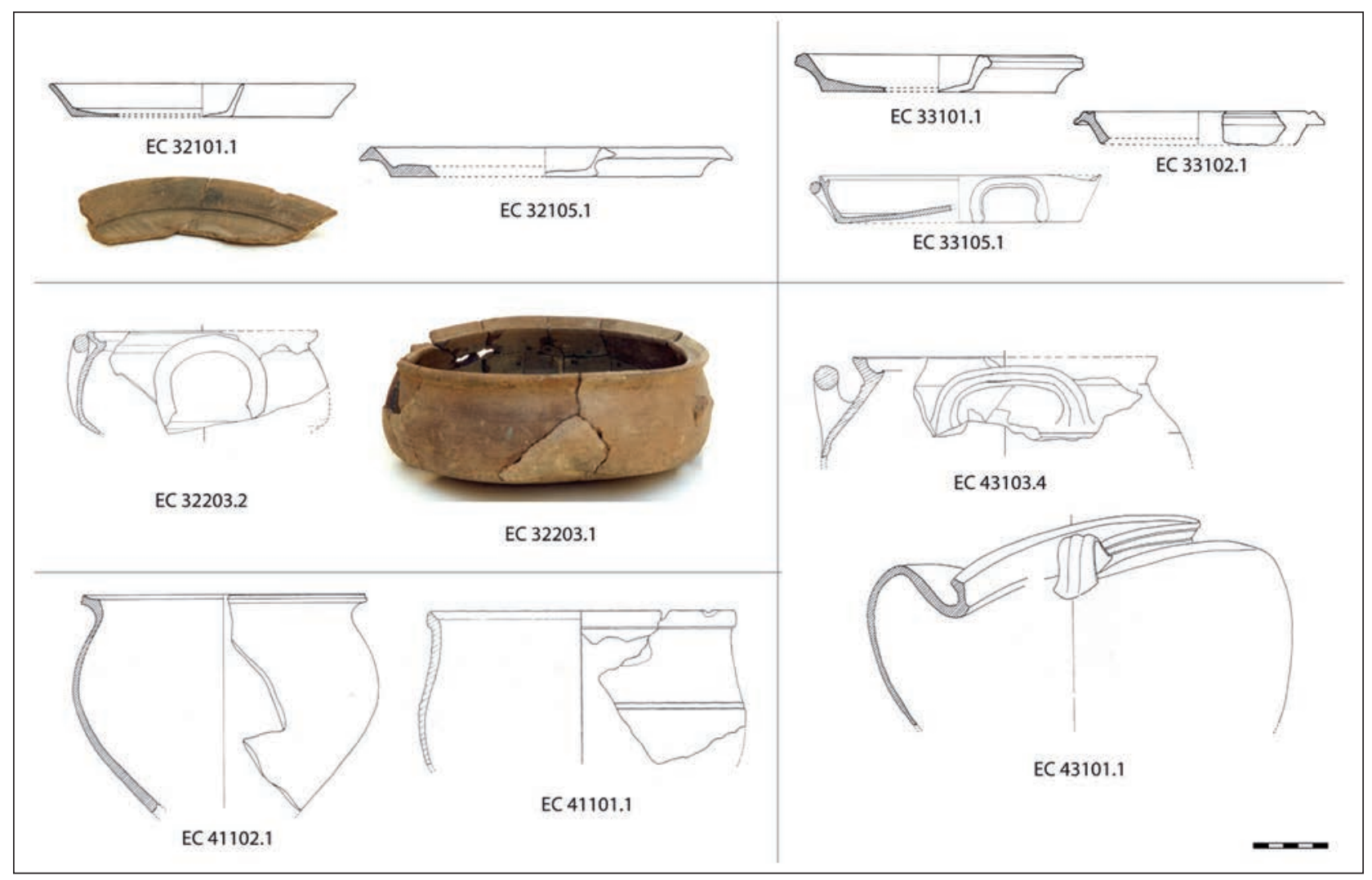

Fig. 9. Herakleia, fornaci di via Napoli. Contenitori per la cottura del cibo (Archivio Soprintendenza per i Beni Archeologici della Basilicata).

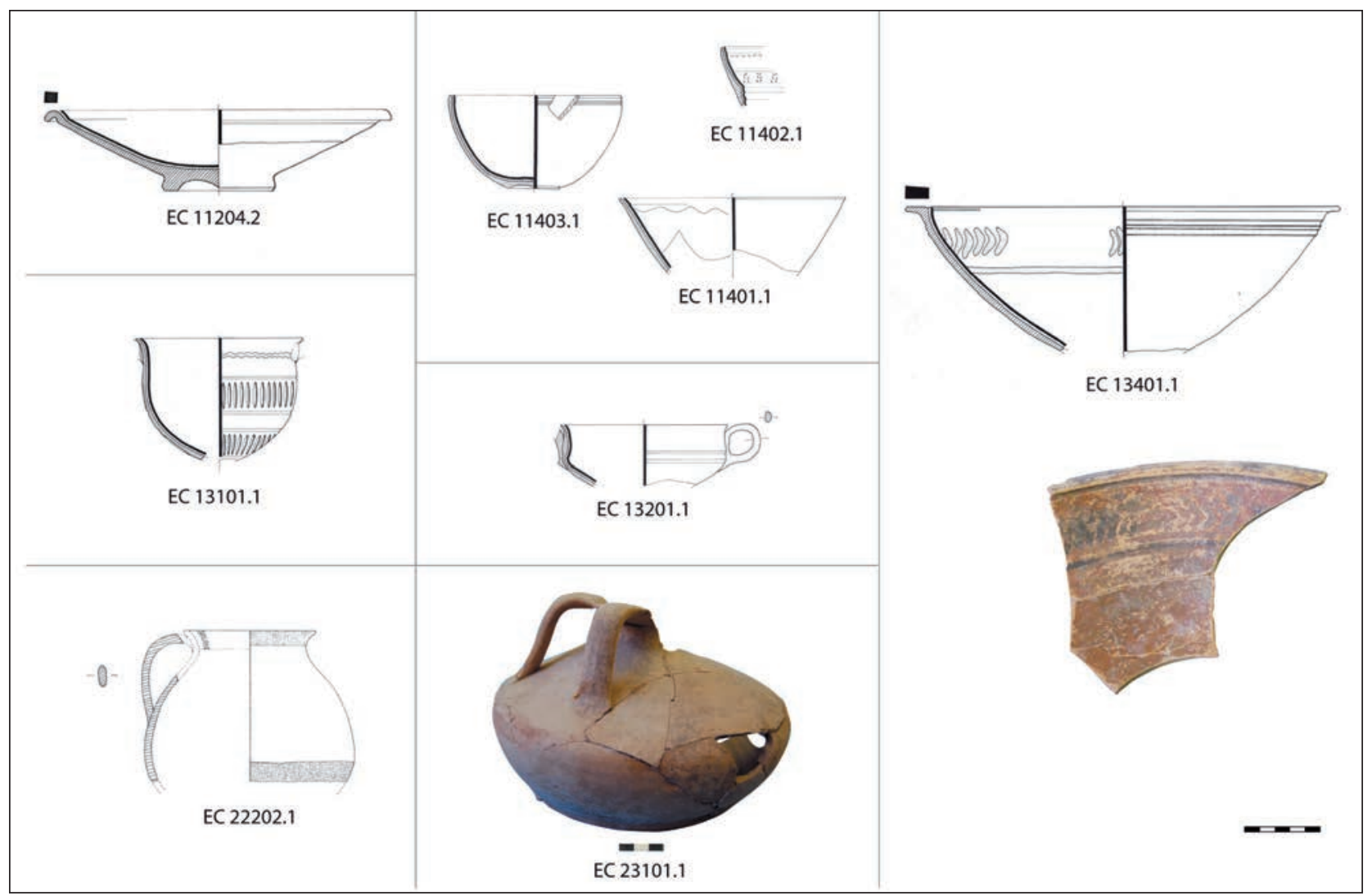

Fig. 10. Herakleia, fornaci di via Napoli. Contenitori per il consumo del cibo (Archivio Soprintendenza per i Beni Archeologici della Basilicata). 


\section{Preparazione del cibo}

A questa funzione sono attribuibili vasi per mescolare, lavare e tritare cibi: bacini, zuppiere, crateri e mortai.

I bacini (fig. 6-8, EC 13402.1, EC 13405.2) sono prodotti in ceramica comune, a fasce e a vernice nera interna (124 individui circa). I primi hanno dimensioni maggiori e anse a presa aderenti all'orlo; gli altri sono più piccoli e privi di anse. Alcuni esemplari hanno una coppia di fori per sospensione sull'orlo. Le zuppiere (fig. 6-8, EC 11502.1) rappresentano un vaso tipicamente eracleota per forma e decorazione. Sono prodotte in ceramica a fasce e, più raramente, a vernice nera interna (30 individui); la loro capacità è simile a quella dei bacini a fasce. E' possibile che le zuppiere fossero utilizzate anche per servire in tavola le pietanze. Sono presenti esemplari malcotti e deformati. I crateri (fig. 6-8, EC 13502.1) sono realizzati in ceramica comune (97 individui) e, in percentuale minore, a vernice nera interna (16 individui). La forma più diffusa ha due piccole anse a maniglia aderenti alla parete. I mortai (fig. 6-8, EC 13301.1) sono documentati da cinque esemplari in ceramica comune, uno dei quali deformato.

\section{Cottura del cibo}

I vasi destinati a questa funzione rappresentano la parte più consistente della produzione delle fornaci di via Napoli. Il repertorio morfologico è costituito da teglie, tegami, casseruole, pentole, olle e coperchi. Le forme aperte prevalgono nettamente su quelle chiuse.

Le teglie (fig. 9, EC 32101.1, EC 32105.1), contraddistinte da una vasca molto ampia e bassa, presentano varianti morfologiche nell'orlo (128 individui). Alcuni esemplari hanno un ingobbio scuro sulla parete interna, realizzato con un' argilla fortemente diluita. I tegami (fig. 9, EC 33101.1, EC 33102.1, EC 33105.1) rappresentano la forma aperta più diffusa (414 esemplari). I due tipi attestati differiscono per la presenza o meno delle anse e dell'alloggiamento per il coperchio sull'orlo. Nelle casseruole (fig. 9, EC 32203.1, EC 32203.2), ricorre un unico tipo (171 individui). Numerosi sono gli esemplari deformati o con difetti di cottura. All'interno delle forme chiuse le pentole (fig. 9, EC 43101.1, EC 43103.4) rappresentano il tipo prevalente (58 individui). La loro morfologia è costante e non presenta sensibili varianti. Gli esemplari deformati e malcotti sono cinque. Per le olle (fig. 9, EC 41101.1, EC 41102.1), sono attestati due tipi morfologici su un totale di 90 individui.

\section{Consumo del cibo}

I recipienti riferibili a questa funzione sono il piatto, la coppa, lo skyphos, la tazza biansata, la brocca e la myke.

I piatti (fig. 10, EC 11204.2) sono documentati da un'unica forma, riportabile alla Lamboglia A36 e prodotta a vernice nera, a vernice nera interna e a fasce (50 individui). Le coppe (fig. 10, EC 11401.2, EC 11402.1, EC 11403.1) corrispondono alla forma maggiormente attestata (96 individui) e i tipi a vasca troncoconica e mastoide sono quelli più diffusi (77 individui). Le coppe sono prodotte solo a vernice nera e molto frequente è la presenza di una decorazione stilizzata incisa all'interno. Alcuni bacini a vernice nera (fig. 10, EC 13401.1), morfologicamente simili a quelli a fasce, hanno una sobria decorazione sovraddipinta all'interno (13 individui). Lo skyphos (fig. 10, EC 13101.1), documentato da 5 individui, è prodotto in una forma ispirata alla ceramica di Gnathia per la vasca baccellata e per la decorazione sovraddipinta sotto l'orlo. Le tazze (fig. 10, EC 13201.1) con anse verticali e vasca carenata, prodotte solo a vernice nera, risultano il tipo più diffuso tra $\mathrm{i}$ vasi per bere (10 individui). Le brocche (fig. 10, EC 22202.1) sono realizzate in ceramica comune e a fasce (39 individui). La myke (fig. 10, EC 23101.1) è attestata da tre esemplari, ma la presenza di un pezzo deformato rappresenta un indizio sicuro della sua produzione nelle fornaci di Via Napoli.

\section{Osservazioni conclusive}

Un precedente lavoro (Calvaruso 2012) è stato dedicato a definire puntualmente la cronologia di ogni singola forma attraverso un'ampia serie di confronti con altri contesti italioti. In questa sede si presentano delle considerazioni sugli aspetti economici e culturali che emergono dalla documentazione ceramica, offrendo così uno spaccato delle abitudini alimentari degli Eracleoti nella seconda metà del III sec. a.C.

Gli indicatori cronologici significativi per una definizione del periodo di attività delle fornaci sono costituiti dalle anfore da trasporto con orlo 'a otto' (Koehler 1979, p. 201-208), dai piatti Lamboglia A36, dalle coppe troncoconiche e mastoidi e dai bacini acromi (Calvaruso 2012). Tutte queste forme sono ampiamente attestate in contesti italioti del III sec. a.C. ${ }^{5}$ e in alcuni casi della seconda metà del sec. (Lippolis 1994, p. 246 e 249; Prazzoli 1996, p. 334-334).

5 Carter 1998, II, p. 653; Manzo 1989, p. 339; Preacco Ancona 1992 , p. 130 e $133, n^{\circ} 67$ e n 97. 
Alcune produzioni, come la ceramica a vernice nera interna e le zuppiere a fasce, appaiono tipiche di Herakleia e al momento documentate unicamente in questo centro. Solo le zuppiere a fasce sono attestate anche a Taranto (Ori Taranto, p. 512, $\mathrm{n}^{\circ} 18$ ). Infine, rispetto alle ceramiche circolanti nella vicina Metaponto e nel suo territorio (Carter 1998; Carter, Prieto 2011) la produzione eracleota si differenzia per forme e classi (Calvaruso 2012; De Siena, Giardino 2001).

Per quanto riguarda l'alimentazione, la netta predominanza di teglie, tegami e casseruole rispetto alle pentole indica una dieta che privilegia il pesce e le verdure rispetto ai legumi (Bats 1988, p.31-59). La produzione locale di anfore da trasporto imitanti le corinzie B, già ipotizzata da Christian Vandermersch per il IV sec. a.C. (Vandermersch 1994, p. 61-65), viene confermata e suggerisce lo sviluppo di monoculture specializzate nel territorio eracleota anche negli ultimi decenni del III sec. a.C., e quindi dopo gli avvenimenti bellici legati alla presenza di Pirro (De Siena, Giardino 2001, p. 149; Giardino 2004 [2005], p. 404-405).

\section{Bibliografia}

Bats 1988 : BATS (M.) - Vaisselle et alimentation à Olbia de Provence (v. 350v. 50 av. J.-C.). Modèles culturels et catégories céramiques. Paris, CNRS, 1988. Carter 1998 : CARTER (J.C.) - The Chora of Metaponto 1. The necropoleis, I-II. Austin, University of Texas Press, 1998.

Carter, Prieto 2011 : CARTER (J.C.), PRIETO (A.) - The Chora of Metaponto 3. Archaeological Field Survey Bradano to Basento, I-III. Austin, University of Texas Press, 2011.

Calvaruso 2012 : CALVARUSO (T.O.) - Herakleia di Lucania. Proposta di classificazione delle ceramiche di III secolo a.C. dalle fornaci della terrazza meridionale. In : Osanna (M.), Zuchtriegel (G.) dir., АМФI $\sum$ IPIO $\sum$ POA $\Sigma$. Nuove ricerche su Eraclea e la Siritide. Venosa, Osanna Edizioni, 2012, p. 241-257

De Siena, Giardino 2001 : DESIENA(A.), GIARDINO (L.) - Trasformazioni delle aree urbane e del paesaggio agrario in età romana nella Basilicata sudorientale. In : Lo Cascio (E.), Storchi Marino (A.) dir., Modalità insediative e strutture agrarie nell'Italia meridionale in età romana. Pragmateiai, VII, Bari, Edipuglia, 2001, p. 129-167.
Giardino 1991 [1998] : GIARDINO (L.) - Aspetti e problemi dell'urbanistica di Herakleia. In : Greco (E.) dir., Siritide e Metapontino. Storie di due territori coloniali, Atti dell'incontro di studi di Policoro (1991), NaplesPaestum, Centre Jean Bérard, 1998, p. 171-220

Giardino 1992 : GIARDINO (L.) - Herakleia, necropoli meridionale. In : Da Leukania a Lucania, Rome, Istituto Poligrafico e Zecca dello Stato, 1992, p. 151-185.

Giardino 1992 [1996] : GIARDINO (L.) - Architettura domestica a Herakleia. Considerazioni preliminari. In : D’Andria (F.), Mannino (K.) dir., Ricerche sulla casa in Magna Grecia, Atti del Colloquio (1992), Galatina, Congedo, 1996, p. 133-159.

Giardino 1996 : GIARDINO (L.) - Herakleia. In : Lippolis (E.) dir., Arte e artigianato in Magna Grecia, Naples, Electa, 1996, p. 35-43.

Giardino 1999: GIARDINO (L.) - Herakleia: città e territorio. In : Adamesteanu (D.) dir., Storia della Basilicata. 1. L'antichità, Bari, Laterza, 1999, p. 295-337.

Giardino 2004 [2005] : GIARDINO (L.) - Herakleia e Metaponto: dalla polis italiota all'abitato protoimperiale. Atti del XLIV Convegno di Studi sulla Magna Grecia (2004), Tarente, 2005, p. 387-432.

Koehler 1979 : KOEHLER (C.G.) - Corinthian A and B Transport Amphoras. Princeton, Princeton University Press, 1979.

Lippolis 1994 : LIPPOLIS (E.) dir. - Catalogo del Museo Nazionale Archeologico di Taranto. III, 1. Taranto la necropoli: aspetti e problemi della documentazione archeologica dal VII al I sec. a.C., Tarente, La Colomba, 1994. Lombardo 1996: LOMBARDO (M.) - Greci, Enotri e Lucani nella Basilicata meridionale (VIII-III sec. a.C.): aspetti e momenti dei processi storici. In : Bianco (S.) et al. dir., I Greci in Occidente. Greci, Enotri e Lucani nella Basilicata meridionale, Naples, Electa, 1996, p. 9-27.

Manzo 1989 : MANZO (L.) - Vasellame da mescita. In : Barra Bagnasco (M.) dir, Locri Epizefiri II, Florence, Le Lettere, 1989, p. 327-343.

Meo 2011 : MEO (F.) - Rediscovering ancient activities: textiles tools in a $3^{\text {nd }}-2^{\text {nd }}$ century B.C. Context from Herakleia, Southern Basilicata, Italy. Archaeological Textiles Newsletter, LIII, 2011, p. 2-11.

Meo 2012 : MEO (F.) - Attestazioni archeologiche di attività laniera a Herakleia di Lucania tra III e II secolo a.C. Nota preliminare. In : Osanna (M.),Zuchtriegel (G.) dir., АМФІ ¿I PIO $\Sigma$ PОА $\Sigma$. Nuove ricerche su Eraclea e la Siritide. Venosa, Osanna Edizioni, 2012, p. 259-271.

Ori di Taranto : DE JULIIS (E.-M.) dir, Gli ori di Taranto in età ellenistica, Milan, A. Mondadori Editore, 1985.

Prazzoli 1996 : PRAZZOLI (S.) - Taranto: la documentazione dal pozzo di via C. Nitti. In : Lippolis (E.) dir., Arte e artigianato in Magna Grecia, Naples, Electa, 1996, p. 333-336.

Preacco Ancona 1992 : PREACCO ANCONA (M.C.) - La ceramica fine della «Casa dei Leoni». In : Barra Bagnasco (M.) dir., Locri Epizefiri IV, Florence, Le Lettere, 1992, p. 113-171.

Vandermersch 1994 : VANDERMERSCH (C.) - Vins et amphores de Grande Grèce et de Sicile IV ${ }^{e}-I I I^{e}$ s. avant J.-C. Naples, Centre Jean Bérard, 1995 



\title{
Les imitations de céramique coloniale des sites ibériques d'Ullastret (Catalogne)
}

\author{
Ferran Codina \\ Aurora Martin \\ Gabriel de Prado \\ Museu d'Arqueologia de Catalunya-Ullastret
}

\section{Résumé}

L'ensemble ibérique d'Ullastret se trouve au nord-est de la péninsule Ibérique, à $15 \mathrm{~km}$ de distance de la colonie grecque d'Emporion. Depuis le Premier Âge du fer, vers la fin du VII ${ }^{\mathrm{e}} \mathrm{s}$., et jusqu'à son abandon, au début du $\mathrm{II}^{\mathrm{e}} \mathrm{s}$. av. n. è., des céramiques d'origine méditerranéenne, phéniciennes, grecques, puniques et italiques y parviennent, la plupart à partir du port emporitain. Elles ont été copiées et/ou réinterprétées dans les ateliers céramiques d'Ullastret, comme c'est le cas également dans d'autres établissements de la Catalogne ibérique. Parmi ces productions, il faut citer la céramique indikète à peinture blanche, caractéristique de cette région du monde ibérique et dont l'atelier principal serait situé à Ullastret, où semble aussi débuter la production de céramique de la côte catalane.

Mots-clés : Ullastret, époque ibérique, contacts coloniaux, ateliers céramiques

\section{Resum}

El conjunt ibèric d'Ullastret es troba situat al Nord-est de la Península Ibèrica, a tan sols uns $15 \mathrm{~km}$ de la colònia grega d'Emporion. Des d'inicis de l'edat del Ferro, a finals del s. VII a.n.e. fins al seu abandonament a inicis del s. II a.n.e hi varen arribar ceràmiques de procedència mediterrània, fenícies, gregues, púniques o itàliques, moltes d'elles a través del port emporità, que varen ser copiades i/o reinterpretades en els tallers de terrisser d'Ullastret, a l'igual que passa en altres centres de la Catalunya ibèrica. Entre aquestes produccions s'ha de fer un esment especial a la ceràmica indiketa, decorada amb pintura blanca, pròpia d'aquesta zona del món ibèric, els tallers centrals de la qual haurien estat a Ullastret, lloc en el qual també sembla haver tingut el seu origen la ceràmica de la costa catalana.

Paraules clau : Ullastret, època ibèrica, contactes colonials, tallers ceràmics 
$\grave{A}$ Ullastret, l'oppidum du Puig de Sant Andreu et l'habitat fortifié de plaine de l'Illa d'en Reixac constituaient, ensemble, la capitale de la tribu ibérique des Indiketes, localisée dans l'extrême nord-est de la péninsule Ibérique (fig. 1-1). Ces habitats, les plus importants de la Catalogne préromaine, se sont développés sur deux sites du début de l'Âge du fer, distants d'à peine $500 \mathrm{~m}$ (fig. 1-2), et ont été occupés jusqu'au début du II ${ }^{\mathrm{e}} \mathrm{s}$. av. n. è. Leur abandon paraît en rapport avec le soulèvement indigène contre la domination romaine en 197 av. n. è., qui entraîne l'intervention du consul Caton.

La localisation des établissements d'Ullastret sur la voie de passage entre l'Ibérie et la Gaule a favorisé les contacts directs avec les marchands méditerranéens qui ont fréquenté cette zone dès le Premier Âge du fer : les Phéniciens pendant la deuxième moitié du VII ${ }^{e}$ s., les Étrusques et les Grecs Phocéens à partir de la fin du siècle (Martín et al. 2010). Ces derniers ont fondé dans le territoire indikète les colonies d'Emporion et de Rhodè. L'arrivée de céramique tournée de production coloniale depuis cette époque, ou encore, dans la première moitié du $\mathrm{VI}^{\mathrm{e}}$ s., en provenance du sud-est péninsulaire, entraîne à Ullastret, mais aussi dans toute la Catalogne, l'adoption du tour rapide de potier, au plus tard vers le milieu du $\mathrm{VI}^{\mathrm{e}} \mathrm{s}$. Parmi les productions de céramique tournée fabriquées à Ullastret dans un contexte indigène, il faut citer à côté d'un répertoire proprement ibérique, les imitations de vases importés. Cette fabrication de céramiques qui copient ou qui réinterprétent les formes importées sera une constante dans les ateliers d'Ullastret, jusqu'à l'abandon du site ${ }^{1}$.

\section{Les imitations des céramiques grecques d'Occident (VI $-V^{\mathrm{e}}$ S. av. n. è.)}

Les premières productions de céramique tournée élaborées à partir de modèles importés sont des imitations de céramiques grecques originaires de l'espace phocéen du golfe du Lion ou de la colonie d'Emporion.

\section{La céramique grise monochrome}

La céramique grise monochrome est copiée depuis le début du troisième quart du $\mathrm{VI}^{\mathrm{e}} \mathrm{s}$. Les analyses de pâtes ont montré que ces productions ont utilisé à Ullastret les mêmes argiles et les mêmes fours, ainsi qu'une cuisson à même température, que les céramiques ibériques peintes

1 Pour la classification des mobiliers céramiques présentés dans ce travail ce sont les typologies du DICOCER qui ont été utilisées. de production locale (Pradell et al. 1995). Parmi les formes fabriquées, les plus nombreuses correspondent à des urnes, de taille variée, à pied annulaire bas du type $7 \mathrm{~b}$, ou à pied haut du type $7 \mathrm{c}$ ou $7 \mathrm{~d}$, en général sans anses, bien que l'on connaisse aussi quelques exemplaires de petites dimensions à deux anses (fig. 2-1 et 2). Les autres formes bien représentées sont les coupes carénées du type $3 a$ ou 3 b (fig. 2-3), diverses variantes de plats à marli, mais le plus souvent de forme $4 \mathrm{a}$ ou $4 \mathrm{c}$ (fig. 2-4), les gobelets du type 12a, 12b ou 12d (fig. 2-5) ou les gobelets carénés du type 13 (fig. 2-6). Il faut noter également la présence d'œnochoès. Comme exception, on peut citer un support à mettre probablement en rapport avec une grande coupe (fig. 2-7) et dont le parallèle formel serait dans le monde ibérique, le type 5212 de la céramique ibérique peinte, alors que la pâte et les motifs décoratifs appartiennent à la catégorie de la céramique grise monochrome.

Les pâtes de ces productions, de couleur gris clair, sont dures et bien épurées, conservant souvent des vestiges d'engobe gris plus foncé que la pâte. Le répertoire décoratif comprend essentiellement des lignes ondulées incisées, réalisées avec un peigne à pointes, ou bien des bandes incisées en utilisant également un peigne (fig. 2-4 et 7). Dans le cas des plats à marli, le décor est souvent uniquement composé de lignes incisées profondes qui suivent le contour de la lèvre à l'intérieur, à l'extérieur, ou les deux à la fois. Exceptionnellement, on trouve un décor plastique de boutons appliqués (fig. 2- 6).

\section{La céramique à pâte claire}

Dans un moment avancé du $\mathrm{V}^{\mathrm{e}} \mathrm{s}$. av. n. è., débute aussi la production des imitations de céramique à pâte claire peinte. L'atelier est bien caractérisé, en activité au dernier quart du $\mathrm{V}^{\mathrm{e}}$ et au premier quart du $\mathrm{IV}^{\mathrm{e}} \mathrm{s}$. La production la plus typique est celle des grandes coupes à pied annulaire du type $\mathrm{Cp} 1$, imitation du type 621 de la céramique à pâte claire massaliète (fig. 2- 8). Les autres formes bien représentées sont les lékanides, proches du type massaliète 435a (fig. 2- 9), dotés de couvercles du type Ln1 reproduisant le type massaliète 721/722 (fig. 2- 10), et les olpès Ol1, imitations du type 521, où, le plus souvent, l'anse ne dépasse pas la hauteur de la lèvre, et qui peuvent être peints ou non (fig. 2-11 et 12). Des urnes de petite taille et des œnochoès ont été également fabriquées.

Les pâtes utilisées, de couleur ocre-beige ou orangé clair, sont peu dures et bien épurées. Les décors peints utilisent la couleur orange ou marron orangé, qui peut devenir noirâtre si la peinture appliquée est plus épaisse. 
Parmi les motifs attestés sur les coupes à pied annulaire, le plus caractéristique est un cercle plein entouré de rayons sur le fond interne (fig. 2-8), interprété comme une représentation solaire ; toujours sur le fond interne, on peut trouver aussi deux palmettes opposées par la base ou encore des cercles concentriques. Près du bord, sur la face interne, il y a une bande de feuilles et, sur la face externe, deux cannelures parallèles et des bandes peintes. Pour les autres vases, les décors sont constitués de bandes de feuilles, de lignes ondulées ou simplement de lignes parallèles horizontales. Dans le cas des lékanides, parfois tout l'intérieur du vase est peint (fig. 2-10).

\section{Les imitations de céramique attique. Fin du $\mathrm{V}^{\mathrm{e}}$ et $\mathrm{IV}^{\mathrm{e}}$-IIII ${ }^{\mathrm{e}} \mathrm{s}$. av. n. è.}

Les changements dans les flux commerciaux méditerranéens ont favorisé, à partir de la deuxième moitié du $V^{\mathrm{e}}$ s., l'arrivée en masse de céramique attique à figures rouges et à vernis noir à Ullastret à partir du port d'Emporion. Ces types céramiques ont exercé une grande influence sur les productions indigènes, qui, à partir de ce moment, connaissent des changements importants, aussi bien en ce qui concerne les techniques de production que les modèles.

\section{La céramique peinte indikète}

Depuis le milieu du Ve s., on assiste à l'abandon lent, mais progressif, de la céramique ibérique peinte élaborée sous la forme de vases à parois épaisses et utilisant des pâtes oxydantes claires. Cette céramique sera remplacée par de nouvelles productions de vases à parois plus fines et avec des pâtes plus dures et foncées, en général grises ou du type «sandwich». Ces vases de céramique commune ibérique, souvent sans décor, présentent aussi parfois des motifs de peinture blanche appliquée après cuisson. À Ullastret, les formes décorées les plus fréquentes correspondent aux types Am3, Cc3 et Jr3 du classement de la céramique commune ibérique du DICOCER. On n'y connaît pas de formes de vaisselle de table utilisant ce décor, alors que d'autres sites de la région, comme Castell de Palamós, Mas Castellar de Pontós ou Castell de Porqueres, en ont fourni des exemplaires.

Cette production a été appelée céramique indikète, car elle est spécifique de la région occupée par cette tribu, qui s'étend des Albères jusqu'au fleuve Tordera. Cependant, bien qu'en faible quantité, cette céramique a été également découverte, au nord, dans certains sites du Roussillon et du Languedoc et, au sud, dans la zone léétanienne (Martín 1978, 1988). Les bandes et les groupements de lignes parallèles horizontales constituent les motifs les plus habituels, mais les motifs géométriques et/ou végétaux de la céramique attique à figures rouges sont également nombreux : feuilles de lierre, fleurs et fruits de divers types, palmettes et volutes (fig. 3-1, 2, 3, 4 et 5), ou encore les motifs des vases de Saint-Valentin (fig. 3-6), très nombreux à Ullastret.

Le décor de peinture blanche sera utilisé dans les productions de céramique commune qui se succèdent à Ullastret jusqu'à l'abandon des sites. En ce sens, il faut noter que les urnes de céramique oxydante, fréquentes depuis la seconde moitié du IVe $\mathrm{s}$. et pendant tout le III ${ }^{\mathrm{e}}$ s., ont été revêtues d'engobes foncés afin de faire ressortir le décor. Les motifs sont plus simples, réduits presque uniquement à des lignes et des bandes parallèles horizontales dans les vases tardifs.

\section{La céramique de la côte catalane}

Dans le dernier quart du V $\mathrm{V}^{\mathrm{e}} \mathrm{s}$. av. n. è. commence à Ullastret la production de vaisselle de table du type dit de la côte catalane, qui, d'ailleurs, paraît trouver ses premières manifestations sur ce site, car elle est déjà présente dans la phase Ullastret IV, datée entre 450 et 380 (Martín, Lafuente 1999). Cette catégorie céramique évolue et perdure jusqu'à l'abandon du site au début du $\mathrm{II}^{\mathrm{e}}$ s. av. n. è.

La céramique de la côte catalane fournira la majorité de la vaisselle de table dans la Catalogne ibérique. De nombreux ateliers sont connus, en plus de ceux d'Ullastret, et sa commercialisation s'est étendue à l'extérieur de la zone de production. Si elle a été fabriquée au début en pâte grise, très rapidement apparaissent aussi des pâtes oxydantes. Cette céramique a fait l'objet à Ullastret d'une étude monographique (Rodriguez et al. 2003). La forme la plus connue et une des plus fréquentes, de tradition indigène, est le vase biconique, mais il y a également de très nombreuses formes qui dérivent de la vaisselle attique : œnochoè (fig. 3-7 et 8), askos (fig. 3- 9), olpè (fig. 3-10), skyphos (fig. 3-12), kylix à pied bas (fig. 3-14), coupe (fig. 3-15), cratérisque (fig. 3-13), ou les réinterprétations de la phiale (fig. 3-11), qui seront également copiées en céramique commune ibérique.

\section{Une kylix exceptionnelle en céramique non tournée}

Le vase le plus exceptionnel d'imitation de la céramique attique est une kylix à pied haut qui reproduit une Vicup (fig. 3-16, 17 et 18). Il présente une perforation 
verticale, qui le rend impropre à la consommation. Le contexte archéologique de découverte, dans le comblement du silo 6, comprenant un ensemble d'une vingtaine de vases attiques à figures rouges et à vernis noir, des urnes de céramique non tournée, des amphores ibériques et de nombreux pesons et fusaïoles (Oliva 1955), correspond probablement à un dépôt rituel en silo, daté du dernier quart du $\mathrm{V}^{\mathrm{e}}$ ou du début du $\mathrm{IV}^{\mathrm{e}} \mathrm{s}$. Ce vase a été fabriqué en céramique non tournée, avec une finition polie caractéristique de la production de cette époque à Ullastret.

\section{Les imitations de céramique punique. IV $^{\mathrm{e}}$-III' ${ }^{\mathrm{e}}$ s. av. n. è.}

$\mathrm{Au} I \mathrm{IV}^{\mathrm{e}}$ s., parallèlement à l'arrivée en nombre d'amphores puniques centro-méditerranéennes à Ullastret, apparaissent des imitations de récipients de cuisine et de vaisselle de table en provenance de l'espace punique.

\section{Les imitations de vaisselle de table punique}

Des imitations de vaisselle de table ébusitaine ont également été découvertes à Ullastret, bien que très minoritaires, produites avec des pâtes oxydantes claires. Les formes connues correspondent à des petites urnes à deux anses, imitation du type Eb-65 (fig. 4-1 et 2), et des œnochoès qui imitent le type Eb-1, avec un décor d'yeux apotropaïques près du bec verseur (Fernández Costa 1998) (fig. 4-3). Ces deux types présentent, autour de la base du col, un décor en forme de collier de gouttes de peinture marron et blanche. Parfois, ils portent également un décor de bandes ou de lignes parallèles horizontales de peinture marron sur la panse du vase.

Dans un moment avancé du $\mathrm{III}^{\mathrm{e}} \mathrm{s}$. av. n. è., on produit à Ullastret des imitations de céramique commune fine carthaginoise. La forme la plus représentée est l'olpè, également fabriquée en céramique de la côte catalane, habituellement recouverte d'un engobe blanchâtre afin de mieux ressembler au modèle (fig. 4-4).

\section{Les céramiques de cuisine tournées}

Bien que les formes de la céramique de cuisine tournée grecque et punique centro-méditerranéenne soient pratiquement identiques, nous estimons à Ullastret que les modèles copiés sont puniques du fait que la fabrication de ces récipients commence précisément au moment de l'arrivée massive d'amphores puniques centro-méditerranéennes. Ces récipients vont prendre la place de certains usages de la céramique non tournée, bien que

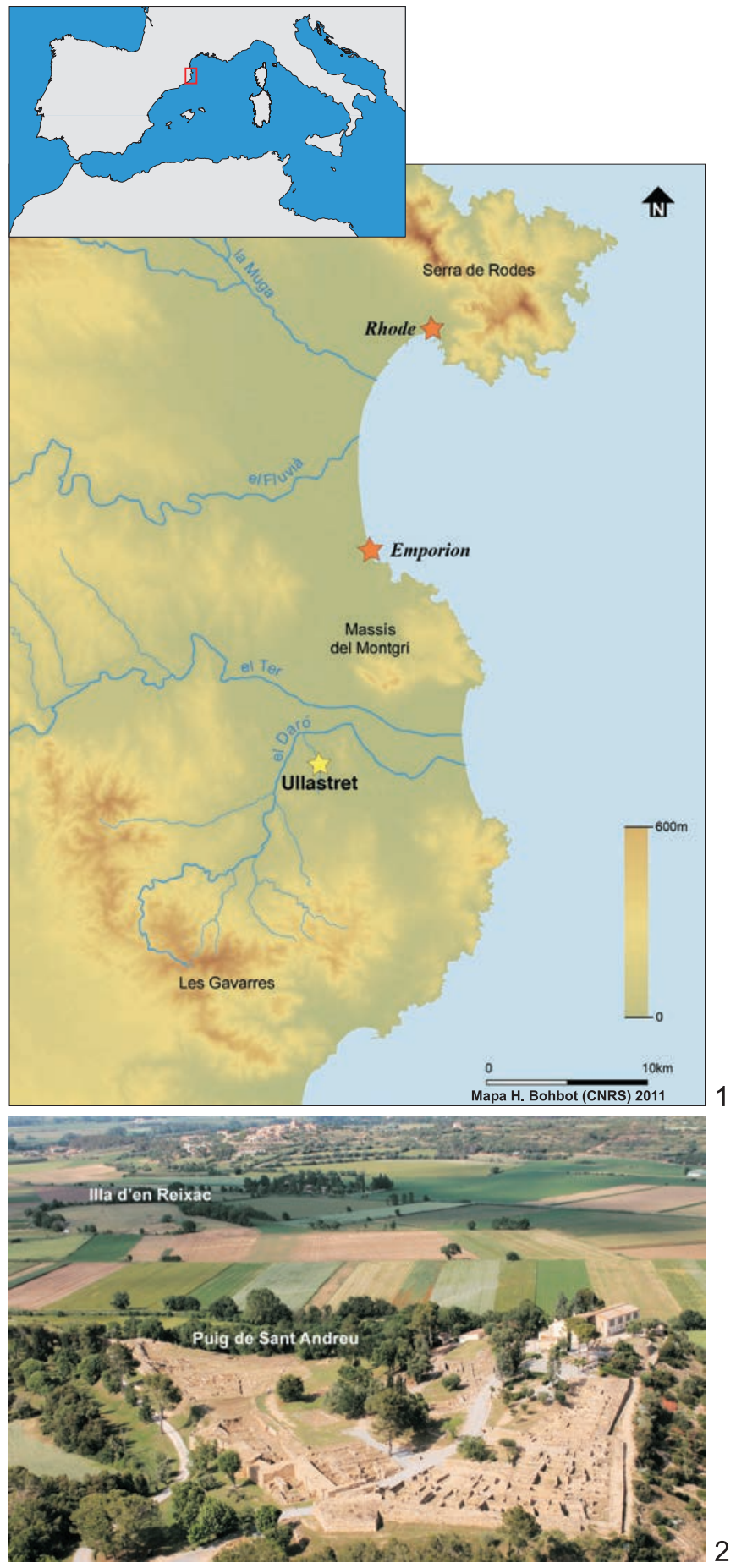

Fig. 1. Localisation des sites archéologiques d'époque ibérique d'Ullastret. 2. Vue aérienne présentant les agglomérations de Puig de Sant Andreu et d'Illa d'en Reixac.

celle-ci continue à être fabriquée jusqu'à l'abandon du site. À l'intérieur de cette production, qui signale l'adoption d'usages culinaires nouveaux, la forme la plus fréquente est un pot du type caccabè (fig. $\mathbf{4 - 5}$ et 6), avec les couvercles associés. Les imitations de lopas ou de chytra sont moins nombreuses. 


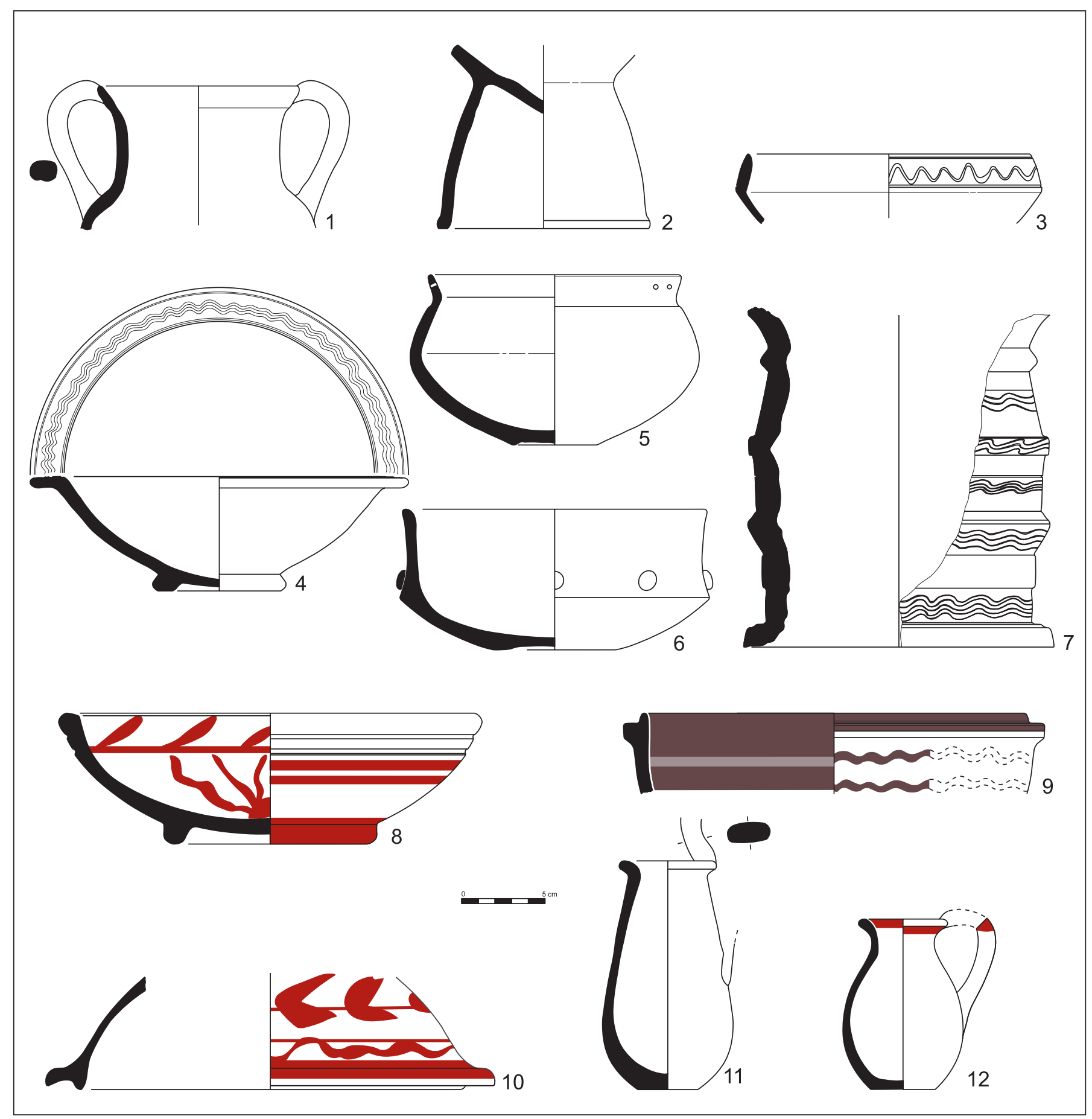

Fig. 2. 1 à 7 : Imitations de vases de céramique grise monochrome ; 8 à 12 : Imitations de vases de céramique à pâte claire peinte. 


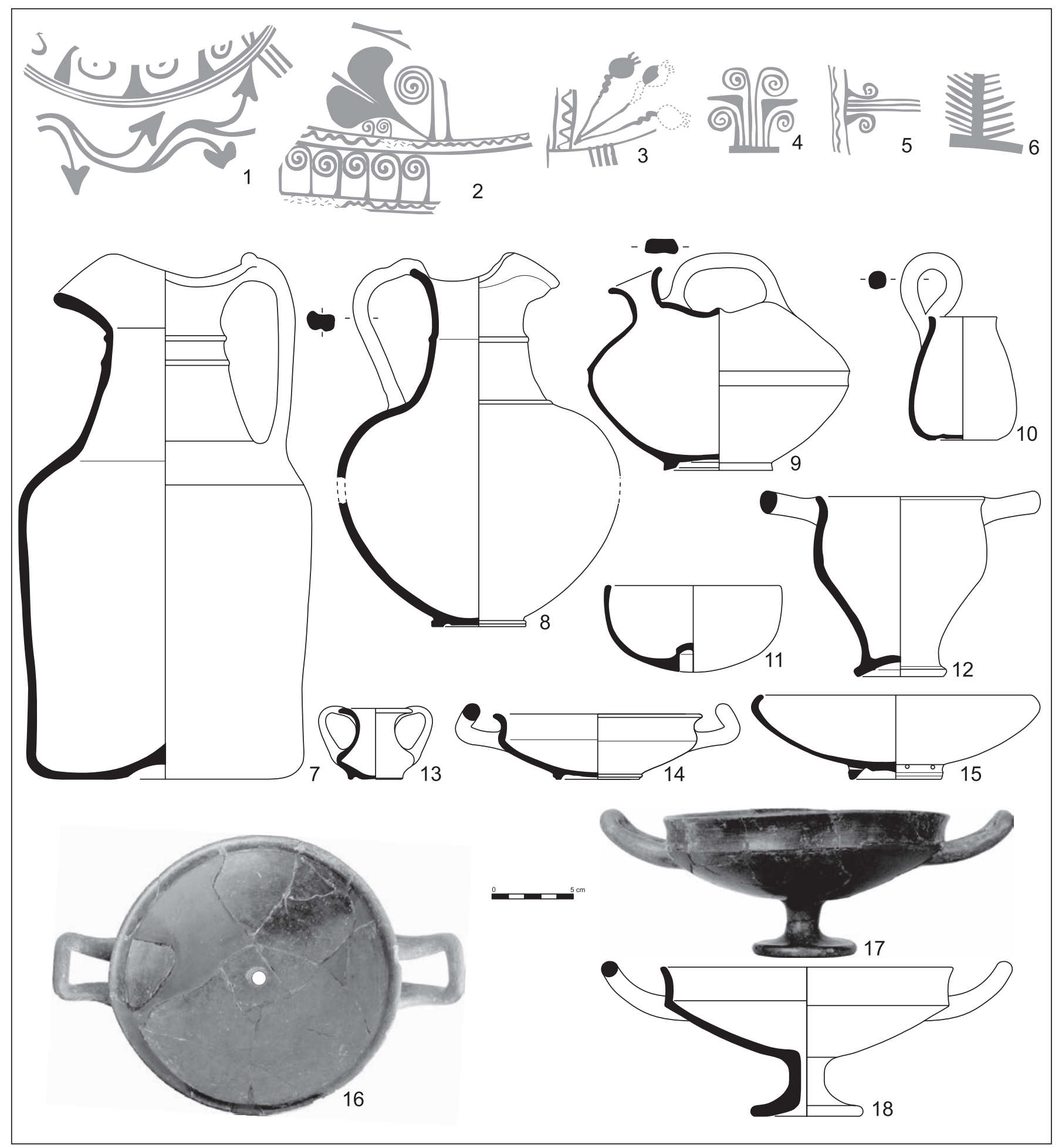

Fig. 3. 1 à 6 : Décors de la céramique indikète ; 7 à 15 : Vases de céramique de la côte catalane qui copient des formes de la céramique attique ; 16 à 18 : Coupe de céramique non tournée imitation d'une coupe attique. 


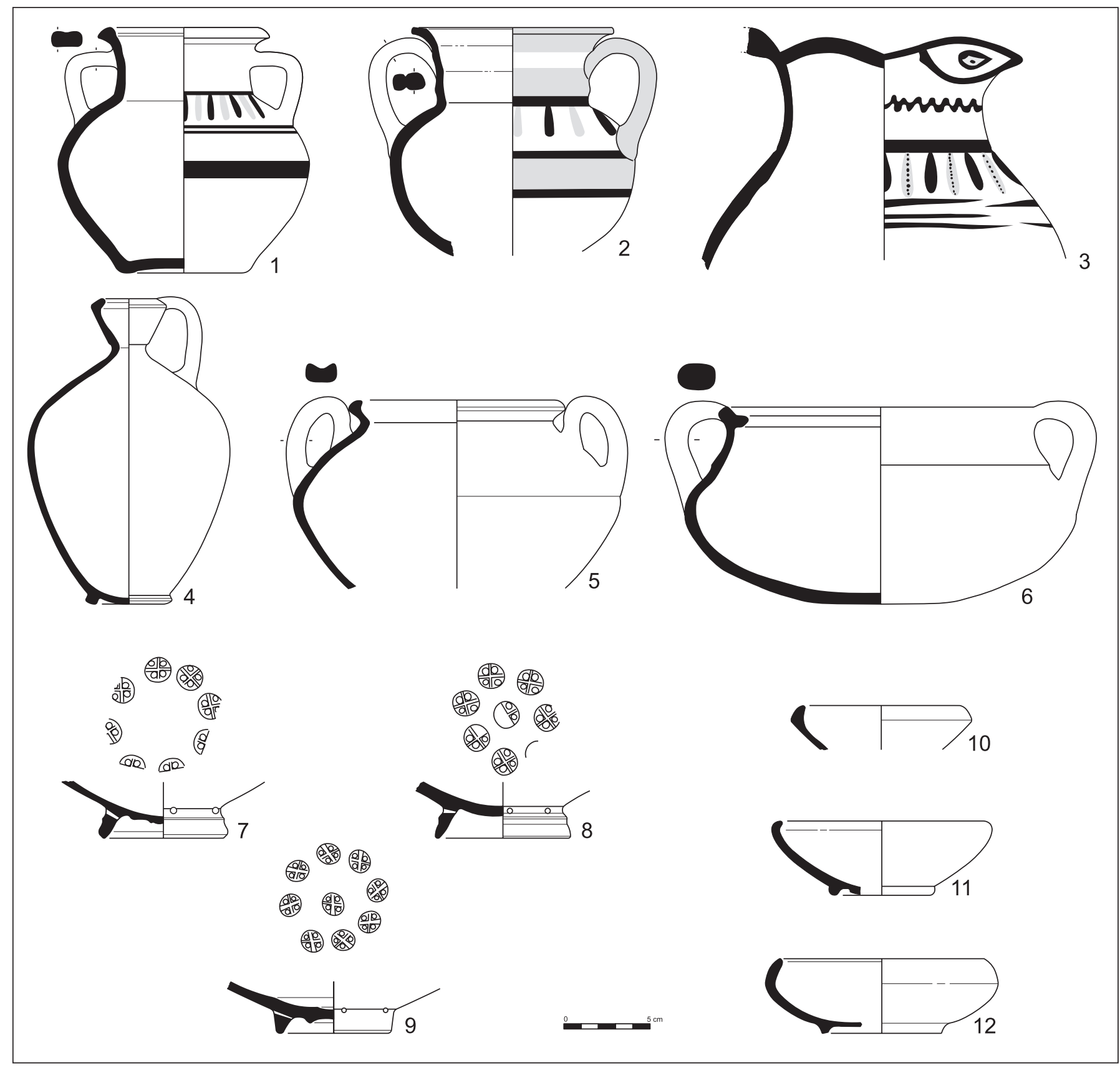

Fig. 4 . 1 à 4 : Imitations de vases de céramique punique-ébusitaine ; 4 : Olpè de céramique de la côte catalane imitation d'une forme carthaginoise ; 5 et 6 : Céramique de cuisine tournée utilisant des modèles puniques centro-méditerranéens ; 7 à 9 : Coupes de céramique de la côte catalane imitation de la forme 27 des Petites Estampilles ; 10 à 12 : Coupes de céramique de la côte catalane imitation de la céramique Campanienne A. 


\section{Les imitations de céramique à vernis noir italique. Fin du IVe et III ${ }^{\mathrm{e}} \mathrm{S}$. av. n. è.}

\section{Les imitations de vases de l'atelier des Petites Estampilles}

Vers la fin du IV e s., l'arrivée de la production des Petites Estampilles à Ullastret provoque l'apparition d'un atelier local qui, à côté de céramique de la côte catalane, fabrique des coupes Lamb. 27 décorées d'estampilles disposées en cercle sur le fonds interne, avec parfois aussi une estampille au centre. Les exemplaires connus ont été datés du début jusqu'à la fin du $\mathrm{III}^{\mathrm{e}}$ s. av. n. è. (fig. 4-7, 8 et 9). S'ils ont été fabriqués de préférence en céramique grise, il y en a aussi en céramique oxydante. Dans tous les cas, le pied présente deux trous réalisés avant cuisson destinés à faciliter leur suspension.

\section{Les imitations de la céramique Campanienne A}

La céramique Campanienne A arrive lors de la phase finale du site d'Ullastret. Cependant, son introduction entraîne la production de petits bols en céramique de la côte catalane qui copient les formes Lamb. 24 et 25 (fig. 4-10, 11 et 12).

\section{Considérations finales}

L'arrivée de céramiques d'origine méditerranéenne à Ullastret se vérifie, on l'a vu, depuis la fondation des deux habitats dans le dernier quart du VII ${ }^{\text {e jusqu'au }}$ début du $\mathrm{II}^{\mathrm{e}}$ s. av. n. è., au moment de leur abandon. Les premières importations arrivent de manière sporadique, par des voies diverses. En effet, la découverte de vases phéniciens dans les nécropoles du Premier Âge du fer de l'arrière-pays, comme Agullana ou Anglès, peut signaler l'utilisation de voies terrestres. Toutefois, c'est la fondation de l'établissement d'Emporion vers 600 av. n. è. qui provoquera un accroissement de l'arrivée des produits coloniaux, qui, à partir de ce moment, entreront avant tout par l'intermédiaire de son port. Les ateliers céramiques locaux copient les objets importés, d'abord les productions des établissements phocéens du Golfe du Lion, mais aussi les productions ébusitaines, qui sont imités de façon relativement fidèle, aussi bien en ce qui concerne les pâtes que les formes et les décors.

L'arrivée de céramiques d'autres provenances, en particulier la céramique attique dès le milieu du $\mathrm{V}^{\mathrm{e}} \mathrm{s}$., entraîne l'introduction de nouvelles modes dans les ateliers indigènes. Désormais, non seulement il y a des imitations, mais les nouvelles formes et modalités de décor de la céramique attique à figures rouges et à vernis noir seront intégrées dans les productions proprement indigènes, comme c'est le cas du décor des urnes de stockage en céramique commune ibérique à décor de peinture blanche ou de la vaisselle de table en céramique de la côte catalane, et le même cas de figure se retrouve avec la vaisselle carthaginoise.

\section{Bibliographie}

Fernández, Costa 1998 : FERNÁNDEZ (J.H.), COSTA (B.) - La ceràmica común púnico-ebusitana: precisiones tipológicas y cronológicas sobre algunas formas, Misceláneas de Arqueologia Ebusitana I, Eivissa, 1998, p.23 - 81.

Martin 1978: MARTIN (A.) - La ceràmica decorada amb pintura blanca de les comarques costeres del NE de Catalunya, Cypsela II, 1978, p. 145-160.

Martin 1988: MARTIN (A.) - Algunes precisions més sobre la ceràmica ibèrica indiketa decorada amb pintura blanca, Fonaments 7, 1988, p. 47-56.

Martin et al. 2010: MARTIN (A.), CODINA (F.), PLANA (R.), DE PRADO (G.) - Le site ibérique d'Ullastret (Baix Empordà, Catalogne) et son rapport avec le monde colonial méditerranéen, In : Tréziny (H.) (éd.) Grecs et indigènes de la Catalogne à la Mer Noire, Actes des Rencontres du Programme Européen Ramses 2 (2006-2008), BIAMA 3, Aix-en-Provence, 2010, p. 89-104.

Martin, Lafuente 1999 : MARTIN (A.), LAFUENTE (A.) - Caracterització de les fàcies culturals per fases, in Martin (A.), Buxó (R.), Lopez (J. B.), Mataró (M.) (dirs.) Excavacions arqueològiques a l'Illa d'en Reixac (19871992), Monografies d'Ullastret 1, 1999, p. 319-324.

Oliva 1955 : OLIVA (M.) - Actividades de la Delegación Provincial del Servicio Nacional de Excavaciones Arqueológicas de Gerona en 1955, A.I.E.G., Girona, p. 317-411.

Pradell et al. 1995 : PRADELL (T.), GARCIA-VALLÈS (M.T.), MARTIN (A.), VENDRELL-SAZ (M.) - Attribution of «Iberian painted» and «Greek grey monochrome» ceramics, from 6th century B.C. to a local production of Ullastret (Catalonia), Estudis sobre ceràmica antiga, Actes del Simposi de Ceràmica Antiga, Barcelona, 1993, p. 23-27.

Py 1993 : PY (M.) (DIR.) - DICOCER, Dictionnaire des céramiques antiques en Méditerranée nord-occidentale. Lattes, 1993 (Lattara 6).

Rodríguez et al. 2003 : RODRÍGUEZ (A.), PRADELL (T.), MOLERA (J.), VENDRELL (M.) - La ceràmica de la costa catalana a Ullastret, Museu d'Arqueologia d'Ullastret, 2003. 


\title{
La céramique fine ibérique du nord-est de la Catalogne. Les formes représentées dans l'oppidum ibérique de Sant Julià de Ramis
}

\author{
Josep Burch \\ Jordi Sagrera
}

Université de Gérone

\section{Résumé}

Nous présentons dans ce travail l'étude de ce que nous avons baptisé la céramique fine ibérique, découverte dans l'oppidum de Sant Julià de Ramis et dans ses champs de silos du Bosc del Congost et des Escalers, et qui appartient à une époque située entre le IV et le I ${ }^{\text {er }}$ s. av. J.-C. Partant des travaux de J. Barberà, J.-M. Nolla et E. Mata, qui ont réalisé un classement systématique de la céramique grise emporitaine, mais adoptant une perspective chronologique plus globale, cette étude offre la classification formelle des poteries ibériques du nord-est catalan qui ont été fabriquées pour la consommation d'aliments, que ceux-ci soient liquides ou solides. Cette classification inclut différentes productions qui ont reçu diverses dénominations : céramique grise emporitaine, céramique grise de la côte catalane ou, en partie, céramique commune ibérique.

Mots-clés : céramique ibérique, Sant Julià de Ramis, Catalogne

\section{Abstract}

We present in this work the study of what we call Iberian fine pottery and appeared in the oppidum of Sant Julia de Ramis and in its silos stores of Bosc del Congost and Escalers, with a chronology between the IV century BC. and I BC. Based on the work done by J. Barberà, J.-M. Nolla et E. Mata, systematic classification of gray ceramic emporitaine, this study includes, in a chronological sense more global, the formal classification of Iberian pottery northeastern Catalan, made the turn and to thoughts be used in food consumption, as they are liquid or solid. It includes various productions that have received various names: ceramic emporitaine gray, gray ceramics of the Catalan coast or, partially, common Iberian pottery.

Keywords: Iberian pottery, Sant Julià de Ramis, Catalonia 


\section{Présentation}

Les productions céramiques ibériques du nord-est de la Catalogne embrassent une grande variété de formes. Cette variété n'est pas due au hasard, mais dépend en fait de la fonction à laquelle ces céramiques étaient destinées. Certaines d'entre elles peuvent en effet être associées à la consommation et à l'ingestion d'aliments dans le cadre de l'alimentation quotidienne. On fabriquait alors tout un éventail de pièces en lien avec les deux grandes manifestations du rituel de l'alimentation : le service et la consommation. La diversité des aliments cuisinés ou des quantités à servir contribua donc à l'apparition d'une remarquable variété dans les formes créées. En plus du critère fonctionnel, il faudrait tenir compte de l'importance exercée par d'autres aspects non négligeables : comme les modes, qui furent probablement à l'origine de changements, surtout dans le domaine de la décoration, et plus particulièrement les influences venues d'ailleurs, qui favorisèrent l'adoption par la population locale de modèles qui ne lui étaient pas propres.

En ce qui concerne les ustensiles ménagers relatifs à la consommation alimentaire, nous présentons dans ce travail l'étude de ce que nous avons baptisé la céramique fine ibérique, provenant de l'oppidum de Sant Julià de Ramis et de ses champs de silo du Bosc del Congost et des Escalers (Burch, Sagrera 2009) et qui appartient à une époque située entre le $\mathrm{IV}^{\mathrm{e}}$ et le $\mathrm{I}^{\mathrm{er}} \mathrm{s}$. av. J.-C. Nous avons volontairement laissé de côté d'autres productions qui, bien que réalisées pour la consommation d'aliments, peuvent être englobées, en raison de leurs caractéristiques, dans d'autres groupes de céramiques : il s'agit notamment de celles fabriquées à la main ou de celles que nous pourrions rattacher à l'ensemble plus large formé par les poteries de cuisine.

Partant des travaux effectués par Barberà, Nolla et Mata (1993), qui ont présenté une classification systématique de la céramique grise emporitaine - une production très caractéristique, fabriquée aux $\mathrm{II}^{\mathrm{e}}$ et $\mathrm{I}^{\mathrm{er}} \mathrm{s}$. av. J.-C. dans les alentours de la ville d'Emporion (Empúries) -, mais adoptant une perspective chronologique plus large (32575 av. J.-C.), cette étude offre la classification formelle des poteries ibériques du nord-est catalan qui ont été produites pour la consommation d'aliments, soit liquides soit solides. Elle se centre donc sur différentes productions caractérisées par une variété de dénominations : céramique grise emporitaine, céramique grise de la côte catalane ou, en partie, céramique commune ibérique.

Concrètement, ce classement regroupe les formes que présentent les poteries selon la fonction à laquelle elles devaient être destinées. Chaque groupe est défini par une lettre de l'alphabet : les bols, probablement employés pour servir et consommer des aliments, sont désignés par la lettre A ; les petits bols, vraisemblablement destinés à d'autres finalités en raison de leurs dimensions, par la lettre $\mathrm{B}$; les plats, par C ; les gobelets biconiques, par D ; les cruches, par E ; les coupes, par F, et ainsi de suite. Finalement, dans chaque groupe, on peut trouver des séries formelles distinctes. De cette façon, il a été possible de mieux connaître les coutumes associées à la consommation alimentaire, tout en approfondissant la sériation des céramiques, une opération qui est utile pour des questions purement archéologiques, comme par exemple la datation.

\section{Le catalogue des formes}

\section{Bol A-Ia}

Cette forme de bol est présente dans le silo $41 \mathrm{du}$ Bosc del Congost (325-275 av. J.-C.), dans le silo 50 (275240 av. J.-C.) et dans le silo 88 (260-240 av. J.-C.), et a la même fonction que la variante A-Ib. Dans le dernier tiers du $\mathrm{III}^{\mathrm{e}} \mathrm{s}$. av. J.-C., elle devient très rare.

\section{Bol A-Ib}

À Sant Julia de Ramis, l'existence de ce type de bol est attestée à partir du milieu ou du dernier tiers du $\mathrm{III}^{\mathrm{e}}$ s. av. J.-C. jusqu'au premier quart du $\mathrm{II}^{\mathrm{e}}$ s. av. J.-C., moment où il est remplacé par la variante A-Ic. Sa présence est marquée par des hauts et des bas, avec des périodes où ses taux d'apparition sont plutôt faibles, comme entre la fin du $\mathrm{III}^{\mathrm{e}} \mathrm{s}$. et le début du $\mathrm{II}^{\mathrm{e}} \mathrm{s}$. av. J.-C. (silos 3, 13 et 8 du Bosc del Congost).

\section{Bol A-Ic}

Cette forme est semblable au bol A-Ib, mais possède une rainure circulaire dans le fond. C'est la variante propre au II ${ }^{\mathrm{e}}$ s. av. J.-C., même si, à partir du milieu du siècle, elle commence à être remplacée par l'A-II (silos 34, 58 et 19 du Bosc del Congost).

\section{Bol A-II}

Dans le Bosc del Congost, cette forme est détectée à partir du deuxième tiers du II e s. av. J.-C. (silo 19). Ces bols, caractérisés d'abord par un profil plutôt bas, gagnent ensuite une certaine hauteur, lors de la seconde moitié du siècle, (silos 2, 4 et 84 du Bosc del Congost). Les silos 49, 65 et 83 du Bosc del Congost indiquent clairement que cette forme de bol est caractéristique de l'époque couvrant le premier tiers du Irr s. av. J.-C.

\section{Bol variante A-IIIa}

C'est l'une des formes les plus anciennes. À Sant-Julia, elle a été identifiée dans le silo 41 du Bosc del Congost (325-275 av. J.-C.), dans le silo 88 (260-240 av. J.-C.) 
et peut-être aussi dans le silo 43 (240 à 220 av. J.-C). Sa chronologie finale doit être située vers le milieu ou le troisième quart du $\mathrm{IIII}^{\mathrm{e}} \mathrm{s}$. av. J.-C.

\section{Bol variante A-IIIb}

Cette forme a une existence qui est parallèle à la variante IIIa. Elle est présente dans la plupart des silos du III s. av. J.-C. du Bosc del Congost (silos 36, 41, $43,50,55$ et 88 ). Sa fourchette chronologique est large (325-220 av. J.-C.).

\section{Bol variante A-IIIc}

Ce bol est très similaire à l'A-III, ce qui nous fait penser qu'il pourrait s'agir d'une évolution naturelle dans le temps. Il se situe dans une période très spécifique, celle couvrant le dernier quart du III e s. av. J.-C. Dans le silo 3 du Bosc del Congost (220-200 av. J.-C.), sa présence est particulièrement forte; en revanche, durant le II ${ }^{\mathrm{e}}$ s. av. J.-C., il disparaîtra rapidement.

\section{Bol variante A-IIId}

Cette forme est la plus représentative du II ${ }^{\mathrm{e}}$ s. av. J.-C. À Sant Julia de Ramis, elle est en effet bien présente dans les silos 8 et 13 du Bosc del Congost (200-180 av. J.-C.), mais est absente dans ceux qui sont d'une époque antérieure, comme les silos 3 (220-200 av. J.-C.), 53 (210-190 av. J.-C.) et 47 (210-180 av. J.-C.). Cela permet de lui octroyer un point de départ situé aux alentours de 200-190 av. J.-C., alors que sa phase finale doit être placée dans le troisième quart du $\mathrm{II}^{\mathrm{e}} \mathrm{s}$. av. J.-C., mais avec un mouvement de baisse qui débute déjà au milieu du siècle.

\section{Bol variante A-IIIe}

À Sant Julia de Ramis, ce type de bol a été documenté dans le champ de silos du Bosc del Congost et correspondrait à une époque très spécifique, qui couvre les vingt dernières années du $\mathrm{III}^{\mathrm{e}} \mathrm{s}$. av. J.-C. et les vingt premières du siècle suivant. Dans le silo 3 (220-200 av. J.-C.), il est en grand nombre. Dans les silos 8 et 13 (200-180 av. J.-C.), il est encore présent, mais dans une moindre mesure. Le dernier exemple a été identifié dans le silo 21 (190-170 av. J.-C.), où il apparaît de façon résiduelle.

\section{Bol A-IV}

Cette forme est assez rare à Sant Julia de Ramis et n'apparaît que dans les niveaux plus modernes correspondant au premier tiers du ${ }^{e r}$ s. av. J.-C. Elle imite clairement la forme Lamboglia 8 du Campanien B. Elle est présente dans les niveaux liés à l'abandon de l'oppidum de Sant Julià, au premier tiers du $\mathrm{I}^{\mathrm{er}} \mathrm{s}$. av. J.-C. Par contre, elle est très peu présente dans le silo 49 du Bosc del Congost (100-80 av. J.-C.). Selon Barberà, Nolla et Mata $(1993,26)$, sa période de production la plus intense se situerait entre 50 et 30 av. J.-C.

\section{Bol A-V}

Il s'agit d'une forme très rare à Sant Julia de Ramis. En fait, on en connaît seulement deux exemplaires, avec une stratigraphie peu sûre. La chronologie doit être fixée par extrapolation à partir d'autres sites.

\section{Bol A-VI}

Il s'agit d'un petit répertoire de bols qui ressemblent vaguement à la forme Lamboglia 28 de la campanienne. En fait, seuls quatre fragments ont été identifiés à Sant Julia de Ramis. Ils proviennent tous des derniers moments de l'oppidum. Il est très probable que cette forme trouve son origine dans le premier tiers du Irer s. av. J.-C. L'un des bols a été décoré avec une peinture rouge semblable à celle qui décore certaines céramiques ibériques plus tardives.

\section{Bol A-VII}

C'est probablement l'une des plus fidèles imitations en gris emporitain de la céramique réalisée en vernis noir. Il s'agit d'une coupe imitant la forme du 10A.b de Roses (Puig, 2006a, 310). Les deux exemples connus viennent du champ de silos des Escalers. Le premier, intact, a été trouvé dans le silo 1 (225-200 av. J.-C.). Le second, dans le silo 15 . Nous pourrions établir une datation qui remonte à la seconde moitié, déjà bien avancée, du III ${ }^{\mathrm{e}} \mathrm{s}$. av. J.-C.

\section{Bol A-VIII}

Dans les silos du Bosc del Congost, il apparaît timidement dans le silo 88 (260-240 av. J.-C.), avec un seul fragment. Par la suite, on le trouve dans le silo 43 (240220 av. J.-C.), avec un exemplaire bien conservé. Depuis lors et jusqu'à la fin du II ${ }^{\mathrm{e}} \mathrm{S}$. av. J.-C., cette forme de bol devient plus régulière. Dans les silos 116 (230-210 av. J.-C.) et 3 (220-200 av. J.-C.), sa fréquence atteint d'ailleurs son maximum. Au début du $\mathrm{II}^{\mathrm{e}}$ s. av. J.-C. débute une raréfaction progressive, bien que ce type de bol soit encore assez commun dans les silos 8,13 et 53 (210-180 av. J.-C.). Cependant, au début du deuxième quart du $\mathrm{II}^{\mathrm{e}} \mathrm{s}$. av. J.-C., sa fréquence devient très faible, un dernier exemplaire étant enregistré dans le silo 19 (170-150 av.J.-C.). Par conséquent, on peut affirmer qu'il y a eu une première étape au milieu du $\mathrm{III}^{\mathrm{e}} \mathrm{s}$. av. J.-C., suivie d'une phase expansive dans le dernier quart du siècle et peut-être au début du $\mathrm{II}^{\mathrm{e}} \mathrm{s}$. av. J.-C., phase qui déboucha finalement sur la disparition de cette forme de bol dans le second quart du $\mathrm{II}^{\mathrm{e}}$ s. av. J.-C.

\section{Bol B}

À Sant Julia de Ramis, ce bol est bien documenté en ce qui concerne presque tous les silos datés du IV 


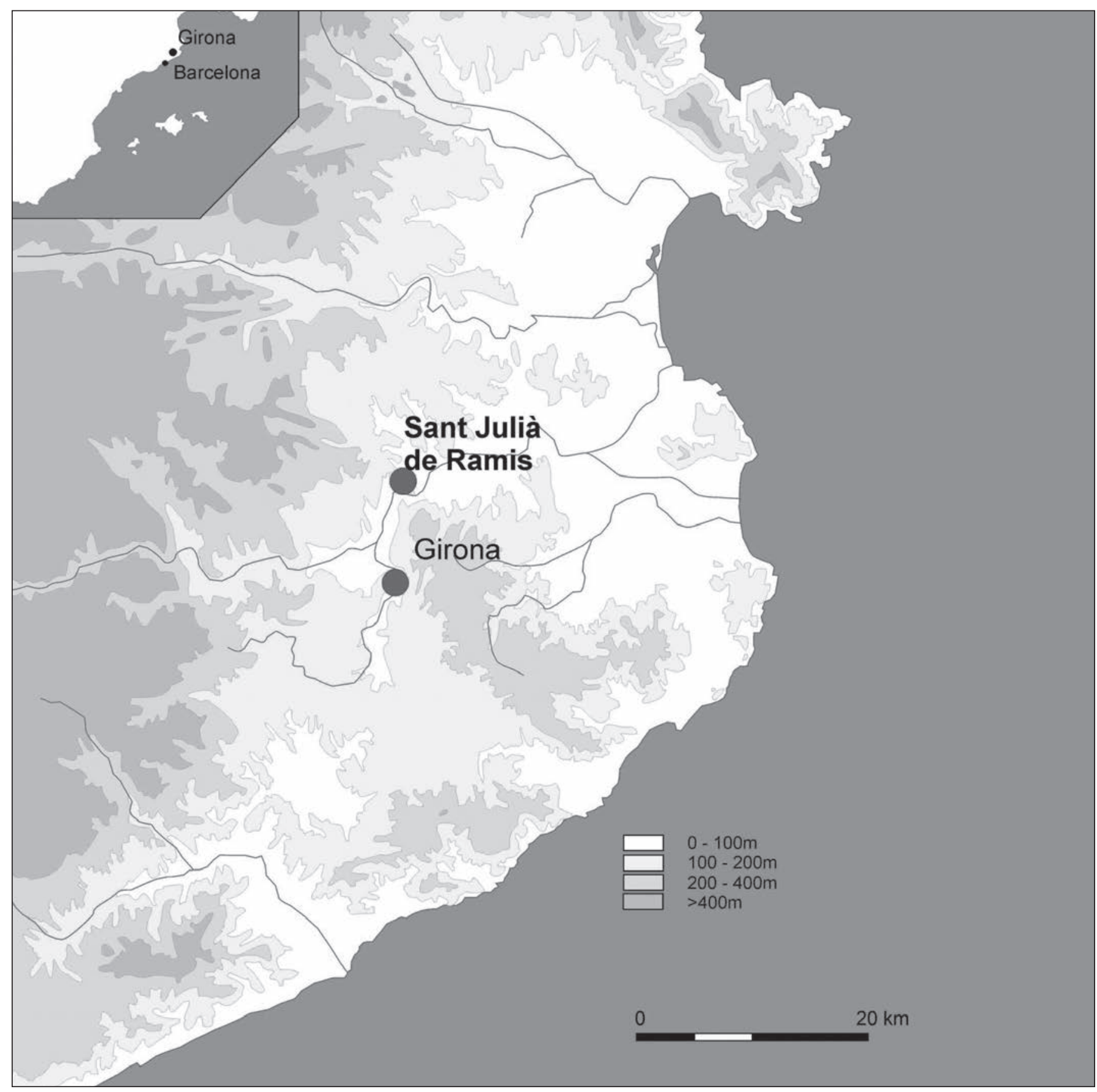

Fig. 5. Carte de localisation de l'oppidum de Sant Julia de Ramis. 
au II s. av. J.-C. Dans le Bosc del Congost, il est présent dans le silo 84 (130-110 av. J.-C.) et dans le 49 (100-80 av. J.-C.). En revanche, cette forme de bol n'est déjà plus identifiée dans les silos 2, 65 et 83 (120-80 av. J.-C.).

\section{Plat C-I}

À Sant Julià de Ramis, ces plats se trouvent tant dans le remblai interne de la plate-forme du temple (ils sont alors datés de 140-120 av. J.-C.) que dans les niveaux modernes de l'oppidum (120-70 av. J.-C.) (Burch et al., 2001, 90, 110-111). Dans le Bosc del Congost, ils sont moins bien documentés, mais appartiennent par contre à des contextes bien délimités dans le temps. Ils apparaissent très tôt dans les silos 84 et 16 (130-110 av. J.-C.) ; ensuite, dans le silo 2 (120-100 av. J.-C.) avec plus d'unités et, dans la même proportion, dans les silos 49, 65 et 83 (100-80 av. J.-C.).

\section{Plat C-II}

C'est l'imitation du plat de poisson, forme Lamboglia 23. À Sant Julia de Ramis, ce plat se réduit à un seul exemplaire trouvé dans l'oppidum. Le contexte permet de le dater du premier tiers du $\mathrm{II}^{\mathrm{e}} \mathrm{s}$. av. J.-C., malgré la présence de nombreux fragments du $\mathrm{III}^{\mathrm{e}} \mathrm{s}$. av J.-C.

\section{Plat C-III}

La forme Lamboglia 6 semble avoir influencé une série de plats en céramique fine locale bien documentée à Sant Julia de Ramis, mais rarement en dehors de cette zone (Castanyer, Sanmartí, Tremoleda 1993 ; Rodríguez 2003). La chronologie fournie par notre site oscille entre le dernier tiers du $\mathrm{II}^{\mathrm{e}}$ s. et le $\mathrm{I}^{\mathrm{er}} \mathrm{s}$. av. J.-C. Cette forme de plat est abondante seulement dans les niveaux correspondant à l'abandon de l'oppidum, mais totalement absente dans les périodes un peu plus anciennes (140-120 av. J.-C). Elle a également été identifiée dans le silo 84 du Bosc del Congost, ce qui atteste sa présence dans le dernier tiers du II e s. av. J.-C. Dans les silos 2, 49 et 83 , on la trouve de façon régulière.

\section{Plat C-IV}

À Sant Julià de Ramis, ce type de plat se situe dans les niveaux relatifs à la dernière occupation de l'oppidum. Dans le Bosc del Congost, il est présent dans les silos 2, 49, 83 et 84 (130-80 av. J.-C.). Sa production commence donc dans le dernier tiers du $\mathrm{II}^{\mathrm{e}} \mathrm{s}$. av. J.-C. et son emploi est toujours en vigueur dans le premier tiers du $\mathrm{I}^{\mathrm{er}}$ s. av. J.-C.

\section{Plat $\mathrm{C}$-V.}

Il s'agit de petits plats inspirés par la forme Lamboglia 23. Tout comme la kylix, mis à part les proportions, ils sont caractérisés par deux anses opposées et disposées sur la lèvre ou au-dessous du bord. À Sant Julia de Ramis, ces plats ont été retrouvés dans le silo 49 et remonteraient à 100-80 av. J.-C.

\section{Gobelet D-I}

C'est l'une des formes les plus originales et les plus fréquentes du répertoire de la céramique grise de la côte catalane. En ce qui concerne le Bosc del Congost, elle apparaît dans tous les silos datés du $\mathrm{IV}^{\mathrm{e}} \mathrm{s}$. et du $\mathrm{III}^{\mathrm{e}} \mathrm{s}$. av. J.-C. et dans certains du premier tiers du II ${ }^{\mathrm{e}} \mathrm{s}$. av. J.-C.

\section{Gobelet D-II}

C'est l'un des gobelets les plus tardifs, assez éloigné des biconiques. Coïncidant avec la datation proposée par Aranegui (Aranegui, 1985, 110), malgré une collection d'exemplaires plus réduite, il se rencontre sur le site de Sant Julia de Ramis uniquement dans le premier quart du $\mathrm{I}^{\mathrm{er}} \mathrm{s}$. av. J.-C. Sa fréquence maximale est observée dans le silo 49 du Bosc del Congost (100-80 av. J.-C.).

\section{Gobelet D-I/III}

Cette forme se limite au premier tiers du $\mathrm{II}^{\mathrm{e}} \mathrm{s}$. av. J.-C. Elle a été identifiée de manière irréfutable dans les silos 8 et 13 du Bosc del Congost (200-180 av. J.-C.). Au deuxième quart du $\mathrm{II}^{\mathrm{e}} \mathrm{s}$. av. J.-C., elle est toujours présente dans les silos 29 (190-170 av. J.-C.), 21 et 58 (180-160 av. J.-C.) ; mais elle est plutôt de nature résiduelle dans le silo 19 (170-150 av. J.-C.), où elle est remplacée par la forme D-III.

\section{Gobelet D-III}

À Sant Julia de Ramis, on trouve cette forme en abondance dans la plupart des stratigraphies du $\mathrm{II}^{\mathrm{e}} \mathrm{s}$. av. J.-C. Dans le Bosc del Congost, elle apparaît d'abord dans le silo 58 (180-160 av. J.-C.), en alternance avec les gobelets DI et DI/III. Dans le silo 19 (170-150 av. J.-C.), elle domine encore totalement la catégorie des gobelets et ce n'est que dans le silo 4 (150-130 av. J.-C.) que cette forme connaît un véritable succès. La même chose se produit dans le silo 84 (130-110 av. J.-C.). Le silo 2 (120-100 av. J.-C.) est intéressant parce que l'on y détecte une chute brutale de sa fréquence, compensée par l'apparition du gobelet D-III/IV et du D-IV. Dans les silos 83 (110-90 av. J.-C.), il est encore documenté, tout comme dans le silo 65 (110-80 av. J.-C.), mais seulement en petite quantité. Enfin il est absent du silo 49 (100-80 av. J.-C.).

\section{Gobelet D-III/IV}

Il s'agit d'une forme rare qui a été nommée ainsi car elle est à mi-chemin entre le gobelet D-III et le gobelet D-IV . Elle pourrait être considérée comme un gobelet D-III avec un col lisse ou un gobelet D-IV avec des proportions anormalement élevées. Cette variante est attestée dans le silo 2 


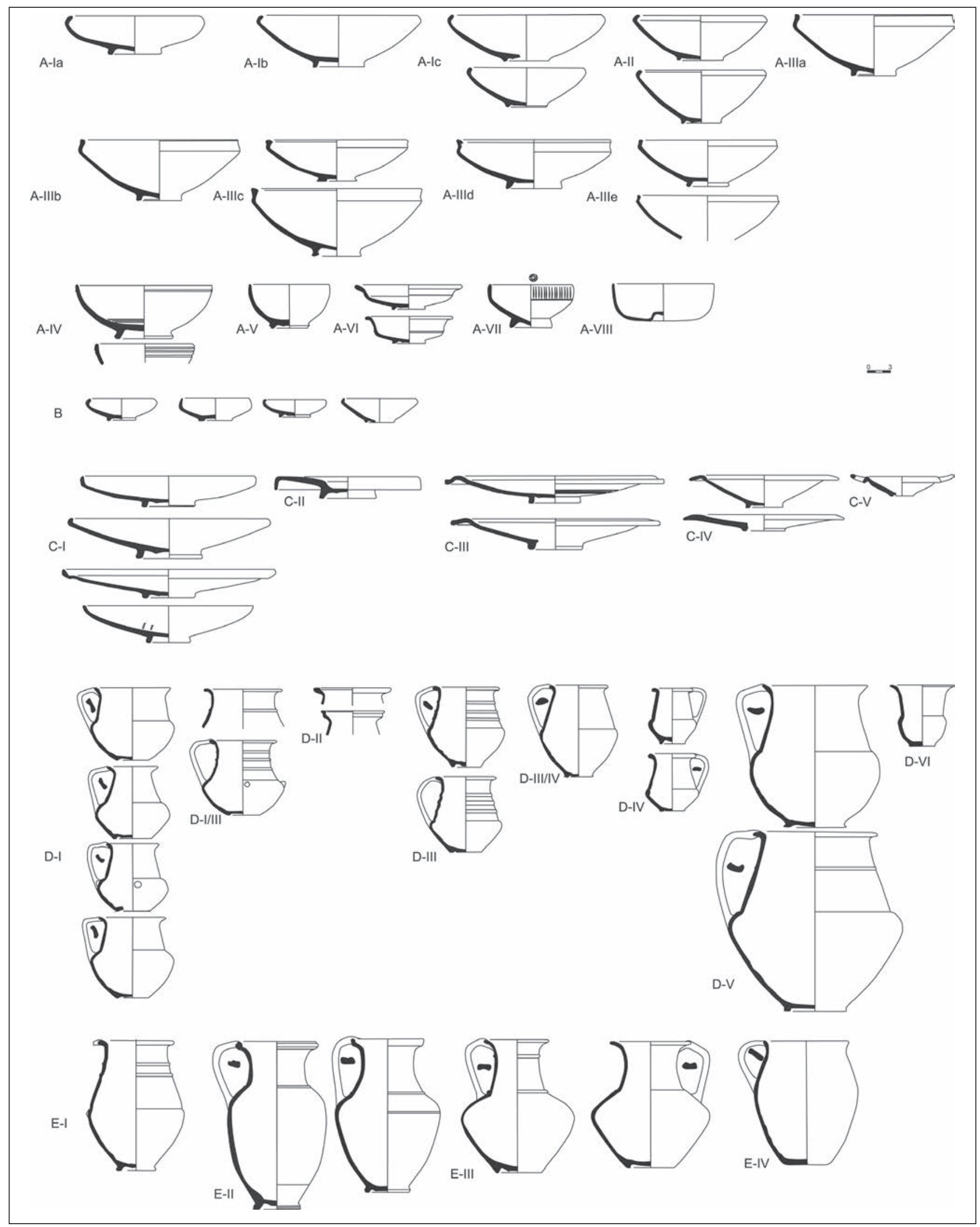

Fig. 6. Catalogue des formes. 


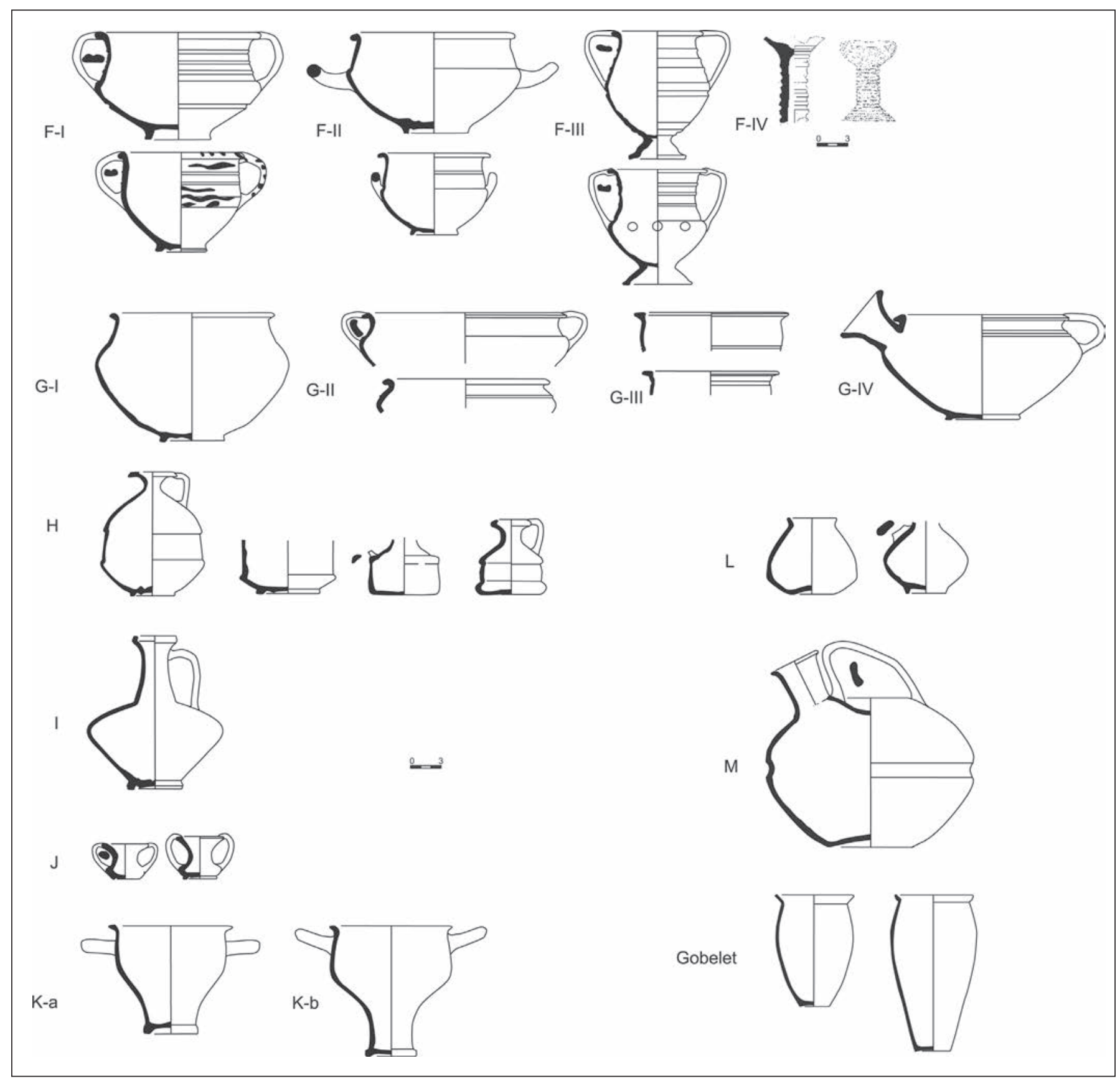

Fig. 7. Catalogue des formes (suite). 
du Bosc del Congost (120-100 av. J.-C.) et également dans les niveaux rattachés à la phase d'abandon de l'oppidum. Sa datation serait contemporaine de la fin de l'usage du gobelet D-III et du début de l'usage du gobelet D-IV.

\section{Gobelet D-IV}

La séquence d'attestation du gobelet D-IV à Sant Julià de Ramis commence à partir du dernier tiers du $\mathrm{II}^{\mathrm{e}}$ s. av. J.-C. Nous l'avons identifié dans le silo 84 (130 à 110 av. J.-C.), dans le silo 2 (120-100 av. J.-C.) et dans le silo 49 (100-80 av. J.-C.) du Bosc del Congost. Il a également été documenté grâce aux fouilles réalisées par Maluquer de Motes à Sant Julià de Ramis et dans les niveaux postérieurs à la construction de la plate-forme du temple de l'oppidum (120-100 av. J.-C.).

\section{Cruche D-V.}

Le plus ancien exemplaire provient des silos 36 (300-240 av. J.-C.) et 43 (240-220 av. J.-C.). On la retrouve ensuite dans le silo 116 (230-210 av. J.-C.), dans le silo 3 en plus grand nombre (220-200 av. J.-C.) et, enfin, dans le silo 13 (200-180 av. J.-C.) avec un fragment d'attribution douteuse. D'un point de vue chronologique, la cruche D-V peut être située dans la seconde moitié du III $\mathrm{e}$ s. av. J.-C.

\section{Gobelet D-VI}

Il s'agit d'une pièce unique à Sant Julia de Ramis. Elle est apparue lors de l'excavation de la zone 1 de l'oppidum et remonterait au dernier tiers du $\mathrm{II}^{\mathrm{e}} \mathrm{s}$. av. J.-C.

\section{Cruche E-I}

Si la cruche D-V imitait bien la forme du gobelet biconique D-I, la cruche E-I imite, quant à elle, le galbe du gobelet D-III. Ce qui les différencie, ce sont les proportions. À Sant Julia de Ramis, elle est documentée principalement dans le Bosc del Congost, avec une chronologie située entre le milieu du $\mathrm{II}^{\mathrm{e}} \mathrm{s}$. av. J.-C et le premier quart du $\mathrm{I}^{\mathrm{er}} \mathrm{s}$. après J.-C. Nous la trouvons peut-être dans le silo 4 (150-130 av. J.-C.) et, avec plus de certitude, dans le silo 16 (130-100 av. J.-C.), dans le silo 2 (120-100 av. J.-C.) et dans le silo 49 (100-80 av. J.-C.), ce dernier livrant l'exemplaire le plus réduit.

\section{Cruche E-II}

Au Bosc del Congost, il y en a deux exemplaires bien documentés, provenant du silo 2 (120-100 av. J.-C.) et du silo 84 (130 à 110 av. J.-C.). Nous lui avons imputé, avec beaucoup de réserves, un fragment apparu dans le silo 8 (200-180 av. J.-C.).

\section{Cruche E-III}

$\mathrm{Au}$ Bosc del Congost, elle est attestée timidement dans le troisième quart du $\mathrm{III}^{\mathrm{e}} \mathrm{s}$. av. J.-C., avec un premier élément dans le silo 43 (240-220 av. J.-C.). Par contre, le silo 3 (220-200 av. J.-C.) affiche un répertoire qui, bien que fragmenté, est très abondant. Dans le premier tiers du II ${ }^{\mathrm{e}}$ s. av. J.-C., ses apparitions sont plutôt rares, bien que constantes, comme dans les silos 53 (210-190 av. J.-C.), 56 (200-150 av. J.-C.), 8 (200-180 av. J.-C.), 29 (190 à 170 av. J.-C.) et 58 (180-160 av. J.-C.). Les résultats mentionnés permettent d'établir sa période de diffusion : dans toute la seconde moitié du III ${ }^{\mathrm{e}} \mathrm{s}$. av. J.-C. et lors du premier tiers du II ${ }^{\mathrm{e}}$ s. av. J.-C.

\section{Cruche E-IV}

Seuls deux exemplaires se trouvent à Sant Julia de Ramis, en particulier dans le silo 2 du Bosc del Congost (120100 av. J.-C.). En l'absence de plus de données, nous pouvons considérer que la faible production de la cruche E-IV se situerait entre le dernier quart du $\mathrm{II}^{\mathrm{e}} \mathrm{s}$. av. J.-C. et le Irr s. av. J.-C.

\section{Coupe F-I}

Dans le cadre de Sant Julia de Ramis, les premiers indices de cette coupe ont été découverts dans le silo 84 (130-110 av. J.-C.). Elle est formellement dérivée de la forme D-III, mais possède une bouche plus ouverte. Ensuite, nous la trouvons dans les niveaux relatifs à l'abandon définitif de l'oppidum, au premier tiers du $\mathrm{I}^{\mathrm{er}} \mathrm{s}$. av. J.-C.

\section{Coupe F-II}

Elle est très rare à Sant Julia de Ramis. Nous pouvons peut-être l'identifier, par exemple, dans le silo 83 (11090 av. J.-C.).

\section{Coupe F-III}

Un exemplaire de cette forme provient des fouilles effectuées par F. Riuró sur l'oppidum de Sant Julia de Ramis (Rodà, 1974, 300, fig. 2, 3 ; Burch et al., 2001, fig. 18, 8). Deux fragments sont présents dans les silos 49 (10080 av. J.-C.) et 65 (110-80 av. J.-C.).

\section{Coupe F-IV}

En provenance de l'oppidum de Sant Julia de Ramis, nous en connaissons une pièce entière suite à l'excavation réalisée par Maluquer de Motes en 1964. Malheureusement, elle a disparu. De plus, un autre fragment de la même forme est attesté sur l'oppidum au II ${ }^{\mathrm{e}} \mathrm{s}$. av. J.-C.

\section{Jatte $G-I$}

Cette forme a été trouvée dans le silo 1 des Escalers (220$190 \mathrm{av}$. J.-C.), ce qui représente une date très précoce par rapport aux autres exemplaires connus. Dans la zone 1 de l'oppidum, elle a été découverte dans les niveaux correspondant à l'abandon du site (120-70 av. J.-C.). 


\section{Jatte $G$-II}

Dans le Bosc del Congost, cette forme apparaît dans le silo 58 (180-160 av. J.-C.). Dans ce même silo, il y a également une autre pièce qui ressemble à un croisement entre la jatte G-I et la jatte G-II : le bord est triangulaire, mais le corps est biconique. Dans le silo 19 (170-150 av. J.-C.), on trouve le dernier exemple de jatte G-II. De l'oppidum proviennent quelques exemplaires datant du II ${ }^{\mathrm{e}} \mathrm{s}$. av. J.-C. et, dans les fouilles réalisées dans les années 1990, ils ont été découverts dans les niveaux liés à l'abandon de l'occupation ibérique (120 av. J.-C).

\section{Jatte G-III}

On trouve cette forme dans le Bosc del Congost, en particulier dans le silo 21 (180-160 av. J.-C.) et dans le silo 19 (170-150 av. J.-C.) ; nous pouvons donc la situer chronologiquement dans le second quart du $\mathrm{II}^{\mathrm{e}} \mathrm{s}$. av. J.-C.

\section{Jatte G-IV}

Dans le champ de silos des Escalers (220-190 av. J.-C.), un bord entier a été conservé ; ce bord est contemporain de ceux apparus dans le silo 116 (230-210 av. J.-C.) et dans le silo 3 (220-200 av. J.-C.) du Bosc del Congost. En ce qui concerne le II $\mathrm{e}$ s. av. J.-C., nous avons identifié un seul fragment dans le silo 4 (150-130 av. J.-C.) du Bosc del Congost. Ce bord n'est pas le même que celui que l'on trouve sur les formes G-I et G-II, ce qui fait penser à la possibilité d'une variante tardive qui pourrait être située vers la seconde moitié du $\mathrm{II}^{\mathrm{e}} \mathrm{s}$. av. J.-C.

\section{Cruche $\mathrm{H}$-I}

Avec trois fragments inventoriés, il s'agit d'une forme très rare à Sant Julia de Ramis. La production emporitaine de cette cruche doit être placée entre 150-100 av. J.-C. et 90-70 av. J.-C (Barberà, Nolla, Mata, 1993, 43), ce qui coïncide parfaitement avec la base qui a été découverte parmi les niveaux plus tardifs de l'oppidum et avec un autre exemplaire du silo 2 du Bosc del Congost (120-100 av. J.-C.). En revanche, le petit pot recueilli dans le silo 57 représente un pas de 100 ans en arrière, vu que la date d'oblitération du dépôt peut se situer vers le milieu du III ${ }^{\mathrm{e}}$ s. av. J.-C.

\section{Cruche I}

Le seul exemplaire connu de Sant Julia de Ramis est apparu lors des fouilles du Bosc del Congost. Sa datation est manifestement à situer dans la seconde moitié du II ${ }^{\mathrm{e}}$ s. av. J.-C.

\section{Gobelet J}

Sur l'oppidum, il y a deux exemplaires du $\mathrm{II}^{\mathrm{e}} \mathrm{s}$. av. J.-C. qui ont été découverts dans la construction de la plate-forme du temple, et deux autres qui ont été trouvés dans des niveaux plus tardifs, datés du premier tiers du Irr s. av. J.-C.
Dans le Bosc del Congost, on le trouve dans le silo 3 (220200 av. J.-C.). Son spectre chronologique débuterait en fait lors des dernières années du $\mathrm{III}^{\mathrm{e}} \mathrm{s}$. av. J.-C. et se prolongerait jusqu'à la fin du premier tiers du ${ }^{\text {er }}$ s. av. J.-C.

\section{Skyphos, K-Ia}

Dans le Bosc del Congost, il a été relevé dans le silo 55 (325-275 av. J.-C.), dans le silo 41 (325-275 av. J.-C.) et éventuellement dans le silo 7 (325-275 av. J.-C.). Il s'agit de la version la plus ancienne de cette forme.

\section{Skyphos, $K-I b$}

Au Bosc del Congost, cette forme est très abondante dans le silo 41 (325-275 av. J.-C.) et dans le silo 7 (325-275 av. J.-C.). Au deuxième quart du $\mathrm{III}^{\mathrm{e}} \mathrm{s}$. av. J.-C., une raréfaction rapide commence à se produire, bien que ce type de céramique se trouve encore dans tous les silos de l'époque : dans le silo 6 (275-250 av. J.-C.), dans le silo 57 (275 à 250 av. J.-C.) et dans le silo 88 (260-240 av. J.-C.). Vers le milieu du III ${ }^{e}$ s., la forme semble se raréfier car elle n'est plus attestées que dans les silos 3 et 116 (230-200 av. J.-C.). Dans les silos du II ${ }^{\mathrm{e}}$ s. av. J.-C., elle n'apparaît déjà plus.

\section{Cruche L}

Petits pots arrondis, peu uniformes, attestés par de rares exempleires à Sant Julia de Ramis. Le premier, sans contexte stratigraphique, provient des fouilles réalisées par F. Riuró à l'oppidum pendant les années 30 du siècle dernier. Les trois autres éléments assimilés à cette forme sont issus du silo $84 \mathrm{du}$ Bosc del Congost, avec une chronologie oscillant entre 130 et 110 av. J.-C.

\section{Askos M}

Il s'agit d'un type peu abondant dans le répertoire des céramiques de Sant Julia de Ramis. Dans le Bosc del Congost, elle est attestée dans le silo 41 (325-275 av. J.-C.) et dans les silos 88 (260-240 av. J.-C.) et 3 (220-200 av. J.C). À cette liste, il faut ajouter un askos provenant des champs de silos des Escalers, à savoir le silo 1 qui a été l'objet de fouilles en 1971 ; il daterait de la fin du III' ${ }^{\mathrm{s}}$ s. av. J.-C.

\section{Gobelets V (forme II)}

Jusqu'à présent, seule la forme II a été documentée à Sant Julia de Ramis. Elle a été découverte dans les silos 2, 83 et $84 \mathrm{du}$ Bosc del Congost, couvrant une période allant du dernier quart du $\mathrm{II}^{\mathrm{e}} \mathrm{s}$. av. J.-C. aux deux premières décennies du premier siècle av. J.-C. Ces gobelets ont également été retrouvés dans les niveaux rattachés à l'abandon de l'oppidum (100-70 av. J.-C.). Les exemplaires de Sant Julia de Ramis se rapportent à la phase initiale des imitations locales de la forme II, phase qui commence dans le dernier quart du II ${ }^{\mathrm{e}} \mathrm{s}$. av. J.-C. et se prolonge jusqu'à la période d'Auguste (Lopez, 1989 99-102). 


\section{Conclusion}

Selon ce qui a été observé ici, on peut trouver à Sant Julià un répertoire très large de céramiques fabriquées pour la consommation des produits alimentaires, principalement des pièces qui étaient employées pour contenir des liquides (gobelets, bols, askos, skyphos, cruches, gobelets et coupes). Nous pouvons parler en même temps d'une typologie qui ne change pas beaucoup au fil du temps. Il existe certes des variations, mais elles sont mineures et associées particulièrement aux décorations, ces dernières n'ayant pas été prises en compte dans ce travail. Un autre élément caractéristique, c'est la similitude avec les formes présentes dans d'autres oppida de la zone se trouvant autour d'Emporion ; pourtant, on peut également relever quelques différences, souvent très difficiles à détecter, liées non seulement à la forme, mais aussi à l'aspect global de la pièce. Tout cela indique donc à la fois une culture commune partagée par les personnes qui ont vécu dans cette zone et une personnalité propre dans le cas de certains oppida, situation qui permettrait d'expliquer les différences repérées.

\section{Bibliographie}

Aranegui 1985: ARANEGUI (C.) -Las jarritas grises de tipo ampuritano. In: Ceràmiques gregues i helenístiques a la Península Ibèrica, Barcelona, 1985 165 p. (Monografies Emporitanes, VII), p. 101-113.

Barberà, Nolla, Mata 1993: BARBERÀ (J.), NOLLA (J.M.), MATA (E.) La ceràmica grisa emporitana, Barcelona, 1993, 93 p. (Cuadernos de arqueología, 6).

Burch, Sagrera 2009: BURCH (J.), SAGRERA (J.) - Els sitjars, Girona, 2009, 280 p. (Excavacions Arqueològiques a la muntanya de Sant Julià de Ramis, 3). Burch et al. 2001: BURCH (J.), NOLLA (J.M.), PALAHÍ, (LL.), SAGRERA (J.), SUREDA (M.), VIVÓ (D.) - El sector de l'antiga església parroquial, Girona 2001, 161 p. (Excavacions Arqueològiques a la muntanya de Sant Julià de Ramis, 1).

Castanyer, Sanmartí, Tremoleda 1993: CASTANYER (P.), SANMARTÍ (E.), TREMOLEDA (J.) -Cerámique grise de la côte catalane. In: PY (M.) dir., Dictionaire des céramiques antiques en Méditerranée nord-occidentale (Provence, Languedoc, Ampurdan), Lattes, 1993, 624 p. (Lattara, 6), p. 391-397.

Rodà, 1974: RODÀ (I.) -Ceramicas exóticas y de imitación en el poblado ibérico de Sant Julià de Ramis (Gerona). In: Miscelánea Arqueológica: XXV aniversario de los cursos internacionales de prehistoria y arqueología en Ampurias, vol. II, Barcelona, 1974, 444 p. 297-301.

Rodríguez, 2003: RODRÍGUEZ (A.) - La ceràmica de la Costa Catalana a Ullastret, Ullastret, 2003, $93 \mathrm{p}$.

Puig, 2006: PUIG (A.M.) -Les ceràmiques de vernís negre. In: PUIG (A.M.), MARTÍN (A.), La colonia grega de Rhode, Girona, 2006, 643 p. (Sèrie Monogràfica, 23), p. 303-471. 


\title{
Caractérisation des ateliers céramiques de Rhodè (Roses, Catalogne)
}

\author{
Anna Maria Puig Griessenberger
}

Technicienne archéologue-conservateur de la commune de Roses - Musée de la Citadelle (2008-2011)

\section{Resumen}

El artículo se centrará en los principales rasgos que caracterizan los talleres y los diversos tipos cerámicos que produjeron, y en el marco cronológico que justifica su aparición en la segunda mitad del siglo IV a. de C. y su final en el 195 a. de C. En primer lugar debemos abandonar la clasificación de los talleres de Roses en función de sus formas y/o combinaciones decorativas, pues no existen concordancias evidentes. La producción más conocida de los talleres es la vajilla de barniz negro, que inicia su producción en el último cuarto del siglo IV a. de C., y evoluciona y se estandariza a partir del siglo III. Una de las hipótesis que se plantean en torno a los talleres de Roses es su filiación massaliota. Los talleres empiezan produciendo cerámica de pastas claras ya en la segunda mitad del siglo IV a. de C., antes de la fabricación de barniz negro, elaborando las formas más comunes y de mayor tradición de los talleres de Marsella. Otros productos secundarios de los talleres son las cerámicas de cocina, y una cerámica gris, que entronca con la cerámica gris de la costa catalana.

Palabras clave: Rhode, barniz negro, pastas claras, cerámicas de cocina, cerámica gris, palmetas, rosetas

\section{Résumé}

L'article se concentrera sur les principaux éléments qui caractérisent les divers ateliers et types céramiques produites, et sur les éléments qui permettent de dater son apparition dans la seconde moitié du IVe s. av. J.-C. et sa fin vers 195 av. J.-C. En premier lieu, il faut abandonner la classification des productions de Roses par ateliers en fonction des formes et/ou des combinaisons décoratives, car il n'existe pas de concordances évidentes. La plus célèbre production des ateliers est la vaisselle à vernis noir, dont la production débute dans le dernier quart du $\mathrm{IV}^{\mathrm{e}} \mathrm{s}$. av. n. è. ouïs évolue et se standardise à partir du III $\mathrm{e}$ s. av. n. è. Une des hypothèses proposées sur les ateliers de Roses est leur filiation massaliète. Les ateliers commencent à produire des pâtes céramiques dans la seconde moitié du IV $\mathrm{e}$. av. J.-C., avant la fabrication de vernis noir, en développant les formes les plus courantes et les plus traditionnelles des ateliers de Marseille. D'autres productions secondaires sont issues des ateliers comme des céramique de cuisine et de la poterie grise, qui correspond à la céramique grise de la côte catalane.

Mots-clés : roses, céramiques, vernis noir, pâte claire, céramique de cuisine céramique grise, estampilles 
$\grave{A}$ la suite de l'étude d'Enric Sanmartí sur les ateliers de céramique à vernis noir de Rhodè en 1978 (Sanmartí 1978a ; 1978b), sa proposition de classification, fondée sur les combinaisons des décors présents sur le fond interne des vases, a été largement reprise dans les études postérieures. C'est le cas, bien connu, de l'atelier des patères à trois palmettes radiales, de celui de la forme Lamboglia 55 et de celui des trois palmettes radiales imprimées sur une bande de guillochures, comme aussi des ateliers de NIKIA-I $\Omega$ N.C et des rosettes nominales/pi-alpha-rho. Certains auteurs, comme Jean-Paul Morel, ont été obligés d'insérer les nouveautés dans cette classification et de distinguer les nouveaux ateliers à partir des formes de vases : ainsi les coupelles 24B ou 25B et les bols 27GL (Morel 1981, p. 51). Par la suite, Miquel Cura et Jordi Principal ont encore ajouté le groupe des trois palmettes radiales à rosette centrale ou 3+1 (Cura, Principal-Ponce 1995 ; Principal-Ponce 1998, p. 111-114).

À partir de ma récente thèse de doctorat sur les productions des ateliers céramiques de Roses (Puig 2006), qui prend en compte la totalité du mobilier découvert sur le site depuis le début des campagnes de fouille, il m'a semblé opportun d'abandonner cette classification confuse par ateliers à partir des décors. D'autant plus qu'on a pu constater une augmentation considérable de leur nombre, avec un total de 11 variantes à palmettes, 5 à rosettes, ainsi que d'autres décors à rosettes et palmettes mêlées ou encore des combinaisons de motifs singuliers en forme de c'ur ou de feuille. En outre, il s'est avéré qu'il n'y a pas une concordance évidente entre décors et formes.

En réalité, il est très difficile d'avancer un nombre précis d'ateliers sans posséder des données archéologiques concluantes. Or, si deux fours de potier ont été découverts dans le quartier dit hellénistique de Roses, on n'a pas conservé de structures permettant de définir des espaces de production différenciés. Pourtant, il y a probablement eu plus d'une officina fonctionnant ensemble dans l'espace et dans le temps, d'autant plus que ces ateliers semblent répondre à une organisation précise du travail, capable d'assurer la cohésion et la supervision des diverses phases de la production. En effet, sans une organisation structurée, il aurait été difficile de garantir la diffusion et la commercialisation de ces productions tout au long du III' s. av. J.-C. C'est pourquoi nous faisons l'hypothèse d'un travail en association, partageant les divers processus de la production.

Malheureusement, l'étude de cette dynamique reste limitée à partir uniquement de l'analyse du mobilier issu du site même de Roses. En tant que centre producteur, les découvertes concernent essentiellement les rebuts de cuisson et les céramiques utilisées par la population locale, ce qui ne reflète pas la réalité commerciale des ateliers. Il est donc nécessaire de compléter la recherche avec l'étude des aires de diffusion, question qui n'a guère avancé ces dernières années : la distribution des céramiques des ateliers de Roses s'étend de part et d'autre des Pyrénées, grosso modo depuis les côtes du Levant jusqu'au Languedoc occidental.

\section{Dans quel contexte les ateliers de Roses apparaissent-ils ?}

E. Sanmartí a défini les céramiques des ateliers de Roses comme des productions protocampaniennes, perpétuant une production précédente du $\mathrm{IV}^{\mathrm{e}} \mathrm{s}$. av. J.-C. Il propose une sorte de "génération spontanée », qu'il date entre 300 et 225 av. J.-C., c'est-à-dire entre la disparition des céramiques attiques à vernis noir et précampaniennes et l'apparition des premières céramiques Campanienne A (Sanmartí 1978a, p. 20 et 576). J.-P. Morel, en revanche, considère l'atelier de Roses comme une production qui remplit le vide existant entre les Petites Estampilles et la Campanienne A (Morel 1998, p. 249). Jordi Principal, quant à lui, pense que ces ateliers surgissent en réponse à une demande précise, liée à la fin du commerce des céramiques à vernis noir attiques (Principal-Ponce 1998, p. 119 et 157). Enfin, A. Adroher, à partir des traits helléniques de la production, envisage la possibilité que les potiers de Roses soient grecs et que la technique soit importée (Adroher 1990, p. 84).

À la lumière de mes recherches, d'autres facteurs doivent être pris en compte. Si les hypothèses émises restent, en général, valables, il faut néanmoins les nuancer. Les céramiques à vernis noir des ateliers de Roses prennent certainement la suite d'une production plus ancienne : on sait qu'elles existaient déjà dans le dernier quart du $\mathrm{IV}^{\mathrm{e}} \mathrm{s}$. av. J.-C. Il est certain aussi qu'elles remplissent le vide entre la fin des exportations des céramiques attiques et des Petites Estampilles et le début des Campanienne A archaïque, mais pas de façon stricte. On a démontré à plusieurs reprises la coexistence des productions de Roses avec celles des Petites Estampilles et celles attiques et, à l'autre extrémité de la fourchette chronologique, avec les céramiques campaniennes ; la période de temps où les ateliers de Roses resteraient seuls est en réalité très courte.

Les traits helléniques soulignés par A. Adroher sont certains et nous en avons observé même de nouveaux, en particulier lors de la phase initiale de la production. Mais il est évident que les ateliers poursuivent la tradition décorative du dernier quart du IV ${ }^{\mathrm{e}} \mathrm{s}$. av. J.-C., comme c'est le cas également des céramiques pseudo-attiques massaliètes et des Petites Estampilles. En somme, les ateliers de Roses adoptent les motifs décoratifs et les formes des 
céramiques contemporaines à fort succès commercial, le but étant d'accéder au marché, en tenant compte des goûts et des habitudes des consommateurs. La tendance hellénisante n'est pas aussi forte, si l'on retient l'absence à Roses d'estampilles en creux, caractéristiques des céramiques à vernis noir attiques et pseudo-attiques. Les estampilles sont ici en relief, comme c'est aussi le cas dès les premières productions des Petites Estampilles, dans le dernier quart du $\mathrm{IV}^{\mathrm{e}} \mathrm{s}$. Nous avons même pu noter que certains vases adoptent le style décoratif de ces productions italiques et présentent des palmettes et des rosettes en groupes de 2 ou de 4 sur le fond interne.

\section{La production à vernis noir}

La connaissance de cette production s'est considérablement enrichie, aussi bien en ce qui concerne le répertoire des formes que du décor (fig. 1 à 4). Les formes majoritaires sont les coupes ROSES 12 et 11 et les plats à poisson ROSES 80 , avec des pourcentages respectivement de l'ordre de 20,57\%, 13,18\% et $11,72 \%$. Les formes qui suivent en importance, avec des pourcentages entre 7,72 \% et 4,50\%, sont le cratérisque ROSES 40, la coupe ROSES 14, la coupelle ROSES 1 et le skyphos ROSES 35. En dernière position, un troisième groupe présente des pourcentages plus réduits, entre $3,87 \%$ et $2,26 \%$ : la coupe ROSES 10 et 10A, le kylix ROSES 30, le plat ROSES 81 et la coupe ROSES 13. Ces services de table sont, non seulement les plus largement produits, mais aussi les plus utilisés dans le site même.

À part ces services de table, les ateliers ont également produit un certain nombre de vases dans des proportions très faibles. On peut citer, comme mobilier domestique, les lekythoi ROSES 60, 63 et 64, l'unguentarium ROSES 101, l'encrier ROSES 103 et la lampe ROSES 102 ; comme ustensiles pour préparer et pour servir les aliments, ou encore pour les contenir, le mortier ROSES 100, les lékanai avec couvercle ROSES 90, 70, 71, 91, 92 et 93, l'urne / olla ROSES 73, la cruche ROSES 57, la péliké ROSES 45 et l'amphore ROSES 44 ; enfin, comme vaisselle de table, les coupes ROSES 15, 16, 17 et 18, les kylix ROSES 31, 32, 33 et 34, les coupelles ROSES 2, les plats ROSES 82, 83, 84, 85, 86 et 87, les askoi et les gutti ROSES 65, 66 et 67, l'olpè ROSES 59, ainsi que la pyxis ROSES 104 ou les possibles dessous-de-plat de la forme ROSES 105.

Pour créer ce répertoire, les ateliers de Roses semblent s'être inspiré de produits déjà existants, pour l'essentiel des céramiques attiques à vernis noir. C'est le cas de formes très largement fabriquées, comme les vases ROSES 12.c, 14.a, 34, 35, 40.e et 80.g, ou encore d'autres de faible diffusion, comme par exemple la coupe ROSES 17, la kylix ROSES 32, la pélikè ROSES 45, les askoi ou gutti ROSES 64 et 65, le plat / patère ROSES 82, la lékanis ROSES 91, les lampes ROSES 102, l'encrier ROSES 103, la pyxis ROSES 104 ou le psykter possible ROSES 106. Quant à la chronologie, la production de ces vases céramiques se situe dans la phase initiale de fonctionnement des ateliers, car une grande partie des formes attiques prises comme référence cessent d'arriver vers la fin du $\mathrm{IV}^{\mathrm{e}} \mathrm{s}$., certaines dans le premier quart du III $\mathrm{e}$.

Pourtant, la source d'inspiration la plus importante provient probablement des productions massaliètes, à vernis noir ou à pâte claire. C'est le cas des formes ROSES 1.a, 1.b et 1.c, 12, 13, 14, 34, 35, 60, 70, 80.g, 81 et 83, certaines sans doute d'inspiration attique. Cependant, d'autres formes se retrouvent uniquement dans le répertoire des céramiques à pâte claire massaliètes, ainsi la coupelle ROSES 2, la coupe ROSES 16A, l'amphore ROSES 44, l'urne / olla ROSES 73, la variante de plat à poisson ROSES 80, le couvercle de lékanis ROSES 90 et les mortiers ROSES 100. Quant à la coupe ROSES 11, avec ses variantes $\mathrm{a}$, b et c, elle a été interprétée comme une imitation directe des bols à Petites Estampilles Lamb. 27 (PET-EST 2783), mais cette forme est aussi largement présente dans les productions massaliètes, soit à pâte claire, soit à vernis noir (CL-MAS 236 et PSEUDO-AT 2783 respectivement). Cette série de coïncidences, qui postule en faveur d'une filiation massaliète des productions des ateliers de Roses, suggère que les productions à vernis noir ont surgi pour combler le marché d'une production éteinte apparemment vers 300 av. J.-C. (Py, Adroher, Sanchez 2001, p. 1.176).

Malgré cette tendance, les ateliers de Roses ont aussi innové et fabriqué des productions propres, qui n'ont pas de parallèles dans les autres types céramiques contemporains. Il s'agit des coupes ROSES 10' et 15, du kylix ROSES 30 et 31, des cruches ROSES 57 et 59, du lécythe ROSES 63, du guttus ROSES 67, de la possible lékanis ROSES 71, des plats ROSES 84, 85, 86 et 87, des plats / couvercles ROSES 92 et 93, et des dessous de plat ROSES 105. Ces formes céramiques ont une représentation minoritaire ainsi qu'une diffusion restreinte, à l'exception des coupes ROSES 10A et 30.a. D'un point de vue chronologique, elles se situent dans la période la plus dynamique des ateliers, en plein $\mathrm{III}^{\mathrm{e}} \mathrm{s}$. av. J.-C., sauf pour le plat ROSES 85 , produit lors de la dernière phase de fonctionnement.

Le cas de la variante de kylix ROSES 30.a mérite une attention particulière, car si elle apparaît dans les niveaux datés à la charnière des $\mathrm{IV}^{\mathrm{e}}$ et $\mathrm{III}^{\mathrm{e}} \mathrm{s}$., elle est néanmoins particulièrement abondante à la fin $\mathrm{du}_{\mathrm{III}}{ }^{\mathrm{e}} \mathrm{s}$. 


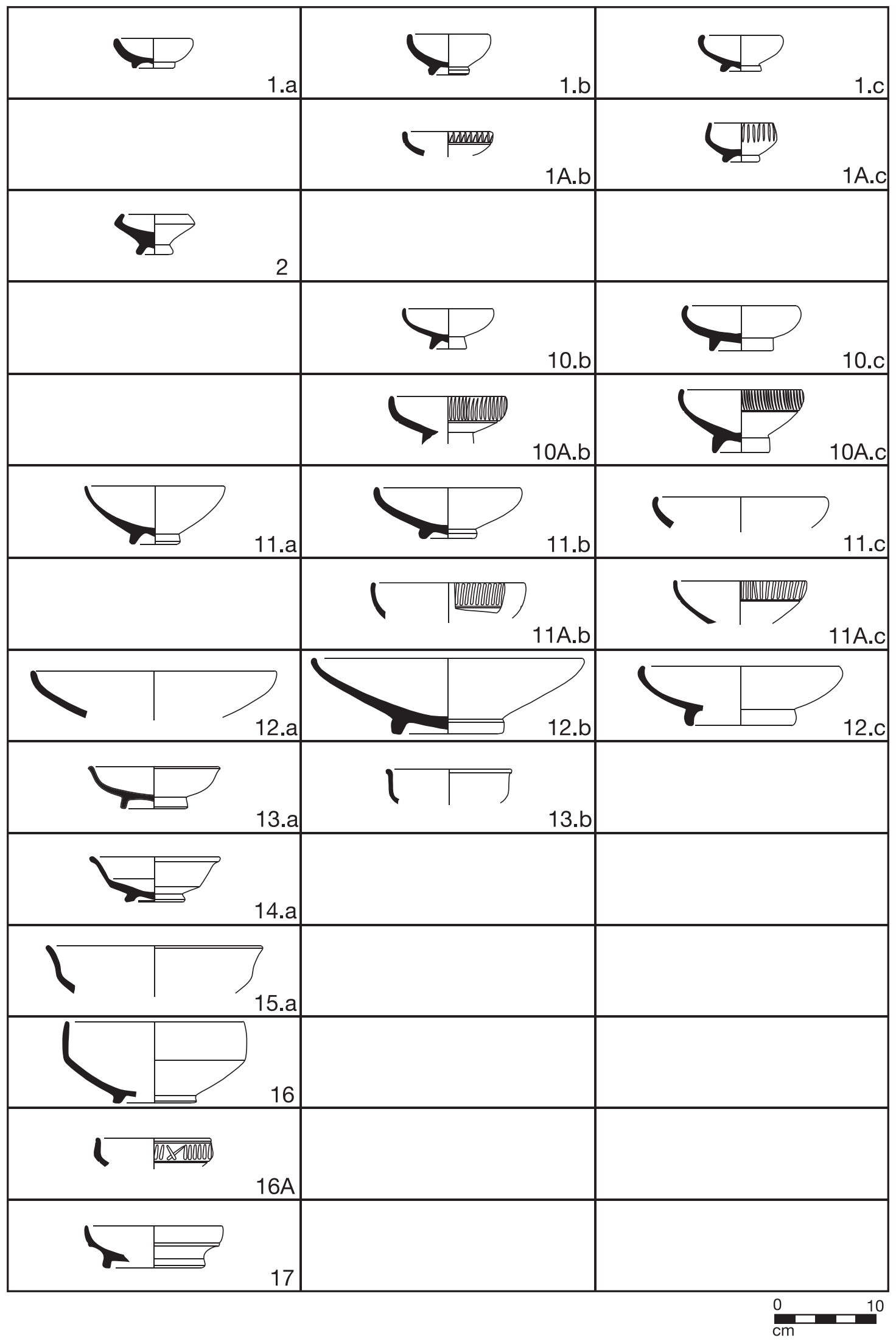

Fig. 1. Table des formes des ateliers de Rhode en vernis noir, pâte claire, céramiques de cuisine et grises (A.M. Puig). 


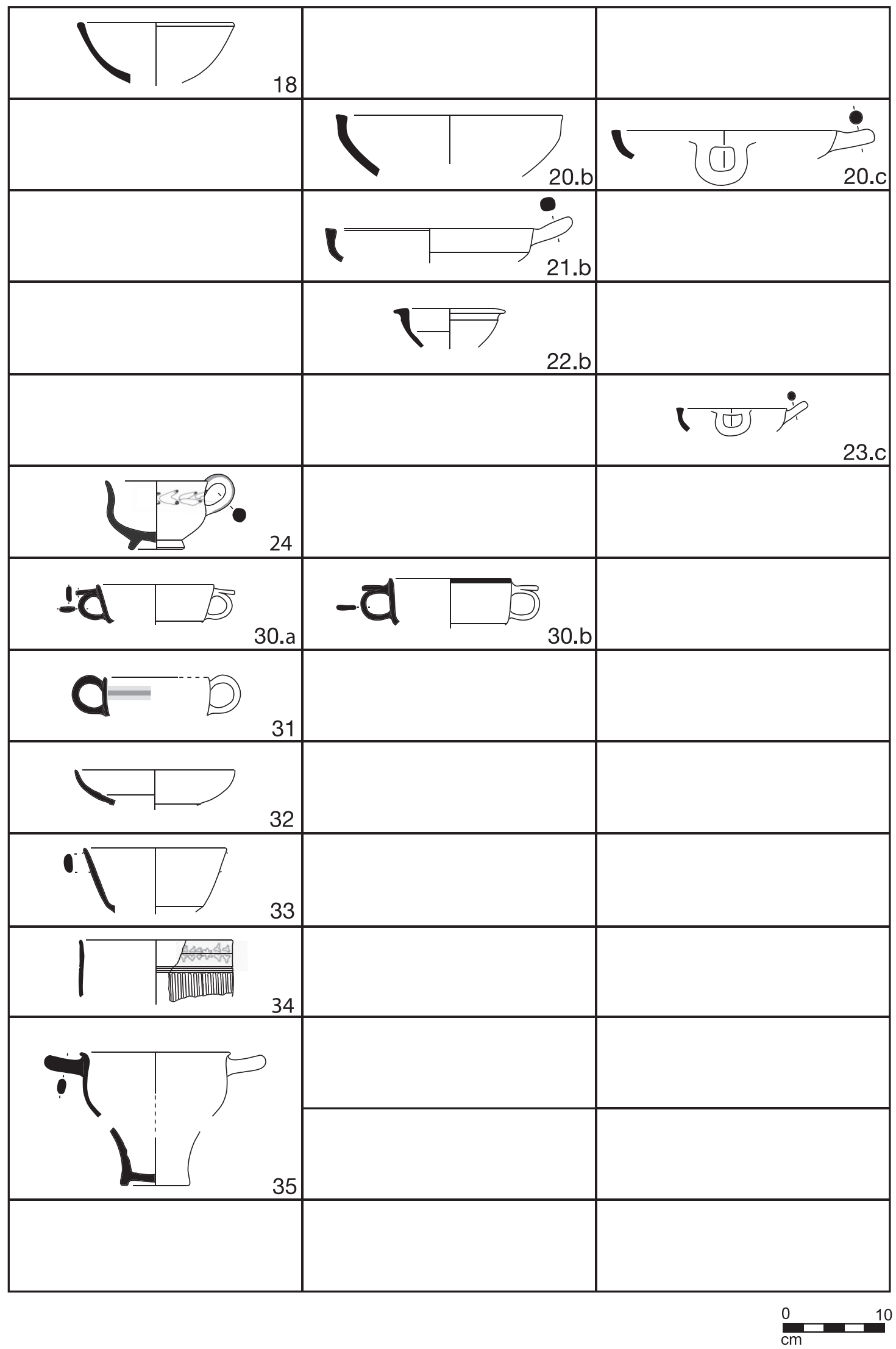

Fig. 2. Table des formes des ateliers de Rhode en vernis noir, pâte claire, céramiques de cuisine et grises (A.M. Puig). 


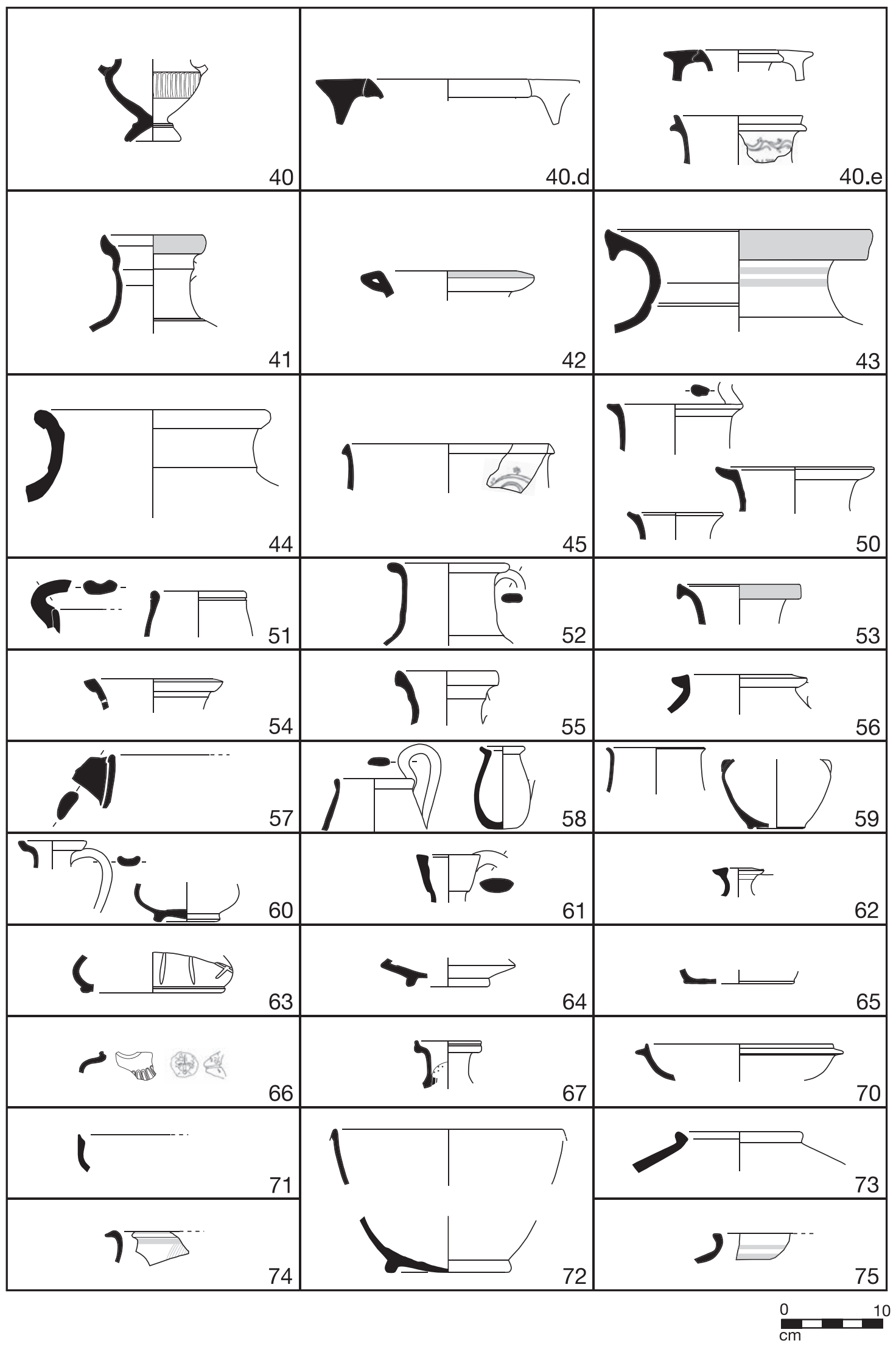

Fig. 3. Table des formes des ateliers de Rhode en vernis noir, pâte claire, céramiques de cuisine et grises (A.M. Puig). 


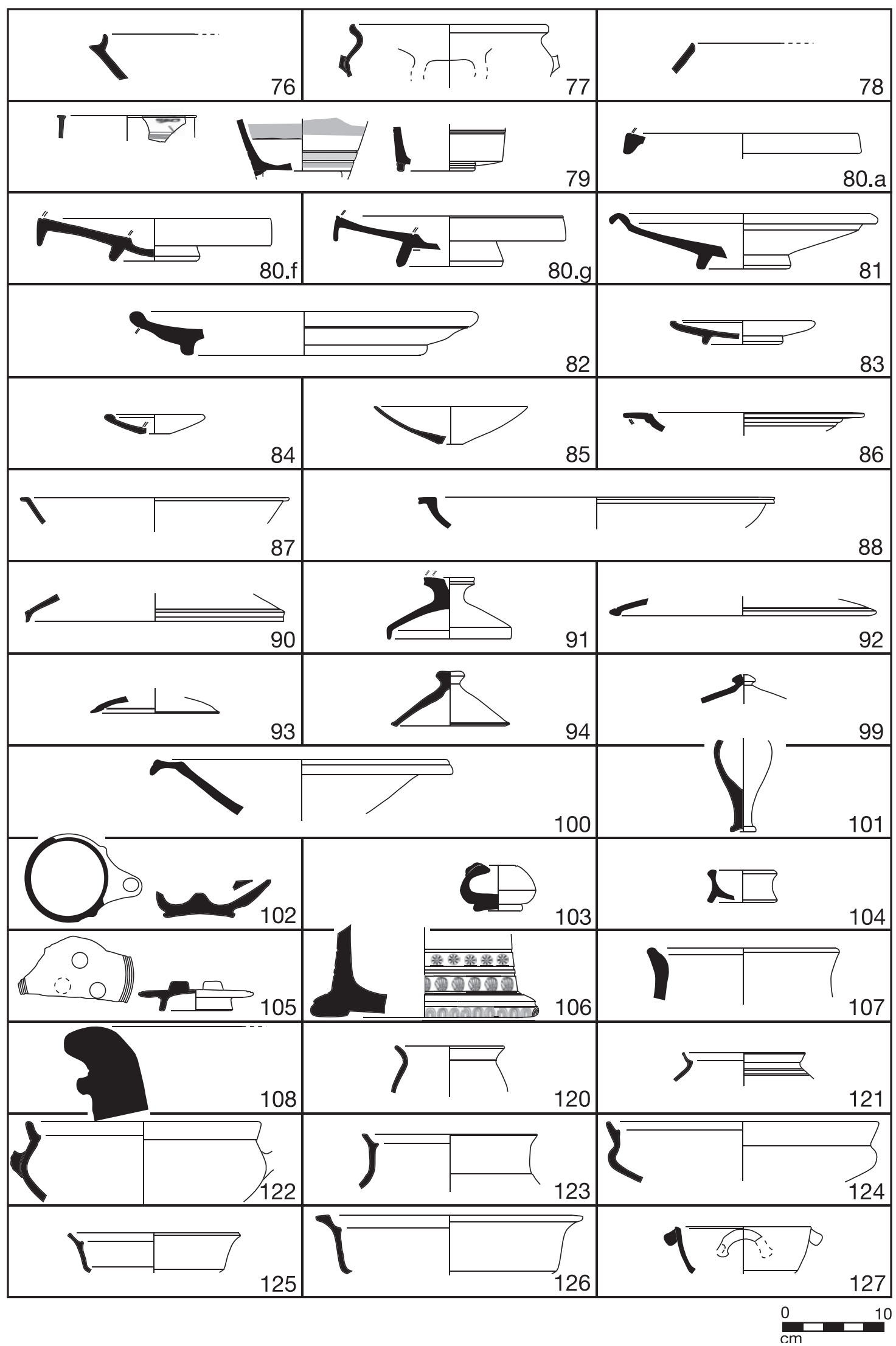

Fig. 4. Table des formes des ateliers de Rhode en vernis noir, pâte claire, céramiques de cuisine et grises (A.M. Puig). 
La coupe ROSES 30 sera la source d'inspiration du type CAMP-A 49B, dont la production débute dans le dernier quart du III $\mathrm{s}$. La forme ROSES 33 pourrait également avoir inspiré la céramique campanienne, en particulier le type CAMP-A 42Bc, avec le bord bd3, qui commence à être produit vers le milieu du $\mathrm{III}^{\mathrm{e}} \mathrm{s}$. Pourtant, il n'est pas possible d'affirmer que cette forme ROSES 33 soit de production aussi ancienne que celle de la ROSES 30 ; par ailleurs, sa diffusion n'est pas similaire, car elle est plus réduite et plus tardive ${ }^{1}$.

Il est évident que la production des céramiques à vernis noir de Roses évolue avec le temps et qu'elle s'adapte aux besoins et aux modes du moment. C'est pourquoi dans les contextes plus tardifs, à partir du dernier quart du III ${ }^{\mathrm{e}} \mathrm{s}$., on trouve des formes qui existent aussi en Campanienne $\mathrm{A}^{2}$, comme le type ROSES 16A.b, avec des parallèles dans la forme CAMP-A 27c, fabriquée dès le dernier quart du $\mathrm{III}^{\mathrm{e}} \mathrm{s}$., ou la coupe ROSES 18, correspondant au type CAMP-A 33b, produit au même moment ; ou encore le guttus ROSES 66, similaire au type CAMP-A 45, fabriqué dès 200 av. J.-C. À propos de cette dernière forme de vase, le type de Roses est sans doute antérieur, étant donnée sa présence dans des niveaux de la seconde moitié du III' $\mathrm{s}$.

\section{Les éléments décoratifs sur le fond interne}

Un grand nombre de vases à vernis noir, comme il a été dit, présente un décor sur le fond interne. Le décor le plus fréquent est celui des rosettes, avec un pourcentage de 55,25\%, tandis que les palmettes représentent $42,03 \%$; les autres décors correspondent à des rosettes combinées avec des palmettes $(1,02 \%)$ et à des motifs divers $(1,69 \%)$. Bien que les rosettes soient plus nombreuses, ce sont les palmettes qui présentent un éventail plus large de combinaisons décoratives.

Dans la ligne de la recherche développée par Enric Sanmartí, on a tenté de vérifier s'il existait un rapport entre les motifs, les diverses combinaisons de décor et les formes céramiques, dans le but de distinguer les traits spécifiques des ateliers. Aussi bien pour les rosettes que pour les palmettes, on a pu noter que certains motifs / poinçons sont propres à des formes céramiques précises, s'associant même parfois dans des combinaisons décoratives particulières. Ce cas de figure est clair dans les formes ROSES 12, 14.a et 11 .

1 Ce détail pourrait remettre en question la filiation de la forme CAMP-A 42 Bc, et même inverser l'hypothèse.

2 Le pourcentage de formes produites également en Campanienne A est de $5,36 \%$, tandis que celles d'inspiration attique représentent $23,21 \%$ et celles d'inspiration massaliote $26,79 \%$.
La combinaison de palmettes (fig. 5 à 8) la plus fréquente est celle par groupes radiaux, de trois $(=3 \mathrm{PR})$ ou de quatre palmettes $(=4 \mathrm{PR})$ '. Le premier groupe, le plus nombreux $(68,38 \%)$, concerne les formes ROSES 12 et 14.a, tandis que le second, moins abondant, est présent sur les formes ROSES 11 et 12. Sans prétendre décrire en détail ici les motifs / poinçons qui se répètent dans chacune des dispositions, il faut néanmoins noter que le groupe NIKIA-ISN.C concerne uniquement le groupe 4PR. Quant à la combinaison intégrant des cercles de stries à la roulette, on constate que, dans les deux variantes (3PR, 4PR), les motifs sont disposés, indistinctement, sur le cercle ou à l'intérieur du cercle. Ce décor à la roulette est plus fréquent sur les fonds présentant des palmettes que des rosettes : 68,80\% contre $19,20 \%$ (la partie restante correspondant à des fragments indéterminés ou divers) ; il n'apparaît pas sur les vases de petite taille, dont les bases ont entre 34 et $76 \mathrm{~mm}$ de diamètre, comme c'est le cas des types ROSES 10.c, 10A.c, $11,13 . a, 14$.a et $83^{3}$.

Les rosettes se retrouvent dans les décors les plus simples, avec un faible nombre de variantes décoratives (fig. 9 à 12). Elles sont caractéristiques des formes ROSES 10.c, 10A, 11, 12, 13.a et 14.a. La forme ROSES 12 concentre les rosettes de grande taille, tandis que celles plus petites se rencontrent en particulier dans les formes ROSES 11 et 14.a. La plupart des rosettes ne sont pas associées à des cercles à la roulette.

En ce qui concerne les motifs divers (fig. 13), en forme de cœur ou de feuille (avec ou sans nervures), ils sont également disposés de façon radiale. Pour le moment, ces décors sont uniquement attestés sur la forme ROSES 12, en particulier dans les productions les plus anciennes, datées à la charnière des $\mathrm{IV}^{\mathrm{e}}$ et $\mathrm{III}^{\mathrm{e}} \mathrm{s}$. La rareté d'individus présentant ce décor suggère qu'il peut s'agir des premières tentatives de la production de Roses, abandonnées plus tard lors de la standardisation des ateliers.

Si l'on veut tirer des conclusions typologiques et chronologiques à partir des combinaisons décoratives, on peut seulement noter que, dans les phases les plus anciennes, une production moins standardisée offre des décors singuliers, comme si les ateliers de Roses manifestaient une phase d'innovation ou d'essai. À la charnière des $\mathrm{IV}^{\mathrm{e}}$ et $\mathrm{III}^{\mathrm{e}} \mathrm{s}$., au début de la production des céramiques à vernis noir, on trouve autant de pièces décorées avec des rosettes qu'avec des palmettes ; s'il n'y a pas des combinaisons décoratives particulières, on constate l'usage dans les deux cas de motifs peu communs. Pendant cette phase, la combinaison décorative

3 Un cas exceptionnel est représenté par un vase ROSES 12, doté d'une base de $90 \mathrm{~mm}$ de diamètre. 
par excellence est celle de palmettes radiales sur stries à la roulette, qui apparaît rarement dans les étapes postérieures. Tout le long du $\mathrm{III}^{\mathrm{e}} \mathrm{s}$., avec la standardisation de la production, on constate l'usage massif du décor des $3 \mathrm{PR}$, imprimées à l'intérieur du cercle à la roulette et disposées au non autour d'un cercle central incisé, ainsi que du décor à rosette centrale (= RCENT), avec ou sans cercle à la roulette. Il y a aussi à cette époque des exemplaires rares, présentant des compositions décoratives singulières, normalement sans cercle tracé à la roulette : des groupes de 2 ou de 4 RCENT - toujours sur la forme ROSES 11, en imitation des fonds du type des Petites Estampilles); dans plusieurs cas, trois rosettes radiales entre des cercles incisés ; une rosette centrale entourée de 3PR ; ou encore 3PR groupées au centre sur la forme ROSES 14.a. Enfin, il faut noter que les exemplaires les plus singuliers, qu'ils soient décorés avec des palmettes ou des rosettes, ont été récupérés dans les niveaux superficiels ou ceux de la période tardo-romaine, comme éléments résiduels, ce qui suggère que la phase finale des ateliers a pu connaître une régression dans le sens d'un retour à une faible standardisation.

Enfin, à propos du décor à la roulette, il faut mentionner qu'il est présent sur 68,10\% des vases à vernis noir analysés. Il est utilisé dès le début de la production et il caractérise toute la durée de fonctionnement des ateliers. Nous avons constaté une grande diversité dans la denture de la roulette et dans la largeur des bandes de stries, entre 4 et $35 \mathrm{~mm}^{4}$, ainsi que dans le nombre de lignes. On ne peut pas dire qu'il existe un type dominant ou caractéristique qui puisse définir les ateliers de Roses, pas plus qu'un modèle décoratif en relation avec certaines formes céramiques ou certaines combinaisons de palmettes et de rosettes, mais plutôt une situation totalement aléatoire.

Dans la phase tardive, il faut situer la nette prédominance des décors composés de rosettes, soit seules, soit complétées avec des cercles à la roulette, au détriment du décor à palmettes. Il semble que cette composition décorative réponde à une mode, qui se généralise à partir de la seconde moitié du III ${ }^{\mathrm{e}}$ s., suivie et appliquée par les ateliers de Roses, sans cercle à la roulette, de préférence sur les formes de petite taille, ainsi par exemple la coupe ROSES 11, et, avec cercle à la roulette, sur les types de grand format, comme ROSES 12 ou plus petits comme ROSES 10.c et 14.a. Cela ne veut pas dire que cette combinaison décorative est tardive, mais qu'elle devient majoritaire et se renforce lors de la dernière phase de

$4 \quad$ Les bandes étroites, entre 4 et $7 \mathrm{~mm}$, se trouvent sur des formes diverses, comme les types ROSES 10.c, 11, 12.b, 13.a et 14.a. Le groupe entre 8 et $14 \mathrm{~mm}$ caractérise uniquement les types ROSES 12 et 14.a. Enfin, les plus larges, à partir de $15 \mathrm{~mm}$ et jusqu'à $35 \mathrm{~mm}$, sont exclusives du type ROSES 12. production des ateliers. Si l'on observe ensemble les ateliers de Roses et la Campanienne A, on se rend compte qu'à partir de la fin du $\mathrm{III}^{\mathrm{e}} \mathrm{s}$. et surtout au $\mathrm{II}^{\mathrm{e}} \mathrm{s}$., le style décoratif imposé par les céramiques attiques à vernis noir - suivi par les pseudo-attiques et, en partie, par les Petites Estampilles et Roses à ses débuts - s'est perdu et a évolué vers des dispositions plus simples avec des motifs moins soignés et de plus grand format. Il est intéressant de noter, dans cette phase tardive, comme Roses utilise des dessins de rosettes et de palmettes proches de ou communs à ceux de la céramique Campanienne $\mathrm{A}$.

\section{Les décors surpeints et gravés}

Enric Sanmartí avait déjà noté que certaines formes, en particulier le cratérisque ROSES 40, étaient décorées avec une frise surpeinte à motifs en général végétaux en combinaison avec des lignes gravées linéaires ou ondulées. Plus tard, Jordi Principal (Principal-Ponce 1998, p. 84-85) a distingué deux types décoratifs : le type CR1, formé de feuilles de lierre ou d'épis disposés de part et d'autre d'une ligne horizontale incisée ; le type CR2, formé de feuilles de lierre ou de feuilles trilobées qui alternent avec des groupes à trois points disposés de chaque côté d'une ligne horizontale ou ondulée incisée. Le même auteur fait également référence à la bande de couleur lie-de-vin présente sous le bord interne du bol de la forme Lamb 31 ab (Principal-Ponce 1998, p. 88).

Les motifs surpeints sont rares à Roses, présents uniquement sur 2,29\% du total des vases. À coup sûr, la forme caractéristique de ce type de décor est le cratérisque ROSES 40, mais il apparaît également sur la coupe / kylix ROSES 34, le skyphos ROSES 35 (Lamb. 43C), la péliké ROSES 45, le plat ROSES 86 et le couvercle de lékanis ROSES 91. E. Sanmartí cite aussi un exemplaire rare de la coupe ROSES 12, découvert dans la nécropole de Cabrera de Mar, à Mataró (Barberà 1968, p. 108 ; Sanmartí 1978b, p. 28). La presque totalité des vases surpeints utilisent la peinture blanche, mais étant donné la disparition importante des couleurs, on ne peut exclure les restes de couleur terreuse-orangée.

Nous avons défini trois grands groupes décoratifs. Le type I, le plus simple, combine une ligne horizontale incisée avec des feuilles surpeintes, soit lancéolées (alternées parfois avec un point), soit de lierre, soit en forme de c'ur. Le type II, plus complexe et plus élaboré, combine une ligne ondulée incisée avec des fleurs et des feuilles surpeintes, dans certains cas avec les tiges correspondantes incisées, et associées avec des groupes de fleurs à trois points ; les fleurs peuvent être à quatre pétales et les feuilles en forme de cœur, de nœud ou de lierre. Le type III combine des bandes géométriques complexes incisées et des motifs simples surpeints. 


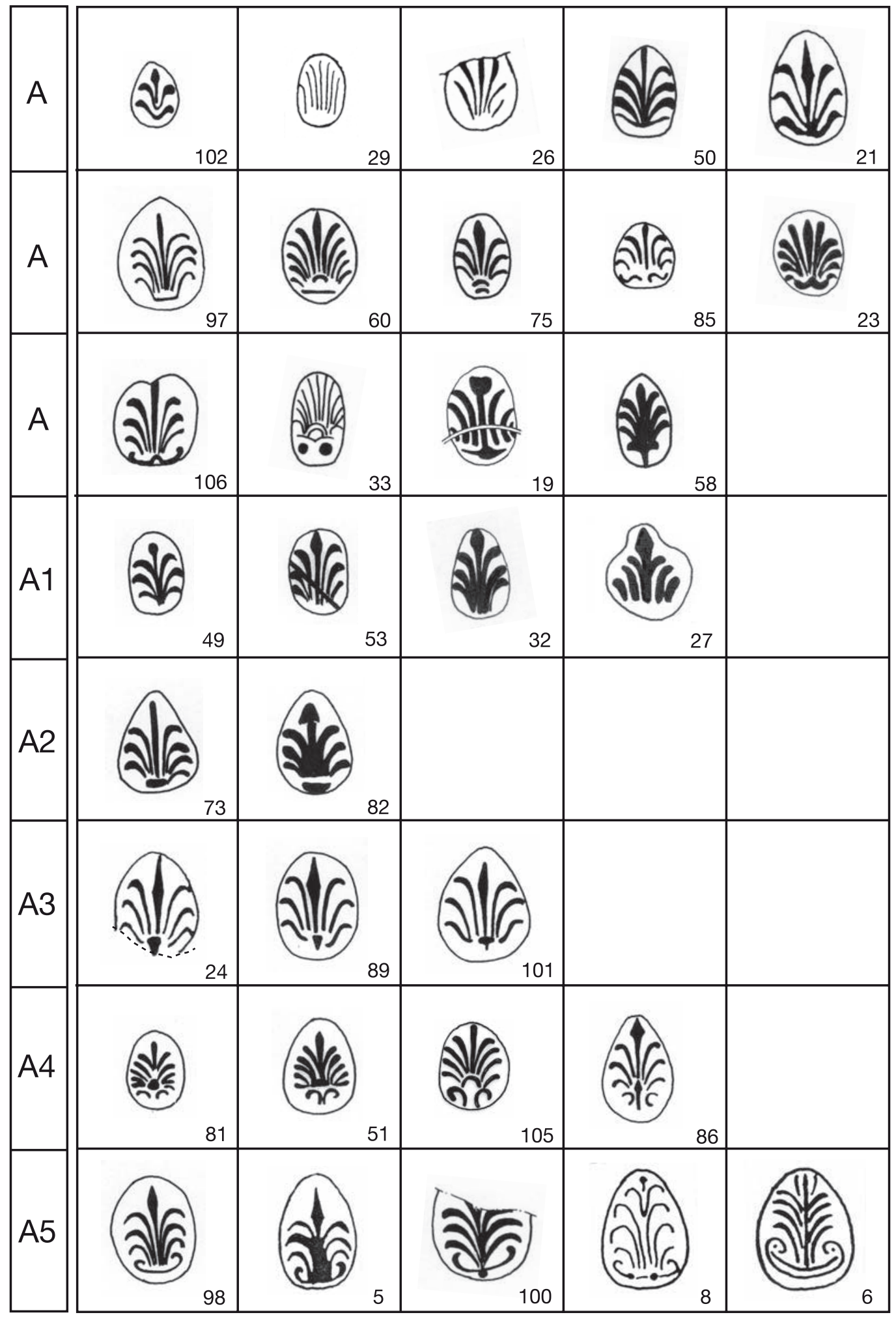

Fig. 5. Décors des palmettes parmi les formes céramiques à vernis noir (échelle 1:1) (A.M. Puig). 


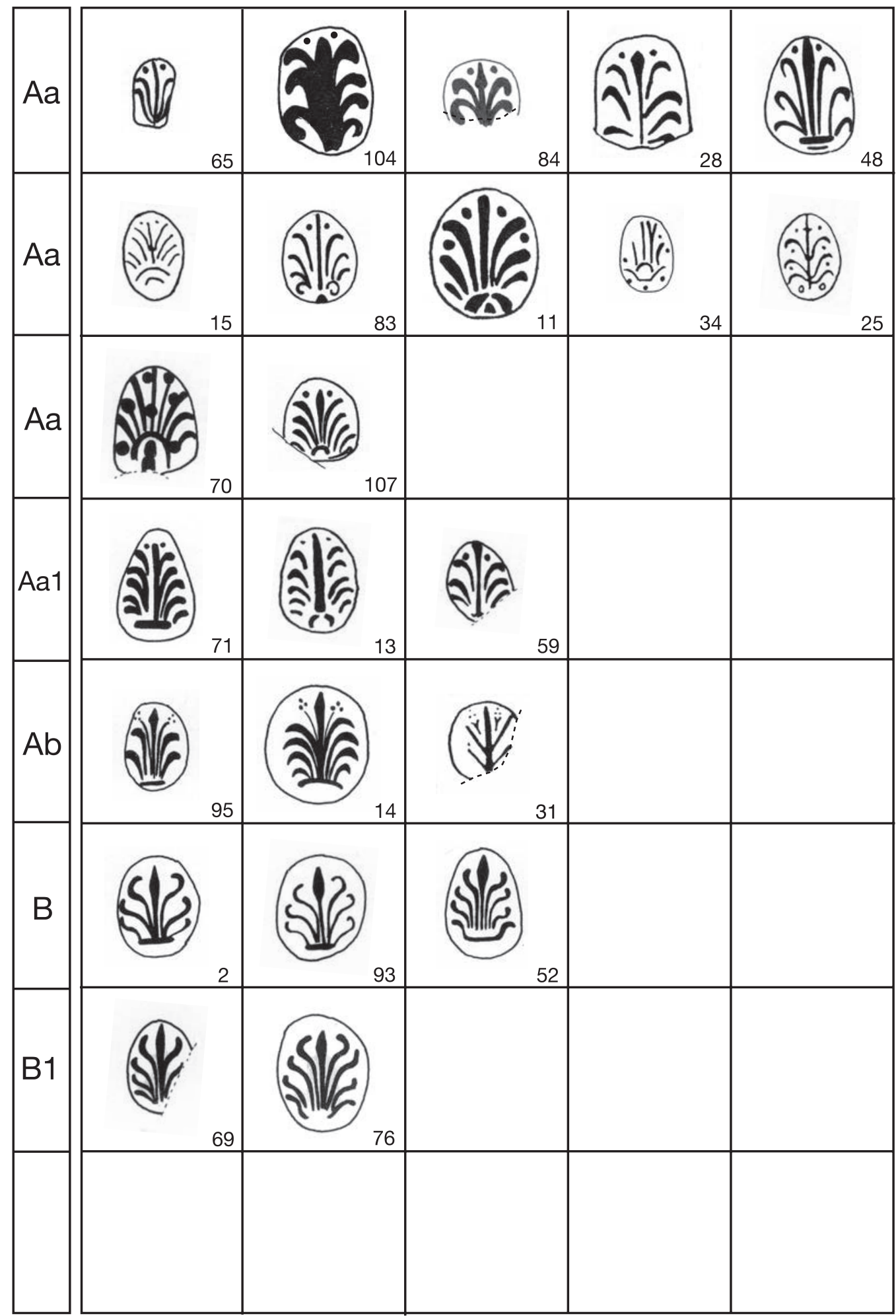

Fig. 6. Décors des palmettes parmi les formes céramiques à vernis noir (échelle 1:1) ( (A.M. Puig). 


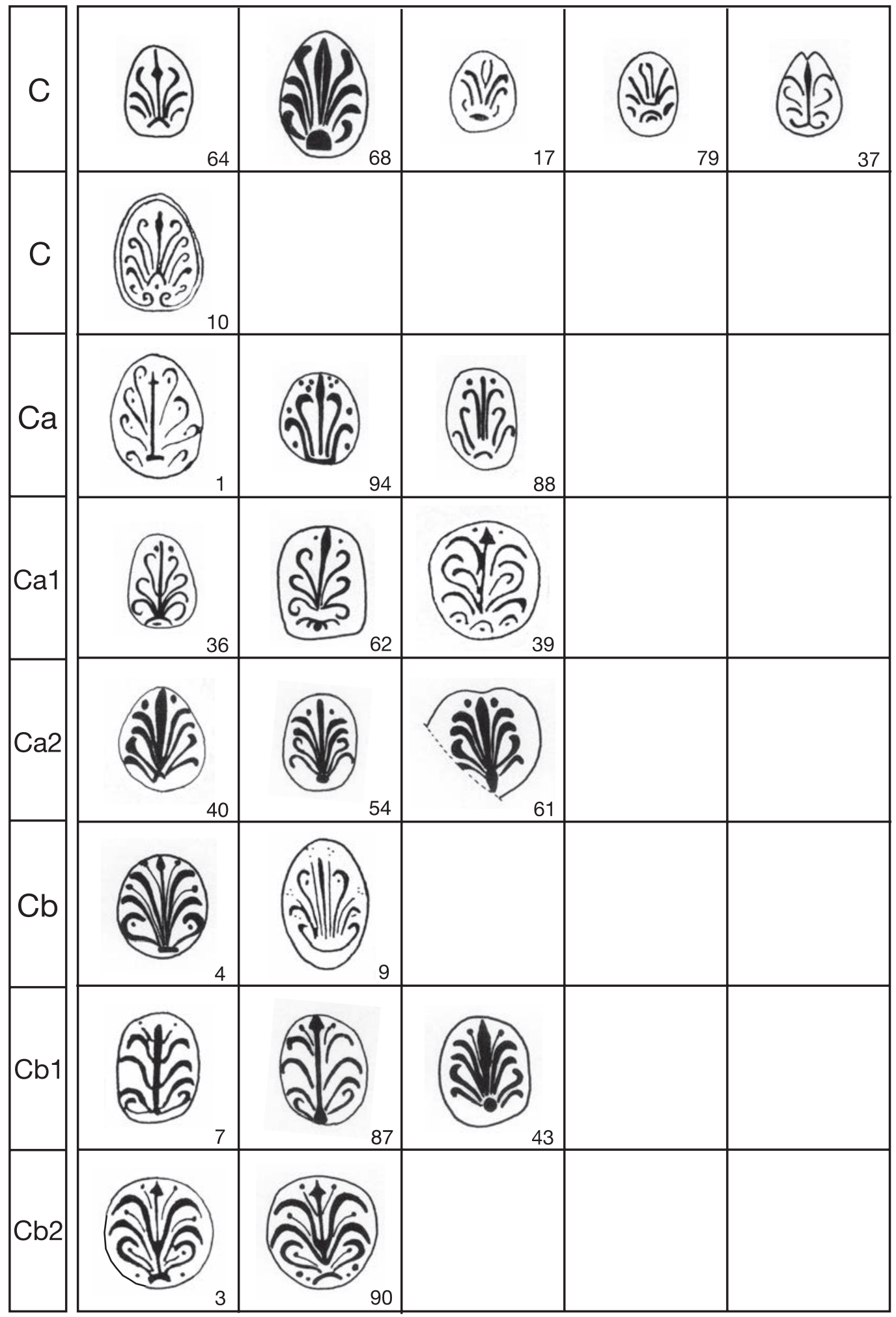

Fig. 7. Décors des palmettes parmi les formes céramiques à vernis noir (échelle 1:1) (A.M. Puig). 


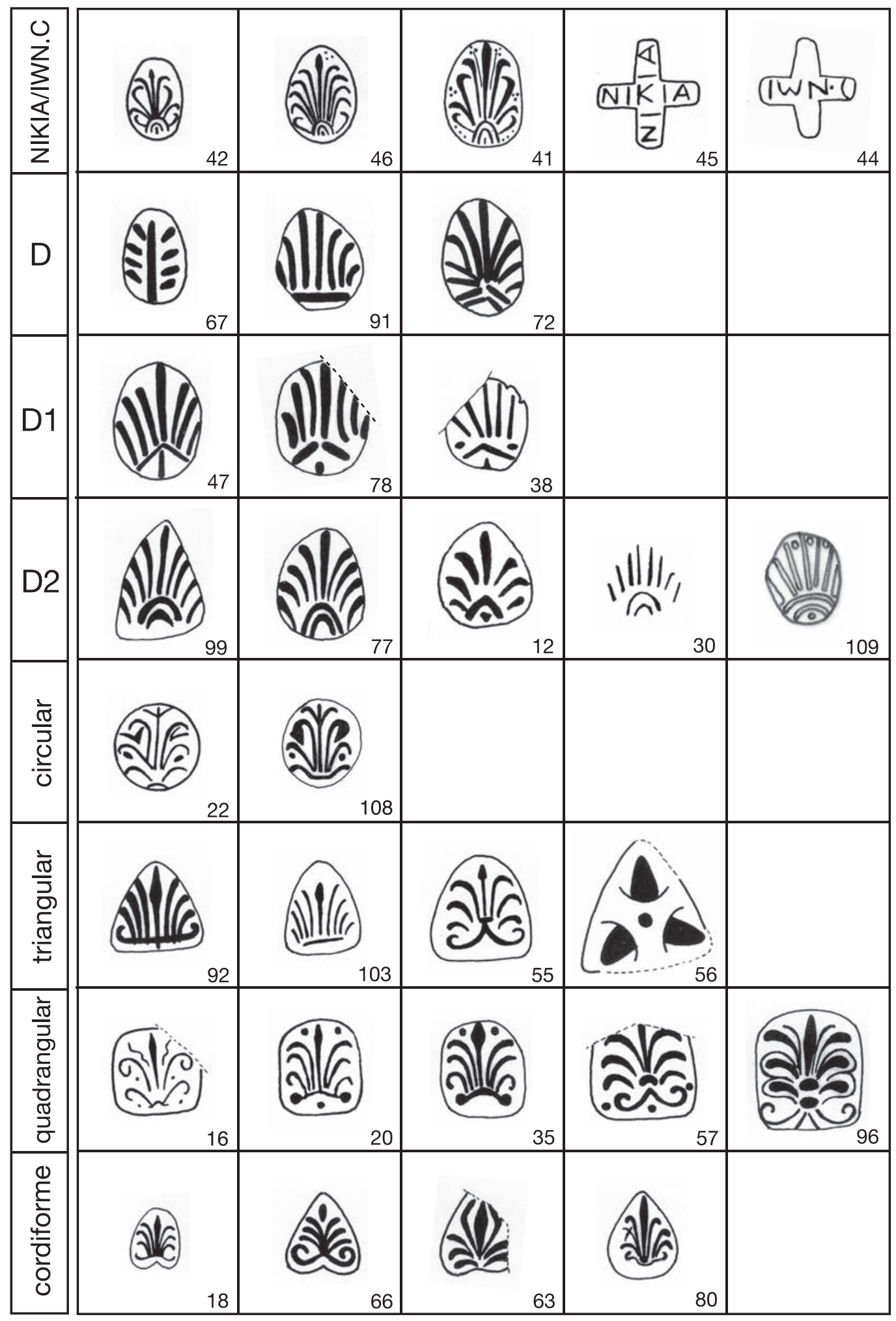

Fig. 8. Décors des palmettes parmi les formes céramiques à vernis noir (échelle 1:1) (A.M. Puig). 
La tentative d'établir la chronologie de ces types décoratifs se heurte à la minceur des données stratigraphiques disponibles. Toutefois, les types I et III semblent être plus tardifs, à l'intérieur du $\mathrm{III}^{\mathrm{e}} \mathrm{s}$., tandis que le type II, plus ancien, pourrait dater de la première moitié de ce siècle. Aucun fragment décoré n'a été découvert dans les niveaux les plus anciens, ce qui suggère que cette technique décorative n'a pas été utilisée lors de la phase initiale des ateliers. Elle a pu apparaître au moment du plus grand développement et de standardisation de la production.

\section{Révision de la chronologie et de la diffusion}

Si les productions de Roses débutent vers le milieu du $\mathrm{IV}^{\mathrm{e}} \mathrm{s}$., avec la fabrication de céramique à pâte claire, dont il sera question plus loin, la production à vernis noir n'apparaît que dans le dernier quart de ce siècle. Cependant, il faudra attendre un certain temps avant que sa diffusion commerciale ne s'élargisse, c'est-à-dire dans la première moitié $d u \mathrm{III}^{\mathrm{e}} \mathrm{s}$. À cette époque, la céramique à vernis noir des ateliers de Roses est en concurrence dans les sites catalans avec la céramique des Petites Estampilles, association qui a été interprétée comme un trait chronologique de la première moitié du $\mathrm{III}^{\mathrm{e}} \mathrm{s}$.

Tout au long du III ${ }^{\mathrm{e}} \mathrm{s}$., jusqu'à la fin du troisième quart de ce siècle, la céramique à vernis noir est présente dans les sites catalans, de la zone occidentale comme de la côte centrale. Pendant cette période, entre la première et la deuxième Guerre Punique, Roses maintient sa position et la commercialisation de ses productions, pleinement intégrée dans l'orbite punique. La situation change à partir du dernier quart du III ${ }^{\mathrm{e}}$ s., avec l'arrivée de la céramique Campanienne A archaïque. Dès ce moment, la présence des céramiques de Roses décline, surtout à partir des deux dernières décennies du siècle, mais elles ne sont pas totalement supplantées. Certains auteurs ont même noté, au moins dans la zone catalane occidentale, une prédominance encore de la céramique de Roses, ou au mieux un relatif équilibre entre les deux productions (Cura, Principal-Ponce 1998, p. 97-110). Une situation semblable caractériserait la côte centrale catalane, où la céramique de Roses, sans être dominante, est encore bien représentée (Sanmarti et al. 1998, p. 122-124). En Catalogne nord-orientale, les données fournies par les sites de Pontós, Empúries et Ullastret montrent que les productions de Roses restent majoritaires dans le dernier quart du $\mathrm{III}^{\mathrm{e}}$ et au tournant du $\mathrm{II}^{\mathrm{e}}$ s. av. J.-C. (Pons et al. 2002, p. 298 ; Equips de Pontós i Ullastret 1998, p. 129-156).

La fin des ateliers de Roses intervient au début du $\mathrm{II}^{\mathrm{e}} \mathrm{s}$., à la suite de la campagne de Caton de 195 av. J.-C., qui entraîne la destruction du site. Les contextes de cette période sur les sites catalans bien connus mettent en évidence le coup de grâce reçu par Roses et la substitution de ses productions par la Campanienne A (Pons et al.2002, p. 298 ; Equips de Pontós i Ullastret 1998, p. 129-156). Ce phénomène est bien perceptible aussi bien dans la zone occidentale que littorale. Les pourcentages très faibles qui apparaissent dans les contextes datant de 175 environ, à Pontós ou à Lattes, s'expliquent par des niveaux de remblais; si les céramiques ne sont plus fabriquées, elles peuvent encore être utilisées dans les sites (Pons et al. 2002, p. 298 ; Py, Adroher, Sánchez 2001, p. 1.218).

Cette fin n'est pas le résultat d'un processus lent et progressif, mais au contraire forcé et soudain. Il ne semble donc pas s'agir d'une absence de réponse de la part de Roses au défi de l'approvisionnement à grande échelle assuré par la céramique campanienne, comme le pense J. Principal (Principal-Ponce 1998, p. 157), mais la fin des ateliers s'inscrit plutôt dans le cadre d'un contexte politique et économique qui entraîne la mort brutale de Rhode. Que serait-il advenu si Roses n'avait pas été condamné par les Romains ? Aurait-on créé les infrastructures nécessaires pour donner aux ateliers de Roses la possibilité de faire le saut vers une production massive ? Il est évident que Roses n'a pas été bénéficiaire du processus de transformation des structures économiques imposé par Rome, au contraire, le marché sera dorénavant dominé par les productions italiques.

\section{La production à pâte claire}

Grâce à la découverte en 1979 de rebuts de cuisson, Aurora Martín fut la première à identifier et classer ces céramiques (Martín 1982, p. 115-116 ; complété dans Py et al. 1993, p. 244-246), qu'elle date dans les trois premiers quarts du III' ${ }^{\mathrm{e}} \mathrm{s}$. av. J.-C., bien qu'elle situe le début des céramiques décorées vers 310 av. J.-C. (fig. 1 à 4). Aujourd'hui cette classification a été élargie jusqu'à un total de 32 formes différentes ${ }^{5}$, dont certaines correspondent à des formes fabriquées également en vernis noir $(31,25 \%$ de ces dernières). Bien que minoritaire par rapport à la production principale des ateliers - elle représente $17,41 \%$ du total -, il a été clairement démontré que cette céramique à pâte claire est la production la plus ancienne de Roses. Elle est déjà présente au milieu

5 Par rapport à la classification précédente, nous n'avons pas attribué un code spécifique au gobelet CL-ROS Gb2, à la lékanis CL-ROS Ln1 et au cratérisque CL-ROS Cr1. En ce qui concerne le gobelet, il a été intégré dans le générique CL-ROS 24 ; la lékanis correspond à la forme CL-ROS 70 ; quand au cratérisque CL-ROS Cr1, en clair parallèle avec la forme CL-MAS 462, son attribution à l'atelier de Roses n'est pas assurée. 
du IVe s., bien qu'en pourcentage restreint, destinée probablement à une consommation locale. Ce fait situe l'origine des productions de Roses dans un contexte fort différent de celui qui avait été envisagé, à travers toute une série de produits, en général des coupes à une anse et des cruches, qui constituent les formes les plus traditionnelles de la céramique massaliote, comme en réponse à la demande des fondateurs de la ville. À partir de la fin du IV ${ }^{\mathrm{e}}$ s., la production des pâtes claires diminue face aux vernis noirs qui s'imposent au cours du $\mathrm{III}^{\mathrm{e}} \mathrm{s}$. La production ne s'arrête pas complètement, mais ses pourcentages deviennent très minoritaires en comparaison du dernier quart du IVe $\mathrm{s}$. où ils étaient prédominants.

Les pâtes claires de Roses adoptent le répertoire des formes massaliotes dont les plus caractéristiques, les plus nombreuses et les plus emblématiques se retrouvent aussi à Roses. C'est le cas, en particulier, de la cruche CL-ROS 50, qui correspond au type CL-MAS 525, et des coupes à une anse CL-ROS 20, 21, 22 et 23, respectivement équivalentes aux types CL-MAS 410, 415 et 417 . Cependant, les ateliers de Roses ont aussi innové et fabriqué des formes spécifiques, ainsi la tasse CL-ROS 24, les cruches CL-ROS 54 et 55, les urnes CL-ROS 74 et 75 (avec des parallèles dans les céramiques ibériques), le gobelet tripode CL-ROS 79, le plat CL-ROS 88 ou le dolium CL-ROS 108.

Les récipients produits dans les plus grandes proportions sont la cruche CL-ROS 50, le stamnos CL-ROS 43, 1'olpè CL-ROS 58 et les coupelles à une anse CL-ROS 21 et 22. Les autres formes céramiques sont très minoritaires, certaines connues à partir d'un seul exemplaire, ainsi CL-ROS 54, 61, 62, 74, 75, 87, 88, 91, 92, 99, 107 et 108. Si on prend en compte les récipients par série, on constate que la production par excellence de la céramique à pâte claire de Roses correspond à des cruches, des olpès et d'autres grands récipients pour des liquides (stamnos et amphores), avec un pourcentage de 69,14\% du total. Il faut noter que ces formes sont absentes du répertoire à vernis noir. La deuxième place est occupée par les coupes à une anse, qui représentent 17,02\% du total. Sont, en revanche, très minoritaires, les formes typiques de coupes et de bols produites à vernis noir, comme, par exemple, les coupes CL-ROS 12 et 11, ou le plat à poisson CL-ROS 80.

En ce qui concerne la chronologie, les formes les plus anciennes sont la cruche CL-ROS 50, 1'olpè CL-ROS 58 et le couvercle CL-ROS 92. Ensuite, à notre connaissance, la coupe CL-ROS 21 et les cruches CL-ROS 51 et 53 sont documentées dans un contexte du dernier quart du IVe s. av. J.-C. Les autres formes apparaissent dans les niveaux du III' s. av. J.-C., : c'est le cas des coupes CL-ROS 12, 20 et 22, des cruches CL-ROS 52 et 55, du stamnos CL-ROS 43 et du type CL-ROS 107. La plupart des formes sont présentes jusqu'à la fin du III et le début du $\mathrm{II}^{\mathrm{e}} \mathrm{s}$. av. J.-C. Parmi les dernières productions, il faut citer la coupe CL-ROS 23, l'amphore CL-ROS 42, la cruche ROSES 56, le possible guttus CL-ROS 67 et la coupe CL-ROS 11.

La céramique à pâte claire de Roses a été mal identifiée et peu étudiée dans les sites de la région, c'est pourquoi il est difficile de procéder à des analyses de marché. En outre, il faudrait procéder sur ces sites à une révision de tous les mobiliers classés comme céramiques communes indigènes pour découvrir la présence éventuelle de productions de Roses. Ceci dit, dans les publications, on ne trouve pas représenté le vaste répertoire formel des pâtes claires de Roses ; si ce n'est quelque profil de coupe ou de cruche, et encore douteux. Il est possible que ces services aient été remplacés par d'autres productions ibériques ou même par les céramiques grises de la côte catalane. C'est le cas, par exemple, dans les sites de Mas Castellar de Pontós (Pons et al. 2002, p. 289), d'Illa d'en Reixac à Ullastret (Martín et al. 1999, p. 99-185) et de Sant Martí d'Empúries (Aquilué et al. 1999, p. 337-339). Il est donc vraisemblable que Roses ait produit cette céramique pour satisfaire les besoins locaux.

\section{Les décors de la céramique à pâte claire}

La céramique à pâte claire présente un pourcentage élevé de vases décorés. On en trouve de deux types, selon qu'ils sont décorés avant ou après cuisson. La finition des premiers présente une couleur qui varie du noir au marron, selon l'épaisseur, comme à la suite d'un coup de pinceau de vernis noir. Les motifs sont pour l'essentiel des lignes horizontales et parallèles combinées avec des frises de motifs végétaux, tels que des épis ou des feuilles en forme de larme; le décor est envahissant, avec peu d'espaces vides. Toutefois, le décor le plus fréquent est celui appliqué à sec, avec des couleurs qui vont du marron orangé au marron foncé en passant par le marron rougeâtre ; il s'agit de bandes et de lignes parallèles horizontales peintes sur la lèvre, le col ou la panse des vases, même parfois sur les anses. Les vases qui portent ce décor sont plutôt de grand format, ainsi les amphores CL-ROS 41 et 42, le stamnos CL-ROS 43, les cruches CL-ROS 50, 53, 54 et 56, et les urnes CL-ROS 74 et 75 . La seule exception est le lécythe CL-ROS 62.

À côté de ces vases à décor peint, il faut citer la présence de vases entièrement recouverts d'un engobe beige orangé ou beige rosé, qui améliore nettement l'aspect et la finition de la céramique. Ce procédé est surtout attesté sur les vases de petit format, comme par exemple les tasses ou les coupes CL-ROS 20, 21, 22 et 23, le guttus CL-ROS 67, le plat CL-ROS 80 et le couvercle CL-ROS 92, mais sans exclusivité. 


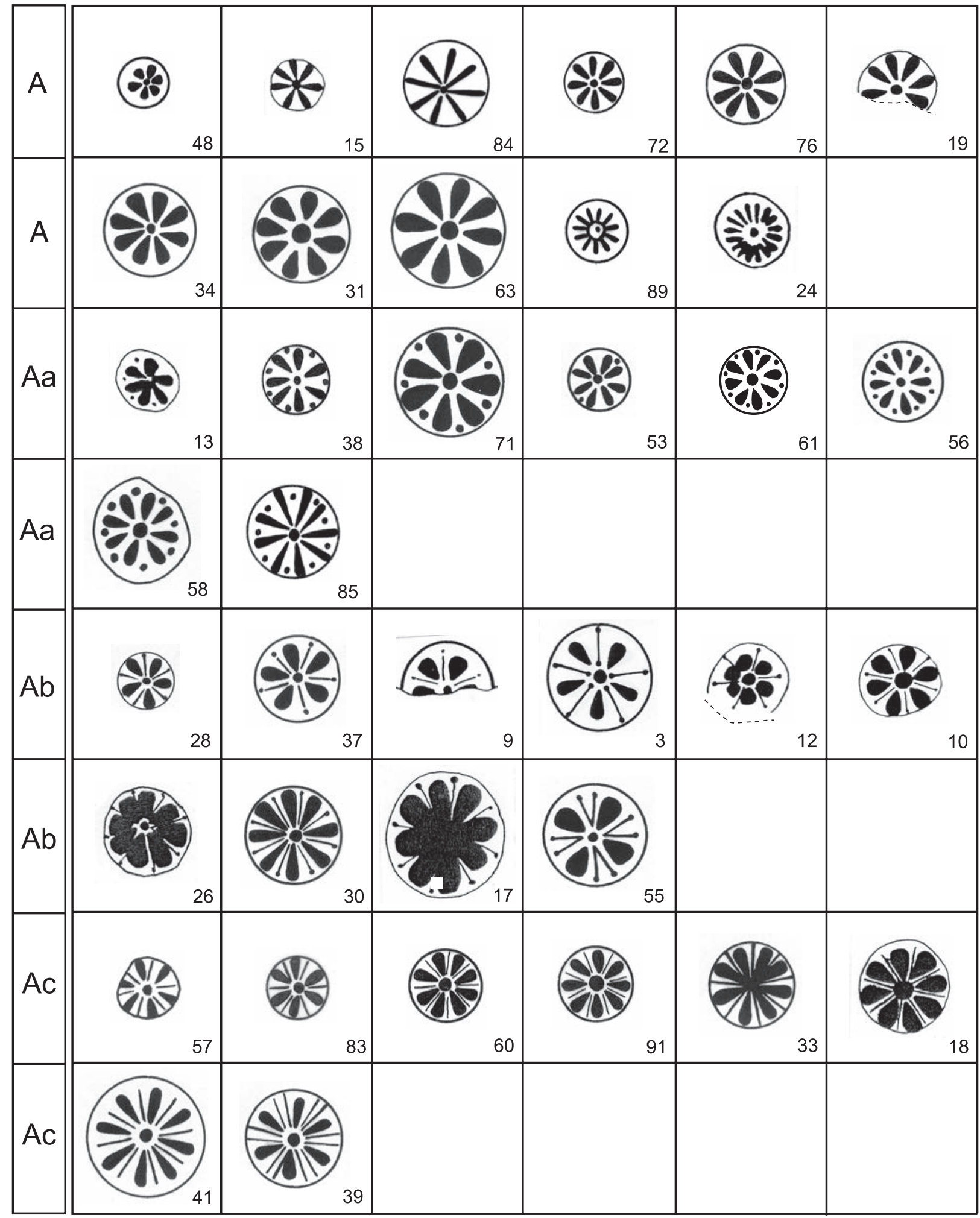

Fig. 9. Décors des rosettes parmi les formes céramiques à vernis noir (échelle 1:1) (A.M. Puig). 


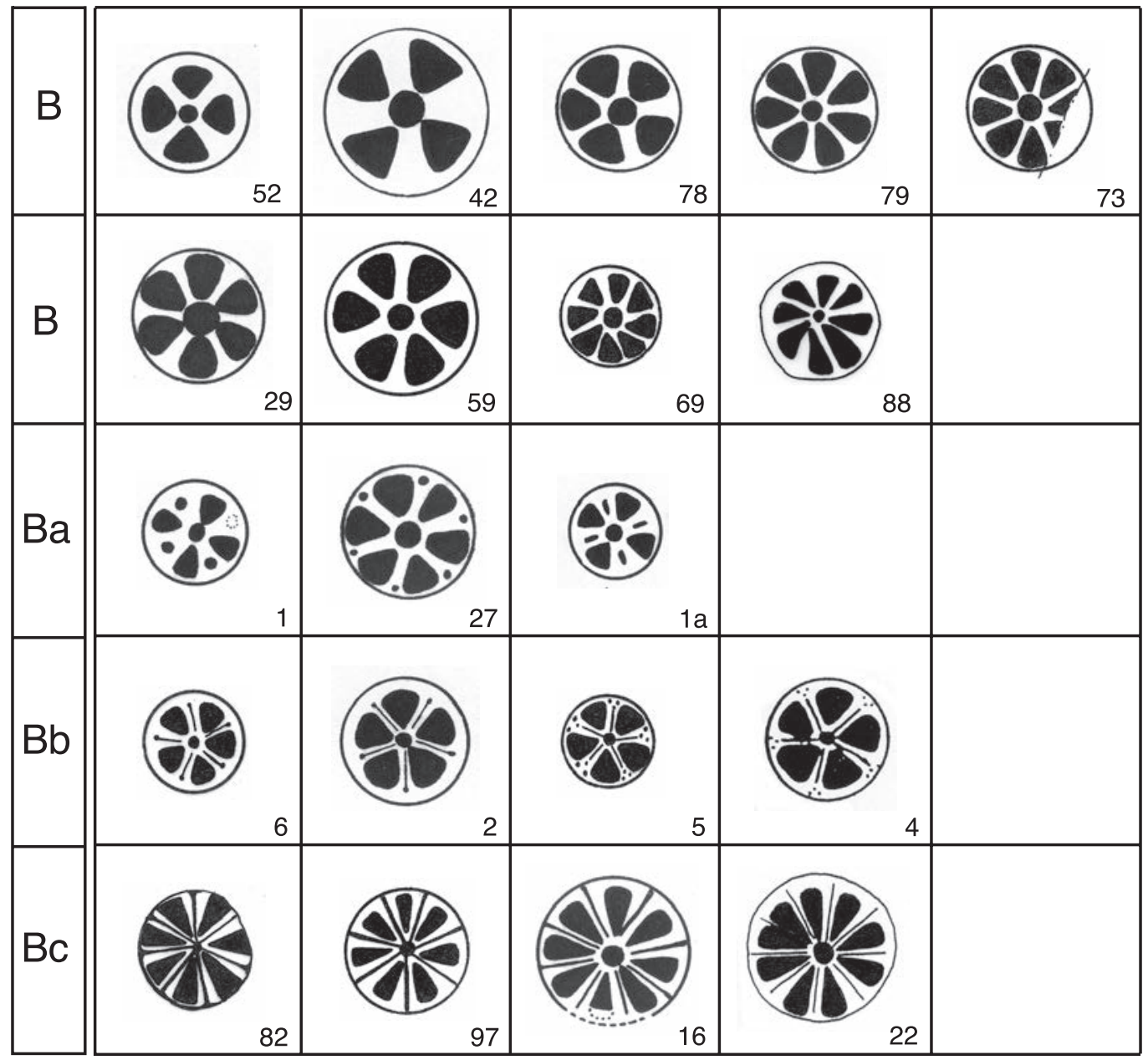

Fig. 10. Décors des rosettes parmi les formes céramiques à vernis noir (échelle 1:1) (A.M. Puig).

Il est intéressant de noter que les pâtes claires à décor peint, auxquelles on avait attribué une datation très ancienne, sont caractéristiques du $\mathrm{III}^{\mathrm{e}}$ s. av. J.-C., avec comme seule exception un exemplaire de guttus du type CL-ROS 68. Les données disponibles confirment, par exemple, la datation tardive des coupes CL-ROS 23 et CL-ROS 12. Il faut situer également au $\mathrm{III}^{\mathrm{e}} \mathrm{s}$. av. J.-C. la production de l'olpè CL-ROS 58 , du gobelet tripode CL-ROS 79, du plat CL-ROS 81 et 87 et du couvercle CL-ROS 99. Enfin, parmi les types présents à l'intérieur des niveaux résiduels tardifs, il faut citer le plat à poisson CL-ROS 80, le plat CL-ROS 88 et la tasse CL-ROS 24.

\section{Les céramiques de cuisine et les céramiques grises}

Ces types correspondent à des productions secondaires des ateliers de Roses (fig. 1 à 4). Les céramiques de cuisine, fabriquées en utilisant une argile spécifique qui résiste au feu, ont une typologie très courante en
Méditerranée. Elles n'ont pas été produites uniquement pour une consommation locale, car des indices signalent une distribution possible dans les sites indigènes de la région, comme c'est le cas du couvercle découvert à Ullastret portant l'estampille NIKIA. Le répertoire apparaît limité aux formes traditionnelles : chytrai, caccabai, lopades et couvercles, correspondant aux types COMROS 120 à 129. Quant à la chronologie, la production semble débuter vers la fin du IV ${ }^{\mathrm{e}} \mathrm{s}$., en même temps que la céramique à vernis noir, se prolongeant tout le long du $\mathrm{III}^{\mathrm{e}}$ s. av. J.-C. Les pourcentages par rapport aux autres productions sont très élevés au début, diminuant considérablement par la suite, avec le développement de la céramique à vernis noir, pour finir très résiduels.

La céramique grise de Roses est à rattacher à la céramique grise de la côte catalane, aussi bien par la couleur de la pâte que par le répertoire de formes. Elle est facilement reconnaissable par sa couleur gris foncé en surface et brun au centre, avec une finition brunâtre et la présence de fines particules de mica. Si le répertoire offre une certaine correspondance avec les types 


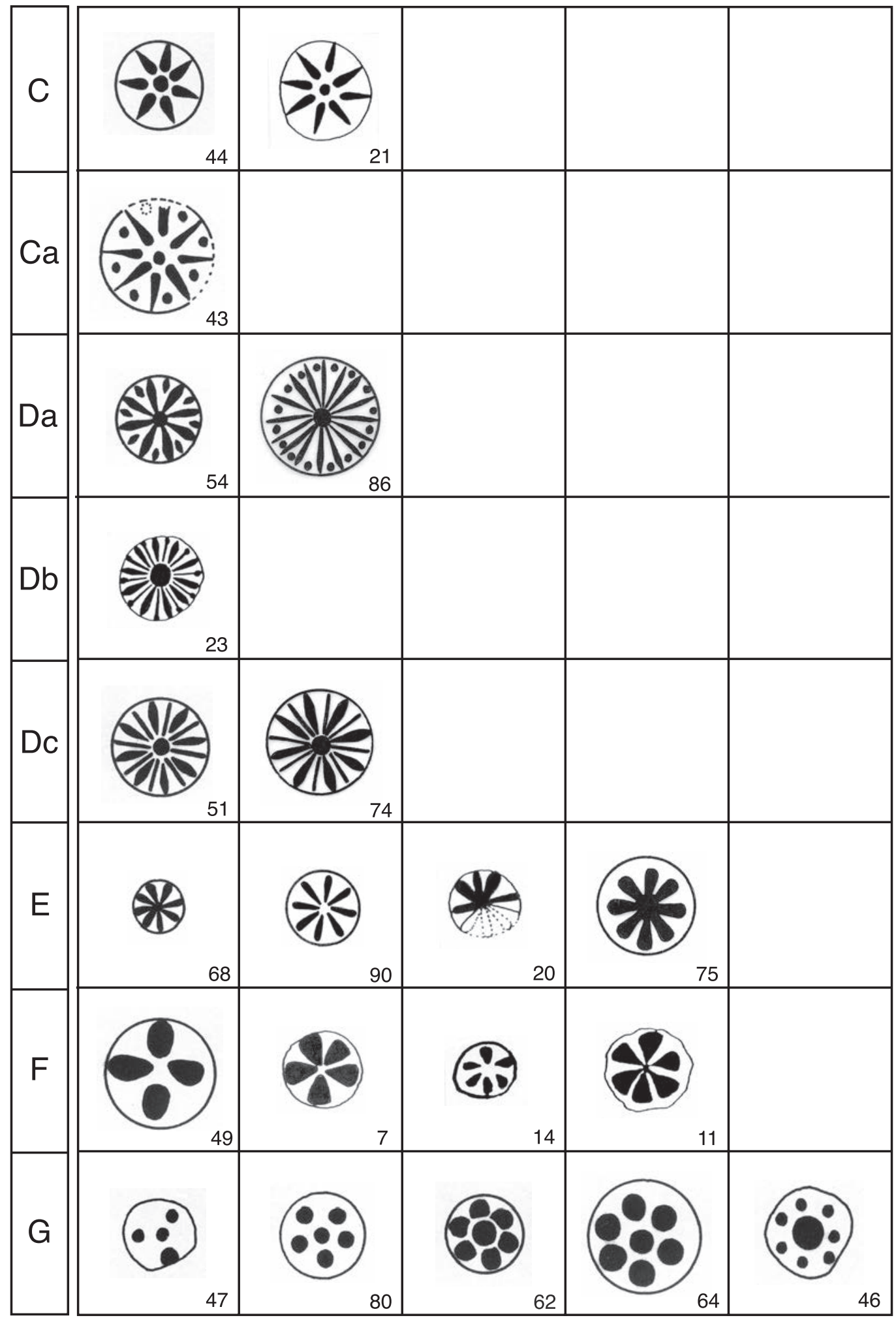

Fig. 11. Décors des rosettes parmi les formes céramiques à vernis noir (échelle 1:1) (A.M. Puig). 


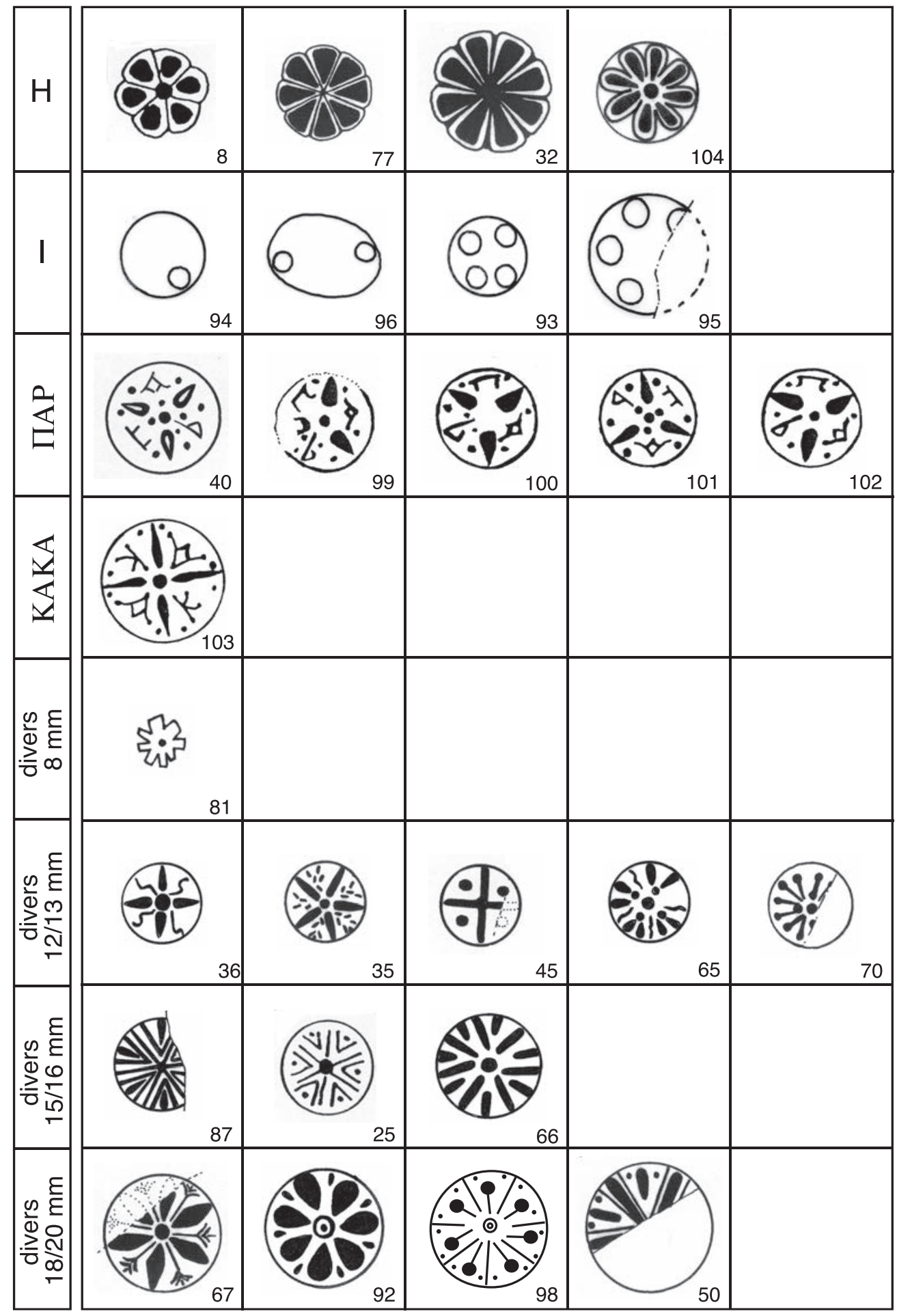

Fig. 12. Décors des rosettes parmi les formes céramiques à vernis noir (échelle 1:1) (A.M. Puig)

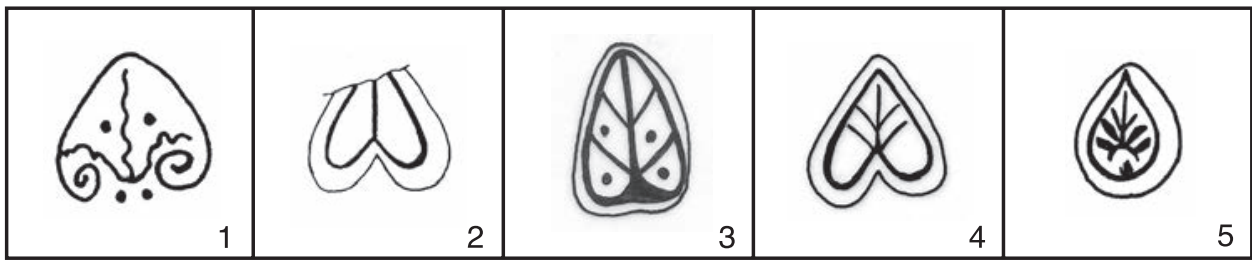

Fig. 13. Décors des motifs divers parmi les formes céramiques à vernis noir (échelle 1:1) (A.M. Puig). 
de la céramique à vernis noir (coupes GR-ROS 1, 11, 12,13 et 18 ) et de la céramique à pâte claire (cruches GR-ROS 52 et 54), l'aspect le plus remarquable est l'adoption de formes typiques de la céramique grise de la côte catalane, en particulier le petit vase biconique (GR-ROS 59) et certains pots (GR-ROS 77 et 78). Les ateliers de Roses ont donc fabriqué également ces produits, très courants à l'époque, mais dans un volume très faible. Cette production, à l'intérieur des ateliers, est la plus minoritaire bien qu'elle apparaisse dès le milieu du $\mathrm{IV}^{\mathrm{e}}$ s., se maintienne pendant la deuxième moitié de ce siècle, avant de décliner au $\mathrm{III}^{\mathrm{e}} \mathrm{s}$. av. J.-C. et disparaître.

\section{Bibliographie}

Adroher 1990 : ADROHER (A.) - Análisis cronológico del yacimiento ibérico de Puig Castellet (Lloret de Mar) a partir de las cerámicas de barniz negro. Cypsela, 8, 1990, p. 79-85.

Aquilué et al. 1999 : AQUILUÉ (X.), BURÉS (L.), BUXÓ (R.), CASTANYER (P.) ESTEBA (J.), FERNÁNDEZ DE LA REGUERA (A.), PONS (E.), SANTOS (M.), SOLÉ (J.), TREMOLEDA (J.) -Intervencions arqueològiques a Sant Martí d'Empúries (1994-1996). De l'assentament precolonial a l'Empúries actual, Girona, 1990, 339 p. (Museu d'Arqueologia de Catalunya- Empúries, Monografies Emporitanes, 9).

Cura, Principal-Ponce 1998 : CURA (M.), PRINCIPAL-PONCE (J.) Ceràmiques de vernís negre i contextos ceràmics d'importació del segle III $\mathrm{aC}$ a la Catalunya occidental. Les fàcies ceràmiques d'importació a la costa ibèrica, les Balears i les Pitiüses durant el segle III aC i la primera meitat del segle II aC, Arqueomediterrània, 4, 1998, p. 97-110.

Equips Pontós i Ullastret 1998 : EQUIPS PONTÓS I ULLASTRET - Les fàcies ceràmiques d'importació de l'Empordà durant el segle III i la primera meitat del segle II aC a través dels jaciments de Pontós i Ullastret. Les fàcies ceràmiques d'importació a la costa ibèrica, les Balears i les Pitiüses durant el segle III aC i la primera meitat del segle II aC. Arqueomediterrània, 4, 1998, p. 129-156.

Martín 1982 : MARTIN (A.) - Aportació de les excavacions de Roses a l'estudi del comerç massaliota a l'Alt Empordà en els segles IV-III aC. Cypsela, IV, 1982, p. 113-122.

Martín et al. 1999 : BUXÓ (R.), LÓPEZ (J.B.), MARTÍN (A.) dir., MATARÓ (M.) - Excavacions arqueològiques a l'Illa d'en Reixac (19871992), Girona, 1999, 371 p. (Museu d'Arqueologia de Catalunya- Ullastret, Monografies d'Ullastret, 1).
Morel 1980 : MOREL (J.-P.) - La céramique campanienne : acquis et problèmes, Céramiques hellénistiques et romaines. Annales Littéraires de l'Université de Besançon, 242, 1980, p. 85-122.

Morel 1981 : MOREL (J.-P.) - Céramique campanienne. Les formes, Rome, 1981, 2 vols., 690 p. (Bibliothèque des Écoles Françaises d'Athénes et de Rome, 244).

Morel 1998 : MOREL (J.-P.) - Les importations de céramiques du III ${ }^{\mathrm{e}}$ siècle et de la première moitié du $1 \mathrm{I}^{\mathrm{e}}$ siècle : quelques remarques à propos de l'lbérie. Les fàcies ceràmiques d'importació a la costa ibèrica, les Balears i les Pitiüses durant el segle III aC i la primera meitat del segle II aC, Arqueomediterrània, 4, 1998, p. 243-249.

Py et al. 1993 : ADROHER (A.M.), ARCELIN (P.), BARTUREN (F.J.), BATS (M.), BONIFAY (M.), CASTANYER (P.), CHAUSSERIE-LAPRÉE (J.), GAILLEDRAT (E.), MARTÍN (A.), MEFFRE (J-C.), NÍN (N.), PASSELAC (M.), PELLECUER (C.), PY (M.) DIR., PONS (E.), RAYNAUD (C.), SANMARTÍ (E.), SOURISSEAU (J-C.), TREMOLEDA (J.), VERNHET (A.) - Dictionnaire des Céramiques Antiques (VII ${ }^{\text {ème }}$ s. av.n. è. - VII ème $s$. de $n$. è.) en Méditerranée nord-occidentale (Provence, Languedoc, Ampurdan), Lattes, 1993, 624 p. (Lattara, 6).

Py, Adroher, Sanchez 2001 : PY (M.), ADROHER (A.M.), SANCHEZ (C.) - Corpus des céramiques de l'Âge du Fer de Lattes (fouilles 1963-1999), Lattes, 2001, 2 t., 1.306 p. (Lattara, 14).

Pons et al. 2002 : ADROHER (A.M.), BOUSO (M.), BUXÓ (R.), FERNÀNDEZ (M.J.), FUERTES (M.), GAGO (N.), GONZALO (C.), LÓPEZ (A.), PONS (E.) DIR., VARGAS (A.) - Mas Castellar de Pontós (Alt Empordà). Un complex arqueològic d'època ibèrica, (Excavacions 19901998), Girona, 2002, 635 p. (Museu d'Arqueologia de Catalunya-Girona, Sèrie Monogràfica, 21).

Puig 2006 : PUIG (A.M.) -Rhode. Caracterització del jaciment $i$ dels seus tallers ceràmics, thèse Universitat de Girona, 2006, http://www.tesisenxarxa. net/TDX-0625107-143754/

Puig, Martín 2006 : PUIG (A.M.), MARTÍN (A.) - La colònia grega de Rhode, Girona, 2006, 643 p. (Museu d'Arqueologia de Catalunya-Girona, Sèrie Monogràfica, 24).

Principal-Ponce, 1998 : PRINCIPAL-PONCE (J.) - Las importaciones de vajilla fina de barníz negro en la Cataluña sur y occidental durante el siglo III a.C., Oxford, 1998, 348 p. (BAR International Series, 729).

Sanmartí 1978a : SANMARTÍ (E.) - La cerámica campaniense de Emporion y Rhode, Barcelona, 1978, 2 vol. (Monografies Emporitanes, IV).

Sanmartí 1978b : SANMARTÍ (E.) - L'atelier des patères à trois palmettes radiales et quelques productions connexes. Archéologie en Languedoc, 1, 1978, p. 21-42.

Sanmartí et al. 1998 : SANMARTI (J.), GARCIA (J.), ASENSIO (D.), PRINCIPAL (J.) - Les fàcies ceràmiques d'importació del segle III aC i la primera meitat del segle II aC a la costa central de Catalunya. Les fàcies ceràmiques d'importació a la costa ibèrica, les Balears $i$ les Pitiüses durant el segle III aC i la primera meitat del segle II aC. Arqueomediterrània, 4, 1998, p. 111-128. 


\title{
Vaisselle et alimentation à Pech Maho (Sigean, Aude) : l'îlot I à la fin du III' s. av. J.-C.
}

\author{
Anne-Marie Curé \\ ASM, Archéologie des Sociétés Méditerranéennes, UMR5140, \\ UPVM, CNRS, MCC, 34000, Montpellier, France
}

\section{Résumé}

La partie nord-est de l'îlot I de Pech Maho (Sigean, Aude) est constituée à la fin du III' s. av. J.-C. d'unités fonctionnelles caractérisées par la concentration d'activités économiques liées au commerce et à l'artisanat. L'étude de la vaisselle de ces unités a pour objectif de caractériser les ensembles de céramique de cuisine et de table d'un point de vue fonctionnel, c'est-à-dire en mettant en avant les possibilités d'utilisation des récipients selon leur morphologie. Les assemblages de vaisselle reflètent ainsi à la fois la prépondérance des traditions indigènes dans les méthodes de préparation et probablement dans les mets consommés, mais aussi une certaine ouverture perceptible à la fois dans l'abondance de céramique de table importée, signe de l'intégration du comptoir commercial à divers réseaux d'échange, mais aussi dans le choix de récipients en rupture avec le répertoire régional traditionnel.

Mots-clés : Pech Maho, deuxième âge du Fer, céramique, vaisselle, fonction, consommation

\footnotetext{
Abstract

By the end of the 3rd century BC, the north-east part of the ilot I of Pech Maho (Sigean, Aude) is constituted of functional units marked by the concentration of economic activities related to trade and craftwork. The study of the kitchen and tableware of these houses aims to caracterize the ceramic assemblages from a functional point of view, and to be more precise by putting forward the possibilities of utilization of the vessels according to their morphology. The kitchen and tableware sets reflect both the preponderance of indigenous customs among cooking and consumption practices, and a constant demand for foreign vessels, sometimes quite different from the traditional local repertoire.
}

Keywords: Pech Maho, Late Iron Age, ceramic, kitchen and tableware, function, consumption 


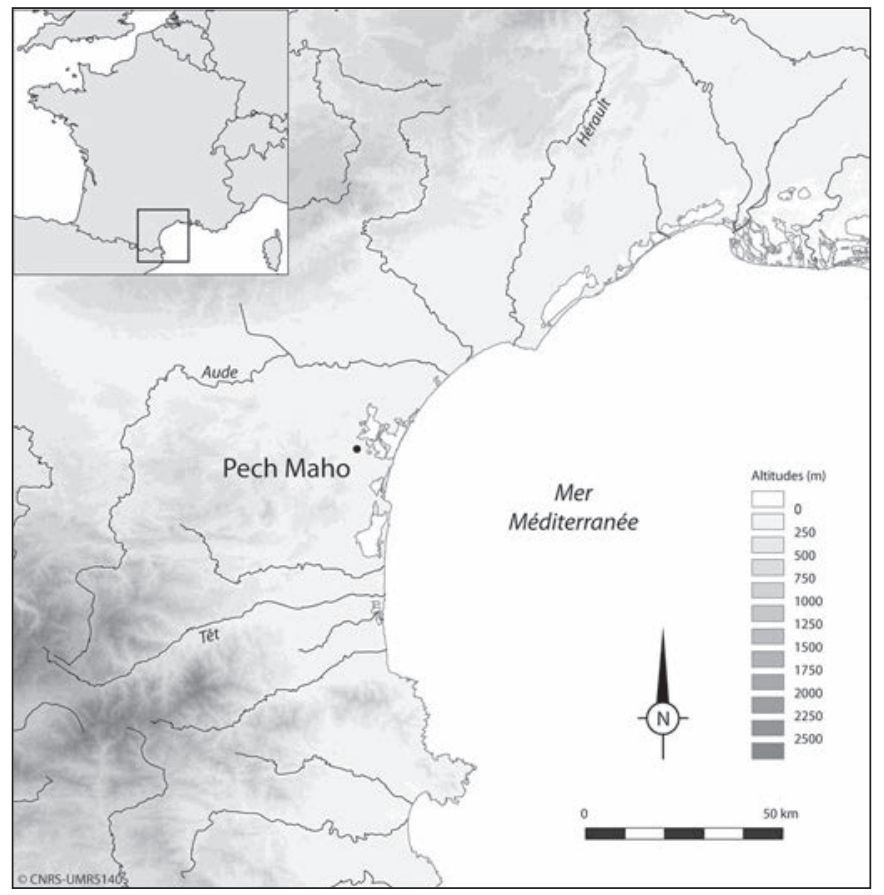

Fig. 1. Localisation de l'oppidum de Pech Maho (Sigean, Aude)

en Languedoc occidental.

Fig. 2. Plan général du site de Pech Maho et localisation des secteurs étudiés.

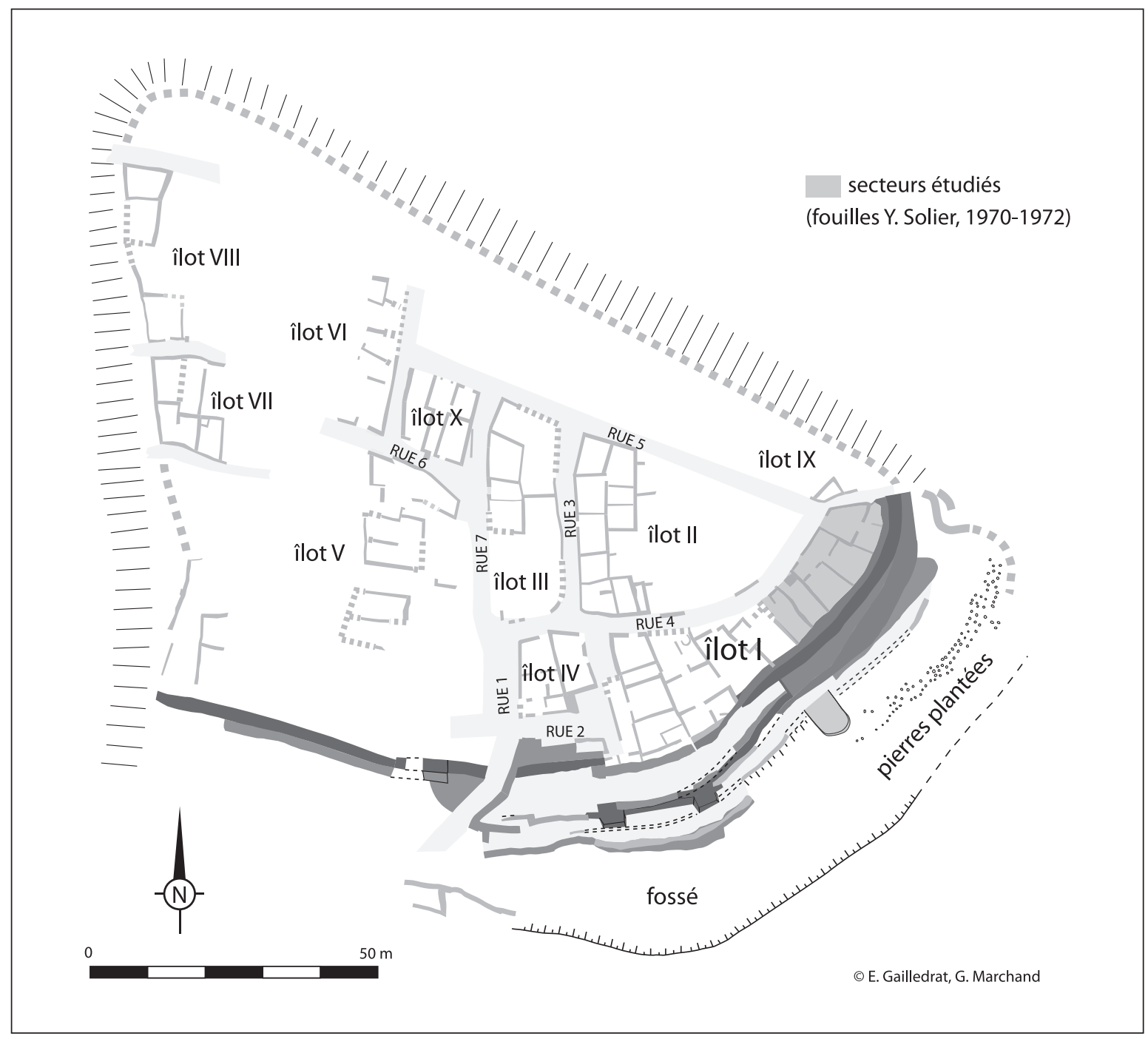




\section{Introduction}

L'oppidum de Pech Maho à Sigean (Aude) est un habitat littoral occupé depuis le milieu du $\mathrm{VI}^{\mathrm{e}} \mathrm{s}$. jusque vers 200 av. J.-C., date à laquelle il subit une destruction par fait de guerre, à laquelle succède une brève réoccupation marquée par la mise en œuvre de pratiques à caractère rituel (fig. 1). Au cours du III' s. av. J.-C., le site se présente comme un comptoir commercial caractérisé par l'abondance des produits d'importation, mais aussi par le rôle prépondérant des activités de stockage et artisanales. L'îlot I, situé dans la partie méridionale du site, présente la spécificité de concentrer ces différentes fonctions économiques, puisqu'il abrite notamment de nombreux espaces de stockage et de travail du métal. L'extrémité nord-est de l'îlot, explorée par Y. Solier entre 1970 et 1972, est constituée de neuf pièces pouvant être regroupées en trois unités fonctionnelles : UNF105, UNF106 et UNF107 (fig. 2). Le dernier niveau d'occupation, scellé par la destruction brutale de l'habitat, renferme un abondant mobilier céramique qui a déjà fait l'objet d'une étude spatiale par M. C. Belarte, É. Gailledrat et J. Principal (2011), dans la perspective d'une analyse fonctionnelle des différents secteurs.

Les pièces $54 \mathrm{~B}$ et $54 \mathrm{C}$ ont ainsi été interprétées comme faisant probablement partie d'une même unité fonctionnelle (UNF105) en raison de la complémentarité des fonctions des deux espaces. L'absence de communication directe entre les deux secteurs ne permet pas toutefois d'exclure complètement la possibilité qu'il s'agisse de deux unités indépendantes. Il semblerait en effet que les deux pièces aient pu servir de lieu de vie avec notamment des activités de préparation et de prise des repas. Par ailleurs, le secteur 54B est caractérisé par une partie avant où se sont déroulées des activités métallurgiques, tandis que le secteur 54C se distingue par la présence d'un important espace de stockage à l'arrière (fig. 3). L'unité fonctionnelle centrale (UNF106) est pour sa part formée par trois

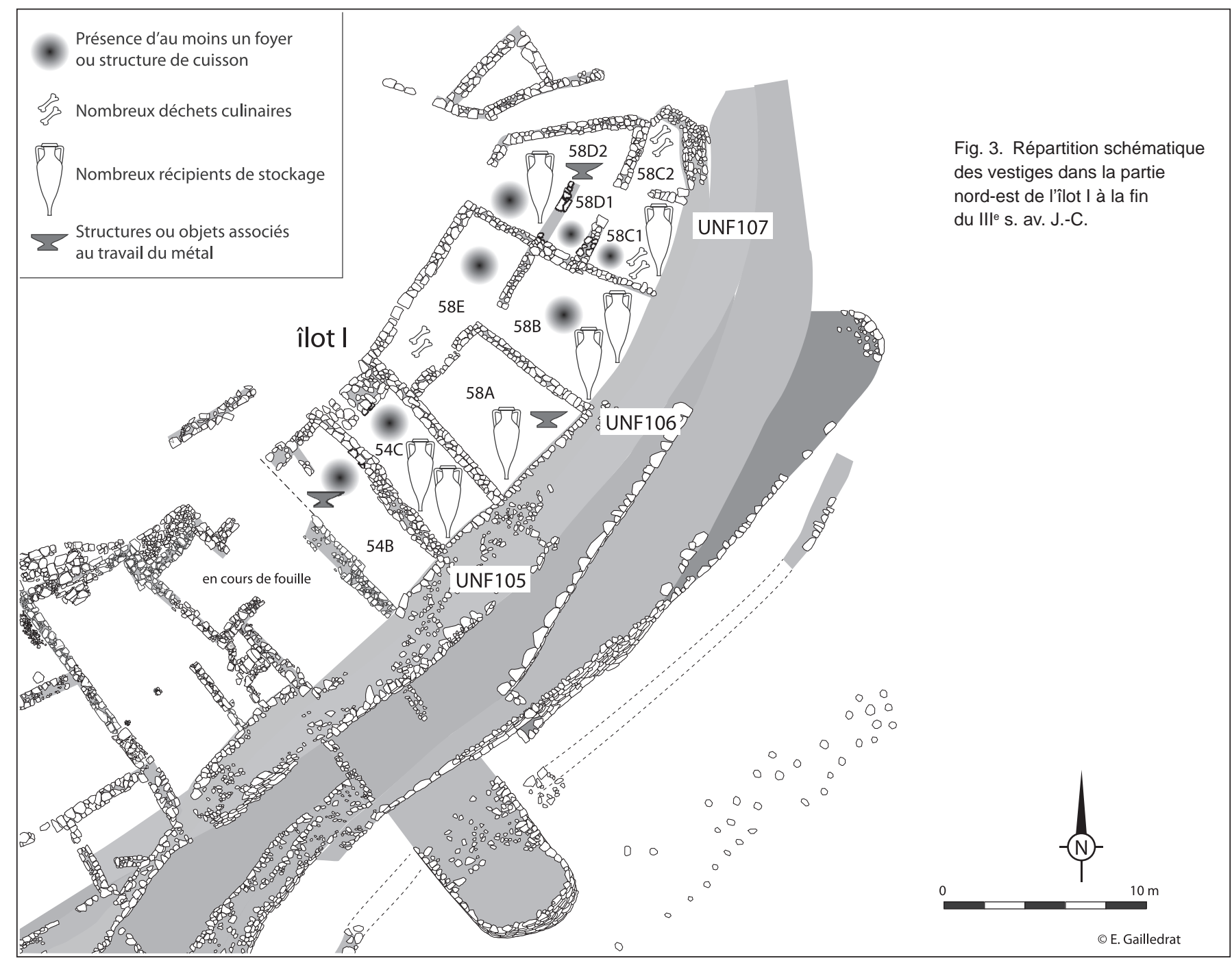




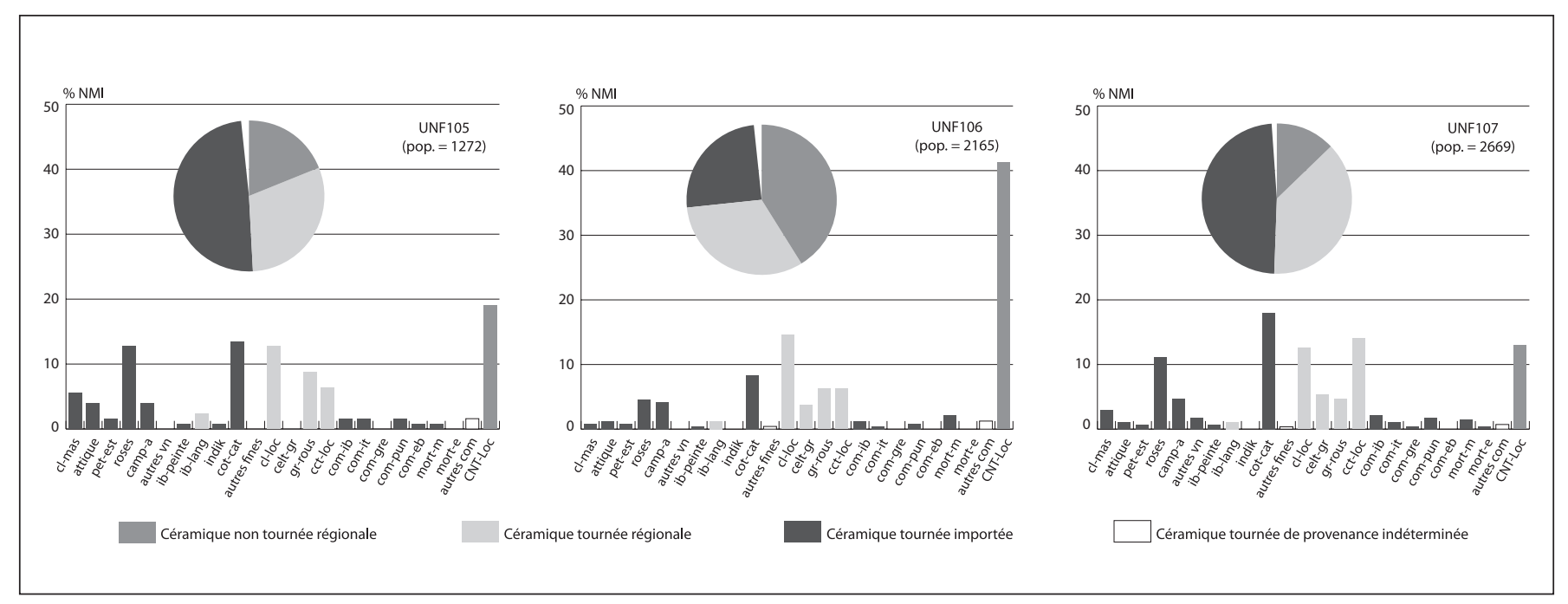

Fig. 4. Distribution des catégories céramiques de vaisselle dans les UNF105, 106 et 107, et répartition selon la provenance (en nombre minimum d'individus).

pièces : $58 \mathrm{~A}, 58 \mathrm{~B}$ et $58 \mathrm{E}$. La pièce avant $58 \mathrm{E}$ semble être un espace de préparation culinaire et de consommation fonctionnant avec deux pièces arrières plus polyvalentes. Ces dernières paraissent avoir pu abriter également des activités de préparation et de prise des repas, en association toutefois avec des zones de stockage, en particulier dans la pièce $58 \mathrm{~B}$, et de travail du métal dans la pièce 58A. Enfin, la dernière unité fonctionnelle (UNF107) est constituée par les espaces 58C1 et C2 à 1'arrière, et 58D1 et D2 à l'avant. Tandis que l'espace 58C1 regroupe des activités de stockage, de préparation et de prise des repas, la fonction du secteur adjacent $58 \mathrm{C} 2$ est incertaine. Les pièces 58D1 et D2 se caractérisent quant à elles par la présence d'aires d'activités métallurgiques associées à des espaces de préparation culinaire et de consommation. En résumé, malgré des architectures différentes, les trois unités fonctionnelles présentent de nombreuses similitudes dans l'organisation des pièces. Celles-ci sont en effet souvent polyvalentes, et associent des espaces de préparation et de prise des repas à des zones de stockage, généralement situées à l'arrière des bâtiments, ainsi qu'à des aires d'activités métallurgiques localisées soit dans les parties avant, donnant sur la rue, soit dans la pièce arrière dans le cas de l'UNF106.

L'étude détaillée de la vaisselle céramique de l'îlot I a pour objectif de mettre en lumière les spécificités des services de cuisine et de table des trois unités fonctionnelles mentionnées, ainsi que d'associer ces services à des modes de consommation. L'essentiel de ce travail se fonde donc sur l'analyse de la répartition des formes et des fonctions des récipients de vaisselle dans chacune des pièces et des unités fonctionnelles.

\section{Distribution des catégories céramiques de vaisselle par unité fonctionnelle}

Parmi les trois unités fonctionnelles, l'UNF105 est celle qui a livré la proportion la plus importante de céramiques à vernis noir $\left(22 \%\right.$ des individus $\left.{ }^{1}\right)$, et notamment les plus fortes proportions de céramique de Roses, attique et de l'atelier des petites estampilles (fig. 4). Cet ensemble se démarque également des autres par une part plus importante de céramique à pâte claire massaliète ( $6 \%$ des individus) et grise roussillonnaise (9\% des individus). L'UNF106 présente pour sa part les taux les plus bas de vaisselle à vernis noir (11\% des individus) et en particulier de céramique de Roses, mais aussi de céramique à pâte claire massaliète $(1 \%$ des individus) et grise de la côte catalane (8\% des individus). Ces faibles taux sont contrebalancés par une proportion particulièrement élevée de céramique non tournée (41\% des individus) par rapport aux deux autres unités fonctionnelles. À l'inverse, l'UNF107 est caractérisée par le taux le plus faible de céramique non tournée (13\% des individus), compensé toutefois par un fort pourcentage de céramique commune tournée du Languedoc occidental (14\% des individus). C'est également dans cette unité que la céramique grise de la côte catalane est la plus fréquente (18\% des individus).

1 Tous les chiffres indiqués dans ce paragraphe correspondent à des pourcentages à l'intérieur de la catégorie « vaisselle » regroupant tous les types de céramiques à l'exception des amphores et des dolium. 
La céramique à pâte claire du Languedoc occidental est quant à elle attestée dans des proportions équivalentes dans les trois unités fonctionnelles (13 à $15 \%$ des individus). Il en va de même pour les catégories plus faiblement représentées de céramique ibérique peinte, ibéro-languedocienne ou encore de céramique commune ibérique, punique, ébusitaine, grecque et italique.

L'étude des faciès céramiques des trois ensembles laisse ainsi transparaître un certain nombre de différences. En particulier, l'UNF106 se distingue des deux autres non seulement par une part plus importante de céramique modelée, mais aussi, si l'on considère l'ensemble de la vaisselle tournée, par une plus forte proportion de productions locales ou régionales que d'importations.

\section{Formes et des fonctions des récipients de vaisselle : questions de méthodologie}

Pour chaque pièce, un comptage minimum d'individus a été effectué à partir des inventaires typologiques, par catégorie et par type de vase. Toutefois, seuls les récipients de forme déterminée ont pu être comptabilisés. Le taux de détermination des formes par pièce varie ainsi entre 69 et $94 \%$ des vases, avec des pourcentages plus faibles enregistrés généralement pour les pièces ayant livré assez peu de mobilier (en particulier $58 \mathrm{E}, 58 \mathrm{C} 1$ et $58 \mathrm{C} 2$, avec un taux de détermination inférieur à $80 \%$ ).

La terminologie adoptée correspond à celle du Dicocer $^{2}$, excepté pour la catégorie des céramiques à vernis noir de Roses, pour laquelle a été reprise la terminologie présentée par J. Principal (2004), terminologie adaptée à la typologie actualisée de cette production (Puig, Martin 2006).

Par ailleurs, malgré les propositions existantes d'associations de types de récipients à des fonctions spécifiques (Bats 1988, Dicocer), nous avons choisi de proposer ici notre propre grille de lecture (fig. 5). La vaisselle de cuisine a été divisée en deux grandes catégories de récipients : les vases pour cuire les aliments d'une part, et les vases pour préparer les aliments - dans un sens restreint du terme - d'autre part. Les vases à cuire, selon leur morphologie, ont pu servir à différents types de cuisson. Hormis une caccabé ou une lopas associée à la fonction bouillirmijoter ou frire-mijoter, l'îlot I n'a livré que des urnes, récipients fermés permettant de faire bouillir et mijoter les aliments. La distinction entre les vases destinés au gros ou au petit stockage et ceux utilisés pour la cuisson étant peu

2 Version en ligne du Dicocer pour la céramique à pâte claire du Languedoc occidental (cl-loc) et pour la céramique grise roussillonnaise (gr-rous).

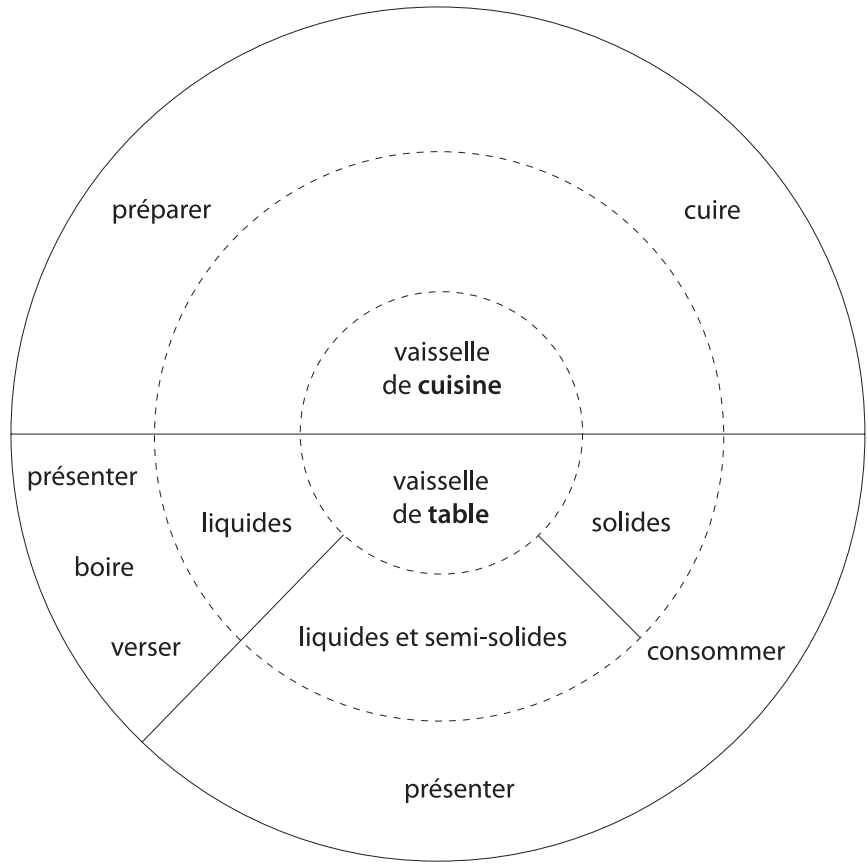

Fig. 5. Schéma des principales fonctions de la vaisselle de cuisine et de table.

probante à partir du seul diamètre à l'embouchure, toutes les urnes en céramique non tournée et céramique commune tournée du Languedoc occidental ont été associées aux fonctions culinaires, bien qu'une partie ait pu servir également de vases de stockage. Les vases de préparation mis au jour sont pour leur part exclusivement des mortiers, utilisés préférentiellement pour écraser et mélanger les aliments.

La vaisselle de table est quant à elle beaucoup plus diversifiée. $\mathrm{Au}$ vu des différents types de récipients attestés, le choix a été fait de distinguer la vaisselle réservée à la boisson d'une part, de celle utilisable pour les aliments liquides, semi-solides et solides d'autre part. Les récipients étroitement associés aux liquides, assez facilement identifiables, se divisent en plusieurs catégories. Ainsi, les cratères et les stamnos sont utilisés pour mélanger et présenter la boisson. Les cruches, de même que certains gobelets à une anse de morphologie semblable (notamment les gobelets en céramique grise de la côte catalane), servent à verser les liquides. Enfin, les vases à boire regroupent deux types distincts de récipients. Les coupes à pieds, coupes et bols à une ou deux anses (dont les kylix), ainsi que les cratérisques et les skyphos ont potentiellement été utilisés dans le cadre de pratiques de consommation spécifiques à caractère social (collectives, cultuelles, etc), probablement en association avec les vases de présentation de la boisson, formant ainsi un service à boire. Parmi ces vases, on note que les cratérisques de plus grands modules ont pu servir, à l'instar des cratères, à mélanger et présenter 
la boisson (Principal 2004, p. 64). À l'inverse, il semblerait que les gobelets et les tasses doivent plutôt être associés à la consommation quotidienne de breuvages.

Les vases associés aux aliments liquides, semi-solides et solides peuvent quant à eux être répartis en deux séries. Ainsi, les récipients profonds ont été associés préférentiellement aux aliments liquides et semi-solides, tandis que les récipients peu profonds paraissent plutôt adéquats pour contenir de la nourriture solide. Ceci étant, on n'exclura pas totalement l'utilisation de récipients profonds pour des aliments solides, et celle de plats peu profonds pour des aliments semi-solides. L'autre difficulté qui apparaît est celle de la distinction entre les fonctions de présentation et de consommation, qui peuvent d'ailleurs être mêlées si le consommateur se sert et mange directement à partir du plat de service, sans utiliser de récipient intermédiaire. Nous avons donc choisi de regrouper ces deux fonctions, tout en gardant la possibilité de raisonner dans certains cas sur la contenance du vase, et par là même d'exclure des récipients probablement réservés à la présentation ou à la consommation collective $^{3}$. Les récipients servant à la présentation et la consommation d'aliments liquides et semi-solides sont des récipients ouverts plus ou moins profonds, comme les coupelles, coupes, bols et écuelles. Les volumes calculés pour huit coupelles, coupes et bols en céramique grise de la côte catalane et roussillonnaise et en céramique à vernis noir de Roses s'échelonnent entre 35 et $60 \mathrm{cl}$, permettant aussi bien une utilisation comme récipient de présentation que comme récipient intermédiaire pour la consommation ${ }^{4}$. En revanche, certains vases de petits modules, comme les coupelles ROSES 1, avec deux volumes calculés autour de $10 \mathrm{cl}$, indiquent plutôt une fonction de présentation, par exemple pour des condiments. À l'inverse, plusieurs récipients plus grands ont probablement été utilisés plutôt pour la présentation ou la consommation collective. C'est le cas notamment des écuelles ROSES 12, avec trois volumes calculés compris entre 1,10 et 21 , ainsi que d'une coupe CL-MAS 233 d'une contenance de 1,80 1. Enfin, les plats à poisson et les assiettes sont des vases appropriés pour la consommation d'aliments solides.

3 Nous rappelons que l'étude a été effectuée sur la base d'un matériel fragmentaire qui permet le plus souvent de connaître au mieux le diamètre à l'embouchure du vase, critère métrique qui s'avère souvent assez peu pertinent pour approcher la contenance du récipient.

4 Les calculs ont été réalisés à l'aide du logiciel Pot_Utility 1.05 (C) J.-P. Thalmann \& ARCANE, 2006).

Les valeurs indiquées sont des volumes maximums (comme si le vase était plein à ras bord); le volume utile est toujours légèrement inférieur.

\section{Formes et fonctions des récipients de vaisselle des principales catégories céramiques}

Parmi la vaisselle fine, les céramiques attiques à figures rouges et à vernis noir, attestées en petite quantité dans chaque unité fonctionnelle, correspondent à de la vaisselle encore en usage à Pech Maho au III' s. av. J.-C., et ne doivent pas être nécessairement considérées comme du matériel intrusif ou résiduel (Belarte, Gailledrat, Principal 2011, p. 65). Si les vases à boire - coupes, skyphos et cratérisques - sont représentés dans toutes les unités fonctionnelles, seule l'UNF107 a livré des fragments de cratères. Les productions des ateliers des petites estampilles sont attestées pour leur part uniquement par des bols. La céramique de Roses est quant à elle illustrée par de nombreux bols, coupelles et écuelles. On retrouve également quelques plats à poisson, une assiette, un cratérisque et un skyphos. De manière similaire, la céramique campanienne A est représentée essentiellement par des bols, coupelles et écuelles, complétés là encore par une poignée de vases moins communs tels que des assiettes, un plat à poisson et un bol à anses. Enfin, on recense deux vases à boire en céramique à vernis noir d'origine indéterminée: un skyphos et un cratérisque. Parmi les autres catégories de vaisselle fine - céramique à pâte claire massaliète et du Languedoc occidental, céramique grise de la côte catalane et roussillonnaise -, les formes les plus représentées sont les coupes et les cruches ou gobelets, accompagnées parfois de vases de morphologie différente. Ainsi, le répertoire de céramique à pâte claire massaliète est complété par de rares assiettes et un cratérisque, celui du Languedoc occidental de gobelets à boire et d'une tasse, et celui de céramique grise de la côte catalane de stamnos et de kylix. Parmi la vaisselle commune, la céramique commune tournée du Languedoc occidental est illustrée uniquement par des urnes. La céramique non tournée est quant à elle représentée majoritairement par des urnes, mais l'on recense également quelques coupes et un mortier. Enfin, on trouve dans les trois unités fonctionnelles des mortiers de productions diversifiées : mortiers régionaux, massaliètes, étrusque et ébusitain.

En résumé, la vaisselle de cuisine est composée en majeure partie d'urnes en céramique non tournée et en céramique commune tournée, accompagnées de quelques mortiers. Pour la vaisselle de table, on remarque que les différents types de vases ne sont pas représentés de manière équivalente selon les catégories. Les vases réservés à la présentation des liquides sont des cratères en céramique attique et des stamnos en céramique grise de la côte catalane. Les vases spécifiquement à boire sont quant à eux des skyphos en céramique vernis noir, des cratérisques, fabriqués surtout 
en céramique à vernis noir mais illustrés également par un exemplaire en pâte claire massaliète, des coupes à anses en céramique à vernis noir et en céramique à pâte claire massaliète et du Languedoc occidental, ainsi que deux kylix en céramique grise de la côte catalane. Les vases conçus pour le service de la boisson, à savoir les cruches ou gobelets, sont bien représentés en céramique à pâte claire et céramique grise, tandis qu'ils sont absents du répertoire des productions à vernis noir. Les récipients utilisés pour présenter et consommer les aliments liquides et semi-solides sont des bols, des coupelles, des coupes et des écuelles. Ces formes simples sont très répandues et attestées dans toutes les principales catégories formant la vaisselle de table. Enfin, la vaisselle appropriée à la présentation et à la consommation d'aliments solides est beaucoup plus rare. Elle est illustrée par des plats à poisson et des assiettes en céramique à vernis noir de Roses et campanienne $\mathrm{A}$, ainsi que par des assiettes en céramique à pâte claire massaliète (fig. 6).

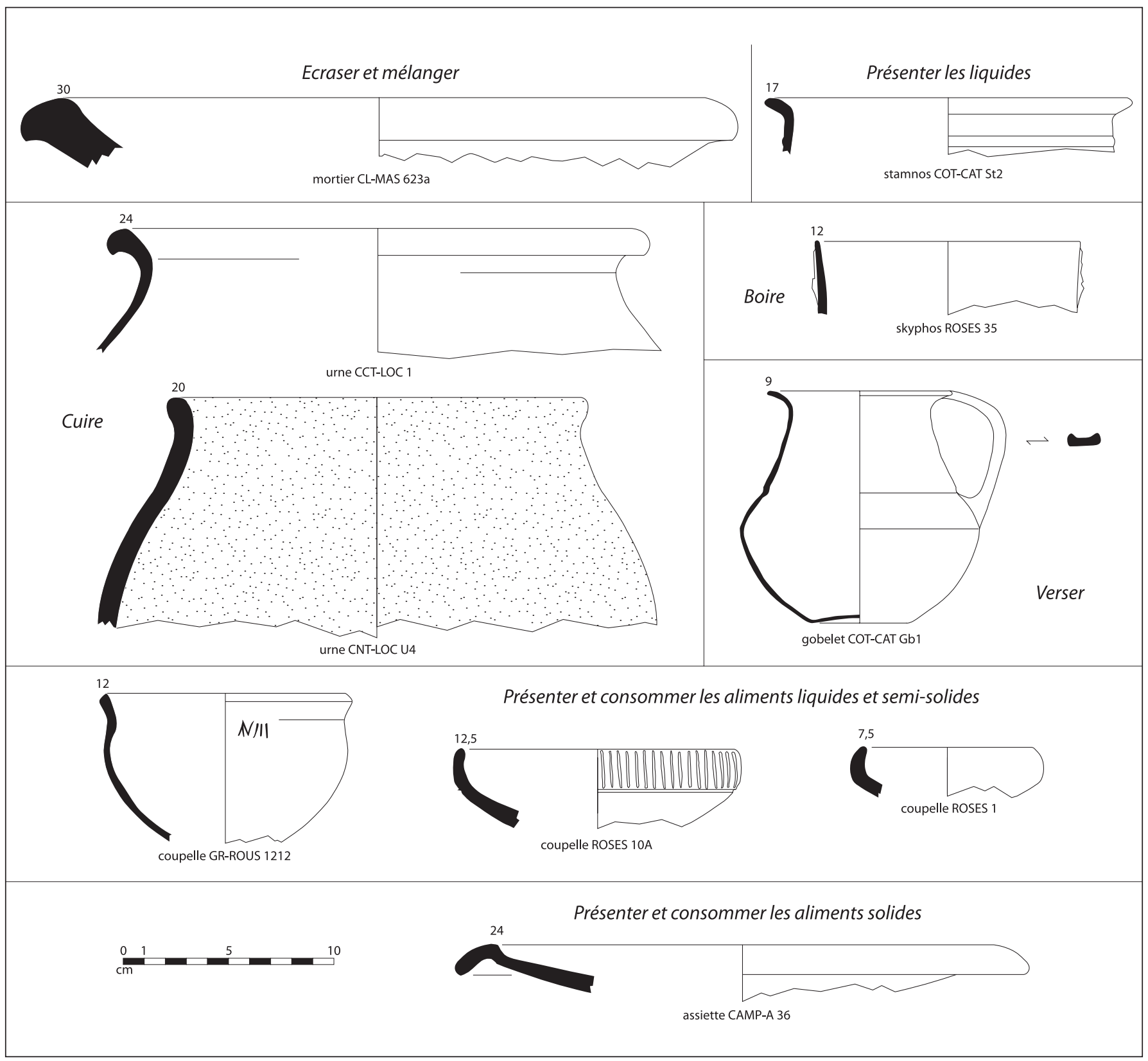

Fig. 6. Exemple de vaisselle provenant de l'UNF106. 


\begin{tabular}{|c|c|c|c|c|}
\hline & & UNF105 & UNF106 & UNF107 \\
\hline \multirow{2}{*}{$\begin{array}{c}\text { Vaisselle } \\
\text { de cuisine }\end{array}$} & Cuire & 27 urnes & 92 urnes & 62 urnes, 1 caccabé/lopas \\
\hline & écraser/mélanger & 2 mortiers & 9 mortiers & 5 mortiers \\
\hline \multirow{6}{*}{$\begin{array}{l}\text { Vaisselle } \\
\text { de table }\end{array}$} & présenter la boisson & 0 vase & 1 vase (1 stamnos) & $\begin{array}{c}7 \text { vases } \\
\text { (2 cratères, } 5 \text { stamnos }\end{array}$ \\
\hline & \multirow[t]{2}{*}{ Boire } & $\begin{array}{l}7 \text { vases (1 skyphos, } 2 \\
\text { cratéristiques, } 4 \text { coupes) }\end{array}$ & $\begin{array}{l}9 \text { vases ( } 2 \text { skyphos, } 1 \\
\text { cratéristiques, } 6 \text { coupes) }\end{array}$ & $\begin{array}{c}17 \text { vases ( } 1 \text { skyphos, } 2 \text { kylix, } \\
5 \text { cratéristiques, } 8 \text { coupes, } 1 \text { bol }\end{array}$ \\
\hline & & 2 gobelets, 1 tasse & 2 gobelets & 6 gobelets \\
\hline & verser & 23 cruches et gobelets & 16 cruches et gobelets & 37 cruches et gobelets \\
\hline & $\begin{array}{c}\text { Présenter/consommer les } \\
\text { aliments liquides et semi-solides }\end{array}$ & \begin{tabular}{|c|}
39 vases (13 coupes, 7 \\
coupelles, 14 bols, 5 écuelles) \\
\end{tabular} & \begin{tabular}{|c|}
48 vases ( 26 coupes, 8 coupelles, \\
9 bols, 4 écuelles, 1 plat)
\end{tabular} & $\begin{array}{c}82 \text { vases ( } 35 \text { coupes, } 15 \\
\text { coupelles, } 23 \text { bols, } 9 \text { écuelles) }\end{array}$ \\
\hline & $\begin{array}{c}\text { Présenter/consommer les } \\
\text { aliments solides }\end{array}$ & $\begin{array}{c}1 \text { vase } \\
\text { (1 plats à poisson) }\end{array}$ & $\begin{array}{c}5 \text { vases } \\
\text { (2 plats à poisson, } 3 \text { assiettes })\end{array}$ & $\begin{array}{c}4 \text { vases } \\
\text { (2 plats à poisson, } 2 \text { assiettes) }\end{array}$ \\
\hline
\end{tabular}

Fig. 7. Distribution de la vaisselle par catégorie fonctionnelle, par ensemble.

\section{Représentation des formes et des catégories fonctionnelles par pièce et par unité fonctionnelle}

Les différents assemblages permettent de mettre en évidence un certain nombre de traits communs aux trois unités fonctionnelles (fig. 7). La vaisselle de cuisine se caractérise ainsi à chaque fois par un rapport d'environ un mortier pour dix à treize urnes. En ce qui concerne la vaisselle de table, les catégories prédominantes sont celles de présentation et de consommation des aliments liquides et semi-solides d'une part, et de service des liquides d'autre part, les récipients pour présenter et consommer les aliments étant deux fois plus nombreux que ceux pour verser. Les vases de présentation et de consommation des aliments solides sont rares, mais on recense tout de même au moins un plat à poisson par unité fonctionnelle. Enfin, la composition du service à boire apparaît assez variable d'un ensemble à l'autre, avec notamment des rapports diversifiés entre le nombre de vases à boire et, lorsque ceux-ci sont attestés, le nombre de récipients de présentation.

Dans l'UNF105, on observe des écarts de proportions importants entre la vaisselle de table et de cuisine d'un secteur à l'autre (fig. 8). La pièce 54B a en effet livré presque $50 \%$ de récipients de cuisson, contre seulement $15 \%$ pour la pièce $54 \mathrm{C}$. Ce dernier secteur présente en outre un répertoire plus diversifié, avec notamment la présence de deux mortiers et d'un plat à poisson, vases absents du secteur adjacent. La distribution des catégories fonctionnelles de l'UNF105 prise dans sa globalité se révèle proche de celle de l'UNF107, avec des taux équivalents de vaisselle culinaire (environ $30 \%$ ) et la même représentation des différentes familles de récipients composant la vaisselle de table, à l'exception des vases de présentation de la boisson, absents de l'UNF105. La complémentarité fonctionnelle des assemblages de vaisselle des secteurs 54B et $54 \mathrm{C}$ constitue dès lors un argument supplémentaire quant à la dépendance mutuelle des deux pièces. L'UNF106, se distingue quant à elle des deux autres par la prépondérance de la vaisselle culinaire. Avec 50 à $60 \%$ de la vaisselle selon les pièces, cette catégorie est plus fréquente dans ces secteurs que dans tous les autres espaces des différentes unités fonctionnelles, la proportion la plus élevée étant enregistrée dans la partie avant 58E. Enfin, la distribution des catégories fonctionnelles observée pour l'UNF107 est proche de celle de l'UNF105. La part de céramique culinaire oscille entre 20 et $40 \%$ de la vaisselle selon les pièces, avec, comme pour l'UNF106, un taux maximum dans la partie avant 58D2. Cette unité fonctionnelle se distingue en outre par la présence d'un bord de caccabé ou de lopas en céramique commune punique, seule attestation de vaisselle culinaire de typologie méditerranéenne pour les ensembles étudiés ici. Par ailleurs, les vases de présentation de la boisson apparaissent relativement nombreux à la fois en chiffre absolu et proportionnellement au nombre de vases à boire.

Ce bilan comparatif semble ainsi indiquer des différences sensibles entre les assemblages des trois unités fonctionnelles, mais aussi de nombreuses caractéristiques communes. Afin de faciliter la lecture de ces données, il a été choisi de prendre l'assemblage de l'UNF105 comme référence, et d'attribuer un coefficient (à l'unité près) à chacune des catégories fonctionnelles des UNF106 et 107 (fig. 9). Hormis pour les vases de présentation de la boisson qui apparaissent en nombres extrêmement variables, la représentation des autres récipients semble obéir à certaines règles de proportionnalité. En ce qui concerne l'UNF106, les différentes catégories de vaisselle de table sont 
numériquement équivalentes à celles de l'UNF105, exception faite pour les plats de présentation et de consommation des aliments solides, qui sont cinq fois plus nombreux. La vaisselle de cuisine est quant à elle beaucoup plus abondante, avec environ trois fois plus de vases de cuisson et cinq fois plus de mortiers. Dans l'UNF107, les catégories les mieux représentées comprennent toutes deux fois plus de récipients que pour l'UNF105. En revanche, les mortiers et les plats de présentation et de consommation des aliments solides sont respectivement trois et quatre fois plus nombreux. S'il n'est pas surprenant d'un point de vue statistique d'observer une plus grande variabilité dans la représentation des catégories fonctionnelles comprenant peu de vases, la relative régularité de la représentation des autres catégories rend possible la proposition d'un modèle de service commun aux trois unités fonctionnelles définies.

\section{Proposition d'un service-type de vaisselle}

Définir un service de vaisselle à partir du mobilier exhumé pose un certain nombre de difficultés, les principales étant d'estimer d'une part la proportion de matériel résiduel « hors service » au moment de la destruction, d'autre part le nombre de groupes occupant les différentes unités fonctionnelles. Si l'on part du principe que la proportion de matériel résiduel est équivalente d'un ensemble à l'autre, alors la variabilité du nombre de vases dans les différentes catégories fonctionnelles doit s'expliquer par d'autres facteurs. En l'occurrence, si l'on considère qu'un groupe (famille nucléaire ?) occupait l'UNF105, alors la présence de deux groupes dans l'UNF107 pourrait justifier que l'on y trouve le double de vaisselle à la fois de cuisine et de table. En revanche, ce raisonnement ne peut expliquer la surreprésentation des récipients de préparation et de cuisson par rapport à la vaisselle de table dans l'UNF106, qui ne semble dès lors pouvoir être interprétée qu'en termes fonctionnels.

Finalement, en se fondant sur les proportions observées dans les trois ensembles pour la vaisselle de table et dans les seules UNF105 et 107 pour la vaisselle de cuisine, et en divisant le nombre de vases dans chaque catégorie fonctionnelle par deux (UNF105 et 106) ou quatre (UNF107) on obtient un service-type tenant compte des différents paramètres précédemment évoqués (fig. 10).

Ce service peut être comparé à ceux proposés par Michel Bats pour la colonie massaliète d'Olbia (Hyères, Var) à la fois pour le $\mathrm{III}^{\mathrm{e}} \mathrm{s}$. et pour la fin du $\mathrm{III}^{\mathrm{e}} /$ début du $\mathrm{II}^{\mathrm{e}}$ s. av. J.-C. (Bats 1988, p. 209). Tandis que la batterie de cuisine est constituée à Olbia de vases typiquement grecs comme le faitout (ou lopas) et la caccabé, la quasi-exclusivité des urnes dans l'îlot I de Pech Maho met en lumière le caractère profondément indigène de la batterie culinaire de cet habitat, et peut être associée à une cuisine privilégiant les préparations bouillies et mijotées. Dans ce contexte, le bord de caccabé ou de lopas en céramique commune punique provenant de l'UNF107 doit probablement être plutôt considéré comme un récipient utilisé par des indigènes plutôt que par des individus d'origine punique éventuellement établis à Pech Maho. Par ailleurs, à l'image de ce que l'on observe à Olbia, la vaisselle culinaire de Pech Maho comprend un mortier. Ce type d'objet, à l'origine typiquement méditerranéen, semble au $\mathrm{III}^{\mathrm{e}} \mathrm{s}$. av. J.-C. pleinement intégré aux batteries de cuisine de la plupart des sites de Gaule méridionale, où il est fréquemment attesté par des pièces importées, mais aussi, dans le cas du Languedoc occidental, par des exemplaires de fabrication locale ou régionale.

En ce qui concerne la vaisselle de table, il semblerait que le service de Pech Maho soit assez proche de celui d'Olbia pour le III s. av. J.-C., avec une prédominance des vases pour la présentation et la consommation des aliments liquides et semi-solides, et un nombre plus restreint de cruches et de vases à boire. Les formes plates sont toutefois moins bien représentées à Pech Maho qu'à Olbia pour le $\mathrm{III}^{\mathrm{e}}$ s., et d'autant plus pour la fin du III et le début du $\mathrm{II}^{\mathrm{e}} \mathrm{s}$. av. J.-C. , période à laquelle leur proportion augmente de manière significative dans la colonie grecque. Cette augmentation indiquerait une plus grande consommation du poisson en friture avec un assaisonnement ou en sauce (Bats 1988, p. 105). À Pech Maho, la présence discrète de ces plats à la fin du $\mathrm{III}^{\mathrm{e}} \mathrm{s}$. av. J.-C. souligne donc à la fois des différences dans les habitudes de consommation des habitants des deux sites, mais peut aussi être associée à la réalisation de plats s'écartant des modèles culinaires traditionnels. On peut se demander si la consommation de ces récipients peu profonds, en rupture avec la vaisselle indigène, pourrait être un trait propre aux comptoirs littoraux. Plats et assiettes sont en effet attestés à Lattara (Lattes, Hérault) dès le IV ${ }^{\mathrm{e}} \mathrm{s}$. av. J.-C., également en petites quantités, à la fois en céramique à vernis noir et en céramique à pâte claire massaliète. En revanche, à une soixantaine de kilomètres de Lattes dans l'arrière-pays gardois, l'habitat du Marduel (Saint-Bonnet-du-Gard, Gard) n'a pour sa part livré aucun récipient de ce type et conserve à la fin du III $\mathrm{s}$. av. J.-C. une vaisselle de présentation et de consommation constituée exclusivement de contenants plus profonds (Py, Lebeaupin 1989). 


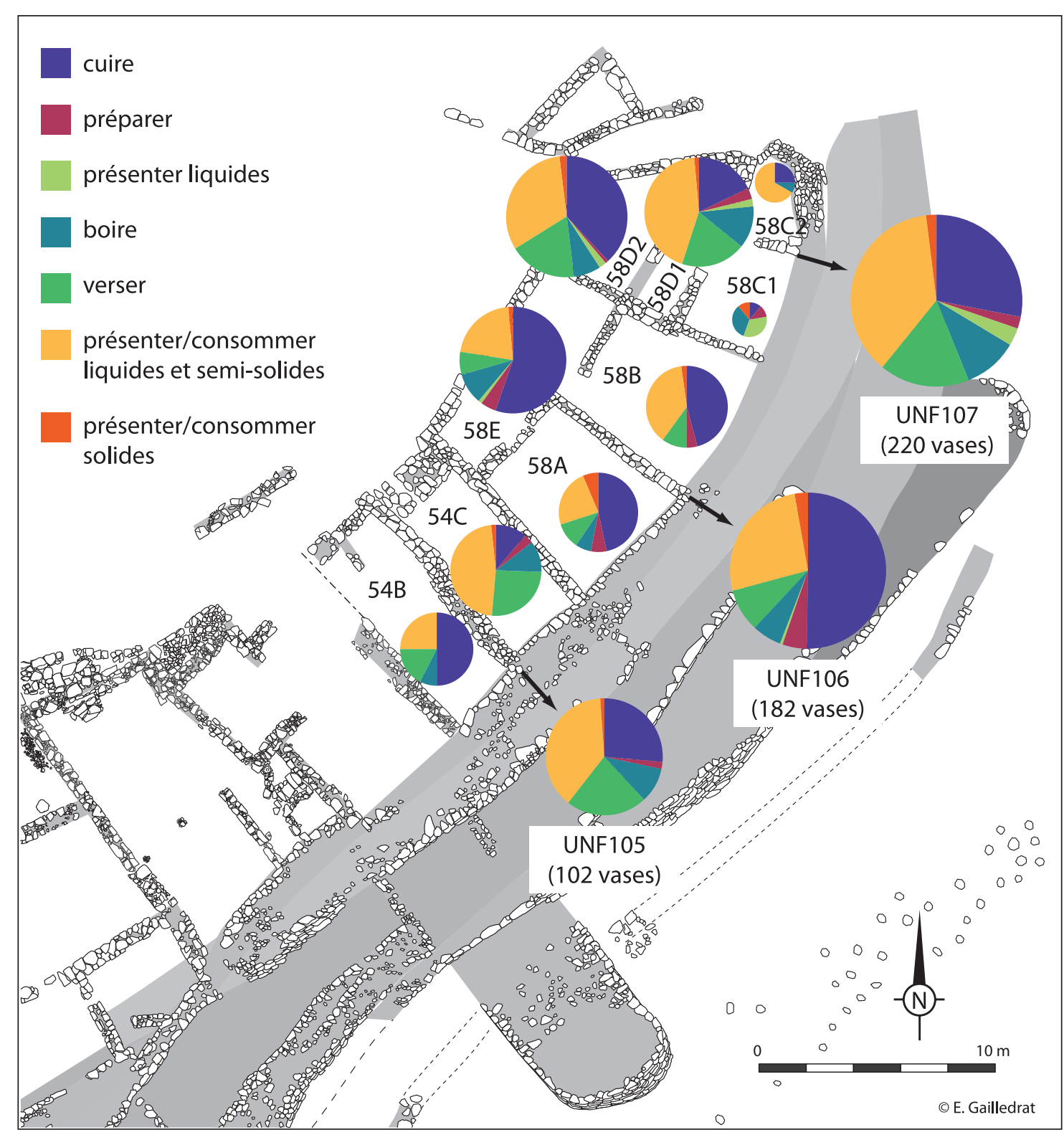

Fig. 8. Distribution de la vaisselle par catégorie fonctionnelle, par pièce et par ensemble.

\section{Caractérisation et spécificités de la vaisselle de l'îlot I de Pech Maho à la fin du III' $\mathbf{s}$. av. J.-C.}

De manière générale, la vaisselle de cuisine de Pech Maho du III ${ }^{e}$ s. av. J.-C. est marquée par la prédominance des productions non tournées, complétées toutefois par de la céramique commune tournée régionale attestée à des taux relativement élevés, ainsi que par des mortiers d'origine diversifiée. La vaisselle de table se caractérise quant à elle par une part importante de productions extra-régionales, provenant majoritairement du nord-est de la péninsule ibérique, mais aussi de la péninsule italique et de la colonie grecque de Marseille. La provenance de la vaisselle importée reflète ainsi non seulement la position économique du comptoir commercial, à l'interface entre les réseaux d'échanges du monde ibérique d'une part et massaliètes d'autre part, mais aussi son ouverture au commerce italique alors en plein développement en Gaule méridionale.

Les différentes productions offrent une complémentarité de répertoire, avec par exemple une majorité de vases ouverts pour la présentation et la consommation parmi les céramiques à vernis noir et une forte proportion de cruches parmi la céramique à pâte grise. Si la 


\begin{tabular}{|c|c|c|c|c|}
\hline & \multirow{3}{*}{\begin{tabular}{|c|} 
UNF105 \\
1 \\
\end{tabular}} & \multirow{3}{*}{$\begin{array}{c}\text { UNF106 } \\
3\end{array}$} & \multirow{3}{*}{\begin{tabular}{|c|} 
UNF107 \\
2 \\
\end{tabular}} \\
\hline & & & & \\
\hline Vaisselle & Cuire & & & \\
\hline $\begin{array}{c}\text { de } \\
\text { cuisine }\end{array}$ & écraser/mélanger & 1 & 5 & 3 \\
\hline \multirow{6}{*}{$\begin{array}{l}\text { Vaisselle } \\
\text { de table }\end{array}$} & présenter la boisson & 0 vase & 1 vase & 7 vases \\
\hline & \multirow{2}{*}{ Boire } & 1 & 1 & 2 \\
\hline & & 1 & 1 & 2 \\
\hline & verser & 1 & 1 & 2 \\
\hline & $\begin{array}{l}\text { Prés./cons. les aliments } \\
\text { liquides et semi-solides }\end{array}$ & 1 & 1 & 2 \\
\hline & $\begin{array}{l}\text { Prés./cons. les aliments } \\
\text { solides }\end{array}$ & 1 & 5 & 4 \\
\hline
\end{tabular}

Fig. 9. Représentation relative des catégories fonctionnelles par ensemble (coefficient 1 attribué aux catégories de l'UNF105).

céramique à pâte claire du Languedoc occidental est la catégorie la plus abondante, les nombreuses urnes de stockage dans son répertoire lui confèrent un moindre poids parmi la vaisselle, donnant ainsi une importance prépondérante aux productions en céramique grise de la côte catalane et roussillonnaise. Enfin, la présence d'éléments de services à boire en céramique attique au III $\mathrm{e}$ s. av. J.-C., utilisés probablement pendant plusieurs générations, est un trait récurrent dans l'ensemble de l'habitat. À tous ces points de vue, les assemblages de l'îlot I s'intègrent parfaitement dans le faciès de la vaisselle du reste du site.

Ceci étant, les unités fonctionnelles étudiées présentent également un certain nombre de spécificités. Tout d'abord, les récipients pour la présentation et la consommation des aliments solides y sont particulièrement fréquents. Si les plats à poisson sont attestés dans tout l'habitat, les assiettes et les plats retrouvés dans les ensembles 58A-58B-58E et 58C-58D (deux assiettes CL-MAS 111, deux plats CAMP-A 36 et une assiette ROSES 81) sont des formes rares à Pech Maho et constituent plus de la moitié des vases de ce type inventoriés sur le site pour le III ${ }^{\mathrm{e}} \mathrm{s}$. av. J.-C. En outre, les deux assiettes en céramique à pâte claire massaliète constituent pour l'heure des unicum dans l'habitat. Par ailleurs, ces deux unités fonctionnelles ont également livré les seuls guttus et lécythe du site (un guttus AT-VN 1192-1196, deux guttus ROSES 66 et un lécythe ROSES 63). Ces récipients, associés généralement au conditionnement et au service de l'huile - alimentaire ou non - ou du parfum, sont assez peu répandus en contexte indigène et renvoient plutôt à des usages des mondes grec et punique. Sans présager de l'utilisation qui a été faite de ces vases, tout comme des plats et des assiettes, leur présence reflète au moins la volonté de la part des occupants de l'îlot I d'acquérir et d'utiliser des objets s'éloignant des standards indigènes et indisponibles parmi les productions régionales.

\begin{tabular}{|c|c|c|}
\hline \multirow{4}{*}{\begin{tabular}{c} 
Vaisselle $\begin{array}{c}\text { de } \\
\text { cuisine }\end{array}$ \\
\cline { 2 - 3 }
\end{tabular}} & Cuire & 10 urnes \\
\cline { 2 - 3 } & présenter la boisson & 1 vase (cratère ou stamnos) \\
\cline { 2 - 3 } Vaisselle & Boire & $\begin{array}{c}4 \text { vases (1 skyphos, } \\
1 \text { cratéristiques, 2 coupes) }\end{array}$ \\
\cline { 2 - 3 } de table & verser & 1 gobelet \\
\cline { 2 - 3 } & $\begin{array}{c}\text { Prés./cons. les aliments } \\
\text { liquides et semi-solides }\end{array}$ & $\begin{array}{c}\text { 20 vases (coupelles, coupes, } \\
\text { bols, écuelles) }\end{array}$ \\
\cline { 2 - 3 } & $\begin{array}{c}\text { Prés./cons. les aliments } \\
\text { solides }\end{array}$ & $\begin{array}{c}1 \text { vase } \\
\text { (plat à poissons ou assiette) }\end{array}$ \\
\hline
\end{tabular}

Fig. 10. Proposition d'un service-type de vaisselle céramique pour la partie nord-est de l'îlot I à la fin du IIIIe S. av. J.-C.

\section{Remarques conclusives}

En définitive, il semblerait que les différences observées en premier lieu dans la distribution des catégories céramiques entre l'UNF106 d'une part et les UNF105 et 107 d'autre part doivent être relativisées. En effet, la forte proportion de vaisselle non tournée dans l'UNF106 semble être étroitement liée à une nécessité fonctionnelle, à savoir celle d'avoir à disposition plus de vases de cuisson et de stockage. Si le déficit de vaisselle d'importation extra-régionale par rapport aux importations régionales est bien réel, le détail des assemblages de vaisselle de table ne donne en rien l'image d'une consommation cantonnée aux modèles indigènes traditionnels. Bien au contraire, à l'instar de ce que l'on observe dans l'UNF107, le mobilier céramique traduit une demande sensible d'objets exogènes de la part des occupants de ce bâtiment. De plus, la présence de véritables services à boire semble indiquer que les habitants de l'îlot I étaient à l'initiative de pratiques de consommation collective de boissons alcoolisées. S'il est probable que ces pratiques s'inscrivent pleinement dans une logique indigène (Dietler 1990), il n'en reste pas moins que les récipients utilisés renvoient à des standards méditerranéens, et plus particulièrement du monde grec. Ainsi, la spécificité de l'équipement domestique dans cette partie du site, alliée à l'importance des activités commerciales et artisanales, paraît être le reflet du statut socio-économique élevé de ses occupants.

De manière plus générale, la vaisselle de Pech Maho à la fin du IIIe s. av. J.-C. est celle d'un comptoir littoral ouvert aux échanges. Un bref aperçu sur le mobilier lattois contemporain permet en effet de mettre en évidence un certain nombre de convergences, bien que, au contraire de Pech Maho, la cité de Lattara soit plus tournée vers Marseille que vers le monde ibérique. Ainsi, dans ces deux habitats, la batterie de cuisine est formée majoritairement d'urnes modelées, les récipients de typologie méditerranéenne n'étant attestés que de 
manière sporadique. La vaisselle de table est pour sa part dominée à Lattes par les importations massaliètes, mais la céramique à vernis noir, et plus particulièrement la céramique campanienne $\mathrm{A}$, tient une place non négligeable avec des bols, coupes et coupelles, mais aussi des vases à boire, des plats à poisson et des assiettes. À l'inverse, le contraste avec la vaisselle du Marduel est frappant. Dans cet oppidum de l'arrière-pays, la vaisselle de cuisine comme celle de table est constituée à la fin du III ${ }^{\mathrm{e}} \mathrm{s}$. av. J.-C. majoritairement de vases modelés (Py, Lebeaupin 1989).

En ce qui concerne les préparations culinaires, nous ne possédons pour l'heure que peu de renseignements sur les aliments consommés, les recherches concernant les niveaux de la fin du $\mathrm{III}^{\mathrm{e}} \mathrm{s}$. av. J.-C. étant encore en cours. En plus des aliments végétaux qui tenaient probablement une place importante dans le régime alimentaire, les habitants de Pech Maho se nourrissaient vraisemblablement de viande, de poisson et de coquillages, et en particulier de moules. Par ailleurs, la morphologie des vases de cuisine et de table suggère une prédominance des préparations bouillies et mijotées. Ceci étant, la présence d'une caccabé ou d'une lopas ainsi que de plusieurs plats à poissons ou assiettes pourrait indiquer la consommation épisodique de mets s'éloignant des recettes traditionnelles.

Enfin, l'étude de la vaisselle de table soulève une question centrale à propos des manières de table. La difficulté à distinguer les récipients de présentation de ceux de consommation est en effet loin d'être anodine puisqu'elle met notamment en relief la possibilité que ces deux fonctions soient mêlées, dans l'hypothèse où le consommateur mangerait directement à partir du récipient de présentation, sans utiliser de contenant intermédiaire. Dans le cas de Pech Maho, il semblerait que si certains vases sont manifestement trop petits (certaines coupelles) ou trop grands (écuelles) pour avoir servi de récipients intermédiaires, les bols et les coupes, attestés en grande quantité, semblent posséder une contenance adaptée à des rations individuelles. L'usage de vaisselle individuelle apparaît donc, dans ce contexte, tout à fait plausible, voire probable.

\section{Bibliographie}

Bats 1988 : BATS (M.) - Vaisselle et alimentation à Olbia de Provence (v. 350 v. 50 av.J.-C.). Modèles culturels et catégories céramiques. Revue Archéologique de Narbonnaise, suppl. 18, Paris, Éd. du CNRS, 1988, 272 p., 72 pl.

Belarte, Gailledrat, Principal 2011 : BELARTE (C.), GAILLEDRAT (E.), PRINCIPAL (J.) - The Functional and Symbolic Uses of Space in Western Mediterranean Protohistory: the Pech Maho Example (Sigean, Western Languedoc, France). Oxford Journal of Archaeology, 30/1, 2011, p. 57-83.

Dicocer : PY (M.) dir. - Dicocer. Dictionnaire des céramiques antiques (VII ${ }^{e}$ s.av.n.è. - VII ${ }^{\text {s }}$. de n.è.) en Méditerranée nord-occidentale (Provence, Languedoc, Ampurdan). Lattara, 6, Lattes, 1993, 624 p.

Dietler 1990 : DIETLER (M.) - Driven by Drink: The Role of Drinking in the Political Economy and the Case of Early Iron Age France. Journal of Anthropological Archaeology, 9, p. 352-406.

Principal 2004 : PRINCIPAL (J.) - Les céramiques à vernis noir. In : Gailledrat (E.) dir., Etude et mise en valeur du site archéologique de Pech Maho (Sigean, Aude), Projet Collectif de Recherche, Rapport final, 2004, p. 11-110.

Puig, Martin 2006 : PUIG (A.M.), MARTIN (A.) dir. - La colònia grega de Rhode (Roses, Alt Empordà). Museu d'Arqueologia de Catalunya, Sèrie Monogràfica, 23, Girona, 2006, 643 p.

Py, Lebeaupin 1989 : PY (M.), LEBEAUPIN (D.) et coll. - Stratigraphie du Marduel (Saint-Bonnet-du-Gard) IV. Les niveaux des IVe et III ${ }^{\mathrm{e}} \mathrm{s}$. av. n. è. sur le Chantier Central. Documents d'Archéologie Méridionale, 12, 1989, p. 121-190. 


\title{
Le mobilier céramique du Cayla de Mailhac (Aude) aux $V^{\mathrm{e}}$ et IV ${ }^{\mathrm{e}}$ s. av. n. è. : premières données
}

\author{
Sébastien Munos \\ Archeodunum (Agence de Nantes)
}

\section{Résumé}

L'oppidum du Cayla de Mailhac (Aude) est sans aucun doute à considérer comme un des gisements majeurs qui ont marqué l'histoire de la recherche en Protohistoire méridionale. Notamment sous l'impulsion de deux chercheurs Mailhacois, Odette et Jean Taffanel, de nombreuses opérations de fouilles ont été menées entre 1934 et 1982, et ces travaux ont été à l'origine de plusieurs publications dont certaines font encore référence. En dépit de cet historique des recherches particulièrement dense sur le Cayla de Mailhac, plusieurs séries de mobiliers issues des phases les plus récentes du site n'ont pas été étudiées. Sans avoir l'ambition de combler ce manque, ce travail propose de présenter les grandes lignes du faciès céramique du Cayla de Mailhac aux $\mathrm{V}^{\mathrm{e}}$ et $\mathrm{IV}^{\mathrm{e}} \mathrm{s}$. av. n. è., série issue des fouilles anciennes et à ce jour inédite.

Mots-clés : Languedoc occidental, Aude, second âge du Fer, céramique, faciès

\begin{abstract}
The settlement of Le Cayla in Maihac (Aude) can be considered as one of the most important archaological site which have count in the history of the research on the Iron Age in the South of France. Two searchers in particular, native of Mailhac, Odette and Jean Taffanel, have driven many excavations between 1934 and 1982, and thanks to all these works, they have published several books and some of them are still used as reference nowadays. In spite of this important story of research on the Cayla of Mailhac, many data related to the more recent phases of the site have not been studied yet. Even if we will not fill this lack in this short paper, we will show the main lines of the pottery of the Vth and IVth c. BC in Le Cayla of Mailhac, which has been discovered in old excavations and are still unpublished.
\end{abstract}

Keywords: western Languedoc, Aude, Second Iron Age, pottery, faciès 


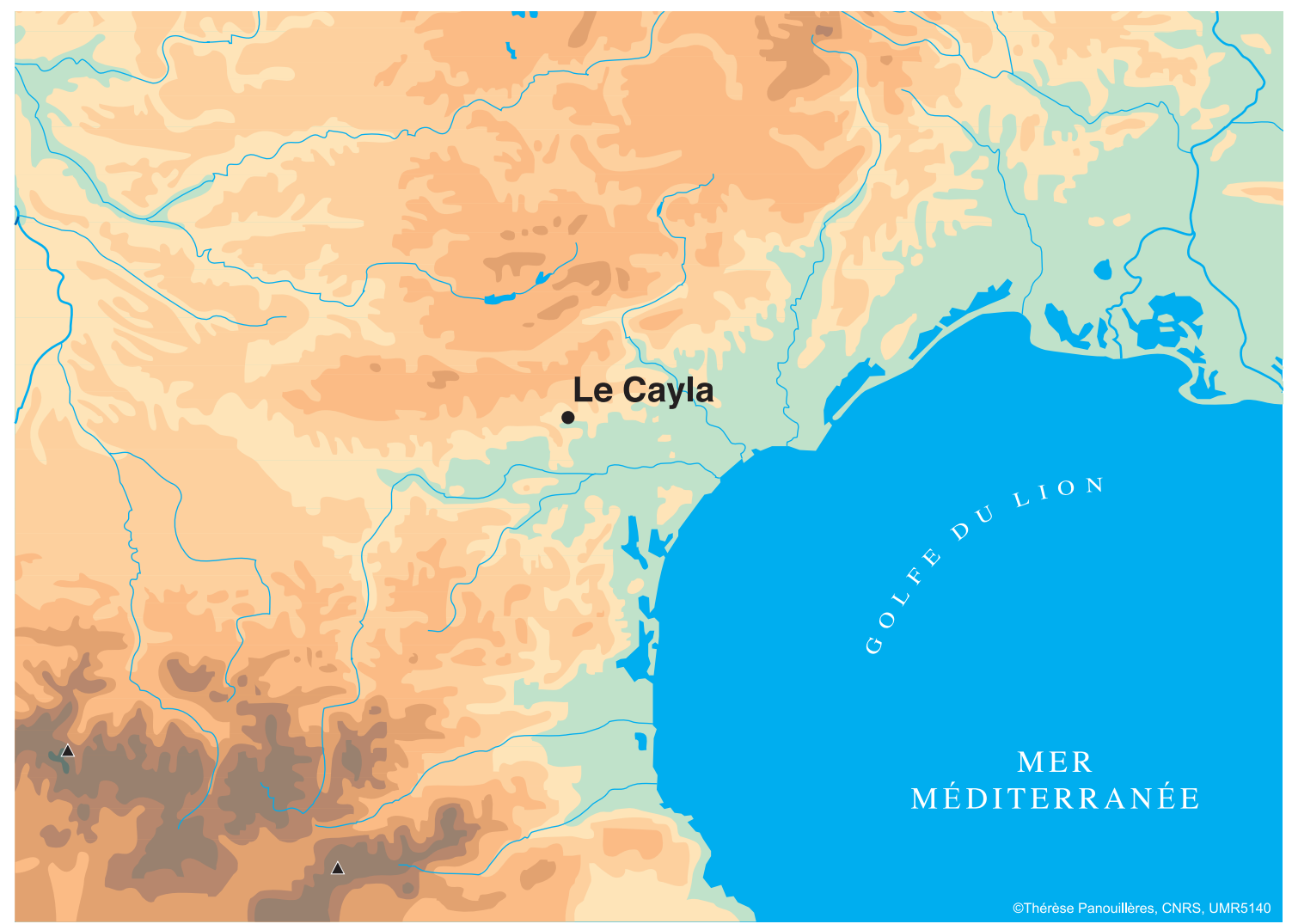

Fig. 1. Localisation de l'oppidum du Cayla de Mailhac (Aude).

\section{Introduction}

L'oppidum du Cayla de Mailhac peut sans aucun doute être considéré comme un des gisements majeurs qui ont marqué l'histoire de la recherche pour la Protohistoire méridionale. L'oppidum fait partie d'un vaste complexe de sites dont l'étude a été un moteur essentiel de la recherche archéologique du $\mathrm{XX}^{\mathrm{e}} \mathrm{s}$., à l'image des nécropoles éponymes du Moulin (Taffanel, Janin 1998) et du Grand-Bassin, contemporaines des premières occupations du Cayla (du IX ${ }^{\mathrm{e}}$ au Ve s. av. n. è.).

Le site, sur la commune de Mailhac dans le département de l'Aude, est installé sur les premiers reliefs des contreforts méridionaux du Minervois et culmine à 144 mètres d'altitude. Il tient une place importante à l'interface de deux entités géographiques différentes, la Montage Noire au nord et la plaine du Narbonnais au sud. À cet aspect, nous pouvons ajouter sa situation en bordure de l'embouchure du couloir audois, vecteur de communication privilégié entre le bassin Toulousain et la mer Méditerranée (fig. 1).

L'importance des vestiges présents sur la commune de Mailhac a été révélée très tôt et les investigations archéologiques y ont été nombreuses. Sous l'impulsion
d'Odette et de Jean Taffanel, une série d'opérations a été menée de manière plus ou moins continue sur le Cayla entre 1934 et 1982. Nonobstant ce nombre important d'investigations, il faut avouer que les travaux les plus complets ont porté sur les nécropoles, et ce malgré la publication en 1955 du premier tome de l'ouvrage de référence Le premier âge du Fer languedocien (Louis, Taffanel 1955). Parmi les nombreux ouvrages portant sur les sites mailhacois, la plupart de ceux concernant le Cayla sont centrés sur le premier Âge du fer, et plus précisément sur le $\mathrm{VI}^{\mathrm{e}}$ et le $\mathrm{V}^{\mathrm{e}} \mathrm{s}$. av. n. è., soit sur la phase dite du Cayla II (Gailledrat 2002). La masse de données accumulée pendant plus d'un demi siècle de recherches est sans aucun doute la raison principale de ce déséquilibre.

En dépit de cet historique des recherches particulièrement dense sur le Cayla de Mailhac et d'un nombre important de publications, plusieurs séries de mobiliers issues des phases les plus récentes du site (Cayla III et IV) restent à ce jour inédites. Sans avoir l'ambition de combler ce manque, ce travail propose de présenter les grandes lignes du faciès céramique du Cayla de Mailhac aux $V^{e}$ et IV ${ }^{e}$ s. av. n. è. (phase Cayla III), à partir de la série issue des fouilles anciennes et à ce jour inédite. 


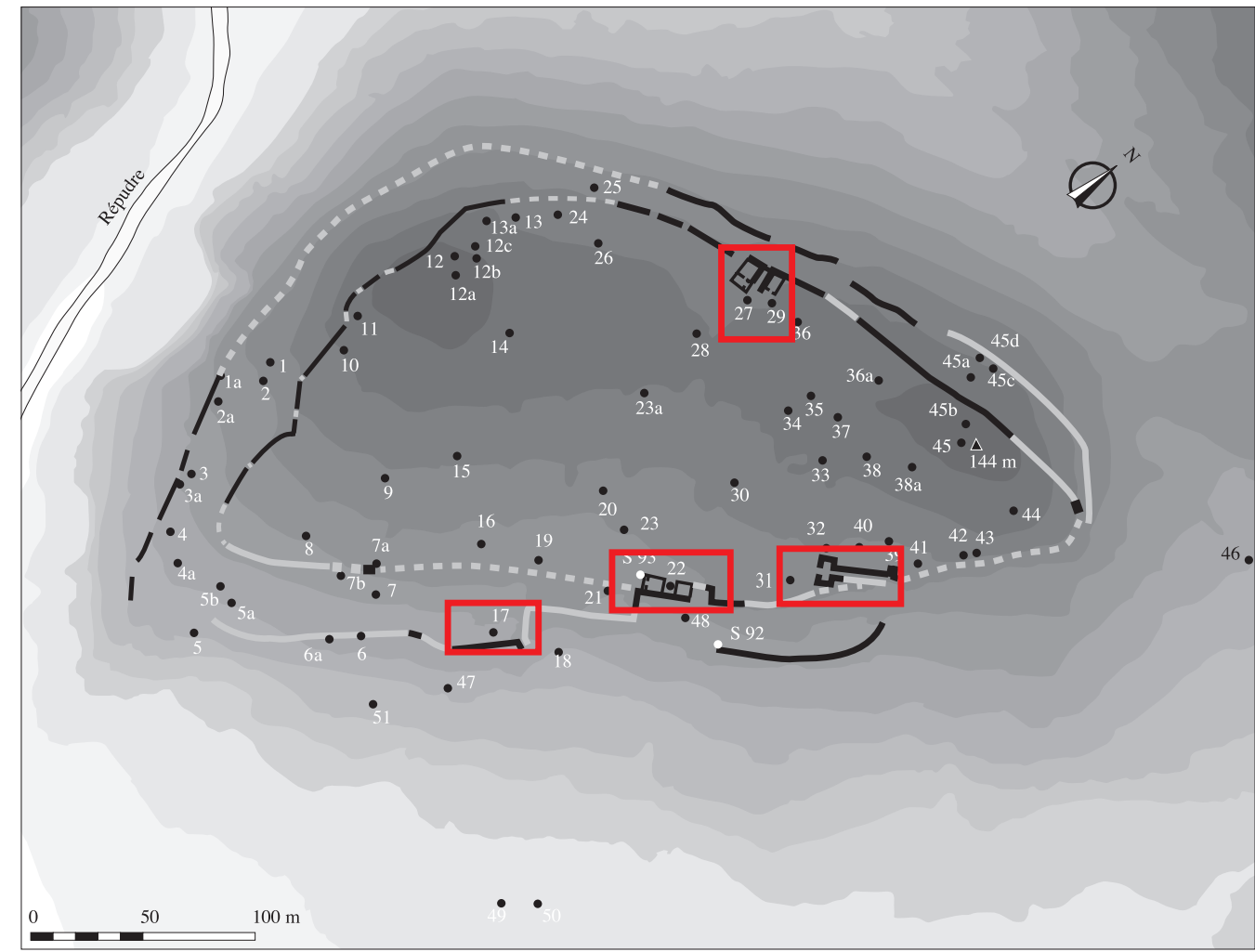

Fig. 2. Plan du Cayla (sont encadrés de rouge les secteurs pris en compte dans le cadre de l'étude).

\section{Le mobilier céramique du Cayla aux $V^{e}$ et $I V^{e} s . a v . n$. è.}

Les travaux détaillés ici reprennent les principaux résultats d'une étude plus complète effectuée dans le cadre d'un Master (Munos 2010). Pour cet article, le mobilier céramique étudié est pris en compte dans sa globalité et analysé par catégorie de céramique. Seule la phase III du Cayla est abordée, soit entre 475 et 325 av. n. è.

\section{Cohérence et limites des séries}

Pour une telle analyse de mobilier, issu exclusivement de fouilles anciennes, s'appliquent des limites qu'il convient de préciser.

En premier lieu, les sondages ouverts sur l'oppidum concernent des surfaces très variables, induisant des quantités de mobiliers différentes suivant les secteurs. Ensuite, la stratigraphie relevée par les fouilleurs est divisée par phase d'occupation, Cayla I à V (Taffanel 1957, Taffanel inédit), les Unités Stratigraphiques, plus fines, n'ont pas été individualisées. Enfin les séries ont dans le meilleur des cas un caractère homogène lâche, en raison de l'incertitude sur l'exhaustivité des ramassages et la présence régulière d'intrusions.
Afin de s'affranchir au mieux de ces limites et de réaliser une étude statistique, le choix de sélectionner les ensembles les plus représentatifs s'est imposé. Ainsi, six secteurs dont le mobilier céramique est suffisamment abondant (environ 15000 fragments au total) et cohérent sont ici pris en compte : les fouilles 17, 22, 27, 29, 31 et 40 (fig. 2).

En ce qui concerne la typologie, les normes employées sont celles utilisées dans le Dicocer (Dicocer 1993, 2001).

\section{Analyse du mobilier}

\section{La céramique grise monochrome}

Sa présence assez limitée dans le mobilier du Cayla III n'est pas une surprise puisqu'on se trouve à la fin de sa période de production. Elle représente en tout et pour tout un peu plus de $4 \%$ (nombre de fragments) de toute la vaisselle étudiée. Elle compte une quarantaine d'éléments typologiques dont le répertoire est essentiellement de la vaisselle de table (fig. 3), à l'exception de quelques exemplaires d'urnes (GR- MONO 7 et 9). La fonction «manger» (Dicocer 1993) est la plus abondante avec une nette majorité de plats à marli dont les éléments typologiques montrent une préférence pour les types GR-MONO $4 \mathrm{a}$ et $4 \mathrm{~b}$. Les coupes de type GR-MONO 1 et 2 sont 
aussi représentées dans la série. Les vases à boire sont exclusivement des gobelets, majoritairement carénés.

L'assemblage typologique de cette catégorie s'inscrit assez bien dans la lignée des observations faites pour la phase précédente, le Cayla II (575 - 475 av. n. è.). On retrouve la prédominance des plats à marli et des gobelets à profil sinueux. L'abondance de ces derniers semble d'ailleurs propre au faciès du Cayla à la fin du premier âge du Fer (Gailledrat 2002, p.232).

Avec des éléments dont les productions s'étirent jusqu'à la fin du $\mathrm{V}^{\mathrm{e}} \mathrm{s}$. av. n. è., il semble que la présence de cette catégorie sont bien attribuable au Cayla III. Plusieurs indices de la persistance des céramiques grises dans la première moitié du $\mathrm{V}^{\mathrm{e}} \mathrm{s}$. en Languedoc viennent renforcer cette remarque. On peut notamment citer un ensemble clos du milieu du Ves. sur le site de La Mayrale à Narbonne (Gailledrat et al.2003), ou encore un four de potier à Béziers (Hérault) qui a livré une petite série dont des rebuts de cuisson attestent une production au moins présente jusqu'en -450 (Ugolini, Olive 1987).

À Mailhac, cette catégorie montre encore certaines tendances du Cayla II où elle prend une part essentielle dans la vaisselle. Avec un répertoire proche mais nettement moins diversifié qu'au Cayla II, la céramique grise monochrome semble persister jusqu'à la fin du $\mathrm{V}^{\mathrm{e}} \mathrm{s}$. av. n. è., bien que plus discrètement.

\section{La céramique attique}

La quantité de cette céramique est anormalement faible d'autant plus que seulement la moitié des secteurs étudiés en ont livré des fragments. Ce constat tranche avec les informations fournies dans certaines publications $\mathrm{d}$ 'O. et $\mathrm{J}$. Taffanel où il est fait mention de coupes issues de la fouille 40 publiée en 1955 (Louis, Taffanel 1955). Cette série n'ayant pas été retrouvée, il est évident que l'échantillon est biaisé et inexploitable dans sa globalité.

Le mobilier de la fouille 22 présente toutefois une série plus abondante et offre un aperçu plus cohérent avec un taux de représentation de $7 \%$ des fragments de la vaisselle. Cette proportion est tout à fait comparable à celles observées sur les sites de Montlaurès (Narbonne, Aude) (Jully 1982) et d'Ensérune (Nissan-les-Ensérune, Hérault) (Dubosse 2007).

Tous secteurs confondus, la céramique attique à figure rouge est marginale avec douze fragments dont essentiellement des kylix et des coupes à tige (AT-FR Ky). Le taux de fragmentation, souvent élevé pour ce type de céramique, ne permet pas d'apprécier des décors pourtant bien présents. En somme, la seule donnée à retenir est que tous les individus témoignent d'apports entre -475 et -400 .

La céramique attique à vernis noir est un peu mieux représentée, notamment dans la fouille 22 . Le répertoire est davantage diversifié mais on note que les formes privilégiées sont les skyphoi et les Castulo cup. À cette vaisselle à boire s'ajoutent un cratère (AT-VN 59-62) et un cratérisque (AT-VN 705). Le seul examen de la fouille 22 montre deux assemblages qui correspondent à deux moments différents. Un premier centré sur le $\mathrm{V}^{\mathrm{e}} \mathrm{s}$. av. n. è., avec un répertoire composé de coupes (coupes sans tiges et Castulo cup) auxquelles on peut ajouter les kylix et les coupes à tiges à figures rouges ; le second, plus caractéristique du IV $\mathrm{e}$ s., voit son répertoire se restreindre aux skyphoi et au cratère.

\section{La céramique à pâte claire}

Les céramiques à pâte claire de type massaliète regroupent ici des productions diverses qui ne sont pas toutes originaires de Marseille. Si les claires peintes massaliètes sont sans doute présentes en complément des amphores de même origine, force est de constater une diversité des pâtes qui témoigne de la présence de productions originaires du Languedoc.

La céramique à pâte claire est présente à hauteur de $10 \%$ des fragments de la vaisselle, chiffre à pondérer avec la difficulté d'isoler certains éléments plus récents. La typologie des séries mailhacoises est assez diversifiée avec une nette abondance des vases liés à la boisson (fig. 4).

Le reste du répertoire est composé majoritairement de petites olpés (CL-MAS 521/522), d'urnes (CL-MAS 510) et d'un exemplaire d'amphore de table (CL-MAS 575). La majorité de ces individus sont vraisemblablement des productions d'influence grecque.

Les cruches représentent près de $30 \%$ des individus avec des formes essentiellement à embouchure ronde (CL-MAS 520 ou 540) et souvent à anse surélevée de type CL-MAS 520.

L'attribution de toutes les coupes à la fonction « boire » est difficilement acceptable en raison des différences dans les diamètres. La fonction " manger », déjà bien représentée par les bols CL-MAS 330, pourrait donc être complétée par quelques coupes. La vaisselle de table offre un large panel typologique (fig. 5) dominé par les coupes à une anse (CL-MAS 410), et notamment par la variante à vasque arrondie et à lèvre biseautée (CL-MAS 412a).

Cette catégorie présente une datation lâche qui englobe les $V^{e}$ et $I V^{e} s$. av. n. è. ; les coupes de type CL-MAS 412a tendent à resserrer cette chronologie entre -450 et -400 .

\section{La céramique ibérique peinte}

Cette catégorie minoritaire au Cayla III (près de $7 \%$ des fragments de la vaisselle) est omniprésente dans tous les ensembles, mais les éléments de formes étant rares, toute approche typologique est difficile. Le répertoire est presque exclusivement composé de vases 
de stockage et de conditionnement, ils se repartissent entre les jarres de type IB-PEINTE 1211, 1411, 1222c et 2222 c, et sont accompagnés de récipients davantage liés au conditionnement. Au sein de ces derniers, deux individus, un stamnos (IB-PEINTE 6131b) et un kalathos (IB-PEINTE 2711), présentent des chronologies postérieures à -400 pour l'un et à -300 pour l'autre.

Deux autres éléments viennent compléter ce panel, un bol à vasque hémisphérique (IB-PEINTE 3831), seul témoin évident de la vaisselle de table, et un support de vase (IB-PEINTE 5212).

De manière générale, ce mobilier présente une chronologie lâche comprise entre le $\mathrm{VI}^{\mathrm{e}} \mathrm{s}$. et le $\mathrm{III}^{\mathrm{e}} \mathrm{s}$. av. n. è. Assez marginale au sein du Cayla III, cette céramique atteste néanmoins d'une persistance des importations de vaisselle fine ibérique tout au long de cette période.

\section{La céramique ibéro-languedocienne}

Cette catégorie est de loin la mieux représentée, avec un taux de près de $50 \%$ de la totalité des fragments de la vaisselle.

Le répertoire typologique est très nettement dominé par les jarres, essentiellement de type IB-LANG 10, suivies par les urnes qui représentent respectivement $45 \%$ et $22 \%$ de la totalité des formes (fig. 6). Une grande diversité dans les formes des bords de jarre est présente sans que des groupes puissent être clairement définis, mais les bords profilés à l'aide d'un calibre sont toutefois les plus représentés. Cette variabilité difficilement quantifiable indique une production non-standardisée dans laquelle on constate cependant des formes privilégiées.

Les urnes (IB-LANG 50) sont majoritairement représentées par le type à col large évasé et à lèvre profilée (IB-LANG 51). Ces formes se répartissent suivant deux grandeurs de diamètres :12 à $16 \mathrm{~cm}$. et 18 à $26 \mathrm{~cm}$, les diamètres intermédiaires (de 16 à $18 \mathrm{~cm}$.) sont bel et bien présents mais de manière plus disparate.

La vaisselle de table, moins nombreuse, est loin d'être absente avec en tête les gobelets carénés et les cruches. Ces dernières comptent une majorité de formes à embouchure ronde (IB-LANG 60) dont une bonne partie est à rapprocher des types à anse surélevée, IB-LANG 63. Quelques exemplaires à embouchure trilobée complètent cet effectif (IB-LANG 70).

Les vases dont les fonctions sont attribuables à « manger » et « boire » sont relativement diversifiés mais les gobelets carénés (IB-LANG 110) dominent nettement (fig. 7). Ils sont essentiellement représentés par le type étroit (IB-LANG 112) à hauteur de $36 \%$ des formes. Les autres types de vases sont plus discrets avec quelques exemplaires de jattes IB-LANG 122 qui peuvent être caractérisées.

Deux assemblages typologiques se distinguent dans le temps, un premier entre -500 et -400 se caractérise par un vaisselier diversifié répartit équitablement entre les plats à marli, les jattes, les bols et quelques gobelets. Le second, entre -400 et -300 , est plus spécialisé avec la présence exclusive des gobelets carénés et l'apparition des coupes à une anse (IB-LANG 143).

La céramique ibéro-languedocienne présente une nette homogénéité dans les pâtes et les techniques de fabrications employées : les pâtes sont souvent bien cuites, fines et homogènes, les vases sont de couleur beige clair à rosé. Les décors sont en majorité des motifs géométriques de couleur brun rouge mat, parfois plus foncé. Les motifs sont essentiellement des bandes peintes horizontales et parallèles. Les cercles concentriques, plutôt caractéristiques du Ve s. av. n. è., sont plus rares mais le taux de fragmentation peut en être une des causes. Ces spécificités techniques couplées aux formes présentes rattachent incontestablement cette série aux productions ibéro-languedociennes dites du « groupe 1 ; aspect 1 »(Gailledrat 1993). Cette homogénéité des pâtes et l'omniprésence d'urnes et de jarres à bords profilés semblent confirmer la présence d'ateliers de productions à proximité du Cayla, hypothèse déjà avancée pour le VI ${ }^{\mathrm{e}}$ s. av. n. è. (Gailledrat 2002, p.235).

\section{La céramique non tournée}

Elle représente $20 \%$ des fragments du total de la vaisselle. Les urnes constituent la majorité du répertoire typologique avec $45 \%$ des formes de la catégorie (fig. 8) et sont suivies par les coupes qui représentent $30 \%$ des individus. Les urnes CNT-LOC U4 sont majoritaires alors que les vases ouverts et notamment les coupes et les jattes sont représentées à part quasiment égales (fig. 9).

Les séries étudiées ont livrées de nombreux éléments datés du premier âge du Fer à l'image des urnes basses (CNT-LOC U9) et des jattes (CNT-LOC J1). Ces formes sont présentes dans des quantités non négligeables et se mêlent aux éléments à chronologie plus lâche ainsi qu'à quelques individus caractéristiques du second âge du Fer. Ces derniers sont essentiellement des couvercles tronconiques (CNT-LOC V1) ou encore des coupes de type CNT- LOC C1b1. Alors que l'on pourrait considérer comme résiduelles les formes jugées anciennes, il suffit de mettre ces anomalies face à d'autres catégories dont l'homogénéité est évidente pour revoir cette affirmation. De ce point de vue, il faut sans doute considérer que certaines formes habituellement datées du premier Âge du fer persistent au moins pendant la première partie du Cayla III.

Enfin, la comparaison des données de cette catégorie avec celles du Cayla II montre certaines similitudes. Le répertoire typologique est en effet sensiblement le même à la différence que les urnes les plus abondantes sont de type CNT-LOC U3. En réalité la principale 


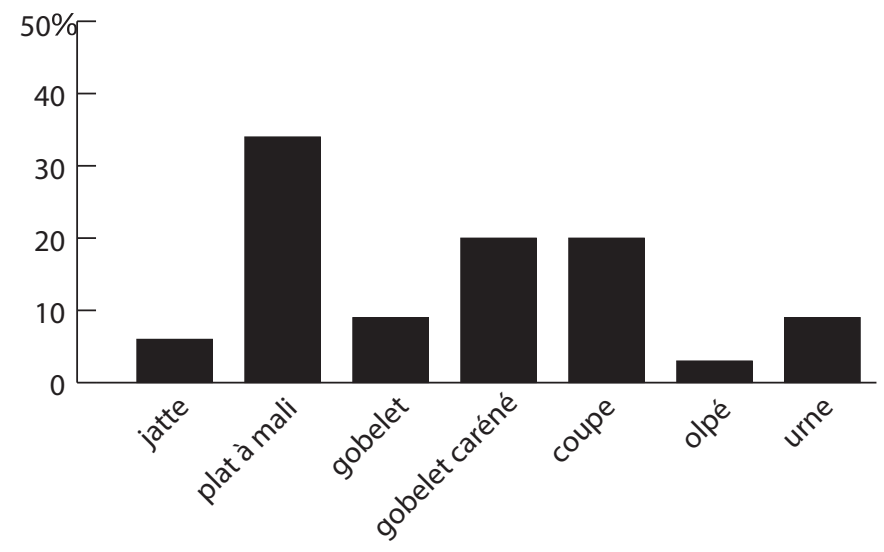

Fig. 3. Répartition typologique de la céramique grise monochrome $(n=48)$.

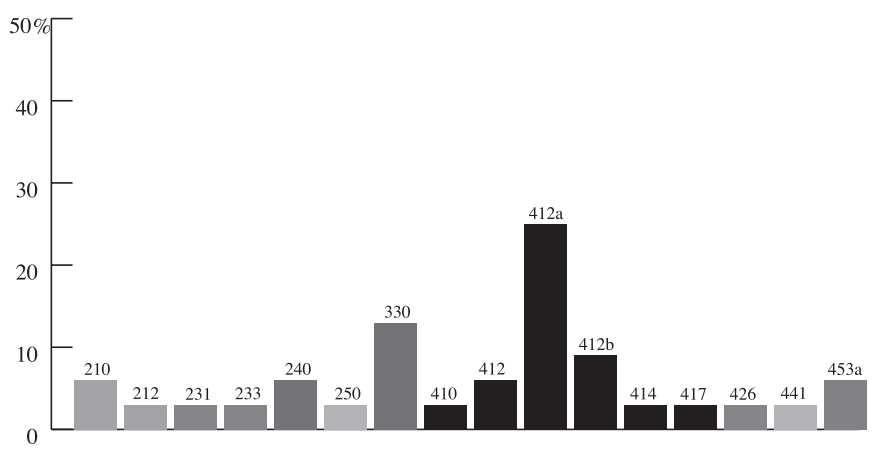

Fig. 5. Répartition typologique de la céramique à pâte claire ; fonction « manger » et « boire » $(n=40)$.

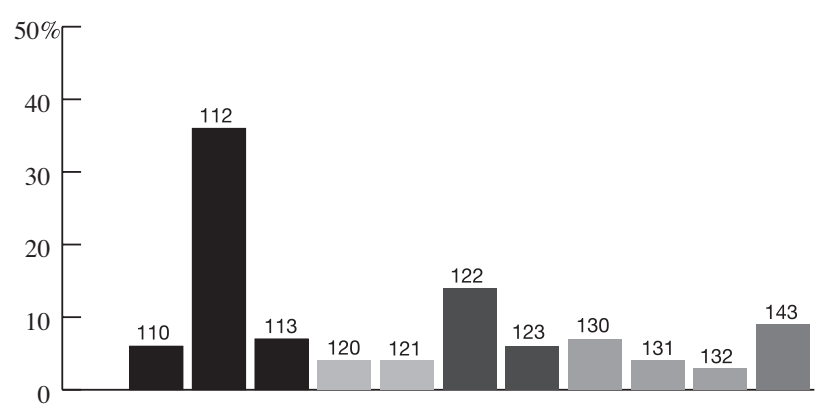

Fig. 7. Répartition typologique de la céramique ibéro-languedocienne ; fonction « manger » et « boire » $(n=80)$.

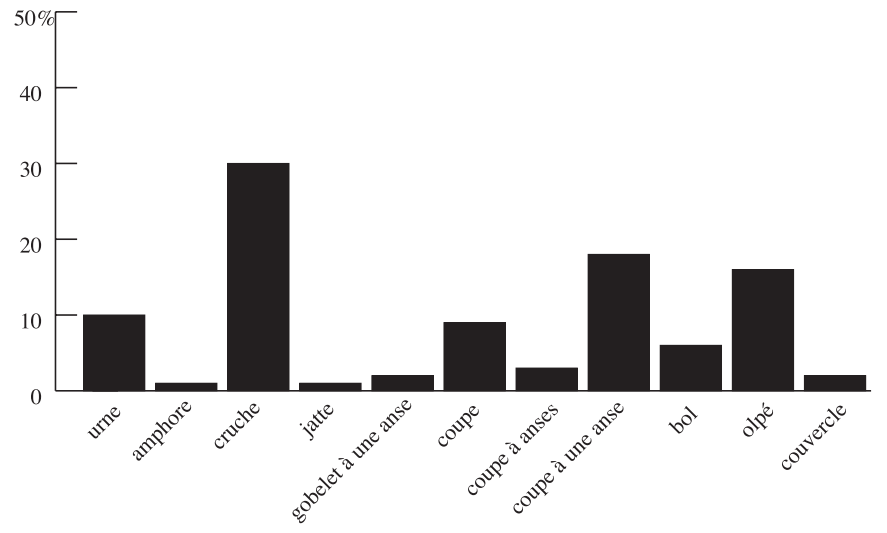

Fig. 4. Répartition typologique de la céramique à pâte claire $(n=91)$.

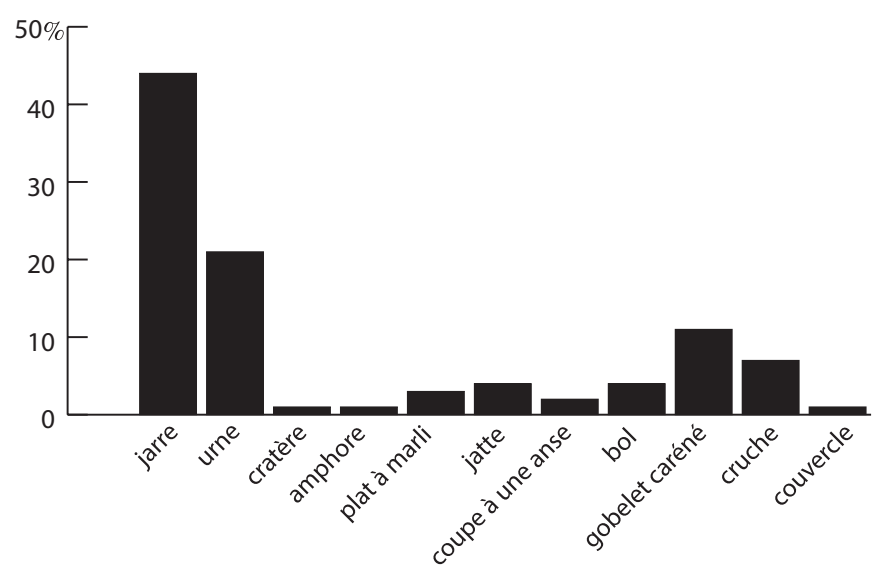

Fig. 6. Répartition typologique de la céramique ibéro-languedocienne $(n=311)$.

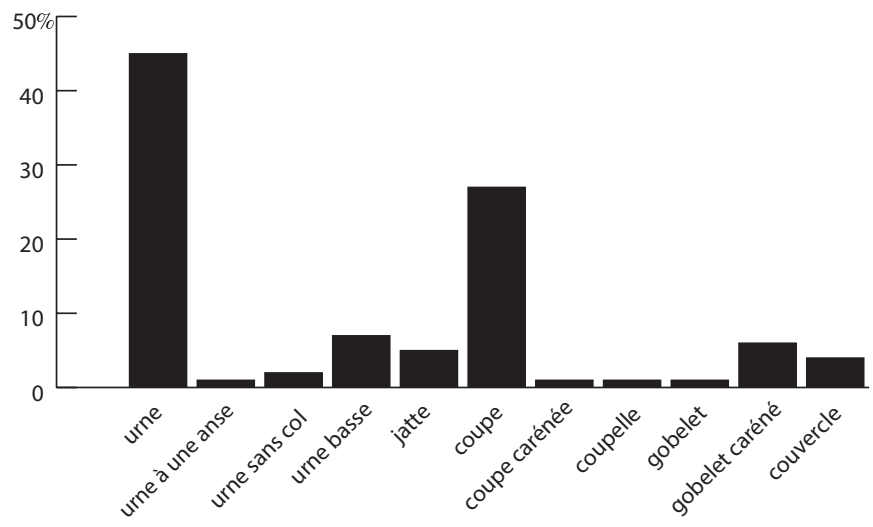

Fig. 8. Répartition typologique de la céramique non tournée $(n=175)$. 


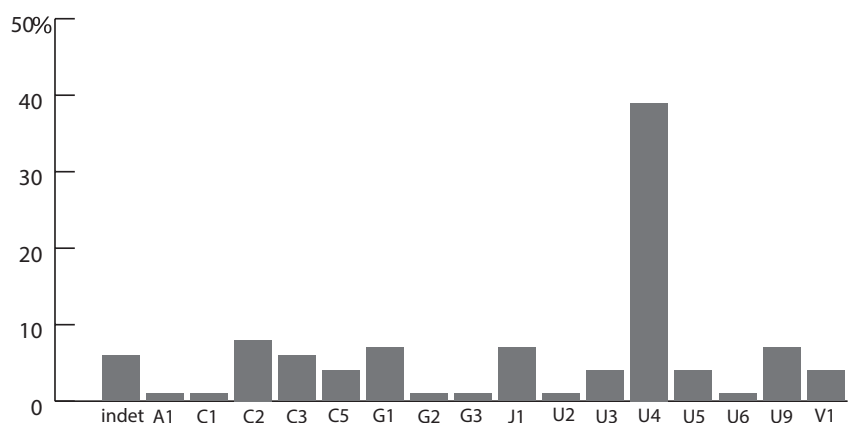

Fig. 9. Répartition typologique de la céramique non tournée $(n=195$, types Dicocer 1993).

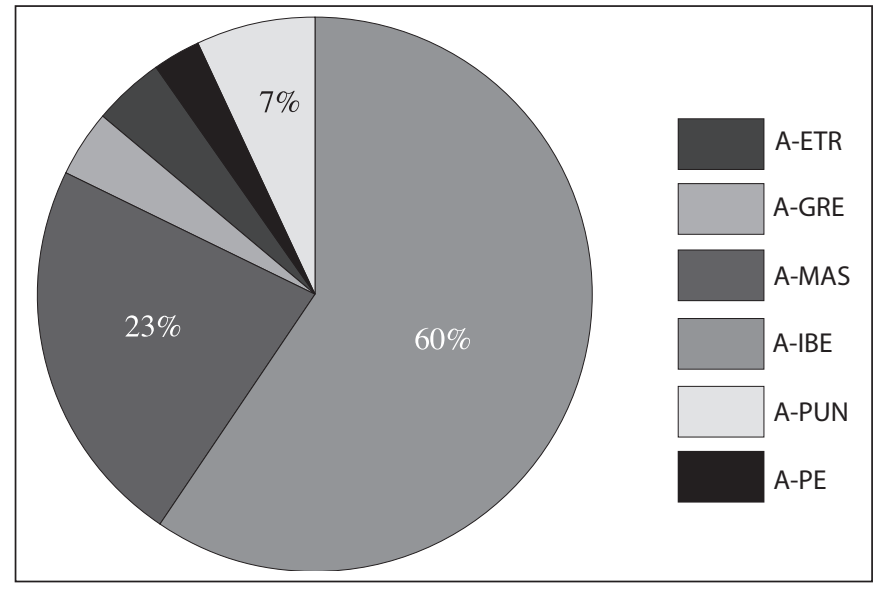

Fig. 10. Répartition par catégories du mobilier amphorique, pourcentages exprimés en NMI ( $\mathrm{n}=142$ bords).

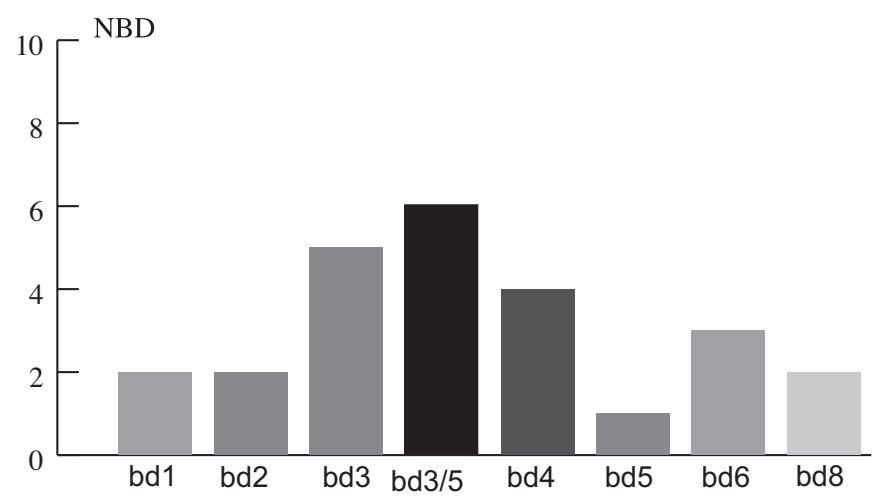

Fig. 11. Répartition typologique des bords d'amphore massaliète, exprimée en nombre de bords (types Dicocer 1993).

différence entre les deux périodes est l'écart de représentation de la céramique modelée dans la vaisselle ; elle est nettement plus importante au Cayla II. Il semble alors que cette céramique traditionnelle conserve le même aspect fonctionnel au second Âge du fer même si sa présence diminue au profit des céramiques tournées fines régionales, et notamment les productions ibéro-languedociennes.

\section{Les amphores}

Ce type de mobilier est évidemment soumis aux mêmes problèmes que ceux constatés pour la vaisselle. Certaines fouilles ont en effet montré des anomalies voire même l'absence d'amphores dans le mobilier. En ce sens, les amphores étrusques et grecques pourraient être considérées comme résiduelles, d'autant plus que la rareté des éléments typologiques s'y rattachant ne permettent pas de discuter de la chronologie. Les amphores puniques représentent $7 \%$ du total des formes. Il est difficile de préciser leur chronologie mais aucun argument ne peut formellement les exclure. Si l'on considère que ces amphores ont emprunté les mêmes réseaux commerciaux que les amphores ibériques, leur présence peut s'expliquer.

Les amphores les plus abondantes sont de loin les productions ibériques qui totalisent $60 \%$ des formes (et $80 \%$ des fragments) (fig. 10). L'état de fragmentation des séries empêche d'évaluer la typologie de ces amphores. De cette façon, les seules indications typologiques sont fournies par les bords ce qui interdit toute réflexion chronologique pour cette catégorie. Au final, la seule considération valable pour cette catégorie est que l'importation d'amphores ibériques est un des piliers du faciès du Cayla pour la période étudiée.

Les amphores massaliètes représentent quant à elles $23 \%$ des formes. Les éléments typologiques proviennent essentiellement des fouilles 22 et 40 et apportent les seuls éléments de datation. Les types de bords présents 
couvrent une période comprise entre le milieu du $\mathrm{VI}^{\mathrm{e}} \mathrm{s}$. et la fin du III ${ }^{\mathrm{e}} \mathrm{s}$. av. n. è. Quelques individus plus récents (A-MAS bd8) sont considérés comme intrusifs. Les formes anciennes, notamment A-MAS bd1 et bd2, sont caractéristiques des premières productions amphoriques de Marseille. Il semble alors clair qu'ils appartiennent à la phase précédente (Cayla II). Les bords de type A-MAS bd3 sont les mieux représentés (fig. 11), leur présence est centrée sur la toute fin du premier âge du Fer et le début du Cayla III. Le point le plus important est vraisemblablement la majorité des éléments datant du Ve $\mathrm{s}$. avec les bords de type A-MAS bd3/5 et 4 qui constituent des marqueurs de la première moitié du $\mathrm{V}^{\mathrm{e}} \mathrm{s}$. av. n. è.

\section{Le faciès céramique du Cayla au début du second âge du Fer}

L'étude de mobiliers issus de fouilles anciennes comporte bien des embûches dont il est souvent difficile de s'affranchir. Toutefois, les séries de céramiques présentées ici offrent une certaine homogénéité et les éléments intrusifs sont finalement assez peu fréquents. O. et J. Taffanel ont fixé les jalons chronologiques du Cayla III en -475/-450 et -325, et l'essentiel des éléments datant que nous avons pu voir vient confirmer cette chronologie. En l'absence de stratigraphie fine, il est impossible de réellement préciser ces dates mais cette étude permet, au moins, d'aborder la question du faciès céramique du Cayla aux Ve et IVe $s$. av. n. è.

En s'intéressant dans le détail à chaque catégorie de céramique, un découpage chronologique en deux temps du Cayla III s'est systématiquement dessiné.

Dans la première partie du Cayla III, on assiste à la raréfaction des céramiques ibériques peintes et grises monochromes. En effet, ces catégories majoritaires au Cayla II deviennent presque anecdotiques. La première est quasiment insignifiante dès le premier quart $\mathrm{du} \mathrm{V}^{\mathrm{e}} \mathrm{s}$. mais sa présence est ressentie tout au long du Cayla III. En revanche la raréfaction de la céramique grise monochrome, si elle est bien nette, doit être pondérée par la persistance des formes caractéristiques de la fin du Cayla II au moins jusqu'en -425 . À cela s'ajoutent des évolutions dans les répertoires typologiques de la vaisselle. En apparence la céramique ibéro-languedocienne, principal marqueur de ce faciès avec les amphores ibériques, connait peu de changement. Cependant une analyse détaillée permet de voir que si les jarres et les urnes sont toujours les récipients centraux, la vaisselle tend à se diversifier en empruntant notamment des formes au répertoire des céramiques grises monochromes. À cette diversification s'ajoute une certaine homogénéisation des formes de jarres et d'urnes, qui semble traduire l'affirmation de la production des ateliers locaux de céramique ibéro-languedocienne. Enfin, on note la persistance de formes en céramiques modelées héritées du premier Âge du fer.

Un peu avant -400 , la céramique grise monochrome semble disparaitre définitivement et on assiste à une réorganisation des répertoires typologiques.

La seconde partie du Cayla III est nettement moins représentée dans l'ensemble mobilier, et elle est même anecdotique dans certains des secteurs étudiés. En raison de cette absence, il est difficile de dessiner des tendances du Cayla III après -400 mais quelques remarques sont révélatrices. La première concerne la céramique ibérolanguedocienne qui connait des mutations au sein de son répertoire, les plats à marli et les jattes disparaissent face à un accroissement des gobelets et des coupes à une anse. On assiste également à l'apparition de nouveaux parallèles typologiques avec les céramiques à pâtes claires de Marseille.

Le second élément concerne la céramique attique dont les apports semblent moins fréquents. Les exemplaires à figures rouges sont désormais rares et ceux à vernis noirs présentent un répertoire typologique bien plus restreint. Ce dernier élément est à manipuler avec précaution étant donné les problèmes de représentativité constatés dans les ensembles. En tout les cas, il semble que la diminution des céramiques importées entamée dans la première partie du Cayla III prend plus d'ampleur.

Au final, la seconde partie du Cayla III est encore mal connue dans l'état actuel des données, et pourrait même correspondre à un hiatus. Il est encore difficile de comprendre les modalités de la diminution du mobilier céramique à cette phase. Beaucoup de raisons peuvent être évoquées dont évidemment le manque de cohérence des données. L'absence de marqueur du $\mathrm{III}^{\mathrm{e}} \mathrm{s}$. va dans le sens d'une limite du Cayla III vers -325. La transition entre le Cayla III et IV est alors marquée par la raréfaction de la céramique ibéro-languedocienne et l'apparition de la céramique non tournée à pâte micacée (Séjalon 2001).

Le faciès céramique du Cayla de Mailhac aux Ve et $I^{\mathrm{e}}$ s. av. n. è. est donc avant tout caractérisé par l'affirmation des productions locales de céramiques tournées fines au détriment des importations. Toutefois il parait clair que cette transition, entamée dans le courant du $\mathrm{VI}^{\mathrm{e}}$ s., prend réellement de l'ampleur dans le premier quart du Ve s. et s'achève peu avant -400. Évidemment il s'agit de premiers résultats qu'il conviendra de compléter avec d'autres données issues du Cayla, avant de pouvoir replacer ce faciès au sein du contexte ibéro-languedocien du début du second âge du Fer. 


\section{Bibliographie}

Dicocer 1993 : PY (M.) DIR. - Dictionnaire des céramiques antiques en Méditerranée nord-occidentale. Lattes, 1993, 622 p. (Lattara, 6).

Dicocer 2001 : PY (M.) DIR., Corpus des céramiques de l'Âge du Fer de Lattes (fouilles 1963-1999). Lattes, 2001. (Lattara, 14)

Dubosse 2007 : DUBOSSE (C.) - Ensérune, Nissan-lez-Ensérune (Hérault) : les céramiques grecques et de type grec dans leurs contextes (VI $\left.{ }^{e}-I V^{e} s . a v . n . \grave{e}.\right)$, Lattes, 2007, 567 p. (Monographies d'Archéologie Méditerranéenne, 23). Gailledrat 1993 : GAILLEDRAT (E.) - Les céramiques peintes ibériques au $\mathrm{V}^{\mathrm{e}}$ siècle avant J.-C. en Languedoc Occidental et Roussillon, dans Contribution au problème ibérique dans l'Emporda et en Languedoc, Documents d'Archéologie Méridionale, 16, Lattes, pp. 64-79.

Gailledrat 2002 : GAILLEDRAT (E.), TAFFANEL (O.), TAFFANEL (J.) - Le Cayla de Mailhac (Aude), les niveaux du premier âge du Fer (VI ${ }^{e}-V^{e}$ s. av.J.-C.), Lattes, 2002, 271 p. (Monographies d'Archéologie Méditerranéenne, 12).

Gailledrat et al. 2003 : GAILLEDRAT (E.), SOLIER (Y.), BOISSON (H.) Une fosse de la seconde moitié du Ve s. av. J.-C. à la Mayrale (Narbonne, Aude), Documents d'Archéologie Méridionale, 26, 2003, pp. 159-169.
Jully 1982 : JULLY (J.-J.) - Céramiques grecques ou de type grec et autres céramiques en Languedoc méditerranéen, Roussillon et Catalogne. Études sur l'Hérault, 13, fascicule 1, 1982, pp. 39-45.

Louis, Taffanel 1955 : LOUIS (M.), TAFFANEL (O.), TAFFANEL (J.) - Le premier âge du fer languedocien, I, Les habitats. Bordighera, Montpellier, 1955, $207 \mathrm{p}$. Munos 2010 : MUNOS (S.) - L'oppidum du Cayla de Mailhac (Aude), le faciès céramique au début du second Âge du fer ( $V^{k}-I V^{k} s . a v . n$.è.). Mémoire de Master 2, Université Paul-Valéry/Montpellier 3, Montpellier, 2010, 141 p. Séjalon 2001 : SEJALON (P.) - La céramique non tournée micacée du bas Languedoc Occidental, Document d'Archéologie Méridionale, 24, Lattes, 2001, pp. 163-171.

Taffanel inédit : TAFFANEL (O.), TAFFANEL (J.) - Cahiers de fouilles $d u$ Cayla, inédits.

Taffanel 1957 : TAFFANEL (O.), TAFFANEL (J.) - L'étude stratigraphique sur l'oppidum du Cayla (commune de Mailhac, Aude), Les études roussillonnaises, VI, fascicules 1-2, Perpignan, 1957, pp. 7-34.

Taffanel, Janin 1998 : TAFFANEL (O.), TAFFANEL (J.), JANIN (Th.) - La nécropole du Moulin à Mailhac (Aude). Lattes, 1998, 436 p. (Monographies d'Archéologie Méditerranéenne 2).

Ugolini, Olive 1987 : UGOLINI (D.) ET OLIVE (C.) - Un four de potier du Ve s. av. J.-C. à Béziers, place de la Madeleine, Gallia, 45, 1987, p. 12-28. 



\title{
La céramique « commune massaliète » du site de Lattara (Lattes, Hérault) au Ve siècle avant notre ère (-475/-375) Première approche typologique et essai de classification
}

\author{
Émilie Compan
}

Chercheur associé UMR 5140, équipe Préhistoire et Protohistoire méditerranéennes, Montpellier-Lattes

\section{Résumé}

L'étude de la céramique claire massaliète du site de Lattes (-475/-375) a permis de mettre en évidence une production massaliète de céramique commune se différenciant des autres productions de céramique claire fine par une pâte plus grossière, au dégraissant de mica en paillettes plus grosses, avec une pâte proche de celle des amphores massaliètes. On regroupera ainsi sous le terme de « céramique commune massaliète » des vases tournés, destinés à la préparation et/ou à la cuisson des aliments, qui s'inspirent des formes des céramiques grecques et non tournées locales, la forme la plus emblématique étant le mortier massaliète. Cette mise en évidence d'une nouvelle catégorie céramique nous permet de progresser dans l'identification des différentes productions dites massaliètes, provenant de la cité phocéenne mais aussi d'ateliers locaux.

Mots-clés : commune, typologie, protohistoire, Languedoc oriental, Lattes, Marseille, mortiers massaliètes, production

\footnotetext{
Abstract

The study of clear massaliet pottery found in the archaeological site of Lattes (-475/-375) has highlighted a common massaliet pottery production differing from other productions of fine pottery clear by a coarse paste, the degreaser mica into larger flakes with a dough similar to that of massaliet amphorae. This will bring together under the term "massaliète rought pottery" turned vases, made of the same stuff that massaliet amphorae, for the preparation and / or cooking, inspired by the shapes of Greek ceramics and hand made pottery, the most iconic shape is massaliet mortar. This demonstration of a new class ceramic enables us to progress in the identification of different productions massaliètes say, from Marseille but also local workshops.
}

Keywords: common pottery, typology, protohistory, western Languedoc, Lattes, Marseille, massaliet mortar, production 


\section{Présentation du corpus}

La ville portuaire antique de Lattara se trouve en Languedoc oriental, à $5 \mathrm{~km}$ au sud de Montpellier, sur la commune de Lattes. Elle est située à l'embouchure du Lez, fleuve côtier du département de l'Hérault et au bord d'un étang lagunaire permettant l'accès à la mer Méditerranée (fig. 1). Lattara fait partie des nombreux comptoirs de commerce gaulois qui maillent le littoral du Languedoc oriental à l'Âge du Fer dont Le Cailar et Espeyran, installés en bord de lagune au cours du $\mathrm{VI}^{\mathrm{e}} \mathrm{s}$. av. n. è., dans la dynamique liée à l'intensification des échanges avec le monde méditerranéen. Intégré dès le $\mathrm{V}^{\mathrm{e}} \mathrm{s}$. av. n. è. à la zone d'influence commerciale de la ville phocéenne de Marseille, Lattara devient un établissement clé pour l'importation des produits massaliètes, qui dominent le répertoire céramique régional, et pour leur redistribution vers l'arrière pays. Ce quasi monopole de Marseille sur le marché lattois perdura jusqu'au $\mathrm{II}^{\mathrm{e}}$ s. av. n. è.

L'étude des collections de la céramique «dite » grecque d'Occident du Ve $s$. av. n. è. du site de Lattes ${ }^{1}$ a permis de mettre en évidence et d'isoler une production massaliète de céramique culinaire que nous nommerons « céramique commune de Marseille ». Les céramiques grecques d'Occident, englobant les mortiers massaliètes, constituent une part essentielle des vases présents sur la table au Ve s. av.n. è., et plus de $40 \%$ de la vaisselle vers -425 . L'utilisation de cette vaisselle grecque ou de tradition grecque témoigne d'un phénomène d'acculturation et de fortes relations entre les populations locales et les marchands grecs. Le répertoire des formes est associé à la consommation du vin.

Les niveaux d'occupation datés du $\mathrm{V}^{\mathrm{e}} \mathrm{s}$. av. n. è. ont été mis au jour à Lattes principalement lors des fouilles archéologiques des îlots d'habitation $\mathrm{n}^{\circ} 1$ (sous la responsabilité d'Eric Gailledrat) et $\mathrm{n}^{\circ} 27$ (sous la responsabilité de Denis Lebeaupin), qui ont livré un grand nombre de contextes homogènes (fig. 3). L'habitat de la zone 27 se situe le long de la courtine sud du rempart, près de la porte, au sud du site ${ }^{2}$; la zone 1 correspond à un quartier d'habitat appuyé au rempart oriental ; pour ces deux zones, la période d'occupation analysée pour cet article s'étend de -475 à -375 .

\footnotetext{
1 Cette étude a été effectuée dans le cadre d'une thèse de doctorat. Elle portait sur quatre types de céramiques : la céramique à pâte claire massaliète, peinte ou non peinte, la céramique grise monochrome, les mortiers massaliètes et la céramique pseudo-attique, au sein du mobilier des fouilles programmées du site de Lattes de 1984 à 2008.

2 Les niveaux d'habitations dits étrusques de cette zone, datés du premier quart du V $V^{\mathrm{e}} \mathrm{s}$. av. n. è. (vers -500/-475) n'ont pas été étudiés.
}

Ces contextes d'habitat permettent de disposer d'un matériel céramique très abondant, plutôt fragmentaire mais très bien conservé. Ces deux zones de fouilles, étudiées depuis près de vingt ans, fournissent une datation précise au quart de siècle près et des niveaux d'occupations homogènes bien définis permettant la mise en place d'une typo-chronologie précise.

\section{Caractérisation de la céramique « commune massaliète »}

\section{Définition et caractéristiques}

La catégorie générale de " céramique à pâte claire massaliète et de tradition massaliète » (Bats 1993, 206) englobe un ensemble de vases à pâte calcaire et à cuisson oxydante produits par Marseille ou produits selon des techniques grecques marseillaises dans d'autres ateliers grecs ou indigènes. Il s'agit donc plus d'un groupe de productions que d'une production particulière (Py et al . 2001). Lors de la création du DICOCER en 1993, il a semblé plus opportun de regrouper sous cette appellation l'ensemble des céramiques dites « massaliètes » à pâte claire fine ; et il n'y a pas eu de création d'une catégorie particulière pour les céramiques communes massaliètes. En effet, peu de productions ont été clairement identifiées et peu d'études ont été menées à leur terme pour permettre ces distinctions qui se révèlent souvent difficiles. Peu d'études archéométriques en particulier ont été menées, visant à mettre en évidence des différenciations dans la provenance des argiles ; ces dernières se retrouvent d'ailleurs souvent confrontées aux contaminations organiques et salines du fait de la nature du terrain d'enfouissement.

Une étude de la texture de la pâte des exemplaires de Lattara a été entreprise au laboratoire d'archéométrie de l'université de Barcelone, ERAUB, afin de mettre en évidence les possibles différences de provenance des argiles et de ce fait les différents ateliers ${ }^{3}$. Une comparaison de cette texture avec celle des exemplaires marseillais et péri-marseillais a également, été effectuée. Selon les analyses, trois tessons classés en COM-MAS ne correspondaient pas au même groupe de pâte.

3 Cette étude a fait l'objet d'un poster en 2009 lors du XVII Colloque du GMPCA, "Ressources, Sociétés, Biodiversité » (6-10 avril 2009, Montpellier) : Émilie Compan et Veronica Martinez, Approximation de la provenance de céramique à pâte claire massaliète. 
Cependant, il devient indispensable aujourd'hui d'isoler clairement les productions connues dans un premier temps, et de mettre en évidence, dans un second temps, les typologies des vases qui leur sont associées comme cela a été le cas pour les productions des sites archéologiques de Martigues (Chausserie-Laprée 1988 et 1995) et de Béziers (Ugolini 1988).

La catégorie céramique appelée désormais « commune massaliète » a était déjà identifiée et isolée dans plusieurs travaux. En 1960, François Villard, dans son étude sur la Céramique grecque de Marseille, $\mathrm{VI}^{\mathrm{e}}-\mathrm{IV}^{\mathrm{e}} \mathrm{s}$. Essai d'histoire économique, différenciait déjà quatre types d'argiles utilisées dans la céramique locale dont « une argile qui varie du brun au rouge clair, tendre, assez grossière, cette technique se caractérise par une quantité inhabituelle de grosses paillettes de mica. La surface qui en est couverte, prend souvent, malgré son irrégularité, un aspect chatoyant » (Villard 1960, p.58). Il note que « l'argile à grosses paillettes de mica est typiquement locale. Elle résulte probablement d'un mélange de terre extraite d'une des deux couches des carrières de Saint-Henry et de fragments de micaschiste, apporté de l'extérieur: des blocs de minéraux très fortement micacés ont été en effet trouvés, à diverses reprises dans les fouilles » (Villard 1960, p.58 note 4). F. Villard précise que « cette argile très micacée a été non seulement utilisée pour des pesons mais aussi pour des canalisations, des tuiles hellénistiques ou romaines et même pour des éléments d'architecture »(Villard 1960, p.58 note 4). Michel Bats différencie de même, dans son ouvrage Vaisselle et alimentation à Olbia de Provence (v.350 - v. 50 av. JC.), modèles culturels et catégories céramiques (Bats 1988, p. 168), deux groupes principaux de pâte. Selon lui, il n'y a pas de différence entre la pâte utilisée pour les vases en céramique dite " claire peinte » et celle des vases en céramique dite " claire ancienne » qui se caractérisent par « une pâte fine, jaune clair ou rose clair, la plupart du temps sans mica visible à l'œil nu et avec peu de particules rouges » (Bats 1988, p.167-168). Les nuances de pâtes sont cependant multiples du fait des différentes productions - identifiées ou non - en Provence et en Languedoc : pâte plus ou moins serrée, bien cuite et dure ou plus souple et friable, de ton beige ou rosâtre, pure ou présentant de fines particules de micas. Le second groupe présente « une pâte relativement grossière, très proche de celle utilisée pour les amphores mais avec des paillettes de mica et des nodules rouges moins gros, de couleur le plus souvent rosée : elle est utilisée essentiellement pour quelques grands récipients (lékanés) et mortiers et exceptionnellement pour des formes de céramique fine » (Bats 1988, p.168).
Cette production de céramique " commune massaliète » se différencie donc des autres productions de vaisselle en céramique claire massaliète à pâte fine, par une pâte plus grossière, dure, beige à rose clair, au dégraissant de mica en paillettes plus grosses (fig. 4). Elle se rapproche très nettement de celle des amphores massaliètes et englobe les pâtes des mortiers massaliètes, jusqu'à présent classés avec la céramique claire massaliète pour la typologie. Notons que les éléments de panses des vases en céramique commune massaliète sont difficilement isolés des tessons d'amphore massaliète lors des comptages et de ce fait cette catégorie céramique se retrouve sous estimée en nombre de fragments par rapport aux autres classes de vaisselle.

\section{Approche typologique et classification}

On regroupera ainsi sous le terme de " céramique commune massaliète » des vases tournés dont la pâte est composée d'une grande quantité de paillettes de micas, plus ou moins grosses, de couleur beige à rougeâtre, proche de celle des amphores massaliètes de même provenance. Les parois sont plus épaisses que celles des vases de service. Il s'agit de formes destinées, dans la grande majorité des cas, à la préparation et/ou à la cuisson des aliments et des boissons. Le répertoire des formes pourrait s'inspirer des céramiques grecques et des céramiques non tournées locales, la forme la plus emblématique étant le mortier massaliète.

Cette nouvelle catégorie céramique sera classée sous le code COM-MAS selon les normes du projet Dicocer, Dictionnaire des céramiques anciennes, et se distinguera ainsi des céramiques de vaisselle classées en CL-MAS. Toutefois, pour une meilleure compréhension et utilisation de cette typologie, la classification des formes en céramique claire massaliète (CL-MAS) établie dans le Dicocer 1 nous servira de base pour élaborer la typologie des vases en céramique commune massaliète, principalement en ce qui concerne les mortiers : la forme bien connue, CL-MAS 621 deviendra la forme COM-MAS 621. Il en sera de même pour les coupes et jarres, identifiées et reconnues comme tels dans la typologie des céramiques claires massaliètes.

\section{Typologie de la céramique commune massaliète}

Dans cet article ne seront classées que les formes provenant des collections des fouilles du site de Lattara, sur une période assez courte d'un siècle (-475/-375), sans prendre en compte ni la totalité de la production ni 


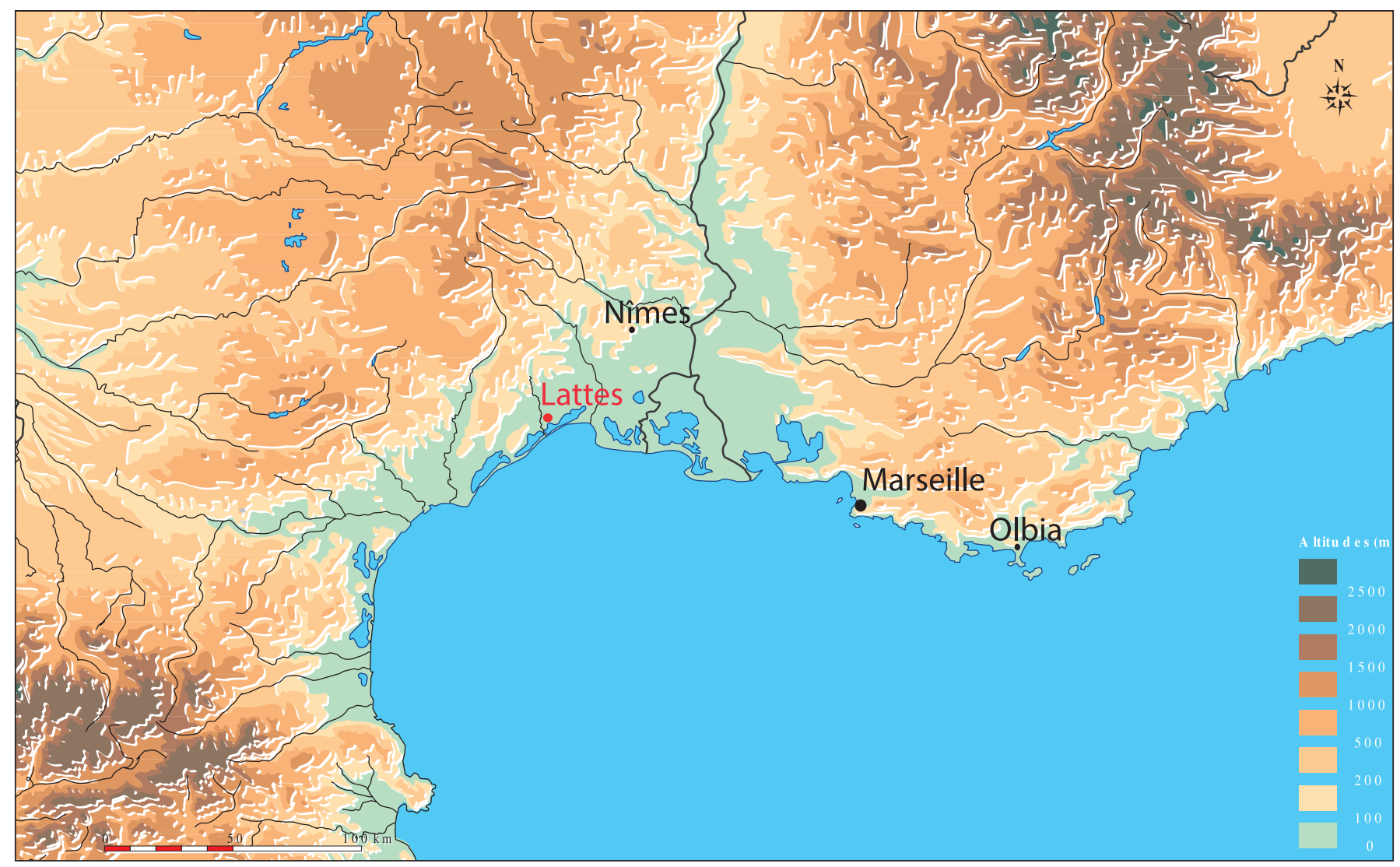

Fig. 1. Situation du site de Lattes (34) (UMR5140).

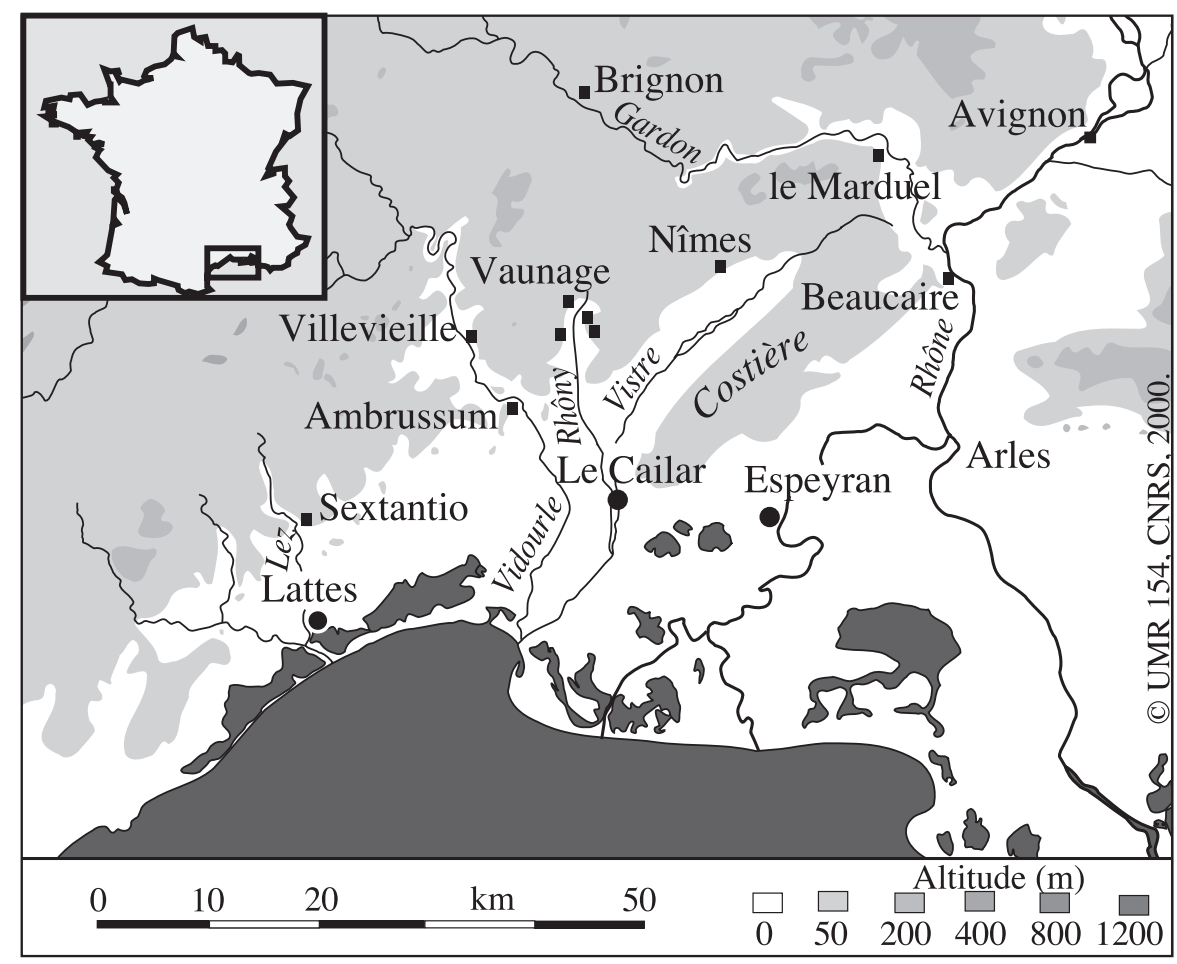

Fig. 2. Carte des comptoirs littoraux du Languedoc oriental (UMR5140). 


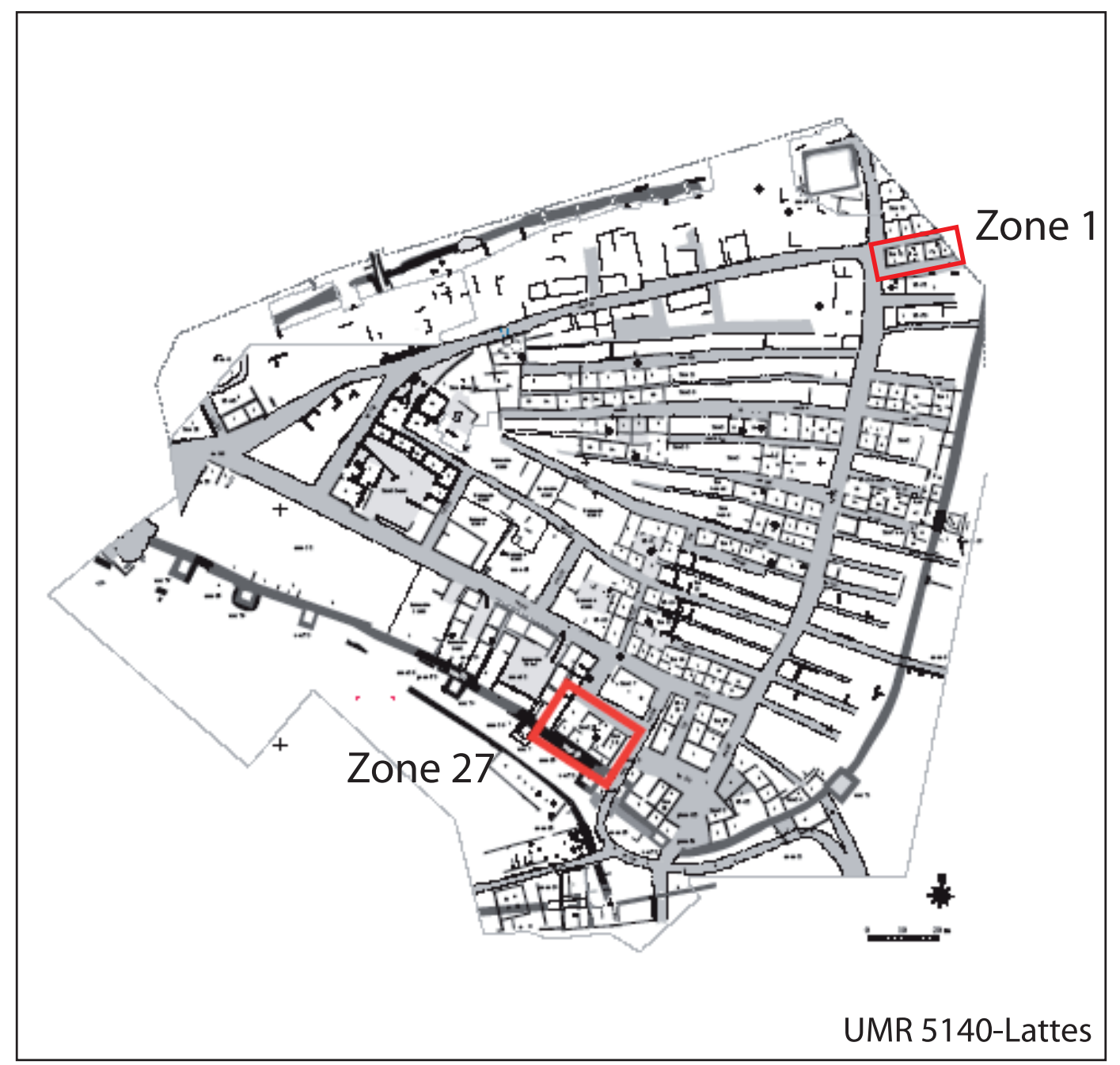

Fig. 3. Plan du site de Lattes et localisation des zones étudiées ; zone 1 et zone 27 (UMR5140).

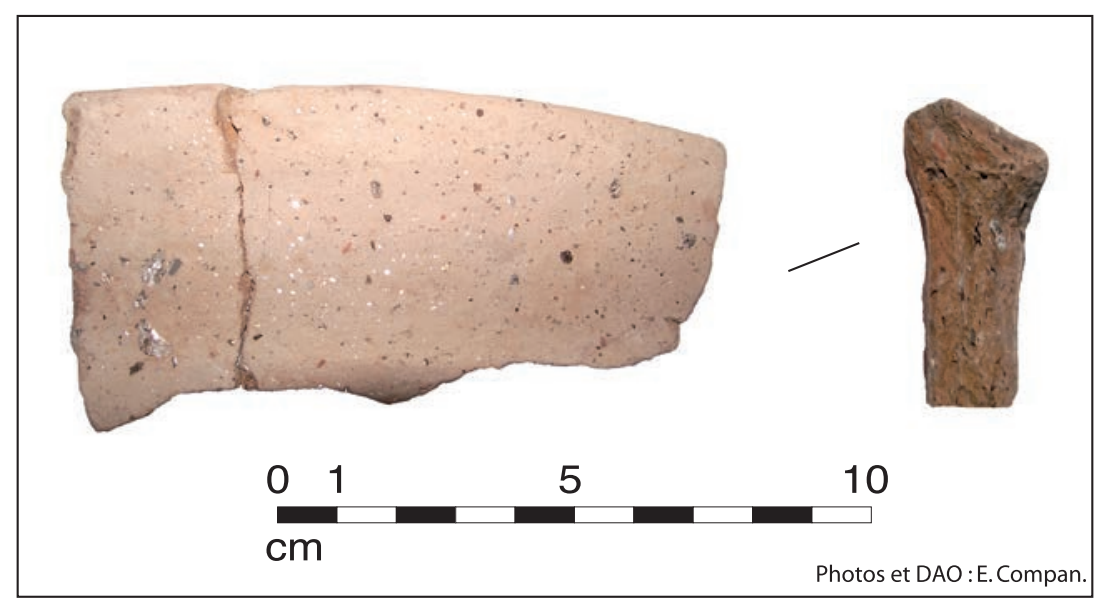

Fig. 4. Profil et coupe de la pâte de la COM-MAS (photo et DAO E. Compan). 


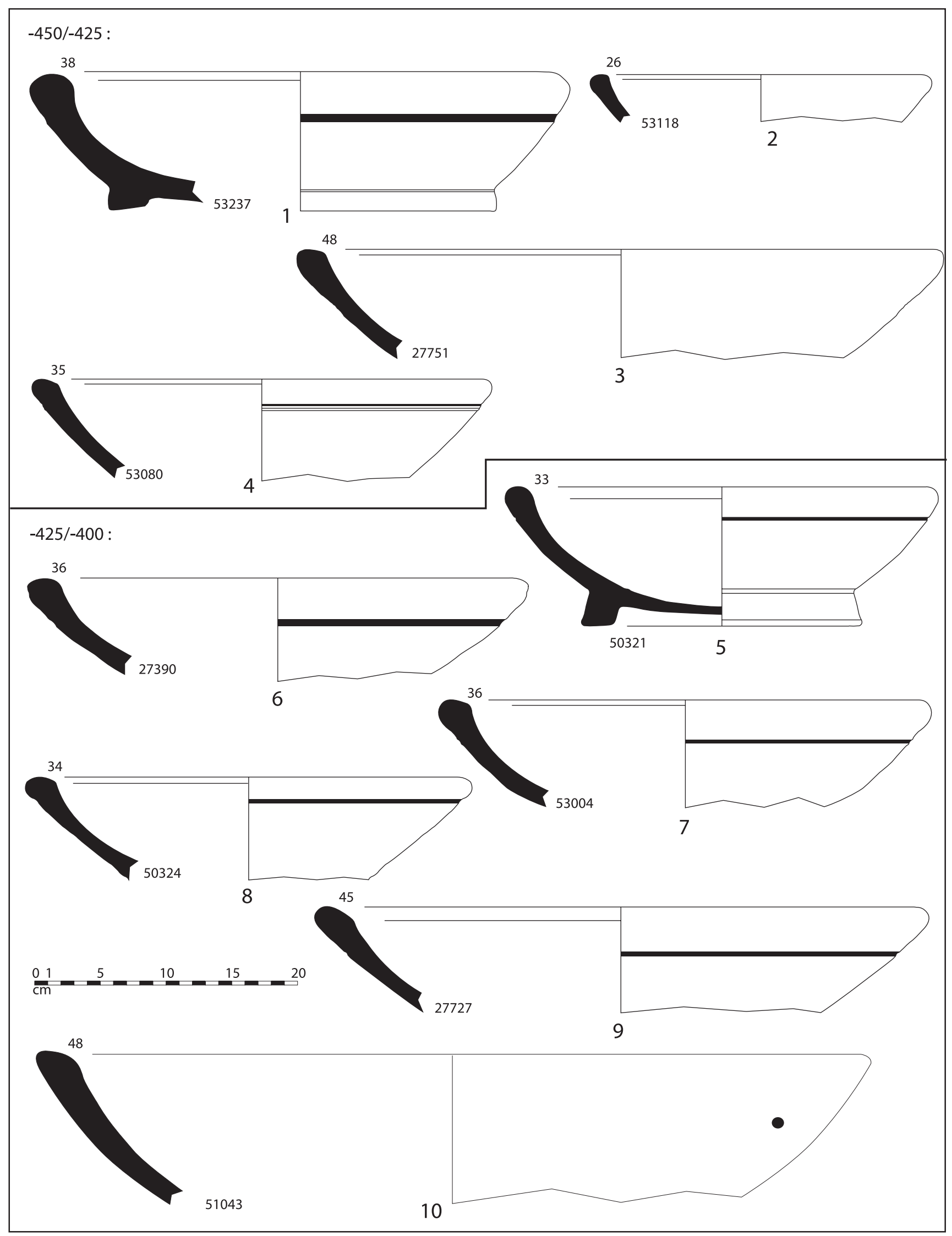

Fig. 5. Mortiers en céramique commune massaliète, série COM-MAS 620 (dessins et DAO E. Compan). 
la répartition de ces céramiques communes dans le sud de la France au cours du Second âge du Fer. Une étude plus étendue sur les plans géographiques et chronologiques est en cours, dans le cadre du projet Dicocer 3.

Deux grands groupes typologiques de vases se distinguent. Dans un premier temps, les mortiers, de grands récipients de préparation culinaire, déjà bien identifiés et répertoriés sous les numéros de séries CL-MAS 620, 630 et 640, dont nous présenterons les formes les plus représentatives du $\mathrm{V}^{\mathrm{e}} \mathrm{s}$. av. n. è. et dans un second temps, un ensemble de récipients de cuisson, classés en céramique claire sous la typologie « jarre » CL-MAS 512, équivalent à une variante des caccabés du monde grec. À ces deux grands groupes s'ajoutent quelques formes destinées plutôt au service des aliments qu'à la préparation/ cuisson culinaire, ces formes sont connues en céramique claire massaliète mais se distinguent par des variantes morphologiques et typologiques.

\section{Les mortiers (fig. 5 à 7)}

Les mortiers massaliètes sont présents dès le début du $\mathrm{VI}^{\mathrm{e}} \mathrm{s}$. av. n. è. en Gaule méditerranéenne et sont attestés à Lattes à partir du milieu du $\mathrm{V}^{\mathrm{e}} \mathrm{s}$. av. n. è., où ils prennent la suite des mortiers étrusques (présents notamment dans la zone 27). Bien que les mortiers soient sous-estimés par les comptages, les fragments de mortiers sans forme n'étant pas différenciable des fragments d'amphores, ils occupent une part non négligeable des importations lattoises. Le répertoire des formes est très diversifié, avec une multitude de spécificités au niveau du bord, mais la forme même du vase reste la même comme l'ensemble des mortiers méditerranéens. Les mortiers représentent $90 \%$ du répertoire des formes de la céramique commune massaliète.

Ce sont des vases ouverts à profil hémisphérique ou tronconique, aux parois plus ou moins épaisses et au fond annulaire bas ; leur pâte est très micacée de ton beige à rose clair, feuilletée comme celle des amphores. Ces vases offrent une grande surface plane intérieure pour écraser et mélanger les aliments, préparer et pétrir les pâtes.

Les mortiers massaliètes présentent une grande variété de types et de nombreuses variantes dans une même forme, du fait d'une longue durée de production et d'usage.

$\mathrm{Au} \mathrm{V}$ e s. av. n. è., à Lattes, trois séries de mortiers sont attestées, comprenant plusieurs formes distinctes : la série COM-MAS 620 regroupant les mortiers à bord épaissi (fig. 5 et 6), la série COM-MAS 630 pour les mortiers présentant un bord à marli et la série 640 correspondant aux mortiers à bord continu (fig. 7).

\section{La série COM-MAS 620}

(fig. 5-6)

Cette série regroupe quatre variantes principales de mortiers, différenciées par la forme de leur bord :

- la forme COM-MAS 621 (fig. 5) : mortier de grande taille dans son ensemble, diamètre d'ouverture compris entre $26 \mathrm{~cm}$ et $48 \mathrm{~cm}$, à parois épaisses, à bord biseauté, plus ou moins prononcé $\left(\mathrm{n}^{\circ} 9\right.$ et $\left.\mathrm{n}^{\circ} 1\right)$. Un grand nombre de ces mortiers présente un sillon soulignant le bord $\left(n^{\circ} 4\right.$ à $\left.n^{\circ} 9\right)$.

C'est la forme la plus caractéristique des mortiers massaliètes et la plus représentée dans le corpus du site de Lattes, pour la période comprise entre -475 et -375 .

- la forme COM-MAS 623 (fig. 6) : mortier de taille moyenne, à bord en bourrelet externe plus ou moins aplati, parois plus minces $\left(\mathrm{n}^{\circ} 11\right)$.

Cette forme n'apparaît dans le corpus de Lattes qu'à la fin $\mathrm{du} \mathrm{V}^{\mathrm{e}} \mathrm{s}$. avant notre ère.

- la forme COM-MAS 626 (fig. 6) : mortier de grande taille, diamètre moyen de $40 \mathrm{~cm}$, à parois plus ou moins fines selon les variantes, à bord en bandeau vertical ou convergent, le bord peut être souligné à sa base par un sillon $\left(n^{\circ} 12-13\right)$.

Ces mortiers sont présents au milieu du $\mathrm{V}^{\mathrm{e}} \mathrm{s}$. av. n. è.

- la forme COM-MAS 627 (fig. 6) : mortier de taille variable, de diamètre de $36 \mathrm{~cm}$ à $48 \mathrm{~cm}$, à parois plus fines que la forme COM-MAS 621, à bord sinueux, la lèvre est arrondie ou repliée vers l'extérieur mais non pendante $\left(\mathrm{n}^{\circ} 14-15\right)$.

Elle est attestée dans la seconde moitié du Ve s. av. n. è. à Lattes et se développe principalement au cours du $\mathrm{IV}^{\mathrm{e}} \mathrm{s}$. av. n. è.

\section{La série COM-MAS 630 \\ (fig. 7)}

Deux variantes de mortiers à bord en marli caractérisent cette série :

- la forme COM-MAS 633 (fig. 7) : mortier de taille variable, de $35 \mathrm{~cm}$ à $40 \mathrm{~cm}$ de diamètre, à bord en marli plus ou moins bombé, horizontal ou incliné vers l'extérieur, la lèvre peut être moulurée $\left(n^{\circ} 16\right)$.

Cette forme est surtout attestée dès le début du IVe $\mathrm{s}$. av. n. è. à Lattes. Elle est très répandue à la période hellénistique dont elle est caractéristique.

- la forme COM-MAS 634 (fig. 7) : mortier de grande taille, diamètre moyen $42 \mathrm{~cm}$, à bord mouluré ou en double bandeau ( $\left.\mathrm{n}^{\circ} 17-18\right)$.

Il s'agit d'une nouvelle forme, absente du classement de Dicocer 1, attestée à Lattes vers $-425 /-400$, par quelques exemplaires incomplets. 

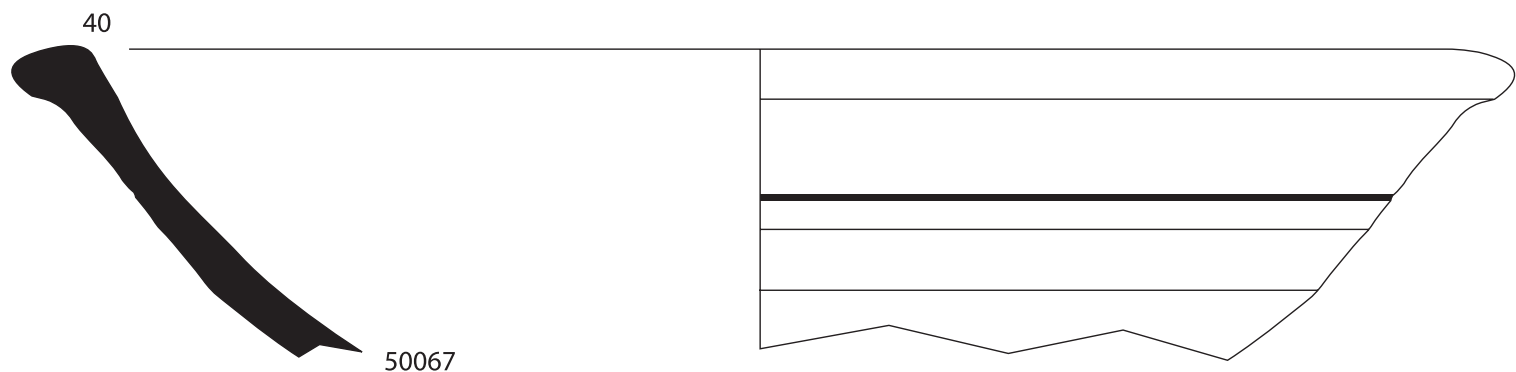

11
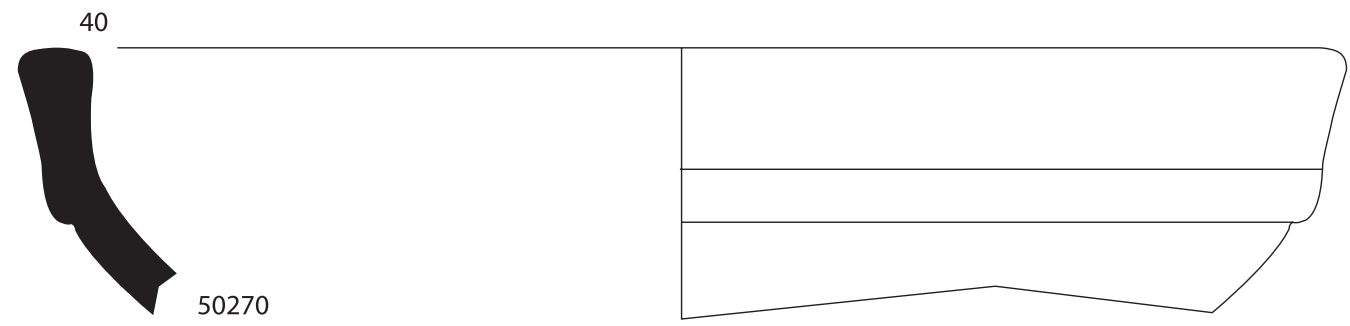

12
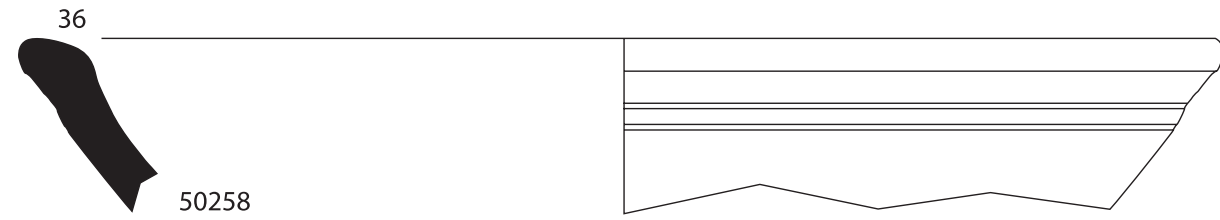

13
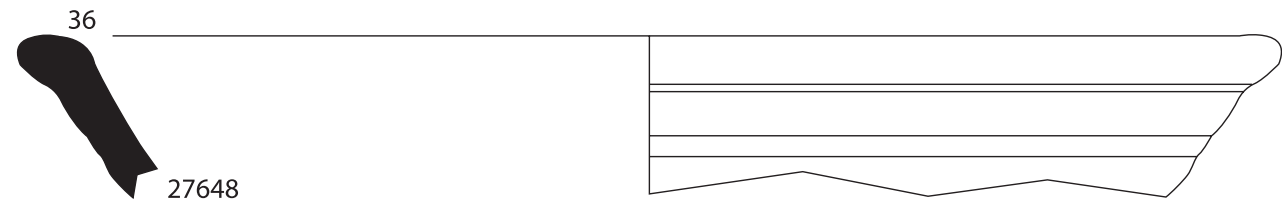

14

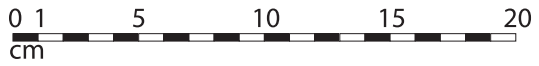

Fig. 6. Mortiers en céramique commune massaliète, série COM-MAS 620 (dessins et DAO E. Compan). 


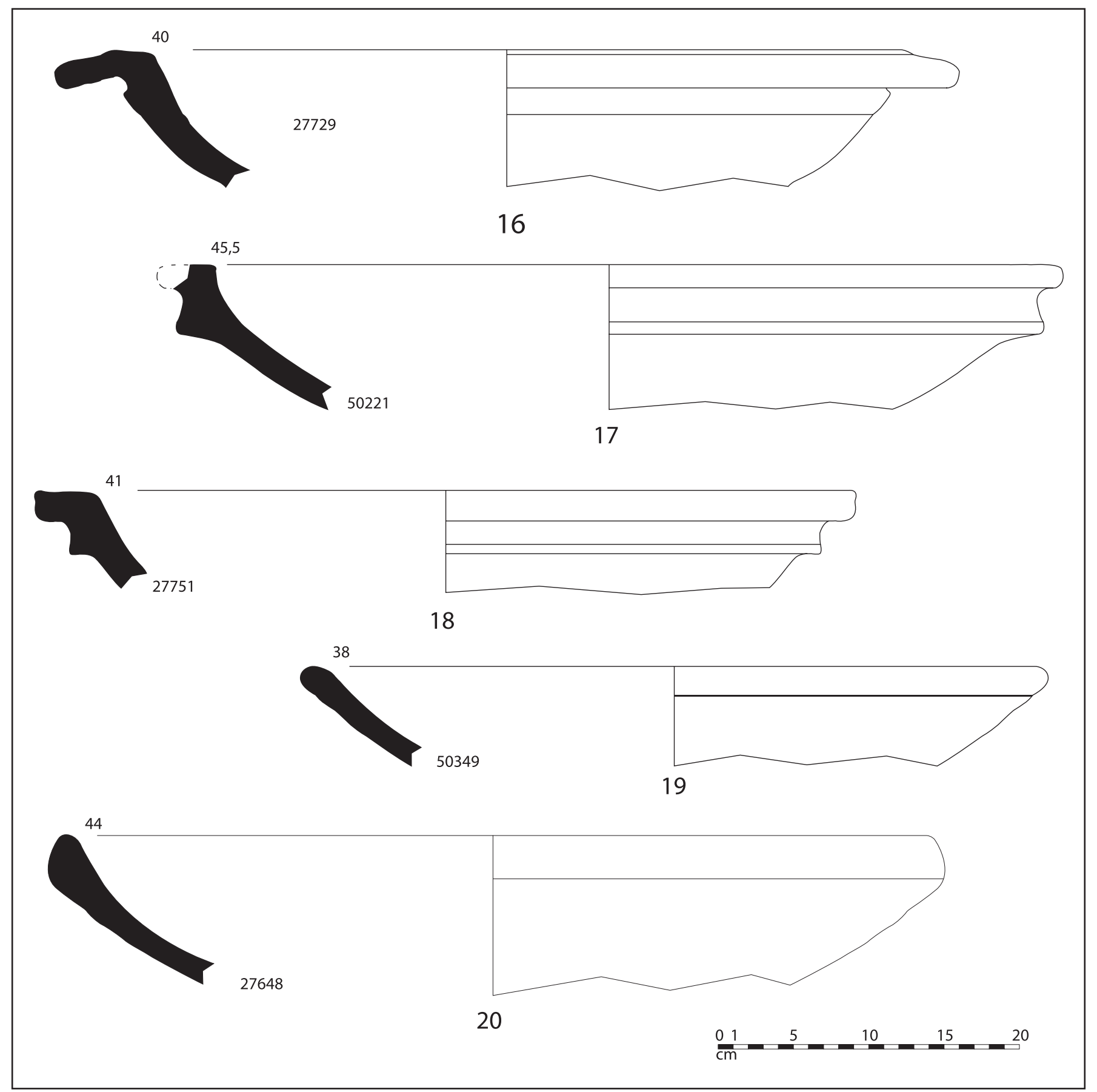

Fig. 7. Mortiers en céramique commune massaliète, série COM-MAS 630 et 640 (dessins et DAO E. Compan). 


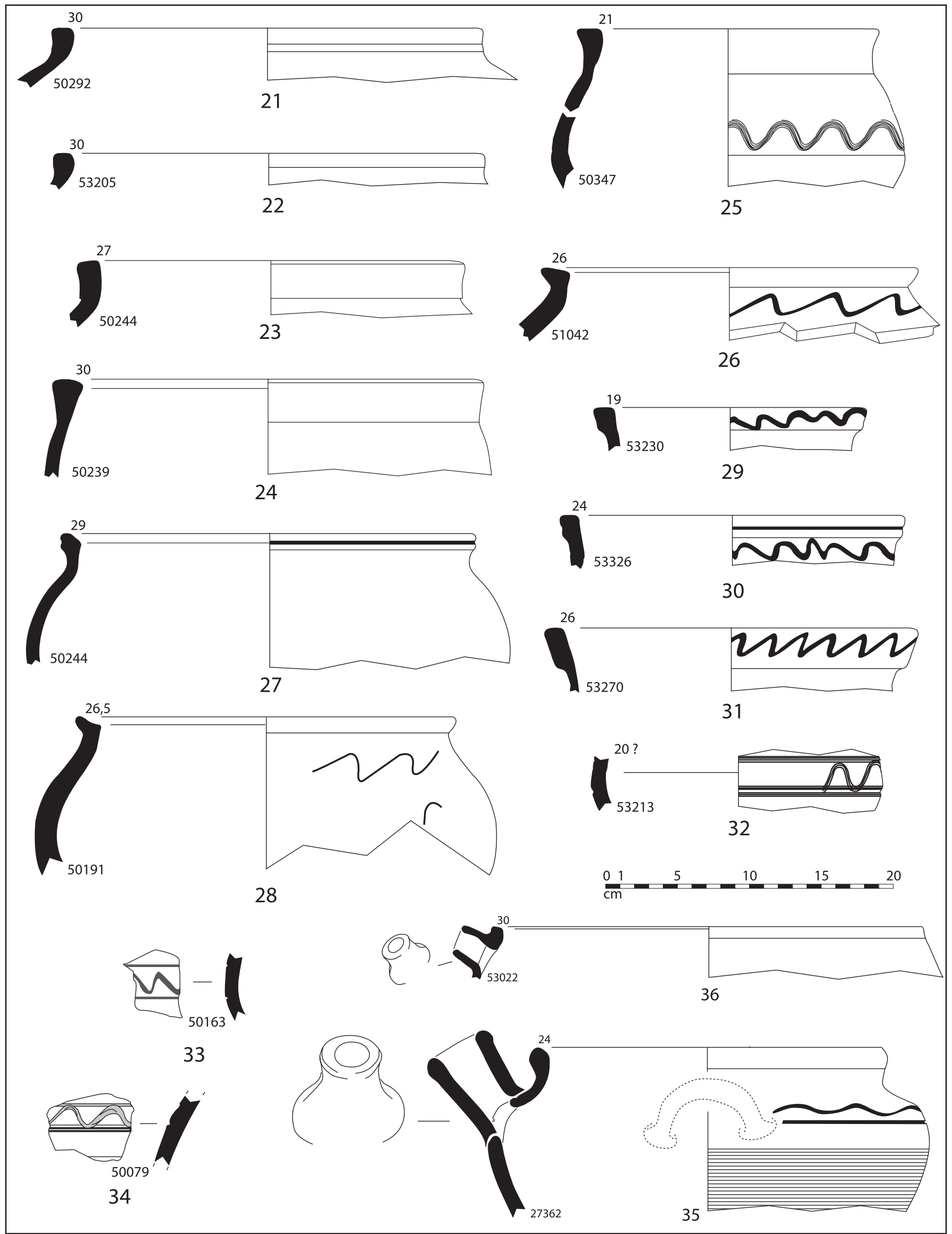

Fig. 8. Jarres en céramique commune massaliète, COM-MAS 512 (dessins et DAO E. Compan). 


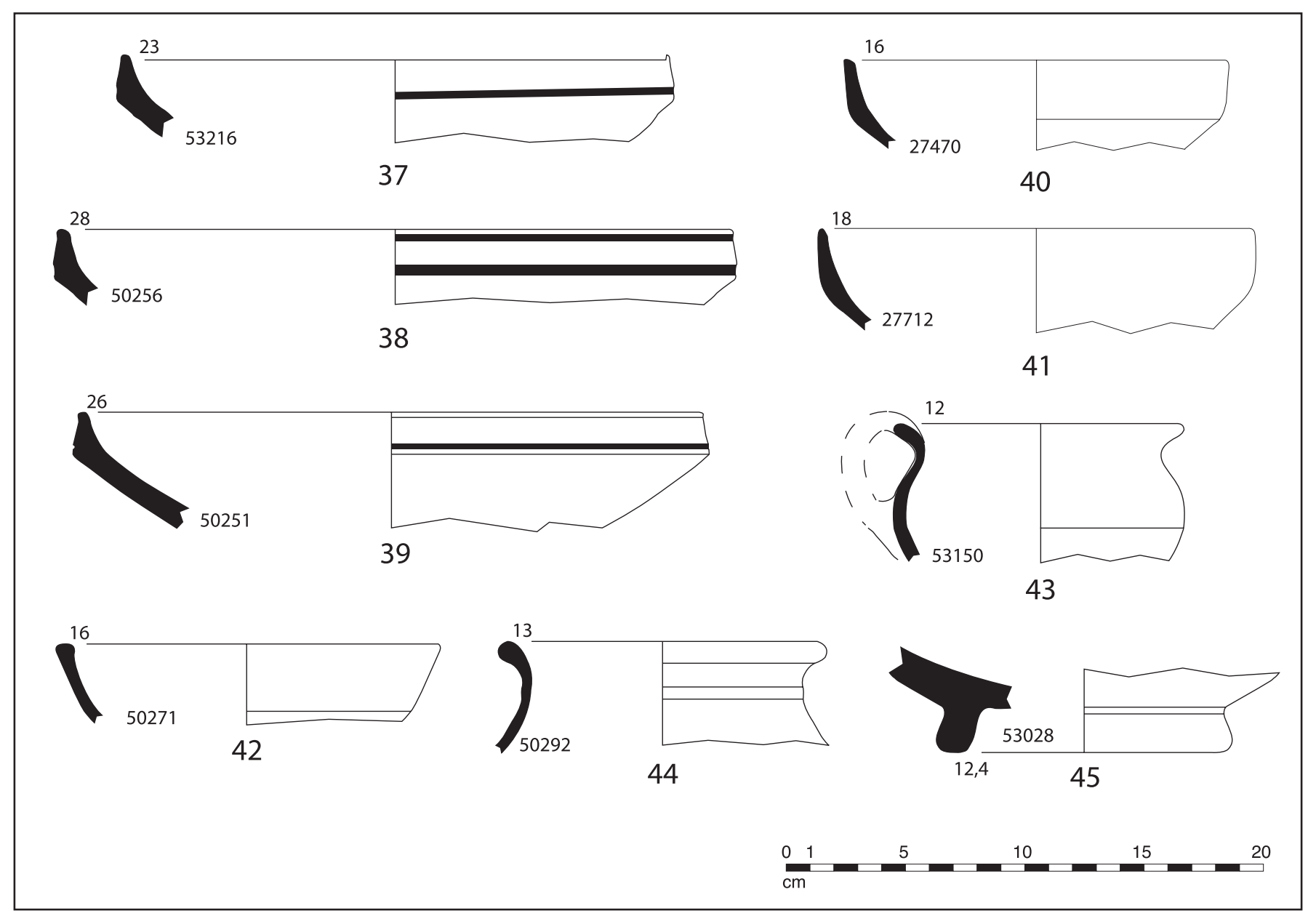

Fig. 9. Autres formes en céramique commune massaliète (dessins et DAO E. Compan).

\section{La série COM-MAS 640}

(fig. 7)

Cette série de mortiers est assez rare sur le site de Lattes, deux formes la représentent :

- la forme COM-MAS 641 (fig. 7) : mortier de taille variable, à parois minces, la lèvre peut être arrondie, à bord continu rectiligne ( $\left.\mathrm{n}^{\circ} 19\right)$.

Cette forme est surtout attestée au IVe $s$. av. n. è.

- la forme COM-MAS 643 (fig. 7) : mortier de grande taille, à cordon digité sous le bord, à bord continu convergent et lèvre arrondie $\left(\mathrm{n}^{\circ} 20\right)$.

Ces mortiers sont présents vers -400 à Lattes.

\section{Les jarres (fig. 8)}

Un ensemble de vases classé sous la typologie «jarre » COM-MAS $512^{4}$ constitue la deuxième forme la plus

4 Dans un premier temps la forme déjà classée de CL-MAS 512 a été reprise pour cette forme en commune massaliète, mais au vue des différentes variables il sera intéressant de représentée en céramique commune massaliète. Il s'agit d'une urne lourde et large à panse arrondie, de diamètre moyen de $28 \mathrm{~cm}$ et fond annulaire ou plat. Ces vases sont très souvent décorés d'ondes incisées avant cuisson et de sillons rappelant les décors caractéristiques de la céramique grise monochrome $\left(\mathrm{n}^{\circ} 32-34\right)$. Certaines formes (n 27 et 28), munies d'un bord en gouttière pouvant être destiné à recevoir un couvercle, rappelle le récipient de cuisson, la caccabé, du monde grec (Bats, 1988, p. 48).

Ce groupe de vases présente des bords aux profils variés et seront classés dans un premier temps sous forme de variante.

\section{La variante COM-MAS 512 variante 1}

(fig. $8, n^{\circ} 21$ à 26)

Il s'agit de jarre à bord épaissi plat $\left(n^{\circ} 21\right)$ ou arrondi $\left(n^{\circ} 24\right)$, sans col distinct de la panse. Un décor d'ondes

créer une série COM-MAS 510 et des variantes COM-MAS $511,512,513 \ldots$ 
incisés peut être placé directement sous le bord ( $\left.\mathrm{n}^{\circ} 26\right)$ ou sur la panse $\left(\mathrm{n}^{\circ} 25\right)$. Les parois s'affinent et le profil est soit globuleux soit plus rectiligne. Le diamètre d'ouverture du vase est compris entre $21 \mathrm{~cm}$ pour le plus petit exemplaire et $30 \mathrm{~cm}$ pour les exemplaires les plus volumineux.

C'est la variante la plus représentée à Lattes, qui compte 6 exemplaires répartis dans la seconde moitié du $\mathrm{V}^{\mathrm{e}} \mathrm{s}$. av. n. è.

\section{La variante COM-MAS 512 variante 2 (fig. $8, n^{\circ} 27$ à 28)}

Cette variante se rapproche des caccabés grecques avec son bord à marli en gouttière interne pouvant recevoir un couvercle et présentant une lèvre arrondie $\left(\mathrm{n}^{\circ} 27\right)$ ou moulurée $\left(\mathrm{n}^{\circ} 28\right)$. La panse est globulaire et peut être décoré d'ondes incisées $\left(\mathrm{n}^{\circ} 28\right)$.

Cette forme est attestée à Lattes vers -400.

\section{La variante COM-MAS 512 variante 3}

\section{(fig. $8, n^{\circ} 29$ à 31)}

Ces jarres ont un profil plus rectiligne associé à un bord à bandeau vertical qui présente un décor d'ondes incisées sur les trois exemplaires retrouvés à Lattes. Ces trois individus très fragmentaires, pour lesquels nous ne connaissons ni la forme de la panse ni celle du fond, pourraient constituer une nouvelle forme en céramique commune massaliète.

Il s'agit d'une variante plus ancienne, attestée exclusivement au milieu du $\mathrm{V}^{\mathrm{e}} \mathrm{s}$. av. n. è. à Lattes.

\section{La variante COM-MAS 512 variante 4}

(fig. $8, n^{\circ} 35$ à 36)

Cette forme était déjà identifiée par la variante CLMAS 512a (Py et al. 2001, p. 708). Il s'agit de jarres plus basses à bord arrondi plus ou moins déversé, muni d'un goulot et d'anses horizontales relevées. L'exemplaire $n^{\circ} 35$ est décoré d'ondes incisées sur la panse et est peigné dans sa partie inférieure. Les diamètres d'ouverture sont compris entre 24 et $30 \mathrm{~cm}$.

Deux exemplaires ont été identifiés à Lattes au cours du milieu du $\mathrm{V}^{\mathrm{e}} \mathrm{s}$. av. n. è.

\section{Les autres formes (fig. 9)}

Un petit nombre d'exemplaires en céramique commune massaliète a été mis en évidence à la suite de cette étude. Il s'agit de vases destinés plutôt au service ou à la consommation des aliments et de la boisson qu'à la préparation et la cuisson culinaire comme l'est l'ensemble des vases déjà présentés. Quatre formes de vases se distinguent.

\section{La forme COM-MAS 222}

(fig. 9, $n^{\circ} 37$ à 41)

Cette forme rappelle les coupes carénées en céramique grise monochrome de type GR-MONO 3 (Arcelin 1982 et 1984), caractéristiques de cette catégorie céramique inspirée des formes indigènes. Les coupes carénées COM-MAS 222 présentent un bord convergent à lèvre amincie, des parois plus ou moins épaisses.

Deux variantes se distinguent:

- La variante COM-MAS 222 var. 1 (n 37 à 39) est caractérisée par un bord court de profil triangulaire, décorés d'un ou deux sillons parallèles horizontaux, la carène est haute et anguleuse, le profil est tendu. Ce sont de grandes coupes de $23 \mathrm{~cm}$ à $28 \mathrm{~cm}$ de diamètre.

Cette variante est attestée à Lattes tout au long de la seconde moitié du Ve s. av. n. è. vers -450/-400.

- La variante COM-MAS 222 var. 2 (n 40 et 41 ) se rapproche plus de la forme en céramique grise monochrome avec un bord adouci et plus long à lèvre arrondie mais un profil tout aussi tendu. Le diamètre d'ouverture est plus petit, compris entre 16 et $18 \mathrm{~cm}$.

Les exemplaires provenant du site de Lattes n'ont pas de décor et sont attestés au dernier quart du $\mathrm{V}^{\mathrm{e}} \mathrm{s}$. av. n. è., vers $-425 /-400$.

\section{La forme COM-MAS 410}

(fig. 9, $n^{\circ} 42$ )

Un unique exemplaire se rapproche des coupes à une anse en céramique claire massaliète. Le bord est élargi et aplati, la vasque présente une courbure continue avec une légère inflexion dans le tiers supérieur, pour un diamètre d'ouverture de $16 \mathrm{~cm}$. L'anse horizontale à section ronde est attachée directement sous le bord.

Cette forme est attestée à Lattes vers -425 .

\section{La forme COM-MAS 450}

(fig. 9, $n^{\circ} 43$ )

Il s'agit d'un petit pichet à une anse verticale surmontant le bord, de $12 \mathrm{~cm}$ de diamètre, aux parois épaisses, rappelant la forme en céramique claire massaliète CLMAS 450 inspirée des formes d'urnes surbaissées du monde indigène.

Le seul exemplaire présent à Lattes et daté du milieu du $\mathrm{V}^{\mathrm{e}} \mathrm{s}$. av.n. è.

\section{La forme COM-MAS 520/540}

(fig. $9, n^{\circ} 44$ et 45 )

Une petite cruche $\left(n^{\circ} 44\right)$ et un large fond annulaire indéterminé $\left(\mathrm{n}^{\circ} 45\right)$ complètent le corpus des vases en céramique commune massaliète du site de Lattes. 
Le bord de cruche, de $13 \mathrm{~cm}$ de diamètre, rappelle les cruches en céramique claire massaliète de type cl-mas 543 (Py et al 2001, p. 738-740) caractérisées par un bord légèrement déversé et par la présence de listels en relief et de sillons placés sous le bord. En l'absence d'anse, cette forme sera classée sous la série générique des cruches COM-MAS 520-540.

Cet exemplaire de cruche est attesté dans le dernier quart du Ve s. av. n. è., vers -425 .

\section{Les mortiers en céramique claire massaliète (fig. 10)}

La caractérisation des mortiers en céramique commune massaliète que nous venons d'aborder dans cette étude, a permis également de mettre en évidence une production de mortiers à pâte claire et fine, sans paillette de mica visible à l'œil nu, aux parois plus minces et de diamètre d'ouverture plus petit compris entre 16 et $28 \mathrm{~cm}$. Ces mortiers resteront classés dans la catégorie céramique claire massaliète en gardant également leur numéro d'identification défini dans le Dicocer 1 mais devront faire l'objet d'une étude plus complète. C'est une forme très présente dans les collections d'Olbia de Provence, qu'il sera intéressant d'analyser pour les périodes plus récentes.

Ces mortiers plus fins présentent soit un bord en amande épaissi rappelant la série CL-MAS 620 ( $\mathrm{n}^{\circ} 46$ à 50) et plus particulièrement les variantes CL-MAS 621 à bord biseauté $\left(n^{\circ} 50\right)$ et CL-MAS 623 à bord en bourrelet externe plus ou moins aplati $\left(n^{\circ} 47\right.$ et 48$)$; soit un bord continu droit ou convergent associé à la série CL-MAS 640 ( $\mathrm{n}^{\circ} 53$ à 57) dont la variante CLMAS 641 à bord continu rectiligne $\left(\mathrm{n}^{\circ} 55\right)$. Le bord peut être souligné par un ou deux sillons horizontaux $\left(n^{\circ} 58\right)$. La finesse de leurs parois et leurs petits diamètres d'ouverture peuvent nous amener à repenser la fonction culinaire de ces vases, moins robustes comparés au modèle en céramique commune massaliète. Il s'agit peut être plus de grands plats de service que d'ustensiles de broyage.

\section{Conclusion}

Cette mise en évidence d'une nouvelle catégorie céramique nous permet de progresser dans l'identification des différentes productions dites massaliètes, provenant très certainement de la cité phocéenne mais aussi d'ateliers locaux comme c'est le cas des productions de céramique claire sub-géométrique rhodanienne ou encore de la céramique claire peinte héraultaise.

Il reste cependant assez difficile d'établir l'ampleur de cette production céramique en raison du fait que les fragments de panse, notamment, de mortiers sont presque quasiment impossibles à isoler des fragment de panse d'amphore massaliète. Pour les formes aux parois plus fines, cela paraît plus aisé du moment qu'une certaine attention y ait apportée lors des tris du matériel céramique.

Comme nous l'avons vu, cette étude présente essentiellement les formes attestées sur une période courte, du deuxième quart du $\mathrm{V}^{\mathrm{e}} \mathrm{s}$. av. n. è. au premier quart du IV s. av. n. è. (-475/-375) et provenant d'un unique gisement, le site archéologique de Lattes, dont les contextes chronologiques sont cependant assurés. Il semble donc évident que la mise en place définitive d'une typologie de la céramique commune de Marseille devra reposer sur une étude plus étendue tant sur le plan géographique que chronologique, en incluant par exemple les collections des sites lagunaires proches du Cailar (Gard) et d'Espeyran (Saint-Gilles, Gard), les collections des sites du Languedoc occidental comme Agde (Hérault) et Pech-Maho (Sigean, Aude) ainsi que les collections des sites provençaux d'Olbia-de-Provence et de Marseille (Bouches-du-Rhône), et tous les autres sites susceptibles d'avoir reçu ces productions. Une étude plus étendue permettra peut-être d'isoler plusieurs productions ou du moins d'identifier des spécificités régionales comme c'est le cas pour la céramique claire massaliète.

La période de production de ces vases reste également à déterminer avec précision mais devrait correspondre à celle de la céramique claire massaliète, c'est à dire du V $\mathrm{V}^{\mathrm{e}}$ au II $\mathrm{e}$ s. av. n. è.

En parallèle de cette étude strictement typologique, il sera intéressant d'approfondir la question de l'utilisation de cette céramique commune massaliète et de sa place dans le faciès céramique local, notamment pour les mortiers dont la forme et de ce fait la fonction se différencient nettement des récipients de cuisson.

\section{Bibliographie}

Arcelin 1982 : ARCELIN-PRADELLE (C.), DEDET (B.), PY (M.) - « La céramique grise monochrome en Languedoc oriental », Revue archéologique de Narbonnaise, 14, 1982, p.19-67.

Arcelin 1984 : ARCELIN-PRADELLE (C.) - La céramique grise monochrome en Provence, Paris, 1984 (RAN supp. 10) 


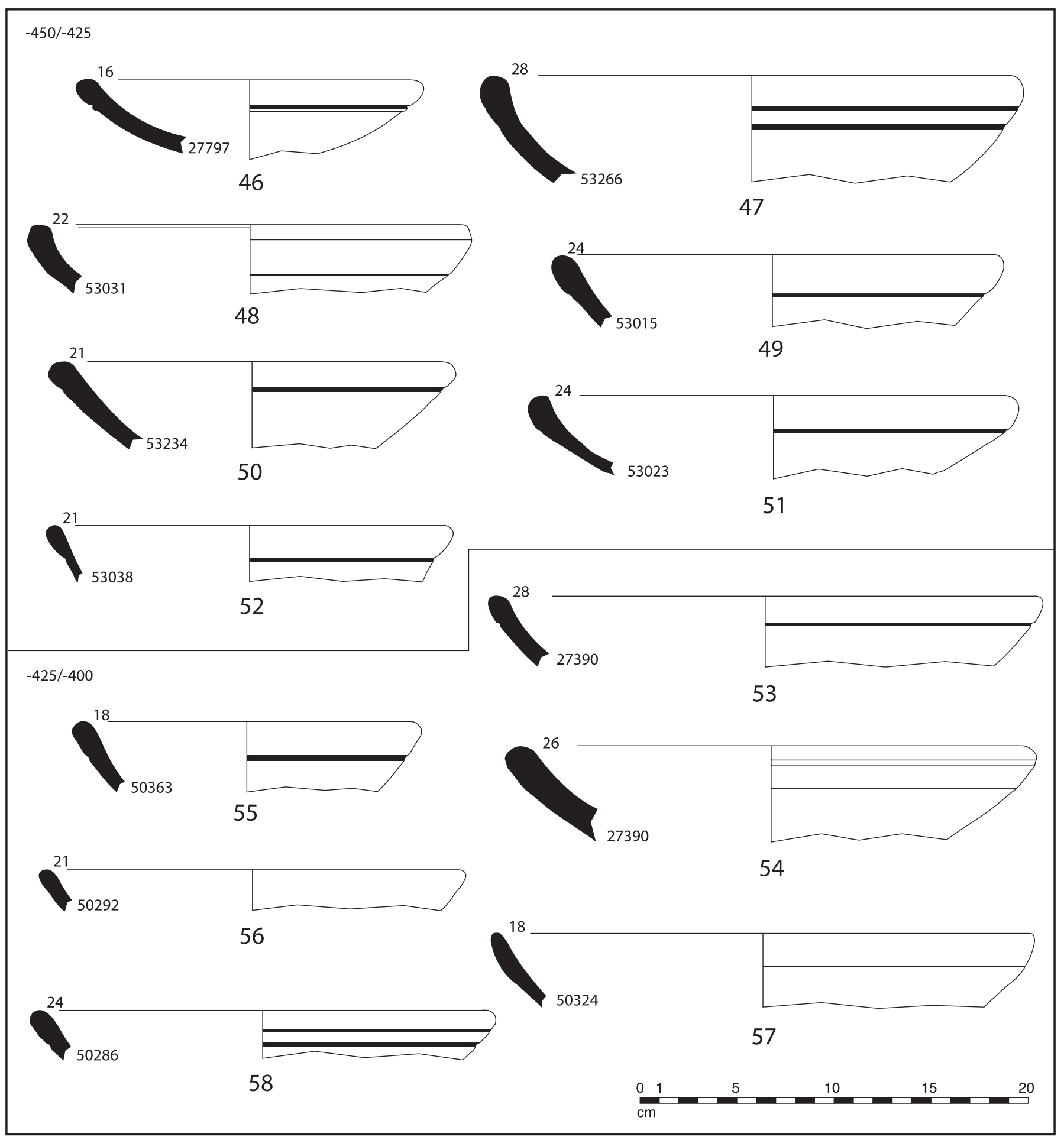

Fig. 10. Mortiers en céramique claire massaliète (dessins et DAO E. Compan). 
Bats 1988 : BATS (M.) - Vaisselle et alimentation à Olbia de Provence (V. 350- v.50 av. JC.), modèles culturels et catégories céramiques, CNRS, Paris, 1988. (RAN suppl. 18)

Bats 1993 : BATS (M.) - Céramique à pâte claire massaliète et de tradition massaliète. In : PY (M.) (dir.) - Dicocer 1, Dictionnaire des céramiques antiques (VII ${ }^{e}$ s. av.n. è.-VII ${ }^{e}$ s. de n. è.) en Méditerranée nord-occidentale (Provence, Languedoc, Ampurdan), Lattara 6, 1993, p. 206-221

Chausserie-Laprée 1988 : CHAUSSERIE-LAPRÉE (J.) ET AL. - Le village gaulois de Martigues, Dossiers Histoire et Archéologie, 128, 1988.

Chausserie-Laprée 1995 : CHAUSSERIE-LAPRÉE (J.), NIN (N.) - La céramique grise monochrome de l'habitat protohistorique de l'Île à Martigues (B.-du-Rh.). In : Sur les pas des Grecs en Occident, 1995, p. 339-362 (Et. Massa. 4).
Py 1993 : PY (M.) (DIR.) - Dicocer 1, Dictionnaire des céramiques antiques (VII ${ }^{e}$ s. av.n.è.-VII ${ }^{e}$ s. de n.è.) en Méditerranée nord-occidentale (Provence, Languedoc, Ampurdan), Lattara 6, 1993, 624 p. (réédité en 2007).

Py 1999 : PY (M.) (DIR.) - Lattara 12, Recherche sur le quatrième siècle avant notre ère à Lattes, Lattes, 1999, p. 287-524.

Py et al. 2001 : PY (M.), ADROHER AUROUX (A.), SANCHEZ (C.) Lattara 14. Corpus des céramiques de l'âge du Fer de Lattes (fouilles 1963-1999), tome 2, Lattes, 2001, p. 1087-1115.

Ugolini, Olive 1987 : UGOLINI (D.), OLIVE (C.) - Un four de potier du Ves av. J.-C. à Béziers, Place de la Madeleine, Gallia, 45, 1987-1988, p. 13-28. Villard 1960 : VILLARD (F.) - La céramique grecque de Marseille (VI ${ }^{\text {- }}$ $I V^{e}$ s.) essai d'histoire économique, Paris, 1960. 



\title{
À propos de quelques imitations de vaisselle campanienne de l'oppidum de l'Ermitage d'Agen (Lot-et-Garonne)
}

\author{
Florence Verdin \\ CNRS, Ausonius, Bordeaux
}

\section{Résumé}

La présence d'éléments de vaisselle imitant certaines formes de campaniennes dans le comblement du puits 41 de l'oppidum de l'Ermitage (Agen, Lot-et-Garonne) permet d'aborder la chronologie de ces productions en Gaule par rapport à la diffusion des modèles d'origine. Leur étude éclaire le début du processus d'adoption de nouvelles manières de table, donc l'histoire des contacts culturels, particulièrement dans l'isthme gaulois.

Mots-clés : second âge du Fer, Isthme gaulois, Agen, Aquitaine, céramique commune régionale, céramique campanienne, contacts culturels

\footnotetext{
Abstract

Many pieces of dishes imitating some shape of campanian ceramics in the filling of the well 41 in Ermitage oppidum (Agen, Lot-et-Garonne) allows to approach the chronology of these productions in Gaul linked with original models. Their study lights the beginning of the process of adoption of table manners, thus the history of cultural contacts, particularly in Gallic Isthmus.
}

Keywords: Second Iron Age, Gallic Isthmus, Agen, Aquitania, Common ceramic, Campanian ceramic, cultural contacts 
$\mathrm{D}$ epuis la voie ouverte par la publication de la vaisselle d'Olbia par M. Bats (Bats 1988), très rares sont de nos jours les études céramologiques qui ne tiennent pas compte des manières de table, donc des modèles culturels que reflètent les ensembles de vaisselles. La fin de l'âge du Fer en Gaule est une période particulièrement propice à ce genre d'approche car elle voit l'amplification des échanges avec l'aire méditerranéenne et la circulation d'un nombre croissant de vases d'importation, essentiellement en provenance d'Italie. Le développement d'imitations de ces vases par les potiers gaulois va de pair avec ce mouvement et reflète l'adoption progressive de nouvelles pratiques de consommation aboutissant à un renouvellement complet du répertoire céramique à la fin du $\mathrm{I}^{\mathrm{er}} \mathrm{s}$. av. J.-C.

L'oppidum de l'Ermitage d'Agen, dont l'occupation principale se situe entre le dernier quart du $\mathrm{II}^{\mathrm{e}} \mathrm{s}$. et les années 40/30 av. J.-C., n'échappe pas à cette tendance. L'important lot de mobilier provenant du puits 41 recèle de la vaisselle importée et des imitations de vases italiques. Or, si l'évolution des ensembles de vaisselle des $\mathrm{II}^{\mathrm{e}} \mathrm{I}^{\mathrm{I}}{ }^{\mathrm{er}} \mathrm{S}$. av. J.-C. est maintenant connue grâce aux études de contextes bien datés de certaines régions de Gaule, le Sud-Ouest souffre encore d'un déficit d'informations qui rend difficiles les approches comparatives. Les études de mobilier s'avèrent pourtant irremplaçables pour retracer l'histoire économique de l'axe Aude-Garonne et les processus d'assimilation culturelle qui en ont découlé.

\section{La vaisselle importée et d'imitation de l'Ermitage}

La partie supérieure du comblement du puits 41 , soit les quatre derniers mètres (fig. 1), est constituée d'une très grande quantité de mobilier (amphores, vaisselle céramique, mobilier métallique, faune, etc). Ce type de colmatage, correspondant à des rejets opérés après que le puits ne soit plus praticable, est caractéristique du processus d'abandon de ces structures à eau, comme le montre bon nombre d'exemples, notamment dans le Sud-Ouest (Verdin, Bardot 2007, p. 255-256).

Le mobilier céramique compte environ $65 \%$ de vaisselle pour environ $35 \%$ d'amphores ${ }^{1}$. Parmi la vaisselle, la majeure partie est constituée de vases tournés et modelés de fabrication locale tandis que les importations ne comptent que pour $7 \%$. Celles-ci sont composées de 4 vases campaniens A, 12 campaniens B, 6 à paroi fine et 1 en céramique commune italique (fig. 2). L'étude faite par C. Sanchez s'appuie sur la prédominance de la

1 Les calculs sont faits à partir du NMI. campanienne $\mathrm{B}$, les formes représentées et la présence d'un gobelet à parois fines de type Rullius, pour dater le comblement du puits vers $80 / 60$ av. J.-C. Le faciès amphorique cadre avec cette fourchette chronologique, même si les marques consulaires sur amphores Dressel 1 sont plus anciennes d'une vingtaine d'années (Verdin, Berthault, Sanchez 2013) ${ }^{2}$.

Si la céramique campanienne A n'est représentée que par quatre petits fragments, dont un rebord de forme L.36, ses imitations sont plus nombreuses puisqu'elles comptent 10 assiettes L.36, un fond à pied annulaire appartenant à une forme non déterminable (fig. 3), un bol s'inspirant de la forme L.31/33 (fig. 4, $\mathrm{n}^{\circ} 2$ ), un bol L.27ab (PB-399)(fig. 4, $\mathrm{n}^{\circ}$ 3). Une assiette L.5 pourrait reproduire aussi bien une forme de campanienne A que $\mathrm{B}$ (fig. $4, \mathrm{n}^{\circ}$ 1) et le bol PB-531 adopte une forme de campanienne B L.1/8 (fig. 4, $\mathrm{n}^{\circ} 4$ ).

Parmi les assiettes L.36, deux formes sont complètes (fig. 3, n ${ }^{\circ} 3$ ), les autres n'étant représentées que par un bord. Ces vases sont tournés, les pâtes à cuisson réductrice sont fines à mi-fines, à dégraissant sableux. De couleur gris foncé, les surfaces sont soigneusement lissées et offrent un aspect lustré, à l'exception d'un seul exemplaire d'aspect plus mat et rugueux. Deux exemplaires sont dotés de lèvres courtes et tombantes (fig. $3, n^{\circ} 1$ et 2 ). Sur les autres, le rebord tend à l'horizontale, conformément à l'évolution tardive de la forme initiale en campanienne $\mathrm{A}$ au ${ }^{\mathrm{Ir}} \mathrm{s}$. av. J.-C. (Arcelin 2000, p. 296 ; Py, Adroher Auroux, Sanchez 2001, p. 497-498). Les diamètres s'échelonnent entre 18 et $25 \mathrm{~cm}$, si l'on excepte un plat de $31 \mathrm{~cm}$ de diamètre qui correspond à une forme légèrement différente (fig. $\mathbf{3}, \mathrm{n}^{\circ}$ 9). Les cercles incisés sur le fond des assiettes italiques se retrouvent sur trois exemplaires seulement, tandis que le flanc extérieur est souvent souligné par des doubles lignes incisées qui n'existent pas sur les originaux. De même, le fond isolé (fig. 3, $\mathrm{n}^{\circ}$ 11) associe, à l'intérieur de la vasque, cercles concentriques et décor de lignes qui semblent être une lointaine évocation des palmettes radiales du $\mathrm{II}^{\mathrm{e}}$ s. av. J.-C. Profils et décor révèlent donc une adaptation des potiers gaulois par rapport aux modèles initiaux.

Quant au bol (fig. 4, $\mathrm{n}^{\circ}$ 2), sa forme est encore plus librement inspirée des L.31. Son décor extérieur, associant lignes incisées et motifs d'ondulations tracées au brunissoir, évoque de loin le décor de rinceaux et lignes peints en blanc à l'intérieur des vases italiques. Ce vase est à rapprocher d'exemplaires d'inspiration analogue découverts à Vieille-Toulouse (Passelac 2007, p. 20) ou sur l'habitat groupé du Marais du Pont à Varennes-surSeine (Séguier, Viand 2012, fig. $2 \mathrm{n}^{\circ} 15$ ).

2 Ce genre de décalage chronologique entre lots de mobiliers pourtant issus d'un même comblement a également été observé à Toulouse : Gorgues 2007, 415-416 ; Benquet et al. 2001, 134 ; Benquet 2009. 


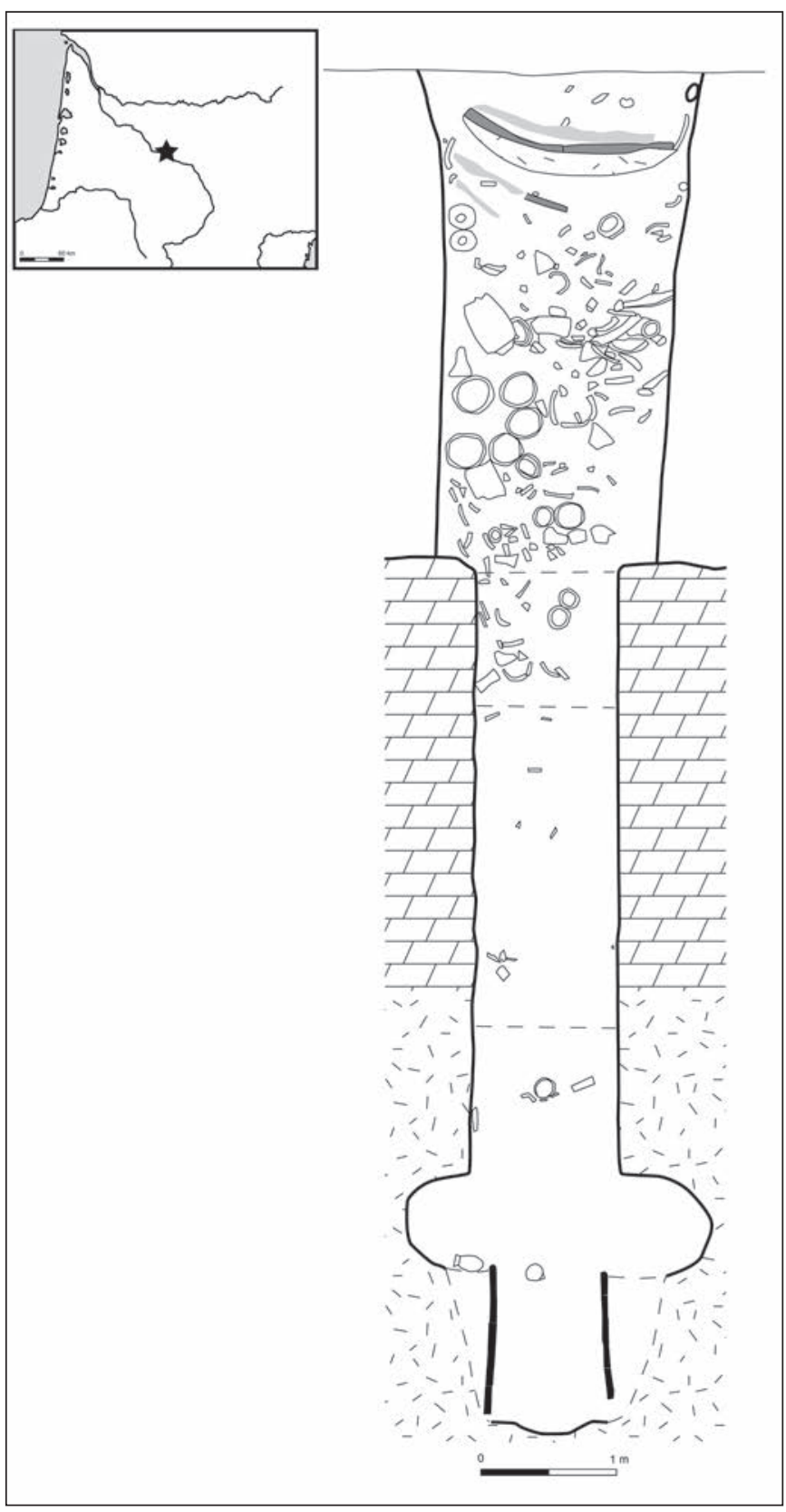

Fig. 1. Vignette de localisation de l'Ermitage et coupe du puits 41.

\section{Diffusion des céramiques à vernis noir et de leurs imitations en Gaule}

En Gaule intérieure, la chronologie des importations méditerranéennes et de leurs imitations est maintenant relativement bien appréhendée. Les premières pièces de vaisselle à vernis noir arrivent dans le courant du $\mathrm{III}^{\mathrm{e}}$ s., mais leur diffusion ne commence véritablement qu'à partir de la fin du siècle pour s'amplifier dans la seconde moitié du $\mathrm{II}^{\mathrm{e}} \mathrm{s}$., dans les régions les plus facilement accessibles par les grandes voies de communication (cf. résumé de la situation et cartographie dans Olmer et al. 2013, p. 676-680). La campanienne A reste majoritaire jusqu'au début du I ${ }^{\text {er }}$ s., puis elle est concurrencée par les campaniennes B qui commencent à arriver dès la fin du siècle précédent. Les deux catégories cessent d'être diffusées après 50/40, mais sont toujours plus ou moins présentes dans les assemblages jusqu'à la fin du $\mathrm{I}^{\mathrm{er}} \mathrm{s}$. av. J.-C.

Les premières imitations en céramique tournée régionale sont produites dès le début de la diffusion massive des campaniennes $\mathrm{A}$, à partir du milieu ou du dernier quart du $\mathrm{II}^{\mathrm{e}} \mathrm{s}$. Jusque dans les années 50, le répertoire des formes est très stéréotypé (L.27, L.31/33, L.36/6, L.5, L.5/5), même si la proportion des différents types varie selon les régions.

En Auvergne, de 150 à 50, les productions en céramique fine régionale reprennent des formes campaniennes dont elles suivent de peu la diffusion et représentent alors la majorité des formes basses. Il s'agit d'abord de L.27, puis de L.31/33, et plus rarement de L.36. Les L.31/33 qui faisaient le plus défaut ont été les plus reproduites. Les formes L.6, L.5 et L.1, moins nombreuses, n'apparaissent qu'à la fin du $\mathrm{II}^{\mathrm{e}} \mathrm{s}$. (Deberge et al. 2007, p. 173).

En pays ségusiave (Roanne, Feurs, Goincet...), les imitations apparaissent en même temps que les premières campaniennes $\mathrm{A}$, peu avant le milieu du $\mathrm{II}^{\mathrm{e}} \mathrm{s}$. Elles deviennent plus nombreuses entre 110 et 70 où elles constituent entre $9 \%$ et $5 \%$ de la vaisselle, puis disparaissent vers 40/30. Jusque vers 90, elles se résument à deux formes, les L.31/33 et L.36, avant que n'apparaissent les imitations de formes campaniennes B, L.5/7 et L.2 (Lavendhomme, Guichard 1997, p. 147 ; Genin, Lavendhomme, Guichard 1992, p. 183).

En territoire éduen (Morvan/Mont-Beuvray et vallée de la Saône), les premières campaniennes A arrivent dans le second quart du $\mathrm{II}^{\mathrm{e}} \mathrm{s}$. et les imitations de bols L.31/33 commencent dans le même temps, suivies des assiettes L.36. Dans le second quart du I ${ }^{\mathrm{er}} \mathrm{s}$. av. J.-C., apparaissent les imitations de L.5 et les importations de vaisselle italique. Des spécificités régionales transparaissent dans la fréquence relative de ces imitations au sein des ensembles de vaisselle et dans la morphologie des vases. Le sud de la région, plus proche de la Provincia, semble davantage concerné par ce phénomène (Barral 1999, p. 373 ; Barral, Videau 2012, p. 106-109).

À la confluence Seine-Yonne, le site du Marais du Pont, à Varennes-sur-Seine semble constituer le point de découverte le plus septentrional d'imitations de formes L.6/36, associées à des formes L.5/7, L. 31/33 et L.1, dans un contexte qui semble dater de la première moitié du Irr s. av. J.-C. (Séguier, Viand 2012, p. 202-204 ; Séguier 1999, p. 358-359). 


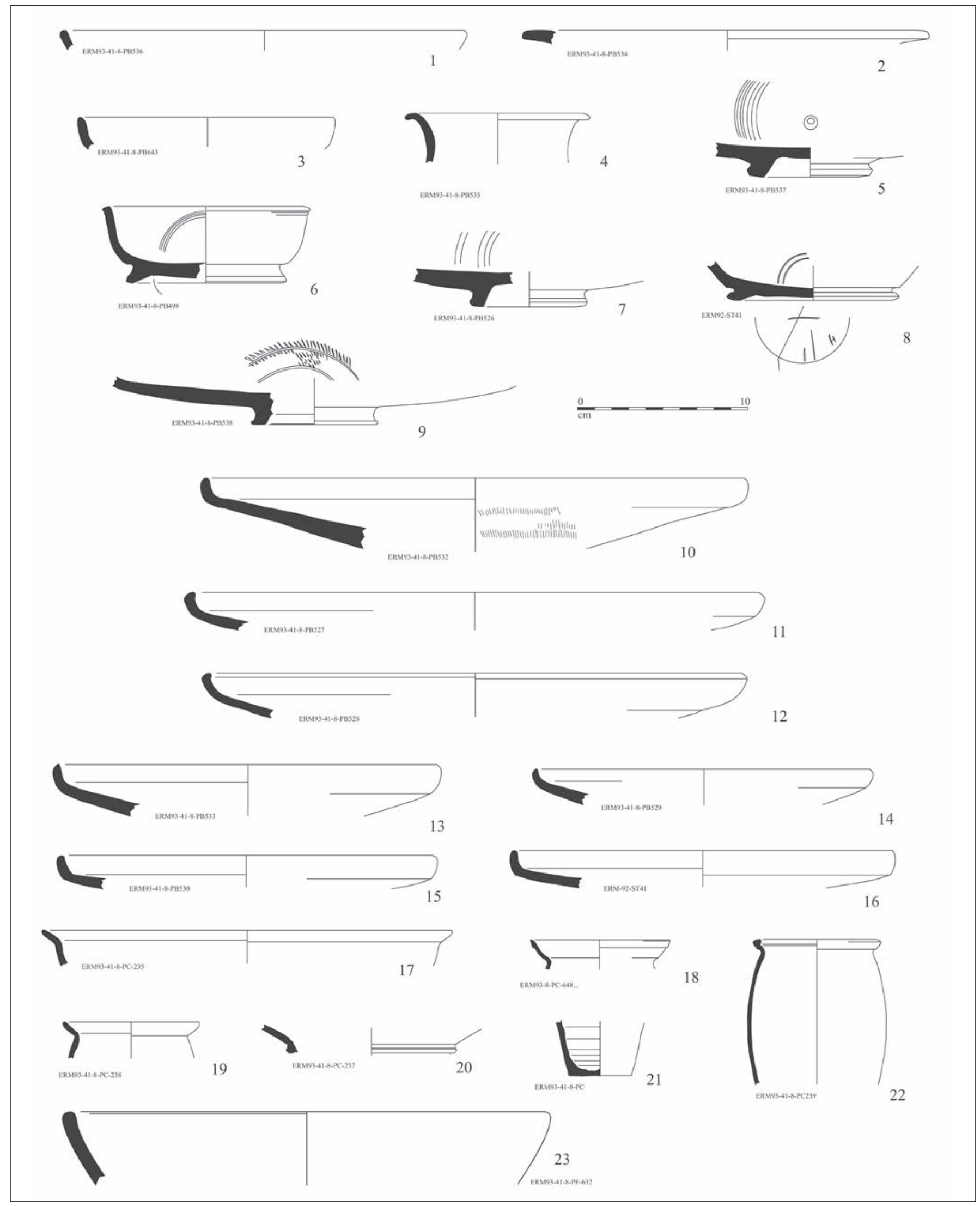

Fig. 2. L'Ermitage d'Agen. Vaisselle importée. 1 à 3 : campanienne $A, 4$ à 16 : campanienne $B$, 17 à 22 : paroi fine, 23 : commune italique (dessins C. Sanchez). 
Dans l'Orléanais, à Cenabum, à partir des années 130/110, en même temps que les campaniennes A, les imitations font leur apparition, avec des formes L.27b, des décors estampés internes, des L.36, L.6, L.31/33. Lors de la phase d'occupation datée entre -80 et -60 , la part de ces productions augmente et s'enrichit de la forme L.5 (Riquier 2012, p. 222-224).

Ce panorama montre que le décalage est très faible entre l'arrivée des premières campaniennes A et la production d'imitations par les potiers gaulois locaux qui reproduisent d'abord les L. 27, puis essentiellement les L.31/33 et L.36. Les L.5 et 5/7 ne se répandent qu'à partir du second quart du Irr $\mathrm{s}$. av. J.-C. tandis que les campaniennes B sont peu imitées. Si les bols L.31/33 et les assiettes L.36 sont diffusés aux environs du second quart du $\mathrm{II}^{\mathrm{e}} \mathrm{s}$., ils ont connu un succès important grosso modo entre 110 et 60 . Une forte proportion de ces formes au sein des ensembles de vaisselle semble donc être un bon marqueur chronologique. La présence de ces récipients dessine également la carte de répartition de l'adoption progressive de modèles culturels méditerranéens qui, dans la fourchette chronologique définie, englobe la Franche-Comté, la Bourgogne, le Forez et l'Auvergne, sans dépasser, au nord, la vallée de la Loire et la confluence Yonne/Seine (Genin, Lavendhomme, Guichard 1992, p. 185).

L'acmé de cette production est clairement lié à la pénurie d'importations puisque la campanienne A est de moins en moins diffusée après le début du I ${ }^{\text {er }}$ s., au profit de la campanienne B. L'offre ne satisfaisant plus la demande, les potiers gaulois se lancent dans la production d'imitations. Y a-t-il pour autant un engouement particulier, propre au monde gaulois non méditerranéen, pour ces formes méditerranéennes ?

Il semblerait que la réponse soit négative car, en Provence et en Languedoc oriental où la céramique campanienne A reste majoritaire tout au long $\mathrm{du} \mathrm{I}^{\mathrm{er}} \mathrm{s}$. av. J.-C., les L.36 sont toujours en usage jusqu'à la fin du siècle. Ces plats apparaissent dès 200 sur certains sites du littoral, se répandent surtout à partir de la seconde moitié du II ${ }^{\mathrm{e}} \mathrm{s}$. vers l'intérieur des terres et constituent la forme qui a eu le plus de succès pour la consommation des mets solides. Ils sont supplantés à partir du second tiers du ${ }^{\text {er }}$ s. av. J.-C. par les L.5/7. Parmi les vases à boire, c'est le bol L.31b qui est le plus couramment utilisé dans le premier tiers du Ir $\mathrm{s}$. av. J.-C., jusque dans le troisième quart du siècle où il est remplacé par les gobelets à parois fines (Arcelin 2000 ; Py, Adroher Auroux, Sanchez 2001, p. 497-498).

Le phénomène des imitations touche également le Midi méditerranéen. On en trouve quelques-unes en céramique à pâte claire massaliète à Lattes, entre 225 à 100 av. J.-C., et en nombre plus important à Olbia
(Py, Adroher Auroux, Sanchez 2001, p. 630-631 ; Bats 1988, p. 168-176, pl. 41-46). La céramique indigène non tournée compte également quelques formes d'imitation qui restent néanmoins très marginales en Provence et en Languedoc oriental au regard de la quantité de vases importés (Py, Adroher Auroux, Raynaud 1993, p. 312 ; Py, Adroher Auroux, Sanchez 2001, p. 894-896). D'une manière générale, la fabrication de dérivées de productions méditerranéennes - parfois par des ateliers produisant des récipients à vernis noir selon des techniques proches des officines italiques ne prend de l'ampleur qu'à partir de -70 pour exploser dans la seconde moitié du I ${ }^{\text {er }}$ s. av. J.-C. Le phénomène coïncide avec l'arrêt progressif de la diffusion des campaniennes, vers -50/-40 et concerne surtout des formes de transition entre dérivées de campaniennes et présigillées (Py, Adroher Auroux, Raynaud 1993, p. 398-399 ; Passelac 2007, p. 22-23 ; Sanchez 2007, p. 6-7).

\section{L'axe Aude-Garonne}

Dans l'isthme gaulois, la diffusion de la céramique campanienne et de ses imitations suit les mêmes étapes chronologiques que dans le reste de la Gaule. La campanienne A y arrive dès la fin du $\mathrm{III}^{\mathrm{e}} \mathrm{s}$. ou le début du $\mathrm{II}^{\mathrm{e}}$ s., elle y est concurrencée par la campanienne B qui devient majoritaire à partir de 75 et les deux catégories ne sont plus diffusées après les années 50/40 (Arcelin 2000 ; Passelac 2001, p. 143-147 ; Sanchez, Sireix 2006, p. 310-312 ; Gorgues 2007, p. 416 ; Lemaître, Sanchez 2009, p. 355).

En Languedoc occidental, en Roussillon et dans le couloir Aude-Garonne jusqu'à Toulouse, les imitations de campaniennes A apparaissent dès la première moitié $\mathrm{du} \mathrm{II}^{\mathrm{e}} \mathrm{s}$. et caractérisent surtout la première moitié du Ier s. av. J.-C. (Vidal 2001, p. 180 ; Passelac 2007, p. 18-19, 29 ; Gorgues 2007, p. 416). Les formes les plus répandues sont les plats L.36 qui devancent les bols L.31 et L.33, contrairement au reste de la Gaule. Ces plats sont parfois dotés d'une vasque plus profonde que les exemplaires importés et s'avèrent ainsi plus proches des écuelles locales. S'ils restent présents ou résiduels jusqu'à la fin du Irer s., ils sont progressivement supplantés après 50 par des formes dérivées des L.5, L.5/7 et L.7. La céramique campanienne B est beaucoup plus rarement imitée ; en témoignent quelques formes de L.1, L.2 et L.6.

Dans le Sud-Ouest, hormis à Toulouse et à Agen, la bibliographie ne mentionne que de rares imitations de campaniennes, ce qui est sûrement loin de refléter la réalité des découvertes : 
- à Puylaurens (Tarn), sur un établissement ouvert de la fin du $\mathrm{II}^{\mathrm{e}}$ s.- $\mathrm{I}^{\mathrm{er}}$ s. av. J.-C., une imitation de L.36 parmi les six imitations de coupes campaniennes dont la forme n'est pas précisée (Grimbert, Merleau, Benquet 2009, p. 516-517),

- à Villeneuve-sur-Lot, un fond de coupe portant une palmette (Alcantara et al. 2011, p. 38)

- à Bordeaux, Cours du Chapeau-Rouge, un fragment de L.36 en terra nigra dans un horizon daté 50/30 (Sireix 2007, p. 65),

- sur l'oppidum du Camp de César à CoulounieixChamiers (Dordogne), des imitations de L.6, L.7 et L.5/7 (Laporte-Cassagne 2007, p. 65-67, fig. $1 \mathrm{n}^{\circ} 1$ ),

- dans la grotte des Perrats, à Agris (Charente), une imitation de L.36 avec estampilles radiales datée LT C2/ D1 (Lemaître, Sanchez 2009, p. 344)

Le faciès de la vaisselle du puits 41 de l'Ermitage s'avère très proche des contextes toulousains de la première moitié du Irr $\mathrm{s}$. av. J.-C. Cette parenté transparaît notamment dans la typologie des pots, dans la présence d'imitations de formes campaniennes et italiques ${ }^{3}$ et dans l'assemblage des importations qui allie campanienne $\mathrm{B}$, vases à parois fines et céramique commune italique. De ce point de vue, l'Ermitage semble se situer à la limite de la sphère d'influence toulousaine.

En aval de la vallée de la Garonne, aucun site ne livre ces catégories de mobilier en proportion équivalente. Ce constat continue d'alimenter des interrogations sur la réalité d'un axe économique reliant la Méditerranée jusqu'à un débouché portuaire atlantique situé sur l'estuaire girondin, dès les $\mathrm{II}^{\mathrm{e}} \mathrm{I}^{\mathrm{er}} \mathrm{S}$. av. J.-C. Si l'on prend en compte les découvertes d'amphores Dressel 1, on constate que les sites aquitains qui en ont livré les plus grandes quantité sont peu nombreux dans la basse vallée de la Garonne (Verdin 2003). Il en va de même des campaniennes A et B (Sanchez, Sireix 2006, p. 312). Ce sont surtout les faibles quantités d'importations à Bordeaux, débouché «naturel » de cet axe, qui suscitent l'étonnement. Pourtant l'agglomération ouverte de Lacoste (Mouliets-et-Villemartin, Gironde), sur la vallée de la Dordogne, est approvisionnée en amphores et en vaisselle à vernis noir dès la fin du $\mathrm{III}^{\mathrm{e}} \mathrm{s}$. L'oppidum de Vil Mortagne (Mortagne, Gironde), sur la rive droite de l'estuaire, parait largement ouvert aux importations entre la fin du II ${ }^{\mathrm{e}}$ s. et le $\mathrm{I}^{\mathrm{er}}$ s. av. J.-C. (Landreau 2009, p. 289). La carte de répartition des céramiques campaniennes révèle des découvertes plus nombreuses dans la partie sud de la région Poitou-Charentes, ce qui confirmerait un approvisionnement de ces régions par l'isthme gaulois

3 Les imitations de céramique commune italique (patina et couvercle). Pour Toulouse, voir Gorgues 2007, 418-419.
(Lemaître, Sanchez 2009, p. 356-357). Cependant, malgré ces indices, dans l'état actuel des connaissances, il demeure difficile d'identifier de véritables relais commerciaux dans la basse vallée de la Garonne. Les marges orientales de celle-ci sont mieux documentées que les terres basses qui la constitue.

\section{Réseaux économiques, politiques et culturels}

L'adoption des formes de campanienne A dans le monde gaulois très peu de temps après la diffusion des premières importations, au point d'imiter celles-ci quand la pénurie se faut sentir, est révélatrice du processus d'évolution culturelle qui s'amorce et connaît son apogée à la fin du $\mathrm{I}^{\mathrm{er}} \mathrm{s}$. av. J.-C. avec le renouvellement complet du répertoire de la céramique culinaire. Dans l'isthme gaulois, la prédominance des formes L.36 traduit probablement l'ancienneté des contacts qui se sont noués le long de cet axe de communication, aux portes de la province de Transalpine. La garantie de libre circulation des marchandises reposait sur les liens diplomatiques - une sorte de pacte de non agression - tissés avec certains membres de l'élite gauloise. César en témoigne lorsqu'il indique qu'Ollovico, père de Teutomatus, le roi des Nitiobroges, avait reçu du Sénat le titre d'ami du peuple romain (B.G. 7.31.5). Dans ces zones de contacts avec la Provincia, les populations locales pouvaient être sensibilisées à de nouveaux modèles culturels soit parce qu'elles étaient directement en relation avec des négociants étrangers, soit parce qu'elles avaient intégré les clientèles romaines, voire les corps auxiliaires de l'armée (Pion 2007, p. 158-159).

Comme cela a été maintes fois souligné, l'utilisation de quelques vases de présentation n'implique pas forcément un changement des pratiques culinaires puisqu'avant le milieu du ${ }^{\text {er }}$ s. av. J.-C., ces imitations ne concernent pas les ustensiles de cuisine (Pion 2007, p. 156). À Agen, la forte proportion de L. 36 au sein des formes méditerranéennes imitées ne peut faire oublier que les écuelles à bord rentrant restent majoritaires parmi les vases bas ouverts. Par ailleurs, plusieurs études soulignent que ces imitations possèdent parfois une vasque plus profonde que le modèle italique, ce qui le rapproche des écuelles gauloises. Un autre élément important est la faible représentation des imitations de bols L.31/33 par rapport à la Gaule centrale. Dès lors, le service des boissons privilégiait probablement les gobelets à flancs droits ou légèrement évasés qui apparaissent dès le $\mathrm{II}^{\mathrm{e}} \mathrm{s}$. et sont caractéristiques du vaisselier d'un large quart sud-ouest de la France (fig. 4, ${ }^{\circ} 5$ et 6). La faible quantité de céramiques campaniennes par rapport aux amphores a pu également inciter à penser 


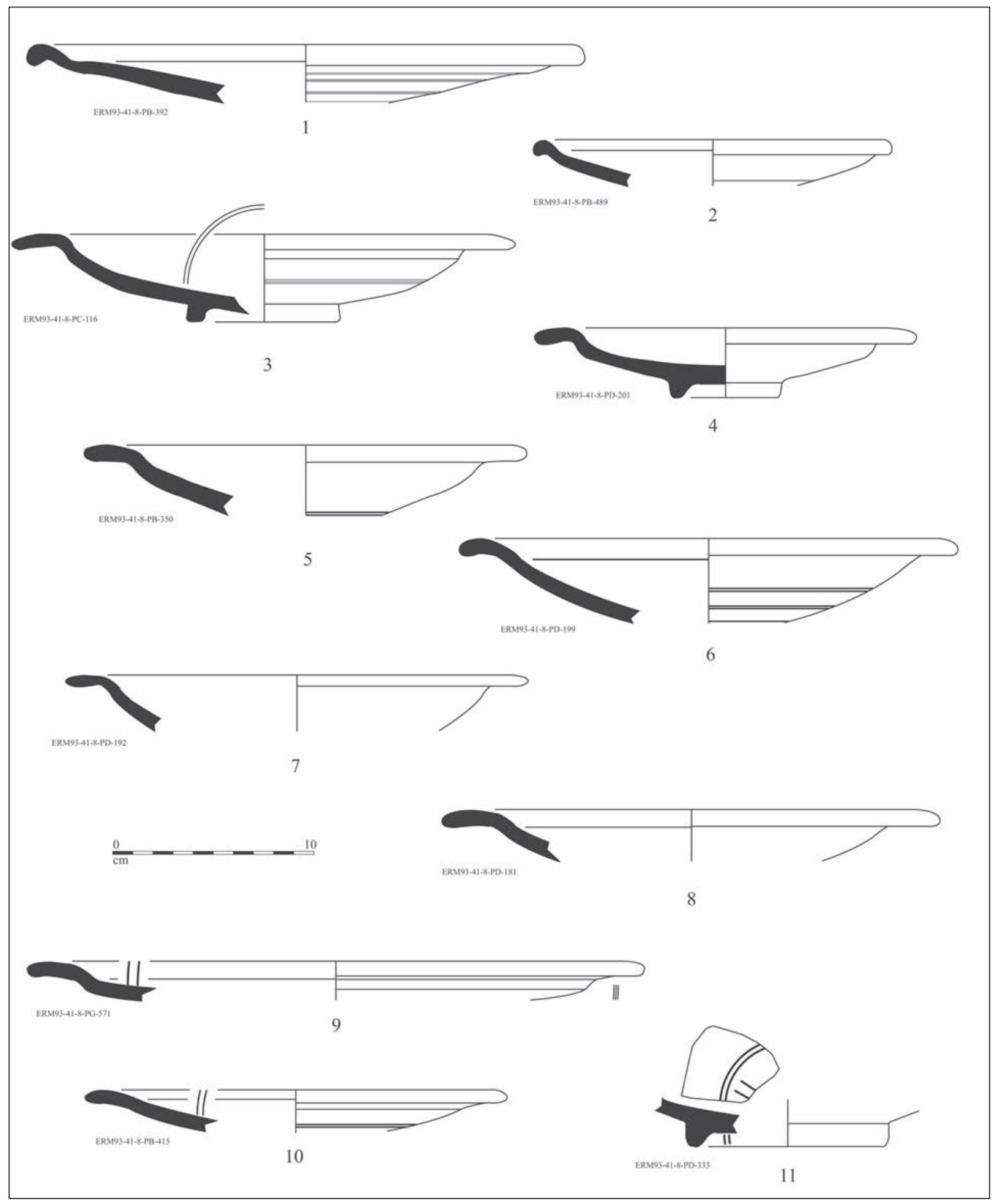

Fig. 3. L'Ermitage d'Agen. Imitations de campaniennes en céramique locale (dessins C. Touquet-Laporte-Cassagne). 


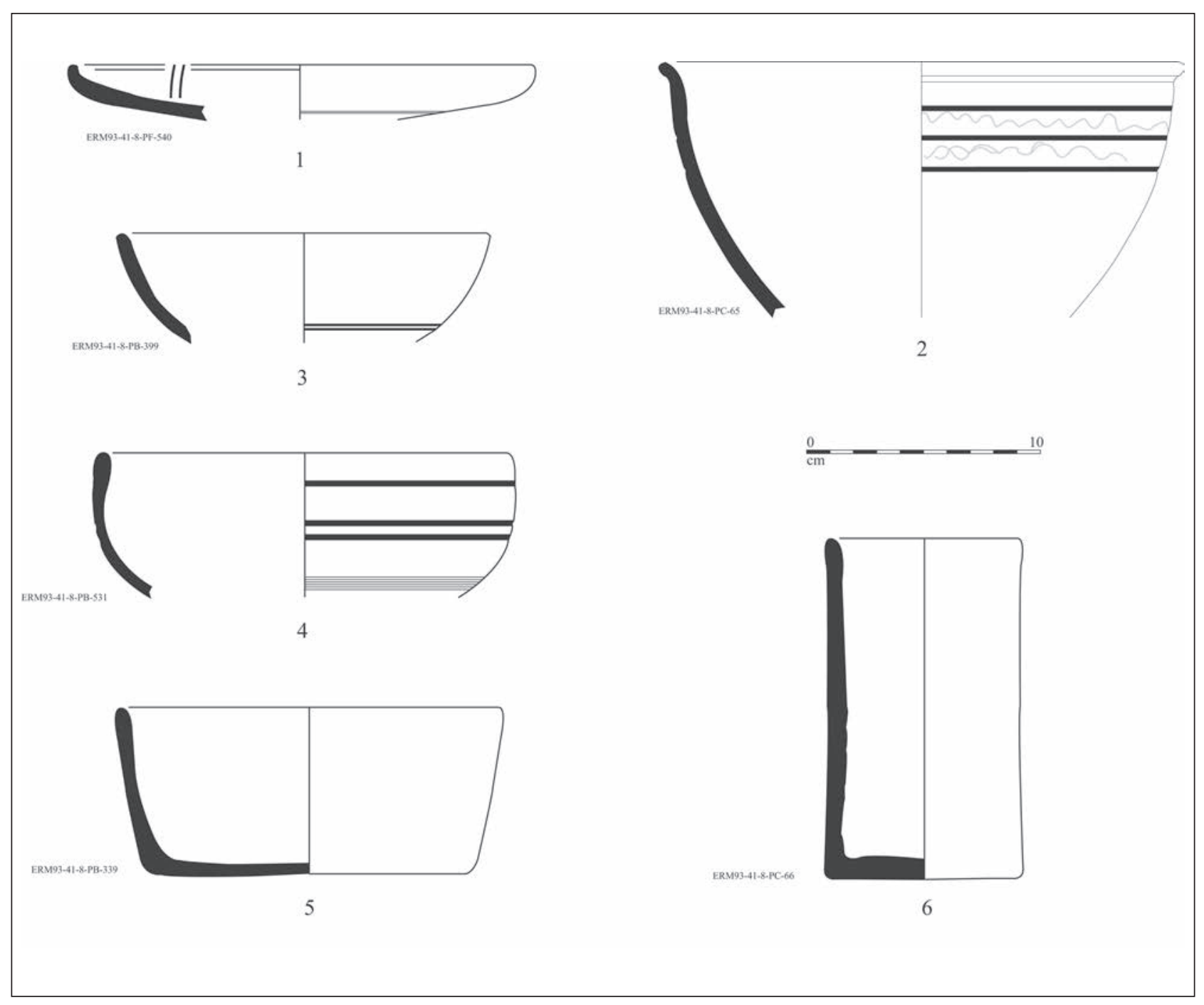

Fig. 4. L'Ermitage d'Agen. 1 à 4 : Imitations de campaniennes en céramique locale, 5-6 : formes régionales (dessins C. Touquet-Laporte-Cassagne).

que, dans les régions situées au nord d'Agen, la consommation du vin n'a pas forcément entraîné d'évolution des pratiques de table avant le milieu du ${ }^{\mathrm{er}} \mathrm{s}$. av. J.-C. (Sanchez, Sireix 2006, p. 312-314 ; Lemaître, Sanchez 2009, p. 355). Une évolution analogue a d'ailleurs été observée en Gaule du nord-est (Pion 2007, p. 154-155).

Le rapport entre la diffusion des céramiques importées et leurs imitations locales s'avère par conséquent non seulement un bon marqueur chronologique mais surtout un révélateur des évolutions culturelles locales. Dans une région comme l'isthme gaulois, très tôt appelée à jouer le rôle de vecteur du commerce méditerranéen, l'étude des faciès mobilier mérite d'être affinée et l'on ne peut que regretter la faiblesse de la documentation présentant des contextes archéologiques fiables.

\section{Bibliographie}

Alcantara et al. 2011 : ALCANTARA (A.), CHABRIÉ (Chr.), RANCHÉ (Chr.), GUÉDON (Fr.), HANRY (A.) - L'agglomération gauloise d'Eysses à Villeneuvesur-Lot (Lot-et-Garonne). In : Colin (A.), Sireix (Chr.), Verdin (Fl.) dir., Gaulois d'Aquitaine, catalogue d'exposition, Bordeaux, 2011, p. 35-38.

Arcelin 2000 : ARCELIN (P.) - Les importations de vaisselle italique à vernis noir au I ${ }^{\text {er }}$ siècle avant J.-C. sur la façade méditerranéenne de la Gaule. Nouveaux regards économiques et culturels. In : Aquilue Abadias (X.), Garcia RosellÓ (J.), Guitart Duran (J.) dir., La ceràmica de vernís negre dels segles II i I aC : Centres productors mediterranis i comercialització a la Península Ibèrica, Taula rododa (Empúries, 4 i 5 de juny de 1998), Mataró, 2000, p. 293-332.

Barral 1999 : BARRAL (Ph.) - Place des influences méditerranéennes dans l'évolution de la céramique indigène en pays éduen aux $\mathrm{II}^{\mathrm{e}}-\mathrm{I}^{\mathrm{er}} \mathrm{s}$. av. $\mathrm{n}$. è. In : Tuffreau-Libre (M.), Jacques (A.) dir., La céramique précoce en Gaule Belgique et dans les régions voisines, Actes de la table ronde d'Arras (octobre 1996), Berck-sur-Mer, 1999 (Nord-Ouest Archéologie, 9), p. 367-384. 
Barral, Videau 2012 : BARRAL (Ph.), VIDEAU (G.) - De Bibracte à Vesontio : esquisse d'une périodisation de la fin de l'âge du Fer en Bourgogne et Franche-Comté. In : Barral (Ph.), Fichtl (St.) dir., Regards sur la chronologie de la fin de l'âge du Fer (III ${ }^{e}$ I $^{e r}$ s. avant notre ère) en Gaule non méditerranéenne, Actes de la table ronde tenue à Bibracte (Glux-en-Glenne, 15-17 oct. 2007), Glux-en-Glenne, 2012 (Bibracte 22), p. 95-113.

Bats 1988 : BATS (M.) - Vaisselle et alimentation à Olbia de Provence : v. 350 - v. 50 av.J.-C.modèles culturels et catégories céramiques, Paris, 1988 (RAN Suppl. 18). Benquet 2009 : BENQUET (L.) - Découvertes récentes dans le quartier Saint-Roch à Toulouse (Haute-Garonne). In : Rivet (L.) dir., SFECAG, Actes du Congrès de Colmar (2009), Marseille, 2009 (SFECAG 2009), p. 655-670. Benquet et al. 2001 : BENQUET (L.), BOUBE (Chr.), DOMERGUE (Cl.), HESNARD (A.), MORET (P.), PASSELAC (M.), SHEERES (S.) - Cinq puits de Vieille-Toulouse : mobilier et chronologie. In : Pailler (J.-M.) dir., Tolosa. Nouvelles recherches sur Toulouse et son territoire dans l'Antiquité, Rome, 2001 (EFR 281), p. 129-155.

Deberge et al. 2007 : DEBERGE (Y.), ORENGO (L.), LOUGHTON (M.), VERRIER (G.) - La culture matérielle de la Grande Limagne d'Auvergne du III ${ }^{e}$ au Irr s. av. J.-C. In : Mennessier-Jouannet (Chr.), Deberge (Y.) dir., L'archéologie de l'âge du Fer en Auvergne, Actes du XXVII ${ }^{e}$ colloque international de l'AFEAF (Clermont-Ferrand, 29 mai- $1^{\text {er }}$ juin 2003), Lattes (MAM), 2007, p. 167-204

Genin, Lavendhomme, Guichard 1992 : GENIN (M.), LAVENDHOMME (M.-O.), GUICHARD (V.) - Les influences méditerranéennes dans le répertoire des céramiques grises de Roanne (Loire) au I ${ }^{\text {er }}$ s. av. J.-C. et au $I^{\text {er }}$ s. ap. J.-C. In : Rivet (L.) dir., SFECAG, Actes du Congrès de Tournai (1992), Marseille (SFECAG 1992), p. 181-188.

Gorgues 2007 : GORGUES (A.) - Les pratiques culinaires à Vieille-Toulouse (Haute-Garonne) au I ${ }^{\mathrm{er}}$ s. a.C. dans leur contexte régional. In : Vaginay (M.), Izac-Imbert (L.) dir., Les âges du Fer dans le Sud-Ouest de la France, Actes du 28 colloque de l'AFEAF (Toulouse, mai 2004), Bordeaux, 2007 (Aquitania Suppl. 14/1), p. 411-433.

Grimbert, Merleau, Benquet 2009 : GRIMBERT (L.), MERLEAU (M.L.), BENQUET (L.) et coll. - Les Gaulois sont dans la plaine. L'occupation du second âge du Fer du site de Puylaurens « la Plaine » (Midi-Pyrénées, Tarn). In : Bertrand (I.), Duval (A.), Gomez de Soto (J.), Maguer (P.) dir., Les Gaulois entre Loire et Dordogne, Actes du XXXI ${ }^{e}$ colloque international de l'AFEAF (17-20 mai 2007), Chauvigny, 2009, p. 510-518.

Landreau 2009 : LANDREAU (G.) et coll. - Entre Isthme gaulois et océan, la Saintonge au second âge du Fer. Etat des connaissances. In : Bertrand (I.), Duval (A.), Gomez de Soto (J.), Maguer (P.) dir., Les Gaulois entre Loire et Dordogne, Actes du XXXI e colloque international de l'AFEAF (17-20 mai 2007), Chauvigny, 2009, p. 245-306

Laporte-Cassagne 2007 : LAPORTE-CASSAGNE (C.) - La céramique gauloise de l'oppidum du Camp de César à Coulounieix-Chamiers (Dordogne). In : Duval (A.), Gomez de Soto (J.) dir., Sites et mobiliers de l'âge du Fer entre Loire et Dordogne, Chauvigny, 2007, p. 53-56.

Lavendhomme, Guichard 1997 : LAVENDHOMME (M.-O.), GUICHARD (V.) - Rodumna (Roanne, Loire), le village gaulois, Paris, 1997 (DAF 62). Lemaître, Sanchez 2009 : LEMAÎTRE (S.), SANCHEZ (C.) - Importations italiques dans le Centre-Ouest de la Gaule à l'époque laténienne. In : Bertrand (I.), Duval (A.), Gomez de Soto (J.), Maguer (P.) dir., Les Gaulois entre Loire et Dordogne, Actes du XXXI ${ }^{e}$ colloque international de l'AFEAF (17-20 mai 2007), Chauvigny, 2009, p. 341-365.

Olmer et al. 2013 : OLMER (F.), GIRARD (B.), VERRIER (G.), BOHBOT (H.) - Voies, acteurs et modalités du grand commerce en Europe occidentale. In : Colin (A.), Verdin (Fl.) dir., L'âge du Fer en Aquitaine et sur ses marges. Mobilité des hommes, diffusion des idées, circulation des biens dans l'espace européen à l'âge du Fer, Actes du XXXVe colloque de l'AFEAF (Bordeaux, 2-5 juin 2011), Bordeaux, 2013 (Aquitania suppl. 30), p. 665-691.

Passelac 2001 : PASSELAC (M.) - Les importations de vaisselle fine. In : Pailler (J.-M.) dir., Tolosa. Nouvelles recherches sur Toulouse et son territoire dans l'Antiquité, Rome, 2001 (EFR 281), p. 143-162.
Passelac 2007 : PASSELAC (M.) - Imitations et fabrications de céramiques fines de type italique en Languedoc occidental et Roussillon à la période tardo-républicaine et au début de l'Empire. In : Roca Roumens (M.), Principal (J.) dir., Les imitacions de vaixella fina importada a la Hispania Citerior (segles I aC $-I d C$ ), Tarragone, p. 17-45.

Pion 2007 : PION (P.) - À la fortune du pot. Céramique, pratiques alimentaires et romanisation des élites indigènes de Gaule nord-orientale au $\mathrm{I}^{\text {er }} \mathrm{s}$. av. J.-C. In : Rouillard (P.) et coll. dir., Mobilités, immobilismes. L'emprunt et son refus, Paris/De Boccard, 2007, p. 153-161.

Py, Adroher Auroux, Raynaud 1993 : PY (M.), ADROHER AUROUX (M.), RAYNAUD (Cl.) et coll. - Dicocer, Dictionnaire des céramiques antiques en Méditerranée nord-occidentale, Lattes, 1993 (Lattara 6).

Py, Adroher Auroux, Sanchez 2001 : PY (M.), ADROHER AUROUX (M.), SANCHEZ (C.) - Dicocer ${ }^{2}$, Corpus des céramiques de l'âge du Fer de Lattes (fouilles 1963-1999), Lattes, 2001 (Lattara 14).

Riquier 2012 : RIQUIER (S.) - La chronologie des mobiliers (II ${ }^{e}-{ }^{\text {Ier }}$ siècle avant J.-C.) de l'oppidum carnute de Cenabum (Orléans, Loiret). In : Barral (Ph.), Fichtl (St.) dir., Regards sur la chronologie de la fin de l'âge du Fer $\left(I I I^{e}-I^{e r} \mathrm{~s}\right.$. avant notre ère) en Gaule non méditerranéenne, Actes de la table ronde tenue à Bibracte (Glux-en-Glenne, 15-17 oct. 2007), Glux-en-Glenne, 2012 (Bibracte 22), p. 219-244.

Sanchez 2007 : SANCHEZ (C.) - Les céramiques d'imitations au $\mathrm{I}^{\mathrm{er}} \mathrm{s}$. av. n. è. en Languedoc : l'exemple des sites de consommation. In : Roca Roumens (M.), Principal (J.) dir., Les imitacions de vaixella fina importada a la Hispania Citerior (segles $I$ aC $-I d C$ ), Tarragone, p. 5-16.

Sanchez, Sireix 2006 : SANCHEZ (C.), SIREIX (Chr.) - Céramiques campaniennes de Bordeaux, Aquitania, 22, 2006, p. 309-317.

Séguier 1999 : SEGUIER (J.-M.) - Un aspect de la romanisation en territoire sénon : la céramique de la fin de l'Age du Fer et du début du Haut-Empire du secteur de la confluence Seine-Yonne. In : Tuffreau-Libre (M.), Jacques (A.) dir., La céramique précoce en Gaule Belgique et dans les régions voisines, Actes de la table ronde d'Arras (octobre 1996), Berck-surMer, 1999 (Nord-Ouest Archéologie, 9), p. 358-359.

Séguier, Viand 2012 : SEGUIER (J.-M.), VIAND (A.) - Chronologie des assemblages de mobilier des trois derniers siècles avant notre ère en Ile-deFrance : un état des lieux dans les territoires des Sénons et des Parisii. In : Barral (Ph.), Fichtl (St.) dir., Regards sur la chronologie de la fin de l'âge $d u$ Fer (III ${ }^{e} \mathrm{I}^{e r}$ s. avant notre ère) en Gaule non méditerranéenne, Actes de la table ronde tenue à Bibracte (Glux-en-Glenne, 15-17 oct. 2007), Glux-enGlenne, 2012 (Bibracte 22), p. 193-207.

Sireix 2007 : SIREIX (Chr.) - Bref aperçu des céramiques de la phase I de la fouille du parking du cours du Chapeau Rouge à Bordeaux (50-40 av./510 ap. J.-C.). In : Duval (A.), Gomez de Soto (J.) dir., Sites et mobiliers de l'âge du Fer entre Loire et Dordogne, Chauvigny, 2007, p. 65-69.

Verdin 2003 : VERDIN (Fl.) - La diffusion des amphores italiques dans la vallée de la Garonne. Bilan préliminaire et perspectives. In : Itinéraire de Saintes à Dougga. Mélanges offerts à Louis Maurin, Bordeaux, 2003 (Ausonius-Mémoires 9), p. 13-29.

Verdin, Bardot 2007 : VERDIN (Fl.), BARDOT (X.) - Les puits de l'oppidum de l'Ermitage (Agen, Lot-et-Garonne). In : Vaginay (M.), IzacImbert (L.), Les âges du Fer dans le Sud-Ouest de la France, Actes du Colloque de l'AFEAF (Toulouse, mai 2004), Bordeaux, 2007 (Aquitania Suppl. 14/1), p. 237-257.

Verdin, Berthault, Sanchez 2013 : VERDIN (Fl.), BERTHAULT (Fr.), SANCHEZ (C.) - Le puits 41 de l'oppidum de l'Ermitage d'Agen (Lot-etGaronne) : aperçu du faciès amphorique et questions de chronologie. In : Olmer (F.) dir., Itinéraires des vins romains en Gaule (III ${ }^{e} \mathrm{I}^{\text {er }}$ siècle av. J.-C.). Confrontations de faciès, Actes du colloque européen de Lattes (31 janvier-2 février 2007), 2013, p. 125-138.

Vidal 2001 : VIDAL (M.) - Les céramiques indigènes. Continuité et évolution. In : Pailler (J.-M.) dir., Tolosa. Nouvelles recherches sur Toulouse et son territoire dans l'Antiquité, Rome, 2001 (EFR 281), p. 179-187. 



\section{Amphores italiques des $\mathrm{II}^{\mathrm{e}}-\mathrm{I}^{\mathrm{er}}$ S. av. J.-C. dans la région de Narbonne : provenances et chronologie*}

\section{Corinne Sanchez}

ASM - Archéologie des Sociétés Méditerranéennes, UMR5140, Univ Montpellier 3, CNRS, MCC, 34000, Montpellier, France

\section{Résumé}

Narbonne au II $/ \mathrm{I}^{\mathrm{er}} \mathrm{s}$. av. n. è. représente à la fois un important lieu de consommation mais également un port de redistribution des importations italiques vers l'Aquitaine. Afin de sérier dans le temps l'évolution de ces importations, nous bénéficions de plusieurs sites bien datés par la stratigraphie et l'association avec les céramiques fines : Sainte-Croix à Montredon-des-Corbières (seconde moitié du $\mathrm{II}^{\mathrm{e}} \mathrm{s}$. av. n. è.), la Gendarmerie (fin du $\mathrm{II}^{\mathrm{e}} \mathrm{s}$. av. n. è.), l'Illette à Peyriac-de-Mer (début I ${ }^{\text {er }}$ s. av. n. è.) et la Médiathèque (niveaux du milieu du ${ }^{\text {er }}$ s. av. n. è.). Les observations typologiques et macroscopiques apportent des éléments sur les ateliers ayant approvisionné Narbonne et sa région.

Mots-clés : amphores, $\mathrm{II}^{\mathrm{e}} \mathrm{I}^{\mathrm{er}}$ av. J.-C., Narbonne, estampilles, chronologie

\section{Abstract}

During the IInd-Ist c. BC, Narbonne is both an important place of consommation and a port of trade for the italic importations towards Aquitania. In order to study the évolution of these importations, we have the chance to have many archaeological sites which are very well dated thanks to stratigraphy and fine pottery : Sainte-Croix à Montredon-des-Corbières (second part of the IInd c. BC), la Gendarmerie (end of the IInd c. BC), l'Illette à Peyriac-de-Mer (beginning of the Ist c. BC) and la Médiathèque (some occupation from the middle of the Ist $\mathrm{c}$. BC). Typologic and macroscopic observations bring to light some knew elements about the workshop having supplied Narbonne and its area.

Keywords: amphoras, IInd-Ist c. BC, Narbonne, stamps, chronology

\footnotetext{
* Ce travail est inscrit dans l'axe thématique «Identités » du programme scientifique du Labex ARCHIMEDE, programme
} IA-ANR-11-LABX-0032-01. 


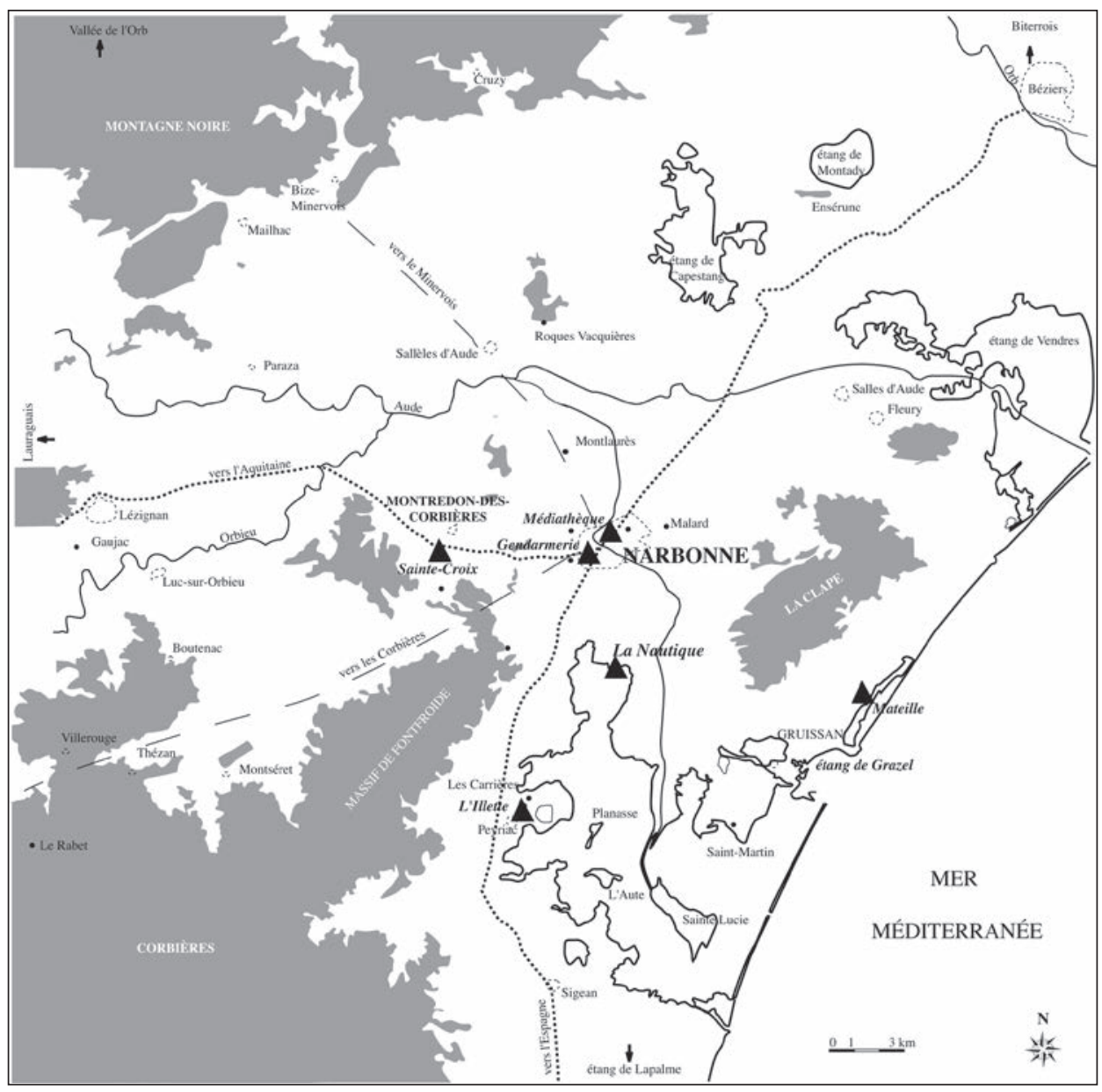

Fig. 1. Zone étudiée et principaux sites de la région de Narbonne (Aude).

$\mathrm{C}$ ette présentation des amphores des $\mathrm{II}^{\mathrm{e}} / \mathrm{I}^{\mathrm{er}} \mathrm{s}$. av. n. è. trouvées à Narbonne et dans sa proche périphérie suit une approche typo-chronologique proposée lors d'une synthèse sur Narbonne tardo-républicaine (Sanchez 2009). Cette synthèse méritait d'être approfondie par des classements par groupe de pâte et une étude des estampilles. Les données narbonnaises constituent pour les questions récurrentes sur les amphores un observatoire des évolutions particulièrement pertinent. Le statut même de Narbonne, première colonie romaine hors d'Italie et tête de pont du commerce romain en Gaule, en fait une référence incontournable. À la charnière entre les mondes ibériques et gaulois, Narbonne semble éloignée des circuits commerciaux massaliètes. L'influence italique prévaut même à des dates anciennes et laisse supposer l'existence d'une administration romaine antérieure à la conquête (Ebel 1976).

Toutes les fouilles urbaines ont livré des amphores italiques mais la plupart du temps en position secondaire.
Les fouilles à Narbonne même, mais aussi en contexte rural et lors des fouilles subaquatiques, permettent de mieux appréhender les quantités de mobilier italique ayant transité par Narbonne. Plusieurs sites de référence (fig. 1) apportent des arguments chronologiques précis (stratigraphie et association avec les céramiques fines) pour la période $\mathrm{II}^{\mathrm{e}} / \mathrm{I}^{\mathrm{er}} \mathrm{s}$. av. n. è. : Sainte-Croix à Montredon-des-Corbières (fouille M. Courrent), la Gendarmerie à Narbonne (fouille Y. Solier, R. Sabrié), l'Illette à Peyriac-de-Mer (ensemble homogène daté par les céramiques fines) et la Médiathèque à Narbonne (fouille Ph. Mellinand, E. Léal, Inrap) (fig. 1). Ces quatre sites sont d'autant plus intéressants qu'ils se succèdent très rapidement. Ils permettent $d$ 'aborder le question des importations par atelier pour définir si les approvisionnements correspondent à des circuits commerciaux différenciés. Cette question est aujourd'hui régulièrement discutée, non seulement à partir de la répartition des estampilles mais également sur la base des analyses de pâte (Benquet 2002). 


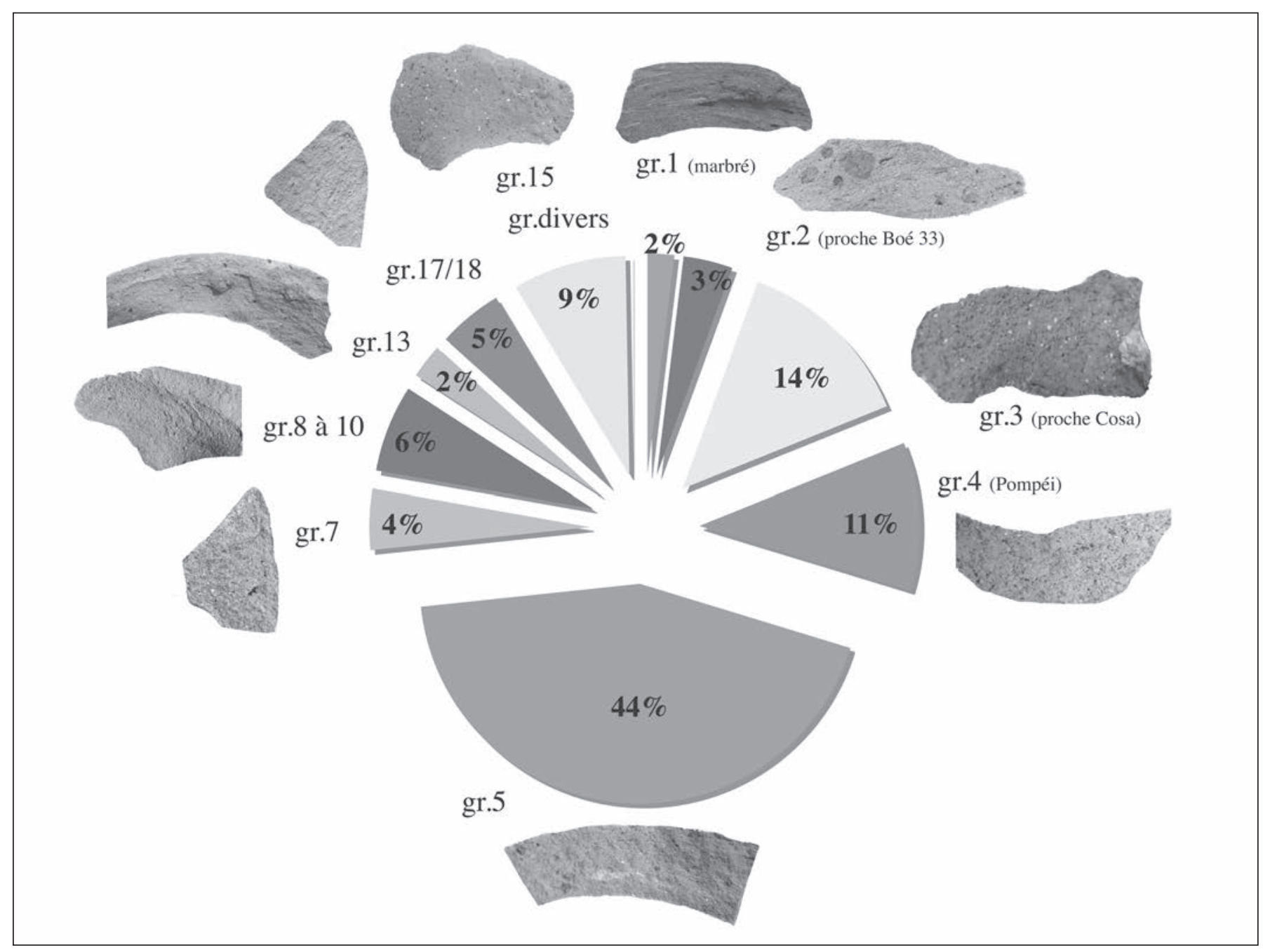

Fig. 2. Sainte-Croix à Montredon-des-Corbières : principaux groupes de pâtes.

\section{Troisième quart du $\mathrm{II}^{\mathrm{e}}$ S. av. n. è. : Sainte-Croix à Montredon-des-Corbières}

Il faut s'éloigner du cadre urbain pour aborder le milieu du II ${ }^{\mathrm{e}}$ s. av. n. è. avec le site de Sainte-Croix à Montredon-des-Corbières (Courrent et al. 2003). Une fosse de 9 sur $6 \mathrm{~m}$ et profonde de $0,4 \mathrm{~m}$ a livré 14000 tessons d'amphores et de vaisselle. L'association des amphores italiques avec les céramiques fines comme les campaniennes A Lamb.25, 27 et 36 apporte des arguments pour une datation dans la seconde moitié du $\mathrm{II}^{\mathrm{e}}$ s. av. n. è. La fourchette chronologique ne permet cependant pas d'affirmer si ce site est antérieur ou contemporain de la première fondation. Les céramiques ibériques peintes sont nombreuses et confirment un commerce important avec la Catalogne.

Les amphores sont représentées par 478 bords, ce qui constitue le plus important ensemble de la région. Pour
Montredon-des-Corbières, le rapport hauteur sur largeur $(\mathrm{H} / \mathrm{L})$ des bords d'amphores est compris en moyenne entre 0,9 et 1,5. Aucun exemplaire sauf une exception sur 478 bords ne dépasse un rapport $\mathrm{H} / \mathrm{L}$ supérieur à $>2$. Aucune observation ne peut-être faite sur les fonds qui présentent tous une très forte usure.

Des observations macroscopiques des pâtes d'amphores de Montredon-des-Corbières ont été réalisées ${ }^{1}$ : 402 bords d'amphores ont été étudiés et la vingtaine de groupes définis a été comparée aux échantillons de référence fournis par F. Olmer. Les groupes les mieux représentés sont les suivants (fig. 2) :

- Tout à fait identique à un échantillon de la tombe de Boé (Boudet 1996) qui porte l'estampille «MOC» connue

1 Ces observations ont été réalisées au centre archéologique de Lattes dans le cadre d'un stage organisé par F. Olmer avec C. Sanchez et des étudiants de l'Université de Montpellier que nous remercions. 
sur l'épave Dramont A (Santamaria 1975), le groupe $n^{\circ} 5$ est constitué par des fragments à pâte beige rosé avec de nombreuses vacuoles, du quartz et des grains de chamotte beiges non calibrés et épars et des grains bruns pouvant correspondre à des oxydes. Il représente plus de la moitié des bords de la couche 5 (fig. 3). Le groupe 8 en serait un sous-groupe (quartz, calcaire et oxydes) tout comme le $\mathrm{n}^{\circ} 9$ et le 10 où les inclusions sont moins nombreuses.

- Le deuxième groupe le plus fréquent est originaire sans doute d'Etrurie méridionale (fig. 3). Ce groupe dit de «Cosa » (groupe $n^{\circ} 3$ ) correspond aux échantillons de référence avec l'estampille de la palme. La pâte est rouge, légèrement feuilletée contenant des inclusions blanches probablement de carbonates et des inclusions noires d'origine volcanique en grande quantité ; la surface extérieure est claire. Le groupe $n^{\circ} 7$ ressemble aux pâtes de Cosa avec des variantes de couleurs.

- Le groupe d'amphores italiques à dégraissants volcaniques dit «faux Eumachii » (groupe 4) est caractérisé par une pâte rouge fortement chargée en minéraux noirs volcaniques accompagnés de deux types de quartz et une surface extérieure claire.

- Les groupes 3 et 4 sont finalement assez proches et les bords à bandeau assez long sont uniquement attestés dans ces séries (fig. 3). Ils illustrent pour une période donnée des différences de hauteur de bords selon les ateliers et à l'intérieur des mêmes ateliers.

Plusieurs groupes sont d'origine indéterminée et bien moins fréquents. Le groupe 1 est à pâte marbrée. Les fragments sont peu nombreux mais présents dans chaque couche. Ces pâtes marbrées ne définissent pas une origine mais une technique de préparation de l'argile (ThierrinMichael 2003). Le groupe 2, à pâte rose beige, avec des inclusions de calcaire et de fragments de chamotte hétérogènes est dénommé Boé 33 car proche de cet échantillon.

D'autres tessons s'intègrent dans des petits groupes mais sont comparables à des échantillons disponibles. C'est le cas pour le groupe 11 (fig. 3) qui est proche des pâte connues à Albinia (pâte dense contenant des quartz, des carbonates et quelques minéraux volcaniques) et qui a été dénommé « pseudo Albinia » car il ne correspond pas exactement à cette série. Sur un départ d'anse hors stratigraphie l'estampille AP témoigne de la présence de ces importations d'Albinia. Le groupe 13 a une pâte dense mais plus aérée à l'intérieur, rose à cœur mais aux franges internes et externes claires, avec la présence de chamotte, de quartz et d'oxydes de fer. Le groupe 14 pourrait être attribué à Sinuessa, dans le Latium, proche de l'échantillon avec estampille L.M, avec sa pâte rosée, contenant des quartz et peut-être des carbonates. Le groupe 15 (pâte beige à cœur rosé contenant des grains rouges et noirs peutêtre d'origine volcanique) a été comparé à l'échantillons
Boé 5 avec l'estampille "Rodé Gali ». Le groupe 16 semble proche du groupe «Lentulus », marque connue sur l'épave Santa Severa (Gianfrotta 1981, p. 75-77). Quant aux groupes $n^{\circ} 17$ et 18, la pâte contient du quartz, des carbonates et des oxydes rouges et noirs.

Cette grande diversité dans un même ensemble qui est pourtant a priori constitué rapidement prouve un approvisionnement multiple. Les analyses minéralogiques pondèrent cette première constatation : les inclusions sont souvent similaires mais diffèrent dans leur densité. Certaines tendances apparaissent cependant clairement comme une préférence pour les produits originaires du Latium, de l'Étrurie Méridionale et de la Campanie. Les comptages ont montré des différences entre les groupes selon les unités stratigraphiques. Ce résultat est intéressant car pour l'instant rien ne nous permettait de préciser si le comblement de la fosse était parfaitement homogène. Ces premières constatations seront à vérifier avec des analyses chimiques pour voir si cette classification est pertinente. Elles permettent dès à présent des observations intrinsèques notamment sur le comblement qui semblait homogène que ce soit pour les céramiques fines ou la typologie des amphores. La répartition des groupes de pâtes par US ne valide pas cette homogénéité. Il serait intéressant de pouvoir observer une évolution des arrivages selon les périodes et dans ce cas, les proportions selon les origines pourraient constituer des indices chronologiques. On peut toutefois également penser qu'il y a une grande diversité des zones d'approvisionnement même à une date précise. En effet, sur un site comme la Lagaste, sur une centaine de lèvres, quarante ateliers peuvent être distingués (Hesnard et al. 1989, p. 56, fig. 27).

\section{Fin du $\mathrm{II}^{\mathrm{e}}$ s. av. n. è. : La Gendarmerie à Narbonne}

Le seul ensemble homogène connu à Narbonne pour l'époque tardo-républicaine se situe à l'emplacement de l'actuelle Gendarmerie, au croisement du tracé primitif de la voie Domitienne et de la voie d'Aquitaine (Héléna 1951) : il est plutôt question d'un site péri-urbain (fig. 1). Ce secteur correspond pour le Haut-Empire à une nécropole mais aucune occupation postérieure n'est venue perturber les vestiges de la fin du $\mathrm{II}^{\mathrm{e}} \mathrm{s}$. av. n. è. Fouillées en 1981 par Y. Solier (Solier 1981), deux fosses du $\mathrm{II}^{\mathrm{e}} \mathrm{s}$. av. n. è. ont été préservées et ont livré une importante série d'amphores : 125 bords et une douzaine d'amphores complètes. Deux hypothèses ont été émises sur ces vestiges : soit il s'agit d'une «bourgade indigène » antérieure à la colonie soit une zone commerciale en relation avec l'exportation des produits italiques vers 


$$
\begin{array}{ccc}
1 & 1 \\
01 & -1 \\
1 & 1 & 1 \\
1 & 1 & 1 \\
0 & & 1
\end{array}
$$




$$
\begin{aligned}
& 10 \\
& 10 \\
& 10
\end{aligned}
$$




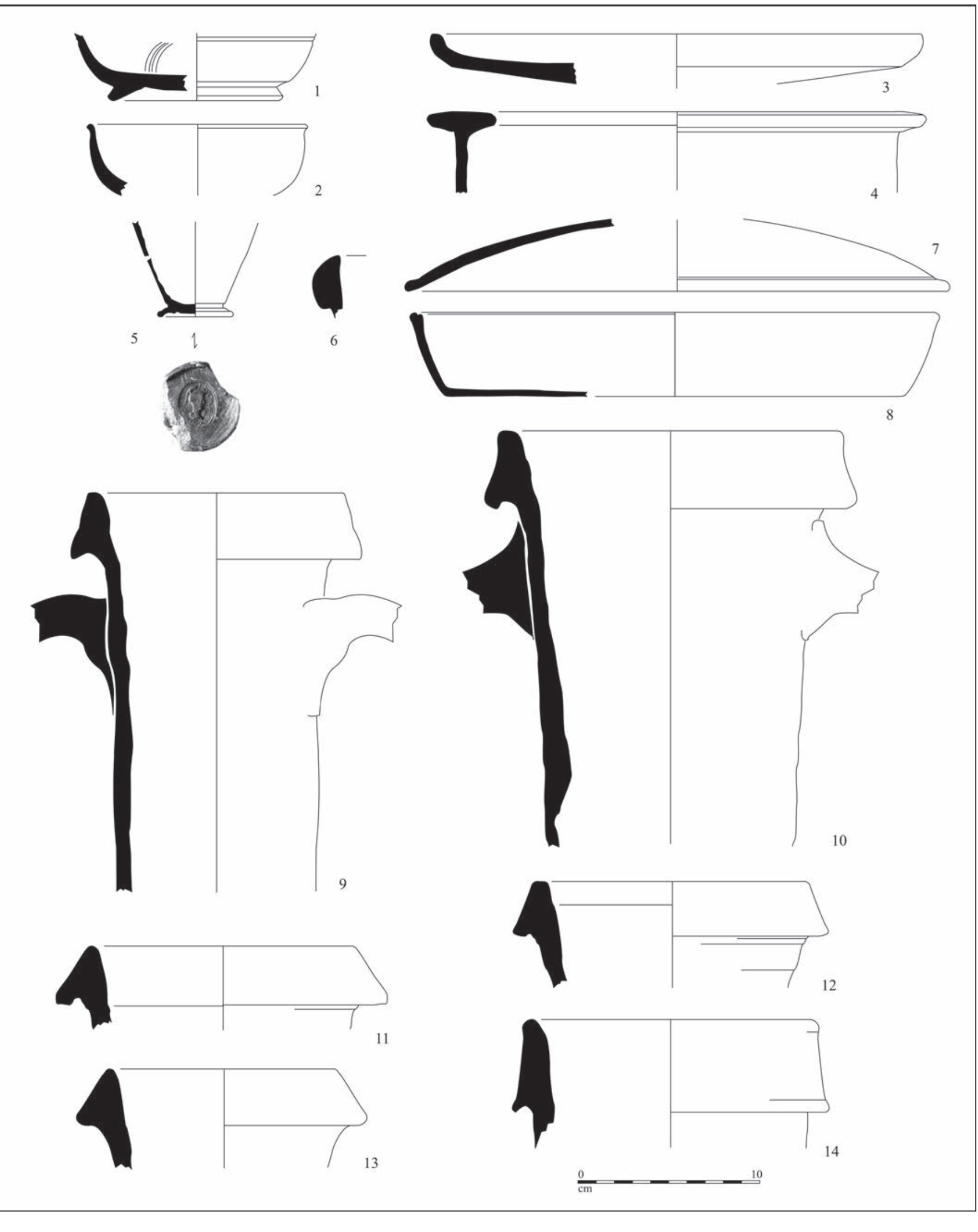


l'ouest. Plusieurs objets particuliers, selon leur interprétation, pourraient valider cette dernière hypothèse :

une anse d'amphore italique retaillée. D'un côté est ciselé un ocelle et de l'autre un pseudo-triskèle (fig. 4, $\mathrm{n}^{\circ} 1$ ). Cette réutilisation des anses d'amphores pour réaliser des poinçons n'est pour l'instant attestée que dans la Vienne et en Charente-Maritime (Maguer 2007, p. 55-56).

Une pierre en calcaire, quadrangulaire, a sur quatre côtés des représentations probablement zoomorphes (fig. $4, n^{\circ} 2$ ). La seule comparaison existante est un « dé à décor zoomorphique sur ses quatre faces » signalé sur le site du Baou-Roux dans les Bouches-du-Rhône (Boissinot 1990, p. 94). Ces motifs rappellent les décors stylisés celtiques. Différents animaux pourraient être représentés comme le sanglier, le bœuf, le coq et un équidé.

Ces deux éléments ont été considérés comme de probables poinçons servant à estampiller à nouveau les bouchons d'amphores. Cette hypothèse signifierait une consommation du vin italique à Narbonne et un reconditionnement d'un autre produit. Cette interprétation paraît peu probable. Les marques peintes sur ces amphores ont fait l'objet de relevés avant d'être perdues. Elles sont généralement simples avec des lignes verticales ou des lettres $\mathrm{KA}, \mathrm{M}$ ou $\mathrm{N}$. Il s'agit très probablement de marques numérales.

Ce site pose des questions majeures pour les chronologies : s'il est lié à la première colonie, il permet de proposer un référentiel sur la base d'une date historique (118 av. n. è.). L'association des céramiques fines est proche de Montredon-des-Corbières mais plusieurs différences sont interprétables comme des éléments chronologiques ou de contextes (site indigène/site colonial : voir développement dans Sanchez 2009). Ainsi, les céramiques campaniennes $\mathrm{B}$ et les parois fines sont présentes alors qu'elles ne sont pas attestées à Montredon (fig. 4). Deux situles en bronze complètes avec leur cerclage de fer ont également été prélevées (fig. 4, n 11 et 12). Face à ce doute sur la question de statut ou de chronologie de ces deux ensembles, les bords d'amphores ont été comparés pour déterminer la part des gréco-italiques de transition $(\mathrm{H} / \mathrm{L}<2)$ et des Dr.1 (Sanchez 2003, p. 685, fig. 361). Effectivement, la part des gréco-italiques semble légèrement plus élevée à Montredon. Un bord plus large que haut correspond à une forme de gréco-italique et porte un double estampillage sur le bord $\mathrm{CH}$ ainsi qu'une marque peinte sur le col composée de traits verticaux parallèles reliés par un trait horizontal (fig. $4 \mathrm{n}^{\circ}$ 9). La plupart des estampilles $\mathrm{CH}$ ont un point de séparation entre les lettres et sont généralement situées sur l'anse à l'exception d'une marque trouvée au Mont-Beuvray ou dans la Saône (Olmer 2003, p. 112). Une autre caractéristique des amphores de la Gendarmerie se présente comme des décors sinueux réalisés avant cuisson sur la lèvre (fig. 4 , $\mathrm{n}^{\circ} 10$ ).
Quant aux observations macroscopiques des pâtes, elles ont aussi souligné la rareté des importations d'Albinia et l'importance des importations d'Italie centrale. À côté de toutes ces importations italiques, se trouvent de rares exemplaires d'amphore ibérique (Sanchez 2003, p. 192, fig. 70, $\mathrm{n}^{\circ}$ 8) ou punico-ébusitaine (Sanchez 2003, p. 192, fig. $\left.70, n^{\circ} 9\right)$.

\section{Le début du $\mathrm{I}^{\mathrm{er}} \mathrm{S}$. av. n. è. : L'Illette à Peyriac-de-Mer}

Après les années -100 et pour une grande partie du $\mathrm{I}^{\mathrm{er}} \mathrm{s}$. av. n. è., le manque d'ensembles clos rend difficile une synthèse sur l'origine des approvisionnements. Pour le début du Irr $\mathrm{s}$. av. n. è. les données à Narbonne même ne sont pas exploitables. Le site de référence pour cette période se trouve à une dizaine de kilomètres de Narbonne au bord des étangs de Bages et Sigean, au lieudit l'Illette. Le mobilier provient d'une fouille réalisée dans les années 1960 suite au creusement d'un puits et du défonçage de la vigne (Gallia, Tome XX, 1962, fasc.1, 618). De nombreux éléments laissent supposer le travail du fer. Dans ce contexte plusieurs monnaies associées apportent des indices chronologiques avec une fausse monnaie en plomb frappée en 92 av. (Lucius Cosconius, Marcus Filius, 10 as ; Lucius Licinius Cneus Domitius). D'autre part, la découverte d'un trésor monétaire de cent dix-sept pièces d'argent de la République romaine à environ $200 \mathrm{~m}$ de l'Illette montre une thésaurisation et peut témoigner de l'installation de commerçants.

Le mobilier se caractérise par l'importance des céramiques campaniennes $\mathrm{B}$, des communes italiques, la présence de dernières importations d'ibériques peintes et de gobelets à parois fines de type Rullius (fig. 5, $\left.\mathrm{n}^{\circ} 5\right)$. Ce site reste exceptionnel par l'importance des communes italiques originaires du Latium avec les pots à bord en amande (COM-IT1B) qui représentent $10 \%$ du total des bords. Le site de l'Illette n'a livré malheureusement qu'une vingtaine de bords d'amphores italiques qui se caractérisent par une très grande variabilité. Plusieurs exemplaires ont un rapport $\mathrm{H} / \mathrm{L}$ supérieur à 2, montrant l'allongement de la hauteur de la lèvre. La hauteur maximum attestée est de $6 \mathrm{~cm}$, ce qui prouve la présence de Dr.1B.

\section{La Médiathèque}

Excepté les fouilles de la Gendarmerie qui sont d'ailleurs à l'extérieur des limites de la colonie, la plupart des niveaux narbonnais ne sont pas datés avant les années 80 av. n. è. 


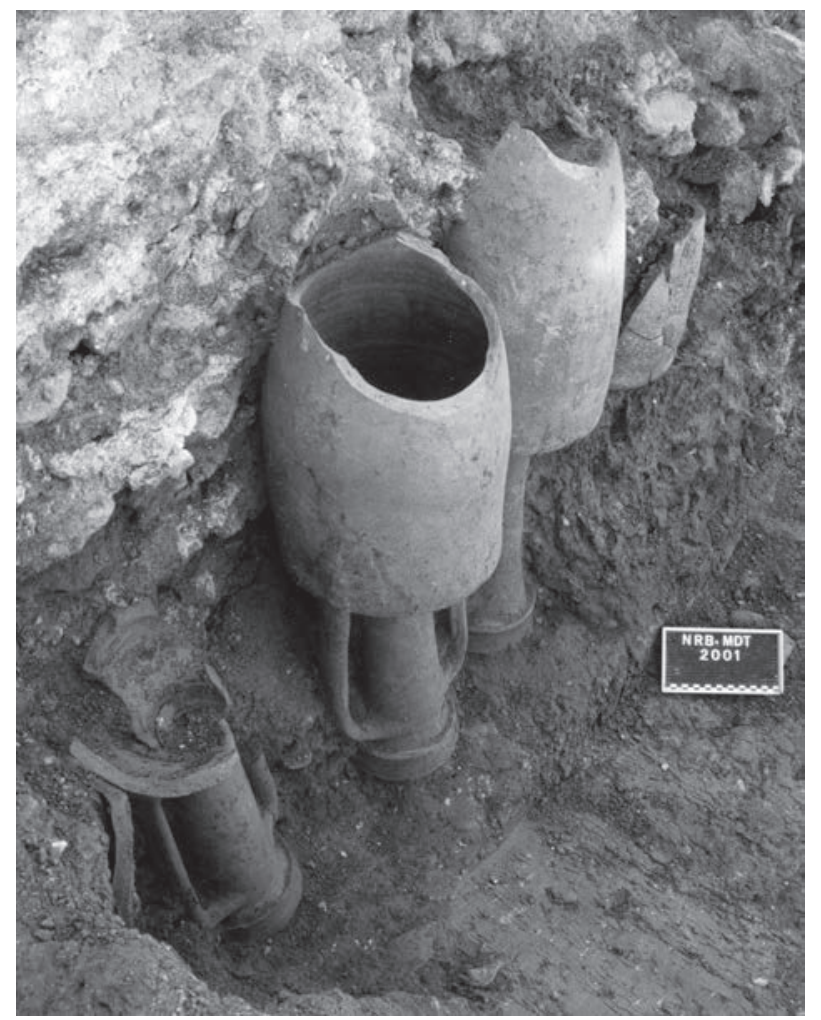

Fig. 6. La Médiathèque à Narbonne : photographie de l'alignement des amphores (cliché F. Cognard, Inrap).

Pour le site de la Médiathèque, 732 fragments pour 70 individus d'amphores italiques ont été répertoriés (Rascalou, Sanchez 2002) ${ }^{2}$. Situé à proximité du fleuve, nous sommes probablement proches d'une zone de stockage ou de débarquement de marchandises.

Les fouilles ont mis au jour des « limites parcellaires » matérialisées par un alignement d'amphores, encore emboîtées (fig. 6). Ces alignements d'amphores italiques correspondent aux US 7112 et 7149 . Ce type d'aménagement est reconnu également à Montlaurès (Laubenheimer 1990, p. 58). La plupart des amphores de ces structures de la Médiathèque sont conservées au trois quart. Leur aspect massif, leur carène très marquée, les anses larges et un bord allongé permettent de les attribuer au type Dr.1B. La hauteur des lèvres est comprise entre 5,3 et $6,1 \mathrm{~cm}$ mais deux exemplaires sont plus petits $(4,3$ et $4,5 \mathrm{~cm})$. Les diamètres caractérisent bien cet ensemble : les plus grands atteignent $20 \mathrm{~cm}$ et la moyenne est autour de $19 \mathrm{~cm}$. Ces amphores ont généralement une pâte assez fine, un peu sableuse avec quelques dégraissants de fines particules brillantes et de calcite. Plusieurs amphores portent des estampilles sur le bord :

2 Je tiens à remercier $\mathrm{Ph}$. Mellinand et $\mathrm{P}$. Rascalou pour la confiance qu'ils m'ont accordée.

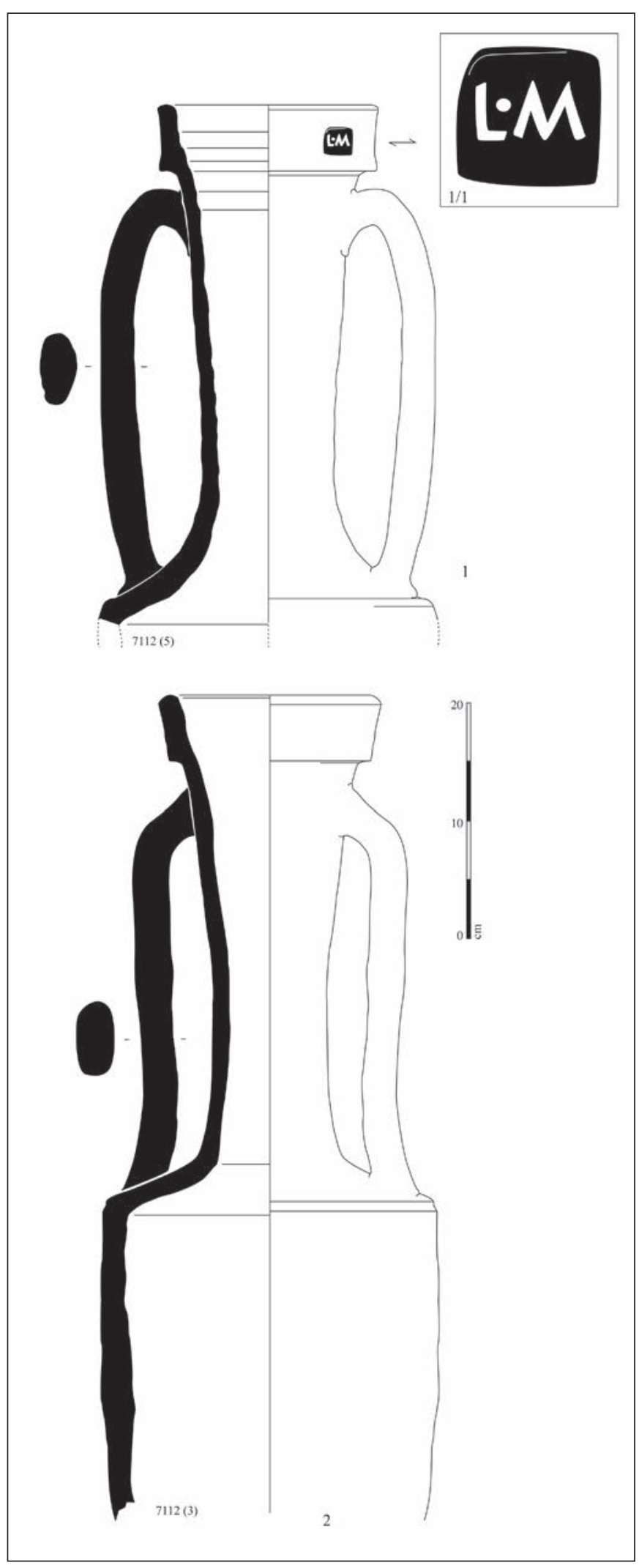

Fig. 7. La Médiathèque à Narbonne : amphores de SB7112 et 7149. 
- L'amphore $\mathrm{n}^{\circ} 5$ (US 7112) a un bord haut de $5,6 \mathrm{~cm}$ pour une épaisseur de $2,8 \mathrm{~cm}$ et un diamètre de $17,6 \mathrm{~cm}$ (fig. 7, $\mathrm{n}^{\circ} 1$ ). Elle porte sur le bord l'estampille L.M qui est généralement attribuée à Sinuessa même si l'examen d'un échantillon de la tombe de Boé a permis de proposer comme autre possibilité d'origine : Albinia (Olmer 2003, 172). Elle est attestée à Ensérune sur une Dr.1B (Lamour, Mayet 1981 ; Ceipac 6162) mais également à Sos-en-Albret (Gruat 1994,p. 194 ; Ceipac 21304) et Rodez (Dausse, Gruat 1991, p. 69 fig. $5 n^{\circ}$ 27). Elle est bien diffusée dans tout l'ouest de la Gaule (voir carte de répartition dans Olmer 2003, p. 172, fig. 35).

- L'amphore n ${ }^{\circ} 8$ de l'US 7149, dont la lèvre mesure $6,1 \mathrm{~cm}$ de haut pour une épaisseur de 2,3 et un diamètre de $18,5 \mathrm{~cm}$, porte une double estampille GACAR de part et d'autre du bord (fig. $8, \mathrm{n}^{\circ} 1$ ). Cette estampille a déjà été trouvée dans la Saône (Olmer 2003, p. 107 et 150), à Chartres (Poux, Sellec 1998, p. 220 fig. 13 n 5) et au Mas d'Agenais en Gironde (Cadenat 1978, p. 204 fig. $3 n^{\circ} 5$ ). L'estampille de la Médiathèque prouve qu'il ne s'agit pas d'un gentilice mais de deux noms associés (esclave/maître) et fait partie d'une série de quatre timbres associant un esclave (Dion(ysius), Rubriaeus, $A p o(l l o$ ?) et maintenant $G a()$ à un maître : $\operatorname{Car}($ ). Cette hypothèse, avancée par F. Olmer (Olmer 2003, p. 197) est validée avec le point de séparation entre GA et CAR à la Médiathèque.

D'autres estampilles ont été découvertes à la Médiathèque :

- SABINA ; sur épaule d'amphore italique Dr.1, US 7001 (fig. 8, $\mathrm{n}^{\circ}$ 2). Cette marque a également été découverte sur l'épave de la Madrague de Giens (Tchernia et al. 1978, p. 33-46). Ce nom, connu sur les amphores de Brindes - un exemplaire au musée de Narbonne (Lamour, Mayet 1981, p. 10, n² 24) - et les Lamb. 2, est attesté sur une Dr.1B à Roanne (Aulas 1981 et Ceipac 8318).

- RV.I ; sur anse d'amphore italique Dr.1 ( ?), US 9095, phase 3 (fig. $8, n^{\circ} 3$ ).

PERIGENE ; sur bord Dr.1A (hauteur 4,5, épaisseur 3,2 et diamètre $17 \mathrm{~cm}$ ), phase 3 US 9012 (fig. 8, $\mathrm{n}^{\circ} 4$ ). Le $\mathrm{P}$ initial a une boucle ouverte.

- PHILOXS.AELI (P et H liés); sur bord Dr.1B (hauteur 5,9, épaisseur 2,8 et diamètre $18 \mathrm{~cm}$ ), US 8001 (fig. 8, $\mathrm{n}^{\circ} 5$ ). Le $\mathrm{S}$ rétrograde correspondrait à servus et le timbre peut être lu comme Philox(enus) servus d'Aelius. Cette estampille, probablement originaire du sud Latium, est connue à Saint-Pierre-sur-Mer mais surtout dans tout l'ouest de la Gaule et notamment à Vieille-Toulouse dans le comblement augustéen d'une citerne (Benquet 2002, t. IV n ${ }^{\circ}$ 55) et à Poitiers (Ceipac 9073).
- Q MAE ANT (MAE liés, ANT liés) ; sur bord d'amphore italique Dr.1B (hauteur 5,7, épaisseur 1,8 et diamètre $15 \mathrm{~cm}$ ), US 9077, phase 5 (fig. 8, $\mathrm{n}^{\circ}$ 6). Cette estampille, peut-être originaire de Terracine, dans la plaine de Fondi, accompagne les amphores de Vevius Papus dans l'épave de la Madrague de Giens. Il s'agit d'un affranchi de la gens Maeci connue à Délos (Olmer 2003, p. 45). Cette estampille a également été trouvée au Mont-Beuvray sur un bord d'amphore qui présente exactement le même profil que celui de Narbonne avec un bord rectiligne (Ceipac 20883) ainsi qu'à Auterive (Alberghi 2005, t. 2 p. $19 \mathrm{n}^{\circ} 26$ ).

- [VE]HILI ; sur anse d'amphore de Brindes, US 7204, phase 1 (fig. 8, $n^{\circ} 7$ ). C. Vehilius est attestée en trois exemplaires à Vieille-Toulouse dans des niveaux datés entre le deuxième quart du ${ }^{\mathrm{er}} \mathrm{s}$. av. n. è. et le changement d'ère (Benquet, Gardes 2008, p. 545 fig. 15, n 6).

- Estampille en lettres grecques, US 8001 (fig. 8, $n^{\circ} 8$ ). - VCCO ; sur anse amphore de Brindes, US 7195, phase 2, (fig. 8, n ${ }^{\circ}$ 9). Connue comme LVCCO à Badalona (Comas y Sola 1997 ; Ceipac 18054) et également à Vieille-Toulouse (Benquet 2002, t. IV n 459).

- SALANI (A et $\mathrm{N}$ liés) : sur anse d'amphore de Brindes, US 7001 (fig. 8, $\mathrm{n}^{\circ} 10$ ).

- Marque cassée sur col d'amphore tripolitaine IA, US 7111 (Sanchez 2003, fig. 107, $\mathrm{n}^{\circ}$ 14).

- ].PHL (lettres liées) ; sur anse d'amphore de Tarraconaise, US 5102;

Cet ensemble d'estampilles est exceptionnel pour Narbonne, la plupart des autres fouilles n'en livrant que quelques rares exemplaires.

Signalons la présence pour cet ensemble d'une amphore Pascual 1 avec une pâte proche des italiques dans l'US 9065 (-50/-1) ainsi que plusieurs importations d'amphores de Brindes, puniques ou punico-ébusitaines (Sanchez 2003, p. 123-168).

Un des apports majeurs du site de la Médiathèque repose sur une stratigraphie fine du $\mathrm{I}^{\mathrm{er}} \mathrm{s}$. av. n. è. Ce site permet de cerner la transition entre les amphores italiques et tarraconaises. L'inversion des courants commerciaux entre 40 et 20 av. montre la chute de ces importations italiques de 85 à $25 \%$. Ces chiffres restent cependant à pondérer avec des sites dont l'occupation débute vers 40 av. n. è. pour avoir des comptages sans mobilier résiduel.

Les données quantifiées restent rares sur l'axe aquitain mais permettent de confirmer les observations réalisées à Narbonne. Les niveaux contemporains de 40 av. n. è. sont essentiellement composés d'amphores italiques (Sanchez 2011). En effet, dans des niveaux où se trouvent des imitations de sigillées italiques du service 1A, les amphores italiques sont majoritaires et appartiennent essentiellement au Dr.1B ou Dr.1A à bord massif. Une phase, 
semble-t-il assez courte, voit l'arrivée des amphores de Tarraconaise à pâte rouge. Autour du changement d'ère, les amphores de Tarraconaise sont majoritaires mais ne correspondent pas aux associations habituelles pour le Sud-Est de la Gaule où les productions à pâte rouge, marron ou orangée sont majoritaires. Les amphores de Tarraconaise à pâte blanche sont les plus nombreuses en Aquitaine et posent la question d'un choix dans les ateliers catalans ou de l'existence d'ateliers intermédiaires comme Aspiran (Genty, Fiches 1978 ; Mauné et al. 2006). Il serait donc intéressant de pouvoir analyser ces productions pour déterminer leur origine.

\section{Les zones commerciales ou portuaires}

L'étude des amphores de Narbonne, outre leur aspect commercial, apporte des éléments sur la chronologie des installations portuaires. Les amphores gréco-italiques sont présentes à Montlaurès et à Port-la-Nautique. Le site de Montlaurès, à quatre kilomètres au nord-est de la ville, est identifié à Naro, capitale des Elysiques. L'existence d'un important lieu d'échanges qu'a pu constituer Montlaurès durant la Protohistoire a sans doute été un argument favorable à la déduction de la colonie romaine. Le passage de l'Aude à Montlaurès soulève l'hypothèse d'un moyen de communication fluvial qui relierait l'oppidum à la mer (Guy 1972). Selon les géologues, Montlaurès dominerait le fleuve sur ses flancs nord au début de l'Âge du Fer. L'oppidum aurait alors accès à la mer par cette voie fluviale. Des entrepôts importants datés des $\mathrm{II} / \mathrm{I}^{\mathrm{er}} \mathrm{s}$. av. n. è. valideraient l'importance de Montlaurès comme zone commerciale. Port-la-Nautique, au sud de Narbonne, présente un rôle portuaire évident seulement à la fin du $\mathrm{I}^{\mathrm{er}} \mathrm{s}$. av. n. è. et jusqu'aux années 70 de n. è. Or, les sondages réalisés par Antéas en 1993 ont démontré l'existence d'un niveau daté vers 150 contenant des amphores gréco-italiques enfouies à 4,90 $\mathrm{m}$ de profondeur.

Ces deux sites posent la question de leur proximité avec le passage du fleuve Aude. L'importance de cette voie d'eau, l'Atax, est soulignée par Pomponius Mela qui appelle Narbo « colonie des Atacini et des Decumani » (II, 5, 75). De cette citation, on considère que l'Aude a donné son nom aux premiers colons installés près du fleuve. Cette hypothèse irait dans le sens d'une installation à vocation commerciale au bord du fleuve pour les transactions par voies navigables. Des installations en ville ont-elles succédé à des aménagements existants au pied de l'oppidum de Montlaurès ? Les fouilles actuelles menées par Antéas dans le canal de la Robine, proche du Pont des marchands, livrent une masse importante d'amphores italiques, voire gréco-italiques. Il est certain que la ville devait disposer d'installations capables de recevoir les marchandises transportées par voie maritime (Rougé 1966, p. 108-110). La reconnaissance d'un paléo-plan d'eau (Ambert 1995) viendrait confirmer la possibilité de l'existence d'un port urbain.

Le gisement de Malard, proche d'un antique bras de l'Aude (Falguéra 1993) est justement en limite d'un paléo-plan d'eau. Il est composé de plusieurs centaines d'amphores, la plupart des Pascual 1, servant à drainer une zone humide.

Parmi les autres sites portuaires potentiels, la découverte des épaves de l'étang de Mateille, du Grazel ou du Grand Bassin et le site de Tintaine à Gruissan montrent une fréquentation de cette zone. Les épaves datables de l'époque républicaine sont Grazel A, (Solier et coll. 1981, 23) et surtout le Grand Bassin B, (Solier et coll. 1981, p. 59) qui constitue un ensemble conséquent avec trente-huit bords d'amphores Dr.1A, treize fonds, deux Dr.1B/1C, deux Dr.2/4 et deux Pascual 1, ainsi que cent cinq fragments de céramique campanienne. Parmi les marques et graffitis se trouvent une anse avec un timbre figuré (joueur de flûte avec marque CCL) sur Dr.1 et une marque sur épaule dans un cartouche rectangulaire [.] MEVI (ME liés) sur amphore de Tarraconaise. La gens Mevia est connue en Italie (Latium et Campanie) (Pena 1998, p. 307). Un graffiti ibère sur amphore italique est également attesté. Le mobilier montre une association Italie/Espagne : on y retrouve en effet des monnaies de Tarragone, des amphores venant d'Italie et un plat en métal avec inscription ibérique.

\section{Conclusion}

Ces différents sites narbonnais constituent un apport aux discussions chronologiques au cours des II $/$ ${ }^{\text {er }} \mathrm{s}$. av. n. è. Bien qu'ils ne permettent pas de datations absolues, ils se présentent comme des séries cohérentes, qui peuvent être situées en chronologie relative. Les résultats métrologiques sur des ensembles conséquents montrent une évolution linéaire car les données sont lissées par le nombre. En revanche, la multitude des sources d'approvisionnement provoque indubitablement de nombreuses variantes de bords qui, sur des petites séries, faussent les résultats.

À partir du faciès des amphores de Narbonne et des observations macroscopiques se dessinent les relations privilégiées avec les régions du Latium, de Campanie et d’Étrurie méridionale. L'épigraphie avait montré que les colons seraient originaires d'Italie centrale et notamment de l'Ombrie, du Latium et de la Campanie (Gayraud 1981, 149-159). Les donnés archéologiques soulignent les liens commerciaux avec ces régions. 


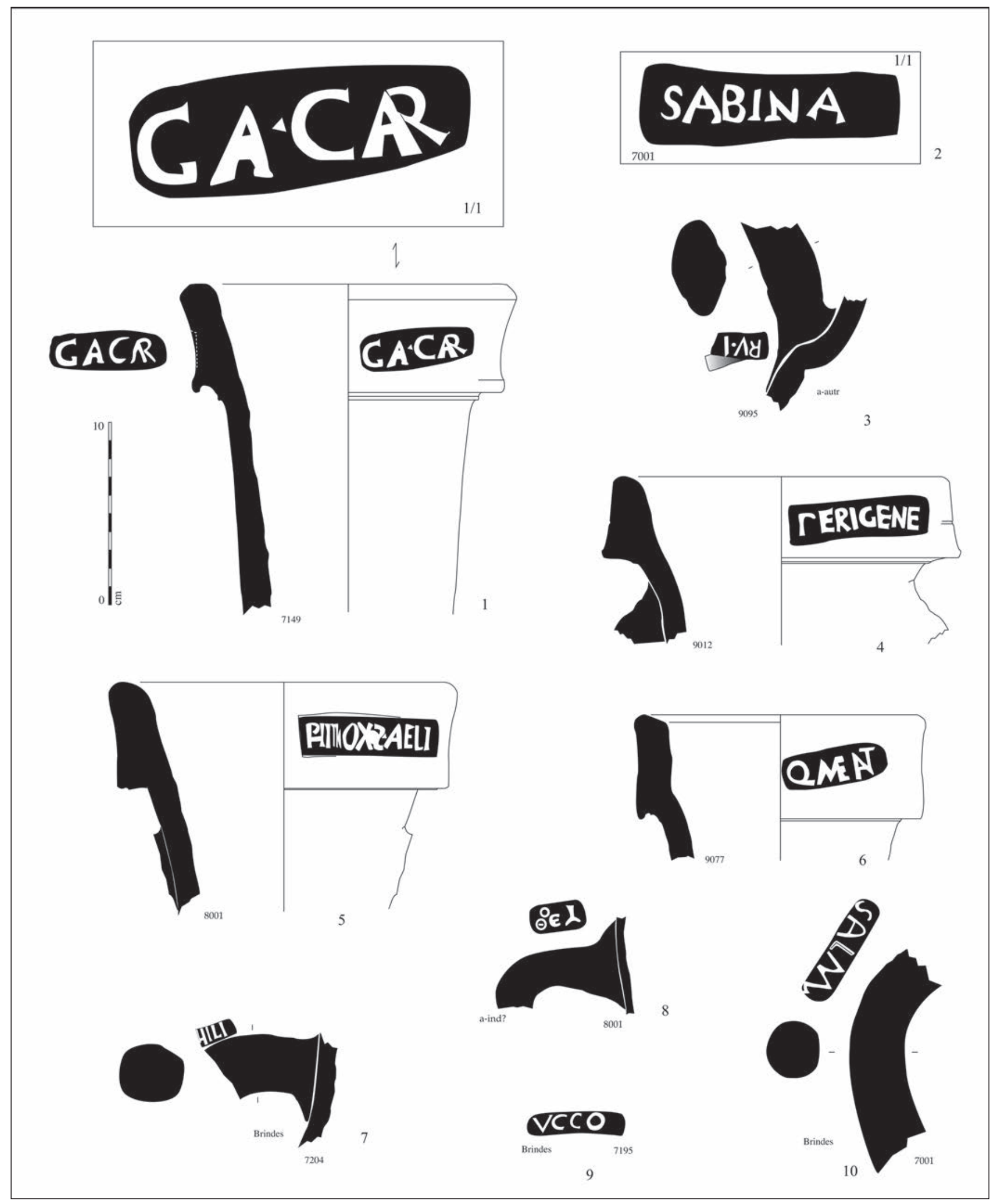

Fig. 8. La Médiathèque à Narbonne : estampilles sur amphores italiques. 
Les estampilles sont nombreuses au $\mathrm{I}^{\mathrm{er}}$ av. n. è. mais extrêmement rares dans les contextes du $\mathrm{II}^{\mathrm{e}} \mathrm{s}$. Pour le $\mathrm{I}^{\mathrm{er}} \mathrm{s}$. av. n. è., il faut souligner la rareté des importations d'Albinia et surtout l'absence des estampilles de Sestius qui rapproche le cas de Narbonne de celui de Lyon. Une estampille au caducée a cependant été trouvée sur l'île de l'Aute (Sanchez 2003, p. 491, fig. 258, n 16). Les marques de Sestius sont diffusées sur l'isthme gaulois et notamment à Mailhac, La Lagaste puis Vieille-Toulouse. La « Provence paraît particulièrement absente des répertoires » (Olmer 2003, p. 209) : cette absence caractériserait-elle une consommation littorale ? Mais, parmi les absences remarquables, les timbres à trois lettres appuient l'hypothèse que les importations de Cosa sont moindres et entérine la faiblesse du commerce avec l'Étrurie. La répartition de certains timbres semble finalement suivre une route septentrionale par rapport à Narbonne passant par Ensérune puis vers Mailhac et au delà l'Aquitaine. Pour les II $/ \mathrm{I}^{\mathrm{er}} \mathrm{s}$. av. n. è., certaines absences à Narbonne posent la question de la perduration de relais grecs comme Ampurias et Agde. X. Nieto avait bien signalé la vitalité d'Ampurias jusqu'à la fin du Ir ${ }^{\text {er }}$ av. n. è., moment où le port connaît un déclin face à la concurrence de Narbonne. Il est envisageable qu'Agde ait eu également encore un rôle actif jusqu'à la défaite de Marseille. La déduction des colonies de Narbonne et d'Arles par César témoigne d'une volonté forte de restructurer des zones commerciales majeures. L'importance de Narbonne dans la redistribution des amphores de Tarraconaise le prouve. Cependant, la part prise par des ateliers de la Vallée de l'Orb et de l'Hérault pourrait aussi souligner la continuité de la fréquentation de cet axe. En effet, les premières observations sur les amphores de Tarraconaise qui sont diffusées vers l'Aquitaine montrent une différence entre ce qui est consommé à Narbonne et ce qui est exporté vers le sudouest : on observe la part moins importante des pâtes rouge typiques au profit de séries à couleur beige et à pâte granuleuse. On pense alors à l'importance d'axes dits secondaires (Orb et Hérault) où des ateliers relais comme Aspiran ont pu occuper une part du marché des vins hispaniques.

\section{Bibliographie}

Alberghi 2005 : ALBERGHI (L.) - Les amphores d'Auterive : commerce aux portes de l'Ariège, Mémoire de Maîtrise sous la direction de C. Rico, UTM, 2005.

Ambert 1995 : AMBERT (P.) - Forages géotechniques dans l'agglomération de Narbonne (Aude), Conséquences paléographiques et archéologiques, Archéologie en Languedoc, 19, 1995, p. 75-84.

Aulas 1981 : Marques et inscriptions retrouvées sur amphores à Roanne, $C A L, 1,1980-1981$, p. 61-91.
Benquet 2002 : BENQUET (L.) - Les amphores des II et $I^{e r} s$. av. J.-C. découvertes dans le Toulousain : production et consommation, Thèse de doctorat sous la direction de J.-M. Pailler, Toulouse-le-Mirail, 4 tomes, 2002, $895 \mathrm{p}$.

Benquet, Gardes 2008 : BENQUET (L.), GARDES (P.) - Les dernières phases de l'occupation de l'oppidum de Vieille-Toulouse (Haute-Garonne), Actes du Congrès de la SFECAG Escala-Empúries, 2008, p. 535-552.

Boissinot 1990 : BOISSINOT (PH.) - Le Baou-Roux, In : Voyage en Massalie, 100 ans d'Archéologie en Gaule du Sud, 1990, p. 91-94 (Musée de Marseille, Edisud).

Boudet 1996 : BOUDET (R.) - Rituels celtes d'Aquitaine, 1996, 128 p. (ed. Errance).

Cadenat 1978 : CADENAT (P.) - Les timbres d'amphores d'Ussubium (Commune du Mas d'Agenais), Revue de l'Agenais, 1978, p. 1-12.

CEIPAC : Centro para el Estudio de la Interdependencia provincial en la Antigüedad classica. http://ceipac.gh.ub.es/

Comas y Sola 1997 : COMAS Y SOLA (M.) - Baetulo. Les marques d'àmfora. Institut d'Estudis Catalans, Barcelona, 1997, $\mathrm{n}^{\circ} 212$.

Courrent et al. 2003 : COURRENT (M.), FOREST (V.), SANCHEZ (C.) Une fosse des années -140/-120 à Montredon-des-Corbières (11), Rapport de fouilles de sauvetage, SRA Languedoc-Roussillon, 2003, $71 \mathrm{p}$.

Dausse, Gruat 1991 : DAUSSE (L.) ET GRUAT (P. ) - Estampilles et inscriptions peintes sur amphores vinaires Dressel 1 trouvées à Rodez, Vivre en Rouergue, Cahier d'Archéologie Aveyronnaise, 5, p. 66-76.

Ebel 1976 : EBEL (CH.) - Transalpine Gaul, the Emergence of a Roman Province, Leyde, 1976, 113 p.

Falguéra 1993 : FALGUÉRA (J.-M.) - Les fouilles de Malard à Narbonne. Résultats préliminaires d'un sondage sur un lit d'amphores du I ${ }^{\mathrm{er}} \mathrm{s}$. ap. J.-C., Cahiers d'Archéologie Subaquatique XI, 1993, p. 67-98.

Gayraud 1981 : GAYRAUD (M.) - Narbonne antique, des origines à la fin du III ${ }^{e}$ s., RAN, suppl.8, 1981, $592 \mathrm{p}$.

Genty, Fiches 1978 : GENTY (P.-Y.), FICHES (J.-L.) - L'atelier de potiers gallo-romains d'Aspiran (Hérault), Synthèses des travaux de 1971 à 1978, Figlina 3, 1978, p. 71-92.

Gianfrotta 1982 : GIANFROTTA (P.A.) - Archeologia sott'acqua, Rinvenimenti sottomarini in Etruria meridionaled, Bolletino d'Arte, 10, avriljuin 1981, p. 69-92, réimprimé dans Archeologia subacquea, (Boll. d'Arte, suppl. 4), 1982, p. 13-36.

Gruat 1994 : Les timbres sur amphores Dr. 1 du sud-ouest de la France : premier inventaire, In : L'Age du Fer en Europe sud-occidentale (Agen, 1992), Aquitania, 12, 1994, p. 183-202.

Guy 1972 : GUY (M.) - Le cadre géographique et géologique de Montlaurès. In : Narbonne, Archéologie et Histoire, XLV Congrès de la Fédération Historique du Languedoc Méditerranéen et du Roussillon, Narbonne, 1972, p. 27-43.

Héléna 1951 : HÉLÉNA (PH.) - Découvertes archéologiques rue de Nancy, Bulletin de la Commission Archéologique de Narbonne, 23, 1951-1955, 107-108, p. 154-155.

Hesnard et al. 1989 : HESNARD (A.), RICO (M.), ARTHUR (P.), PICON (M.) ET TCHERNIA (A.) - Aires de production des gréco-italiques et des Dressel 1, Amphores romaines et histoire économique, Rome, 1989, p. 21-65.

Lamour, Mayet 1981 : LAMOUR (C.), MAYET (F.) - Glanes amphoriques : II.- Régions de Montpellier, Sète, Ensérune, Le Cayla (Mailhac). Études sur Pézenas et l'Hérault 12, Les Amis de Pézenas, Pézenas, p. 3-18; n.30, p. 8 , pl.II, pl.VII.2.

Laubenheimer 1990 : LAUBENHEIMER (F.) - Le temps des amphores en Gaule : vin, huile et sauces, Paris, 1990, 181 p. (Coll. Des Hespérides).

Maguer et al. 2012 : MAGUER (P.), LEMAÎTRE (S.), DUVAL (A.) avec la collab. de BOLLE (A.), MANIQUET (C.), SANCHEZ (C.) - Des seaux gravés sur anses d'amphores, témoins de l'activité des premiers boulangers gaulois?, SFECAG, Actes du congrès de Poitiers, 2012, p. 431-436.

Mauné et al. 2006 : MAUNÉ (S.), BOURGAUT (R.), LESCURE (J.), CARRATO (C.) ET SANTRAN (C.) - Nouvelles données sur les productions céramiques de l'atelier de la Dourbie à Aspiran (Hérault) (première moitié du Irer s. ap. J.-C., SFECAG, Actes du Congrès de Pézenas, 2006, p. 157-188. 
Mellinand, Léal 2002 : MELLINAND (PH.), LÉAL (E.) - Une occupation suburbaine antique et médiévale à Narbonne (Aude), la Médiathèque, DFS de fouilles archéologiques, Archives SRA Montpellier, INRAP, 2002, 221 p. Olmer 2003 : OLMER (F.) - Les amphores de Bibracte 2, Le commerce du vin chez les Éduens d'après les timbres d'amphores, Coll. Bibracte 7, 375 p. Pena 1998 : PENA (M.-J.) - Productores y comerciantes de vino layetano, El vi a l'Antiguitat. Economia, produccio i comerç al Mediterrani occidental, 2on Col.loqui internacional d'Arqueologia romana, Badalona, 1998, p. $305-318$

Poux, Selles 1998 : POUX (M.) ET SELLES (H.) - Vin italique en pays Carnute. À propos d'un lot d'amphores Dressel 1 découvert à Chartres, rue Sainte-Thérèse, Actes du congrès de la SFECAG, Istres, 1998, p. 207-223.

Rascalou, Sanchez 2002 : RASCALOU (P.), SANCHEZ (C.) - Étude du mobilier céramique, La médiathèque, Narbonne, SRA Languedoc-Roussillon, Montpellier, AFAN. In : Mellinand (P.), Léal (E.) - Une occupation suburbaine antique et médiévale à Narbonne (Aude), la Médiathèque, DFS de fouilles archéologiques, Archives SRA Montpellier, INRAP, 2002.

Rougé 1966 : ROUGÉ (J.) - Recherches sur l'organisation du commerce maritime en Méditerranée sous l'Empire romain. Paris, 1966.

Sanchez 2003 : SANCHEZ (C.) - Le mobilier céramique de Narbonne et sa région, (II $s$. av. n.è./I ${ }^{e r}$ s. de n.è.), Pour une analyse du processus de romanisation, Thèse de doctorat, Lyon 2003, 1021p.
Sanchez 2009 : SANCHEZ (C.) - Narbonne à l'époque tardo-républicaine : chronologie, commerce et artisanat céramique, Supplément à la Revue Archéologique de Narbonnaise, 2009.

Sanchez 2011 : SANCHEZ (C.) avec la collaboration de ROBERT (B.), GAUDUCHON (S.) et BERNIER (M.), La céramique du secteur d'habitat à l'ouest des thermes entre 50 a.C. et le III s. p.C.In: BOUET (A.) (dir.), Un secteur d'habitat dans le quartier du sanctuaire du Moulin du Fâ à Barzan (CharenteMaritime), Aquitania, Mémoires 26, Supplément 27, 2011, p. 329-454.

Santamaria 1975 : SANTAMARIA (C.) - L'épave A du Cap Dramont (Saint-Raphaël) : fouilles 1971-1974, Revue archéologique de Narbonnaise, 8, 1975, p. 185-198.

Solier 1981 : SOLIER (Y.) - Sépultures et fosses à amphores à Narbonne, avenue Anatole France, rapport dact., archives SRA, Montpellier 1981, 6 p.

Solier et coll. 1981 : SOLIER (Y.) ET COLLAB. - Les épaves de Gruissan, Archaeonautica, 3, 1981, p. 8-264.

Tchernia et al. 1978 : TCHERNIA (A.), POMEY (P.), HESNARD (A.) L'épave romaine de la Madrague de Giens (Var), XXXIVe Sup. à Gallia, Paris, 1978, $122 \mathrm{p}$.

Thierrin-Michael 2003 : THIERRIN-MICHAEL (G.) - Classification des amphores vinaires italiques par l'examen macroscopique des pâtes : possibilités et limites, Actes du congrès de la SFECAG, Saint-Romain-en-Gal, 2003, p. 319-323. 


\title{
L'évolution du timbrage sur amphores vinaires italiques aux $I^{\mathrm{e}}$ et $\mathrm{I}^{\mathrm{er}}$ av. J.-C. à partir du corpus toulousain
}

\author{
Laurence Benquet \\ (INRAP GSO, UMR 5608)
}

\section{Résumé}

Le corpus établi pour une thèse soutenue en 2002 réunissait près de 670 estampilles provenant des fouilles anciennes dont 570 sur amphores vinaires italiques ce qui en fait le plus important répertoire de références pour le bassin méditerranéen. La révision de la chronologie des contextes de découverte entamée lors de l'ACR « Toulouse gauloise » ainsi que de la typochronologie ont permis de proposer un schéma évolutif des courants commerciaux entre les côtes tyrrhéniennes de l'Italie et l'isthme gaulois durant les deux derniers siècles avant notre ère. Les fouilles d'archéologie préventive menées par l'INRAP dans le quartier Saint-Roch et sur l'oppidum de Vieille-Toulouse depuis le début des années 2000 ont fait augmenter de près de $20 \%$ ce corpus avec la particularité de fournir des contextes stratigraphiques sûrs. Cette masse de matériel permet une approche statistique objective afin de proposer une évolution chronologique du timbrage.

Mots-clés : amphores italiques, Dressel 1 - timbres, Toulouse, Vieille-Toulouse, âge du Fer, vin, atelier

\footnotetext{
Abstract

The corpus set up for a $\mathrm{PhD}$ presented in 2002 gathered nearly 670 stamps from old excavations, with 570 on italic wine amphorae, which is the largest directory references for the Mediterranean Sea. The reviewing of the chronology of the contexts of discovery started through a research program (ACR "Toulouse gauloise") and the typo-chronology allowed to propose an evolutive pattern of trade flows between the Tyrrhenian coast of Italy and the Gaul isthmus during the last two centuries B.C. The preventive archaeological excavations led by the INRAP in the Saint-Roch district and in the oppidum of Vieille-Toulouse since the early 2000s have increased by nearly $20 \%$ this corpus with the particularity to provide stratigraphic contexts safe. This mass of material gives an objective statistical approach to propose a chronological evolution of stamping.
}

Keywords: Italic Amphorae, Dressel 1- stamps, Toulouse, Vieille-Toulouse, Iron age, wine, factory 
L es marques sur amphores découvertes sur les sites de la fin de l'âge du Fer dans le Toulousain forment le plus important corpus réuni jusqu'à présent en Gaule. Il recense un millier d'estampilles dont près de 900 sur amphores vinaires produites sur les côtes tyrrhéniennes de l'Italie. Ce catalogue regroupe les objets des fouilles anciennes, menées depuis le milieu du $\mathrm{XX}^{\mathrm{e}}$ s. par diverses équipes de chercheurs sous la direction de G. Fouet puis de M. Vidal sur l'oppidum de Vieille-Toulouse, les coteaux d'Estarac et à Toulouse dans et autour de la caserne Niel (quartier Saint-Roch) auxquelles il faut ajouter les investigations de l'abbé G. Baccrabère dans le quartier du Port SaintSauveur et de la Flambère. Depuis le début des années 2000 , les travaux d'aménagement urbain ont permis à l'INRAP de mener de nombreuses fouilles sur divers sites dans Toulouse, Vieille-Toulouse et Blagnac et ainsi de développer d'un tiers le corpus initial.

La soutenance d'une thèse de doctorat sur les amphores découvertes dans le Toulousain (Benquet 2002) ainsi que l'ACR «Toulouse gauloise» ont permis de réactualiser les données anciennes et de proposer de nouvelles chronologies à des ensembles, plus particulièrement les lots provenant de puits et de fosses. Les dernières fouilles menées par l'INRAP ont mis au jour des horizons stratigraphiques bien calés chronologiquement et confirment la contemporanéité des trois grandes zones d'occupation dans la région, c'est-à-dire Blagnac, Vieille-Toulouse et le quartier Saint-Roch bien que ce dernier ne perdure guère au-delà du début du I ${ }^{\operatorname{er}} \mathrm{s}$. av. J.-C. Au total, nous disposons d'un corpus riche de 600 timbres provenant de Vieille-Toulouse, 226 du quartier Saint-Roch et 72 de Blagnac.

Malheureusement, du fait d'une majorité de découvertes anciennes, un quart d'entre elles ne peuvent se rattacher à un horizon chronologique précis.

\section{Interprétation des timbres}

Le caractère aléatoire du marquage des amphores est au centre de la problématique concernant l'interprétation des estampilles. A quels facteurs économiques ou fiscaux doit-on ce phénomène ? Il s'avère, en effet, qu'au sein d'une même cargaison un certain nombre de conteneurs pouvait être estampillé, tandis que certains chargements ne l'étaient pas du tout. L'hypothèse selon laquelle l'acquéreur pouvait remonter, grâce à la lecture des marques, à l'officine qui a produit l'amphore ou au fundus qui a fourni la denrée peut également être proposée. De cette façon, la marque peut être envisagée comme la garantie de plusieurs normes (Manacorda, Panella 1993, p. 60-61) :
- une norme qualitative relative à la rigueur des soins apportés tant au produit qu'à l'emballage (Pline, H.N. $35,161)$;

- une norme fiscale ;

- une norme commerciale, afin de protéger l'acheteur de toute fraude liée au poids excessif de l'amphore et à sa capacité moindre.

Toutes ces garanties seraient le reflet d'un contrôle en aval par une instance supérieure, peut-être du sénat. Le développement du timbrage peut refléter un processus de standardisation de la production des amphores et un développement avancé de l'organisation du travail au sein de l'atelier. Conditionnée par le développement d'une main-d'œuvre servile dans les officines, des exigences de production pouvaient donc être requises par des dispositions législatives prises par le sénat. Dans cette dernière perspective, on peut se demander pourquoi le processus de timbrage ne s'est pas généralisé à tous les objets en considérant la simplicité technique de l'opération.

\section{Organisation de la production}

Les estampilles permettent de nommer certains acteurs, restés totalement anonymes dans les sources littéraires, de l'activité artisanale. Il est admis que les gentilices connus par les timbres renvoient aux propriétaires de figlinae, qui peuvent également être des propriétaires terriens, mais dont nous ne saisissons ici que la fonction d'exploitant de carrières d'argile et de dirigeant d'un atelier de potier (Tchernia 1993, p. 184). L'identité nominative de la main d'œuvre travaillant à la production ou à la gestion de l'officine est manifeste par la présence sur les amphores de noms uniques - majoritairement d'origine grecque - mais aucun élément n'indique leur position dans le processus opératoire. Le nombre restreint des noms qui nous sont parvenus pour une même production, qui comportait la réalisation de milliers d'objets, laisse supposer que ces noms ne mentionnaient pas les figuli, de simples exécutants. Il devait s'agir de personnages qui tenaient un rôle important dans la chaîne productive : « des serviteurs ayant une capacité d'entrepreneur applicable au schéma d'une responsabilité illimitée (institor recevant le titre de praepositus à la production des conteneurs) à celui à responsabilité limitée (servus ayant investi son patrimoine dans l'activité d'une figlina, avec l'éventuelle collaboration de vicarii)» (Manacorda 1985, p. 145). Cette étroite association entre un grand propriétaire foncier et un personnage de statut social inférieur est bien attestee par les combinaisons dans un même cartouche du nom d'une grande famille et celui d'un ou plusieurs serviles, par exemple : la gens Aelia 
associée aux personnages Artemo, He( ), Nestor, Philoxenes (Benquet et al. 2012) ; un certain P. Mar() associé aux personnages Bias, Diocl(es), Ones() (Gruat 1994, p. 197) ; la gens Car( ) associée aux personnages Apo( ), Dion( ), Gas( ), Rubricae (Olmer 2003, 150) ; la gens Lucceia associée aux personnages $\operatorname{Mosc}(h) a$, Antio(chus), Manes, Mele(te) (Chiosi 1991, p. 195). Par contre, la fonction exacte de ces personnages est rarement mentionnée et uniquement sur des conteneurs datés du I ${ }^{\mathrm{er}} \mathrm{s}$. av. J.-C. Un certain Philox( ) et un $\operatorname{Mosc}(h) a$ peuvent être qualifiés de $s$ (ervus) (fig. $4 \mathrm{n}^{\circ} 1$ et 3), tandis que One( $(s)$, Diocl( ) et Bias peuvent chacun être qualifiés de $m e(n)$ sor (fig. $3 \mathrm{n}^{\circ} 12$ à 14) charge liée soit à la fabrication des amphores elles-mêmes, soit à une étape du processus de la commercialisation comme le remplissage des conteneurs. La plupart des exemples ne mentionnent qu'un nom individuel qui peut être retranscrit entièrement ou de façon abrégée sans que l'on soit certain qu'il s'agisse de la même personne (Benquet, Rouquette 2004). Les analyses pétrographiques montrent que deux timbres portant le même nom mais dont la graphie, la position et la forme du cartouche diffèrent n'appartiennent généralement pas à une même officine (Capelli et al.2013).

La place des timbres nominatifs reste relativement stable durant un siècle et demi, ils forment en moyenne $48,5 \%$ du total des marques italiques découvertes dans le Toulousain avec un taux maximum de $60 \%$ durant la LTC2/D1a. C'est durant cette même période ainsi que pendant la LTD2 que les gentilices sont majoritaires.

\section{Organisation administrative}

Ces estampilles ne peuvent correspondre à des initiales de prénom ou de nom, comme nous l'avons déjà fait remarquer précédemment pour les timbres ne comportant qu'une ou deux lettres. Elles illustrent plus certainement un code dans lequel la première et la seconde lettre, parfois séparées par un point, changent alternativement. La mise en évidence d'une telle série de timbres permet de suggérer l'hypothèse que cet estampillage reflète un système de comptage. Cette explication est séduisante mais il s'agirait alors d'une comptabilité originale puisqu'elle n'utilise pas les signes numériques habituels composés de sept lettres : $\mathrm{I}, \mathrm{V}, \mathrm{X}, \mathrm{L}, \mathrm{C}, \mathrm{D}$, et M. Ce système peut être interprété de plusieurs façons différentes. Il utilise donc toutes les lettres en les combinant par paires de manière interchangeable : AA AB AC... puis BA, CA etc. jusqu'à la fin de l'alphabet. Il pourrait s'agir d'un système de comptage alphabétique (Olmer 2003, p.157-168) dans lequel chaque lettre possède une signification intrinsèque. La seconde explication serait d'attribuer à ces timbres l'identification d'un individu propre qui se définirait par son appartenance à un atelier (la première lettre) et par sa lettre individuelle (Hesnard, Carre 1998, p. 297). Il est très difficile de formuler une interprétation plus précise de ce système de timbrage, car ce type d'estampilles n'est pas homogène ni par la forme et la position du cartouche sur l'amphore, ni même dans la graphie du timbre. De plus, si cette façon de timbrer apparaît préférentiellement à la fin du II ${ }^{\mathrm{e}} \mathrm{s}$. av. J.-C., tous les ateliers des côtes tyrrhéniennes semblent l'adopter. L'étude des échantillons de pâtes provenant des amphores timbrées de deux lettres découvertes dans le Toulousain a bien montré la diversité des origines et l'absence quasi totale des productions d'Etrurie de l'atelier d'Albinia, phénomène tout à fait contraire aux constatations effectuées sur les pâtes provenant du Mont-Beuvray (Olmer 2003, p. 170).

Des séries «alphabétiques », en caractères grecs, ont été repérées sur les amphores marseillaises sur les sites d'Olbia et de Marseille même. Elles ont également été interprétées comme un système de numérotation alphabétique qui individualiserait les amphores selon un rythme annuel suivant l'exemple des prêtres éponymes mentionnés dans les cartouches imprimés sur les amphores rhodiennes (Bertucchi 1992, p. 167). Il est peut-être un peu osé d'appliquer cette explication aux séries précédemment mises en évidence, mais une autre série de timbres présentant à la fois le nom d'un personnage suivi d'un point et d'une lettre isolée (BARG.A, DIO.I, EVPO.A, TIGRA.A...) peut être interprétée de cette façon.

Cette manière de marquer les amphores apparaît tôt mais c'est au cours de la LTD1b qu'elle se diffuse très largement et semble se généraliser durant le $\mathrm{I}^{\mathrm{er}} \mathrm{s}$. av. J.-C. Cette méthode comptable perdure à période augustéenne puisque les ateliers de Tarraconaise usent du même système.

\section{Les symboles}

Les symboles utilisés proviennent du répertoire iconographique de la Grèce classique ; plusieurs interprétations ont été formulées en partant de l'analyse des timbres sur les amphores rhodiennes. Si l'imagerie utilisée pour ces dernières est clairement à vocation politique, par la reconnaissance immédiate de l'origine de la denrée à l'aide de l'emblème de la cité productrice, il n'en va pas de même pour les amphores des côtes tyrrhéniennes italiques. Le répertoire iconographique est beaucoup plus large, même si, dans une certaine mesure, de nombreux symboles peuvent être rattachés au commerce maritime et aux traditions bachiques. Il semble que pour les productions italiques ce ne sont donc pas 


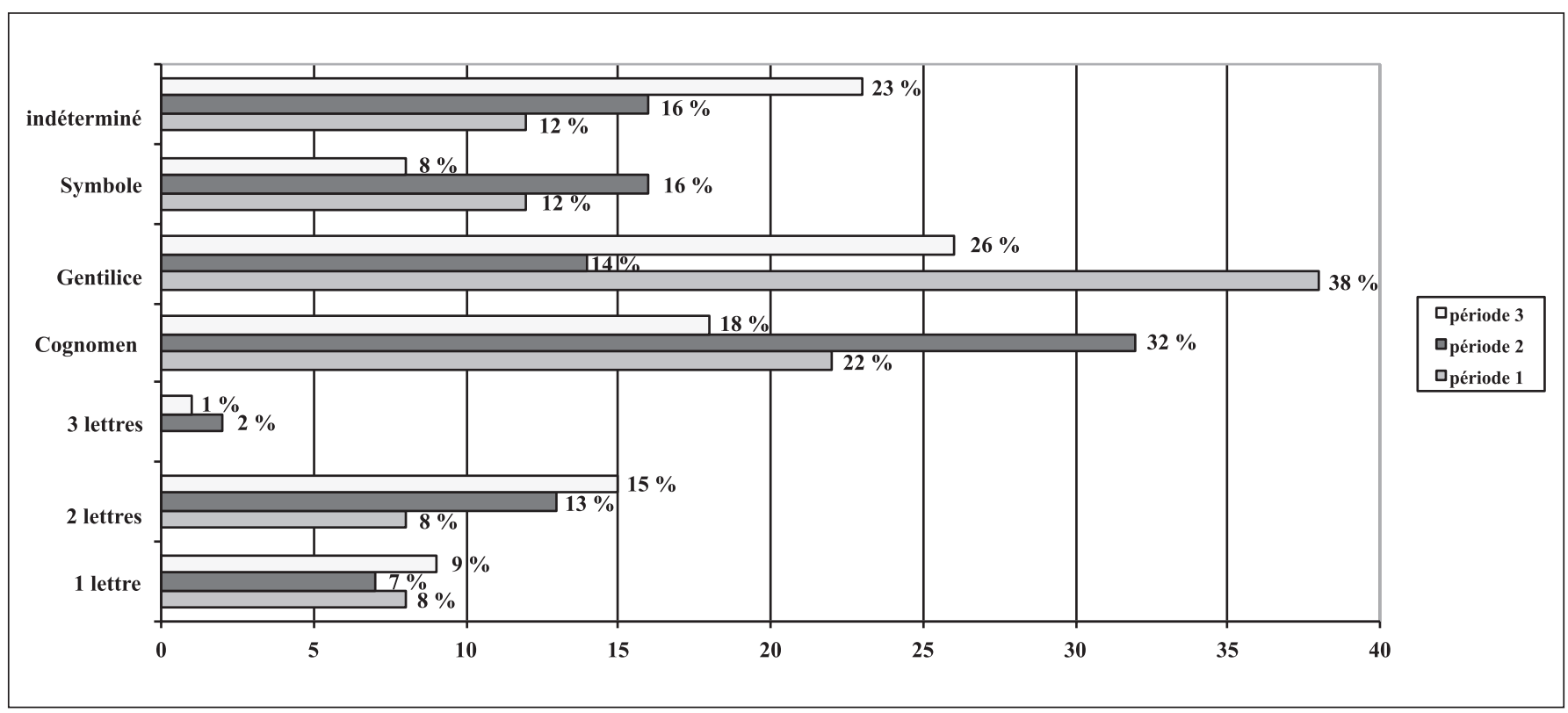

Fig. 1. Répartition des timbres par période et par indexation.

les images elles-mêmes qui caractérisent un atelier mais plutôt la position et la forme des cartouches. Il est cependant pratiquement certain que ce n'est pas là que se situe le rôle primordial de ces estampilles. Si nous excluons le fait que ces timbres identifient un potier ou tout autre personnage ayant une responsabilité dans la chaîne opératoire de la fabrication, du remplissage ou de la commercialisation de l'amphore, émergent alors les hypothèses suivantes : il pourrait s'agir d'un système de comptabilité ou bien d'un marqueur saisonnier ; ces deux explications peuvent également être combinées. S'il s'agit bien d'un système de comptage, nous devrions rapprocher la série des SES suivie d'un symbole, plus particulièrement, de celle exposée précédemment et regroupant les noms serviles suivis ou précédés d'une lettre latine. Les symboles semblent avoir été également utilisés comme système de comptabilité dans les civilisations helléniques, par exemple : sur les monnaies de bronze massaliètes, sur les anses d'amphores corinthiennes "la présence de lettres ou de monogrammes combinés avec celles de symboles suggère un moyen d'identification ou de comptabilité » (Koehler 1982, p. 289).

Cet article n'est qu'un bref aperçu du corpus toulousain extrait de mon doctorat auquel les dernières découvertes ont été ajoutées (fig. 1); ne sont présentés ici que les estampilles les plus remarquables ou les plus emblématiques d'une période. Une publication de l'intégralité du corpus est programmée très prochainement.

\section{Période 1 (LTC2 / LTD1a)}

Une soixantaine d'exemplaires est attribuable à cette période, tous estampillés sur des amphores de type gréco-italique ou de transition. Les mentions de gentilices ou personnages d'origine servile sont largement majoritaires $(60 \%)$ tandis que le nombre de timbres «alphabétiques » et symboliques est pratiquement égal (respectivement 16 et $12 \%$ ).

\section{Les acteurs}

Quatre grandes familles bien implantées en Campanie (Castrén 1975, p.132) illustrent les principales importations attestées dans le Toulousain à cette période (fig. $2 \mathrm{n}^{\circ} 1$ à 5). La mention de la gens est généralement abrégée et précédée de l'initiale du praenomen. Les plus fréquemment attestées sont la gens Alfia (4 ex. sur haut d'anse) et celle de Pac(onia) ou Pac(ia) (11 ex. sur attache inférieure) toutes deux d'origine osque (Solin, Salomies 1988, p. 12 et 135) et également connues en Orient pour leurs activités commerciales (Hatzfeld 1919, p. 384, 398-399). Un timbre découvert en Sicile (CIL I, 3489 (b-c)), sur le site de Lacoste à Mouliets-et-Villemartin (Benquet, Piot 2000, p. 160) ainsi qu'à Saint-Gence La Gagnerie (Lintz 2007, p. 269) nous donne la filiation complète de notre personnage : $N$. Alfi N(umeri) f(ilii). Il serait tentant de rapprocher ce personnage du naviculaire connu par les bouchons découverts dans des amphores Dr. 1B de l'épave de Planier 3 de Marseille (Benoît 1962, 


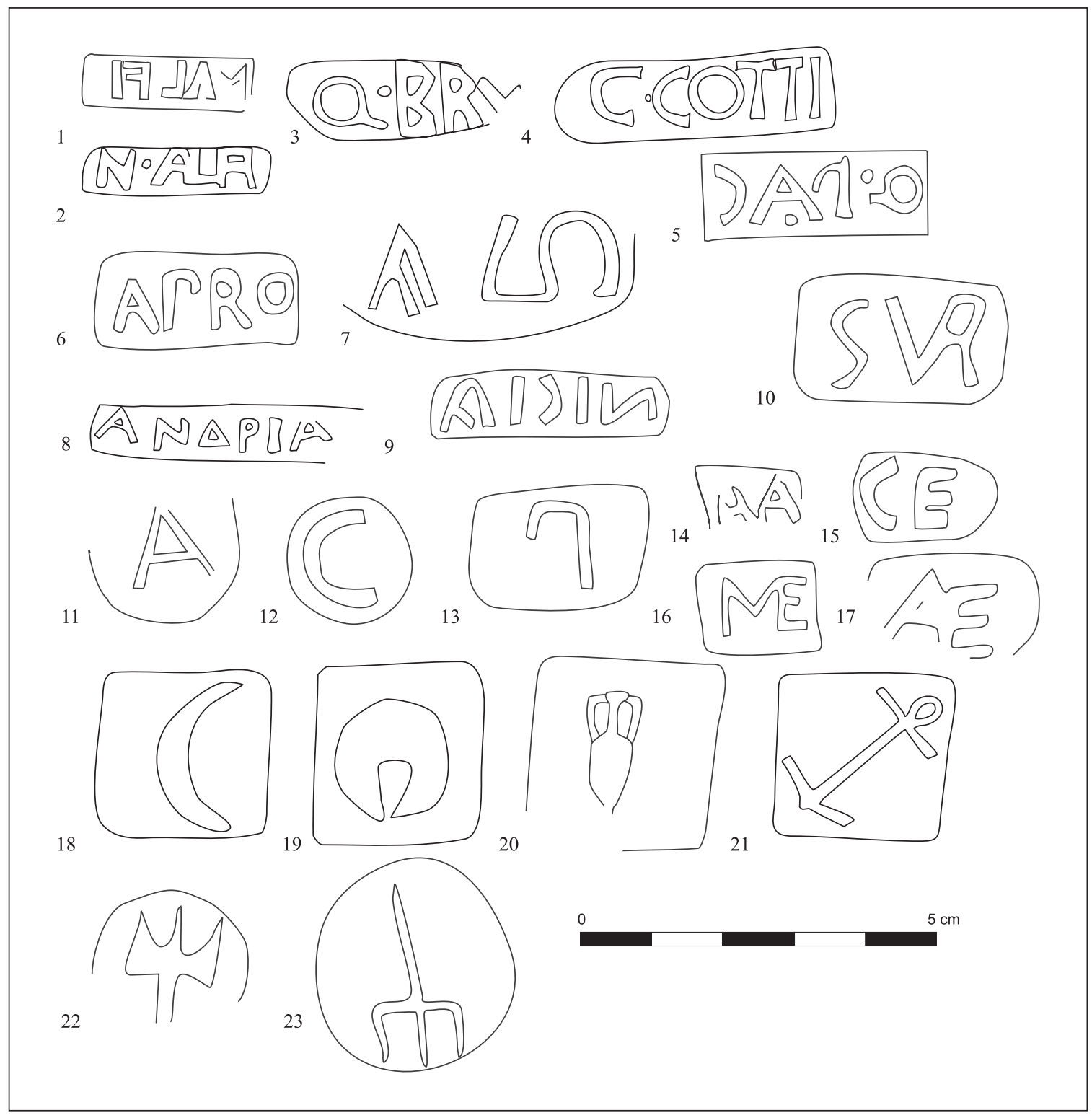

Fig. 2. Période $1: n^{\circ} 4$ à 6,8 à 16 : Vieille-Toulouse ; n4, 7, 17 à 23 : Toulouse, quartier Saint-Roch.

p. 153 fig. 12) M. Alfi M(arci) f(ilii) Vng(guentari) qui pourrait être un de ses descendants. La seconde est uniquement référencée sur le site du Castellas de Rognac (Chabot 1968, p. 187, fig. 64). De nombreuses interprétations peuvent être proposées. Un timbre imprimé sur une coupe à vernis noir découvert sur l'Esquilin $C$. Paco(nius) C.f(ilius) Q.n(epos) (CIL XV, 6097) met en avant l'hypothèse que la gens Paconia posséderait une figlina dans la région de Calès. Q. Paconius, le grandpère pourrait être l'aïeul du céramiste $C$. Paconius et de notre personnage (Pedroni 1986, p. 381). La famille des Paconii serait donc spécialisée dans la fabrication de céramique dite "de table" ainsi que dans celle des amphores. Un autre personnage permet d'accréditer cette origine campanienne, Q. Paconius Leptis résidant à Calès et ami de Cicéron (ad Att. V, 17-2 ; ad Fam. IX, 13 et III, 7, 4) fut chargé de fournir le vin pour les jeux romains de 45 av. J.-C. (Cébeillac 1998, p. 151). Enfin, un certain $Q$. Paccius fut édile de Formies à la fin du $\mathrm{II}^{\mathrm{e}} \mathrm{s}$. av. J.-C. et avait offert à la ville une des portes de la muraille (Cébeillac 1998, p. 116).

Le gentilice Bruttius dérive probablement du nom d'une ethnie (Castrén 1975, p. 143-144 n 76). Des consuls portant ce même nom semblent avoir été originaires de Lucanie (Pline, Ep. 7, 3). Un Q. Brutius $Q$. $f$. est répertorié dans le CIL I, 1259 (Treggiari 1969, p. 211), ainsi que dans le $C I L \mathrm{~V}, 1886-87$ et 7344. 
Quant aux noms de personnages uniques (22\%), ils sont préférentiellement imprimés sur la lèvre ou sur l'attache inférieure de l'anse, en caractères grecs ou latins (fig. $2 \mathrm{n}^{\circ} 6$ à 10). Les plus fréquents sont d'origine grecque : Andrias, Ap(h)ro( ), Nicia, P(h)il( ), Sur(us) etc.

\section{Timbres alphabétiques et symboles}

Les premiers sont relativement peu nombreux $(16 \%)$, les timbres mentionnant une ou deux lettres, toujours latines, parfois ligaturées, n'ont ni forme de cartouche ni positionnement préférentiels (fig. $2 \mathrm{n}^{\circ} 11$ à 17). Quant aux symboles, ils forment deux séries bien homogènes uniquement sur des amphores de type de transition (fig. $2 \mathrm{n}^{\circ} 18$ à 23 ) : celle au cartouche carré (25 x $25 \mathrm{~mm}$ ) estampés sur le haut du col et celle au cartouche circulaire sur le haut de la panse. Les exemplaires de confrontation sont peu nombreux: Eburomagus / Bram dans l'Aude (Passelac 1970, p. 84 fig. 7 n 1, 3 et 4) pour la première et Châteaumeillant (Laubenheimer, Barthélemy 2010, p. 29 n47) pour la seconde.

\section{Période 2 (LTD1b)}

Elle forme la majeure partie du corpus, près de 400 timbres ont été découverts dans des niveaux datés de la LTD1b. Nous avons décidé de réunir dans un même paragraphe les estampilles attribuées au dernier quart du $\mathrm{II}^{\mathrm{e}} \mathrm{s}$. et ceux du premier quart du $\mathrm{I}^{\mathrm{er}} \mathrm{s}$. av. J.-C. car le nombre d'estampilles est sensiblement le même (209 / 185 ex.) et leur répartition au sein des diverses catégories d'indexation est comparable.

\section{Les acteurs}

Si la période précédente était caractérisée par les timbres mentionnant un gentilice, durant la LTD1b les mentions de personnages uniques sont majoritaires $(46 \%)$. Trois grandes familles de trois régions de production différentes sont attestées dans le Toulousain pour cette époque. Tout d'abord, la plus connue originaire d'Etrurie et dont l'atelier est localisé près du port de Cosa, est celle des Sestii. Plusieurs personnages de la gens Sestia sont connus grâce à la correspondance de Cicéron. Des estampilles ont été découvertes sur des tuiles à Rome et dans les régions voisines au nom de L. Sestius Albanianus Quirinius (ou Quirinalis), consul suffect en 23 av. J.-C. Il est le fils de P. Sestius, questeur en 63 av. J.-C., tribun de la plèbe en 57, prêteur en 54 ou 50 , proconsul de Sicile de 49 à 48 av. J.-C. (Cicéron, Ad Atticum, 15.29.1, 15.27.1) et ami de Cicéron que ce dernier défendit en 56 (Cicéron, Pro Sestio). Ce dernier pourrait être identifié au personnage qui timbre les amphores de son nom (Manacorda 1981, p. 32). Il possédait une propriété terrienne dans l'Ager Cosanus ainsi que des navires (Cicéron, Ad Atticum, 15, 2,$7 ; 16,4,4$ ). Un dernier argument en faveur de P. Sestius, il a effectué deux voyages en Gaule pour des raisons familiales, politiques et probablement économiques avant son procès (Cicéron, Pro Sestio, 3,7 et 33,7). La production d'amphores attribuée à cette famille semble longue puisque les tous premiers timbres apparaissent dans les niveaux datés de la fin du $\mathrm{II}^{\mathrm{e}} \mathrm{s}$. av. J.-C. (9 ex.) mais c'est surtout à partir du premier quart du siècle suivant que les découvertes se multiplient (15 ex.) et ceci sur tous les grands sites de consommation en Gaule (fig. $3 \mathrm{n}^{\circ} 1$ à 10). La multiplicité des timbres dans la graphie des lettres (ligaturées ou non) et des différents symboles témoignent d'une gestion bien maîtrisée de la production qui perdure jusqu'au milieu du $\mathrm{I}^{\mathrm{er}} \mathrm{s}$. av. J.-C. De ce fait, plusieurs membres de cette famille peuvent se dissimuler derrière les abréviations : SES, SEST (E et T ligaturés) et SEST (S et T ligaturés).

La seconde famille emblématique est celle des Sextilii bien répertoriée en Campanie. Ce développement a été proposé à partir des découvertes faites sur les sites de Lyon. Plusieurs estampilles différentes permettent de connaître deux personnages impliqués dans la fabrication des amphores, C. et L. Sextilius implanté en Campanie, peut-être aux environs de La Mondragone (Desbat et al. 1997, p. 514-515). Peu d'exemplaires ont été découverts dans le Toulousain (4 ex.) l'un estampillé au nom de L. Sex(tili) à Toulouse, les autres à VieilleToulouse au nom de C. Sex(tili) (fig. $\left.3 \mathrm{n}^{\circ} 11\right)$.

Une dernière famille illustrée par un seul membre est celle des $\operatorname{Mar}\left(\right.$ ) (10 ex. à Vieille-Toulouse fig. $3 \mathrm{n}^{\circ} 12$ à 14). Aucun développement ne peut être proposé pour ce gentilice, de nombreux noms commencent de cette façon (Solin, Salomies 1988, p. 112-113). Cette série de timbres tri-linéaires estampillée sur le haut de la panse d'amphores de transition Dr. 1A/B semble être diffusée exclusivement dans le sud-ouest de la Gaule (Gruat 1994, p. 200-201) auquel il faut ajouter un exemplaire découvert à Corent en Bourgogne (Loughton 2005, p. 693 fig. 15). Les analyses effectuées proposent le sud Latium comme zone de production (Capelli et al. 2013) de l'officine de P. Mar() employant Bias(), Diocl(), Ones()...

Fig. 3. Période 2 : $n^{\circ} 5$ à 9, 15, 17 à 21, 23 à 25, 31, 33, 36 à 61 : Vieille-Toulouse : $n^{\circ} 1$ à $5,10,16,22,26$ à $30,32,34 ; n^{\circ} 35$ : Blagnac. 


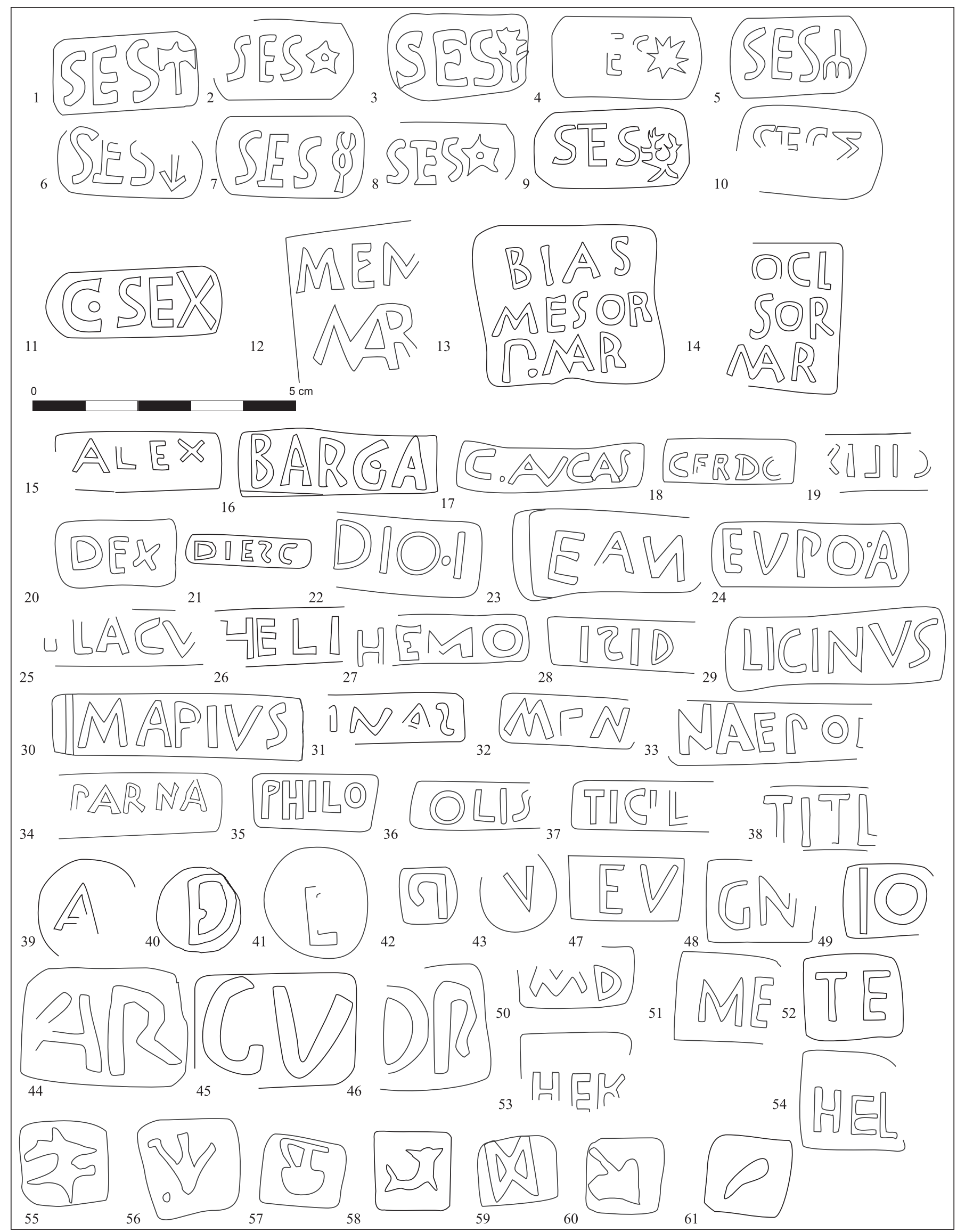


Si le nombre de grandes familles impliquées dans la production d'amphores est relativement peu élevé $(14 \%)$, les cognomina sont nombreux (32\%). Une quarantaine de noms différents ont été inventoriés, très majoritairement d'origine grecque. Pratiquement toujours abrégé, un même nom peut être décliné de diverses façons (Benquet, Rouquette 2007) sans pour autant avoir la même origine géographique. Les plus répandus sont ceux présents dans l'épave de la Ciotat 3 en provenance probable des côtes du Latium (Long et al. 2010) : Antio(),Diesc(), Flac(cus), P(h)arna(ces), Philo() ou bien encore Alex(ander), Barg(athes), Cilix, Cerdo(), Dasi(), Dex(ter), Dio(),Ean(eas), Eupo(r), Heli(),Hemo(), Isid(orus), Licinus, Marius, Mnase(a), Naepor, Nicia(s), Silo(nis), Ticil(), Titl(es) etc. (fig. $3 \mathrm{n}^{\circ} 15$ à 38). Ils sont préférentiellement estampillés sur le haut de l'anse.

\section{Timbres alphabétiques et symboles}

Le nombre de timbres liés à la gestion de la production est en nette augmentation ; ils forment $22 \%$ du répertoire durant la LTD1b. Dans le corpus Toulousain, ils sont estampillés sur le haut de l'anse ou plus généralement sur l'attache inférieure. Comme pour la période précédente, la forme des cartouches et la graphie des lettres sont très hétérogènes et il est difficile de les regrouper par association morphologique (fig. 3 n³9 à 54).

Une série de timbres conséquente (78 exemplaires sur un total de 118 classés comme «symbole») est emblématique du corpus (fig. 3 n$^{\circ} 55$ à 61 ). Elle semble être diffusée uniquement sur l'axe Aude-Garonne, plus particulièrement dans le Toulousain et ses environs (Benquet 2007, p. 441 fig. 5). Ces timbres ont été découverts sporadiquement en Espagne, Italie et sur un site de production d'amphores en Sardaigne près d'Olbia (Sanciu 1997, p. 85) sans que l'on puisse en déduire son origine. Tous présentent des cartouches ayant les mêmes caractéristiques morphologiques (Benquet et al. 2012, p. 375-376) : carré (13 mm de côté environ), estampés à deux reprises sur la lèvre au-dessus de l'attache de l'anse. Si le profil de la lèvre, généralement courte et de forme triangulaire, rappelle singulièrement les grécoitaliques, les exemplaires entiers démontrent de façon indubitable la forme Dr. 1A (Sireix et al. 2007, p. 324 fig. $33 \mathrm{n}^{\circ} 7$ ).

Ces timbres, en tant que simples images, peuvent être interprétés de différentes façons. Ils se référent à deux thèmes iconographiques, celui de la mer et celui du vin. Le premier regroupe les timbres figurant un dauphin, une ancre, un trident et un symbole que nous avons également interprété comme un autre type d'ancre. Le deuxième, quant à lui, regroupe le lagynos, la feuille de pampre et de lierre ainsi que le dauphin, trois images du répertoire dionysiaque. Ces symboles sont autant de traces de la permanence du répertoire mythologique traditionnel de la Grèce classique du Ve s. av. J.-C. De nombreux exemples dans la statuaire ou sur les vases à figures noires viennent illustrer cet état de fait. Les thèmes de Dionysos/Bacchus se superposent souvent avec la navigation, telle la coupe d'Exekias (conservée à au Staatliche Antikensammlungen de Munich) représentant Dionysos dans une barque entourée de dauphins et sont donc parfaitement en symbiose avec l'objet sur lequel ils sont apposés. Le double poinçonnage méticuleusement effectué au-dessus de chaque anse pourrait être le signe distinctif de la production d'un ouvrier / d'une équipe, ou bien le marquage d'une même fournée. Les exemplaires de cette série issus de structures et de niveaux bien datés sont essentiellement découverts durant le dernier quart du $\mathrm{II}^{\mathrm{e}} \mathrm{s}$. av. J.-C. (67\%), toutefois ces mêmes estampilles peuvent se retrouver durant les périodes suivantes mais très certainement en position résiduelle.

\section{Période 3 (LTD2)}

Nous disposons d'un total de 131 timbres attribués à cette période. Ce faible nombre est certainement la conséquence des perturbations liées à la phase d'occupation augustéenne de l'oppidum de Vieille-Toulouse ou du site de Blagnac qui perdure jusqu'au règne de Tibère.

\section{Les acteurs}

Si la proportion des timbres nominatifs baisse légèrement par rapport à la période précédente, ils restent majoritaires (44\%). La mention de gentilices est de nouveau supérieure à celle des noms uniques, phénomène consécutif à l'association dans un même cartouche du nom du propriétaire et de l'employé. C'est le cas pour La gens Lucceia (fig. $4 \mathrm{n}^{\circ} 1$ ) connue en Orient pour ses activités commerciales (Hatzfeld 1919, p.395) et en Campanie comme riche propriétaire terrien (Chiosi, Gasperetti 1994, p. 297). Un complexe artisanal dans le nord du Latium, sur la rive du fleuve Garigliano, sur le site de Rocca d'Evantro à Caserta produisant des Dr. 1 a été découvert. Son timbrage est caractérisé par des cartouches circulaires imprimés sur la panse de Dr. 1B associant le nom d'un membre anonyme de la famille des Lucceii, celui d'un servile entourant une spirale, aucun autre exemplaire n'est répertorié en Gaule. La gens Aelia (fig. $4 n^{\circ} 2-3$ ), vieille famille républicaine originaire de la Campanie, possédait des terres sur le territoire de Véies (Valère Maxime 4, 4, 8). Les timbres apposés 


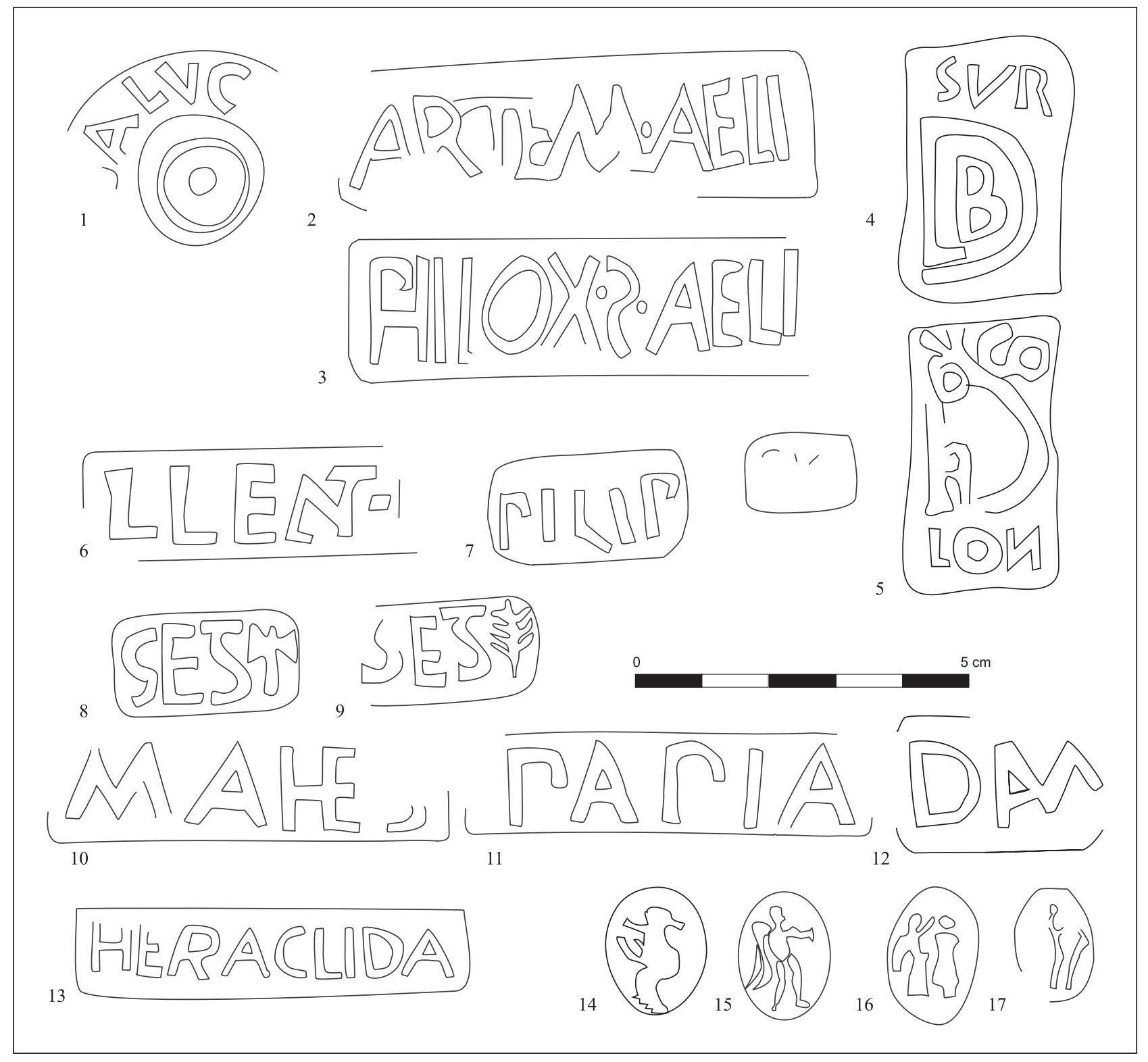

Fig. 4. Période $3: n^{\circ} 1$ à 17 : Vieille-Toulouse.

sur Dr. 1B mentionnent toujours ce gentilice associé à un personnage servile. Si aucun atelier n'a encore été découvert, des similitudes avec des échantillons provenant de l'épave de La Plane à Marseille permettent de supposer une origine latiale de cette production (Benquet et al. 2012, p. 379-381). La mention de tria nomina est assez peu fréquente sur les amphores Dr. 1. Le corpus livre deux estampilles sur lèvre de Dr. 1B mentionnant 3 lettres ligaturées associées aux cognomina Sur(us) et Apol(lonida) (fig. $4 \mathrm{n}^{\circ} 4-5$ ). Bien que ce timbre soit également répertorié sur le site Cybèle à Lyon (Lemaître et al. 1998 , p. 53 fig. $6 n^{\circ} 1$ ) et au musée de Cagliari en Sardaigne (Pianu 1980, p. $17 \mathrm{n}^{\circ}$ 2) aucun développement ne peut être proposé. Le dernier exemple est celui du timbre L. Lentulus $P($ ubli) $f(i l i)$ imprimé sur lèvre Dr. 1B (fig. $4 \mathrm{n}^{\circ}$ 6). Ce personnage a été identifié comme L. Cornelius Lentulus Crus, sénateur en 49 av. J.-C. (Gianfrotta 1982, p. 20). Ses activités sont connues grâce aux écrits de Cicéron (ad. Atticus, VII, 12, 2 ) qui mentionne, outre ses propriétés foncières près de la ville de Minturnes dans le sud du Latium, ses activités commerciales vers les marchés orientaux (Hatzfeld 1919, p. 389), plus particulièrement vers la Grèce au moyen de ses propres navires. La découverte des épaves de Santa Severa près de Pyrgi et du Dramont A dans la rade de Saint-Raphaël (Santamaria 1975) confirme l'implication de ce personnage dans le commerce de vin, plus particulièrement dans la fabrication d'amphores Dr. 1B 
timbrées à son nom. Une à deux contremarques (fig. 4 $\mathrm{n}^{\circ} 7$ ) sont régulièrement apposées permettant de recréer l'organigramme de l'officine située près de Minturnes et des activités externes qui lui sont rattachées (Manacorda 1985). Concernant la gens Sestia toujours bien présente durant cette période, un nouveau graphisme apparaît mentionnant un certain Sest(ius) dont les deux dernières lettres sont ligaturées (fig. $4 \mathrm{n}^{\circ}$ 8-9).

Les mentions de personnages uniques sont peu nombreuses $(18 \%)$, certains timbres sont en position résiduelle, les nouveaux se caractérisent par leur cartouche de grandes dimensions apposé sur l'épaulement (fig. $4 n^{\circ} 10$ à 13).

\section{Timbres alphabétiques et symboles}

La part des estampilles alphabétiques reste stable par rapport à la période précédente $(25 \%)$. Aucune évolution n'est perceptible dans cette façon de timbrer.

La part des timbres symboliques chute singulièrement $(8 \%)$, toutefois un nouveau timbrage apparait : l'impression d'intaille sur la panse. Bien que peu répandus, quelques exemples ont été reconnus sur l'oppidum de Bibracte sur lèvre et épaulement de Dr. 1B (Olmer 2003, p. 70-71 n 485-486), en Auvergne sur le site de la Grande Borne Aulnat sur la panse (Loughton 2005, p. 691 fig. 12) et une dernière sur la panse d'une Dr. 1B dans l'épave de la Fourmigue $\mathrm{C}$ à Golfe Juan (Pollino 1975, p. 74 pl. II-b). Il est souvent difficile d'interpréter l'image qui est imprimée très légèrement dans la pâte certainement pour ne pas abîmer le bijou. Les thèmes abordés sur les amphores du corpus (fig. $4 \mathrm{n}^{\circ} 14$ à 17) sont ceux liés à la mer (hippocampe), au commerce (Mercure) et à la Fortune (Victoire couronnant un trophée).

Ce bref aperçu de l'évolution du timbrage sur amphores vinaires italiques à partir du corpus toulousain permet de mettre en évidence deux grandes considérations. D'une part, les importations vinaires dans la région Toulousaine semblent fortement liées aux officines implantées sur les côtes du Latium et de Campanie. D'autre part, la nette évolution du timbrage montre un changement dans la gestion de la production à l'intérieur des ateliers. Dans un premier temps, le nom du supposé propriétaire de l'officine est clairement indiqué : praenomen et nomen parfois accompagnés de sa filiation. Dans un second temps, les grandes familles deviennent plus rares, seule la gens est inscrite de façon abrégée, la mention de personnages individuels d'origine servile est courante. La comptabilité liée à la gestion de la production semble également se mettre en place de façon générale sur tous les ateliers. Enfin, c'est là l'indication claire de tous les acteurs liés à la production et à la commercialisation du vin que l'on retrouve sur les conteneurs. Un changement politique semble s'amorcer vers le milieu du Ir ${ }^{\mathrm{er}} \mathrm{s}$. av. J.-C. sur la participation admise et reconnue de tous des élites municipales dans la production manufacturière et le commerce auparavant cachée derrière le nom d'un employé dont le statut social n'est pas connu : esclave, affranchi, homme libre...

Il reste encore beaucoup de recherches à effectuer afin de comprendre le rôle et le statut de chaque personnage. Le schéma esquissé à partir du corpus toulousain demande à être confronté avec d'autres collections dont peu sont aussi volumineuses.

\section{Bibliographie}

Benoit 1962 : BENOIT (F.) - Nouvelles épaves de Provence III. Gallia, 20 , 1, 1962, p. 148-176.

Benquet 2002 : BENQUET (L.). - Les amphores des II et $I^{e r} s$. av. J.-C. découvertes dans le Toulousain : production et consommation, Thèse de doctorat sous la direction de J.-M. Pailler, Toulouse-le-Mirail, 4 tomes, 2002.

Benquet 2007 : BENQUET (L.) - Les importations de vin italique dans le Toulousain au cours du II ${ }^{\mathrm{e}} \mathrm{s}$. av. J.-C. In: Les Âges du Fer dans le sud-ouest de la France, Actes du colloque AFEAF (Toulouse, 2004), 2007, p. 435-448. Benquet, Piot 2000 : BENQUET (L.), PIOT (C.) - Les amphores de Lacoste (Mouliets-et-Villemartin, Gironde). In: Actes du colloque de la SFECAG (Libourne), 2000, p. 155-165.

Benquet, Rouquette 2004: BENQUET (L.), ROUQUETTE (D.) L'abréviation des noms sur amphores Dr. 1. Tentative d'interprétation à partir de quelques exemples. CAS, XV, 2004, p. 145-152.

Benquet et al. 2012 : BENQUET (L.), LEMAITRE (S.), GUITTON (D.), MORTREAU (M.) - Entre Volques et Pictons : la diffusion des amphores vinaires aux $\mathrm{II}^{\mathrm{e}}$ et $\mathrm{I}^{\mathrm{er}} \mathrm{s}$. av. n. è. à partir des témoignages épigraphiques. In : Actes du colloque de la SFECAG (Poitiers), 2012, p. 375-388.

Bertucchi 1992 : BERTUCCHI (G.) - Les amphores et le vin de Marseille du $V I^{e}$ s. av. J.-C. au II s. ap. J.-C.RAN, supplt 25, 1992.

Capelli et al. 2013: CAPELLI (C.), CABELLA (R.), PIAZZA (M.) - Albinia o non Albinia ? Analisi in microscopia ottica su anfore Dressel 1 rinvenute in Francia meridionale. In : OLMER (F.) dir.,: Itinéraires des vins romains en Gaule $I I I^{e}-I^{e r}$ s. av. J.-C., confrontation de faciès, colloque de Lattes (janv. - fév. 2007), MAM, HS n ${ }^{\circ}$, p. 481-486.

Castrén 1975 : CASTREN (P.) - Ordo Populusque Pompeianus : polity and society in Roman Pompeii, Rome, 1975.

Cébeillac 1998 : CEBEILLAC GERVASON (M.) - Les magistrats des cités italiennes de la seconde guerre punique à Auguste : le Latium et la Campanie, coll. EFR n²99, 1998.

Chabot 1968 : CHABOT (L.) - Le Castellas de Rognac et l'étang de Berre à l'époque pré-romaine. $R S L, 34,1968$, p. 151-215.

Chiosi 1991 : CHIOSI (E.). - Rocca d'Evandro (Caserta) - Località Porto. Un quartiere produttivo romano sulla riva sinistra del fiume, lo scavo, Bolletino d'Archeologia, 11-12, 1991, p. 121-124.

Chiosi, Gasperetti 1994 : CHIOSI (E.), GASPERETTI (G.) - Rocca d'Evandro (Caserta) - Località Porto, un quartiere artigianale romano sul fiume. In : Ceramica romana e archeometria : lo stato degli studi, a cura di G. Olcese (Castello di Montegufoni, aprile 1993), Firenze, 1994, p. 293-299.

Desbat et al. 1997 : DESBAT (A.), MAZA (G.), PICON (M.) - Les marques de C.L. SEX sur Dr. 1A. In: Actes du colloque de la SFECAG (Le Mans), 1997, p. 511-516.

Gianfrotta 1982 : GIANFROTTA (P.-A.) - Archeologia sott'acqua, rinvenimenti sottomarini in Etruria meridionale. Bolletino d'Arte, supplément 4, 1982, p. 13-36. 
Gruat 1994 : GRUAT (P.) - Les timbres sur amphores Dr.1 du sud-ouest de la France : premier inventaire. Aquitania, XII, 1994, p. 183-202.

Hatzfeld 1919 : HATZFELD (J.) - Les trafiquants italiens dans l'Orient hellénistique, Paris, 1919.

Hesnard, Carre 1998 : HESNARD (A.), CARRE (M.-B.) - Les timbres DIO. sur amphores Dr.1 et Lamb.2. RTAR, 2, 1998, p. 295-299.

Koehler 1982 : KOEHLER (C.G.) - Amphoras on amphoras. Hesperia, 51, 3, 1982, p. 284-292.

Laubenheimer, Barthélémy 2010: LAUBENHEIMER (F.) et BERTHELEMY-SYLVAND (C.) - Les amphores de l'oppidum de Châteaumeillant. Le matériel des fouilles des $\mathrm{XIX}^{\mathrm{e}}$ et $\mathrm{XX}^{\mathrm{e}}$ s. Gallia, 67-2, 2010, p. 1-39.

Lemaître et al. 1998 : LEMAITRE (S.), DESBAT (A.), MAZA (G.) - Les amphores de site du " sanctuaire de Cybèle " à Lyon : étude préliminaire. In : Actes du congrès de la SFECAG (Istres), 1998, p. 49-59.

Lintz 2007 : LINTZ (G.) - Saint-Gence (Haute-Vienne). In : De pierre et de terre : Les Gaulois entre Loire et Dordogne, 2007, p. 268-275.

Long et al. 2010 : LONG (L.), VOLPE (G.), TURCHIANO (M.) - Circulation des amphores et des céramiques sur le littoral méridional. Le cas de l'épave d'époque républicaine La Ciotat 3. Bollettino di Archeologia on line, I, 2010. www.archeologia.beniculturali.it/pages/pubblicazioni.htlm

Loughton 2005 : LOUGHTON (M.) - The republican amphora stamps from the Auvergne. In: Actes de la SFECAG (Blois), 2005, p. 683-700.

Manacorda 1981 : MANACORDA (D.) - Produzione agricola, produzione ceramica e proprietari nell'Ager Cosanus nel I A.C. In : SRPS, II, 1981, Rome-Bari, p. 3-57.

Manacorda 1985 : MANACORDA (D.) - Schiavo 'manager' e anfore romane : a propositto dei rapporti tra archeologia e storia del diritto. Opus, IV, 1985, p. 141-151.

Manacorda, Panella 1993 : MANACORDA (D.), PANELLA (C.) - Anfore. In : The inscribed economy : production and distribution in the roman empire in the light of instrumentum domesticum, (Roma, janv. 1992), JRA supplément 6, 1993, p. 55-64.
Olmer 2003 : OLMER (F.) - Les amphores de Bibracte 2 - Le commerce du vin chez les Eduens d'après les timbres d'amphores, coll. Bibracte, 7, Gluxen-Glenne, 2003.

Passelac 1970 : PASSELAC (M.) - Le vicus Eburomagus : éléments de topographie, documents archéologiques. Revue Archéologique de Narbonnaise, III, 1970, p. 71-101.

Pedroni 1986 : PEDRONI (L.) - La ceramica a vernice nera da Cales, Naples, 1986.

Pianu 1980 : PIANU (G.) - Contributo ad un corpus del materiale anforario della Sardegna. Le anfore rodie e le anfore Dr.1 e Dr.2-4. Archivo Storico Sardo, 31, 1980, p. 11-28.

Pollino 1975 : POLLINO (A.) - L'épave de la Fourmigue dans le golfe de Juan. CAS, IV, 1975, p. 71-81.

Sanciu 1997 : SANCIU (A.) - Una fattoria d'età romana nell'agro di Olbia. Sassari, 1997.

Santamaria 1975 : SANTAMARIA (C.) - L'épave A du cap Dramont (Saint Raphaël): fouilles 1971-1974. Revue Archéologique de Narbonnaise, 8, 1975, p. $185-198$

Sireix et al. 2007 : SIREIX (C.), BENQUET (L.), BERTHET (A.-L.), CONVERTINI (F.), GE (T.), MARTIN (H.), POIRIE (P.), PRADAT (B.), TIXIER (C.) - Raspide 1 (Blagnac, Haute-Garonne) et Les Vergnasses (Gours, Gironde) : deux exemples de fermes gauloises dans le sud-ouest de la France. In : Les âges du Fer dans le sud-ouest de la France, actes du colloque de l'AFEAF à Toulouse (20-23 mai 2004), 2007, p. 285-292.

Solin, Salomies 1988 : SOLIN (H.), SALOMIES (O.) - Repertorium nominum gentilium et cognominum Latinorum, Hildesheim-Zürich-New-York, 1988.

Tchernia 1993 : TCHERNIA (A.) - Des timbres d'amphores à l'organisation du commerce. In: The inscribed economy : production and distribution in the roman empire in the light of instrumentum domesticum, (Roma, janv. 1992), JRA supplément 6,1993, p. 183-185.

Treggiari 1969: TREGGIARI (S.). - Roman freedmen during the late Republic, Oxford, 1969. 



\title{
La nécropole augustéenne de la villa de Sivier (Istres, Bouches-du-Rhône)
}

\author{
Frédéric Marty \\ Pôle Intercommunal du Patrimoine Culturel du SAN Ouest Provence (Istres) \\ Bérengère Perez \\ Éducation Nationale
}

\section{Résumé}

La fouille d'une petite nécropole rurale dépendant d'un domaine agricole gallo-romain a permis de mettre au jour une fosse-bûcher, une tombe à incinération secondaire ainsi qu'une petite fosse charbonneuse. L'étude archéologique et anthropologique a montré la complémentarité des deux premières structures qui concernent toutefois deux individus distincts. Ce noyau funéraire est daté par le mobilier d'accompagnement - composé notamment d'urnes en céramique non tournée des ateliers des Alpilles et de balsamaires en céramique - du dernier quart du Irr s. av. J.-C. Des offrandes alimentaires ainsi que des objets de parure et de toilette ont aussi été identifiés. En outre, la fossebûcher a pour particularité d'avoir livré deux planches en bois d'olivier pouvant appartenir au plancher du bûcher ou à un lit funéraire. Ces pratiques funéraires, en rupture avec celles en vigueur dans le monde indigène du ${ }^{\text {er }} \mathrm{s}$. av. J.-C., marquent la romanisation des campagnes.

Mots-clés : Sivier, Istres, Bouches-du-Rhône, nécropole, fosse-bûcher, incinération secondaire, Ir s. av. J.-C.

\begin{abstract}
The excavation of a small rural necropolis dependent on a Gallo-Roman agricultural domain revealed a woodshed-pit, a grave with secondary cremation and a small sooty pit. The archaeological and anthropological studies showed how were related the first two structures which concern however two different persons. This funeral site is dated by the artefacts of the last quarter of Ist c. BC, thanks to in particular some handmade potteries from the workshops of the Alpilles and ceramic balsamaires. Food offerings as well as objects of finery and dress were also identified. Besides, the woodshed-pit has delivered two wooden boards of olive tree which can belong to the floor of the woodshed or a funeral bed. These funeral practices, different of those current for native populations during the Ist $\mathrm{c} . \mathrm{BC}$, show the romanization of the rural country.
\end{abstract}

Keywords: Sivier, Istres, Bouches-du-Rhône, necropolis, woodshed-pit, secondary cremation, Ist c. BC 


\section{Contexte géographique et archéologique}

Le site de Sivier, à Istres, est situé à $900 \mathrm{~m}$ au nord de l'étang de l'Olivier, en bordure septentrionale de la dépression de Saint-Jean, sur d'anciennes terrasses cultivées, entre 40 et $60 \mathrm{~m}$ d'altitude. Le vallon, largement ouvert sur l'étang, dont le niveau est proche de la cote 0 , est encadré par de petits reliefs tabulaires miocènes, faiblement élevés : Miouvin, Sulauze et Montméjean.

Les différentes recherches menées depuis quelques années ont permis de mettre en évidence, sur plus d'un hectare, des vestiges s'échelonnant du Néolithique moyen à l'Antiquité tardive. Ainsi, différentes traces d'occupation néolithiques, dont chasséennes, sont disséminées sur une grande étendue : fossé, architecture de pierre... (Marty et al. 2010). Les témoins des Premier et Second âge du Fer restent ténus. Ils se résument à quelques tessons de céramiques, peut-être liés aux façons culturales. Pour l'Antiquité (fig. 1), les prospections pédestres ont permis de localiser une villa gallo-romaine implantée en bordure du plateau qui domine le vallon. Les céramiques recueillies autorisent une datation entre la fin du Irr s. av. J.-C. et le $\mathrm{VI}^{\mathrm{e}}$ s. ap. J.-C. (Trément 1999, IS 4). La villa se dote d'un atelier de potiers, situé en contrebas (four, carrière d'argile...), dont la production, entre les années 50 et 80-100, est principalement constituée de tuiles et d'amphores gauloises à fond plat ne laissant aucun doute quant à la vocation viticole du domaine à cette époque (Marty 2003). Des murs de terrasse, contemporains de cette occupation, ont été repérés en différents points dans le vallon, témoignant de sa mise en valeur à des fins culturales (Vecchione, Duflot 2003 ; De Luca, Chevillot, Collinet 2005 ; De Luca 2006 ; Marty et al. 2006). Enfin, des sondages en 2006, suivis d'une fouille sur $125 \mathrm{~m}^{2}$ en 2007, ont révélé l'existence d'une petite nécropole du début de l'époque romaine, à $70 \mathrm{~m}$ en aval de la villa. On retiendra dans cet article les résultats qui s'y rapportent.

\section{La nécropole}

Le décapage préliminaire à la pelle mécanique a permis de mettre en évidence une fosse-bûcher, une tombe à incinération secondaire ainsi qu'une fosse charbonneuse contemporaines (fig. 2). Les trois structures se situent approximativement au centre de la zone de fouille, à une altitude comparable. La distance qui sépare chacune d'entre elles est comprise entre 1,75 et $2,55 \mathrm{~m}$. Sur les $125 \mathrm{~m}^{2}$ décapés, l'espace investi par la nécropole, telle que nous la percevons aujourd'hui, ne dépasse pas $8,50 \mathrm{~m}^{2}$. Nous ne pouvons pas savoir dans quelle mesure la topographie ou les aménagements anthropiques (terrasses, chemins...) ont pu avoir une incidence sur sa localisation et ses limites, les niveaux de circulation contemporains ayant été détruits par l'érosion ou les cultures. Tout au plus, nous constatons que la fosse-bûcher est approximativement orientée est / ouest, tandis que la tombe à incinération secondaire et la fosse charbonneuse sont globalement orientées nord-ouest / sud-est.

\section{La fosse-bûcher}

\section{Étude archéologique}

Une fosse-bûcher, de plan rectangulaire $(1,69 \mathrm{x}$ $0,65 \mathrm{~m}$ ), à angles arrondis et fond plat, a été creusée dans un niveau argileux (fig. 3). Sa profondeur $(0,72 \mathrm{~m})$ est conforme à la moyenne observée à Vernègues $(0,20$ à $0,80 \mathrm{~m}$ : Chapon et al. 2004, 115) ou à Aix-en-Provence $(0,30$ à $1 \mathrm{~m}: \mathrm{Nin} 2006,118$, tabl. 10). Il en est de même pour sa longueur $(1,20$ à $2,60 \mathrm{~m}$ à Vernègues ; 0,70 à $2 \mathrm{~m}$ à Aix-en-Provence) et sa largeur $(0,60$ à $0,80 \mathrm{~m}$ à Vernègues ; 0,30 à 1,30 m à Aix-en-Provence). Bien que nous ayons affaire à une incinération primaire, on constate la rareté des traces de rubéfaction sur les parois de la fosse et leur absence à sa périphérie, à la hauteur de son niveau d'ouverture. L'absence de rubéfaction au fond des fosses de crémation a déjà été signalée (Nin 2006, 118) et s'explique par une montée en température rapide directement suivie d'une accumulation de braises et de cendres qui limite les processus d'altération des sols (Andrieux 1994, 263).

La fouille du comblement montre la superposition de 5 unités stratigraphiques. Au fond, l'US 4026, peu épaisse (4 à $6 \mathrm{~cm}$ ), est composée de charbons de bois et de fragments de branches carbonisées orientés préférentiellement dans le sens longitudinal, mêlés à des nodules d'argile cuite ou crue (parois de la fosse effondrées). Au-dessus se placent deux planches d'olivier carbonisées jointives (US 4025 ; épaisseur : $1 \mathrm{~cm}$ ), d'orientation analogue. Il s'agit là, probablement, des restes du plancher du bûcher ou d'un lit funéraire. Aucun système d'assemblage particulier n'a été observé. À notre connaissance, l'identification d'un plancher en bois reste exceptionnelle, alors que la découverte de bûches est davantage fréquente. Les planches se sont légèrement recourbées sous l'action du feu. Elles dessinent une forme allongée aux contours irréguliers $(1,18 \times 0,31 \mathrm{~m})$. Vient ensuite l'US charbonneuse 4013, contenant un sédiment argileux non rubéfié issu de l'effondrement des parois de la fosse (épaisseur : 0,15 m), surmontée d'une épaisse couche de charbons de bois (US 4012 ; épaisseur : 0,43 m) 


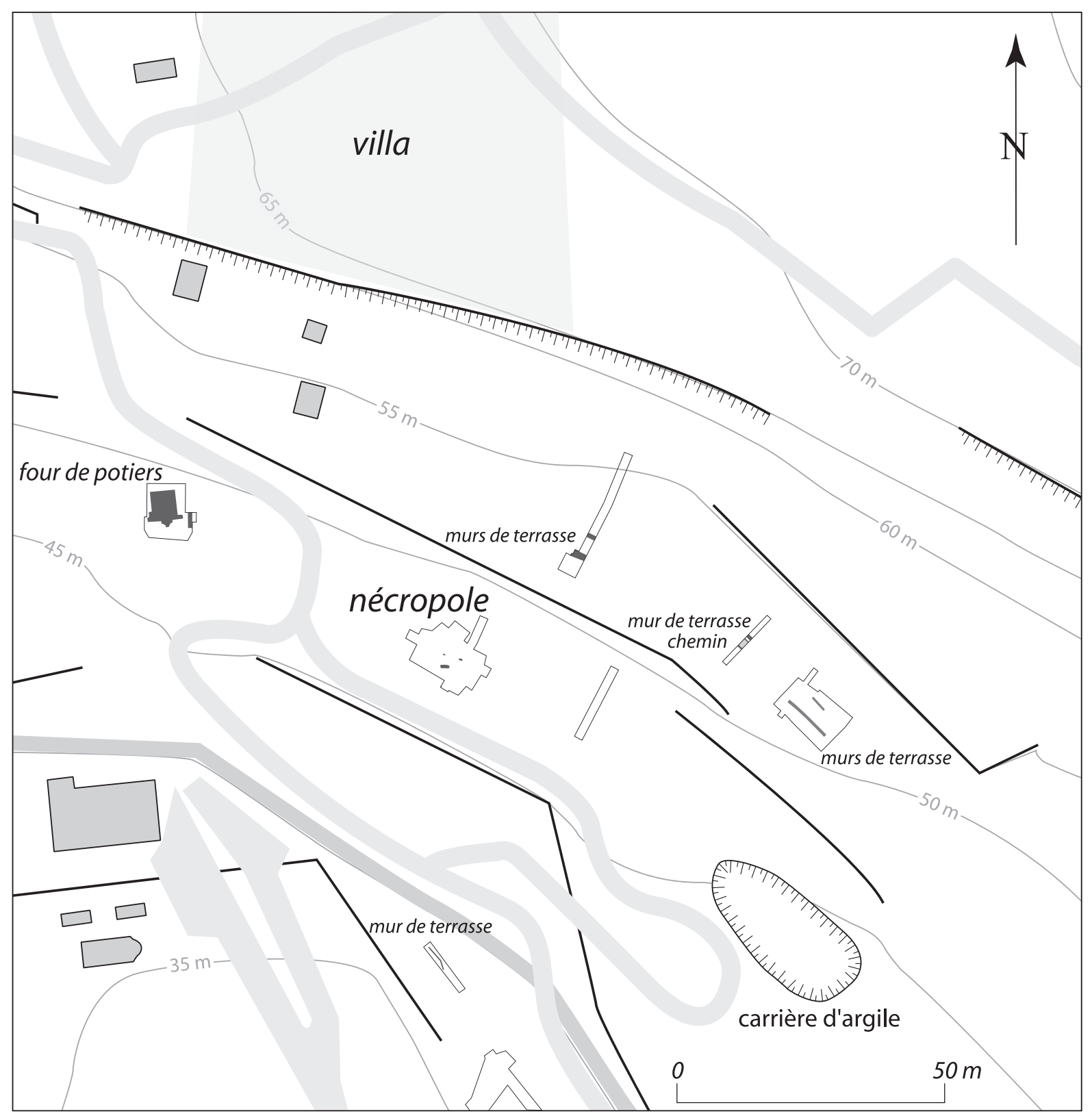

Fig. 1. Sivier. Répartition des vestiges antiques et localisation de la nécropole (DAO F. Marty).

incluant un cailloutis épars. L'analyse des charbons de bois (ARC07/R2619B) contenus dans ces deux derniers niveaux montre la prédominance du pin (Pinus sp. : 114 frag.), suivi de l'olivier (Olea europaea : 38 frag.) et du chêne à feuille persistantes (Quercus t. ilex : 9 frag.). La partie supérieure du comblement charbonneux semble avoir été creusée, car elle prend la forme d'une cuvette bien marquée de $\mathbf{0 , 1 7} \mathbf{~ m}$ de profondeur. S'agit-il du résultat d'un acte de prélèvement ? Un remblai argileux à cailloutis épars vient sceller la fosse (volontairement ou non ?), peut-être après un certain temps d'exposition à l'air libre comme l'indique la présence de plus de 2500 coquilles d'escargots millimétriques.
Des ossements incinérés très fragmentés, ne présentant aucun ordre apparent, ont été récoltés dans les US 4026, 4013 et 4012. Tous les objets présents dans la fosse ont également subi les effets de la crémation. Aucune offrande secondaire n'a, par conséquent, été déposée à l'intérieur. Une urne complète en céramique non tournée des ateliers des Alpilles CNT-ALP 1a3, contenant au fond 9 fragments de coquilles de moules brûlés, constitue la seule véritable offrande primaire avérée (fig. 4). Cette urne s'est brisée et ses parois se sont desquamées sous l'action des chocs thermiques. Tous les fragments étaient regroupés contre la paroi sud de la fosse, du côté ouest, sur le plancher en bois, 


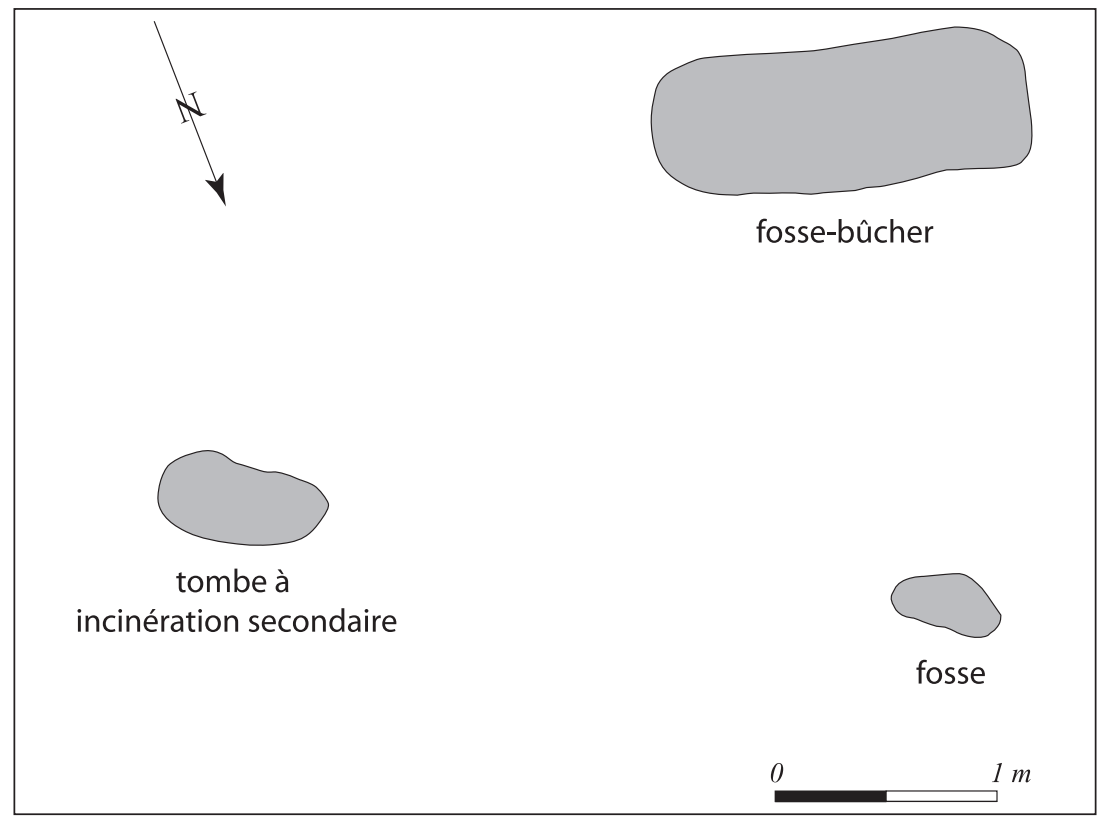

Fig. 2. Plan de la nécropole (relevé F. Marty et V. Prades ; DAO F. Marty).

à l'exception d'un bord découvert au même niveau altimétrique, dans le quart nord-est. Au total, 657 fragments de coquilles de moules ont été décomptés dans la fosse-bûcher. En dehors de ceux contenus dans l'urne, une partie pourrait être intrusive dans la mesure où l'ensemble de la stratigraphie du site a livré un nombre important de restes de ce type. Quoi qu'il en soit, les dépôts de coquillages accompagnant le défunt, tels que pectens, coques, tellines, pétoncles et huîtres, sont relativement fréquents dès le $\mathrm{I}^{\mathrm{er}} \mathrm{S}$. av. J.-C. (Bel 2002, 137 ; Bel et al.2008, 249-250 ; Moliner 2003, 185 ; Nin 2006, 132). Quatre fragments d'amande et quatre fragments de pulpe de fruits sont peut-être l'indice d'autres offrandes alimentaires. Une écaille de pomme de pin se rapporte plus probablement au combustible.

L'unique objet faisant partie des effets personnels du défunt est un fragment de fibule en bronze, partiellement fondu. Seul est conservé le porte-ardillon, à double fenêtre et extrémité ornée d'un bouton qui se rapproche du type 9a (à fenêtre unique) de Michel Feugère (1985, pl. $\left.76, \mathrm{n}^{\circ} 1046\right)$.

La clouterie est bien représentée avec 8 clous robustes en fer dispersés dans les différents niveaux. Deux sont nettement repliés après avoir traversé des supports de 53 et $71 \mathrm{~mm}$. On suppose que ces clous ont servi à assembler les éléments du bûcher ou d'un lit funéraire. Cependant, leur répartition n'apporte pas d'élément d'interprétation supplémentaire. Les clavettes en fer sont relativement bien représentées avec
13 exemplaires complets et 20 fragments. Toutes sont repliées à angle droit. Elles sont localisées dans toute l'épaisseur de l'US 4012 et dans l'US 4026. On ignore ce qu'elles ont pu fixer et le type d'objet en matière périssable qui se cache derrière elles. Néanmoins, étant donné que l'ethnographie nous montre des bûchers parfois élaborés (Chapon et al. 2004, 134 ; Pautreau 2010, fig. 115), on peut suggérer que les clavettes aient servi à y fixer des éléments ornementaux. 24 fragments de fer informes complètent cet inventaire.

Le mobilier résiduel se compose d'une lamelle en silex, de céramique non tournée, campanienne $\mathrm{A}$, à parois fines, à pâte claire, d'amphore punique et italique (Dressel 1A). Le remblai de scellement contient aussi de la céramique non tournée, campanienne $\mathrm{A}$ et à pâte claire. Immédiatement au-dessus de la tombe, a également été trouvé un fragment de pot non tourné Mellinand $1 \mathrm{~b}$ datable entre 20-10 av. J.-C. et 20-30 ap. J.-C. (Marty 2004, 99-100).

\section{Étude anthropologique}

Les os recueillis dans la fosse-bûcher présentent une fragmentation très élevée, due à la température de crémation et aux manipulations ou traitements subis, qui a constitué un obstacle à leur identification et aux remontages de diaphyses. La part de membres non déterminés y est donc importante et la diagnose sexuelle ainsi que la détermination d'un âge au décès n'ont pu être envisagées. Le décompte et l'observation des pièces osseuses 


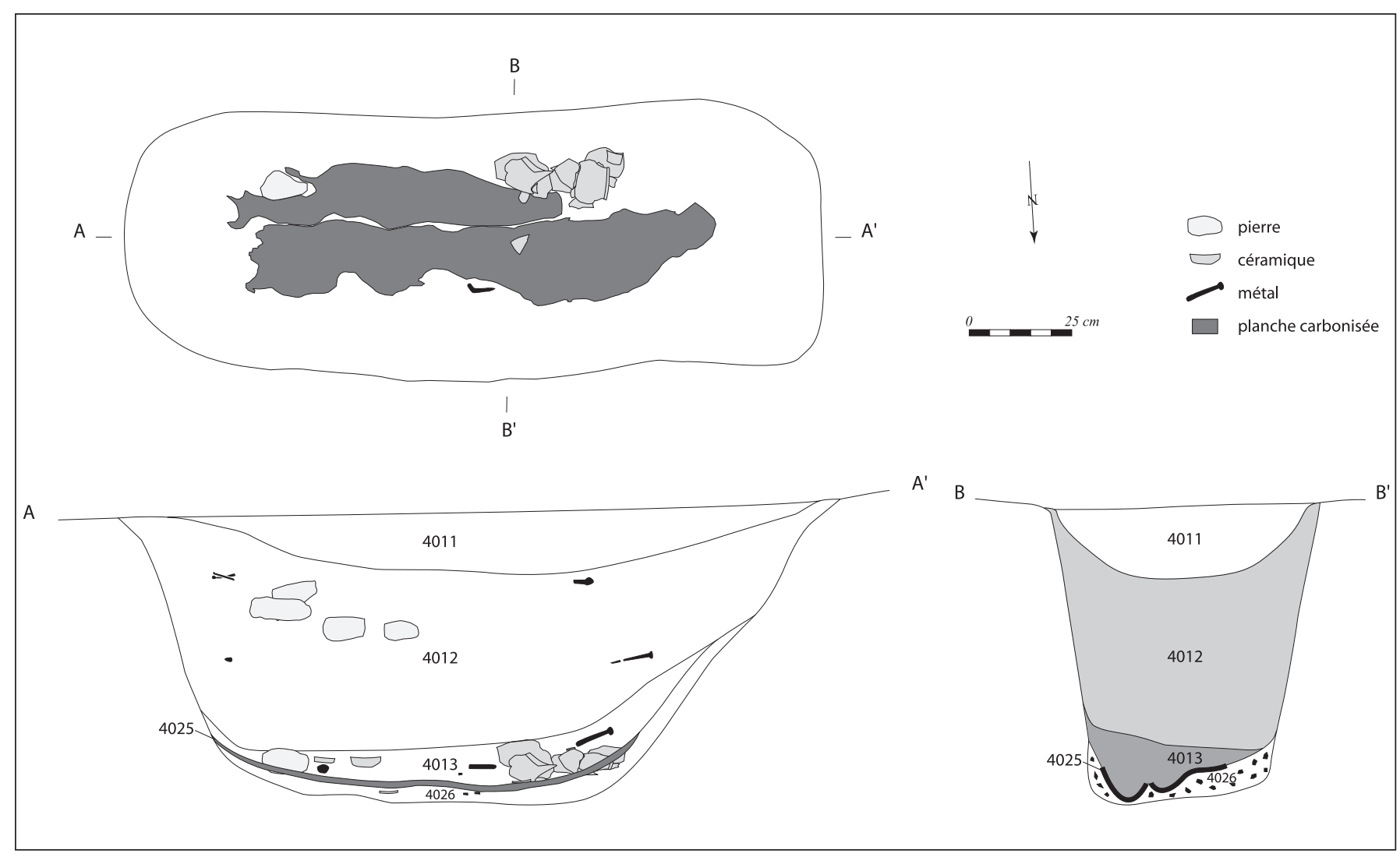

Fig. 3. Fosse-bûcher. Vues en plan (au niveau des planches) et en coupe (relevé F. Marty et B. Perez ; DAO F. Marty).

ont, néanmoins, permis d'identifier la présence d'un seul individu de taille adulte. En outre, aucune trace de pathologie ou d'arthrose visibles n'a été relevée sur l'ensemble du volume osseux identifié.

On observe une coloration majoritairement blanche des os de l'ensemble du corps avec parfois, pour les plus petites esquilles, une couleur grise à noire ainsi que des fissurations et des déformations spiroïdales qui indiquent une température de crémation assez élevée $\left(500\right.$ à $600{ }^{\circ} \mathrm{C}$ au moins), homogène et longue. Le poids total du volume osseux récolté est de 424,9 g. Cette masse est très inférieure aux valeurs de référence les plus basses pour le poids total d'un squelette adulte incinéré, dont la moyenne varie selon les auteurs entre 1001,5 g et 2422,5 g (poids moyen de $1625 \mathrm{~g}$ tous sexes confondus : Duday, Depierre, Janin 2000, 8 ; Mackinley 1993, 283-287). C'est donc à peine plus de $25 \%$ du poids total attendu qui est conservé dans cette structure. Ainsi, il est tout à fait raisonnable d'envisager que les restes osseux aient été en grande partie prélevés pour être déposés dans une tombe située ailleurs. Sur le site de Saint-Paul-Trois-Châteaux, dans la Drôme, V. Bel a mis en évidence la récurrence des crémations pratiquées dans une fosse individuelle, à proximité de la sépulture définitive (Bel, 2002, 77).

\section{La tombe à incinération secondaire}

\section{Étude archéologique}

Une fosse sépulcrale peu profonde $(0,32 \mathrm{~m}$ maximum), à fond plat, de plan ovale $(0,76$ x $0,38 \mathrm{~m})$, dont les parois vont en se rétrécissant vers le fond, a été creusée dans un niveau argileux (fig. 5). Elle contenait les restes d'une incinération en position secondaire. L'ensemble des objets et ossements récoltés sur le bûcher était dispersé sans ordre apparent dans le loculus, sur toute sa profondeur. On remarque, toutefois, un regroupement plus important des vases en céramique dans les deux tiers orientaux, sans que cela n'implique de rituel particulier. La crémation a touché la totalité des éléments contenus dans la tombe.

Les offrandes en céramique se composent de trois vases complets après recollage (fig. 6). Deux balsamaires en pâte claire de type UNGUENT D1 devaient contenir des huiles parfumées répandues sur le bûcher (Bel 2002, 141). Leur couleur a été modifiée au contact du feu, la pâte et l'engobe du col, habituellement brunrouge, ayant viré au gris. Une urne non tournée des ateliers des Alpilles CNT-ALP 1a8 contenait peut-être 


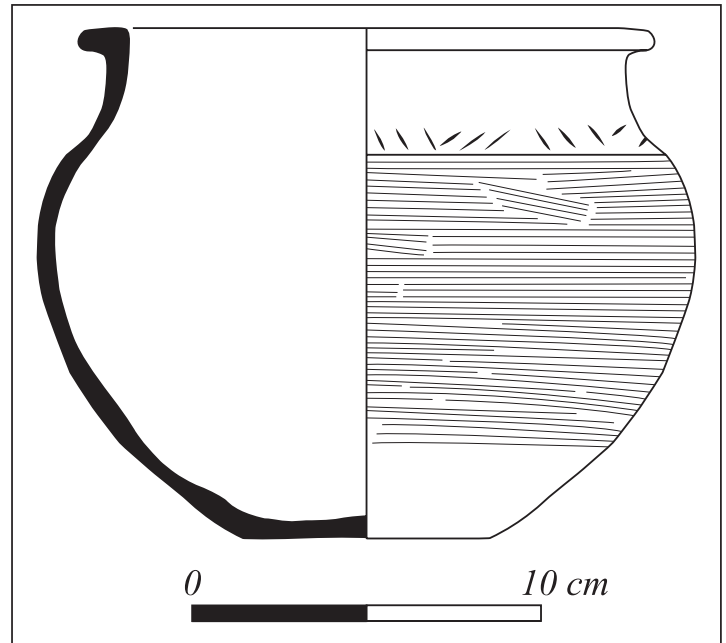

Fig. 4. Fosse-bûcher. Urne en céramique non tournée de la région des Alpilles (F. Marty).

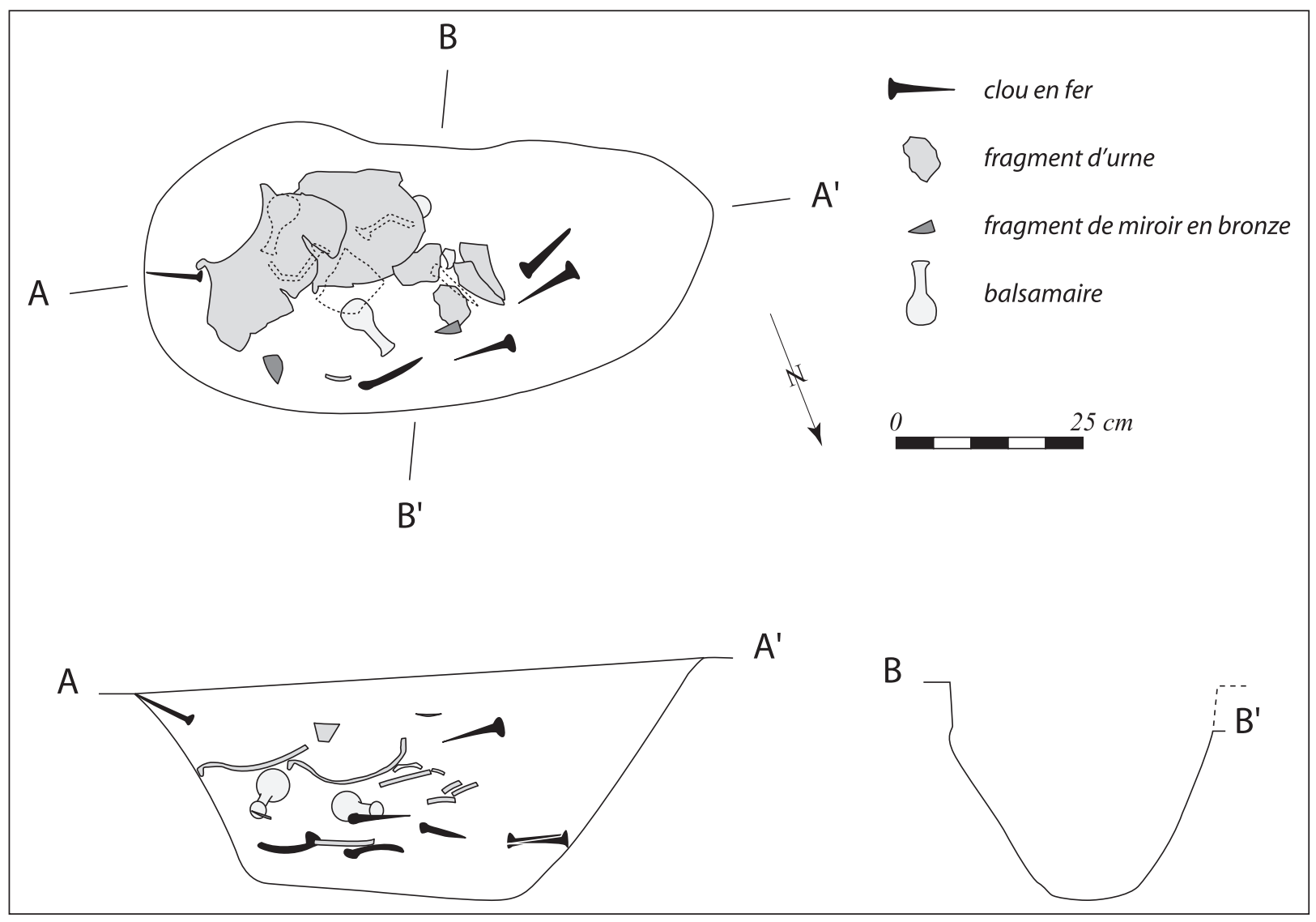

Fig. 5. Tombe à incinération secondaire. Vues en plan et en coupe (F. Marty). 


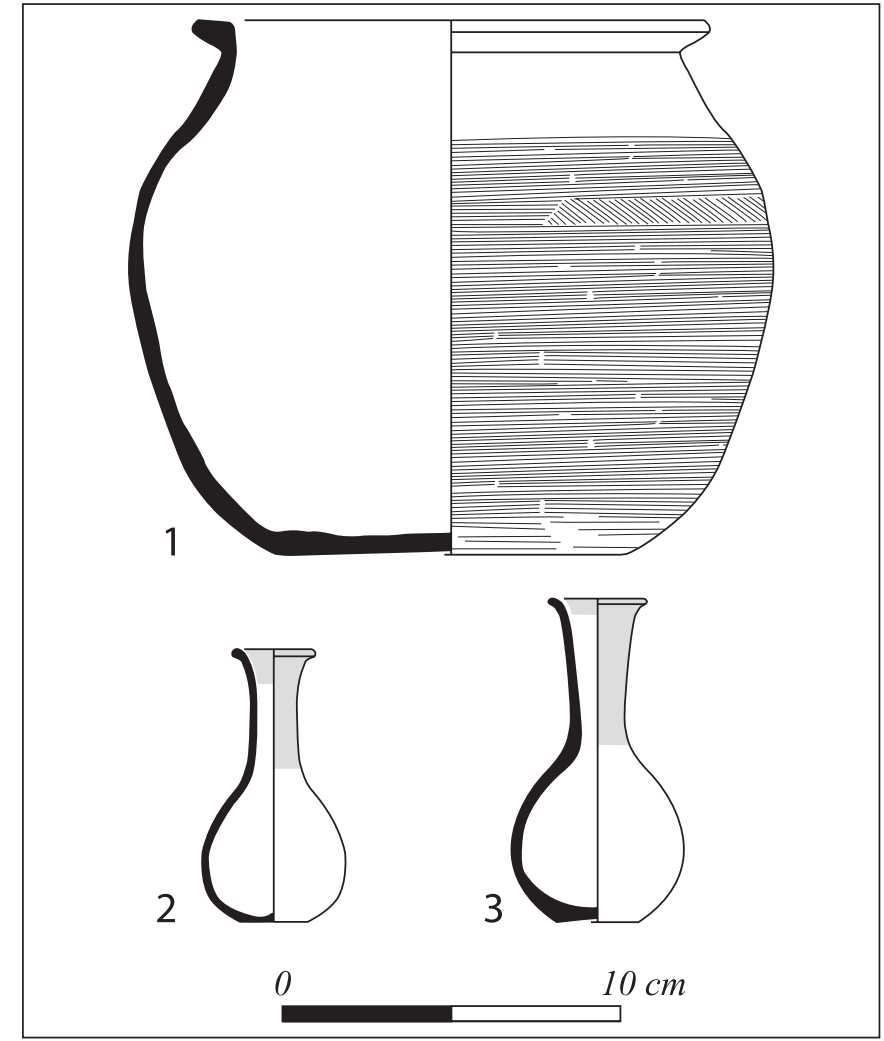

Fig. 6. ombe à incinération secondaire. 1 : urne en céramique non tournée de la région des Alpilles ; 2-3 : balsamaires en céramique (F. Marty).

une offrande alimentaire. 83 fragments millimétriques de valves de moules brûlées suggèrent l'existence de ce type de rituel. 3 pépins de raisin avec de la pulpe et des fragments d'un autre pépin, au moins trois grains de seigle (plutôt que d'orge ?) ainsi qu'un fragment de l'amande d'un fruit (ARC06/R3394B) signalent également la présence d'une préparation culinaire, de galettes ou de pains. L'urne a subi une forte desquamation, due à un choc thermique, dans sa partie basse. Ceci pourrait indiquer qu'elle était, initialement, complète et en position horizontale sur le bûcher. Elle s'est ensuite brisée, puis les fragments se sont déformés sous l'action du feu.

Quelques objets métalliques composent les effets personnels du défunt : trois fragments de tige en fer appartenant probablement à un ardillon de fibule, un miroir circulaire en bronze incomplet, habituellement interprété comme un accessoire de toilette typiquement féminin (Bel 2002, 148) et deux clous en fer de semelle de chaussure.

La clouterie recueillie (fig. 7) comprend aussi deux petits clous décoratifs en bronze, de section carrée, à tête en calotte de sphère, repliés à angle droit après avoir traversé un support de $4 \mathrm{~mm}$ d'épaisseur. Ce type de clou

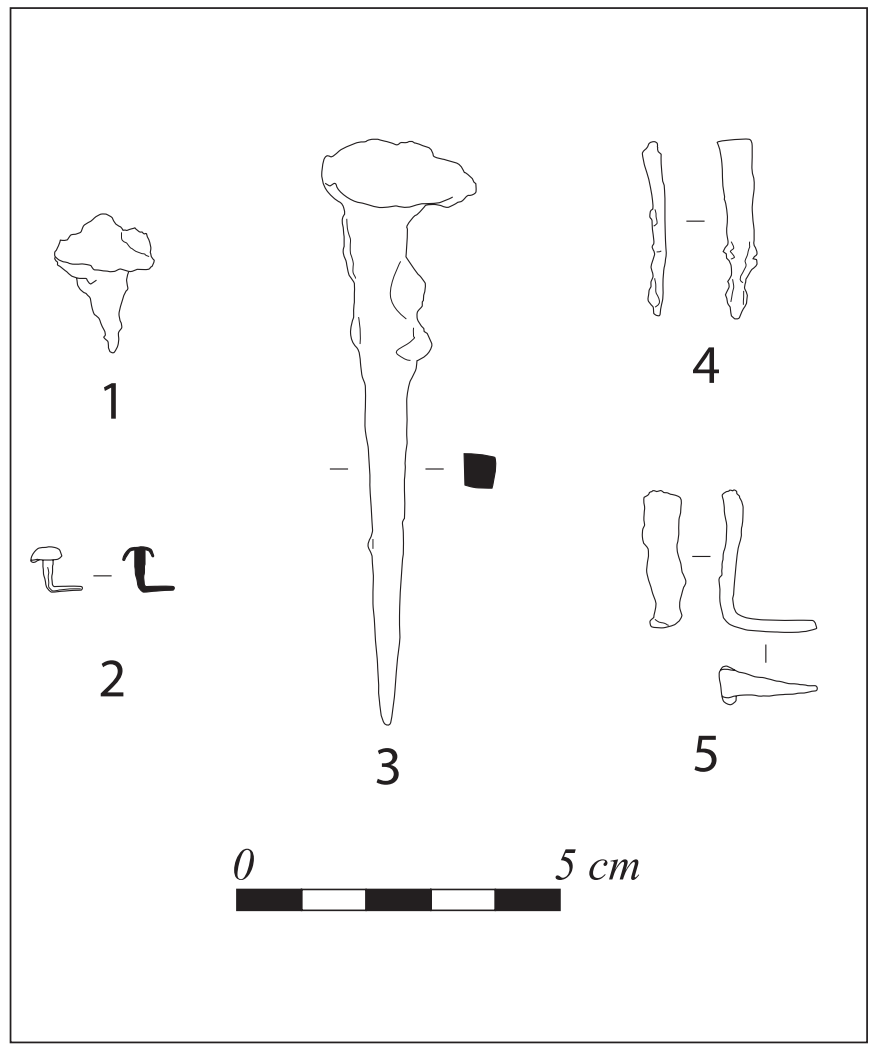

Fig. 7. Tombe à incinération secondaire. Exemples de clouterie. 1 : clou de chaussure en fer ; 2 : clou décoratif en bronze ; 3 : clou robuste en fer ; 4-5: clavettes en fer (F. Marty).

est généralement associé à un coffret (Chapon et al. 2004, 133). On note également la présence de 8 clous robustes en fer, de section carrée, à tête plate, de 80 à $107 \mathrm{~mm}$ de long. Deux sont repliés après avoir traversé un support de 37 et $45 \mathrm{~mm}$. Ces clous devaient servir à assembler les éléments du bûcher ou d'un lit funéraire. 5 fragments de clous en fer très dégradés complètent le corpus. L'objet métallique le plus abondant reste toutefois la clavette en fer, dont on a récupéré 34 exemplaires complets et 49 fragments. À l'exception d'une seule, toutes sont repliées à angle droit. Enfin, un lot de 21 fragments informes de fer, se rapportant très probablement à la clouterie, complète l'inventaire.

Trois intrusions ont été reconnues dans le remplissage de la fosse : un petit tesson de céramique non tournée et deux minuscules éclats de silex ramassés sur le sol en même temps que les restes de la crémation.

\section{Étude anthropologique}

Parmi l'ensemble des os recueillis, regroupés en amas plus ou moins concentrés, aucun doublet n'a été identifié. Il semble que nous ayons les restes d'un seul sujet, de taille adulte. Si la diagnose sexuelle reste 
difficile à établir, la gracilité des os pourrait toutefois induire un individu de sexe féminin, ce que ne contredit pas l'association avec un miroir en bronze. Concernant l'âge au décès du sujet, l'examen des os n'a révélé aucun signe de sénescence qui permettrait d'avancer un âge. Les éléments du bloc cranio-facial sont, d'autre part, trop fragmentaires pour être utilisés dans le but d'une détermination approximative. En outre, aucune trace de pathologie ou d'arthrose visible n'a été relevée sur l'ensemble du volume osseux.

Au sein de ce dernier, toutes les régions anatomiques ne sont pas représentées de manière régulière. En effet, on note une sur-représentation des os de la tête par rapport au reste du corps et une sous-représentation des membres inférieurs. Il est cependant probable qu'une part de ces éléments manquants se trouve dans le lot des « diaphyses indéterminées » ou des « esquilles ». En effet, la quasi-totalité des os indéterminés appartient aux membres sans qu'il soit naturellement possible de préciser s'il s'agit du membre supérieur ou du membre inférieur. Il est néanmoins difficile, pour le moment, de conclure à un choix qualitatif et / ou quantitatif des os de la crémation de la part des préposés aux funérailles. Dans le niveau supérieur du remplissage de la fosse, se trouvaient des os de taille importante (os longs, fragments de crâne, vertèbre), tandis que le niveau inférieur se composait d'os plus fragmentés et de plus petites dimensions, de sorte que la détermination est moins aisée.

Le poids total du volume osseux récolté est de $880,1 \mathrm{~g}$. Cette masse est de moitié inférieure aux valeurs de référence pour le poids total d'un squelette (supposé) de femme adulte incinérée, dont la moyenne varie, selon les auteurs, entre $1540 \mathrm{~g}$ et $1820 \mathrm{~g}$ (Duday, Depierre, Janin 2000, 8 ; Mackinley 1993, 283-287), induisant une collecte partielle après la crémation (Duday 2005, 74).

Enfin, la coloration majoritairement blanche des os de l'ensemble du corps, avec parfois pour les esquilles et les os des mains et des pieds une couleur grise à noire, ainsi que des fissurations et des déformations spiroïdales, indiquent une température de crémation assez élevée et homogène. Le gradient de couleur respecte de manière assez satisfaisante la topographie anatomique d'un sujet couché en extension.

\section{La fosse charbonneuse}

Une petite fosse charbonneuse se situe à $1,75 \mathrm{~m}$ au nord de la fosse-bûcher. Elle adopte un plan aux contours arrondis $(0,50 \times 0,25 \mathrm{~m}$; profondeur : $0,10 \mathrm{~m})$.
Ses parois ne sont pas rubéfiées, excluant a priori une combustion sur place. Son comblement est composé de deux unités stratigraphiques. Au fond, un sédiment argileux beige contient des cailloutis et charbons de bois épars. La couche qui le recouvre possède d'abondants charbons de bois ainsi que quelques nodules d'argile rubéfiée et un petit cailloutis peu abondant. À l'intérieur ont été recueillis 4 fragments millimétriques d'ossements brûlés de couleur blanche, un fragment de lamelle en silex blond, un fragment de céramique non tournée ainsi qu'un fragment d'amphore italique.

La fonction exacte de cette fosse nous échappe (vidange de bûcher ?). La quantité négligeable d'ossements récoltés permet d'écarter l'hypothèse d'une tombe. La complémentarité éventuelle avec la tombe à incinération secondaire et la fosse-bûcher est, par ailleurs, peu évidente malgré leur proximité.

\section{Datation}

La datation de la nécropole repose sur le mobilier céramique recueilli dans la fosse-bûcher et dans la sépulture secondaire. Pour cette dernière, trois objets retiennent notre attention : deux balsamaires et une urne non tournée. Ainsi, les balsamaires en céramique de type UNGUENT D1 apparaissent vers 20 av. J.-C. (Arcelin 1973, 150) et sont encore utilisés dans la première moitié du ${ }^{\text {er }}$ s. ap. J.-C. (Béraud et al. 1985, 40 ; Moliner 2003, 123). Cette fourchette chronologique, relativement large, peut être resserrée grâce à l'urne CNT-ALP 1a8 dont quelques exemplaires sont assez bien datés par ailleurs. P. Arcelin note que la forme a fait l'objet d'une petite production, très limitée dans le temps, réalisée par un ou deux potiers (Arcelin 1979, 251). On la retrouve dans la tombe I de Saint-Rémy-deProvence, datée du dernier quart du Irr s. av. J.-C. par la céramique (coupe en céramique campanienne A Morel F2943, cruche CL-REC 2b, urne de type «celtique », urne CNT-ALP 1a3). En outre, l'urne contenait un as de la colonie de Nîmes de la première émission (dès 27 av. J.-C.). C'est également le cas de l'urne de la tombe XII (Arcelin 1975, 93-95 et 126-127 ; 1979, 254). Sur la nécropole de Servanes-Cagalou, à Mouriès, une urne identique, utilisée comme vase à offrande, contenait quelques ossements de faune et une petite cruche CNT-ALP 2b4, habituellement datée vers -40/-20 (Marcadal, Marcadal, Paillet 2003, 269). La tombe 4 de la même nécropole a livré une urne - à l'exception de toute autre céramique - contenant des ossements humains et de faune ainsi qu'une monnaie en bronze à l'effigie d'Auguste, légendée SEGALIVS 
LUPERCVS et émise en 16 av. J.-C. (Marcadal, Marcadal, Paillet 2003, 275-276). Ces quelques comparaisons permettent de dater la forme CNT-ALP 1a8 du dernier quart du Ier s. av. J.-C.

La fosse-bûcher, pour sa part, a livré une urne CNT-ALP 1a3. Le type est connu par de très nombreux exemplaires trouvés en contexte funéraire et sur des habitats. Il est diffusé dans la seconde moitié du Ir s. av. J.-C. (Arcelin 1979, 233-236). Les petites dimensions de la nécropole ainsi que le niveau d'ouverture identique des deux structures funéraires, conservées intégralement, plaident en faveur d'une contemporanéité de ces dernières. C'est pourquoi nous proposons de dater l'ensemble du dernier quart du I ${ }^{\text {er }}$ s. av. J.-C.

\section{Interprétation}

L'ensemble funéraire de Sivier constitue un exemple intéressant de petite nécropole rurale ayant fonctionné au dernier quart du $\mathrm{I}^{\mathrm{er}} \mathrm{s}$. av. J.-C. En effet, la plupart des nécropoles du $\mathrm{I}^{\mathrm{er}} \mathrm{s}$. av. J.-C. publiées régionalement sont en relation avec une agglomération ${ }^{1}$. À Sivier, les crémations sont visiblement liées à une phase d'occupation ancienne de l'habitat gallo-romain situé à $70 \mathrm{~m}$ au nord, en bordure du plateau dominant le site. L'organisation et l'importance de l'établissement sont encore mal connues. Seules des prospections pédestres nous renseignent sur son étendue probable et sur sa datation, centrée sur le Haut Empire (Trément 1999, 268). Si, dans la région, les exemples de nécropoles rurales du Haut-Empire fouillées exhaustivement et publiées sont encore peu nombreux, le modèle de Sivier semble toutefois s'inscrire dans un schéma général plus vaste. Ainsi, les secteurs ayant fait l'objet de fouilles extensives sur de vastes superficies, notamment à Saint-Priest, dans le Rhône, livrent de petits noyaux funéraires, de une à plus d'une vingtaine de structures, dispersés à quelques dizaines ou centaines de mètres de l'établissement dont ils dépendent, dans des zones cultivées (Blaizot 2009, 254-260).

Bien que le nombre de crémations soit réduit à deux, leurs types sont à la fois différents et complémentaires

1 Elles sont reconnues principalement dans la basse vallée du Rhône, des deux côtés du fleuve : Nages, Nîmes, Boissières, Beaucaire, Saint-Laurent-des-Arbres, Sauveterre et Aramon, dans le Gard ; Arles, Le Paradou, Les Baux-de-Provence, Saint-Rémyde-Provence, Eyguières et Mouriès, dans les Bouches-du-Rhône ; Cavaillon, dans le Vaucluse. D'autres nécropoles ou tombes isolées existent dans ce secteur, mais n'ont été mentionnées que de manière rapide, sans que les contextes de découverte puissent être clairement établis (bibliographie dans Bats 1990 et Bel et al. 2008). dans leur fonction. Différents car les deux dépôts sont bien distincts et caractérisés (bûcher puis lieu de sépulture de deux individus identifiés). Complémentaires en raison du faible pourcentage d'ossements humains par rapport aux valeurs de références et de la proportion très importante d'esquilles recueillies dans la fosse-bûcher en regard de leur faible représentation dans la sépulture secondaire. Enfin, si l'on additionne le poids de la masse osseuse de la sépulture secondaire $(880,1 \mathrm{~g})$ au volume osseux prélevés dans la fosse-bûcher (424,9 g), nous obtenons un indice pondéral de $1305 \mathrm{~g}$ qui s'approche alors davantage des valeurs de référence d'un squelette adulte incinéré.

L'incinération sur un bûcher posé au-dessus d'une fosse, suivie du dépôt d'une partie des résidus de la crémation dans une autre fosse, sans organisation apparente, constitue un rite en rupture avec les pratiques indigènes du $\mathrm{I}^{\text {er }} \mathrm{s}$. av. J.-C. où la coutume veut que les ossements soient triés et qu'une partie d'entre eux soit placée dans un vase cinéraire, le plus souvent accompagné d'offrandes secondaires. Le tout est habituellement disposé dans une fosse, protégée ou non par des pierres ou par un caisson monolithique, en dalles de pierre ou en bois. La sépulture secondaire de Sivier s'en distingue par le rituel qui a accompagné l'ensevelissement des restes mortuaires. En effet, les ossements brûlés recueillis sur le bûcher sont relativement abondants $(880 \mathrm{~g})$ comparés à la poignée d'ossements que l'on retrouve le plus souvent (Bel et al. 2008, 218-219). D'autre part, ils étaient dispersés sans ordre apparent dans le loculus, au milieu des offrandes primaires, des clous et des cendres.

L'enfouissement en pleine terre des ossements brûlés, restes d'offrandes et charbons de bois provenant du bûcher existe dès la fin du III' ${ }^{\mathrm{e}}$ s. av. J.-C. à Ambrussum (Fiches 1989, 30-39) et à Nîmes (Bel et al. 2008, 222). Toutefois, l'incinération secondaire avec couche de cendre, sans séparation des ossements, apparaît réellement à l'époque augustéenne et se poursuit jusqu' au $\mathrm{III}^{\mathrm{e}} \mathrm{s}$. (Blaizot 2009, 176-183). De la même manière, les premières fossesbûcher et tombes-bûcher sont attestées dès l'époque augustéenne dans la nécropole de Saint-Lambert, à Fréjus, et vont connaître un réel essor à partir du milieu du I ${ }^{\mathrm{er}} \mathrm{s}$. (Bel 2002, 86-87 ; Blaizot 2009, 102-103) allant jusqu’à représenter l'intégralité des 48 tombes de la nécropole des Communaux de Saint-Cézaire, à Vernègues, utilisée du milieu du ${ }^{\text {er }} \mathrm{s}$. au début du III' $\mathrm{s}$. (Chapon et al. 2004). Nous observons donc, à Sivier, les prémices de nouvelles pratiques funéraires introduites par la romanisation qu'il faut probablement mettre en relation avec l'installation de colons venus implanter leur établissement afin d'exploiter les terres du vallon de Saint-Jean. 


\section{Bibliographie}

Andrieux 1994 : ANDRIEUX (PH.) - Étude de la combustion du bûcher. In : Lambot (B.), Friboulet (M.), Meniel (P.), Delestree (L.-P.), Guillot (H.), LE GOFF (I.), Le site protohistorique d'Acy-Romance (Ardennes), II. Les nécropoles dans leur contexte régional (Thugny-Trugny et tombes aristocratiques) 1986-1988-1989. (Bulletin de la Société Archéologique Champenoise, suppl. 2), Reims, 1994, p. 262-279. (Dossiers de Protohistoire, 5).

Arcelin 1973 : ARCELIN (P.) - La nécropole protohistorique de La Catalane aux Baux-de-Provence. Revue Archéologique de Narbonnaise, 6, 1973, p. 91-195.

Arcelin 1975 : ARCELIN (P.) ET (CH.) - Les sépultures préromaines de Saint-Rémy-de-Provence (Bouches-du-Rhône). Revue Archéologique de Narbonnaise, 8, 1975, p. 67-135.

Arcelin 1979 : ARCELIN (P.) - La céramique modelée au Ir siècle av. J.-C. dans les Bouches-du-Rhône, La vaisselle culinaire autochtone de la Conquête à la Romanisation (125 av. J.-C. - règne d'Auguste), Thèse de doctorat de $3^{\mathrm{e}}$ cycle, LAPMO, Université de Provence, Aix-en-Provence, 1979, 2 vol.

Bats 1990 : BATS (M.) - Tombes et nécropoles de Narbonnaise aux IIe-Ier s. av. J.-C. : problèmes de datation et de chronologie. In : Duval (A.), Morel (J.-P.), ROMAN (Y.) éd., Gaule interne et Gaule méditerranéenne aux IIe et $I^{e r}$ siècles avant J.-C. : confrontations chronologiques, Actes de la table ronde de Valbonne (1986), (Revue Archéologique de Narbonnaise, suppl. 21), 1990, p. 269-290.

Bel 2002 : BEL V. DIR. - Pratiques funéraires du Haut-Empire dans le Midi de la Gaule. La nécropole gallo-romaine du Valladas à Saint-Paul-TroisChâteaux (Drôme), (Monographies d'Archéologie Méditerranéenne, 11), Lattes, 2002, $539 \mathrm{p}$.

Bel et al. 2008 : BEL (V.), BARBERAN (S.), CHARDENON (N.), FOREST (V.), RODET-BELARBI (I.), VIDAL (L.) - Tombes et espaces funéraires de la fin de l'âge du Fer et du début de l'époque romaine à Nîmes (Gard), (Monographies d'Archéologie Méditerranéenne, 24), 2008, 519 p.

Béraud et al. 1985 : BERAUD (I.), BRUN (J.-P.), CONGES (G.), GEBARA (CH.), PASQUALINI (M.) - Les nécropoles gallo-romaines de Fréjus. Trois années d'action du service archéologique municipal, Catalogue d'exposition, Fréjus, 1985, $45 \mathrm{p}$.

Blaizot 2009 : BLAIZOT (F.) DIR. - Pratiques et espaces funéraires de la Gaule durant l'Antiquité, (Gallia, 66.1), 2009, 383 p.

Chapon et al. 2004 : CHAPON (PH.), BUSSIERE (J.), DELATTRE (L.), FEUGERE (M.), RICHIER (A.), ROTH-CONGES (A.), VILLEMEUR (I.) Les nécropoles de Vernègues (B.-du-Rh.). Deux ensembles funéraires du Haut-Empire à la périphérie d'une agglomération secondaire. Revue Archéologique de Narbonnaise, 37, 2004, p. 109-209.

De Luca 2006 : DE LUCAS (B.) - Chemin de Saint-Jean IV à Istres (Bouches-du-Rhône), Rapport final d'opération de diagnostic, INRAP, SRAPACA, 2006, 29 p.

De Luca, Chevillot, Collinet 2005 : DE LUCAS (B.), CHEVILLOT (P.), COLLINET (J.) - Chemin de Saint-Jean I à Istres (Bouches-du-Rhône), Rapport final d'opération de diagnostic, INRAP, SRA-PACA, 2005, 34 p.

Duday 2005 : DUDAY (H.) - Archéologie du rituel. Fouille des enclos 23, 25 et 25 A de la nécropole de Porta Nocera à Pompéi. Campagne 2005.
École Française de Rome, Soprintendenza di Pompei, CNRS, Université de Picardie, vol. 1, 173 p.

Duday, Depierre, Janin 2000 : DUDAY (H.), DEPIERRE (G.), JANIN (T.) Validation des paramètres de quantification, protocoles et stratégies dans l'étude anthropologique des sépultures secondaires à incinération. L'exemple des nécropoles protohistoriques du Midi de la France. In : Archéologie de la mort, archéologie de la tombe au premier âge du Fer, Actes du $21^{\mathrm{e}} \mathrm{col}-$ loque international de l'Association Française pour l'Etude de l'Age du Fer (Conques-Montrozier, 1997), Lattes, CNRS, 2000, p. 7-29. (Monographies d'Archéologie Méditerranéenne, 5).

Feugère 1985 : FEUGERE (M.) - Les fibules en Gaule méridionale de la conquête à la fin du $V^{e}$ siècle après J.-C., (Revue Archéologique de Narbonnaise, supp. 12), 1985, 503 p.

Fiches 1989 : FICHES (J.-L.) DIR. - L'oppidum d'Ambrussum et son territoire, (Monographie du CRA), 1989, 286 p.

Mackinley 1993 : MACKINLEY (J.-I.) - Bone fragment size and weights of bone from modern british cremations and its implications on archaeological cremations. International Journal of Osteoarchaeology, 3, 1993, p. 283-287. Marcadal, Marcadal, Paillet 2003 : MARCADAL (N.), MARCADAL (Y.), PAILLET (J.-L.) - La nécropole protohistorique et gallo-romaine de Servanes - Cagalou (Irr s. av. J.-C. - IIIe s. ap. J.-C.) à Mouriès (Bouches-du-Rhône) : sépultures et monuments funéraires. Documents d'Archéologie Méridionale, 26, 2003, p. 251-348.

Marty 2003 : MARTY (F.) - L'atelier de potiers gallo-romain de Sivier (Istres, B.-du-Rh.). Revue Archéologique de Narbonnaise, 36, 2003, p. 259-282.

Marty 2004 : MARTY (F.) - La vaisselle de cuisson du port antique de Fos (Bouches-du-Rhône). In : SFECAG, Actes du congrès de Vallauris, 2004, p. 97-128.

Marty et al. 2006 : MARTY (F.), BLAISE (E.), FURESTIER (R.), GILABERT (C.), LEMERCIER (O.), PEREZ (B.) - Sivier, DFS d'opération de sondage, Musée Archéologique Intercommunal, SRA de PACA, 2006, 131 p.

Marty et al. 2010 : MARTY (F.), LEMERCIER (O.), FURESTIER (R.), BLAISE (E.) - Premiers résultats sur l'occupation néolithique du site de Sivier (Istres, Bouches-du-Rhône). In : Lemercier (O.), Furestier (R.), Blaise (E.) dir., 4e Millénaire. La transition du Néolithique moyen au Néolithique final dans le sud-est de la France et les régions voisines, 2010, p. 91-108. (Monographies d'Archéologie Méditerranéenne, 27).

Moliner 2003 : MOLINER (M.) DIR. - La nécropole de Sainte-Barbe à Marseille (IVe s. av.J.-C. - IIe s. ap. J.-C.), (Études Massaliètes, 8), Edisud CCJ, 2003, $487 \mathrm{p}$.

Nin 2006 : NIN (N.) dir. - La nécropole méridionale d'Aix-en-Provence. (Revue Archéologique de Narbonnaise, suppl. 37), 2006, 240 p.

Pautreau 2010 : PAUTREAU (J.-P.) - Crémations traditionnelles en Thaillande du nord. In : Porra-Kuteni (V.) dir., Des vases pour l'éternité. La nécropole de Negabous et la Protohistoire du Roussillon, Catalogue d'exposition, Conseil Général des Pyrénées-Orientales - Pôle Archéologique Départemental, 2010, p. 118-126.

Trément 1999 : TREMENT (F.) - Archéologie d'un paysage, Les étangs de Saint-Blaise (Bouches-du-Rhône), (Documents d'Archéologie Française, 74), 1999, $314 \mathrm{p}$.

Vecchione, Duflot 2003 : VECCHIONE (M.), DUFLOT (L.) - Chemin de Saint-Jean à Istres (Bouches-du-Rhône), DFS de fouille d'évaluation archéologique, INRAP, SRA de PACA, 2003, 18 p. 


\section{La logique de l'écriture}





\section{L'écriture après l'économie ? Peuples et réponses"}

\section{Javier de Hoz}

\section{Resumen}

La lengua ibérica se considera tradicionalmente como una de las lenguas vehiculares que permitieron, durante la Edad del Hierro, el desarrollo de intercambios económicos entre el nordeste de la península ibérica y el mediodía galo. Al revisar la documentación de un yacimiento muy importante para la epigrafía paleohispánica, Ensérune en el Lenguadoc occidental, es necesario reevaluar la cuestión del estatus del ibérico como lengua vehicular. Entre las diversas escrituras disponibles allí, se eligió claramente la escritura paleohispánica levantina. Tanto el estudio onomástico de esas inscripciones, el de los soportes como el del contexto arqueológico permiten precisar los usos gráficos y los agentes, en particular en el marco de los intercambios intercomunitarios entre pueblos locales.

Palabras-claves: epigrafía prerromana, onomástica, lengua paleohispánica, Ensérune, semi-silabario levantino, alfabeto etrusco, escritura gallo-griega

\footnotetext{
Abstract

There are different functions that motivated the creation of a new script; we can speak of the economical, civilising, prestige and religious models. In the ancient world the economical model is the most frequently found, but there are other alternatives. Examples of the economical model are the oldest Greek alphabet and the Iberian and Tartessian scripts. Examples of other alternatives are the Cretan and Spartan alphabets, the Celtiberian script and the GalloGreek alphabet.
}

Keywords: Writing, original function, Celtiberian script, Cretan alphabet, Gallo-Greek alphabet, Greek alphabet, Iberian script, Spartan alphabet, Tartessian script

\footnotetext{
* Cet article a été réalisé dans le cadre des projets du Ministerio de Ciencia e Innovación espagnol FFI2009-07645, dirigé par Marisa del Barrio, et FFI2009-13292-C03-02, dirigé par J. Gorrochategui et E. Luján. J'ai une grande dette envers Coline Ruiz Darasse qui a revu le texte français et m'a sauvé de beaucoup d'erreurs.
} 
1. Le seul cas de création d'une écriture dont nous puissions suivre l'évolution pas à pas, en partant d'un système pour conserver et transmettre l'information prélittéraire jusqu'à une écriture proprement dite, est celui de l'écriture cunéiforme.

Nous savons que l'objectif, tant de ses antécédents non graphématiques que de l'écriture cunéiforme, était le contrôle de l'information économique et que c'est seulement plus tard que d'autres classes de textes apparurent pour arriver, enfin, aux textes religieux et littéraires qui se sont accumulés dans la bibliothèque d'Assurbanipal.

Dans d'autres cas de création ou d'adoption d'une écriture préexistante, nous n'avons pas assez d'informations sur ce processus et ses motivations, mais, depuis quelque temps, contrairement aux idées répandues antérieurement et encore très populaires, on insiste sur l'idée que rien dans nos données ne s'oppose à ce que l'origine de l'écriture ait également été le désir de contrôler les ressources économiques disponibles ou les transactions effectuées (Postgate, Wang, Wilkinson 1995). C'est apparemment l'explication historiquement la plus plausible. En particulier, comme nous allons le voir, le contact entre commerçants de langues différentes en diverses occasions a fourni un contexte favorable à l'adoption de l'écriture par un groupe à qui elle faisait défaut auparavant à partir d'un autre qui la possédait déjà. Je dois admettre que jusqu'à récemment, j'ai donné comme évidente cette vision, disons « commerciale », mais que je suis à présent en train de reconsidérer.

Il est vrai que, à une date ultérieure, et presque jusqu'à aujourd'hui, nous connaissons de nombreux cas dans lesquels une écriture a été adoptée ou inventée avec des objectifs très différents : aider à l'expansion d'une religion, fournir à un peuple primitif, mais en contact avec une culture technologiquement plus avancée, généralement de style occidental, les moyens de se développer et de s'intégrer, ou encore satisfaire le désir d'un souverain qui a vu dans l'écriture un élément essentiel pour son prestige ; il s'agit de modèles que nous pourrions appeler religieux, civilisateur, et de prestige, par opposition à celui mentionné précédemment qui serait le modèle économique ou même commercial. Mais, dans le monde antique, le modèle religieux ne semble pas avoir existé et le modèle civilisateur semble exclu. Pour celui du prestige, il n'y a aucun cas évident : comme il ne peut pas a priori être exclu, il vaut la peine d'en envisager la possibilité.

La question des motivations, qui conduisent, par emprunt ou par invention, au développement de l'écriture, et celle de ses caractéristiques les plus communes, sont avant tout des questions pour lesquelles il faut rester dans le domaine des hypothèses plausibles, à partir d'indices peu nombreux et de ce que nous savons sur le contexte historique dans lequel l'écriture est utilisée. En général, les supports les plus fréquents sont périssables et ceux qui sont durables, soit correspondent à des usages de prestige et à des fins symboliques (le plus souvent des inscriptions sur pierre ou en bronze), soit sont marginaux et secondaires, comme c'est le cas des graffiti omniprésents sur céramique.

Aussi, les considérations qui suivent ne peuvent correspondre à des résultats avérés, mais sont des interprétations simplement plausibles, qui au mieux ne connaissent aucune alternative plus économique ou justifiée.

2. Les cas que je traiterai ont des caractéristiques différentes, correspondant à des sociétés aux complexités également très distinctes, que nous connaissons à partir d'informations pouvant varier considérablement en volume et en clarté. J'espère que cela permettra au moins une approche de la complexité du problème et de la variété des attitudes et réponses données dans le monde antique au phénomène de l'écriture.

Nous ne tiendrons pas compte ici de l'évolution exceptionnelle de ce phénomène à Athènes au $\mathrm{V}^{\mathrm{e}}$ siècle et dans l'épigraphie hellénistique ; sa réception à Rome deviendra l'epigraphic habit, caractéristique du monde gréco-romain (MacMullen 1982). Dans la perspective où nous nous plaçons ici, en pensant à l'épigraphie grecque de l'époque classique, nous devons considérer ce que peuvent offrir les diverses poleis qui n'ont pas participé à ce que j'appelle « le modèle athénien » (de Hoz 2004a), et qui se prêtent plus facilement à la comparaison avec les épigraphies italiques, anatoliennes ou celles de la Méditerranée occidentale.

3. Je voudrais d'abord m'occuper d'une écriture dont l'origine (sinon la source) est très obscure, mais pour laquelle les documents qui nous sont parvenus indiquent clairement que son rôle était essentiellement d'ordre économique ; ils nous disent que cette écriture a dû presque certainement trouver son origine dans ce domaine. Je veux parler de l'écriture la plus abondamment représentée parmi les écritures paléohispaniques : l'écriture ibérique du Levant ${ }^{1}$.

Nous connaissons l'écriture ibérique par près de deux mille inscriptions dont la distribution est en partie très normale, car la plupart sont de simples graffites, et en partie très particulière. Bien qu'il existe des types communs à d'autres épigraphies méditerranéennes - inscriptions funéraires, signatures d'artisans, dipinti accompagnant des scènes figuratives

1 Corpus de référence : MLH III ; additions dans Moncunill 2007, p. 437-50. En général de Hoz 2011. 
sur céramique -, les inscriptions qui les représentent sont rares. D'un autre côté, plusieurs types couramment présents (en plus ou moins grand nombre) dans d'autres cultures sont totalement (ou presque totalement) absents : les lois et autres textes institutionnels et, apparemment, les textes votifs. En outre, certains des types mentionnés précédemment apparaissent uniquement à une date avancée et au cours du processus de romanisation.

En revanche, le plus caractéristique des documents épigraphiques ibériques est la plaque de plomb inscrite. Manifestement, ce n'est pas une création originale des Ibères, qui ont simplement adopté un usage grec avec des antécédents orientaux. Toutefois, nous connaissons à présent davantage de plombs inscrits ibériques que de plombs grecs, abstraction faite des defixiones et de certaines séries spéciales, comme les plombs de la cavalerie athénienne ou les plombs civiques de Camarine. En tout cas, l'origine grecque de ce type épigraphique nous aide à apprécier les plombs ibériques, étant donné le peu que nous pouvons comprendre de la langue ibérique.

Les plombs grecs sont, pour la plupart, des documents commerciaux et des lettres d'affaires relatives au monde des commerçants. Les caractéristiques extérieures des plombs ibériques coöncident avec celles des plombs grecs, ce qui permet de supposer que leurs fonctions étaient les mêmes. Cette hypothèse se renforce, avec d'autres indices que je ne discuterai pas ici, par la présence fréquente de chiffres dans les plombs ibériques et par leurs contextes archéologiques qui appartiennent au domaine privé et quelquefois aux espaces de stockage.

Il semble donc que les utilisateurs de l'écriture ibérique ont été essentiellement des commerçants ou, du moins, des personnes ayant des intérêts économiques qui ont utilisé l'écriture pour des annotations relatives à ces intérêts : inventaires, contrôle de commandes ou de dettes, conservation ou transmission de renseignements sur les marchandises et les transactions.

Il ne semble pas plausible que l'écriture ibérique ait été créée avec une finalité et qu'elle ait été appliquée, à partir du moment même où sont conservés les textes, entièrement avec un autre dessein. Son origine doit donc être recherchée dans le domaine économique, probablement en particulier chez les commerçants. Nous avons ainsi, de façon particulièrement claire et bien documentée, un exemple d'une écriture dont l'origine correspond au modèle économique.

4. Il y a d'autres cas qui, selon moi, peuvent être considérés comme tout aussi clairs, mais dont la documentation n'est pas aussi importante. C'est le cas de l'alphabet grec et de l'écriture tartessienne.
Ce n'est évidemment pas le lieu de discuter en détail le problème complexe de l'origine de l'alphabet grec $^{2}$. Je voudrais juste dire ceci : je pense que l'environnement dans lequel des personnes bilingues, qui connaissaient l'écriture phénicienne consonantique et l'ont adaptée pour écrire la langue grecque, créant ainsi le premier alphabet, a été celui des ports de commerce internationaux comme Al Mina et Kommos. L'alphabet est bien placé au sein du complexe des phénomènes que nous appelons « orientalisants », tous dérivés à des degrés divers des nouvelles relations commerciales établies entre la Grèce et l'Orient depuis le $\mathrm{IX}^{\mathrm{e}}$ siècle. Ces phénomènes donnent lieu à un nouveau dynamisme économique, qui se diffuse par la suite chez d'autres peuples de la Méditerranée, y compris chez les Tartessiens atlantiques.

Ces relations commerciales ne sont pas uniformes dans toutes les régions de la Grèce. L'alphabet est certainement né chez des Grecs activement impliqués dans le commerce orientalisant, probablement des Eubéens, et non pas chez des bénéficiaires passifs de ce commerce. Sa réception dans d'autres parties de la Grèce pourrait être due à des motivations et des circonstances différentes. Ce qui importe ici, c'est que le premier alphabet grec, dont sont issus les alphabets locaux, doit son origine au modèle économique. Cela concorde avec le contexte historique, même si les plus anciens témoignages sont d'abord de banals graffites de propriété, puis des textes déjà plus sophistiqués avec des fonctions diverses (et parfois spécifiquement grecques, comme les inscriptions ludiques en vers) qui ne laissent pas voir les usages économiques que je crois premiers. Naturellement, ils dépendaient de supports périssables qui ne laissèrent une empreinte directe abondante qu'à des époques postérieures, dans des conditions écologiques qui n'existent pas en Grèce même.

Plus maigre encore est le témoignage de l'épigraphie tartessienne, presque inexistante bien que les Tartessiens soient ceux à qui nous attribuons la première écriture paléohispanique, où prennent leurs racines toutes les écritures qui appartiennent à cette famille, y compris l'ibérique levantine dont nous avons déjà parlé. Je ne ferai pas une présentation détaillée du problème, qui nécessiterait un développement plus vaste que ne le permettent les limites de ce travail ; je renvoie à des travaux récents où j'arrivais à une conclusion plausible (de Hoz 2010). L'écriture tartessienne serait une création de l'aristocratie

2 Une sélection bibliographique où on peut trouver des idées très différentes : Amadasi dans Baurain, Bonnet, Krings 1991 ; Baurain, Bonnet, Krings 1994 ; Bagnasco, Cordano 1999; Brixhe 1991 et dans Christidis 2007 ; Csapo, Johnston, Geagan 2000 ; Heubeck 1979 (encore à lire) ; de Hoz 1983, 2004 ; Johnston 2003 ; Lombardo 1998 ; LSAG ; Naveh 1982, 1991 ; Powell 1991 ; Sass 1988, 1991 ; SchnappGourbeillon 2002, p. 255-314 ; Wachter 1989 ; Woodard 1997. 
locale et des marchands à son service pour gérer une économie en expansion, résultat des échanges croissants avec les Phéniciens. Naturellement, le modèle utilisé a été l'écriture consonantique phénicienne.

5. Cela signifie que l'énigmatique et presque invisible écriture tartessienne peut être mieux expliquée par le modèle économique que par toute autre hypothèse. Il existe toutefois des cas où l'application du modèle économique est particulièrement difficile : par exemple les cas de l'alphabet crétois, de l'alphabet laconien et de l'écriture celtibérique. Il est vrai que les alphabets crétois et laconien sont simplement des variantes locales de l'alphabet grec, dont nous avons déjà parlé. Mais, comme je l'ai dit, une fois créé l'alphabet grec, sa réception dans les différentes régions de langue grecque obéira aux conditions de chaque période et aux traditions culturelles, parfois sensiblement différentes au sein de l'ensemble des caractéristiques grecques communes à chacune de ces régions.

L'île de Crète semble avoir été l'une des premières régions de la Grèce, en dehors de la zone d'origine, à recevoir l'alphabet grec, mais le témoignage de ses inscriptions est extrêmement particulier. Comme dans le cas de Tartessos, les graffiti sont rares, mais en retour, le nombre de textes juridiques est remarquable, et ce très tôt. En fait, la première loi grecque conservée, datant de la première moitié du $\mathrm{VIII}^{\mathrm{e}}$ siècle, vient de Drèros en Crète (M-L 2 ; Nomima I, 81). Des études récentes ont dessiné une image de l'usage de l'écriture dans la Crète archaïque qui semble très plausible: celle d'une société conservatrice et aristocratique dans laquelle l'alphabétisation est très peu développée, mais où l'on donne une grande importance à l'exposition de la loi, autorité traditionnelle de la polis gouvernée par une minorité d'aristocrates (Stoddart, Whitley 1988 ; Whitley 1997). Comme monument, elle a une valeur symbolique qui rappelle l'affichage des textes commémorant les actes ou les bâtiments du souverain dans les sociétés de l'Orient, où seule une fraction de la population était en mesure de lire ces textes.

Le problème est de savoir comment s'est produite la réception de l'écriture dans une société qui n'était pas parvenue à trouver pour elle d'autres usages que cette manifestation purement symbolique et presque totalement dénuée de sens pratique. Le problème de la possible influence orientale est important, mais nous ne pouvons nous satisfaire de cette solution, car les Crétois ont adopté le même alphabet que celui des autres régions grecques, dans une version, certes tout à fait particulière, mais qui s'explique par des traits du dialecte crétois et non par une tentative d'originalité qui répondrait à des raisons culturelles ou sociales.
Il ne semble pas possible qu'à une date très précoce, quand l'alphabet n'était sans doute pas encore connu dans de nombreuses parties de la Grèce (car les plus anciennes inscriptions crétoises datent du VIII ${ }^{e}$ siècle), les Crétois aient connu l'alphabet et l'aient adopté tout simplement pour lui donner un usage cérémoniel. Je ne pense pas que nous puissions parvenir à une solution réelle du problème, mais je crois que nous pouvons soulever quelques hypothèses raisonnables.

Certains éléments du modèle économique existent en Crète, une île pionnière dans le mouvement orientalisant grec où nous avons un excellent exemple du port of trade archaïque à Kommos, où arrivaient des Phéniciens et des Grecs déjà alphabétisés. En fait, l'île a fourni quelques inscriptions phéniciennes de date ancienne; il y a des graffiti grecs à Kommos, mais pas seulement en alphabet crétois ${ }^{3}$. Le problème est que l'île semble avoir joué un rôle très passif du point de vue du commerce. Les échanges étaient importants : elle recevait des commerçants de provenances diverses, mais peut-être ceux-ci étaient les seuls responsables de ces échanges. Bien sûr, ces commerçants avaient besoin de partenaires sur l'île et, étant donné le type de société et d'organisation politique clairement aristocratiques, ces acteurs ont dû être membres de groupes privilégiés qui contrôlaient les produits de l'île pouvant être exportés, ou membres des oikoi qui les représentaient. Autrement dit, la situation a pu être similaire à celle que l'on reconstruit pour la société tartessienne, et l'écriture a pu être adoptée pour contrôler l'économie, même si celle-ci était très statique, par le biais d'inventaires et d'annotations de marchandises entrantes et sortantes. Ce serait un cas du modèle économique, mais dans lequel la minorité d'usagers de l'écriture aurait trouvé immédiatement une autre utilisation très différente, qui aurait supprimé le monopole de l'utilisation d'origine.

Alternativement, car il semble qu'en aucune façon l'écriture ait été indispensable aux aristocrates crétois pour gérer leurs propriétés, nous pourrions trouver une réponse en-dehors du modèle économique. Les Crétois, ou plutôt l'aristocratie crétoise, pourraient avoir vu dès le départ dans l'écriture un véhicule pour les monuments cérémoniels. Cela impliquerait toutefois qu'ils eussent établi des contacts suffisamment étroits avec une société déjà en possession de l'alphabet pour remarquer les potentialités de l'écriture et pour pouvoir l'adopter. Bien que n'étant pas un intervenant actif dans le commerce international de cette époque, la Crète ne fut pas isolée ; les Crétois, sans être commerçants eux-mêmes, étaient des pirates et recevaient fréquemment des marins

3 Inscription phénicienne : Sznycer 1979 ; Amadasi 1987, p. 13-6. Kommos : Csapo 1991 ; 1993 ; Csapo, Johnston, Geagan 2000. 
d'autres régions du monde grec, d'Orient et d'Égypte ; il y avait sans doute des liens d'hospitalité entre les membres de l'aristocratie crétoise et ceux des autres aristocraties grecques, de sorte que la transmission à ce niveau social et dans lequel, dès le départ, on aurait considéré l'utilisation cérémonielle de l'alphabet n'est pas invraisemblable.

Le problème est donc réduit à celui du modèle de l'alphabet dont est dérivé l'alphabet crétois, une question très complexe que je n'ai pas le temps de développer. Qu'il suffise de dire que le préjugé exprimé par le nom sous lequel sont connus les alphabets crétois, ainsi que celui de Théra et de Mélos, les alphabets «primitifs », est basé uniquement sur la localisation géographique de l'île, sur l'absence de certains des signes normaux dans d'autres alphabets grecs et sur quelques variantes particulières. Mais aucun de ces faits n'est particulièrement important. À l'exception de Théra et de Mélos, les relations que l'on a tenté d'établir entre l'alphabet crétois et les autres alphabets, en considérant en général celui-là comme donneur, peuvent bien avoir marché dans une direction contraire.

6. Le cas de Sparte (Cartledge 1978 ; Boring 1979 ; Millender 2001) peut sembler similaire à celui de la Crète, en suivant un point de vue très souvent exprimé et qui a ses racines dans l'Antiquité. Mais ce parallèle est trompeur, puisqu'il n'existe aucune similitude entre les inscriptions réellement préservées dans les deux zones. Les inscriptions archaïques en alphabet laconien sont relativement abondantes et variées, bien qu'avec une large représentation des inscriptions votives. Nous ne trouvons pas en eux la prépondérance des textes juridiques qui caractérise la Crète ; en fait, c'est à peine si l'on peut mentionner quatre textes de lois ou contenant quelque type de résolution publique ( $L S A G$ p. 186). Cependant, dans le cas de Sparte, nous disposons d'une documentation littéraire majeure qui montre qu'il y avait des lois écrites et d'autres documents officiels. L'usage de l'écriture était très répandu, surtout dans l'administration des affaires publiques, et les Spartiates, membres de l'oligarchie militaire qui contrôlait le pays, devaient être largement alphabétisés. La différence avec la Crète est cependant claire : lois et autres documents publics ont été écrits pour des raisons pratiques et donc sur des supports non cérémoniels, conservés dans des archives, tandis qu'en Crète, ils ont été écrits pour des raisons symboliques et cérémonielles et exposés au public.

La question de savoir comment les Spartiates ont reçu l'écriture n'est pas facile et porte sur deux points car les Spartiates de plein droit et les périèques ont utilisé le même alphabet laconien. Il est évident que le commerce n'était pas ce qui a mis les premiers en contact avec l'alphabet, mais ç'aurait pu être le cas pour les derniers. Cependant, il y a plusieurs raisons de croire que les périèques ne furent pas les introducteurs de l'écriture à Sparte. Il n'existe pas de témoignages épigraphiques significatifs pouvant leur être attribués, même s'il est probable que les dipinti sur poterie laconienne soient l'œuvre de périèques. Il ne semble pas que leurs activités mercantiles, incontestables, puissent avoir eu une vaste emprise et atteindre des zones reculées. Les témoignages qui parlent d'une ample alphabétisation laconienne se réfèrent fondamentalement aux Spartiates et ce sont eux qui ont dû importer une écriture qui a eu une grande influence sur leur environnement, car elle semble s'être diffusée de Sparte en Messénie, en Arcadie, en Élide à Olympie et en Argolide orientale. Mais il est difficile de déterminer d'où ils ont reçu cet alphabet. L. H. Jeffery proposait deux alternatives, Rhodes et Delphes, qui pourraient fournir des modèles aux particularités laconiennes. L'alternative rhodienne serait basée sur d'hypothétiques relations d'affaires qui n'ont aucun fondement, en-dehors de la présence de poteries laconiennes à Rhodes, preuve seulement de l'importance de la Laconie en tant que centre de production aux temps archaïques, seulement dépassé par Athènes et Corinthe. Cela ne nous dit rien sur l'identité de ceux qui ont transporté ces vases. L'alternative de Delphes a une base beaucoup plus solide et nous introduit tout à fait dans le modèle d'alphabétisation spartiate.

Très tôt, les Spartiates montrent pour l'écriture un intérêt supérieur à celui des autres états grecs, grâce à l'oracle de Delphes, qu'ils consultent régulièrement. Nous savons que les réponses reçues ont été soigneusement préservées sous la garde de magistrats spéciaux, les quatre pythioi, qui avaient la mission de faire des enquêtes pour le compte de l'État spartiate. L'hypothèse de L.H. Jeffery ( $L S A G 385)$ selon laquelle ces consultations auraient pu donner lieu à l'emprunt de l'écriture, emprunt dont nous pourrions préciser même la date en supposant que les plus anciens pythioi ont été ceux qui l'ont introduite à Sparte, est plausible. Elle a en sa faveur de faire intervenir les textes laconiens les plus anciens que nous connaissions, car la fameuse rethra de Lycurgue ne peut être séparée des réponses oraculaires.

$\mathrm{Si}$ nous acceptons cette hypothèse, l'adoption de l'écriture est entièrement indépendante de raisons économiques, puisqu'elle a dès le départ vocation à fournir un outil pratique pour le fonctionnement de l'État. Ce nouveau modèle, à ajouter aux quatre autres mentionnés, pourrait s'appeler «institutionnel ». Bien sûr, comme dans d'autres cas, l'utilisation pratique fut bientôt accompagnée par au moins une utilisation symbolique très abondante : les inscriptions votives, en particulier celles liées aux victoires sportives obtenues par les Spartiates. 
Elles trouvent des parallèles avec celles trouvées dans d'autres états aristocratiques, comme celui de l'Athènes archaïque, mais furent rejetées par les aristocrates crétois, plus sévères, qui étaient davantage intéressés par l'exaltation de l'état symbolisé par ses lois que par leur propre exaltation.

7. Dans le cas de l'écriture celtibérique, nous trouvons une situation quelque peu similaire à celle de l'écriture crétoise archaïque, à savoir une épigraphie dominée par des inscriptions à caractère juridique au sens large et dans laquelle les graffites ne sont pas abondants ${ }^{4}$. Nous connaissons quelques bronzes qui semblent être des lois ou des dispositions à caractère officiel, des ateliers monétaires qui frappent monnaie avec une légende concernant la ville et un grand nombre de tessères d'hospitalité. Le modèle des légendes monétaires semble être ibérique, mais l'ensemble du processus de monétisation a été largement inspiré par Rome. Les documents officiels sur bronze montrent clairement dans leurs traits extérieurs l'influence romaine. Quant aux tessères d'hospitalité, elles répondent sans aucun doute à une tradition institutionnelle indigène visible dans le vocabulaire technique, purement celtibère, et dans les parallèles non écrits d'autres peuples d'origine indo-européenne et culturellement proches, comme les Gaulois. Mais, en dépit de quelques particularités formelles de certaines tessères, elles suivent fondamentalement le modèle des tesserae latines républicaines.

Contrairement à cette influence romaine que montrent les types épigraphiques, en général reflet de relations institutionnelles, l'écriture utilisée, à l'exception d'un petit nombre de documents tardifs écrits en alphabet latin, est ibérique, utilisée en éliminant certains signes et avec certaines conventions spécifiques nécessaires pour adapter les signes syllabiques à une langue indo-européenne très différente de l'ibérique par la phonologie et la structure syllabique.

Évidemment, l'utilisation simultanée de l'écriture ibérique et des usages latins est un problème qui ne peut être dissocié de la fonction d'origine de l'écriture chez les Celtibères, c'est-à-dire de la raison pour laquelle ils ont commencé à écrire. Il semble que dans la moyenne vallée de l'Èbre, en territoire non celtibérique, on ait commencé à écrire bien avant le début du $\mathrm{II}^{\mathrm{e}}$ siècle, qui correspond plus ou moins au moment où les Celtibères ont commencé à écrire. Les usages de l'épigraphie ibérique de la zone ne sont pas différents de ceux du monde ibérique en général, dominés par une épigraphie privée, d'ordre économique, totalement différente de celle qui

4 J. de Hoz 1986 ; 1995 ; 2001 ; F. Beltrán 1993 ; 1995 ; 2005 ; W. Meid 1994 ; F. Burillo 2007. caractérise les Celtibères. Dans ces circonstances, et compte tenu de l'aspect romain des inscriptions celtibères les plus typiques, je pense qu'il y a deux alternatives.

Le contact des Celtibères avec l'épigraphie ibérique est antérieur au contact avec les Romains et a provoqué l'adoption des usages courants ibériques, en même temps que celle de l'écriture. Mais pour des raisons que l'on ne peut deviner, on a opté pour des supports non durables, des tissus ou des matériaux similaires, qui peuvent également avoir été utilisés par les Ibères ; plus tard, une fois consolidée l'utilisation de l'écriture ibérique, le contact avec le monde romain, en particulier le contact des groupes dirigeants celtibères avec les représentants officiels du monde romain, conduit à l'apparition des inscriptions que nous connaissons, en grande partie inscrites sur bronze et donc susceptibles de durer.

L'existence d'un premier et unique plomb celtibère - une lettre sans aucun doute, qui répond pleinement au modèle ibérique - vient appuyer cette hypothèse (Lorrio, Velaza 2005 ; Prósper 2007) ; si cette inscription est préservée, il est possible qu'il y en ait beaucoup d'autres semblables qui ont été perdues. Cependant, il existe plusieurs arguments contre cette hypothèse. Il semble peu probable que les Celtibères aient à peine utilisé un matériau aussi aisément disponible que les tablettes de plomb, alors qu'ils créaient fréquemment des documents pour lesquels il aurait été approprié. D'autre part, si le comportement épigraphique initial avait été similaire pour les Celtibères et pour les Ibères, nous trouverions beaucoup plus de graffiti. Enfin, la progression de l'épigraphie ibérique dans la vallée de l'Èbre semble avoir accompagné l'avancée des légions romaines : les commerçants ibériques les fournissaient en marchandises transportées sur les côtes de l'Espagne par les marchands italiques, qui n'étaient pas encore organisés pour pénétrer à l'intérieur. Globalement, l'hypothèse d'une épigraphie celtibérique de type ibérique qui n'aurait pas laissé de traces et qui aurait été rejointe seulement plus tard par les types épigraphiques de tradition romaine ne semble pas très probable.

Une seconde alternative est basée sur des données tangibles du point de vue épigraphique, mais elle implique une reconstruction historique fondée uniquement sur des preuves circonstancielles. Il y a de bonnes raisons de croire que la langue ibérique a été une lingua franca, et non vernaculaire, dans une grande partie du territoire méditerranéen où l'on retrouve l'épigraphie ibérique. On peut dire la même chose de la vallée de l'Èbre. La réception de l'écriture ibérique par les Celtibères a dû être le fait de personnes bilingues, qui ont utilisé le celtibère comme langue maternelle ou de convenance, et la langue ibérique comme langue véhiculaire, même si elle 
a été dans certains cas leur langue vernaculaire. Les circonstances dans lesquelles sont apparues ces personnes bilingues ne peuvent être reconstruites avec certitude, en l'absence de données précises, mais il est possible de proposer une hypothèse vraisemblable. L'expansion apparente de la langue ibérique qui accompagne l'avancée romaine à l'intérieur des terres ne veut pas seulement dire que les Romains n'ont mis aucun obstacle à l'utilisation de cette langue, mais probablement, comme cela s'est produit en d'autres occasions où une puissance impériale occupait un territoire dans lequel il y avait déjà une langue véhiculaire, l'ont-ils encouragée comme un moyen pratique d'interagir avec une population complexe parlant des langues différentes. Dans ces circonstances, il ne serait pas surprenant que, dans la partie orientale de la Celtibérie, la langue ibérique en soit venue à être la langue commune utilisée par les classes privilégiées celtibères, en traitant non seulement avec les commerçants qui ont introduit les marchandises méditerranéennes qui les intéressaient, mais aussi avec les intermédiaires indigènes de la puissance romaine.

Nous avons des preuves que, vers 100 av. J.-C., deux inscriptions sur mosaïque à caractère édilitaire, œuvre de grands entrepreneurs celtibères, ont été écrites en langue ibérique (MLH IV, K.5.3, K.28.1). En outre, le troisième bronze de Botorrita, une liste de personnes de la civitas celtibérique de Contrebia Belaisca, qui devaient au moins appartenir à la classe moyenne de la communauté, comprend de nombreux noms ibériques (MLH IV, K.1.3 ; cf. J. Untermann in Beltrán, de Hoz, Untermann 1996).

Ceci étant, il est normal que des Celtibères, capables de parler la langue ibérique et en contact étroit avec des locuteurs ibériques lettrés, en arrivent à sentir un intérêt pour l'écriture et, dans certains cas, à écrire en ibérique. L'étape suivante aurait été l'adaptation de l'écriture à leur propre langage, suivie par une nouvelle innovation un peu plus tard, dans laquelle les groupes dirigeants celtibériques seraient arrivés à un contact plus étroit avec les Romains eux-mêmes. Cette nouvelle étape aurait été l'adoption de certaines pratiques de l'épigraphie romaine idéalement adaptées au caractère de la société celtibérique, fortement institutionnalisée et dans laquelle des relations comme les liens de l'hospitalité jouaient un rôle prioritaire (Häussler (dir.) 2008).

Dans ce second scénario, il ne serait pas nécessaire de prendre en considération les marchands celtibères qui, dans leurs rapports avec les Ibères, se rendent compte de l'utilité de l'écriture pour leurs opérations et, profitant du bilinguisme professionnel qu'ils possédaient déjà, adoptent cette technique comme un outil de travail apprécié. En fait, les marchands celtibères, un groupe qui a dû exister, mais qui semble n'avoir joué aucun rôle important dans la société celtibère, ne sont peut-être pas du tout intervenus dans le processus d'adoption de l'écriture ; dans ce cas, nous ajouterions une autre exception au modèle économique le plus fréquent avec lequel nous avons commencé.

8. Compte tenu des différents cas considérés, nous devons maintenant aborder une écriture qui a occupé longtemps une place privilégiée dans le travail de Michel Bats, à qui nous devons une grande partie des connaissances et des idées qui nous permettent de traiter la question (Bats 1988, 1988 (=1990), 2000, 2003, 2004, 2011) ; je parle évidemment de l'écriture gallo-grecque, ou plus spécifiquement du problème de l'adoption de l'alphabet de Marseille par les Gaulois.

Le problème initial posé ici est d'ordre chronologique. $\mathrm{Au} \mathrm{IV}^{\mathrm{e}}$ siècle, certains Gaulois qui vivaient dans le Languedoc ont appris la langue et l'écriture ibériques, nous laissant des textes reconnaissables par l'anthroponymie, qu'on peut facilement insérer dans le répertoire gaulois (Untermann 1969; Correa 1993) ; mais à l'est de l'Hérault, il n'y a pas de situation comparable. Ce n'est qu'au III ${ }^{\mathrm{e}}$ siècle que nous commençons à trouver des Gaulois qui nous ont laissé leur nom dans l'alphabet grec.

L'épigraphie gallo-grecque proprement dite, c'està-dire une épigraphie qui utilise une écriture adaptée de l'alphabet grec afin de bien transcrire la langue gauloise, n'apparaît qu'au II' siècle ${ }^{5}$. La lenteur des Gaulois de la Provence à adopter l'écriture, qui contraste avec le comportement de ceux du Languedoc et de beaucoup d'autres peuples de la Méditerranée, soulève un problème qui n'est pas résolu. Michel Bats croit, de façon plausible, que la langue grecque a été la langue véhiculaire dans la région, ce qui pourrait expliquer que nous n'ayons aucun témoignage écrit du gaulois, parce que l'écrit aurait été exclusivement grec. Les graffiti du III ${ }^{e}$ siècle seraient l'œuvre de Gaulois alphabétisés en grec. L'apparition de l'épigraphie gallo-grecque au $\mathrm{II}^{\mathrm{e}}$ siècle serait une manifestation du sentiment identitaire né au moment où l'on commençait à sentir le poids de la domination romaine.

Cette hypothèse pose différentes alternatives du point de vue de cette communication. Il a peut-être existé une première épigraphie gauloise, mais en grec, qui serait devenue épigraphie gauloise de langue gauloise; ou bien l'écriture gallo-grecque pourrait avoir été créée pour des usages non épigraphiques qui seraient apparus seulement plus tard. La première alternative semble peu probable, car il n'y a aucun témoignage de cette épigraphie gauloise en grec, sauf pour quelques graffiti

5 Lejeune 1985 ; 1988 ; 1990 ; Lejeune, Lambert 1996; Meid 1989 ; 1992 ; Mullen 2008 ; de Hoz 2010a. 
et quelques-unes des inscriptions votives du sanctuaire d'Aristée, qui sont déjà de date tardive (Coupry, Giffault $1982 ; 1984 ;$ IGF $\left.68^{1-48}\right)$.

La seconde alternative est possible, mais, en tout cas, la question importante est que dans l'épigraphie gallo-grecque, l'usage public destiné à durer est créé tardivement, et que cette épigraphie est de même type que l'épigraphie la plus usuelle parmi les peuples qui ont adopté l'alphabet grec, car, outre les graffites omniprésents, elle est composée par les genres de documents habituels dans ces cas : majoritairement des stèles funéraires et des inscriptions votives. C'est une raison pour chercher d'autres motivations à l'adoption de l'écriture en plus du sentiment identitaire.

Il y a,par ailleurs, d'autres témoignages épigraphiques d'usages de l'écriture gallo-grecque à caractère simplement utilitaire. La tablette de plomb d'Elne ${ }^{6}$, malgré son mauvais état qui rend impossible toute interprétation, appartient au même type que les plombs ibériques qui ont été occasionnellement écrits par ou pour des Gaulois. La jarre de Villevieille (Gard, RIG G-281) présente, près du nom du potier, des symboles sans interprétation possible pour le moment, mais qui sont sans doute en partie des indications de quantité. Le torque de Mailly-le-Champ (RIG G-275-8), trouvé plus au nord mais provenant sans doute de la région d'Agen, car il appartenait à un trésor des Nitiobroges, a servi pendant un certain temps comme support pour des annotations où les nouvelles offrandes ou les apports à un trésor sacré ou civique étaient énumérés d'une façon informelle. Et naturellement, il faudrait prendre en considération la monnaie, mais ceci nécessiterait une étude propre.

Mis à part ces maigres témoignages des autres usages de l'écriture gallo-grecque, reste le problème fondamental des textes littéraires où des documents litteris graecis sont mentionnés. Ces documents sont tantôt des textes administratifs, tantôt des lettres privées, ou bien enfin ils semblent avoir parfois, comme le torque de Mailly-leChamp, un caractère économique. La tournure litterae grecae est en soi très ambiguë, comme Michel Bats l'a montré (Bats 2003, 370-1). Dans certains contextes, elle signifie sans doute « en lettres de l'alphabet grec », dans d'autres, elle désigne des textes en langue grecque.

Mais dans les cas intéressants pour nous, particulièrement les fameuses listes trouvées par César dans le camp helvète, nous dépendons du contexte historique pour interpréter la tournure litteris graecis car le contexte textuel est ambigu. Je pense que ce contexte renvoie nettement non à la langue grecque mais à l'écriture grecque, c'est-à-dire, langue gauloise en écriture grecque.

6 Lejeune 1960 ; Schmoll 1963, p. 49-50 ; MLH II, p. 379-80.
Pour voir avec plus de clarté le problème, il faut se placer chez les Helvètes, c'est-à-dire en Suisse. Le grec n'était pas une langue véhiculaire dans la région et son influence a dû être tout au plus très modeste à cette époque. Mais nous savons maintenant qu'en Suisse et au sud de l'Allemagne, on savait écrire avec des lettres grecques. Ceci est démontré par l'alphabet de Manching (Krämer 1982 ; cf. Bammesberger 1997) et par la nouvelle inscription gallo-grecque de Berne (Stüber 2005), qui, contrairement aux doutes provoqués par une autre pièce suisse, l'épée de Korisios (G-280), a été inscrite sur place. Cependant, à la différence de la région de Marseille, nous ne pouvons pas ici compter sur une influence grecque directe, mais plutôt sur un processus d'expansion en territoire de langue gauloise par contact entre les différentes communautés. D'un autre côté, la raison qui a conduit les Helvètes à adopter l'écriture ne peut être une réaction identitaire à la présence romaine, mais des raisons d'un autre type, très probablement les mêmes qui ont motivé les Gaulois du Bas-Rhône.

Deux possibilités existent :

- création selon le modèle économique et ouverture postérieure à des types variés d'épigraphie comme une autoaffirmation de l'aristocratie gauloise en réponse à la présence romaine ;

- ou création possible selon le modèle institutionnel ou administratif, à la manière spartiate ou celtibérique, avec l'ouverture postérieure déjà mentionnée.

Dans les deux alternatives, l'apparition de l'écriture gallo-grecque devrait être antérieure au $\mathrm{II}^{\mathrm{e}}$ siècle, car la rapide éclosion des types de prestige présuppose un véhicule pour leur donner forme.

Évidemment ce sont des hypothèses vraisemblables mais qui ne sont pas démontrées pour le moment. Le problème reste entier, même si Michel Bats a réussi à en circonscrire les contours, ce qui m'a permis d'ajouter à la question quelques spéculations alternatives.

9. En tout cas, l'écriture gallo-greque, comme d'autres que nous avons considérées, nous permet de voir avec plus de clarté les raisons pour lesquelles, dans l'Antiquité, des sociétés très différentes ont adopté l'écriture. Je pense toujours que le modèle économique ou mercantile explique la plupart des cas, mais le modèle de prestige, qui peut prendre des formes tout à fait particulières (comme dans le cas crétois), a joué aussi un rôle d'une certaine importance. Les cas spartiate et celtibère auxquels on pourrait peut-être ajouter le gallogrec, nous forcent à prendre en considération un modèle administratif ou institutionnel, propre à des sociétés qui prêtaient beaucoup d'attention à la définition légale de la 
citoyenneté et aux liens qui unissaient les citoyens entre eux. Naturellement, la prépondérance de ces modèles est décisive dans les premiers temps de l'adoption d'une écriture ; par la suite, et en accord avec les particularités de chaque société, l'on voit apparaître toutes sortes d'usages qui constituent les scénarios variés et compliqués que nous rencontrons habituellement.

\section{Bibliographie}

Actas V 1993 : Actas V, Actas del V Coloquio sobre lenguas y culturas prerromanas de la Península Ibérica (Colonia 1989) = Lengua y cultura en la Hispania prerromana, Salamanca, 1993.

Actas IX 2005 : Actas IX, Actas del IX coloquio sobre lenguas y culturas paleohispánicas (= Paleohispanica 5), Zaragoza, 2005.

Amadasi 1987 : AMADASI GUZZO (Ma.G.) - Iscrizioni semitiche di Nord-Ovest in contesti greci e italici (X-VII sec. a. C.). DArch 5, 1987, p. 13-27.

Amadasi 1991 : AMADASI GUZZO (Ma.G.) - "The Shadow Line". Réflexions sur l'introduction de l'alphabet en Grèce. In: Baurain (Cl.), Bonnet (C.), Krings (V.) - Phoinikeia Grammata. Lire et écrire en Méditerranée, Liège-Namur, 1991, p. 000293-000309.

Bagnasco, Cordano (éd.) 1999: BAGNASCO GIANNI (G.) et CORDANO (F.) éd. - Scritture Mediterranee tra il IX e il VII secolo a.C., Milano, 1999.

Baurain, Bonnet, Krings 1991 : BAURAIN (Cl.), BONNET (C.) et KRINGS (V.) - Phoinikeia Grammata. Lire et écrire en Méditerranée, LiègeNamur, 1991.

Baurain, Bonnet, Krings 1994 : BAURAIN (Cl.), BONNET (C.) et KRINGS (V.) - La saga de l'alphabet et la collaboration des cultures. In : Mélanges François Kerlouégan, Besançon-Paris, 1994, p. 79-94.

Bats 1988 : BATS (M.) - Les inscriptions et graffites sur vases céramiques de Lattara protohistorique (Lattes, Hérault). Lattara 1, 1988, p. 147-160.

Bats 1988 (=1990) : BATS (M.) - La logique de l'écriture d'une société à l'autre en Gaule méridionale protohistorique. RAN 21, 1988, p. 121-148.

Bats 2000 : BATS (M.) - Du grec au gallo-grec, les débuts de l'écriture dans le Midi gaulois. In : Le temps des Gaulois en Provence, 2000, p. 74-78.

Bats 2003 : BATS (M.) - Les Gaulois et l'écriture aux II $\mathrm{I}^{\mathrm{e}} \mathrm{I}^{\mathrm{er}} \mathrm{s}$. av. J.-C. In: Articulations entre culture matérielle et sources antiques dans la recherche sur l'Age du fer européen. Actes du XXIII ${ }^{e}$ Colloque de l'AFEAF (Nantes, 1999), Rennes (Supl. 10 de la RAO), 2003, p. 369-380.

Bats 2004 : BATS (M.) - Grec et gallo-grec : les graffites sur céramique aux sources de l'écriture en Gaule méridionale (II $-\mathrm{I}^{\mathrm{er}} \mathrm{s}$. av. J.-C.). Gallia, 2004, p. 7-20.

Bats 2011 : BATS (M.) - Emmêlements de langues et de systèmes graphiques en Gaule méridionale (VIe-Ier s. av. J.-C.). In : C. Ruiz Darasse, E. R. Lujan (éd.), Contacts linguistiques dans l'Occident méditerranéen antique. Actas del Coloquio internacional (Madrid, 23-24 avril 2009), Madrid, 2011, p. 197226 (Coll. CVZ 126).

Beltrán 1993 : BELTRÁN (F.) - La epigrafía como índice de aculturación en el valle medio del Ebro (s. II a. e.-II d. e.). Actas del V Coloquio, 1993, p. 235-272.

Beltrán 1995 : BELTRÁN (F.) - La escritura en la frontera. Inscripciones y cultura epigráfica en el valle medio del Ebro. In : Roma y el nacimiento, 1995, p. 169-195.

Beltrán 2005 : BELTRÁN (F.) - Cultura escrita, epigrafía y ciudad en el ámbito paleohispánico. Actas IX, 2005, p. 21-56.

Beltrán, de Hoz, Untermann 1996 : BELTRÁN (F.), DE HOZ (J.) et UNTERMANN (J.) - El tercer bronce de Botorrita (Contrebia Belaisca), Zaragoza, 1996.

Boring 1979 : BORING (T.A.) - Literacy in Ancient Sparta, Leiden, 1979.
Brixhe 1991 : BRIXHE (C.) - De la phonologie à l'écriture : quelques aspects de l'adaptation de l'alphabet cananéen au grec. In : Phoinikeia Grammata, 1991, p. 313-356.

Brixhe 1994 : BRIXHE (C.) - La saga de l'alphabet et la collaboration des cultures, In : Mélanges François Kerlouégan, Besançon-Paris, 1994, p. 79-94. Burillo 2007 : BURILLO (F.) - Los celtíberos. Etnias y Estados, Barcelona, 2007.

Cartledge 1978 : CARTLEDGE (P.) - Literacy and the Spartan Oligarchy. JHS 98, 1978, p. 25-37.

Christidis 2007 : CHRISTIDIS (A.-Ph.) éd. - A History of Ancient Greek. From the Beginnings to Late Antiquity, Cambridge U. P. , 2007.

Correa 1993 : CORREA (J.A.) - Antropónimos galos y ligures en inscripciones ibéricas. In : Studia palaeohispanica J. Untermann, 1993, p. 101-116. Csapo 1991 : CSAPO (E.) - An International Community of Traders in Late 8th-7th c. b.c. Kommosin Southern Crete. ZPE 88, 1991, p. 211-216.

Csapo 1993 : CSAPO (E.) - A Postscript to 'An International Community of Traders in Late 8th-7th c. b.c. Kommosin Southern Crete', ZPE 96, 1993, p. 235-236.

Csapo, Johnston, Geagan 2000 : CSAPO (E.), JOHNSTON (W.W.), GEAGAN (D.) - The Iron Age Inscriptions. In : Schaw (J.W.) \& (M.C.) éd., 2000, p 101-134.

Coupry, Giffault 1982 : COUPRY (J.), GIFFAULT (M.) - La clientèle d'un sanctuaire d'Aristée aux îles d'Hyères, I Focei, p. 360-370.

Coupry, Giffault 1984 : COUPRY (J.) et GIFFAULT (M.) - Onomastique non hellénique dans l'anthroponymie olbienne et massaliète, en Ligurie marseillaise, à la fin de l'époque hellénistique, d'après les ex-voto du sanctuaire d'Aristée à l'Acapte, Hommages à Lucien Lerat I, Paris, 1984, p. 209-219.

Häussler (dir.) 2008 : HÄUSSLER (R.) dir. - Romanisation et épigraphie. Études interdisciplinaires sur l'acculturation et l'identité dans l'Empire romain, Montagnac, 2008.

Heubeck 1979 : HEUBECK (A.) 1979 - Schrift, Arqueologia Homerica X, Göttingen.

de Hoz 1983 : DE HOZ (J.) - Algunas consideraciones sobre los orígenes del alfabeto griego, Est.Metod.Leng.Griega, Cáceres, p. 11-50.

de Hoz 1986 : DE HOZ (J.) - La epigrafía celtibérica, Reunión sobre epigrafía, 1986, p. 43-102.

de Hoz 1995 : DE HOZ (J.) - Las sociedades celtibérica y lusitana y la escritura, AEspA 68, 1995, p. 3-30.

de Hoz 2001 : DE HOZ (J.) - Dans le sillage hispanique de Michel Lejeune. Quelques problèmes d'histoire de l'écriture, CRAI, 197-212 = Hommage Lejeune, 2001, p. 55-70.

de Hoz 2004 : DE HOZ (J.) - La recepción de la escritura fenicia consonántica en Grecia, In : Bartolomé, (J.), González, (Ma.-C.) \& Quijada, (M.) eds., 2004, La escritura, p. 37-54.

de Hoz 2004a : DE HOZ (J.) - La escritura en Grecia arcaica y clásica: funciones y modelos, In : Bartolomé, (J.), González, (Ma.-C.) \& Quijada, (M.) eds., 2004, La escritura, p. 211-237.

de Hoz 2010 : DE HOZ (J.) - Historia lingüística de la Península Ibérica en la antigüedad. I. Preliminares y mundo meridional prerromano, Madrid, $2010,735 \mathrm{p}$.

de Hoz 2010a : DE HOZ (J.) - L'écriture gréco-ibérique et l'influence hellène sur les usages de l'écriture en Hispanie et dans le sud de la France, Grecs et indigènes, 2010, p. 637-657.

de Hoz 2011 : DE HOZ (J.) - Historia lingüística de la Península Ibérica en la antigüedad. II. El mundo ibérico prerromano y la indoeuropeización, Madrid, 2011.

IGF $=$ DECOURT (J.-C.) - Inscriptions grecques de la France, Lyon, 2004 (Maison de l'Orient).

Johnston 2003 : JOHNSTON (A.) - The Alphabet. In : Stampolidis (N.Ch.) et Karageorghis (V.) éd., PLOES, 2003, p. 263-276.

Krämer 1982 : KRÄMER (W.) - Graffiti auf Spätlatènekeramik aus Manching, Germania 60, 1982, p. 489-499.

Lambert 2003 : LAMBERT (P.-Y.) - Les inscriptions gallo-grecques parues depuis les Textes Gallo-Grecs de Michel Lejeune (1985), EC 35, 2003, p. 169-179. Lejeune 1960 : LEJEUNE (M.) - À propos d'un plomb inscrit d'Elne, REA 62,1960, p. $62-79$. 
Lejeune 1985 : LEJEUNE (M.) - Recueil des Inscriptions Gauloises I. Textes gallo-grecs, Paris, 1985.

Lejeune 1988 : LEJEUNE (M.) - Compléments gallo-grecs, EC 25, 1988, p. 79-106.

Lejeune 1990 : LEJEUNE (M.) - Compléments gallo-grecs, EC 27, 1990, p. $175-177$.

Lejeune, Lambert 1996 : LEJEUNE (M.) et LAMBERT (P.-Y.) Compléments gallo-grecs, EC 32, 1996, p. 131-137.

Lombardo 1988 : LOMBARDO (M.) - Marchands, transactions économiques, écriture. In: M. Détienne, dir., Les savoirs de l'écriture en Grèce ancienne, Lille, 1988, p. 159-187.

Lorrio, Velaza 2005 : LORRIO (A.J.) et VELAZA (J.) - La primera inscripción celtibérica sobre plomo, Actas IX, 2005, p. 1031-1048.

LSAG = JEFFERY (L.H.) - The Local Scripts of Archaic Greece, revised éd. w. suppl. by (A.W.) Johnston, Oxford, 1990.

MacMullen 1982 : MACMULLEN (R.) - The epigraphic habit in the Roman Empire. AJPh 103, 1982, p. 233-246.

Meid 1989 : MEID (W.) - Zur Lesung und Deutung gallischer Inschriften, Innsbruck, 1989.

Meid 1992 : MEID (W.) - Gaulish Inscriptions, Budapest, 1992.

Meid 1994 : MEID (W.) - Celtiberian Inscriptions, Budapest, 1994.

Millender 2001: MILLENDER (E.G.) - Spartan Literacy Revisited. Classical Antiquity 20, 2001, p. 121-164.

M-L = MEIGGS, (R.) \& LEWIS, (D.) - A Selection of Greek Historical Inscriptions to the End of the Fith Century B.C., Oxford, 1969.

MLH = UNTERMANN (J.) - Monumenta Linguarum hispanicarum. I. Die Münzlegenden. II. Inschriften in iberischer Schrift aus Südfrankreich. III. Die iberischen Inschriften aus Spanien,Wiesbaden, 1975/1980/1990.

Moncunill 2007 : MONCUNILL (N.) - Lèxic d'inscripcions ibèriques (19912006). Thèse de doctorat de l'Université de Barcelone, inédite, accessible sur Internet, 2007.

Mullen 2008 : MULLEN (A.) - Rethinking "Hellenization" in South-eastern Gaul: the Gallo-Greek epigraphic record. In : Häussler, R. dir., Romanisation, 2008, p. 249-266.

Naveh 1982 : NAVEH (J.) - Early History of the Alphabet, JerusalemLeiden, 1982.

Naveh 1991 : NAVEH (J.) - Semitic Epigraphy and the Antiquity of the Greek Alphabet. Kadmos 30, 1991, p. 143-151.
Postgate, Wang, Wilkinson 1995 : POSTGATE (N.), WANG (T.) et WILKINSON (T.) - The evidence for early writing: utilitarian or cérémonial. Antiquity 69, 1995, p. 459-480.

Powell 1991: POWELL (B.B.) - Homer and the Origin of the Greek Alphabet, Cambridge, 1991.

Prósper 2007 : PRÓSPER (B.) - Estudio lingüístico del plomo celtibérico de Iniesta, Salamanca, 2007.

Reunión sobre epigrafía hispánica de época romano-republicana, 1986, Zaragoza.

RIG I = LEJEUNE (M.) - Recueil des Inscriptions Gauloises, I, 1985.

Sass 1988 : SASS (B.) - The Genesis of the Alphabet and its Development in the Second Millennium B. C., Wiesbaden, 1988.

Sass 1991 : SASS (B.) - Studia Alphabetica, Freiburg, 1991.

Schaw (éd.) 2000 : SCHAW (J.W.) et (M.C.) éd. - Kommos IV. The Greek Sanctuary, 1-2. Princeton \& Oxford, 2000.

Schmoll 1963 : SCHMOLL (U.) - Althispanische Miszellen I. KZ 78, 1963, p. 47-52.

Schnapp-Gourbeillon 2002 : SCHNAPP-GOURBEILLON (A.) - Aux origines de la Grèce, Paris, 2002.

Stampolidis, Karageorghis 2003 : STAMPOLIDIS (N. Ch.) \& KARAGEORGHIS (V.) , eds. - PLOES... Sea Routes... Interconnections in the Mediterranean. 16th-6th BC, Athens (University of Crete \& A. G. Leventis Foundation), 2003.

Stoddart, Whitley 1988 : STODDART (S.) et WHITLEY (J.) - The social context of literacy in Archaic Greece and Etruria. Antiquity 62, 1988, p. 761-772.

Stuiber 2005 : STÜBER (K.) - Schmied und Frau. Studien zur gallischen Epigraphik und Onomastik [= Archaeolingua. Series Minor 19], Budapest, 2005. Sznycer 1979 : SZNYCER (M.) - L'inscription phénicienne de Tekke, près de Cnossos. Kadmos 18, 1979, p. 89-93.

Untermann 1969 : UNTERMANN (J.) - Lengua ibérica y lengua gala en la Galia Narbonensis. APL 12, 1969, p. 99-161.

Wachter 1989 : Wachter (R.) - Zur Vorgeschichte des griechischen Alphabets. Kadmos 28, 1989, p. 19-78.

Whitley 1997 : Whitley (J.) - Cretan Laws and Cretan Literacy. AJA 101, 1997, p. 635-661.

Woodard 1997 : Woodard (R.D.) - Greek Writing from Knossos to Homer, New York-Oxford, 1997. 


\title{
Alphabet grec et langues indigènes de la Grande Grèce entre unité et variété
}

\author{
Paolo Poccetti
}

Université de Rome

\section{Résumé}

Les langues sabelliques occupent une place tout à fait spéciale qui les distingue des autres domaines linguistiques non seulement de la Péninsule italienne, mais aussi de la Méditerranée ancienne dans son ensemble. Les populations installées en Grande-Grèce et en Sicile sont demeurées fidèles aux modèles de l'alphabet grec, avec lesquels elles étaient plus directement en contact, alors que les populations indigènes du centre de la Péninsule ont développé très tôt des systèmes d'écriture autonomes les uns par rapport aux autres. La conquête de cette autonomie non seulement vis-à-vis de l'alphabet grec, qui a fourni le modèle, mais aussi par rapport aux autres langues voisines (telles que le latin et l'étrusque) se réalise à travers deux procédés fondamentaux, l'innovation et la conservation, qui concernent à la fois la forme et la valeur des signes. Dès l'époque archaïque, le domaine sabellique se distingue des autres langues de la Péninsule non seulement par l'emploi de systèmes d'écriture différents, mais aussi par les évolutions et le réseau des contacts qui accompagnent l'histoire de ces communautés réparties entre l'Ombrie et la Calabre, jusqu'à leur absorption dans le monde romain.

Mots-clés : épigraphie, écriture, osque, osco-grec, Grande Grèce

\begin{abstract}
The Sabellian languages are very different from other language areas not only of the Italian peninsula, but also of the whole ancient Mediterranean. Native peoples of Magna Graecia and Sicily have taken models of the Greek alphabet, with which they were more in touch, while the native peoples from the center of the Peninsula have developed early writing systems, all autonomous from each other. The conquest of autonomy not only with respect to the Greek alphabet, which provided the model, but also in relation to other neighboring languages (such as Latin and Etruscan) takes place through two fundamental processes, innovation and conservation, which concern both the form and the value of signs. Since the Archaic period, the Sabellian field differs from other languages of the peninsula not only by the use of different writing systems, but also by the changes and the network of contacts that accompany the history of these communities spread between Umbria and Calabria, until their absorption in the Roman world.
\end{abstract}

Keywords: epigraphy, writing, Oscan, Oscan-Greek, Magna Grecia 
A u sein des systèmes d'écriture, les langues sabelliques occupent une place tout à fait spéciale qui les distingue des autres domaines linguistiques non seulement de la Péninsule italienne, mais aussi de la Méditerranée ancienne dans son ensemble. Mise à part la diffusion de l'alphabet latin, qui intervint à la suite du rayonnement de l'influence romaine, et dont les traces dans l'écriture ne sont pas antérieures au III s. av. J.-C., ces langues font appel à deux systèmes graphiques distincts, dès le moment où elles commencent à être documentées. Les populations installées en Grande-Grèce et en Sicile sont demeurées fidèles aux modèles de l'alphabet grec, avec lesquels elles étaient plus directement en contact, alors que les populations indigènes du centre de la Péninsule ont développé très tôt des systèmes d'écriture autonomes les uns par rapport aux autres. La conquête de cette autonomie non seulement vis-à-vis de l'alphabet grec, qui a fourni le modèle, mais aussi par rapport aux autres langues voisines (telles que le latin et l'étrusque) se réalise à travers deux procédés fondamentaux, l'innovation et la conservation, qui concernent à la fois la forme et la valeur des signes. Ainsi, par exemple, ce sont l'emploi des lettres «mortes » (comme le samek en milieu sabin), l'attribution de valeurs différentes à un même signe (comme le digamma respectivement en contexte latin et étrusque), et l'introduction de signes tout à fait nouveaux (les notations du /f/ en falisque et en étrusque) qui donnent lieu à la naissance de systèmes alphabétiques distincts. De cette manière, dès la seconde moitié du VIe s. av. J.-C., trois grandes aires d'écritures nationales, latine, étrusque et sabine, se distribuent dans la partie centrale de la Péninsule. Dans ces grandes aires s'inscrivent des variations locales avec des aboutissements différents : d'une part, la fixation, plus ou moins rigide, d'un système d'écriture «national », comme celui de l'étrusque et celui du latin, et, de l'autre, l'affaiblissement ou la disparition de certaines écritures, comme dans le cas des alphabets employés par les langues sabelliques à l'époque archaïque.

Dès l'époque archaïque, le domaine sabellique se distingue des autres langues de la Péninsule non seulement par l'emploi de systèmes d'écriture différents, mais aussi par les évolutions et le réseau des contacts qui accompagnent l'histoire de ces communautés réparties entre l'Ombrie et la Calabre, jusqu'à leur absorption dans le monde romain. La « crise » et les transformations qui ont affecté l'organisation sociale et politique des communautés de la Péninsule au Ve s. av. J.-C. n'ont pas eu de répercussions remarquables dans les lignes fondamentales des systèmes alphabétiques de l'étrusque et du latin, qui pour l'essentiel sont demeurés intacts (sauf l'évolution du tracé des signes) alors que le domaine des langues sabelliques se caractérise par des changements remarquables qui mettent en question les modèles alphabétiques eux-mêmes ${ }^{\mathbf{1}}$. Ces changements se nourrissent de la relation dialectique, d'une part entre discontinuité et continuité, et, de l'autre, entre l'unité et les variations, où l'axe chronologique se croise avec les coordonnées géographiques.

Avant le IVe s. av. J.-C. deux grandes aires d'écriture se distinguent, représentées respectivement par l'alphabet des inscriptions appelées «sud-picéniennes » et par l'alphabet qui s'est répandu depuis les colonies achéennes en Lucanie et dans le Bruttium. Dans ce panorama, une place tout à fait spéciale est réservée à la Campanie. Au cours du Ve s., cette région présente une partition entre deux zones alphabétiques pour écrire une même langue. Ces zones sont séparées par le Vésuve : au nord du volcan, on utilise l'alphabet étrusque, alors qu'au sud, plus précisément dans la zone avoisinant la presqu'île de Sorrento, on rencontre un alphabet indigène (Poccetti 2010).

Mais à l'intérieur de ces aires alphabétiques, on constate des variations dans l'emploi et dans la valeur des signes ainsi que dans les procédés orthographiques. Ainsi, tout comme la vingtaine d'inscriptions du corpus «sud-picénien » présente des variantes éparpillées dans des localités toutes proches les unes des autres, les quelques textes sabelliques écrits en alphabet du réseau des colonies achéennes font ressortir des distinctions dans le tracé des signes et dans l'orthographe. Par exemple, parmi les inscriptions en alphabet achéen, la graphie de la diphtongue dans l'inscription de Tortora $(<\mathrm{o} F\rangle$, Rix 2002, ps 20) se différencie de celle du vase de Castelluccio sul Lao (<ov>, Rix 2002, ps 1). De même, le tout petit corpus d'inscriptions en alphabet indigène de Campanie, concentrées autour de la Presqu'île de Sorrento, présente des différenciations à la fois dans l'orientation des lettres et dans les signes de ponctuation (Poccetti 2010).

A partir de la fin du IVe s. avant J.-C., la partition du domaine sabellique entre deux grandes aires alphabétiques se répète, mais les modèles sont différents : il s'agit de l'alphabet étrusque et de l'alphabet grec hellénistique. Le rapport avec l'alphabet qui a fourni le modèle se différencie d'une zone à l'autre, ce qui se manifeste dans les procédés d'adaptation suivis par chaque aire alphabétique. Pour expliquer ces modifications, M. Lejeune avait appliqué le critère de la distinction entre alphabet qui a fourni le modèle principal et alphabet qui a fourni le modèle accessoire (Lejeune 1970, p. 5 ; Lejeune 1983). Mais d'autres faits ont joué un rôle important dans la

1 Sur le lien entre diffusion de l'écriture et organisation politique cf. Cristofani 1999. 
partition alphabétique, notamment la continuité avec la tradition graphique qui précède et les contacts avec d'autres cultures alphabétiques. La continuité avec une tradition graphique antérieure se manifeste d'une manière différente d'une région ou d'un site à l'autre, ou parfois d'un texte à l'autre. Quelques exemples apparemment isolés s'insèrent de manière cohérente dans une ligne de continuité alphabétique lors du remplacement d'un alphabet par un autre alphabet. Par exemple, l'introduction des deux signes vocaliques transcrits $<u ́>$ et <í caractérisant la "réforme orthographique » de l'alphabet osque d'origine étrusque s'est inspirée de l'emploi de certains signes de l'alphabet « sud-picénien » dont la fonction correspondait à celle de <ú $>$ et $<i ́>$. Plus précisément, la forme de <ú $>$ reproduit celle de l'alphabet « sud-picénien » (sauf l'orientation, différente, du signe), alors que la forme de <í a été créée par imitation de celle de <ú>, ce qui donne lieu à un parallélisme formel entre les deux signes nouveaux, qui n'existe pas dans l'alphabet qui a fourni le modèle.

D'autres échos de l'écriture « sud-picénienne »se retrouvent sporadiquement dans les textes en alphabet latin, adopté de très bonne heure par les populations des Abruzzes, notamment les Marses, les Vestins, les Péligniens. Ainsi, l'orientation boustrophédique appliquée à l'alphabet latin, dans les inscriptions provenant des pays des Marses ${ }^{2}$ et des Vestins (Poccetti 2007, p. 377), est un trait qui trouve son origine dans l'écriture archaïque locale. Une autre trace de l'alphabet « sudpicénien » se retrouve dans l'emploi de deux signes distincts pour les sifflantes dans une inscription en alphabet latin du pays des Vestins ${ }^{3}$. Il paraît donc certain que, au moins au seuil du III ${ }^{\mathrm{e}}$ s. av. J.-C., le souvenir de l'alphabet sud-picénien ne s'était pas affaibli, puisque des traces de celui-ci se manifestent dans les alphabets qui s'y substituent. D'ailleurs, la continuité du système graphique plus ancien est directement attestée par des casques inscrits qui conservent ce type d'écriture encore aux $\mathrm{IV}^{\mathrm{e}}-\mathrm{III}{ }^{\mathrm{e}} \mathrm{s}$. av. J.-C. ${ }^{4}$. Ces objets correspondant à un usage personnel nous montrent que l'emploi du système d'écriture archaïque se poursuivait au niveau informel des objets privés.

2 C'est le cas de l'inscription célèbre de Caso Cantovios (CIL $\mathrm{I}^{2} 5=$ ILLRP 7), datant du début du III siècle av. J.-C : cf. Del Tutto-Prosdocimi-Rocca 2002, 417, qui identifient le lapicide de cette inscription comme « uno scriba sud-piceno che scrive così nel III secolo ».

3 Rix 2002, MV 2. En ce qui concerne l'origine de deux tracés différents pour les sifflantes, cf. Poccetti 2007, p. 378; Dupraz 2010 , p. 365.

4 En ce qui concerne la datation de ces casques, voir Del TuttoProsdocimi-Rocca 2002, 411-417.
Un autre aspect important qui a contribué à la formation des systèmes d'écriture chez les populations parlant les langues sabelliques concerne les contacts avec les traditions voisines. Ces contacts ont produit des résultats différents, qui vont de l'adoption d'un signe isolé jusqu'à l'emprunt d'une série de signes aboutissant à la création d'un alphabet nouveau. C'est grâce à la proximité de l'alphabet grec que l'écriture de l'osque de la Campanie et du Samnium a introduit les signes pour les consonnes sonores $/ \mathrm{b} /, / \mathrm{d} /, / \mathrm{g} /$, en se fondant sur l'alphabet étrusque, ce qui a donné naissance à un système nouveau. Ce n'est pas un hasard si cette exigence ne s'est pas manifestée dans l'alphabet étrusque appelé à écrire l'ombrien, qui, en revanche, révèle l'influence des traditions alphabétiques voisines essentiellement à travers les tracés des signes (Maggiani 1984).

La relation dialectique entre continuité et discontinuité, et entre unité et variété caractérise d'une manière tout à fait particulière les régions de l'Italie du sud qui ont adopté l'alphabet grec en tant que " modèle principal » de leurs systèmes d'écriture. Le lien strict et profond avec l'alphabet grec, et dans ses variations locales, et dans son développement historique, a donné lieu à une différenciation cruciale entre les écritures des langues indigènes de l'Italie méridionale et celles du reste de la Péninsule. Les alphabets adoptés par les populations indigènes de la Grande-Grèce demeurent strictement liés à l'alphabet modèle, en suivant ses variations et en s'adaptant aux innovations qui touchèrent la forme des signes et l'orthographe, alors que - comme on vient de le rappeler - les systèmes graphiques du centre-nord cherchent à gagner leur autonomie.

Les dernières décennies ont marqué un progrès énorme dans la connaissance des systèmes alphabétiques utilisés pour écrire les langues indigènes de GrandeGrèce et de Sicile, qu'on peut identifier en trois grands domaines : celui des langues indigènes de la Sicile, celui du messapien dans l'Apulie et celui des langues sabelliques qui occupent la Lucanie et le Bruttium.

C'est le domaine des langues sabelliques qui a connu le développement le plus important des systèmes d'écriture utilisant l'alphabet grec grâce à l'enrichissement remarquable du corpus. En effet, jusqu'à la fin des années 1960 la documentation épigraphique de ces langues en alphabet grec était très pauvre, en diachronie et en synchronie, comme le montre le recueil de Vetter (1953), qui contient moins d'une dizaine d'inscriptions en osque, auxquelles se rajoutaient deux textes, que M. Lejeune regroupait encore en 1973 sous la définition descriptive "épigraphie indigène du Bruttium » (Lejeune 1973). Ces deux documents sont demeurés tout à fait isolés et en partie énigmatiques jusqu'à la publication du cippe inscrit de Tortora trente ans plus tard 


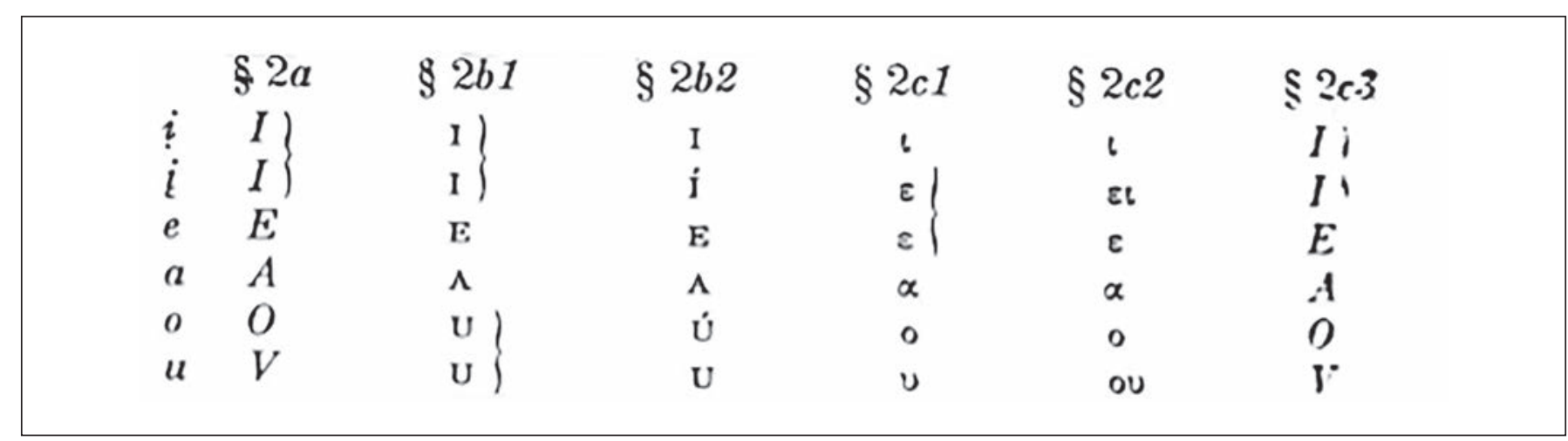

Fig. 1. Tableau du système des voyelles de l'osque esquissé par Lejeune 1975, p. 9.

(Lazzarini-Poccetti 2001). Ce document nouveau nous a dévoilé la diffusion de l'alphabet achéen pour écrire la langue des communautés indigènes, au niveau de leur organisation politique.

La connaissance de l'alphabet hellénistique employé pour écrire la langue osque au cours du IVe s. av. J.-C. s'est élargie grâce aux découvertes de l'épigraphie osque de Rossano di Vaglio, dont les fouilles entre la fin des années 1960 et le tout début des années 1970 ont mis au jour environ soixante textes nouveaux. Cette période connut un essor particulier à la suite des discussions au sein des Congrès de Tarente, grâce à l'intuition et à la sensibilité de M. Lejeune, en collaboration avec le Surintendant de la Lucanie D. Adamesteanu (Poccetti 2001). Dans ce domaine M. Lejeune a joué un rôle tout à fait fondamental et irremplaçable en tant que « maîtrefondateur » d'une sorte de nouvelle discipline, qu'il nomme lui-même "l'osque-grec ». Les problèmes liés à la transcription des textes nouveaux, au fur et à mesure de leur découverte lors des fouilles, et à leur encadrement chronologique, ont stimulé les efforts pour retracer les lignes d'un système d'écriture cohérent avec le système phonologique, dont la reconstruction avait attiré l'intérêt de M. Lejeune depuis longtemps (Lejeune 1962).

Par ailleurs, le corpus épigraphique de Rossano di Vaglio impliquait non seulement la découverte d'un système d'écriture employé pour une langue, déjà connue à travers un autre alphabet, mais aussi l'acquisition d'une variété nouvelle de cette même langue, reflétée par un système graphique différent (Del Tutto Palma 1989). De ce point de vue, l'étiquette «osco-grec» devient ambigüe, se prêtant à être indifféremment appliquée à la variété graphique et/ou linguistique. En effet les témoignages de l'osque en graphie grecque font ressortir des éléments de variations à l'intérieur du domaine osque que l'écriture fort standardisée de la Campanie et du Samnium ne permettent pas d'apprécier. Plus généralement, c'est la connaissance du système phonologique de l'osque dans sa totalité qui a bénéficié de l'acquisition du dossier « osco-grec » surtout en ce qui concerne la notation des voyelles, que M. Lejeune avait synthétisée dans le tableau suivant en 1975 (fig. 1).

Cependant, à la différence de l'osque en alphabet étrusque, la graphie "osco-grecque » semble échapper à un encadrement unitaire et cohérent. Deux points sont essentiels, portant l'un sur la forme des signes, à comparer avec celle de l'alphabet grec, l'autre, sur l'orthographe, à comparer avec celui de l'alphabet étrusque. Les consonnes sont également concernées par des variations, dont la distribution relève d'origines et de fonctions diverses. Par exemple, les deux signes pour la sifflante, notamment le sigma à quatre tirets $\langle\Sigma\rangle$ et le sigma lunatum $<\mathrm{C}>$, présentés généralement comme se succédant chronologiquement (fig. 4), se retrouvent à l'intérieur d'une même tablette d'imprécation avec des fonctions morphosyntaxiques différentes ${ }^{5}$.

Ailleurs les graphies de sifflantes semblent indiquer des différences phonétiques d'une région à l'autre. Par exemple, le digraphe $\langle\sigma \delta>$ au lieu $d u<\zeta>$ dans le prénom Nıv $\mu \sigma \delta ı \eta ı s$ attesté par la célèbre inscription des Mamertins (Mamertini) ${ }^{6}$ révèle la fidélité des Mamertins à la tradition locale (Arena 2001, p. 9), tandis que la sifflante sonore dans les inscriptions de Rossano est notée par le signe $\langle\zeta\rangle$ (ex. $\varepsilon i \zeta$ l $\delta$ o $\mu$ ) conformément à l'orthographe grecque de la Lucanie (ex. $\Delta \alpha \zeta \mu$ o $\zeta$ au lieu de

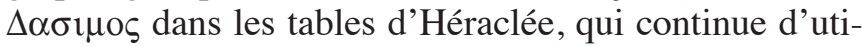
liser la graphie en alphabet achéen ${ }^{7}$. Mais la graphie de Nıv $\mu \sigma \delta ı \eta ı s$, à identifier, comme l'avait souligné Pisani ${ }^{8}$, avec le prénom noté Niumsis en alphabet étrusque et

5 Rix $2002 \mathrm{Lu}$ 47. Sur la distribution des signes dans le texte voir Poccetti 1993, 219.

6 Rix 2002 Me 1. Sur l'histoire des textes des Mamertini, cf. Orioles 1992 ; Crawford 2006.

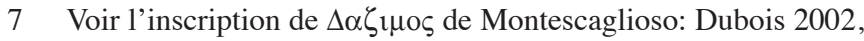
p. 123.

8 Référence dans Arena 2001, 9. 


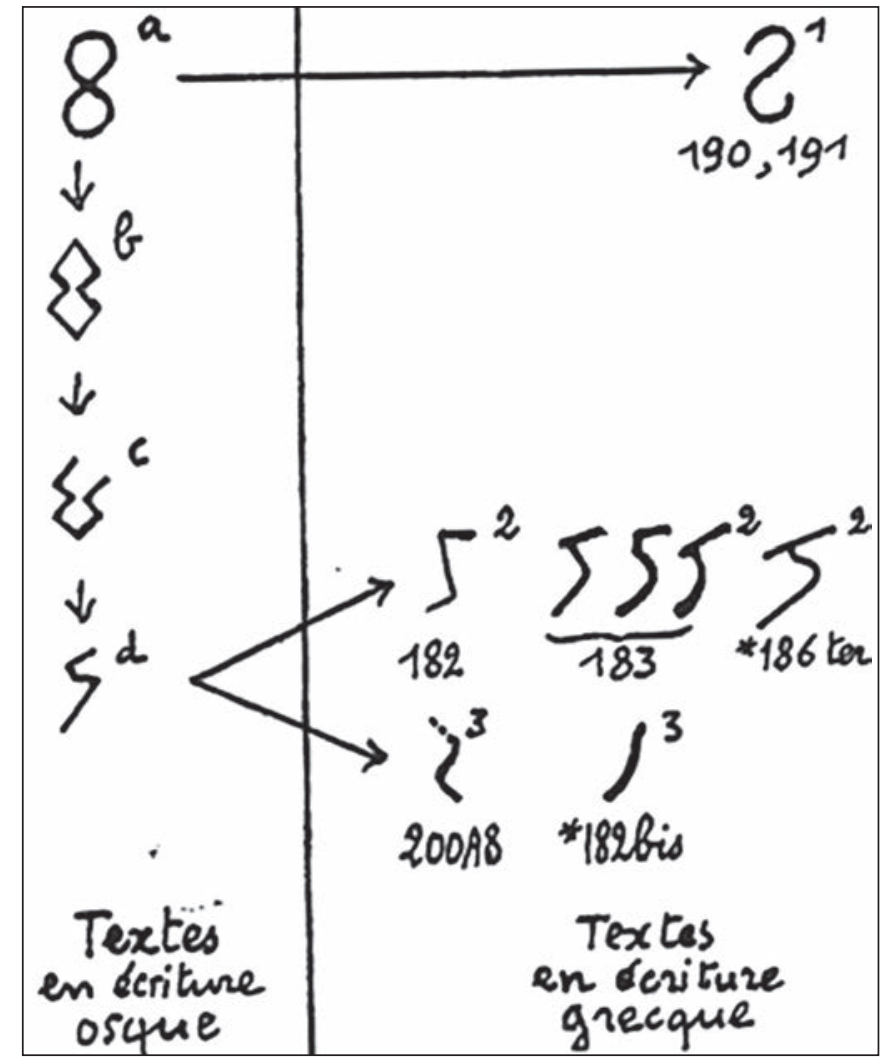

Fig. 2. L'évolution des tracés du /f/ d'après Lejeune 1966, p. 174.

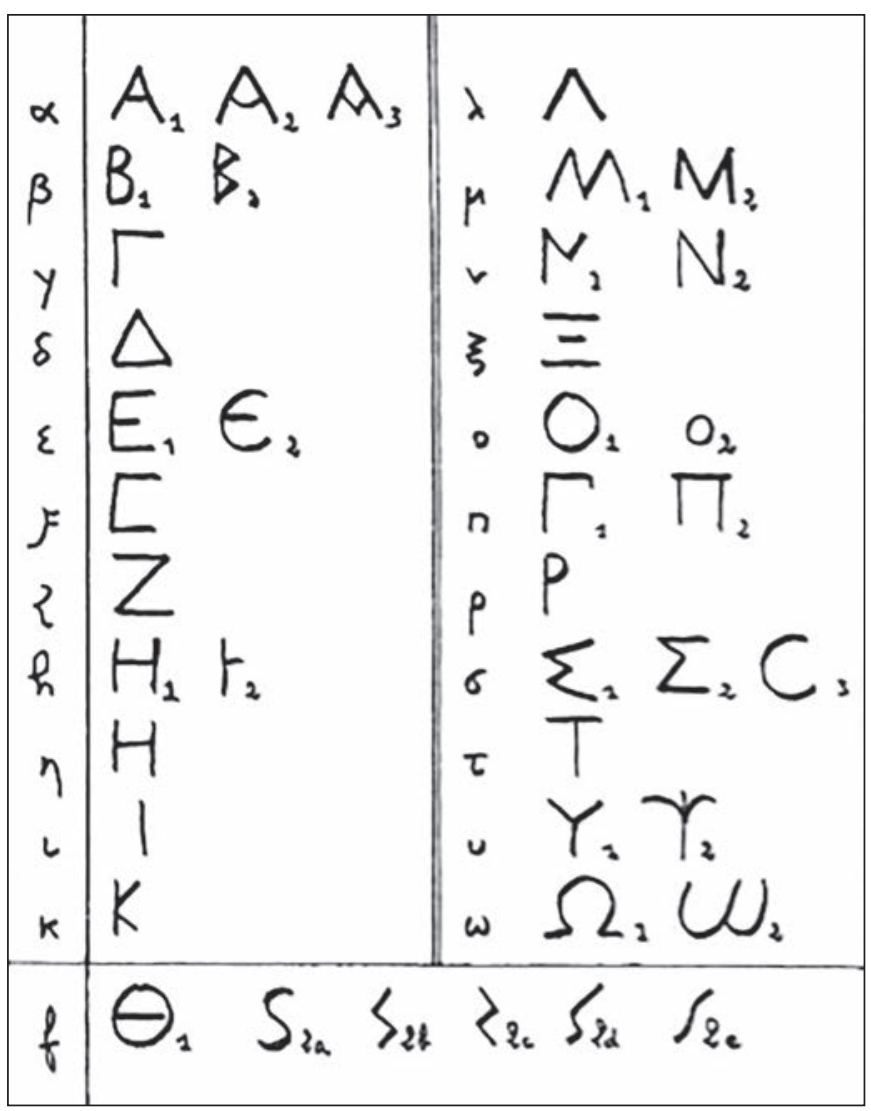

Fig. 4. L'évolution des tracés du /f/ d'après Lejeune 1990, p. 29.

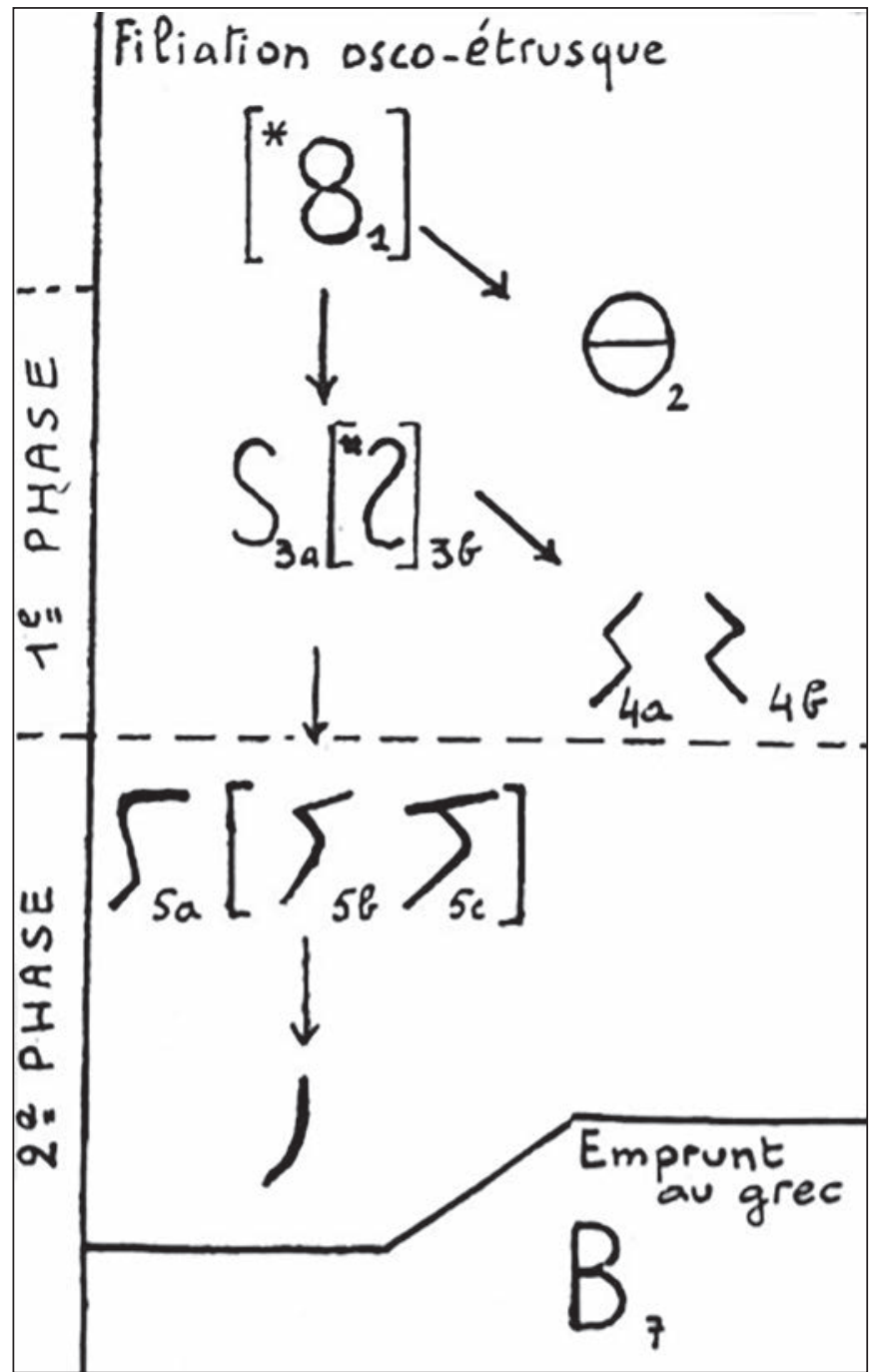

Fig. 3. L'évolution des tracés du /f/ d'après Lejeune 1971, p. 50

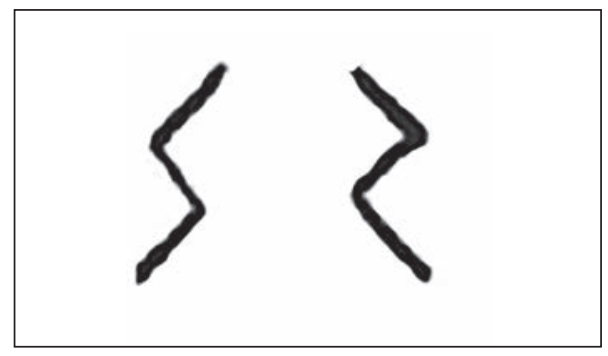

Fig. 5. Tracé du /f/ en forme de sigma à trois tirets. 


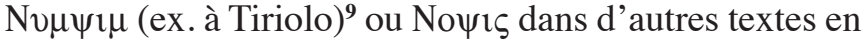
alphabet grec (ex. à Laos) (Rix 2002 Lu 46), nous dévoile d'un coup la sonorisation de la sifflante dans le groupe $/ m s /$, qui n'est pas signalée en alphabet étrusque. En

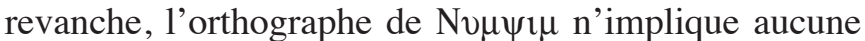
sonorisation : au contraire, le traitement du groupe consonantique $/ \mathrm{ms} />/ \mathrm{mps} /$ produit l'affaiblissent de la nasale, conforme à la phonétique grecque ${ }^{\mathbf{1 0}}$, qui se retrouve dans

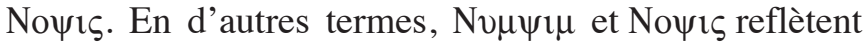
le traitement du groupe consonantique $/ \mathrm{ms} /$ typique $\mathrm{du}$ grec parlé. L'exemple de ce prénom nous montre que les variations graphiques à l'intérieur du domaine osco-grec correspondent à de véritables différenciations dans la langue.

Au fur et à mesure que les inscriptions de Rossano di Vaglio étaient mises au jour, l'édition du corpus devait se confronter à deux problèmes préalables, à savoir le classement chronologique et la fixation de la valeur de chaque signe en fonction de l'interprétation des textes.

Dans cette perspective, un rôle tout à fait fondamental a été joué par les variantes du signe pour noter la consonne /f/ et par les variantes d'orthographe des voyelles. Le nombre exceptionnel des signes pour /f/ dans l'alphabet osco-grec n'a rien de comparable avec d'autres systèmes d'écriture de l'Italie, étant donné que presque toutes les langues de l'Italie ont été obligées de trouver un outil pour noter un phonème que le répertoire grec ne possédait pas. Mais la distribution et l'origine de la variété des signes pour /f/ - parfois employés en synchronie - ne sont pas encore totalement claires. M. Lejeune, qui était conscient de ce problème bien avant les importantes découvertes de Rossano di Vaglio (Lejeune 1967), est toujours demeuré fidèle à son idée de fond que tous les signes employés dans l'écriture osco-grecque pour noter /f/ ne remontent qu'à un seul archétype commun, à savoir le signe de l'alphabet étrusque qui a l'allure du chiffre 8. Mais il a changé d'avis en ce qui concerne les filières qui ont produit l'évolution des variantes. La comparaison entre le schéma de 1966 (fig. 2) et celui de 1971, formulé à la suite des nouvelles trouvailles du sanctuaire lucanien de Rossano (fig. 3), nous montre le changement de son modèle de reconstruction. Une dernière modification se retrouve dans le tableau résumant les signes de Rossano (fig. 4), qui d'une manière surprenante ne prend pas en compte tous les signes attestés dans l'épigraphie du sanctuaire, par exemple le signe pour $\langle\beta>$ appelé à noter /f/.

L'explication de la variété des signes pour /f/, proposée par M. Lejeune, s'inscrivait, d'une part, dans une

9 Rix $2002 \mathrm{Lu} 43$, où ce prénom est reproduit avec la graphie fau-

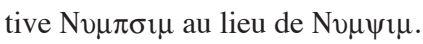

10 Pour d'autres reflets de ce traitement en milieu osco-grec, voir Poccetti 2001, 87. perspective strictement évolutive et, de l'autre, dans son idée originelle (mais appliquée de manière trop rigide) de modèle alphabétique «accessoire » opérant sur le modèle alphabétique « principal » (Lejeune 1970). D'après cette vision des choses, les créateurs de l'écriture oscogrecque, embarrassés pour la notation de /f/, phonème qui n'existait pas en grec, se seraient tournés vers la graphie étrusque en empruntant le signe caractéristique de cet alphabet (Lejeune 1970, p. 274). Mais cet épisode initial mis à part, il n'admettait plus de contacts, par la suite, entre la culture graphique des Osques méridionaux et celle des Osques centraux, en parvenant à la conclusion que la lettre $<\mathrm{f}>$ dépourvue d'attaches grecques et dont les attaches originelles avec l'osque-étrusque ont été très vite rompus a évolué isolément et de façon, en quelque sorte désemparée (Lejeune 1970, p. 276).

Or l'interruption totale des contacts entre les deux systèmes graphiques, imaginée pour expliquer l'évolution du signe pour /f/, ne s'accorde pas avec le parallélisme et la cohésion entre les deux domaines en ce qui concerne la notation des voyelles, qu'il avait souligné à plusieurs reprises. Les relations étroites entre les deux systèmes se manifestent à travers une réforme orthographique du système vocalique, qui se déroule de manière parallèle dans les deux domaines au début du III' siècle av. J.-C. Cette « réforme » consiste, d'une part, en l'introduction de signes nouveaux dans le répertoire alphabétique et, de l'autre, en une distribution différente des graphèmes mis à disposition par l'alphabet grec. Bien évidemment, ce parallélisme ne peut pas relever du seul hasard.

Cependant, la difficulté insurmontable dans l'idée de l'archétype et de l'évolution formulée par M. Lejeune repose, en premier lieu, sur le fait que le signe pour /f/ de l'alphabet étrusque ne se retrouve nulle part dans l'épigraphie osco-grecque. Inversement, des signes attestés dans l'alphabet osco-grec se retrouvent dans le domaine alphabétique d'origine étrusque. C'est le cas du signe à trois tirets, que $\mathrm{M}$. Lejeune avait d'abord conçu comme une évolution du signe étrusque, avant son « exportation » en milieu osco-grec. Il se retrouve dans les légendes monétaires des Fenserni (Colonna 1984, p. 235) (fig. 5). On pourrait envisager là une influence dans le sens inverse.

Mais la preuve décisive contre l'évolution tardive du signe étrusque vers les formes attestées dans l'alphabet osco-grec nous est fournie par de nouvelles découvertes, qui montrent que le signe de forme la plus évoluée était déjà diffusé dans des textes remontant à la fin du IVe s. av. J.-C., provenant de sites divers, et se rangeant à des niveaux socio-linguistiques différents, comme la tablette d'imprécation de Tiriolo dans le Bruttium (Rix $2002 \mathrm{Lu} 43$ ) et la plaque en bronze de Roccagloriosa, découverte plus récemment. 


\begin{tabular}{|l|c|c|c|}
\hline & Alphabet « sud-picénien » & $\begin{array}{c}\text { Alphabet indigène } \\
\text { de Campanie }\end{array}$ & Alphabet de « Tortora » \\
\hline Tracé du signe & C & /f/ & /f/ \\
\hline Valeur phonétique & /w/ & \\
\hline
\end{tabular}

Fig. 6. Forme et valeur phonétique du /f/.
Il paraît désormais hors de discussion que les signes employés pour noter /f/ dans la graphie osco-grecque ont des origines diverses et que, par conséquent, ils ne peuvent être ramenés à un archétype unique. Trois signes pour /f/ sont issus de l'alphabet grec, d'une manière indépendante l'un de l'autre : il s'agit des lettres $\beta, \theta$ et $\varphi$, dont l'évolution précoce vers les valeurs phonétiques des spirantes, attestée par l'épigraphie grecque dès l'époque classique ${ }^{11}$, a favorisé leur emploi pour noter la fricative bilabiale italique. D'ailleurs, l'emploi $\mathrm{du}\langle\mathrm{b}\rangle$ pour noter /f/ se retrouve dans d'autres domaines alphabétiques, comme dans l'épigraphie des langues indigènes de la Sicile.

Tous ces signes de l'alphabet grec appelés à noter /f/ se retrouvent dans les monnaies frappées en partie en osque, en partie en grec, par les villes de Campanie. Mais, dans ces monnaies tantôt en alphabet étrusque tantôt en alphabet grec figurent aussi des tracés inconnus à l'épigraphie osco-grecque, tels que le simple cercle $<0>$ ou le rhomboïde $\langle\diamond>$ (Colonna 1984, p. 235). Tout cela implique évidemment des contacts entre les deux zones alphabétiques, mais en même temps semble exclure le rayonnement d'un modèle unique d'une part ou de l'autre' ${ }^{12}$. Finalement, à la pluralité des notation du /f/, que l'on constate au cours du $\mathrm{V}^{\mathrm{e}} \mathrm{s}$. sur les monnaies de Campanie, l'écriture osque de cette région a substitué un seul signe, celui appartenant à l'alphabet étrusque, alors que l'écriture en alphabet grec ne semble avoir adopté aucun modèle unique. Dans cette perspective, la graphie osco-grecque est plus conservatrice que la graphie osco-étrusque.

Les autres signes pour noter /f/ qui figurent plus fréquemment dans la documentation osco-grecque ne semblent pas non plus remonter à une source unique. La chronologie des nouvelles découvertes plaide contre la filière évolutive esquissée par M. Lejeune, étant donné que les occurrences du signe en forme de $\left\langle\mathrm{S}>^{13}\right.$ sont plus ou moins simultanées avec celles qu'on a supposé être le résultat de son évolution, les deux cas se rencontrant à la fin du IVe s. av. J.-C.

11 Voir Threatte 1980, p.470; en ce qui concerne plus spécifiquement les flottements entre ces consonnes dans l'épigraphie, voir Arena 1983.

12 Comme, par ex., l'admet Cristofani 1998.

13 C'est le signe numéroté $3 a$ de la fig. 3 et 2 a de la fig. 4.
En outre, la relation entre les autres signes échelonnés sur des périodes différentes représente le point le plus délicat de la question. Il se peut que ces signes relèvent des lettres grecques pour les « sifflantes » ou bien de leurs variantes : mais à quel niveau se situe cet aboutissement et quel est son point de départ ? L'emploi du signe pour sigma à quatre tirets (à savoir $\langle\Sigma>$ ) et son évolution vers le sigma lunatum (à savoir $<\mathrm{C}>$ ) dans le corpus oscogrec (fig.4), invitent à exclure toute relation synchronique avec les signes appelés à noter /f/ dans le même alphabet. Donc, s'il y a eu un emprunt du signe à trois tirets avec valeur de sifflante, il doit avoir eu lieu en dehors de l'alphabet « ionien », répandu au IVe s. av. J.-C. dans le monde hellénistique, qui a fourni le répertoire des signes à l'écriture osco-grecque. Le sigma à trois tirets est connu par des alphabets locaux qui précèdent le rayonnement de l'alphabet hellénistique, comme, en Grande-Grèce, l'alphabet des colonies eubéennes, où ce signe est très commun (Jeffery 1990, p. 34). En revanche, dans l'alphabet achéen, diffusé dans la Lucanie occidentale et au nord du Bruttium, le signe à trois tirets correspond à la lettre iota, alors que cet alphabet adoptait le san pour noter la sifflante. Quant à la proximité phonétique avec la consonne /f/, donc, l'adaptation du signe à valeur vocalique de l'alphabet achéen semblerait moins probable qu'un emprunt au sigma à trois tirets des colonies eubéennes ${ }^{14}$.

Toutefois le parcours de l'emprunt à l'alphabet eubéen demeure obscur, sauf à envisager les relations possibles des Lucaniens avec la zone de rayonnement de l'alphabet eubéen en Campanie, dont la limite méridionale, marquée par la Presqu'île de Sorrente et son arrière-pays au sud du golfe de Naples, se caractérise par la rencontre et les contacts entre des alphabets différents dès l'époque archaïque. Cependant une inscription osque en alphabet grec eubéen provenant de cette zone présente dans le nom Fípiveıs le signe final à quatre tirets (Rix 2002 Cm 16 ; Poccetti 2010, p. 84).

Or le nouveau texte archaïque en alphabet achéen de Tortora sur la cote tyrrhénienne nous permet de formuler d'autres hypothèses sur l'origine de certains signes pour/f/ en graphie osco-grecque. En effet, la nouveauté la plus remarquable de ce document indigène à l'égard de l'écriture réside dans le signe employé pour noter /f/.

14 Comme l'admet Del Tutto Palma 1989, 110. 
Ce signe résulte d'une innovation introduite dans l'alphabet achéen utilisé par les langues indigènes à l'époque archaïque. Les similitudes frappantes de ce signe avec celui qui figure avec la même valeur dans les inscriptions en alphabet indigène de la Campanie méridionale, autour de la Presqu'île de Sorrente, indiquent des relations entre les deux domaines alphabétiques avant la diffusion de l'alphabet hellénistique (Poccetti 2010, p. 71). Ces relations viennent d'être confirmées par des textes nouveaux découverts plus récemment.

Mais l'histoire de ce signe appelé à noter/f/ semble bien plus complexe, parce que son aspect se rapproche de la forme d'un signe attesté dans le corpus « sud-picénien » avec la valeur de /w/, qui n'est qu'une modification de l'ancien digamma, dont il a gardé la valeur phonétique. Bref, dans un horizon chronologique homogène $\left(\mathrm{VI}^{\mathrm{e}}-\mathrm{V}^{\mathrm{e}} \mathrm{s}\right.$.), le même signe, hérité du digamma, garde la valeur de /w/ dans l'alphabet « sud-picénien », diffusé au centre de la Péninsule italienne, alors qu'au sud, dans deux aires alphabétiques distinctes, mais contigües - celle du sud de la Campanie et celle de la Lucanie il se présente avec la valeur de /f/. On peut résumer la situation par le schéma de la fig. 6.

Le sens de diffusion de ce signe est orienté du nord vers le sud en donnant lieu à des variations mineures dans la forme. Ce sens de diffusion nous est confirmé par les valeurs différentes de ce signe, qui suppose l'évolution de /w/ vers /f/ et non pas l'inverse. Le changement de la valeur phonétique $/ \mathrm{w} / \rightarrow$ /f/ (suivant un cheminement comparable à celui du signe pour digamma en latin) a eu lieu dans les régions méridionales, où les alphabets des populations indigènes ne possédaient aucun signe pour noter /f/, alors que l'alphabet « sud-picénien » avait à sa disposition un signe autonome (celui à deux points $<:>)^{15}$. En revanche, les alphabets du sud disposaient d'un signe pour le digamma, comme nous le montre l'inscription de Tortora, ce qui rendait inutile l'emprunt d'un autre signe avec la même valeur.

Ce qui nous intéresse ici, c'est de souligner que les populations indigènes de la Lucanie occidentale qui se servaient de l'alphabet achéen pour écrire leur langue (appartenant au groupe sabellique) à la fin de l'époque archaïque ont emprunté le signe pour /f/ à un alphabet indigène, employé un peu plus au nord pour noter la même langue. Ce phénomène révèle les contacts entre les deux aires alphabétiques à une époque antérieure à la formation de l'écriture osco-grecque. Rappelons que la limite qui sépare les deux domaines alphabétiques des langues sabelliques demeure intacte de l'époque archaïque à l'époque hellénistique, lors du remplacement

15 Voir la tables des signes « sud-picéniens » dans Marinetti 1985, p.59-60

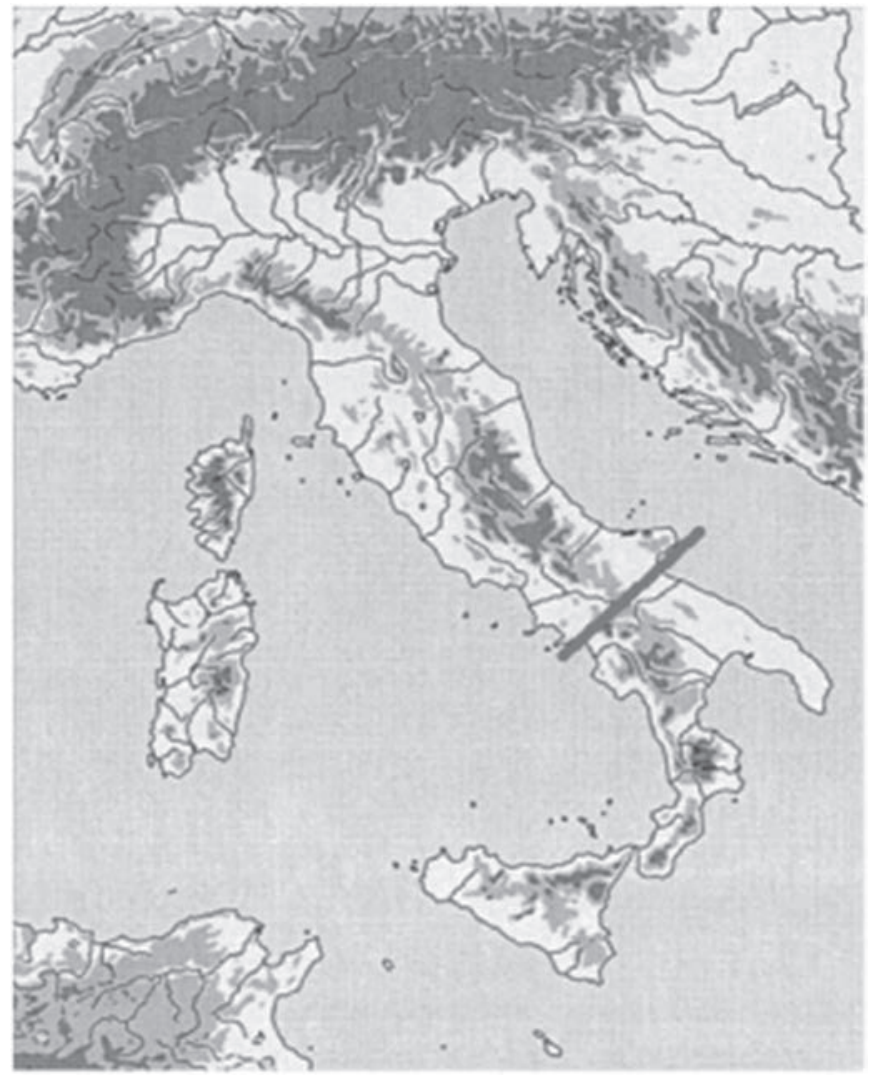

Fig. 7. Une frontière alphabétique (le trait noir indique la limite de l'emploi de l'alphabet grec (toutes variantes confondues) pour écrire les langues indigènes).

des alphabets qui ont fourni le modèle principal au cours du IVe s. Cette limite, située autour de la Presqu'île de Sorrente, coïncide avec l'ancienne ligne de séparation entre Campanie et Lucanie, qui continue d'exister jusqu'à l'époque romaine (fig.7). En d'autres termes, le changement des alphabets dans les deux systèmes d'écriture des langues sabelliques s'insère dans une continuité d'alphabétisation, qui respecte la distribution géographique des systèmes graphiques plus anciens. En effet, la limite méridionale du Golfe de Naples séparait la zone d'influence de l'alphabet de la colonie eubéenne de Cumes de la zone d'influence de l'alphabet achéen, dont la diffusion avait pour point de départ la colonie de Poseidonia.

Dans cette ligne de continuité de l'alphabétisation des communautés indigènes, reliant l'alphabet achéen à l'alphabet osco-grec, s'inscrit l'évolution de certains signes pour noter/f/. Des tracés pour /f/ dans la graphie « osco-grecque » sont susceptibles d'être rapportés à la modification du signe employé avec la même valeur dans l'inscription archaïque de Tortora, en alphabet achéen, et dans les inscriptions de Campanie méridionale. Plus précisément, il s'agit de la forme du signe attestée par les inscriptions en alphabet osco-grec, 
datant de l'époque plus ancienne, comme par exemple la tablette d'imprécation de Tiriolo et le bronze de Roccagloriosa (fig. 8).

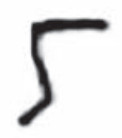

Fig. 8. Signe pour /f/ du bronze de Roccagloriosa et de la tablette d'imprécation de Tiriolo.

On peut envisager ce signe comme un développement de la forme du /f/ de l'inscription de Tortora et de l'alphabet indigène de Sorrente, avec la filiation suivante (fig. 9).

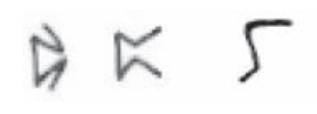

Fig. 9. /f/ de l'alphabet achéen à l'alphabet hellénistique.

Du point de vue historique, le parcours le plus probable est la transmission du signe le plus ancien de l'écriture des langues indigènes en alphabet achéen à l'alphabet grec hellénistique. La raison qui nous amène à exclure l'alphabet indigène de la Campanie méridionale en tant que source du tracé en question réside dans le fait que ce système d'écriture semble disparaître au cours du $V^{e}$ s. av. J.-C. : il semble donc invraisemblable qu'un siècle plus tard les communautés de la Lucanie et du Bruttium se soient tournées vers un système d'écriture qui n'appartenait pas à la tradition locale, et qui n'était pas non plus en usage à ce moment-là. En revanche, il nous paraît probable qu'au moment du remplacement de l'alphabet achéen par l'alphabet « ionien » hellénistique, le souvenir de ce signe ne s'était pas totalement effacé dans la tradition de l'écriture des langues indigènes. Concrètement, la connaissance du signe spécial pour noter une consonne si importante dans le système phonologique des langues sabelliques se serait transmise d'un alphabet à l'autre lors de la phase d'adoption de l'alphabet nouveau.

La continuité de l'écriture chez les communautés de la Lucanie et du Bruttium lors du passage de l'alphabet achéen à l'alphabet diffusé dans le monde hellénistique n'est pas surprenante, parce qu'elle correspond au même procédé que l'on vient de rappeler ci-dessus : le remplacement d'un système alphabétique par l'autre dans d'autres domaines des langues sabelliques du nord s'est déroulé sans solution de continuité d'un système d'écriture à l'autre. Cela fait ressortir le parallélisme entre les deux domaines alphabétiques en ce qui concerne la continuité de l'écriture, lors du passage d'un alphabet à l'autre. Ainsi s'explique la présence de ce signe (fig. 8) dans les documents datables de la phase la plus ancienne de l'écriture osco-grecque.

En conclusion, les nombreuses variantes du signe pour /f/, que l'on trouve dans la graphie osco-grecque même à l'intérieur d'un même site (c'est le cas du sanctuaire de Rossano), ne peuvent qu'être issues de sources différentes. Parmi ces sources, il faut prendre en compte le tracé pour /f/ de l'alphabet achéen employé par les communautés indigènes en Lucanie et dans le Bruttium, au cours de l'époque antérieure à la diffusion de l'alphabet hellénistique. La forme évoluée de ce signe figure dans les documents les plus anciens de l'écriture oscogrecque et de la Lucanie et du Bruttium, ce qui indique à la fois l'antiquité et la diffusion de son emploi dans l'aire alphabétique en question.

Mais, à côté des faits unitaires, nombre de divergences entre la Lucanie et le Bruttium signalent que les deux régions ont développé séparément des « écoles graphiques », comme on l'a souligné depuis longtemps (Poccetti 1988, p. 141-146). Y compris à l'intérieur d'une même région, dans des textes du même type, et dont la datation est identique, on constate des variations. Par exemple, dans une tablette d'imprécation de Petelia, le /f/ est indiqué par le signe grec $\langle\varphi\rangle$ (Lazzarini 2004), alors que la tablette de Tiriolo datant de la même époque utilise le même signe que le bronze de Roccagloriosa, que nous avons mentionné précédemment. Quant aux voyelles, les écritures du Bruttium demeurent fidèles à la notation du second élément de la diphtongue par la voyelle $\langle v\rangle$, alors qu'en Lucanie, on trouve le plus souvent le digamma dans le digraphe $\langle\omega F\rangle$ ou $\langle\mathrm{o} F\rangle$. Cet emploi du digamma pour la notation de la diphtongue avait été attribué à l'influence de la graphie étrusque, qui se serait exercée en Lucanie d'une manière plus marquée qu'au Bruttium, qui, lui, semble rester plus fidèle à la graphie utilisant la voyelle <v> (Lazzarini 1983, p. 173 ; Poccetti 1988, p. 153). Mais la documentation nouvelle nous invite à nuancer cette conclusion. D'abord la tablette d'imprécation de Petelia, dans le Bruttium, présente la coexistence des deux graphies, par

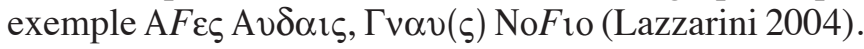
Inversement, la plaque en bronze de Roccagloriosa ne présente que la graphie avec $<v>$ (par exemple dans les

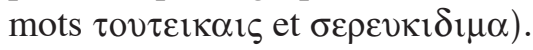

Or le même type de flottement entre $\langle v\rangle$ et $\langle F\rangle$ dans la notation des diphtongues se retrouve dans les écritures indigènes archaïques en alphabet achéen, comme

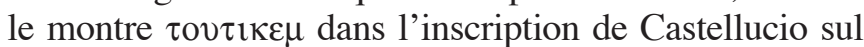
Lao, à comparer à $\tau o F \tau \imath \delta$ que l'on trouve à Tortora. La pauvreté des textes archaïques ne nous permet pas de retracer les lignes de distribution de ces graphèmes entre Lucanie et Bruttium. Mais il paraît certain que les deux 
systèmes de notation des diphtongues employés dans l'alphabet hellénistique appartenaient déjà à l'alphabet achéen diffusé dans les mêmes régions. Cela n'exclut pas que la convergence avec la graphie diffusée dans la zone alphabétique étrusque ait stimulé la diffusion du digamma pour noter les diphtongues, qui sont plus prononcées en Lucanie qu'au Bruttium. Cependant, il faut souligner que les données épigraphiques des deux régions sont très déséquilibrées et dans la quantité et dans la chronologie, ce qui impose une certaine prudence dans leur évaluation.

Les variations dans les tracés du /f/ et dans l'écriture des diphtongues correspondent bien au panorama très varié offert par la notation du système vocalique. Ces variations se situent au niveau des règles d'orthographe qui affectent plus directement la «forme intérieure » du système, alors que les tracés de signes concernent « la forme extérieure » de l'écriture ${ }^{16}$. A cet égard, les différentiations s'inscrivent dans les lignes de développement du système osco-grec plutôt que dans l'héritage de l'alphabet achéen, qui ne mettait à disposition que cinq signes vocaliques, tandis que l'alphabet hellénistique en possédait sept, en rajoutant les signes pour $\langle\eta\rangle$ et $\langle\omega\rangle$.

Les nouvelles découvertes ont à plusieurs reprises contraint de modifier le tableau précédemment esquissé. M. Lejeune lui-même, qui en 1970 avait consacré un grand travail à la «phonologie osque et graphie grecque » (Lejeune 1970), se vit obligé deux ans plus tard de modifier ses conclusions à la suite d'une nouvelle inscription qui montrait que «dans la série qui ne présente pas de confusions et flottements (voyelles postérieures en syllabe non finale), le système de notations $(\alpha-\omega-0)$ diffère du système lucanien classique ( $\alpha$-o-ov), attesté notamment sur ce même site de Rossano » (Lejeune 1972a, p. 10). Ces nouvelles données avaient amené M. Lejeune à reformuler deux conclusions, l'une portant sur l'évolution du système phonologique, l'autre sur la question de l'origine de l'écriture «osco-grecque » : «L'osque a toujours donné l'impression d'être la plus stable, phonétiquement, des langues italiques, la moins affectée, à date historique, d'altérations majeures. Un certain nombre de données apportées par l'osque méridional (et valables au moins pour celui-ci) invitent à retoucher cette impression : peu avant le moment (début du $\mathrm{I}^{\text {er }}$ siècle avant notre ère) où elle cesse de s'écrire, cette langue était engagée dans une série de transformations bouleversant, plus ou moins profondément, son système phonologique : tendance à réduire de trois à deux les phonèmes vocaliques de la série antérieure et, en syllabe finale seulement, les phonèmes vocaliques de la série postérieure » (Lejeune 1972a, p. 13). «Jusqu'ici le

16 On applique ici à l'écriture la notion de «forme intérieure » et « forme extérieure » conçue pour la langue. caractère aberrant des notations vocaliques à Sorrente et à Vibo Valentia nous avait porté à envisager différentes " naissances » indépendantes d'une écriture osque à modèle grec. On corrigera cette vue en la ramenant à l'idée d'une seule naissance de l'alphabet osco-grec (en Lucanie ?), avec diffusion dans l'ensemble du monde osque méridional, mais avec des écoles orthographiques variant selon les lieux et les époques » (Lejeune 1972a, p. 10). Mais désormais, la vision d'un seul point de départ ou d'une naissance de l'alphabet osco-grec dans un endroit unique n'est plus à retenir. Les données nouvelles qui sont apparues depuis ces dernières années dessinent un tableau encore plus complexe du point de vue de la distribution et chronologique et diatopique, avec des éléments importants en ce qui concerne l' « origine » et le rayonnement de l'écriture « osco-grecque ». Dans le cadre qui soude les communautés indigènes de la Grande-Grèce à la fidélité à l'alphabet grec, s'insèrent des variations remarquables et des différentiations même à l'intérieur d'un seul endroit, qui nous révèlent que l'activité des lapicides osques n'est que « il risultato di una interna dialettica tra la realtà linguistica dell'ambiente in cui operavano e la tradizione che rappresentavano » (Campanile 1981, p. 39).

Trois documents, mis au jour plus récemment, ont révolutionné le tableau précédemment esquissé : $(a)$ le fragment de plaque en bronze de Roccagloriosa, $(b)$ une inscription votive de Rossano, (c) le cippe de Tortora, en alphabet achéen. Ces trois documents présentent une certaine cohésion topographique, se concentrant dans la Lucanie occidentale, mais ils s'échelonnent sur des niveaux chronologiques bien différents. L'inscription votive de Rossano $(b)$ appartient à la dernière phase de l'épigraphie du sanctuaire, c'est-à-dire au cours du II ${ }^{\mathrm{e}}$ s. (Nava-Poccetti 2001), alors que le bronze de Roccagloriosa $(a)$ remonte à deux siècles plus tôt (fin IV s.) (Gualtieri-Poccetti 2001) et que la pierre de Tortora $(c)$ date de la fin du $\mathrm{VI}^{\mathrm{e}} \mathrm{s}$.

On attirera ici l'attention sur quelques faits essentiels que nous apportent ces documents connus plus récemment. D'abord la notation des voyelles vélaires qui ne concerne que les deux textes osques $(a)$ et $(b)$ en alphabet hellénistique. La dédicace de Rossano atteste un système de notation des voyelles vélaires différent de celui esquissé sur la base du corpus du sanctuaire déjà connu : le signe $\langle\omega\rangle$ y est employé pour la voyelle issue de [ŏ], correspondant au signe <ú $>$ de l'alphabet étrusque, tandis que $<0 v>$ indique la voyelle issue de [ō] correspondant au signe $<\mathrm{u}>$ de l'alphabet étrusque.

Ainsi l'épigraphie osque du sanctuaire lucanien fait ressortir trois systèmes différents de notation des voyelles vélaires (Nava-Poccetti 2001, p. 103) qu'on peut synthétiser dans le schéma suivant (fig. 10). 


\begin{tabular}{|c|c|}
\hline$<\mathrm{u}>\leftarrow[\overline{\mathrm{o}}]$ & $<\mathrm{u}>\leftarrow[\overline{\mathrm{o}}]$ \\
\hline $\mathrm{o}$ & $\omega$ \\
\hline $\mathrm{ov}$ & $\mathrm{o}$ \\
\hline $\mathrm{ov}$ & $\omega$ \\
\hline
\end{tabular}

Fig. 10. Couples de graphèmes pour les voyelles vélaires dans l'épigraphie du sanctuaire de Rossano.

En outre, le signe $\langle\omega\rangle$ sert à noter les diphtongues,

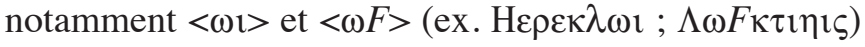
en parallèle à l'emploi de $\langle\eta\rangle$ dans $\langle\eta 〉\rangle$. Comme on le sait, l'aboutissement de [eu] à [ou] dans les langues italiques ne permet pas l'attestation de $\langle\eta F\rangle^{17}$.

A la différence de $\langle\omega\rangle$ qui est employé et comme voyelle libre et dans les diphtongues, le signe pour $\langle\eta\rangle$ ne se retrouve que dans la diphtongue [ei] notée $\langle\eta\rangle$. L'écriture osco-grecque semble ignorer l'emploi du $\langle\eta\rangle$ en tant que simple voyelle, ce qui relève probablement de la valeur phonétique dont le signe $<\eta>$ s'est chargé en grec de très bonne heure, c'est-à-dire [i]. Cette évolution, bien connue en grec sous le nom de « iotacisme » de $\langle\eta\rangle$, mettait, donc, en concurrence le signe $\langle\eta\rangle$ avec $<l>$. C'est ainsi que le digraphe $<\eta \imath$, qui n'aurait aucun sens en grec, se dessine comme un outil créé exprès par l'écriture osco-grecque pour noter la diphtongue [ei]. Dans cette fonction le digraphe $\langle\eta l\rangle$ a remplacé $\langle\varepsilon l\rangle$, qui se retrouve dans les textes plus anciens avec deux fonctions différentes, à savoir celle de simple voyelle reproduisant la valeur qui s'était répandue en grec, et celle de la diphtongue (Lejeune 1970 ; Lejeune 1972a). Cette double fonction se manifeste dans le bronze de

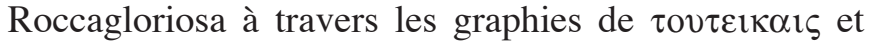
$\mu \varepsilon \delta \varepsilon \imath \kappa \alpha$ - (correspondant à túvtík- et meddík-), à coté de $\varepsilon \imath \sigma \varepsilon \imath^{\prime}$ (correspondant à eíseís), qui est cohérent avec la graphie $\delta ı v F \varepsilon \imath F \varepsilon \rho \sigma o \rho \varepsilon \imath$ de la tablette de Vibo (Rix $2002 \mathrm{Lu} \mathrm{25),} \mathrm{considérée} \mathrm{comme} \mathrm{un} \mathrm{des} \mathrm{documents}$ les plus anciens du dossier osco-grec. La datation du bronze de Roccagloriosa à la fin du $\mathrm{IV}^{\mathrm{e}} \mathrm{s}$. confirme que le digraphe $\langle\eta 1\rangle$ pour noter la diphtongue n'est qu'une création postérieure.

La conscience du statut phonétique de $<\eta>$ en grec, qui relève du bilinguisme au niveau et de l'oralité et de l'écriture, se reflète dans les variations de son emploi dans l'écriture osco-grecque. Par exemple, une inscription provenant du temple d'Apollon Alaios au cœur du Bruttium, présente des flottements saisissants dans l'em-

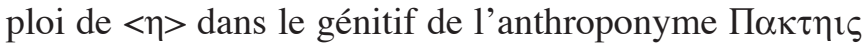

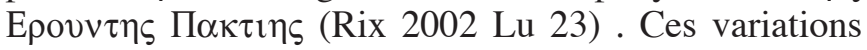
relèvent, plutôt que des raisons morphologiques, des

17 La seule attestation de /eu/ se trouve dans le mot $\sigma \varepsilon \rho \varepsilon v \kappa i \delta \mu \alpha$ (bronze de Roccagloriosa), dont l'origine demeure encore obscure. hésitations dans l'emploi du digraphe $<\eta ı$ qui allait se diffuser dans l'orthographe osco-grecque ${ }^{18}$.

Une preuve inverse de la conscience de la valeur phonétique du signe $<\eta>$ dans l'alphabet grec nous est

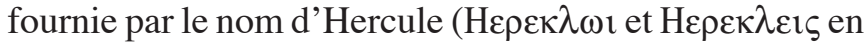
Lucanie) (respectivement Rix 2002 Lu 64 et Lu 26), qui ne reproduit pas l'orthographe originaire du nom grec

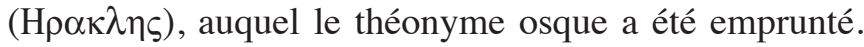
Cette graphie est respectueuse de la prononciation /e/ de la voyelle initiale, qui s'était diffusée dans la langue osque à l'époque de l'emprunt, comme le montre la graphie Herekleís de l'alphabet d'origine étrusque.

Les parcours différents suivis par l'adoption des signes pour $\langle\eta\rangle$ et $\langle\omega\rangle$ dans les règles de l'orthographe osco-grecque nous sont confirmés par les textes datant du tournant du $\mathrm{IV}^{\mathrm{e}} \mathrm{s}$., qui montrent que l'emploi de ces signes n'a pas été symétrique et que l'introduction de $\langle\eta\rangle$ précède celle de $\langle\omega\rangle$. Ainsi, la loi de Roccagloriosa ignore $\langle\omega\rangle$, alors que $\langle\eta\rangle$ ne figure que d'une manière sporadique et non systématique, en accompagnement d'autres voyelles, comme par exemple dans les digraphes $\langle\eta \alpha\rangle$ et $\langle\eta \uparrow\rangle$. D'une manière parallèle, un autre texte datant de la même époque, mais s'inscrivant dans un contexte bien différent, à savoir la tablette d'imprécation de Petelia, présente $\langle\omega\rangle$ uniquement dans la partie en grec, notamment dans la flexion « dorienne » du génitif en $-\omega$ des prénoms, alors que $\langle\eta\rangle$ figure dans un mot

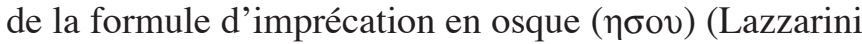
2004). De même les deux textes provenant du sanctuaire d'Apollon Alaios présentent le signe $\langle\eta\rangle$, mais $\langle\omega\rangle$ ne figure que dans un seul, précisément dans le digraphe $<\omega v\rangle$, inconnu par ailleurs, du prénom $\Omega v \delta \delta ı \eta ı$ (Rix $2002 \mathrm{Lu} 24)$. Ces documents, datés entre la fin du IVe et le début $\mathrm{III}^{\mathrm{e}} \mathrm{s}$., confirment d'une manière convergente que l'adoption du signe $\langle\eta\rangle$ précède celle de $\langle\omega\rangle$. En outre, alors que les textes qui présentent $\langle\omega\rangle$ exhibent constamment $\langle\eta\rangle$, l'inverse n'est pas vrai. Dans une inscription de Rossano, la diphtongue palatale est notée $\langle\eta \uparrow\rangle$, tandis que la vélaire est écrite $<0 F\rangle$ (et non pas $\langle\omega F\rangle$ ) : c'est le théonyme $\Delta$ 1o $F \eta 1 \varsigma$ (Rix 2002 Lu 27) qui se distingue de $\Delta \imath \omega F \eta 1 \varsigma$ et $Z \omega F \eta 1$ (respectivement Rix 2002 Lu 5 et Lu 35) dans le même endroit.

Les parcours différents suivis par l'introduction de $\langle\eta\rangle$ et $\langle\omega\rangle$ se reflètent dans l'emploi asymétrique de ces signes qui accompagnent l'histoire de l'écriture osco-grecque de son début jusqu'à sa disparition. De ces traitements distincts sont responsables, d'une part, l'évolution mentionnée de $\langle\eta\rangle$, qui n'était pas symétrique à celle de $\langle\omega\rangle$ dans le versant vélaire, et, de l'autre, la

18 Une autre explication qui fait appel à des morphèmes différents a été propose par Prosdocimi 2002, 73. 


\begin{tabular}{|c|c|c|}
\hline & Série vélaire & Série palatale \\
\hline Alphabet étrusque & $<\mathrm{U}>,<\mathrm{u}>$ & $<\mathrm{i}>,<\mathrm{i}>,<\mathrm{e}>$ \\
\hline Alphabet grec & $<\mathrm{O}>,<\omega>$ & $<\mathrm{l}>,<\varepsilon>,<\varepsilon \mathrm{l}>$ \\
\hline & $<\mathrm{O} v>,<\mathrm{O}>$ & \\
\hline & $<\mathrm{O} v>,<\omega>$ & \\
\hline
\end{tabular}

Fig. 11. Les graphèmes vocaliques de l'osque.

structure asymétrique du système vocalique de l'osque dont témoigne l'alphabet d'origine étrusque.

En effet, les trois systèmes graphiques des voyelles attestés à Rossano (fig. 10) ont pour dénominateur commun l'asymétrie entre la série des voyelles vélaires et celle des voyelles palatales. Même si l'alphabet hellénistique mettait à disposition trois graphèmes pour la série vélaire, à savoir $\langle 0\rangle,\langle 0 v\rangle,\langle\omega\rangle$, les lapicides en activité dans le sanctuaire lucanien n'ont jamais employé plus de deux signes à chaque fois. Ce choix reproduit le système de deux signes dont disposait l'écriture en alphabet étrusque, c'est-à-dire $<u>$ et $<$ ú $>$, ce qui rend manifestes les contacts entre les deux aires alphabétiques (Lazzeroni 1983). Le parallélisme avec le système graphique osco-étrusque se répète pour les voyelles palatales, pour lesquelles on constate en revanche l'emploi simultané de trois signes $\langle l\rangle,\langle\varepsilon\rangle,\langle\varepsilon l\rangle$ avec valeur de simple voyelle. En conclusion, l'alphabet osco-grec dans ses variantes reproduit constamment l'asymétrie de l'alphabet étrusque entre deux seuls graphèmes dans la série vélaire et trois graphèmes de la série palatale (fig.11).

\section{Conclusion}

Les documents qui ont enrichi récemment le dossier épigraphique de l'osco-grec dessinent une image de ce système d'écriture plus complexe que celle qui avait été esquissée auparavant. Ce système s'insère dans un cadre unitaire et commun, mais avec des différenciations locales remarquables concernant et les tracés de certains signes et l'orthographe, ce qui le distingue profondément du domaine de l'alphabet osque d'origine étrusque. L'alphabet osco-grec s'inscrit dans une ligne de continuité de l'écriture en alphabet achéen chez les communautés de Lucanie et du Bruttium, dont les traces se retrouvent dans un des signes employés pour noter /f/, vraisemblablement issu de celui qu'on trouve dans l'inscription de Tortora en alphabet achéen. De même, l'écriture osco-grecque a hérité des flottements et des variations qu'on constate dans les inscriptions archaïques en alphabet achéen, comme par exemple dans la notation des diphtongues. Ces variations ont été occasionnellement encouragées par les contacts avec le système alphabétique campanien d'origine étrusque.
Les documents nouveaux confirment que la formation de l'écriture osco-grecque est le résultat de parcours différenciés d'un endroit à l'autre et aussi, le plus souvent, des expériences individuelles qui impliquent des influences de chaque milieu local, en rapport dialectique avec les tendances générales du système. De plus, les diverses «écoles graphiques », qui se concentrent dans l'épigraphie du sanctuaire de Rossano, se montrent très attentives à la cohérence avec le système phonétique de la langue, constamment sousjacent dans les choix orthographiques. Ces choix sont respectueux de la symétrie avec l'écriture de l'osque en alphabet étrusque, ce qui rend manifestes, surtout à une époque plus tardive et en Lucanie, les efforts d'harmonisation entre les deux zones alphabétiques contigües. D'ailleurs, les contacts ininterrompus avec le domaine alphabétique de la Campanie, d'une part, et les évolutions de l'alphabet grec de l'autre, constituent la clé essentielle pour comprendre les écritures des langues sabelliques dès l'époque archaïque. La fidélité aux traditions graphiques plus anciennes se manifeste dans la continuité de la ligne de démarcation graphique entre les deux zones, qui n'a pas été modifiée par le changement des alphabets.

Cette mosaïque si complexe confère aux écritures des langues sabelliques une place tout à fait à part dans les systèmes d'écriture de la Méditerranée ancienne. On ne serait pas trop surpris que dans l'avenir de nouvelles découvertes conduisent à modifier, sur certains points, le tableau qu'on vient d'esquisser.

\section{Bibliographie}

Arena 1983 : ARENA(R.) - Valori differenziati di alcune lettere nelle diverse tradizioni alfabetiche della Grecia antica. $A I \Omega N 5,1983$, p. 197-227.

Arena 2001 : ARENA (R.) - Varianti fonetiche e morfologiche nel greco di Sicilia. In : Norma e variazione nel diasistema greco, a cura di C. Consani e L. Mucciante, Alessandria, 2001, p. 7-16.

Campanile 1981 : CAMPANILE (E.) - Prolegomeni ad un'analisi della varaizione linguistica nei dialetti italici e nel gallico. $A I \Omega N 3,1981$, p. 37-46 (réimpr. dans Latina \& Italica. Scritti minori sulle lingue dell'Italia antica, Pise-Rome, 2008, p. 735-744).

Colonna 1984 : COLONNA (G.) - Un « trofeo » di Novio Fannio comandante sannita. In : Studi di antichità in onore di Guglielmo Maetzke, Rome, 1984, p. 229-241 
Crawford 2006 : CRAWFORD (M.) - The Oscan Inscriptions from Messana. In : Guerra e pace in Sicilia e nel Mediterraneo antico (VIII-III sec. A.C.), Pise, 2006, p. 521-525.

Cristofani 1998 : CRISTOFANI (M.) - Sull'origine della scrittura oscogreca. Studi Etruschi 62, 1998, p. 275-279.

Cristofani 1999 : CRISTOFANI (M.) - Litterazione e processi di autoidentificazione etnica fra le genti dell'Italia arcaica. In : La colonisation grecque en Méditerranée Occidentale, Actes de la rencontre scientifique en hommage à Georges Vallet (Rome-Naples, 15-18 novembre 1995), Rome, 1999, p. 345-360. Del Tutto Palma 1989 : DEL TUTTO PALMA (L.) - Epigrafia lucana. Quaderni dell'Istituto di Linguistica dell'Università di Urbino 6, 1989, p. 93-118.

Del Tutto Palma, Prosdocimi, Rocca 2001 : DEL TUTTO PALMA (L.), PROSDOCIMI (A. L.), ROCCA (G.) - Lingue e cultura intorno al 295 a.C. : tra Roma e gli italici del Nord. In : La battaglia del Sentino. Scontro fra nazioni e incontro in una nazione, (Quaderni Linguistici e Filologici Università di Macerata XIV), p. 407-665

Dubois 2002 : DUBOIS (L.) - Inscriptions grecques dialectales de Grande Grèce. II Colonies Achéennes. Genève, 2002.

Dupraz 2010 : DUPRAZ (E.) - Les Vestins à l'époque tardo-républicaine. Du nord-osque au latin. Publication des Universités de Rouen et du Havre, 2010.

Gualtieri, Poccetti 2001 : GUALTIERI (M.), POCCETTI (P.) - La Tabula Bronzea di Roccagloriosa. In : Roccagloriosa II. L'oppidum Lucano e il territorio, (Collection du Centre Jean Bérard), Naples, 2001, p. 197-274.

Jeffery 1990 : JEFFERY (L.) - The Local Script of Archaic Greece. Oxford, 1990.

Lazzarini 2004 : LAZZARINI (M. L.) - Lamina plumbea iscritta da Petelia. Mediterraneo Antico 7, 2004, p. 673-680.

Lazzarini 2009 : LAZZARINI (M. L.) - Interazioni onomastiche nel Bruzio ionico. In : L'onomastica dell'Italia antica : aspetti linguistici, storici, culturali, tipologici e classificatori, Collection de l'École Française de Rome 413, Rome, 2009, p. 425-431.

Lazzarini, Poccetti 2001 : LAZZARINI (M.L.), POCCETTI (P.) - L'iscrizione paleoitalica di Tortora. In : Il mondo enotrio tra VI e V secolo a.C., Atti dei seminari napoletani (1996-1998), (Quaderni di Ostraka 1, 2) Naples, 2001.

Lazzeroni 1983 : LAZZERONI (R.) - Contatti di lingue e di culture nell'Italia antica. Modelli egemoni e modelli subordinati nelle iscrizioni osche in grafia greca. $A I \Omega N 5,1983$, p. 171-182.

Lejeune 1949 : LEJEUNE (M.) - Sur le traitement osque de *-ā final. Bulletin de la Société de Linguistique 45, 1949, p. 104-110.

Lejeune 1962 : LEJEUNE (M.) - Notes de linguistique italique XVI, Sur la notation des voyelles vélaires dans les alphabets d'origine étrusque. Revue des Études Latines 40, 1962, p. 149-169.

Lejeune 1967 : LEJEUNE (M.) - Notes de linguistique italique XXI, Les notations de f dans l'Italie ancienne. Revue des Études Latines 44, 1967, p. 141-181.

Lejeune 1970 : LEJEUNE (M.) - Phonologie osque et graphie grecque, I. Revue des Études Anciennes 72, 1970, p. 271-316.

Lejeune 1971 : LEJEUNE (M.) - Il santuario lucano di Macchia di Rossano di Vaglio (en collaboration avec D. Adamesteanu). Memorie dell'Accademia Nazionale dei Lincei, s. VIII, 16, p. 39-83.
Lejeune 1972a : LEJEUNE (M.) - Phonologie osque et graphie grecque, II. Revue des Études Anciennes 74, p. 5-13.

Lejeune 1972b : LEJEUNE (M.) - Les épigraphies indigènes de Bruttium. Revue des Études Anciennes 75, p. 1-12

Lejeune 1975 : LEJEUNE (M.) - Réflexions sur la phonologie du vocalisme osque. Bulletin de la Société de Linguistique 70, p. 233-251.

Lejeune 1983 : LEJEUNE (M.) - Rencontres de l'alphabet grec avec les langues barbares au cours du Irr millénaire avant J.-C. In : Modes de contact et processus de transformation dans les sociétés anciennes (Actes du Colloque de Cortona, mai 1981) [Collection de l'École Française de Rome, 67], p. 731-751. Lejeune 1990 : LEJEUNE (M.) - Méfitis d'après les dédicaces lucaniennes de Rossano di Vaglio. Louvain-La-Neuve, 1990.

Maggiani 1984 : MAGGIANI (A.) - Iscrizioni iguvine e usi grafici dell'Etruria settentrionale. In : Prosdocimi (A. L.) (éd.), Le Tavole Iguvine, Florence, 1984, p. 217-237.

Marinetti 1985 : MARINETTI (A.) - Le iscrizioni sud-picene, I. Testi. Florence, 1985

Nava, Poccetti 2001 : NAVA (M. L.), POCCETTI (P.) - Il santuario lucano di Rossano di Vaglio. Una nuova dedica ad Ercole. Mélanges de l'École Française de Rome (Antiquité) 113/1, 2001, p. 95-122.

Orioles 1992 : ORIOLES (V.) - Bilinguismo e biculturalismo nella Messana Mamertina. In : Studi linguistici e filologici offerti a G. Caracausi, Palerme, 1992, p. 331-345.

Poccetti 1988 : POCCETTI (P.) - Lingua e cultura dei Brettii. In : Per un'identità culturale dei Brettii, a cura di P. Poccetti, Naples, 1988, p. 3-158. Poccetti 1993 : POCCETTI (P.) - Nuova laminetta plumbea osca dal Bruzio., In : Crotone e la sua storia tra IV e III secolo a.C., Naples, 1993, p. 213-232. Poccetti 2000 : POCCETTI (P.) - Note sulla stratigrafia della toponomastica della Calabria antica. In : Toponomastica calabrese, a cura di J. B.Trumper, A. Mendicino, M. Maddalon, Rome, 2000, p. 87-116.

Poccetti 2001 : POCCETTI (P.) - Perspectives actuelles dans le domaine des langues italiques dans le sillage de Michel Lejeune. Comptes Rendus Académie des Inscriptions et Belles-Lettres, 2001, p. 185-196.

Poccetti 2007 : POCCETTI (P.) - Profilo linguistico dell'area vestina tra età preromana e romana. In: "I campi aperti di Peltuinum dove tramonto il sole....". Saggi sulla terra di Prata d'Ansidonia dalla protostoria all'età moderna, a cura di A. Clementi, Deputazione Abruzzese di Storia Patria, L'Aquila, 2007, p. 359-389.

Poccetti 2010 : POCCETTI (P.) - Intorno ai nuovi documenti di area sorrentina : riflessioni sul novum e sul notum. In: Sorrento e la Penisola Sorrentina tra Italici, Etruschi e Greci nel contesto della Campania antica, Atti della giornata di studio in omaggio a Paola Zancani Montuoro (1901-1987), Sorrento, 19 maggio 2007, a cura di Felice Senatore e Mario Russo (Quaderni di OEBALUS 1), Rome, 2010, p. 65-102.

Prosdocimi 2002 : PROSDOCIMI (A. L.) - Il genitivo dei temi in -o nelle varietà italiche (osco, sannita, sudpiceno, etc.). Incontri Linguistici 25 , p. 65-76.

Rix 2002 : RIX (H.) - Sabellische Texte, Heidelberg, 2002.

Threatte 1980 : THREATTE (L.) - The Grammar of Attic Inscriptions, I. Phonology. Berlin-New York, 1980. 



\title{
Varietà scrittorie in ambito celtico
}

\author{
Aldo L. Prosdocimi \\ Professeur Université de Padoue
}

\section{Résumé}

Cet article revient sur la question de l'existence d'un alphabet celtique «national » et de l'identification de celuici avec le lépontique ou avec le gallo-grec. Il retrace avec précision l'histoire des différents types d'écriture de la langue celtique : le lépontique - des inscriptions les plus anciennes, comme celle de la « tombe du Guerrier » de Sesto Celende, à la phase de romanisation ; le gallo-grec ; le celtibérique. En conclusion, même si l'alphabet lépontique a été utilisé dans un vaste espace, on ne peut pas le considérer comme porteur de l'identité celtique ; cette dernière ne se s'est pas exprimée à travers l'écriture. L'article revient aussi sur l'hypothétique interdit druidique relatif à l'écriture et propose plutôt de lier l'absence de développement de l'écriture au fait que le monde celtique ne possédait pas de structures urbaines.

Mots-clés : écriture, lépontique, gallo-grec, celtibérique, celtique, identité

\begin{abstract}
This paper wonder if a celtic "national" alphabet exists and if the lepontic or the gallo-greek might be this "national" alphabet. The history of each alphabet is drawn with precision : lepontic -from the oldest inscriptions, as the one discovered into the "tomb of the Warrior" at Sesto Celende, to the romanization ; gallo-greek ; celiberic. In conclusion, even if the lepontic alphabet has been used in a wide area, it can't be considered as something that carried celtic identity ; this identity does not express itself through writing. The paper also deals with the fact that druids would forbidden to write and propose instead that not writing is linked to the lack of urban culture in the celtic world.
\end{abstract}

Keywords: writing, lepontic, gello-greek, celtiberic, celtic, identity 


\section{Premessa generale}

Sulla trasmissione della scrittura, quale genus della species "alfabeto", ho scritto parecchio; ho posto prospettive, forse errate o estremiste, comunque diverse e, in alcuni aspetti, opposte alla concezione tradizionale delle trasmissioni/ricezioni della scrittura; in particolare ho cercato di specificare dizioni corrette ma generiche quali: "portato-esigenza culturale", "tramiti commerciali" e simili; a lato, e non contro, ho messo in risalto la funzione e correlata "prospettiva dei maestri" che danno-adattano scrittura/corpora scrittori e documentali, in ciò rivedendo il concetto di alfabeto princeps $^{1}$; etc. Sulla ricezione-creazione di nuovi alfabeti per Abstand e autoidentità ho riproposto le rune germaniche, anche in seguito a novità documentali dall'area venetica alpina ${ }^{2}$ (questo con valore euristico anche per tradizioni alfabetiche celtiche). Senza le premesse di principio di questi (e altri) scritti, quanto dirò apparirà anche più oscuro e/o banale di quello che merita l'argomentare; tuttavia, se sono validi criteri quali "culturalità" e "auto-identità etnica o culturale" riflessa nelle varietà scrittorie, da prospettiva dei "maestri”" datori di scrittura e la scrittura come "scuola", anche ove sia riflessa nelle manifestazioni più misere, e altro ancora - alcune conseguenze da me tratte sono forse errate ma comunque non banali. Anzi, la mia concezione si oppone alla banalizzazione portata dalle vulgate epigrafiche correnti, che di norma si attengono agli effetti di presenze scrittorie e non risalgono alle cause; scambiano cioè le pre-condizioni di trasmissione-ricezione (quali contatto, commercio etc.) con la causalità specifica della ricezione della scrittura: questa consiste nel volere, nel sentire il bisogno della scrittura, anche solo ideologico-culturale, da parte di chi la riceve; a sua volta la ricezione ha un correlato obbligato, a quanto mi consta trascurato, ed è il rapporto fra chi dà la scrittura rispetto a chi la riceve: l'acquisizione della scrittura è voluta dai riceventi, ma la prospettiva dell'insegnamento e la scrittura stessa sono insegnamento e "scuola" da parte di chi dà la scrittura (i "maestri'); una "scuola" di norma usa una sola scrittura, ma conosce altre varietà d'uso o di forme scrittorie, così nel presente, così nel passato: di qui la sostituzione concettuale, e non solo fenomenologica, di "corpus scrittorio princeps" ad "alfabeto/scrittura princeps".

1 Ho raccolto precedenti scritti in Prosdocimi 1990 "Alfabetari”, rivisto da prospettiva più "linguistica" in Prosdocimi 2009; per il côté celtico Marinetti, Prosdocimi 1994 e Marinetti, Prosdocimi, Solinas 2000.

2 Prosdocimi 1985; Prosdocimi 2004; a seguito delle nuove iscrizioni da Auronzo di Cadore: Prosdocimi 2006, Marinetti, Prosdocimi 2011 .

\section{Autoidentità e generalia}

Il titolo che avevo proposto, "Sur les débuts de l'écriture dans le domaine celtique", era provvisorio e pretenzioso pur se incompleto, in quanto intendevo considerare il principio e/o concetto di identità sotteso in generale al fatto scrittorio, applicato alla scrittura nelle varietà, alfabetiche e non, specialmente ove le varietà scrittorie non siano (solamente) funzionali alla notazione fonetica ma segno distintivo rispetto ad "altro", quale ipseità rispetto ad alterità ${ }^{3}$. Anche al seguito degli interventi al Convegno, e per lo spazio consentito, vorrei precisare i limiti di quanto porrò, in parte allontanando possibili fraintendimenti.

1) Il concetto di "identità" costituisce un problema logico non indifferente, particolarmente rilevato nel "clima" post-russelliano ma anche, e prima, post-hegeliano, da cui Gadamer. Ha a che fare con il mio (e di altri) approccio, ma lo accantono per la dimensione antropologica in cui la questione (aporia) astratta si reifica; in questo:

2) Il problema centrale, logicamente prius ma fattualmente ultimo, è l'emergere dell'AuTO-identità. Può darsi che "auto-identità" sia una tautologia per "identità", ma nella mia prospettiva è un punto di arrivo, un concetto ottenuto quasi per bricolage, tra alterità e ipseità ${ }^{4}$. L'autoidentità-ipseità può realizzarsi storicamente per causalità varia, ma quale causalità primaria per la scrittura come principio di auto-identità individuo, vi è l'alterità, cioè l'essere ALTRO rispetto ad ALTRO ("alter et alter" con dialettica fra TU ed EGO): il tutto con le complicazioni dell'estrinsecarsi storico degli schemi logici: there's the rub..., ostacolo forse non superabile ma, identificabile nella razionalizzazione di quello che è dato e/o di quello che è passato. Di più:

3) La base nella fenomenologia documentale, con attenzione a presenze ma anche assenze (queste significative se rispondenti ad aspettative non realizzate), per tutte le aree celtiche alfabetizzate (= "scritturizzate') si traduce nello scarto cronologico tra la compresenza di scrittura in aree limitrofe e in contatto con la celticità rispetto alla tardività della ricezione della scrittura da parte delle varie comunità celtiche; di qui:

4) L'opportunità, se non necessità, di chiarire il concetto stesso di fonte/fonti, non solo nel rapporto (in positivo) di "chi" e "perché" riceve in quanto vUOLE la scrittura da

3 Sono stato confortato in quello che avevo in calamo dai non pochi titoli sul concetto di identità da varie angolazioni, e uno esplicito del collega e amico Paolo Poccetti su Écritures et identités ethniques de l'Italie entre $V I I^{e}$ et $I V^{e} s$. av. J.-C., in questo stesso Colloquio.

4 Ne ho trattato in Prosdocimi 2011; v. anche Prosdocimi, in stampa. L'identità quale "autoidentità è dialettica tra TU-EGO, alterità-ipseità (varianti da [Fichte], Hegel, Gadamer). 
parte di un (alter) "chi" e "come" può dare la scrittura (i "maestri'), ma anche di "chi" e "perché" accoglie l'ideologia di scrittura da parte diun "chi", a priori egemone ma "negativo", diverso dalla fonte da cui è accolta la scrittura: sottolineo questo punto perché, salvo che per l'alfabeto "leponzio" (alle sue origini di \pm 600 a. C.), la dinamica sottesa mi appare quale costante per l'acquisizione e l'uso della scrittura nella celticità, dalla Narbonese e dall'Iberia fino all'ogam. Credo che la dinamica valga, almeno come tendenza, anche per molte altre culture ${ }^{5}$ : qui mi limiterò al mondo celtico e, anche qui, mi limito a spunti ed exempla.

\section{Scrittura dal VI secolo a. C. nel celtico d'Italia}

\section{Premessa specifica}

Non tratto qui la celticità linguistica di/in Italia, ora documentata con un ante quem al \pm 600 a. C.; è una celticità come FARSI e non come ESSERE DA SEMPRE, SOstanzialmente con i tratti che la identificano per ampi tempi e aree: a queste afferiscono temi individuati nel passato tipo "Renania germano-celtica", "Germanen und Kelten", etc.; afferiscono anche temi già identificati nei contorni ma da rivedere, quali la pre-celticità di aree poi celtiche, tra non celticità assoluta e pre-celticità in quanto NON ANCORA celticità, e ciò per aree periferiche quali la Liguria (in senso antico) o la (sud)Lusitania.

Pur costituendo la base di realtà linguistico-culturali cui appartiene una determinata scrittura, spesso intrinsecamente, qui focalizziamo la scrittura non in chiave linguistica (anche se non se ne può prescindere), bensì in chiave culturale quale indice di identità, sinonimo di auto-identità, etnico-culturale ove la scrittura, sia pure in varietà non strutturali, si estenda a macro-aree. All'interno delle macro-aree identificate da una scrittura di origine comune (vulgatamente "protoalfabeto", cui io ho sostituito il termine di "corpus scrittorio'), ci sono micro-aree che si caratterizzano per tratti che differenziano formalmente ma non strutturalmente le varietà locali, così da avere funzione di auto-identità, o almeno di distintività, rispetto ad altre comunità: ai massimi livelli per qualità e quantità è sostanzialmente la fenomenologia dell'epigrafia greca; a livelli ben più modesti è quanto si realizza nell'epigrafia venetica (Lejeune, Prosdocimi). La varietà interna è meno evidente per altri alfabeti che hanno arealità anche maggiore, quale è il caso dell'alfabeto leponzio; anche qui, comunque, si vanno riconoscendo varietà per aree e cronologia:

5 Tra queste, prossima, per la genesi, quella dell'alfabeto runico (alfabeto e non "rune'!) cfr. avanti e Prosdocimi 2006. affioramenti di tratti arcaici o dislocazioni spaziali per lo più hanno trovato spiegazioni (banalizzanti) nelle casualità e/o nella conservazione in aree periferiche (formula passe-partout), tuttavia si dovrebbe perseguire primariamente una causalità nella scelta grafica quale volontà di significare uno status del committente, sia questo un re/principe (regulus) per le monete ${ }^{6}$, sia questo un ceppo familiare come è il caso della bilingue di Todi secondo la brillante ricostruzione storico-avvenimentale di Lejeune, che ha forti implicazioni ideologiche e strutturali (secondo cui sarebbero da rivedere anche le iscrizioni di Briona e Vercelli, questa bigrafe-bilingue ${ }^{7}$ ).

Il rilievo qui dato alla/e grafia/e del celtico di/in Italia (e ciò che all'Italia afferisce) è dovuta in parte al fatto che l'Italia è l'ambito che conosco meglio, ma anche al fatto che presenta una quantità e qualità paleografica incomparabile per estensione cronologica, areale, sociopolitica. Credo che, finora, ne siano stati considerati solo aspetti parziali, ove fossero sollecitati da caratteristiche particolari rilevanti, ma che non ne sia stato tentato un quadro d'insieme in sé e in confronto - contrasto con altre aree di celticità (epi)grafica. E" un desideratum che né qui né altrove sono in grado di riempire, ma che segnalo in sé e perché pone i limiti, ristrettissimi, di quanto dirò concentrando alcuni spunti ${ }^{8}$ con mira al quadro più ampio; in particolare considero l'inizio ( \pm 600 a. C.) e la fine (I sec. a. C.): l'inizio perché smentisce e/o fa reinterpretare il topos della cultura druidica come anti-scrittoria; la fine quale riprova della scrittura "leponzia" quale indice di auto-identità, ivi compreso il senso di (non?) alfabeto nazionale celtico.

In questi primordi di \pm 600 a. C. è essenziale che non si ha una scrittura etrusca che nota celtico bensì una (varietà di) scrittura etrusca ADATTATA, cioè RICREATA per notare celtico in modo distinto dall'alfabeto fonte, e anche da altri alfabeti di culture diverse derivati dalla medesima fonte (corpus scrittorio etrusco). Come sottolineo da un trentennio, e ho ricordato sopra, la ricezione di alfabeto adattato dai "maestri" datori di scrittura è un processo complesso, che implica un determinato milieu culturale ben diverso dal semplice primitivismo delle acquisizioni definite genericamente "per commerci", "contatti", o simili: "commerci", "contatti" e simili sono le premesse, le condizioni ma NON sono le cause della creazione di nuovi alfabeti.

\footnotetext{
6 Sulle legende monetali Marinetti, Prosdocimi 1994 e Marinetti, Prosdocimi, Solinas 2000.

7 Per l'iscrizione bilingue di Todi come per quella di Vercelli si veda Lejeune $1988(R I G)$. Sull'iscrizione di Vercelli in prospettiva soprattutto "storica" si veda anche Wataghin Cantino 2011.

8 I più rimandano a sedi precedenti ove ne ho trattato analiticamente: per questi vedi Prosdocimi 1987, Prosdocimi 1991.
} 


\section{L'iscrizione di fine VII a. C. dalla "tomba del Guerriero" di Sesto Calende}

Come ho mostrato 9 , l'iscrizione di Sesto Calende

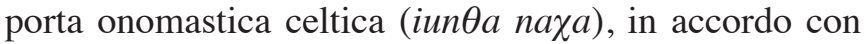
la cultura materiale del contesto, ma è scritta in alfabeto etrusco NON ancora adattato a notare la realtà linguistica locale, e ciò aveva fatto interpretare il breve testo come in lingua etrusca; il riconoscimento di celticità dell'onomastica è stato recepito come valido complemento per confermare e meglio delineare il quadro archeologico in cui si inserisce la tomba; tuttavia non è stato sufficientemente sottolineato quanto concerne la scrittura quale indice di auto-identità: l'iscrizione di Sesto Calende notante personaggio celtico in alfabeto etrusco PRECEDE di poco la creazione della scrittura leponzia, derivata da alfabeto etrusco ma continuata come non-etrusca bensì locale, cioè CELTICA. La creazione di una scrittura locale (alfabeto "leponzio"), di matrice etrusca ma ormai non propriamente etrusca perché modificata per notare la diversa realtà linguistica del luogo, pone un principio ideologico di auto-identità etnico-linguistica almeno per questo nucleo di celticità e che, per vari tramiti, continuerà fino a notare celticità diversa ("gallicità" La Tène) dall'inizio del \pm 400 a. C., fino alla romanizzazione e, per arealità più ampia del nucleo iniziale (di \pm 600 a.C.), questo da identificare con la regione dei laghi (Como, Varese e minori).

Nell'avere puntualizzato che vi è sequenza cronologica pressoché immediata ma IATO culturale tra Sesto Calende (fine VII) e alfabeto leponzio (inizio VI a. C.), non si ignorano altre aree dove alfabeti etruschi non adattati notano onomastica e morfologia celtica; altre aree in cui onomastica e, forse, morfonologia (cioè lingua) celtica è notata in alfabeti e lingue allotrie (venetico e, meno trasparente, il "retico') e altro ancora - tuttavia sequenza e compattezza strutturale e sistemica (pur nelle varianti alfabetiche) del nucleo "leponzio" offrono un ubi consistam per il nostro inizio e per le diramazioni che seguiranno nel tempo e spazio.

$\mathrm{Al} \pm 600$ a. C. l'acquisizione e l'uso dell'alfabeto non sono soggetti ad alcun interdetto da parte della cultura celtica ("druidica" secondo la tradizione), almeno in Italia. Di contro, sarà da considerare l'ex silentio di altre aree potenzialmente esposte ad irradiazione/acquisizione della scrittura, più o meno alla medesima data, l'area circum Massalia (fondata nel 600) e l'area iberica (inizi della scrittura iberica al VII-VI a. C.): la non notazione in alfabeto iberico di una lingua celtica, FINO ad una certa data

9 Prosdocimi 1990, p. 298: Prosdocimi 1991, p. 148 sgg. Su questa iscrizione si vedano anche De Marinis 1986, p. 60; Gambari, Colonna 1988.
( \pm inizio III a. C.), è un ex silentio che va INTERPRETATO e non solo constatato (avanti). Qui pongo alcune note sull'area cisalpina (con incursioni circum/trans alpine) perché è una arealità che offre, sia pure con i vuoti e le incognite delle acquisizioni archeologiche, una continuità documentale di circa sei secoli: dall'alfabeto ancora etrusco di Sesto Calende (sopra) all'alfabeto leponzio di Castelletto Ticino ( \pm 550 a. C.) e di Prestino (circa \pm 500 a. C.) con tipologia di alfabeto etrusco di almeno inizio VII-VI a. C., ivi compresa la $o$ quale lettera dell'alfabeto "teorico" etrusco ancora vitale e insegnato nel VI a. C.

\section{La fase di romanizzazione}

In Italia la dimensione cronologica si collega intrinsecamente all'arealità, a sua volta conseguenza di vicende storiche e culturali di relativa identificabilità ma certo superiore a quella di altre aree "celtiche/celtizzate". Per quanto concerne la fase di romanizzazione, la documentazione si va arricchendo in modo fino a poco tempo fa impensabile, non tanto e non solo per quantità ma per qualità: nuove aree, e, soprattutto un nuovo modo di essere della scrittura leponzia entro la scrittura romana, per lo più senza funzionalità fonetica individuabile quindi, per esclusione e verisimiglianza, una volontà di significare la loro identità come non romana, anche se in piena romanizzazione.

Finora le aree interessate da novità significative che si collocano a cronologie di romanizzazione più o meno avanzata sono quella veneta del territorio della provincia di Verona (già edite le necropoli di Santa Maria di Zevio, di Isola Rizza, Valeggio sul Mincio, non ancora ad esempio quella di Povegliano ${ }^{10}$ ), quella piemontese della provincia di Biella, in particolare dalla necropoli di Cerrione ${ }^{11}$, quella lombarda dell'alta Val Brembana ${ }^{12}$. Da segnalare è anche l'iscrizione in alfabeto leponzio rinvenuta a Ayent nel Vallese, in un contesto di III/IV sec. d. C. che però rivela segni di insediamento precedente, fin dal IV-II a. C.: l'importanza del documento è evidentemente legata alla sua provenienza e in questa chiave sarà da studiare e contestuare ${ }^{13}$.

Buona parte dei materiali è in corso di studio, alcune aree sono oggetto di scavo e stanno offrendo materiali significativi. Un bilancio è ovviamente prematuro, ma

10 Cfr. Solinas 1995, Solinas 1996, Solinas 1998, Solinas 2002.

11 Per i materiali iscritti in alfabeto leponzio e latino dal sepolcreto di Cerrione (Biella; II sec. a. C. al II d. C.) cfr. Cresci Marrone, Solinas 2012.

12 Per le nuove iscrizioni in alfabeto leponzio riconosciute in mezzo a numerosissimi disegni e scritti rupestri di varie epoche (prevalentemente posteriori al XIII sec. d. C.) e datate alla seconda età del Ferro ossia al III-II sec. a. C. cfr. Motta 2008.

13 L'iscrizione è stata pubblicata da Paccolat, Rubat-Borel 2009. 
si possono avanzare delle previsioni e delle direttive di lavoro sul senso storico-culturale di tale fenomenologia che amplia sia per cronologia, arealità e culturalità quanto era affiorato in precedenza, a partire dal senso delle bilingui e bigrafi - questione già individuata da M. Lejeune - e, in seguito, alla interpretazione della reviviscenza - almeno documentale - delle iscrizioni "leponzie" in II-I a. C. e di altro.

\section{Sul topos "Druidi" e gli inizi della scrittura in area celtica}

Do per scontato il topos sull'avversione dei druidi per la scrittura, esaltato o dimensionato fino a negarlo. Mi limito ad una osservazione di buon senso: ogni tradizione ha un fondamento, anche se il tempo e le varie traversie e/o ideologizzazioni trasformano il nucleo di partenza. Ciò posto, non intendo entrare nella questione bensì porre alcune riflessioni.

Un'area di celticità nell'Italia settentrionale a ragione o a torto definita come "leponzia" dalla tradizione ${ }^{14}$, riceve la scrittura da alfabeti etruschi al \pm 600 a. C., contemporaneamente ad altre aree contigue, linguisticamente non celtiche, quali il venetico o il retico. Non ci sono elementi per differenziare lo status di ricezione ed adattamento della scrittura per insegnamento tra aree celtiche e non celtiche: evidentemente (almeno) questa celticità non è ostile all'uso della scrittura in monumenti "pubblici" (iscrizione di Prestino) e privati in funzione pubblica (iscrizioni funerarie e/o celebrative); il tutto in un quadro per cui non si tratta semplicemente dell'uso di scrittura in ambiente di lingua (e cultura) celtica: non è una generica varietà scrittoria "nordetrusca" - come nella dizione ottocentesca (Mommsen 1853; Pauli 1885) bensì una scrittura differenziata rispetto ad altre scritture "nordetrusche" quali la venetica e la retica, e, come tale, è una scrittura caratterizzante QUESTA celticità, quale primo affiorare documentale di celticità tout court (sopra).

\section{La distribuzione cronologica delle iscrizioni: lo schema "a clessidra"}

L'aver riportato l'iscrizione di Prestino al \pm 500 a. C. ("ante" più che "post"); una serie di iscrizioni monumentali di V-IV a. C.; la proiezione all'inizio del VI a. C. dell'alfabeto leponzio (sopra); l'aver riconosciuto

14 Tale CONVEnZIONE terminologica si è da tempo per varie ragioni mostrata inadeguata all'identificazione delle testimonianze epigrafiche della celticità linguistica in Italia; ritengo tuttavia inutile se non nocivo confondere ulteriormente la questione con ulteriori etichette e corrispondenti contenuti: cfr Prosdocimi 1991; sulla questione storiografica di questa ed altre "etichette" impiegate per il celtico d'Italia v. Solinas 1992-1993 e Solinas 1993-1994. varietà nell'alfabeto leponzio che affiorano anche in epoche recenti (specialmente nelle monete); l'avere incrementato il corpus ${ }^{15}$, in particolare nella fase recente o recentissima ${ }^{16}$; l'avere dissolto la contrapposizione tra "leponzio" e "gallico (così Lejeune) in favore di "dialettologia celtica' ${ }^{17}$ - questo ed altro fanno rilevare per l'alfabeto "leponzio" una documentazione distribuita a clessidra in funzione del tempo (e, meno evidentemente, dell'arealità); pertanto si può schematizzare (fig. 1).

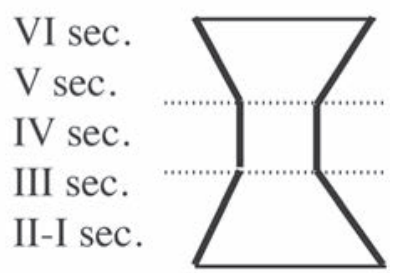

Fig. 1.

La graficizzazione, per quanto rozza e imprecisa, mette in evidenza una fenomenologia che va interpretata e spiegata nelle cause storico-culturali e non solo constatata per quei (non molti) che l'hanno rilevata. L'interpretazione non può restringersi a singoli aspetti (cronologici e/o areali e/o culturali) perché la fenomenologia così graficizzata non propone né concerne elementi singoli - anche se questi ne sono la base materiale, spesso frammentata per la singolarità delle "scoperte" di nuovi dati - bensì strutture tali che propongono un

15 La documentazione epigrafica celtica d'Italia non ha atttualmente un'edizione d'insieme e unitaria per qualità e metodo cosicché, pur nell'evidenza di imprecisioni e incompletezza di un'opera datata, spesso ancora oggi si rimanda a Conway. Johnson, Whatmough 1933 , in sigla $P I D$; per le iscrizioni rinvenute più recentemente si usa richiamare Lejeune 1971 o Tibiletti-Bruno 1978 e per le iscrizioni cosiddette "galliche d'Italia" il riferimento rimane il Lejeune del RIG (1988). Una silloge preliminare ad un'edizione è stata proposta da Solinas 1994 ma, pubblicata ormai da più di un decennio, anche questa necessita di varie integrazioni; significativa ma non completa è la raccolta di testi proposta da Motta 2002. Di recente sono apparsi anche i due volumi intitolati I Celti d'Italia (Piana-Agostinetti, Morandi 2004). Il volume "archeologico" curato da P. Piana-Agostinetti si è mostrato utile e utilizzabile per il reperimento dei materiali e per la loro contestuazione archeologica, mentre quello "epigrafico-linguistico", curato da A. Morandi, è caratterizzato da numerose incongruenze e da evidenti carenze sia sul fronte della tecnica epigrafica sia su quello della riflessione linguistica e per questo è utilizzabile solamente come riferimento per un'idea complessiva dell'insieme quantitativo dei testi.

16 Le principali novità pertinenti a cronologia tarda sono già state messe menzionate sopra in testo e note relative.

17 Con la varietà fisiologica per tempi, spazi e stratificazione sociale, anche se con iati e/o giunzioni qualitativamente e quantitativamente: Prosdocimi, nei lavori citati a nota 8. 
sistema, articolato sì ma où tout se tient (o dovrebbe tenersi) storicamente per tempo, aree, culture. Per ragioni contingenti, in questa sede focalizzo (brevemente) la fase finale, in quanto è una fase particolarmente significativa per il tema "alfabeto nazionale". Tuttavia, per l'interpretazione di una struttura crono-areale in cui tout se tient, si deve premettere quanto precede l'ultima fase crono-areale (e culturale...). La prima fase (VI-inizio IV a. C.) ha una specificità "leponzia" ma, come detto, rientra nella fenomenologia degli inizi epigrafici dell'Italia antica: nelle varietà linguistiche e culturali dell'Italia antica la fase iniziale dell'acquisizione della scrittura ha iscrizioni testualmente più lunghe, non per ripetitività ma per concettualità del contenuto: per tutte richiamo le iscrizioni falische di VII-VI a. C. o, per Roma, le iscrizioni "di dueno" e del cippo del Foro. E" altresì un dato statistico che le iscrizioni successive (e per spazio di secoli) sono inferiori per quantità e/o qualità, e a questo non fa eccezione l'area di alfabeto leponzio, quale che sia la varietà di celtico che nota, entro cui la gallicità "La Tène' ${ }^{\prime}$.

Lo strozzamento della clessidra deve essere approfondito nella causalità storico-culturale, tuttavia, quale ne sia la motivazione causale, è un fatto che dopo la "strettoia" di IV-III sec. a. C. la clessidra si apre con iscrizioni di quantità, e in alcuni casi di qualità, ben superiore a quella di due secoli precedenti.

Le iscrizioni leponzie più recenti (fine III-II sec. a. C.), la maggior parte delle quali "tradizionali" (tipo Ornavasso), con l'aggiunta delle leggende monetali dovrebbero spiegarsi - secondo il modello "clessidra' - con gli avvenimenti storici cronologicamente corrispondenti e cioè la presenza di Roma, prima con una conflittualità bellica (per tutti il 225 a. C.), in seguito con una conflittualità latente, così come è latente e strisciante la romanizzazione con affioramenti quali il kuitos lekatos di Briona o la bilingue-bigrafe di Vercelli. In questo "odi et amo" una posizione particolare assume l'iscrizione bilingue-bigrafe di Todi, di un nucleo di Celti per il quale Lejeune ha ipotizzato una provenienza settentrionale e precisamente da quell'angolo della Cisalpina, fra Pavia, Vercelli e Novara, dove la varietà di alfabeto leponzio impiegato nell'iscrizione di Todi pare aver avuto origine. Per ragioni immaginabili ma non individuabili nello specifico, questi migrants avrebbero mantenuto le tradizioni di grafia, di lingua e di

18 A tale gallicità nella vulgata associata al nome "storico" dei Senones di Brenno e al correlato sacco di Roma (inizio IV a. C.); al proposito ho mostrato (1987) che l'inizio della celticità con il La Tène associato a Brenno e ai suoi Senones è errata nei fatti di lingua anteriori al \pm 400 a. C. e in una rivisitazione delle notizie che riportano l'arrivo dei celti (di Bellovesus e Segovesus) alla sincronia con Tarquinio Prisco e cioè al \pm 600 a. C. onomastica del loro luogo di origine per un periodo che non si riesce a circoscrivere, in quanto non è possibile datare con certezza né la "migrazione" né l'iscrizione ${ }^{19}$.

In un quadro del tipo posto sopra, il riemergere quantitativo e qualitativo ${ }^{20} \mathrm{di}$ iscrizioni in alfabeto leponzio tra fine III e I a. C. non può essere attribuita che alla presenza romana, di fatto egemone a più livelli, che sollecita per Abstand una reazione di cui alfabeto e lingua sono una manifestazione ideologica ${ }^{21}$.

L'arricchimento documentale degli ultimi anni ha portato qualcosa di nuovo e, almeno, una nuova angolazione nella fase di passaggio dalla celticità alla romanizzazione, tra lingua e alfabeto: in aree già celtiche la transizione da lingua e alfabeto "leponzio" a lingua e alfabeto latino si realizza con grafia leponzia entro grafia latina, e con varia linguisticità e onomastica tra latino e celtico ${ }^{22}$ : si ha una prova di volontà di connotarsi come celti quali DIVERSI dalla romanità; qui appare una evidenza in sé ma ci sono conferme da altre aree:

- in venetico, arealmente prossimo, c'è continuità culturale e linguistica ma non ci sono iscrizioni con grafie miste, anche se ci sono casi di parallelo di compresenza scrittoria ${ }^{23}$;

- nelle aree di scrittura "gallo-greca" e "celtiberica" non si ha, per ora, attestata una fenomenologia "tipo Cisalpina". Anche facendo la tara alla costitutiva impenetrabilità tra grafia iberica e latina, l'aspetto è significativo;

- una ulteriore conferma, ma anche da storicizzare come fenomenologia in sé, è il complesso di grafia latina per notare celtico in Gallia: a parte un paio di grafi, funzionali a notare $(\theta)$ un fonema locale, estranei alla

19 Per Lejeune infatti non è rintracciabile alcun elemento per una certa attribuzione cronologica: da una tomba isolata, senza contesto con indicazioni di cronologia, un'iscrizione bilingue può a priori collocarsi a partire almeno dall'età graccana (forse dalla metà del II sec. a. C.) fino alla fine della repubblica; EI, ortografia latina per $\bar{l}$, comincia ad affermarsi almeno dal 150 a. C. e dunque, unico indice per la cronologia rimane, secondo Lejeune, l'onomastica completamente indigena: cfr. Lejeune $R I G * \mathrm{E}-2$.

20 Nella "qualità" e oltre alla concettosità dei testi epigrafici, è compreso anche il riaffiorare e/o riappropriarsi di forme alfabetiche arcaiche.

21 In questo, con mezzi diversi, si ha il medesimo comportamento che per l'adozione dell'alfabeto greco nella Narbonese e dell'alfabeto iberico per il celtiberico: avanti.

22 Si veda ad esempio il caso dell'iscrizione dalla necropoli di Santa Maria di Zevio a testo ateporix (composto squisitamente celtico a secondo elemento -rix) che, oltre che per l'evidente celticità onomastica è significativa per essere redatta in un alfabeto latino in cui sono inseriti grafi dell'alfabeto leponzio ( $a$ e $p)$ : gallica è la tomba dalla quale il documento proviene, gallica la forma onomastica ateporix, leponzio il modello grafico a cui allude la soluzione grafica adottata: cfr. Solinas 2002.

23 Si veda in particolare il caso della tavoletta alfabetica votiva da Este (Es 23), bigrafe e bilingue: Prosdocimi 1988, p. 271-274. 
grafia latina e quindi "non ideologici", l'alfabeto latino è - a partire da una certa data - espressione di novità socio-culturali e, quindi, di un variato rapporto ideologico con la grafia dei "conquistatori" (il che non implica un post-quem alla battaglia-guerra di Alesia, ma solo un circa-quem ideologico, a priori diverso per cronologia dalla grafia gallo-greca della Narbonese).

Ci sarebbero appendici sulle scritte non monumentali e/o pubbliche, tipo Graufesenque o il corsivo latino tipo Larzac, ma quanto abbiamo posto pare sufficiente, insieme con l'ogam, alle considerazioni che trarrò alla fine della rassegna.

\section{L'alfabeto gallo-greco}

In questa sede, in primis alla presenza del caro Festeggiato, mi sento particolarmente inadeguato a trattare di una arealità culturale complessa e che, dal punto di vista epigrafico conosco principalmente per l'opera di Lejeune (e Colbert de Beaulieu). Per quanto concerne le legende monetali, soprattutto per il nome Nemauso-/ Namauso- e le conseguenze per la morfonologia di -em/-am- rimando ad altra sede. Per le legende delle monete del Rodano in alfabeto "leponzio", anche al seguito delle obbiezioni rivoltemi, mi propongo di rimeditare la loro rilevanza per il tema "alfabeto nazionale celtico" attribuito all'alfabeto leponzio: contro all'affermazione di $\mathrm{M}$. Lejeune che - se di alfabeto nazionale si doveva parlare - questo era da riconoscere nell'alfabeto gallogreco. A tale identificazione, per altro sfumata come era nello stile del Maestro, ho contrapposto che, se di "alfabeto nazionale" si deve parlare, questo era da riconoscere nell'alfabeto leponzio di \pm 600 a. C. durato fin entro la romanizzazione in Italia, e specialmente secondo i dati emersi nell'ultimo ventennio ${ }^{24}$, con resistenza entro l'alfabeto romano, residuali forse ma in senso attivo e non passivo: dalla fenomenologia appare non una incapacità di ricezione/uso dell'alfabeto latino, quanto un inserimento di tratti dell'alfabeto leponzio, per volontà di connotare la propria identità celtica entro la romanizzazione conclusa o in via di conclusione: è l'ultimo atto, ormai in via di esaurimento ma volutamente persistente della configurazione a "clessidra" dell'uso dell'alfabeto leponzio di cui sopra.

Le obbiezioni a singoli punti - in particolare sulla monetazione della Narbonese "rodaniana" e all'altro estremo, del Noricum - mi hanno portato a una riconsiderazione generale, e cioè sulla esistenza stessa o, meglio, sul SENSO stesso di esistenza o non esistenza

24 Vedi sopra e per una sintesi Solinas 2010. di un "alfabeto nazionale" celtico e/o anche restrittivamente gallico ${ }^{25}$ : qui, sia pure con alcuni correttivi, mi attengo, currenti calamo, alla situazione della epigrafia gallo-greca quale si evince dal magnum opus Récueil des Inscriptions Gauloises.

Parto da alcuni dati di fatto, latamente cronologici ma, pur nel non approfondimento al decennio o anche a più decenni, sufficientemente significativi per le varie sfaccettature storico-culturali che può assumere il rapporto post hoc $=$ propter hoc?: ho lasciato interrogativo il topico ergo perché qui assume una configurazione particolare che va accettata quale fenomenologia/factum da interpretare in quello che non c'è ("aspettative mancate') più ancora che in quello che c'è, e di quello che c'è va considerato oltre il "quando", il "come" - da cui forse "il perché" o "un perché" causale della fenomenologia.

Massalia è fondata nel 600 a. C.; è, o comunque diviene, un centro di cultura materiale, tra cui la monetazione che irradia in buona parte della celticità anche realmente lontana e, se si può dire, sovra-cantonale e, in quanto non olet, sovra-nazionale. Non ho competenze numismatiche specifiche, anche se ho dovuto occuparmi di monete per le legende e le problematiche sottostanti per varie aree dell'Italia antica e afferenti; tra queste, in particolare, per la monetazione celtica a grafia leponzia ${ }^{26}$ : vi rimando per quel poco che ho apportato affronte ad una problematica che, almeno dal mio punto di vista, presenta non poche incognite e lati da esplorare. In questa sede mi limiterò a riprenderne un paio: qui, termine immediato, l'evoluzione iconica della legenda MA $\Sigma \Sigma A$, in sé e in rapporto alle successive legende sovrimpresse in alfabeto leponzio; più avanti sull'uso dell'alfabeto leponzio in aree periferiche e/o esposte ad altri poli alfabetici in cui ci si sarebbe aspettato l'uso di altro alfabeto (venetico? gallo-greco? latino?).

Massalia per secoli non irradia cultura alfabetica o, più precisamente il suo irradiare politico-economico e culturale non contempla l'uso dell'alfabeto come forma e contenuti: a priori pare perché l'ambiente circostante non è interessato alla "cultura alfabetica': l'ex silentio di secoli ha la forza di un factum positivo, che si potrebbe ascrivere al dossier "antiscrittualità druidica" ma che può, e meglio, essere imputato ad una indifferenza culturale nei riguardi della scrittualità senza che ci fosse alcuna preclusione quale divieto oggettivo. $\mathrm{Al}$ proposito ricordo che buona parte dell'area balcanica è stata senza scrittura fino alla romanizzazione avanzata,

25 Su questo tornerò avanti in sé e in contrasto con un caso analogizzabile quale è la nuclearità iniziale e la (quasi) pangermanicità delle rune in ambito germanico.

26 Per questi documenti rimando a Marinetti, Prosdocimi 1994 e Marinetti, Prosdocimi, Solinas 2000 
pur essendo esposta alla potenza culturale greca prima e greco-romana dopo. Pertanto l'attribuzione a un presupposto socio-politico "druidico" quale norma esplicita, può semplicemente essere ascritto ad una cultura che non avverte l'istanza di fissazione scrittoria, almeno fino a che non vi è una motivazione ideologica e/o funzionale alla struttura sociale o al contesto politico per assumerla: ritengo sia il caso di tutte le ricezione delle scritture notanti lingue celtiche (dal leponzio di \pm 600 a. C. all'ogam di V d. C.), ciascuna con varia motivazione avvenimentale ma analoga causalità strutturale (salvo forse particolarità concernenti l'alfabeto leponzio di \pm 600 a. C. non di principio ma per il diverso rapporto "politico" tra datori e ricettori della scrittura). Riprendo.

Massalia già dal VI a. C. è un polo che irradia, ma per secoli non c'è ricezione di scrittura greca né greca adattata, cioè la futura scrittura "gallo-greca". Lejeune attribuisce la creazione ${ }^{27}$ alla seconda metà del III a. C., ma è una cronologia approssimata (per induzione o deduzione, non mi è chiaro) che non trova supporto documentale per andare oltre la fine del III-inizio II sec. a. C.: sull'importanza di questo circa-quem tornerò, per una ragionevole motivazione politico-ideologica della invenzione della scrittura gallo-greca in quanto più o meno corrispondente al passaggio dell'Ebro (226 a. C.) da parte delle truppe romane (début de l'imperialisme ?). Riprendo dalle monete portanti le legende $\mathrm{MA} \Sigma \Sigma \mathrm{A}$, in quanto recepite (e riprodotte) ben prima della scrittura e in cui la legenda NON è recepita come scrittura bensì come ICONA che identifica il conio; un parallelo è nelle imitazioni danubiane delle dracme macedoni: l'icona di Zeus di Olimpia è trattata come tale nella dissoluzione formale da "organicità" a "astrazione", secondo la celebre formulazione di Bianchi Bandinelli ${ }^{28}$. Tuttavia pari evidenza formale, anche se meno evidente per la aniconicità, è l'evoluzione delle legende $\mathrm{MA} \Sigma \Sigma \mathrm{A}^{29}$ che evolve in forme che non hanno

27 Il modo di concepire il processo di "dare-ricevere" la scrittura da parte di Lejeune è alquanto diverso, quasi antitetico rispetto al mio, non tanto nelle cose risultanti quanto nella catena causale degli avvenimenti che determinano le "cose" e che spiegano perché per almeno tre/quattro secoli i Celti che contornano e/o gravitano su Marsiglia non abbiano scrittura, più esattamente: non avvertono la necessità culturale di esprimersi socialmente e etnicamente (culturalmente?) tramite il mezzo scrittorio.

28 Bianchi Bandinelli, 1957.

29 Non sono in grado (e chi lo è?) di sapere chi fosse in grado di riconoscere l'elemento scrittorio entro l'icona monetale, ma è verosimile che, almeno alla fonte, qualcuno lo fosse; in ogni caso la scrittura per i Celti fa parte della moneta greca quale icona e non quale scrittura, ed evolverà formalmente come icona fino a quando si dissolverà e le sarà sovrapposta una nuova iscrizione, celtica in alfabeto leponzio, anche fuori dall'area epigrafica propriamente leponzia o (alfabeticamente) gallo-leponzia; da cui riflessioni parziali da confrontare con quelle su altre aree celtiche. niente a che fare con la scritta originaria, non solo, ma su cui si sovrappongono poi le scritte in alfabeto leponzio.

Pur con l'irradiare da Massalia, la gallicità circostante acquisisce la scrittura dopo tre o quattro secoli dalla sua presenza, ed è scrittura greca tenuemente adattata per notare il gallico. Domanda legittima: perché a quest'epoca ? Domanda apparentemente superflua, se non si affianca: perché il greco e non il latino ? La risposta alla prima non rende superflua la seconda, anzi possono completarsi in una ipotesi di lavoro che, in questo contesto, rappresenta una (buona) possibilità ma che, riportata ad una tipologia più generale, si presenta come una soluzione ragionevole.

L'inizio dell'uso della scrittura è concomitante al contatto con la romanità, non semplicemente conoscitivo o commerciale, ma con gli aspetti iniziali di imperialismo che, avendo di mira l'Iberia già di influenza cartaginese, non può ignorare (almeno) la fascia gallica che congiunge Liguria ed Ebro. La romanità si presenta con tratti di dominio, cui sono associati aspetti culturali caratterizzanti, tra questi l'uso della scrittura, e questa viene assunta quale tratto distintivo associato al dominatore e pertanto acquisito quale connotazione di pari grado. Perché non è avvenuto prima per la scrittura greco-massaliota ? Perché per imitare viene adottato il greco ? La risposta è unica anche se articolata: l'elemento "scatenante" non è la grecità dei secoli precedenti, perché il rapporto d'insieme di quella grecità era diverso da quello con la romanità: è la diversità in cui si presenta la romanità che causa una ingerenza culturale e ideologica non avvertita prima. Il ricorso all'alfabeto greco potrebbe avere (almeno) due spiegazioni: la maggior rilevanza e familiarità (prestigio ?) ; oppure la negazione del modello romano, causa ideologica dell'acquisizione ma, proprio per questo, modello negato per Abstand. Le due spiegazioni non sono reciprocamente esclusive, ma la motivazione per Abstand - e correlata auto-identità si giustifica meglio all'interno, e rientra in una tipologia che tocca altri casi di acquisizioni dell'alfabeto da parte dei Celti: il celtiberico, l'ogam, per analogia l'uso, anche come sopravvivenze, dell'alfabeto leponzio quale combinazione di Abstand ed affermazione di auto-identità. Caso paradigmatico per evidenza ed elaborazione nel creare il massimo di Abstand sono, secondo la mia interpretazione, le rune ${ }^{30}$.

30 Prosdocimi 1985; Prosdocimi 2004; Prosdocimi 2006; Marinetti, Prosdocimi 2011 


\section{L'alfabeto iberico notante celtiberico}

Non è un caso che io, al seguito di altri, abbia riconosciuto come valida la decifrazione di Gomez Moreno dalla sua applicazione a testi celtiberici da parte di A. Tovar: in qualche modo l'applicazione ai testi celtiberici (relativamente pochi) allora conosciuti (anni '40-'50) ha avuto la medesima funzione convalidante del greco quale appariva dalla applicazione della griglia di Ventris al miceneo. Non vado oltre questa analogia basica perché il resto - lineare A vs. B; medesimo alfabeto per iberico e celtiberico - rappresenta una storia del tutto diversa. Tuttavia, come per l'uso dell'alfabeto greco per il gallo-greco di Lejeune, l'eccezionalità della acquisizione di una "decifrazione" e di documenti linguistici prima inaccessibili - l'iberico per l'Iberia/ibericità e il celtiberico per la celticità iberica $\mathrm{e}$, in generale, extra-/preiberica - hanno posto in secondo piano il QUANDO e il PERCHÉ (e, meno, il COME) di tale scelta alfabetica, specialmente ove il quando - come è il caso di Marsiglia - abbia secoli di vuoto precedenti e, insieme, abbia inizio con l'affacciarsi della romanità (una romanità ormai matura ad una vocazione imperialistica) e ciò anche senza abbracciare completamente la data del Carcopino, forse troppo schematica e ideologizzata.

Il ritrovamento del primo bronzo di Botorrita (1971) è stato seguito dagli altri, forse meno importanti ma atti ad un incremento eccezionale in assoluto: il bronzo, in quanto bene da fondere, non è peremne (malgrado Orazio...) e, nello specifico, sollecita un problema storico nella esecuzione, prima, in quanto celtiberico, e nella conservazione poi in quanto bronzo. Non mi avventuro oltre su un terreno che altri, presenti e assenti, conoscono ben più di me, se non per una semplice riflessione, forse ingenua: perché si scrive in alfabeto/sillabario celtiberico ? Perché in celtiberico e non in latino ? Credo che i due aspetti siano intrinsecamente connessi, pertanto - più che non mi sembra sia stato fatto - saranno da ricercare FORME di lingua latine sotto il dettato testosintattico celtiberico, o tecnicismi anche trasparenti secondo la logica del calco semantico; tuttavia quello che per il nostro tema particolarmente rilevante è: perché in alfabeto celtiberico ? Più ancora: perché non vi è niente, o pressoché niente, in alfabeto latino ? ${ }^{31}$ Se compariamo la fenomenologia scrittoria in Italia tra alfabeto latino e non latino a partire dall'inizio del III sec. a. C. (sopra), e soprattutto intorno alla guerra sociale (91-89 a. C.), si riscontra una fenomenologia del tutto diversa

31 Lascio ovviamente da parte le iscrizioni lusitane. Ho idee diverse da autorevoli autori; lascio pure da parte - ma qui con maggiore attenzione al fatto alfabetico rispetto alle basi linguistiche - il registro della turma salluvitana alleata di Roma; e altro ancora - ma comunque resta il vuoto di cui in testo. nell'intersezione tra romanità e non-romanità (= italicità), tra lingua ed alfabeti che la notano e, nella lingua i contenuti sostanzialmente romani come nel caso della Tabula Bantina ${ }^{32}$.

Credo ci sia da approfondire - a partire dalla seconda metà del III sec. a. C.: così secondo una vulgata che non sono in grado di verificare nelle motivazioni di grafia iberica e lingua celtica, tuttavia un elemento accomunante appare la scelta di non-romanità e/o antiromanità, un caso di Abstand che trasforma un uso allotrio in uso "nazionale", non in sé, ma perché opposto all'alfabeto latino. Si può aggiungere che è un alfabeto "nazionale" relativo all'area di adozione, per opposizione alla romanità, come parimenti per opposizione alla romanità è l'alfabeto gallo-greco, pressoché coevo, di arealità prossima anche se distinta, salvo altre intrusioni alfabetiche dall'ovest iberico, dall'est leponzio. E' un segno che non c'è alfabeto celtico comune, tale cioè da connotare la celticità allo stesso modo in cui le rune connotano la germanicità, ma c'è una celticità quale auto identità per Abstand: c'è l'etnicità celtica in negativo, ma non in positivo, frazionata nelle aree e non accomunata in una etnicità "alfabetica" come è invece la germanicità delle rune. $\mathrm{Al}$ proposito c'è un tema a mio avviso correlato, anche se angolato da varie prospettive anche contrastanti: l'identità (auto-) celtica affronte all'identità (auto-) germanica; già affiorante in Cesare, il tema è riapparso nell'ultimo secolo da più angolazioni e da studiosi di varia disciplinarità e caratura: L. Weisgerber, W. Scherer, A. Tovar, H. Birkham etc. (prima e dopo). In ogni caso, pur nella diversità, fino alla tesi estremistica di Tovar ("die späte Bildung des Germanischen"), sono comunque credibili, non le tesi e/o ipotesi ma la base che le ha causate: la varietà dell'(auto-) identità tra Celti e Germani, non tanto in contrapposizione e/o nella non spiegazione della fenomenologia variata, quanto per la base storica strutturale realizzata in avvenimentalità varia per tempo, aree, culture, società, etc.; non in separazione estrinseca ("prospettiva del riconoscimento'), bensì in interazione intrinseca (continuità del/nel 'reale').

A parte eccessi cripto-nazionalistici, le rune dovrebbero essere create con un post-quem alla vittoria di Teutoburgo; l'a priori di probabilità sulla motivazione ideologica era confortato dall'emergere documentale non anteriore al \pm II sec. d. C. Fino ai recenti documenti di Auronzo di Cadore (appresso) una tesi accreditata vede (una?) matrice delle rune nell'alfabeto venetico ${ }^{33}$, arrivato alla fine del I sec. a. C. ma non oltre, pertanto

32 Sulla lingua della Tabula Bantina rimando a Del Tutto 1983.

33 Oltre ai lavori citati a nota 2, sull'origine delle rune a partire dall'alfabeto venetico si veda il recentissimo intervento di Mancini 2012. 
restava un vuoto di almeno un secolo, nonché, essenziale, la compresenza di più alfabeti all'origine dell'alfabeto runico; la "compresenza di più alfabeti" non è effetto di una casualità di rapporti commerciali (o assimilabili: commercium), ma ha quali cause o concause, da una parte - matrice/i delle rune - la conoscenza di più varietà alfabetiche da parte di "scuole di scrittura", dall'altra la volontà di acquisire la scrittura, ma una scrittura che fosse il più possibile lontana dal modello di riferimento, l'alfabeto di Roma: di qui le rune con tutte le (apparenti) contraddizioni rispetto alle aspettative tradizionali di trafile alfabetiche lineari.

Le rune hanno inizio una sola volta quale alfabeto et germanico et (= perché NON) romano; la storia è all'interno della germanicità, sia pure con varietà di vicende nell'essere con vuoti (alfabeto merovingico), evolvere, finire (anche contaminarsi...) ma con una sostanziale unitarietà. Niente o poco di simile è per gli alfabeti che notano varietà celtiche, salvo per alcuni aspetti dell'alfabeto leponzio perché, pur in continuità areale, le varie forme alfabetiche si propongono sostanzialmente come horti conclusi o, per lo meno, sono comunicanti nella misura in cui si sarebbe potuto aspettare: salvo che per le iscrizioni, tarde, in alfabeto latino, ciò che accomuna gli alfabeti celtici è la non-romanità, da intendere come auto identità alfabetica per avere Roma quale "polo negato". L'ogam è l'evidenza non solo per la romanità alfabetica quale "polo negato" ma, verosimilmente, anche per le rune se, come credo, erano presenti alla/e scuola/e scrittoria/e che ha creato l'ogam, evidente scrittura ideologica fondata su una base alfabetica romana (verisimilmente non esclusiva), ma creata per essere "se stessa", una affermazione di auto-identità in un momento in cui la stessa romanità insulare declinava non solo per forze interne (celticità) ma per i prodromi della futura germanità (Sassoni, Angli, Iuti etc.). Per quanto l'ogam sia stato oggetto di approfonditi studi dal côté celtologico (et pour cause), ritengo che le motivazioni ideologiche più ancora che funzionali e genetiche meritino ulteriore considerazione da angolazione propriamente scrittoria.

Analoghe motivazioni ideologiche, ma con tutt'altre manifestazioni anche per le diverse condizioni storico-culturali si hanno nella fase finale dell'alfabeto leponzio nella Cisalpina (su ciò sopra); di qui una considerazione finale.

\section{Considerazioni finali}

Nella relazione avevo avanzato l'idea che SE c'è stato un alfabeto nazionale celtico, questo non era l'alfabeto gallo-greco (Lejeune; ristretto al gallico), ma l'alfabeto leponzio. L'autorevole intervento di Bats $\mathrm{mi}$ ha fatto riflettere sulla questione, nella sostanza e sul "come" era stata da Lejeune e da me posta. Per quanto concerne Lejeune c'era (latente) l'equivoco tra celticità e gallicità; per quanto concerne me, oltre la medesima non chiarezza, c'era un punto forse non sufficientemente chiarito: SE (e non CHE) c'è stato un alfabeto nazionale: è su questo "se" che intendo chiarire.

In negativo:

1) Non c'è stato un alfabeto celtico nazionale, come mostra l'evidenza dei vari alfabeti usati per notare il celtico, dal leponzio all'ogam.

2) Non c'è stato neppure un alfabeto gallico nazionale, perché la gallicità della Narbonense (e dintorni) è un episodio entro la gallicità, e la gallicità è da considerare articolata, in sé ed entro la celticità.

3) Se c'è stato un alfabto con velleità non panceltiche, ma almeno sovracantonali come arealità, questo è da riconoscere nell'alfabeto leponzio, specialmente nella fase finale.

A ciò si affianca:

4) La recenziorità di alfabetizzazione della altre aree celtiche, tutte passibili di sollecitazione per Abstand dalla scrittualità della romanità, orami egemone se non già imperialista.

Il tutto porta ad un positivo come risultato per quanto concerne la cultura scrittoria presso i Galli:

5) La cultura identificata dalla lingua come celtica non è "scrittoria", e questo può essere in senso che è insito nel topos della "proibizione" druidica" che, preso alla lettera, è smentito dagli inizi "leponzi”" al \pm 600 a. C.; da cui una considerazione riassuntiva:

6) Non è la proibizione druidica, bensì la struttura non-urbana della/e cultura/e di lingua celtica che è non-scrittoria; la scrittura è sollecitata dal contatto con strutture culturali urbane:

a) nel \pm 600 a. C. (leponzio) per imitazione di cultura etrusca, da cui la prima sezione della "clessidra", con la strozzatura mediana quando il modello primario viene meno;

b) nel (III?) II sec. a. C., quando vi è il contatto conflittuale (da cui l'Abstand) con la romanità: la parte inferiore della clessidra "leponzia", l'alfabeto gallo-greco, l'alfabeto semisillabario celtiberico;

c) l'ogam di V sec. d. C. non solo è la riprova della creazione di alfabeto per Abstand, ma è la conferma della settorialità d'uso di forme scrittorie nelle aree di lingua celtica, cioè la negazione di una cultura scrittoria non solo panceltica ma neppure celtica.

Con l'ogam mi sono avventurato in un terreno (per me) minato; tuttavia credo sia da riprendere non tanto la motivazione ideologica, che è evidente, quanto il livello culturale alla base della sua creazione secondo la concezione di "scuole di scrittura" (sopra, § 1). 


\section{Bibliografia}

Bianchi Bandinelli, 1956 : BIANCHI BANDINELLI, (R.) - Organicità e astrazione. Milan, Feltrinelli, 126 p. (Universale economica; 219, serie Arte, vol. II)

Conway, Johnson, Whatmough 1933 : CONWAY (R. S.), JOHNSON (S. E.), WHATMOUGH (J.) - The prae-italic dialects of Italy, Cambridge, Mass., Harvard University Press, 1933, 3 vol.

Cresci-Marrone, Solinas 2012 : CRESCI-MARRONE (G.), SOLINAS (P.) - Microstorie di romanizzazione. Venise, Edizioni Ca' Foscari, 2012.

Del Tutto 1983 : DEL TUTTO (L.) - La Tavola Bantina (sezione osca) : proposte di rilettura. Padoue-Urbino, 1983.

De Marinis 1986 : DE MARINIS (R.) - I commerci dell'Etruria con i paesi a nord del Po dal IX al VI sec. a. C. In :Gli Etruschi a nord del Po, I, Catalogo della Mostra. Mantoue, 1986, p. 52-80.

Gambari, Colonna 1988 : GAMBARI (F.), COLONNA (G.) - Il bicchiere con l'iscrizione arcaica da Castelletto Ticino e l'adozione della scrittura nell'Italia nord-occidentale. StEtr 54, 1988, p. 119-164.

Lejeune 1971 : LEJEUNE (M.) - Lepontica. Paris, 1971.

Lejeune 1988 : LEJEUNE (M.) - Recueil des inscriptions gauloises (R.I.G.), vol II, fasc. 1, Textes gallo-étrusques. Textes gallo-latins sur pierre. Paris, 1988. Mancini 2012 : MANCINI (M.) - La "via del ferro" alle rune : un nuovo capitolo di storia della scrittura. In : Dovetto (F. M.), Micillo (V.), Morlicchio (E.) (dir.), Traguardi e prospettive nelle scienze del linguaggio. Riflessioni con Federico Albano Leoni. Rome, 2012, p. 37-131.

Marinetti, Prosdocimi 1994 : MARINETTI (A.), PROSDOCIMI (A. L.) Le legende monetali in alfabeto leponzio. In : Numismatica e archeologia del celtismo padano, Atti del convegno internazionale (Saint-Vincent, 8-9 settembre 1989). Aoste, 1994, p. 23-48

Marinetti, Prosdocimi 2011 : MARINETTI (A.), PROSDOCIMI (A. L.) Varietà alfabetiche e scuole scrittorie nel Veneto antico. Nuovi dati da Auronzo di Cadore. In : Tra protostoria e storia. Studi in onore di Loredana Capuis. Rome, Quasar, 2011, p. 305-324

Marinetti, Prosdocimi, Solinas 2000 : MARINETTI (A.), PROSDOCIMI (A. L.), SOLINAS (P.) - Il celtico e le legende monetali in alfabeto leponzio. In : I Leponti e la moneta, Atti della Giornata di studio (Locarno 16 novembre 1996). Locarno, 2000, p. 71-119.

Motta 2002 : MOTTA (F.) - Testimonianze dirette e testimonianze indirette della celticità linguistica in Italia. In : Protostoria in Lombardia, Atti del $3^{\circ}$ Convegno Archeologico Regionale (Como, 22-24 ottobre 1999). Côme, 2002, p. 301-324

Motta 2008 : MOTTA (F.) - Le iscrizioni in alfabeto leponzio in Alta Val Brembana : un nuovo gruppo di testimonianze celtiche? Quaderni Brembani 6, 2008, p. 15-24.

Paccolat, Rubat-Borel 2009 : PACCOLAT (O.), RUBAT-BOREL (F.) Une inscription lépontique découverte au-dessous de Sion (Valais). Jahrbuch Archäologie Schweiz/Annuaire d'Archéologie Suisse 91, 2009, p. 127-133.

Piana-Agostinetti, Morandi 2004 : PIANA-AGOSTINETTI (P.), MORANDI (A.) - I Celti d'Italia.Rome, Spazio Tre, 2004, 2 vol., 811p.

Prosdocimi 1985 : PROSDOCIMI (A. L.) - L'origine delle rune come trasmissione di alfabeti. In : Studi linguistici e filologici per Carlo Alberto Mastrelli. Pise,1985, p. 387-399

Prosdocimi 1987 : PROSDOCIMI (A. L.) - I più antichi documenti del celtico in Italia. In : Atti del $2^{\circ}$ Convegno Archeologico Regionale, (Como 13-15 aprile 1984), Côme, 1987,p. 67-92.
Prosdocimi 1988 : PROSDOCIMI (A. L.) - La lingua. In : FOGOLARI (G.), Prosdocimi (A. L.), I Veneti antichi. Lingua e cultura. Padoue, 1988 , p. 221-420

Prosdocimi 1990 : PROSDOCIMI (A. L.) - Insegnamento e apprendimento della scrittura nell'Italia antica. In : Pandolfini (M.), Prosdocimi (A. L.), Alfabetari e insegnamento della scrittura in Etruria e nell'Italia antica. Florence, Olschki, 1990, p. 155-301.

Prosdocimi 1991 : PROSDOCIMI (A. L.) - Note sul celtico in Italia. StEtr 57, 1991, p. 139-177.

Prosdocimi 2004 : PROSDOCIMI (A. L.) - Sulla formazione dell'alfabeto runico. Promessa di novità documentali forse decisive. In :Corona Alpium II. Miscellanea di studi in onore di Carlo Alberto Mastrelli. Florence, p. $427-440$

Prosdocimi 2006 : PROSDOCIMI (A. L.) - Luogo, ambiente e nascita delle rune : una proposta. In : Letture dell'Edda. Poesia e prosa. Alessandria, p. $147-202$.

Prosdocimi 2009 : PROSDOCIMI (A. L.) - Sulla scrittura nell'Italia antica. In : Scrittura e scritture : le figure della lingua, Atti del Convegno SIG (Viterbo, 28-30 ottobre 2004). Rome, Il Calamo, 2009, p. 143-231.

Prosdocimi 2011 : PROSDOCIMI (A. L.) - Ipseità e alterità tra etnonimia e poleonimia. Suessa, Suessula, Opikoi, Oinotroi e simili. In : Gli Etruschi e la Campania Settentrionale, Atti del XXVI Convegno dell'Istituto di Studi Etruschi ed Italici (Caserta, Santa Maria Capua Vetere, Capua, Teano 11-15 novembre 2007). Pise-Rome, 2011, p. 251-281.

Prosdocimi in stampa : PROSDOCIMI (A. L.) - Safini/Sabini, Samnium, Samnites. In : I Sanniti e Roma, Atti del Convegno (Isernia, 7-11 novembre 2006). in stampa.

Solinas 1992-1993 : SOLINAS (P.) - Sulla celticità linguistica nell'Italia antica : il leponzio. Da Biondelli e Mommsen ai nostri giorni. Parte I. Atti IstVeneto 151, 1992-1993, p. 1237-1335.

Solinas 1993-1994 : SOLINAS (P.) - Sulla celticità linguistica nell'Italia antica : il leponzio. Da Biondelli e Mommsen ai nostri giorni. Parte II. Atti IstVeneto 152,1993-1994, p. 873-935.

Solinas 1994 : SOLINAS (P.) - Il celtico in Italia. StEtr 60, 1994, p. 311-408 Solinas 1995 : SOLINAS (P.) - Le iscrizioni in alfabeto leponzio da Valeggio sul Mincio. In : SALZANI (L.) (dir.), La necropoli gallica di Valeggio sul Mincio. Mantoue, 1995, p. 85-88.

Solinas 1996 : SOLINAS (P.) - I materiali iscritti dalla necropoli gallica di S. Maria di Zevio. In : SALZANI (L.) (dir.), La necropoli gallica e romana di S Maria di Zevio. Mantoue, 1996, p. 221- 228.

Solinas 1998 : SOLINAS (P.) - Le iscrizioni in alfabeto leponzio dalla necropoli di Casalandri (Isola Rizza - VR). In : SALZANI (L.) (dir.), La necropoli gallica di Casalandri a Isola Rizza (Verona). Mantoue,1998, p. 143-148.

Solinas 2002 : SOLINAS (P.) - Spie di ideologia etnica in epigrafi celtiche di area veronese. StEtr 65-68, 2002, p. 275-298.

Solinas 2010 : SOLINAS (P.) - Sulle epigrafie pre-romane dell'Italia settentrionale (con particolare riguardo al celtico). Incontri Linguistici 33, 2010, p. $125-160$

Tibiletti-Bruno 1978 : TIBILETTI-BRUNO (M. G.) - Ligure Leponzio e Gallico. In : Prosdocimi (A. L.) (dir.), Popoli e civiltà dell'Italia antica VI. Rome, 1978, p. 131-208.

Wataghin Cantino 2011 : WATAGHIN CANTINO (G.) (DIR.) - Finem dare : il confine, tra sacro, profano e immaginario : a margine della stele bilingue del Museo Leone di Vercelli, Atti del Convegno internazionale (Vercelli 22-24 maggio 2008). Vercelli, 2011 



\title{
Graffiti etruschi dalla Gallia e il piombo di Pech Maho : alcune questioni paleografiche e contenutistiche
}

\author{
Valentina Belfiore
}

\begin{abstract}
Archaeological discoveries made in recent years off the coast of southern Gaul (both on the coast and in the sea, as shown in the wreck of the Grand Ribaud) demonstrate in a more and more clear way how were important not only contacts and trade between the region and the southern Etruria (as evidenced by the large number of transport amphorae), but also the Etruscan presence at least in places that have returned an epigraphic documentation (Saint Blaise , Lattes, Pech Maho, etc.).

Through considerations on the paleography of the documents found in Languedoc, we try to underline the "peripheral" character of some Languedoc inscriptions, and to indicate on the contrary Etruscan, graphic and linguistic, character of the text of Pech Maho, in the light of comparisons with contemporary texts products in Etruria. The interpretation of its contents allows finally to formulate the hypothesis of a major involvement of the massaliote local community in the business transaction recorded on the lead.
\end{abstract}

Keywords: lead, Etruscan inscription, Marseille, mataliai mele, Lattes

\section{Résumé}

Les découvertes archéologiques faites ces dernières années près des côtes de la Gaule méridionale (tant sur le littoral et que dans la mer, comme le montre l'épave du Grand Ribaud) témoignent de manière de plus en plus claire non seulement des contacts et du commerce entre cette région et l'Étrurie méridionale (attesté par le grand nombre d'amphores de transport), mais aussi de la présence étrusque au moins dans les lieux qui ont restitué une documentation épigraphique (Saint Blaise, Lattes, Pech Maho, etc.).

À travers des considérations sur la paléographie des documents du Languedoc, on essaye de souligner le caractère « périphérique »d'une partie des inscriptions languedociennes, et de signaler au contraire le caractère étrusque, graphique et linguistique, du texte de Pech Maho, à la lumière de comparaisons avec des textes contemporains produits en Étrurie. L'interprétation de son contenu permet enfin de formuler l'hypothèse d'une implication majeure de la communauté locale massaliote dans la transaction commerciale enregistrée dans le document.

Mots-clés : plomb, inscription étrusque, Marseille, mataliai mele, Lattes 


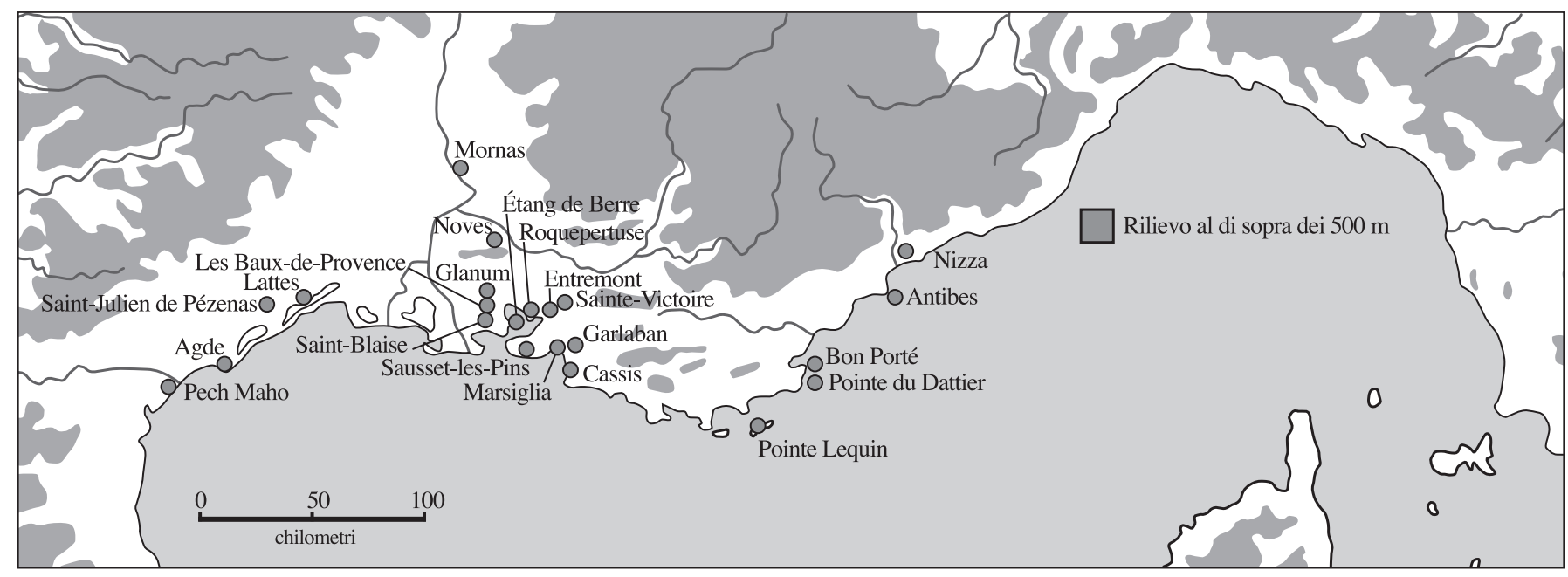

Fig. 1. Siti di rinvenimento di materiali etruschi (Bouloumié 1992, p. 168).

\section{I dati archeologici}

Vari rinvenimenti dagli anni Settanta in poi del secolo scorso hanno dimostrato la presenza etrusca lungo le coste francesi che si affacciano sul Tirreno. Al sito di Lattes è stata riservata una particolare attenzione dagli studi di Michel $\mathrm{Py}$, che ha riscontrato l'abbondanza di anfore da trasporto etrusche, in particolare del tipo Py 4, oltre a tipi più tardivi, 3C e 5, di V sec. (Py 1995, Py 2001). I centri etruschi da cui questo tipo di commercio si dipana sono stati riconosciuti in Cerveteri (anfore a fondo bombato, tipo Py 3A, 3B; 4 e 4A) e Vulci (anfore a fondo piatto, tipo Py $1 / 2$ e 5). Dalla seconda metà del VI sec., le importazioni etrusche appaiono in declino rispetto all'aumentare dei materiali provenienti da Marsiglia, dato su cui si fonda anche l'idea che Lattes abbia conosciuto un legame diretto con l'espansione politica e commerciale della Marsiglia greca.

Le testimonianze etrusche da Marsiglia sono copiose soprattutto a partire dal secondo quarto del VI sec. a.C., come rivela la ceramica fine d'importazione e la quantità di anfore per il trasporto del vino che affianca la produzione locale (Antonelli 2008, p. 131).

Tanto i siti di terra prossimi alla costa quanto i relitti hanno restituito una grande quantità di anfore etrusche databili dagli ultimi decenni del VII al terzo quarto del VI sec. (di Cap d'Antibes, con ben 180 anfore etrusche, di Bon Porté con una ventina di esemplari, di Pointe du Dattier; e infine quello di Cassidaigne a Cassis, che ne conteneva una quindicina (fig. 1).

Anche il relitto del Grand Ribaud (fig. 2), scoperto in anni più recenti, ha restituito uno straordinario carico di anfore da trasporto etrusche, circa 1000, del tipo Py 4 (525-500 a.C.), di produzione ceretana (Long, Gantès,

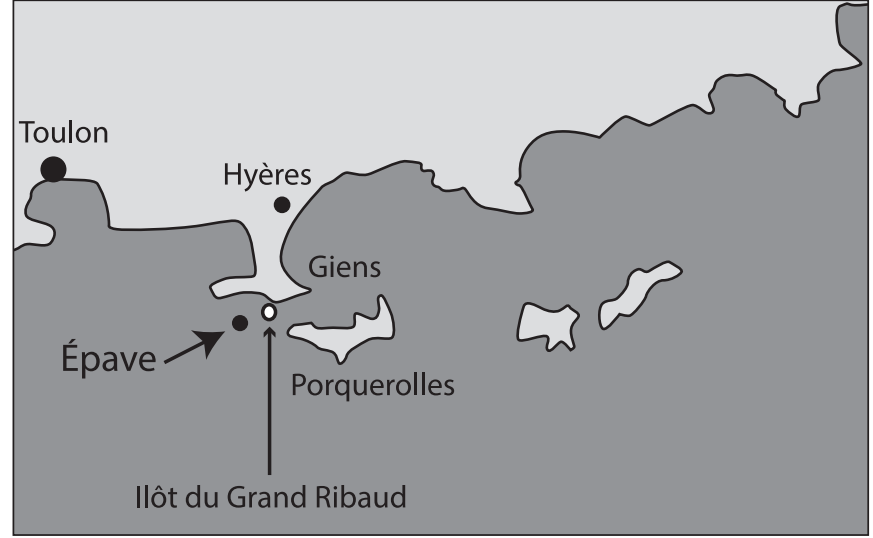

Fig. 2. Luogo di rinvenimento del relitto del Grand Ribaud (Long, Gantès, Rival 2006, p. 456).

Rival 2006). Curiosamente, l'unica iscrizione recante un nome piuttosto che una sigla era su un'anfora di tipo greco, o meglio magno-greco, come si tende ora a considerare il tipo ionico-massaliota (fig. 3). Tali testimonianze della presenza etrusca in area costiera sono state valutate in relazione alla presenza di emporoi e paragonate alla situazione di altri siti prossimi alla costa.

Nella più recente rilettura del testo di Pech Maho da parte di Cristofani, i confronti sono stati estesi anche all'area di Aleria, della quale sono stati ricordati i lotti ortogonali di terreno, le tombe a camera con dromos che si affacciano parallele sulla via sepolcrale, i corredi comprendenti elementi di armamento, che hanno indotto a pensare ad una classe guerriera e ad una società di tipo coloniale (Cristofani 1993). La presenza di armi e l'associazione di suppellettili bronzee con le ceramiche attiche è stata avvicinata alla situazione dei ceti emergenti di Vulci, con cui i territori conquistati in Corsica dovevano presentare strette relazioni. 


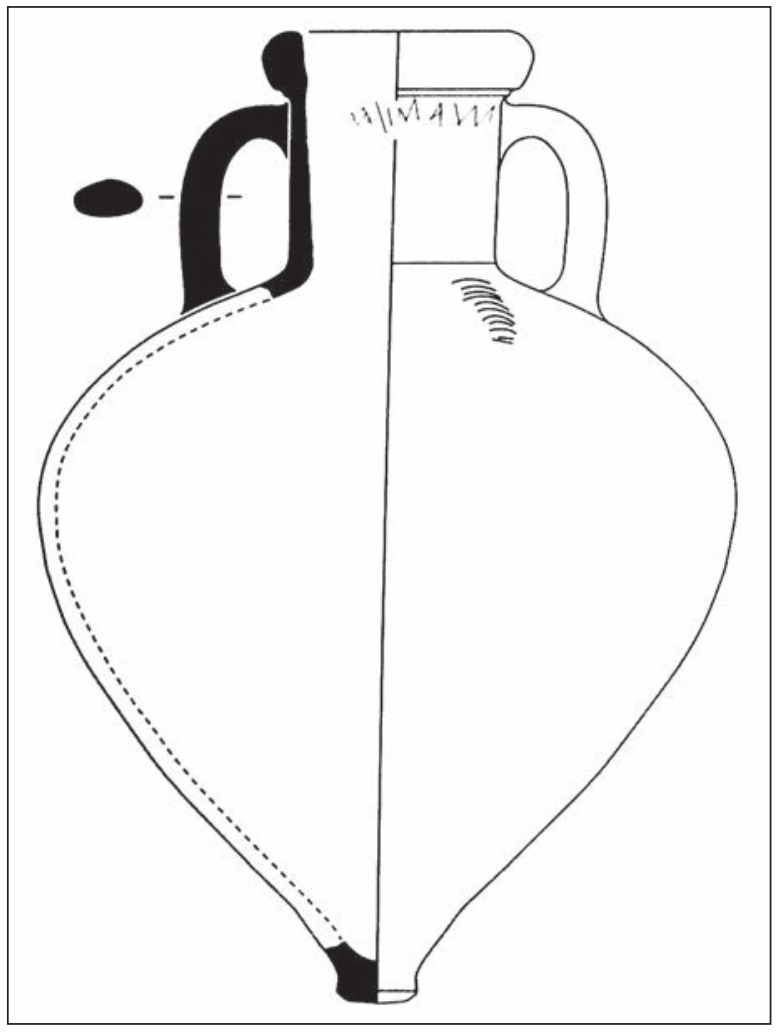

Fig. 3. Anfora ionico-massaliota del Grand Ribaud (Long, Gantès, Rival 2006, p. 468) con iscrizione ET Na 2.4

amaniies ${ }^{\mathrm{C}}$ CCCCCCCCCII interpretata con riferimento al numero totale delle anfore nel carico (Colonna 2006, pp. 672-673).

\section{Le iscrizioni etrusche dalla costa}

In quest'ambito va (ri)considerata la testimonianza del Piombo di Pech Maho, di cui sono stati già evidenziati i caratteri epigrafici 'misti' (distribuzione delle sibilanti secondo l'uso grafico meridionale, alternanza di $-s /-z$ in posizione finale, ben attestata a Volsinii, uso del kappa in età tardo arcaica, che rimanda invece all'Etruria settentrionale) (Colonna 2006, p. 668).

Lo stesso testo va inoltre esaminato in relazione alle altre iscrizioni restituite dalla costa meridionale francese. Oltre alla menzionata iscrizione su anfora dal relitto del Grand Ribaud, si tratta principalmente delle iscrizioni provenienti dall'abitato di Lattes su tre ciotole (Colonna 1980; id. 2006; Py et al. 2006), di cui due in bucchero nero e una in ceramica grezza, lette come vcial oppure $v c a l$ in legatura, e di un'olla in ceramica grezza con sigla $k a$. Le iscrizioni sono state incise probabilmente dalla stessa mano (Colonna 2006, p. 664-665). La sigla $k a$ restituirebbe un nome personale da intendere come kae, kavie (ibid.), mentre i genitivi permettono di risalire a un nome femminile vci. Nel complesso, si tratterebbe di attestazioni di un'influenza vulcente/ tarquiniese/ orvietana piuttosto che ceretana per motivi paleografici

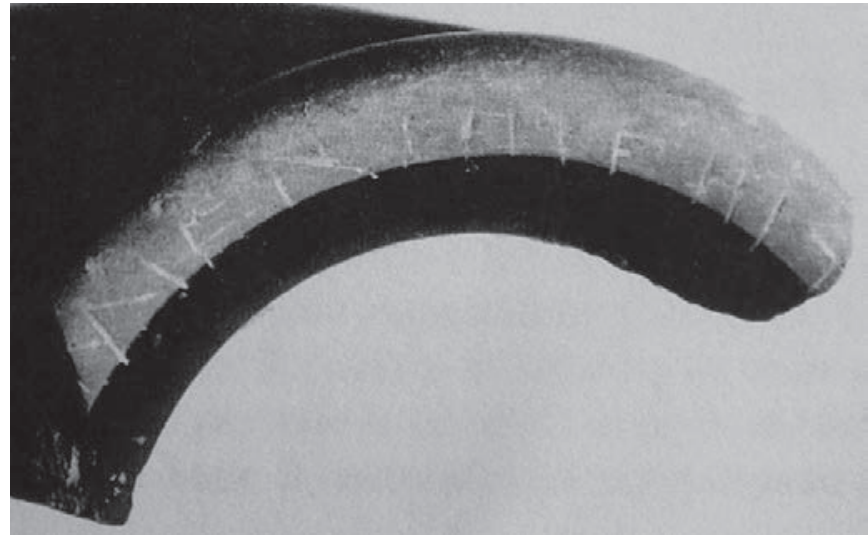

Fig. 4. Iscrizione ET Na 3.1 da Saint-Blaise in alfabeto greco e lingua etrusca (Colonna 2006, p. 677).

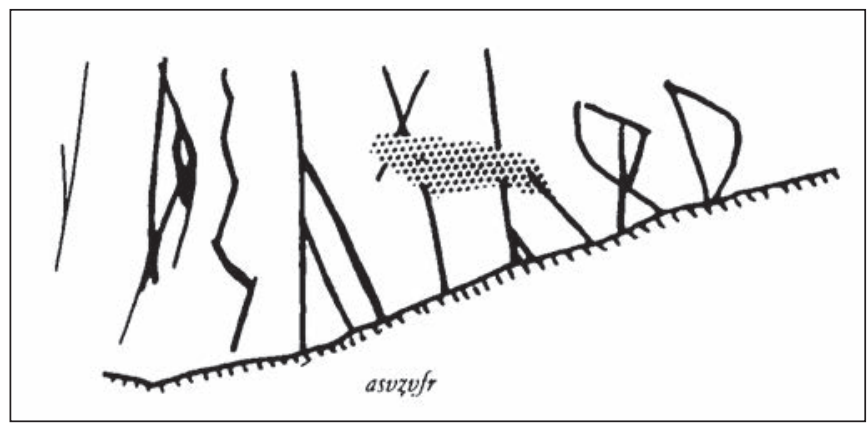

Fig. 5. Iscrizione ET Na 0.2 asv zvfr(e) sull'anfora Py 3A da St. Blaise (G. Colonna, REE 64, n. 101).

(traversa discendente di $<a>$ ). Le iscrizioni di Lattes, con digamma per il suono vocalico [u], presentano un fenomeno ascritto all'influsso italico, con riferimento alla monottongazione di area 'sabina' oppure all'esigenza di correggere una $<u>$ vocalica sentita come errore (es. auvilesi) ${ }^{1}$.

Piuttosto sembra di rilevare che l'uso di $\langle\mathrm{v}\rangle$ per /u/ dipenda da un'ipodifferenziazione grafica. Guardando alle altre attestazioni dall'area costiera, l'impiego di digamma con valore vocalico ricorre anche nell'iscrizione da Saint Blaise su una stemless cup a vernice nera datata al secondo quarto-metà del V sec., scritta nell'alfabeto ionico di Massalia (fig. 4), e letta da Colonna come mi vnipi vhit [ dunque come dedica a Uni. Lo stesso uso è inoltre attestato dall'iscrizione asv zvfr[, graffita su un'anfora Py 3A ancora da Saint Blaise (fig. 5), del pieno VI sec. (Colonna 2006, p. 664, fig. 2). Oltre a $<v>$ per $/ \mathrm{u} /$, nel testo è impiegato anche un sigma multilineare per il quale è stata richiamata la tradizione veiente e falisca: come si vedrà, certi usi grafici possono essere stati mutuati da aree più vicine.

1 Per ulteriori considerazioni, Cf. Colonna, REE, 69, 2002, p. 461, $n^{\circ} 139$. 


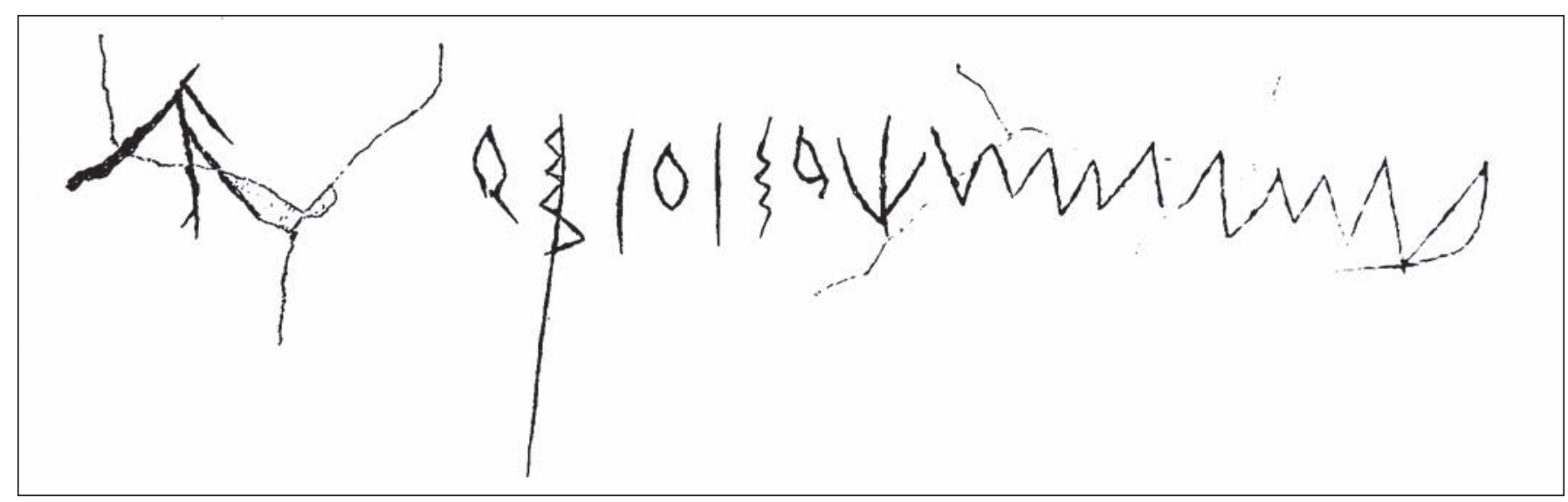

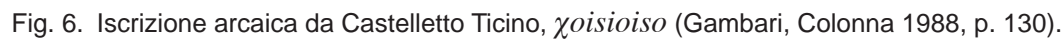

Qualche confronto per il sigma multilineare, si può in effetti trovare anche in area leponzio-gallica: si veda ad es. l'iscrizione arcaica sul bicchiere da Castelletto Ticino, interpretato come $\chi o s i o i s o$ (fig. 6). Presenta una sibilante multilineare la maggioranza delle iscrizioni galliche, normalmente datate fra il III e il I sec. a.C., dove il sigma viene per lo più realizzato nella variante a quattro tratti ${ }^{2}$.

E' stato supposto che alcune caratteristiche grafiche dell'area leponzia, che ha restituito epigrafi a partire dal VI sec., provengano dall'ambito etrusco meridionale, come per la sibilante altrimenti resa con segno a farfalla, ritenuta di probabile provenienza vulcente, mentre quella multilineare è attribuita ad un'origine veiente ${ }^{3}$.

In quest'ambito inoltre, rispetto alla resa dei fonemi $[\mathrm{u}]$ e $[\mathrm{w}]^{4}$ mediante l'unico grafema $<\mathrm{v}>$ come notato per le iscrizioni di Lattes e Saint Blaise, si assiste alla scelta inversa, dell'unico grafema $\langle\mathrm{u}>$ per i suoni $[\mathrm{u}] \mathrm{e}$ [w]. L'iscrizione arcaica di Prestino dimostra la conoscenza di entrambi i segni, a fronte della quale l'opzione quasi immediatamente operata per uno solo rappresenta la riduzione del "sistema potenziale del corpus per il sistema in uso". Nell'iscrizione di Prestino è presente "l'uso di $\langle v\rangle=F$ che appare solo nel digrafo $u v$ e in posizione iniziale, mentre si ha $\langle\mathrm{u}\rangle=\mathrm{V}[\mathrm{w}]$ altrove, il che indica una transizione alla affermazione del solo $\langle\mathrm{u}\rangle=\mathrm{V}$ e per $[\mathrm{u}]$ vocale e per $[\mathrm{u}=\mathrm{w}]$ consonante" (Pandolfini, Prosdocimi 1990, p. 296-297).

Complessivamente si può dunque supporre che la diffusione di mode grafiche dall'Etruria meridionale

2 Cf. anche l'iscrizione più recente PCIA 12, II, p. 543, n 34 , 1slaniai: uerkalai: pala ${ }^{2}$ tisiui: piuotialu: pala, da Davesco, IV-III sec.

3 A. Morandi, "Epigrafia e Lingua", in PCIA 12, II, p. 470.

4 Cf. Morandi 1999, p. 171; PCIA 12, II, p. 519, nº 1 , fig. 8.1. p. 525, ${ }^{1}$ raneni ${ }^{2}$ ualaunal da Mesocco, III sec.; ibid., p. 549, $\mathrm{n}^{\circ} 47$, fig. 11, p. 548, uasekia. alla costa francese non sia sempre diretto, ma piuttosto filtrato dal contatto con le popolazioni locali o circonvicine, come quelli riscontrati in ambiente leponzio-ligure, o come si presume per i caratteri paleografici dichiaratamente anetruschi delle iscrizioni da Saint Blaise. Queste ultime, insieme alle epigrafi di Lattes, si distinguono dal punto di vista paleografico, rispetto al testo di Pech Maho e all'iscrizione su anfora del Grand Ribaud, nel senso di una più pronunciata "etruscità grafica" delle seconde.

\section{Il testo di Pech Maho}

\section{La paleografia}

Passando ora a considerare più da vicino il testo di Pech Maho, conviene valutarne la paleografia alla luce dei riconosciuti contatti fra la Linguadoca e l'Etruria meridionale, considerando l'origine ceretana o vulcente delle principali correnti commerciali.

Testi su lamina di una certa estensione cronologicamente vicini al piombo di Pech Maho sono in effetti principalmente attestati da area ceretana o vulcente, basti pensare alla lamina di piombo di Castellina, alle lamine di Pyrgi, al Piombo di Magliano e a quello molto lacunoso e breve restituito dall'area della città di Vulci. Non va neanche trascurata la testimonianza della lamina di Poggio Gaiella, sebbene quest'ultima possa considerarsi di qualche decennio seriore ${ }^{5}$.

La paleografia del piombo di Pech Maho mostra maggiori analogie con il piombo di Magliano per la forma "a bandiera" della <a>, e per l'heta a scaletta (fig. 7). Diversa invece la grafia impiegata nelle lamine di provenienza cerite. L'alfa della lamina di Santa Marinella /

5 Per i testi su piombo è ora in corso di stampa un lavoro di riesame complessivo delle testimonianze (Massarelli 2010). 


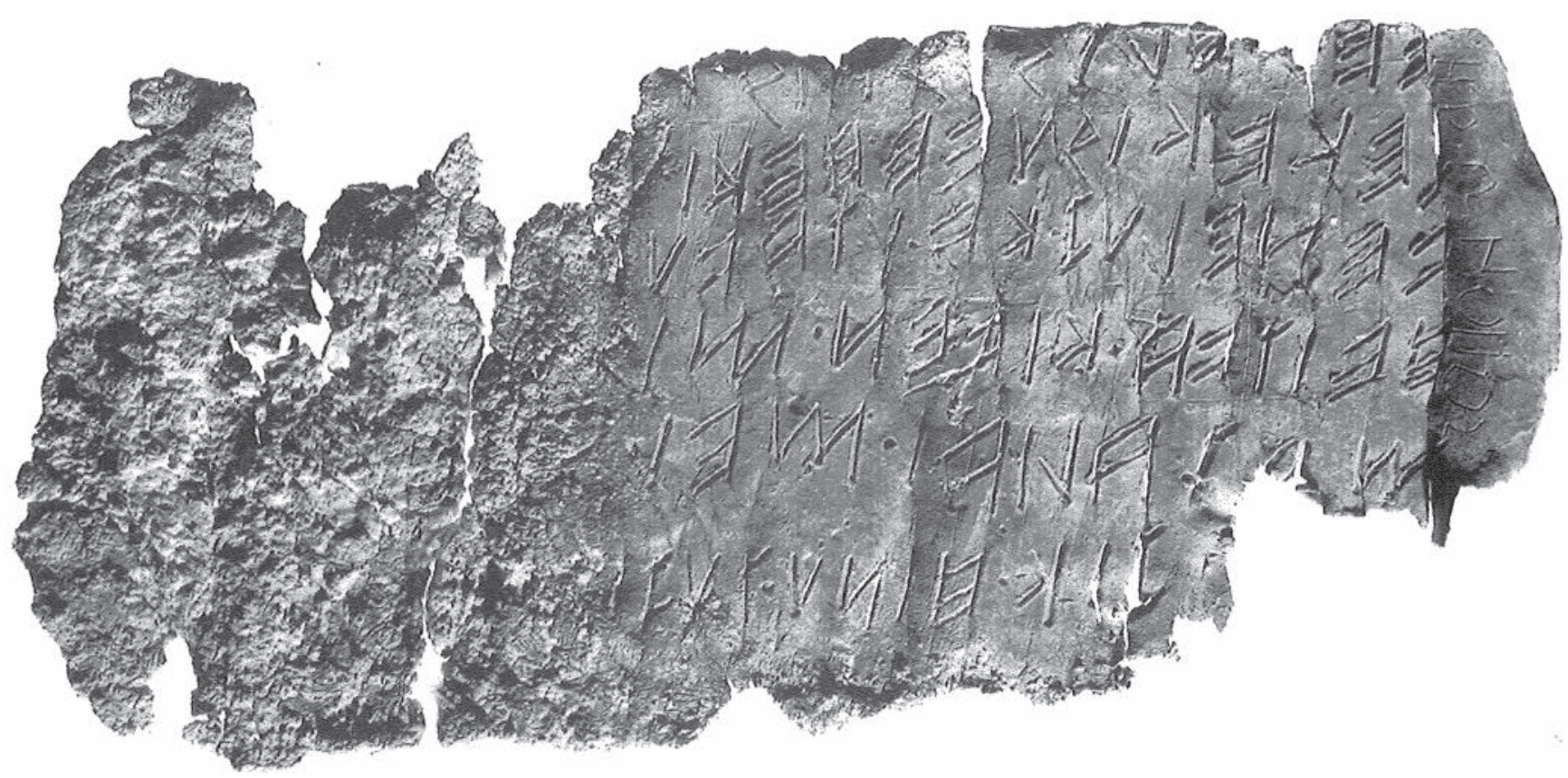

Fig. 7. Lamina di piombo di Pech Maho (Bouloumié 1992, p. 172). Sigean, Musée des Corbières, cat. 293.

Punta della Vipera è infatti più stretta, così come anche la resa del my e del ny a cinque e tre tratti (con my oscillante con la resa con asta destra più allungata, come nella grafia più arcaica). Le stesse lettere, nelle lamine di Pech Maho e di Magliano sono più spaziate. Maggiori affinità si riscontrano con la forma di alpha in un'iscrizione vascolare dallo stesso santuario di Punta della Vipera, ma diversa l'inclinazione della traversa di tau (ET Cr 0.32) ${ }^{6}$.

D'altro canto, il Piombo e la lamina di Castrum Novum condividono la forma a losanga del theta con punto centrale, assente dal testo di Pech Maho. Con l'iscrizione di Castrum Novum invece, la lamina di Pech Maho mostra tau e zeta comparabili, con segmenti obliqui discendenti nel senso della scrittura, impostati agli estremi delle aste verticali. Per lo stesso motivo, le grafie di questo documento e di quello di Magliano divergono: la resa del tau e di zeta, con segmenti obliqui ancora discendenti nel senso della scrittura, non incrociano l'asta verticale, né risultano secanti. Ma più significativo è l'uso sistematico di kappa nel testo di Pech Maho rispetto a quello di gamma nell'altro.

La lamina di Santa Marinella presenta poi in sé alcune incongruenze grafiche, come elementi sicuramente

6 Cf. Maras 2009, p. 267, ET Cr co.8. ceretani nell'utilizzo della sibilante a quattro tratti, accanto ad altri, come l'alpha con traversa discendente, tipica invece dell'area di Vulci-Orvieto-Tarquinia, il $p i$ a tre tratti, diffuso in Campania, e uno sporadico uso di kappa attestato dalla parola mlaka[ (Massarelli 2010, p. 133).

Anche per la lamina di Poggio Gaiella, Colonna ha osservato la veste epigrafica mista, con alpha triangolari di tipo cerite e sigma finale retrogrado secondo una moda volsiniese, come anche il persistere in quest'area del theta crociato (Colonna, REE 58, 1993, p. 311). Cerite è però anche l'aspetto dell'heta a scaletta, vicino a quella dei testi pyrgensi. L'impiego di kappa è invece motivato con la cronologia al terzo quarto del VI sec.

Diversamente, la lamina di Santa Marinella, di ambiente cerite, accanto alla sibilante a tre e a quattro tratti tipica di quest'area, presenta piuttosto per alpha e heta maggiori confronti con l'area di Vulci-Volsinii-Tarquinia.

Considerando la testimonianza restituita dagli alfabetari, la situazione è ancora più problematica: gli alfabeti di Magliano (Le Mollaie), nel Vulcentano, quello su fusaiola da Vulci (ET Vc 9.2), probabilmente quello in steatite da Castro (ET Vc 9.2) e inoltre l'alfabetario ceretano di Sasso di Furbara presentano caratteristiche settentrionali nell'assenza di gamma, ma meridionali nel tipo di grafia. 
ET Na 0.1 prima metà $\mathrm{V}$ sec.

1ve[n]elus. sais. -[-?-]

2zeke. kisne\{ e\}. hekiu[-?-]

3veneluz. ka. utavum [-?-]

$4\{h\}$ eitva. kiven. mis[-?-]

5mataliai. mele [-?-]

6(VACAT) zik. hinu. tuzu[

\section{Il contenuto}

Passando a questioni contenutistiche, poco si può aggiungere rispetto a quanto già osservato dagli studiosi. E' comunque opportuno avanzare alcune considerazioni sulle forme riconoscibili come predicati, in quanto centrali nell'economia del testo: le interpretazioni proposte sono infatti varie, a cominciare dalla forma zeke rispetto a zik, alla forma hekiu (*heki/*heke $+u$ ?), alla funzione di hinu e dell'incompleto tuzu[.

Se zeke rappresenta un preterito potremmo pensare ad un'analisi del tipo $*$ zi $\chi+k e>$ zike $>$ zeke con assimilazione vocalica regressiva come nel caso di mine $>$ mene. L'altra possibilità, vista la forma zik finale, è che il predicato sia formato piuttosto come $z i k+c e$, ovvero con finale priva di aspirazione, da spiegare come forma dialettale. Il locativo kisnee indicherebbe una caparra ("la terza parte") secondo una proposta di Cristofani, in considerazione di una possibile analogia con il testo greco inciso sul retro ${ }^{7}$. Naturalmente il numerale ordinale può essere riferito ad altro (giorno/mese ad es., se la referenza è piuttosto temporale).

La linea si conclude con la forma hekiu[, con kappa sovrascritto a una $<\mathrm{u}>$ sottostante. La forma, come anticipato, può considerarsi verbale se confrontata con gli infiniti in funzione di imperativi attestati nel liber linteus come heci (analogamente all'impiego di capi) e in possibile relazione anche con la forma hecia, intesa come congiuntivo (*heci-a) (Belfiore 2010, p. 147). Un ulteriore confronto rimanda anche alla forma arcaica hecece di Tarquinia (ET Ta 5.1 ara 0 spuriana [ac]il hecece fariceka), già interpretata nel senso di "fare, porre" in relazione con l'altro predicato farice-ka, e inoltre ai recenti preteriti hece, hecce, sincopati ${ }^{8}$. Il senso è dunque quello di indicare una scrittura e la realizzazione di un'opera di qualche tipo, dal momento che il predicato *hec- di "fare, porre", è solitamente in relazione con la forma acil (Wylin 2000, p. 187-189).

Il senso di heitva non è ancora chiaro. Si può solo ricordare che la bibliografia in materia è stata di recente riepilogata da Giannecchini ${ }^{9}$. Rispetto all'oscillazione

7 Cristofani 1993, p. 835 per trite, "caparra".

8 Cf. ET I, indici.

9 G. Giannecchini, REE, 69, 2003, p. 371-375, nº77. fra senso pronominale e aggettivale è complessivamente preferibile il secondo (qualcosa come "la presente (tomba)", nei contesti di area etrusca), comunque riferito all'individuazione dell'oggetto menzionato.

La forma zik finale è stata ugualmente da alcuni interpretata come predicato seguito da una fomula onomastica ("scrive Hinu Tuz..."), ${ }^{10}$ ma per coerenza questo dovrebbe presentarsi al preterito, come qualche linea sopra: sembra dunque preferibile considerare $z i k$ in funzione nominale, mentre hinu può rappresentare viceversa un nome verbale in $-u$, comunque hapax.

La forma $t u z u$ [, con cui si conclude la parte conservata del testo, piuttosto che onomastica, sembra inoltre da confrontare con un gruppo di voci lessicali, la cui radice è attestata a Cortona come tuś- (si vedano le iscrizioni funerarie con tuśsi, tuśur $\theta i$, tuśuvas), a Cerveteri come tus[ (sul peso di Sant'Antonio, ET Cr 4.22). La voce, di senso ancora incerto, sembra comunque indicare un luogo circoscritto (vedi la locuzione $\theta u s ́ s i \theta u i$ hupnine $\theta i$ "nel $\theta u s$ - qui nella camera/luogo funerario")

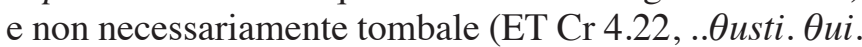
$m e \theta \operatorname{lm} \theta$ "nel $\theta u s$ - qui nell' area urbana"). L'interscambio di $\langle$ S $>$ con $\langle\mathrm{z}>$ d'altro canto è già presente nel prenome veneluz della linea 3. La frase finale del testo di Pech Maho in tal modo indicherebbe il luogo in cui è conservato (? hinu) lo scritto.

\section{Contratto privato o pubblico?}

Il testo, contenente due nomi, Venel e Utavu, è normalmente ritenuto un contratto commerciale tra contraenti privati, uno dei quali probabilmente originario di mataliai, ovvero Marsiglia. Il toponimo tuttavia è in diretta connessione con il termine melẹ [, da cui è seguito, che si può interpretare facendo riferimento alle formule ripetitive dei rituali del liber.

Le preghiere della III e IV colonna (ma non dell'VIII-IX, pure giudicati testi "paralleli") contengono infatti la locuzione meleri. sveleric. svec an cś. mele. Oun. mutince indicante i beneficiari del rituale (Belfiore 2010, p. 85). Altri confronti vanno alla locuzione mele crapisces dell'elogio di Pulenas (ET Ta 1.17), dove vengono ricordate le benemerenze del personaggio nell'ambito del rito (costruzione di templi, sostegno ai culti) ${ }^{11}$. L'ipotesi già suggerita per l'interpretazione del passo del liber è stata quella di un termine con referenza animata: dunque meleri può indicare qualcosa come "comunità, popolo" come insieme vs. i singoli uomini (svele-ri) (Belfiore 2010, p. 85).

10 M. Cristofani, REE, 57, 1991, n54; Colonna 2006, p. 668 e n ${ }^{\circ} 5$. 11 V. Belfiore, Studi sul lessico "sacro": Laris Pulenas, le lamine di Pyrgi e la bilingue di Pesaro, in scholarworks.umass.edu/rasennal vol3/iss $1 / 3 /$. 
In tal modo sarebbe ipotizzabile che l'accordo riguardi in qualche misura la comunità di Marsiglia, anche se non è possibile stabilire con sufficiente certezza se questo coinvolgesse i due personaggi in una attività con i Massalioti.

\section{Conclusioni}

Non solo i materiali restituiti dalla Provenza e dalla Linguadoca, ma anche il numero sempre più alto delle iscrizioni, sebbene molto frammentarie, spesso limitate a sigle, monogrammi, o di poche lettere, dimostrano che la presenza etrusca in questi luoghi è sempre meno da considerarsi come un fenomeno sporadico.

Il dato paleografico attesta che accanto all'uso della lingua etrusca, la grafia di alcune attestazioni rivela maggiori influssi locali, come di per sé l'uso dell'alfabeto greco, o di caratteri più vicini alla paleografia di area leponzia.

Il testo di Pech Maho, al contrario, si iscrive, pur nel suo carattere di testo 'misto', nella fattispecie dei testi etruschi di cronologia comparabile, nessuno dei quali perfettamente 'regolare' dal punto di vista grafico o linguistico.

In base all'interpretazione del suo contenuto, parrebbero esistere anche i presupposti per considerare l'esistenza di contatti con altri centri costieri vicini, come indicato dal coinvolgimento in qualche misura di Marsiglia stessa. La cronologia del documento, entro la prima metà del V sec., ben si iscrive nella fase della maggiore importanza acquisita da questa città e dell'aumentato volume delle sue esportazioni rispetto alla merce proveniente dall'Etruria stessa, come osservato per i materiali che raggiungono il sito di Lattes.

\section{Abréviations}

ET : MEISER (G.) - Etruskische Texte. Editio Minor, I. Index, II. Texte. Tübingen, Narr, 2012.

REE : Rivista di Epigrafia Etrusca. In : Studi Etruschi.

\section{Bibliografia}

Antonelli 2008 : ANTONELLI (L.) - Traffici focei di età arcaica. Rome, L'«Erma» di Bretschneider, 2008 (Hesperìa 23).

Belfiore 2010 : BELFIORE (V.) - Il liber linteus di Zagabria. Testualità e contenuto. Pise-Rome, Serra, 2010.

Bouloumié 1992 : BOULOUMIÉ (B.) - Il commercio etrusco nel sud della Francia. In: Pallottino (M.) dir., Gli Etruschi e l'Europa, Catalogo della mostra, Parigi 1992 - Berlino 1993, Milan, Bompiani, 1992, p. 168-173.

Colonna 1980 : COLONNA (G.) - Graffiti etruschi in Linguadoca. Studi Etruschi, 58, 1980, p. 181-185.

Colonna 2006 : COLONNA (G.) - A proposito della presenza etrusca nella Gallia Meridionale. In : Gli Etruschi da Genova ad Ampurias, Atti del XXIV Convegno di Studi Etruschi e Italici, 26 settembre - 1 ottobre 2002, Pise-Rome, Serra, 2006, p. 657-673.

Cristofani 1993 : CRISTOFANI (M.) - Il testo di Pech Maho, Aleria e i traffici del V sec. Mélanges de l'École Française de Rome, 105-2, 1993, p. 833-845.

Gambari, Colonna 1988 : GAMBARI (F.M.), COLONNA (G.) - Il bicchiere con iscrizione arcaica da Castelletto Ticino e l'adozione della scrittura nell'Italia nord-occidentale. Studi Etruschi, 54, 1988, p. 119-164.

Long, Gantès, Rival 2006 : LONG (L.), GANTÈS (L.-F.), RIVAL (M.) L'épave Grand Ribaud F. Un chargement de produits étrusques du début du Ve siècle avant J.-C. In : Gli Etruschi da Genova ad Ampurias, Atti del XXIV Convegno di Studi Etruschi e Italici, 26 settembre - 1 ottobre 2002, Pise-Rome, Serra, 2006, p. 455-496.

Maras 2009 : MARAS (D.F.) - Il dono votivo. Gli dei e il sacro nelle iscrizioni etrusche di culto. Pise-Rome, Serra, 2009.

Massarelli 2010 : MASSARELLI (R.) - Testi etruschi su piombo, Tesi di Dottorato in Filologia Romanza e Linguistica Generale, XXI ciclo, aa. 20082009, in corso di stampa.

Morandi 1999 : MORANDI (A.) - Epigrafia vascolare celtica fra Ticino e Como. Revue Belge de Philologie et d'Histoire, 77, 1, 1999, p. 151-204.

Pandolfini, Prosdocimi 1990 : PANDOLFINI (M.), PROSDOCIMI (A.L.) - Alfabetari e insegnamento della scrittura in Etruria e nell'Italia antica. Florence, Olschki, 1990.

PCIA 12 : PIANA AGOSTINETTI (P.) dir. - Popoli e Civiltà dell'Italia antica, ${ }^{\circ} 12$, Celti d'Italia, vol. II. Rome, Spazio Tre, 2004.

Py 1995 : PY (M.) - Les Étrusques, les Grecs et la fondation de Lattes. In : Marceline (P.) et al., Sur les pas des Grecs en Occident. Hommages à André Nickels, Paris-Lattes, 1995 (Ét. Massa. 4), p. 261-276.

Py 2001: PY (M.) - Corpus des céramiques de l'âge du Fer de Lattes (fouilles 1963-1999), I-II, Lattes, 1995 (Lattara 14), p. 261-276.

Py et al. 2006 : PY (M.), LEBEUPIN (D.), SÉJALON (P.), ROURE (R.) Les Étrusques et Lattara : nouvelles données. In : Gli Etruschi da Genova ad Ampurias, Atti del XXIV Convegno di Studi Etruschi e Italici, 26 settembre - 1 ottobre 2002, Pise-Rome, Serra, 2006, p. 583-608.

Wylin 2000 : WYLIN (K.) - Il verbo etrusco. Ricerca morfosintattica delle forme usate in funzione verbale. Rome, L'«Erma» di Bretschneider, 2000. 



\title{
Contacts d'écritures : l'épigraphie paléohispanique du Midi gaulois
}

\author{
Coline Ruiz Darasse
}

\section{Résumé}

La langue ibère est traditionnellement considérée comme l'une des langues véhiculaires ayant permis, à l'âge du Fer, le développement d'échanges économiques entre le Nord-Est de la péninsule Ibérique et le Midi gaulois. La reprise de la documentation d'un site majeur de l'épigraphie paléohispanique de la zone, le site d'Ensérune en Languedoc occidental, montre que le caractère véhiculaire de cette langue doit être à nouveau questionné. Parmi les multiples écritures en présence, le choix, à Ensérune, s'est nettement porté sur l'une d'entre elles : l'écriture paléohispanique levantine. L'étude de l'onomastique lue dans ces inscriptions, celle des supports, ainsi que leur remise en contexte archéologique permet de préciser les pratiques graphiques et leurs acteurs, en particulier dans le cadre d'échanges inter-communautaires entre populations locales.

Mots-clés : épigraphie préromaine, onomastique, langue paléohispanique, Ensérune, semi-syllabaire levantin, alphabet étrusque, écriture gallo-grecque.

\section{Resumen}

La lengua ibérica se considera tradicionalmente como una de las lenguas vehiculares que permitieron, durante la Edad del Hierro, el desarrollo de intercambios económicos entre el nordeste de la península ibérica y el mediodía galo. Al revisar la documentación de un yacimiento muy importante para la epigrafía paleohispánica, Ensérune en el Lenguadoc occidental, es necesario reevaluar la cuestión del estatus del ibérico como lengua vehicular. Entre las diversas escrituras disponibles allí, se eligió claramente la escritura paleohispánica levantina. Tanto el estudio onomástico de esas inscripciones, el de los soportes como el del contexto arqueológico permiten precisar los usos gráficos y los agentes, en particular en el marco de los intercambios intercomunitarios entre pueblos locales.

Palabras-claves: epigrafía prerromana, onomástica, lengua paleohispánica, Ensérune, semi-silabario levantino, alfabeto etrusco, escritura gallo-griega 
$\mathrm{C}$ 'est grâce à Michel Bats que nous avons pu avoir accès aux collections du musée d'Ensérune au cours de notre travail de doctorat ${ }^{1}$. Le site présente en effet une épigraphie riche et variée dont l'inventaire et la chronologie précise sont encore mal connus. Il existe, pour Ensérune, deux ouvrages de référence, celui de Jean Jannoray remontant au milieu du XX $X^{\mathrm{e}}$ siècle (Jannoray 1955) et une étude plus récente consacrée à la céramique attique (Dubosse 2007). Ce dernier comporte un catalogue des objets mentionnant la plupart du temps les inscriptions qui y sont portées, mais il ne concerne qu'une seule des catégories de céramiques ayant reçu des inscriptions.

Les inscriptions les plus nombreuses sont celles en semi-syllabaire paléohispanique dans sa variante levantine, écriture que l'on trouve sur le littoral méditerranéen de la péninsule Ibérique jusqu'aux rivages du golfe du Lion. Dans l'inventaire publié par Jürgen Untermann en 1980 ( $M L H$ II), le nombre d'objets inscrits s'élevait déjà à 372 pièces. Il faut y ajouter un plomb publié en 1988 (Solier-Barbouteau 1988, p. 61-95). Javier de Hoz précise certaines concordances entre les trois ouvrages de références (de $\mathrm{Hoz} 2011$, p. 401, note 81). Une mise à jour de ce corpus est en cours par les membres de l'équipe Hesperia (http://hesperia.ucm.es/, Orduña, Luján, Estarán 2009, p. 83-92).

\section{Écritures}

À l'exception d'un seul document présentant un texte élaboré (le plomb mentionné plus haut), les inscriptions lues à Ensérune sont très majoritairement à interpréter comme des marques de propriété $(71 \%$ de la documentation - pour comparaison, les marques de propriété représentent par rapport à l'ensemble de l'épigraphie $71 \%$ à Ullastret et 33,7\% à Azaila). Il s'agit de marques incisées après cuisson sur des supports céramiques, donnant à lire des noms propres. Elles livrent un paysage onomastique contrasté, où noms celtiques et noms latins sont adaptés aux possibilités de notation phonétique de l'écriture paléohispanique (Ruiz Darasse 2010, p. 335-354).

1 Interfaces épigraphiques. Les contacts linguistiques entre Celtes et Ibères dans le Nord-Est de la péninsule Ibérique et le Sud de la Gaule (Ve et I Ir siècles avant J.-C.). Thèse de Doctorat en Sciences de l'Antiquité préparée à l'École pratique des Hautes Études sous la direction de Pierre-Yves Lambert (École pratique des Hautes Études, IV $V^{\mathrm{e}}$ section) et soutenue à Paris, le 2 juillet 2011.
Les noms celtiques (fig. 1) apparaissent dans l'épigraphie paléohispanique d'Ensérune dès le $\mathrm{IV}^{\mathrm{e}} \mathrm{s}$. av. J.-C. (terminus post quem avec les inscriptions B.1.15 [dernier quart du $\mathrm{IV}^{\mathrm{e}} \mathrm{s}$.] ou B.1.59, mais qui reste sans contexte).

Un cas isolé - et, en fait, un cas unique à ce jour - pourrait garder la trace de contacts entre Celtes et Étrusques dans cette zone du Languedoc à une époque antérieure à 375 av. J.-C. : il s'agit d'un nom celtique pré-gaulois (re)lu en alphabet étrusque (de Hoz 2008, p. 17-27 ; de Hoz 2011, p. 156-157 [§ 1.26.]). La présence étrusque est connue en Languedoc occidental dès le VII ${ }^{\mathrm{e}}$ s. av. J.-C., illustrée notamment par la face A du célèbre plomb de Pech Maho (B.7.34) vers 450, et par des inscriptions à Lattes (MLH II B.2.1 et 2 ; Colonna, 1980, p. 181-185).

Mais, le cas d'Ensérune mis à part, on ne connaît jusqu'à présent aucun texte en langue celtique dans une autre écriture que le semi-syllabaire levantin dans la même zone géographique, avant les inscriptions gallolatines qui n'apparaîtront que plus tardivement, aux $\mathrm{I}^{\mathrm{er}} \mathrm{s}$. av. J.-C. - IVe s. ap. J.-C. (RIG 2002).

Malgré une présence grecque importante sur le littoral dès les VII $-\mathrm{VI}^{\mathrm{e}}$ siècles et une culture grecque florissante, illustrée par exemple par les lettres sur plomb trouvées à Lattes, en 2005 et 2006 (Bats 2011a, p. 197-226 [notamment p. 202]), il semble qu'il n'existe pas de nom celtique ou de nom ibère écrit en alphabet grec à Ensérune.

Le gallo-grec, écriture utilisée au $\mathrm{II}^{\mathrm{e}} \mathrm{s}$. av. J.-C. pour noter une langue celtique, n'est pas attesté en Languedoc occidental. Plus au sud encore, le plomb d'Elne ( $M L H$, II, B.9 Anhang), très discuté, pourrait se référer, selon $\mathrm{J}$. de Hoz, à des individus provenant de régions à l'est de l'Hérault (de Hoz 2011, p. 160).

Le gréco-ibère, variante ionienne pour noter une langue ibérique attestée sur le site de Campello en Espagne (MLH III, région G, site G.9), n'existe pas à proprement parler en Languedoc. Un seul exemple, étudié par Michel Bats et provenant de l'oppidum du Moulin à Peyriac-de-Mer (près de Sigean) pourrait s'en rapprocher. Il s'agit d'un nom ibère translittéré en alphabet grec sur deux skyphoi attiques à vernis noir (deuxième moitié du $\mathrm{IV}^{\mathrm{e}} \mathrm{s}$. av. J.-C.) : KANIK $\Omega$ NE (Bats 1988, p. 126, fig. 2).

Les habitants du golfe du Lion ont donc clairement préféré l'écriture paléohispanique à toute autre disponible, et ce malgré les nombreuses adaptations nécessaires, pour signaler leur nom sur des objets. Paradoxalement, aux $\mathrm{III}^{\mathrm{e}}-\mathrm{II}^{\mathrm{e}}$ av. J.-C., les noms celtiques sont plus nombreux que les noms ibères dans l'épigraphie paléohispanique du site d'Ensérune. 
Il faut donc comprendre qu'il y avait un intérêt pour les Celtes locaux à écrire en utilisant la graphie paléohispanique.

\section{Supports}

L'étude des supports sur lesquels sont portées les inscriptions permet de préciser le cadre de l'utilisation de l'écriture sur le site d'Ensérune. À défaut d'un examen approfondi des collections du musée, il n'est possible de se fonder pour l'instant que sur l'identification des supports proposée dans les $M L H$, vieille de plus de trente ans.

Cette identification montre que la céramique commune ne constitue pas le support privilégié de l'écriture à Ensérune et que les supports sur lesquels les noms sont les plus variés sont ceux en céramique d'importation (fig. 2).

La céramique campanienne est celle qui porte le plus de noms inscrits en écriture ibérique levantine. La même remarque peut être faite pour les inscriptions sur céramique attique. Les contacts et les échanges semblent donc avoir eu lieu dans un contexte d'économie de luxe. Le commerce avec les populations proches, illustré par la présence de céramiques de la côte catalane, paraît être plus modeste. Il faut toutefois tenir compte des fouilles anciennes du site, qui ont eu tendance à privilégier le «bel objet » aux productions en céramique commune.

Trois noms celtiques sont inscrits sur des céramiques locales, soit autant que de noms ibères ; deux noms à connotation celtique sont incisés sur une céramique de type celtique, à pâte grise, et trois sur une céramique provenant de la Catalogne voisine. Certaines estampilles, qui portent des noms gaulois, se trouvent sur des dolia.

Comme a pu le souligner Michel Bats, la société ibéro-gauloise "pratique un marquage plus systématique mais moins ostentatoire » (Bats 1988, p. 147) que dans le monde des inscriptions gallo-grecques.

De même, le plomb retrouvé en 1988 comporte plusieurs noms celtiques ou à connotation celtique écrits en semi-syllabaire levantin. Il est impossible, à partir des données phonétiques et linguistiques à notre disposition, de préciser dans quelle mesure les Celtes d'Ensérune étaient ibérisés. Compte tenu de la quantité des inscriptions en écriture paléohispanique à Ensérune et de la variété de l'onomastique lue, il est envisageable de penser que les seuls détenteurs de la pratique graphique ont été des Ibères, tenant le rôle d'intermédiaires locaux auprès d'une population gauloise fortunée, et que cette écriture levantine servait à garder trace d'échanges intercommunautaires. Très récemment, J. de Hoz a suggéré la présence de véritables emporia ibères, consentis par la population locale du Languedoc (de Hoz 2011, p. 119). Michel Bats propose de son côté de rapprocher les fonctions des populations ibères plutôt de celles des kapeloi que de celles des emporoi (Bats 2011b, p. 134).

Une épitaphe en langue ibère, trouvée à Cruzy mais qui semble provenir d'Ensérune, a été présentée par J. Untermann en 1999 puis étudiée en 2002 (Untermann 2002, p. 355-361). Datée vraisemblablement du III ${ }^{\mathrm{e}} \mathrm{s}$. av. J.-C. mais trouvée hors stratigraphie, elle suggère, à notre avis (et contra Untermann 1992, p. 27) une implantation locale non exclusivement commerciale.

Une étude exhaustive des données épigraphiques du site permettrait de préciser la chronologie des pratiques graphiques à Ensérune et de mieux définir le rôle des Ibères dans le cadre des contacts avec les autres populations de la Gaule méridionale occidentale.

\section{Bibliographie}

Bats 1988 : BATS (M.) - La logique de l'écriture d'une société à l'autre en Gaule méridionale protohistorique. R.A.N.21, p. 121-149.

Bats 2011a : BATS (M.) - Emmêlements de langues et de systèmes graphiques en Gaule méridionale protohistorique ( $\mathrm{VI}^{\mathrm{e}} \mathrm{I}^{\mathrm{er}} \mathrm{s}$. av. J.-C.). In : Luján Martínez (E. R.), Ruiz Darasse (C.) (éd.), Contacts linguistiques dans l'Occident méditerranéen antique, , Madrid, (Collection de la Casa de Velázquez, 216), p. 197-226.

Bats 2011b : BATS (M.) - Entre Ibères et Celtes : l'écriture à Ensérune dans le contexte de la Gaule du Sud (V $\mathrm{V}^{\mathrm{e}} \mathrm{II} \mathrm{I}^{\mathrm{e}} \mathrm{s}$. av. J.-C.). In : Luján Martínez (E. R.), García Alonso (J. L.) (éd.)A greek man in the Iberian street, (Innsbrucker Beiträge zur Sprachwissenschaft 140), Innsbrück, 2011, p. 129-137.

Colonna 1980 : COLONNA (G.) - Grafitti etruschi in Liguadoca. In : Studi Etruschi 48, p. 181-185.

Dubosse 2007 : DUBOSSE (C.) - Ensérune (Nissan-lez-Ensérune, Hérault) : les céramiques grecques et de type grec dans leurs contextes (VI ${ }^{e}-I V^{e} s$. av. n.è.), 2007.

de Hoz, 2008 : DE HOZ (J.) - A Celtic Personal Name on an Etruscan Inscription from Ensérune, Previously Considered Iberian (MLH B.1.2b). In : García Alonso (J. L.) (éd.), Celtic and other languages in ancient Europe, Salamanca, p. 17-27.

de Hoz 2011 : DE HOZ (J.) - Historia lingüística de la Península Ibérica en la Antigüedad II, El mundo ibérico prerromano y la indoeuropeización, Madrid, 2011.

Jannoray 1955 : JANNORAY (J.) - Ensérune. Contribution à l'étude des Civilisations préromaines de la Gaule méridionale, 1955.

MLH II : UNTERMANN (J.) - Monumenta Linguarum Hispanicarum, Band II, Die Inschriften in Iberischer Schrift aus Südfrankreich, 1980, Wiesbaden, L. Reichert. 


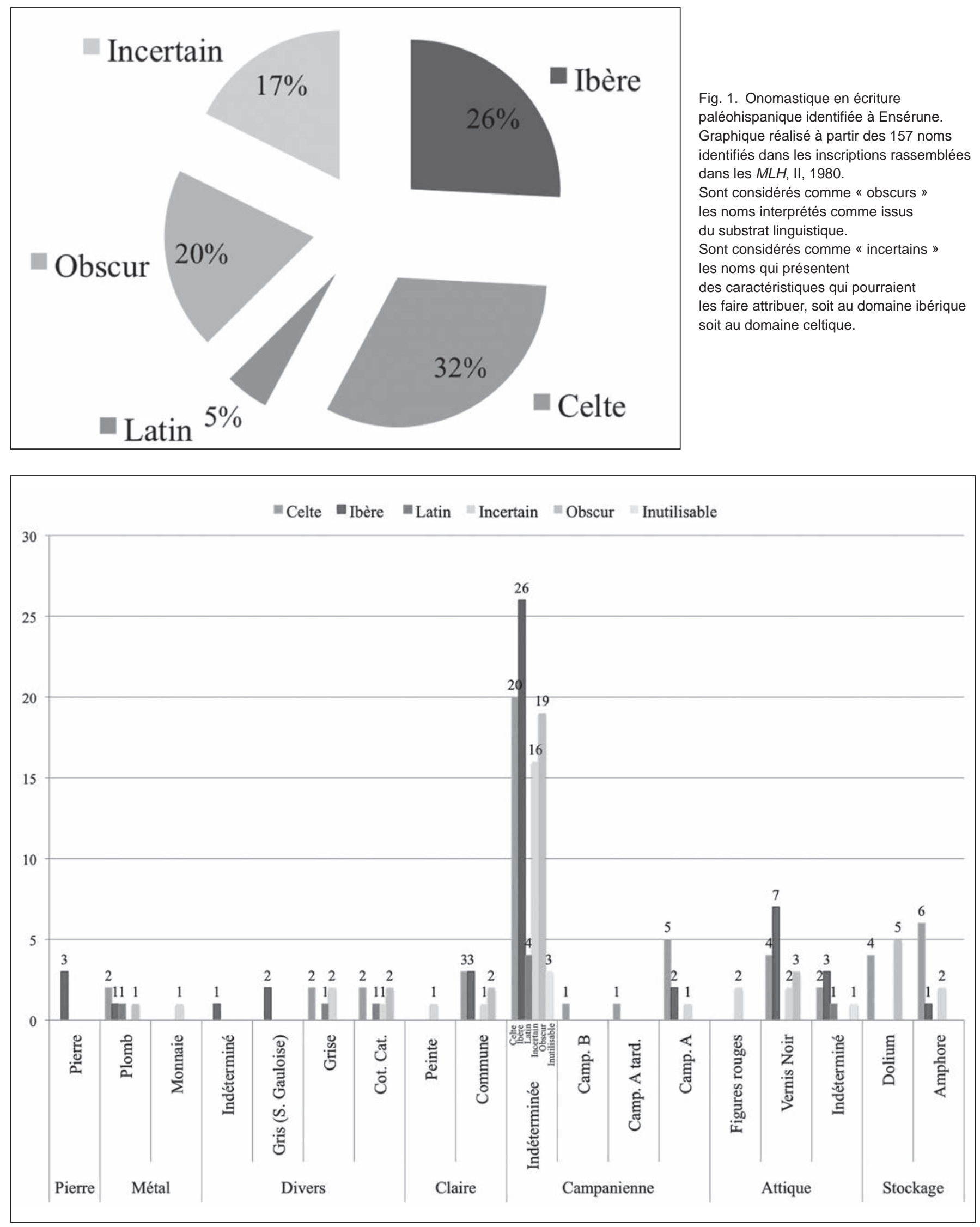

Fig. 2. Répartition des noms identifiés à Ensérune à partir des $M L H$ II, selon leur support. 
MLH III : UNTERMANN (J.) - Monumenta Linguarum Hispanicarum, Band III, Die Iberischen Inschriften aus Spanien, 1990, Wiesbaden, L. Reichert.

Orduña, Luján, Estarán 2009: ORDUÑA (E.), LUJAN (E.R.), ESTARAN (M.J.) 2009-El banco de datos 'Hesperia'. In : Acta palaeohispanica $X$, Actas do x colóquio internacional sobre línguas e culturas paleo-hispânicas, Lisboa, 26-28 de Fevereiro de 2009, Palaeohispanica 9, p. 83-92.

RIG 2002 : Lambert (P.-Y.) (éd.), Recueil des inscriptions gauloises, II, 2, Textes gallo-latins sur instrumentum, 2002, Paris, CNRS.

Ruiz Darasse 2010 : RUIZ DARASSE (C.) - Les Ibères en Languedoc : l'onomastique celtique d'Ensérune en écriture paléohispanique. In:
Palaeohispanica 10 - Serta Palaeohispanica in honorem Javier de Hoz, p. 335-354.

Solier, Barbouteau 1988 : SOLIER (Y.), BARBOUTEAU (H.) Découverte de nouveaux plombs, inscrits en ibère, dans la région de Narbonne. Revue archéologique de Narbonnaise 21, p. 61-95.

Untermann 1992 : UNTERMANN (J.) - Quelle langue parlait-on dans l'Hérault dans l'Antiquité ? Revue archéologique de Narbonnaise 25, p. 19-27.

Untermann 2002 : UNTERMANN (J.) - Dos nuevos textos ibéricos del sur de Francia. Palaeohispanica 2, p. 355-361 



\title{
Noms de personnes et identités dans les inscriptions d'Olbia de Provence (IVe-Ier s. av. J.-C.)*
}

\section{Clément Sarrazanas}

Doctorant Université Montpellier 3, EA CRISES

\section{Résumé}

Cette contribution présente un certain nombre de graffites alphabétiques grecs gravés sur céramique, retrouvés lors des fouilles de la colonie massaliète d'Olbia de Provence. Pour la plupart inédits, les graffites retenus sont des marques de propriété datés entre le $\mathrm{IV}^{\mathrm{e}}$ et le $\mathrm{I}^{\mathrm{er}} \mathrm{s}$. av. J.-C., qui révèlent sous forme abrégée des noms de personnes. Ces anthroponymes sont clairement à consonance hellénique, à l'exception de quelques cas douteux discutés en détail. Plusieurs d'entre eux trouvent des parallèles avec des noms bien attestés dans le domaine phocéen d'Occident ; les graffites d'Olbia paraissent donc s'inscrire dans la tradition onomastique des cités massaliètes, jusqu'à la fin de l'époque hellénistique.

Mots-clés : colonisation grecque, Olbia de Provence, épigraphie, onomastique, graffites, marques de propriété

\begin{abstract}
This paper presents some Greek alphabetical graffiti carved on ceramics that have been found during archaeological excavations in the Massalian colony, Olbia de Provence (France). Those mostly unpublished graffiti, dated from 4th to 1st century BC are property marks, generally a person's name in an abbreviated form. These names are clearly hellenic, excepted some dubious cases that are discussed in greater detail. Some of these graffiti can be paralleled with well-attested names from western Phocaean cities. Graffiti from Olbia are therefore representative of the onomastical tradition of the Massalian cities, until the end of the Hellenistic period.
\end{abstract}

Keywords: greek colonization, Olbia de Provence, epigraphy, onomastics, graffiti, property marks, Greek Personal names

\footnotetext{
* Il m'est particulièrement agréable d'avoir l'occasion de rendre hommage à Michel Bats, dont l'accueil chaleureux et bienveillant à Olbia

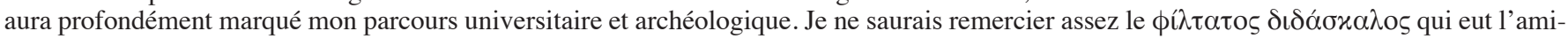
tié de me confier le dossier des inscriptions d'Olbia. Mes remerciements vont aussi à Christophe Chandezon, Réjane Roure et Henri Tréziny pour leur aide et leurs suggestions extrêmement précieuses.
} 
$\mathrm{L}$ e site d'Olbia de Provence (Hyères, Var), comme la plupart des autres cités phocéennes et massaliètes d'Occident, a livré peu d'inscriptions sur pierre : tout juste une dizaine en comptant les inscriptions grecques et latines. Ce maigre corpus épigraphique s'enrichit en revanche considérablement de tous les graffites inscrits sur céramique, retrouvés en nombre lors des fouilles archéologiques menées sur le site par Jacques Coupry, de 1956 à 1972, puis, à partir de 1982, par Michel Bats. Sur l'ensemble des tessons retrouvés, on a ainsi pu recenser deux cent quarante-deux graffites alphabétiques grecs comportant au moins une lettre lisible.

La plupart de ces graffites ont été gravés après cuisson, avec une pointe métallique, sur les parois ou sous le pied de la céramique. On a retrouvé la grande majorité de ces inscriptions sur des céramiques dites « campaniennes », produites dans la région de Naples entre le IV ${ }^{e}$ et le $\mathrm{I}^{\text {er }}$ s. av. J.-C., principalement des campaniennes A (CAMP-A) ${ }^{1}$, mais aussi des campaniennes B (CAMP-B). Les graffites retrouvés lors des fouilles menées par Jacques Coupry ne peuvent être datés précisément d'après la stratigraphie : dans la plupart des cas, c'est donc l'identification et la typologie du support céramique qui fournit un repère de datation ${ }^{2}$. Ces fourchettes chronologiques, parfois étendues, demeurent insatisfaisantes, puisqu'une même céramique a pu servir de nombreuses années, ou avoir été transmise entre générations, sans que l'on sache à quel moment le graffite a été inscrit. Pour les graffites trouvés au cours des fouilles menées par Michel Bats, la datation par le contexte stratigraphique offre plus de précision, mais avec les mêmes réserves que précédemment : le contexte de la trouvaille ne fournit jamais qu'un terminus ante quem pour la datation du graffite.

Le présent article s'attache à l'étude des documents inscrits pendant la phase proprement grecque d'Olbia, depuis sa fondation vers 325 av. J.-C. jusqu'à la période augustéenne, qui marque sur le site la quasi-disparition des céramiques campaniennes en même temps qu'une grande raréfaction des graffites sur céramique ; c'est aussi le moment où apparaissent quelques graffites en caractères latins. La période retenue est donc celle pour laquelle nous avons le plus de chances de rencontrer des inscriptions en alphabet et en langue grecs ${ }^{3}$.

\footnotetext{
1 Pour désigner le type et la forme du support céramique des graffites, nous suivons les abréviations et les classifications définies dans le DICOCER.

2 L'identification typologique et la datation des supports céramiques présentés dans cet article ont été effectuées par Michel Bats en juillet 2009.

3 La forme des caractères dans les graffites olbiens est relativement homogène pour toute la période hellénistique, et correspond largement à l'alphabet ionien usité pour noter la koinè, comme dans
}

Sur les 242 graffites alphabétiques retrouvés, seulement cent trente et un comportent deux lettres et plus, et 51 en comportent trois et plus. Nous avons choisi de ne commenter dans le présent travail, sauf exception, que des graffites comportant au moins trois lettres. Cette limitation, bien que relativement arbitraire, permet toutefois d'écarter la grande majorité des marques commerciales ${ }^{4}$ (et donc gravées en dehors du site), et de retenir avant tout, avec une confiance raisonnable, les graffites de propriété inscrits par les habitants d'Olbia. Nous avons également écarté les inscriptions qui n'étaient clairement pas des marques de propriété, comme les abécédaires, les exercices d'écriture ou encore les suites de lettres ne formant pas de syllabes, et qui sont sans doute des documents de comptes.

Plus épineuse est la question de certains graffites ambigus, que l'on pourrait a priori lire aussi bien comme une dédicace abrégée que comme une marque de propriété. C'est le cas, par exemple, d'un graffite comme HPA[-] (i 88), où l'on pourrait hésiter entre un nom de divinité (Héra ou Héraklès, à restituer alors au datif) et un anthroponyme théophore (avec par exemple un banal Héraklitos, attesté parmi les fidèles de l'Acapte ; le nom serait alors à restituer au nominatif ou au génitif). Jacques Coupry avait tendance à lire ces graffites douteux comme des dédicaces avec des noms de divinités abrégées, et privilégiait cette dernière interprétation dès qu'elle était possible (Coupry 1970 et 1992). À Olbia, pourtant, la plupart de ces tessons inscrits ont été retrouvés dans un contexte archéologique domestique : cet élément semble donc plutôt écarter, en général, la possibilité d'y lire des dédicaces à des divinités, un type de document que l'on s'attendrait plutôt à retrouver à l'intérieur ou à proximité des sanctuaires. De plus, la comparaison avec le sanctuaire de l'Acapte montre que les Olbiens écrivaient en toutes lettres le nom du dieu Aristée lorsqu'ils lui consacraient des céramiques comme offrandes. Même si cela n'est pas impossible en soi, on comprendrait mal pourquoi ils se mettraient soudain à abréger les noms des divinités une fois revenus dans l'enceinte de leur cité.

le reste du monde grec. Les alpha à barrette droite, majoritaires, côtoient cependant une grosse minorité d'alpha à barrette brisée. Les epsilon sont parfois - mais rarement - lunaires. On notera également quelques traits récurrents : les sigma sont exclusivement lunaires ; les oméga sont tous de forme cursive.

4 D'après les travaux fondateurs de Johnston, les graffites à caractère commercial prennent souvent une forme particulière (monogrammes, signes non alphabétiques), et consistent rarement en des suites de plus de deux lettres (cf. Johnston 1979 et 2006). Toujours selon cet auteur, ces marques se retrouvent presque exclusivement sous le pied de la céramique, ce qui ne constitue pas la majorité des cas pour les graffites ici retenus. 
Malgré les critères de sélection adoptés, les difficultés d'interprétation de ces marques de propriété demeurent évidentes : pour des textes aussi courts, il est souvent malaisé d'identifier avec précision l'anthroponyme qui a été abrégé. L'absence quasi-systématique de désinence nous confronte à plusieurs problèmes, comme le sexe du scripteur, ou le cas grammatical du nom abrégé : étaitil écrit au génitif ou au nominatif ? Lorsqu'elles sont complètes, les marques de propriété sont communément exprimées avec un génitif, marquant la possession. Mais il arrive aussi relativement fréquemment que des graffites de propriété soient exprimés au nominatif ${ }^{5}$. La question peut avoir son importance, comme nous le verrons, dans le cas de certains graffites qui pourraient être lus soit comme des noms courts complets au nominatif, soit comme des noms plus longs au génitif, abrégés et réduits aux premières syllabes ${ }^{6}$.

En dépit des difficultés évoquées, la mise en série et l'étude de ces graffites apportent plusieurs enseignements, notamment sur la population (alphabétisée) d'Olbia. Surtout, ces témoignages écrits permettent de compléter notre connaissance des pratiques onomastiques des Olbiens et, par extension, ils viennent enrichir le corpus des anthroponymes grecs attestés dans les cités phocéennes d'Occident ${ }^{7}$.

Enfin, il convient de rappeler que les inscriptions présentées ici constituent une sélection des documents olbiens les plus lisibles ou les plus intéressants concernant l'onomastique massaliète. Le présent travail, qui sera nécessairement complété ${ }^{8}$, n'a pour ambition que de proposer un premier aperçu de la question.

5 Voir par exemple Lang 1976, p. 26-27, qui recense $40 \%$ de marques de propriété exprimées au nominatif parmi les graffites de propriété retrouvés sur l'agora d'Athènes (contre $57 \%$ au génitif).

6 Voir ci-après un cas douteux comme KAEA (i 816).

7 Si des savants, et des plus illustres, ont déjà étudié plusieurs caractéristiques de l'onomastique phocéenne, il n'existe toujours aucun catalogue qui dresserait une liste de tous les anthroponymes attestés dans les colonies occidentales de Phocée. Même une somme scientifique telle que le $L G P N$ ne recense pas les noms connus à Marseille. Clerc (1927-1929), le premier, avait réuni un certain nombre d'anthroponymes massaliètes connus par des inscriptions lapidaires ; son travail a été complété et corrigé par Robert 1968, qui demeure la référence des travaux sur l'onomastique marseillaise. Depuis, les principales avancées ont été apportées par Coupry, Giffault 1982 (sur la « clientèle » du sanctuaire d'Aristée), Hermary, Tréziny 2000 (sur les anthroponymes en rapport avec des divinités), $C A G 13 / 3$, p. 169 (rapide catalogue des noms grecs attestés à Marseille) et del Barrio Vega 2007 (sur les particularités dialectales des noms phocéens).

8 Le corpus exhaustif des inscriptions et des graffites olbiens sera publié dans l'ouvrage de synthèse : M. Bats (dir.), Olbia de Provence à l'époque hellénistique (en préparation).

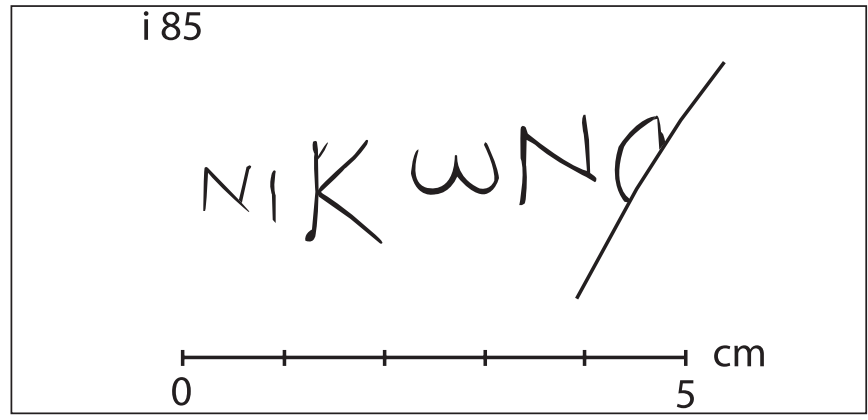

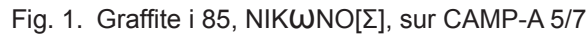
(dessin Cl. Sarrazanas).

\section{Une onomastique clairement hellénique}

Comme attendu dans un site fondé et occupé par des Grecs, les inscriptions et les graffites de propriété révèlent des noms bien grecs, aux racines phonétiques et sémantiques aisément reconnaissables.

Malheureusement, les documents retrouvés à Olbia même (hors sanctuaire de L'Acapte) ont livré peu de

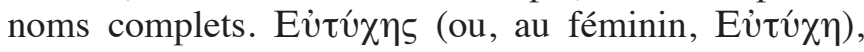
vraisemblablement le destinataire d'une lettre sur ostrakon $^{9}$ (i 451), porte un nom qui signifie « heureux, prospère », parfaitement bien attesté dans le monde grec. Le nom Níxwv, quasiment complet sur la panse d'une CAMP-A (graffite NIKWNO[ $\Sigma]$, i 85 ; fig. 1),

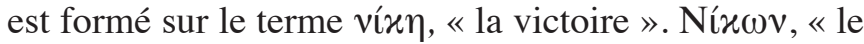
victorieux », est là encore un anthroponyme fréquent. La tablette de défixion judiciaire ${ }^{10}$ retrouvée dans le « sanctuaire de l'Ouest », et datée des II $^{\mathrm{e}} \mathrm{I}^{\mathrm{er}} \mathrm{S}$. av. J.-C.,

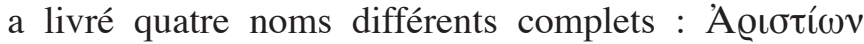

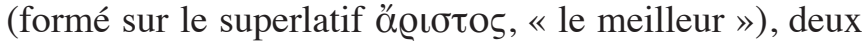
$\Delta$ ıovúoıs (nom théophore renvoyant à Dionysos), "Hovios (qui constitue vraisemblablement une forme hypocoristique du nom d'Héraklès, ou de l'un de ses

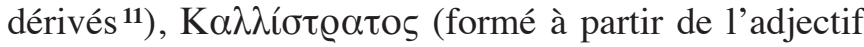

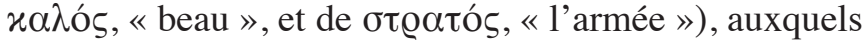
il faut ajouter un incomplet Пoбı $\delta \omega v . .$. , mais qui, vu

9 Jacques Coupry y voyait, plutôt qu'un nom propre, une formule de salutation, équivalente d'eưtúxદı (Coupry 1970, p. 145). Cette interprétation se heurte toutefois à des problèmes de morphologie et d'orthographe, et demeure bien moins convaincante qu'une adresse au destinataire (voir le commentaire de Jean-Claude Decourt, IGF 71).

10 Le texte complet est publié dans Bats, Giffault 1997 (= IGF 70).

11 Cette étymologie est confirmée par plusieurs témoignages de grammairiens et de lexicographes, comme par exemple Hésychius,

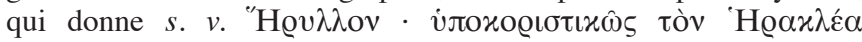
(« Hèryllos : forme hypocoristique d'Héraklès »). Le nom est le plus souvent écrit avec deux lambda, parfois avec un seul; il doit vraisemblablement s'agir du même nom dans tous les cas, avec le suffixe diminutif $-v \lambda \circ \varsigma$ ou $-v \lambda \lambda \mathrm{o}$, tous deux habituels dans la formation des noms grecs (tout comme on trouve, à côté du très fréquent

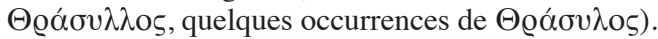


la faiblesse de la lacune, ne saurait être restitué qu'en

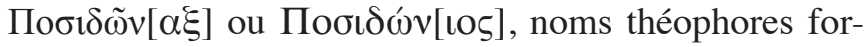
més sur Poséidon. Tous ces noms sont formés sur des racines tout à fait banales et fréquentes dans l'ono-

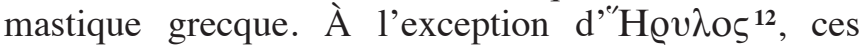
anthroponymes se révèlent par ailleurs extrêmement souvent attestés dans l'ensemble du monde grec, particulièrement à l'époque hellénistique.

Enfin, on mentionnera pour mémoire une possible

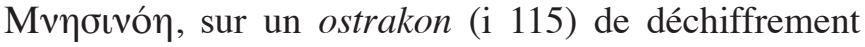
et d'interprétation malaisés. Jeanne et Louis Robert, ou plus récemment Jean-Claude Decourt ont ainsi rejeté la lecture du nom (au génitif) Mvๆбıvóns plusieurs fois présentée comme certaine par Jacques Coupry ${ }^{13}$. Si le nom sonne parfaitement grec, il n'est attesté que par une seule mention de Plutarque, lequel indique qu'il s'agit, selon les érudits de son temps, du nom primitif de Léda (Plutarque, Les oracles de la Pythie, 14), ce qui fragilise encore la validité de cette lecture ${ }^{14}$. De plus, l'ostrakon pourrait être, d'après Jacques Coupry, un exercice scolaire, par conséquent sans lien avec l'onomastique olbienne. On évitera donc d'accorder trop d'importance à ce document dans le cadre de notre propos.

Les constats établis jusqu'ici se vérifient encore aisément à la lecture des marques de propriété gravées sur céramique, même abrégées. Cette identification est particulièrement facile avec des noms théophores, mieux reconnaissables : c'est le cas des graffites $\Delta \mathrm{HM}[-]$ (i 45 , hell.) qui renvoie vraisemblablement à Déméter ; $\triangle \mathrm{IO \Gamma EN}[-]$ (OLB 03, 61138, II ${ }^{\mathrm{e}}$ s. av. J.-C.), à Zeus ; $\triangle \mathrm{IONY}[-]$ (i 609, II ${ }^{\mathrm{e}}-\mathrm{I}^{\mathrm{er}}$ s. av. J.-C.), à Dionysos ; HPA[-] (i 88, hell.), à Héra ou Héraklès, ou encore $\Pi Y \Theta[-]$ (i 723, II $^{\mathrm{e}} \mathrm{I}^{\mathrm{er}}$ s. av. J.-C.), qui fait écho à l'épiclèse d'Apollon Pythien.

L'origine grecque des noms portés par les habitants d'Olbia se vérifie encore pour des graffites suffisamment développés (en général d'au moins trois lettres). On trouve ainsi des cas clairs, comme ACTY[-] (i 254,

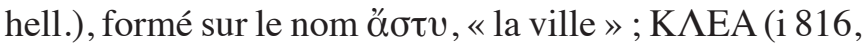

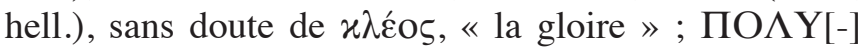

12 Bien que rare en général, le nom "H@vios est porté par un archonte de Delphes (V ${ }^{\mathrm{e}}$ s. av. J.-C., cf. FD III 4.369), et par un Platéen ( $I V^{\mathrm{e}}$ s. av. J.-C., cf. $I G \mathrm{II}^{2}$ 10092) ; il est encore attesté à Himère, au II ${ }^{\mathrm{e}} \mathrm{s}$. apr. J.-C. Les différents éditeurs hésitent d'ailleurs parfois sur la nature de l'esprit, sur la place de l'accent, et sur le nombre de lambda dans leurs transcriptions en lettres minuscules.

13 Voir Coupry 1970, p. 145 (cf. J. et L. Robert, Bulletin Épigraphique 1971, 728), et, en dernier lieu, IGF 72 (dont l'auteur n'a pu voir le document original, et qui propose une lecture moins assurée).

14 En dépit de l'existence du proche Mvnoivoc, attesté au IVe s. av. J.-C. à Athènes et à Apollonia de Thrace. (i 95, fin du Irr s. av. J.-C.), de l'adjectif лoגús, «nombreux »; $\underline{\mathrm{C} \Theta \mathrm{E}}[-]$ (i 472, hell.) de $\sigma \theta \dot{\varepsilon} v o \varsigma$, « la force »; CTP[-] ; (i 625, i 868 et i 458, tous hell.), vraisemblable-

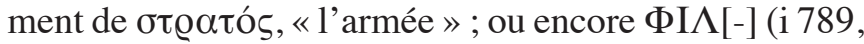

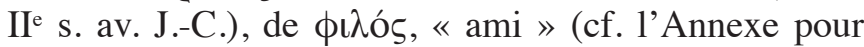
les restitutions possibles). On notera, une fois de plus, la grande banalité de la plupart de ces racines et phonèmes dans l'anthroponymie grecque en général, notamment pour l'époque hellénistique.

La situation particulière d'Olbia, cité massaliète installée en milieu gaulois, a depuis longtemps soulevé la question de la composition de la population du site, et notamment de la possible présence, parmi les habitants grecs, d'éléments indigènes qui auraient pu venir s'installer dans la cité (comme cela a pu être par exemple le cas à Emporion, où Grecs et indigènes Ibères cohabitèrent et finirent par former une population mêlée, aux dires de Strabon, III, 4, 8). Jacques Coupry évoquait ainsi, à propos justement des graffites d'Olbia, la question de «la présence des langues (grecque, celtique, ligure, ibérique...), ou l'emploi des caractères grecs et non grecs » (Coupry 1970, p. 144), question renouvelée par la découverte postérieure des dédicaces du sanctuaire d'Aristée, où sont apparus quelques fidèles portant des noms gaulois, mais écrivant en grec ${ }^{15}$.

On sait que les Celtes du Midi se sont mis à pratiquer l'écriture tardivement, surtout à partir du $\mathrm{II}^{\mathrm{e}} \mathrm{s}$. av. J.-C., et, dans de nombreux sites de la Gaule méridionale, on a retrouvé des graffites sur céramique écrits en gallogrec ${ }^{16}$. Des Gaulois du voisinage d'Olbia auraient pu venir s'installer dans la ville, où ils auraient eux aussi marqué leur vaisselle, en utilisant des caractères grecs pour transcrire leurs noms celtes, soit qu'ils connussent déjà l'alphabet gallo-grec, soit qu'ils eussent appris sur place l'usage de l'alphabet grec.

Toutefois, ce scénario ne trouve aucun support dans la documentation écrite d'Olbia : aucun graffite retrouvé sur le site ne révèle à coup sûr un ou des phonèmes celtes (contrairement à L'Acapte, ou à d'autres sites indigènes du Midi de la Gaule). Tout au plus peut-on relever quelques rares cas douteux, où l'on ne peut trancher avec certitude entre racines grecques et racines gauloises.

Le graffite OY[-], particulièrement représenté à Olbia (5 occurrences au moins d'époque hellénistique) s'avère relativement ambigu, puisque très peu de noms grecs commencent par cette syllabe. En revanche, plusieurs

15 J. Coupry dénombrait 225 noms (liste complète dans Coupry, Giffault 1982), parmi lesquels 22 ou 23 celtiques. Pour un commentaire sur les anthroponymes non helléniques dans les inscriptions de l'Acapte, voir Coupry, Giffault 1984. Sur les dédicaces faites en grec par les fidèles portant des noms gaulois, voir Bats $2010 \mathrm{~b}$.

16 Cf. Bats 2003 et Bats 2004. 


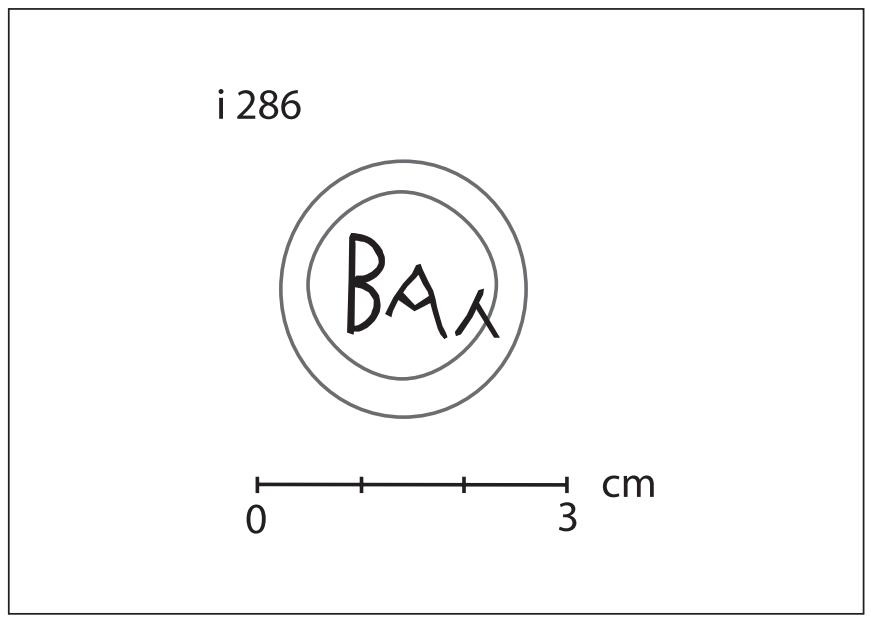

Fig. 2. Graffite i 286, BA^[-], sur fond de lampe de CAMP-A (dessin Cl. Sarrazanas).

anthroponymes celtes du Sud de la Gaule débutent, justement, par le son /u/ (Ouloodos à Lattes, Ourit[-] à Saint-Blaise, Ourou[-] à Beaucaire), ou, plus souvent, par le digramme OY pour transcrire le son $/ w /$, inexistant en grec (Ouelaunos, Oueninos ou Ouibotnos à l'Acapte, Ouebro[-] à Tholon, Ouanaikos à Nîmes). On pourrait donc être tenté de voir là la trace d'une présence celte à Olbia.

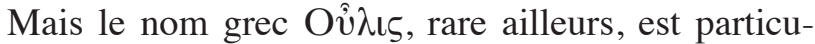
lièrement bien représenté dans le domaine massaliète (dix attestations à l'Acapte, deux à Marseille, quatre à

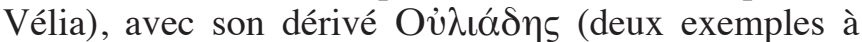
Marseille, un à Vélia) ${ }^{17}$. Il semblerait donc difficile, $a$ priori, de trancher entre l'une et l'autre interprétation. Mais l'absence de toute autre trace de phonème gaulois sur le site, ainsi que la grande popularité d'OÛ̉ı dans les cités phocéennes, nous conduisent plus volontiers à y voir l'abréviation de ce nom grec.

Le cas du graffite BA $\Lambda$ [-] (i 286, hell. ; fig. 2), inscrit sous le pied d'une lampe de CAMP-A, ne paraît pas à première vue poser de problème. Des noms grecs en $\mathrm{B} \alpha \lambda \ldots$ existent, même s'ils sont relativement peu nom-

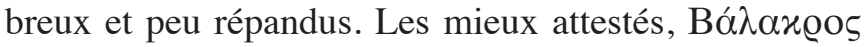
ou Bád $\lambda \gamma$ @os, sont des anthroponymes d'origine macédonienne, qu'il serait étonnant de retrouver à Olbia. On trouve aussi, en Ionie, un unique Bód $\alpha$ $\theta$ os à Éphèse

17 Sur l'anthroponyme Oủ̀ıs, son rattachement à Apollon Oừıs, et sa popularité dans les cités massaliètes, voir Masson 1988, Hermary, Tréziny 2000, p. 153-154, Morel 2000a p. 43-44, Morel 2000b, Morel 2005 (actuellement la synthèse la plus complète sur ce nom et ses dérivés, dans le domaine phocéen), ainsi que del Barrio Vega 2007, p. 23.

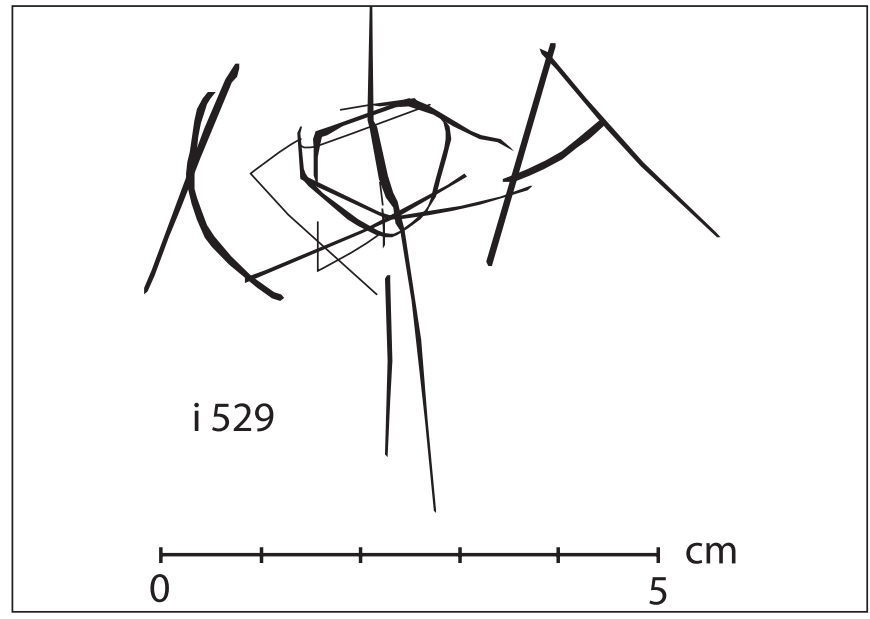

Fig. 3. Graffite i 529, CФA[-], sur CAMP-B1 (dessin Cl. Sarrazanas).

(dès le IVe s. av. J.-C.) ; Bád $\lambda \lambda \alpha \varsigma$ et Bá $\lambda \lambda ı$ à Colophon $\left(I V^{e}\right.$ s. av. J.-C.) ; ou B $\alpha \lambda \lambda i ́ \omega v$, encore à Colophon (IVe s. av. J.-C.) et à Smyrne (Ir s. av. J.-C.). Les noms grecs en $\mathrm{B} \alpha \lambda$... semblent donc surtout se rencontrer dans cette région de l'Ionie dont Phocée faisait également partie.

En réalité, un élément surtout peut faire douter du caractère grec de ce nom : le site languedocien d'Ensérune a en effet livré, lui aussi, un graffite $\mathrm{BA} \Lambda[-]$, en caractères grecs, sur un cratérisque attique à vernis noir (daté de 375-350 av. J.-C.). Selon C. Ruiz Darasse, qui n'envisage pas la possibilité de l'abréviation d'un nom grec, « il peut s'agir tout aussi bien d'un début de nom ibère, comme d'un nom gaulois » ${ }^{18}$. Si l'hypothèse d'un nom ibère vient naturellement à l'esprit dans le contexte d'Ensérune, où l'on ne connaît pas de nom grec ${ }^{19}$, elle semble en revanche improbable à Olbia, où, à l'inverse, aucun nom ibère n'est attesté. En considérant même le seul cas d'Ensérune, l'hypothèse d'une inscription en « alphabet gréco-ibérique », proposée par Ruiz Darasse 2010 et envisagée par Bats 2011, p. 210 n. 24 serait un exemple unique sur le site. L'existence du parallèle

18 Cf. Ruiz Darasse 2010, p. 340, qui propose des parallèles ibères et gaulois ; photographie et description de la céramique dans Dubosse 2007, p. 286.

19 Même si le site pourrait avoir livré des inscriptions grecques encore non publiées, aux dires de Ruiz Darasse 2010, p. 337 : « le dossier épigraphique complet du site n'est pas connu. Notamment, l'épigraphie latine n'est pas publiée, pas plus que l'épigraphie grecque. [...] Les réserves débordent encore d'inscriptions à étudier. » 
olbien ${ }^{20}$ semble encore fragiliser cette interprétation. On imaginerait mieux qu'il puisse s'agir du début d'un nom celte : pour le graffite d'Ensérune, le scripteur, gaulois, aurait pu apprendre le grec au contact des Marseillais (lors d'échanges commerciaux ?), et aurait ensuite inscrit son nom abrégé dans l'alphabet qui lui était le plus familier, plutôt qu'en ibère. À Olbia, il pourrait facilement s'agir d'un Gaulois du voisinage qui aurait, lui aussi, appris le grec, ou bien le gallo-grec. Ce scénario, qui n'est pas impossible a priori, se heurte toutefois à un problème de chronologie, puisque les Gaulois du Languedoc semblent commencer à écrire en caractères grecs seulement à partir de la fin du $\mathrm{III}^{\mathrm{e}} \mathrm{s}$. au plus tôt ${ }^{21}$, ce qui correspond mal avec la datation de la céramique d'Ensérune.

La solution la plus simple reste de considérer que, dans les deux cas, nous avons affaire à des Grecs, sans doute des Massaliètes : un commerçant installé à Ensérune dans le milieu du IV ${ }^{\mathrm{e}} \mathrm{s}$. dans le premier cas, et un habitant d'Olbia à l'époque hellénistique dans l'autre, tous deux porteurs d'un nom grec, ionien, en $\mathrm{B} \alpha \lambda \ldots$... . Ce serait ainsi la façon la plus naturelle d'expliquer l'usage des caractères grecs dans ces deux graffites géographiquement et chronologiquement éloignés.

Cette absence presque complète de noms gaulois dans le corpus des graffites d'Olbia ${ }^{22}$ peut s'interpréter, nous semble-t-il, de trois façons :

- Si des Gaulois sont venus habiter à Olbia, ils n'ont pas écrit leurs noms sur leurs céramiques. La chose ne serait pas étonnante, venant d'individus peu familiers de l'écriture, même si les marques de propriété en gallogrec apparaissent sur les sites indigènes du Midi à partir du $\mathrm{II}^{\mathrm{e}}$ s. av. J.-C.

- Il est aussi possible que des Gaulois aient habité Olbia, mais qu'ils aient pris des noms grecs : on a peu d'indices d'un tel phénomène, si ce n'est, à l'Acapte, quelques cas d'individus portant un nom grec, avec un patronyme celte, ou vice-versa ${ }^{23}$. On trouve ainsi, par exemple, un Eú $\mu \eta \lambda \mathrm{s}$, au nom bien grec, fils de

20 Le graffite olbien i 286, inconnu des deux auteurs, n'était il est vrai que très brièvement mentionné dans Coupry 1970, p. 144.

21 Voir la n. 16.

22 Il faut signaler, pour être complet, le graffite atypique i 527, gravé sur fond de CAMP-B (support daté de 150-25 av. J.-C.), dont la lecture et la nature sont incertaines. Il pourrait s'agir d'une inscription en alphabet lépontien (où un nom, sans doute abrégé, pourrait alors avoir des consonances gauloises) ou bien latin. Ce bref graffite, qui fera l'objet d'une analyse plus détaillée, fait en tout cas figure d'exception à Olbia.

23 Coupry, Giffault 1984, p. 218, recensent cinq cas de figure de ce genre : à trois reprises le dédicant a un nom grec et un patronyme celte, à deux reprises c'est le cas inverse. Mais les identifications ethniques proposées doivent être considérées avec prudence, ainsi que les auteurs de l'article eux-mêmes y invitaient. $\sum \varepsilon \gamma \cup v v o 5$, qui porte vraisemblablement un nom celte ${ }^{24}$. $\sum \varepsilon$ yuvvos a-t-il choisi de donner un nom grec à son fils ? Ce dernier portait-il au départ un nom celte, puis aurait-il choisi de prendre un nom grec, par exemple à un moment où il serait allé vivre à Olbia ? Il est impossible de se prononcer, et, en tout état de cause, si des Gaulois prennent (et écrivent) des noms grecs, il devient impossible pour nous de les distinguer, dans la documentation épigraphique, des Grecs « de souche » descendants des colons massaliètes.

- Enfin, on peut encore considérer que le site d'Olbia est demeuré, pendant toute la période hellénistique, peuplé par des individus grecs, descendants des premiers colons installés à la fin du $\mathrm{IV}^{\mathrm{e}} \mathrm{s}$., ou par d'autres Marseillais venus habiter Olbia à des époques postérieures. Les contacts avec les populations gauloises avoisinantes auraient alors eu lieu sur un autre mode que celui de la cohabitation durable sur un même site.

En définitive, l'épigraphie olbienne, dans son état actuel, paraît confirmer que seuls les individus grecs, ou hellénisés, pratiquaient l'écriture à l'intérieur du site. L'impression qui se dégage est celle d'un site et d'une population qui ont conservé, jusqu'à l'époque augustéenne, des pratiques et une identité bien grecques. Mais là encore, la prudence est de mise, eu égard à la nature et au caractère fragmentaire et partiel des témoignages écrits retrouvés au cours des fouilles archéologiques.

\section{Les graffites d'Olbia et les dédicaces du sanctuaire de L'Acapte}

La découverte à L'Acapte (presqu'île de Giens), à partir de 1973, des dédicaces votives adressées à Aristée, a permis de connaitre environ 225 anthroponymes des « fidèles » du dieu. Ce corpus de noms ${ }^{25}$, en général complets, est essentiel pour notre connaissance de l'onomastique massaliète, mal connue par ailleurs ; il fournit quelques parallèles possibles, ainsi que des hypothèses de restitution, aux graffites d'Olbia ${ }^{26}$.

Comme on l'a vu, les graffites olbiens, très abrégés, correspondent souvent à des racines très banales en grec, et ne permettent pas toujours d'affirmer à coup sûr que tel ou tel fidèle du sanctuaire venait bien de la cité d'Olbia, et non d'une autre cité grecque (ainsi

\section{Cf. IGF 68-42.}

25 Dans l'attente de la publication exhaustive des inscriptions du sanctuaire de l'Acapte, voir encore Coupry, Giffault 1982, et, plus récemment, les textes rassemblés dans $I G F$, p. 78-86.

26 On se reportera au tableau récapitulatif (voir l'Annexe) pour le détail des parallèles possibles. 


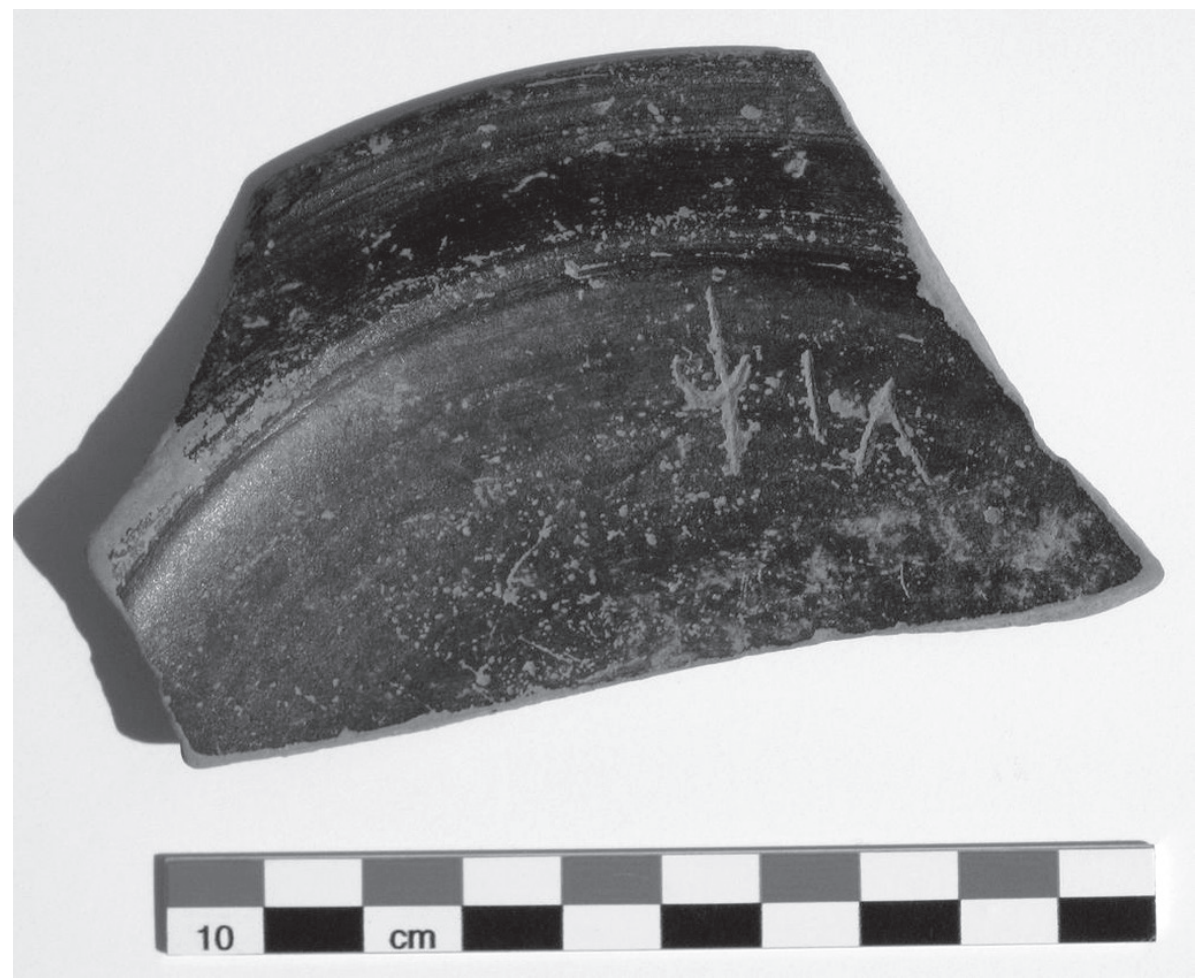

Fig. 4. Graffite i 477, $\Psi \mathrm{I}$ [-], sur CAMP-A6 (cliché Cl. Sarrazanas).

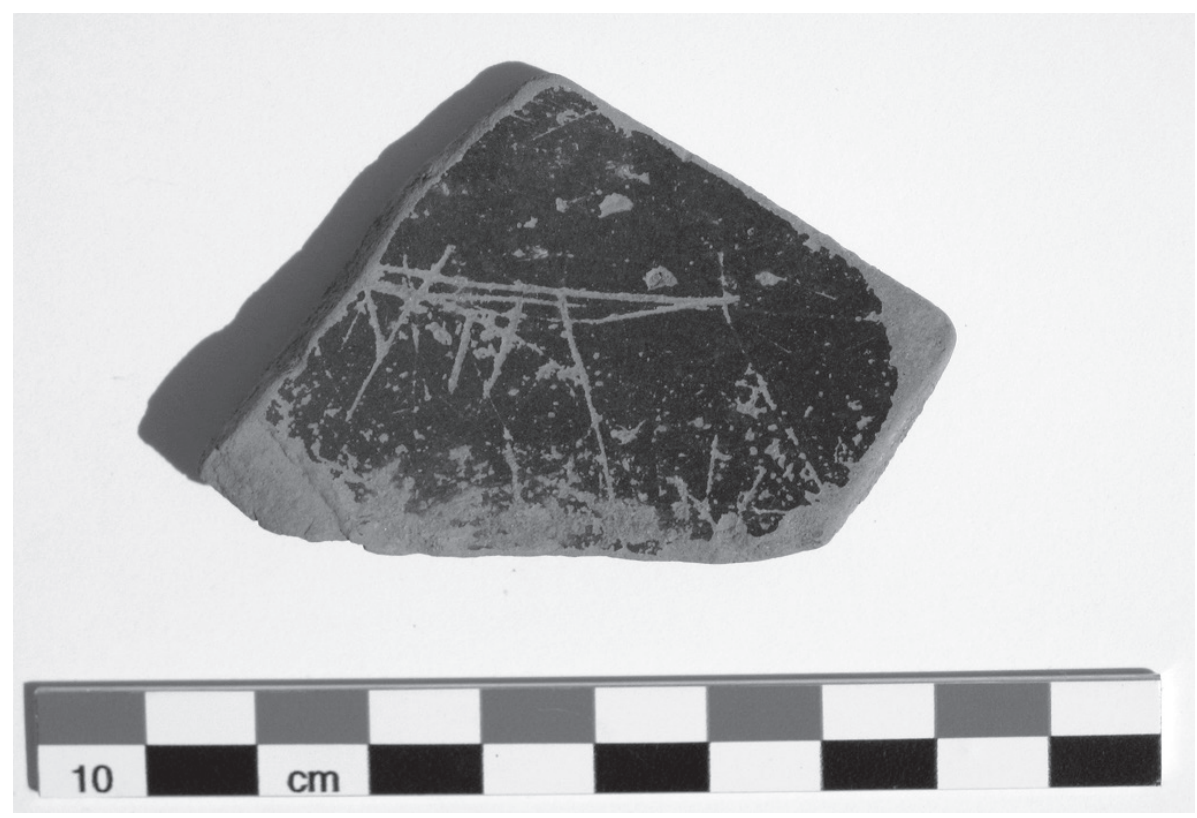

Fig. 5. Graffite i 524, [-]YПT[-], sur CAMP-A (cliché Cl. Sarrazanas). 


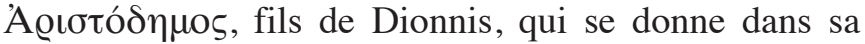

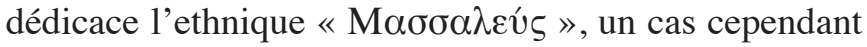
unique ${ }^{27}$ ). Néanmoins, des parallèles possibles pour quelques noms particuliers (les nombreux OY[-] pour

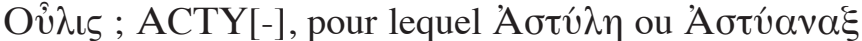

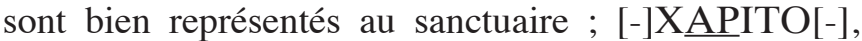

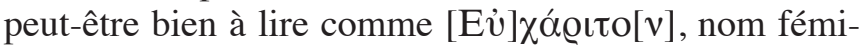
nin attesté à l'Acapte ; et surtout "H@vios, mentionné dans la tablette de défixion olbienne, nom assez rare qu'on retrouve treize fois au sanctuaire), ainsi que l'absence quasi-générale de l'ethnique du dédicant, tendent à montrer que le gros des fidèles du sanctuaire d'Aristée était constitué des habitants même de la voisine Olbia. Il semble de toute façon naturel que ce petit sanctuaire sans structure bâtie, aux offrandes modestes, n'ait eu qu'une renommée locale et un rayonnement finalement limité à ses abords immédiats.

\section{Les graffites olbiens dans le contexte du monde phocéen}

Il n'est pas nécessaire de rappeler en détail les usages des Grecs en matière d'onomastique, généralement marqués par la perpétuation d'un même nom sur plusieurs générations, souvent transmis du grand-père au petitfils, de l'oncle au neveu, ou encore du père au fils. Ce conservatisme onomastique permet de postuler a priori que les Olbiens ont conservé un stock de noms pour la plupart semblables à ceux de leurs ancêtres massaliètes et phocéens. Une comparaison entre les graffites olbiens et les noms attestés ailleurs dans le domaine phocéen permet donc, là encore, de fournir des parallèles.

Ainsi, le graffite K $\Lambda \mathrm{EA}$ (i 816) peut être lu comme un nom féminin complet $\mathrm{K} \lambda \dot{\varepsilon} \alpha$ (attesté à l'Acapte). Mais une inscription de Palerme (IG XIV, 295) mentionne aussi un Marseillais du nom de K $\lambda \varepsilon \alpha \gamma o ́ \varrho \alpha \zeta$, et une lettre sur plomb de Lattes, récemment publiée par Michel Bats, implique un courtier, vraisemblablement

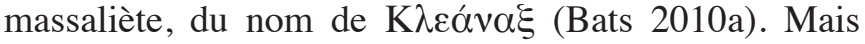
le nom peut encore faire écho, peut-être, à la nymphe Kléia/Kléa, qui pourrait avoir joui d'un culte particulier à Marseille ${ }^{28}$.

Bien que les noms grecs commençant par $\Pi$ o $\lambda v \ldots$ soient fréquents, on ne trouve à l'Acapte aucun parallèle pour le graffite $\Pi \mathrm{O} \Lambda \mathrm{Y}[-]$ (i 95) ; mais on connaît à

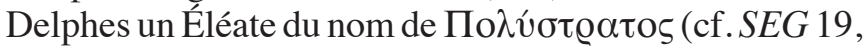
400) ; ou encore à Louxor, au $\mathrm{II}^{\mathrm{e}} \mathrm{s}$., un Marseillais, Poseidônax, qui a laissé un graffiti sur l'un des tombeaux de la vallée des rois, en mentionnant le nom de

27 Cf. IGF 68-3.

28 Cf. Hermary, Tréziny 2000, p. 150-153. son père, Пoגú $\xi \varepsilon v o s$ (Baillet 1920-1926, n 1936). Le graffite CФA[-] (i 529, $\mathrm{II}^{\mathrm{e}}-\mathrm{I}^{\text {er }}$ s. av. J.-C. ; fig. 3), sans parallèle à l'Acapte, trouve une restitution assurée dans

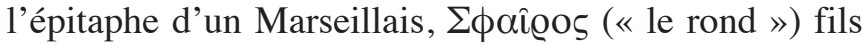
de Platôn, retrouvée à Athènes $\left(I G \mathrm{II}^{2}\right.$ 9297), et datée des $\mathrm{II}^{\mathrm{e}}$ - $\mathrm{Ier}^{\mathrm{er}}$ S. av. J.-C.

Le graffite rare $\Psi \mathrm{I} \Lambda[-]$ (i 477 ; fig. 4) ne paraît pas à première vue trouver d'écho dans le monde phocéen : en effet, seuls deux parallèles sont attestés pour tout le monde grec, un $\Psi$ í $\lambda \alpha \cup \chi 0 \varsigma$ au $\mathrm{III}^{\mathrm{e}}$ av. J.-C. en Thessalie (cf. SEG 36, 548), et un $\Psi$ í $\lambda$ os à Thespies au $\mathrm{II}^{\mathrm{e}}$ s. av. J.-C. (Roesch 2007, $\mathrm{n}^{\circ}$ 106). Mais on trouve encore le graffite $\Psi \mathrm{I}[-]$ à Olbia (i 266), et surtout à Lattes (DICOCER ${ }^{2}, \mathrm{n}^{\circ}$ 2907). Sur ce site languedocien, le graffite ne saurait transcrire un nom gaulois, puisque, comme le rappelle Michel Bats, « l'alphabet gallo-grec se distingue du grec par l'absence de signes inutiles et inutilisés, $\zeta$, $\phi$ et $\psi »$ (Bats 2004, p. 15). Le scripteur était donc grec à coup sûr, vraisemblablement un courtier massaliète installé à Lattes comme devait l'être le Kléanax mentionné dans la lettre sur plomb. Vu le faible nombre de mots grecs débutant par $\psi$ ı..., ces trois graffites constituent sans doute des noms formés sur l'adjectif $\psi \hat{\prime} \mathbf{\lambda}_{\mathrm{O}}$, « chauve, dégarni » : on a donc utilisé un sobriquet renvoyant à une caractéristique physique marquante pour former un anthroponyme. Si le procédé est tout à fait fréquent et bien connu, on notera que l'utilisation de la racine $\psi$ í $\lambda$ - dans l'onomastique paraît être propre surtout aux Phocéens d'Occident.

Pour le graffite $\Gamma E N[-]$ (FB 1981, US 25-39 1, $\mathrm{II}^{\mathrm{e}}-\mathrm{I}^{\mathrm{er}}$ s. av. J.-C.), il existe des restitutions possibles

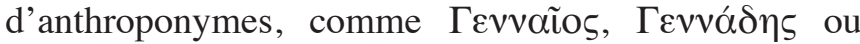

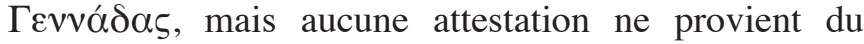
domaine phocéen. Dans le domaine ionien, seul un Гevvádıs est connu à Éphèse, à l'époque impériale (cf. $S E G 55,1224)$. Cependant, l'épiclèse divine $\gamma \varepsilon v \varepsilon ́ \theta \lambda ı$ เ est peut-être à lire sur un graffite de Marseille ${ }^{29}$, ce qui pourrait expliquer que $\Gamma \varepsilon v \varepsilon ́ \theta \lambda ı \varsigma$ (nom lui aussi bien attesté en Grèce, mais plutôt à l'époque romaine impériale tardive) se retrouve à Olbia comme anthroponyme. Ou bien peut-être faut-il considérer un autre nom théophore, faisant allusion au culte des déesses Gennaïdes de Phocée, documentées par Pausanias $(\mathrm{I}, 1,5)$ ?

Un cas plus particulier est peut-être celui du graffite [-]YПТ[-] (i 724 ; I ${ }^{\text {er }}$ s. av. J.-C. ; fig. 5). Peu de noms, en effet, comportent cette suite de lettres. Il faut d'emblée remarquer, sur le graffite, la longueur des hastes horizontales qui se poursuivaient au-delà de la cassure du tesson à gauche, et qui semblent bien provenir d'une lettre qui précédait l'Y. Parmi les anthroponymes grecs

29 Cf. le graffite Bourse E214/06/01, publié et commenté dans Hermary, Tréziny 2000, p. 149-153. 
attestés par le $L G P N$, quatre lettres seulement peuvent

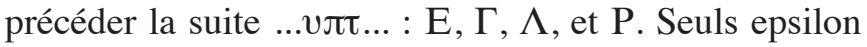
ou gamma possèdent une haste horizontale qui pourrait se poursuivre à droite, au-dessus des lettres suivantes.

Ce constat écarterait ainsi une restitution en

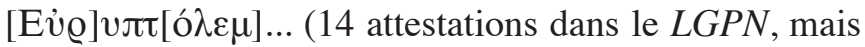
aucun parallèle dans le domaine phocéen). Un nom en $[E] \dot{v} \pi \tau$... est possible, mais peu probable : les attestations en sont peu nombreuses (six occurrences seulement), et aucune ne provient d'une cité de l'aire ionienne. La restitution $[\Gamma] v \pi \tau \ldots$ semble donc à retenir de préférence.

Dans le monde grec, les noms les plus répandus qui comportent cette suite de lettres sont ceux en Aiyúлt... (42 attestations) : il s'agit de noms relativement communs à l'époque hellénistique, et présents en Ionie dès l'époque classique. Une autre hypothèse paraît toutefois envisageable pour ce graffite retrouvé en territoire massaliète.

Dans l'horizon des cités phocéennes, c'est le récit de la fondation de Marseille qui fournit un parallèle possible. En effet, aucun nom connu du domaine massaliète ne présente la suite de lettres ...vлt..., si ce n'est la célèbre Gyptis, princesse gauloise qui, selon la légende de la fondation de Marseille, épousa le Phocéen Prôtis, le fondateur de Marseille (voir Justin, Abrégé des Philippiques, XIII, 3). Gyptis est sans doute la version hellénisée du véritable nom gaulois de la princesse, peut-être plus proche du nom Petta, transmis par un texte d'Aristote, malheureusement peu clair et peut-être corrompu (où Aristote fait de Petta/Gyptis la mère, et non l'épouse, de Prôtis ; Aristote, frg. 549 Rose = Athénée, Deipnosophistes, XIII, 576a) ${ }^{30}$. Le caractère légendaire ou semi-légendaire de cette princesse n'empêche pas, nous semble-t-il, la possibilité que, cinq siècles environ après la fondation de Marseille, les habitants des cités massaliètes aient perpétué le souvenir de son nom en le donnant à leurs enfants. Il s'agit certes d'un nom gaulois à l'origine, mais le rôle essentiel de la princesse dans la légende massaliète, ainsi que la visible hellénisation de son nom (ce dont témoigne le texte de Justin, qui reprend Trogue-Pompée), font de Gyptis un personnage pleinement intégré à l'histoire et à la culture massaliète. À la basse époque hellénistique, la geste de Prôtis était, à n'en pas douter, bien établie et répandue, et les habitants des cités massaliètes en avaient fait depuis longtemps le fonds de leur histoire «nationale ». Cela est d'autant plus vraisemblable que, au témoignage d'Aristote, le genos des Prôtiades (qui se voulaient les descendants de Prôtis) était encore influent à Marseille à la fin du $\mathrm{IV}^{\mathrm{e}} \mathrm{s}$. Les Prôtiades ont sans doute favorisé la large diffusion du mythe de la fondation de la cité par leurs ancêtres.

30 Sur les versions de la légende, voir Pralon 1992, p. 52-53, n. 6 et 11 , et plus récemment Raviola 2000.
Est-on fondé à lire ce graffite comme l'abréviation de

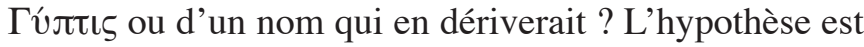
quelque peu aventureuse, mais séduisante. Si elle devait être avérée, elle fournirait un témoignage précieux de la pénétration de la légende et de l'identité proprement massaliète, y compris dans les possessions coloniales qui dépendaient de la métropole.

\section{Conclusions}

Les graffites de propriété d'époque hellénistique retrouvés à Olbia, malgré leur caractère très souvent fragmentaire, constituent un témoignage du caractère hellénique que paraît bien avoir conservé cette forteresse massaliète installée en pays celte. Il est clair que les habitants d'Olbia étaient alphabétisés ${ }^{31}$ et utilisaient l'écriture pour des usages quotidiens ${ }^{32}$, dont ne subsistent, malheureusement, que les témoignages laissés sur des matériaux non périssables.

Ces modestes fragments d'écriture permettent toutefois de compléter nos connaissances en matière d'onomastique, notamment grâce aux marques de propriété sur céramique. Bien sûr, on remarquera certains faits banals et attendus dans ce domaine, comme la grande fréquence des noms théophores, un phénomène commun à l'ensemble du monde grec. On regrettera également qu'en l'état actuel, les graffites retrouvés à Olbia de Provence ne permettent pas de confirmer certains traits marquants de l'onomastique phocéenne (ainsi, par exemple, l'usage fréquent de noms de fleuves d'Asie Mineure dans la formation des noms propres, phénomène que Louis Robert avait particulièrement mis en évidence ${ }^{33}$ ).

Mais ces documents laissent entrevoir, toutefois, la possibilité de dégager quelques conclusions : certains noms sembleraient propres surtout, ou avant tout, aux cités phocéennes, comme $\mathrm{O} \tilde{v}[\lambda \iota \varsigma],{ }^{\circ} \mathrm{H} \rho v \lambda \circ \varsigma, \mathrm{B} \alpha \lambda[\ldots]$, ou peut-être, si l'on songe aux cultes propres à ces mêmes cités, K $\lambda \dot{\varepsilon} \alpha$ et $\Gamma \varepsilon v[\ldots]$ ? Peut-être même pourrait-on déceler une identité plus particulièrement massaliète, avec $[\Gamma] u ́ \tau \tau[ı \zeta]$. On remarquera aussi, à deux reprises au moins, l'usage de sobriquets, fondés sur des caractères physiques, utilisés comme anthroponymes, un phénomène parfaitement banal là encore. Toutefois, à côté du fréquent $\Sigma \phi \alpha \tilde{i} \varrho \circ$, la formation de noms en $\Psi$ เ $\lambda[\ldots]$ semble plutôt particulière aux Olbiens.

31 Ce que montrent aussi plusieurs exercices d'écriture retrouvés à Olbia, pour la plupart encore inédits.

32 Comme le montrent les lettres sur ostrakon retrouvées à Olbia (Coupry 1970, p. 145).

33 Cf. Robert 1968, surtout p. 206-213. 
Ces quelques conclusions sont bien entendu avancées avec prudence, dans l'espoir que de nouveaux documents viendront encore permettre d'approfondir nos connaissances en ce domaine. Le corpus onomastique des cités phocéennes d'Occident s'accroît d'ailleurs chaque année, grâce aux découvertes régulières d'inscriptions attestant de nouveaux anthroponymes, aussi bien en Espagne, en France, qu'en Italie. Une publication établissant un catalogue onomastique des cités phocéennes, en rassemblant les données présentées dans des travaux souvent dispersés (et absentes des grands corpus), s'avèrerait sans doute bienvenue pour faciliter le travail des chercheurs qui s'intéressent à ces questions ${ }^{34}$.

\section{Bibliographie}

Baillet 1920-1926 : BAILLET (J.) - Inscriptions grecques et latines des rois ou syringes à Thèbes. Le Caire, I.F.A.O., 1920-1926.

Bats 2003 : BATS (M.) - Les Gaulois et l'écriture aux $\mathrm{II}^{\mathrm{e}} \mathrm{I}^{\mathrm{er}} \mathrm{s}$. av. J.-C. RAO, Suppl. 10, 2003, p. 369-380.

Bats 2004 : BATS (M.) - Grec et gallo-grec. Les graffites sur céramique aux sources de l'écriture en Gaule méridionale (II $-{ }^{\mathrm{e}}{ }^{\mathrm{er}} \mathrm{s}$. av. J.-C.). Gallia, 61, 2004, p. 7-20.

Bats 2010a : BATS (M.) - Une lettre sur plomb à Lattes. Lattara, 21, 2010, p. 749-756.

Bats 2010b : BATS (M.) - Les dédicants gaulois du sanctuaire d'Aristée de la chôra d'Olbia de Provence (Hyères, Var) connaissaient-ils le gallo-grec ? Studia Celtica Classica et Romana Nicolae Szabó septuagesimo dedicata. Budapest, 2010, p. 51-54.

Bats 2011 : BATS (M.) - Emmêlements de langues et de systèmes graphiques en Gaule méridionale ( $\mathrm{VI}^{\mathrm{e}}-\mathrm{I}^{\mathrm{er}}$ siècle av. J.-C.). In : Lujan Martinez (E. R.), Ruiz-Darasse (C.) éd., Contacts linguistiques dans l'Occident méditerranéen antique. Madrid, Collection de la Casa de Velazquez 126, 2011, p. 197-226

Bats, Giffault 1997 : BATS (M.), GIFFAULT (M.) - Une tablette d'envoûtement en plomb à Olbia de Provence. REA, 99, 1997, p. 459-462.

CAG 13/3 : ROTHÉ (M.-P.), TRÉZINY (H.) DIR. - Carte archéologique de la Gaule. Marseille et ses alentours, 13/3. Paris, Académie des Inscriptions et Belles-Lettres, 2005.

Clerc 1927-1929 : CLERC (M.) - Massalia, histoire de Marseille dans l'antiquité des origines à la fin de l'Empire d'Occident (476 ap. J.-C.). Marseille, éd. A. Tacussel, 2 vol., 1927 et 1929.

Coupry 1970 : COUPRY (J.) - Apports d'Olbia de Provence à l'épigraphie grecque d'Occident. In : Acta of the Fifth Epigraphic Congress. Cambridge, 1967 [1970], p. 141-147.

Coupry 1992 : COUPRY (J.) - Catalogue chronologique, par générations, dans leur existence mythique, des dieux et héros helléniques à Marseille et dans les horizons massaliètes. In : Bats (M.), Bertucchi (G.), Congès (G.), Tréziny (H.) éd., Marseille grecque et la Gaule. Lattes, ADAM, et Aix-enProvence, Université de Provence, 1992, p. 155-160 (Ét. Massa. 3).

Coupry, Giffault 1982 : COUPRY (J.), GIFFAULT (M.) - La clientèle d'un sanctuaire d'Aristée aux îles d'Hyères ( ${ }^{\text {er }}$ siècle av. J.-C.). Actes du colloque de décembre 1981 sur "Vélia et les Phocéens : un bilan dix ans après », PP, 204-207, 1982 [1983], p. 350-360.

34 Ce travail est actuellement en cours de préparation par nos soins, en collaboration avec Henri Tréziny.
Coupry, Giffault 1984 : COUPRY (J.), GIFFAULT (M.) - Onomastique non hellénique dans l'anthroponymie olbienne et massaliète, en Ligurie marseillaise, à la fin de l'époque hellénistique, d'après les ex-voto du sanctuaire d'Aristée à L'Acapte. In : Walter (H.) éd., Hommages à Lucien Lerat. Paris, 1984, p. 209-219.

del Barrio Vega 2007 : DEL BARRIO VEGA (M.) - H $\triangle$ IA AEKTO $\Sigma$ TH $\Sigma$ $\Phi \Omega$ KAIA $\Sigma$ YПO TO $\Phi \Omega \Sigma$ TH $\Sigma$ E $\Lambda \Lambda H N I K H \Sigma \Delta$ YTIKH $\Sigma$ ЕПІГРАФІКН $\Sigma$. In : Hatzopoulos (B.) dir., $\Phi \Omega N H \Sigma$ XAPAKTHP E $\Theta N I K O \Sigma$, Actes du Ve congrès international de dialectologie grecque (Athènes 28-30 septembre 2006). Athènes, 2007, p. 9-27.

DICOCER : PY (M.) dir.-DICOCER: Dictionnaire des céramiques antiques en Méditerranée nord-occidentale : VII ème s. av. n. è. - VII ème s. ap. n. è., Provence, Languedoc, Ampurdan. Lattes, 1993 (Lattara, 6).

DICOCER $^{2}$ : PY (M.) dir. - DICOCER ${ }^{2}$ : Corpus des céramiques de l'âge du Fer à Lattes (fouilles 1963-1999), Lattes, 2001, 2 vol. (Lattara, 14).

Dubosse 2007 : DUBOSSE (C.) - Ensérune (Nissan-lez-Ensérune, Hérault). Les céramiques grecques et de type grec dans leurs contextes (VIeIVe s. av. n. è.). Lattes, 2007.

FD III 4 : Fouilles de Delphes III. Épigraphie. Fascicule 4, Inscriptions de la terrasse du temple et la région Nord du sanctuaire. Athènes et Paris, École française d'Athènes, 1970-1976.

Hermary, Tréziny 2000 : HERMARY (A.), TRÉZINY (H.) - Les cultes massaliètes : documentation épigraphique et onomastique. In : Hermary (A.), Tréziny (H.) éd., Les cultes des cités phocéennes, Actes du colloque international organisé par le centre Camille-Jullian (Aix-en-Provence/Marseille, 1999), (Trav. du Centre C.-Jullian), Aix-en-Provence, 2000, 202 p. (Et. Massa. 6).

IGF : DECOURT (J.-C.) - Inscriptions Grecques de la France (IGF). Lyon, Travaux de la Maison de l'Orient et de la Méditerranée Jean Pouilloux, 38, 2004. Johnston 1979 : JOHNSTON (A. W.) - Trademarks on Greek vases. Warminster, 1979.

Johnston 2006 : JOHNSTON (A. W.) - Trademarks on Greek vases. Addenda. Oxford, 2006.

Lang 1976 : LANG (M.) - Graffiti and Dipinti. Princeton, The American School of Classical Studies, 1976 (The Athenian Agora XXI).

LGPN VA : CORSTEN (T.) éd. - A Lexicon of Greek Personal Names, V A. Coastal Asia Minor: from Pontos to Ionia. Oxford, 2010.

Masson 1988 : MASSON (O.) - Le culte ionien d'Apollon Oulios, d'après des données onomastiques nouvelles. Journal des Savants, 1988, p. $173-183$

Morel 2000a : MOREL (J.-P.) - Observations sur les cultes de Velia. In : Hermary (A.), Tréziny (H.) éd., Les cultes des cités phocéennes. Aix-enProvence, Édisud et Centre Camille Jullian, 2000, p. 33-49, (Ét. Massa. 6).

Morel 2000b : MOREL (J.-P.) - « Oulis », de Velia à Olbia de Provence et à Marseille. In : Berlingo (I.) et alii, éd. - Damarato. Scritti in onore di Paola Pelagatti. Milan, 2000, p. 336-340.

Morel 2005 : MOREL (J.-P.) - « Oulis » à Velia : l'hypothèse phocéenne. In : Breglia Pulci Doria (L.), Lupi (M.) éd., Da Elea a Samo : filosofi e politici di fronte all'impero ateniese. Atti del convegno di studi Santa Maria Capua Vetere, 4-5 giugno 2003. Naples, 2005, p. 31-47.

Pralon 1992 : PRALON (D.) - La légende de la fondation de Marseille. In : Bats (M.), Bertucchi (G.), Congès (G.), Tréziny (H.) éd., Marseille grecque et la Gaule. Lattes, ADAM, et Aix-en-Provence, Université de Provence, 1992, p. 51-56 (Ét. Massa. 3).

Raviola 2000 : RAVIOLA (F.) - La tradizione letteraria sulla fondazione di Massalia. Hesperìa 10. Studi sulla grecita di Occidente, 2000, p. 57-97.

Roesch 2007 : ROESCH (P.) - Les inscriptions de Thespies, édition électronique mise en forme par Argoud (G.), Schachter (A.) et Vottéro (G.), Lyon, Maison de l'Orient et de la Méditerranée Jean Pouilloux, 2007.

Robert 1968 : ROBERT (L.) - Noms de personnes et civilisation grecque. Journal des Savants, 1968, p. 197-213.

Ruiz Darasse 2010 : RUIZ DARASSE (C.) - Les Ibères en Languedoc : l'onomastique celtique d'Ensérune en écriture paléohispanique. Palaeohispanica, 10, 2010, p. 335-354 


\section{Annexe}

\section{Tableau récapitulatif des anthroponymes d'Olbia étudiés}

\begin{tabular}{|c|c|c|c|c|c|}
\hline $\begin{array}{l}\text { Lecture du nom } \\
\text { complet } \\
\text { ou du graffite }\end{array}$ & $\begin{array}{c}\text { Numéro } \\
\text { d'inventaire } \\
\text { ou référence } \\
\text { bibliographique }\end{array}$ & Support & Datation & Interprétation & $\begin{array}{l}\text { Parallèles dans le } \\
\text { domaine phocéen }\end{array}$ \\
\hline 'Арıбтíwv & $\begin{array}{c}\text { Bats, Giffault } \\
1997\end{array}$ & $\begin{array}{l}\text { Feuille de plomb } \\
\text { (defixio) }\end{array}$ & Ile-jer S. av. J.-C. & & Aucun \\
\hline ACTY[-] & i 254 & CAMP-A & $\mathrm{Ill}^{\mathrm{e}} \mathrm{J}^{\mathrm{er}}$ S. av. J.-C. & & $\begin{array}{c}6 \text { Astylè, } \\
2 \text { Astyanax } \\
\text { et } 1 \text { Astydikè } \\
\text { à l'Acapte ; } 1 \\
\text { Astykritè } \\
\text { à Marseille }\end{array}$ \\
\hline $\mathrm{BA} \wedge[-]$ & i 286 & $\begin{array}{l}\text { Lampe de } \\
\text { CAMP-A }\end{array}$ & III $\mathrm{e}_{-} \mathrm{er}$ S. av. J.-C. & $\begin{array}{c}\text { Nom ionien en Bal..., } \\
\text { plutôt qu'un nom ibère } \\
\text { ou gaulois (?) }\end{array}$ & $\begin{array}{l}\text { Un graffite } B A \wedge[-] \\
\text { à Ensérune } \\
(375-350 \text { av. J.-C. })\end{array}$ \\
\hline ГEN[-] & $\begin{array}{l}\text { FB 1981, } \\
\text { US 25-39 } 1\end{array}$ & CAMP-B & $150-25$ av. J.-C & & $\begin{array}{c}\text { Écho possible } \\
\text { aux déesses } \\
\text { Gennaïdes } \\
\text { de Phocée (?) }\end{array}$ \\
\hline$\Delta \mathrm{HM}[-]$ & i 45 & CAMP-A & $\mathrm{III}^{\mathrm{e}} \mathrm{J}^{\mathrm{er}}$ S. av. J.-C. & & $\begin{array}{c}18 \text { Démétrios, } \\
2 \text { Dèmô, } 1 \text { Démètriè } \\
\text { à l'Acapte ; Dêmôn } \\
\text { à Marseille, } \\
\text { Emporion et Velia. }\end{array}$ \\
\hline$\triangle \mathrm{IOГEN[-]}$ & $\begin{array}{c}\text { OLB 03, US } \\
61138\end{array}$ & CAMP-A class. & $I^{\mathrm{e}}$ s. av. J.-C. & & Aucun \\
\hline$\triangle \mathrm{IONY}[-]$ & i 609 & CAMP-B 5 & $150-25$ av. J.-C. & & $\begin{array}{c}27 \text { Dionysios et } \\
1 \text { Dionysermos à } \\
\text { l'Acapte }\end{array}$ \\
\hline 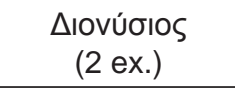 & $\begin{array}{c}\text { Bats, Giffault } \\
1997 \\
\end{array}$ & $\begin{array}{c}\text { Feuille de plomb } \\
\text { (defixio) }\end{array}$ & $\|^{e}-I^{e r} S$. av. J.-C. & & $\begin{array}{c}27 \text { Dionysios } \\
\text { à l'Acapte }\end{array}$ \\
\hline $\begin{array}{c}\text { EútúXns ou } \\
\text { EútúXワ }\end{array}$ & i 451 & $\begin{array}{l}\text { Ostrakon de } \\
\text { CAMP-A 31a }\end{array}$ & Ile $^{\mathrm{e}}$ s. av. J.-C. & & $\begin{array}{l}1 \text { [E]utyches dans } \\
\text { une inscription } \\
\text { latine de Marseille } \\
\text { (?), CIL XII, } 489 ; \\
1 \text { Eutykhos à } \\
\text { l'Acapte }\end{array}$ \\
\hline HPA[-] & i 88 & CAMP-A & Ille-|er s. av. J.-C. & & $\begin{array}{l}\text { Nom théophore } \\
\text { en Héra... plutôt } \\
\text { qu'une dédicace à } \\
\text { Héra ou Héraklès. } \\
1 \text { Hé[r]aklitos } \\
\text { à l'Acapte }\end{array}$ \\
\hline 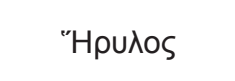 & $\begin{array}{c}\text { Bats, Giffault } \\
1997\end{array}$ & $\begin{array}{l}\text { Feuille de plomb } \\
\text { (defixio) }\end{array}$ & $\|^{e}-J^{e r}$ S. av. J.-C. & & $\begin{array}{l}8 \text { Hèrylos } \\
\text { à l'Acapte }\end{array}$ \\
\hline
\end{tabular}




\begin{tabular}{|c|c|c|c|c|c|}
\hline 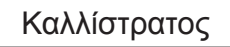 & idem & idem & idem & & Aucun \\
\hline $\mathrm{K} \wedge \mathrm{EA}$ & i 816 & CL-MAS & $\mathrm{IV}^{\mathrm{e}}$ |er s. av. J.-C. & $\begin{array}{c}\text { Nom féminin complet } \\
\text { Kléa ou abréviation d'un } \\
\text { nom en Kléa... }\end{array}$ & $\begin{array}{l}1 \text { Kléa, } 1 \text { Kléas } \\
\text { à l'Acapte ; } \\
\text { Kléagoras, } \\
\text { Marseillais; } \\
\text { Kléanax à Lattes }\end{array}$ \\
\hline Mvnбıvón (?) & i 115 & CAMP-A tard & $125-25$ av. J.-C. & Lecture incertaine & Aucun \\
\hline 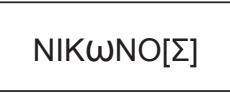 & i 85 & $\begin{array}{l}\text { CAMP-A 5/7 } \\
\text { tard }\end{array}$ & $125-25$ av. J.-C. & & 3 Nikôn à l'Acapte \\
\hline OY[-] (5 ex.) & & & & $\begin{array}{l}\text { Abréviation des noms } \\
\text { grecs Oulis ou Ouliadès, } \\
\text { plutôt que de noms } \\
\text { gaulois }\end{array}$ & $\begin{array}{l}10 \text { Oulis, } 2 \text { Oula } \\
\text { à l'Acapte ; Oulis } \\
\text { et Ouliadès } \\
\text { à Marseille et Vélia }\end{array}$ \\
\hline ПОАY[-] & i 95 & $\begin{array}{l}\text { CL-RO-P A1 } \\
\text { Bats }\end{array}$ & $\begin{array}{l}\text { Deuxième moitié du } \\
\text { Jer s. av. J.-C. }\end{array}$ & & $\begin{array}{c}\text { Polystratos, } \\
\text { Eléate ; Polyxenos, } \\
\text { Marseillais }\end{array}$ \\
\hline Побıठळv[...] & $\begin{array}{c}\text { Bats, Giffault } \\
1997\end{array}$ & $\begin{array}{l}\text { Feuille de plomb } \\
\qquad(\text { defixio })\end{array}$ & 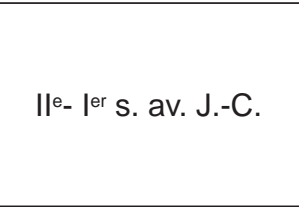 & 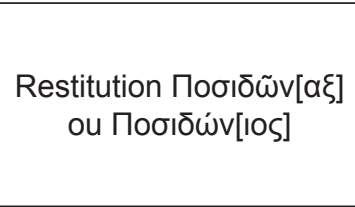 & $\begin{array}{c}\text { Pos(e)idônax } \\
\text { à l'Acapte et } \\
\text { à Marseille ; } \\
\text { Posidônas } \\
\text { à Emporion }\end{array}$ \\
\hline ПҮӨ[-] & i 723 & CAMP-A tard. & $125-25$ av. J.-C. & & $\begin{array}{c}\text { Pythagoras } \\
\text { à Marseille et } \\
\text { Emporion ; Pythias } \\
\text { à Marseille ; } \\
\text { Pythis et Pytha } \\
\text { à l'Acapte ; } \\
\text { Pythermos, } \\
\text { Phocéen }\end{array}$ \\
\hline COE[-] & i 472 & CAMP-A & Ille-ler s. av. J.-C. & Nom en Sthén... & Aucun \\
\hline CTP[-] (3 ex.) & $\begin{array}{l}\text { i } 458 \\
\text { i } 625 \\
\text { i } 868\end{array}$ & $\begin{array}{l}\text { CAMP-A } \\
\text { CAMP-A } 5 \text { tard. } \\
\text { CAMP-A tard. }\end{array}$ & $\begin{array}{l}\text { IIIe-Jer S. av. J.-C. } \\
175-50 \text { av. J.-C. } \\
125-25 \text { av. J.-C. }\end{array}$ & Nom en Strato... & Aucun \\
\hline СФА[-] & i 529 & CAMP-B 1 & $150-25$ av. J.-C. & & $\begin{array}{c}\text { Sphairos, } \\
\text { Marseillais (IG II² } \\
9297)\end{array}$ \\
\hline [...]YПТ[-] & i 724 & CAMP-A tard. & $125-25$ av. J.-C. & 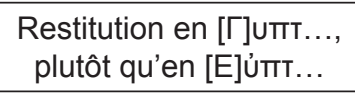 & $\begin{array}{c}\text { Gyptis (?), } \\
\text { princesse gauloise }\end{array}$ \\
\hline$\Phi \mid \wedge[-]$ & i 789 & CAMP-A class. & $180-100$ av. J.-C. & & $\begin{array}{l}9 \text { parallèles } \\
\text { différents } \\
\text { à l'Acapte }\end{array}$ \\
\hline$[\ldots ?] \mathrm{XAPITO}[-]$ & $\begin{array}{l}\text { OLB } 2011 \\
\text { US } 46017\end{array}$ & CAMP-A & Ille-|er s. av. J.-C. & & $\begin{array}{c}1 \text { Eukhariton à } \\
\text { l'Acapte }\end{array}$ \\
\hline$\Psi \mathrm{I}[-]$ & і 266 & CAMP-B 5 & $150-25$ av. J.-C. & & $\begin{array}{l}\text { Un graffite } \Psi \mathrm{I}[-] \\
\text { à Lattes }\end{array}$ \\
\hline$\Psi \mid \wedge[-]$ & i 477 & CAMP-A 6 & $150-25$ av. J.-C. & & $\begin{array}{l}\text { Un graffite } \Psi \mathrm{\Psi I}[-] \\
\text { à Lattes }\end{array}$ \\
\hline
\end{tabular}




\section{Liste des auteurs}

Dr. PhD Laura AMBROSINI

Ricercatore

Istituto di Studi sul Mediterraneo Antico (ISMA)

Consiglio Nazionale delle Ricerche (CNRS) - Roma

- Italia

Laura.ambrosini@isma.cnr.it

Carmen ARANEGUI GASCÓ

Professeur

Université de Valence (Espagne)

Carmen.Aranegui@uv.es

David ASENSIO I VILARÓ

Universitat de Barcelona

Universitat Autònoma de Barcelona

MónIberRocs SL

davidasensio@ozu.es

Giacomo BARDELLI

Romänisch-Germanisches Zentralmuseum Mainz

Universität Innsbruck

bardelli@rgzm.de

Valentina BELFIORE

belfiorev@yahoo.de

Laurence BENQUET

INRAP Grand Sud Ouest

TRACES - UMR 5608 - Toulouse

laurence.benquet@inrap.fr

Loup BERNARD

Maître de Conférences, Université de Strasbourg, UMR7044, MISHA

loup.bernard@unistra.fr

Catia BIANCO

Dipartimento di Beni Culturali

Università del Salento

catia.bianco@libero.it

Philippe BOISSINOT

EHESS

TRACES - UMR 5608 - CNRS, Université de Toulouse II philippe.boissinot@free.fr

\author{
Alain BOUET \\ Université de Toulouse 2-Le Mirail \\ TRACES - UMR 5608 - Toulouse \\ abouet@univ-tlse2.fr \\ Sophie BOUFFIER \\ Professeur, Aix Marseille Université, CNRS, Ministère \\ de la Culture et de la Communication, CCJ UMR 7299, \\ 13094, Aix en Provence, France \\ sbouffier@mmsh.univ-aix.fr
}

Laura BOURDAJAUD

doctorante ASM - Archéologie des Sociétés Méditerranéennes, UMR5140,

Univ Montpellier 3,CNRS, MCC, 34000, Montpellier,France laura.bourdajaud@univ-montp3.fr

Jean-Pierre BRUN

Centre Jean Bérard, Naples, Italie (USR 3133, CNRS - ÉfR)

berard@unina.it

Josep BURCH

Université de Gérone

josep.burch@udg.edu

\section{Teresa Oda CALVARUSO}

Dipartimento di Beni Culturali, Università del Salento oda.calvaruso@libero.it

\section{Pere CASTANYER}

Museu d'Arqueologia de Catalunya - Empúries

pcastanyer@gencat.cat

\section{Laetitia CAVASSA}

Centre Jean Bérard, Naples, Italie (USR 3133, CNRS - ÉfR) berard@unina.it

\section{Luca CERCHIAI}

Dipartimento di Scienze del Patrimonio Culturale Università di Salerno

lcerchiai@alice.it

Ferran CODINA

Museu d'Arqueologia de Catalunya-Ullastret

fcodinafalgas@gmail.com 


\section{Émilie COMPAN}

Chercheur associé UMR 5140, ASM - Archéologie des Sociétés Méditerranéennes, équipe Préhistoire et Protohistoire méditerranéennes, Montpellier-Lattes

emicomp@free.fr

Anne-Marie CURÉ

doctorante ASM - Archéologie des Sociétés Méditerranéennes, UMR5140,

Univ Montpellier 3, CNRS, MCC, 34000, Montpellier, France

am.cure@yahoo.fr

Isabelle DAVEAU

Ingénieur chargé de recherche, Institut National des Recherches Archéologiques Préventives

isabelle.daveau@inrap.fr

Carine DEAL

Ville de Hyères-les-Palmiers

cdeal@mairie-hyeres.com

Bernard DEDET

Directeur de recherche au CNRS

ASM - Archéologie des Sociétés Méditerranéennes, UMR5140,

Univ Montpellier 3, CNRS, MCC, 34000, Montpellier, France

bernard.dedet@cnrs.fr

Javier DE HOZ

Professeur honoraire Université de Madrid

dehoz@filol.ucm.es

Gabriel DE PRADO

Museu d'Arqueologia de Catalunya-Ullastret

gdeprado@gencat.cat

Michael DIETLER

Université de Chicago

mdietler@uchicago.edu

Pierre EXCOFFON

Ville de Fréjus

p.excoffon@voila.fr

Verena GASSNER

Professeur université de Vienne

Verena.Gassner@univie.ac.at

Liliana GIARDINO

Dipartimento di Beni Culturali, Università del Salento liliana.giardino@libero.it
Raimon GRAELLS FABREGAT

Römisch-Germanisches Zentralmuseum,

Ernst-Ludwig Plaz, 2. 55116, Mainz

graells@rgzm.de

\section{Antoine HERMARY}

Professeur, Aix Marseille Université, CNRS, Ministère de la Culture et de la Communication, CCJ UMR 7299, 13094, Aix en Provence, France

ahermary@mmsh.univ-aix.fr

Delphine ISOARDI

CR CNRS, Aix Marseille Université, CNRS, Ministère de la Culture et de la Communication, CCJ UMR 7299, 13094, Aix en Provence, France

Isoardi@mmsh.univ-aix.fr

Thierry JANIN

Professeur de Protohistoire, ASM - Archéologie des Sociétés Méditerranéennes, UMR5140, Univ Montpellier 3, CNRS, MCC, 34000, Montpellier, France thierry.janin@cnrs.fr

Claire JONCHERAY

Docteur Université Paris X Nanterre

claire.joncheray@free.fr

Martine LEGUILLOUX

Centre Jean Bérard, Naples, Italie (USR 3133, CNRS - ÉfR) berard@unina.it

Natacha LUBTCHANSKY

Université François-Rabelais de Tours - CeTHiS

nathalie.lubtchansky@univ-tours.fr

Irad MALKIN

Cummings Chair of Mediterranean History and Culture, Tel Aviv University, Department of History

méditer@post.tau.ac.il

http://telaviv.academia.edu/IradMalkin

\section{Aurora MARTIN}

Museu d'Arqueologia de Catalunya-Ullastret

auroramartin2407@gmail.com

Frédéric MARTY

Pôle Intercommunal du Patrimoine Culturel du SAN Ouest Provence (Istres)

frederic.marty@ouestprovence.fr

Laurence MERCURI

Maître de Conférences, Université Nice Sophia Antipolis CNRS, CEPAM, UMR 7264, 06300 Nice, France Laurence.MERCURI@unice.fr 
Francesco MEO

Dipartimento di Beni Culturali, Università del Salento

francesco.meo@unisalento.it

Pierre MORET

UMR 5608 TRACES, Université de Toulouse - Le Mirail moret@univ-tlse2.fr

Sébastien MUNOS

Archeodunum

s.munos@archeodunum.fr

Priscilla MUNZI

Centre Jean Bérard, Naples, Italie (USR 3133, CNRS - ÉfR)

berard@unina.it

Cristina NERVI

cristinanervi@libero.it

David OLLIVIER

CNRS-LA3M

dollivier@mmsh.univ-aix.fr

Richard PELLÉ

Archéologue Inrap, Centre de Nîmes, USR 3155 CNRS,

IRAA

Société Française de Numismatique

richard.pelle@inrap.fr

Bérengère PEREZ

Éducation Nationale

Hervé PETITOT

Archéologue Inrap, Centre de Villeneuve les Béziers

herve.petitot@inrap.fr

Eliana PICCARDI

elianapiccardi@gmail.com

Rosa PLANA-MALLART

Professeur Université Paul-Valéry Montpellier 3

ASM - Archéologie des Sociétés Méditerranéennes, UMR5140, Univ Montpellier 3, CNRS, MCC, 34000, Montpellier, France

rosa.plana@univ-montp3.fr

Paolo POCCETTI

Université de Rome

poccetti@lettere.uniroma2.it

Enriqueta PONS I BRUN

Museu d'Arqueologia de Catalunya - Girona

eponsbrun@terra.com
Angela PONTRANDOLFO

Université de Salerne

apontrandolfo@unisa.it

Claude POUZADOUX

Centre Jean Bérard, Naples, Italie (USR 3133, CNRS - ÉfR)

berard@unina.it

Aldo L. PROSDOCIMI

Professeur Université de Padoue

linda@unive.it

\section{Anna Maria PUIG GRIESSENBERGER}

Technicienne archéologue-conservateur de la commune de Roses - Musée de la Citadelle (2008-2011)

amp.griessenberger@wanadoo.es

Michel PY

Directeur de recherche honoraire au CNRS

michel-py@orange.fr

André RIVALAN

associé UMR5140 Archéologie des Sociétés

Méditerranéennes

rivalanandre@yahoo.fr

Pierre ROUILLARD

UMR 7041 ArScAn, Maison Archéologie et Ethnologie

René Ginouvès,

Nanterre, Labex Les passés dans le présent

pierre.rouillard@mae.u-paris10.fr

Réjane ROURE

Maître de Conférences, Université Paul-Valéry Montpellier 3

ASM - Archéologie des Sociétés Méditerranéennes, UMR5140, Univ Montpellier 3, CNRS, MCC, 34000, Montpellier, France

rejane.roure@univ-montp3.fr

Coline RUIZ DARASSE

r.coline@free.fr

Jordi SAGRERA

Université de Gérone

jordi.sagrera@udg.edu

Valérie SALLE

Ministère de la Culture

valerie.salle@culture.gouv.fr 
Corinne SANCHEZ

Chargée de Recherche CNRS

ASM - Archéologie des Sociétés Méditerranéennes, UMR5140, Univ Montpellier 3, CNRS, MCC, 34000, Montpellier, France

corinne.sanchez@cnrs.fr

\section{Joan SANMARTÍ}

Professeur à l'Université de Barcelone

Membre de l'Institut d'Estudis Catalans (UAI)

Departament de Prehistòria, Història Antiga i Arqueologia

Facultat de Geografia i Història

C/ Montalegre 6-8, 08001 Barcelone (E)

sanmarti@ub.edu

Marta SANTOS

Museu d'Arqueologia de Catalunya - Empúries

msantosr@gencat.cat

Alfonso SANTORIELLO

Université de Salerne

asantoriello@unisa.it

Clément SARRAZANAS

Doctorant Université Montpellier 3, EA CRISES

clement.sarrazanas@univ-montp3.fr

Martine SCHWALLER

Conservateur en chef du Patrimoine, DRAC-SRA Languedoc-Roussillon

ASM - Archéologie des Sociétés Méditerranéennes, UMR5140, Univ Montpellier 3, CNRS, MCC, 34000, Montpellier, France

martine.schwaller@hotmail.fr
Maeva SERIEYS

Département du Vaucluse

maeva.serieys@cg84.fr

Francesca SPATAFORA

Direttore Parco Archeologico di Himera

spataf@tiscali.it

Joaquim TREMOLEDA

Museu d'Arqueologia de Catalunya - Empúries

jtremoleda@gencat.cat

\section{Henri TRÉZINY}

DR CNRS, Aix Marseille Université, CNRS, Ministère de la Culture et de la Communication, CCJ UMR 7299, 13094, Aix en Provence, France

henri.treziny@orange.fr

\section{Daniela UGOLINI}

CR CNRS, Aix Marseille Université, CNRS, Ministère de la Culture et de la Communication, CCJ UMR 7299, 13094, Aix en Provence, France

dugolini@club-internet.fr

Florence VERDIN

CNRS, Ausonius, Bordeaux

florence.verdin@u-bordeaux3.fr

Laurent VIDAL

Archéologue Inrap, Centre de Nîmes

laurent.vidal@inrap.fr 


\section{PUBLICATIONS \\ DU CENTRE CAMILLE JULLIAN}

http://ccj.cnrs.fr/spip.php?rubrique79

\section{LES REVUES ET COLLECTIONS DU CENTRE CAMILLE JULLIAN SONT DISPONIBLES GRATUITEMENT EN LIGNE :}

REVUE ANTIQUITÉS AFRICAINES, n¹ (1967) à 35 (1999), sur le portail Persée :

(http://www.persee.fr/web/revues/home/prescript/revue/antaf)

COLLECTION ARCHAEONAUTICA, nº 1 (1977) à 14 (1998), sur le portail Persée :

(http://www.persee.fr/web/revues/home/prescript/revue/nauti)

Barrière mobile à 3 ans.

COLLECTION ÉTUDES MASSALIÈTES, n¹ (1986) à 10 (2011), sur le site du CCJ :

(http://ccj.cnrs.fr/spip.php?rubrique83)

ou sur celui du Centre de Conservation du Livre à Arles :

(http://www.e-corpus.org/search/search.php?search=search\&page=1\&q=études+massaliètes\&search=Rechercher)

BIBLIOTHÈQUE D'ARCHÉOLOGIE MÉDITERRANÉENNE ET AFRICAINE (BIAMA) :

À partir de 2014 (barrière mobile à 3 ans) sur le site Revues.org 
Achevé d'imprimer en mars par l'imprimerie Printer Portuguesa

Dépôt légal : avril 2015

$\mathrm{n}^{\circ}$ d'imprimeur :

Imprimé au Portugal 